
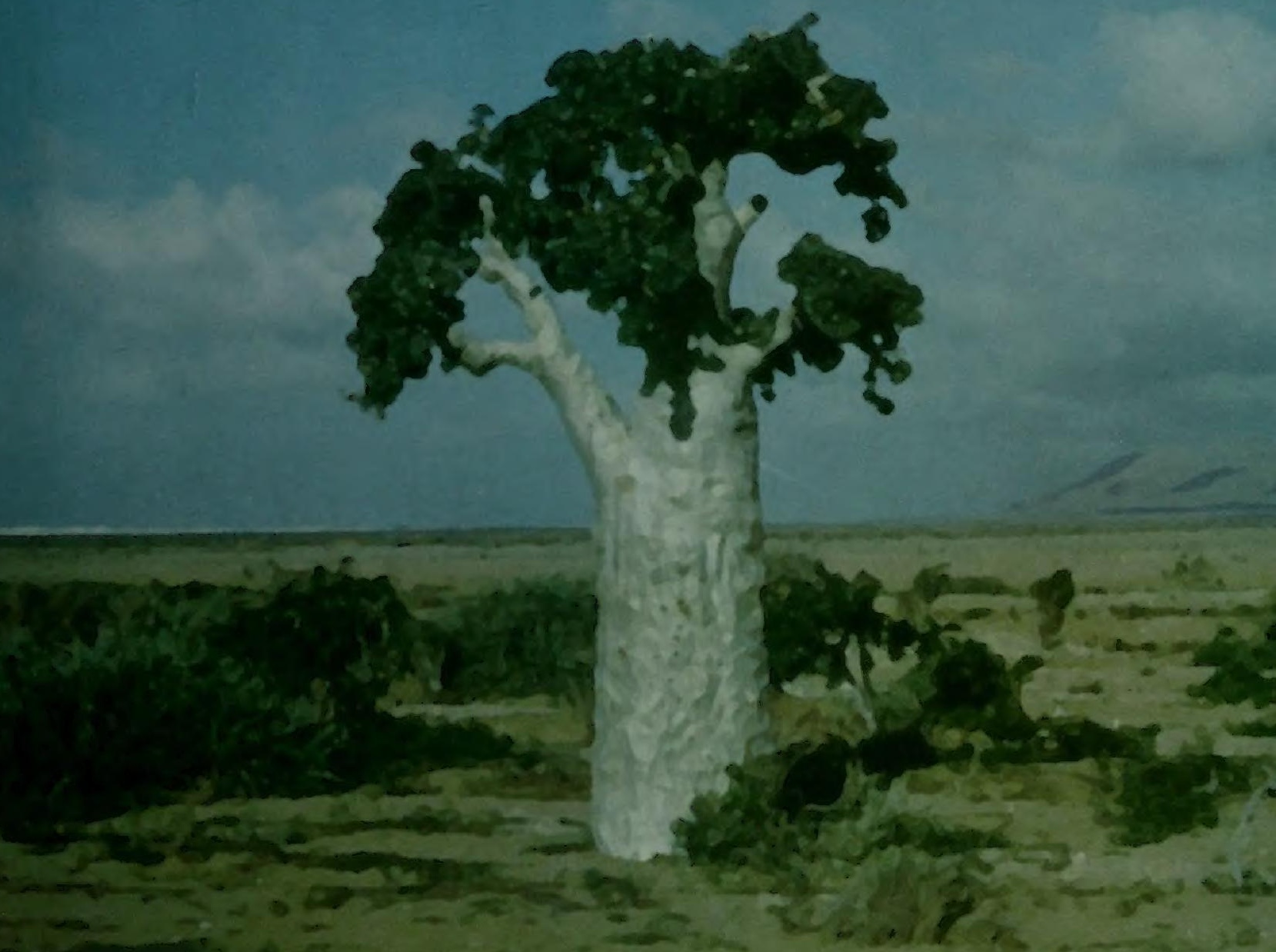
The Word List of Whealened Trees World Conservation Press 1998 
Digitized by the Internet Archive in 2010 with funding from UNEP-WCMC, Cambridge

http://www.archive.org/details/worldlistofthrea98oldf 


\section{The World List of Threatened Trees}

Compiled by

Sara Oldfield, Charlotte Lusty and Amy MacKinven

\section{World Conservation Press}

1998 


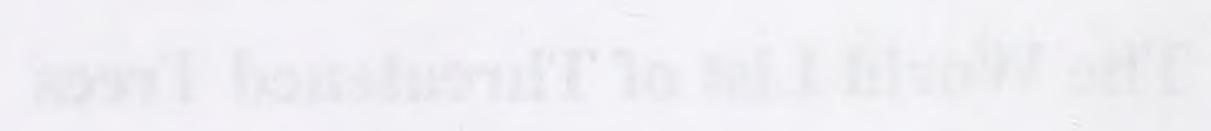

$x^{2}-x^{2}$

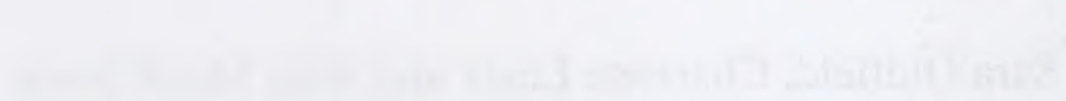


The World Conservation Monitoring Centre, based in Cambridge, UK, is a joint venture between three partners in the World Conservation Strategy and its successor Caring for the Earth: IUCN - The World Conservation Union, UNEP - United Nations Environment Programme, and WWF - World Wide Fund for Nature. The Centre provides information services on the conservation and sustainable use of species and ecosystems and supports others in the development of their own information systems.

Founded in 1948, The World Conservation Union brings together States, government agencies and a diverse range of non-governmental organizations in a unique world partnership: over 895 members in all, spread across some 137 countries.

As a Union, IUCN seeks to influence, encourage and assist societies throughout the world to conserve the integrity and diversity of nature and to ensure that any use of natural resources is equitable and ecologically sustainable.

The World Conservation Union builds on the strengths of its members, networks and partners to enhance their capacity and to support global alliances to safeguard natural resources at local, regional and global levels.

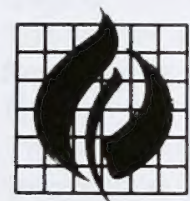

WORLD CONSERVATION MONITORING CENTRE

Published by:

ISBN:

Copyright:

Citation:

Cover design:

Cover photo:

Printed by:

Available from:

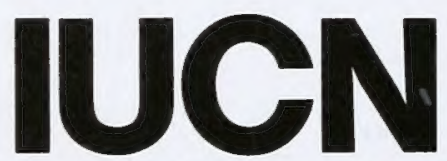

The World Conservation Union
World Conservation Press, Cambridge, UK.

\section{$189962810 \mathrm{X}$}

(c) 1998 World Conservation Monitoring Centre and International Union for Conservation of Nature and Natural Resources

Reproduction of this publication for educational or other noncommercial purposes is authorised without prior permission from the copyright holders, provided the source is acknowledged

Reproduction for resale or other commercial purpose is prohibited without the prior written permission of the copyright holders. The views expressed in this book do not necessarily reflect those of WCMC or its collaborators

The designations of geographical entities in this report and the presentation of the material, do not imply the expression of any opinion whatsoever on the part of WCMC or IUCN or other participating organisations concerning the legal status of any country, territory, or area, or of its authorities, or concerning the delimitation of its frontiers or boundaries

Oldfield, S., Lusty, C. and MacKinven, A. (1998). The World List of Threatened Trees. 650pp. World Conservation Press, Cambridge, UK.

Trevor Bounford, Chapman \& Bounford

Cucumber Tree Dendrosicyos socotrana by Tony Miller

Unwin Brothers, Martins Printing Group, Old Woking, Surrey

IUCN Publications Services Unit

219 Huntingdon Road, Cambridge, CB3 ODL, UK

Tel: +44 1223 277894; Fax: +44 1223277175

Email: iucn-psu@wcmc.org.uk

http://www.iucn.org/bookstore/index.html 



\section{CONTENTS}

FOREWORD 2

ACKNOWLEDGEMENTS

$\begin{array}{ll}\text { INTRODUCTION } & 7\end{array}$

Why species information is needed $\quad 8$

Collection and recording of information 9

Storing information $\quad 11$

Application of the IUCN threat categories and criteria $\quad 12$

Gaps in information $\quad 15$

The species summaries $\quad 16$

Summary of results $\quad 17$

Uses 18

The conservation of tree species

International policy implications $\quad 19$

$\begin{array}{ll}\text { The next steps } & 21\end{array}$

$\begin{array}{ll}\text { REFERENCES } & 23\end{array}$

$\begin{array}{lr}\text { SPECIES SUMMARIES } & 25\end{array}$

$\begin{array}{ll}\text { APPENDIX } 1 \text { Globally Threatened Tree Species of Australia } & 617\end{array}$

APPENDIX 2 Globally Threatened Tree Species of Japan $\quad 619$

APPENDIX 3 Not Evaluated Globally Threatened Tree Species $\quad 621$

APPENDIX 4 IUCN Red List Categories $\quad 629$

APPENDIX 5 Standard Data Collection Form $\quad 645$

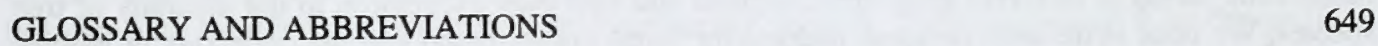




\section{FOREWORD}

I welcome this publication from WCMC of The World List of Threatened Trees. The importance of this unique document is reflected in the comprehensive collection and methodological analysis of information of the conservation status of tree species worldwide. The preparation of this work, which documents the threatened status of around ten percent of the world's tree species, is an impressive task, made possible through a collaborative and networking approach. WCMC has worked closely with the Species Survival Commission of the World Conservation Union and has successfully drawn together herbarium taxonomists, field botanists, forest genetic resources specialists, foresters and conservation biologists to pool their collective expertise on the world's trees in a remarkably short space of time.

Through its forest genetic resources programmes initiated in 1991, IPGRI has forged linkages with WCMC on this work, particularly in the process of the collection of information through workshops in collaboration with and for the benefit of national programmes. Some elements of IPGRI's activities on forest genetic resources which will benefit from the information in this publication are:

- Setting priorities for forest genetic resources conservation and use.

- Assessing patterns of species distribution, genetic variation and threats in forest ecosystems.

- In situ conservation: methodologies for assessing impacts of anthropogenic pressures in forest ecosystems and trees.

- Ex situ conservation: practical procedures for seed handling, storage and germination of species of high economic value in tropical forest ecosystems.

- $\quad$ Regional collaboration: networking and training activities in forest genetic resources.

Given the range and scale of threats to global forest biodiversity, the scope of forest conservation is clearly broad and activities that focus on conservation of ecosystems, species and intraspecific genetic diversity are all required. Within this broad approach, realistic targets are needed through focusing on priority species, priority populations and the level and extent of genotypic variation. In the location and assessment of diversity in forest ecosystems, IPGRI is looking at patterns of genetic diversity and levels of genetic erosion. These vary according to the nature of different forest ecosystems in different geographic regions and find their expression in the diversity of tree species. We need systematic decision making for forest conservation and the collection of species information is of great relevance in setting forest conservation priorities.

Information is needed on the kinds of species, threats and levels of threat, conservation status of species, in situ and ex situ conservation activities and requirements. Economic data are also needed. WCMC has made major strides forward in locating this information on tree species and encouraging others to develop more detailed national information.

I hope that the information contained in this publication and the supporting data management resources developed by WCMC will make an important contribution to the planning and implementation of forest conservation and sustainable management worldwide. We need to go further in refining and developing the information but with this impressive start and working in partnership with all key organisations we can give tree conservation the importance it deserves in the twenty first century.

Abdou-Salam Ouédraogo

Forest Genetic Resources, IPGRI Chairman, African Tree Specialist Group 


\section{ACKNOWLEDGEMENTS}

The World List of Threatened Trees is the principal report from a three year project entitled the Conservation and Sustainable Management of Trees, generously funded by the Government of the Netherlands. We are most grateful for this financial support, and would like to express our thanks in particular to Ton van der Zon, Gerrie Willems and Felix Hoogveld of the Netherlands Ministry of International Affairs.

The Conservation and Sustainable Management of Trees project has been undertaken by a team working at WCMC in collaboration with SSC Groups and other experts worldwide. The WCMC team consisted of Sara Oldfield, Project Leader; Charlotte Lusty, Data Management Officer; Martin Sneary, Information Analyst; Amy MacKinven, Research Assistant and Julie Reay, Project Administrator. Many other staff members at WCMC have supported the development of the project and particular thanks are due to Tim Johnson who supervised the project and to Harriet Gillett, Manager of the Threatened Plants Database. Sam Kanyamibwa and Javier Beltran have assisted with translation and communication with experts involved in the project in French and Spanish speaking countries. In addition the following volunteers, temporary staff and students have worked on the project at WCMC: Harriet Elson, Alejandro Flamenco-Sandoval, Kevin Holohan, Bill Oates, Liz Porter, Gemma Smith and Simon Reeve.

Charlotte Lusty has compiled the majority of species entries contained within this book and has reviewed the species data received from experts. She designed the standard data collection form incorporating ideas from David Hunt, Susan Iremonger, Valerie Kapos and others at WCMC. Martin Sneary has been responsible for the design and development of the Tree Conservation Database from which the species summaries have been produced as direct outputs, with support from Cardinal Consultants. Julie Reay has undertaken the formatting of this document for publication. The species summaries were proof-read by Margaret Deith.

Fifteen consultants, either institutions or individuals, have been involved in the Conservation and Sustainable Management of Trees project, evaluating and reviewing tree species data under contract to WCMC. We are grateful for all their work on the project. Joaquina Pires-O'Brien played an important role in coordinating input from experts on the Brazilian flora. Dennis Johnson coordinated the collection of data on palm species drawing on an extensive network of contacts. Collaborative contracts with various national institutions proved to be successful in ensuring linkages with the development of national biodiversity datasets. The contribution from experts in a voluntary capacity has, in addition, been of major significance with, for example, many herbarium botanists generously contributing their time to this tree conservation initiative.

SSC Groups have been closely involved in implementation of the project. Members of the Conifer Specialist Group, Charied by Aljos Farjon, have held a series of meetings in the UK funded by the project. They have used the standard data collection form to compile information on about 300 conifer species and have decided to continue this procedure for future updating. Members of the Temperate Broadleaved Trees Specialist Group, Chaired by Vicomte Philippe de Spoelberch, have provided data on selected genera and species and have prepared detailed species case studies for publication in Broadleaves, the Group's newsletter. Wendy Strahm has provided liaison between the project and the plant conservation activities of IUCN and we are grateful for her support.

Craig Hilton-Taylor, of the National Botanical Institute (NBI) of South Africa has coordinated the assessment of Southem African trees. To do this he has drawn on the responses of 11 amateur and professional botanists and combined this with information from NBI's Southern African Threatened Plants Database (SARARES) and literature references. This contribution is gratefully appreciated. 
The experts listed below have all made invaluable contributions to the project and we are most grateful for the information and expertise they have provided. For the provision of moral support, guidance and encouragement throughout the project we would like to express our particular gratitude to Peter Ashton, Aljos Farjon, William Hawthome, David Hunt, Jon Lovett, Adrian Newton and Abdou Salam Ouédraogo.

We also acknowledge with gratitude the institutional support provided by leading botanical and forestry institutes. Leiden's Rijksherbarium/Hortus Botanicus and Missouri Botanical Garden have been major sources of taxonomic and conservation status information on tree species of Southeast Asia and Latin America respectively. Links with botanists working in the field have also been facilitated greatly by contact with these two institutions. A wide range of organisations responded to the user needs survey undertaken in the early stages of the project and their information and suggestions were all appreciated.

The Forest Resources Division of FAO has been supportive of the project and a Memorandum of Agreement has been developed between WCMC and FAO covering tree species conservation data exchange. The International Plant Genetic Resources Institute (IPGRI) has also been involved in the development of the project and we are grateful for the support of these two organisations.

The Plant Resources of South-East Asia (PROSEA) project has been an invaluable source of information particularly on the uses of tree species. We are grateful for the cooperation with this project particularly through its office at Wageningen Agricultural University in the Netherlands.

The Center for Plant Conservation has generously provided information and advice with regard to trees of North America. The California Native Plant Society (CNPS) kindly provided a dataset of rare trees of California for inclusion in The World List of Threatened Trees.

Information compiled by WCMC for the 1997 IUCN Red List of Threatened Plants formed an important starting point for the World List of Threatened Trees. Harriet Gillett and Kerry Walter, the editors of the Red List are thanked for their help with the Conservation and Sustainable Management of Trees Project. The IUCN Red List was compiled in partnership with the following organisations: Nature Conservancy (TNC); National Botanical Institute (NBI), South Africa; Smithsonian Institution; Environment Australia ; Royal Botanic Garden; Royal Botanic Gardens, Kew and NYBG - The New York Botanical Garden.

For their help in preparing The World List of Threatened Trees, we thank in particular all the following experts who have participated in workshops, provided information and carried out assessments of the conservation status of trees around the world: Tony Abbott, Dennis Adams, Frits Adema, Javed Ahmed, Tania Ammour, Nguyen Hoang Anh, Robert Archer, Alberto ArecesMallea, Peter Ashton, Aké Assi, Lucia d'Avila, M Tekin Babac, C.R. Babu, Kevin Balkwill, Nguyen Tien Ban, Ninh Khac Ban, Angel Bañares Baudet, Salomao Bandeira, G.M. Barroso, Auriol Batten, David Baum, John Beaman, Henk Beentje, Peter Bellingham, John Benson, Keith Bennett, Dr van der Berg, R. Bernal, Jurgen Blaser, Lynn Bohs, Wolfgang Bopp, Adam Boratynski, F. Borchsenius, Philippe Bouchet, Loutfy Boulos, F.J. Breteler, Alvarez Brito, E. M. Lammerts van Bueren, Ximena Buitrón, Daniel Burke, John Burrows, P. Burrows, Fred Burton, Eduardo Calderon Saenz, Bruce Campbell, A. Carlstrom, Eduardo Carqué Álamo, Susan CarterHolmes, Freire de Carvalho, T.B. Cavalcanti, Jan Cerovsky, Andre Chanderbali, Miguel Chazaro, Lillian Chua, R.C.K. Chung, Philip Clarke, Margarita Clemente-Muñoz, Elize Cloete, Allen J. Coombes, Luis Corrales, Helen Corrigan, Patricia Craven, Quentin Cronk, Le Trong Cuc, Myriam Cukier, Cristina M.C. Curi Silva, Eduardo Dalcin, Barbara van Dam, Doam Diem, Bob Drummond, Tony Dold, Ali A. Dönmez, J.L. Dowl, Pham Hoai Duc, David Dupuy, Vu Van Dzung, Arthur Ebgret, Sue Edwards, Peter Eddowes, F.B. Essig, Barry Evans, R. Evans, Peter Evers, Aljos Farjon, Estrela Figueiredo, Jon Fjeldsa, Bryan Finnegan, Gennady Firsov, Jacques Florence, S. Fontinha, Enrique Forero, D. Forman, Steve Fourie, M.P. Frankis, David Frodin, D. Fuller, Fuh-Juinn Pan, Washington Galiano-Sanchez, Flavio Bertin Gandara-Mendes, Martin Gardner, Giuseppe Garfi, Demetrio Gaudagnin, C. Gemmill, Justin Gerlach, Coert Geldenhuys, 
Shahina A. Ghazanfar, Mario González-Espinosa, Mauro Gonzalez, Peter Goodman, J.J. de Granville, Alistair Griffiths, Ana Maria Guilietti, Nimal Gunatilleke, Adil Güner, Norbert Hahn, Stephen Halloy, Clare Hankamer, David Harris, Teresa Hart, William Hawthome, A. Henderson, Esteban Hernandez-Bermejo, William J. Hess, Craig Hilton-Taylor, Nick Hodgetts, Colin Hughes, Jonathan Hughes, David Hunt, Dang Huy Huynh, Pierre Ibisch, R. Jardim, Jim Jarvis, Jose Joaquim Campos, Peter Moller Jørgensen, Bob Johns, David Johnson, Dennis Johnson, Piet C. de Jong, Edith Kabesiime, Kees Kalkman, Martinus de Kam, Markku Kanninen, Anthony B. Katende, Phan Ke Loc, Ronald Keay, Shirley Keel, Daniel Kelly, Michael Kessler, Paul Kessler, Le Dinh Kha, Timothy Killeen, Yong Shik Kim, Naomi Kingston, K.M. Kochumenn, Herta Kolberg, Patricia Koleff, Jan de Koning, J.-N. Labat, Peter J. de Lange, Severinn M. Ten Houte de Lange, Antonio Lara, David de Laubenfels, J. Lejoly, Jinxing Lin, Silvia Llamozas, Jon Lovett, Janell Loving, Pete Lowry, Jose Luis Vivero, Domingo Madulid, Robert Magill, Colleen Mannheimer, Vongxay Manivong, Francisco Manuel Fernandes, Alfred Maroyi, Manuel Marrero, Nina Marshall, A. Mauchamp, Ruud van der Meijden, Wim Meijer, Brien Meilleur, Nico Mentik, Jean Yves Meyer, Detlev Metzing, Ndjele Miandi-Bungi, David Middleton, Tony Miller, Martín Mitré, Johanis P. Mogea, Norma M. Molinyawe, Brian Molloy, Sanjay Molur, Alex Montgomery, Dora E. Mora de Retana, S. Moraes, C. Moya, Tom Müller, Pugazhendhi Murugaiyan, Patrick Muthoka, Hidetoshi Nagamasu, Dominique N'Sosso, Carlos Navarra Pereira, Cyril H. NelsonSutherland, Adrian Newton, Geoff Nichols, Tony Nikolic, Dr Ngamusa, Nguyen Hoang Nghia, Chu Tuan Nha, Kevin Nixon, L. Noblick, Hans Nooteboom, Michael Oates, Jeff Odera, Hideaki Ohba, Jonathan C. Okafor, Salmon Okelo Achieng', Dr Ola-Adams, Abdou-Salam Ouédraogo, Garth Owen-Smith, Angeles Padilla, Chris Page, Wayne Page, Fuh-Juinn Pan, Caroline Pannell, Gilberto Pedralli, Tchouto Peguy, A.L. Peixoto, T.D. Pennington, J.P. Pereira Carauta, Oliver Phillips, Patrick S.M. Phiri, Nguyen Thanh Phong, Tran Lien Phong, Christian Pilegaard Hansen, Joaquina Pires-O'Brien, Derek Pomeroy, Darién E. Prado, H.J. Quero, Neptali Ramírez-Marcial, Tony Rebelo, Fay Robertson, Maricela Rodriguez Acosta, W.A. Rodrigues, Cathy Rogers, Renaat van Rompaey, J. Rosseel, John Rourke, Jens Rowher, Keith Rushforth, Mark Sandiford, L.G. Saw, George Schatz, Nico Schellevis, Peter Schmidt, Klaus Schmitt, Jochem Schneemann, Chris Schurmann, Robert Scott-Shaw, Kade Sidiyasa, N.M.F. Silva, Philippe de Spoelberch, J.S. Siemonsma, Stella Simiyu, G. Sita, Tonny Soehartono, Nicholas C. Songwe, Marc Sosef, Stephen A. Spongberg, F. Stauffer, Guy Stemberg, Wendy Strahm, Anukriti Sud, Weibang Sun, Cao Van Sung, Terry Sutherland, Marianne Syrylak-Sandison, James Taplin, Philip Thomas, Lex Thomson, Mats Thulin, Jonathan Timberlake, Duong Thi To, Roseli B. Torres, Piers Trehane, Thai Van Trung, Nguyen Van Truong, Allan Tye, Christopher Uhl, Carmen Ulloa Ulloa, Johan van Valkenburg, Israel Vargas, Nigel Varty, A.M.S. Vaz, Nohemy Elizabeth Ventura-Centeno, Carl Vernon, Carlos Villamil, J.L. Vivero, Andrew Vovides, Harrie Vreeman, Steve Waldren, Alistair Watt, Anna Weitzman, Pamela Wellner, Peter van Welzen, Marga Werkhoven, A. Whistler, Lee White, Martin Wiggington, Win de Wilde, Gary Wiles, Claire Williams, Braam van Wyk, Tetsukazu Yahara, Nelson Zamora, Elsa Zardini, James Zarruchi, Dr Zobeiry and S. Zona.

We record with great sadness that Salmon Okelo Achieng' was tragically killed during the time he was collecting data on the conservation status of endemic trees of Kenya. He was an enthusiastic field worker and contributed considerably to the discussions at the regional workshop for the project held in Harare in July, 1996, the first time he travelled out of his home country. We will remember Salmon with gratitude for his contribution to African tree conservation.

We are grateful for the help extended by the staff of the libraries at WCMC, the Department of Plant Sciences, Cambridge University, and at the Cory Lodge, Cambridge Botanic Gardens.

Tony Miller kindly supplied the cover photograph used in the cover design.

Additional financial support for publication of this book by the Owen Family Trust is gratefully acknowledged. 


\section{INTRODUCTION}

The conservation of biodiversity and its sustainable management are internationally recognised as vital global concerns. Identification of the components of biodiversity and the threats they face are important steps in planning for conservation action. Tree species are ecologically, culturally and economically valuable components of biodiversity and their conservation is essential to the well-being of people in all countries of the world. With increasing general pressures on ecosystems and selective pressures on species, it has become apparent that many tree species are threatened with extinction. Information on the degree and extent of threat has, however, previously been scattered and scarce. The World List of Threatened Trees presents the results of the first survey of the conservation status of trees species worldwide.

Assessment of the conservation status of the world's tree species is a major task given the overall number of trees believed to exist. The world's tree flora is estimated to total around 100,000 species. It is not yet possible to give a precise figure because definitions of the term "tree" vary as do species concepts. One definition of "tree" which is commonly followed in temperate regions is a woody plant growing on a single stem usually to a height of over two metres. This definition has been adopted by the IUCN/SSC Temperate Broadleaved Tree Specialist Group. The Group recently compiled a list of temperate woody plant genera and estimated the number of tree species within these genera. This was undertaken to establish the scale of the task of conservation evaluation for temperate tree species. The tentative result was that there are 21,000 species in plant genera which are predominantly woody and temperate in distribution (Hunt, 1996). The richness of the world's tropical tree flora is certainly much greater and is also in greater need of taxonomic attention. In reality we can only make an informed guess at the total number of tree species. Nevertheless there is an urgency to document all available information on the growing number of tree species which are of conservation concern.

In evaluating the global conservation status of tree species the new IUCN Red List categories and criteria have been followed. The general aim of the new IUCN system of categorising threat is "to provide an explicit, objective framework for the classification of species according to their extinction risk" (IUCN, 1994). The IUCN categories and criteria have been applied to a broad selection of restricted range and exploited tree species as part of a major collaborative information gathering and evaluation exercise. In pre-selecting tree species for conservation evaluation, species from all parts of the world and most taxonomic groups were considered. Certain taxonomic groups were, however, excluded for pragmatic reasons. These include tree ferns in the families Cyatheaceae and Dicksoniaceae, tree species in the cycad families Cycadaceae and Zamiaceae, and arborescent members of the Cactaceae family. It was anticipated that the conservation status of species in these families would be evaluated in parallel exercises by the appropriate SSC Plant Specialist Groups.

As part of the conservation evaluation, the taxonomy and nomenclature of each of the tree species categorised as globally threatened have been checked, wherever possible, against current literature or by appropriate experts. Supporting information has been collected on the distribution, threats, conservation measures, the habitat type of the species, the uses of the species, level of use and ecological information. This more detailed information is available in electronic form in the Tree Conservation Database supplementing the summary information on individual species provided in The World List of Threatened Trees.

Over 7300 tree species are documented as globally threatened in this publication (see Table 2), based on the 1994 IUCN categories and criteria. In addition, in the Appendices, supplementary lists of globally threatened trees are given. Appendix 1 is a list of Australian globally threatened trees prepared for this publication by Lyn Meredith, Threatened Species and Communities Section, Environment Australia. Appendix 2 provides a list of Japanese tree species taken from the 1997 Red List of Japanese Vascular Plants compiled by the Threatened Species Committee, Japan Society of Plant Taxonomists (Yahara, T. 1997). Unfortunately this publication was not available in time to prepare 
species summaries for inclusion in the main text of the book. Appendix 3 provides a supplementary list of tree species from other parts of the world which are included as globally threatened in the 1997 IUCN Red List of Threatened Plants but which have not yet been evaluated against the new IUCN categories and criteria. Generally this reflects lack of current information on the species concerned.

Taking all this information together, nearly nine percent of the world's tree flora is documented as globally threatened with extinction. Given the economic and local value of tree species and their role in defining ecosystems, this represents a profound diminution of the world's biodiversity. The availability, for the first time of consolidated tree species conservation information should have a significant impact on international conservation policy and planning. It is hoped that this book will highlight the need for sustained efforts to conserve maximum tree species diversity for the benefit of people worldwide.

Evaluating the global conservation status of the world's trees is clearly a major undertaking and has only been possible through collaboration with a wide range of experts and institutions with local knowledge of tree biodiversity. A full list of contributors is given in the acknowledgements section and the assessors of the conservation status of individual tree species are noted with the species summaries. The identification of a network of botanists willing to contribute their expertise to the conservation of tree species is in itself an important factor in the promotion of global biodiversity conservation.

\section{WHY SPECIES INFORMATION IS NEEDED}

The need for sound biodiversity information on which to base conservation policy is now widely accepted. The need for biodiversity information to support policy and management objectives for tropical forests is, for example, highlighted in Box 1. Biodiversity is generally considered at three levels: the ecosystem, species and genetic resource level. As a broad indicator of the expression of biodiversity on a global scale, ecosystems are generally considered and ecosystem diversity is taken as a measure of species and genetic diversity. This is partly because of the sheer complexity of biodiversity below the ecosystem level, the lack of consistent and comparable information for most groups of organisms and the need to make rapid progress in biodiversity assessment for conservation action. Species information can, however, when organised in a coherent manner, following accepted information standards, reinforce ecosystem information and provide a crucial link with information on the component genetic resources. Various recent initiatives (SBSTTA, 1996; Van Bueren and Duivendoom, 1996) have recognised that tree species diversity in particular can be used as a surrogate for overall species diversity in forest ecosystems given the relatively good availability of tree species information. Information on the distributions and convergences of restricted range species can be used to determine patterns of biodiversity.

Information on the threat status of species is essential in planning for conservation and sustainable management of individual species and also for use as an indication of ecosystem status. Information on threatened species is becoming increasingly available, at least for selected taxonomic groups. For plants in general, many national lists of threatened species and plant Red Data Books have been produced and recently the first international Red List of plants was published by IUCN (Walter and Gillett, 1998). This global list represents many years of effort to record and collate the names, conservation status and distribution of rare and declining plants. The database from which the global list was produced and national Red Lists and databases vary in the extent to which they record habit. Information on the habit, in other words whether the plant is a tree, shrub or herb, can provide an important indication of the ecological role of the species. Information on tree species has been seen as a particular requirement to support forest conservation policy but has not, until now, been readily available at an international level. 
Box 1. Biodiversity information for conservation and wise use of tropical forests

Biodiversity information is needed to support the following policy and management objectives:

Land use planning for conservation and sustainable use of forest land

Designation and management of totally protected natural forest areas

Protection and reintroduction of endangered species

Support, adoption and documentation of indigenous management of tropical rain forests

Use and valuation of non-timber forest products

Sustainable timber production

Rehabilitation and productive use of secondary forests

Van Bueren and Duivenvoorden, 1996

\section{COLLECTION AND RECORDING OF INFORMATION}

The starting point for the collection of information on the conservation status of trees has been data holdings in the Threatened Plants Database maintained by WCMC. This records information on the distribution, global and national conservation status of plant species worldwide and has been used to produce the 1997 IUCN Red List of Threatened Plants. Important sources of conservation status information within this database include the IUCN/SSC Plant Specialist Groups, individual experts, national red lists and Red Data Books and, of major importance, the partner organisations listed in the acknowledgements section of this book.

Information on the conservation status of trees included in the Threatened Plants Database was derived from various studies in addition to the general information sources referred to above. The conservation status of temperate tree species was, for example, reviewed by WCMC in collacoration with the International Dendrological Society (IDS) and a Threatened Temperate Tree List was published in 1990 (Lear, 1990). This was updated for an IDS Symposium held in 1994 (Lear and Hunt, 1996). Information on the conservation status of conifer species has been developed by the SSC Conifer Group (Farjon, Page and Schevellis, 1993, Farjon, 1996) and made available for incorporation in the Threatened Plants Database. Information on the conservation status of tropical timbers in trade was collected for the International Tropical Timber Organisation with data collection concentrating on timber species of Southeast Asia and Africa (Oldfield, 1991). Collection of data on trees of Latin America was subsequently undertaken by WCMC with support from the UK Govemment.

When the tree species conservation survey was initiated, the Threatened Plants Database maintained by WCMC contained records of about 5000 tree species, 4,000 of which are tropical and 1,000 temperate in distribution. Over 600 of these species were recorded as globally threatened using the old IUCN categories of threat. Initial tasks in preparation for The World List of Threatened Trees were to identify and flag tree species in the Threatened Plants Database and to add a significant number of tree species name and distribution records from various parts of the world. Main geographical areas for which tree name and distribution records were added initially include Ghana, Nigeria, East Africa, Madagascar and Indonesia. Additional tree species name and distribution records were added through the electronic data merges in preparation for the 1997 IUCN Red List of Threatened Plants. In the first 
year of data collection, tree species records were increased from 5000 to 14,000 . A list of 3200 tree species recorded as globally threatened according to the old IUCN categories of threat was prepared for review at a Technical Workshop held in Wageningen in November 1995.

Following the Technical Workshop, a data collection form was designed for experts to provide updates to existing data holdings on tree species in the Threatened Plants Database, and to record new information on species of conservation concern. This is reproduced in Appendix 5. Species were selected for review if they were believed to be single country endemics, threatened in significant parts of their distribution ranges or known to be widely exploited.

Standard data collection forms were sent to over 300 botanists or foresters with expertise in a particular geographical area or taxonomic group of trees. In addition a series of meetings, workshops and interviews was held to discuss the conservation status of tree species and to assign the IUCN categories. Four international workshops were held. The first was the Technical Workshop held in Wageningen which was successful in refining the scope, objectives and methodology for data collection. Three regional workshops have subsequently been held in Zimbabwe, July 1996; Costa Rica, November 1996 and Viet Nam in August 1997. These workshops provided an opportunity for participants to present and discuss national case studies on the conservation status of trees, to discuss conservation status in relation to sustainability issues and to work on species conservation assessments in small working groups. Training in the application of the IUCN categories and criteria was provided. The conservation assessments focussed on relatively widespread, exploited species which are difficult to evaluate without information from a significant proportion of the species' range. The evaluations were based on preliminary species profiles prepared by WCMC.

At the regional workshop held in Zimbabwe a draft list of globally threatened tree species occurring in Africa was reviewed. A follow-up meeting was held during the AETFAT Congress in February 1997 to review African data collection and hold an inaugural meeting of the SSC African Tree Specialist Group. Also following the Zimbabwe regional workshop, assessment of the conservation status of trees of Southern Africa was coordinated by Craig Hilton-Taylor of the South African National Botanical Institute. Data sheets for all tree species considered to be threatened in southern Africa were sent to 23 amateur and professional botanists situated in Namibia, South Africa and Swaziland. Documentation explaining how to fill in the data sheets and how to use the new IUCN Red List Criteria and Categories was provided. Each person was asked to fill in data sheets for those species which they were familiar with in the field. Eleven people responded. Information from the replies was combined with information from the National Botanical Institute's southem African Threatened Plants Database (SARARES) and information from the literature to obtain an overall assessment.

Discussions held with botanists at the Rijksherbarium, Leiden and Missouri Botanic Garden have also enhanced the tree conservation evaluation process. Botanists at the Rijksherbarium provided information on the taxonomy and conservation status of trees in Southeast Asia. Assistance provided by Missouri included information from various major checklist projects notably for Peru (Brako and Zarucchi, 1996) and Ecuador (Jorgensen and León, in prep.) and the facilitation of contacts with botanists working in many Latin American countries.

Collection of tree conservation information was also facilitated by collaborative arrangements with national agencies. These have both provided information for the global tree conservation dataset and stimulated the collection of data for national use. Examples include:

Production of A Draft Red List of Woody Plants of Uganda through a contract with Makere University Institute of Environment and Natural Resources, Uganda.

Support for the collection of information on endemic trees of Kenya by the Plant Conservation Programme, National Museums of Kenya.

Collection of data on endemic tree species of Peninsular Malaysia through a contract with Dr Lillian Chua, Forest Research Institute of Malaysia. 
Compilation of data on the conservation status of Panama's trees by Martin Mitré, Smithsonian Tropical Research Institute, Panama.

Compilation of data on the endemic and indigenous tree species of the Seychelles by the Conservation Section of the Ministry of Foreign Affairs, Planning and Environment, Seychelles.

Provision of information from a Mexican tree specimen database and conservation evaluation by Dr Mario González-Espinosa and Neptali Ramírez-Marcial, ECOSUR, Chiapas following agreement with CONABIO.

Preparation of a list of rare and threatened trees of Suriname by Marga Werkhoven, National herbarium of Suriname, updating the Rare and Endemic Plant Species in Suriname from the Conservation Action Plan for Suriname (1990) and subsequent 1997 list of Rare and Endemic Plant Species in Suriname.

Provision of information on threatened trees of Viet Nam at the regional workshop and decision by Vietnamese botanists represented to adopt the new IUCN categories of threat and apply them through the continuation of a national working group.

The SSC Plant Specialist Groups have been a major source of information and conservation evaluations for The World List of Threatened Trees. Members of the Conifer Specialist Group have used the standard data collection form to compile information on about 300 conifer species and have adopted this procedure for future updating of conservation status information. Members of the Temperate Broadleaved Trees Specialist Group have provided data on selected genera and have prepared detailed species case studies for publication in Broadleaves, the Group's newsletter. In addition over 300 palm species, identified as trees from an initial list of threatened palms, have been evaluated using the standard data collection form by members of the Palm Specialist Group, coordinated by Dr Dennis Johnson.

In order to supplement the information provided by experts, WCMC has reviewed a wide variety of data sources including electronic databases, published Floras and Monographs, Red Data Books and grey literature. On the basis of this information, conservation evaluations have been undertaken by WCMC for species apparently of significant conservation concem. Wherever possible these have been sent out for expert review. Compilers at WCMC also recorded supplementary information on ecology and uses of species, drawing heavily for Southeast Asian species on the excellent PROSEA publications (Soerianegara and Lemmens, 1993; Lemmens, Soerianegara and Wong, 1995).

\section{STORING INFORMATION}

Following the Technical Workshop in Wageningen, a new database was designed to record tree species conservation information, resulting from the completed standard data collection forms. Amendments to the species and distribution records were initially recorded in the Threatened Plants Database maintained by WCMC, to ensure consistency with the broader global plant conservation dataset. Subsequently tree species scientific and common names, distribution records and in some cases use records were transferred electronically to a new Tree Conservation Database. The design of the Tree Conservation Database took into account a user needs survey of 500 organisations carried out prior to the Wageningen Technical Workshop, and discussions with FAO and IPGRI concerning tree conservation data management. The potential for harmonised data management with the following data management systems was an important consideration.

REFORGEN database system, developed by the Forest Resources Division of FAO, is a global database system designed to house information related to the world's forest genetic resources. 
TREESOURCE, a global information system on forest genetic resources, represents a collaborative effort between FAO, CIFOR, ICRAF and IPGRI, and has been designed to provide readily, reliable and accessible information on forest genetic resources.

A further key consideration was the requirement for a distributed database which could be made widely available in support of tree conservation initiatives. The database has been implemented using the latest generation of Microsoft Windows based software. It is designed to be simple to use and intuitive in operation, as well as conforming to recognised Windows standards. The choice of software tool was further influenced by the ability to link with other applications, including mapping tools. In addition, a Windows-style searchable help system has been developed. The system is implemented in Microsoft ${ }^{\circ}$ Visual Basic and Access.

The species summaries recorded in The World List of Threatened Trees have been derived directly from the Tree Conservation Database which also records a considerable amount of supplementary information on each tree species.

\section{APPLICATION OF THE IUCN THREAT CATEGORIES AND CRITERIA}

IUCN categories of threat have been in use for over thirty years and are widely recognised as a standard for indicating the conservation status of individual species. The revised categories and criteria published in 1994 (IUCN, 1994) were developed to make the threat categories more quantitative, objective and equally applicable to all higher taxa of plants and animals. Under the new system, a category can only be assigned to a species if one or more of five criteria apply. Thus in order to qualify as Critically Endangered, Endangered or Vulnerable, evidence is needed to demonstrate that a species is experiencing, to various degrees, at least one of the following:

Criterion A

Criterion B

$\begin{array}{ll}\text { Criterion C } & \text { Population is small, according to specified numbers, and either } \\ \text { defined rate or declining and with a specified population structure. }\end{array}$

Population is seriously declining, or is expected to decline, at a defined rate. Population is localised, within defined limits, fragmented and declining.

Criterion D Population is very small, according to specified numbers, and acutely restricted, within defined limits.

Criterion E Quantitiative analysis showing the probability of extinction.

The use of criteria helps both to guide the assessor and to give transparency to the evaluation process. The rules for applying the IUCN categories and criteria are set out with explanatory notes in Appendix 4. Various criteria can be applied to any one species. The extent to which different criteria have been used in the tree species evaluations is summarised in Table 1. The use of Criterion $\mathrm{E}$ has been negligible for trees.

Table 1. Use of Criteria

\begin{tabular}{|l|r|r|r|c|}
\hline Criterion & \multicolumn{1}{|c|}{$\begin{array}{c}\text { A } \\
\text { Population } \\
\text { decline }\end{array}$} & $\begin{array}{c}\text { Bopulation } \\
\text { localised }\end{array}$ & $\begin{array}{c}\text { C } \\
\text { Population } \\
\text { numerically } \\
\text { small }\end{array}$ & $\begin{array}{c}\text { Dopulation } \\
\text { very small \& } \\
\text { restricted }\end{array}$ \\
\hline Percentage of criteria applications & 22 & 56 & 6 & 16 \\
\hline
\end{tabular}

At the outset of data collection for The World List of Threatened Trees experience with the application of the new categories was very limited. The new system differs quite radically in its method of application from the previous IUCN categories with which most botanists and conservation agencies have become familiar. Concems were expressed initially about the applicability of the categories to tree species, mainly because of the lack of knowledge of reproductive biology and population numbers 
for the majority of tree species. Furthermore it soon became apparent that the longevity of tree species poses a particular problem in application of the categories, with regard to interpretation of rates of decline. Guidelines were prepared by Charlotte Lusty to assist expert evaluations for tree species and to help ensure consistency in application of the categories by different assessors, especially those working in isolation. The guidelines for trees were developed from recommendations made by William Hawthome, following a detailed review of the application of the categories to Ghanaian tree species, and incorporated suggestions from other botanists using the categories for trees. The guidelines provide both assistance with interpretation of the criteria through suggested supplementary definitions of terms relevant to tree species and suggestions as to how different sources of information can be used to aid the evaluation process.

In order to qualify as globally threatened based on population reduction (A Criterion), the population of a species should have an observed, estimated, inferred or suspected reduction of at least 20 percent over the last 10 years or three generations. The expression of generation time as specified by IUCN, 1994 is the average age of parents in the population. Defining the generation time of a tree species is very difficult given that the capability of reproduction in tree species varies widely according to the age/size class of individuals. For evaluation purposes, the guidelines for trees suggest that where no information is available the generation time should be taken as 50 years for most tree species, 10-20 for pioneer species or small trees, 100 years or more for slow-growing trees. Following this estimation very many tree species potentially fall within at least the Vulnerable category given the rates of deforestation, and therefore implied population decline, or the rates of exploitation of mature timber trees, over the past 150 years.

Linking tree species distribution data with knowledge of the extent and decline of the ecosystem in which the species occurs has been the means by which the IUCN categories have been most commonly applied to trees. Criterion B and D are appropriately used for such cases where the threat status is based on the geographical restriction of species.

GIS (Geographical Information System) analysis of species distribution information has proved to be a very useful tool in applying Criterion $B$ and Criterion D, Where species point localities, ideally based on verified specimen data, can be stored in a GIS, data can be very successfully manipulated to assess whether their AOO (Area of Occupancy) or EOO (Extent of Occurrence) are within the limits set by the Criteria B and D. David DuPuy and Jonathan Hughes have evaluated the conservation status of a subset of Madagascan leguminous trees in this way, combining species distribution data with vegetation and substrate data in a GIS application.

The guidelines encourage evaluators to use all available sources of secondary information to assess the situation faced by a particular species. In ideal circumstances information from verified herbarium specimens and field survey of populations would be combined with general knowledge of vegetation types and decline throughout the range of a tree species, together with information on levels of exploitation through time where appropriate. Where such information is not available, however, it has been possible, by examining geographical and altitudinal ranges, and habitat requirements of the species, to make preliminary evaluations of the conservation status.

In general the categories have not been applied using fully quantifiable information. This is fully compatible with the guidance provided by IUCN, 1994 which states that, the absence of high quality data should not deter attempts at applying the criteria, as methods involving estimation, inference and projection are emphasised to be acceptable throughout. Furthermore, given that data are rarely available for the whole range or population of a taxon, it may often be appropriate to use the information that is available to make intelligent inferences about the overall status of the taxon in question. In cases where a wide variation in estimates is found, it is legitimate to apply the precautionary principle and use the estimate (providing it is credible) that leads to listing in the category of highest risk.

Although the new IUCN Red List Categories are much more objective than their predecessors, there is inevitably considerable scope for subjectivity. Different expert assessors have applied the categories with differing levels of confidence with regard to available information and different 
degrees of optimism regarding future trends. This has even applied when different assessors looked at the same species, where some, for example, have used Data Deficient and others have applied Critically Endangered. Some assessors have felt that they should use Data Deficient unless there have been recent field assessments of the species. This approach may be more appropriate where there are active conservation monitoring programmes but generally a greater degree of inference has been necessary. In such cases of divergent views the compilers have acted as referees and applied the category which appeared more appropriate in consultation with the assessors.

The use of the Lower Risk categories has also varied according to the opinion of different assessors. It is not always clear how much inference is appropriate to decide whether a species is Lower Risk or Vulnerable, particularly with regard to Criterion A. The category Lower Risk: conservation dependent should only be used for those species where a species-specific conservation measure ensures that the species does not qualify for Vulnerable, Endangered or Critically Endangered. Inclusion in a protected area is considered to be a sufficiently secure conservation measure to prevent a species being in a higher risk category by some assessors but there has not been uniformity of opinion on this issue.

Some assessors have probably followed the IUCN rules more rigidly than others. After careful consideration, the compilers decided not to apply a blanket standardisation of the categories and criteria across all tree species following the application by experts, although in some cases adjustments to particular species have been made through consultation. The compilers do not have the intrinsic knowledge of species in particular geographic regions and taxonomic groups which may have contributed to the expert evaluations. The listing of species should be seen as a fluid process, with scope for re-evaluations of species as more information becomes available, and as further debate on the categorisation process takes place.

Particular mention needs to be made concerning the dipterocarp trees of southeast Asia. Over 250 of these species have been listed in the most threatened category of Critically Endangered, using Criterion A. The basis for this assessment is the very rapid rates of forest loss in southeast Asia. Criterion A measures decline rates for long-lived species, such as trees, over a period of three generations. This amounts to at least 150 years for the dipterocarp species. Thus over 250 species of dipterocarp are believed to have lost over 80 percent of their forest habitat over the last three generations and are therefore listed as Critically Endangered. These listings might seem somewhat out of place alongside most other species listed as Critically Endangered, which tend to occur in tiny populations, sometimes of only a small number of individual trees. However, it is very important to be clear that extinction times scale with a species' generation time, and not with absolute time. All other things being the same, a long-lived species takes longer to go extinct than a short-lived species. If one considers a time window that is short relative to the lifetime of the species, one might miss the fact that it is in trouble, even if it is heading inexorably to extinction. To take a simple example, if one counts the numbers of a short-lived species with four generations per year and declining at 50 percent per generation, the population will have declined to 6.25 percent of the starting number after one year. Conversely, a species with a long generation time (say 100 years), but also declining at 50 percent per generation will exhibit almost no detectable decline as measured over a one-year period. The listing of the dipterocarps is therefore more logical and appropriate than appears at first sight.

Nevertheless, there is controversy concerning the use of Criterion A in this manner, and this is being studied as part of the SSC's ongoing review of the Red List Criteria. Three areas are currently being considered for possible revision of Criterion A: a) whether or not there should be a maximum time-limit set for estimates of generation-time, to make inference and projection more restricted in time for long-lived species and therefore more reliable; (b) the extent to which listing should incorporate information on whether or not the decline is controlled or managed, and therefore how likely it is to continue into the future; and (c) whether or not the current decline rates specified in the criteria are appropriate. 


\section{GAPS IN INFORMATION}

The three year time period for preparation of The World List of Threatened Trees has allowed for rapid assembly and review of currently available information on the conservation status of trees. There are, however, clear information gaps. These result from lack of identified expertise on particular taxa or geographical areas or lack of time for information to be compiled where experts were contacted in the later stages of the data collection process. For some parts of the world and certain taxonomic families information is not yet available on which to base sound conservation assessments. The design of the data management system, the involvement of a wide network of experts and the further coordinated development of the SSC Plant Specialist Groups, with capacity to manage their own decentralised data, will allow continual updating of the global Tree Conservation Database.

\section{Taxonomic uncertainty}

In some cases it has been very difficult to apply categories because of taxonomic uncertainty. This is the case for example with the genus Ardisia in the family Myrsinaceae. In Panama, alone, about 110 species have been described mainly on the basis of original collections which often did not have flowers or fruiting material. There is a need for taxonomic revision taking into account the wealth of unverified herbarium specimens. The situation is similar for many other genera of trees.

\section{Areas which are poorly known}

Papua New Guinea provides an example of a biodiversity rich country which remains poorly explored. As outlined by Frodin (1997) a relatively intense phase of biological study took place within the country from 1946 through the 1980s. This generated various major publications on vegetation, biogeography and ecology but there has subsequently been a general decline in new research work and particularly in botanical exploration in Papua New Guinea (Conn, 1994). Frodin (1997) notes that at the present time, there is no crticial and effective study of trees for Papua New Guinea and little prospect of one without substantial outside support. Given the low current exploration rate and the serious research and documentation backlog in general the conservation status of tree species is one of "data deficiency". Enough is known, however, about certain timber species to apply the IUCN categories and criteria and species summaries are included in the book for such species.

\section{Scientific reluctance}

In general there has been overwhelming support from the botanical community for the preparation of The World List of Threatened Trees. There have, however, been instances where botanists were reluctant to share unpublished information. This has resulted in some cases from a sense of frustration with the difficulty of securing resources for the publication of taxonomic work and equally with concerns about incorporating new species names which have not been previously validly published in the scientific literature. In other cases herbarium botanists did not feel they had sufficient field knowledge to make conservation evaluations.

\section{Time constraints}

Locating and compiling information on the conservation status of trees has proceeded rapidly in preparation of The World List of Threatened Trees but unfortunately it has not proved possible to develop or incorporate all the information located. More comprehensive evaluation of the conservation status of tree species for many countries would add significant numbers of species to the list of globally threatened tree species. Countries for which very little new information has been compiled include Cameroon, Dominican Republic, Fiji, Guatemala, Haiti, Korea, the Philippines and Thailand. In some cases this was because of lack of time to establish contacts within the countries.

Information on African tree species, compiled in the early stages of data collection, has been subject to a more extensive period of review. Less time was available to incorporate and review the more extensive tree data for other tropical regions. Examples of countries for which data has only been 
partially processed for this publication include Bolivia, Costa Rica, Japan, Mexico, Peru and Viet Nam. To provide one specific example, the specimen database provided by ECOSUR provided a very rich source of data. This database contains data from 14000 herbarium specimens for Mexican tree species, with information on vegetation type, associated genera, and altitude. For each tree species recorded in the database the new IUCN category was added by experts at ECOSUR and, with approval from CONABIO, this data was provided to WCMC. Information has been added to the Tree Conservation Database for endemic trees of Mexico but there has been no time to seek information on the wider distribution and conservation status for non-endemic trees.

\section{THE SPECIES SUMMARIES}

The main body of this book is the compilation of conservation summaries for the 7388 tree species which have been evaluated as globally threatened. The summaries are arranged alphabetically by genus. In order to reduce the size of the species accounts, scientific authorities for species names and common names are not given although these are recorded in the Tree Conservation Database.

The threatened tree species included are those which have been evaluated as Critically Endangered, Endangered and Vulnerable. Species which have been evaluated as Lower Risk: near threatened and Lower Risk: conservation dependent are also included because, in most cases, the supporting information suggests that these trees are of equal conservation concern to species in the Vulnerable category. Furthermore summaries are also included for species evaluated as Data Deficient where it is apparent that the species are in a precarious situation even though some verification is needed of the taxonomic status or further field investigation is desirable. Frequently these species have been referred to as threatened elsewhere in the literature.

For each species the following information is given:

Botanical family name The standard followed for family and generic names is Brummitt, 1992.

IUCN Red List category and criteria These are reproduced in full with the explanatory notes in Appendix 4.

Distribution The complete geographical distribution of species is recorded, as far as is known. Biological Recording Units are generally given, following Hollis and Brummitt, 1992. The only changes from this standard are for the Provinces of South Africa, Eritrea and the Democratic Republic of Congo (the former Zaire).

Conservation summary This is based primarily on information provided by experts in the standard data collection forms (see Appendix 5), or from literature sources. In some cases the summary has been prepared by the expert who has evaluated the species and in other cases by the compilers at WCMC. Words which are preceded by an asterisk are further defined in the glossary.

Assessor This is either the expert whom, or organisation or regional workshop which, has assigned the IUCN category and criteria.

References The references relate either to botanical literature linked to the taxonomy, nomenclature and distribution of the species or to the source of conservation information including the conservation assessment. 
Table 2. Summary of the number of tree species assessed according to the 1994 IUCN threat categories for inclusion in The World List of Threatened Trees.

\begin{tabular}{|c|c|}
\hline \multicolumn{2}{|c|}{ Globally threatened tree species } \\
\hline 1994 IUCN Threat Category & Number of trees \\
\hline Extinct & 77 \\
\hline Extinct in the wild & 18 \\
\hline Critically Endangered & 976 \\
\hline Endangered & 1,319 \\
\hline Vulnerable & 3,609 \\
\hline Lower Risk: near threatened & 752 \\
\hline Lower Risk: conservation dependent & 262 \\
\hline Data Deficient & 375 \\
\hline Sub Total & $\mathbf{7 , 3 8 8}$ \\
\hline Lower Risk: least concem & 1,971 \\
\hline Not evaluated & 732 \\
\hline Total number of species reviewed & 10,091 \\
\hline Globally threatened Australian tree species & 141 \\
\hline Globally threatened Japanese tree species & 202 \\
\hline $\begin{array}{l}\text { Additional globally threatened species - old IUCN } \\
\text { threat categories }\end{array}$ & 1,022 \\
\hline Total number of globally threatened tree species & 8,753 \\
\hline
\end{tabular}

Note: Numbers of species given in the supplementary tree species lists in the Appendices are also included to give a global total.

The reasons for the decline and rarity for these tree species are varied. In addition to the threats mentioned in the species summaries, supplementary threats to each species are recorded in the Tree Conservation Database. In general, the threatened status of tree species results from processes of habitat modification and destruction. Specific threats may also result from direct exploitation of the species for timber or other products at rates which are unsustainable. The threats most commonly recorded in the Tree Conservation Database are summarised in Table 3.

Table 3. Most frequently recorded threats to globally threatened tree species

\begin{tabular}{|l|r|r|r|r|}
\hline Threat & \multicolumn{1}{|c|}{ CR } & \multicolumn{1}{|c|}{ EN } & \multicolumn{1}{c|}{ VU } & \multicolumn{1}{c|}{ Total } \\
\hline Felling & 168 & 360 & 762 & 1290 \\
\hline Agriculture & 127 & 232 & 560 & 919 \\
\hline Expansion of settlement & 119 & 209 & 423 & 751 \\
\hline Grazing & 97 & 122 & 198 & 417 \\
\hline Burning & 50 & 77 & 158 & 285 \\
\hline Invasive plants & 88 & 78 & 79 & 245 \\
\hline Forest management & 12 & 61 & 141 & 220 \\
\hline Local use & 13 & 55 & 105 & 173 \\
\hline Mining/exploration & 19 & 31 & 101 & 151 \\
\hline Tourism/leisure & 23 & 51 & 60 & 134 \\
\hline
\end{tabular}

Threats have been recorded primarily as a basis for determining the required actions needed to reverse the decline of individual species. The threats to tree species are based on personal observations and assumptions and there will be a bias according to the geographical areas where most species 
information has been collected. The relative importance of different threats implied by the above table should therefore be read with a degree of caution. It is interesting to note, however, the perceived impact of felling as a major threat to tree species. This threat includes both clear felling and selective felling. The fact that over 1000 tree species are considered to be globally threatened as a result of felling reinforces the need for timber harvesting regimes to be managed on a sustainable basis taking into account the impact on non-commercial species.

\section{USES}

Information on use and level of use of tree species is recorded in the Tree Conservation Database. The information collated on globally threatened tree species illustrates that 25 percent have at least one recorded use. The use data remains incomplete but nevertheless Table 4 indicates the utility value of the tree species which are threatened with extinction.

Table 4. The recorded uses of globally threatened tree species

\begin{tabular}{|l|r|r|r|r|r|r|}
\hline Use & \multicolumn{1}{c|}{ CR } & \multicolumn{1}{c|}{ EN } & VU & \multicolumn{1}{c|}{ DD } & \multicolumn{1}{c|}{ LR nt } & \multicolumn{1}{c|}{ LR cd } \\
\hline Timber & 257 & 281 & 535 & 49 & 184 & 45 \\
\hline Fuel & 17 & 46 & 141 & 8 & 34 & 8 \\
\hline Medicinal & 17 & 33 & 91 & 12 & 34 & 6 \\
\hline Food & 26 & 45 & 105 & 14 & 43 & 8 \\
\hline Oil, gum, resin & 43 & 40 & 60 & 7 & 15 & 5 \\
\hline
\end{tabular}

\section{THE CONSERVATION OF TREE SPECIES}

The assignment of conservation categories can be an important step in deciding priorities for conservation action. As has already been noted a particularly wide range of tree species fall within the Vulnerable category as a result of the decline of their forest ecosystems over the past 150 years and the longevity of individual trees within this time frame. Furthermore, the rate of exploitation of mature individuals of timber species over this period inclines the species to the Vulnerable category. It is suggested that in developing priority conservation actions for tree species based on the categories of threat, the development of sustainable use rather than protection mechanisms per se should be the focus for economically valuable species which are categorised as Vulnerable based on levels of exploitation.

Most of the species categorised as Vulnerable are those which have a restricted range and are found in habitats which are fragmented and declining (Criterion B); or have very small and restricted populations (Criterion D). For these species in situ protection is particularly important either within areas set aside for conservation or as protected stands within areas, for example, of agricultural or forestry land use. Clearly where the locations of restricted range and threatened tree species converge, these sites should be protected to conserve the maximum number of threatened trees.

Tree species which are Critically Endangered or Endangered are those for which remedial conservation action should be a priority to prevent further decline towards extinction. Where more widespread species fall into these categories because of the rates of decline (Criterion A), however, as with the dipterocarp species, sustainable use initiatives may be equally appropriate. Information in the species summaries indicates those species for which immediate rescue attention is needed.

Measures to secure the conservation of tree species include research into the reasons for decline, protective legislation, in situ protection within designated conservation areas, management of populations in their natural habitats, ecological restoration measures, control of invasive species, and ex situ conservation in botanic gardens, arboreta and seed banks. Where in situ and ex situ conservation measures are already known to be in place for globally threatened tree species, this 
information is recorded in the Tree Conservation Database. It is apparent, however, that the majority of globally threatened species are not subject to any specific conservation measures.

It is also apparent that many more tree species will be evaluated and recorded as globally threatened as more information becomes available. The preparation of botanical checklists is a very important step in the evaluation of conservation status. There is also a great need for more field data on the conservation status and distribution of tree species.

Major efforts are needed to prevent tree species extinctions. The primary focus for action needs to be at a national level through the actions of government agencies, NGOs and local resource managers. International conservation instruments should reinforce these efforts and provide a broader policy context for activities on the ground.

\section{INTERNATIONAL POLICY IMPLICATIONS}

International policy for the conservation and sustainable use of forest biodiversity has generally concentrated on ecosystem prioritisation and action. In order to prevent the loss of tree species diversity there is a need to shift the emphasis towards a complementary species-based approach. The World List of Threatened Trees and Tree Conservation Databcise provide the information resource to start doing so. The information now available can be used to refine implementation of policy through, for example, the selection of conservation sites based on tree species diversity and threat, the development of species indicators of ecosystem condition and the development of sustainable use initiatives for economically valuable components of forest biological diversity.

\section{Convention on Biological Diversity (CBD)}

The objectives of CBD are the conservation of biological diversity, the sustainable use of its components and the fair and equitable sharing of the benefits arising out of the utilisation of genetic resources. Biological diversity, as defined by this Convention, includes diversity within species, between species and of ecosystems. Forest biodiversity is recognised as a current priority.

Forests are the most biologically diverse terrestrial ecosystems. Although still rich in absolute and relative terms, the biological diversity of all types of forests has been diminished by the impacts of human societies. Those impacts are greater now than at any time in human history and they are still increasing. They are eroding contemporary forest biological diversity and challenging the processes which maintain it in forest communities and their constituent populations. (SBSTTA, 1997).

Parties to the Convention have agreed that the ecosystem approach to the conservation of forest biodiversity should be the primary framework of action to be taken under the Convention. Within this framework priority activities relating to tree species include:

i. assessment of methodologies which improve the long-term persistence of genetic variability within and between the populations of forest species.

ii. development of methodologies for reporting on the distribution of fragile species.

More broadly, Article 7 of the Convention calls for the identification by Parties of components of biodiversity important for conservation and sustainable use having regard to:

Species and communities which are: threatened; wild relatives of domesticated or cultivated species; of medicinal, agricultural or other economic value; or social, scientific or cultural importance; or importance for research into the conservation and sustainable use of biological diversity, such as indicator species. 
Article 17 of the Convention calls for the facilitation of the exchange of information, from all publicly available sources, relevant to the conservation and sustainable use of biological diversity, taking into account the special needs of developing countries.

Actions to be taken to conserve biological diversity, in accordance with the provisions of CBD, include the development of national strategies, plans or programmes for the conservation and sustainable use of biological diversity (Article 6); establishment of protected area systems where special measures need to be taken to conserve biodiversity (Article 8); adopt measures for the ex situ conservation of components of biodiversity, preferably in the country of origin (Article 9); promote and encourage public awareness and education on the importance and measures required for biodiversity conservation.

\section{Convention on International Trade in Endangered Species of Wild Fauna and Flora (CITES)}

The main objective of CITES is to protect species of wild fauna and flora against overexploitation through international trade, by means of international cooperation. Species which are covered by the provisions of the Convention are included in appendices. To qualify for Appendix I, taxa must be "threatened by extinction" and "are or may be threatened by trade". Species included in Appendix II are those which " although not necessarily now threatened with extinction, may become so unless trade in specimens of such species is subject to strict regulation in order to avoid utilisation incompatible with their survival".

In 1994, the Parties adopted new criteria for amendment of Appendices I and II, and specified information requirements for amendment proposals (Wijnstekers, 1995). The CITES listing criteria were developed at the same time as the development of the 1994 IUCN Red List Categories and are loosely related to them.

The CITES appendices include around twenty tree species which are traded internationally as timber. They also include other tree species which yield medicinal products or which are in genera listed because of the threat from commercial horticultural collection, for example succulent Euphorbia spp. and Aloe spp. The provisions of the Convention and subsequent guidance on species listing do not generally distinguish between different species groups in their application. There has, however, been international debate about the suitability of the Convention as a tool to help conserve particular species groups. Increased interest in the use of CITES for timber species over recent years has contributed to this debate. Various amendment proposals have been submitted to CITES for timber species and have been considered by the Parties at the Eighth and Ninth Conferences, prior to the adoption of the 1994 amendment criteria.

The CITES Timber Working Group (TWG) was formed at the Ninth Conference of the Parties to review implementation issues relating to timber species, notably the control of parts and derivatives of listed species, and relationships with other intemational organisations dealing with the conservation and sustainable use of timber. The final report of TWG was endorsed by the Tenth Conference of the Parties in Harare, June 1997.

In its final report the TWG recommended that: many internationally traded timber species, boreal, temperate and tropical, can be managed on a sustainable basis through the application of appropriate silvicultural techniques, but that for other timber species such knowledge is currently lacking; and that there may be timber species which are under threat because of detrimental levels of use and international trade.

Consequently the TWG recommended that: The range states should pay particular attention to internationally traded timber species within their territories for which knowledge of biological status and silvicultural requirements indicates concern. 


\section{International Tropical Timber Agreement (ITTA)}

The preamble of the ITTA, 1994 which came into force on 1 January 1997 notes the commitment of all members, made in Bali, Indonesia, in May 1990, to achieve exports of tropical timber products from sustainably managed sources by the year 2000. One of the objectives of the Agreement is: To encourage members to develop national policies aimed at sustainable utilization and conservation of timber producing forests and their genetic resources and at maintaining the ecological balance in the regions concerned, in the context of tropical timber trade.

With regard to cooperation and coordination with other organisations, Article 14 of the Agreement states that the Council (ITTC) shall make arrangements for consultation and cooperation with the United Nations and its organs, intergovernmental organizations including CITES and NGOs. The Organization (ITTO) shall, to the maximum extent possible, utilize the facilities, services and expertise of existing intergovernmental, governmental or non-governmental organizations, in order to avoid duplication of efforts in achieving the objectives of the Agreement.

\section{THE NEXT STEPS}

\section{Political}

At an international level, mechanisms for promoting the conservation of individual tree species and areas of maximum tree species richness and diversity within forest ecosytems, need to be developed. The CBD is currently the most appropriate policy instrument given the commitment of parties to the conservation of biological diversity, the sustainable use of its components and the fair and equitable sharing of the benefits arising out of the utilisation of genetic resources. Furthermore CITES can be used to ensure that commercially valuable globally threatened trees are traded intemationally at sustainable levels and ITTA can be used to ensure that sustainable forest management and trade in forest products promotes the conservation of tree species.

The emphasis on implementation of CBD, CITES species selection and ITTA policy development and projects is at a national level with international exchange of information, financial support and technical expertise where appropriate. Subsets of information from the Tree Conservation Database will be made available as tools for the development of national threatened tree lists on which to base national policy and action. Convergence of national and international systems for collection of information and categorisation of threat needs to be considered further identifying, for example, which data elements are common requirements and guidelines for rapid collection of such data. There is a need for flexibility and incremental development of conservation information systems based on available knowledge.

\section{Scientific}

The sharing of information between scientific and conservation institutions is important to build on the results of the tree species conservation assessments and fill in current gaps on tree species information as new scientific data becomes available. Baseline field survey is urgently required for many areas and the collection of additional distribution data for species known or suspected to be of concern. The spatial accuracy of current data can be significantly improved, and the application of the IUCN threat categories reinforced, by the use of GIS linking herbarium, species inventory and forest cover data. Enhanced use of distribution data will be particularly valuable in planning in situ conservation measures for trees.

Research is urgently needed on the population biology and autecology of globally threatened tree species. For practical application, research and information exchange are also needed on aspects of sustainability relating to tree species utilisation, particularly for those species categorised as Vulnerable. Silvicultural research and exchange of information on silvicultural techniques should 
be components of this. The links between forest certification initiatives and the sustainability of tree species should also be considered further.

\section{Networking}

Collaboration with international, regional and national agencies is essential in collecting information on the conservation status of trees. The preparation of The World List of Threatened Trees has fostered good links with international and national organisations, IUCN/SSC Specialist Groups and individual experts. Further collaboration with IPGRI and FAO in relation to information systems for tree species and their genetic resources (in turn linking with ICRAF and CIFOR) will be very valuable. National herbaria are an essential source of primary information on the conservation of tree biodiversity. Networking of information and expertise needs to be maintained and developed.

\section{Education and awareness raising}

A strong message to emerge from the preparation of The World List of Threatened Trees is that tree species are threatened with extinction throughout the world. Numerically more species are threatened in tropical regions reflecting the greater tree species richness in these regions. Nevertheless, the potential for tree species loss is a universal problem and needs to be tackled in all countries and at all levels. Information products are needed to convey the information in this book to a wide audience including the managers of natural resources in rural communities. Local people may not always appreciate that a species they harvest has a narrow geographic distribution and is wholly dependent on local wise use for its conservation.

\section{Conservation action}

Above all The World List of Threatened Trees should be used to develop conservation action on the ground. Urgent attention is needed to reverse the progression towards extinction for Critically Endangered and Endangered tree species. Attention is also needed to prevent Vulnerable species moving into the higher categories of threat. In some instances ex situ measures may provide important back up. In situ mechanisms are generally the most appropriate way to conserve tree species either within designated conservation areas or through sustainable use initiatives in the wider environment.

The threats to tree species are increasing and conservation actions must consequently be intensified. As Dallmeier, 1998, points out,

The loss of even one species diminishes the earth's store of biological diversity, for once eliminated, a species cannot be recovered or regenerated. All possibilities the species had for bettering life are gone, including its potential to provide the basis of life-saving medicines or new or improved foodstuffs to feed a burgeoning human population. Species losses are also felt at the genetic, community and landscape levels. When a species is gone so is its genetic heritage. 


\section{REFERENCES}

Brako, L. and Zarucchi, J.L. 1996. Catalogue of the Flowering Plants and Gymnosperms of Peru. Missouri Botanical Garden.

Brummitt, R.K. (comp.) 1992. Vascular Plant Families and Genera. A listing of the genera of vascular plants of the world according to their families, as recognised in the Kew Herbarium, with an analysis of relationships of the flowering plant families according to eight systems of classification. Royal Botanic Gardens, Kew.

van Bueren, E.L. and Duivenvoorden, J.F. 1996. Towards priorities of biodiversity research in support of policy and management of tropical rain forests. The Tropenbos Foundation, Wageningen.

Conn, B.J. 1994. Documentation of the flora of New Guinea. In: C.-I. Peng and C.-H. Chou, eds., Biodiversity and terrestrial ecosystems: 123-156. Academia Sinica, Taipei (Institute of Botany, Monograph Series 14).

Dallmeier, F. 1998. Measuring and monitoring forest biodiversity: the SI/MAB model. In: Bachmann, P., Köhl, M. and Païvinen, R. (eds.) Assessment of biodiversity for improved forest planning. Proceedings of the Conference on Assessment of Biodiversity for Improved Forest Planning, 7-11 October 1996, held in Monte Verità, Switzerland. Kluwer Academic Publishers, Dordrecht.

Farjon, A. 1996. A world list of threatened conifers: How much do we know? In: Hunt, D.R. (ed) Temperate trees under threat. Proceedings of an IDS Symposium on the Conservation Status of Temperate Trees. University of Bonn 30 September - 1 October 1994. International Dendrological Society, Morpeth

Farjon, A. Page, C.N. and Schevellis, N. 1993. A preliminary world list of threatened conifer taxa. Biodiversity and Conservation 2: 304-326.

Frodin, D. 1997. State of knowledge of tree species in Papua New Guinea. In: Report of the Third Regional Workshop, Hanoi, 18-21 August, Conservation and Sustainable Management of Trees Project, WCMC, Cambridge.

Hollis, S. and Brummitt, R.K. (eds). 1992. World Geographical Scheme for Recording Plant Distributions. Plant Taxonomic Database Standards No. 2. Hunt Institute for Botanical Documentation, Pittsburgh.

Hunt, D.R. 1996. The genera of temperate broadleaved trees. Broadleaves 2:4-5

IUCN.1994. IUCN Red List Categories. IUCN, Gland, Switzerland.

Jorgensen, P.M. and S. Leon Y (in prep.) Catalogue of vascular plants of Ecuador. Monogr. Syst. Bot. Missouri Bot. Gard.

Lear, M.1990. The threatened temperate tree list. International Dendrology Society Yearbook 1990: $130-152$.

Lear, M. and Hunt, D. 1996. Updating the Threatened Temperate Tree List. In: Hunt, D.R. (ed) Temperate trees under threat. Proceedings of an IDS Symposium on the Conservation Status of Temperate Trees. University of Bonn 30 September - 1 October 1994. International Dendrological Society, Morpeth

Lemmens, R.H.M.J. Soerianegara, I. and Wong, W.C. 1995. Plant Resources of South-East Asia (PROSEA) 5(2) Timber trees: minor commercial timbers. Pudoc Scientific Publishers, Wageningen

Oldfield, S.F.(Compiler). 1991. Pre-project study on the conservation status of tropical timbers in trade. Prepared by the World Conservation Monitoring Centre under contract to the International Tropical Timer Organisation.

SBSTTA.1996. Biological diversity in forests. Note by the Secretariat. Convention on Biological Diversity. UNEP/CBD/SBSTTA/2/11

SBSTTA.1997. Scientific, technical and technological advice on forest biological diversity, taking account of research and technical priorities previously identified. Draft programme of work for forest biological diversity. Note by the Executive Secretary. Convention on Biological Diversity. UNEP/CBD/SBSTTA/3/5

Soerianegara, I. \& Lemmens, R.H.M.J. (Eds.).1993. Plant Resources of South-East Asia (PROSEA) 5(1) Timber trees: major commercial timbers. Pudoc Scientific Publishers, Wageningen 
Walter, K.S. and Gillett, H.J. (eds.) 1998. 1997 IUCN Red List of Threatened Plants. Compiled by the World Conservation Monitoring Centre. IUCN - The World Conservation Union, Gland, Switzerland and Cambridge, UK.

Wijnstekers, W. 1995. The evolution of CITES. A reference to the Convention on International Trade in Endangered Species of Wild Fauna and Flora. $4^{\text {th }}$ Edition. CITES Secretariat, Geneva, Switzerland.

Yahara, T. et al. 1997. Red List of Japanese Plants. Japanese Agency of Environment. 


\section{Abarema abbottii}

Leguminosae

VU B $1+2 c$

Dominican Republic

A tree restricted to broadleaved woodland on limestone soils in north-east Dominican Republic.

Assessor: World Conservation Monitoring Centre

Refs: 5994

\section{Abarema alexandri var. alexandri}

Leguminosae

LR/nt

Jamaica

One of two varieties of this Jamaican endemic, occurring in remaining areas of woodland or thicket on limestone soils.

Assessor: World Conservation Monitoring Centre Refs: 5994

\section{Abarema alexandri var. troyana}

Leguminosae

LR/nt

Jamaica

One of two varieties of this Jamaican endemic, occurring in remaining areas of woodland and thickets on limestone soils.

Assessor: World Conservation Monitoring Centre

Refs: 5994

\section{Abarema bigemina}

Leguminosae

VUAlc

Sri Lanka

A species confined to the lowland wet evergreen forests of south-west Sri Lanka. This tree was found in 33 forest localities in the recent National Conservation Review, including Sinharaja Biosphere Reserve.

Assessor: World Conservation Monitoring Centre

Refs: 15431, 17195, 19112

\section{Abarema callejasii}

Leguminosae

VU D2

Colombia

A small tree of montane rainforest only known from the east slope of the Cordillera Central in Antioquia.

Assessor: World Conservation Monitoring Centre

Refs: 5994

\section{Abarema centiflora}

Leguminosae

VU B $1+2 c$

Bolivia

A small tree known only from humid montane forest on the east slope of the Bolivian Andes.

Assessor: World Conservation Monitoring Centre

Refs: 5994

\section{Abarema cochleata var. moniliformis}

Leguminosae

VU B $1+2 \mathrm{c}$

Brazil (Amazonas)

This variety is extremely local in *terra firme forest in Manaus.

Assessor: World Conservation Monitoring Centre

Refs: 5994

\section{Abarema cochliacarpos}

Leguminosae

VU B $1+2 \mathrm{c}$

Brazil (Bahia, Espírito Santo, Paraíba)

A tree or arborescent shrub of the Atlantic coastal forest, disjunctly distributed from Paraiba to Bahia. In Bahia, this species is also found inland on disturbed *mata do cipo, ${ }^{*}$ cerrado or ${ }^{*}$ campo rupestre, sometimes reaching an altitude of $1100 \mathrm{~m}$.

Assessor: World Conservation Monitoring Centre Refs: 5994

\section{Abarema curvicarpa var, rodriguesü}

Leguminosae

VU B1+2c, D2

Brazil (Amazonas)

This forest tree is only known from the Reserva Ducke near Manaus, central Amazonian Brazil.

Assessor: World Conservation Monitoring Centre Refs: 5994

\section{Abarema filamentosa}

Leguminosae

VU B1+2c

Brazil (Bahia, Espírito Santo)

A formerly common tree found in lowland wet Atlantic forest and *restinga along the coast of Bahia and Espirito Santo.

Assessor: World Conservation Monitoring Centre Refs: 5994

\section{Abarema ganymedea}

Leguminosae

VU D2

Colombia, Ecuador

A lowland wet forest species, known only from two disjunct collections, one gathered from North Antioquia, Colombia, the other from Esmeraldas, Ecuador. Assessor: World Conservation Monitoring Centre Refs: 5994

\section{Abarema josephi}

Leguminosae

Colombia

A small tree known only from the type locality. It was found in montane woodland near the west boundary of Comisaría del Caquetá.

Assessor: World Conservation Monitoring Centre Refs: 5994

\section{Abarema killipüi}

Leguminosae

VU D2

Colombia, Ecuador

A small tree known from a single collection from Caldas, Colombia, and from two localities on the eastern slope of the Ecuadorean Andes. It occurs in submontane and montane forest, meadows and open hillsides. Trees sometimes survive forest clearing.

Assessor: World Conservation Monitoring Centre Refs: 5994

Abarema lehmannüi

Leguminosae

VU D2

Colombia

A tree restricted to the margin of humid montane forest in the Cordillera Central in Antioquia.

Assessor: World Conservation Monitoring Centre Refs: 5994

\section{Abarema leucophylla var. vaupesensis}

\section{Leguminosae}

VU D2

Colombia

A small tree or shrub restricted to an area along Río

Vaupés and Apaporis in Vaupés.

Assessor: World Conservation Monitoring Centre

Refs: 5994 
Abarema longipedunculata

Leguminosae

LR/nt

Venezuela

Endemic to Bolivar in the Venezuelan Guayana, this tree or shrub grows on rocky summits, cliff ledges and in gullies in the sandstone table mountains.

Assessor: World Conservation Monitoring Centre

Refs: 5994

\section{Abarema obovata}

Leguminosae

VU B $1+2 c$

Brazil (Minas Gerais)

A tree confined to wooded hillsides in east and northcentral Minas Gerais.

Assessor: World Conservation Monitoring Centre

Refs: 5994

\section{Abarema oxyphyllidia}

Leguminosae

VU D2

Honduras

Known only from a single collection dating from 1964 , this tree occurs in mixed montane forest in the Cordillera Guajiquiro, south-west Honduras.

Assessor: World Conservation Monitoring Centre Refs: 5994

\section{Abarema racemiflora}

Leguminosae

$\mathrm{VUBI}+2 \mathrm{C}$

Costa Rica

This tree is known only from wooded hills near Turrialba in Cartago and Villa Quesada in Alajuela. Assessor: World Conservation Monitoring Centre Refs: 5994

\section{Abarema turbinata}

Leguminosae

Brazil (Bahia)

VU B1+2c

A species restricted to the remnants of Atlantic coastal forest and *restinga along the coast of Bahia between $14^{\circ}$ and $16^{\circ} \mathrm{S}$.

Assessor: World Conservation Monitoring Centre

Refs: 5994

\section{Abarema villifera}

Leguminosae

LR/nt

Brazil (Amazonas), Venezuela

A tree localised to periodically inundated riparian forest in the upper tributaries of the Rio Negro in Venezuela. An unconfirmed variant of the species is also found growing in *terra firme forest in the lower Río Negro basin in Brazil.

Assessor: World Conservation Monitoring Centre Refs: 5994

\footnotetext{
Abdulmajidia chaniana

Lecythidaceae

VU Bl $1+2 c$

Malaysia (Peninsular Malaysia)

A small tree found in the lowlands and hill forests of Pahang and Johore, up to $570 \mathrm{~m}$. Increasing settlement is the principal pressure exerted on this already rare species.

Assessor: Chua, L.S.L.

Refs: 19073

\section{Abdulmajidia maxwelliana}

Lecythidaceae

VU B $1+2 c$

Malaysia (Peninsular Malaysia)

A small tree occurring on steep ridges and hillsides in submontane forest, at approximately $600 \mathrm{~m}$. The species
}

is confined to Maxwell Hill in the state of Perak. The main threats to the tree come from expanding settlements and tourism.

Assessor: Chua, L.S.L.

Refs: 19073

\section{Abies beshanzuensis}

Pinaceae

CR D1

China (Zhejiang)

Only five living specimens are known in the wild. The species occurs in mixed forest on Baishanzu Mountain. Expansive agriculture and fires, coupled with poor regeneration, are thought to have largely been responsible for the decline of the species.

Assessor: SSC Conifer Specialist Group

Refs: $3630,11725,11847$

\section{Abies bracteata \\ Pinaceae}

LR/cd

USA (Califomia)

Confined to mountain ridges, the species is now known to be more widespread in the Santa Lucia Mountains than originally thought. Fire is a threat but the area is generally inaccessible to grazing animals.

Assessor: SSC Conifer Specialist Group

Refs: 374, 13041, 19193

\section{Abies cephalonica \\ Pinaceae}

LR/nt

Greece (East Aegean Is)

The species is known to occur on Cephalonia, Euboea and Peloponnesos.

Assessor: SSC Conifer Specialist Group

Refs: 13041

\section{Abies chengü}

Pinaceae

China? (Yunnan?)

The populations in the wild remain unknown. The species was described from a specimen in cultivation at Hilliers, UK. Repeated attempts to discover the whereabouts of the wild population have failed. Assessor: SSC Conifer Specialist Group Refs: 374,13041

\section{Abies chensiensis ssp. chensiensis}

Pinaceae

VU Alc+2c

China (Gansu, Henan, Hubei, Shaanxi, Sichuan?)

The distribution of the subspecies is fairly wide and unresolved. Populations are scattered and confined to areas of dense montane forest. Levels of exploitation of the forest habitat have been high throughout the area. Regeneration does not appear to be good. Assessor: SSC Conifer Specialist Group Refs: $374,1818,18751$

\section{Abies chensiensis ssp. yulongxueshanensis}

China (Yunnan)

A relatively recently published name. The taxonomy remains questionable. The population is restricted to a small area of forest. Its status is not presently known but Lijiangshan is one of the best preserved areas. Assessor: SSC Conifer Specialist Group Refs: 374, 7610, 13041 


\section{Abies cilicica ssp. isaurica}

Pinaceae

Turkey

The species appears to be endemic to Isaurian Taurus.

Assessor: SSC Conifer Specialist Group

Refs: $4863,11888,13041$

\section{Abies durangensis var. coahuilensis}

Pinaceae

VU D2

Mexico (Coahuila)

Occurring in a sparsely populated area, there are no obvious threats to the two or three subpopulations that exist. These are restricted to wet north slopes in two river valleys.

Assessor: SSC Conifer Specialist Group

Refs: 374,13041

\section{Abies fanjingshanensis \\ Pinaceae}

EN D1

China (Guizhou)

A relict species occurring only in inaccessible areas on Fanjing Mountain. It grows on northern slopes at an elevation of $2100-2300 \mathrm{~m}$, forming pure or mixed stands. The populations are not obviously threatened but there are unlikely to be more than 250 mature trees.

Assessor: SSC Conifer Specialist Group

Refs: 374,11847

\section{Abies forrestii var. georgei}

Pinaceae

$\mathrm{LR} / \mathrm{nt}$

China (Sichuan, Xizang, Yunnan)

Chinese taxonomists refer to this taxon as a species. Extensive forests of it were known to occur above $3000 \mathrm{~m}$ in south-west Sichuan and north-west Yunnan. Large-scale deforestation and replanting with commercial species have since taken place in the area and populations have declined.

Assessor: SSC Conifer Specialist Group

Refs: $374,11191,13041$

\section{Abies fraseri}

Pinaceae

VU D2

USA (North Carolina, Tennessee, Virginia)

Populations are known from six peaks, including the Smoky Mountains National Park. They are small, windswept and unhealthy. Regeneration appears to be poor.

Assessor: SSC Conifer Specialist Group

Refs: 374,13041

\section{Abies guatemalensis var. guatemalensis}

Pinaceae

VUAld

El Salvador, Guatemala, Honduras, Mexico

The Guatemalan Fir is the southernmost member of its genus. It was reported to be common until the 1940 s and large populations may still remain in Honduras. There has been heavy timber exploitation throughout the range. There is disputable evidence that the remaining stands in Guatemala extend no more than 3 ha. Isolated stands continue to be exploited heavily by local inhabitants and the deep fertile soils, on which the tree grows, are attractive to agricultural development. Cone crops are irregular and germination is poor. Programmes to improve its status are being run by CAMCORE. Felling is prohibited in some countries and the species is listed in * CITES Appendix 1 .

Assessor: SSC Conifer Specialist Group

Refs: $374,3951,13041$

\section{Abies guatemalensis var. jaliscana}

Pinaceae

VU Ald

Mexico (Jalisco)

The taxonomy of the variety is based on fallen cone material. It is common but found at lower altitudes, which may leave it more vulnerable to exploitation. The species is listed in *CITES Appendix I.

Assessor: SSC Conifer Specialist Group

Refs: $374,3951,5287,13041$

\section{Abies guatemalensis var. tacanensis}

Pinaceae

VU Ald

Mexico (Chiapas)

The species is restricted to forest areas up to $3000 \mathrm{~m}$ or more. The taxonomy of the variety may be questionable. The species is listed in *CITES Appendix I.

Assessor: SSC Conifer Specialist Group

Refs: $6541,10722,13041,19161$

\section{Abies hickelii var. hickelii}

Pinaceae

VU Ald

Mexico (Chiapas, Guerrero, Oaxaca)

A variety which is found in very low densities and continues to suffer from extensive logging and habitat loss.

Assessor: SSC Conifer Specialist Group

Refs: $374,6541,13041$

\section{Abies hickelii var. oaxacana}

Pinaceae

VUAld

Mexico (Guerrero, Oaxaca)

A variety which occurs in very low densities and continues to suffer from extensive logging and habitat loss.

Assessor: SSC Conifer Specialist Group

Refs: $374,10722,11191,13041$

\section{Abies kawakamii}

Pinaceae

LR/nt

Taiwan

The species is widespread but appears to suffer from frequent fire damage.

Assessor: SSC Conifer Specialist Group

Refs: 374,6469

\section{Abies koreana}

Pinaceae

LR/nt

Russia, South Korea

The species is recorded from Cheju Island, Chiri-san, Halla-san and Tokyu-san in South Korea and from the Sikhote Alin range in Russia.

Assessor: SSC Conifer Specialist Group

Refs: 11117,13041

\section{Abies nebrodensis}

Pinaceae

CR D1

Italy (Sicily)

Endemic to Sicily, the species is known from a small population containing less than 20 individuals. Only a fraction of them appear to be reproductively capable. A propagation programme is under way.

Assessor: SSC Conifer Specialist Group

Refs: $374,4506,7222,19021$

\section{Abies nordmanniana ssp. equi-trojani}

Pinaceae

LR/nt

Turkey

This taxon presently includes ssp. bornmuelleriana, which stands as a separate taxon in Turkey. Populations 
are restricted to the northern mountain slopes in Kaz-Dagh and Ulu-Dagh. The stands appear to be reasonably extensive and healthy.

Assessor: SSC Conifer Specialist Group

Refs: $374,3489,11888,13041,18751$

\section{Abies numidica}

Pinaceae

VU D2

Algeria

This species is restricted to Mount Babor and Tababor, and is highly scattered where it occurs. Recent collecting expeditions in the area uncovered only one plant.

Assessor: SSC Conifer Specialist Group

Refs: 374, 10598

\section{Abies pinsapo var. marocana}

Pinaceae

LR/nt

Morocco

Although this variety is less threatened than the Spanish variety, it is restricted to the Rif Mountains and is vulnerable to overgrazing.

Assessor: SSC Conifer Specialist Group

Refs: 374, 13041

\section{Abies pinsapo var. pinsapo}

Pinaceae

VU D2

Spain

Three healthy populations are known. One in Grazelema National Park consists of a few thousand trees. Overgrazing by goats, droughts and the threat of fire affect the survival of all three populations.

Assessor: SSC Conifer Specialist Group

Refs: 10625, 13041

\section{Abies pinsapo var. tazaotana}

Pinaceae

VU D2

Morocco

This variety is locally common, perhaps numbering 2500 individuals, but restricted to between 1600 and $2000 \mathrm{~m}$ on Mount Tazaot.

Assessor: SSC Conifer Specialist Group

Refs: 374

\section{Abies recurvata var. recurvata}

Pinaceae

VU D2

China (Sichuan)

A rare variety with a very restricted range confined to Songpan. Var. emestii appears to be more widespread in the west of Sichuan Province.

Assessor: SSC Conifer Specialist Group

Refs: 374,13041

\section{Abies sibirica ssp. semenovii}

Pinaceae

VU D2

China, Kyrgyzstan

The known populations are confined to Talasskij Ala

Tau but they are suspected to extend into China. The species as a whole is considered threatened in China.

Assessor: SSC Conifer Specialist Group

Refs: $374,13041,18751$

\section{Abies squamata}

Pinaceae

VU Ald

China (Gansu?, Qinghai, Sichuan, Xizang)

A species confined to forest in an area which is

experiencing high levels of deforestation and habitat degradation.

Assessor: SSC Conifer Specialist Group

Refs: 374

Abies veitchii var. sikokiana

Pinaceae

LR/nt

Japan

This variant is known from Shikoku Island. There are no obvious threats at present.

Assessor: SSC Conifer Specialist Group

Refs: 374,6879

Abies vejarii ssp. mexicana

Pinaceae

VU D2

Mexico (Coahuila, Nuevo León)

The taxonomy of this subspecies is questionable. It occurs in the Sierra Santa Catarina, in a single locality that probably extends less than $100 \mathrm{~km}^{2}$.

Assessor: SSC Conifer Specialist Group

Refs: $374,6879,13041$

Abies yuanbaoshanensis

Pinaceae

CR B $1+2 c, C 2 b$

China (Guangxi)

A relatively recently discovered species confined to Yuanbao Mountain., which is outside the general range of fir species. There are in the region of 100 individuals mostly over 100 years old. Young trees are very rare and regeneration is hampered by long coning intervals, seed predation by squirrels and competition with Sinarundinaria species. Effective protection of the population is given by the Forest Department. Assessor: SSC Conifer Specialist Group

Refs: $374,1818,11847$

\section{Abies ziyuanensis}

Pinaceae

CR B1+2ce

China (Guangxi, Hunan)

An endemic of the Nanling range, where the species occurs in middle elevation mixed forest on Mount Yinzhulao, Mount Shunhuang and Mount Erbaoding. As with A. yuanbaoshanensis, the distribution lies outside the general range of fir species. Population density is low and regeneration is poor because of the long coning interval and competition with other plants.

Assessor: SSC Conifer Specialist Group

Refs: $374,1818,11847$

\section{Abutilon sachetianum}

Malvaceae

VU B $1+2 c$

French Polynesia (Marquesas Is.)

Only recorded from the Marquesas, the species is found in small populations on the islands of Eiao, Hatutaa, Hiva Oa, Mohotani and Nuku Hiva. Those on Eiao and Hatutaa are in a notably critical state. The species has been propagated at the Museum of Natural History in Washington, D.C. in the USA.

Assessor: Florence, J.

Refs: 14513 
Acacia albicorticata

Leguminosae

VU BI+2c

Argentina, Bolivia

Endemic to the piedmont forest of north-west Argentina and Bolivia, the species occurs in an unprotected

ecosystem, which is rapidly being replaced by agricultural systems.

Assessor: Prado, D.

Refs: 19122

\section{Acacia ankokib}

Leguminosae

Somalia

A species of restricted range, only known from semidesert bushland, usually in rocky places on limestone in north-eastern Somalia. The habitat is vulnerable to degradation. The tree is an important local source of gum.

Assessor: Thulin, M.

Refs: 7550,18665

\section{Acacia aulacocarpa}

Leguminosae

LR/nt

Australia, Indonesia (Irian Jaya), Papua New Guinea

In New Guinea, this tree of savanna and monsoon forest up to an an altitude of $50 \mathrm{~m}$ is restricted to Digul District in Irian Jaya and the Oriomo River area in the Western Province of Papua New Guinea. Part of the range is subject to logging. Continued exploitation and habitat destruction have reduced the number of mature individuals and, if not halted, will render the species as a whole vulnerable. More information is needed on populations in eastem and northern Australia.

Assessor: Eddowes, P.J.

Refs: 19114

\section{Acacia belairioides}

Leguminosae

CR B $1+2 c$

Cuba

A very rare tree up to $7 \mathrm{~m}$ tall, confined to the serpentine outcrop of Holguin in north-eastern Cuba. The habitat is severely degraded in most places, mainly due to grazing and urbanisation.

Assessor: Areces-Mallea, A.E.

Refs: 9522, 16327, 19149

\section{Acacia bucheri}

Leguminosae

$\mathrm{EN} \mathrm{B} 1+2 \mathrm{c}$

Cuba

An uncommon tree up to $8 \mathrm{~m}$ in height occurring in woodlands and dry forests over limestone and serpentine bedrocks in the provinces of Guantánamo, Baracoa and Holguín.

Assessor: Areces-Mallea, A.E.

Refs: $9522,11403,19149$

\section{Acacia campbellii}

Leguminosae

VUAlcd

India (Andhra Pradesh)

A small tree distributed throughout much of Andra Pradesh in deciduous forest or thorny scrub, often on black cotton soils. It has been heavily collected as a fuelwood and its habitat has also declined in extent. Assessor: World Conservation Monitoring Centre Refs: 4799
Acacia caraniana

Leguminosae

LR/nt

Somalia

A Somali endemic known only from areas of sparse vegetation on gypsum hills in the north-east. The habitat is vulnerable to degradation.

Assessor: Thulin, M.

Refs: 7550,18665

\section{Acacia cernuo}

Leguminosae

LR/nt

Somalia

A species which is endemic to northern Somalia in a habitat which is vulnerable to degradation.

Assessor: Thulin, $\mathrm{M}$.

Refs: 18665

\section{Acacia condyloclada}

Leguminosae

Ethiopia, Kenya, Somalia

$\mathrm{LR} / \mathrm{nt}$

Restricted to limestone outcrops, this tree, characterised by its peeling bark, is known from two collections west of Ramu in Kenya, from parts of the Ogaden in Ethiopia and from northern Somalia.

Assessor: Thulin, $\mathrm{M}$.

Refs: 1330, 6396, 10961, 12067

\section{Acacia crassicarpa}

Leguminosae

VU Alcd $+2 c d, B 1+2 a b c d$

Australia (Queensland), Papua New Guinea

A tree of savanna woodland, monsoon forest and gallery-type forest at altitudes of between 10 and $30 \mathrm{~m}$ restricted to the Western Province, Papua New Guinea, and to Queensland, Australia. Logging is occurring and the timber is actively sought-after.

Assessor: Eddowes, P.J.

Refs: 19114

\section{Acacia daemon}

Leguminosae

$\mathrm{EN} B 1+2 \mathrm{c}$

Cuba

A fairly uncommon tree, up to $5 \mathrm{~m}$ tall, confined to the rocky serpentine hillsides of Habana, Matanzas, Villaclara and Camaguey Provinces. These areas are under constant pressure from cutting and clearing.

Assessor: Areces-Mallea, A.E.

Refs: 9522, 11403, 19149

\section{Acacia densispina}

Leguminosae

VU $B 1+2 c$

Somalia

Known only from central Somalia, this small tree is restricted to Acacia-Commiphora bushland in limestone areas. Large-scale charcoal production is causing the loss and degradation of the habitat.

Assessor: Thulin, M.

Refs: 8697,18665

\section{Acacia dolichostachya}

Leguminosae LR/nt

Guatemala, Mexico (Campeche, Quintana Roo, Yucatán)

Endemic to the Yucatán Peninsula, this rainforest tree is an important component of the canopy. The habitat is generally disturbed and declining in extent.

Assessor: World Conservation Monitoring Centre Refs: 5993, 19124, 19162 
Acacia etilis

Leguminosae

VU $B 1+2 c$

Argentina, Bolivia

Endemic to the piedmont forest of north-west Argentina and Bolivia, the species occurs in an unprotected ecosystem, which is rapidly being replaced by agricultural systems.

Assessor: Prado, D.

Refs: 19122

\section{Acacia ferruginea}

Leguminosae

VU Alc

Sri Lanka

This tree was commonly found in the dry zone of Sri Lanka but it is now very rare. The wood is used for its medicinal properties.

Assessor: World Conservation Monitoring Centre

Refs: 18796,19110

\section{Acacia flagellaris}

Leguminosae

$\mathrm{VU} B 1+2 \mathrm{c}$

Somalia

A tree of exposed limestone ridges in low vegetation, known only from north-eastern Somalia. It occurs in an area less than $20,000 \mathrm{~km}^{2}$ and its habitat continues to be degraded and destroyed by overgrazing and overcutting. Assessor: Thulin, M.

Refs: 8697,18665

\section{Acacia gaumeri}

Leguminosae

$\mathrm{LR} / \mathrm{nt}$

Mexico (Campeche, Quintana Roo, Yucatán)

A weedy tree, abundant in but confined to semievergreen forest and secondary formations in the Yucatán Peninsula.

Assessor: World Conservation Monitoring Centre

Refs: 19162

\section{Acacia koaia}

Leguminosae

VU Alce

USA (Hawaii)

A taxon which is included in the wider concept of $A$. $k o a$. This is a small and gnarled form found in small numbers in dry and open habitats on Molokai, Lanai, Maui and Hawaii.

Assessor: World Conservation Monitoring Centre Refs: 3372

\section{Acacia manubensis}

Leguminosae

VU B $1+2 c$

Somalia

Confined to semi-evergreen bushland on limestone in the Al Miskat Mountains, this tree has the same common name and valuable gum as $A$. ankokib but it is ecologically distinct, occurring at higher altitudes.

Assessor: Thulin, $\mathrm{M}$.

Refs: $7550,8697,18665$

\section{Acacia mathuataensis}

Leguminosae

CR D1

Fiji

Only known from the type collection of 1947, the species was found in dense thickets on the summit ridge of Mount Numbuiloa, east of Lambasa, Vanua Levu. Assessor: World Conservation Monitoring Centre Refs: 18818

\section{Acacia moggii}

Leguminosae

LR/nt

Somalia

A shrubby spreading tree known only from AcaciaCommiphora bushland on limestone, south of Beled Weyne. This habitat is vulnerable to degradation.

Assessor: Thulin, M.

Refs: 18665

\section{Acacia montis-usti}

Leguminosae

$\mathrm{LR} / \mathrm{nt}$

A graceful tree, often branching from the base. It occurs on granite outcrops, ridges and inselbergs from the Brandberg to southern Kaokoveld. Trees in the Twyfelfontein area are infested with insects, which may have some effect on recruitment and population size and structure. Many mature trees died during the severe drought in the 1980s. However, healthy levels of recruitment are observed in some subpopulations.

Assessor: Hilton-Taylor, C. et al.

Refs: $689,7550,19218$

Acacia ochracea

Leguminosae

LR/nt

Somalia

Numerous trees were recorded in 1990 in the southwest, where the species is endemic. It occurs in AcaciaCommiphora bushland, usually in shallow soil over limestone. Habitat destruction because of charcoal production and overgrazing is a continuing threat.

Assessor: Thulin, M.

Refs: 18665

\section{Acacia origena}

Leguminosae

LR/nt

Eritrea, Ethiopia, Yemen (Former North Yemen, Former South Yemen)

A species from the Welo and Hararge highlands of Ethiopia, west Eritrea and also across the Red Sea in Yemen. It occurs in upland wooded grasslands above $1700 \mathrm{~m}$.

Assessor: World Conservation Monitoring Centre

Refs: 1330

\section{Acacia pachyceras var. najdensis}

Leguminosae

LR/nt

Egypt, Iraq, Israel, Jordan, Kuwait, Oman, Saudi Arabia An important component of and often the sole tree species in desert wadis and hilly areas, extending from Egypt through Arabia into southern Iraq. The tree is very vulnerable to overcutting and overgrazing and appears to have become extinct in Kuwait. In the Negev Desert in Israel mortality rates have been observed to be as high as $60 \%$, largely because road building has cut off vital river beds. In other areas, such as the northern mountains of Oman, populations are well established and not threatened.

Assessor: World Conservation Monitoring Centre Refs: $1517,2863,5100,6988$

\section{Acacia pennivenia}

Leguminosae VU D2

Yemen (Socotra)

A tree of submontane dry woodland. The population is stable and there are no immediate threats.

Assessor: Miller, A.G.

Refs: $2354,7550,19083$ 
Acacia prasinata

Leguminosae

VU B $1+2 c$

Ethiopia

A species known only from areas of dry woodland or semi-desert bushland in Afar and Shewa in Ethiopia. Its habitat is vulnerable to overgrazing and cutting for fuelwood.

Assessor: World Conservation Monitoring Centre

Refs: 1330,18523

Acacia pseudonigrescens

Leguminosae

VU D2

Ethiopia

A species with a very restricted range known only from a limestone area of succulent shrubland on the track to Kelafo in the Ogaden. The area, although susceptible to degradation, is relatively unthreatened.

Assessor: World Conservation Monitoring Centre

Refs: $1330,5654,7550,18523$

\section{Acacia purpurea}

Leguminosae

VU D2

Mozambique

A poorly known species, collected from waterside localities on the plains on the southern side of the Zambezi.

Assessor: World Conservation Monitoring Centre

Refs: 7401,7550

\section{Acacia robynsiana}

Leguminosae

$\mathrm{LR} / \mathrm{nt}$

Namibia

A bushy tree, frequently with upright or drooping whiplike branches, occurring on granite outcrops, ridges and inselbergs in Outjo and Kaokoveld Districts. General habitat degradation through poor land management, coupled with recent droughts may have affected population size and recruitment. The species is not protected within any designated protected areas, although it is given some protection on land registered as conservancies or as hunting concessions. Its range extends up to the Angola border but, so far, it has not been recorded from Angola itself.

Assessor: Hilton-Taylor, C. et al.

Refs: 689, 7401, 7550, 19218

\section{Acacia roigii}

Leguminosae

CR BI+2C

Cuba

Very restricted in range, this endemic tree, up to $8 \mathrm{~m}$ tall, is restricted to the dry evergreen forests of Puerto Padre in north-eastern Cuba. The habitat is severely degraded in many places because of cutting, grazing and settlement.

Assessor: Areces-Mallea, A.E.

Refs: $11403,18485,19149$

\section{Acacia sarcophylla}

Leguminosae

LR/nt

Somalia, Yemen (Socotra)

A species found in northem Somalia and also on the island of Socotra. Habitat degradation largely from overcutting and charcoal production is a threat.

Assessor: Thulin, M.

Refs: $7550,18665,19083$
Acacia schlechteri

Leguminosae

Mozambique

A species which is taxonomically unconfimed and poorly known. It may represent $\boldsymbol{A}$. burkei.

Assessor: Bandeira, $\mathbf{S}$.

Refs: 5117,7550

\section{Acacia venosa}

Leguminosae

Eritrea, Ethiopia

VU Alc+2c

A woodland species confined to parts of west Eritrea, Tigray and Gondar on the high plateau where the majority of the Ethiopian population lives. The northem forests have diminished most noticeably because of the expansion of farmed land and human habitation and overcutting for fuelwood.

Assessor: World Conservation Monitoring Centre

Refs: 1330,18523

\section{Acacia villosa \\ Leguminosae}

VU B $1+2 \mathrm{C}$

Jamaica

Found only in St Andrew and St Thomas Parishes, the species is locally comron in thickets on gravel.

Assessor: Bellingham, $\mathbf{P}$.

Refs: $6057,7980,19116$

\section{Acacia zapatensis}

Leguminosae

$\mathrm{EN} \mathrm{B} 1+2 \mathrm{c}$

Cuba

An endemic shrub, sometimes a small tree, confined to the Peninsula de Zapata, Matanzas Province in eastem Cuba. Development for tourism is currently the major threat to the species.

Assessor: Areces-Mallea, A.E.

Refs: 11403, 18485, 19149

Acalypha hontauyuensis

Euphorbiaceae

VU D2

Taiwan

An omamental shrub confined to Lanyu Island, where it is locally abundant in areas of dry scrub. None of the populations are protected and, in places, they are susceptible to increasing settlement and cultivation of the land.

Assessor: Pan, F.J.

Refs: $3295,7933,19050$

\section{Acalypha lepinei}

Euphorbiaceae

VU B1 $+2 \mathrm{c}$

French Polynesia (Society Is.)

Populations are recorded from Bora Bora, Raiatea and Tahiti, where the species is most seriously threatened.

Assessor: Florence, J.

Refs: 14513

\section{Acalypha raivavensis}

Euphorbiaceae CR B $1+2 \mathrm{c}$

French Polynesia (Tubuai Is.)

A shrub or shrubby tree recorded from Raivavae and Tubuai.

Assessor: Florence, J.

Refs: 14513 


\section{Acalypha rubrinervis}

Euphorbiaceae

EX

St Helena

Formerly a rare shrub or small tree of thickets on the central ridge above $600 \mathrm{~m}$. It became extinct in 1870 .

Assessor: Cronk, Q.C.B.

Refs: 19081

\section{Acalypha suirenbiensis}

Euphorbiaceae

VU D2

Taiwan

Only known from the Taitung coast, this shrubby species occurs abundantly in dry scrub in a single small location. There are no conservation or protection measures in place and habitat clearance for agriculture or housing threatens much of the area.

Assessor: Pan, F.J.

Refs: $3295,6469,19050$

\section{Acanthopanax malayanus}

Araliaceae

LR/cd

Malaysia (Peninsular Malaysia)

A small tree inhabiting montane rainforest in Pahang (Cameron Highlands) and Kelantan (Gunung Stong).

The species is given a degree of protection, where it occurs within the permanent forest estate.

Assessor: Chua, L.S.L.

Refs: 8464,19073

\section{Acanthophoenix rubra}

Palmae

CR B $1+2 \mathrm{C}$

Mauritius, Réunion

A palm tree of mixed moist forest, occurring between 250 and $650 \mathrm{~m}$ in Réunion and south-west Mauritius. On the latter island only a single population of 150 mature individuals in Etoile valley in the eastem range remains viable. Regeneration is occasional and seed production is monitored. This species is widely cultivated in gardens in Mauritius.

Assessor: Page, W

Refs: 19118

\section{Acanthosyris asipapote}

Santalaceae

VU D2

Bolivia

A recently described species, known only from very few sites in Santa Cruz. It appears to be a relict species, occurring in the outskirts of a rapidly growing city. Assessor: World Conservation Monitoring Centre Refs: 19180

\section{Acca lanuginosa}

Myrtaceae

VU B1 $1+2 c, D 2$

Peru

A shrub or small tree known from only a few, possibly only three, localities of low forest up to $2700 \mathrm{~m}$ on the eastern slopes of the Peruvian Andes.

Assessor: World Conservation Monitoring Centre

Refs: 5435,7980

\section{Acer buergerianum ssp. formosanum}

Aceraceae

CR C2a, D1

Taiwan

Only two populations are known, confined to small areas of lowland evergreen forest in Wanli and Yingshihchien in the north of Taiwan. The species is mainly threatened by the uprooting of whole plants for ornamental use.

Assessor: Lu, S.Y. \& F.J. Pan

Refs: $3295,6469,8507,19050,19051$

\section{Acer caesium ssp. caesium}

Aceraceae

China, India (Himachal Pradesh, Jammu-Kashmir, Uttar Pradesh), Nepal, Pakistan

A large tree, relatively poorly known but distributed over a relatively large area from Pakistan to Westem China. It was once common in the Western Himalayas, usually found in open grassy places and in moist patches of broadleaved forest. Overexploitation of the timber for commercial and local use has caused a decline in population numbers. Seeds and plants are also present in the ornamental trade.

Assessor: World Conservation Monitoring Centre Refs: $2538,5995,8507$

\section{Acer duplicatoserratum}

Aceraceae

VU B1+2ab

Taiwan

Populations are scattered in central to northem parts of Taiwan in submontane broadleaved forest. Declines in numbers have been caused by the illegal digging up of whole trees for the trade in omamental plants. No conservation or protection measures are in place in any part of the species' range. A variety of the species occurs in Anhui, China.

Assessor: Pan, F.J.

Refs: 8507,19050

\section{Acer erythranthum}

Aceraceae

LR/nt

Viet Nam

A large tree occurring in Thua Thien-Hue, Gia Lai, Kon Tum and Lam Dong Provinces, usually in evergreen forests above $500 \mathrm{~m}$ on deep fertile soils. Natural regeneration does not appear to be good, despite good fruit crops. The fine timber is used for construction and making household appliances.

Assessor: World Conservation Monitoring Centre Refs: 11530,15357

\section{Acer longipes ssp. catalpifolium}

Aceraceae

VUAlcd

China (Guangdong, Sichuan)

This subspecies is recognised as a species in China. It is recorded infrequently in the Chengdu Plain in Sichuan and also in Guangdong. Apparently valuable as a timber, the species is threatened with overcutting and loss of habitat.

Assessor: World Conservation Monitoring Centre Refs: 8507, 11847

\section{Acer miyabei ssp. miaotaiense}

Aceraceae

VU B $1+2 c e$

China (Gansu, Shaanxi, Zhejiang)

A forest tree known from two main populations which occur disjunctly and were previously known under two different species names, $\boldsymbol{A}$. miaotaiense and $\boldsymbol{A}$. yangjuechi. The former is confined to the Qinling and Bashan Mountains occurring singly or in small groves showing poor regeneration and under some threat from forest clearance. The second population contains two individuals on Xitianmu Mountain to the east in 
Zhejiang. Although the seeds appear to be frequently sterile, the population is given protection from felling or damage.

Assessor: World Conservation Monitoring Centre Refs: $1818,8507,11847$

\section{Acer negundo ssp. mexicanum}

Aceraceae

VU B $1+2 \mathrm{c}$

Guatemala, Mexico (Chiapas, Jalisco, Oaxaca, Tamaulipas, Veracruz)

A dioecious species, which grows along watercourses and streams in mountain areas, between 1500 and $2400 \mathrm{~m}$. It is observed to be relatively abundant in Veracruz but in Jalisco it occurs only in state forest outside Tapalpa. Throughout the range it is suffering from habitat loss.

Assessor: World Conservation Monitoring Centre Refs: 8507, 15436, 16907, 19068, 19161

\section{Acer oblongum var. membranaceum}

Aceraceae

CR B $1+2 \mathrm{~d}$

India (Uttar Pradesh)

One of the several varieties of a widespread species. It has been collected only a few times, from a single locality on the upper ridges of the Mussoorie Hills, near Dehra Dun in Uttar Pradesh. It does not appear to have been seen in the wild for 40 years.

Assessor: World Conservation Monitoring Centre

Refs: 2538,4799

\section{Acer oblongum var, microcarpum}

Aceraceae

VU D2

India (Arunachal Pradesh)

Specimens from this tree were collected just once during colonial times from subtropical pine forest in the Mishmee Hills, Lohit District. The area is relatively remote but there is some concern that the forests have become vulnerable to clearance for jhum or agriculture. Assessor: World Conservation Monitoring Centre Refs: 2538,4799

\section{Acer undulatum}

Aceraceae

LR/nt

Turkey

A tree of montane scrub, endemic to a small area in Babadag, near Fethiye in Mugla.

Assessor: Güner, A.

Refs: $3489,4863,19165$

\section{Acidocroton gentryi}

Euphorbiaceae

$\mathrm{EN} \mathrm{B1}+2 \mathrm{c}$

Colombia

An endemic to Cundinamarca.

Assessor: Calderon, E.

Refs: 19069

\section{Acidocrotan verrucosus}

Euphorbiaceae

VU B $1+2 \mathrm{c}$

Jamaica

Known only from Clarendon and Trelawny Parishes, the species occurs in rare and local populations in remaining areas of woodland on limestone rocks.

Assessor: World Conservation Monitoring Centre

Refs: 401,7980

\section{Acioa cinerea}

Chrysobalanaceae

Cameroon

This species has been collected only once from lowland rainforest, around the Bipindi area. It is not known whether the population still exists. There has been much habitat loss through expanding agriculture.

Assessor: World Conservation Monitoring Centre

Refs: 12597

\section{Acioa dichotoma}

Chrysobalanaceae

CR Alc, Bl+2c

Nigeria

A species for which there is little information. Like $A$. eketensis, it is apparently endemic to the Eket area, where oil exploration operations have extensively, if not completely, destroyed the habitat.

Assessor: World Conservation Monitoring Centre Refs: 450,2773

\section{Acioa eketensis}

Chrysobalanaceae

CR Alc, B1+2c

Nigeria

As with $A$. dichotoma, this species is poorly known and endemic to Eket in south-east Nigeria, where the effects of oil exploration operations have caused the extensive, if not complete, destruction of the habitat.

Assessor: World Conservation Monitoring Centre Refs: 450,2773

\section{Acmopyle sahniana}

Podocarpaceae

VU D1+2

Fiji

The species appears to be restricted to forested ridges on two mountain tops in central Viti Levu. Very few individuals have been found and there is little evidence of regeneration.

Assessor: SSC Conifer Specialist Group

Refs: $9631,13041,18818,19125$

\section{Acridocarpus socotranus}

Malpighiaceae

VU D2

Yemen (Socotra)

A small tree or shrub, occurring as scattered solitary individuals in dry woodland or shrubland. There are no immediate threats.

Assessor: Miller, A.G.

Refs: 2354, 19083

\section{Acronychia porteri}

Rutaceae

LR/cd

Malaysia (Peninsular Malaysia), Singapore

Occurring throughout Peninsular Malaysia, this tree, of up to $40 \mathrm{~m}$ height, is found in moist forest up to an altitude of $1060 \mathrm{~m}$. A protected population is contained within Taman Negara National Park.

Assessor: Chua, L.S.L.

Refs: $9199,11647,19073$

Acropogon aoupiniensis

Sterculiaceae

VU D2

New Caledonia

Assessor: Jaffré, T. el al.

Refs: 10351 
Acropogon bullatus

Sterculiaceae

New Caledonia

Assessor: Jaffré, T. et al.

Refs: 10351

Acropogon domatifer

Sterculiaceae

VU D2

New Caledonia

Assessor: Jaffré, T. et al.

Refs: 10351

\section{Acropogon fatsioides}

Sterculiaceae

New Caledonia

VU B $1+2 c$

Assessor: Jaffré, T. et al.

Refs: 10351

Acropogon megaphyllus

Sterculiaceae

VU D2

New Caledonia

Assessor: Jaffré, T. et al.

Refs: 10351

\section{Acropogon veillonii}

Sterculiaceae

New Caledonia

Assessor: Jaffré, T. et al.

Refs: 10351

\section{Acsmithia vitiense}

Cunoniaceae

EN D1

Fij

A small gnarled tree growing in thickets on ridges and crests in upland areas. The species represents the easternmost member of the genus with definite occurrences on Viti Levu, Ovalau and Vanua Levu. There are few trees in each location and the total population consists of less than a hundred individuals. Assessor: World Conservation Monitoring Centre Refs: $5515,6053,18818$

\section{Actinodaphne albifrons}

Lauraceae

VU Alc

Sri Lanka

A tree occurring in the lowland wet evergreen forests of south-west Sri Lanka.

Assessor: World Conservation Monitoring Centre

Refs: 8203, 17195

\section{Actinodaphne bourneae}

Lauraceae

$\mathrm{EN} B 1+2 \mathrm{c}$

India (Tamil Nadu)

A small tree known from only a small area of * shola forest above $1600 \mathrm{~m}$ in the Palni Hills. Declines in the habitat have resulted in subpopulations becoming further restricted.

Assessor: World Conservation Monitoring Centre

Refs: 14276, 19144

\section{Actinodaphne campanulata var. campanulata}

Lauraceae

VU B $1+2 c$

India (Tamil Nadu)

A small tree of evergreen forest between 1200 and $1800 \mathrm{~m}$. The main concentration of populations occur along the Agastyamalai range. A collection has also been made in an outlying area in the Elamalai.

Assessor: World Conservation Monitoring Centre

Refs: 19144
Actinodaphne campanulata var. obtusa

Lauraceae

$\mathrm{EN} \mathrm{Bl+2c}$

India (Kerala)

Recorded only from the type locality, this variety occurs on the Agastyamalai Hills in evergreen forest between 1000 and $1300 \mathrm{~m}$. Large areas have been exposed to fires, grazing, the establishment of commercial plantations and cutting for fuelwood but about $1000 \mathrm{~km}^{2}$ of forest are protected within sanctuaries.

Assessor: World Conservation Monitoring Centre

Refs: 4627,19144

\section{Actinodaphne cuspidata}

Lauraceae

$\mathrm{CR} B 1+2 \mathrm{c}$

Malaysia (Peninsular Malaysia)

Known only from Ulu Bera in Perak, a single collection of this small tree was made in the last century. It is uncertain whether the collection locality is still forested as there has been much settlement and forest clearance in the area.

Assessor: World Conservation Monitoring Centre

Refs: 8464,19073

\section{Actinodaphne ellipticbacca}

Lauraceae

VUD2

Viet Nam

A small tree endemic to a single high mountain locality, $\mathrm{Sa} \mathrm{Pa}$ in Lao Kai Province in north Viet Nam. It occurs in subtropical open forests at about $1500 \mathrm{~m}$.

Assessor: World Conservation Monitoring Centre

Refs: 848,15357

\section{Actinodaphne fragilis}

Lauraceae

VU D2

Malaysia (Peninsular Malaysia)

Restricted to the Ulu Bubong Hills, this tree of lowland forest has been collected twice only.

Assessor: Kochummen, K.M.

Refs: 8464,19073

\section{Actinodaphne johorensis}

Lauraceae

$\mathrm{VUBl}+2 \mathrm{C}$

Malaysia (Peninsular Malaysia)

Known from very few collections from Pahang and Johore, this species occurs in lowland forest, which is threatened by land conversion for agriculture.

Assessor: Kochummen, K.M.

Refs: 8464, 19073

\section{Actinodaphne lanata}

Lauraceae

CR B1+2c

India (Tamil Nadu)

Endemic to the Nilgiri Hills, where the only recorded population occurred in *shola forest between 1500 and $1800 \mathrm{~m}$. There have been no records since 1889 .

Assessor: World Conservation Monitoring Centre

Refs: 14276,19144

\section{Actinodaphne lawsonii}

Lauraceae

VU B1+2c

India (Kamataka, Kerala, Tamil Nadu)

A small tree of evergreen forest, known from scattered populations in the Western Ghats. It has been collected mostly from isolated peaks in the Nilgiris, occurring up to $2500 \mathrm{~m}$. Populations have also been recorded from outlying areas, mainly at high altitudes, from South Kanara in Karnataka and the Anamalai range. The 
habitat is threatened in places with clearance for the cultivation of commercial crops.

Assessor: World Conservation Monitoring Centre

Refs: 14276,19144

\section{Actinodaphne salicina}

Lauraceae

India (Kerala, Tamil Nadu)

EN B $1+2 c$

Only two collections of the species appear to have been made. The type specimen was found in the Nilgiri Hills in Tamil Nadu. A second occurrence has been recorded from the north of the Travancore range in Kerala.

Assessor: World Conservation Monitoring Centre Refs: 19144

\section{Actinokentia huerlimannü \\ Palmae}

$\mathrm{LR} / \mathrm{cd}$

New Caledonia

A species of south-eastern New Caledonia, occurring on serpentine soils in wet forest at an altitude of $850-880 \mathrm{~m}$. Assessor: Jaffré, T. et al.

Refs: 10351,19118

\section{Actinostrobus acuminatus \\ Cupressaceae}

Australia (Western Australia)

$\mathrm{LR} / \mathrm{nt}$

A shrubby tree which is confined to Westem Australia. It is not heavily exploited but if fires were to increase the species might become threatened.

Assessor: World Conservation Monitoring Centre

Refs: 374,8843

\section{Actinostrobus pyramidalis}

Cupressaceae

LR/nt

Australia (Western Australia)

A shrubby tree confined to Western Australia. There are no obvious threats to the species other than its sensitivity to fires.

Assessor: World Conservation Monitoring Centre

Refs: 374,10488

\begin{abstract}
Adansonia grandidieri
Bombacaceae

EN Alc+2c

Madagascar

A large tree collected from five locations distributed between Lac Ihotry, near Morombe, and Bereboka, north of Morondava. It probably occurred in dry deciduous forest, frequently close to bodies of water, but mature trees are now largely found in degraded agricultural lands where regeneration is poor. It is the most commercially valuable of the Malagasy baobabs on account of the high-quality oil that is extracted from the seed.
\end{abstract}

Assessor: World Conservation Monitoring Centre

Refs: 14208, 15649

\section{Adansonia madagascariensis}

Bombacaceae

LR/nt

Madagascar

Occurring in dry or moist forest, the species extends from Antsiranana to the Sambirano region and perhaps Soalala. Occurrences in the south-east of the country appear to be Adansonia za. Little is known of the conservation status but the clearance of the habitat has been extensive in places.

Assessor: World Conservation Monitoring Centre Refs: 15649

\section{Adansonia perrieri}

Bombacaceae

$\mathrm{EN} \mathrm{B1+2c,} \mathrm{C2a}$

Madagascar

Confined to the northern tip of Madagascar the species is known from just five sites. Although further locations are likely to be found the known populations are evidently very small; only one, at Ambondromifehy, contains more than a dozen individuals. This region of northern Madagascar is considerably disturbed by fire and the extraction of firewood and timber. Seed predation by rats also appears to be limiting the chances of population recruitment.

Assessor: World Conservation Monitoring Centre Refs: 11959,15649

\section{Adansonia rubrostipa}

Bombacaceae

LR/nt

Madagascar

The species extends along the west coast from near Itampolo in the south-west to Soalala in the north-west, occurring in spiny and dry forest. This wide distribution ensures the species is conservationally secure, although populations north of Toliara are threatened with destruction for charcoal production. There has been considerable population declines in the past because of the dramatic rate of habitat loss. The long generation time of baobabs makes them more vulnerable. This species plays a significant role in providing important resources for humans, lemurs, insects and other animals. Assessor: World Conservation Monitoring Centre Refs: 15649

\section{Adansonia suarezensis}

Bombacaceae

$\mathrm{EN} B 1+2 \mathrm{c}$

Madagascar

Until recently the species was thought to be restricted to the northem tip of Madagascar around the Baie d'Antsiranana. A population has since been found further south in Mahory forest between Ankarana and Analamera Reserves. Its natural habitat is deciduous forest on limestone, although small trees are also found in disturbed sublittoral scrub. Individuals are found in local abundance but are regenerating healthily only in Mahory. The forest's proximity to a rapidly growing mining town leads to intensive wood and charcoal extraction, grazing and hunting. Populations elsewhere are smaller, show few signs of regeneration and are threatened by the rapid depletion of the habitat through charcoal and timber production. The trees are protected from cutting, in places, because of their valued uses. Assessor: World Conservation Monitoring Centre Refs: 14208, 15649, 19024

\section{Adansonia za}

Bombacaceae

$\mathrm{LR} / \mathrm{nt}$ Madagascar

A species of dry or spiny forest, savannas and scrubland from Andohahela and the Mandrare River in the southwest through southem and western Madagascar to the Boina region and the Sambirano River basin. It is less abundant and restricted to riverine areas in the northwest. The abundance and the wide range of the species ensures that it is relatively safe. However, several populations are threatened with forest clearance and, given the long generation time of the baobab and the dramatic habitat loss that has occurred in the past, the 
species may be more vulnerable. It is a key species in providing nesting holes and perches for various animals, as well as food for insects, birds and lemurs.

Assessor: World Conservation Monitoring Centre Refs: 15649

\section{Adelobotrys panamensis \\ Melastomataceae \\ CR B $1+2 \mathrm{c}$ \\ Panama}

Endemic to the mountains of El Copé in Coclé Province, the species occurs in cloud forest, mostly on riversides, to the north of the community. It appears to be common in this small area. The forest here has been much reduced by the increasing settlement of the area.

Assessor: Mitré, M.

Refs: 16772

\section{Adenanthera bicolor \\ Leguminosae \\ VU Alc \\ Sri Lanka \\ An endemic tree restricted to the lowland wet evergreen forests of south-west Sri Lanka. It was discovered in 25 forests during the recent National Conservation Review, including the Sinharaja Biosphere Reserve. \\ Assessor: World Conservation Monitoring Centre \\ Refs: 15431, 17195, 19112}

\section{Adenanthera intermedia \\ Leguminosae \\ Philippines}

VU Alcd

A timber tree, endemic to the Philippines. Rates of habitat loss through logging and shifting cultivation have led to considerable population declines.

Assessor: World Conservation Monitoring Centre

Refs: $2072,4919,18088$

\section{Adenium obesum ssp. socotranum}

Apocynaceae

VU D2

Yemen (Socotra)

A succulent tree which is widespread on the plains, foothills and limestone plateau. It is very common in some areas and because of its poisonous nature is avoided by grazing animals.

Assessor: Miller, A.G.

Refs: $2354,6044,19083$

\section{Adenopodia rotundifolia}

Leguminosae

VU Bl+2c

Somalia, Tanzania

This species is known from southern Somalia and eastern Tanzania. It occurs in deciduous bushland or woodland in seasonally flooded areas. It is highly restricted in occurrence, in a habitat which is experiencing declines because of overcutting for charcoal production and grazing.

Assessor: Thulin, $\mathrm{M}$.

Refs: $7550,8697,18665$

\section{Adinandra angulata}

Theaceae

$\mathrm{LR} / \mathrm{cd}$

Malaysia (Peninsular Malaysia)

A small tree of cloud forest, distributed between $1700 \mathrm{~m}$ and $1800 \mathrm{~m}$, confined to Pahang on Gunung Tahan, where it is protected within Taman Negara National Park.

Assessor: Chua, L.S.L.

Refs: 8464, 19073

\section{Adinandra corneriana}

Theaceae

VU B1+2c

Malaysia (Peninsular Malaysia)

A small tree occurring in lowland forest, hill forest and occasionally along sandy river banks in Terengganu, Pahang (Gunung Tahan) and Johore.

Assessor: Chua, L.S.L.

Refs: $8464,17140,19073$

\section{Adinandra forbesü}

Theaceae

LR/nt

Indonesia (Irian Jaya), Papua New Guinea

A tree scattered in monsoon forest, savanna woodland and lower montane forest up to $1200 \mathrm{~m}$. In Papua New Guinea, the population has suffered from logging activities over recent years in the Oriomo River area, Western Province, where the species was once fairly common.

Assessor: Eddowes, P.J.

Refs: 19114

\section{Adinandra griffithii}

Theaceae

EN Alc, Bl+2c

India (Meghalaya)

A small tree confined to Cherrapunji and Shongpung forests. At Cherrapunji a cement factory has caused the loss of habitat. The species has not been recorded since 1938 and has clearly suffered from habitat declines.

Assessor: World Conservation Monitoring Centre

Refs: 2538

\section{Adinandra integerrima}

Theaceae

LR/cd

Malaysia (Peninsular Malaysia), Singapore

Occurring in lowland, submontane and hill rainforests of Kedah, Perak, Penang, Pahang, Johore and Singapore, this species can be found in state parks.

Assessor: Chua, L.S.L.

Refs: $5550,9199,11647,19073$

\section{Adinandra parvifolia}

Theaceae

LR/cd

Malaysia (Peninsular Malaysia)

This rare tree inhabits cloud forest between 1500 and $2000 \mathrm{~m}$ in Kedah, Perak and Pahang. It receives a degree of protection within the permanent forest estate.

Assessor: Chua, L.S.L.

Refs: 8464, 19073

\section{Adonidia merrillii}

Palmae

LR/nt

Philippines

A palm tree occurring in open forest on steep limestone slopes in coastal areas of Coron, Palawan Island. The species is protected by its inaccessable location. The supply of plants and seeds in the nursery trade appear to be abundant.

Assessor: Johnson, D.

Refs: 19118

\section{Aegiphila cuneata var. hirsutissima}

Verbenaceae

VU D2

Peru

A variety known only from the type collection taken from lowland Amazon forest in the department of Loreto.

Assessor: World Conservation Monitoring Centre Refs: 1984 
Acgiphila fasciculata

Verbenaceae

VU Alc, C2a

Guatemala, Honduras, Nicaragua

A tree of middle elevation, occurring in areas of humid forest, which are reduced in extent and continue to be extensively degraded.

Assessor: Nelson, C.

Refs: $4861,4974,13995$

\section{Aegiphila ferruginea}

Verbenaceae

VU B $1+2 c$

Ecuador

This endemic tree of the Ecuadorean High Andes inhabits montane and upper montane cloud forest between $2500 \mathrm{~m}$ and $3900 \mathrm{~m}$.

Assessor: World Conservation Monitoring Centre

Refs: 19119,19120

\section{Aegiphila monstrosa}

Verbenaceae

VU Alc, C2a

Belize, Guatemala, Honduras, Mexicn

A small tree or treelet of wet thickets within thin forest or in second growth, principally in the Atlaritic lowlands. The habitat is reduced through conversion to agriculture.

Assessor: Nelson, C.

Refs: 13995

\section{Aegiphila monticola}

Verbenaceae

$\mathrm{VUBI}+2 \mathrm{c}$

Ecuador

An endemic tree of Ecuador, inhabiting montane cloud forest at altitudes between 2200 and $3000 \mathrm{~m}$ in Cotopaxi and Bolívar.

Assessor: World Conservation Monitoring Centre

Refs: 19119,19120

\section{Aegiphila panamensis}

Verbenaceac

VUAlc

Belize, Colombia, Costa Rica, El Salvador, Guatemala, Honduras, Mexico, Nicaragua, Panama

Although widespread, the species is never abundant, occurring in remaining areas of lowland rainforest and thickets, often in marshy places.

Assessor: Nelson, C.

Refs: 13995

\section{Aegiphila purpurascens \\ Verbenaceae}

VU $B 1+2 c$

Ecuador

This Ecuadorean endemic inhabits cloud forest at altitudes between 2440 and $2950 \mathrm{~m}$. It is currently known only from Azuay Province.

Assessor: World Conservation Monitoring Centre

Refs: 19119,19120

\section{Aegiphila rimbachì}

Verbenaceae

VU B1 $+2 \mathrm{c}$

Ecuador

This endemic tree of Ecuador inhabits cloud forest at $2600 \mathrm{~m}$ altitude in the High Andean areas of Bolivar Province.

Assessor: World Conservation Monitoring Centre

Refs: 19119,19120

\section{Aegiphila skutchii}

Verbenaceae

VU C2a

Guatemala, Honduras, Mexico

An uncommon species of humid forest, occurring at medium elevation.

Assessor: Nelson, C.

Refs: 13995

\section{Aequatorium asterotrichum}

Compositae

VU B1+2c

Ecuador

A species which is confined to upper montane forest of the Ecuadorean Andes.

Assessor: World Conservation Monitoring Centre

Refs: 19119,19120

\section{Aequatorium rimachianum}

Compositae

VU D2

Peru

So far the species is known only from the type collection taken from rocky slopes between 2500 and $3000 \mathrm{~m}$ in the department of Huánuco.

Assessor: World Conservation Monitoring Centre

Refs: 1984

Aerisilvaea sylvestris

Euphorbiaceae

EN C2b, D1

Tanzania

The species is confined to an area no greater than $0.1 \mathrm{~km}^{2}$ within swamp forest in Kimboza Forest Reserve $\left(4 \mathrm{~km}^{2}\right)$. The surrounding area is densely populated and there is strong pressure on the reserve because of the demand for land. The Tanzanian Catchment Forest Project employs two forest guards to prevent illegal activities. This species is the only member of the genus.

Assessor: Lovett, J. \& G.P. Clarke

Refs: 16796

\section{Aesculus wangii}

Hippocastanaceae

VU Ala, Bl+2a, Cl+2a

China (Yunnan), Viet Nam

Populations are known from south Yunnan and Lào Chi Province in north Viet Nam. Trees occur singly or in groves in remaining areas of semi-evergreen broadleaved forest on limestone mountains. The present knowledge of the species distribution is not complete but significant habitat declines are occurring in the areas where the species is known, largely because of encroaching agriculture but also logging for timber.

Assessor: Rushforth, $\mathrm{K}$.

Refs: $1818,6163,11847,19055$

\section{Aextoxicon punctatum}

Aextoxicaceae

Argentina (Chubut), Chile

A taxonomically interesting species, the only member of the family. Occurring in broadleaved evergreen montane forest, its distribution is restricted in Argentina to the north-west of Chubut in Lago Puelo, probably in the protected area of that name. Data are not yet available on the status and distribution of the species in Chile. Assessor: Prado, D.

Refs: 1262,5112

\section{Afrocarpus mannii}

Podocarpaceae

VU D2

São Tomé \& Príncipe (São Tomé)

A montane species endemic, occurring in rainforest above $1300 \mathrm{~m}$ to the summit of the Pico. There is little 
threat to the habitat, although there was extensive deforestation earlier in the century up to $1500 \mathrm{~m}$.

Assessor: SSC Conifer Specialist Group

Refs: 2421, 2773, 13041

Afrocarpus usambarensis

Podocarpaceae

Tanzania

Assessor: SSC Conifer Specialist Group

Refs: $374,4391,13041$

\section{Afrostyrax lepidophyllus}

Huaceae

VU Alc, B I+2c

Cameroon, Gabon, Ghana

The species is rare, with a disjunct distribution. Populations are confined to areas of wet evergreen forest contained within Subri and Cape Three Points Forest Reserve in Ghana, in parts of the South West Province in Cameroon and in Gabon in an area to the north and in Lopé Forest Reserve. The forest has been converted into a commercial plantation in Subri and in Cape Three Points mining has destroyed areas of forest.

Assessor: Hawthorne, W.

Refs: 2773, 7142, 8854, 12061, 19043

\section{Afzelia africana}

Leguminosae

VU Ald

Benin, Burkina Faso, Cameroon, Central African Republic, Chad, Congo, Côte d'Ivoire, Democratic Republic of Congo, Ghana, Guinea, Guinea-Bissau, Mali, Niger, Nigeria, Senegal, Sierra Leone, Sudan, Togo, Uganda

A widespread species of dry forest and woodland which has declined in population numbers through exploitation of the timber for the international market.

Assessor: African Regional Workshop

Refs: 2362, 2773, 7550, 7808, 10961, 16021

\section{Afzelia bipindensis}

Leguminosae

VU Alcd Angola, Cameroon, Central African Republic, Congo, Democratic Republic of Congo, Gabon, Nigeria, Uganda A widespread rainforest species. It is heavily exploited throughout its range for its valuable timber. In some areas there are reported to be few seed trees remaining.

Assessor: African Regional Workshop

Refs: $2362,2773,6718,14667,17408$

\section{Afzelia pachyloba}

Leguminosae

VU Ald

Angola, Cameroon, Congo, Democratic Republic of Congo, Gabon, Nigeria

A rainforest species which is heavily exploited for its commercial timber. Relatively few seed trees remain throughout its range.

Assessor: African Regional Workshop

Refs: $2362,2773,6718,17408$

\section{Afzelia rhomboidea}

Leguminosae

VU Alcd

Indonesia (Sumatra), Malaysia (Peninsular Malaysia), Philippines

A slow-growing species scattered on low hills and ridges and temporarily inundated sites. The timber is regarded as very valuable locally and, in the past, exploitation has been considerable in the Philippines.

Assessor: Asian Regional Workshop

Refs: $4919,5550,12937,14573,19057$
Afzelia xylocarpa

Leguminosae

EN Alcd

Cambodia, Laos, Myanmar, Thailand, Viet Nam

A tree found throughout Indo-China, where it grows in dense forest, and in transitional areas between evergreen and dry open dipterocarp forest. In Viet Nam the hard, attractive wood is highly valued for carpentry. Because of high levels of exploitation and habitat loss, large trees are scarce and hard to find.

Assessor: Nghia, N.H.

Refs: $848,6646,11530,14573$

Agathis atropurpurea

Araucariaceae

LR/nt

Australia (Queensland)

A timber species scattered in montane rainforest. Wherever logging is allowed exploitation has been very heavy and populations have declined. A large percentage of the forests is now protected.

Assessor: SSC Conifer Specialist Group

Refs: 707, 3092, 13041, 17200

\section{Agathis corbassonii}

Araucariaceae

VU B $1+2 c$

New Caledonia

Endemic to northern New Caledonia, this species is scattered in areas of lowland moist forest on nonultramafic substrates. It is exploited for its timber, most heavily at a local level.

Assessor: SSC Conifer Specialist Group

Refs: 10351,12630

\section{Agathis dammara}

Araucariaceae

VU Alcd

Brunei, Indonesia (Java, Kalimantan, Sumatra), Malaysia (Peninsular Malaysia, Sabah, Sarawak)

The taxonomy and nomenclature of the species is still widely confused with $A$. borneensis and $A$. philippinensis. Agathis species are distinctive, highly sought-after and exploited for their valuable timber. Large stands of this species have been completely extracted throughout much of its range, most notably in Kalimantan. Exploitation continues to be heavy and regeneration in residual stands is insufficient to replace lost populations. In the past the tree has also been destructively exploited for copal. Plantations are now established.

Assessor: SSC Conifer Specialist Group

Refs: $6845,10938,13041,14573$

\section{Agathis endertii}

Araucariaceae LR/nt

Indonesia (Kalimantan), Malaysia (Sabah, Sarawak) Although the species is widespread, it occurs in isolated populations in moist lowland forest associated with sandstone *kerangas. The timber is heavily exploited. Assessor: SSC Conifer Specialist Group

Refs: 374,6851

\section{Agathis flavescens}

Araucariaceae

VU D2

Malaysia (Peninsular Malaysia)

Less than 10,000 individuals are likely to exist in three separate populations, occurring in moist montane forest. Individuals frequently display yellowing leaves suggestive of poor nutrient conditions. The species 
receives a degree of protection within the permanent forest estate.

Assessor: SSC Conifer Specialist Group

Refs: $6851,13041,19073$

\section{Agathis kinabaluensis}

Araucariaceae

Malaysia (Sabah, Sarawak)

VU D2

The species is only known from Mount Kinabalu in Sabah, where it is apparently relatively common in mossy ridge forest above $1500 \mathrm{~m}$. There is also a disjunct population, which occurs within a highly restricted area on the summit ridge of Mount Murud in Sarawak. This latter occurrence has been refered to as A. orbicula by de Laubenfels. The Mount Kinabalu population is almost entirely contained within a national park. The Mount Murud population is unprotected and the area is under considerable pressure for development.

Assessor: SSC Conifer Specialist Group

Refs: 6851, 13041, 19017, 19125, 19192

\section{Agathis lanceolata}

Araucariaceae

LR/ed

New Caledonia

A species endemic to New Caledonia, which occurs in areas of rainforest on the southern ultramafic massifs. The species continues to be over exploited. The species is also sensitive to wildfires and in some places it has retreated to sheltered valleys. There is effective protection of populations occurring in Rivière Bleu Provincial Park.

Assessor: SSC Conifer Specialist Group

Refs: 10351,12630

\section{Agathis lenticula}

Araucariaceae

VU D2

Malaysia (Sabah)

Occurring in lower montane forest and possibly hill forest, this large tree is known only from Mount Kinabalu and the adjacent Crocker range. Populations in the former are relatively well protected. The Crocker range, however, is a large area with a poorly defined boundary. There are frequent illegal incursions, mainly to remove timber from this species.

Assessor: SSC Conifer Specialist Group

Refs: $374,6851,19125$

\section{Agathis microstachya}

Araucariaceae

LR/cd

Australia (Queensland)

As with $A$. atropurpurea, this timber species is found in low densities in localised lowland rainforest. Logging is heavy where the forest is unprotected. Before 1985 the population had been halved by logging but $70 \%$ of the forests are now protected.

Assessor: SSC Conifer Specialist Group

Refs: 17200,18170

\section{Agathis montana}

Araucariaceae

$\mathrm{LR} / \mathrm{cd}$

New Caledonia

A species restricted to high altitude rainforests on Mount Panié. It is locally abundant and in an area which is relatively inaccessible and well protected.

Assessor: SSC Conifer Specialist Group

Refs: $2230,9631,12630$
Agathis moorei

Araucariaceae

New Caledonia

VU B $1+2 c$

Scattered throughout the northem half of the island, the species is found in areas of lowland rainforest mostly on non-ultramafic substrates. Substantial declines have occurred through overexploitation of the timber in recent years. Copal is also extracted at moderate levels.

Assessor: SSC Conifer Specialist Group

Refs: 10351,12630

\section{Agathis orbicula}

Araucariaceae

Malaysia (Sabah, Sarawak)

VUB $1+2 c$

Ranging from southern Sabah to central Sarawak, this tree is found scattered in relatively few locations in rainforests and "kerangas on low mountains and plateaux. Levels of timber exploitation and the effects on populations are little known but are likely to be considerable.

Assessor: SSC Conifer Specialist Group

Refs: 374,6851

\section{Agathis ovata}

Araucariaceae

New Caledonia

The species is scattered in maquis shrubland in a few localities on ultramafic soils in the south. Pressures are exerted by mining activities, fires and also by logging. The species is slow growing but regenerates well where there is no burning. Populations in Rivière Bleue Provincial Park are effectively protected.

Assessor: SSC Conifer Specialist Group

Refs: 10351, 12630

\section{Agathis philippinensis}

Araucariaceae

VUAlcd

Indonesia (Moluccas, Sulawesi), Philippines

Assessor: SSC Conifer Specialist Group

Refs: 4919, 12937, 13041, 14573

\section{Agathis silbae}

Araucariaceae

VU D2

Vanuatu

The Forestry Department in Vanuatu recognise this species as a synonym of $A$. macrophylla, which in turn is synonymous with $A$. vitiensis. The taxon encompassing A. silbae according to the SSC Conifer Specialist Group is confined to Santo Peak on the island of Santo. Logging is a major threat, but at present land disputes have halted logging activities temporarily.

Assessor: SSC Conifer Specialist Group

Refs: $374,11632,12656,19192$

\section{Agathis spathulata}

Araucariaceae

$\mathrm{LR} / \mathrm{nt}$

Papua New Guinea

Scattered emergents survive in small exposed groves of rainforest in the eastem highlands. Overexploitation of the timber is a threat.

Assessor: SSC Conifer Specialist Group

Refs: $374,6851,13041$

\section{Agathis vitiensis}

Araucariaceae

LR/nt

Fiji, Solomon Islands (Santa Cruz Is), Vanuatu

A massive tree and important timber species. It is found 
in low densities. It could become of conservation concern if logging were to become more intensive.

Assessor: SSC Conifer Specialist Group

Refs: $374,13041,18818$

\section{Aglaia agglomerata}

Meliaceae

LR/nt

Indonesia (Irian Jaya), Papua New Guinea

Endemic to the island of New Guinea, this tree is scattered in lowland to midmontane primary and secondary forest. Habitat loss is a potential threat to this species.

Assessor: Pannell, C.M.

Refs: $6509,11145,19129$

\section{Aglaia aherniana}

Meliaceae

VUAlc

Philippines

A tree endemic to the Philippines. The species is threatened by habitat destruction.

Assessor: Pannell, C.M.

Refs: 6509,19129

\section{Aglaia amplexicaulis}

Meliaceae

VU D2

Fiji

A Fijian endemic of dense forest, known only from three collections.

Assessor: Pannell, C.M.

Refs: 6509, 19129

\section{Aglaia angustifolia}

Meliaceae

VU Alc

Brunei, Indonesia (Kalimantan, Sumatra), Malaysia (Peninsular Malaysia, Sarawak), Philippines

A tree of primary forest and swamp forest up to $1450 \mathrm{~m}$, suffering from habitat loss.

Assessor: Pannell, C.M.

Refs: $6509,17140,19129$

\section{Aglaia apiocarpa}

Meliaceae

VUAlc

India, Sri Lanka

This species is found in wet evergreen forest, primary and secondary forest in southern India and Sri Lanka. It is threatened by habitat destruction.

Assessor: Pannell, C.M.

Refs: 6509,19129

\section{Aglaia archiboldiana}

Meliaceae

VU D2

Fij

A forest tree known only from three localities on Viti

Levu.

Assessor: Pannell, C.M.

Refs: 6509,19129

\section{Aglaia australiensis}

Meliaceae

VU D2

Australia (Queensland)

This small tree occurs in lowland rainforest, coastal rainforest and complex mesophyll forest in the Cook District, Queensland. However, more information is needed on the status of the forest in this region.

Assessor: Pannell, C.M.

Refs: 6509, 19129
Aglaia barbanthera

Meliaceae

VU Alc

Indonesia (Irian Jaya), Papua New Guinea

This species is restricted to primary forest in New Guinea between 60 and $2000 \mathrm{~m}$. Habitat loss threatens this species.

Assessor: Pannell, C.M.

Refs: 6509,19129

\section{Aglaia basiphylla}

Meliaceae

VU Alc

Fiji

Found between 50 and $1075 \mathrm{~m}$, this primary forest tree is endemic to Fiji. Habitat loss is a threat to this species.

Assessor: Pannell, C.M.

Refs: 6509, 19129

\section{Aglaia bourdillonii}

Meliaceae

VU B1+2c

India

This species is restricted to the Agastyamalai Hills in southem India, where large areas have been exposed to fires, grazing, the establishment of commercial plantations and cutting for fuelwood but about $1000 \mathrm{~km}^{2}$ of forest are protected within sanctuaries.

Assessor: Pannell, C.M.

Refs: 6509,19129

\section{Aglaia brassï}

Meliaceae

VUAlc

Australia (Queensland), Indonesia (Irian Jaya), Papua New Guinea (North Solomons, Papua New Guinea), Solomon Islands (South Solomon)

This understorey tree is fairly common in lowland primary and secondary forest up to $500 \mathrm{~m}$. The main threat to the species is loss of habitat.

Assessor: Pannell, C.M.

Refs: $6509,17200,19129$

\section{Aglaia brownii}

Meliaceae

VU Alc

Australia (Northern Territory, Queensland), Indonesia (Irian Jaya), Papua New Guinea

A small tree mainly found in coastal forest. Habitat destruction is the main threat to the species.

Assessor: Pannell, C.M.

Refs: 6509,19129

\section{Aglaia ceramica}

Meliaceae

VU D2

Indonesia (Moluccas)

A small tree endemic to primary forest in the Moluccas; it is apparently confined to four localities.

Assessor: Pannell, C.M.

Refs: 6509,19129

\section{Aglaia chittagonga}

Meliaceae

VU Alc

Bangladesh, Taiwan, Thailand

A small tree of lowland forest found along rivers and near beaches. It is named after the type location in Chittagong, Bangladesh. Habitat destruction is the main threat to the species.

Assessor: Pannell, C.M.

Refs: $6509,7933,19053,19129$ 


\section{Aglaia cinnamomea}

Meliaceae

VU Alc

Indonesia (Irian Jaya), Papua New Guinea

Confined to New Guinea, this species is suffering from habitat destruction.

Assessor: Pannell, C.M.

Refs: $6509,7510,19129$

\section{Aglaia coriacea}

Meliaceae

VU Alc

Indonesia (Kalimantan), Malaysia (Peninsular Malaysia)

A small tree of primary lowland forest found in only a few localities in east and central Peninsular Malaysia. In Bomeo, this species is known only from the type collection. It is threatened by forest destruction.

Assessor: Pannell, C.M.

Refs: 6509,19129

\section{Aglaia costata}

Meliaceae

VU D2

Philippines

A small tree endemic to the Philippines. It is threatened by habitat loss.

Assessor: Pannell, C.M.

Refs: $6509,11145,19129$

\section{Aglaia crassinervia}

Meliaceae

LR/nt

Brunei, India (Andaman and Nicobar Is. - Nicobar Is.), Indonesia (Kalimantan, Sumatra), Malaysia (Peninsular Malaysia, Sabah, Sarawak), Myanmar, Philippines, Thailand

A widespread tree found in forest and seasonal swamp up to $1570 \mathrm{~m}$. Habitat destruction is a potential threat to the species.

Assessor: Pannell, C.M.

Refs: 6509,7087

\section{Aglaia cremea}

\section{Meliaceae}

VU Alc

Papua New Guinea

A small tree endemic to Papua New Guinea where it grows in secondary forest and hill forest. The main threat to the species is habitat destruction.

Assessor: Pannell, C.M.

Refs: 6509,19129

\section{Aglaia cucullata}

Meliaceae

LR/nt

Bangladesh, India (Andaman and Nicobar Is. - Andaman Is., Orissa), Indonesia (Irian Jaya, Java, Sumatra), Malaysia (Peninsular Malaysia, Sarawak), Myanmar, Nepal, Papua New Guinea, Philippines, Singapore, Thailand, Viet Nam

This widespread tree is the only member of the genus found in areas of mangrove, nipah (Nypa fruticans) swamp and estuaries. It provides an important timber for house, bridge and boat construction and is found in trade as Pacific Maple. Habitat loss is a potential threat. Assessor: Pannell, C.M.

Refs: $6509,7147,9199,11145,12937,19129$

\section{Aglaia cumingiana}

Meliaceae VUAlc

Brunei, Malaysia (Sabah, Sarawak), Philippines

A species of primary, secondary and gallery forest up to
$1330 \mathrm{~m}$, confined to northem Borneo and the Philippines.

Forest destruction threatens this species.

Assessor: Pannell, C.M

Refs: 6509,19129

\section{Aglaia cuspidata}

Meliaceae

VU D2

Papua New Guinea

A rainforest tree, known only from three localities.

Assessor: Pannell, C.M.

Refs: 6509, 19129

\section{Aglaia densisquama}

Meliaceae

VU D2

Malaysia (Sarawak)

A species, endemic to Sarawak, confined to primary and riverine forest.

Assessor: Pannell, C.M.

Refs: 6509,19129

\section{Aglaia densitricha}

Meliaceae

Malaysia (Peninsular Malaysia)

CR D1

A small tree known only from the type collection found in 1953 along the Terengganu-Besut road. It may now be extinct.

Assessor: Pannell, C.M.

Refs: 6509,19129

\section{Aglaia edulis}

Meliaceae

LR/nt

Bhutan, Cambodia, China (Guangdong - Hainan), India (Andaman and Nicobar Is. - Nicobar Is.), Indonesia (Bali, Java, Lesser Sunda Is., Moluccas, Sulawesi, Sumatra), Malaysia (Peninsular Malaysia), Myanmar, Philippines, Thailand, Viet Nam

A rare, scattered timber tree primarily found in evergreen and primary forest along rocky coasts. It is potentially threatened by habitat loss. This species might have some value as a fruit tree.

Assessor: Pannell, C.M.

Refs: $4919,6509,11145,19129$

\section{Aglaia erythrosperma}

Meliaceae

$\mathrm{LR} / \mathrm{nt}$

Indonesia (Sumatra), Malaysia (Peninsular Malaysia), Thailand

A large, occasionally emergent, tree found growing in primary and evergreen forest. It is threatened by habitat loss. It has potential as a valuable timber.

Assessor: Pannell, C.M.

Refs: $6509,11145,19129$

\section{Aglaia euryanthera}

Meliaceae

LR/nt

Australia (Queensland), Indonesia (Irian Jaya), Papua New Guinea

A small tree found in many forest habitats up to $2100 \mathrm{~m}$. Habitat loss could threaten this species.

Assessor: Pannell, C.M.

Refs: 6509,19129

\section{Aglaia evansensis}

Meliaceae

CR D1

Fiji

A forest shrub or tree confined to the Mount Evans range of north-west Viti Levu.

Assessor: Pannell, C.M

Refs: 6509 


\section{Aglaia exstipulata}

Meliaceae

LR/nt

Malaysia (Peninsular Malaysia), Myanmar, Singapore, Thailand, Viet Nam

This tree is quite common in the primary and secondary forests of Peninsular Malaysia. It is potentially threatened by habitat loss.

Assessor: Pannell, C.M.

Refs: $6509,9199,11145,19129$

\section{Aglaia flavescens}

Meliaceae

VU D2

Indonesia (Irian Jaya), Papua New Guinea

A small tree confined to the island of New Guinea. So far it is known from only four localities.

Assessor: Pannell, C.M.

Refs: 6509,19129

\section{Aglaia flavida}

Meliaceae

LR/nt

Indonesia (Irian Jaya), Papua New Guinea (Bismarck Archipelago, North Solomons, Papua New Guinea), Solomon Islands (South Solomon)

The wood of this common tree is used for construction of houses, tools and canoes. Habitat destruction is possibly a threat.

Assessor: Pannell, C.M.

Refs: $6509,11145,19129$

Aglaia forbesii

Meliaceae

LR/nt

Brunei, Indonesia (Kalimantan, Sumatra), Malaysia (Peninsular Malaysia, Sabah, Sarawak), Myanmar, Thailand

Found up to $1000 \mathrm{~m}$, this widespread tree occurs in forest, and is potentially threatened by habitat loss.

Assessor: Pannell, C.M

Refs: $6509,7087,11145,19129$

\section{Aglaia foveolata}

Meliaceae

LR/nt

Brunei, Indonesia (Sumatra), Malaysia (Peninsular Malaysia, Sabah, Sarawak)

Occurring in lowland forest and swamp forest up to $1000 \mathrm{~m}$, this tree could be threatened by habitat loss.

Assessor: Pannell, C.M

Refs: $6509,11145,19129$

\section{Aglaia fragilis}

Meliaceae

VU D2

Fiji

A forest tree endemic to Fiji. It appears to be confined to a single locality, but may be extinct.

Assessor: Pannell, C.M

Refs: 6509,19129

\section{Aglaia glabrata}

Meliaceae

LR/n

Brunei, Indonesia (Kalimantan, Moluccas, Sumatra), Malaysia (Peninsular Malaysia, Sabah, Sarawak)

A fairly common tree of forest and *kerangas, possibly threatened in the future by habitat loss.

Assessor: Pannell, C.M.

Refs: $6509,7087,19129$
Aglaia gracilis

Meliaceae

CR D1

Fiji

A small slender tree only known from two forest localities on Viti Levu.

Assessor: Pannell, C.M.

Refs: 6509,19129

\section{Aglaia grandis}

Meliaceae

LR/nt

Indonesia (Sulawesi), Malaysia (Peninsular Malaysia), Philippines, Thailand, Viet Nam

A tree apparently confined to primary forest, a habitat type which is being destroyed. $A$. perfulva may be synonymous or possibly a subspecies of this taxon.

Assessor: Pannell, C.M.

Refs: $6509,11145,19129$

\section{Aglaia heterotricha}

Meliaceae

CR D1

Tonga

This species is known only from the type collection in 1952 from Eua Island, Tonga. It might be extinct.

Assessor: Pannell, C.M.

Refs: 6509,19129

\section{Aglaia hiernü}

Meliaceae

Indonesia (Sumatra), Malaysia (Peninsular Malaysia)

Occurring between 20 and $1700 \mathrm{~m}$, this tree is found in primary and secondary forest and in old wasteland. Habitat destruction is a potential threat to the species. Assessor: Pannell, C.M.

Refs: $6509,11145,19129$

\section{Aglaia integrifolia}

Meliaceae

VU D2

Papua New Guinea

A small tree restricted to lowland deciduous hill forest in Papua New Guinea. So far it is known from only four localities.

Assessor: Pannell, C.M.

Refs: 6509, 19129

\section{Aglaia korthalsii}

Meliaceae

LR/nt

Bhutan, Brunei, India (Assam), Indonesia (Kalimantan, Lesser Sunda Is., Sulawesi, Sumatra), Malaysia (Peninsular Malaysia, Sabah, Sarawak), Philippines, Thailand

Found up to $1700 \mathrm{~m}$, this tree grows in primary and secondary forest as well as peat swamp forest. Habitat loss could pose a threat to this species. The arillate seeds of this species are dispersed by primates.

Assessor: Pannell, C.M.

Refs: 6509, 7087, 19129

\section{Aglaia lancilimba}

Meliaceae

$\mathrm{LR} / \mathrm{nt}$

Indonesia (Bali, Lesser Sunda Is., Sulawesi), Malaysia (Sabah), Philippines

A tree found in forest, including swamp forests in the Philippines, Bumbun Island of Sabah, Bali, Sumbawa, Flores and Sulawesi of Indonesia. The species might be at risk in the near future from habitat loss.

Assessor: Pannell, C.M

Refs: 6509,19129 


\section{Aglaia laxiflora}

Meliaceae

VU Alc

Brunei, Indonesia (Kalimantan), Malaysia (Sabah)

A tree species restricted to the primary forest and periodically inundated dipterocarp forest of Bomeo, excluding Sarawak. Loss of habitat threatens this species.

Assessor: Pannell, C.M

Refs: 6509,19129

\section{Aglaia lepidopetala}

Meliaceae

$\mathrm{LR} / \mathrm{nt}$

Indonesia (Irian Jaya), Papua New Guinea

Fairly widespread but rare, this understorey forest species is restricted to New Guinea where there is a potential threat from logging and forest conversion.

Assessor: Pannell, C.M

Refs: 6509,19129

\section{Aglaia lepiorrhachis}

Meliaceae

Indonesia (Irian Jaya), Papua New Guinea

VUAlc

A small tree endemic to the lowland and hill forests of New Guinea. Habitat destruction poses a threat to this species.

Assessor: Pannell, C.M.

Refs: 6509,19129

\section{Aglaia leptantho}

Meliaceae

LR/nt

Indonesia (Java, Lesser Sunda Is., Sumatra), Malaysia (Peninsular Malaysia), Philippines, Singapore, Thailand, Viet Nam?

A tree occurring in many forest habitats and in seasonal swamps; habitat loss is the main threat to this species. The wood of this widespread tree is used for fumiture and house construction.

Assessor: Pannell, C.M.

Refs: $4919,6509,9199,10547,11145,19129$

\section{Aglaia leucoclada}

Meliaceae

VUAlc

Papua New Guinea

An understorey tree endemic to Papua New Guinea.

Habitat destruction is the main threat to this species.

Assessor: Pannell, C.M.

Refs: 6509,19129

\section{Aglaia leucophylla}

Meliaceae

LR/nt

Brunei, Indonesia (Kalimantan, Sulawesi, Sumatra), Malaysia (Peninsular Malaysia, Sabah, Sarawak), Philippines, Thailand

This species, usually found in secondary forest, is potentially under threat from habitat destruction. It is used for house poles in Bomeo.

Assessor: Pannell, C.M.

Refs: $6509,7087,11145,19129$

\section{Aglaia luzoniensis}

Meliaceae

LR/nt

Indonesia (Sulawesi), Philippines

A small tree scattered in primary and secondary forest near the mangrove zone. Habitat decline might threaten this species. The wood is used for construction.

Assessor: Pannell, C.M.

Refs: 2072, 4919, 6509, 11145
Aglaia mackiana

Meliaceae

CR D1

Papua New Guinea

A canopy tree most commonly found in mid-elevation forest. Trees may be easily overlooked as this dioecious species is only identified from the fruit. It is only definitely known from the type locality. Additional collections, which differ from the type specimen but may represent the same species, have been gathered from three localities. Forest fragmentation is likely to impede reproduction as it has been found that pollination is most efficient when individuals are less than $250 \mathrm{~m}$ apart. The enormous seeds are dispersed by cassowaries. Assessor: Pannell, C.M.

Refs: $7510,19129,19139$

\section{Aglaia macrocarpa}

Meliaceae

LR/nt

Brunei, Indonesia (Java, Kalimantan, Moluccas?, Sulawesi, Sumatra), Malaysia (Peninsular Malaysia, Sabah, Sarawak), Philippines?, Singapore, Thailand, Viet Nam

A species of lowland, hill and ridge forest up to $1740 \mathrm{~m}$, potentially threatened by habitat destruction.

Assessor: Pannell, C.M.

Refs: $6509,7087,8865,9199,11145,19129$

\section{Aglaia macrostigma}

Meliaceae

VU D2

Malaysia (Peninsular Malaysia)

This species is restricted to primary forest in Peninsular Malaysia. It is known from only four localities.

Assessor: Pannell, C.M.

Refs: 6509,19129

Aglaia malabarica

Meliaceae

CR D1

India (Kerala)

A fairly common tree where it occurs, restricted to the type locality in evergreen forest in northern Kerala. There is also a second field record of an occurrence further north in Wayanad.

Assessor: Pannell, C.M.

Refs: $6509,19129,19144$

\section{Aglaia malaccensis}

Meliaceae LR/nt

Indonesia (Kalimantan, Sumatra), Malaysia (Penizsular Malaysia), Philippines

A timber tree of primary and secondary forest threatened by habitat destruction.

Assessor: Pannell, C.M.

Refs: $6509,8865,10547,11145,18327,19129$

\section{Aglaia mariannensis}

Meliaceae

VU Alc

Guam, Northem Marianas, Palau

A variable species found in thickets and secondary forest on the larger Marianne and Caroline Islands. It is threatened by habitat decline.

Assessor: Pannell, C.M.

Refs: $6509,15533,19129$

Aglaia membranifolia

Meliaceae

VU Alc

Indonesia (Sumatra), Malaysia (Peninsular Malaysia)

This tree of primary forest between 330 and $500 \mathrm{~m}$, is 
known only from five localities in Peninsular Malaysia and Sumatra. It is threatened by habitat loss.

Assessor: Pannell, C.M.

Refs: 6509,19129

\section{Aglaia meridionalis}

Meliaceae

LR/nt

Australia (Queensland)

A small, understorey tree endemic to the east side of the Cape York Peninsula from Atherton Tableland south to Mount Bartle Frere, where it occurs mainly in montane and ridge-top rainforest. Loss of habitat is the main threat to the species.

Assessor: Pannell, C.M.

Refs: 6509, 19129

\section{Aglaia monozyga}

Meliaceae

LR/nt

Indonesia (Kalimantan), Malaysia (Peninsular Malaysia, Sabah)

A small forest tree ascending up to altitudes of $2000 \mathrm{~m}$, sometimes occurring in freshwater swamp forest. It is confined to Sabah and Kalimantan, except for a single collection from eastern Peninsular Malaysia. It is potentially threatened by habitat destruction.

Assessor: Pannell, C.M.

Refs: 6509,19129

\section{Aglaia multinervis}

Meliaceae

LR/nt

Indonesia (Sumatra), Malaysia (Peninsular Malaysia), Singapore

A timber tree of lowland forest, often on hillsides threatened by habitat destruction.

Assessor: Pannell, C.M.

Refs: $6509,9199,11145,19129$

\section{Aglaia odorata}

\section{Meliaceae}

$\mathrm{LR} / \mathrm{nt}$

Cambodia, China (Guangdong - Hainan), Indonesia (Moluccas?), Laos?, Myanmar, Thailand, Viet Nam

A shrub or small tree found in the evergreen and secondary forest. It is an important omamental species, commonly cultivated, especially the male specimens. The species status in the wild remains unclear. The wood is particularly good for tumery.

Assessor: Pannell, C.M.

Refs: $6509,11145,19129$

\section{Aglaia oligophylla}

Meliaceae LR/nt

Brunei, India (Andaman and Nicobar Is. - Andaman Is.), Indonesia (Kalimantan, Sumatra), Malaysia (Peninsular Malaysia, Sabah, Sarawak), Philippines, Singapore, Thailand

A species found in many forest habitats which are threatened by habitat destruction.

Assessor: Pannell, C.M.

Refs: $6509,7087,7147,9199,19129$

\section{Aglaia pachyphylla}

Meliaceae LR/nt

Indonesia (Java, Sulawesi, Sumatra), Malaysia (Peninsular Malaysia), Philippines, Thailand

A large tree found in primary forest, secondary swamp forest and on forest margins. It is threatened by habitat destruction.

Assessor: Pannell, C.M.

Refs: $6509,10547,11145,19129$

\section{Aglaia palembanica}

Meliaceae

LR/nt

Indonesia (Kalimantan, Sumatra), Malaysia (Peninsular Malaysia, Sarawak), Philippines, Singapore

A tree found in primary and secondary, moist, lowland forest; habitat loss could pose a threat.

Assessor: Pannell, C.M.

Refs: $6509,9199,19129$

\section{Aglaia parksii}

Meliaceae

VU Alc

Fiji, Papua New Guinea (North Solomons), Solomon Islands (South Solomon)

A small tree of lowland primary forest threatened by habitat destruction.

Assessor: Pannell, C.M.

Refs: 6509,19129

\section{Aglaia parviflora}

Meliaceae

LR/nt

Indonesia (Irian Jaya, Moluccas), Papua New Guinea (Bismarck Archipelago, North Solomons, Papua New Guinea), Solomon Islands (South Solomon)

Widespread in the Moluccas, New Guinea and the Solomon Islands, this forest tree could soon be threatened by habitat loss. The wood of this tree is used for house construction in Papua New Guinea.

Assessor: Pannell, C.M.

Refs: $6509,11145,19129$

\section{Aglaia penningtoniana}

Meliaceae

VUAlc

Papua New Guinea

A taxonomically variable species endemic to Papua New Guinea where it occurs in rainforest from low to montane elevations. Potentially serious threats are posed by selective logging and conversion of forest to agriculture.

Assessor: Pannell, C.M.

Refs: $6509,11145,19129$

\section{Aglaia perviridis}

Meliaceae

VUAlc

Bangladesh, Bhutan, China, India (Andaman and Nicobar Is. - Andaman Is.), Malaysia (Peninsular Malaysia), Thailand, Viet Nam

A common species found scattered in primary and secondary evergreen forest on limestone. It is threatened by habitat destruction.

Assessor: Pannell, C.M.

Refs: $6509,11145,19129$

\section{Aglaia pleuropteris}

Meliaceae

Cambodia?, Viet Nam

CR D1

A small tree found only in south Viet Nam, although there are unconfirmed reports of an occurrence in Cambodia. It is only known from two 19th century collections. This species might be extinct.

Assessor: Pannell, C.M.

Refs: 6509, 19129

\section{Aglaia polyneura}

Meliaceae

VU D2

Indonesia (Irian Jaya), Papua New Guinea

A small, shrubby tree endemic to New Guinea. It is apparently confined to two forest localities.

Assessor: Pannell, C.M.

Refs: 6509,19129 
Aglaia puberulanthera

Meliaceae

VU D2

Indonesia (Irian Jaya), Papua New Guinea

A very small tree, endemic to New Guinea, found growing in the understorey of primary and montane forest. The species is probably confined to only four localities.

Assessor: Pannell, C.M

Refs: 6509,19129

\section{Aglaia pyriformis}

Meliaceae

$\mathrm{EN} \mathrm{Bl+2c}$

Philippines

This tree is known only from two collections from Luzon. It was last collected in 1916 and may be extinct. Assessor: World Conservation Monitoring Centre

Refs: 6509,19129

\section{Aglaia ramotricha}

Meliaceae

VU Alc

Brunei, Indonesia (Kalimantan), Malaysia (Sabah, Sarawak)

An understorey tree restricted to primary forest on limestone in Bomeo. Habitat destruction is a threat to this species.

Assessor: Pannell, C.M.

Refs: 6509,19129

\section{Aglaia rimosa}

Meliaceae

LR/nt

Indonesia (Irian Jaya, Moluccas, Sulawesi), Papua New Guinea (Bismarck Archipelago, Papua New Guinea), Philippines, Taiwan

This shrub or tree is found in secondary forests along rivers and in coastal areas. Habitat loss cuuld pose a threat.

Assessor: Pannell, C.M.

Refs: $6509,11145,19129$

\section{Aglaia rivularis}

Meliaceae

VUAlc

Indonesia (Kalimantan), Malaysia (Sabah)

A small, rheophytic tree confined to riverine forest on sandy soils in eastem Borneo. Habitat loss poses a threat to the species. The wood is used locally for fence posts in Sabah.

Assessor: Pannell, C.M

Refs: $6509,11145,19129$

\section{Aglaia rubiginosa}

Meliaceae

LR/nt

Indonesia (Kalimantan, Sumatra), Malaysia (Peninsular Malaysia, Sarawak), Philippines, Singapore

An emergent tree mainly found in freshwater peat swamp forest, an area particularly vulnerable to exploitation. The species is also found in dry heath forest, *kerangas, lowland primary forest and hill forest. The wood is used in house and boat building.

Assessor: Pannell, C.M.

Refs: 5550, 6509, 8865, 9199, 10547, 11145, 12937, 18327,19129
Aglaia rubrivenia

Meliaceae

VU Alc

Papua New Guinea (North Solomons), Solomon Islands (South Solomon)

Restricted to the Solomon Islands, this small tree is found in primary montane forest.

Assessor: Pannell, C.M.

Refs: 6509

\section{Aglaia rufinervis}

Meliaceae

LR/nt

Brunei, Indonesia (Java, Kalimantan, Sumatra), Malaysia (Peninsular Malaysia, Sabah, Sarawak), Singapore, Thailand

A common tree found in both primary and secondary forest. Habitat loss could pose a threat to this species.

Assessor: Pannell, C.M.

Refs: $6509,7087,9199,11145,19129$

\section{Aglaia rugulosa}

Meliaceae

Indonesia (Kalimantan, Sumatra), Malaysia (Peninsular

Malaysia, Sarawak)

A small tree occurring in lowland and hill forest up to $830 \mathrm{~m}$; habitat loss could pose a threat.

Assessor: Pannell, C.M.

Refs: 6509,19129

\section{Aglaia saltatorum}

Meliaceae

VU A1c

Fiji, Solomon Islands (Santa Cruz Is), Tonga, Vanuatu, Wallis and Futuna Islands

Occurring in lowland forest up to $520 \mathrm{~m}$, this small tree is threatened by habitat loss. The species was probably introduced to Niue.

Assessor: Pannell, C.M.

Refs: 6509,19129

\section{Aglaia samoensis}

Meliaceae

LR/nt

American Samoa, Indonesia (Irian Jaya), Papua New Guinea (Bismarck Archipelago, North Solomons, Papua New Guinea), Solomon Islands (Santa Cruz Is, South Solomon), Vanuatu, Wallis and Futuna Islands, Western Samoa

A small tree occurring in primary and secondary forest up to $830 \mathrm{~m}$; habitat loss could pose a threat.

Assessor: Pannell, C.M.

Refs: $6509,16765,19129$

\section{Aglaia scortechinii}

Meliaceae

VU Alc

Brunei, Indonesia (Kalimantan), Malaysia (Peninsular Malaysia, Sabah, Sarawak)

This species is restricted to primary forest on limestone. It is threatened by habitat destruction.

Assessor: Pannell, C.M.

Refs: 6509,19129

\section{Aglaia sexipetala}

Meliaceae

LR/nt

Indonesia (Irian Jaya, Java, Sumatra), Malaysia (Peninsular Malaysia), Papua New Guinea, Philippines?, Singapore, Thailand

Assessor: Pannell, C.M.

Refs: $6509,7510,9199$ 


\section{Aglaia silvestris}

Meliaceae

$\mathrm{LR} / \mathrm{nt}$

Cambodia, India (Andaman and Nicobar Is. - Andaman Is., Andaman and Nicobar Is. - Nicobar Is.), Indonesia (Irian Jaya, Java, Kalimantan, Moluccas, Sulawesi, Sumatra), Malaysia (Peninsular Malaysia, Sabah, Sarawak), Papua New Guinea (Bismarck Archipelago, North Solomons, Papua New Guinea), Philippines, Solomon Islands (South Solomon), Thailand, Viet Nam A widespread, variable species of various habitat types, occurring up to $2100 \mathrm{~m}$. Habitat destruction could be a serious threat in the near future. An important source of timber

Assessor: Pannell, C.M.

Refs: $6509,7087,11145,19129$

\section{Aglaia simplicifolia}

Meliaceae

LR/nt

Brunei, India, Indonesia (Kalimantan, Sumatra), Laos,

Malaysia (Peninsular Malaysia, Sabah, Sarawak),

Thailand

A widepread species found in the understorey of many different forest types. Habitat loss could pose a threat.

Assessor: Pannell, C.M.

Refs: $6509,7087,19129$

\section{Aglaia smithii}

Meliaceae

VU Alc

Indonesia (Irian Jaya, Lesser Sunda Is., Moluccas, Sulawesi), Philippines

A small, locally common tree found in lowland primary and coastal forests. Habitat destruction poses a threat to the species. It is used for poles in Irian Jaya and for temporary construction in the Philippines.

Assessor: Pannell, C.M.

Refs: $6509,11145,19129$

\section{Aglaia speciosa}

Meliaceae

VU Alc

Indonesia (Kalimantan, Sulawesi, Sumatra), Malaysia (Peninsular Malaysia, Sabah)

Found between 5 and $2200 \mathrm{~m}$, this tree of primary and secondary forest is threatened by habitat destruction.

Assessor: Pannell, C.M.

Refs: $6509,11145,19129$

\section{Aglaia squamulosa}

Meliaceae

$\mathrm{LR} / \mathrm{nt}$

Indonesia (Sulawesi, Sumatra), Malaysia (Peninsular Malaysia, Sabah, Sarawak), Philippines

This widespread tree is found in primary and secondary forest up to $2000 \mathrm{~m}$. Loss of habitat is a potential threat to the species.

Assessor: Pannell, C.M.

Refs: 6509,19129

\section{Aglaia subcuprea}

Meliaceae

LR/nt

Indonesia (Irian Jaya), Papua New Guinea (Bismarck Archipelago, Papua New Guinea)

A tree of primary and secondary forest up to $2570 \mathrm{~m}$, often in periodically inundated areas. The main potential threat to the species is habitat destruction. The Solomon Islands specimen might be a new undescribed species.

Assessor: Pannell, C.M.

Refs: $6509,11145,19129$
Aglaia subsesilis

Meliaceae

VUAlc

Malaysia (Sabah, Sarawak)

This species is confined to primary forest between 430 and $840 \mathrm{~m}$ in Sabah and Sarawak. It is threatened by habitat loss.

Assessor: Pannell, C.M.

Refs: 6509,19129

\section{Aglaia tenuicaulis}

Meliaceae

VUAlc

Brunei, Indonesia, Malaysia (Peninsular Malaysia, Sabah), Philippines?, Singapore, Thailand

A variable species noted to be common in Peninsular Malaysia. Habitat loss is the main threat to this tree.

Assessor: Pannell, C.M.

Refs: $6509,9199,19129$

\section{Aglaia teysmanniana}

Meliaceae

LR/nt

China, Indonesia (Irian Jaya?, Java, Kalimantan, Moluccas?, Sulawesi), Malaysia, Papua New Guinea?, Philippines, Thailand

A widespread tree of primary and secondary forest up to $1670 \mathrm{~m}$. Declines in habitat could pose a threat to this species. Collections from the Moluccas and New Guinea may represent a distinct species.

Assessor: Pannell, C.M.

Refs: 6509,19129

\section{Aglaia unifolia}

Meliaceae

CR D1

Fiji

A small tree known only from the type collection taken in 1947 from a forest on the ridge between Mount Nanggaranambuluta and Mount Namama, Viti Levu. It is possibly extinct.

Assessor: Pannell, C.M.

Refs: 6509,19129

\section{Aglaia variisquama}

Meliaceae

VUAlc

Indonesia (Kalimantan), Malaysia (Peninsular Malaysia, Sabah, Sarawak)

A tree scattered throughout primary and secondary forest, *kerangas, swamps and along rivers between 200 and $430 \mathrm{~m}$. Habitat loss is the main threat to the species.

Assessor: Pannell, C.M.

Refs: 6509,19129

\section{Aglaia vitiensis}

Meliaceae

LR/nt

Fiji

This endemic species is found in both secondary and primary forests. Loss of habitat is a potential threat to the species.

Assessor: Pannell, C.M.

Refs: 6509, 19129

\section{Aglaia yzermannii}

Meliaceae

VU D2

Indonesia (Sumatra), Malaysia (Peninsular Malaysia)

A small rheophyte, locally common but confined to riverine forest on granite soils, especially next to the deeper areas of fast-flowing stony rivers. It is known from only three localites.

Assessor: Pannell, C.M.

Refs: 6509,19129 
Agonandra loranthoides

Opiliaceae

VU Cl

Honduras

A tree of open forest on dry lowland plains, frequently affected by fires.

Assessor: Nelson, C.

Refs: 13995

\section{Agonandra macrocarpa}

Opiliaceae

VU C2a

Costa Rica, Honduras

A species of low elevations, occurring in rocky thickets along streams. Fires are a frequent threat.

Assessor: Nelson, C.

Refs: 8100,13995

\section{Agrostistachys coriacea}

Euphorbiaceae

VU Alc

Sri Lanka

A tree occurring in the lowland wet evergreen forests of south-west Sri Lanka.

Assessor: World Conservation Monitoring Centre

Refs: 9176,17195

\section{Agrostistachys hookeri}

Euphorbiaceae

$\mathrm{CR} B 1+2 \mathrm{C}$

Sri Lanka

A tree restricted to lowland wet evergreen forest in south-west Sri Lanka. During the extensive National Conservation Review forest surveys, only four individuals were found at a single locality in Ratnapura District.

Assessor: World Conservation Monitoring Centre Refs: 8203, 17195, 19112

\section{Ailanthus altissima var. tanakai}

Simaroubaceae

EN Ala, $\mathrm{B} 1+2 \mathrm{ab}$

Taiwan

A Taiwanese form of a widely occurring and naturalised species. Populations, containing few mature individuals, are restricted to submontane forest in the northern part of the central mountain range. Declines in numbers have occurred because of habitat clearance for settlements and industrial plantations. No protection or conservation measures are in place.

Assessor: Pan, F.J.

Refs: $3295,6469,19050$

\section{Aiouea angulata}

Lauraceae

$\mathrm{EN} \mathrm{B1+2c}$

Colombia

Known only from the type collected in 1933, this species is restricted to submontane forest in Boyaca.

Assessor: Calderon, E.

Refs: $7950,7980,19069$

\section{Aiouea bracteata}

Lauraceae

VU B1+2c

Brazil (São Paulo)

Known only from São Paulo, this species is confined to gallery forest within the *cerrado.

Assessor: World Conservation Monitoring Centre

Refs: 7950,7980

\section{Aiouea macedoana}

Lauraceae

VU D2

Brazil (Goiás)

The type collection from Goiás is the only record of this species.

Assessor: World Conservation Monitoring Centre

Refs: 7950,7980

\section{Aionea obscura}

Lauraceae

$\mathrm{EN} \mathrm{B} 1+2 \mathrm{c}$

Panama

Known only from a collection made in 1986, the species occurs on the southem Pacific slopes, south-east of Palmar north, on steep slopes of evergreen lowland rainforest.

Assessor: World Conservation Monitoring Centre Refs: 15719

\section{Aiphanes duquei}

Palmae

VU BI+2c

Colombia

A montane rainforest species, endemic to an area of approximately $200 \mathrm{~km}^{2}$ in the Cordillera Occidental. It is primarily found in Munchique and Farallones de Cali National Parks. Agricultural expansion and forest management activities are the principal causes of habitat loss.

Assessor: Bernal, $\mathrm{R}$.

Refs: 19069,19118

Aiphanes leiostachys

Palmae

$\mathrm{EN} \mathrm{B1}+2 \mathrm{c}$

Colombia

A species of broadleaved montane rainforest, occurring only in a few forest fragments in the Cordillera Central. Increasing pressure is felt from habitat conversion to agriculture and plantations.

Assessor: Bernal, $\mathrm{R}$.

Refs: 19069,19118

\section{Aiphanes lindeniana}

Palmae

VU B $1+2 \mathrm{C}$

Colombia

A widely distributed endemic occurring in the montane rainforest in the central and eastern corcilleras. The habitat is gradually losing way to increasing agriculture and forestry activities.

Assessor: Bernal, $\mathbf{R}$.

Refs: 19118

\section{Aiphanes verrucosa}

Palmae

VU B $1+2 c$

Ecuador

Restricted to the Andes of south-east Ecuador, this small palm tree is scattered in cloud forest and montane open forest between 2200 and $2800 \mathrm{~m}$. So far it is known only from two localities and one historical record. At least one of these populations has suffered from a severe reduction in numbers from fire and felling. The species is expected to occur in more inaccessible areas of southeast Ecuador.

Assessor: World Conservation Monitoring Centre Refs: 19118 


\section{Alangium circulare}

Alangiaceae

VU D2

Malaysia (Sarawak)

A small forest tree, apparently a component of * kerangas forest, known only from Bukit Siol, Sempadi Forest Reserve and Gunung Pueh, Ist Division.

Assessor: World Conservation Monitoring Centre

Refs: 19017

\section{Alangium havilandii}

Alangiaceae VU Alc

Brunei, Indonesia (Kalimantan), Malaysia (Sarawak)

This lowland tree is relatively common but restricted to remaining peat swamp forest.

Assessor: World Conservation Monitoring Centre

Refs: 18327,19017

\section{Alangium longiflorum}

Alangiaceae

VU Alc

Indonesia (Kalimantan), Malaysia (Sabah, Sarawak),

Philippines

A tree of primary mixed dipterocarp forest, occurring up to $1200 \mathrm{~m}$. It is found occasionally in Sabah and Sarawak.

Assessor: World Conservation Monitoring Centre

Refs: 19017

\section{Alberta magna}

Rubiaceae

LR/cd

South Africa (Eastern Cape, KwaZulu-Natal)

Largely occurring in KwaZulu-Natal but extending into the Eastern Cape, this species is found on the margins of small remnants of evergreen forest and on rocky sandstone outcrops, often near rivers and streams. It is vulnerable to the effects of fire and other habitat disturbances. Population numbers have almost certainly declined for these reasons. In KwaZulu-Natal, the species occurs in a number of protected areas, of which at least one is managed to exclude fire. In the Eastern Cape, there are populations in several protected areas, but the protected area system has vitually collapsed since 1994. Although legally protected, the bark is widely used as a source of traditional medicine. The tree is also commonly planted as an omamental.

Assessor: Hilton-Taylor, C. et al.

Refs: $689,7401,19218$

\section{Albizia berteriana}

Leguminosae

VU B $1+2 \mathrm{c}$

Cuba, Dominican Republic, Haiti, Jamaica

An uncommon species of dry, evergreen forest found in eastern and central Cuba, Jamaica and Hispaniola.

Assessor: Areces-Mallea, A.E.

Refs: 19149

\section{Albizia buntingii \\ Leguminosae \\ Venezuela \\ A small tree known only from the type locality in the Maracaibo basin \\ Assessor: World Conservation Monitoring Centre \\ Refs: 5994}

VU D2

\section{Albizia burkartiana}

Leguminosae

VU B1+2c

Brazil (Paraná, Santa Catarina)

A species of Araucaria woodland, found only in south- west Paraná and west Santa Catarina in the basins of Río Iguaçú and Rio Uruguai.

Assessor: World Conservation Monitoring Centre

Refs: 5994

\section{Albizia carrii \\ Leguminosae \\ VU B $1+2 c$ \\ Papua New Guinea}

This endemic tree is so far known only from areas of monsoon forest in the Port Moresby region and Motupore Island.

Assessor: World Conservation Monitoring Centre

Refs: 19140

\section{Albizia edwarllii}

Leguminosae

VU B $1+2 c$

Argentina (Misiones), Brazil (Paraná, Santa Catarina, Sāo Paulo)

This species is restricted to Atlantic forest in the Atlantic-Uruguay River watershed, occurring in Araucaria forest.

Assessor: World Conservation Monitoring Centre Refs: 5994

\section{Albizia ferruginea}

Leguminosae

VUAlcd

Angola, Benin, Cameroon, Central African Republic, Congo, Côte d'Ivoire, Democratic Republic of Congo, Gabon, Gambia, Ghana, Guinea, Guinea-Bissau, Nigeria, Senegal, Sierra Leone, Togo, Uganda

A widespread and often common timber species which has suffered heavy exploitation. Mature individuals are scattered and becoming rare in places.

Assessor: Hawthome, W.

Refs: $2362,2773,6718,14667,15790,17408$

\section{Albizia glabripetala}

Leguminosae

LR/nt

Brazil (Roraima), Guyana, Venezuela

Assessor: World Conservation Monitoring Centre

Refs: 5994

\section{Albizia guillainii}

Leguminosae

CR B $1+2 \mathrm{c}$

New Caledonia

A species restricted to remaining fragments of sclerophyllous forest. Occurrences are known from Nouméa, Pouembout and Koumac. The habitat is unprotected and severely threatened by fires, grazing and encroaching agriculture.

Assessor: Jaffré, T. et al.

Refs: 4492, 10351, 12630

\section{Albizia leonardii}

Leguminosae

VU B $1+2 c$

Haiti

A small tree, localised in dry thickets in the north-west of Haiti.

Assessor: World Conservation Monitoring Centre Refs: 5994

\section{Albizia malacophylla var, malacophylla}

Leguminosae

Eritrea, Ethiopia

VU Alc+2c

Restricted to wooded grasslands in the western highlands of Eritrea, Tigray and Welo, this variety 
continues to lose large parts of its habitat to agriculture, human settlement and overcutting for fuelwood. Assessor: World Conservation Monitoring Centre Refs: 1330,18523

\section{Albizia multiflora var. sagasteguii \\ Leguminosae}

Peru

VU D2

A tree known only from the type collection, near San Benito, in Cajamarca.

Assessor: World Conservation Monitoring Centre Refs: 5994

\section{Albizia obbiadensis}

Leguminosae

VU $B 1+2 c$

Somalia

A distinct species of uncertain affinity. It is confined to the coast, where it occurs in bushland on sand. Habitat degradation is a threat.

Assessor: Thulin, M.

Refs: $7550,8697,18665$

\section{Albizia plurijuga}

Leguminosae

$\mathrm{EN} \mathrm{Bl+2c}$

Mexico

Assessor: Ramirez-Marcial, N. \& M. González-Espinosa Refs: 12985,17165

\section{Albizia suluensis}

Leguminosae

VU Alcd, B1+2a, C2a, D2

South Africa (KwaZulu-Natal)

Endemic to a small area in the Hlabisa District of northern Zululand, this tree occurs in forest, riverine thicket and open woodland. It was once very common before the habitat became severely fragmenied through agricultural activities and increasing settlement. Frequent fires are also a problem in parts of the range. Recent assessments of the population have revealed no evidence of recruitment. The bark is used as a source of traditional medicine and the timber is used for making furniture. The species may be confused with the introduced $A$. lebbeck, which has become naturalised along the northem KwaZulu-Natal coast.

Assessor: Hilton-Taylor, C. el al.

Refs: 689, 7401, 16730, 19218

\section{Albizia tanganyicensis ssp. adamsoniorum}

Leguminosae

VU B $1+2 \mathrm{c}$

Kenya

A rare endemic to central Kenya, occurring in open woodland on rocky domes or river banks. Declines in the extent of the habitat have been caused by cutting and changing land use. The population in Meru National Park is protected. The Plant Conservation Programme in Kenya is managing living collections and seed stocks. Assessor: World Conservation Monitoring Centre Refs: $6396,12067,17859$

\section{Albizia vaughanii}

Leguminosae

CR D1

Mauritius

The largest population of just six individuals occurs in the Tamarind Falls Gorge and another single tree is known from lowland forest in Yemen. Natural regeneration appears to be non-existent. Two individuals have been introduced into Mondrain Nature Reserve. Assessor: Page, W.

Refs: $1411,9120,16426$
Alectryon macrococcus var, auwahiensis

Sapindaceae

USA (Hawaii)

CR D1

A variety confined to East Maui, where it once occurred in various forest types in Auwahi and Kanaio Districts between 790 to $1070 \mathrm{~m}$. The population size was reported to be large in the first half of the century but has subsequently declined to about nine individuals within 29 ha of private and state-owned ranchland. Trees are protected from damage by cattle but the population suffers from an infestation of the black twig borer. The species as a whole is protected by the US Endangered Species Act.

Assessor: World Conservation Monitoring Centre Refs: 3372, 19087

\section{Alectryon macrococcus var. macrococcus}

Sapindaceae

USA (Hawaii)

EN C2a

This variety has been recorded from various lowland forest types in the Waianae and Koolau Mountains on Orhu, in Waimea Canyon and Na Pali Coast State Park on Kauai, on Molokai and on the Honokowai Ditch Trail on West Maui. Oahu holds the largest populations, totalling about 400 plants. Fewer than 100 plants exist on Kauai and only a very few plants are known from the other islands. It has disappeared from parts of its former range and populations continue to be affected by insect infestations, grazing feral ungulates, fire and competition with introduced plants. It is protected by the US Endangered Species Act.

Assessor: World Conservation Monitoring Centre Refs: 3372,19087

\section{Alectryon ramiflorus}

Sapindaceae

$\mathrm{EN} \mathrm{B1+2c}$

Australia (Queensland)

Occurring in rainforest in Childers District on the southem coast of Queensland, the species is threatened because of habitat clearance. Only a single population of about 20 plants is known to be relatively well protected within a state forest.

Assessor: World Conservation Monitoring Centre Refs: 4246,17200

\section{Alectryon refandodentus}

Sapindaceae

VU B $1+2 \mathrm{c}$

Australia, Papua New Guinea

A small tree of scrub and savanna, only known from the Port Moresby region and Motupore Island in Papua New Guinea and Murray Island in Australia.

Assessor: World Conservation Monitoring Centre Refs: 19140

\section{Alfaroa hondurensis \\ Juglandaceae \\ Honduras}

VU B 1+2abcde

This endemic tree occurs in mixed forest at high elevations. Population numbers are low and the habitat is in continuing decline. Some populations occur within protected areas.

Assessor: Nelson, C.

Refs: 14487

\section{Alfaroa mexicana}

Juglandaceae

VU B $1+2 c$

Mexico

Assessor: Ramirez-Marcial, N. \& M. González-Espinosa

Refs: 10792,14487 


\section{Allanblackia stuhlmannii} Guttiferae

VU B1 $+2 c$

Tanzania

This tall tree may be found in some abundance in moist upland forest only in eastern Tanzania. It is an important source of oils and timber.

Assessor: Lovett, J. \& G.P. Clarke

Refs: $3356,10961,11449$

Allanblackia ulugurensis

Guttiferae

VU B $1+2 c$

Tanzania

A cloud forest species found in good numbers in the North Udzungwa, Nguru Mountains and Ulugurs Mountains.

Assessor: Lovett, J. \& G.P. Clarke

Refs: 3356,7089

\section{Allantospermum borneense var. rostratrum}

Ixonanthaceae

$\mathrm{EN} \mathrm{B1}+2 \mathrm{c}$

Malaysia (Sabah)

This enormous tree, sometimes reaching heights of $90 \mathrm{~m}$, is so far known only from ultramafic soils around Sandakan and Lahad Datu. Populations in localities to the south of Telupid have has most probably disappeared.

Assessor: World Conservation Monitoring Centre Refs: 19017,19026

\section{Alleizettella rubra}

Rubiaceae

VU D2

Viet Nam

Endemic to Viet Nam, the species is confined to a single locality in Lam Dong Province (Lac Duong) in the south.

Assessor: World Conservation Monitoring Centre

Refs: 848,11530

\section{Allenanthus hondurensis}

Rubiaceae

VU C2a

Honduras, Mexico

A species occurring disjunctly, with populations in Mexico and Honduras. The species is found in deciduous forest in the Caribbean lowlands in Honduras. Assessor: Nelson, C.

Refs: 4974, 13995

\section{Allexis cauliflora}

Violaceae

VU Alc, B1+2c

Ghana, Nigeria

A small tree with a disjunct, Guinea-wide distribution. It is confined to areas of wet evergreen forest. Few records of it appear to exist. Extensive logging, mining and clearing of the forest for cultivating crops have caused considerable declines in the habitat.

Assessor: Hawthorne, W.

Refs: $1577,8854,12061$

\section{Allexis obanensis}

Violaceae

VU $B 1+2 c$

Cameroon, Nigeria

A rarely recorded small tree of the violet family. It is known from the contiguous forest area covered by the Oban Division of the Cross River National Park in Nigeria and Korup National Park in Cameroon. Areas outside the parks have been heavily deforested and cleared for agriculture and commercial crops.

Assessor: World Conservation Monitoring Centre

Refs: 2773, 4977, 11504
Allophylus agbala

Sapindaceae

VU D2

Democratic Republic of Congo

A species restricted to areas of gallery forest in Ubangi-

Uele.

Assessor: Ndjele, M.B.

Refs: 17185,17951

\section{Allophylus aldabricus}

Sapindaceae

VU D2

Seychelles (Aldabra)

A small tree or shrub which occurs on most of the islands making up Aldabra, Assumption, Cosmoledo and Astove. It is a constituent of inland mixed scrub. Aldabra is protected as a Strict Nature Reserve. Assumption has experienced strip-mining for phosphate or guano and the other islands have been cleared to some degree for the establishment of coconut and Casuarina plantations.

Assessor: World Conservation Monitoring Centre Refs: 19027,19062

\section{Allophylus chirindensis}

Sapindaceae

VU D2

Mozambique, Zimbabwe

Existing information suggests this species is endemic to Chirinda forest in Zimbabwe and the adjacent Espungabera forest in Mozambique. This area is very restricted $\left(6 \mathrm{~km}^{2}\right)$ and, although it has been disturbed in the past by logging activities, it is now well protected. Assessor: World Conservation Monitoring Centre Refs: $2044,6725,15360,17335$

\section{Allophylus hispidus}

Sapindaceae

$\mathrm{CR} \mathrm{B} 1+2 \mathrm{c}$

Sri Lanka

A tree of lowland wet evergreen forest, endemic to south-west Sri Lanka. The species occurred in a single plot in Sinharaja Biosphere Reserve in the 1980s. However, it did not tum up during the extensive National Conservation Review forest surveys, suggesting that it is extremely rare or possibly extinct. Assessor: World Conservation Monitoring Centre Refs: 9176, 17195, 19112

\section{Allophylus marquesensis}

Sapindaceae

French Polynesia (Marquesas Is.)

A shrub or small tree recorded from Fatu Hiva, Hiva Oa, Tahuata and Ua Huka.

Assessor: Florence, J.

Refs: 14513

\section{Allophylus pachyphyllus}

Sapindaceae

VU B1+2c

Jamaica

A rare bushy tree confined to highland areas of woodland on limestone in the parishes of Manchester and St Ann.

Assessor: World Conservation Monitoring Centre Refs: 401, 7980

\section{Allophylus rapensis}

Sapindaceae

DD

French Polynesia (Tubuai Is.)

This species is endemic to Rapa Iti.

Assessor: Florence, J.

Refs: 14513 
Allophylus rhoidiphyllus

Sapindaceae

$\mathrm{LR} / \mathrm{nt}$

Yemen (Socotra)

A fairly common tree, found in areas of submontane woodland. It is under no immediate threat.

Assessor: Miller, A.G.

Refs: 2354, 19083

\section{Allophylus roigii}

Sapindaceae

VU B1 $+2 \mathrm{c}$

Cuba

An uncommon shrub or small tree localised to a few sites in Pinar del Rio Province and the adjacent Isla de Pinos. This species formerly occupied a much larger area in westem Cuba.

Assessor: Areces-Mallea, A.E.

Refs: 11403, 18485, 19149

\section{Allophylus zeylanicus}

Sapindaceae

VUAlc

Sri Lanka

A tree confined to the lowland wet evergreen forests of south-west Sri Lanka.

Assessor: World Conservation Monitoring Centre

Refs: 9176, 17195

\section{Allophylus zimmermannianus}

Sapindaceae

VU B $1+2 c$

Kenya, Tanzania

A shrub or tree confined to the forest at $375 \mathrm{~m}$ in the Shimba Hills in Kenya and to coastal forest patches in Tanzania.

Assessor: Lovett, J. \& G.P. Clarke

Refs: $3356,5654,6396$

\section{Alloschmidia glabrata}

Palmae

VU D2

New Caledonia

A localised species of north-eastern New Caledonia. It occurs in wet forest, often on schists or mica-schists. The edible heart is harvested locally.

Assessor: Jaffré, T. el al.

Refs: 10351,19118

\section{Alloxylon brachycarpum}

Proteaceae

EN A2cd

Indonesia (Irian Jaya, Moluccas), Papua New Guinea

Confined to Western Province in south Papua New

Guinea and adjacent Digul District, Irian Jaya, extending into the Aru Islands, this tree is scattered in lowland rainforest and monsoon forest. The population around the Oriomo River in Westem Province, is a relatively restricted and confined to a fragile ecosystem, which is under pressure from logging and destructive activities. It is expected that the population across the border into Irian Jaya is similarly threatened.

Assessor: Eddowes, P.J.

Refs: 19114,19147

\section{Alluaudia procera}

Didiereaceae

$L R / n t$

Madagascar

A major component of dry scrub and forest in the extreme south of Madagascar, beyond the Tropic of Capricorn. The habitat type has been replaced by grassland over much of its range. The wood is useful and the species is a focus of silvicultural studies.

Assessor: World Conservation Monitoring Centre

Refs: $4628,5651,6161,14208$
Alnus maritima

Betulaceae

USA (Delaware, Maryland, Oklahoma)

LR/nt

A shrub or tree, known from widely disjunct populations, occurring at the edges of ponds, small streams or standing water. The current distribution is thought to reflect remnant populations of a mors widespread Pleistocene or post-Pleistocene distribution. Assessor: World Conservation Monitoring Centre Refs: 19033,19163

\section{Aloe ballit}

Aloaceae

Mozambique, Zimbabwe

$\mathrm{EN} \mathrm{BI+2c}$

Not to be confused with $A$. ballyi this species is confined to the cliffs in the lower Rusitu valley, south Chimanimani in Zimbabwe and adjacent Mozambique. The species is listed in * CITES Appendix II.

Assessor: World Conservation Monitoring Centre Refs: 2044

\section{Aloe ballyi}

Aloaceae

Kenya, Tanzania

VU $B 1+2 c$

A rare tree aloe which smells strongly of rats. In Kenya it is confined to dense bush near Mwatate in the Taita Hills. It also occurs further south in Tanzania in the South Pare Mountains, Manyara escarpment, Ngubora River and Lake Eyassi. This dry bushland is extensively exploited for charcoal production. The species is listed in * CITES Appendix II.

Assessor: World Conservation Monitoring Centre

Refs: 6396, 12067

\section{Aloe comosa}

Aloaceae

South Africa (Western Cape, Northern Cape)

A single-stemmed aloe confined to a small area just north of Clanwilliam, where it occurs in *karroid scrub. lllegal collection and land degradation through overgrazing and expanding agriculture may have some impact on the species. No field assessments of the population status have been made. The species is included in *CITES Appendix II.

Assessor: Hilton-Taylor, C. et al.

Refs: 689

\section{Aloe eminens}

Aloaceae

LR/nt

Somalia

A tree aloe which was seen in considerable numbers in 1995, but continues to be threatened by the destruction of the habitat to which it is confined in northem Somalia. The species is listed in *CITES Appendix II. Assessor: Thulin, $\mathrm{M}$.

Refs: 18665

\section{Aloe helerae}

Aloaceae

Madagascar

CR D1

An arborescent aloe, endemic to southern Madagascar, where two or three populations are known to occur in thomy bush on sandy shores in the Fort Dauphin region. Each population consists of less than 10 adult individuals. No regeneration has been observed. The species is listed in Appendix I of *CITES.

Assessor: World Conservation Monitoring Centre Refs: 19205 


\section{Aloe Khamiesensis}

Aloaceae

South Africa (Westem Cape, Northem Cape)

A single-stemmed aloe with a fairly restricted distribution in the mountainous areas of Namaqualand and from near Calvinia. At some localities, the number of plants have declined markedly as a result of unscrupulous collection. However, it is not clear what affect this has had on the overall population. The species is listed in *CITES Appendix II.

Assessor: Hilton-Taylor, C. et al.

Refs: 689,19218

\section{Aloe pillansii}

Aloaceae

$\mathrm{CR} \mathrm{A} 2 \mathrm{~b}, \mathrm{Bl}+2 \mathrm{e}$

Namibia, South Africa (Northem Cape)

Growing up to $10 \mathrm{~m}$, this aloe is largely confined to an intensely hot and arid area in the Richtersveld in the Northern Cape. There are records suggesting the species extends as far north as Brandberg in Namibia, but these need confirmation. A serious decline in the population has reduced the numbers to less than 200 individuals. There is no recruitment and the older plants are dying. There is evidence of baboons and porcupines gnawing the stems in up to a third of the population. The impact of goats, donkeys and plant collectors may also be detrimental. It has been suggested that this species, along with $A$. dichotoma and Pachypodium namaquanum, represents a keystone in the ecosystem, being one of the few perennial plants able to tolerate the conditions and provide an important source of shelter, nectar, food and moisture, especially to the avifauna. It is listed in * CITES Appendix I.

Assessor: Hilton-Taylor, C. et al.

Refs: $689,19141,19218$

\section{Aloe ramosissima}

Aloaceae

VU C2a, D2

Namibia, South Africa (Northern Cape)

A bushy aloe which is doubtfully distinct from $A$. dichotoma, except that the main stem rarely exceeds $60 \mathrm{~cm}$. It is confined to desert mountainsides and arid ravines in the Richtersveld of the Northern Cape and southem Namibia. Some localities are affected by mining activities and overgrazing by livestock. Limited field experience suggests there are few signs of regeneration. The species is listed in *CITES Appendix I.

Assessor: Hilton-Taylor, C. et al.

Refs: 689,19218

\section{Aloe suzannae}

Aloaceae

Madagascar

CR D1

An arborescent aloe confined to thomy bush on sandy shores in the Amboasary region and Itampolo in south and south-west Madagascar. Only a few adult individuals are known in each population and there is no evidence of regeneration. The species has been cultivated from wild seed, but fewer than six reared plants exist in nurserys in Madagascar. The species is listed in *CITES Appendix I.

Assessor: World Conservation Monitoring Centre

Refs: 19205
Alphitonia erubescens

Rhamnaceae

VU B1+2c

New Caledonia

Assessor: Jaffré, T. et al.

Refs: 10351

\section{Alphonsea kingii}

Annonaceae

Malaysia (Peninsular Malaysia)

CR B $1+2 c$

A lowland forest species known only by a single collection from Kinta, Perak. The exact locality of the collection is uncertain. The Kinta area is now mainly mined over and the survival of the species is doubtful. Assessor: World Conservation Monitoring Centre Refs: 8464,19073

\section{Alphonsea lucida}

Annonaceae

VU D2

Malaysia (Peninsular Malaysia)

A very rare species, of lowland forest, collected only twice, once in Perak and the other time in Pahang. It is hoped the species is conserved in the protected area of Maxwell's Hills. The collection from Perak possibly comes from these hills.

Assessor: Kochummen, K.M.

Refs: 7181,19073

\section{Alseodaphne dura}

Lauraceae

$\mathrm{LR} / \mathrm{cd}$

Malaysia (Peninsular Malaysia)

A lowland forest tree confined to the states of Terengganu and Pahang. It is known only from a few herbarium specimens, but there is hope that the species receives a degree of protection within the permanent forest estate. It could be a species of Dehaasia.

Assessor: Kochummen, K.M.

Refs: 8464,19073

\section{Alseodaphne garciniaecarpa}

Lauraceae

LR/cd

Malaysia (Peninsular Malaysia)

Confined to the lowland forests of Perak, the species may receive a degree of protection within the permanent forest estate.

Assessor: Kochummen, K.M.

Refs: 8464,19073

\section{Alseodaphne hainanensis}

Lauraceae

VU Alcd

China (Guangdong - Hainan), Viet Nam

An important timber tree with a distribution restricted to submontane rainforest on the mountains of southem Hainan Island and on Bu Kep Mountain in northern Viet Nam. It is a slow-growing tree which produces highquality wood, susceptible to overexploitation.

Assessor: World Conservation Monitoring Centre Refs: $1818,11847,15357$

\section{Alseodaphne micrantha \\ Lauraceae \\ Malaysia (Peninsular Malaysia)}

VU B $1+2 \mathrm{c}$

A scattered tree confined to lowland forest in Johore. Most of the lowland forest has been cleared for agriculture in this region, but the species may receive a degree of protection within permanent forest reserves.

Assessor: Chua, L.S.L.

Refs: 8464, 19073, 19182 


\section{Alseodaphne paludosa}

Lauraceae

Malaysia (Peninsular Malaysia)

Confined to the swamp forests of Selangor and Perak, the species is known only from a few collections. It is threatened by felling, but there is hope that the species receives a degree of protection within permanent forest reserves.

Assessor: Chua, L.S.L.

Refs: $17140,19073,19182$

\section{Alseodaphne rugosa}

Lauraceae

$\mathrm{EN} \mathrm{B1}+2 \mathrm{c}$

China (Guangdong - Hainan)

Restricted to a small area of dense forest in Qiongzhong and Baoting Counties on Hainan Island, the species is exposed to the same levels of harvesting as $A$. hainanensis.

Assessor: World Conservation Monitoring Centre

Refs: 1818,11847

\section{Alsmithia longipes}

Palmae

EN Alc

Fiji

A monotypic genus, restricted to Taveuni, Vanua Levu. Populations occur on ridges and steep slopes in moist forest. The habitat suffers some pressure from increasing agriculture and forestry activities.

Assessor: Fuller, D.

Refs: 19118

\section{Alsodeiopsis schumannii \\ Icacinaceae}

VUB $1+2 b$

Tanzania

Endemic to eastem Tanzania, this species is confined to areas of upland moist evergreen forest in the Usambara, Uluguru and North Udzungwa Mountains.

Assessor: Lovett, J. \& G.P. Clarke

Refs: 3356,18145

Alstonia annamensis

Apocynaceae

$\mathrm{EN} \mathrm{B1}+2 \mathrm{C}$

Viet Nam

To date this tree has been collected only three times from a single locality of dry montane forest.

Assessor: Sidiyasa, K.

Refs: 17692, 19046

\section{Alstonia beatricis}

Apocynaceae

VU D2

Indonesia (Irian Jaya)

Known only from the type locality, this small tree is found in open woodland on Waigeo Island, where it is locally common.

Assessor: Sidiyasa, $\mathrm{K}$.

Refs: 14811, 19046

\section{Alstonia breviloba}

Apocynaceae

VU B $1+2 c$

Papua New Guinea

Collected only three times, the species occurs in secondary and primary montane forest.

Assessor: World Conservation Monitoring Centre

Refs: 17692,19046
Alstonia marquisensis

Apocynaceae

LR/nt

French Polynesia (Marquesas Is.)

Populations occur on Fatu Hiva, Hiva Oa, Nuku Hiva,

Tahuata and Ua Huka.

Assessor: Florence, J.

Refs: 14513

\section{Alstonia penangiana}

Apocynaceae

Malaysia (Peninsular Malaysia)

VU D2

This species is known from only two collections from Penang Island, where it is found in primary and disturbed forest.

Assessor: Sidiyasa, $\mathrm{K}$.

Refs: 17692, 19046

\section{Alstonia rubiginosa}

Apocynaceae

VU $B 1+2 c$

Papua New Guinea

Endemic to Papua New Guinea, this tree has been collected twice in areas of primary and secondary montane forest.

Assessor: World Conservation Monitoring Centre

Refs: 17692,19046

\section{Alvaradoa jamaicensis}

Simaroubaceae

VU B1+2c

Jamaica

The species is uncommon and local in woodlands and thickets on rocky limestone in the central and north-west parishes.

Assessor: World Conservation Monitoring Centre

Refs: 6057,7980

\section{Alyxia taiwanensis}

Apocynaceae

EN D1

Taiwan

A single small population is confined to Chingshan in the centre of the island, where it occurs in dry open forest at $1100 \mathrm{~m}$. The area is given no protection and is somewhat threatened by increasing settlement. Regeneration appears to be poor.

Assessor: Lu, S.Y. \& F.J. Pan

Refs: 3295, 6469, 19050, 19051

\section{Amanoa bracteosa}

Euphorbiaceae

VU Alc, B1+2c

Côte d'Ivoire, Ghana, Liberia, Sierra Leone

A species found in swamp forest or along stream banks in wet evergreen forest. It occurs in Ankasa Game Production Reserve, along with $A$. strobilacea, in Ghana, but is too rare to be recorded in forest inventories. Although it is common on parts of Mount Nimba in Liberia, the forest has been cleared extensively by mining operations and by the effects of an increasing population requiring land for farming.

Assessor: Hawthorne, W.

Refs: $2773,8369,12061$

\section{Amanoa strobilacea}

Euphorbiaceae

Angola (Cabinda), Cameroon, Ghana, Liberia

This species is restricted largely to swampy areas within lowland evergreen rainforest. The general loss of its habitat, because of commercial forestry activities and mining, has continued at a considerable rate.

Assessor: Hawthome, W.

Refs: $2773,8369,12061$ 


\section{Amburana acreana}

Leguminosae

VU Ald $+2 d$

Bolivia, Brazil (Acre, Mato Grosso, Rondônia), Peru

Formerly abundant in non-flooded forest, this species has been heavily exploited for its wood, used for making luxury furniture. In Rondônia the number of sawmills, which principally process $A$. acreana, increased eightfold between 1975 and 1982 . The species is now on the official list of threatened species compiled by *IBAMA in 1992. The taxonomic status of the genus is not consolidated, there being confusion between this and A. cearensis.

Assessor: Varty, N. \& D.L. Guadagnin

Refs: $4870,8815,15478,15539,16123$

\section{Amburana cearensis}

Leguminosae

EN Alacd $+2 c d$

Argentina, Bolivia, Brazil, Paraguay, Peru

A frequent tree of ${ }^{*}$ caatinga, occasional in the Andes, becoming rarer in deciduous forest further south into Argentina. An important timber source, all stands of large trees are being or have been destroyed, previously through mahogany logging and now through selective logging. Small trees grow around granite outcrops where they are safe from commercial exploitation. Regeneration appears to be poor where adequate management is not in place. The taxonomic status of the genus is not consolidated, there being confusion between this species and $A$. acreana.

Assessor: Americas Regional Workshop

Refs: 1262, 11936, 12268, 12837, 13295, 13947, 19170, 19179

\section{Amentotaxus argotaenia}

\section{Taxaceae}

VU Alc

China (Fujian?, Gansu, Guangdong, Guangxi, Hubei, Hunan, Jiangsu?, Jiangxi, Sichuan, Xizang, Zhejiang?), Viet Nam

The status of this widely occurring forest species is affected by slow growth rates, infrequent regeneration, poor seed dispersal and predation by rats. Forest clearing and habitat modification have also contributed to population declines.

Assessor: SSC Conifer Specialist Group

Refs: 374,11191

\section{Amentotaxus argotaenia var. brevifolia}

Taxaceae

VU Alc

China (Guizhou)

Assessor: SSC Conifer Specialist Group

Refs: 374, 11038, 13041

\section{Amentotarus assamica}

Taxaceae

VU A1c, D2

China, India (Arunachal Pradesh)

Two collections are known from moist deciduous forest in the Delei valley and a valley in the Dafla Hills in India, and another single collection has been made from Medog in China. Deforestation has occurred extensively in the area.

Assessor: SSC Conifer Specialist Group

Refs: $374,5759,13041$

\section{Amentotaxus formosana}

Taxaceae

CR C2a, D1

Taiwan

The species was previously recognised as a variant of $A$ argotaenia. Populations are small and restricted to four localities of cloud forest in the Hengchan Peninsula:
Tawu, Kutzulunshan, Chachayalaishan and Lilungshan. The species is covered by Taiwan's Cultural Heritage Preservation Law and a reserve has been set up specifically to conserve the remaining populations.

Assessor: Pan, F.J.

Refs: $2106,6469,13041,19050$

\section{Amentotaxus poilanei}

Taxaceae

VU Alc, B1+2c

Viet Nam

A montane species, only known from Kon Tum Province in Ngoc Linh Nature Reserve.

Assessor: SSC Conifer Specialist Group

Refs: $848,1491,11191$

\section{Amentotaxus yunnanensis}

Taxaceae

EN Alc

China (Guizhou?, Yunnan), Viet Nam

Confined to moist deciduous forest on limestone hills, remaining populations are small and threatened. The forest habitat is being extensively cleared. The population in Viet Nam is confined to Hoang Lien Son Nature Reserve and is considered to be in a critical state. Assessor: SSC Conifer Specialist Group

Refs: $848,1739,1818,11847,13041,15357$

\section{Amesiodendron chinense}

Sapindaceae

China, Indonesia (Sumatra), Laos, Malaysia (Peninsular Malaysia), Viet Nam

A genus, probably monotypic, which is widely occurring in primary rainforest. In Viet Nam, it is a dominant component of some forest localities and has been observed to regenerate well, although population reductions have occurred. In China the species, recognised under the synonym $A$. tienlinensis, is restricted to limestone areas in the Dayao Mountains, Tianlin and Leye Counties in Guangxi and Luodian, Wangmo and Zhenfeng Counties in Guizhou. A valuable timber is harvested from the tree and in some places is overexploited.

Assessor: World Conservation Monitoring Centre Refs: $848,7673,11847,15357,18389$

\section{Amoora dasyclada}

Meliaceae

VU Alc

China (Guangdong - Hainan, Yunnan), Viet Nam

A large evergreen tree of lowland tropical monsoon forest and rainforest, known from occurrences in Menla, Menhai and Jinghong in south Yunnan and Hainan Island in China, and from populations in the northerm half of Viet Nam. The levels of exploitation both of the tree as a timber and of the habitat in general have caused population declines throughout the species range. Assessor: Sun, W.

Refs: $1818,11847,15357,19055$

\section{Amphitecna isthmica}

Bignoniaceae

VU A2c

Colombia, Costa Ríca, Panama

Occurring in lowland forest, the species extends in range from Costa Rica to the Urabá region of north-west Colombia. In Panama, populations are small and scattered principally in the humid forests on the Pacific side, few collections coming from the Atlantic slopes. In 
Costa Rica populations are also largely confined to the Pacific side. Most parts of the range are experiencing moderate to high human impact.

Assessor: Mitré, M.

Refs: 7980,16772

\section{Amphitecra molinae}

Bignoniaceae

EN C1

El Salvador, Honduras, Nicaragua

A cloud forest tree, occurring in a habitat which is rapidly declining through deforestation.

Assessor: Nelson, C

Refs: $730,3917,7980,13316,13995,16973$

\section{Amphitecna sessilifolius}

Bignoniaceae

VU Cl

Costa Rica, Panama

A cloud forest tree, distributed widely from mid to high elevations in Costa Rica but only in a restricted area of high forest in Chiriquí and Bocas del Toro in Panama near the Costa Rica border. Populations are relatively sparse, with few juvenile individuals. Most of the highaltitude localities are contained within protected areas, but outside these populations are highly susceptible to clearing and encroaching agriculture.

Assessor: Mitré, M.

Refs: 7980,16772

\section{Amphitecna spathicalyx}

Bignoniaceae

CR B $1+2 b$

Panama

A single population is known. It occurs within lowland evergreen forest between 800 and $900 \mathrm{~m}$ in the Altos de Campana National Park. Attempts to locate it outside of the park have been unsuccessful

Assessor: Mitré, M.

Refs: $5335,7980,13316,16772$

\section{Amygdalus korshinskyi}

Rosaceae

VU Ala

Turkey

This species is scattered in middle elevations in dry areas. Population numbers have been observed to decline through the effects of growing settlement and agriculture, pests and diseases and industrial development.

Assessor: Güner, A.

Refs: 3489,19165

\section{Amygdalus trichamygdalus var. elongata}

Rosaceae

$\mathrm{LR} / \mathrm{nt}$

Turkey

Occurring within a restricted area of montane dry scrub and woodlands, the species is under some threat from grazing and cutting.

Assessor: Güner, A.

Refs: 3489,19165

\section{Amyris polymorpha}

Rutaceae

VU D2

Cuba

This endemic tree is only found in the remaining forests of Cabo Cruz in Granma Province of south-eastern Cuba. Its habitat is degraded in places.

Assessor: Areces-Mallea, A.E.

Refs: 11403, 18485, 19149
Anacolosa densiflora

Olacaceae

India (Kerala, Tamil Nadu)

$\mathrm{EN} \mathrm{B1+2c}$

A large tree, collected three times from separate localities of lowland evergreen rainforest at the southem end of the Westem Ghats.

Assessor: World Conservation Monitoring Centre

Refs: 19144

\section{Anaxagorea costaricensis}

Annonaceae

EN C1

Costa Rica, Honduras

A rare species of wet lowland forest.

Assessor: Nelson, C.

Refs: 13995

\section{Andira galeottiana}

Leguminosae

Mexico (Chiapas, Oaxaca, Veracruz)

VU Alc

A canopy tree of remnant rainforest in the Gulf region of Mexico.

Assessor: World Conservation Monitoring Centre

Refs: 5993, 15791, 19124

\section{Angylocalyx brauni}

Leguminosae

VU B $1+2 b$

Kenya, Tanzania

A species restricted to patches of riverine forest and moist forest. Populations occur in the Tana River area and $\mathrm{K}$ wale in south-east Kenya and in eastern Tanzania. Assessor: Lovett, J. \& G.P. Clarke

Refs: $3356,6396,10961$

\section{Aniba ferrea}

Lauraceae

VU $B 1+2 c$

Brazil (Amazonas)

Restricted to high non-flooded forest, this tree is endemic to the vicinity of Manaus, where increasing human settlement is a serious threat.

Assessor: World Conservation Monitoring Centre Refs: 7950,7980

\section{Aniba ferruginea}

Lauraceae

VU D2

Venezuela

Known only from the type collection, the species appears to be confined to high, non-flooded forests in the Venezuelan Amazon.

Assessor: World Conservation Monitoring Centre Refs: 7950, 7980

\section{Aniba intermedia}

Lauraceae

VU Bl $+2 \mathrm{c}$

Brazil (Bahia)

This species, endemic to Bahia, is fairly wide-ranging but confined to an area which continues to be deforested. Assessor: World Conservation Monitoring Centre Refs: 7950,7980

\section{Aniba novo-granatensis}

Lauraceae

VU B $1+2 c$

Colombia

A high-altitude species, confined to Cauca and Meta.

Assessor: Calderon, E.

Refs: $7950,7980,19069$ 


\author{
Aniba pedicellata \\ Lauraceae \\ CR B $1+2 \mathrm{c}$ \\ Brazil (Rio de Janeiro) \\ A species known solely from a type specimen collected \\ in 1938 from Rio de Janeiro. \\ Assessor: World Conservation Monitoring Centre \\ Refs: 7950,7980
}

\section{Aniba percoriacea}

Lauraceae

VU D2

Suriname

A species only recorded from the type collection, gathered at Tafelberg.

Assessor: World Conservation Monitoring Centre

Refs: $7950,7980,19196$

\section{Aniba rosaeodora}

Lauraceae

EN Ald $+2 d$

Brazil (Amapá, Amazonas, Pará), Colombia, Ecuador, French Guiana, Guyana, Peru, Suriname, Venezuela Populations throughout the species range have seriously declined because of rosewood oil extraction. Substantial wild stands are believed to exist still in areas which are unlikely to be exploited, but where there has been exploitation the population is devoid of mature trees and significant signs of regeneration are absent. Trees of all sizes are harvested indiscriminately, the whole tree and its roots being destroyed. The sole producer at present is Brazil, although the species was wiped out through exploitation over large areas in French Guiana between 1910 and 1930. Harvesting is costly and is taking place in more and more remote locations concentrated around Amazon tributaries, principally in Amazonas and Pará. Mobile distillation factories have also moved deep into the forest and trees. Levels of exploitation have significantly declined with increased use of synthetic oils, the current world market resting at about 100 tonnes pa. Silvicultural studies are being carried out by *FCAP with the assistance of UK institutions.

Assessor: Varty, N.

Refs: $4506,7950,8815,12109,15539,15714,19069$, $19077,19095,19179$

\section{Aniba santalodora \\ Lauraceae}

VU D2

Brazil (Amazonas)

This species is restricted to a small area of high Amazon forest and secondary growth.

Assessor: World Conservation Monitoring Centre

Refs: 7950,7980

\section{Aniba vaupesiana \\ Lauraceae}

VU D2

Colombia

Known only from the type specimen, this species is confined to Vaupés.

Assessor: World Conservation Monitoring Centre

Refs: 7950,7980

\section{Anisophyllea apetala}

Anisophylleaceae

Malaysia (Peninsular Malaysia)

A tree of moist lowland and hill forest.

Assessor: Chua, L.S.L.

Refs: 19073

\section{Anisophyllea cabole}

Anisophylleaceae

Sāo Tomé \& Príncipe (São Tomé)

A tree or shrub, known from two sites towards the northwest of the island at altitudes of 1350 to $1410 \mathrm{~m}$.

Populations appear to be healthy and regenerating. The species produces a good wood which has moderate value as a timber.

Assessor: World Conservation Monitoring Centre

Refs: 2724, 19042, 19111

Anisophyllea chartacea

Anisophylleaceae

VU D2

Malaysia (Sarawak)

A tree known only from the type specimen collected in lowland mixed dipterocarp forest from Ulu Balleh in the Kapit District.

Assessor: World Conservation Monitoring Centre Refs: 19017

\section{Anisophyllea cinnamomoides}

Anisophylleaceae

VU Alc

Sri Lanka

A tree restricted to the lowland wet evergreen forests of south-west Sri Lanka.

Assessor: World Conservation Monitoring Centre

Refs: 15431, 17195

\section{Anisophyllea curtisii}

Anisophylleaceae

VU B1+2a

Malaysia (Peninsular Malaysia)

Occurring in rainforest up to $260 \mathrm{~m}$, the most prominent threat to this species is the expansion of settlements.

Assessor: Chua, L.S.L.

Refs: 19073

\section{Anisophyllea ferruginea}

Anisophylleaceae VU Alcd

Brunei, Indonesia (Kalimantan), Malaysia (Sarawak)

A generally uncommon tree, occurring in mixed dipterocarp forest up to $600 \mathrm{~m}$. It is locally abundant in places.

Assessor: World Conservation Monitoring Centre

Refs: 19017

Anisophyllea globosa

Anisophylleaceae

Malaysia (Sabah)

VU D2

A tree of open secondary vegetation known only from its type locality at the edge of a steep gully in Bengkoka in the Kudat District.

Assessor: World Conservation Monitoring Centre Refs: 19017

\section{Anisophyllea grandis}

Anisophylleaceae

VU B $1+2 a$

Malaysia (Peninsular Malaysia)

A species of lowland and hill rainforest up to $700 \mathrm{~m}$, threatened mainly by the expansion of settlements.

Assessor: Chua, L.S.L.

Refs: 19073

\section{Anisophyllea impressinervia}

Anisophylleaceae

VU D2

Malaysia (Sabah)

Known only from the type collection from Bengkoka in 
the Kudat District, this tree occurs in secondary lowland forest at an altitude of $50 \mathrm{~m}$.

Assessor: World Conservation Monitoring Centre Refs: 19017

\section{Anisophyllea nitida}

Anisophylleaceae

Malaysia (Sabah, Sarawak)

This species is highly localised and known only from Kuala Penyu in south-west Sabah and the Niah area of north-east Sarawak, where it grows in lowland secondary or disturbed mixed dipterocarp forest on sandy soils.

Assessor: World Conservation Monitoring Centre Refs: 19017

\section{Anisophyllea reticulata}

Anisophylleaceae

VU D2

Malaysia (Peninsular Malaysia)

This species is known from only one collection on a ridge top in hill forest at $180 \mathrm{~m}$, Endau State Park, Johore.

Assessor: World Conservation Monitoring Centre

Refs: 8464, 19073

\section{Anisophyllea rhomboidea}

Anisophylleaceae

VU Alc

Indonesia (Kalimantan), Malaysia (Sarawak)

A shrub or tree of lowland mixed dipterocarp forest, endemic to west Bomeo. It is restricted to the $1 \mathrm{st}$ Division of Sarawak and Kalimantan

Assessor: World Conservation Monitoring Centre

Refs: 19017

\section{Anisoptera costata}

Dipterocarpaceae

EN Alcd $+2 c d$

Brunei, Cambodia, Indonesia (Java, Kalimantan, Sumatra), Malaysia (Peninsular Malaysia, Sabah, Sarawak), Myanmar, Philippines, Singapore, Thailand, Viet Nam

A large tree of semi-evergreen dipterocarp, evergreen and humid lowland forest, which occurs on premium land for agriculture. In some areas it is an exceptionally rare tree; in the Philippines only a single collection exists. It produces a major commercial timber, used for general construction, veneer and plywood. Some populations occur within reserves.

Assessor: Ashton, P.

Refs: $7673,9169,9199,10013,13857,14573$

\section{Anisoptera curtisii}

Dipterocarpaceae

CR Alcd+2cd

Indonesia (Sumatra), Malaysia (Peninsular Malaysia), Thailand

A species which occurs in mixed dipterocarp forest, mainly on coastal hills and inland ridges. The wood is utilised. A. curtistii may hybridise with $A$. costata.

Assessor: Ashton, P.

Refs: $5550,7673,9169,13857,14573,18243$

\section{Anisoptera grossivenia}

Dipterocarpaceae

EN Alcd+2cd

Brunei, Indonesia (Kalimantan), Malaysia (Sabah, Sarawak)

A lowland dipterocarp forest species found growing on sandy clay soils. Its timber is often used for plywood.

Assessor: Ashton, $\mathrm{P}$.

Refs: 11295, 13857, 14573
Anisoptera laevis

Dipterocarpaceae

Sarawak), Singapore

(Sumatra), Malaysia (Sabah,

A timber tree which is widespread and recorded in a number of proposed reserve sites. The conservation status of the tree results from land conversion and destruction over the past century.

Assessor: Ashton, $\mathrm{P}$.

Refs: $7673,7875,9169,9199,13857$

\section{Anisoptera marginata}

Dipterocarpaceae

EN Alcd $+2 c d$

Indonesia (Sumatra), Malaysia (Peninsular Malaysia)

A species of mixed peat-swamp forest and heath forest.The timber is used for house construction.

Assessor: Ashton, $\mathrm{P}$.

Refs: $7673,9169,13857$

\section{Anisoptera megistocarpa}

Dipterocarpaceae

CR Alcd +2cd

Indonesia (Sumatra), Malaysia (Peninsular Malaysia), Singapore

A large tree scattered throughout mixed dipterocarp forest on well-drained soil. The habitat has been widely cleared and destroyed.

Assessor: Ashton. P.

Refs: $5550,7673,9169,9199,13857$

\section{Anisoptera reticulata}

Dipterocarpaceae

Brunei, Malaysia (Sabah, Sarawak)

A species of mixed dipterocarp forest, where it is threatened by habitat loss.

Assessor: Ashton, P.

Refs: $7673,9169,13857$

\section{Anisoptera scaphula}

Dipterocarpaceae

CR Alcd+2cd

Bangladesh, Malaysia (Peninsular Malaysia), Myanmar, Thailand, Viet Nam

A species scattered in semi-evergreen and evergreen dipterocarp forest. Regeneration is poor.

Assessor: Ashton, $\mathrm{P}$.

Refs: $5550,7673,9169,13857,19093$

\section{Anisoptera thurifera ssp. thurifera}

Dipterocarpaceae

CR Alcd $+2 \mathrm{~cd}$

Philippines

This variety is found growing in the evergreen and semievergreen dipterocarp forests. The species, as a whole, represents the only dipterocarp which readily reinvades cultivated land. The conservation status of the species is based upon the rate of habitat loss.

Assessor: Ashton, $\mathrm{P}$.

Refs: $7673,9169,13857,14573$

\section{Annamocarya sinensis}

Juglandaceae

EN B $1+2$ cde

China (Guangxi, Guizhou, Hunan, Yunnan), Viet Nam

Occurring in small groves or as isolated individuals, this relict species is recorded from a few forest localities in north-west Guangxi, south-east Guizhou, south-east Yunnan in China, and from a few localised populations in north and west Viet Nam. In China the species has been difficult to locate at recorded localities and the 
habitat has declined considerably with extensive agriculture and logging. It is the only member of the genus.

Assessor: Sun, W.

Refs: $848,1818,11530,11847,15357,19055,19061$

\section{Anneslea fragrans var. lanceolata}

Theaceae

VUAla, D1

Taiwan

A species with scattered populations occurring on the eastern hills of the Hengchun Peninsula. There are a few protected localities in Kenting National Park. Elsewhere the species habitat is under some pressure from the establishment of industrial plantations and increasing land settlement and agriculture.

Assessor: Lu, S.Y. \& F.J. Pan

Refs: $3295,19050,19053$

\section{Annona asplundiana}

Annonaceae

VU D2

Peru

A species, so far, known only from the type specimen collected from lowland Amazon forest in the department of Loreto.

Assessor: World Conservation Monitoring Centre Refs: 1984

\section{Annona atabapensis}

Annonaceae

VU D2

Venezuela

No collections have been made of this species since it was first discovered by Humboldt and Bonpland in flooded riparian forest on the Río Atabapo in Amazonas, early in the 19th century.

Assessor: World Conservation Monitoring Centre Refs: 19128

\section{Annona cristalensis}

Annonaceae

VU B1+2c

Cuba

A rare tree, up to $8 \mathrm{~m}$ tall, found in montane shrubwoods and forests on ferritic soils derived from serpentine bedrock in Sierra del Cristal, Sierra de Micara and the upper Toa area in north-eastern Cuba.

Assessor: Areces-Mallea, A.E.

Refs: $16327,18485,19149$

\section{Annona deminuta}

Annonaceae

VU D2

Peru

At present the species is known only from the type collection taken from San Martin.

Assessor: World Conservation Monitoring Centre Refs: 1984

\section{Annona dolichophylla}

Annonaceae

VU D2

Peru

Currently known only from the type collection, the species is found in lowland Amazon forest in the department of Loreto.

Assessor: World Conservation Monitoring Centre Refs: 1984

\section{Annona ekmanï}

Annonaceae

VU D2

Cuba

A small tree locally confined to the serpentine plateau of Sierra de Nipe in north-eastern Cuba, where it occurs in montane shrubwoods and forests on ferritic soils.

Assessor: Areces-Mallea, A.E.

Refs: $11403,18485,19149$

\section{Annona jamaicensis}

Annonaceae

LR/nt

Jamaica

The species is scattered in pasture margins and woodlands on limestone in the central parishes.

Assessor: World Conservation Monitoring Centre Refs: 6057,7980

\section{Annona praetermissa}

Annonaceae

VU B $1+2 \mathrm{c}$

Jamaica

The species is uncommon and confined to the St Andrew and St Thomas Parishes, where it occurs on wooded hillsides. Almost all the forest in these parishes is either severely degraded or destroyed.

Assessor: Bellingham, $\mathrm{P}$.

Refs: $401,5653,7980,19116$

\section{Annona spraguei}

Annonaceae

VU Alc

Panama

Known only from the centre and east of Panama, the species occurs in moist evergreen forest up to $1000 \mathrm{~m}$. The main populations are found within protected areas. Elsewhere the habitat is susceptible to clearance and logging.

Assessor: Mitré, M.

Refs: $7272,7980,16772$

\section{Annona trunciflora \\ Annonaceae}

LR/nt

Venezuela

Endemic to the Venezuelan Guyana, the species occurs in secondary forest and riparian forest in the upper reaches of the Río Parguaza in Bolívar and on Río Sipapo near the confluence with Río Orinoco in Amazonas.

Assessor: World Conservation Monitoring Centre Refs: 19128

\section{Anodendron rhinosporum \\ Apocynaceae}

$\mathrm{CR} B 1+2 \mathrm{c}$

Sri Lanka

An extremely rare species scattered in lowland wet evergreen forest in south-west Sri Lanka. It was not found during the extensive National Conservation Review forest surveys.

Assessor: World Conservation Monitoring Centre Refs: $15431,17195,19112$

\section{Anogeissus bentii \\ Combretaceae}

$\mathrm{EN} \mathrm{B1+2e}$

Yemen

One of the largest trees in Yemen. It occurs as ancient solitary individuals or in small groups, restricted to the large wadis which dissect the inhospitable limestone plateau of the Hadramaut in South Yemen. Regeneration is lacking in most areas.

Assessor: Miller, A.G.

Refs: 19083 


\section{Anogeissus dhofarico}

Combretaceae

VUAlcd

Oman, Yemen

A common tree of deciduous escarpment woodland on the mountains extending from Dhofar in Oman to neighbouring Hauf in Yemen. It also occurs as an outlier in Yemen in Ras Fartak. Trees near water-holes are severely damaged and in other areas grazing pressure is high, especially in Oman, where there has been a sharp rise in the population.

Assessor: Ghazanfar, S.A.

Refs: 16380

\section{Anonidium usambarense}

Annonaceae

Tanzania

EX

A single collection from 1910 is the only record of this species. It occurred in the Usambara Mountains but has not been found again despite extensive botanical work in the area. The forest has suffered from the encroachment of agriculture and commercial forestry but is now the focus of a conservation programme.

Assessor: World Conservation Monitoring Centre

Refs: 3356,9302

\section{Anopyxis klaineana}

Rhizophoraceae

VUAlcd

Cameroon, Congo, Côte d'Ivoire, Ethiopia, Ghana, Liberia, Nigeria, Sierra Leone, Sudan

A timber species which occurs in some abundance especially in wetter evergreen forest. Habitat loss and exploitation are serious threats in most places. Seeds have poor viability and regeneration has been observed to be poor. The genus is monotypic.

Assessor: Hawthorne, W.

Refs: $2362,2773,6128,6718$

\section{Anthodiscus chocoensis}

Caryocaraceae

VU C1

\section{Colombia, Costa Rica, Panama}

The species is known mainly from the rclatively large and protected populations in Costa Rica. Elsewhere populations are small, scattered and show low recruitment. In Panama small populations are apparently confined to Darién National Park. There are also occurrences in the Chocó in Colombia. The wood is used both locally and commercially as fuel and timber.

Assessor: Mitré, M.

Refs: $7980,10686,14717,16772$

\section{Anthodiscus montanus}

Caryocaraceae

$\mathrm{EN} \mathrm{B1}+2 \mathrm{c}$

Colombia

An endemic to Boyacá.

Assessor: Calderon, E.

Refs: 4217, 7980, 19069

\section{Anthonotha lebrunii}

Leguminosae

VU D2

Democratic Republic of Congo

Known only from one locality, this species occurs in part of the Forestier Central at Bumbuli. Pressures exist from overcutting and agricultural expansion.

Assessor: Ndjele, M.B.

Refs: $7550,17185,17951$

\section{Anthonotha nigerica}

Leguminosae

Democratic Republic of Congo, Nigeria

VUAlc

A small forest tree with an apparently disjunct distribution, occurring in the remaining forest in southeast Nigeria and also in DR Congo, where the extent of its occurrence is not at present known. In Nigeria the largest, if not only, intact population occurs in the Oban Division of the Cross River National Park. Deforestation in the region has been extensive.

Assessor: World Conservation Monitoring Centre Refs: 4977, 11504

\section{Anthonotha obanensis}

Leguminosae

VU B1+2c, D2

Nigeria

This distinctive species is recorded soley from the Oban Division of the Cross River National Park. The population is well protected but logging and conversion of land to agriculture are extensive in the surrounding area.

Assessor: World Conservation Monitoring Centre Refs: 2773, 4977, 7550, 11504

\section{Anthonotha vignei}

Leguminosae

Côte d'Ivoire, Ghana, Liberia, Sierra Leone

VU Alc, B1+2c

A species which is confined to riversides or swampy areas within lowland wet evergreen forest in Upper Guinea. Losses of this habitat through felling for timber, mining and planting of commercial species have been extensive.

Assessor: Hawthome, W.

Refs: 2773, 8369, 12061

\section{Antidesma cruciforme}

Euphorbiaceae

LR/cd

Malaysia (Peninsular Malaysia)

A montane forest species, occurring between 1000 and $1400 \mathrm{~m}$ in Perak and Selangor. The forest in these mountain areas is generally protected.

Assessor: Kochummen, K.M.

Refs: 8464,19073

\section{Antidesma obliquinervium}

Euphorbiaceae

VUB $1+2 \mathrm{c}$

Philippines

An endemic tree of Palawan, found in primary forests at low altitude. The main island is declared a biosphere reserve.

Assessor: World Conservation Monitoring Centre

Refs: 4986

\section{Antidesma pyrifolium}

Euphorbiaceae

VU Alc

Sri Lanka

A tree occurring in the lowland wet evergreen forests of south-west Sri Lanka.

Assessor: World Conservation Monitoring Centre

Refs: 9176,17195

\section{Antidesma subolivaceum}

Euphorbiaceae

VU B $1+2 c$

Philippines

Endemic to Palawan, the species is found in primary forests at low altitude.

Assessor: World Conservation Monitoring Centre

Refs: 4986 


\author{
Antirhea aromatica \\ Rubiaceae \\ $\mathrm{EN} \mathrm{B} 1+2 \mathrm{c}$ \\ Mexico (Veracruz) \\ Three populations of a few mature trees, exist in central \\ Veracruz in deciduous thorn forest on karst hills near \\ Jalcomulco and Apazapan. They are situated on \\ relatively inaccessible slopes, but trees still appear to be \\ cut for the wood, which is used in house construction. \\ Natural regeneration is evident and the species is being \\ grown from seed at the Botanic Garden in Xalapa. \\ Assessor: Vovides, A.P. \\ Refs: 7980, 10919, 19206
}

Antirhea jamaicensis

Rubiaceae

LR/nt

Jamaica

A tree useful for its wood, found only occasionally in woodlands on limestone in moderately wet areas.

Assessor: World Conservation Monitoring Centre Refs: 6057, 7980

\section{Antirhea portoricensis}

Rubiaceae

VU Bl+2c

Puerto Rico

A tree of moist forests with a localised distibution in areas which have experienced habitat destruction. Assessor: World Conservation Monitoring Centre Refs: 7931, 7980, 17124

\section{Antirhea radiata}

Rubiaceae

VU B1+2c

Cuba, Dominican Republic, Haiti

A tree of montane rainforest and submontane semideciduous forest, occurring in central and eastern parts of Cuba and in the province of Pinar del Rio, and also Hispaniola. The habitat of this species is under threat from felling.

Assessor: Areces-Mallea, A.E.

Refs: 19149

\section{Antirhea sintenisii}

Rubiaceae

VU B $1+2 c$

Puerto Rico

A tree of moist forest with a localised distribution in areas which have been experiencing habitat destruction. Assessor: World Conservation Monitoring Centre Refs: 7931,7980,17124

\section{Antirhea tomentosa}

Rubiaceae

CR B $1+2 \mathrm{c}$

Jamaica

Until 1975 the species was known only from the type specimen collected in thickets in Trelawny Parish in 1780. It was rediscovered in an area which was being rapidly cleared. It is not known whether the species has survived.

Assessor: World Conservation Monitoring Centre

Refs: 401,7980

\section{Antrocaryon micraster}

Anacardiaceae

VU Alcd

Cameroon, Côte d'lvoire, Democratic Republic of Congo, Ghana, Nigeria, Sierra Leone, Uganda

Scattered throughout semi-deciduous forests in tropical Africa, this emergent species is heavily exploited for its timber. It regenerates in canopy gaps and its fruit provides an important food source to the mammal community. It performs less well in bumt or heavily disturbed forests.

Assessor: Hawthome, W.

Refs: $2362,2773,6128,6718,14667$

\section{Aoranthe penduliflora}

Rubiaceae

VU B $1+2 b c$

Tanzania

A shrubby species known from remaining forest patches largely existing within Forest Reserves. Populations are known from Pugu and Rondo Forest Reserves. These have both been heavily disturbed in the past by a range of human activities including logging and agriculture. Pugu is now part of an active conservation programme and the forest management activities in Rondo are discouraging local exploitation.

Assessor: Lovett, J. \& G.P. Clarke

Refs: 3356,8814

\section{Apeiba intermedia}

Tiliaceae

DD

Suriname

The species was described in 1925, based upon incomplete material from a single tree. It is possibly a hybrid of $\boldsymbol{A}$. glabra and A. petonmo.

Assessor: World Conservation Monitoring Centre

Refs: 6493,7951

\section{Aphanamixis cumingiana}

Meliaceae

VU Alcd

Philippines

A timber tree, endemic to the Philippines. Rates of habitat loss through logging and shifting cultivation have led to considerable population declines.

Assessor: World Conservation Monitoring Centre

Refs: $2072,4919,18088$

Apiopetalum velutinum

Araliaceae

LR/cd

New Caledonia

Assessor: Jaffré, T. et al.

Refs: 10351

\section{Apollonias barbujana ssp. barbujana}

Lauraceae

LR/nt

Portugal (Madeira), Spain (Canary Is.)

In Madeira the species has a sporadic distribution in lowland forest and *laurisilva up to $1000 \mathrm{~m}$. In some of the lower zones it is locally abundant, and parts of the range occur within the National Park of Madeira. There are pressures from grazing and burning throughout the island. A population also exists on Desertas Island in the Madeira Group.

Assessor: World Conservation Monitoring Centre Refs: 19131

\section{Apollonias barbujana ssp. ceballosi}

\section{Lauraceae}

EN B1+2abcde

Spain (Canary Is.)

Previously referred to as a distinct species, this cloud forest tree is confined to the island of Gomera. In the past the timber was heavily harvested. As a result, populations are now small and fragmented. The major threat at present comes from fire. The taxon is listed in government legislation of 1991.

Assessor: Bañares, A. et al.

Refs: 451, 19022 
Aporosa fusiformis

Euphorbiaceae

CR B $1+2 \mathrm{c}$

Sri Lanka

During the extensive National Conservation Review forest surveys, only two individuals were found at a single locality in the lowland rainforest of Kegalle District.

Assessor: World Conservation Monitoring Centre Refs: 19112

\section{Aporusa bourdillonii}

Euphorbiaceae

$\mathrm{EN} \mathrm{B1+2c}$

India (Kamataka, Kerala)

A poorly collected species, reported from a few scattered locations in lowland rainforest.

Assessor: World Conservation Monitoring Centre

Refs: 19144

\section{Aporusa cardiosperma}

Euphorbiaceae

VUAlc

Sri Lanka

A tree occurring in the lowland wet evergreen forests of south-west Sri Lanka.

Assessor: World Conservation Monitoring Centre

Refs: 17195

\section{Aporusa elliptifolia}

Euphorbiaceae

VU B $1+2 \mathrm{c}$

Philippines

A Palawan endemic, confined to forested slopes at low altitude. The main island is declared a biosphere reserve. Assessor: World Conservation Monitoring Centre

Refs: 4986,5651

\section{Aporusa isabellina}

Euphorbiaceae

LR/nt

Malaysia (Peninsular Malaysia)

A lowland rainforest species, confined to a restricted area in the Sungei Lebi Basin in south-east Kelantan.

Assessor: World Conservation Monitoring Centre

Refs: 8464, 19073

\section{Aporusa lanceolata}

Euphorbiaceae

VUAlc

Sri Lanka

A tree confined to the lowland wet evergreen forests of south-west Sri Lanka.

Assessor: World Conservation Monitoring Centre

Refs: 9176,17195

\section{Apterosperma oblata}

Theaceae

VU B $1+2 c$

\section{China (Guangdong, Guangxi)}

First discovered in the 1960 s, the species is thought to have become extinct in its original location on Mount Hewei, which has been cleared of forest. Further localities have been identified in Xinyi in Guangdong and Guping in Guangxi, where it occurs in the remaining forest below $600 \mathrm{~m}$. The genus is monospecific.

Assessor: World Conservation Monitoring Centre

Refs: 1818,11847

\section{Aquilaria banaensae}

Thymelaeaceae

Viet Nam

A small tree or shrub which appears to be endemic to
Viet Nam, where it is very rare and restricted to Tây Quàng Nam in Da Nang.

Assessor: World Conservation Monitoring Centre

Refs: 848

\section{Aquilaria beccariana}

Thymelaeaceae

VUAld

Indonesia (Kalimantan, Sumatra), Malaysia

This species occurs in primary and secondary forest, sometimes in swamp forest, up to $800 \mathrm{~m}$. The fungiinfected heartwood, characteristic of all members of the genus, has high commercial value for making incense, perfume and traditional medicine. Numerous trees are cut down, many uninfected, to harvest just a few kilogrammes of the diseased wood. The increase in levels of trade over the past decade has resulted in overexploitation throughout its range.

Assessor: World Conservation Monitoring Centre Refs: 1766, 19059

\section{Aquilaria crassna}

Thymelaeaceae

Cambodia, Laos, Thailand, Viet Nam

The red list category is largely based on the situation in Viet Nam, where the species is distributed sparsely but widely throughout the country in primary and secondary forest. Exploitation of the diseased wood for the perfume industry has resulted in population declines exceeding $80 \%$ over recent years. There is a strong indication that the same losses are occurring in the rest of Indo-China. Other parts of the plant are also widely used: the roots for incense, cosmetics and medicines and the bark for fibre.

Assessor: Nghia, N.H.

Refs: $848,6646,11530,15357,19060$

\section{Aquilaria cumingiana}

Thymelaeaceae

VU Ald

Indonesia (Kalimantan, Moluccas), Philippines

A shrub or small tree of primary forest distributed in East Kalimantan, the Moluccas and the Philippines. The fungi-infected heartwood, characteristic of all members of the genus, has high commercial value in the production of incense, perfume and traditional medicine. Numerous trees are cut down, many uninfected, to harvest just a few kilogrammes of the diseased wood. The increase in levels of trade over the past decade has resulted in overexploitation throughout its range. Assessor: World Conservation Monitoring Centre Refs: 1766,19059

\section{Aquilaria hirta}

Thymelaeaceae

VU Ald

\section{Indonesia (Sumatra), Singapore}

A small tree occurring in lowland forest on hill slopes. The fungi-infected heartwood, characteristic of all members of the genus, has high commercial value in the producticn of incense, perfume and traditional medicine. Numerous trees are cut down, many uninfected, to harvest just a few kilogrammes of the diseased wood. The increase in levels of trade over the past decade has resulted in overexploitation throughout its range. Assessor: World Conservation Monitoring Centre Refs: 9199,19059 


\section{Aquilaria malaccensis}

Thymelaeaceae VUAlcd

Bangladesh, Bhutan, India (Assam, Manipur, Meghalaya, Tripura), Indonesia (Kalimantan, Sumatra), Iran, Malaysia (Peninsular Malaysia), Myanmar, Philippines, Singapore, Thailand

A large evergreen tree occurring in forests at the base of mountainous areas. For centuries the species has been traded internationally for the wood infected with fungi, called agar or gaharu amongst other things; it is used as incense, perfume and in traditional medicine. Most of the agarwood on the market is collected from the wild since the few plantations set up in the early 1900 s are either under serious pressure or have been destroyed. The species is considered critically endangered in India and export has been prohibited. It is included in Appendix II of *CITES.

Assessor: Asian Regional Workshop

Refs: $1086,5550,5626,6646,8865,9199,9328,10471$, $12959,14490,17140,19058,19059,19209$

\section{Aquilaria microcarpa}

Thymelaeaceae

VU Ald

Indonesia (Kalimantan, Sumatra), Singapore

This species grows in lowland forest up to $200 \mathrm{~m}$ altitude. The fungi-infected heartwood, characteristic of all members of the genus, has high commercial value in the production of incense, perfume and traditional medicine. Numerous trees are cut down, many uninfected, to harvest just a few kilogrammes of the diseased wood. The increase in levels of trade over the past decade has resulted in overexploitation throughout its range.

Assessor: World Conservation Monitoring Centre Refs: $9199,16104,19059$

\section{Aquilaria rostrata}

Thymelaeaceae

Malaysia (Peninsular Malaysia)

A rare submontane rainforest species, found only in Pahang, at Wray's camp on Gunung Tahan in Taman Negara National Park. The species taxonomic status is doubtful. It is similar to $A$. malaccensis but the specimen material is too poor to verify the floral characters. Assessor: World Conservation Monitoring Centre Refs: $8464,8865,19073$

\section{Aquilaria sinensis}

Thymelaeaceae

VU B $1+2$ cde China (Guangdong, Guangdong - Hainan, Guangxi, Yunnan)

An important source of medicine, the species is restricted to Jinghong in Yunnan, Guangdong, including Hainan Island and Guangxi. It is mainly found in semievergreen monsoon forest up to altitudes of $400 \mathrm{~m}$. There is concem over the rates of exploitation and the damage to trees incurred during the harvesting of the medicinal balm. Habitat loss and clearance are also frequent.

Assessor: Sun, W.

Refs: $1818,11847,19055$

\section{Aralia javanica}

Araliaceae

Indonesia (Java)

The species is possibly synonymous with $A$. dasyphylla. It occurs in montane forests between 2000 and $3000 \mathrm{~m}$ on Mount Papandayan, Malabar and Dieng.

Assessor: World Conservation Monitoring Centre Refs: 9078

\section{Aralia malabarica}

Araliaceae

VU B $1+2 \mathrm{c}$

India (Kerala, Tamil Nadu)

An understorey tree, known from sparse collections from submontane evergreen forest in the southern end of the Western Ghats.

Assessor: World Conservation Monitoring Centre Refs: 19144

\section{Arapatiella psilophylla}

Leguminosae

Brazil (Bahia)

VU B1+2c

The species is endemic to areas of Atlantic forest in the south of the state.

Assessor: World Conservation Monitoring Centre Refs: 19098,19100

\section{Araucaria angustifolia}

Araucariaceae

VUAlcd $+2 c d$

Argentina (Misiones), Brazil (Minas Gerais, Paraná, Rio de Janeiro?, Rio Grande do Sul, Santa Catarina, São Paulo), Paraguay

Parana pine is the most important timber species in Brazil. Although an abundant species, it has undergone continuous decline in the extent of its occurrence through logging. The original extent of Araucaria forest, estimated at $200,000 \mathrm{~km}^{2}$, is believed to have declined by more than $80 \%$ in the last century. In Rio Grande do Sul, for instance, the forest area, over half of which was made up of Araucaria, has plummetted from $40 \%$ land cover to $3 \%$ today. Araucaria forest in São Paulo covers $4.3 \%$ of its original area. In addition, 3,400 tons per annum of fruit and seeds are collected for human consumption. The Paraguay population is small and confined to Alto Paraná. Seeding trees are scarce. Small relict populations, covering less than $1000 \mathrm{ha}$, in northeast Misiones, Argentina, are all that remain of the forest that in 1960 covered 210,000 ha. The species is included on the official list compiled by *IBAMA of threatened Brazilian plants.

Assessor: Varty, N. \& D.L. Guadagnin

Refs: 4506, 5112, 7980, 8815, 11374, 13041, 13947, $15539,16595,19124,19179$

\section{Araucaria araucana}

Araucariaceae

VU Alcd Argentina (Neuquén), Chile

Known widely as the Monkey Puzzle tree, this species ranges from the Coastal Cordillera of Chile to the Andes in Argentina. The populations on the coast are restricted and highly threatened. Andean populations are severely fragmented. Chile holds the largest populations, most of which are being illegally felied in and outside national park boundaries. The Chilean populations are listed in ${ }^{*}$ CITES Appendix I and the Argentinian in Appendix II. Assessor: SSC Conifer Specialist Group

Refs: $5112,7980,11147,16328$

\section{Araucaria bernieri}

Araucariaceae

LR/cd

New Caledonia

Confined to areas of moist evergreen forest in the south, this valued timber species is under some pressure from logging. It is well represented in protected areas including Rivière Bleue Provincial Park and Montagne des Sources Nature Reserve, where it is safe from being felled.

Assessor: SSC Conifer Specialist Group

Refs: 10351,12630 


\section{Araucaria biramulata}

Araucariaceae

$\mathrm{LR} / \mathrm{cd}$

New Caledonia

Similar to A.bernieri the species is confined to areas of moist evergreen forest in the southem ultramafic massifs. It is under some pressure from logging and also fires. Well-protected populations exist in Rivière Bleue Provincial Park.

Assessor: SSC Conifer Specialist Group

Refs: 10351,12630

\section{Araucaria heterophylla}

Araucariaceae

VU B $1+2 \mathrm{C}$

Norfolk Island

The Norfolk Island pine has experienced large historical population declines in its natural range. Much of the habitat continues to be converted into agriculture and human habitation. The species is very widely planted throughout the world.

Assessor: SSC Conifer Specialist Group

Refs: 6144, 13041

\section{Araucaria humboldtensis}

Araucariaceae

LR/cd

New Caledonia

Occurring in cloud forest on three mountain ridges, the species is localised but not threatened or declining. Severe drought in recent years may have caused the death of about $10 \%$ of the Mount Humboldt population. Regeneration on Montagne des Sources, where it is protected in a nature reserve, appears to be good.

Assessor: SSC Conifer Specialist Group

Refs: 12630, 13041

\section{Araucaria hunsteini}

Araucariaceae

LR/nt

Papua New Guinea

Recorded to be the tallest tree in Malesia, reaching $90 \mathrm{~m}$ in height, the species occurs mainly in Fagaceae forest between 520 and $2100 \mathrm{~m}$. It has been reduced to scattered stands because of heavy exploitation of the good-quality timber. The species habitat is also threatened by shifting agriculture, fire and damage caused by feral pigs. Small plantations of 8000 ha exist in Papua New Guinea and it has been introduced to Australia, Fiji and Peninsular Malaysia on an experimental scale. The export of Araucaria logs has been banned in Papua New Guinea.

Assessor: SSC Conifer Specialist Group

Refs: 707, 4506, 13041, 13204, 14573, 19147

\section{Araucaria laubenfelsü}

Araucariaceae

LR/cd

New Caledonia

A species scattered on the southern ultramafic massifs. It is uncommon and confined to a few localities of submontane forest where wildfires can be a hazard.

Assessor: SSC Conifer Specialist Group

Refs: 10351, 12630

\section{Araucaria lururians}

Araucariaceae

$\mathrm{EN} \mathrm{B1}+2 \mathrm{c}$

New Caledonia

Small populations are confined to fewer than five coastal sites on ultramafic soils in the south of the island. None of the populations is protected and in places, e.g. Plum, they are seriously threatened by fire and erosion. Mining and the increasing settlement of the area are also concerns.

Assessor: SSC Conifer Specialist Group

Refs: 10351,12630

\section{Araucaria muelleri}

Araucariaceae

LR/cd

New Caledonia

The species is known from a few small populations in maquis shrubland on ultramafic soils in the southem massifs. Growth and regeneration appear to be slow and susceptible to the frequent wildfires. Effective protection is given to populations in Montagne des Sources Nature Reserve.

Assessor: SSC Conifer Specialist Group

Refs: $374,9631,12630$

\section{Araucaria nemorosa}

Araucariaceae

$\mathrm{CR} B 1+2 \mathrm{c}$

New Caledonia

A single population exists at Port Boisé on the southem coast. It is on private land and is vulnerable to fires, felling and the expansion of human habitation, perhaps also to potential tourism.

Assessor: SSC Conifer Specialist Group

Refs: 10351,12630

\section{Araucaria rulei}

Araucariaceae

$\mathrm{EN} \mathrm{Cl}$

New Caledonia

Occurring in small areas of maquis shrubland on the ultramafic massifs in the north-west, the species has experienced severe population declines because of nickel mining activities. Mining is now more strictly controlled and there have been good results from attempts to recolonise the mine spoil. However, this species appears to regenerate poorly and grow slowly. None of the populations is protected.

Assessor: SSC Conifer Specialist Group

Refs: 10351,12630

\section{Araucaria schmidii}

Araucariaceae

VU D2

New Caledonia

A well-protected species confined to montane cloud forest on Mont Panie. The area is inaccessible and not under threat. However, the species is confined to an area considerably less than $100 \mathrm{~km}^{2}$.

Assessor: SSC Conifer Specialist Group

Refs: 12630,13041

\section{Araucaria scopulorum}

Araucariaceae

$\mathrm{EN} B 1+2 \mathrm{C}$

New Caledonia

Small populations occur in maquis shrubland on ultramafic soil in two or three sites on the north-east coast. They are completely unprotected in a wellpopulated area. Fire and mining activities are also causes for concern.

Assessor: SSC Conifer Specialist Group

Refs: 10351,12630

\section{Araucaria subulata}

Araucariaceae

LR/cd

New Caledonia

Endemic to New Caledonia, the species is scattered in the ultramafic massifs in the south. It occurs in abundance in submontane forest and is well protected in 
Rivière Bleu Provincial Park and Montagne des Sources Nature Reserve. Threats exist from fire and felling. Assessor: SSC Conifer Specialist Group Refs: 12630

\section{Arbutus canariensis}

Ericaceae

VU D2

Spain (Canary Is.)

Endemic to the islands of Tenerife, Gomera, Hierro and Gran Canaria, this cloud forest tree is known from approximately 10 populations, probably containing no more than 10,000 individuals. Numbers appear to be stable, although declining water availability and fires may affect some areas. The species is listed in government legislation of 1991.

Assessor: Bañares, A. et al.

Refs: 451, 1512, 19022

\section{Arbutus glandulosa}

Ericaceae

LR/cd

Guatemala, Mexico

A species of montane pine-oak forest, occurring from central and southern Mexico to Guatemala. Parts of the range are contained within protected areas but most regions have experienced large-scale deforestation.

Assessor: Ramirez-Marcial, N. \& M. González-Espinosa Refs: 19161

\section{Arbutus pavarii}

Ericaceae

VU D2

Libya

A species endemic to the Gebel Akhdar on the coast of Libya. The population range and status are little known at present.

Assessor: World Conservation Monitoring Centre

Refs: 195

\section{Arbutus xalapensis}

Ericaceae

$\mathrm{LR} / \mathrm{cd}$

Guatemala, Mexico

A species of montane pine-oak forest, occurring from central and southern Mexico to Guatemala. Parts of the range are contained within protected areas but most regions have experienced large-scale deforestation.

Assessor: Ramirez-Marcial, N. \& M. González-Espinosa Refs: 19161

\section{Archidendron forbesii}

Leguminosae

VU $B 1+2 c$

Papua New Guinea

A late secondary tree scattered in lowland rainforest; it is confined to the Central Province. The species is threatened by habitat destruction from felling and urban expansion.

Assessor: Eddowes, P.J.

Refs: 19114

\section{Archidendron oblongum}

Leguminosae

Solomon Islands (South Solomon)

VU B $1+2 c$

Endemic to the Solomon Islands, this large tree is restricted to lowland rainforest in alluvial valleys. It is traditionally utilised as a timber for construction and fuel.

Assessor: World Conservation Monitoring Centre Refs: 16292,16612

\section{Archidendron pahangense}

Leguminosae

Malaysia (Peninsular Malaysia)

LR/cd

Confined to the Genting Highlands, the species is found in hill rainforest on sandstone between 600 and $1500 \mathrm{~m}$. There are pressures of increasing settlement and tourism development in the area, but a degree of protection is given to populations under the permanent forest estate.

Assessor: Chua, L.S.L.

Refs: 19073

\section{Archidendropsis glandulosa}

Leguminosae

VU B $1+2 c$

New Caledonia

A relatively widespread species, occurring in various habitat types, thicket, maquis or gallery forest on rocky ultramafic soils. Various threats exist from fires, mining and agricultural encroachment.

Assessor: Jaffré, T. et al.

Refs: 10351,12630

\section{Archidendropsis lentiscifolia}

Leguminosae

VU B $1+2 c$

New Caledonia

The species occurs in a few localities in the north-west of Grand Terre in maquis on ultramafic substrate. It is nowhere protected and the habitat is exposed to threats from fires, mining and clearance.

Assessor: Jaffré, T. et al.

Refs: 10351,12630

\section{Archidendropsis paivana}

Leguminosae

New Caledonia

VU C2a

The species can be divided into three subspecies, which take up distributions in the north-west, north-east and southem regions of Grand Terre, including some of the neighbouring islands. All forms occur largely in rainforest on ultramafic soils and are exposed to threats from fire, mining activities and habitat clearance or degradation.

Assessor: Jaffré, T. et al.

Refs: 10351,12630

\section{Archontophoenix myolensis}

Palmae

Australia (Queensland)

VU C2a

Restricted to an altitudinal range of 350 to $400 \mathrm{~m}$, the species occurs in riverine rainforest on metamorphic rocks in the Myola area and Black Mountain in the Kuranda range. The total population is estimated to contain 400 to 500 mature trees and remains unprotected. Regeneration is good.

Assessor: Dowl, J.L.

Refs: 19118

\section{Arctostaphylos catalinae}

Ericaceae

VU D2

USA (Califomia)

A shrub or small tree endemic to Catalina Island. Assessor: World Conservation Monitoring Centre Refs: 19033

\section{Ardisia alstonii}

Myrsinaceae

Panama

VU A2c

The species occurs principally as a shrub, in areas of semi-deciduous rainforest up to $1100 \mathrm{~m}$ in three provinces in the east of Panama, including Chiriquí near 
the border with Costa Rica. The habitat is declining under increasing human activities, logging, agriculture and farming.

Assessor: Mitré, M.

Refs: 16772

\section{Ardisia amplexicaulis}

Myrsinaceae

$\mathrm{EN} \mathrm{Bl}+2 \mathrm{c}$

India (Kerala)

A poorly known species, occurring as a small tree in submontane evergreen forest in the Western Ghats. Only two imprecise collections exist, one from the Agastyamalai Hills and the other from the Wayanad area.

Assessor: World Conservation Monitoring Centre Refs: 19144

\section{Ardisia antonensis \\ Myrsinaceae \\ Panama}

DD

The species has been collected only once from the province of Cocle. No further records have been made, but many more collections from the family await identification.

Assessor: Mitre, M.

Refs: 7272, 7980, 14873, 16772

\section{Ardisia blatteri}

Myrsinaceae

$\mathrm{EN} \mathrm{B} 1+2 \mathrm{c}$

India (Kerala, Tamil Nadu)

Known from just two collections, the species occurs in submontane evergreen forest at the southern end of the Western Ghats.

Assessor: World Conservation Monitoring Centre

Refs: 19144

\section{Ardisia brittonii}

Myrsinaceae

EN B $1+2 c$

Jamaica

A small tree endemic to St Thomas Parish. Forest areas in the parish have almost completely disappeared or are severely degraded.

Assessor: World Conservation Monitoring Centre

Refs: $401,7980,19116$

\section{Ardisia byrsonimae}

Myrsinaceae

Jamaica

The species is known from a single locality in Peckham Woods, Clarendon, where it occurs on a rocky limestone hilltop at about $760 \mathrm{~m}$.

Assessor: Kelly, D.L.

Refs: 5653,19085

\section{Ardisia chiriquiana \\ Myrsinaceae}

DD

Panama

Only two records of the species have been made since the type specimen was collected from Cerro Pate Macho in Chiriqui Province. All records come from the same region. Although it would be possible tentatively to evaluate the species status as Critically Endangered, it may not be appropriate given that the species described by Lundell are frequently identified as synonyms.

Assessor: Mitré, M.

Refs: 16772

\section{Ardisia colonensis}

Myrsinaceae

$\mathrm{EN} \mathrm{B} 1+2 \mathrm{bd}$

Panama

A scarce species of lowland moist open forest, known only from a few collections in the region of Santa Rita in Colón Province. The area is relatively well studied. It is also unprotected and has experienced an influx of people over recent years, resulting in the loss of a large part of the forest.

Assessor: Mitré, M.

Refs: 16772

\section{Ardisia darienensis}

Myrsinaceae

DD

Panama

Collections have been made only in Darien, the type collection coming from Darién National Park.

Assessor: Mitré, M.

Refs: 16772

\section{Ardisia dukei}

Myrsinaceae

$\mathrm{EN} \mathrm{B} 1+2 \mathrm{c}$

Panama

The species has been found only in Darién Province, where it is present in reasonable numbers in Cerro Pirre within Darién National Park.

Assessor: Mitré, M.

Refs: 7980,16772

\section{Ardisia eugenioides}

Myrsinaceae

$\mathrm{EN} \mathrm{B1+2c}$

Panama

Known under the genus Ardisia in Panama, this species is confined to cloud forest between 2000 and $2600 \mathrm{~m}$ in Fortuna Forest Reserve and its vicinity in Gualaca, Chiriqui Province. It is known only from a few collections and appears to be particularly sparse outside the reserve boundaries, where the growth in ranching and agriculture has caused considerable habitat loss.

Assessor: Mitré, M.

Refs: 16772

\section{Ardisia furfuracella}

Myrsinaceae

VU Cl

Costa Rica, Panama

In Panama the species is known only from the Cordillera Central in the province of Chiriquí, where it occurs sparsely in various open forest and scrub types up to $1900 \mathrm{~m}$, including areas opened up by ranching. It is a relatively common plant within a restricted area of Corcovado National Park in Puntarenas, Costa Rica. This is the only population which is protected.

Assessor: Mitré, M

Refs: $7272,7980,14873,16772$

\section{Ardisia geniculata}

Myrsinaceae

DD

Panama

Known only from the type specimen dated 1940, the species was collected from an area which is now a banana plantation. However, it is probable that the taxon represents a variation of another species.

Assessor: Mitré, M.

Refs: $7272,7980,14873,16772$ 


\begin{abstract}
Ardisia glomerata
Myrsinaceae

Panama

All collections of the species come from two neighbouring localities in the Valle de Antón in Coclé Province. It is a relatively common component of undisturbed cloud forest between 600 and $1000 \mathrm{~m}$. This area of forest is gradually disappearing through encroachment and, although at present unprotected, is being considered for designation as a protected area.

Assessor: Mitré, M.
\end{abstract}

Refs: $7272,7980,14873,16772$

\section{Ardisia hagenii}

Myrsinaceae

Panama

The species has been collected only once from the province of Chiriquí in 1940.

Assessor: Mitré, M.

Refs: $7272,7980,14873,16772$

\section{Ardisia jamaicensis}

Myrsinaceae

VU B $1+2 c$

Jamaica

Known only from localities in Westmoreland, Hanover and St James, the species is infrequent and generally confined to rocky limestone hilltops.

Assessor: World Conservation Monitoring Centre Refs: 6057,7980

\section{Ardisia jefeana \\ Myrsinaceae}

VU C2a

Panama

A cloud forest species, occurring commonly in the Cordillera de Cerro Jefe, including the Cerro Azul, and in the Serrania de Pirre, very close to the border with Colombia. Much of the species range coincides with either Chagres National Park or Darién National Park.

Assessor: Mitré, M.

Refs: 16772

\section{Ardisia martinensis}

Myrsinaceae

VU D2

Peru

Known only from the type collection, the species is found in *terra firme forest in San Martin.

Assessor: World Conservation Monitoring Centre Refs: 1984

\section{Ardisia maxonii}

Myrsinaceae

LR/nt

Costa Rica, Panama

Usually known under the genus Ardisia, the species occurs in the Cordillera de Talamanca in south-east Costa Rica and westem Panama, where it is fairly common in areas of closed and open rainforest above $800 \mathrm{~m}$. There are protected populations in La Amistad National Park and in the Valle de Antón in Panama. Large populations also occur in Boquete and Volcán in Chiriqui, Panama, but these are diminishing because of agricultural development.

Assessor: Mitré, $\mathbf{M}$.

Refs: 16772

\section{Ardisia microcalyx}

Myrsinaceae

$\mathrm{EN} \mathrm{B} 1+2 \mathrm{~b}$

Panama

Endemic to the mountains of Chiriqui Province, the species appears to be fairly frequent but confined to a small area of forest between 800 and $1100 \mathrm{~m}$. The area is becoming extensively converted to agriculture and pastoralism. It is supposed that the species will be found in neighbouring protected areas, Volcán Barú National Park and Fortuna Forest Reserve.

Assessor: Mitré, M.

Refs: $7272,7980,14873,16772$

\section{Ardisia nigrovirens}

Myrsinaceae

LR/nt

Peru

A Peru endemic, occurring in lowland Amazonian forest in Huánuco, Loreto and Madre de Dios.

Assessor: World Conservation Monitoring Centre

Refs: 1984

\section{Ardisia opaca}

Myrsinaceae

LR/nt

Colombia, Costa Rica, Panama

Occurring in various forest types over a wide altitudinal range, the species exists in sparsely scattered populations, except in Chiniqui Province, Panama, where it appears to be relatively common. In Santa Rita, Colón Province, Panama, the population is threatened by extensive forest clearance. There are also records of occurrences in Coto Brus in Costa Rica and in the Choco in Colombia.

Assessor: Mitré, M.

Refs: $7272,7980,14873,16772$

\section{Ardisia panamensis \\ Myrsinaceae}

VU B1+2c

Panama

Originally known only from the type collection from Cerro Hoqueta, the species name has now been attached to a number of previously unidentified herbarium collections from the same region. The species occurs between 2000 and $2300 \mathrm{~m}$ in cloud forest. There are populations recorded in Fortuna Forest Reserve and Volcán Barú National Park.

Assessor: Mitré, M.

Refs: $7272,7980,15310,16772$

\section{Ardisia premontana}

Myrsinaceae

VU D2

Ecuador, Peru

A tree currently known only from two collections from the lower eastern slopes of the Andes at the rim of the Amazon basin. The type was collected in central Peru and the other specimen is from southem Ecuador. The area is botanically undercollected.

Assessor: World Conservation Monitoring Centre

Refs: 1984,2909

\section{Ardisia rufa \\ Myrsinaceae}

Panama

EN C2a

Originally collected from Cerro Punta in Chiriquí Province, the species is known from few other collections in the same region and from Cerro Azul in Panamá Province. Although no further occurrences have been identified, it is possible that populations exist in the Cordillera Central in between these two areas. It occurs in moist evergreen forest from 800 to $2500 \mathrm{~m}$ and appears to be uncommon.

Assessor: Mitré, M.

Refs: 16772 
Ardisia scheryi

Myrsinaceae

EN C2a

Panama

Endemic to the Cordillera Central, the species is known only from a few records, all originating from highaltitude forest in the province of Chiriqui. It is possible the species range is more extensive but current information suggests the species is rare and restricted in range.

Assessor: Mitre, M.

Refs: $7272,7980,14873,16772$

\section{Ardisia scortechini}

Myrsinaceae

DD

Malaysia (Peninsular Malaysia)

A small, rare tree of lowland rainforest.

Assessor: Chua, L.S.L.

Refs: 8464, 19073

\section{Ardisia sonchifolia}

Myrsinaceae

EN B $1+2 c$

India (Kerala)

Probably also extending into Tamil Nadu, the species has only been collected from scattered localities of submontane forest in the Anamalai Hills. A single occurrence is also recorded further south nearer the Travancore range.

Assessor: World Conservation Monitoring Centre

Refs: 19144

\section{Ardisia squamulosa}

Myrsinaceae

VUAlcd

Philippines

An endemic species to the Philippines. Rates of habitat loss through logging and shifting cultivation have led to considerable population declines.

Assessor: World Conservation Monitoring Centre

Refs: 2072,4919

\section{Ardisia subsessilifolia}

Myrsinaceae

VU B $1+2 \mathrm{c}$

Panama

Occurring in cloud forest above $1500 \mathrm{~m}$, the species is known from various localities in the Cordillera Central and the mountains which divide the provinces of Chiriqui and Bocas del Toro. It occurs in Volcán Barú National Park and a small part in the south-east of La Amistad National Park.

Assessor: Mitré, M.

Refs: $7272,7980,14873,16772$

\section{Ardisia urbanii}

Myrsinaceae

VU B $1+2 c$

Jamaica

An uncommon tree confined to woodland on limestone in Trelawny.

Assessor: World Conservation Monitoring Centre

Refs: $401,5653,7980$

\section{Ardisia websterii}

Myrsinaceae

$\mathrm{LR} / \mathrm{cd}$

Ecuador

This small understorey tree is locally common in montane rainforest along streams, apparently only in the Maquipucuna Forest Reserve.

Assessor: World Conservation Monitoring Centre Refs: 2909

\section{Ardisia zakii}

Myrsinaceae

VU D2

Ecuador

This tree is known only from the type collection from remnant cloud forest on steep slopes. Road construction in the area has been responsible for the removal of a considerable area of forest.

Assessor: World Conservation Monitoring Centre Refs: 2909

\section{Areca andersoni}

Palmae

Brunei, Indonesia (Kalimantan), Malaysia (Sarawak)

A solitary palm of lowland moist forest, often occurring in limestone crevices. A single collection is also recorded in Brunei.

Assessor: Dransfield, J.

Refs: 19118

\section{Areca chaiana}

Palmae

Indonesia (Kalimantan), Malaysia (Sarawak)

A single-stemmed palm of lowland moist forest, often located near river banks, on slopes or in open areas. It is known to occur in the Entiman-Lanjak Wildlife Sanctuary, and is in cultivation at Semengoh Arboretum near Kuching, Sarawak, Forest management activities are affecting some areas within the species range.

Assessor: Dransfield, J.

Refs: 19118

\section{Areca concinna}

Palmae

EN Alc

Sri Lanka

Endemic to Sri Lanka, this small clustering palm tree is restricted to lowland rainforest. Its habitat is threatened by the expansion of human habitation. The seeds are used locally as a betel nut substitute.

Assessor: Johnson, D.

Refs: 19118

\section{Areca glandiformis}

Palmae

DD

Indonesia (Moluccas)

An endemic palm tree of the Moluccas, occurring in lowland forest. Although it is likely to be threatened by increasing agriculture and forest management activities, more fieldwork is needed to assign a category.

Assessor: Johnson, D.

Refs: 19118

\section{Areca guppyana}

Palmae

Solomon Islands

A small palm tree of primary forest, endemic to the Solomon Islands, where it is under threat from logging, increasing agriculture and mining. Trees are planted in sacred places and cemeteries.

Assessor: Dowl, J.L.

Refs: 19118

\section{Areca hutchinsoniana}

Palmae

LR/nt

Philippines

A poorly known species found in only a few localities of primary forest at low altitude in Mindanao.

Assessor: Madulid, D.

Refs: 19118 
Areca ipot

Palmae

Philippines

A species of streamsides and forest at low to medium altitude. It is confined to southern Luzon and is of significant importance as an omamental.

Assessor: Madulid, D.

Refs: 19118

\section{Areca macrocarpa}

Palmae

Philippines

Very scanty information is available on the species. It may be a variety of $A$. catechu. Populations appear to be confined to lowland rainforest in Zambanga, Mindanao. Assessor: Madulid, D.

Refs: 19118

\section{Areca parens}

Palmae

VU Alc

Philippines

A species of lowland rainforest, occurring along streamsides, only in Camarines Province in Luzon. The area is strongly affected by slash and bum agriculture.

Assessor: Madulid, D.

Refs: 19118

\section{Areca whitfardii}

Palmae

VUAlc

Philippines

There are two varieties, var. whitfordii and var. luzonensis, based on the size of the fruit. The species occurs in several localities in Luzon and Mindoro in areas of semi-swampy forest at low altitude. Slash and bum agriculture affects most localities.

Assessor: Madulid, D.

Refs: 19118

\section{Arenga listeri}

Palmae

VU D2

Christmas Island

Endemic to Christmas Island, this palm tree is scattered in lowland rainforest on plateaux and terraces. Christmas Island is only $140 \mathrm{~km}^{2}$ and phosphate mining is a major threat to all of the native flora. The species, which has only one flowering phase during its life cycle, is further threatened by seed-predating crabs which limit the potential for regeneration.

Assessor: Johnson, D.

Refs: 19118

\section{Arenga wightii}

Palmae

VU B1+2c

India (Karnataka, Kerala, Tamil Nadu)

A monocarpic palm of dense forest, occurring on slopes between 150 and $1000 \mathrm{~m}$. It is threatened by logging activities and increasing settlement and agriculture.

Assessor: Johnson, D.

Refs: 19118

\section{Aristeguietia arborea \\ Compositae}

VU $B I+2 c$

Ecuador

A tree species which is endemic to the High Andes of Ecuador.

Assessor: World Conservation Monitoring Centre

Refs: 19119,19120
Aristeguietia discolor

Compositae

LR/nt

Peru

A widespread species of *elfin forest and shrublands, endemic to the Peruvian Andes between 2000 and $4000 \mathrm{~m}$.

Assessor: World Conservation Monitoring Centre Refs: 1984

\section{Aristogeitonia monophylla}

Euphorbiaceae

VU B I + 2b

Kenya, Tanzania

Restricted to patches of dry forest or thicket on coral or limestone, the species ranges from south-east Kenya into north-east Tanzania in the Pangani River basin. There are two other species in the genus, occurring in Angola and Madagascar.

Assessor: Lovett, J. \& G.P. Clarke

Refs: $2074,3356,6396,9198$

\section{Arthrocarpum gracile}

Leguminosae

VU D2

Yemen (Socotra)

A small tree or shrub which occurs relatively commonly in lowland and submontane woodland. It is an important cattle browse.

Assessor: Miller, A.G.

Refs: 2354, 19083

\section{Arthrophyllum montanum}

Araliaceae

LR/cd

Malaysia (Peninsular Malaysia)

A small tree of moist montane rainforest in Terengganu, Kelantan, Pahang and Kedah (Gunung Jerai).

Assessor: Chua, L.S.L.

Refs: 8464,19073

\section{Arthrophyllum proliferum}

Araliaceae

VUD2

Papua New Guinea

Known only from two collections, this medium-sized tree is confined to submontane rainforest on steep slopes in the Kuper range, Morobe District.

Assessor: World Conservation Monitoring Centre

Refs: 19031

\section{Arthrophyllum pulgarense}

Araliaceae

VU B1 $+2 c, D 2$

Philippines

Endemic to Palawan, the species is found on the upper part of Mount Pulgar at about $1200 \mathrm{~m}$. The main island is declared a biosphere reserve.

Assessor: World Conservation Monitoring Centre Refs: 4986

\section{Artocarpus blancoi}

Moraceae

Philippines

This species of lowland seasonal forest and thicket is used for timber and the production of pulp and paper.

Assessor: World Conservation Monitoring Centre Refs: 4919, 12937

\section{Artocarpus hypargyreus}

China (Fujian, Guangdong, Guangxi, Hunan, Jiangxi, Yunnan)

A timber species which occurs in broadleaved deciduous 
woodland up to $1300 \mathrm{~m}$. Population numbers have declined because of overexploitation and habitat loss. Assessor: Sun, W.

Refs: 1818,19055

\section{Antocarpus nobilis}

Moraceae

Sri Lanka

A tree restricted to lowland rainforest in south-west Sri Lanka.

Assessor: World Conservation Monitoring Centre

Refs: 15431, 17195

\section{Artocarpus rubrovenus}

\section{Moraceae}

Philippines

VU Ald

A lowland forest species which yields keledang timber used for light construction.

Assessor: World Conservation Monitoring Centre

Refs: $4919,11145,12937$

\section{Artocarpus treculianus}

Moraceae

Philippines

VU Ald

A valuable source of keledang timber, this species occurs in lowland forest.

Assessor: World Conservation Monitoring Centre

Refs: $4919,11145,12937$

\section{Arytera nekorensis}

Sapindaceae

VU B $1+2 c$

New Caledonia

Assessor: Jaffré, T. et al.

Refs: 10351

\section{Asimina tetramera}

Annonaceae

EN C2a

USA (Florida)

A large shrub or small tree of scrub vegetation, occurring near the Atlantic coast in Jonathan Dickinson State Park, a Palm Beach County park and several privately owned areas. The total population consists of about 500 plants. The plant is adapted to disturbance, in the absence of which it becomes shaded out by oaks and pines. Although protected in Jonathan Dickinson State Park, elsewhere stands have become confined and scattered as the habitat has been cleared for commercial and residential development. The species is protected by the US Endangered Species Act.

Assessor: World Conservation Monitoring Centre

Refs: $7078,8400,19167$

\section{Aspidosperma curranii}

Apocynaceae

VU B1+2de

Colombia, Panama

Most records of the species come from Darien National

Park, where small populations occur in lowland evergreen forest. There is little human or other impact here, although some small clearings have been made for cultivation. An occurrence is also reported from the Urabá region in Columbia.

Assessor: Mitré, M.

Refs: $4217,15037,16772$

\section{Aspidosperma darienense}

Apocynaceae

EN C2a

Panama

Occurring in lowland evergreen rainforest, the species is

known only from the Panama side of the Colombia-
Panama border. Although the entire population is contained within protected areas, it is restricted in range and numbers, particularly of larger individuals.

Assessor: Mitré, $\mathrm{M}$.

Refs: $7272,7980,16772$

\section{Aspidosperma megalocarpon}

Apocynaceae

LR/nt

Belize, Colombia, Ecuador, El Salvador, Guatemala, Honduras, Mexico, Nicaragua, Panama, Suriname, Venezuela

A common canopy tree of lowland seasonal rainforest. The timber is exploited on a small scale. General habitat losses have been considerable in the last 50 years. Populations are considered threatened at a national level in Ecuador, Mexico and throughout Central America. Assessor: World Conservation Monitoring Centre Refs: $3917,7140,11449,15037,19161$

\section{Aspidosperma polyneuron}

Apocynaceae

EN A lacd $+2 \mathrm{~cd}$

Argentina (Misiones), Bolivia, Brazil, Colombia Paraguay, Peru

Peroba rosa is a popular timber tree, which has suffered intense exploitation anc habitat loss over the past few decades. The Brazilian populations are largely eroded. Populations in Colombia are seriously threatened. In Paraguay, the species was relatively recently described as one of the dominant components of some areas of forest, but here too rapid population declines have resulted in the species being hard to find and no longer commercially viable to exploit. In Argentina the species is rare and confined to the north of Misiones.

Assessor: Americas Regional Workshop

Refs: $4217,4506,5112,7980,19069,19179,19210$

\section{Aspidosperma triternatum}

Apocynaceae

LR/nt

Argentina, Paraguay

The species is restricted to lowland dry forest in the Chaco of Argentina and neighbouring Paraguay. The species range may be extensive but the ecosystem is susceptible to damage caused by human activities. Assessor: World Conservation Monitoring Centre Refs: 1262,7980

Asteranthe asterias ssp. asterias

Annonaceae

VU B $1+2 b$

Kenya, Tanzania

This subspecies appears to be relatively widely spread along the Kenyan coast down through Tanzania to Zanzibar. It occurs in dry forests and Brachystegia woodland.

Assessor: Lovett, J. \& G.P. Clarke

Refs: 3356, 10961

Asteranthe asterias ssp. triangularis

Annonaceae

VU B $1+2 b$

Tanzania

An endemic to the East Usambaras, the species is confined to patches of forest and also evergreen bushland on Sindeni Hill.

Assessor: Lovett, J. \& G.P. Clarke

Refs: 3356,9302 


\section{Asteranthos brasiliensis}

Lecythidaceae

$\mathrm{LR} / \mathrm{nt}$

Brazil (Amazonas), Colombia, Venezuela

A species which grows quite abundantly, but only in flooded forest in the upper Rio Negro.

Assessor: Pires O'Brien, J.

Refs: $1503,7980,9632$

\section{Asterogyne spicata}

Palmae

VU BI+2c

Venezuela

A palm tree of lowland rainforest, restricted to Guatopo National Park and Cerro Bachiller of Miranda State. Increasing settlement has caused habitat losses in some areas. No reports exist of occurrences elsewhere in suitable habitat types.

Assessor: Stauffer, F.

Refs: 19118

\section{Asterogyne yaracuyense}

Palmae

CR Alc, B1+2c, C1

Venezuela

A small palm, up to $5 \mathrm{~m}$ tall, restricted to cloud forest on the mountain ridge of Santa Maria and on La Chapa ridge in Yaracuy state. Two years ago, a team from the Herbario Nacional de Venezuela visited this area and found a massive deterioration of the habitat mainly due to agriculture and logging. This tree was not found in any of the neighbouring cloud forests and is presumed to have a very restricted distribution.

Assessor: Stauffer, F.

Refs: 19118

\section{Asterophorum mennegae}

Tiliaceae

VU D2

Suriname

This small tree of evergreen seasonal forest is known from just two collections. The type specimen was gathered from a forest island in the Sipaliwini Savanna. Assessor: World Conservation Monitoring Centre Refs: 7951

\section{Astrocaryum alatum}

Palmae

LR/nt

Costa Rica, Nicaragua, Panama

A small palm tree common in the fragmented lowland rainforest found along the Atlantic coast. The main threat is the expansion of human habitation. It is possibly conspecific with $\boldsymbol{A}$. alatum.

Assessor: Henderson, A.

Refs: 19118

\section{Astrocaryum minus}

Palmae

CR D1

Brazil (Amazonas), French Guiana

An extremely rare single-stemmed palm of $2-5 \mathrm{~m}$ height.

The species occurs in the western Amazon basin and more recently two individuals were discovered on the Mont Grand Maroury, near Cayenne, French Gujana. The principal threats to remaining individuals are fire and logging.

Assessor: de Granville, J.J

Refs: 19118

\section{Astrocaryum triandrum}

Palmae

$\mathrm{EN} \mathrm{B} 1+2 \mathrm{c}$

Colombia

A lowland rainforest palm, which occurs on alluvial plains or gentle slopes. Its distribution is currently restricted to forest fragments in the middle Magdalena River valley. The timber is harvested for local use. The main threats come from increasing agriculture and forest management.

Assessor: Bernal, R.

Refs: 19069,19118

\section{Astronidium degeneri}

Melastomataceae

VU D2

Fiji

A shrub or tree often occurring in dry forest or forest edges along watercourses up to $900 \mathrm{~m}$. It is so far known from a few collections from western Viti Levu. Assessor: World Conservation Monitoring Centre Refs: $5515,6053,18818$

\section{Astronidium floribundum}

Melastomataceae

CR D 1

Fiji

A small tree known only from the type collection, which was gathered in 1927 from the south-eastem slope of Mount Korombamba on Viti Levu.

Assessor: World Conservation Monitoring Centre

Refs: $5515,6053,18818$

\section{Astronidium inflatum}

Melastomataceae

CR D1

Fiji

Known only from Vanua Levu, the species occurs in dense forest or thickets on crests or open hillsides between 700 and $1030 \mathrm{~m}$. Only a few sites are known, each containing about 12 plants.

Assessor: World Conservation Monitoring Centre

Refs: $5515,6053,18818$

\section{Astronidium kasiense}

Melastomataceae

CR D1

Fiji

The single collection known was gathered in 1934 on Mount Kasi in dense forest between 300 and $430 \mathrm{~m}$. The area has been exposed to mineral exploitation and the species may now be extinct.

Assessor: World Conservation Monitoring Centre Refs: $5515,6053,18818$

\section{Astronidium lepidotum}

Melastomataceae

CR D1

Fiji

A poorly known species, collected twice from the same locality in forest below $200 \mathrm{~m}$ near the copper mine at Waimaro River, Viti Levu. It has not been seen since 1964.

Assessor: World Conservation Monitoring Centre Refs: 5372, 5515, 6053, 18818

\section{Astronidium macranthum}

Melastomataceae

LR/nt

Fiji

Known from Viti Levu and Vanua Lev, the species occurs dry forest or forest edges up to $900 \mathrm{~m}$. Assessor: World Conservation Monitoring Centre Refs: $5515,6053,18818$

\section{Astronidium ovalifolium}

Melastomataceae
The species is known only from Raiatea.

Assessor: Florence, J.

Refs: 14513 


\section{Astronidium pallidiflorum}

Melastomataceae

Fiji

Known only from the type collection, the species is confined to an area of dense forest, between 50 and $150 \mathrm{~m}$, in the hills west of Waivunu Creek, Viti Levu. It has not been seen since 1953.

Assessor: World Conservation Monitoring Centre

Refs: $5515,6053,18818$

\section{Astronidium saulae \\ Melastomataceae \\ Fiji}

CR D1

A slender tree localised in dense lowland forest at two sites on Viti Levu. One site of 27 plants on the southern slopes of Mount Korombamba was logged in 1980 but appears to be regenerating. The other site, consisting of 20 plants within an area of $10 \times 20 \mathrm{~m}$, exists at Navua. Assessor: World Conservation Monitoring Centre

Refs: $5515,6053,15965,18818$

\section{Astronidium storckii}

Melastomataceae

$\mathrm{LR} / \mathrm{nt}$

Fiji

Except for the type collection at Ovalau, the species is known only from Viti Levu. It has been collected in dense forest and thickets on crests and ridges between 30 and $1153 \mathrm{~m}$.

Assessor: World Conservation Monitoring Centre

Refs: $5515,6053,18818$

\section{Astronidium tomentosum}

Melastomataceae

LR/nt

Fiji

Relatively rarely collected, this shrub or small tree is found in thickets on crests and summits, between 600 and $1200 \mathrm{~m}$. It occurs in a restricted area of Namosi

Province in Viti Levu.

Assessor: World Conservation Monitoring Centre

Refs: $5515,6053,18818$

\section{Astronium urundeuva}

Anacardiaceae

Argentina (Jujuy, Salta), Bolivia, Brazil (Bahia, Goiás, Maranháo, Mato Grosso, Minas Gerais, Piaui, São Paulo), Paraguay

A dominant component of *caatinga, also occurring widely in *cerrado. It is commercially overexploited for the decay-resistant dense wood. Large natural stands have become scarce in places. All size classes are exploited for a variety of uses: small trees for fencing and larger trees for railroad ties, posts and other construction work. Some taxonomists still refer to the species under the small genus Myracrodruon.

Assessor: Prado, D.

Refs: $1262,4506,5112,11936,12837,13686,14291$, 15539, 19170

\section{Atalaya capensis}

Sapindaceae

LR/cd

South Africa (Eastem Cape)

A small tree found in forest and bush, often on steep wooded hill slopes, in the vicinity of Port Elizabeth and supposedly further eastwards in the Transkei, although there are no records to confirm this. It has been recorded from several localities, at least two of which are now contained within protected areas. The extent of occurrence and number of mature trees have declined as a result of habitat loss through the invasion of introduced Acacia species. The funure of the species should be secure provided that an alien eradication programme is maintained.

Assessor: Hilton-Taylor, C. et al.

Refs: 689,19218

\section{Atalaya natalensis}

Sapindaceae

VU D2

South Africa (Eastem Cape, KwaZulu-Natal)

A very scarce tree with a highly scattered distribution in patches of coastal escarpment forest, from near Port St John's in the Transkei, Eastern Cape, northwards to Ngome forest in Zululand, KwaZulu-Natal. It appears to be associated with granite outcrops, but at present is known from only five localities within an area of $100 \mathrm{~km}^{2}$. Although most of the localities are contained within protected areas, the degree of protection afforded to them varies greatly. Uncontrolled activities, particularly cutting for firewood and timber, could rapidly result in the local demise of the species.

Assessor: Hilton-Taylor, C. et al.

Refs: 689,19218

\section{Ateleia gummifero}

Leguminosae

Cuba

EN Alc

An uncommon tree, up to $7 \mathrm{~m}$ tall, occurring in the dry evergreen forests of Matanzas Province and eastern Cuba. Habitat declines have been considerable over the past decades.

Assessor: Areces-Mallea, A.E.

Refs: $9522,16327,19149$

\section{Ateleia popenoei}

Leguminosae

DD

Bahamas

There is little information on this endemic to the Bahamas. There are still substantial areas which remain undeveloped on the islands and the species is not thought to be under threat.

Assessor: World Conservation Monitoring Centre

Refs: 10173,19207

\section{Ateleia salicifolia}

Leguminosae

VU B $1+2 c$

Cuba

A small tree, up to $8 \mathrm{~m}$ tall, confined to the dry forests on the southem slopes of the Escambray mountain range in central Cuba. The habitat is degraded in places and felling or forest clearance is a constant threat.

Assessor: Areces-Mallea, A.E.

Refs: 16327, 18485, 19149

\section{Ateramnus glandulosus}

Euphorbiaceae

VU B1+2c

Cuba, Jamaica

In Cuba this small tree is confined to the deeply eroded haystack mountain ranges of Pinar del Rio Province and the Isla de Pinos.

Assessor: Areces-Mallea, A.E.

Refs: 19118,19149

\section{Ateramnus integer}

Euphorbiaceae

LR/nt

Jamaica

An uncommon species confined to remaining areas of thickets and woodlands on limestone in the central and 
western parishes. General habitat declines have been considerable, mostly caused by increasing agriculture. Assessor: World Conservation Monitoring Centre Refs: 6057,7980

\section{Athrotaxis cupressoides}

Taxodiaceae

LR/nt

Australia (Tasmania)

A widespread taxon, which responds poorly to fires. About $80 \%$ of the population is contained within protected areas. The genus is endemic to Tasmania and comprises three species.

Assessor: SSC Conifer Specialist Group

Refs: $374,13041,17636$

\section{Athrotaxis laxifolia}

Taxodiaceae

LR/nt

Australia (Tasmania)

The existence of this taxon is questioned by Tasmanian botanists, who believe it represents a hybrid of $A$. cupressoides and $A$. selaginoides. It is rarely encountered and occurs only in association with one or other of the latter two species. About $80 \%$ of the population is contained within protected areas. The genus is endemic to Tasmania and comprises three species.

Assessor: SSC Conifer Specialist Group

Refs: 374, 13041, 17636

\section{Athrotaxis selaginoides}

Taxodiaceae

VU Alc

Australia (Tasmania)

Although $83 \%$ of the entire population is contained within protected areas, the species has been observed to decline by $32 \%$ in less than 100 years through the effects of fire. No regeneration is evident after burning. The genus is endemic to Tasmania and comprises three species.

Assessor: SSC Conifer Specialist Group

Refs: 374, 13041, 13789

\section{Athyana weinmannifolia}

Sapindaceae

VU B1+2ac

Argentina, Bolivia

Endemic to the piedmont forest of north-west Argentina and Bolivia, the species is confined to an unprotected ecosystem which is being rapidly replaced by agricultural systems.

Assessor: Prado, D.

Refs: 12837,19122

\section{Atkinsia cubensis}

Malvaceae

EN Alc

Cuba

This tree was formerly common in areas of lowland semi-deciduous forest throughout Cuba. As a result of burning and grazing, the habitat has been largely replaced by secondary savanna.

Assessor: Areces-Mallea, A.E.

Refs: 19118,19149

\section{Attalea crassispatha}

Palmae

CR D1

\section{Haiti}

A palm tree of lowland forest in river valleys, confined to the south-west peninsula of Haiti. In 1996, fewer than 30 individuals were found in two adjacent river valleys. The species is threatened by encroaching agriculture and local exploitation of the edible seeds. It is in cultivation at the Fairchild Tropical Garden, but the mature palms do not flower.

Assessor: Johnson, D.

Refs: 19118,19166

\section{Attalea septuagenata}

Palmae

Colombia

Confined to Rio Miriti-Parana, the species occurs in lowland rainforest. It has previously been listed as endangered according to the old IUCN Red List Categories. However, it has not been possible to attain an accurate reflection of the species abundance and status since it is located in a remote and poorly-visited area.

Assessor: Bernal, $\mathbf{R}$

Refs: 19118

\section{Attalea tessmannii}

Palmae

LR/nt

Brazil (Acre), Peru

Widespread in the western Amazon region, this palm tree grows in lowland *terra firme rainforest. It is possibly of hybrid origin.

Assessor: Henderson, A.

Refs: 19118

\section{Atuna cordata}

Chrysobalanaceae

Malaysia (Sabah)

VU D2

This large tree is locally common on ultramafic soils up to $1200 \mathrm{~m}$. It is endemic to Sabah.

Assessor: World Conservation Monitoring Centre

Refs: 19017

\section{Atuna elliptica}

Chrysobalanaceae

Fiji

Endemic to Viti Levu in Fiji, this small tree has been recorded rarely from areas of open forest, often near streams, below $100 \mathrm{~m}$. Trees have a number of uses: the timber is used locally for poles or posts, while the leafy branches can be used as thatch.

Assessor: World Conservation Monitoring Centre Refs: 18818

\section{Atuna indica}

Chrysobalanaceae

India (Tamil Nadu)

EN B $1+2 c$

The species has been recorded only twice from a small area of submontane evergreen forest to the north-west of the Nilgiri range.

Assessor: World Conservation Monitoring Centre Refs: 19144

\section{Atuna penangiana}

Chrysobalanaceae

Malaysia (Peninsular Malaysia)

VU B1+2c

A tree endemic to Peninsular Malaysia, inhabiting lowland and hill rainforest.

Assessor: Chua, L.S.L.

Refs: 5550,19073

\section{Atuna travancorica}

Chrysobalanaceae

India (Tamil Nadu)

$\mathrm{EN} \mathrm{B1}+2 \mathrm{c}$

Collections of the species are concentrated on the Travancore Hills, just to the north of Agastyamalai. There is also a single record of it further north in the 
range. It was noted to be scarce at the tum of the century and few, if any, more recent records have been made, despite the area being relatively well surveyed.

Assessor: World Conservation Monitoring Centre

Refs: $6431,14276,19144$

\section{Aubregrinia taiensis}

Sapotaceae

$\mathrm{CR} \mathrm{B1+2c}$

Côte d'Ivoire, Ghana

Scattered in moist semi-deciduous forest, this large tree is very rare and declining in numbers. In Côte d'Ivoire it is known only from a few specimens in Tai National Park, a World Heritage Site, where its regeneration is observed to be poor. The habitat in both countries has substantially decreased in extent because of logging and agricultural encroachment. It is the sole member of the genus and the only close relative of Breviea, which is also a monotypic genus.

Assessor: Assi, A

Refs: $2773,8854,12061,12822$

\section{Aucoumea klaineana}

Burseraceae VUAled

Cameroon, Congo, Equatorial Guinea, Gabon

Okoumé occurs abundantly in an area covering west and central Gabon and small areas of neighbouring countries. It continues to be Gabon's most important commercial timber. Repeated felling has led to the deterioration of the gene pool in certain areas. There is some concern as to the long-term status of the species.

Assessor: White, L.

Refs: 5595, 13947, 17408, 19043

\section{Auerodendron jamaicense}

Rhamnaceae

VU B $1+2 c$

Jamaica

The species is confined to coastal woodlands on limestone and sand dunes.

Assessor: World Conservation Monitoring Centre Refs: 6057,7980

\section{Auerodendron pauciflorum}

Rhamnaceae

CR D1

Puerto Rico

A small tree from a single site of woodland on a limestone cliff. There are 10 individuals in the population, the majority of which are on land owned by a development company. The trees have not been seen to seed but efforts are being made to cultivate the plant from tissue culture.

Assessor: World Conservation Monitoring Centre

Refs: $3786,7980,17124$

\section{Aulacocalyx pallens ssp. pallens}

Rubiaceae

VU D2

São Tomé \& Príncipe

Rarely collected, the taxon is known from submontane forest in two locations, S. Pedro and S. Nicolau. It is noticeably absent from recent collections, although large areas of Sāo Tomé remain to be explored.

Assessor: World Conservation Monitoring Centre

Refs: 2724

\section{Aureliana fasciculato}

Solanaceae LR/cd

Brazil (Espírito Santo, Minas Gerais, Rio de Janeiro, Rio Grande do Sul, Santa Catarina, Sāo Paulo)

A frequent species of Atlantic coastal vegetation types in the south and south-east. It occurs in a number of protected areas.

Assessor: Carvalho, L.d'A.F.

Refs: 19098, 19103

Austrobuxus cracens

Euphorbiaceae

VU DI

New Caledonia

Assessor: Jaffré, T. et al.

Refs: 10351

\section{Austrobuxus montis-do}

Euphorbiaceae

LR/cd

New Caledonia

Assessor: Jaffré, T, et al.

Refs: 10351

\section{Austrocedrus chilensis}

Cupressaceae

VU Alc

Argentina, Chile (Bíobío, Los Lagos)

A species of submontane woodland and scrub, known to occur in two separate localities in Chile: Antuco in Biobio and further south in Valdivia, Los Lagos, and also over the border in Questrihue in Argentina. Declines in population numbers have been reported, at least in Argentina, caused by logging and habitat loss through fires, grazing and replanting with exotic conifers: $85 \%$ of the Argentinian population occurs outside protected areas and is being actively exploited. Insect predation of the seed is also, apparently, affecting regeneration in the wild and in small plantations. Assessor: SSC Conifer Specialist Group Refs: $374,4893,11147,13041$

\section{Austromyrtus horizontalis}

Myrtaceae

VU B $1+2 c$

New Caledonia

Confined to a few locations in sclerophyllous woodlands the species has experienced the severe reduction and fragmentation of its habitat. It remains ineffectively protected and threatened by fire, grazing and encroaching agriculture.

Assessor: Jaffré, T. et al.

Refs: 4492, 10351

\section{Austromyrtus lotoides}

Myrtaceae

VU B $1+2 c$

New Caledonia

Confined to a few locations in sclerophyllous woodlands the species has experienced the severe reduction and fragmentation of its habitat. It remains ineffectively protected and threatened by fire, grazing and encroaching agriculture.

Assessor: Jaffré, T. et al.

Refs: 4492, 10351

\section{Autranella congolensis}

Sapotaceae

Cameroon, Congo, Gabon, Nigeria

CR Alcd

A relatively rare rainforest species. Heavy exploitation for the timber is the main cause of its decline. The seeds are used locally and traded as rattles for dancers.

Assessor: African Regional Workshop

Refs: $2362,2773,6718,17408$

\section{Avicennia lanato}

Avicenniaceae

VU B1+2c

Malaysia (Peninsular Malaysia)

Found throughout Peninsular Malaysia, this species 
grows in open clusters in moist coastal forest. Tourism and housing developments are this species' greatest threats.

Assessor: Chua, L.S.L.

Refs: $5550,11647,17214,19073$

\section{Axinaea merianiae}

Melastomataceae

VU B $1+2 c$

Ecuador

An endemic of the High Andes in Ecuador, inhabiting cloud forest between $2200 \mathrm{~m}$ and $3715 \mathrm{~m}$ in the provinces of Pichincha, Morona-Santiago, Cañar, Azuay and Loja. Assessor: World Conservation Monitoring Centre Refs: 19119,19120

\section{Axinaea nitida}

Melastomataceae

LR/nt

Peru

Restricted to the departments of Amazonas, Cajamarca and Huánuco, the species occurs at middle elevations in disturbed areas of forest.

Assessor: World Conservation Monitoring Centre Refs: 1984

\section{Axinaea pauciflora}

Melastomataceae

VU B $1+2 \mathrm{c}$

Ecuador

A rare tree species which is endemic to montane forest in the Ecuadorean High Andes.

Assessor: World Conservation Monitoring Centre

Refs: 2989, 6596, 19119, 19120

\section{Axinaea sclerophylla}

Melastomataceae

VU B $1+2 c$

Ecuador

A rare species of tree or shrub, restricted to the High Andes of Ecuador, where it occurs in the montane forest zone.

Assessor: World Conservation Monitoring Centre

Refs: $2989,6596,19119,19120$

\section{Axinaea sessilifolia}

Melastomataceae

VU B $1+2 c$

Ecuador

A rare tree species which is endemic to the High Andes of Ecuador.

Assessor: World Conservation Monitoring Centre

Refs: 2989, 6596, 19119, 19120

\section{Axinandra zeylanica}

Crypteroniaceae

VU Alc

Sri Lanka

A tree occurring in the lowland wet evergreen forests of south-west Sri Lanka.

Assessor: World Conservation Monitoring Centre

Refs: 9176, 17195

\section{Ayenia laevigata var. acuminata}

Sterculiaceae

EN B $1+2 c$

Jamaica

A variant of a Jamaican endemic. It grows largely as a shrub, in thickets on rocky limestone hillsides in Trelawny.

Assessor: World Conservation Monitoring Centre Refs: 401, 7980
Ayenia laevigata var. laevigata

Sterculiaceae

VU Bl+2c

Jamaica

The type variety of a shrubby endemic, which is confined to remnants of dry lowland thicket and woodland on limestone in St Andrew and St Thomas Parishes. Almost all forest areas have been deforested or severely degraded.

Assessor: Bellingham, $\mathrm{P}$.

Refs: $401,7980,19116$

\section{Baccaurea glabrifolia}

Euphorbiaceae

VU B $1+2 c$

Philippines

An endemic tree of Palawan, found on forested slopes at low altitude. The main island is declared a biosphere reserve.

Assessor: World Conservation Monitoring Centre.

Refs: 4986

\section{Baccaurea hookeri}

Euphorbiaceae

Malaysia (Peninsular Malaysia), Singapore

LR/cd

A rare species of lowland rainforest, recorded from Perak and Johore in Peninsular Malaysia.

Assessor: Kochummen, K.M.

Refs: $9199,17140,19073$

\section{Baccaurea latifolia}

Euphorbiaceae

LR/cd

Malaysia (Peninsular Malaysia), Singapore

A lowland rainforest species, which has been rarely collected. In Peninsular Malaysia it is known from Terengganu and Perak.

Assessor: Kochummen, K.M.

Refs: 9199, 19073

\section{Baccaurea odoratissima}

Euphorbiaceae

VU B $1+2 c$

Philippines

An endemic tree of Palawan, found on forested slopes at low altitude. The main island is declared a biosphere reserve.

Assessor: World Conservation Monitoring Centre Refs: 4986

\section{Baccaurea polyneura}

Euphorbiaceae

Malaysia (Peninsular Malaysia)

Records of the species come from Perak and Melaka.

Assessor: Kochummen, K.M.

Refs: 19073

\section{Bactris coloniate}

Palmae

VU B $1+2 c$

Colombia, Panama, Peru

Occurring in lowland dry forest, the species is mainly threatened by the loss and degradation of its habitat through forest management activities, increasing agriculture and settlement.

Assessor: Bernal, R.

Refs: 19118

\section{Bactris jamaicana}

Palmae

VU A2c

Jamaica

Restricted to John Crow Mountain and Cockpit Country, this rare palm tree grows in submontane rainforest 
between 300 and $750 \mathrm{~m}$. The species can survive forest degradation and destruction and is reputed to grow in pastures.

Assessor: Johnson, D.

Refs: 19118

\section{Bactris longiseta}

Palmae

VU A2c

Costa Rica

A small palm tree of lowland rainforest, occurring up to $1000 \mathrm{~m}$ in Alajuela, Heredia and Limón. The species is scarce and threatened by habitat destruction and disturbance.

Assessor: Johnson, D.

Refs: 19118

\section{Bactris nancibensis}

Palmae

CR DI

French Guiana

A small multi-stemmed palm found in the understorey of swamp forest. Only two specimens are known: occurring south of the Cayenne area. One has been transplanted to Orstom Botanical Garden, where it has been observed to flower. The other specimen is located close to a road where it may come under threat from logging activities or clearing for settlement and agriculture.

Assessor: de Granville, J.J

Refs: 19118

\section{Bactris pickelii}

Palmae

VU Alc

Brazil (Alagoas, Bahia, Espírito Santo, Paraíba, Pernambuco, Sergipe)

A small palm tree, up to $2.5 \mathrm{~m}$ tall, scattered in lowland Atlantic rainforest and *restinga up to $500 \mathrm{~m}$. Populations have been greatly reduced because of building work and plantation agriculture near the coast. The species does not survive outside the rainforest.

Assessor: Noblick, L.

Refs: 19118

\section{Bactris setuloso}

Palmae

LR/nt

Colombia, Ecuador, Peru, Trinidad and Tobago,

Venezuela

A widely occurring palm tree of rainforest up to $1700 \mathrm{~m}$. It occurs in many areas which have been subject to habitat clearance.

Assessor: Henderson, A.

Refs: 19118

\section{Badula crassa}

Myrsinaceae

Mauritius, Réunion

CR Cl, D1

A treelet known from two sites of rocky sclerophyllous woodland, one in Tourelle du Tamarin Mountain in the south-west and the other, only recently discovered, in Yemen. Neither population consists of more than 10 individuals. There has not been any seed production and propagation by cuttings has failed. Information is lacking on the population on Reunion.

Assessor: Page, W.

Refs: $1411,9120,16426$
Badula platyphylla

Myrsinaceae

EX

Mauritius

A cloud forest tree once known from the Savanne and Mount Cocotte range. Recent searches for the species throughout its known range have failed to uncover any individuals.

Assessor: Page, W.

Refs: $1411,9120,16426$

\section{Badula reticulata}

Myrsinaceae

CR D1

Mauritius

Just five individuals appear to remain of this cloud forest treelet, three in the Savanne range, where an 8 ha conservation area has now been designated, and single plants have been recently discovered at Macchabe and Mount Cocotte. No flowering or seeding individuals have been observed and propagation has not been possible.

Assessor: Page, W.

Refs: $1411,9120,16426$

\section{Bafodeya benna}

Chrysobalanaceae

VU Bl+2c

Guinea, Sierra Leone

A monotypic species endemic to upland areas between 700 and $1000 \mathrm{~m}$ in Guinea and neighbouring Sierra Leone. There is little information on its population status. Few areas exist which are not threatened with overcutting and agricultural activities.

Assessor: World Conservation Monitoring Centre

Refs: 10090

\section{Baikiaea ghesquiereana}

Leguminosae

$\mathrm{EN} \mathrm{Bl}+2 \mathrm{c}$

Tanzania

The only record of the species is from coastal forest in the Matumbi Hills, within Namakutwa and Tong'omba Forest Reserves $\left(46 \mathrm{~km}^{2}\right.$ and $25 \mathrm{~km}^{2}$ respectively). The former is a productive reserve: forest on the plateau continues to be cleared for agriculture and illegal logging has been occurring in the more riverine areas. The latter also experiences some agricultural encroachment but its boundaries are being cleared, which will help to prevent further declines.

Assessor: Lovett, J. \& G.P. Clarke

Refs: 2459,16796

\section{Baikiaea plurijuga}

Leguminosae

LR/nt

Angola, Botswana, Namibia, Zambia, Zimbabwe

The dominant species of lowland tropical forest on Kalahari sands. Its timber is known as Zambezi teak. The forests are now degraded and considerably diminished because of increased logging over the last 50 years. Older individuals are also scarce. However, the range of the species has declined fractionally as it can regenerate in modified habitat types and also coppices well.

Assessor: World Conservation Monitoring Centre

Refs: 16608,17335

\section{Baillonella toxisperma}

Sapotaceae

VU Alcd

Cameroon, Congo, Gabon, Nigeria

Moabi is restricted to areas of primary evergreen and old secondary rainforest. The species is overexploited for its timber and is seriously declining in large parts of its 
range. It is the second most important exported wood in Gabon. Amongst other local uses the tree produces edible oil which can fetch high market prices. Maturation rates are slow: 90-100 years, and regeneration occurs only under a closed canopy. Minimum exploitable diameters have been set in several countries. Baillonella is a monotypic genus endemic to the Guinea-Congolian Regional Centre of Endemism.

Assessor: White, L.

Refs: 2362, 2773, 6718, 17408, 19043

\section{Balaka macrocarpa}

Palmae

CR Alc

Fiji

A palm of submontane dense forest, confined to Viti Levu. Its habitat is severely reduced because of conversion to agriculture and forestry plantations.

Assessor: Fuller, D.

Refs: 19118

\section{Balaka microcarpa}

Palmae

EN Alc

Fiji

Occurring in dense lowland forest over a very narrow altitudinal range, the species is confined to localities on Viti Levu and Vanua Levu. Its habitat is severely reduced because of conversion to agriculture and forestry plantations.

Assessor: Fuller, D.

Refs: 19118

\section{Balanops balansae}

Balanopaceae

LR/cd

New Caledonia

Assessor: Jaffré, T. et al.

Refs: 10351

\section{Balfourodendron riedelianum}

Rutaceae

EN Al acd $+2 c d$

Argentina, Brazil (Paraná, Rio Grande do Sul, Santa Catarina, São Paulo), Paraguay

A common species of lowland forest along the banks of the Parana and Unuguay River systems. It also extends into *cerrado. The species has become scarce in places because of overexploitation of the timber and deforestation, but it is still reported to occur in abundance in a large part of its range. The genus is under taxonomic review.

Assessor: Americas Regional Workshop

Refs: $4506,13947,19179$

\section{Baloghia pininsularis}

Euphorbiaceae

$\mathrm{EN} \mathrm{B} 1+2 \mathrm{c}$

New Caledonia

Assessor: Jaffré, T. et al.

Refs: 10351

\section{Balsamocitrus camerunensis}

Rutaceae

Cameroon, Central African Republic

A small forest tree known from occurrences at Batouri and Bertona in the Eastern Province of Cameroon and from Boukoko in Central African Republic. Little is known on the status of the populations.

Assessor: World Conservation Monitoring Centre Refs: 12597

\section{Balthasaria mannii}

Theaceae

São Tomé \& Príncipe (São Tomé)

Endemic to São Tomé, this species occurs in rainforests from $1300 \mathrm{~m}$ to the summit of Pico. There are no significant threats, although the forest below $1500 \mathrm{~m}$ was largely cleared at the beginning of the century. The genus is represented elsewhere only by an East African Afromontane species of restricted range.

Assessor: World Conservation Monitoring Centre

Refs: 2421

\section{Balthasaria schliebenii}

Theaceae

LR/nt

Democratic Republic of Congo, Rwanda, Tanzania

Isolated populations are known from forested areas in the Uluguru Mountains, West Usambara Mountains and the Albertine Rift. There is a distinct variance between the populations but it is not thought to be taxonomically significant. The only other member of the genus is endemic to São Tomé.

Assessor: Lovett, J. \& G.P. Clarke

Refs: 3356,8814

\section{Banara brasiliensis}

Flacourtiaceae

VUB $1+2 \mathrm{ac}$

Brazil (Rio de Janeiro)

Known only from Rio de Janeiro, the species has been recorded from littoral habitats and small mountains. The paucity of recent collections suggests that the species has become scarce.

Assessor: Pires O'Brien, J.

Refs:' 7980, 19099

\section{Banara ibaguensis}

Flacourtiaceae

$\mathrm{EN} \mathrm{B} 1+2 c$

Colombia

Assessor: Calderon, E.

Refs: 7980,19069

\section{Banara vanderbiltii}

Flacourtiaceae

CR DI

Puerto Rico

A horticulturally attractive small tree, known from two populations in the wild, accounting for about 18 individuals. One population occurs on a moist limestone hill, where it may be under potential threat from quarrying. Grazing and farming are also concerns. The numbers of plants in cultivation, mostly located in Fairchild Tropical Garden, exceed those in the wild Assessor: World Conservation Monitoring Centre Refs: 17124

\section{Banara wilsonii \\ Flacourtiaceae}

Cuba

$\mathrm{EN} \mathrm{B} 1+2 \mathrm{c}$

An endemic shrub which rarely attains the size of a small tree. It occurs in coastal and subcoastal dry evergreen forests and scrub in the Puerto Padre area of central Cuba. The habitat is severely degraded in many places and the remaining areas continue to be susceptible to cutting and clearing. Development for tourism is the present major threat.

Assessor: Areces-Mallea, A.E.

Refs: 19149 
Baphia abyssinica

Leguminosae

Ethiopia, Sudan

A small tree, common in places, restricted to small enclaves of moist forest on the north-western highlands of Ethiopia and adjacent parts of Sudan on the Boma Plateau and MountTomadur. Large expanses of this forest in Ethiopia have been replaced by coffee plantations in the last two decades.

Assessor: World Conservation Monitoring Centre

Refs: $1330,2361,18523$

\section{Baphia dewildeana \\ Leguminosae}

VU Alc, B1+2c

Cameroon, Nigeria

A forest species scattered within an area extending from south-east Nigeria into Cameroon. It is not recorded in the Oban Hills and its habitat outside protected areas has experienced heavy declines because of logging and clearing for commercial and subsistence agriculture. The present status of remaining populations is unknown and may be more seriously threatened.

Assessor: World Conservation Monitoring Centre Refs: 11504

\section{Baphia heudelotiana}

Leguminosae

VU B $1+2 \mathrm{c}$

Guinea, Senegal

A shrub or small tree of dry savanna and dry river beds, known from few collections, the precise localities of which are unknown.

Assessor: World Conservation Monitoring Centre

Refs: 2773

\section{Baphia incerta ssp. lebrunii}

Leguminosae

Democratic Republic of Congo

This subspecies is endemic to the Kivu Plateau in DR Congo, where it occurs in the transitional zone between forest and savanna between 1000 and $1350 \mathrm{~m}$.

Assessor: World Conservation Monitoring Centre Refs: 7550

\section{Baphia keniensis}

Leguminosae

VU B $1+2 c$

Kenya

A shrub or tree of riverine forest, endemic to the central mountains of Kenya. Populations in Meru National Park are protected, although tourism may exert some pressure on them. Elsewhere there is no protection and some threat from habitat clearance and land development. Assessor: World Conservation Monitoring Centre Refs: $1308,6396,13072,17859$

\section{Baphia kirkii}

\section{Leguminosae}

Kenya?, Mozambique, Tanzania

The range of this coastal forest species extends from eastern Tanzania and Mafia Island to northern Mozambique. The populations in Mozambique may be extensive. Much of the habitat has suffered from conversion to agriculture and local exploitation.

Assessor: Lovett, J. \& G.P. Clarke

Refs: $2459,3356,5117,7550,8814$

\section{Baphia latiloi}

Leguminosae

Cameroon, Nigeria

A small forest tree which occurs within a range extending from south-east Nigeria just into Cameroon. Populations in the Oban Hills, in Cross River National Park, are protected. There has been extensive deforestation in the surrounding area.

Assessor: World Conservation Monitoring Centre Refs: 4977,11504

\section{Baphia leptostemma ssp. leptostemma}

Leguminosae

Cameroon, Gabon

VU BI+2c

A species of coastal forest occurring in one location in eastern Cameroon and further south around Libreville in Gabon. There have been large declines in the extent of this habitat, mainly through logging. The present status of these populations, if they are still extant, is uncertain. Assessor: World Conservation Monitoring Centre Refs: 9001

\section{Baphia leptostemma var. conraui}

Leguminosae

VU D2

Cameroon

A species for which there is little information and few collections. It is found in the mountains in the west. Assessor: World Conservation Monitoring Centre Refs: 9001

\section{Baphia macrocalyx}

Leguminosae

VU B $1+2 b$

Mozambique, Tanzania

Ranging from south-east Tanzania to northem Mozambique, this species is found only in patches of dry forest. The habitat has suffered extensively from the exploitation of timber resources and agricultural encroachment.

Assessor: Lovett, J. \& G.P. Clarke

Refs: $1308,3356,10961$

\section{Baphia marceliana ssp. marquesii}

Leguminosae

VU D2

Angola

Only a single collection has been made of this subspecies.

Assessor: World Conservation Monitoring Centre Refs: 7550,9001

\section{Baphia obanensis}

Leguminosae

VUAlc, B1+2c

Cameroon, Nigeria

A morphologically unusual and rare Baphia species, which is confined to an area extending from south-east Nigeria into adjacent parts of Cameroon. The Nigerian population occurs in the Oban Hills, in Cross River National Park. Unprotected forest has been heavily logged and taken over for cultivation.

Assessor: World Conservation Monitoring Centre Refs: 4977,11504

\section{Baphia pauloi}

Leguminosae

EN C2b, Dl

Tanzania

A coastal forest tree only known from Kimboza forest, a $4 \mathrm{~km}^{2}$ patch of forest in the foothills of the Uluguru Mountains. The forest has been heavily logged for valuable timber in the past and the planted Cedrela has become invasive. The surrounding area is densely 
populated and there is a strong demand for land to cultivate. There are now two forest guards working under the Tanzanian Catchment Forest Project to prevent illegal logging, cutting and encroachment.

Assessor: Lovett, J. \& G.P. Clarke

Refs: $2459,5204,16796$

\section{Baphia puguensis}

Leguminosae

$\mathrm{EN} \mathrm{B} 1+2 \mathrm{c}$

Tanzania

Endemic to the Pugu Hills, the population is likely to be confined to the remaining forested areas contained within the Pugu $\left(22 \mathrm{~km}^{2}\right)$ and Kazimzumbwi $\left(49 \mathrm{~km}^{2}\right)$. These areas are heavily disturbed by previous logging and charcoal production, and by industrial, agricultural, military and mining activities. A conservation programme and the employment of forest guards has halted further exploitation.

Assessor: Lovett, J. \& G.P. Clarke

Refs: $2459,3356,5204$

\section{Baphia punctulata ssp. punctulata}

Leguminosae

VU B $1+2 b$

Tanzania

This subspecies is restricted to a single area of dry coastal forest in south-east Tanzania.

Assessor: Lovett, J. \& G.P. Clarke

Refs: 3356,7550

\section{Baphia semseiana}

Leguminosae

VU B1 $+2 b, D 2$

Tanzania

A coastal forest species known from the vicinity of Ifakara and Tiriani Fall in southern Tanzania. The area is not well explored.

Assessor: Lovett, J. \& G.P. Clarke

Refs: $2459,3356,7550$

\section{Baphia speciosa}

Leguminosae

VU D2

Zambia

An endernic to north Zambia, where the species is confined to a restricted range of scrub and thicket on sandy soil occurring at altitudes between 900 and $1000 \mathrm{~m}$.

Assessor: World Conservation Monitoring Centre

Refs: 7550,9001

\section{Barleria popovii}

Acanthaceae

VU D2

Yemen (Socotra)

Endemic to the Haggier Mountains, the species occurs very rarely, as a small tree or shrub in montane thickets. The populations are stable.

Assessor: Miller, A.G.

Refs: 19083

\section{Barringtonia payensiana}

Lecythidaceae

Malaysia (Peninsular Malaysia)

VU D2

An endemic of Peninsular Malaysia, confined to lowland primary rainforest in Selangor and Perak. This species is known only from two collections.

Assessor: World Conservation Monitoring Centre Refs: 19073

\section{Basselinia favieri}

Palmae

VUDI

New Caledonia

This species is confined to a small area on Mont Banie.

Assessor: Jaffré, T. et al.

Refs: 19118

\section{Basselinia humboldtiana}

Palmae

LR/cd

New Caledonia

Although the species is confined to a small area in the south-east, it is effectively protected in a national park.

Assessor: Jaffré, T. et al.

Refs: 10351,19118

\section{Basselinia iterata}

Palmae

VU D2

New Caledonia

A species occurring as solitary individuals in wet forest on ridges on schist or mica-schist soils, confined to the north-east.

Assessor: Jaffré, T. et al.

Refs: 10351,19118

\section{Basselinia porphyrea}

Palmae

LR/ed

New Caledonia

A localised species, confined to the south-west, where it is found in wet forest on serpentine between 900 and $950 \mathrm{~m}$. It is effectively protected within a national park.

Assessor: Jaffré, T. et al.

Refs: 10351,19118

\section{Basselinia tomentosa}

Palmae

VU D2

New Caledonia

This species is confined to a schistose ridge between 1000 and $1100 \mathrm{~m}$ on Mount Nakada.

Assessor: Jaffré, T. et al.

Refs: 10351,19118

\section{Basselinia vestita}

Palmae

VU D2

New Caledonia

Assessor: Jaffré, T. et al.

Refs: 10351

\section{Bauhinia augusti}

Leguminosae

VU D2

Peru

A species currently known only from the type collection taken from disturbed areas of lowland forest and shrublands in the Cajamarca region of the Peruvian Andes.

Assessor: World Conservation Monitoring Centre Refs: 1984

\section{Bauhinia bowkeri}

Leguminosae

VU D2

South Africa (Eastem Cape)

Historically, this scrambling shrub or small tree was known from a few localities along the Eastern Cape coast (mainly in the Transkei), where it occurred in riverine scrub. At present it is known from a single locality, where there are 20 mature plants. It is probable that the species will be discovered in other localities. 
The observed declines have been largely caused by cutting for firewood and grazing by livestock.

Assessor: Hilton-Taylor, $\mathrm{C}_{\mathrm{o}}$ et al.

Refs: 689,19218

\section{Bauhinia integerrima}

Leguminosae

$\mathrm{EN} \mathrm{B} 1+2 \mathrm{c}$

Brazil (Bahia)

The distribution of this species is restricted, occurring in Atlantic forest in the south of the state. The habitat appears to have been taken over by commerical crops and the current status of remaining populations is uncertain.

Assessor: World Conservation Monitoring Centre

Refs: 19098,19100

\section{Bauhinia loeseneriana}

Leguminosae

VU B1 $+2 b, \mathrm{D} 2$

Tanzania

Endemic to coastal forest in Tanzania, this species is known only from four sites. One population is protected, occurring in Rondo Forest Reserve $\left(140 \mathrm{~km}^{2}\right)$, where human activities have caused extensive disturbance in the past but are presently discouraged by an active forestry programme.

Assessor: Lovett, J. \& G.P. Clarke

Refs: 3356, 16796

\section{Bauhinia mombassae}

Leguminosae

$\mathrm{EN} \mathrm{B1}+2 \mathrm{c}$

Kenya

A small tree of rocky riverine areas, reportedly common in places. Populations are known from Shimba Hills National Reserve, Kaya Rabai, a locality along Mwache River and Mkongani North. Of these four sites, only Kaya Rabai is not legally protected. There is a threat of habitat degradation and increasing elephant numbers could also pose a problem.

Assessor: CAMP Workshop in Kenya

Refs: 19181

\section{Bauhinia paradisi}

Leguminosae

Honduras

A species of doubtful nomenclature, known only from an area of dry submontane forest.

Assessor: Nelson, C.

Refs: 13995

\section{Beauprea congesta}

Proteaceae

New Caledonia

Assessor: Jaffre, T. et al.

Refs: 10351

\section{Beauprea crassifolia}

Proteaceae

New Caledonia

Assessor: Jaffré, T, et al

Refs: 10351

\section{Beccariella brevipedicellata}

Sapotaceae

$\mathrm{EN} B 1+2 \mathrm{c}$

New Caledonia

The genus has been moved to Pouteria.

Assessor: Jaffré, T, et al.

Refs: 10351, 10781
Beccariophoenix madagascariensis

Palmae

Madagascar

$\mathrm{CR} \mathrm{Bl}+2 \mathrm{~cd}$

Only two populations are known, occurring in Mantady and the south-west. The timber, food and fibre are of local use.

Assessor: Johnson, D.

Refs: 19118

\section{Behaimia cubensis}

Leguminosae

EN Alcd

Cuba

A slow-growing shrub or tree found only occasionally in woodlands and dry evergreen forests on dog-tooth limestone, rocky terraces and cliffs. The species has been overexploited for its hard, precious wood.

Assessor: Areces-Mallea, A.E.

Refs: 9522, 16327, 19149

\section{Beilschmiedia ambigua}

Lauraceae

VU B1+2b, D2

Democratic Republic of Congo

A rare species found in one locality of gallery forest along the Pweto to Moba road on the Marungu Plateau, situated on the western shores of Lake Tanganyika. There are serious threats of habitat degradation because of logging and the erosion of stream banks caused by cattle.

Assessor: Ndjele, M.B.

Refs: 17185,17951

\section{Beilschmiedia bracteata}

Lauraceae

VU D2

Democratic Republic of Congo

Known only from a single locality, the species exists in equatorial swamp forest along the Congo River in the Lulonga region. Overcutting and encroaching agriculture are putting pressure on the habitat.

Assessor: Ndjele, M.B.

Refs: 17185,17951

\section{Beilschmiedia brevipes}

Lauraceae

Malaysia (Peniusular Malaysia)

VU D2

Recorded from Kelantan, Terengganu and Pahang by a single collection from each state, the species grows in lowland forest between the altitudes of 30 and $60 \mathrm{~m}$. It may receive a degree of protection within permanent forest reserves or virgin jungle-reserves.

Assessor: World Conservation Monitoring Centre Refs: 8464, 19073

\section{Beilschmiedia giorgii}

\section{Lauraceae}

Democratic Republic of Congo

A species which seems to be rare and known from a single locality in closed *terra firme forest north of the Forestier Centrale at Likimi. There are some threats of overcutting and encroaching agriculture. The leaves are popular locally for greasing the skin.

Assessor: Ndjele, M.B.

Refs: 17185, 17951 


\section{Beilschmiedia kweo}

Lauraceae

VU B $1+2 b$

Tanzania

A large tree confined to moist submontane forest in the East Usambara Mountains and the North Udzungwa Mountains.

Assessor: Lovett, J. \& G.P. Clarke

Refs: 3356, 10961

\section{Beilschmiedia mayumbensis}

Lauraceae

VU B1+2c, D2

Democratic Republic of Congo

A Mayombe endemic occurring in modified old forest in the Luki area, where there is a forest reserve. The surrounding area is densely populated and there are heavy demands on the forest for timber and charcoal production and also land for agriculture.

Assessor: Ndjele, M.B.

Refs: 7221, 17951

\section{Beilschmiedia membranacea}

Lauraceae

VU D2

Malaysia (Peninsular Malaysia)

A hill forest tree known only from two collections, originating from Pahang and Perak. The species is believed to be protected in permanent forest reserves and/or Taman Negara National Park.

Assessor: World Conservation Monitoring Centre

Refs: 8464,19073

\section{Beilschmiedia penangiana}

Lauraceae

$\mathrm{CR} B 1+2 \mathrm{c}$

Malaysia (Peninsular Malaysia)

This species is known from a single collection from Penare Bukit, Penang at about $300 \mathrm{~m}$. Most parts of Penang have been developed since the collection was made, so the species' existence is uncertain.

Assessor: World Conservation Monitoring Centre

Refs: 8464, 19073

\section{Beilschmiedia ugandensis}

Lauraceae

VU A2d

Democratic Republic of Congo, Sudan, Tanzania, Uganda

A species well known for its timber. It occurs in forests, usually in swampy areas. The tree is felled to make dugout canoes. It is also used in mine shafts and as a fuelwood. The levels of exploitation, notably in Uganda, as well as a general decline in the extent or condition of the habitat, are major threats.

Assessor: *MUIENR

Refs: 9605

\section{Beilschmiedia vermoesenii}

Lauraceae

VU B1 $+2 b, \mathrm{D} 2$

Democratic Republic of Congo

A rare endemic to Mayombe, occurring in remaining areas of closed forest. This habitat has been greatly reduced in extent because of logging and agriculture: $35 \%$ of the forest was under concession in 1980 .

Assessor: Ndjele, M.B.

Refs: 5651, 17185, 17951

\section{Beilschmiedia zeylanica}

Lauraceae

$\mathrm{EN} \mathrm{Bl}+2 \mathrm{c}$

Sri Lanka

A tree occurring in lowland wet evergreen forest in south-west Sri Lanka. During the extensive National Conservation Review forest surveys, the species was found only in three localities in Ratnapura, Matara and Kalutara Districts.

Assessor: World Conservation Monitoring Centre

Refs: 9176, 17195, 19112

\section{Belairia parvifolia}

Leguminosae

VU B $1+2 c$

Cuba

Populations of this shrub or small tree are restricted to the dry forests and scrublands on limestone terraces in Pilon in Granma Province. The species is still locally common, but the habitat has declined and is threatened by overcutting and tourism-related development.

Assessor: Areces-Mallea, A.E.

Refs: 11403, 18485, 19149

\section{Belonophora talbotï}

Rubiaceae

VU $B 1+2 c$

Nigeria

The species range appears to be confined to the Oban Hills in Cross River National Park. Large-scale deforestation and clearance for crops have taken place extensively outside the park boundaries.

Assessor: World Conservation Monitoring Centre

Refs: 2773,4977

\section{Bennettiodendron cordatum}

Flacourtiaceae

VU $B 1+2 c$

Viet Nam

Endemic to north Viet Nam, the species is found in a number of localities in Lang Son, Quang Ninh, Hoa Binh and Ha Tay.

Assessor: World Conservation Monitoring Centre

Refs: 848,11530

\section{Bentinckia condapanna}

Palmae

VU Alc

India (Kerala, Tamil Nadu)

A single-stemmed palm tree, confined to the southern Western Ghats, where it occurs on slopes in moist evergreen hill forest. The species is locally traded as an omamental. It is also present in protected areas and planted in several botanic gardens.

Assessor: Johnson, D.

Refs: 19118,19144

\section{Bentinckia nicobarica}

India (Andaman and Nicobar Is. - Nicobar Is.)

EN C2a

A palm of importance omamentally, known only from Great Nicobar Island. No recent collections exist and increasing settlement has caused habitat losses.

Assessor: Johnson, D.

Refs: 19118

\section{Berberis dryandriphylla}

Berberidaceae

VUB $1+2 c$

Peru

A species known only from the Andes in Cuzco, between 2000 and $3000 \mathrm{~m}$.

Assessor: World Conservation Monitoring Centre Refs: 1984 
Berberis nilghiriensis

Berberidaceae

India (Tamil Nadu)

A poorly known species, recorded only once, from an unspecified location in the Nilgiri Hills.

Assessor: World Conservation Monitoring Centre

Refs: $8483,16435,19144$

\section{Berlinia coriacea}

Leguminosae

VU B1+2ac

Nigeria

Occurring in swampy forests, this small tree with showy flowers is recorded only from south-western Nigeria. Large-scale deforestation and clearing for commercial and subsistence agriculture in the country have caused a rapid decline in all forest types.

Assessor: World Conservation Monitoring Centre

Refs: 2773, 7550, 11504

\section{Berlinia hollandii}

Leguminosae

$\mathrm{EN} \mathrm{B1}+2 \mathrm{c}$

Nigeria

A rare forest tree, apparently endemic to south-eastern Nigeria. Current information indicates that it does not occur in the Oban Hills in Cross River National Park. Unprotected areas have been heavily logged and cleared for agriculture.

Assessor: World Conservation Monitoring Centre Refs: 2773, 7550, 11504

\section{Berlinia occidentalis}

Leguminosae VU Alc, BI+2c

Côte d'Ivoire, Ghana, Liberia, Sierra Leone

Confined to wet lowland evergreen forest from Sierra Leone to Ghana, this species is restricted largely to swampy areas. The general loss of its habitat, because of commercial forestry activities and mining, has been extensive.

Assessor: Hawthome, W.

Refs: 7550, 8369, 12061

\section{Berlinia orientalis}

Leguminosae

Mozambique, Tanzania

VU B $1+2 b$

Populations are known to occur in dry forest in southeast Tanzania and further south in neighbouring Mozambique.

Assessor: Lovett, J. \& G.P. Clarke

Refs: 3356, 10961

\section{Bersama rosea}

Melianthaceae

VU B $1+2 b$

Tanzania

A cloud forest species endemic to the South Udzungwa

Mountains.

Assessor: Lovett, J. \& G.P. Clarke

Refs: 3356,5204

\section{Bersama swynnertonii}

Melianthaceae

$\mathrm{EN} \mathrm{B} 1+2 \mathrm{c}, \mathrm{D} 1$

Zimbabwe

A species apparently endemic to Zimbabwe, where it is rare, and confined to areas of moist forest. Populations occur in Chirinda forest, on *kloofs near the Chimanimani Mountains and more commonly in forest near Stapleford.

Assessor: World Conservation Monitoring Centre

Refs: 6725,18965

\section{Bertholletia excelsa}

Lecythidaceae

VU Alacd $+2 \mathrm{~cd}$

Bolivia, Brazil (Acre, Amapá, Amazonas, Maranháo, Mato Grosso, Pará, Rondônia), Colombia, French Guiana, Guyana, Peru, Suriname, Venezuela

A widely occurring emergent of the Amazonian forest, the Brazil nut tree has experienced major declines in its population because of deforestation. One of the greatest concentrations of trees exists in Tocantins valley where various activities, from the construction of the transamazon railway to the building of a reservoir, have brought about a shrinking in the gene pool. An area of 200,000 ha in south Pará has been purchased by the govemment with the aim of settling landless farmers. Trees remaining in the vast cattle ranches of Para and Acre are neglected and dying. Large natural stands, however, still exist in northern Bolivia and the species is locally abundant in Suriname. There are also various populations in protected areas and on protected corporate properties. The production of Brazil nuts more than halved between 1970 and 1980, apparently because of deforestation. Almost all Brazil nuts consumed around the world still come from wild trees. Little is known about the impact of seed gathering on regeneration, but it clearly can be detrimental under some regimes where agoutis, the natural disperser of the the Brazil nut, are hunted or chased away. There have been relatively few successes at establishing plantations. The sustainable harvesting of nuts by indigenous people in extractive forest reserves offers the most promising protection for the remaining natural stands.

Assessor: Americas Regional Workshop

Refs: $3791,4506,6493,13947,15539,16121,19170$, $19179,19183,19196,19211$

\section{Bertiera pauloi}

Rubiaceae

VU $B 1+2 b$

Tanzania

A small montane forest tree. It is known from the Uluguru and Udzungwa Mountains Populations are confined to Muraihara and Lulanda in the Udzungwa Mountains.

Assessor: Lovett, J. \& G.P. Clarke

Refs: 3356,10961

\section{Betula browicziana}

Betulaceae

$\mathrm{LR} / \mathrm{cd}$

Georgia, Turkey

A species of montane areas.

Assessor: Güner, A.

Refs: $3489,4863,19165$

\section{Betula halophila}

Betulaceae CR Ala, Bl+2e, C2b, D1

China (Xinjiang)

Only recently discovered, the species occurs in Balibagai where it is the only tree species found in wet alkaline land dominated by herbaceous vegetation. The population was apparently reduced to one sprouting stump when the site was taken over for farming. Assessor: World Conservation Monitoring Centre Refs: 1818, 11847

\section{Betula oycoviensis}

Betulaceae

VU Alae

Czechoslovakia, Denmark, Poland, Romania, Russia, Sweden, Ukraine

A taxon of hybrid origin with parent taxa $B$. pendula and $B$. szaferi, the second of which appears to be known only 
from specimens in a botanic garden. The hybrid occurs at forest edges and in birch groves wherever the two parent species have met in the past. In Poland the number of localities known has halved and the total population is now estimated to number 350 individuals. Regeneration is generally poor but has been observed in certain places.

Assessor: Boratynski, A.

Refs: $2915,5226,5287,7222$

\section{Betula pendula ssp. fontqueri}

Betulaceae

$\mathrm{EN} \mathrm{B} 1+2 \mathrm{c}, \mathrm{C} 2 \mathrm{a}$

Morocco, Spain

A species of dry montane woodland occurring in three mountain systems in Spain, the Sistema Central, Sienra Nevada and Sierra de Cazorla and possibly also the Sierra Moreno, and in the Rif Mountains in Morocco. The populations are small and dispersed. The spread of housing developments, as well as decline in water availability, fires, cutting and tourism, pose serious threats. A reintroduction progamme is being developed at Cordoba Botanic Garden.

Assessor: Vivero, J.L. et al.

Refs: 7741

\section{Betula pendula var. parvibracteata}

Betulaceae

Spain

$\mathrm{EN} \mathrm{B} 1+2 \mathrm{c}, \mathrm{C} 2 \mathrm{a}$

A taxon restricted to areas of lowland dry forest along Río Estena in Montes de Toledo and to the Sierra de Rio Frio in the Sierra Morena. Some populations are protected, others are exposed to housing and tourist developments, declines in water availability and fires.

Assessor: Vivero, J.L. et al.

Refs: 7741

\section{Betula raddeana}

Betulaceae

LR/nt

Georgia, Russia

Scattered throughout pine, mixed or beech forest in the subalpine belt of the central Caucasus range, this widespread species is represented by relatively large population numbers but occupies a range which is declining. The main threats to the species are grazing and cutting for timber and firewood. It is listed as rare (Status 3) in the Red Data Book of Russia and USSR and occurs in several reserves.

Assessor: Firsov, G.A.

Refs: 1956,19056

\section{Betula recurvata}

Betulaceae

LR/nt

Turkey

A endemic to Hatila National Park.

Assessor: Güner, A. \& J. Zielinski

Refs: 3489,19165

\section{Betula szaferi}

Betulaceae

Poland

No wild populations are presently known, but there is a specimen planted in Krakow Botanical Garden. It is also thought to be possible to reconstruct the taxon from the natural hybrid, $B$. oycoviensis, produced when $B$. szafer and $B$. pendula are crossed. Although the hybrid still occurs in the wild in several central European countries, the parent species evidently do not still coexist in the wild.

Assessor: Boratynski, A.

Refs: 2915,4839

\section{Betula uber}

Betulaceae

CR DI

USA (Virginia)

Described in 1918 and subsequently thought to have become extinct, the species was rediscovered along the banks of Cressy Creek in 1975. The population is found in highly disturbed second-growth forest along a $1 \mathrm{~km}$ stretch of the river owned by private and federal government parties. The number of individuals has been reduced from 41 to 11 . Protective measures are in place and a large-scale replanting programme has resulted in the establishment of 20 populations of subadult trees. The species is interfertile with $B$. lenta and introduced populations contain hybrids. It is protected by the US Endangered Species Act.

Assessor: World Conservation Monitoring Centre Refs: 6013,19167

\section{Bhesa ceylanica}

Celastraceae

VU Alc

Sri Lanka

A fairly common species occurring in the lowland wet evergreen forests of south-west Sri Lanka.

Assessor: World Conservation Monitoring Centre Refs: 17195

\section{Bhesa nitidissima}

Celastraceae

CR Bl $+2 \mathrm{c}$

Sri Lanka

A rare species restricted to lowland wet evergreen forest in south-west Sri Lanka. During the extensive National Conservation Review forest surveys, only one individual was found in a single forest reserve.

Assessor: World Conservation Monitoring Centre

Refs: $3181,17195,19112$

\section{Bhesa sinica}

Celastraceae

CR D1

China (Guangxi)

A relatively recently discovered monoecious species known only from a single tree which apparently has flowered and set seed, although seldom. It grows on a hillside at an altitude of $50 \mathrm{~m}$ in Nankan near the coast. As far as is known, the tree is given no protection. Assessor: World Conservation Monitoring Centre Refs: 11847

\section{Bicuiba oleifera \\ Myristicaceae}

Brazil

This monotypic genus is quite widespread but restricted to the threatened Atlantic coastal forests of south-east Brazil.

Assessor: de Wilde, W.J.J.O.

Refs: 18187

\section{Bidens hendersonensis var. hendersonensis}

Compositae

Pitcairn Islands

VU D2

A caulescent shrub or tree endemic to Henderson Island and occurring with var. subspathulata in gaps in the plateau forest. The population of both varieties together is calculated to be about 40,000 individuals. 
Regeneration appears to be good, although the species appears to be monocarpic. Henderson Island is a World Heritage Site.

Assessor: Waldren, S.

Refs: $12900,13604,16427$

\section{Bidens hendersonensis var. oenoensis}

Compositae

CR D1

Pitcaim Islands

A caulescent tree or shrub endemic to Oeno Island, where it occurs in Argusia argentea/Pisonia grandis formations. A botanical expedition in 1991 failed to find any living specimens despite thorough searches. A sterile specimen was found in 1997 in the south-west of the island. Natural vegetation changes may be the cause of the evident scarcity of the species. Henderson Island is a World Heritage Site.

Assessor: Waldren, S. \& N. Kingston

Refs: $5259,13604,19154$

\section{Bidens hendersonensis var. subspathulata}

Compositae

VU D2

Pitcaim Islands

This variety is endemic to Henderson Island and occurs with the type variety in open gaps in the plateau forest. The total number of individuals of the two varieties together has been calculated to be about 40,000 . Regeneration appears to be good, although the species is possibly monocarpic. Henderson Island is a World Heritage Site.

Assessor: Waldren, S.

Refs: 12900,16427

\section{Bikkia kaalaensis}

Rubiaceae

$\mathrm{EN} \mathrm{B} 1+2 \mathrm{c}$

New Caledonia

Assessor: Jaffré, T. et al.

Refs: 10351

\section{Bikkia lenormandii}

Rubiaceae

$\mathrm{EN} \mathrm{B1}+2 \mathrm{c}$

New Caledonia

Assessor: Jaffré, T. et al.

Refs: 10351

\section{Bikkia pachyphylla}

Rubiaceae

LR/cd

New Caledonia

Assessor: Jaffré, T. et al.

Refs: 10351

\section{Bivinia jalberti}

Flacourtiaceae

LR/nt

Kenya, Madagascar, Mozambique, Zimbabwe

A tree of the evergreen forest, known from restricted localities in Zimbabwe and Mozambique. It is a little more widespread in Kenya in Diani, Mrima and Witu. The Madagascan material could be genetically different. Assessor: World Conservation Monitoring Centre Refs: 6396, 19172

\section{Blakea brunnea}

Melastomataceae

EN C2a

Honduras, Panama

In Panama the species occurs in cloud forest in the high mountains of Chiriquí, Bocas del Toro and Veraguas Provinces, occurring between 1500 and $2300 \mathrm{~m}$. It appears to be more or less common but the area is influenced by human activities and ranching.
*TROPICOS records the species from Honduras but nothing more is known about this occurrence.

Assessor: Mitré, M.

Refs: $3913,7272,7980,16772$

\section{Blakea granatensis}

Melastomataceae

Colombia

An endemic to Cundinamarca.

Assessor: Calderon, E.

Refs: 19069

\section{Blakea oldemanii}

Melastomataceae

VU B1+2c

Ecuador

Endemic to Pichincha Province, Ecuador, this small tree species inhabits cloud forest between 2500 and $3250 \mathrm{~m}$.

Assessor: World Conservation Monitoring Centre

Refs: 2989, 6596, 19119

\section{Bleasdalea papuana}

Proteaceae

EN C2a

Indonesia (Irian Jaya), Papus New Guinea

An uncommon species of isolated occurrence in lower montane forest on serpentine soils. It has been recorded from the Vogelkop Peninsula and Jayapura in Irian Jaya and the East Sepik and Morobe Provinces in Papua New Guinea. It is threatened by habitat destruction.

Assessor: Eddowes, P.J.

Refs: 19114

\section{Blepharidium guatemalense}

Rubiaceae

EN C2a

Guatemala, Honduras

A rare tree of the Atlantic rainforest. In Honduras, the species is known only from a single collection.

Assessor: Nelson, $\mathrm{C}$.

Refs: $3977,4491,4974,13995$

\section{Blepharis dhofarensis}

Acanthaceae

VI B $1+2 c$

Oman, Yemen

A species restricted to escarpment woodland in Dhofar, Oman, extending into Hauf and Ras Fartak in southern Yemen. In Oman, there has been a sharp population rise in the area and a subsequent increase in grazing pressure and the cutting of wood for domestic use. The leaves and fruiting heads of this species are used for animal fodder.

Assessor: Ghazanfar, S.A.

Refs: 16380

\section{Blepharispermum hirtum}

Compositae

VUAlcd

Oman, Yemen

A small tree, sometimes dominant, in areas of escarpment woodland in Dhofar, Oman, and neighbouring south-east Yemen. In some areas, particularly in Oman, where there has been dramatic population increase, the tree is vulnerable to overcutting for domestic use.

Assessor: Ghazanfar, S.A.

Refs: 16380 


\section{Blepharocalyx cruckshanksii}

Myrtaceae

LR/nt

Argentina (Neuquén, Rio Negro), Chile (Bíobío, Coquimbo, La Araucania, Los Lagos, Maule, O'Higgins, Santiago, Valparaiso)

The species occurs in wet or swampy areas in lowland forest. The habitat is under particular pressure in the Metropolitana region (IV-VI) of Chile, mainly from felling and clearing for agriculture and pastoralism. There is some confusion over the taxonomy. It appears that the same taxon occurs in Argentina as two species, Temu divaricatum and $T$. crucksanksii. Whether these are all the same entity remains to be confirmed.

Assessor: González, M.

Refs: $5112,11140,16328$

\section{Bobea sandwicensis}

Rubiaceae

VU Alce

USA (Hawaii)

A species occurring in dry to moist forest and on open, sparsely vegetated lava flows up to $1220 \mathrm{~m}$ altitude on Oahu, Molokai, Lanai and Maui. The genus consists of four species endemic to the Hawaiian Islands.

Assessor: World Conservation Monitoring Centre

Refs: 3372

\section{Bobea timonioides}

Rubiaceae

VU A1ce

USA (Hawaii)

A species of dry to occasionally moist forest up to an altitude of $580 \mathrm{~m}$. It has been collected from Puna and south Kona Districts on Hawaii and on the southern slopes of Haleakala on Maui. There are also collections elsewhere which may be assignable to the species. The genus consists of four species endemic to the Hawaiian Islands.

Assessor: World Conservation Monitoring Centre

Refs: 3372

\section{Bocquillonia arborea}

Euphorbiaceae

$\mathrm{EN} \mathrm{Bl+2c}$

New Caledonia

Assessor: Jaffré, T. et al.

Refs: 10351

Bocquillonia castaneifolia

Euphorbiaceae

New Caledonia

Assessor: Jaffré, T. et al.

Refs: 10351

\section{Bocquillonia longipes}

Euphorbiaceae

New Caledonia

$\mathrm{EN} \mathrm{B} 1+2 \mathrm{c}$

Assessor: Jaffré, T. et al.

Refs: 10351

\section{Boehmeria australis var. dealbata}

Urticaceae

EN D1

New Zealand (Kermadec Is.)

A small pioneer tree which is confined to Raoul Island of the Kermedec Group, the population on Macaulay Island having become extinct. It grows in forest clearings and disturbed areas and appears to be increasing in numbers since the removal of goats.

Assessor: de Lange, P.J.

Refs: $1551,5563,9800,19133,19134$
Boehmeria jamaicensis

Unticaceae

LR/nt

Jamaica

A relatively commonly occurring species in secondary thickets, along paths and gullies, generally on limestone. Assessor: World Conservation Monitoring Centre Refs: 6057,7980

\section{Bombacopsis quinata}

Bombacaceae

VU Alcd

Colombia, Costa Rica, Honduras, Nicaragua, Panama, Venezuela

A taxonomically controversial species, which has a strong possibility of being sunk into Pachira. Distributed from southern Honduras to northern Colombia and Venezuela, populations are fragmented within remaining areas of seasonally dry lowland forest. The species is threatened at the provenance level, most notably in the Choluteca valley in Honduras, eastern Nicaragua and northern Colombia. Burning, overexploitation of the timber and increasing settlement and conversion of the habitat for agriculture are the main causes of population and genetic losses. Although occurring in national parks, the habitat is relatively poorly represented in protected areas. Much interest has been generated in replanting programmes and various institutes are involved in research into wild populations and the conservation of representative genetic samples of remaining populations in the form of, for example, clonal seed orchards. The species is grown in smallscale species trials in Kenya and the Solomon Islands.

Assessor: Sandiford, M.

Refs: 4506, 5966, 6317, 12109, 14873, 15037, 19069, 19130,19152

\section{Bombax insigne var. polystemon}

Bombacaceae

India (Andaman and Nicobar Is. - Nicobar Is.)

A large tree known only from the type location on Narcodam Island which covers an area of just $12 \mathrm{ha}$. Most of the island is designated as a wildlife sanctuary. Recent explorations have failed to find the taxon. Assessor: World Conservation Monitoring Centre Refs: 4799,7147

\section{Bombax mossambicense}

Bombacaceae

Mozambique

A species endemic to Mozambique. The extent of the population and its status are not known.

Assessor: Bandeira, $\mathrm{S}$.

Refs: 5117,18965

\section{Bombax rhodognaphalon var. tomentosum}

Bombacaceae

Mozambique, Tanzania

VU B $1+2 b$

A poorly known taxon confined to remnants of moist lowland and submontane coastal forest, where it is relatively common. A population is known from Rungwe in Tanzania and further south in Mozambique up to the mouth of the Zambesi River.

Assessor: Lovett, J. \& G.P. Clarke

Refs: $3356,8814,18965$

\section{Bonnetia bolivarensis}

Guttiferae

VU D2

Venezuela

A species known only from a single locality in the summit savanna of Ptari-tepui, in Canaima National 
Park in Bolivar. The habitat is very fragile. At lower elevations, out of the range of this species, pressures exist from mining and tourism.

Assessor: World Conservation Monitoring Centre

Refs: 5070,13574

\section{Bonnetia celiae}

Guttiferae

VU D2

Venezuela

A small tree known only from two localities on Cerro Yutaje in Amazonas, where it occurs in the fragile habitat of the *tepui summit. The area is a Natural Monument but not otherwise protected.

Assessor: World Conservation Monitoring Centre

Refs: 5070, 13574

\section{Bonnetia chimantensis}

Guttiferae

VU D2

Venezuela

A species known only from three localities in fragile summit savanna in Bolívar; Uaipán-tepui and Apradatepui. It occurs in Canaima National Park, where mining and tourism are threatening habitats at lower elevations. Assessor: World Conservation Monitoring Centre Refs: 5070,13574

\section{Bonnetia cordifolia}

Guttiferae

VU D2

Venezuela

A small tree, known only from the type specimen, which was collected in 1974 from the summit savanna of Cerro Guanacoco in Bolívar. The habitat is very fragile, although not imminently threatened. The area is given the status of a National Monument but is otherwise unprotected.

Assessor: World Conservation Monitoring Centre

Refs: 5070,13574

\section{Bonnetia fasciculata}

Guttiferae

LR/nt

Venezuela

A small tree collected from several localities in summit savanna on the Chimantá Massif in the Boliar region. It occurs within the Canaima National Park.

Assessor: World Conservation Monitoring Centre

Refs: 5070

\section{Bonnetia holostyla}

Guttiferae

VU D2

Colombia

A species known only from three localities in Amazonas and Vaupés, Colombia. No habitat information is available.

Assessor: World Conservation Monitoring Centre

Refs: 5070,13574

\section{Bonnetia jauensis}

Guttiferae

VU D2

Venezuela

A species known only from two localities in fragile *tepui summit savanna in Bolivar. It occurs within JáuaSarisariñama National Park.

Assessor: World Conservation Monitoring Centre

Refs: 13574

\section{Bonnetia kathleenae}

Guttiferae

VU D2

Venezuela

A small tree known from only two localities in low forests and thickets on the summits of Cerro Sipapo and Cerro Autana (a single collection) in Amazonas State. Its range is contained within Sipapo Forest Reserve.

Assessor: World Conservation Monitoring Centre Refs: 5070

\section{Bonnetia lanceifolia}

Guttiferae

VU D2

Venezuela

A species which only rarely attains the status of a tree. It is known from various localities on swampy flats or savanna on the summit and slopes of a single mountain, Cerro Guaquinima, in Bolivar. The area is a Natural Monument within La Paragua Forest Reserve. Assessor: World Conservation Monitoring Centre Refs: 5070

\section{Bonnetia maguireorum}

Guttiferae

VU D2

Venezuela

This species is known from several localities on the summit plateau and slopes of a single mountain, Cerro de la Neblina inside Serranía de la Neblina National Park, Amazonas State.

Assessor: World Conservation Monitoring Centre Refs: 5070

\section{Bonnetia multinervia}

Guttiferae

VU D2

Venezuela

A woodland species known from three *lepui summits in Bolívar State: Ilu-tepui, Yuruaní-tepui and Sierra de Lema, all of which are contained within the borders of Canaima National Park. Mining and tourism threaten habitats at lower elevations.

Assessor: World Conservation Monitoring Centre Refs: 5070

\section{Bonnetia ptariensis}

Guttiferae

CR D1

Venezuela

A species collected only once, in 1978 , from a densely wooded area on the summit of Ptari-tepui, Bolívar, within Canaima National Park. It has not been seen recently despite efforts to locate it. It is clearly extremely rare or perhaps even extinct.

Assessor: World Conservation Monitoring Centre Refs: 5070, 13574

\section{Bonnetia rubicunda}

Guttiferae

VU D2

Guyana

This species is known only from three localities in exposed summit areas at Roraima, Wokomung and Ayanganna.

Assessor: World Conservation Monitoring Centre

Refs: 5070

\section{Borassodendron machadonis}

Palnae

VU D2

Malaysia (Peninsular Malaysia), Thailand

This palm species occurs in lowland rainforest up to $500 \mathrm{~m}$ in northern Peninsular Malaysia and Peninsular 
Thailand. A number of high-density populations are known but they are somewhat threatened by forest management activities and limestone mining.

Assessor: Saw, L.G.

Refs: 19118

\section{Borassus madagascariensis}

Palmae

VU Alc

Madagascar

Endemic to western Madagascar, the species inhabits lowland open forest along rivers, on alluvium. Encroaching settlement is the most imminent threat. Some consider the species to be conspecific with $B$. aethiopum.

Assessor: Dransfield, J. \& H.J. Beentje

Refs: 18986,19118

\section{Borassus sambiranensis}

Palmae

EN Alc

Madagascar

This majestic species is endemic to the lowland alluvial plains of north-west Madagascar. It has been poorly collected. Fifteen mature individuals have been found in Sambirano. Although seedlings exist there are no young trees. Fire is suspected to prevent establishment.

Assessor: Dransfield, J. \& H.J. Beentje

Refs: 18986,19118

\section{Boronella koniamboensis}

Rutaceae

VU B $1+2 c$

New Caledonia

Assessor: Jaffré, T. et al.

Refs: 10351

\section{Boscia arabica}

Capparaceae

VU Alcd

Oman, Yemen

The species occurs in the foothills of the escarpment mountains in Dhofar, Oman, and neighbouring southeast Yemen. It is vulnerable to cutting for fodder, timber and firewood. Trees are frequently damaged and regeneration is not evident in several populations. The problem is more acute in Oman, where there has been a sharp influx of people since 1975.

Assessor: Ghazanfar, S.A.

Refs: 16380

\section{Boswellia ameero}

Burseraceae

VU D2

Yemen (Socotra)

A dry woodland species, endemic to Socotra. Some Boswellia species on Socotra are exploited for the resin but none at a commercial level.

Assessor: Miller, A.G.

Refs: 2354, 19083

\section{Boswellia elongata}

Burseraceae

VU D2

Yemen (Socotra)

A dry woodland species, endemic to Socotra. Some Boswellia species on Socotra are exploited for the resin but none at a commercial level.

Assessor: Miller, A.G.

Refs: 2354, 19083
Boswellia ogadensis

Burseraceae

VU D2

Ethiopia

A distinct but little-known species which is recorded only from the type locality near Webi Schebele River in Ethiopia. It is confined to a small but relatively undisturbed area of bushland on limestone slopes.

Assessor: World Conservation Monitoring Centre

Refs: 1330, 18523

\section{Boswellia pirottae}

Burseraceae

LR/nt

Ethiopia

Populations are isolated and restricted to woodland on steep rocky slopes along the Tekeze, Abay and Gibe River systems. The human population and agricultural activities are increasing in the area.

Assessor: World Conservation Monitoring Centre Refs: 1330,18523

\section{Boswellia popoviana}

Burseraceae

VU D2

Yemen (Socotra)

A dry woodland species, endemic to Socotra. Some Boswellia species are exploited for the resin but none at a commercial level.

Assessor: Miller, A.G.

Refs: 19083

\section{Boswellia sacra}

Burseraceae

LR/nt

Oman, Somalia, Yemen (Former South Yemen)

The largest and most widespread occurrence of the species is in northern Somalia. It is also a dominant component of desert-woodland on the escarpment mountains in Dhofar in Oman, extending into Yemen. The resin provides incense, perfume and medicine. In Oman the tree is so heavily browsed that it rarely flowers or sets seed. Trees appear to be dying and regeneration is poor.

Assessor: Thulin, $\mathrm{M}$.

Refs: 6746,16380

\section{Boswellia socotrana}

Burseraceae

VU D2

Yemen (Socotra)

A dry woodland species, endemic to Socotra. Some Boswellia species are exploited for the resin but none at a commercial level.

Assessor: Miller, A.G.

Refs: 2354, 19083

\section{Bottegoa insignis}

Sapindaceae

LR/nt

Ethiopia, Kenya, Somalia

A rare species of Acacia-Commiphora woodland. The largest population occurs in central and southem Somalia. The species extends into small areas of the Ogaden in Ethiopia and north-east Kenya. In places the habitat is under some threat of degradation because of farming activities and overcutting for charcoal production.

Assessor: Thulin, $\mathrm{M}$.

Refs: $1330,6396,18665$ 


\section{Bourreria baccata}

Boraginaceae

Jamaica

LR/nt

A locally common species occurring in thickets and woodlands on limestone, mostly in dry coastal or exposed areas.

Assessor: World Conservation Monitoring Centre

Refs: 6057,7980

\section{Bourreria velutina}

Boraginaceae

Jamaica

$\mathrm{EN} \mathrm{B1}+2 \mathrm{c}$

Very restricted in range, the species occurs in low coastal scrub on dog-tooth limestone in the area of Port Henderson Hill.

Assessor: World Conservation Monitoring Centre

Refs: 401, 5653, 7980

\section{Brachychiton carruthersii}

Sterculiaceae

VU B1+2c, C2a

Papua New Guinea

A tree scattered in lowland coastal and monsoon forest, often in the transition zone between savanna woodland and lowland forest. It is mainly restricted to monsoon forest in Central Province.

Assessor: Eddowes, P.J.

Refs: 19114

\section{Brachychiton velutinosus}

Sterculiaceae

Australia (Queensland), Papua New Guinea

VU B1+2c, $\mathrm{C} 2 \mathrm{a}$

A tree scattered in lowland coastal and monsoon forest, often in the transition zone between savanna woodland and lowland forest. In Papua New Guinea, it is mainly restricted to monsoon forest in Central Province. It occurs also on the Cape York Peninsula, Queensland, Australia.

Assessor: Eddowes, P.J.

Refs: 17200,19114

\section{Brachyglottis arborescens \\ Compositae}

EN D1

New Zealand (North Is.)

Endemic to Three King Islands, this small tree occurs on steep scree slopes. In 1981, three populations of between one and twelve scattered trees were recorded. The islands are protected and goats have been removed.

Assessor: de Lange, P.J.

Refs: $902,17637,19133,19134$

\section{Brachyglottis huntii}

Compositae

VU B $1+2 c$

New Zealand (Chatham Is.)

A small tree, endemic to the Chatham Islands, where it has suffered the wholescale destruction of the forest habitat type.

Assessor: de Lange, P.J.

Refs: $902,9800,19133,19134$

\section{Brachyglottis pentacopa}

Compositae

VU D2

New Zealand (North Is.)

A small tree or shrub, known only from Mount Percy.

Assessor: de Lange, P.J.

Refs: 19133

\section{Brachyglottis perdicioides}

Compositae

New Zealand (North Is.)

LR/nt

A small tree or shrub with a localised distribution only on the east coast of the North Island.

Assessor: de Lange, P.J.

Refs: 19133

\section{Brachylaena huillensis}

Compositae

LR/nt

Angola, Kenya, Mozambique, South Africa (KwaZuluNatal, Mpumalanga, Northern Province), Tanzania, Uganda, Zimbabwe

A timber species occurring in various forest types from upland semi-deciduous forest to coastal dry forest or thicket. The wood is heavily exploitated in the wood carving industries in Kenya and Tanzania. Populations in South Africa are secure, with a number of subpopulations occurring in protected areas. Dense stands have been recorded from the northem parts of Kruger National Park. Increased logging in Mozambique may pose a threat.

Assessor: World Conservation Monitoring Centre Refs: $4506,13191,14667,19218$

\section{Brachyotum gleasonì}

Melastomataceae

VU B $1+2 c$

Ecuador

A shrub or tree endemic to the montane and upper montane cloud forests of the High Andes in Ecuador. Populations are known to occur in the provinces of Imbabura, Pichincha, Cotopaxi, Cañar and Azuay. Assessor: World Conservation Monitoring Centre Refs: $2989,6596,19119$

\section{Brachystegia bakeriana}

Leguminosae

VU $B 1+2 c$

Angola, Zambia

Confined to woodland on Kalahari sands in areas of low rainfall, this species occurs in Mongu and Senanga Districts of western Zambia and adjacent parts of Angola. It is associated with Baikiaea plurijuga and is frequently cut for charcoal production. Populations in traditional areas are given a degree of protection.

Assessor: Phiri, P.S.M.

Refs: 6727,7550

\section{Brachystegia kennedyi}

Leguminosae

VU B $1+2 \mathrm{c}$

Cameroon, Nigeria

A tall straight timber tree of local cultural importance, recorded from several localities of lowland rainforest, including Ejagham, Mamfe, Tabo-agbokem in Cameroon. The largest and most stable population probably occurs in Cross River National Park in Nigeria. Forest outside protected areas has significantly declined because of large-scale logging and clearing for agriculture.

Assessor: World Conservation Monitoring Centre Refs: $5595,7550,12597,15251$

\section{Brachystegia nigerica}

Leguminosae

VU B $1+2 c$

\section{Cameroon, Nigeria}

An uncommon and large canopy tree, sometimes gregarious near water. It is known from lowland rainforest in southem Nigeria and the South-West Province of Cameroon. One of the largest remaining areas of forest is in the Oban Hills of Cross River 
National Park. Deforestation and clearance for crops have been comprehensive outside protected areas. Assessor: World Conservation Monitoring Centre Refs: 2773, 4977, 7550, 11504, 12597

\section{Brachystegia zenkeri}

Leguminosae

VU B $1+2 c$

Cameroon

A timber tree restricted to remaining areas of Atlantic forest in Cameroon.

Assessor: World Conservation Monitoring Centre

Refs: 5595, 5651, 15251

\section{Brackenridgea palustris}

Ochnaceae

Indonesia (Kalimantan, Sulawesi, Sumatra), Malaysia

(Peninsular Malaysia, Sabah, Sarawak), Philippines, Singapore

Usually found in lowland peat swamp and *kerangas forest, the species has come under pressure from habitat loss through most of its range.

Assessor: World Conservation Monitoring Centre

Refs: $9199,17140,19017$

\section{Brahea aculeata}

Palmae

VUAlc

Mexico (Durango, Sinaloa, Sonora)

An endemic palm of open forest, occurring in very dry areas on rocky soils up to $600 \mathrm{~m}$. A local source of forage and fibre, and also of omamental interest.

Assessor: Quero, H.J.

Refs: 19118

\section{Brahea edulis}

Palmae

EN C1

Mexico (Guadalupe Is.)

Endemic to Guadalupe Island, this omamental palm tree is confined to dry scrub on rocky volcanic slopes and cliffs on the foggy north-west slope. Approximately 1100 moribund individuals were counted in 1988. Introduced feral goats predate the seeds and are believed to be inhibiting natural regeneration.

Assessor: Johnson, D.

Refs: 19118

\section{Brahea nitida}

Palmae

VU C2a

Guatemala, Mexico (Colima, Guerrero, Jalisco, Michoacan, Nayarit, Oaxaca, Sinaloa)

A palm of oak forest, occurring in dry areas on limestone hills between 900 and $1500 \mathrm{~m}$. Regeneration is poor.

Assessor: Quero, H.J.

Refs: 19118

\section{Brahea pimo}

Palmae

VU C2a

Mexico (Guerrero, Jalisco, Michoacan, Nayarit)

A Mexican endemic confined to temperate and tropical pine-oak forest in areas near streams and on hillsides in the west. Population numbers are small. Fibre from the leaves is traded in local markets and used locally in handicraft.

Assessor: Quero, H.J.

Refs: 19118
Brassaiopsis minor

Araliaceae

VU D2

Malaysia (Peninsular Malaysia)

A rare small tree, known from only two collections. The species is confined to the lowland and montane rainforest of Terengganu, where it is protected in Taman Negara National Park.

Assessor: World Conservation Monitoring Centre

Refs: 8464, 19073

\section{Brassaiopsis simplex}

Araliaceae

VU B $1+2 c$

Malaysia (Peninsular Malaysia)

A small tree of moist hill forest. This rare species is confined to Perak (Ulu Kerling. Slim Hills Forest Reserve at $800 \mathrm{~m}$ ) and Selangor (Ulu Selangor at $400 \mathrm{~m}$ ).

Assessor: Chua, L.S.L.

Refs: 8464,19073

\section{Brazzeia longipedicellata}

Scytopetalaceae

EN B $1+2 c$

Democratic Republic of Congo, Uganda

Populations are known to occur in upland areas of Bwindi Impenetrable National Park, Ishasha Gorge and Budongo Forest Reserve in Uganda and also in eastem DR Congo.

Assessor: *MUIENR

Refs: 9605, 9837, 10961, 16021

\section{Bretschneidera sinensis}

Bretschneideraceae

EN Alcd

China (Fujian, Guangdong, Guangxi, Guizhou, Hubei, Hunan, Jiangxi, Sichuan, Yunnan, Zhejiang), Taiwan, Viet Nam

Uncommon and thought to be getting rarer, the species is scattered in low to middle elevation forest in ravines and by streams throughout south-east China extending to Lai Chau in Viet Nam and Taibei and Ilan Counties in northern Taiwan. Habitat loss and logging are the main causes of declines. The population in Viet Nam is considered to be threatened and in Taiwan populations are highly localised and contain few individuals. The species is protected under Taiwan's Cultural Heritage Preservation Law. The family is monotypic.

Assessor: Sun, W.

Refs: $848,1818,11530,11847,19050,19055$

\section{Breviea sericea}

Sapotaceae

LR/nt

Côte d'Ivoire, Democratic Republic of Congo, Ghana

Scattered in moist semi-deciduous forest from Côte d'Ivoire to DR Congo, this species is relatively well represented in population numbers. Its habitat has substantially reduced in extent because of logging activities and the encroachment of agriculture. It is the only species of the genus and the only close relative of the endangered Aubregrinia taiensis.

Assessor: Hawthorne, W.

Refs: $8369,8854,12061,12822$

\section{Brexia madagascariensis ssp. mircrocarpa}

Escalloniaceae

VU D2

Seychelles

Scattered individuals occur on the islands of Mahe, Silhouette, Praslin and Felicité. Thought to be once more abundant, the subspecies is now restricted mainly to 
higher altitudes. Populations once known on Round and Long Island are now extinct. These declines are probably attributable to historical deforestation.

Assessor: Nature Protection Trust of Seychelles

Refs: 10610, 19025

\section{Bridelia kurzii}

Euphorbiaceae

VU B $1+2 c$

India (Andaman and Nicobar Is. - Andaman Is., Andaman and Nicobar Is. - Nicobar Is.)

A forest tree with populations on Kamorta Island in the Nicobars and also on the Andaman Islands. Large-scale logging and conversion of the forest for agriculture have caused the loss of the species habitat from much of the Andamans.

Assessor: World Conservation Monitoring Centre

Refs: 4799,7147

\section{Bridelia moonii}

Euphorbiaceae

VU Alc

Sri Lanka

A tree confined to the lowland wet evergreen forests of south-west Sri Lanka.

Assessor: World Conservation Monitoring Centre

Refs: 9176, 17195

\section{Bridelia whitmorei}

Euphorbiaceae

VU D2

Malaysia (Peninsular Malaysia)

Known only from the type collection, the species is found in lowland rainforest in Ulu Tembeling in Pahang. The area falls within a permanent forest reserve.

Assessor: World Conservation Monitoring Centre

Refs: 8464,19073

\section{Brongniartikentia lanuginosa}

Palmae

$\mathrm{LR} / \mathrm{cd}$

New Caledonia

A species of wet forests on schists and siliceous soils, confined to the north-east.

Assessor: Jaffré, T. et al.

Refs: 10351,19118

\section{Brosimum glaziovii}

Moraceae

$\mathrm{EN} \mathrm{B1}+2 \mathrm{bc}$

Brazil (Paraná, Rio de Janeiro, Santa Catarina, São Paulo)

The habitat of this species continues to be rapidly destroyed. Populations are now very restricted and largely confined to the Serra do Mar. It occurs in Tijuca National Park and on the official list of threatened Brazilian plants compiled by *IBAMA.

Assessor: Varty, N.

Refs: $8815,15539,16123$

\section{Brosimum utile ssp. darienense}

Moraceae

VU B1+2c

Panama

The Panamanian form of a widely distributed species. It occurs relatively commonly in Kunayala Indigenous Reserve, including Puerto Obaldia on the border with Colombia. Other collections from Colón, Bocas del Toro and Darién have not been identified down to the subspecies level.

Assessor: Mitré, M.

Refs: $7980,12584,16772$
Brosimum utile ssp. magdalenense

Moraceae

$\mathrm{EN} \mathrm{B1}+2 \mathrm{c}$

Colombia

Endemic to Colombia, this subspecies is restricted to Boyacá.

Assessor: Calderon, E.

Refs: 7980, 19069

\section{Brownea santanderensis}

Leguminosae

Colombia

$\mathrm{EN} \mathrm{B1+2c}$

An endemic to Santander.

Assessor: Calderon, E.

Refs: 19069

\section{Browneopsis excelsa}

Leguminosae

VU Cl

Colombia, Panama, Peru

At present, the species is known from three isolated localities in Darién in Panama, and from localities in Colombia and Peru. It occurs, occasionally commonly, in lowland semi-deciduous rainforest up to $600 \mathrm{~m}$. A small part of the Panamanian population is found in Darién National Park. Elsewhere the habitat is exposed to increasing agriculture and settlement.

Assessor: Mitré, M.

Refs: $7272,7980,16772$

\section{Brownlowia kleinhovioidea}

Tiliaceae

VU D2

Malaysia (Peninsular Malaysia)

Known from a single collection, this tree was found in lowland rainforest on Gunung Bubu, Perak.

Assessor: Chung, R.C.K.

Refs: 19073

\section{Brownlowia velutina}

Tiliaceae

Malaysia (Peninsular Malaysia)

$\mathrm{EN} \mathrm{B1}+2 \mathrm{c}$

A very rare tree of lowland moist forest known only from Kuala, Terengganu.

Assessor: Chung, R.C.K

Refs: 8464,19073

\section{Brucea macrocarpa}

Simaroubaceae

EN B1+2c

Kenya

This shrub or small tree is endemic to central Kenya, where it is confined to areas of riverine or swamp forest, such as Kamiti, Thika Falls, Rojwero Swamp and Kiambu. Population numbers are small and the habitat is under pressure from increasing agricultural and settlement of the area. The Plant Conservation Programme in Kenya maintains living and seed collections.

Assessor: World Conservation Monitoring Centre Refs: 6396, 17859

\section{Brugmansia aurea}

Solanaceae

VU B1+2c

Ecuador

This endemic of Ecuador inhabits the montane cloud forest of the High Andes. Currently it is known to occur in Imbabura, Pichincha and Tungurahua.

Assessor: World Conservation Monitoring Centre Refs: 19119,19120 
Brugmansia versicolor

Solanaceae

VU BI+2c

Ecuador

A montane cloud forest tree, endemic to the High

Andean areas of Pichincha, Ecuador.

Assessor: World Conservation Monitoring Centre

Refs: 19119,19120

\section{Brunellia acostae}

Brunelliaceae

VU B $1+2 c$

Ecuador

A tree species endemic to the Ecuadorean Andes.

Assessor: World Conservation Monitoring Centre

Refs: $7980,19119,19120$

\section{Brunellia almaguerensis}

Brunelliaceae

$\mathrm{EN} \mathrm{B} 1+2 \mathrm{c}$

Colombia

An endemic to Nariño.

Assessor: Calderon, E.

Refs: $4217,7980,8869,19069$

\section{Brunellia antioquensis}

Brunelliaceae

VU B $1+2 c$

Colombia

An endemic to Antioquia.

Assessor: Calderon, E.

Refs: 7980, 19069

\section{Brunellia boqueronensis}

Brunelliaceae

VU $B 1+2 c$

Colombia

An endemic to Antioquia.

Assessor: Calderon, E.

Refs: 7980,19069

\section{Brunellia cayambensis}

Brunelliaceae

VU B $1+2 \mathrm{C}$

Ecuador

A tree species endemic to the upper montane forest zone of the Ecuadorean High Andes.

Assessor: World Conservation Monitoring Centre

Refs: $7980,19119,19120$

\section{Brunellia comocladifolia ssp. boyacensis}

Brunelliaceae

$\mathrm{EN} \mathrm{Bl}+2 \mathrm{c}$

Colombia

An endemic to Boyacá.

Assessor: Calderon, E.

Refs: 7980,19069

\section{Brunellia darienensis}

Brunelliaceae

EN C2a

Colombia, Panama

The few collections known have come from the Cordillera del Darién in Panama, and only recently from Colombia. The species is scarce and highly restricted in distribution, occurring in evergreen rainforest between 1000 and $1500 \mathrm{~m}$. Although the species range is entirely contained within a national park, there is still some risk of deforestation.

Assessor: Mitré, $\mathrm{M}$

Refs: 7980,16772
Brunellia ecuadoriensis

Brunelliaceae

VU B $1+2 c$

Ecuador

A tree species endemic to the montane forest zone of the Ecuadorean High Andes.

Assessor: World Conservation Monitoring Centre

Refs: $7980,19119,19120$

\section{Brunellia elliptica}

Brunelliaceae

EN B $1+2 c$

Colombia

An endemic to Norte de Santander.

Assessor: Calderon, E.

Refs: 7980, 19069

\section{Brunellia farallonensis}

Brunelliaceae

LR/cd

Colombia

Although restricted to a small area near Cali, the species is not threatened. The area is steeply sloping and unsuitable for agriculture or other uses. It is also protected within Farallones de Cali National Park.

Assessor: Calderon, E.

Refs: 7980

\section{Brunellia grandiflora ssp. grandiflora}

Brunelliaceae

LR/nt

Peru

Relatively widespread, this subspecies occurs on the eastern slopes of the Andes up to $2000 \mathrm{~m}$ altitude in disturbed areas and *terra firme forest.

Assessor: World Conservation Monitoring Centre

Refs: 1984

Brunellia inermis var. inermis

Brunelliaceae

LR/nt

Pen

A variety of middle elevation forest currently restricted to the departments of Cuzco, Huanuco and Pasco. Assessor: World Conservation Monitoring Centre Refs: 1984

Brunellia littlei ssp. caucana

Brunelliaceae

$\mathrm{EN} \mathrm{B} 1+2 \mathrm{c}$

Colombia

An endemic to Cauca.

Assessor: Calderon, E.

Refs: 7980,19069

\section{Brunellia macrophylla}

Brunelliaceae

VU B1+2c

Colombia

A Colombian endemic, occurring only in Caquetá and Huila.

Assessor: Calderon, E.

Refs: 7980,19069

\section{Brunellia morii}

Brunelliaceae

$\mathrm{EN} \mathrm{C2a}$

Panama

A cloud forest species, which is considered to be endemic to Panama but possibly also exists in Costa Rica. Only a few collections are known from areas of forest between 1000 and $2500 \mathrm{~m}$ in the Central Cordillera. There are no protective measures in place and the habitat is somewhat exposed to clearing for settlements and agriculture

Assessor: Mitré, M.

Refs: 7980,16772 
Brunellia occidentalis

Brunelliaceae

VU B $1+2 c$

Colombia

An endemic to Valle.

Assessor: Calderon, E.

Refs: $4217,7980,8869,19069$

\section{Brunellia ovalifolia}

Brunelliaceae

VU B $1+2 c$

Ecuador

A tree species endemic to the High Andes of Ecuador.

Assessor: World Conservation Monitoring Centre

Refs: 7980,19120

\section{Brunellia pauciflora}

Brunelliaceae

VU B $1+2 c$

Ecuador

A tree species restricted to a narrow altitudinal range in the High Andes of Ecuador.

Assessor: World Conservation Monitoring Centre

Refs: 19119

\section{Brunellia penderiscana}

Brunelliaceae

$\mathrm{EN} \mathrm{B} 1+2 \mathrm{c}$

Colombia

An endemic to Antioquia.

Assessor: Calderon, E.

Refs: 7980, 19069

\section{Brunellia racemifera}

Brunelliaceae

VU B $1+2 c$

Colombia

An endemic to Cundinamarca.

Assessor: Calderon, E.

Refs: 7980, 19069

\section{Brunellia rufa}

Brunelliaceae

Colombia

$\mathrm{EN} \mathrm{B1}+2 \mathrm{c}$

An endemic to Caquetá.

Assessor: Calderon, E.

Refs: 7980,19069

\section{Brunellia subsessilis}

Brunelliaceae

VU B $1+2 \mathrm{c}$

Colombia

An endernic to Antioguia.

Assessor: Calderon, E.

Refs: 7980,19069

\section{Brunellia zamorensis}

Brunelliaceae

VU B $1+2 c$

Ecuador

An endemic tree species of the Ecuadorean High Andes. Assessor: World Conservation Monitoring Centre Refs: $7980,19119,19120$

\section{Brunfelsia jamaicensis}

Solanaceae

VU B $1+2 \mathrm{c}$

Jamaica

A montane forest species occurring commonly near the summit of John Crow Peak, scattered in southern catchments and rare in northem catchments. Its restriction to altitudes above $1400 \mathrm{~m}$ has led to the species escaping much of the disturbance at lower elevations, although soil erosion and invasive plants still cause habitat degradation.

Assessor: World Conservation Monitoring Centre Refs: 7980, 12564

\section{Brunfelsia membranacea}

Solanaceae

VU Bl+2c

Jamaica

The species occurs locally in thickets on limestone in St Andrew and St Catherine Parishes.

Assessor: Kelly, D.L.

Refs: 5653, 19085

\section{Brunfelsia portoricensis}

Solanaceae

$\mathrm{EN} \mathrm{Cl}$

Puerto Rico

This small tree or tall shrub is located in at least 15-20 sites of wet forest below $600 \mathrm{~m}$. There are about 300 individuals in total. Sexual reproduction appears to be successful. The major threat to the habitat is the establishment of commercial and forestry plantations.

Assessor: World Conservation Monitoring Centre

Refs: 7980,17124

\section{Brunfelsia splendida}

Solanaceae

VU B $1+2 c$ Jamaica

Known from occurrences in St Catherine, Clarendon and Trelawny, the species is uncommon and confined to woodland on limestone.

Assessor: World Conservation Monitoring Centre Refs: 6057,7980

\section{Buchanania barberi}

Anacardiaceae

India (Kerala)

CR B $1+2 \mathrm{c}$

A hill forest species, known only from the type locality at Nadari, Travancore District. It has not been recorded since colonial times.

Assessor: World Conservation Monitoring Centre

Refs: 14276, 19144

\section{Buchanania lanceolata}

Anacardiaceae

VU BI+2c India (Kerala)

A tree of lowland dipterocarp forest, known from a few scattered collections in Travancore and Quilon Districts. Assessor: World Conservation Monitoring Centre Refs: 19144

\section{Buchanania platyneura}

Anacardiaceae

VU D2

India (Andaman and Nicobar Is. - Andaman Is.)

A tall tree of evergreen forest, apparently known only from the type collection.

Assessor: World Conservation Monitoring Centre Refs: 4799

\section{Buchenavia hoehneana}

Combretaceae

Brazil (Bahia, Rio de Janeiro, São Paulo)

In the last 20 years of herbarium collections and records, the species is notably scarce. It is restricted to remaining areas of Atlantic forest on the road to Engenheiro Passos in São Paulo, in Itatiaia National Park in Rio de Janeiro and in Belmonte and Canavieiras in Bahia. The record from Itatiaia dates back to 1941 .

Assessor: Silva, N.M.F.

Refs: 7655, 19098, 19105

\section{Buchenavia iguaratensis}

Combretaceae

$\mathrm{EN} B 1+2 \mathrm{c}$

Brazil (Sāo Paulo)

First described in 1981 from a specimen taken from 
scrubby vegetation in Santa Izabel, the species is poorly known. Only two additional collections are recorded, from earlier dates, one of unknown origin and the other from Miguel Arcanjo.

Assessor: Silva, N.M.F.

Refs: 19105

\section{Buchenavia kleinii}

Combretaceae

LR/nt

Brazil (Rio de Janeiro, Rio Grande do Sul, Santa

Catarina, São Paulo)

Assessor: Silva, N.M.F.

Refs: 7655, 9173, 19105

\section{Buchenavia pabstii}

Combretaceae

$\mathrm{EN} \mathrm{B} 1+2 \mathrm{c}$

Brazil (Sāo Paulo)

Known only from the Linares Forest Reserve, the species is extremely rare and has not been collected since 1982.

Assessor: Silva, N.M.F.

Refs: 19105

\section{Buchenavia rabelloana}

Combretaceae

Brazil (Espírito Santo, São Paulo)

$\mathrm{EN} \mathrm{B1+2c}$

Populations have been recorded at Boracéia Biological Station, Salenópolis in São Paulo and Linhares Forest Reserve in Espírito Santo. It was last collected in 1985. Of the three collections from Salenópolis, the most recent dates to 1967.

Assessor: Silva, N.M.F.

Refs: 19105

\section{Bucida ophiticole}

Combretaceae

EN Alc, B1+2c

Cuba

A shrub or small tree restricted in range to dry serpentine shrubwoods of Habana and Matanzas Provinces. In the past this species was locally abundant, but its habitat has declined considerably through urbanisation, agriculture and grazing.

Assessor: Areces-Mallea, A.E.

Refs: 19149

\section{Buddleja formosana}

Buddlejaceae

$\mathrm{CR} \mathrm{Bl}+2 \mathrm{ab}$

Taiwan

Occurring in the eastern part of the island, this shrub or small tree is found in small fragmented populations in lowland dry deciduous scrub. The loss of habitat has been severe, caused mainly by increasing land settlement. Little regeneration is evident. No protection or conservation measures are in place.

Assessor: Pan, F.J.

Refs: 3295,19050

\section{Bulnesia carrapo}

Zygophyllaceae

$\mathrm{EN} \mathrm{B1}+2 \mathrm{c}$

Colombia

Endemic to Colombia, the species is restricted to localities in Cundinamarca and Tolima.

Assessor: Calderon, E.

Refs: 19069

\section{Bulnesia sarmientoi}

Zygophyllaceae

LR/cd

Argentina, Bolivia, Paraguay

A Chaco endemic, moderately exploited for its fragrant wood. One of the last and also the largest unexploited populations is said to occur in the newly established Kaa-Iya del Gran Chaco National Park, which covers $34,410 \mathrm{~km}^{2}$, in south-east Bolivia.

Assessor: World Conservation Monitoring Centre

Refs: $11140,11936,19136,19170$

Bunchosia diphylla ssp. brevisurcularis

Malpighiaceae

EN C2a

Panama

A lowland rainforest species, so far only known from Colón and Darién, being a little more abundant in the latter. Small populations are protected in Darién National Park. It is also suspected to be in Kunayala Indigenous Reserve and perhaps also Colombia. Occurrences outside protected areas are exposed to habitat clearance.

Assessor: Mitré, $\mathrm{M}$.

Refs: $7980,15037,16772$

\section{Bunchosia hartwegiana}

Malpighiaceae

DD

Colombia, Panama

In Colombia the species is known from the Choco and Antioquia, appearing uncommon in both places. In Panama, all of the collections are identified under the variety brevisurcularis, which is considered threatened. Further work is needed to consolidate whether the separation into different varieties is valid.

Assessor: Mitré, $\mathrm{M}$.

Refs: 15037,16772

\section{Bunchosia hartwegiana var. brevisurcularis}

Malpighiaceae

VU C2a

Panama

Endemic to Panama, this variety is known from a few collections gathered in the province of Darien, including Darién National Park, and from a very sparse distribution in the coastal zone of Colón Province, where it is under particular threat from human activities.

Assessor: Mitré, M.

Refs: 15037,16772

Bunchosia jamaicensis

Malpighiaceae

VU B $1+2 c$

Jamaica

Populations are restricted to woodland on limestone in Trelawny and St Ann.

Assessor: World Conservation Monitoring Centre Refs: 6057,7980

\section{Bunchosia linearifolia}

Malpighiaceae

VU D2

Cuba

An endemic shrub that rarely attains the size of a small tree. It is occasionally found in the dry, thorny shrubwoods on limestone in south-eastern Cuba.

Assessor: Areces-Mallea, A.E.

Refs: $11403,18485,19149$

\section{Bunchosia tutensis}

Malpighiaceae

DD

Panama

Known only from two collections from the Cerro Tute in Verguas, the species appears to be confined to an area which is not botanically well studied.

Assessor: Mitré, $\mathrm{M}$.

Refs: $7980,15037,16772$ 


\section{Burckella sorei}

Sapotaceae

Papua New Guinea (North Solomons, Papua New

Guinea), Solomon Islands (South Solomon)

Confined to the islands of Bougainville in the North Solomons and Guadalcanal in the South Solomons, this timber tree is found mainly in primary lowland rainforest. It is threatened by logging activities and overexploitation, especially as it occurs in a region subject to heavy logging activities.

Assessor: Eddowes, P.J.

Refs: 19114

\section{Burkillanthus malaccensis}

Rutaceae

VU C2a

Indonesia (Sumatra), Malaysia (Peninsular Malaysia (ex), Sarawak)

A small tree from a monotypic genus. Solitary trees or small groups of trees occur on stream banks, slopes and on ridge tops in primary and secondary forest in lowland areas. In Sarawak, the species is known from a single specimen collected in 1961 from primary riparian forest in the Labang Forest Reserve, Bintulu. The species is now extinct in Peninsular Malaysia.

Assessor: World Conservation Monitoring Centre Refs: 14541, 19017

\section{Burretiodendron esquirolii}

\section{Tiliaceae}

VU B $1+2 \mathrm{c}$

China (Guangxi, Guizhou, Yunnan), Myanmar, Thailand A tree of lowland deciduous forest, occurring up to $1100 \mathrm{~m}$. The timber is commercially useful and rates of logging, as well as general habitat loss, have caused considerable declines in the Chinese part of the range. Information is needed on populations in Tharland and Myanmar.

Assessor: World Conservation Monitoring Centre

Refs: 1818, 2891, 11847, 19055

\section{Burretiodendron hsienmu}

\section{Tiliaceae}

VU Alcd

China (Guangxi, Yunnan)

The centre of the species' distribution is in south-west Guangxi, extending into limestone areas of Yunnan. Populations in Viet Nam represent a separate species. A slow-growing tree, it is found, sometimes as a dominant component, in lowland semi-deciduous woodland. Regeneration is observed to be strong in forest gaps. The timber is highly valued, and in many parts of its range mature trees have become very scarce or been eliminated. There are several occurrences within nature reserves, including $\mathrm{Ba} \mathrm{Be}$ National Park in Viet Nam. Habitat loss and degradation have also contributed to the decline.

Assessor: Sun, W.

Refs: 5054, 11530, 11847, 13838, 15357, 19055

\section{Burretiodendron tonkinense}

Tiliaceae

EN Ald

China (Guangxi, Yunnan), Viet Nam

The species is confined to forest in limestone areas extending from southem China to northern Viet Nam. Considerable population declines have been observed from overexploitation of the timber and lack of sufficient regeneration.

Assessor: Ban, N.T.

Refs: 848,19060

\section{Bursera aromatica}

Burseraceae

VU B $1+2 \mathrm{c}$

Jamaica

Populations are confined to hillside woodland on limestone only in the parishes of Hanover, St James and Trelawny.

Assessor: World Conservation Monitoring Centre

Refs: 401,7980

\section{Bursera hollickii}

Burseraceae

$\mathrm{EN} \mathrm{B} 1+2 \mathrm{c}$

Jamaica

Known only from St Catherine Parish, the species is confined to a few areas of dry thicket on rocky limestone hills. Collections are recorded from Port Henderson and Great Goat Island.

Assessor: World Conservation Monitoring Centre

Refs: 401,5653

\section{Bursera lunanii}

Burseraceae

$\mathrm{LR} / \mathrm{nt}$

Jamaica

A species which is locally common in dry thickets and woodlands on limestone near the sea.

Assessor: World Conservation Monitoring Centre

Refs: 6057,7980

\section{Bursera tonkinensis}

Burseraceae

VU B $1+2 c$

Viet Nam

A rare species restricted to primary and secondary evergreen forest on limestone mountains in $\mathrm{Nam} \mathrm{Ha}$ (Phu Li), Ninh Binh (Pho Sau) and $\mathrm{Ha}$ Tay (Chua Huong). Its status and distribution elsewhere are poorly known.

Assessor: World Conservation Monitoring Centre Refs: 848

\section{Bussea eggelingii}

Leguminosae

$\mathrm{EN} \mathrm{B} 1+2 \mathrm{c}$

Tanzania

The species is now thought to be restricted to undisturbed forest areas in the Rondo Forest Reserve $\left(140 \mathrm{~km}^{2}\right)$. Severe disturbance of the habitat has been caused by past activities, including logging of the largest East African pupulation of Milicia excelsa, planting of exotic timbers, shifting cultivation and wood collection. Current forest management activities are unintentionally discouraging local exploitation.

Assessor: Lovett, J. \& G.P. Clarke

Refs: 3925, 16796

\section{Bussea xylocarpa}

Leguminosae

VU B1+2cde, D2

Mozambique

This species is confined to a small area of woodland along the Zambezi River, which is currently being cleared for agriculture. Further indications as to the extent of the species location and its reduction may lead to a more serious status of threat.

Assessor: Bandeira, S.

Refs: 5117,7550

\section{Butea monosperma var. lutea}

Leguminosae

DD

India

A small tree of dry deciduous forest, occurring in central India and Orissa, Gujarat and Maharashtra. About 20 fragmented populations are known within a range of less 
than $20,000 \mathrm{~km}^{2}$. It is not known if population or habitat declines have taken place.

Assessor: CAMP Workshops on Medicinal Plants in India

Refs: 19209

\section{Butia eriospatha}

Palmae VU Alc

Brazil (Paraná, Rio Grande do Sul, Santa Catarina)

A small palm tree of open forest and Araucaria forest between 700 and $1200 \mathrm{~m}$, restricted to southern Brazil. Wild populations are declining, but the species is widely cultivated.

Assessor: Noblick, L.

Refs: 19118

\section{Butia purpurascens}

Palmae

$\mathrm{VUB}+2 \mathrm{c}$

Brazil (Goiás)

A small palm tree known only from an area of *cerrado in Goias. The only confirmed population occurs near Jatar, where individuals are doing well in an area protected by the Brazilian military. Trees in nearby pastureland are not regenerating. Seed predation by bean weevils is very high.

Assessor: Noblick, L.

Refs: 19118

\section{Buxus arborea}

Buxaceae

VU B $1+2 \mathrm{c}$

Jamaica

A Cockpit Country endemic found in a confined area of remaining woodland on limestone in St James and Trelawny.

Assessor: World Conservation Monitoring Centre

Refs: $401,5653,7980$

\section{Buxus citrifolia}

Buxaceae

$\mathrm{LR} / \mathrm{nt}$

Colombia, Panama, Venezuela

The few reports of the species in Panama indicate that it is uncommon and restricted to a narrow range, occurring in the Canal area and in the provinces of Panamá and Colón. In Colombia it is known from Cartagena and Sucre, where it appears to be rare. The larger Venezuelan population is recorded under the genus Tricera. There are further suggestions of conspecific taxa occurring in the Caribbean.

Assessor: Mitré, M.

Refs: $3156,7272,16772$

\section{Buxus colchica}

Buxaceae

Azerbaijan, Georgia, Russia, Turkey

LR/nt

This understorey tree is a common species in ravinine moist forest. It is in decline because of forest clearance and environmental changes.

Assessor: Firsov, G.A.

Refs: 1956,19056

\section{Burus nyasica}

Buxaceae

$\mathrm{EN} B 1+2 \mathrm{ac}$

Malawi

A Malawi endemic known from two forest reserves $70 \mathrm{~km}$ apart. Near Blantyre the species occurs on Mount Soche in a forest that has been reduced to $1.5 \mathrm{~km}^{2}$ and continues to suffer from illegal logging. A population also occurs on Mount Chese in the Mulanje Massif, where the forest is also much reduced by illegal activities and encroaching agriculture.

Assessor: World Conservation Monitoring Centre

Refs: 5651, 7058, 17610

\section{Buxus obtusifolia}

Buxaceae

VU B $1+2 b$

Kenya, Tanzania

Typically a shrub, this species extends in a range from south-east Kenya through to south-east Tanzania, confined to pockets of dry coastal forest or wooded bushland

Assessar: Lovett, J. \& G.P. Clarke

Refs: $3356,5811,6396,12067$

\section{Buxus vahlii}

Buxaceae CR A2c, C2ab, D1

Jamaica, Puerto Rico, Virgin Islands (US) (ex)

A shrub or tree of coastal limestone hills, restricted to forested ledges and ravines. Reports of the species occurring on St Croix in the US Virgin Islands date to the 1700 s and the occurrence in Jamaica is also doubtful. In Puerto Rico, there are two locations: the nuclear power plant site at Rincon and Hato Tejas, Bayamon, consisting of 16 and 12 plants respectively. The Hato Tejas population was larger but was partially destroyed by limestone mining in the 1980 s. The remaining individuals are threatened with development of a coalfueled power plant, further mining and industrial or commercial developments. The species is protected by the US Endangered Species Act.

Assessor: World Conservation Monitoring Centre

Refs: $7980,14424,17124,19167$

\section{Byrsonima horneana}

Malpighiaceae

Puerto Rico

A very rare tree, localised on moist slopes in westem Puerto Rico.

Assessor: World Conservation Monitoring Centre

Refs: $3786,5988,7931,17124$

\section{Byrsonima nemoralis ssp. dressleri}

Malpighiaceae

CR B $1+2 \mathrm{c}$

Panama

Although the species is known from various sites in Panama and north Colombia, this subspecies is considered endemic to the Cordillera de Cerro Jefe, to the north-east of Panamá city. It is uncommon and in Cerro Azul has experienced considerable habitat loss through urban and industrial development. Most of the populations in Cerro Jefe are protected within Chagres National Park.

Assessor: Mitré, M.

Refs: 7272,16772

\section{Byrsonima ophiticola}

Malpighiaceae

Puerto Rico

As with $B$. homeana the species is rare and scattered on moist slopes in western Puerto Rico.

Assessor: World Conservation Monitoring Centre Refs: 3786, 5988, 7931, 17124 


\section{Byrsophyllum ellipticum}

Rubiaceae

VU Alc

\section{Sri Lanka}

A tree restricted to the lowland wet evergreen forests of south-west Sri Lanka.

Assessor: World Conservation Monitoring Centre

Refs: 8203, 17195

\section{Byrsophyllum tetrandrum}

Rubiaceae

India (Kerala, Tamil Nadu)

A small tree, known only from a few localities of submontane forest in the Agastyamalai Hills. Large areas have been exposed to fires, grazing, the establishment of commercial plantations and cutting for fuelwood, but about $1000 \mathrm{~km}^{2}$ of forest remain protected within sanctuaries.

Assessor: World Conservation Monitoring Centre

Refs: 10733,19144

\section{Byttneria ivorensis}

Sterculiaceae

Côte d'Ivoire

This species is only known from the herbarium specimen collected in 1896 from the edges of moist semi-deciduous forest.

Assessor: Assi, A.

Refs: 12822

\section{Cabralea canjerana ssp. polytricha}

Meliaceae

$\mathrm{LR} / \mathrm{nt}$

Brazil (Goiás, Minas Gerais)

The taxon is confined to a small area of submontane * cerrado, where it is relatively safe from threat.

Assessor: Pires O'Brien, J.

Refs: $5942,7980,12281$

\section{Caesalpinia echinata}

\section{Leguminosae}

EN Alacd

Brazil (Alagoas, Bahia, Espírito Santo, Minas Gerais, Pararba, Pemambuco, Rio de Janeiro, Rio Grande do Norte, Sergipe)

The exploitation of this species as a dyewood dates back to 1501. The original collectors of the dyewood were called brasileiros, after whom the country is now named. Synthetic dyes only became available in 1875 , by which time dramatic population declines had already taken place and continued to occur until the 1920 s. Natural stands were almost completely destroyed but some populations remained in a few areas on the coastal plain, where they have since suffered from deforestation. The species is recorded in reserves in Bahia and Pernambuco. There is also a reintroduction programme at Linareas Reserve and the species is listed on the official list of threatened Brazilian plants by *IBAMA.

Assessor: Varty, N.

Refs: $8815,15539,16123,19212$

\section{Caesalpinia kavaiensis}

\section{Leguminosae}

\section{USA (Hawaii)}

Currently fewer than 50 individuals are known. They are restricted to populations found in dry and moist forest in the Waianae Mountains on Oahu, Hualalai on Hawaii and on Lanai. Populations on Maui and Kauai are now apparently extinct. Various factors have contributed to the decline, from overexploitation and habitat clearance to damage caused by feral animals and invasive plants. The species is protected by the US Endangered Species Act.

Assessor: World Conservation Monitoring Centre Refs: 3372

\section{Caesalpinia nhatrangense}

Leguminosae

VU D2

Viet Nam

Apparently endemic to Viet Nam, the species is known only from two localities, Ninh Hoà and Diên Khánh in Khánh Hoà on the east coast.

Assessor: World Conservation Monitoring Centre

Refs: 848

\section{Caesalpinia paraguariensis}

Leguminosae

VU Alacd Argentina (Catamarca, Chaco, Cordoba, Corrientes, Formosa, Jujuy, La Rioja, Mendoza, Misiones, Salta, San Juan, San Luis, Santa Fé, Santiago del Estero, Tucumán), Bolivia, Brazil, Paraguay

Widely occurring and relatively common in the Chaco region, the species is found in lowland deciduous forest. It reaches the margins of its range in Brazil, where it is confined to Porto Murtinho. In Bolivia the species is well represented in herbarium collections. Throughout its range it is exploited as a popular source of timber, but the most serious threat is habitat loss.

Assessor: Americas Regional Workshop

Refs: 1262, 5112, 11936, 13661, 15377, 19170, 19179

\section{Calatola columbiana}

Icacinaceae

$\mathrm{EN} \mathrm{Bl}+2 \mathrm{c}$

Colombia

A poorly known species, thought to occur in Valle.

Assessor: Calderon, E.

Refs: 7980,19069

\section{Calliandra comosa}

Leguminosae

VU D2

Jamaica

Known only from Manchester and Trelawny, the species is found on jagged limestone cliffs. The somewhat inaccessible distribution of the species habitat is likely to have impeded excessive clearing.

Assessor: World Conservation Monitoring Centre

Refs: 6057,7980

\section{Calliandra decrescens}

Leguminosae

VU D2

Peru

A species known only from the type collection taken from lowland Amazonian forest in Loreto.

Assessor: World Conservation Monitoring Centre Refs: 1984

\section{Calliandra paniculata}

Leguminosae

VU B $1+2 c$

Jamaica

A species of scrub and woodland on arid rocky limestone, occurring in low-lying parts of Manchester and Clarendon Parishes. The woodland has been extensively destroyed in this area since 1980, mainly for the production of charcoal.

Assessor: Kelly, D.L.

Refs: 5653, 19085 


\section{Calliandra pilosa}

Leguminosae

VU B $1+2 \mathrm{c}$

Jamaica

This species is endemic to Manchester Parish, where it is confined to arid limestone rocks.

Assessor: World Conservation Monitoring Centre

Refs: 6057,7980

\section{Calliandra tumbeziana}

Leguminosae

VU D2

Peru

A species of submontane forest currently known only from the Tumbes delta in the north-west.

Assessor: World Conservation Monitoring Centre

Refs: 1984

\section{Callicarpa ampla}

Verbenaceae

CR C2a

Puerto Rico, Virgin Islands (US)

A seemingly dioecious tree of lower montane moist forest. In Puerto Rico there is a population of about 30 individuals scattered in six or seven sites, mostly contained within state forest land. Evidence of natural regeneration is absent and seed germination trials have not been successful.

Assessor: World Conservation Monitoring Centre

Refs. 7980, 17124, 17540

\section{Callitris baileyi}

Cupressaceae

VU Alc

Australia (New South Wales, Queensland)

As with all Callitris species, populations have declined because of previous exploitation. Although protection is afforded in various national parks, the species is vulnerable to grazing, logging and fire in the rest of its range.

Assessor: SSC Conifer Specialist Group

Refs: 374, 15615, 17200

\section{Callitris drummondì}

Cupressaceae

VU Alc

Australia (Western Australia)

Populations in the south-west appear to be under threat from fire and overgrazing.

Assessor: SSC Conifer Specialist Group

Refs: 4581, 8842, 13041

\section{Callitris monticola}

Cupressaceae

VU Alc

Australia (New South Wales, Queensland)

A species which is restricted in range and under some threat from logging, fires and grazing.

Assessor: SSC Conifer Specialist Group

Refs: 707, 15615, 17200

\section{Callitris neocaledonica}

Cupressaceae

LR/cd

New Caledonia

A shrub usually occurring in small populations which are limited to high altitude cloud forest in the southern ultramafic massif. Slow growth and regeneration rates have been observed and there are some threats from fires and tourism. Populations are effectively protected in Montagne des Sources and also Mont Humboldt Botanical Reserve.

Assessor: SSC Conifer Specialist Group

Refs: 9631,12630

\section{Callitris oblonga}

Cupressaceae

Australia (New South Wales, Tasmania)

VUAlc

Previously known only from Tasmania, the species has been recently found in New South Wales (NSW), although this could be a distinct taxon. The Tasmanian populations are restricted to a small area of sclerophyllous scrubland $\left(<100 \mathrm{~km}^{2}\right)$ along the north-east coast and about 12,000 mature trees have been counted in NSW along intermittent streams. Fires and conversion of the habitat to agriculture are the main threats to the species. Some small populations occur inside protected areas.

Assessor: SSC Conifer Specialist Group

Refs: 707,17200

\section{Callitris roei}

Cupressaceae

VUAlc

Australia (Western Australia)

Populations in the south-west appear to under threat from logging.

Assessor: SSC Conifer Specialist Group

Refs: 4581, 8843, 13041

\section{Callitris sulcata}

Cupressaceae

$\mathrm{EN} \mathrm{B1}+2 \mathrm{c}$

New Caledonia

Occurring in mixed woodlands in valley bottoms, the species is known from only a few sites in the north which are prone to wild fires and disturbance. One site in the Comboui valley has been logged. Regeneration has also been noted as poor. No populations are properly protected.

Assessor: SSC Conifer Specialist Group

Refs: 10351,12630

\section{Calocedrus formosana}

Cupressaceae

$\mathrm{EN} \mathrm{B} 1+2 \mathrm{~b}$

Taiwan

Occurring in mixed evergreen forest, sometimes cloud forest, at medium elevations, the species is scattered in isolated populations in the central and northem parts of Taiwan. Part of the range is covered by Shueipa National Park. In other areas felling and forest management activitues pose threats.

Assessor: Lu, S.Y. \& F.J. Pan

Refs: $2106,6469,11191,19050,19051$

\section{Calocedrus macrolepis}

Cupressaceae

VUAlc China (Guangdong - Hainan, Guangxi, Guizhou, Yunnan), Myanmar, Thailand, Viet Nam

Throughout the species range, populations are rapidly being reduced to the more inaccessible areas where logging and cutting are limited. It is still found commonly in some valleys in Yunnan. In Viet Nam the populations are small (EN D), but some are contained within protected areas, such as Ba Vi National Park and Bidoup Nature Reserve.

Assessor: SSC Conifer Specialist Group

Refs: $374,848,1818,11530,13041,15357$

\section{Calodendrum eickii}

Rutaceae

$\mathrm{CR} B 1+2 \mathrm{C}$

Tanzania

Known only from the West Usambara Mountains, the species occurs in montane Juniperus forest, which has been reduced to $11 \%$ of its original cover because of the establishment of commercial pine plantations and the 
excision of the Shume-Magamba Forest Reserve for local cultivation.

Assessor: Lovett, J. \& G.P. Clarke

Refs: 3356, 10961

\section{Caloncoba lophocarpa}

Flacourtiaceae

VU D2

Cameroon

A small tree of montane forest descending to $400 \mathrm{~m}$.

Occurrences have been recorded at Bangem, Mamfe,

Bakossi Mountains and Mount Cameroon. Expanding agriculture is the most serious threat to the habitat.

Assessor: World Conservation Monitoring Centre

Refs: 12597, 18965

\section{Calophyllum acutiputamen}

Guttiferae

CR B l+2abcde

Papua New Guinea

Known only from Rossel Island, this canopy species is found on ridges in colline forest. The fragile ecosystem of Rossel Island is possibly threatened by logging and mining for copper and gold.

Assessor: Eddowes, P.J.

Refs: 19031,19032

\section{Calophyllum bifurcatum}

Guttiferae

VU D2

Indonesia (Irian Jaya)

A poorly known species collected only once from Japen Island.

Assessor: Stevens, P.F.

Refs: 19031

\section{Calophyllum bracteatum}

Guttiferae

VUAlc

Sri Lanka

A scattered species restricted to the lowland wet evergreen forests of south-west Sri Lanka.

Assessor: World Conservation Monitoring Centre

Refs: 15431,17195

\section{Calophyllum brassii}

Guttiferae

Indonesia (Irian Jaya), Papua New Guinea

A montane forest tree known only from the Westem District in Papua New Guina and Irian Jaya mainly between 400 and $900 \mathrm{~m}$ altitude. Sterile material may be incorrectly assigned to this species.

Assessor: Stevens, P.F.

Refs: 19031,19113

\section{Calophyllum carrii var. carrii}

Guttiferae

VU D2

Papua New Guinea

A tree of lower montane rainforest that is found in the Central and Northern Provinces between 1050 and $1525 \mathrm{~m}$.

Assessor: Stevens, P.F.

Refs: 19031

\section{Calophylum carrii var. longigemmatum}

Guttiferae

VU BI +2abcde

Indonesia (Irian Jaya), Papua New Guinea

This variety is found in lowland rainforest up to $300 \mathrm{~m}$ altitude near Jayapura, Irian Jaya and in the West Sepik District of Papua New Guinea. It is a fine timber tree restricted to areas being extensively logged and therefore is threatened by felling and habitat loss.

Assessor: Eddowes, P.J.

Refs: $19031,19113,19114$

\section{Calophyllum caudarum}

Guttiferae

VU D2

Indonesia (Irian Jaya)

A small tree collected only once, from Dalmar in Geelvink Bay.

Assessor: Stevens, P.F.

Refs: 19031, 19113

\section{Calophyllum chapelieri}

Guttiferae

VUAlcd

Madagascar

The species occurs in lowland rainforest in a range extending from Vohémar to Manakara. The forest type is much reduced in extent. The wood is useful and the species is a focus of silvicultural studies.

Assessor: World Conservation Monitoring Centre

Refs: 6161

\section{Calophyllum collinum}

Guttiferae

DD

Indonesia (Irian Jaya), Papua New Guinea

Endemic to New Guinea, this species is found in lowland and hill forest up to an elevation of $500 \mathrm{~m}$ in the Snow Mountains, Irian Jaya and the Western and Morobe Districts of Papua New Guinea. These areas are poorly collected. It is suspected that the timber is traded as 'Calophyllum' in Papua New Guinea.

Assessor: Stevens, P.F.

Refs: 19031, 19113

\section{Calophyllum confusum}

Guttiferae

VU B $1+2 a b c d e$

Solomon Islands (South Solomon)

A tree known only from the New Georgia group in welldrained, lowland, primary rainforest.

Assessor: Eddowes, P.J.

Refs: 19031,19114

\section{Calophyllum cordato-oblongum}

Guttiferae

VU A $1 c, B 1+2 c$

Sri Lanka

This uncommon tree is restricted to the lowlend rainforests of south-west Sri Lanka. The species has not been refound in the Hinidumkanda MAB Reserve even though the area has been carefully surveyed, possibly due to disturbance caused by illegal felling. It has, however, been recorded recently during the extensive National Conservation Review forest surveys in several forest reserves and proposed reserves.

Assessor: World Conservation Monitoring Centre Refs: 15431, 16916, 16943, 17195

\section{Calophyllum cuneifolium}

Guttiferae

CR B1+2c

Sri Lanka

A locally common tree restricted to upper montane rainforest in Sri Lanka. Only $31 \mathrm{~km}^{2}$ of montane forest remains in Sri Lanka. This species was not found during the extensive National Conservation Review forest surveys.

Assessor: World Conservation Monitoring Centre Refs: $15431,18796,19106,19112$ 


\section{Calophyllum havilandii}

Guttiferae

Brunei, Indonesia (Kalimantan), Malaysia (Sabah,

Sarawak)

Restricted to north-west Borneo, this peat swamp species is cut for its bintangor timber. It is locally used for planks.

Assessor: World Conservation Monitoring Centre

Refs: 14573,18327

\section{Calophyllum heterophyllum}

Guttiferae

Indonesia (Irian Jaya), Papua New Guinea

This species is so far known from the Vogelkop Peninsula and the Snow Mountains in Irian Jaya and in the Westem Province in Papua New Guinea. This species appears to grow into canopy trees on low ridges at $100 \mathrm{~m}$ altitude but forms only shrubs and treelets on poor loam soils at 1200 to $1300 \mathrm{~m}$. This species is very poorly known and probably undercollected. The taxonomic limits of this species are also unknown. Assessor: World Conservation Monitoring Centre Refs: 19031, 19113

\section{Calophylum hirasimum}

Guttiferae

Indonesia (Irian Jaya)

A locally abundant small tree confined to the Arfak Mountains and the Wissel Lake region. It occurs mainly in Nothofagus-conifer forest.

Assessor: Stevens, P.F.

Refs: 19031,19113

\section{Calophyllum insularum}

Guttiferae

$\mathrm{EN} \mathrm{Bl}+2 \mathrm{c}$

Indonesia (Irian Jaya)

This tree is known only from the islands in Geelvink Bay, where it occurs in colline rainforest at approximately $200 \mathrm{~m}$ altitude. Because of its restricted distribution and the possibility of exploitation, this species is considered seriously endangered.

Assessor: Eddowes, P.J.

Refs: 19031, 19113, 19114

\section{Calophyllum laticostatum}

Guttiferae

Papua New Guinea, Philippines?

A large tree found in well-drained lowland or lower montane rainforest. This species is possibly traded for its Calophyllum timber in Papua New Guinea.

Assessor: Stevens, P.F.

\section{Calophyllum macrophyllum}

Guttiferae

VU D2

Indonesia (Moluccas)

A very poorly known species of Gebeh Island, known only from the type collection made last century.

Assessor: Stevens, P.F.

Refs: 19031,19113

\section{Calophyllum mooni}

Guttiferae

VUAlc

Sri Lanka

A species scattered in the lowland wet evergreen forests of south-west Sri Lanka.

Assessor: World Conservation Monitoring Centre

Refs: 17195

\section{Calophyllum morobense}

Guttiferae

$\mathrm{EN} B 1+2 \mathrm{c}$

Papua New Guinea

Endemic to Morobe Province, this tree occurs in lowland rainforest on alluvium, where it is under threat mainly from logging.

Assessor: Eddowes, P.J.

Refs: 19031, 19114

\section{Calophyllum nubicola}

Guttiferae

$\mathrm{EN} \mathrm{B1}+2 \mathrm{c}$

Panama

Originally the species was known only from Cerro Jefe but it has since been recorded close by in Kunayala Indigenous Reserve. The species, occurring in lowland semi-deciduous rainforest, is fairly common and its range is almost completely contained within protected areas. Outside these areas the habitat is declining because of increasing settlement of the land.

Assessor: Mitré, M.

Refs: $7980,15037,16772$

\section{Calophyllum obscurum}

Guttiferae

VU B1+2c

Solomon Islands (South Solomon)

Restricted to primary forest on ridges or flooded coral platforms, this tree is found on the islands of Choiseul, Santa Isabel and Malaita.

Assessor: World Conservation Monitoring Centre

Refs: 19031,19113

\section{Calophyllum parvifolium}

Guttiferae

VU D2

Indonesia (Irian Jaya, Moluccas)

A montane forest species known from only two specimens, one from Gebeh Island of the Moluccas and the other from Waigeo Island of Irian Jaya.

Assessor: Stevens, P.F.

Refs: 19031,19113

\section{Calophyllum persimile}

Guttiferae

Indonesia (Irian Jaya), Papua New Guinea

A rainforest tree occurring up to $560 \mathrm{~m}$ altitude near Kiunga. This species is poorly known and variation is seen in the sterile material. The timber is probably traded as calophyllum in Papua New Guinea.

Assessor: Stevens, P.F.

Refs: 14573, 19031, 19113

\section{Calophyllum piluliferum}

Guttiferae

Indonesia (Irian Jaya), Papua New Guinea

A tree found in forest in or near swamps below $40 \mathrm{~m}$ altitude in Digul, Irian Jaya and the Western District of Papua New Guinea; this area is poorly collected.

Assessor: Stevens, P.F

Refs: 19031,19113

\section{Calophyllum robustum}

Guttiferae

VU Bl+2abcde

\section{Papua New Guinea}

This uncommon tree is found in lowland rainforest in the Morobe District and near Ioma in the Northern District. It is vulnerable on account of restricted distribution and possible exploitation. However, the limits of this taxon are unclear.

Assessor: Eddowes, P.J.

Refs: 19031, 19113, 19114 
Calophyllum rufinerve

Guttiferae

VU D2

Indonesia (Irian Jaya)

A very poorly known tree known only from Geelvink Bay, where it was found in Agathis forest at $400 \mathrm{~m}$ altitude.

Assessor: Stevens, P.F.

Refs: 19031,19113

\section{Calophyllum savannarum}

Guttiferae

VU D2

Indonesia (Irian Jaya)

A tree found in secondary forest and as the main component of forest clumps in secondary savanna. So far it is only known from Japen Island and from an area near Jayapura.

Assessor: Stevens, P.F

Refs: 19031

\section{Calophyllum streimannii}

Guttiferae

Papua New Guinea

Known only from Morobe District, the species is rarely collected, occurring on ridges and hillsides between 30 and $300 \mathrm{~m}$, often associated with dipterocarps.

Assessor: Stevens, P.F.

Refs: 19031,19114

\section{Calophyllum thwaitesii}

Guttiferae

VU Alc

Sri Lanka

A species occurring in the lowland wet evergreen forests of south-west Sri Lanka.

Assessor: World Conservation Monitoring Centre

Refs: 15431,17195

\section{Calophyllum tomentosum}

Guttiferae

VU Alc, Bl+2c

Sri Lanka

During the extensive National Conservation Review forest surveys, this species was recorded in seven forests.

Assessor: World Conservation Monitoring Centre

Refs: $15431,17759,19112$

\section{Calophyllum trapezifolium}

Guttiferae

$\mathrm{EN} \mathrm{B1}+2 \mathrm{c}$

Sri Lanka

A prominent species of upper montane rainforest, endemic to Sri Lanka, occurring occasionally in lowland rainforest. The species was found in only three of the localities surveyed during the extensive National Conservation Review.

Assessor: World Conservation Monitoring Centre

Refs: 15431, 17195, 17759, 19106, 19112

\section{Calophyllum waliense}

Guttiferae

EN B1+2abcde

Papua New Guinea (Bismarck Archipelago)

A species restricted to lowland rainforest on ridges on Manus Island. The habitat has been heavily logged and degraded.

Assessor: Eddowes, P.J.

Refs: 19031, 19113, 19114
Calophyllum walkeri

Guttiferae

VUAlc

Sri Lanka

An emergent tree found in upper montane rainforests in Sri Lanka; it occasionally occurs in the lowland rainforests.

Assessor: World Conservation Monitoring Centre

Refs: $15431,17195,17759,19106$

\section{Calpocalyx atlanticus}

Leguminosae

VUAlc

Cameroon

A Cameroon endemic restricted to remnant forest.

Assessor: World Conservation Monitoring Centre

Refs: 5595, 7550

\section{Calpocalyx brevifolius}

Leguminosae

VU D2

Gabon

A tree collected from the south and known only from its type locality. The species may be more widespread given that the country's forests are relatively unexplored. Many forest areas, however, are under concession to logging companies.

Assessor: World Conservation Monitoring Centre Refs: 7550,8506

\section{Calpocalyx cauliflorus}

\section{Leguminosae}

VU Alc, B1+2c

Cameroon, Nigeria

A shade-bearing lowland forest species known from one outlying population west of the Niger River in Nigeria and otherwise confined to remaining forest in the east extending into Cameroon. The most significant area of forest is contained within the Oban Division of Cross River National Park in Nigeria and Korup National Park in Cameroon. The forest habitat has been extensively felled outside protected areas.

Assessor: World Conservation Monitoring Centre

Refs: $2773,7550,11504$

\section{Calpocalyx heitzii}

Leguminosae

VU Alc, Bl+2c

Cameroon, Equatorial Guinea, Gabon

Relatively restricted in range, this coastal forest species occurs in the south of Cameroon on the border with Equatorial Guinea and north of the Ogooué River in Gabon. Both populations are threatened because of the extent of felling and degradation of the habitat.

Assessor: World Conservation Monitoring Centre Refs: 15790

\section{Calpocalyx klainei}

Leguminosae

VUAlc

Cameroon, Gabon

This species is easily confused with the more widespread $C$. dinklagei. It is confined to remaining areas of coastal forest in the south of Cameroon, extending into Gabon. There is a population in Lopé Forest Reserve, a portion of which has become Gabon's first national park. It is also locally common in the rabiKounga area.

Assessor: World Conservation Monitoring Centre Refs: 8506, 19043 


\section{Calpocalyx letestui}

Leguminosae

VU D2

Gabon

A small tree limited to two localities in mountainous areas in the east and central south. Although the species may be found to be more widespread, given that large areas of Gabon's forests are unexplored, these areas are also largely under concession to logging companies. Assessor: World Conservation Monitoring Centre Refs: 8506, 14958

\section{Calpocalyx ngouiensis}

Leguminosae

VUAlc

Cameroon, Gabon

In southem Cameroon this tree is known to occur in coastal forest extending inland along rivers. One population is also known in central south Gabon. Both areas of forest have been heavily degraded in places where there have been logging and agricultural activities.

Assessor: World Conservation Monitoring Centre

Refs: 8506

\section{Calycolpus excisus}

Myrtaceae

VU D2

Cuba

A small tree known only from the deeply eroded limestone mountains of south-western part of Sierra de Nipe in eastern Cuba.

Assessor: Areces-Mallea, A.E.

Refs: 9522, 11403, 19149

\section{Calycorectes australis}

Myrtaceae

EN B1+2acde

Brazil (Rio de Janeiro, Santa Catarina)

Known from few collections, the species is confined to areas of rainforest on the Atlantic coast. The type specimen is from Santa Catarina and it has also been found at Parati in Rio de Janeiro near the border with Sāo Paulo.

Assessor: Pires O'Brien, J.

Refs: 19097

\section{Calycorectes duarteanus}

Myrtaceae

EN B1+2acde

Brazil (Pará, Rio de Janeiro, Santa Catarina, Sāo Paulo)

A tree or treelet, which occurs infrequently in remaining areas of Atlantic forest.

Assessor: Pires O'Brien, J.

Refs: 19097

\section{Calycorectes schottianus}

Myrtaceae

CR B1+2acd

Brazil (Rio de Janeiro)

The species is known only from the type collection.

Assessor: Pires O'Brien, J.

Refs: 19097

\section{Calycorectes sellowianus}

Myrtaceae

EN Alacd

Brazil (Rio de Janeiro)

Present information suggests the species is endemic to Rio de Janeiro. It has been found in the Poço das Antas Biological Reserve and on Mage.

Assessor: Pires O'Brien. J.

Refs: 19097

\section{Calycorectes wurdackii}

Myrtaceae

VU D2

Peru

The only record of the species is from the type collection, which was taken from lowland Amazon forest in the department of Amazonas.

Assessor: World Conservation Monitoring Centre Refs: 1984

\section{Calyptranthes acutissima}

Myrtaceae

CR B $1+2 \mathrm{C}$

Jamaica

An endemic to Dolphin Head and Bubby Hill where the species is found in low numbers in wooded areas on the summit.

Assessor: World Conservation Monitoring Centre

Refs: $401,5653,7980$

\section{Calyptranthes arenicola}

Myrtaceae

$\mathrm{CR} B 1+2 \mathrm{c}$

Cuba

A small tree, imperfectly known, described more than half a century ago from El Morrillo in Pinar del Rio Province. Fieldwork is needed to confirm whether the population still exists.

Assessor: Areces-Mallea, A.E

Refs: $11403,18485,19149$

\section{Calyptranthes brevispicata}

Myrtaceae

VU D2

Peru

Currently recorded only from the type collection, the species occurs in lowland Amazon forest in Loreto. Assessor: World Conservation Monitoring Centre Refs: 1984

\section{Calyptranthes capitata}

Myrtaceae

VU BI+2c

Jamaica

The species is distributed between 670 and $950 \mathrm{~m}$ in St Ann and Clarendon Parishes.

Assessor: World Conservation Monitoring Centre Refs: $401,5653,7980$

\section{Calyptranthes crebra}

Myrtaceae

VU D2

Pers

Known only from the type, this species occurs in lowland Amazon forest on white sand in Loreto. Assessor: World Conservation Monitoring Centre Refs: 1984

\section{Calyptranthes densiflora}

Myrtaceae

Per

This species is endemic to the lowland eastern slopes of the Andes in Peru.

Assessor: World Conservation Monitoring Centre Refs: 1984

\section{Calyptranthes discolor}

Myrtaceae

$\mathrm{EN} \mathrm{Bl}+2 \mathrm{c}$

Jamaica

The species is rare and confined to forested slopes on Dolphin Head. The habitat has experienced selective logging and hurricane damage.

Assessor: World Conservation Monitoring Centre Refs: $401,5653,7980$ 
Calyptranthes ekmanii

Myrtaceae

VU B $1+2 c$

Haiti, Jamaica

Confined to areas of wet woodland or thicket on limestone, this shrubby species occurs in south-west Haiti and Portland in Jamaica. The habitat in both islands has suffered severe decline largely because of forestry and agricultural expansion. Threats of cutting and clearing are still strong in remaining wooded areas. Assessor: World Conservation Monitoring Centre Refs: $261,401,5653,7980$

\section{Calyptranthes favo-viridis}

\section{Myrtaceae}

$\mathrm{CR} B 1+2 \mathrm{C}$

Cuba

This small tree, along with its relative $C$. arenicola, was discovered many years ago at a single locality in Pinar del Rio Province. The site, near the Santa Cruz River, has suffered severe degradation from settlement and agriculture. Fieldwork is necessary to verify the existence of this species.

Assessor: Areces-Mallea, A.E.

Refs: 11403, 18485, 19149

\section{Calyptranthes johnstoni}

Myrtaceae

Panama

This species is described on the basis of three collections, all from south-west of Fort Sherman in the Canal area. Other Calyptranthes in the same region are identified as other species.

Assessor: Mitré, M.

Refs: 3467,16772

\section{Calyptranthes kiaerskovii}

Myrtaceae

CR D1

Puerto Rico, Virgin Islands (British)

A small tree of moist forest or wet areas in dry forest. In Puerto Rico three sites, each containing a single individual, were originally recorded, only one of which may still be extant. A population on the offshore island of Vieques has been destroyed in the construction of a helipad. On Virgin Gorda in the British Virgin Islands, there are several very small populations within the national park and there may be others still to discover. On Tortola, however, the population has not been seen for some time.

Assessor: World Conservation Monitoring Centre

Refs: 16898,17124

\section{Calyptranthes luquillensis}

Myrtaceae

VU D2

Puerto Rico

An endemic to the Luquillo Mountains, occurring in wet areas at middle elevation in the El Verde region. More information may indicate a more serious threat category is appropriate.

Assessor: World Conservation Monitoring Centre

Refs: $5988,7931,7980,12389,17124$

\section{Calyptranthes nodosa}

Myrtaceae

VU B $1+2 \mathrm{c}$

Jamaica

A tree of moist thickets, especially along streams, found only in Trelawny and Clarendon. A doubtrul record also comes from Hanover.

Assessor: World Conservation Monitoring Centre

Refs: 401, 5653, 7980

\section{Calyptranthes polyneura}

Myrtaceae

VU D2

Cuba

An uncommon shrub or small tree confined to the serpentine plateau of Sierra de Nipe in north-eastern Cuba.

Assessor: Areces-Mallea, A.E.

Refs: 11403, 18485, 19149

\section{Calyptranthes portoricensis}

Myrtaceae

EN C2a

Puerto Rico

A poorly known species, which was recorded in 1981 from two localities in the upper regions of Monte del Estado, Maricao.

Assessor: World Conservation Monitoring Centre

Refs: 7980,17124

\section{Calyptranthes pozasiana}

Myrtaceae

CR B1+2c

Cuba

Many years ago this small tree was reported to occur locally in the Río del Medio region of Pinar del Rio Province in western Cuba. The habitat in this area is very disturbed. Fieldwork is needed to check whether the original population stili exists.

Assessor: Areces-Mallea, A.E.

Refs: $11403,18485,19149$

\section{Calyptranthes rostrata}

Myrtaceae

EN B $1+2 c$

Cuba

A shrub, sometimes a small tree, endemic to the scrub and karstic woods on limestone of Monte Verde in the Nipe-Yateras District of eastern Cuba. Few collections have been made of this species.

Assessor: Areces-Mallea, A.E.

Refs: 11403, 18485, 19149

\section{Calyptranthes sessilis}

Myrtaceae

DD

Pers

A lowland forest species known only from Loreto and San Martin.

Assessor: World Conservation Monitoring Centre

Refs: 1984

\section{Calyptranthes simulata}

Myrtaceae

$\mathrm{LR} / \mathrm{nt}$

Peru

Occurring in seasonally inundated areas and *terra firme forest, the species is known only from the departments of Amazonas, Loreto and Madre de Dios.

Assessor: World Conservation Monitoring Centre Refs: 1984

\section{Calyptranthes thomasiana}

Myrtaceae

Puerto Rico, Virgin Islands (British), Virgin Islands (US)

Recorded as a shrub or tree, the species is known from scattered small populations in moist forest. There are about 30-50 individuals remaining in three localities in Puerto Rico. In the US Virgin Islands the best known pupulation consists of $15-20$ plants on Bordeaux Mountain on St John. The site of the St Thomas population is now developed and no plants remain. 
except in cultivation. In the British Virgin Islands there is thought to be a population of at least 100 individuals on Gorda Peak.

Assessor: World Conservation Monitoring Centre

Refs: $5988,7980,17124$

\section{Calyptranthes umbelliformis}

Myrtaceae

VU B1+2c

Jamaica

The distribution of the species is disjunct, with populations - possibly representing different taxa occurring in St James in the west and Portland in the east. The species is confined to moist wooded limestone hills.

Assessor: World Conservation Monitoring Centre

Refs: 6057,7980

\section{Calyptranthes uniflora \\ Myrtaceae}

$\mathrm{CR} \mathrm{B} 1+2 \mathrm{c}, \mathrm{C} 2 \mathrm{~b}$

Jamaica

Known from only a single locality, the species occurs at the base of a wooded limestone cliff in Cooks Bottom, St Elizabeth Parish.

Assessor: World Conservation Monitoring Centre

Refs: $401,5653,7980$

\section{Calyptranthes wilsonii}

Myrtaceae

$\mathrm{VU} B 1+2 \mathrm{c}$

Jamaica

Although the species appears to be locally abundant, it is confined to mossy woodland areas between 450 and $900 \mathrm{~m}$ in Portland and St Thomas. Almost the entire forest in the latter parish has been either severely degraded or completely lost. Areas in the former are also reduced and threatened by forestry activities.

Assessor: World Conservation Monitoring Centre

Refs: $6057,7980,19116$

\section{Camellia chrysantha}

Theaceae

VUAlcd

China (Guangxi), Viet Nam

A shrub or small tree restricted to wet areas of forest below $500 \mathrm{~m}$ in south-west Guangxi extending into Viet Nam. Populations are given formal protection over much of the range in China but continue to be threatened by overcollection of seedlings and habitat disturbance. The species was included in Appendix II of *CITES in 1985 and deleted from the Appendix in 1997.

Assessor: World Conservation Monitoring Centre

Refs: 1818,11847

\section{Camellia crapnelliana}

Theaceae

VU Alc

China (Fujian, Guangxi, Zhejiang), Hong Kong

A species of the broadleaved forest, occurring along the coast in Fujian, south-west Zhejiang, southem Guangdong and southern Guangxi. Populations are steadily diminishing with increasing habitat loss and curting.

Assessor: World Conservation Monitoring Centre

Refs: 1818,11847

\section{Camellia euphlebia}

Theaceae

VU Alc, D2

China (Guangxi), Viet Nam

A shrub or small tree found in northern Viet Nam and one location in Fangcheng, southern Guangxi, where it grows in forested valleys between 150 and $480 \mathrm{~m}$. There are constant threats of cutting or habitat clearance. Assessor: World Conservation Monitoring Centre Refs: 1818,11847

\section{Camellia fleuryi}

Theaceae

VU D2

Viet Nam

A small tree which appears to be confined to a single locality between 800 and $1000 \mathrm{~m}$ at Dien Khanh in Khanh Hoa Province.

Assessor: World Conservation Monitoring Centre

Refs: 848,11530

\section{Camellia gilbertii}

Theaceae

VU D2

Viet Nam

A small tree, apparently endemic to Viet Nam, where it occurs at about $300 \mathrm{~m}$ in Phu Tho in Vinh Phu Province. Assessor: World Conservation Monitoring Centre Refs: 848

\section{Camellia grijsii}

Theaceae VU Alc

China (Fujian, Guangxi, Hubei, Hunan, Jiangxi)

Confined to areas of evergreen broadleaved forest between 150 and $500 \mathrm{~m}$, the species occurs in a few scattered locations in the east of China. The numbers of populations are steadily diminishing with increasing habitat loss and disturbance.

Assessor: World Conservation Monitoring Centre Refs: 1818,11847

\section{Camellia hengchunensis}

Theaceae

EN C2a

Taiwan

A species restricted to dry lowland forest on windward hills and ridges in the Nanjenshan area on the Hengchun Peninsula. The entire range is contained within Kenting National Park. Little regeneration is evident.

Assessor: Pan, F.J.

Refs: 3295, 19050

\section{Camellia pleurocarpa}

Theaceae

VU D2

Viet Nam

A small tree which has been collected only from Hoi Xuan in Thanh Hoa Province, near the Laos border. Assessor: World Conservation Monitoring Centre Refs: 848

\section{Camellia pubipetala}

Theaceae

$\mathrm{VU} B 1+2 \mathrm{c}, \mathrm{D} 2$ China (Guangxi)

A shrub or small tree known from two locations, Long'an and Daxin, occurring in evergreen broadleaved forest at the base of limestone mountains, between 190 and $230 \mathrm{~m}$. There are constant threats of cutting and habitat clearance.

Assessor: World Conservation Monitoring Centre

Refs: 1818,11847

\section{Camellia reticulata}

Theaceae

VU B $1+2 c$ China (Yunnan)

Although the species occurs widely in cultivation, wild populations are restricted to mixed montane forest in 
western and central Yunnan, where they are in decline. The demand from the horticultural industry is causing significant depletion of plants in the wild.

Assessor: Sun, W.

Refs: $1818,11847,19055$

\section{Camellia tunghinensis}

Theaceae

VU B1+2c, D2

China (Guangxi)

A shrub or small tree confined to Fangcheng in southern Guangxi, where it occurs in forest between 180 and $440 \mathrm{~m}$. There are constant threats of cutting or habitat clearance.

Assessor: World Conservation Monitoring Centre

Refs: 1818,11847

\section{Cameraria microphylla}

Apocynaceae

$\mathrm{EN} \mathrm{B1+2c}$

Cuba

A small tree, up to $5 \mathrm{~m}$ tall, occurring in evergreen thomy shrubwoods on serpentine-derived soils in the lowlands of Camaguey and Ciego de Avila Provinces. The species' habitat has been severely degraded and transformed into savanna by buming and grazing.

Assessor: Areces-Mallea, A.E.

Refs: 11403, 18485, 19149

\section{Campnosperma seychellarum}

Anacardiaceae

$\mathrm{EN} \mathrm{B1}+2 \mathrm{c}$

Seychelles

A tree scattered as isolated individuals or small groups in moist forest on Mahé. A single individual is also known near Vallee de Mai on Praslin. Historical records indicate populations were once large but have declined through heavy exploitation for fuelwood and timber used in boat and house building. Natural regeneration is now rare and seriously hampered by the invasion of Cinnamomum verum. The entire species range lies largely within Mome Seychellois National Park. Propagation from seeds is now being attempted.

Assessor: Nature Protection Trust of Seychelles

Refs: 9859, 17229, 19023, 19025

\section{Campnosperma zeylanicum}

Anacardiaceae

VUAlc

Sri Lanka

A tree restricted to the lowland evergreen rainforests of south-west Sri Lanka.

Assessor: World Conservation Monitoring Centre

Refs: 15431,17195

\section{Campomanesia aromatica}

Myrtaceae

VU B $1+2 c$

Brazil

Restricted to Atlantic coastal forest in the south-east, the species has suffered from extensive reductions in habitat.

Assessor: Pires O'Brien, J.

Refs: 19097

\section{Campomanesia espiritosantensis}

Myrtaceae

VU B $1+2 c$

Brazil

Restricted to Atlantic coastal forest in the south-east, the species has suffered from extensive reductions in habitat.

Assessor: Pires O'Brien, J.

Refs: 19097
Campomanesia hirsuta

Myrtaceae

Brazil (Rio de Janeiro)

$\mathrm{EN} B 1+2 \mathrm{c}$

Restricted to the mountains of Rio de Janeiro near Petrópolis and Terezópolis, this tree was last collected in 1968. It is not known whether the species is still extant. Assessor: World Conservation Monitoring Centre

Refs: 5435,7980

\section{Campomanesia Laurifolia}

Myrtaceae

EN B $1+2 c$

Brazil (Rio de Janeiro)

A forest tree apparently restricted to the mountains around Rio de Janeiro. The most recent collection is dated 1961.

Assessor: World Conservation Monitoring Centre

Refs: 5435,7980

\section{Campomanesia lundiana}

Myrtaceae

Brazil (Rio de Janeiro)

This species is known only from the type collection, which supposedly came from Rio de Janeiro in 1825 . Although this area has since been well studied, the species has not been found again.

Assessor: World Conservation Monitoring Centre

Refs: 5435,7980

\section{Campomanesia neriiflora}

Myrtaceae

VU B $1+2 c$

Brazil (Paraná, Sāo Paulo)

A tree confined to the remaining patches of coastal forest in São Paulo and Paraná. Large-scale destruction of these forests has taken place over several centuries. Assessor: World Conservation Monitoring Centre

Refs: 5435,7980

\section{Campomanesia phaea}

Myrtaceae

VU Bl $+2 \mathrm{c}$

Brazil (Rio de Janeiro, São Paulo)

A small tree known only from sites near Sāo Paulo city and Serra dos Orgâos National Park near Teresópolis in Rio de Janeiro. It is also cultivated on a small scale for its much appreciated edible fruits which are shaped like Indian clay pots, or cambuci, from which it derives its vernacular name.

Assessor: World Conservation Monitoring Centre Refs: 5435,7980

\section{Campomanesia prosthecesepala}

Myrtaceae

DD

Brazil (Minas Gerais)

The species is known only from a collection made in the last century at a location called Rio Manso in Minas Gerais. There is more than one Rio Manso in the state and the species has not been found again.

Assessor: World Conservation Monitoring Centre

Refs: 5435, 7980

\section{Campomanesia reitziana}

Myrtaceae

LR/nt

Brazil (Santa Catarina)

Although common where it occurs, this small tree is confined to a small area of coastal forest in Santa Catarina. The declines in this habitat over centuries have been dramatic.

Assessor: Barroso, G.M.

Refs: 5435, 7906, 7980, 19097 


\section{Campomanesia rufa}

Myrtaceae

DD

Brazil (Minas Gerais)

This species is poorly known. It is apparently restricted to Minas Gerais, where it probably occurs in *cerrado vegetation.

Assessor: World Conservation Monitoring Centre

Refs: 5435, 7980

Campomanesia schlechtendaliana

Myrtaceae

Brazil (Paraná, Rio de Janeiro)

schlechtendaliana var.

VU $B 1+2 c$

An Atlantic coastal forest tree from locations in Paraná and Rio de Janeiro. The decline in its habitat has been dramatic.

Assessor: World Conservation Monitoring Centre

Refs: 5435,7980

\section{Campomanesia sessiliflora var. sessiliflora}

Myrtaceae

$\mathrm{EN} \mathrm{B} 1+2 \mathrm{c}$

Brazil (São Paulo)

According to current knowledge, two collections from the last century and one more recent collection, this variety is confined to coastal forests in Sāo Paulo and Rio de Janeiro. The other varieties appear to be more commonly collected and located in the interior.

Assessor: World Conservation Monitoring Centre Refs: 5435,7980

\section{Campomanesia speciosa}

Myrtaceae

$\mathrm{LR} / \mathrm{nt}$

Peru

A small tree which has a relatively wide range on the eastern slopes of the Peruvian Andes. Recent collections have been few.

Assessor: World Conservation Monitoring Centre Refs: 1984

\section{Campomanesia viatoris}

Myrtaceae

$\mathrm{EN} \mathrm{B} 1+2 \mathrm{c}$

Brazil (Alagoas)

Apparently collected only twice, this rare species is poorly known but believed to be distributed in forest on the banks of Rio São Francisco in coastal Alagoas. Assessor: World Conservation Monitoring Centre Refs: 5435,7980

\section{Camptolepis ramiflora}

Sapindaceae

VU B $1+2 c$

Kenya, Madagascar?, Somalia, Tanzania

An evergreen tree of riverine forest. It occurs from southern Somalia along the lower Jubba River into eastern Kenya and Tanzania. Although the range appears extensive, populations are localised and confined to disappearing habitat. Information on the possible occurrence in Madagascar may alter the current status of the species.

Assessor: Thulin, $\mathrm{M}$.

Refs: 1308, 2361, 6396, 8697, 18665

\section{Campylospermum scheffleri}

Ochnaceae

VU B $1+2 b$

Tanzania

A species restricted to the East Usambara Mountains within moist evergreen forest in upland areas.

Assessor: Lovett, J. \& G.P. Clarke

Refs: $3356,8814,11631$

\section{Campylospermum vogelii var. molleri}

\section{Ochnaceae}

São Tomé \& Príncipe (Prîncipe, Sāo Tomé)

A small tree which is found in three sites above $1300 \mathrm{~m}$, where it occurs commonly in secondary forest. Regeneration is good in at least one of the sites.

Assessor: World Conservation Monitoring Centre Refs: 19111

\section{Canarium fusco-calycinum}

Burseraceae

VU Alcd $+2 c d$

Malaysia (Sarawak)

An uncommon tree endemic to Sarawak, where it occurs in lowland mixed dipterocarp forest.

Assessor: World Conservation Monitoring Centre

Refs: 18327

\section{Canarium kipella}

Burseraceae

$\mathrm{EN} B 1+2 c$

Indonesia (Java)

This species is apparently sparsely distributed in hill forest on Mount Salak and near Pelabuhan Ratu. Both areas, close to Bogor city, appear to be without official protection and are susceptible to encroachment and cutting.

Assessor: World Conservation Monitoring Centre Refs: 9078

\section{Canarium liguliferum}

Burseraceae

DD

Solomon Islands (South Solomon)

A lowland rainforest species known only from the Solomon Islands.

Assessor: World Conservation Monitoring Centre

Refs: 16292,16612

\section{Canarium luzonicum}

Burseraceae

VU Alcd

Philippines

Endemic to the Philippines, this tree occurs in primary forest at low to medium altitudes. The kedondong timber is used for light construction, a valuable oil is tapped from the tree and the seeds are edible.

Assessor: World Conservation Monitoring Centre Refs: 2072, 11145

\section{Canarium ovatum}

Burseraceae

VuAled

Philippines

A lowland primary forest tree, endemic to the Philippines, valued for its kedondong timber and the commercially traded seeds called pilinuts. It is commonly planted.

Assessor: World Conservation Monitoring Centre Refs: $4919,7673,11145$

\section{Canarium paniculatum}

Burseraceae

EN Alcde $+2 c e$

Mauritius

Assessor: Strahm, W

Refs: $9120,16426,19208$

\section{Canarium perlisanum}

Burseraceae

VU D2

Malaysia (Peninsular Malaysia)

A small tree known from a single collection in moist scrub on a limestone hill, Perlis (Kaki Bukit).

Assessor: World Conservation Monitoring Centre Refs: 8464, 19073 
Canarium pseudodecumanum

Burseraceae

VU Alcd $+2 \mathrm{~cd}$

Indonesia (Kalimantan, Sumatra), Malaysia (Peninsular Malaysia, Sabah), Thailand

An uncommon large tree found scattered in primary forest on undulating swamp land up to $280 \mathrm{~m}$. The timber is traded as kedondong. There is concem over its status in Sabah

Assessor: World Conservation Monitoring Centre

Refs: $7673,11145,17140,19017,19026$

\section{Canarium pseudopatentinervium}

Burseraceae

VU Alc

Indonesia (Kalimantan, Sumatra), Malaysia (Sarawak)

An uncommon tree restricted to lowland primary forest.

In Sarawak, the species is only known from a single collection from Belaga.

Assessor: World Conservation Monitoring Centre

Refs: 11145,19017

\section{Canarium pseudopimela}

Burseraceae

VU D2

Malaysia (Sarawak)

A small tree known only from two collections, taken from lowland rainforest in Gunung Lambir and Gunung Raya.

Assessor: World Conservation Monitoring Centre

Refs: 19017

\section{Canarium pseudosumatranum \\ Burseraceae}

$\mathrm{LR} / \mathrm{cd}$

Malaysia (Peninsular Malaysia)

This imperfectly known species is scattered in lowland and hill forest of Perlis, Kedah, Perak, Selangor, Negeri Sembilan and Pahang. The wood is traded as kedondong timber.

Assessor: Chua, L.S.L.

Refs: 11145,19073

\section{Canarium reniforme}

Burseraceae

$\mathrm{LR} / \mathrm{cd}$

Malaysia (Peninsular Malaysia)

A species of moist coastal hill forest, found in Perak and Selangor.

Assessor: Chua, L.S.L.

Refs: 8464,19073

\section{Canarium sarawakanum}

Burseraceae

VU D2

Malaysia (Sarawak)

Endemic to Sarawak, this small uncommon tree occurs in lowland to low submontane forest. So far collections are known from Kapit, Lubok Antu, Gunung Penrissen and Simanggang.

Assessor: World Conservation Monitoring Centre

Refs: 19017

\section{Canarium whitei}

Burseraceae

New Caledonia

A rainforest tree recorded from Rivière des Pirogues.

Assessor: Jaffré, T. et al

Refs: 10351

\section{Canarium zeylanicum}

Burseraceae

VU Alc

Sri Lanka

A scattered tree confined to the lowland wet evergreen forests of south-west Sri Lanka.

Assessor: World Conservation Monitoring Centre

Refs: 9176, 17195

\section{Canthium dicoccum}

Rubiaceae

VU Alc

Sri Lanka

A tree restricted to the lowland wet evergreen forests of south-west Sri Lanka.

Assessor: World Conservation Monitoring Centre Refs: 9176, 17195

\section{Canthium ficiforme}

Rubiaceae

$\mathrm{EN} \mathrm{B1}+2 \mathrm{c}$

India (Kerala, Tamil Nadu)

This species is known from a collection taken from a confined area of submontane forest in the Elamalai Hills and from an imprecisely recorded locality futher south. Assessor: World Conservation Monitoring Centre Refs: 19144

\section{Canthium glaucum ssp. frangula}

Rubiaceae

Kenya

A shrub or small tree, known from Meru National Park, where it occurs in Combretum woodland at $790 \mathrm{~m}$. More detailed information on population numbers may indicate a more serious threat category is appropriate. The type subspecies is more widespread.

Assessor: World Conservation Monitoring Centre Refs: 6396

\section{Canthium impressinervium}

Rubiaceae

VU B 1 +2b, D2

Tanzania

A coastal forest species known from three sites in southeast Tanzania. It has been collected from an unprotected tract of forest on the Noto Plateau and from the nearby Rondo Plateau. Forest covering $140 \mathrm{~km}^{2}$ is protected in the latter site as a forest reserve. Much of it is heavily disturbed because of previous logging, planting of commercial timbers, shifting agriculture and local exploitation. The presence of an active forest management programme is discouraging further exploitative activities.

Assessor: Lovett, J. \& G.P. Clarke

Refs: 3356,8814

\section{Canthium keniense}

Rubiaceae

VU B $1+2 c$

Kenya

A Kenyan endemic of dry upland forest, occurring in localised populations in the Nairobi-Machakos region. The surrounding area is densely populated and agricultural activities, firewood collection and recent droughts are causing habitat degradation.

Assessor: World Conservation Monitoring Centre Refs: 6396 


\section{Canthium kilifiensis}

Rubiaceae

VU B $1+2 c$

Kenya

Confined to areas of Brachystegia woodland, this shrub or small tree is known only from populations in Arabuko-Sokoke and Mangea.

Assessor: World Conservation Monitoring Centre Refs: 6396

\section{Canthium montanum}

Rubiaceae

VU B1+2c

Sri Lanka

This species was found in 10 forest localities, mainly in Nuwara Eliya District, during the extensive forest surveys conducted between 1991 and 1996 for the National Conservation Review.

Assessor: World Conservation Monitoring Centre

Refs: 19112

\section{Canthium neilgherrense var. neilgherrense}

Rubiaceae VU B $1+2 c$

India (Tamil Nadu)

A small tree of montane forest, occurring in the Nilgiris and in the Agastymalai Hills further south

Assessor: World Conservation Monitoring Centre

Refs: 19144

\section{Canthium oligocarpum ssp. intermedium}

Rubiaceae

VU $B l+2 b$

Kenya, Tanzania

A subspecies of dry montane forest. A single collection is known from south-west Mau in Kenya. In Tanzania occurrences are known from Mount Kilamanjaro, Kilomeni and the Nguru Mountains.

Assessor: Lovett, J. \& G.P. Clarke

Refs: $1308,3356,8814$

\section{Canthium pergracilis}

Rubiaceae

$\mathrm{EN} \mathrm{B} 1+2 \mathrm{c}$

India (Kerala)

A relatively large tree, which has only been recorded from a small locality of lowland rainforest in south Kerala.

Assessor: World Conservation Monitoring Centre

Refs: 19144

\section{Canthium racemulosum var. nanguanum}

Rubiaceae

VU B $1+2 b$

Mozambique, Tanzania

A variety from dry forest patches scattered in a relatively unexplored region extending from Kilwa in southem Tanzania to northem Mozambique.

Assessor: Lovett, J. \& G.P. Clarke

Refs: $1308,3356,8814$

\section{Canthium robynsianum}

Rubiaceae

Kenya, Tanzania

VU Bl $+2 \mathrm{C}$

Occurrences are recorded in the Usambara Mountains and Uluguru Mountains in Tanzania and in ArabukoSokoke and Witu in Kenya, in Brachystegia woodland. Assessor: World Conservation Monitoring Centre Refs: 6396, 12067

\section{Canthium rondoense}

Rubiaceae

$\mathrm{EN} \mathrm{B1+2bc}$

Tanzania

A coastal forest species which appears to be confined to the remaining areas of undisturbed forest within Rondo
Forest Reserve. Logging activities, shifting cultivation, pole and fuelwood collection and the establishment of commercial plantations have disturbed the forest extensively in the past. The presence of an active forestry programme is discouraging local exploitation at the present time.

Assessor: Lovett, J. \& G.P. Clarke

Refs: 3356,16796

\section{Canthium shabanì}

Rubiaceae

VU B1+2b

Tanzania

The range of the species appears to be confined to the Usambara Mountains, where it occurs in moist montane forest.

Assessor: Lovett, J. \& G.P. Clarke

Refs: 3356,8814

\section{Canthium siebenlistii}

Rubiaceae

VU B $1+2 c$

Tanzania

Confined to the Usambara and Udzungwa Mountains, the species is known from four moist forest localities at altitudes above $1000 \mathrm{~m}$ : Shume-Magamba, Mwanihara, Myumbenito and Monga.

Assessor: Lovett, J. \& G.P. Clarke

Refs: 3356,10961

\section{Canthium suborbiculare}

Rubiaceae

VU D2

Papua New Guinea

This shrub or small tree is restricted to the Port Moresby region and Monupore Island, where it is found in savanna or scrub. It is known only from five or six collections.

Assessor: World Conservation Monitoring Centre Refs: 19140

\section{Canthium vollensenü}

Rubiaceae

VU $B 1+2 b$

Tanzania

The species ranges in south-east Tanzania, where it occurs in moist semi-deciduous forest remnants.

Assessor: Lovett, J. \& G.P. Clarke

Refs: 3356, 10961

\section{Cantleya corniculata}

Icacinaceae

VUAlcd Indonesia (Sumatra), Malaysia (Peninsular Malaysia?, Sabah, Sarawak)

Scattered below $300 \mathrm{~m}$ in primary freshwater swamp forests and hill forests in drier areas, this tree is exploited for its highly valued timber. The heavy, hard wood has a similar fragrance to sandalwood and is often used as a substitute.

Assessor: Asian Regional Workshop

Refs: 5550, 6426, 12937

\section{Capparis crotonantha}

Capparaceae

DD

Panama

The species is known only from the type collection in San Blas. The specimen is not complete and was probably described erroneously as a separate species from $C$. filipes, which occurs widely in the same area.

Assessor: Mitré, M.

Refs: $7272,7980,16772$ 


\section{Capparis discolor}

Capparaceae

Colombia, Costa Rica, Mexico, Nicaragua, Panama

Ranging from the Gulf Region of Mexico to Colombia in areas of lowland rainforest, the species is reported to be most common in Costa Rica and Nicaragua. In Panama small populations have been recorded from the provinces of Panamá and Darién, including an occurrence in Darién National Park. The Colombian population appears to be confined to Antioquia. Throughout the species range the habitat has been extensively cleared for agriculture, settlement and its timber resources.

Assessor: Mitré, M.

Refs: 16772

\section{Capparis mirifica}

Capparaceae

CR C2a

Panama

A small tree, known from very few collections taken from a small area of lowland semi-deciduous rainforest to the north-east of the Panama Canal. The area has suffered much deforestation, although forest is protected within the national parks of Chagres and Portobelo. Occurrences are evidently rare, but it is possible further exploration will uncover additional localities.

Assessor: Mitré, $\mathbf{M}$.

Refs: 7272, 7980, 16772

\section{Capparis mollicella}

Capparaceae

VUAlc

Mexico

A relatively widepsread Mexican endemic, occurring in rainforest and also drier forest types in the Gulf region and the Pacific slopes.

Assessor: World Conservation Monitoring Centre

Refs: 5993, 19124

\section{Capparis pachyphylla}

Capparaceae

$\mathrm{EN} \mathrm{B} 1+2 \mathrm{c}$

India (Arunachal Pradesh)

Once reported to be common along windswept steep cliffs and slopes, the species has not been recoilected since 1935 from the known localities in the Aka Hills and Tuzu River Gorge. The area is remote and the species is likely to be found again.

Assessor: World Conservation Monitoring Centre

Refs: 4799

\section{Capparis panamensis}

Capparaceae

CR C2a

Panama

All collections of this species come from a small area of lowland evergreen rainforest to the north-east of Panamá City. The populations are small and strongly affected by logging and other activities. There is a possibility that there are further populations occur in Chagres National Park in south-east Colon and around the Canal.

Assessor: Mitré, M.

Refs: $1370,7980,16772,18416$

\section{Capparis sprucei}

Capparaceae

VU D2

Peru

A species known only from the type collection from San Martin.

Assessor: World Conservation Monitoring Centre

Refs: 1984
Capparis uniflora

Capparaceae

DD

Panama

Originally collected from Cocle in 1941 and identified as $C$. baducca, the specimen was redescribed as a new species, $C$. uniflora. No recent collections have been made and there is insufficient evidence to confirm the taxonomy.

Assessor: Mitré, $\mathrm{M}$.

Refs: 7272,16772

\section{Captaincookia margaretae}

Rubiaceae

$\mathrm{CR} \mathrm{BI}+2 \mathrm{c}$

New Caledonia

A species from a genus endemic to New Caledonia. It is confined to a small area of threatened sclerophyllous forest. Fires, grazing and encroaching agriculture are continuous problems.

Assessor: Jaffré, T. et al.

Refs: $1833,4492,10351$

\section{Caraipa jaramilloi}

Guttiferae

LR/nt

Peru

A species of *terra firme forest occurring in the departments of Loreto, Madie de Dios and Pasco. Assessor: World Conservation Monitoring Centre Refs: 1984

\section{Caraipa utilis}

Guttiferae

VU D2

Peru

Occurring in *terra firme forest on white sand, the species is known only from the type collection. Assessor: World Conservation Monitoring Centre Refs: 1984

\section{Carallia calycina}

Rhizophoraceae

Sri Lanka

A tree restricted to the lowland wet evergreen forests of south-west Sri Lanka.

Assessor: World Conservation Monitoring Centre

Refs: 15431, 17195, 17759

\section{Carallia diplopetala}

Rhizophoraceae

LR/nt

China (Guangxi), Viet Nam

Confined to the Shiwan Mountains in southem Guangxi, the species appears to occur in such low numbers that repeated recent searches for it have failed. In Viet Nam it appears to be more widespread in secondary forest and forest margins in central provinces and mountain areas.

Natural regeneration is reported to be good here.

Assessor: World Conservation Monitoring Centre

Refs: $1818,11847,15357,19060$

\section{Carallia euryoides}

Rhizophoraceae

Malaysia (Peninsular Malaysia)

LR/nt

A species of lowland and hill forest, rarely reaching an altitude of $900 \mathrm{~m}$, occasionally found on quartz ridges. Populations are recorded in Selangor, Pahang and Johore, where it is protected in Taman Negara National Park.

Assessor: Chua, L.S.L.

Refs: 8464, 19073 


\section{Carica jamaicensis}

Caricaceae

VU $B 1+2 c$

Jamaica

The species has a local distribution on rocky banks or in thickets and pastures on coral limestone or sandy soils near the sea.

Assessor: World Conservation Monitoring Centre

Refs: 6057,7980

\section{Cariniana ianeirensis \\ Lecythidaceae}

Brazil (Rio de Janeiro)

$\mathrm{EN} \mathrm{B1}+2 \mathrm{c}$

A species known only from four collections in the Allantic forests of Tijuca and Itaocara. Its proximity to Rio de Janeiro places it under serious pressure from urban encroachment and recent intensive fieldwork in the area has failed to find living specimens. Much of Tijuca forest is protected. The species is included in the official list of threatened Brazilian plants compiled by *IBAMA.

Assessor: Varty, N

Refs: $7980,8815,16123$

\section{Cariniana integrifolia}

\section{Lecythidaceae}

VU B1+2c

Brazil (Amazonas)

Confined to non-flooded forest of central Amazonia, near Manaus, the species is under threat from increasing land settlement and fires. It occurs in the Ducke Forest Reserve.

Assessor: Pires O'Brien, J.

Refs: $1503,5942,7980,9632$

\section{Cariniana kuhlmanni}

Lecythidaceae

Brazil (Rondônia)

CR B I $+2 \mathrm{C}$

A savanna tree, known only from the type collection from Campos dos Urupa's. There is a serious threat of habitat loss through increasing land settlement.

Assessor: Pires O'Brien, J.

Refs: 1503, 3791, 7980, 9632

\section{Cariniana legalis}

Lecythidaceae

VUAlac

Brazil (Alagoas, Bahia, Espirito Santo, Minas Gerais, Paraíba, Pernambuco, Rio de Janeiro, São Paulo), Colombia?, Venezuela?

A large emergent tree, sparsely scattered in areas of lowland non-flooded rainforest, such as Atlantic forest, mesophyllous, riverine or hygrophyllous forest and semi-deciduous woodland. Large trees are also left standing in agricultural areas and coffee plantations. Populations frequently occur on fertile land and considerable habitat loss has caused declines in the species.

Assessor: Americas Regional Workshop

Refs: $1503,7980,9632,11449,19179,19184$

\section{Cariniana pachyantha}

Lecythidaceae

$\mathrm{VU} B 1+2 \mathrm{c}, \mathrm{D} 2$

Brazil (Amazonas)

A large tree, endemic to lowland rainforest in São Paulo de Olivença. It is known only from the type collection.

Assessor: Pires O'Brien, J.

Refs: 1503, 3791, 7980, 9632

\section{Cariniana pauciramosa}

Lecythidaceae

$\mathrm{EN} \mathrm{B} 1+2 \mathrm{C}$

Brazil (Amazonas)

This species has only ever been collected from a single site of lowland rainforest along the Manaus to Itacoatiana road.

Assessor: Pires O'Brien, J.

Refs: $1503,5942,7980,9632$

\section{Cariniana penduliflora}

Lecythidaceae

CR B $1+2 \mathrm{c}$

Brazil (Rondônia)

A species of savanna or open woodland, known only from Mutumparaná. Much of the narural vegetation has been lost to agricultural encroachment.

Assessor: Pires O'Brien, J.

Refs: $1503,3791,7980,9632$

\section{Cariniana pyriformis}

Lecythidaceae

LR/nt

Brazil, Colombia, Costa Rica, Venezuela

A relatively wide ranging species of primary forest. It is threatened at a national level in Colombia and is causing some concern in Venezuela. The wood has been commercially expoited but is considered hard to work. It has been cultivated outside its natural range in Jamaica,

Trinidad and Singapore.

Assessor: World Conservation Monitoring Centre

Refs: $1503,5942,7980,9632,12109,19069$

\section{Cariniana uaupensis}

Lecythidaceae

VU B $1+2 c$

Brazil (Amazonas)

The known distribution of this rainforest species is confined to its type locality in Imeri

Assessor: Pires O'Brien, J.

Refs: 1503, 3791, 5942, 7980, 9632

\section{Carissa edulis var. sechellensis}

Apocynaceae

EN D1

Seychelles

The main population is confined to Silhouette. On Aldabra there are two trees and the population on Mahé became extinct by 1874 , probably because of habitat clearance. About 150 mature trees exist in total, a large population occurring at Mont Cocos Marrons. The trees were also felled in the past for the production of aromatic oils and fuelwood for copra dryers. All populations are within areas which are given protection. Assessor: Nature Protection Trust of Seychelles

Refs: 10610

\section{Cappinus putoensis}

Corylaceae

CR D1

China (Zhejiang)

A single fenced tree is left in the wild on Mount Froding on Putuo Island in the Zhoushan Archipelago. Originally occurring in evergreen broadleaved forest, the remaining tree now exists at the edge of a sparse mixed forest. The species is monoecious.

Assessor: World Conservation Monitoring Centre Refs: $1818,11725,11847$ 


\section{Carpodiptera mirabilis}

Tiliaceae

CR B1+2C

Cuba

This beautiful tree is localised in montane rainforest on limestone-derived soils within Guantanamo Province. No flowering specimens have ever been collected.

Assessor: Areces-Mallea, A.E.

Refs: $16327,18485,19149$

\section{Carpodiptera ophiticola}

Tiliaceae

$\mathrm{EN} \mathrm{B} 1+2 \mathrm{c}$

Cuba

An uncommon shrub or small tree occurring locally near ravines and washes in the serpentine outcrop of Canasí, Matanzas Province. The habitat is under constant threat of being completely cut and cleared.

Assessor: Areces-Mallea, A.E.

Refs: $16327,18485,19149$

\section{Carpoxylon macrospermum}

Palmae

CR DI

Vanuatu

A palm tree of omamental interest, confined to areas of lowland rainforest in Aneityum, Tanna and Futuna. Approximately 40 individuals exist in the wild and another 120 mature trees are cultivated around villages. Regeneration is moderate. The species is protected and the subject of a conservation plan managed by the Vanuatu Forestry Department.

Assessor: Dowl, J.L.

Refs: 19118

\section{Caryocar amygdaliforme}

Caryocaraceae

$\mathrm{EN} \mathrm{B1+2c}$

Colombia, Panama, Peru

Apparently endemic to Colombia, the species is known to occur in Antioquia, Bolivar, Caldas, Santander, Tolima and possibly Caquetá. The Peruvian distribution requires confirmation. There may also be a collection from Darién in Panama. The species is closely related to C. costaricense to such a degree that they may be forms of the same taxon.

Assessor: Calderon, E.

Refs: $7980,19069,19216$

\section{Caryocar coriaceum}

Caryocaraceae

EN Ala+2c

Brazil

A species of *cerrado, restricted to the Chapado do Araripe in Brazil.

Assessor: Prado, D.

Refs: 1262,7980

\section{Caryocar costaricense}

Caryocaraceae

VU Alacd

Colombia, Costa Rica, Panama, Venezuela

The species is known from scattered populations in lowland evergreen rainforest. In Costa Rica occurrences are very scarce and confined to protected areas. Similarly in Panama, the species is restricted to Darién and San Blas, where populations appear to be in a poor state with little evidence of regeneration. Levels of exploitation of the timber are reported to be high but there are differences in opinion as to whether timber trade is a serious threat to the species. Habitat loss has, however, been severe. Populations extend into the
Chocó in Colombia. There may some confusion with populations of the closely related species, $C$. amygdaliforme. The species is listed on Appendix II of *CITES.

Assessor: Americas Regional Workshop

Refs: $7980,14487,16772,19179,19185$

Caryodaphnopsis cogolloi

Lauraceae

Colombia

$\mathrm{EN} \mathrm{B1}+2 \mathrm{c}$

An endemic to Antioquia.

Assessor: Calderon, E.

Refs: 19069

\section{Caryodendron angustifolium}

Euphorbiaceae

DD

Panama

The species appears to be known only from the type specimen, collected in Progresso in Chiriqui in the first half of the century, although it possibly occurs in the Golfo Dulce area in Costa Rica. Additional specimens originally recorded as this species from other parts of Panama have since been identified as Senefeldera testiculata. It is not known whether the species is now extinct.

Assessor: Mitré, $\mathrm{M}$.

Refs: $7272,7980,16772,19177$

\section{Casasia longipes}

Rubiaceae

LR/nt

Jamaica

An uncommon tree found in remaining areas of woodland on limestone in central parishes.

Assessor: World Conservation Monitoring Centre

Refs: 6057,7980

\section{Casearia albicans}

Flacourtiaceae

Malaysia (Peninsular Malaysia)

A small tree confined to the moist forest of Penang and Perak.

Assessor: Chua, L.S.L.

Refs: 8464,19073

\section{Casearia atlantica}

Flacourtiaceae

EN C2a

Panama

Occurring chiefly along forested riversides, the species appears to be confined to the Atlantic side of three provinces. The few living specimens known are sparsely scattered in forest that is not well studied and, in parts, disappearing through encroaching agriculture and settlements.

Assessor: Mitré, M.

Refs: $7980,12756,16772$

\section{Casearia coriffolia}

Flacourtiaceae

$\mathrm{LR} / \mathrm{cd}$

New Caledonia

Assessor: Jaffré, T. et al.

Refs: 10351

\section{Casearia crassinervis}

Flacourtiaceae

VU D2

Cuba

A shrub which sometimes reaches the size of a small tree. It occurs in pine woodland and forest and is 
confined to the mountains of the Nipe-Baracoa Massif in eastern Cuba.

Assessor: Areces-Mallea, A.E.

Refs: 7980,19149

\section{Casearia engleri}

Flacourtiaceae

VU $B 1+2 b$

Tanzania

A montane forest tree restricted in range to the West Usambara Mountains.

Assessor: Lovett, J. \& G.P. Clarke

Refs: $3356,5020,5204$

\section{Casearia flavovirens}

Flacourtiaceae

VU B $1+2 c$

Indonesia (Bali, Java)

A species of various forest types occurring up to an altitude of $800 \mathrm{~m}$ in eastem Java and Bali. All forested areas at these elevations have experienced heavy clearing and are under intense pressure from the activities of local populations.

Assessor: World Conservation Monitoring Centre

Refs: 7673,9078

\section{Casearia flexula}

Flacourtiaceae

Malaysia (Peninsular Malaysia)

An uncommon shrub or small tree of submontane and hill forest confined to Kedah Peak. Similar specimens, which could be this species, have been collected elsewhere in Peninsular Malaysia and in Sumatra and Borneo.

Assessor: Chua, L.S.L.

Refs: 8464,19073

\section{Casearia kaalaensis}

Flacourtiaceae

$\mathrm{EN} \mathrm{B} 1+2 \mathrm{c}$

New Caledonia

Assessor: Jaffré, T. et al.

Refs: 10351

\section{Casearia lasiophylla}

Flacourtiaceae

Brazil (Alagoas, Minas Gerais, Paraná, Piauí, Rio de Janeiro, Santa Catarina, São Paulo)

Although the species is geographically widespread, its distribution is discontinuous. It is found principally in areas of Araucaria forest, but also in more open areas and pastureland. Occurrences are rare in Sāo Paulo and questionable in Rio de Janeiro. It has, however, been recently collected from Paraná.

Assessor: Torres, R.B.

Refs: 19098,19099

\section{Casearia macrocarpa}

Flacourtiaceae

Malaysia (Peninsular Malaysia)

VU B $1+2 c$

This small tree species is found only in areas of rainforest in Penang.

Assessor: Chua, L.S.L.

Refs: 8464,19073

\section{Casearia mannii}

Flacourtiaceae

São Tomé \& Príncipe (Príncipe)

VU D2

The species has been collected only twice and no information on its exact locality has been recorded.
There have been no recent botanical surveys of the island.

Assessor: World Conservation Monitoring Centre

Refs: 2724

\section{Casearia mauritiana}

Flacourtiaceae

Mauritius

Assessor: Strahm, W

Refs: $9120,16426,19208$

\section{Casearia megacarpa}

Flacourtiaceae

VU B $1+2 c$

Colombia

This endemic Colombian species occurs in Valle and Vaupes.

Assessor: Calderon, E.

Refs: 7980, 19069

\section{Casearia mexiae}

Flacourtiaceae

VU B $1+2 c$

Ecuador

An endemic of Ecuador, inhabiting montane and upper montane cloud forest. Currently this species is only known from the High Andean areas of Imbabura and Pichincha.

Assessor: World Conservation Monitoring Centre

Refs: $7980,19119,19120$

\section{Casearia quinduensis}

Flacourtiaceae

Colombia

An extinct species, previously recorded in Tolima and possibly Quindio.

Assessor: Calderon, E.

Refs: 7980, 19063, 19069

\section{Casearia tinifolia}

Flacourtiaceae

Mauritius

No specimens have been found since 1976.

Assessor: Strahm, W.

Refs: $9120,16426,19208$

\section{Casearia williamsiana}

Flacourtiaceae

CR C2a

Honduras

A species of *matorral, thickets and dry forest along rivers, at low to middle elevations.

Assessor: Nelson, C.

Refs: $7980,12756,13995$

\section{Casearia wynadensis}

Flacourtiaceae

India (Kerala, Tamil Nadu)

VU B $1+2 c$

A small tree of low to medium elevation evergreen forest, occurring in scattered localities in Wayanad and the Nilgiris with some outlying populations further south.

Assessor: World Conservation Monitoring Centre Refs: 19144

\section{Cassia aldabrensis}

Leguminosae

VU D2

Seychelles (Aldabra)

This species appears on Assumption and all the main islands of Aldabra, except the westem portion of Grand Terre. It occupies crevices on limestone pavement (platin) and on pinnacled micro-karst limestone 
(champignon). Aldabra is protected as a Strict Nature Reserve. Assumption has experienced some habitat clearance for strip-mining for phosphate or guano.

Assessor: World Conservation Monitoring Centre Refs: 19027

\section{Cassia artensis}

Leguminosae

New Caledonia

Assessor: Jaffré, T, et al.

Refs: 10351

\section{Cassia aubrevillei}

Leguminosae

VU Alc, B1+2c

Côte d'Ivoire, Gabon

The distribution of this rare species is disjunct. It is known only from lowland moist semi-deciduous forest in Gabon and further west in Côte d'Ivoire. This type of forest in the latter country has disappeared outside protected areas. In the former country forest areas are unprotected, with the exception of the newly established national park at Lopé, and largely under concession to logging companies.

Assessor: World Conservation Monitoring Centre

Refs: 2773, 12822

\section{Cassia fikifiki}

Leguminosae

$\mathrm{EN} \mathrm{B1+2c}$

Côte d'Ivoire

A species endemic to lowland forest in south-west Côte d'Ivoire, between the rivers Sassandra and Cavally. Severe deforestation in the area has resulted in there being little forest outside Tai National Park.

Assessor: Assi, A.

Refs: 12822

\section{Cassine koordersii}

Celastraceae

$\mathrm{CR} B 1+2 \mathrm{c}$

Indonesia (Java)

It is not known whether the species is still extant in the wild. The only known location, which was siruated in a seasonally dry area in Pugur in the Lampesan Valley and Watangan Hills, is now deforested. Intense population pressure has been the main cause of habitat loss.

Assessor: World Conservation Monitoring Centre

Refs: 9078

\section{Cassipourea brittoniana}

Rhizophoraceae

$\mathrm{EN} \mathrm{B1}+2 \mathrm{c}$

Jamaica

An uncommon tree confined to areas of woodland on limestone hills in Trelawny.

Assessor: World Conservation Monitoring Centre

Refs: 401, 5653, 7980

\section{Cassipourea eketensis}

Rhizophoraceae

CR Alc Nigeria

Recorded only from Eket in south-eastem Nigeria, the habitat of this species is likely to have been destroyed by operations for oil exploration. A botanical survey of the area is required to ascertain whether the species is now extinct.

Assessor: World Conservation Monitoring Centre Refs: 450, 2773, 11504
Cassipourea fanshawei

Rhizophoraceae

VU D2

Zambia

The type collection, made in Musondwa in 1958, is the only known record of this species.

Assessor: World Conservation Monitoring Centre

Refs: 18965

\section{Cassipourea flanaganii}

Rhizophoraceae

VU A2c

South Africa (Eastern Cape)

Found in evergreen forest along the Eastern Cape coast and further inland, mainly in Transkei, the species occurs in many localities which are supposedly protected as demarcated forest. However, the system of protection has not been successfully upheld since 1994 . Much of the forest, including that which is not demarcated, is threatened by increasing settlement and cutting for firewood and timber.

Assessor: Hilton-Taylor, C. et al.

Refs: 689,19218

\section{Cassipourea hiotou}

Rhizophoraceae

VU Alc, B1+2c

Côte d'Ivoire, Ghana

A tree which can be common where it occurs but is strictly confined to wet evergreen forests. In Côte d'Ivoire it is restricted to the south-west, mainly in Tai National Park. This type of forest has reduced in extent significantly because of logging and mining and also the establishment of industrial plantations.

Assessor: Assi, A

Refs: $8369,12061,12822$

Cassipourea obovata

Rhizophoraceae

DD

Mozambique

Assessor: Bandeira, S.

Refs: 5117,18965

\section{Cassipourea subcordata}

Rhizophoraceae

$\mathrm{CR} \mathrm{Bl}+2 \mathrm{c}$

Jamaica

A small tree known only from an area of marsh and one other site along a brook in limestone hills in Trelawny. Assessor: World Conservation Monitoring Centre Refs: 401, 5653, 7980

\section{Cassipourea subsessilis}

Rhizophoraceae

$\mathrm{CR} \mathrm{B} 1+2 \mathrm{c}$

Jamaica

A very uncommon tree endemic to Dolphin Head, where it is confined to areas of woodland on limestone in the north-east.

Assessor: World Conservation Monitoring Centre Refs: 401, 5653, 7980

\section{Cassipourea swaziensis}

Rhizophoraceae

South Africa (KwaZulu-Natal), Swaziland

There is taxonomic confusion over this species. Little is known about its abundance and precise distribution. It has been found on exposed quartzite rock ridges in only three definite localities, where the habitat is under threat from cutting as a source of firewood and timber.

Assessor: Hilton-Taylor, C. et al.

Refs: $689,11785,19218$ 


\section{Cassipourea thomassetii}

Rhizophoraceae

VU D2

Seychelles (Aldabra)

A shrub or small tree which appears to be very sparsely distributed in inland mixed scrub on Malabar, Polymnie and the west of Picard. The islands are under protection in a Strict Nature Reserve and only Picard is inhabited by staff of a research station.

Assessor: World Conservation Monitoring Centre

Refs: 11577, 19027, 19062

\section{Castanopsis catappaefolia}

Fagaceae

$\mathrm{CR} \mathrm{Bl}+2 \mathrm{c}$

Malaysia (Peninsular Malaysia)

This lowland tree of open rainforest is known only from the type collection, gathered in 1886 from the district of Gopeng, Perak.

Assessor: World Conservation Monitoring Centre Refs: 19073

\section{Castanopsis concinna}

Fagaceae

VU B $1+2 \mathrm{ce}$

China (Guangdong, Guangxi), Hong Kong

A tree known only from scattered small populations on low-lying hills on the coast from the mouth of Zhujiang River to Shiwan Mountain. Numbers are believed to be very small and declining because of cutting for the timber. Some populations, e.g. at Datan in Hong Kong and Chengman in Jiulong, are protected.

Assessor: World Conservation Monitoring Centre

Refs: 1818,11847

\section{Castanopsis curtisii}

Fagaceae

LR/nt

Malaysia (Peninsular Malaysia)

A medium-sized tree, distributed in lowland rainforest areas in Perlis, Kedah, Kelantan, Penang, Pahang and Selangor. Protected populations are found within Taman Negara National Park.

Assessor: Chua, L.S.L.

Refs: 8464, 19073

\section{Castanopsis kawakamii}

Fagaceae

LR/nt

China (Fujian, Guangdong, Jiangxi), Taiwan, Viet Nam

A massive tree scattered in subtropical evergreen broadleaved forest along the south-east coast of China and in Taiwain, and widespread in northern and central Viet Nam. Trees are heavily cut in many areas for the timber, which is used in construction work. Regeneration, at least in Viet Nam, is reported to be poor and limited to forest edges.

Assessor: SSC Temperate Broadleaved Trees Specialist Group

Refs: $1818,6469,11847,15357$

\section{Castanopsis nephelioides}

Fagaceae

VUAlc

Malaysia (Peninsular Malaysia), Singapore

Occurring up to $1600 \mathrm{~m}$, the species is found in both open and closed rainforest in Kedah, Kelantan, Penang, Pahang and Selangor.

Assessor: Chua, L.S.L.

Refs: $8464,9199,11647,19073$

\section{Castanopsis scortechinii}

Fagaceae

VU B $1+2 \mathrm{c}$

Malaysia (Peninsular Malaysia)

A rare tree occurring in the hill forests of Perak and
Pahang. The localities are given a degree of protection within the permanent forest estate. However, large areas remain threatened by encroaching agriculture.

Assessor: Chua, L.S.L.

Refs: 8464, 19073

\section{Castanopsis wallichï}

Fagaceae

VU B $1+2 c$

Malaysia (Peninsular Malaysia), Singapore

This tree is found in the lowland rainforests of Kedah, Penang, Perak, Selangor, Malacca and Singapore. Much of the remaining habitat is under threat from development, although four small localities are contained within forest reserves.

Assessor: Chua, L.S.L.

Refs: $8464,9199,19073$

\section{Catalpa brevipes}

Bignoniaceae

Cuba, Dominican Republic, Haiti

VU $B 1+2 c$

In Cuba, this small tree is known from the limestone hills of Baire on the northern side of the Sierra Maestra mountain range and from the dry forests on coastal limestone in Cabo Cruz. It has also been collected from Azua in the Dominican Republic and the Massif de la Hotte in Haiti.

Assessor: Areces-Mallea, A.E.

Refs: 7980, 8451, 11403, 18485, 19149

\section{Cathaya argyrophylla}

Pinaceae

$\mathrm{LR} / \mathrm{cd}$

China (Guangxi, Guizhou, Hunan, Sichuan)

A monospecific genus occurring in a few disjunct localities in the eastern Dalou Mountains and in the Yuecheng range. Around 30 small to medium-sized stands occur in areas which are fairly inaccessible. The populations are well protected but there is concern that they will be replaced by faster growing broadleaved species if regeneration continues to be poor.

Assessor: SSC Conifer Specialist Group

Refs: $1818,5624,11847,13041$

\section{Cavanillesia platanifolia}

Bombacaceae

LR/nt

Colombia, Costa Rica, Nicaragua, Panama, Peru

A widely distributed species, occurring in lowland rainforest and in areas which have been disturbed or cleared of forest. The Colombian population is considered to be endangered. In Panama, the largest populations are found in the Canal area and in Darien. It is one of the few trees often left uncut after forest clearance because its large size makes handling difficult. Solitary individuals and scattered populations are distributed throughout the rest of Panama, and in neighbouring Central American countries it is relatively common.

Assessor: Mitré, $\mathrm{M}$

Refs: $11449,16772,19069$

\section{Cecropia longipes}

Cecropiaceae

EN C2a

Colombia, Panama

In Panama the species occurs in moist forest, woodland and scrub habitats from the Canal area to Darién. Populations are small and dispersed and there are few young individuals. A small part of the species range is 
contained within protected areas. More information is needed on the population status in Colombia.

Assessor: Mitré, $M$.

Refs: 7272, 7980, 16772

\section{Cecropia maxonii}

Cecropiaceae

DD

Panama

Occurring in Boquete in the province of Chiriqui, the species has been collected only twice, although the area has been relatively well studied. There is not enough information to categorise the species as extinct and it is possible that more recent collections have been identified under a different species name.

Assessor: Mitre, M.

Refs: $7272,7980,16772$

\section{Cecropia multiflora}

Cecropiaceae

Peru

$\mathrm{LR} / \mathrm{nt}$

A lowland forest species restricted to the departments of Amazonas, Cuzco and Junín.

Assessor: World Conservation Monitoring Centre Refs: 1984

\section{Cecropia tubulosa}

Cecropiaceae

VU D2

Peru

Known only from the type collected in Huanuco, this species occurs in lowland rainforest.

Assessor: World Conservation Monitoring Centre

Refs: 1984

\section{Cecropia utcubambana}

Cecropiaceae

VU D2

Peru

Recorded from the type only, this species occurs in lowland rainforest in Amazonas Department.

Assessor: World Conservation Monitoring Centre

Refs: 1984

\section{Cedrela fissilis}

Meliaceae

EN Alacd +2 cd

Argentina (Jujuy, Misiones, Salta, Tucumán), Bolivia,

Brazil (Rio Grande do Sul, Santa Catarina), Colombia,

Costa Rica, Ecuador, Panama, Paraguay, Peru, Venezuela

At one time an abundant and wide-ranging species in lowland forest types. Populations throughout its range have been decimated by overexploitation and habitat loss. Overexploitation has resulted in the species becoming threatened in Colombia and Amazonian Peru. Most natural populations in Ecuador have been destroyed. Some large trees remain in Cuyabeno but they are being felled for export to Colombia. The species has become rare in Bolivia and is now only harvested opportunistically whilst mahogany, Amburana and Machaerium are being sought-after. It is apparently still abundant in the Región Oriental in Paraguay, especially along the Paraná valley. Populations in Argentina are restricted to the north, where they are partly contained within subandean piedmont forest, a habitat which is under severe threat. In Central America there are very few individuals in Costa Rica, if any at all, and few in
Panama. The timber is considered inferior to $C$. odorata, but is sold with the latter in mixed batches.

Assessor: Americas Regional Workshop

Refs: 1262, 4506, 5112, 7272, 7906, 9173, 11374, $11936,12281,14873,19170,19179,19195,19213$

Cedrela lilloi

Meliaceae

EN Ala+2cd

Argentina, Bolivia, Brazil (Santa Catarina), Paraguay, Peru

A commercial timber species of montane forest, occurring between 800 and $3400 \mathrm{~m}$. Colonising land after substantial disturbances, the species occurs in large, almost monodominant stands. In many areas these have been drastically reduced, the largest now remaining in regions of Santa Cruz, Bolivia.

Assessor: Llamozas, $\mathrm{S}$.

Refs: $1262,7980,12281,14040,19121,19170$

\section{Cedrela odorata}

Meliaceae

VU Alcd+2cd

Antigua and Barbuda, Argentina, Barbados, Belize, Bolivia, Brazil, Cayman Islands, Colombia, Costa Rica, Cuba, Dominica, Dominican Republic, Ecuador, El Salvador, French Guiana, Grenada, Guadeloupe, Guatemala, Guyana, Haiti, Honduras, Jamaica, Mexico (Quintana Roo), Montserrat, Nicaragua, Panama, Peru, St Kitts and Nevis, St Lucia, Suriname, Venezuela

One of the world's most important timber species. It occurs in humid or dry lowland forest, preferring welldrained soils. Exploitation has continued on a large scale over the past 200 years and the species is now widely threatened at the provenance level. Large individuals. have become scarce, especially in Amazonia. Trees are often cut opportunistically while other species, such as mahogany, Amburana and Machaerium, are being sought-after. Natural regeneration is generally good, but there are reports of trees being felled before they reach maturity. Populations are protected within national parks and agricultural landscapes. Attempts are being made to establish plantations throughout the tropics.

Assessor: Americas Regional Workshop

Refs: $4147,4217,4506,5519,6602,8503,12109$, $12281,14873,15037,16235,16261,19170,19179$

\section{Cedrus brevifolia}

Pinaceae

VU D2

Cyprus

Only one population is known, from Mount Triphylos.

Assessor: SSC Conifer Specialist Group

Refs: 374,13041

\section{Cedrus libani var, libani}

Pinaceae

LR/nt

Lebanon, Syria, Turkey

Although this variety is not threatened in Turkey, it is heavily threatened in Lebanon and extremely restricted in Syria.

Assessor: SSC Conifer Specialist Group

Refs: $374,4506,9058,12984,13041$

\section{Ceiba rosea}

\section{Bombacaceae}

Colombia, Costa Rica, Panama

VU C2a

Occurring in medium-altitude forest, the species is found in scattered populations, which are never large, on the Pacific side of the Cordillera Central throughout 
Panama, and in the Chocó in Colombia and Alajuela in Costa Rica. Throughout the species range, there is evidence of medium to high human disturbance. In Chiriqui, Panama, the population is affected by annual buming.

Assessor: Mitré, $\mathbf{M}$.

Refs: 7980,16772

\section{Celtis balansae}

Ulmaceae

VU B $1+2 c$

New Caledonia

Assessor: Jaffre, T. et al.

Refs: 10351

\section{Celtis hypoleuca}

Ulmaceae

$\mathrm{EN} B 1+2 \mathrm{c}$

New Caledonia

Assessor: Jaffré, T. et al.

Refs: 10351

\section{Celtis jamaicensis}

Ulmaceae

$\mathrm{LR} / \mathrm{nt}$

Jamaica

A species found occasionally in woodland on steep limestone hillsides in the central and eastern parishes. General habitat declines have been considerable, mostly caused by increasing agriculture.

Assessor: World Conservation Monitoring Centre

Refs: 6057,7980

\section{Celtis lindheimeri}

Ulmaceae

VU B $1+2 c$

Mexico, USA (Texas)

A tree of brushlands and ravines, in Texas occurring near San Antonio and Edward's Plateau and in Mexico confined to the north.

Assessor: World Conservation Monitoring Centre

Refs: $3786,7980,19163$

\section{Celtis luzonico}

Ulmaceae

VU Alcd

Philippines

A timber species, endemic to the Philippines. Rates of habitat loss through logging and shifting cultivation have led to considerable population declines.

Assessor: World Conservation Monitoring Centre

Refs: 4919,12937

\section{Centaurodendron dracaenoides}

Compositae

CR B $1+2 \mathrm{C}$

Chile (Juan Fernández Is)

Preliminary data indicate the species is confined to less than $100 \mathrm{~km}^{2}$ and declining in numbers through the effects of grazing by feral animals and spread of introduced weeds. More detailed information on the species should become available to confirm this evaluation. The islands are designated as a national park and biosphere reserve and work is being carried out by *CONAF to save the native plants. The genus contains three species, endemic to Juan Femandez.

Assessor: World Conservation Monitoring Centre

Refs: $3241,5651,14140$

\section{Centaurodendron palmiforme}

Compositae

$\mathrm{CR} B 1+2 \mathrm{c}$

Chile (Juan Fernández Is)

Preliminary data indicate the species is confined to less than $100 \mathrm{~km}^{2}$ and declining in numbers through the effects of grazing by feral animals and spread of introduced weeds. More detailed information on the species should become available to confirm this evaluation. The islands are designated as a national park and biosphere reserve and work is being carried out by *CONAF to save the native plants. The genus contains three species, endemic to Juan Fernandez.

Assessor: World Conservation Monitoring Centre

Refs: 3241,14140

\section{Centrolobium yavizanum}

Leguminosae

VU Cl

Colombia, Panama

Known only from the province of Darien, the species is uncommon and restricted to small groups of trees, principally occurring in open woodlands at river edges. Populations in Darién National Park appear to be slightly more common and well protected. Also recorded in Colombia, the species occurs equally infrequently in the Valle del Cauca and the Choco.

Assessor: Mitré, M.

Refs: $3156,7272,7980,16772$

\section{Centronia brachycera}

Melastomataceae

VU B $1+2 c$

Colombia

Endemic to Colombia, the species has been recorded from Cundinamarca, Huila and Santander.

Assessor: Calderon, E.

Refs: 19069

\section{Centronia laurifolia}

Melastomataceae

VU D2

Peru

A species known only from a single collection in Huánuco Department.

Assessor: World Conservation Monitoring Centre Refs: 1984

\section{Centronia mutisii}

Melastomataceae

VU B $1+2 c$

Colombia

An endemic to Cundinamarca.

Assessor: Calderon, E.

Refs: 19069

\section{Centronia peruviana}

Melastomataceae

VU B $1+2 c$

Peru

A cloud forest species apparently confined to the department of Huánuco between altitudes of 3000 and $3500 \mathrm{~m}$ in the Peruvian Andes.

Assessor: World Conservation Monitoring Centre Refs: 1984

\section{Cephalomappa sinensis}

Euphorbiaceae

China (Guangxi), Viet Nam

VU B $1+2 c$

The species occurs in limestone areas in south-west Guangxi, China, and in Cao Bang in Viet Nam, where it can become dominant in moist forest below $500 \mathrm{~m}$. Overcutting and use of the tree as cattle forage are the main threats. In Viet Nam seedlings and young trees are abundant where the trees have been planted, but regeneration in the wild is almost non-existent. However, trees coppice well. Assessor: World Conservation Monitoring Centre Refs: $1818,11847,15357$ 


\section{Cephalosphaera usambarensis}

Myristicaceae

VU B $1+2 b$

Kenya, Tanzania

A monotypic genus restricted to small areas of upper moist evergreen forest in the Usambara Mountains, Southern Nguru Mountains, Uluguru Mountains and Udzungwa Mountains. A population also occurs in the Shimba Hills in Kenya. The timber, used for veneer, has been overexploited in the recent past and habitat degradation has also caused population declines. The nearest relative is a small genus, Brochoneura, in Madagascar.

Assessor: Lovett, J. \& G.P. Clarke

Refs: $3356,11631,19181$

\section{Cephalotarus fortunei}

Cephalotaxaceae

LR/nt

China (Anhui, Fujian, Gansu, Guangdong, Guangxi, Guizhou, Hubei, Hunan, Jiangxi, Sichuan, Yunnan, Zhejiang), Myanmar, Viet Nam

Assessor: SSC Conifer Specialist Group

Refs: $374,6190,11191,11530,13041,17186,18751$

\section{Cephalotaxus hainanensis}

Cephalotaxaceae

EN A2d

China (Guangdong - Hainan)

This species has previously been included in $C$. mannii and has likewise suffered population declines because of logging and more recently exploitation of bark and leaves which contain the valuable medicinal extracts, cephalotaxine and harringtonine. It is endemic to, and widespread in, lowland forest on Hainan Island. As with other members of the genus, the maturation rate of the seed is slow and regeneration is relatively infrequent.

Assessor: SSC Conifer Specialist Group

Refs: 848, 11191, 11847, 13041, 17186

\section{Cephalotaxus harringtonia var. drupacea}

Cephalotaxaceae

LR/nt

China, Japan

Assessor: SSC Conifer Specialist Group

Refs: $374,13041,17186$

\section{Cephalotaxus lanceolata}

\section{Cephalotaxaceae}

China (Yunnan), Myanmar?

VU D2

Although closely related to $C$. fortunei, this species is considered to be a distinct taxon in China. It occurs in small groves within forested valleys up to $1900 \mathrm{~m}$ in Gongshan County. An occurrence in Myanmar is recorded, but there is no collected material from here. Exploitation of the taxon for the medicinal properties of its bark, and also of the habitat for its timber resources, are the main threats to the species.

Assessor: SSC Conifer Specialist Group

Refs: $1818,11191,13041,17186$

\section{Cephalotaxus mannii}

Cephalotaxaceae

VU A1d

China (Guangdong, Guangxi, Xizang, Yunnan), India (Assam, Meghalaya, Nagaland), Myanmar, Viet Nam Although widespread, the species has become rarer because of heavy exploitation, initially of the timber in the 1960 s, but now of the bark and leaves which contain medicinal extracts, shown to be effective against leukaemia and lymphoma. The populations in China often only occur in low densities and in remote areas. Parts of the Indian population are sometimes referred to as $C$. griffithii.

Assessor: SSC Conifer Specialist Group

Refs: $374,1818,11191,11530,11847,13041$

\section{Cephalotaxus oliveri}

Cephalotaxaceae

China (Guangdong, Guangxi, Guizhou, Hubei, Hunan, Jiangxi, Sichuan, Yunnan), India, Laos, Thailand, Viet Nam

Populations of this relict species are being rapidly depleted through logging and clearing of the lowland moist forest habitat. The plant has strong sprouting capacity but regeneration by sexual reproduction appears to be slow, possibly because of its dioecious nature. It is also a rich source of the anti-cancer extracts cephalotaxine and harringtonine, but exploitation does not appear to be large-scale.

Assessor: SSC Conifer Specialist Group

Refs: $374,1818,11530,11847,13041,15357$

\section{Cephalotaxus wilsoniana}

Cephalotaxaceae

EN C2a

Taiwan

Widely distributed but locally very scarce, the species occurs in areas of forest above $1800 \mathrm{~m}$ which have been subject to extensive conversion into agricultural crops, commercial plantations and settlements. There are protected populations within Yushan and Taroko National Parks.

Assessor: Lu, S.Y. \& F.J. Pan

Refs: $374,2106,13041,19050$

\section{Ceratonia oreothauma ssp. oreothauma}

Leguminosae

VU Alcd

Oman, Yemen

The main distribution of this species lies in the eastern Hajar Mountains in northem Oman in wadis and at the summit above $1500 \mathrm{~m}$. An isolated population is recorded from Hadramaut in South Yemen. The eastern part of the Hajar population is contained within Wadi Siren Nature Reserve. In the north-west the population is not regenerating.

Assessor: Ghazanfar, S.A.

Refs: 13174,16380

\section{Ceratonia oreothauma ssp. somalensis \\ Leguminosae $\quad \mathrm{EN} \mathrm{B} 1+2 \mathrm{~d}, \mathrm{Cl}+2 \mathrm{a}, \mathrm{D} 1$}

Somalia

Less than 10 trees have been seen during the last 15 years in the escarpment area south of Mait. Two individuals were seen in January 1997 south-west of Qandala some $280 \mathrm{~km}$ to the east. More individuals are likely to exist in both areas. The habitat and the wood from this tree are used for multiple purposes and remain unprotected.

Assessor: Thulin, M.

Refs: 13174,18665

\section{Ceratopetalum succirubrum}

Cunoniaceae VU A2cd

Australia, Indonesia (Irian Jaya), Papua New Guinea

In Papua New Guinea populations are mainly confined to Westem Province, where they are scattered in primary rainforest or monsoon forest. They are confined to an area which is heavily logged. The wood is decorative 
and exported in small quantities. Ongoing exploitation will result in population decline and habitat destruction. More information is needed on the population status in Australia.

Assessor: Eddowes, P.J.

Refs: 19114

\section{Cerberiopsis nerïfolia}

Apocynaceae

$\mathrm{EN} \mathrm{B} 1+2 \mathrm{c}$

New Caledonia

The species is uncommon and confined to a small area in the south-east of Grand Terre encompassing parts of the Ouinne valley and along the Coniboue River.

Assessor: Jaffre, T. et al.

Refs: 10351,12630

\section{Cerberiopsis obtusifolia}

Apocynaceae

VU B $1+2 c$

New Caledonia

A relatively widely occurring species confined to remnant patches of sclerophyllous forest along the northern half of the west coast. The habitat is fragmented and reduced in extent. Fires, grazing and encroaching agriculture are continuing threats.

Assessor: Jaffré, T. et al.

Refs: 10351,12630

\section{Cercidiphyllum japonicum}

Cercidiphyllaceae

China (Anhui, Gansu, Henan, Hubei, Hunan, Jiangxi, Shaanxi, Shanxi, Sichuan, Zhejiang), Japan

A rare tree found in temperate beech forests in Japan and in remnant patches of broadleaved forest in China. The main threat to the species is poor regeneration. The katsura-tree is an important timber species in Japan. Assessor: World Conservation Monitoring Centre

Refs: $1818,4506,11847$

\section{Cercis canadensis}

Leguminosae

Canada (Ontario), USA (Connecticut)

Assessor: World Conservation Monitoring Centre

Refs: 13404,15828

\section{Cercocarpus traskiae}

Rosaceae

USA (Califomia)

A shrub or small tree, which is endemic to Catalina Island. A single wild population exists, consisting of seven individuals in a canyon covering an area of approximately $250 \mathrm{~m}^{2}$.

Assessor: World Conservation Monitoring Centre

Refs: 19033

\section{Ceroxylon alpinum}

Palmae

Colombia, Ecuador, Venezuela

$\mathrm{EN} \mathrm{B1}+2 \mathrm{c}$

A species of montane rainforest. In Colombia, the species is particularly under threat from habitat conversion to agriculture, but trees survive in deforested areas or coffee plantations. Regeneration is poor.

Assessor: Bernal, R.

Refs: 19069,19118

\section{Ceroxylon quindiuense}

Palmae

VU B $1+2 \mathrm{c}$

Colombia

The national tree of Colombia, occurring in montane rainforest in the Andes. The habitat has come under severe pressure from increasing agriculture. Adult trees, although protected by law, are removed for omamental use. The leaves, too, are collected in large quantities for use in religious festivals, although there is now mounting pressure to halt overcollection.

Assessor: Bernal, R.

Refs: 19069,19118

\section{Ceroxylon sasaimae}

Palmae

$\mathrm{CR} B \mathrm{~B}+2 \mathrm{c}$

Colombia

A palm tree of montane rainforest, principally found in the Cordillera Oriental. Trees survive in coffee plantations. Leaves are used in religious festivals.

Assessor: Bernal, R.

Refs: 19069,19118

\section{Cestrum chimborazinum}

Solanaceae

VU B $1+2 c$

Ecuador

An endemic of Ecuador currently known from the upper montane cloud forest of Chimborazo in the High Andes. Assessor: World Conservation Monitoring Centre Refs: 19119,19120

\section{Chaetocarpus coriaceus}

Euphorbiaceae

VUAlc

Sri Lanka

A tree occurring in the lowland wet evergreen forests of south-west Sri Lanka.

Assessor: World Conservation Monitoring Centre Refs: 9176, 17195

\section{Chaetocarpus pubescens}

Euphorbiaceae

CR B1+2c

Sri Lanka

A tree confined to the lowland rainforests of south-west Sri Lanka. This species was not rediscovered during the comprehensive National Conservation Review forest surveys, suggesting it is either extremely rare or possibly extinct.

Assessor: World Conservation Monitoring Centre Refs: 8203, 17195, 19112

\section{Chamaecrista bucherae}

Leguminosae

VU D2

Cuba

This shnub rarely attains the size of a small tree. An uncommon species, it is confined to the lowland serpentine shrublands of the coastal zone north of the Moa Mountains. In some places the habitat is degraded. Assessor: Areces-Mallea, A.E.

Refs: 19149

\section{Chamaecyparis formosensis}

Cupressaceae

VUAla

Taiwan

A long-living emergent, which usually forms pure stands in medium to high elevation cloud forest. Many large trees were felled in the past and exported as timber to Japan. Over a hundred large trees have been preserved as a monument near Yuenyang Lake and Lala Mountain. Regeneration is good where it is not prevented by the planting of commercial species and the invasion of broadleaved species in the undergrowth. Plantations are now being established.

Assessor: Lu, S.Y. \& F.J. Pan

Refs: 2106, 11847, 13041, 19050, 19051 


\section{Chamaecyparis lawsoniana}

Cupressaceae

VU Alde+2de

USA (Califomia, Oregon)

Natural populations of Port Orford cedar are confined to coniferous forest in coastal areas from Coos Bay to Mad River. International trade in the timber has put enormous pressure on the remaining old growth stands. The spread of the introduced pathogen Phytophthora lateralis continues at a rapid rate and prevents successful regeneration in many areas, especially those accessible by road.

Assessor: SSC Conifer Specialist Group

Refs: 7222, 13041

\section{Chamaecyparis obtusa var. formosana}

\section{Cupressaceae}

VU Alacd

\section{Taiwan}

Occuming in association with, but in a more restricted range than, $C$. formosensis, this variety is found in moist evergreen forest at medium elevations. It aiso provides a more valuable timber, and rates of exploitation have in the past been very high. Protected populations occur in Yuanyang Lake Reserve and Yushan National Park. Plantations have also been established. The species is sometimes known under the name $C$. taiwanensis.

Assessor: Lu, S.Y. \& F.J. Pan

Refs: 374, 2106, 13041, 19050, 19051

\section{Chamaecyparis obtusa var. obtusa}

Cupressaceae

VUAlc

Japan

There is concern over this species because of the extent of timber exploitation. Japan has apparently tumed to importing $C$. Lawsoniana from the USA because of the low levels of supply of the native species. A ban on logging is now in effect. Remnant populations are known to occur in submontane forest in South Honshu, Shikoku and Kyushu Islands.

Assessor: SSC Conifer Specialist Group

Refs: 5287, 7222

\section{Chamaecyparis thyoides var. henryae}

\section{Cupressaceae}

$\mathrm{LR} / \mathrm{nt}$

USA (Alabama, Florida, Mississippi)

A variety which is very scattered in the drier parts ofTaxodium forests, but it is not under any threat.

Assessor: SSC Conifer Specialist Group

Refs: 374, 11886, 13041

\section{Chamaesyce atoto}

Euphorbiaceae

VU B $1+2 c$

French Polynesia (Society Is.)

An endemic to Tahiti.

Assessor: Florence, J.

Refs: 14513

\section{Chamaesyce atrococca}

Euphorbiaceae

USA (Hawaii)

Known only from an area in the west of Kauai, the species occurs in various forest types up to an altitude of $900 \mathrm{~m}$ altitiude. A population once recorded in the north of the island near Kilauea is thought no longer to exist. Assessor: World Conservation Monitoring Centre Refs: 3372

\section{Chamaesyce celastroides var. celastroides}

Euphorbiaceae

USA (Hawaii)

LR/nt

One of the recognised varieties of a widespread and variable species. It occurs at low elevations on Nihoa, Niihau and Kauai.

Assessor: World Conservation Monitoring Centre Refs: 3372

\section{Chamaesyce celastroides var. hanopepensis}

Euphorbiaceae

USA (Hawaii)

One of the recognised varieties of a widespread and variable species. It is endemic to Kauai where it is restricted to rainforest at high elevations.

Assessor: World Conservation Monitoring Centre Refs: 3372

\section{Chamaesyce celastroides var. kaenana}

Euphorbiaceae

$\mathrm{EN} \mathrm{B} 1+2 \mathrm{c}$

USA (Hawaii)

One of the recognised varieties of a widespread and variable species. Approximately 10 populations, consisting of about 545 individuals in total, are located in coastal dry shrubland, pnncipally at Kaena Point but with small populations in Alau Gulch, Waianae Kai and Keawaula. Fires and alien species are the major threats to remaining populations. The variety is protected by the US Endangered Species Act.

Assessor: World Conservation Monitoring Centre Refs: 3372,19168

\section{Chamaesyce celastroides var. Laehiensis}

Euphorbiaceae

VU Alce

USA (Hawaii)

One of the recognised varieties of a widespread and variable species. It is known from low elevations on Lanai and near Manawainui on East Maui.

Assessor: World Conservation Monitoring Centre Refs: 3372

\section{Chamaesyce celastroides var. lorifolia}

\section{Euphorbiaceae}

USA (Hawaii)

VUAlce

One of the recognised varieties of a widespread and variable species. It is one of the dominant components of high elevation dry forest on Maui and Lanai, on which it has become particularly scarce. Disturbance caused by grazing, conversion to pastureland and the invasion of alien grasses, increasing the likelihood of serious fires, have all contributed to the decline in the habitat.

Assessor: World Conservation Monitoring Centre Refs: 3372

\section{Chamaesyce celastroides var. stokesii}

Euphorbiaceae

VU Alce USA (Hawaii)

One of the recognised varieties of a widespread and variable species. It is found in beach vegetation on Niihau, Kauai, Molokai and Kahoolawe. The habitat has been in rapid decline because of the spread of goats and other feral animals and invasive plants.

Assessor: World Conservation Monitoring Centre Refs: 3372 
Chamaesyce celastroides var. tomentella

Euphorbiaceae

USA (Hawaii)

One of the recognised varieties of a widespread and variable species. Specimens were known only from Oahu. It has not been found in recent decades and is now presumed extinct.

Assessor: World Conservation Monitoring Centre

Refs: 3372

\section{Chamaesyce herbstii}

Euphorbiaceae

$\mathrm{EN} \mathrm{B} 1+2 \mathrm{c}, \mathrm{C} 2 \mathrm{a}, \mathrm{D} 1$

USA (Hawaii)

Currently the species is known from four populations in the north and central Waianae Mountains on Oahu. There are estimated to be fewer than 200 plants in total. The lowland rainforest habitat is steadily being degraded by feral pigs and invasive plants. Protective and monitoring measures are being carried out on the population in Pahole Natural Area Reserve. The species is protected by the US Endangered Species Act.

Assessor: World Conservation Monitoring Centre Refs: $3372,12359,19168$

\section{Chamaesyce olowaluana}

Euphorbiaceae

VU Alce

USA (Hawaii)

This species was once common over a wide altitudinal range forming dry open forests up to $2800 \mathrm{~m}$ on western Maui and Hawaii. Disturbance caused by grazing, conversion to pastureland and the consequent invasion of introduced grasses increasing the likelihood of serious fires have all contributed to the decline in this habitat. Assessor: World Conservation Monitoring Centre Refs: 3372

\section{Chamaesyce rockii}

Euphorbiaceae

EN C2a

USA (Hawaii)

Usually a compact shrub but sometimes a tree, the species is confined to the Koolau Mountains on Oahu, where it is scattered in rainforest, primarily along cloudswept ridges up to $830 \mathrm{~m}$. Between 200 and 400 plants are estimated to exist in 11 populations, the majority of which lie in the Kawailoa Training Area. The vegetation is liable to be damaged or degraded by feral goats, invasive plants and military activities. The species is protected by the US Endangered Species Act. Assessor: World Conservation Monitoring Centre Refs: $3372,12359,19168$

\section{Chamaesyce sachetiana}

Euphorbiaceae

VU B1+2c

French Polynesia (Society Is.)

The species is endemic to the Marquesas, occurring as a herb, shrub or small tree in Eiao, Nuku Hiva, Ua Huka, $\mathrm{Ua}$ Pou in the northern group and Fatu Hiva, Hiva Oa and Mohotani in the south. It is a strictly littoral species, occurring from sea level to $450 \mathrm{~m}$ on rocky beaches, cliffs and rarely in secondary forest and abandoned pasturage.

Assessor: Florence, J.

Refs: 19169
Chambeyronia lepidota

Palmae

LR/cd

New Caledonia

A species of schistose soils, restricted to the north-east of the island.

Assessor: Jaffré, T. et al.

Refs: 10351,19118

\section{Charpentiera densiflora}

Amaranthaceae

EN Alce

USA (Hawaii)

The species is confined to Kauai, where it occurs, sometimes as a dominant component, in *hala forest up to $250 \mathrm{~m}$ along the Napali coast. The habitat has declined severely and is widely replaced by introduced flora. Assessor: World Conservation Monitoring Centre Refs: 3372

\section{Chassalia albiflora}

Rubiaceae

VU $B 1+2 b$

Tanzania

The range of the species is confined to the East Usambara Mountains, where it occurs within moist forests at altitudes of $800 \mathrm{~m}$ to $1050 \mathrm{~m}$.

Assessor: Lovett, J. \& G.P. Clarke

Refs: 3356,8814

\section{Cheirodendron dominii}

Araliaceae

$\mathrm{EN} \mathrm{B} 1+2 \mathrm{c}$

USA (Hawaii)

One of the four endemic Cheirodendron taxa restricted to Kauai. It is ecologically and altitudinally distinct occurring in rainforest between 1525 and $1550 \mathrm{~m}$ just below the summit of Mount Waialeale.

Assessor: World Conservation Monitoring Centre Refs: 3372

\section{Cheirodendron forbesii \\ Araliaceae USA (Hawaii)}

VU D2

A tree known from three locations on Kauai Island. It is restricted to rainforest up to $890 \mathrm{~m}$ on Mount Kahili, Makaleha Mountains and the Powerline Trail. Assessor: World Conservation Monitoring Centre Refs: 3372

\section{Chelyocarpus dianeurus}

Palmae

LR/nt

Colombia

A single-stemmed palm of rainforest, occurring on welldrained soils in the Pacific lowlands of Colombia. In some undisturbed areas, the species occurs in abundance and is under little threat at present. Leaf sheath fibre is used locally for pillow stuffing.

Assessor: World Conservation Monitoring Centre Refs: 19118

\section{Chiangiodendron mexicanum}

Flacourtiaceae

EN Alc

Mexico (Chiapas, Veracruz)

This monotypic genus is confined to the remnant rainforest of the Gulf region of Mexico, only occurring in abundance in Uxpanapa. It is the only New World member of its tribe.

Assessor: World Conservation Monitoring Centre Refs: $5651,5993,7980$ 
Chimarhis cymosa ssp. jamaicensis

Rubiaceae

LR/nt

Jamaica

This subspecies is found infrequently in remaining areas of woodland on limestone in areas of high rainfall. Other subspecies are confined to the Lesser Antilles and Cuba. Assessor: World Conservation Monitoring Centre Refs: 6057,7980

\section{Chionanthus adamsii}

\section{Oleaceae}

$\mathrm{EN} \mathrm{Bl}+2 \mathrm{C}$

Jamaica

Known only from Trelawny, the species is uncommon and restricted to areas of woodland on limestone hilltops.

Assessor: World Conservation Monitoring Centre

Refs: 401, 5653, 7980

\section{Chionanthus avilensis}

Oleaceae

VU D2

Venezuela

An evergreen tree, apparently restricted to a single location in forest on Cerro Avila in north Venezuela. Assessor: World Conservation Monitoring Centre Refs: 1030

\section{Chionanthus caudifolius}

Oleaceae

LR/ed

Malaysia (Peninsular Malaysia)

A rare tree inhabiting montane rainforest between 1210 and $1450 \mathrm{~m}$ in Perak and Pehang (Cameron Highlands).

Assessor: Chua, L.S.L.

Refs: 8464, 19073

\section{Chionanthus caymanensis var. caymanensis}

Oleaceae

VU D2

Cayman Islands

Confined to Cayman Brac and Little Cayman, the species occurs in dry evergreen woodland on dolomite karst. Populations are stable and there are extensive primary stands of the habitat remaining. However. if the trends in real estate development spread from Grand Cayman, there is potential for rapid deforestation. Assessor: World Conservation Monitoring Centre Refs: 19137

\section{Chionanthus caymanensis var. longipetala}

\section{Oleaceae}

EN B $1+2 b c d$

Cayman Islands

The species is endemic to the Cayman Islands, occurring in dry evergreen woodland on dolomite karst. This variety is confined to Grand Cayman, where the habitat has been $95 \%$ destroyed in the west. Clearing continues and trees are cut for fence posts and house construction. No trees are retained for landscaping, nor are they being replanted. There are, however, some areas where the taxon occurs abundantly and it is well represented in protected areas.

Assessor: World Conservation Monitoring Centre

Refs: $16261,17038,19137$

\section{Chionanthus filiformis}

Oleaceae

Brazil (Paraná, Rio de Janeiro, Santa Catarina, Sāo Paulo)

An evergreen species found in rainforest, often near rivers, in south-east coastal Brazil. It is well collected which may indicate that it is common. However, it is restricted to a habitat which has been extensively destroyed.

Assessor: World Conservation Monitoring Centre

Refs: 1030

\section{Chionanthus fluminensis}

Oleaceae

$\mathrm{CRB} \mathrm{B}+2 \mathrm{C}$

Brazil (Rio de Janeiro)

A species with a very local distribution. It was once well collected, probably because of its proximity to the city of Rio de Janeiro. It does not appear to have been collected this century.

Assessor: World Conservation Monitoring Centre

Refs: 1030

\section{Chionanthus jamaicensis}

Oleaceae

VU B $1+2 c$

Jamaica

This species is found only in areas of woodland in St Andrew Parish. Almost all forested areas in this parish are completely cleared or severely degraded.

Assessor: Bellingham, $\mathrm{P}$.

Refs: $401,5653,7980,19116$

\section{Chionanthus lancifolius}

Oleaceae

Malaysia (Peninsular Malaysia)

$\mathrm{LR} / \mathrm{cd}$

A small tree of montane rainforest up to $1600 \mathrm{~m}$. It receives a degree of protection within the permanent forest estate.

Assessor: Chua, L.S.L.

Refs: 8464, 9073, 19073

\section{Chionanthus leprocarpa var. courtallensis}

Oleaceae

$\mathrm{EN} \mathrm{B} 1+2 \mathrm{c}$

India (Kerala, Tamil Nadu)

A medium-sized tree, recorded from scattered localities in the Agastyamalai Hills and in two sites in the mountain ranges further north. It occurs in evergreen forest between 700 and $1500 \mathrm{~m}$.

Assessor: World Conservation Monitoring Centre Refs: 19144

\section{Chionanthus linocieroides}

Oleaceae

$\mathrm{EN} \mathrm{B1+2c}$

India (Kerala, Tamil Nadu)

A species of lowland forest, recorded only rarely from scattered localities in the vicinity of the Agastyamalai Hills. Large areas have been exposed to fires, grazing, the establishment of commercial plantations and cutting for fuelwood, but about $1000 \mathrm{~km}^{2}$ of forest remain protected within sanctuaries.

Assessor: World Conservation Monitoring Centre Refs: 19144

\section{Chionanthus micranthus}

Oleaceae

VU B $1+2 c$

Brazil (Bahia)

Endemic to the coastal forest of Bahia, this small evergreen tree is little known and rare.

Assessor: World Conservation Monitoring Centre

Refs: 1030 
Chionanthus proctorii

Oleaceae

CR B $1+2 \mathrm{c}$

Jamaica

A poorly known and uncommon species. It is found on a wooded limestone hillside in Westmoreland.

Assessor: World Conservation Monitoring Centre

Refs: $401,5653,7980$

\section{Chionanthus richardsiae}

Oleaceae

VU D2

Zambia

This species occurs in open bush, often on steep slopes on sandy or stony soil, but so far it is recorded only in the vicinity of the Kalambo Falls.

Assessor: World Conservation Monitoring Centre

Refs: 18965

\section{Chionanthus spiciferus}

Oleaceae

VU D2

Malaysia (Peninsular Malaysia)

A very rare tree confined to one locality in Selangor.

Assessor: World Conservation Monitoring Centre

Refs: 19073

\section{Chionanthus subsessilis}

Oleaceae

$\mathrm{CR} B 1+2 \mathrm{c}$

Brazil (Minas Gerais)

Presumed to be an evergreen tree, this species was collected only once, over a century ago, from Minas Gerais.

Assessor: World Conservation Monitoring Centre

Refs: 1030

\section{Chionanthus tenuis}

Oleaceae

$\mathrm{CR} \mathrm{B} 1+2 \mathrm{c}$

Brazil (Rio de Janeiro)

A small tree which has been collected only once, over 50 years ago, from remnant forest in Rio de Janeiro. Assessor: World Conservation Monitoring Centre

Refs: 1030

\section{Chionanthus wurdackii}

Oleaceae

VU D2

Peru

A tree known only from one location along Río Marañon in the Amazonas region of Peru. Its wood has been described as extremely hard.

Assessor: World Conservation Monitoring Centre Refs: 1030

\section{Chisocheton pauciflorus}

Meliaceae VU $B 1+2 c$

Malaysia (Peninsular Malaysia), Singapore?

A shrubby tree up to $16 \mathrm{~m}$ tall, inhabiting moist lowland primary forest up to an altitude of $550 \mathrm{~m}$. It can be found throughout westem and southem parts of Peninsular Malaysia, in many areas which have been converted for non-forest land use.

Assessor: Chua, L.S.L.

Refs: $9199,17140,19073$

\section{Chisocheton perakensis}

Meliaceae

VU D2

Malaysia (Peninsular Malaysia)

This tree grows up to $16 \mathrm{~m}$ tall and is confined to the upper hill forest on Maxwell Hill, Taiping, in the state of Perak

Assessor: Chua, L.S.L.

Refs: 8464, 19073
Chisocheton stellatus

Meliaceae

VU B $1+2 c, C 2 a$

Indonesia (Irian Jaya), Papua New Guinea

Endemic to New Guinea, this tree of primary and secondary rainforest is known from only a few collections. In Papua New Guinea, the species was collected once in an area in Madang Province that is subject to ongoing logging, including wood chipping operations. In Irian Jaya, the species is known only from Geelvink Bay and Jayapura.

Assessor: Eddowes, P.J.

Refs: 19114

\section{Chlorocardium rodiei}

Lauraceae

VU Alad

Brazil, French Guiana, Guyana, Suriname, Venezuela

Occurring in northern Brazil, Venezuela and the Guyanas, the species is a dominant component of a restricted belt of lowland rainforest on brown sand, and is also found occasionally in other forest types. A large part of the total population is confined to Guyana. The species is found in low densities in westem Venezuela and only in a small concentration along Maratakka River in Suriname. The production of greenheart timber has declined significantly over the past 50 years. It is not known whether this represents falling supplies or just a greater interest in the plywood market. Regeneration in natural stands is very slow and poor germination success is inhibiting the establishment of plantations.

Assessor: Americas Regional Workshop

Refs: 5672, 10263, 13947, 17854, 19159, 19179, 19196

\section{Chloroleucon chacoense}

\section{Leguminosae}

VU A2c, B1+2ac

Argentina (Salta), Bolivia, Paraguay

An endemic to a small area of subandean piedmont forest, occurring from north-west Argentina to Paraguay, possibly extending into Bolivia. It is a notably uncommon tree within a habitat which is unprotected and under constant decline with logging, encroaching agriculture and pastoralism.

Assessor: Prado, D.

Refs: $1262,5994,7980$

Chloroleucon eurycyclum

Leguminosae

VU D2

Venezuela

This species is known only from the type locality, in the lower Río Paragua, Bolívar State.

Assessor: World Conservation Monitoring Centre

Refs: 5994

\section{Chloroleucon extortum}

Leguminosae

VU D2

Brazil (Bahia)

This species of semi-deciduous woodland is known only from the type collection, gathered from north Bahia. Assessor: World Conservation Monitoring Centre Refs: 5994

\section{Chloroleucon mangense var. tetrazyx}

Leguminosae

LR/nt

Venezuela

A tree of xeromorphic scrub woodland endemic to Bolívar.

Assessor: World Conservation Monitoring Centre

Refs: 5994 
Chloroleucon tortum

Leguminosae

Brazil (Rio de Janeiro)

A shrubby tree restricted to *restinga and thickets on sandy soils along the coast of Rio de Janeiro State.

Assessor: World Conservation Monitoring Centre

Refs: 5994

\section{Chloroxylon swietenia}

Rutaceae

VU Alc

India (Andhra Pradesh, Kerala, Tamil Nadu), Madagascar, Sri Lanka

East Indian satinwood occurs in dry mixed evergreen forest. It is a slow-growing species which has become very scarce in most areas because of timber exploitation.

Assessor: Asian Regional Workshop

Refs: 6431, 8483, 15431, 17759, 18796, 19057

\section{Chodanthus montecillensis}

Bignoniaceae

CR C2a

Honduras

A tree of humid forest at high elevations. Its nomenclatural status is somewhat uncertain.

Assessor: Nelson, C.

Refs: 13995

\section{Chordospartium muritai}

Leguminosae

CR DI

New Zealand (South Is.)

Confined to a site in Clifford Bay in Marlborough, only twelve wild plants survive in a remnant of coastal forest. There are only two species in the genus, both endemic to New Zealand.

Assessor: Oates, M.R. \& P. J. de Lange

Refs: $902,9800,10734,17368,19133$

\section{Chordospartium stevensonii}

Leguminosae

VU D2

New Zealand (South Is.)

Endemic to Marlborough, this small tree usually grows in scrubby sites near streams, except in one area where it forms its own forest type. Surveys in the early 1980 s estimated a population figure of less than 200 individuals in total, but the number has now increased. Habitat deterioration has resulted in the invasion of grasses and weeds in places, and regeneration is sometimes prevented by grazing deer and livestock. There are only two species in the genus, both endemic to New Zealand.

Assessor: de Lange, P.J.

Refs: $902,17637,19133,19134$

\section{Chosenia arbutifolia}

Salicaceae

VUAlc

China (Heilongjiang, Jilin, Liaoning), Former USSR

(Russia North, Sakhalin), Japan, North Korea

Although occurring over a wide range, the species is confined to lowland forest and is in severe decline because of loss and degradation of this habitat. Regeneration is poor. The genus is monotypic.

Assessor: World Conservation Monitoring Centre

Refs: $1818,9957,11847,13143,16250$

\section{Chrysophyllum acreanum}

Sapotaceae

VU $B 1+2 c$

Brazil (Acre, Amazonas)

A timber species recorded from *várzea and non- flooded lowland forests in a few sites in western Amazonia.

Assessor: Pires O'Brien, J.

Refs: $1983,7980,8816$

\section{Chrysophyllum albipilum}

Sapotaceae

VU D2

Peru

Apparently the species has not been recorded since it was first collected in the first half of the century from San Martin, where it occurred in lowland rainforest between 400 and $800 \mathrm{~m}$.

Assessor: World Conservation Monitoring Centre

Refs: 7980,8816

\section{Chrysophyllum arenarium}

Sapotaceae

LR/nt

Brazil (Ceará, Maranháo, Pemambuco)

Widely scattered in dry open forest locations, the species is relatively well collected and does not appear to be declining in any way.

Assessor: Pires O'Brien, J.

Refs: $1983,7980,8816$

\section{Chrysophyllum azaguieanım}

Sapotaceae

$\mathrm{EN} \mathrm{B1}+2 \mathrm{c}$

Côte d'Ivoire, Ghana

This species is strictly confined to wet evergreen forest in Ghana and Côte d'Ivoire, where general losses of this forest type have been significant over the past century. It is an understorey tree quite unlike other members of the genus.

Assessor: Hawthome, W.

Refs: 8369,12061

\section{Chrysophyllum bombycinum}

Sapotaceae

$\mathrm{LR} / \mathrm{nt}$

Brazil (Amazonas), Peru

A newly described species currently known from two main locations in the western Amazon. Several occurrences are recorded in non-flooded forest, usually on white sand in Loreto in Peru. The species also occurs further east in Brazil.

Assessor: World Conservation Monitoring Centre

Refs: 7980,8816

\section{Chrysophyllum brenesii}

Sapotaceae

$\mathrm{LR} / \mathrm{cd}$

Costa Rica, Panama

A species mainly known from Costa Rica, but also occurring in Coclé in Panama. It is found in semideciduous forest and in association with oak, ascending to $1100 \mathrm{~m}$. It has been recorded in Santa Rosa, Braulio Carillo and Santa Ana National Parks in Costa Rica. Assessor: World Conservation Monitoring Centre Refs: 8816

\section{Chrysophyllum claraense}

Sapotaceae

$\mathrm{CR} \mathrm{B} 1+2 \mathrm{c}$

Cuba

A shrub or small tree known from coastal scrub and forest in Casilda, Sancti-Spíritus Province. The habitat in this area has become severely degraded by urban expansion and tourism. Another unconfirmed record of this species has been made from Pinar del Rio.

Assessor: Areces-Mallea, A.E.

Refs: $16327,18485,19149$ 
Chrysophyllum durifructum

Sapotaceae

$\mathrm{CR} B \mathrm{~B}+2 \mathrm{c}$

Brazil (Amazonas)

A tree species of non-flooded lowland forest. It is known only from the type collection from the north of Manaus.

Assessor: Pires O'Brien, J.

Refs: $1983,7980,8816$

\section{Chrysophyllum euryphyllum}

Sapotaceae

$\mathrm{CR} \mathrm{B} 1+2 \mathrm{c}$

Colombia

A newly described species, known from the type specimen, which was collected from César some 50 years ago and from one other collection from Bolívar. It is recorded as a straggling treelet scattered on the forest edge and in savanna.

Assessor: Calderon, E.

Refs: $7980,8816,19069$

\section{Chrysophyllum flexuosum}

Sapotaceae

LR/cd

Brazil (Bahia, Minas Gerais, Rio de Janeiro, São Paulo)

A small tree of lowland coastal rainforest and gallery forest in drier inland localities. It has recently been collected from a number of new sites, including Ilha do Cardoso State Park in São Paulo.

Assessor: Pires O'Brien, J.

Refs: $1983,7980,8816$

\section{Chrysophyllum hirsutum}

Sapotaceae

LR/nt

Costa Rica, Panama

A montane or cloud forest species recorded from a number of sites in Alajuela in Costa Rica and Coclé, Colón and Panamá Provinces in Panama.

Assessor: World Conservation Monitoring Centre

Refs: 8816

\section{Chrysophyllum imperiale}

Sapotaceae

$\mathrm{EN} \mathrm{B1}+2 \mathrm{c}$

Brazil (Minas Gerais, Rio de Janeiro)

A large tree known from several sites of lowland rainforest, one being a plantation, on the Atlantic coast. The natural habitat of the species has been greatly reduced in recent decades.

Assessor: Pires O'Brien, J.

Refs: $1983,7980,8816$

\section{Chrysophyllum inornatum}

Sapotaceae

Brazil (Paraná, Rio Grande do Sul, Santa Catarina)

A small tree of coastal rainforest. The known range of this species has increased. It also occurs in Ilha do Cordoso State Park in São Paulo.

Assessor: Pires O'Brien, J.

Refs: $1983,7980,8816$

\section{Chrysophyllum januariense}

Sapotaceae

Brazil (Rio de Janeiro)

A tree of lowland coastal rainforest. It has been collected only from the type locality in Laranjeiras Forest, Rio de Janeiro, but it can no longer be found there.

Assessor: Pires O'Brien, J.

Refs: $1983,7980,8816$
Chrysophyllum lanatum

Sapotaceae

Colombia

A newly described species, endemic to Colombia, and currently known only from an area of montane rainforest between 2700 and $3000 \mathrm{~m}$ in Cauca.

Assessor: Calderon, E.

Refs: $7980,8816,19069$

\section{Chrysophyllum lucentifolium ssp. lucentifolium}

Sapotaceae

LR/cd

Brazil (Bahia, Espirito Santo, Rio de Janeiro)

The more restricted of the two subspecies. The taxon is confined to the coast of Brazil between Bahia and Rio de Janeiro, where the lowland forest habitat has seriously declined in extent and continues to be threatened by development and settlement. It has been recorded in Linhares Forest Reserve in Espírito Santo.

Assessor: Pires O'Brien, J.

Refs: $1983,7980,8816$

Chrysophyllum ovale

Sapotaceae

LR/nt

Bolivia, Brazil (Acre), Peru

A lowland rainforest tree recorded from separate localities, one in Amazonian Peru and the other in the border area between Acre in Brazil and Beni in Bolivia. Assessor: World Conservation Monitoring Centre Refs: 7980,8816

\section{Chrysophyllum paranaense}

Sapotaceae

VU B1 $+2 \mathrm{c}, \mathrm{D} 2$

Brazil (Paraná, São Paulo)

A tree confined to lowland evergreen coastal forest in an area where increasing development and settlement are causing serious habitat declines.

Assessor: Pires O'Brien, J.

Refs: $1983,7980,8816$

\section{Chrysophyllum parvulum}

Sapotaceae

LR/nt

Colombia, Venezuela

A tree which is currently known from two widely separated areas, occurring in several sites in lowland evergreen rainforest in Carabobo and Lara in northem Venezuela and in a small endangered population in montane forest at $2000 \mathrm{~m}$ in Valle in Colombia. Assessor: World Conservation Monitoring Centre Refs: $7980,8816,19069$

\section{Chrysophyllum pauciflorum}

Sapotaceae

VU B $1+2 \mathrm{c}$

Puerto Rico, Virgin Islands (US)

A tree of semi-deciduous dry forest and thickets on hills up to $750 \mathrm{~m}$. Occurrences are recorded from the serpentine barrens in Puerto Rico and from St Croix, St John and St Thomas in the Virgin Islands.

Assessor: World Conservation Monitoring Centre Refs: 7980,8816

\section{Chrysophyllum revolutum}

Sapotaceae

VU D2

Peru

A small tree known only from the region of Tarapoto in

San Martín, where it occurs in rainforest at an altitude of $750 \mathrm{~m}$.

Assessor: World Conservation Monitoring Centre

Refs: 7980,8816 
Chrysophyllum splendens

Sapotaceae

VU B $1+2 c$

Brazil (Bahia, Espírito Santo, Pernambuco)

A species restricted to remaining wet coastal rainforest in an area which is seriously threatened by increasing settlement and development. An occurrence is recorded in the Linhares Forest Reserve in Espírito Santo.

Assessor: Pires O'Brien, J.

Refs: $1983,7980,8816$

\section{Chrysophyllum subspinosum}

Sapotaceae

EN D 1

Brazil (Bahia)

Little information is available on this species. It apparently occurs in two sites of dry forest.

Assessor: Pires O'Brien, J.

Refs: $1983,7980,8816$

\section{Chrysophyllum superbum}

Sapotaceae

CR C2b

Brazil (Amazonas)

A lowland forest species, only known from the type collection made in 1941 in western Amazonia.

Assessor: Pires O'Brien, J.

Refs: $1983,7980,8816$

\section{Chrysophyllum viride}

Sapotaceae

Brazil (Espírito Santo, Paraná, Rio de Janeiro, Santa Catarina, Sāo Paulo)

A widely occurring species of the Atlantic slopes of Brazil from Espirito Santo to Santa Catarina and Paraná. It occurs in rainforest up to $1000 \mathrm{~m}$ and also in periodically flooded forest.

Assessor: World Conservation Monitoring Centre Refs: 8816

\section{Chunia bucklandioides}

Hamamelidaceae

VUAlc

China (Guangdong - Hainan)

Confined to Hainan Island the species is now only found on Dialuo Mountain and Jingfeng Mountain occurring in forested gullies at altitudes of 600 to $700 \mathrm{~m}$. Populations in Ding'an Qiongzhong, Baoting and Yaxian have apparently disappeared. It is the only species in the genus.

Assessor: World Conservation Monitoring Centre

Refs: 1818,11847

\section{Chytranthus mannü}

Sapindaceae

LR/nt

São Tomé \& Príncipe

A shrub or small tree collected numerous times. Its fruit are edible and traded locally. Trees must be planted if the resource is to be harvested sustainably over the long term.

Assessor: World Conservation Monitoring Centre Refs: 2724

\section{Chytranthus obliquinervis}

Sapindaceae

VU B $1+2 \mathrm{c}$

Kenya, Tanzania

A tree of dry forest, restricted to localised populations on the East African coast. Pressures exist from a growing human population and the demand for land to cultivate.

Assessor: World Conservation Monitoring Centre

Refs: 6396, 12067

\section{Cinnadenia malayano}

Lauraceae

VU $B 1+2 C$

Malaysia (Peninsular Malaysia)

A newly described species, known only from two collections, found in hill forest in Selangor and Negri Sembilan.

Assessor: Chua, L.S.L.

Refs: $8464,19073,19182$

\section{Cinnamodendron corticosum}

Canellaceae

VU $B 1+2 c$

Jamaica

The species has a local distribution confined to Portland and St Thomas in remaining areas of rainforest between 300 and $1000 \mathrm{~m}$. The habitat, especially in St Thomas, has been heavily destroyed and degraded. Very little forest remains.

Assessor: Bellingham, $\mathrm{P}$.

Refs: $401,5653,7980,19116$

\section{Cinnamodendron cubense}

Canellaceae

EN Alc, B $1+2 c$

Cuba

A very rare tree found in rainforest and the upper limit of the montane semi-deciduous forest in eastern Cuba. Habitat declines have been severe in places.

Assessor: Areces-Mallea, A.E.

Refs: 9522, 11403, 19149

Cinnamomum balansae

Lauraceae

EN Alcd, B1+2c

Viet Nam

A large tree restricted to lowland primary evergreen forest in Hà Tây ( $\mathrm{Ba} \mathrm{Vi}$ ) and Ninh Bình (Cúc Phuong) in northern Viet Nam. Very little habitat remains and the species is also suffering from poor regeneration, with a complete absence of seedlings and young trees under the canopy of parent trees. The durable wood is exploited for construction and joinery.

Assessor: World Conservation Monitoring Centre Refs: 848,15357

\section{Cinnamomum brevipedunculatum}

Lauraceae

EN B $1+2 a$

Taiwan

A tree of dry lowland forest, confined to the southem part of the Hengchun Peninsula, partially contained within Kenting National Park. Increasing human activities, agriculture and settlement have caused extensive habitat losses.

Assessor: Pan, F.J.

Refs: 3295,19050

\section{Cinnamomum capparu-coronde}

Lauraceae

VU Alc, B1+2c

Sri Lanka

This uncommon tree is restricted to the lowland wet evergreen forests of south-west Sri Lanka. During the extensive National Conservation Review forest surveys, this species was recorded in 10 localities.

Assessor: World Conservation Monitoring Centre Refs: $17195,17278,19112$

\section{Cinnamomum chemungianum}

Lauraceae

$\mathrm{EN} \mathrm{Bl}+2 \mathrm{c}$

India (Tamil Nadu)

Known only from the type collection, the species occurs in the forest understorey at $1400 \mathrm{~m}$ in the Agastyamalai Hills. Large areas have been exposed to fires, grazing, 
the establishment of commercial plantations and cutting for fuelwood, but about $1000 \mathrm{~km}^{2}$ of forest remain protected within sanctuaries.

Assessor: World Conservation Monitoring Centre Refs: 19144

\section{Cinnamomum cilriodorum}

Lauraceae

$\mathrm{EN} \mathrm{B1+2c}$

Sri Lanka

A threatened species apparently restricted to Ratnapura and Monaragala Districts. It was discovered in only five forest localities surveyed for the comprehensive National Conservation Review.

Assessor: World Conservation Monitoring Centre

Refs: $8203,12129,18796,19112$

\section{Cinnamomum filipedicellatum}

Lauraceae

$\mathrm{EN} \mathrm{B} 1+2 \mathrm{c}$

India (Kerala, Tamil Nadu)

A tree of submontane forest, known from three or four collections from scattered localities at the southern end of the Western Ghats.

Assessor: World Conservation Monitoring Centre

Refs: 19144

\section{Cinnamomum heyneanum}

Lauraceae

India (Kamataka)

A very poorly known species, recorded from a single unspecified locality.

Assessor: World Conservation Monitoring Centre

Refs: 19144

\section{Cinnamomum japonicum}

Lauraceae

China (Jiangsu, Zhejiang), Japan, North Korea, South Korea, Taiwan

A tree occurring in isolated populations on coastal islands in China, throughout Taiwan and parts of North and South Korea and Japan. It is found in lowland evergreen forest, where it is susceptible to habitat clearance and conversion to agriculture.

Assessor: World Conservation Monitoring Centre

Refs: $1818,6469,11847,16250$

\section{Cinnamomum kanahirae}

Lauraceae

EN Alacd

Taiwan

A tree of low to mid-elevation broadleaved forest. Populations are scattered over a relatively wide range.

Assessor: Lu, S.Y. \& F.J. Pan

Refs: 6469,19051

\section{Cinnamomum kotoense}

Lauraceae

CR C2a

Taiwan

A beautiful tree restricted to a few small populations in lowland broadleaved forest on Lanyu Island. Although, there are up to $\mathbf{2 0 0}$ or more mature trees, only a small fraction of that number set seed. The species is of local importance as an omamental and as a source of medicine

Assessor: Lu, S.Y. \& F.J. Pan

Refs: 3295, 7933, 19050, 19051
Cinnamomum litseifolium

Lauraceae

VU $B 1+2 c$

Sri Lanka

During the extensive forest surveys conducted between 1991 and 1996 for the National Conservation Review, the species was found in three forest localities. It appears to be locally common in Horton Plains National Park. Assessor: World Conservation Monitoring Centre Refs: $17759,18796,19112$

\section{Cinnamomum macrostemon}

Lauraceae

VU C2a

Taiwan

Although the species is widely scattered in low to medium elevation forest throughout the island, populations are mostly isolated and under heavy exploitation for the medicinal extract that can be obtained from the leaves and bark. Establishment of industrial plantations and increasing land settlement have also had an extensive impact on the habitat.

Assessor: Lu, S.Y. \& F.J. Pan

Refs: 19050,19051

\section{Cinnamomum mairei}

Lauraceae

$\mathrm{EN} \mathrm{B} 1+2 \mathrm{c}$

China (Sichuan, Yunnan)

Restricted to south-west Sichuan and north-east Yunnan in submontane forest, the populations have been seriously reduced because of overexploitation of the bark for medicinal use and habitat clearance. Regeneration is reported to be poor and the species is being rapidly replaced by other broadleaved species in places.

Assessor: Sun, W.

Refs: $1818,11847,19055$

\section{Cinnamomum mathewsii}

Lauraceae

VU D2

Peru

A species known only from its type collected from Amazonas Department in the Peruvian Amazon.

Assessor: World Conservation Monitoring Centre Refs: 1984

\section{Cinnamomum mercadoi}

Lauraceae

VU Ald

Philippines

A timber species of lowland and hill forest, the bark of which yields cinnamon.

Assessor: World Conservation Monitoring Centre

Refs: 2072,4919

\section{Cinnamomum micranthum}

Lauraceae LR/cd

China (Fujian, Guangdong, Guangxi, Hunan, Jiangxi, Zhejiang), Taiwan, Viet Nam

Although relatively widespread in lowland rainforest, the species has experienced considerable habitat declines, largely because of conversion to agriculture. Remaining populations are believed to be well protected in nature reserves.

Assessor: World Conservation Monitoring Centre

Refs: $1818,6469,11847$

\section{Cinnamomum osmophloeum}

Lauraceae

VU Alacd, B1+2a

Taiwan

An important source of medicine and spice. The species

is widespread in lowland broadleaved forest. 
Populations have come under heavy exploitation and have also declined in extent because of habitat loss.

Assessor: Pan, F.J.

Refs: $3295,6469,19050$

\section{Cinnamomum parthenoxylon}

\section{Lauraceae}

DD

Indonesia, Malaysia (Sabah), Philippines, Thailand?, Viet Nam

In Viet Nam, although the species occurs commonly in areas of evergreen rainforest in the north, exploitation of the roots for their commercial essence has caused severe population declines, resulting in the species being critically endangered at a national level (CR Alcd).

Assessor: Asian Regional Workshop

Refs: 848, 9328, 12937, 15357, 19060

\section{Cinnamomum parviflorum}

Lauraceae

VU B $1+2 \mathrm{c}$

Cuba, Dominican Republic, Haiti

A shrub or tree up to $15 \mathrm{~m}$ tall, occurring in montane rainforest and cloud forest. It is uncommon in Cuba.

Assessor: Areces-Mallea, A.E.

Refs: 19149

\section{Cinnamomum perrottetii}

Lauraceae

VU Bl+2c

India (Kerala, Tamil Nadu)

A medium-sized tree of montane forest, occurring in two main locations, the Nilgiri Hills and Anaimalai range. Assessor: World Conservation Monitoring Centre Refs: $8483,16438,19144$

\section{Cinnamomum reticulatum}

Lauraceae

VU C2a, D2

Taiwan

Confined to the Hengchun Peninsula in the southern tip of Taiwan, populations are small and isolated, in dry forest on rocky seashores and coastal localities. Observations of poor regeneration and habitat clearance for housing developments have led to concems for the species. A population is recorded in Kenting National Park

Assessor: Lu, S.Y. \& F.J. Pan

Refs: $6469,19050,19051$

\section{Cinnamomum riparium}

Lauraceae

VU B $1+2 c$

India (Karnataka, Kerala, Tamil Nadu)

Few collections of this riverine tree exist. It occurs in lowland to medium elevation forest along the coast and Western Ghats.

Assessor: World Conservation Monitoring Centre

Refs: 6431, 8483, 19144

\section{Cinnamomum rivulorum}

Lauraceae

$\mathrm{CR} B \mathrm{Bl}+2 \mathrm{c}$

Sri Lanka

During the extensive forest surveys conducted between 1991 and 1996 for the National Conservation Review, this species was found in only one forest locality in Badulla District.

Assessor: World Conservation Monitoring Centre Refs: 19112

\section{Cinnamomum walaiwarense}

Lauraceae

CR B $1+2 c$

India (Tamil Nadu)

A small tree known a single collection, occurring in a restricted area of submontane forest.

Assessor: World Conservation Monitoring Centre

Refs: 19144

\section{Citharexylum quereifolium}

Verbenaceae

VU B $1+2 c$

Peru

A species confined to the Peruvian Andes, recorded from rocky areas of forest between 2500 and $4000 \mathrm{~m}$ in the departments of Cajamarca, Cuzco, Lima and La Libertad. Extensive buming and clearing have caused declines and fragmentation of the habitat.

Assessor: World Conservation Monitoring Centre

Refs: 1984

\section{Citharexylum rimbachii}

Verbenaceae

VU B $1+2 c$

Ecuador

This endemic tree of the Ecuadorean High Andes inhabits montane cloud forest at $2500 \mathrm{~m}$ in Bolivar.

Assessor: World Conservation Monitoring Centre

Refs: 19119,19120

\section{Citharexylum suberosum}

Verbenaceae

VU B1+2c, D2

Peru

A small tree apparently confined to a single area of disturbed forest between the altitudes of 2500 and $3000 \mathrm{~m}$ in the department of Apirimac in the Peruvian Andes. Extensive buming and clearing have caused declines and fragmentation of the habitat.

Assessor: World Conservation Monitoring Centre Refs: 1984

\section{Citharexylum ternatum}

Verbenaceae

VU D2

Cuba

An endemic shrub or small tree locally confined to the mountainous area of Nagua in the west of the Sierra Maestra range in Granma Province.

Assessor: Areces-Mallea, A.E.

Refs: 11403, 18485, 19149

\section{Citropsis gabunensis}

Rutaceae

VU Alc, Bl+2c

Ghana

A tree confined to wet evergreen forest in an area which has experienced significant declines in this habitat because of logging, mining and the commercial planting of exotics.

Assessor: Hawthome, W.

Refs: $6127,12061,15251$

\section{Citrus taiwanica}

Rutaceae

$\mathrm{CR} B 1+2 \mathrm{ab}, \mathrm{C} 2 \mathrm{a}$

Taiwan

Once widely scattered, the species has become scarce and confined to a few isolated populations in lowland forest in the region of Hsinchu and Taitung. The future prospects of its survival are poor as regeneration is severely hampered by the use of the tree as a rootstock in citrus plantations and by the extensive loss of habitat.

Assessor: Pan, F.J.

Refs: 3295, 19050 


\section{Claoxylon ooumuense}

Euphorbiaceae

French Polynesia (Marquesas Is.)

Endemic to Nuku Hiva

Assessor: Florence, J.

Refs: 14513

\section{Claoxylon taitense}

Euphorbiaceae

French Polynesia (Society Is.)

Populations are recorded from Moorea, Raiatea, Tahaa and Tahiti.

Assessor: Florence, J.

Refs: 14513

\section{Clausena calciphila}

Rutaceae

VU D2

Malaysia (Sarawak)

Restricted to the rocky limestone slopes between 150 and $300 \mathrm{~m}$, this small tree is known only from three localities; Bukit Pa'it and Bukit Bra'ang in Kuching District and Bukit Mentagai in Baram District.

Assessor: World Conservation Monitoring Centre

Refs: 19017

\section{Clavija jelskii}

Theophrastaceae

VU B $1+2 c$

Peru

A forest species, found between 2000 and $2500 \mathrm{~m}$ only in the department of Cajamarca in the Peruvian Andes.

Assessor: World Conservation Monitoring Centre Refs: 1984

\section{Clavija longifolia}

Theophrastaceae

Peru

LR/nt

Endemic to Peru, the species is found in lowland rainforest in the departments of Huánuco, Loreto, Madre de Dios and San Martin.

Assessor: World Conservation Monitoring Centre

Refs: 1984

\section{Cleidiocarpon cavaleriei}

Euphorbiaceae VU B1+2c

China (Guangxi, Guizhou, Yunnan), Myanmar, Viet Nam

This multi-purpose tree occurs in small populations in broadleaved forest on limestone over a relatively wide range, covering parts of southem China, Son La, Lao $\mathrm{Kai}$ and Yen Bai in north Vietnam and northem Myanmar. In China, particularly over the past 10 years, trees have been cut for timber at unsustainable levels. In Viet Nam the timber is said to be more rarely used because of its susceptibility to insect and termite attack. Seeds contain up to $30 \%$ edible oil. The genus contains just two species.

Assessor: Sun, W.

Refs: $1818,11847,19055$

\section{Cleidiocarpon lourinum}

Euphorbiaceae

Myanmar, Viet Nam

There is some dispute over the wild origins of this species, but it is generally believed to be the more restricted in range of the two members of the genus. Wild populations are recorded in Son La in Viet Nam and in Myanmar in areas of evergreen broadleaved forest from low to medium elevation. Various parts of the plant are harvested for use, including the timber. It is widely planted as a fruit tree.

Assessor: World Conservation Monitoring Centre Refs: $848,11530,15357$

\section{Cleidion lemurum}

Euphorbiaceae

CR D1

New Caledonia

Once known from the Caves of Hienghene, the species has not been found since 1871. It is questionable whether it should not now be considered extinct.

Assessor: Jaffré, T. et al.

Refs: 4492, 10351

\section{Cleidion lochmios}

Euphorbiaceae

$\mathrm{VUBI}+2 \mathrm{C}$

New Caledonia

Assessor: Jaffré, T. el al.

Refs: 1035

\section{Cleidion marginatum}

Euphorbiaceae

New Caledonia

Assessor: Jaffré, T. et al.

Refs: 10351

\section{Cleidion veillonï}

Euphorbiaceae

VU D2

New Caledonia

Assessor: Jaffré, T. et al.

Refs: 10351

\section{Cleistanthus bracteosus}

Euphorbiaceae

VUD2

Malaysia (Peninsular Malaysia)

Confined to Perak, the species is recorded from just two localities of lowland rainforest.

Assessor: World Conservation Monitoring Centre

Refs: 8464, 19073

\section{Cleistanthus collinus}

Euphorbiaceae

VU Ald

Sri Lanka

The endemic status of this tree is uncertain. In Sri Lanka, this forest species is possibly extinct due to overexploitation. It was not found in the recent National Conservation Review forest survey indicating that the species is either extremely rare or extinct. The conservation category is inferred from the situation in Sri Lanka.

Assessor: World Conservation Monitoring Centre

Refs: 18796,19112

\section{Cleistanthus evrardii}

Euphorbiaceae

VU D2

Democratic Republic of Congo

The species is restricted to a single locality in the Maringa valley, where it occurs in dense swamp forest often associated with Gilberriodendron dewevrei. The habitat is threatened by logging and agriculture.

Assessor: Ndjele, M.B.

Refs: 17185,17951 
Cleistanthus ferrugineus

Euphorbiaceae

VU Alc

Sri Lanka

A tree occurring in the lowland wet evergreen forests of south-west Sri Lanka.

Assessor: World Conservation Monitoring Centre

Refs: 9176, 17195

\section{Cleistanthus flavescens}

Euphorbiaceae

$\mathrm{LR} / \mathrm{nt}$

Malaysia (Peninsular Malaysia)

A rare species of lowland rainforest in Perak and Terengganu.

Assessor: World Conservation Monitoring Centre

Refs: 8464, 19073

\section{Cleistanthus glandulosus}

\section{Euphortiaceae}

VU D2

Malaysia (Peninsular Malaysia)

A small tree of primary evergreen rainforest, known only from a single collection from Gunung Keledang in Perak.

Assessor: Kochummen, K.M.

Refs: 8464, 19073

\section{Cleistanthus glaucus}

Euphorbiaceae

VU D2

Malaysia (Peninsular Malaysia)

Confined to Perak, the species is distributed in lowland forest, below $200 \mathrm{~m}$, mainly on limestone.

Assessor: World Conservation Monitoring Centre

Refs: 19073

\section{Cleistanthus kingii}

Euphorbiaceae

LR/cd

Malaysia (Peninsular Malaysia)

A rare species of lowland forest and swamp forest, occurring on limestone below $150 \mathrm{~m}$ in Perak and Johore.

Assessor: Kochummen, K.M.

Refs: 17140,19073

\section{Cleistanthus lanuginosus}

Euphorbiaceae

LR/cd

Malaysia (Peninsular Malaysia)

Confined to Mount Ophir in Johore, the species is scattered in submontane forest at $500 \mathrm{~m}$. The area is conserved.

Assessor: Kochummen, K.M.

Refs: 8464, 19073

\section{Cleistanthus major}

Euphorbiaceae

CR B $1+2 \mathrm{c}$

Malaysia (Peninsular Malaysia)

A small tree of primary evergreen rainforest, known only from a single collection from Kemaman in south Terengganu. Its continued existence is somewhat in doubt since the area has been under development of various kinds and much of the forest has been cleared.

Assessor: World Conservation Monitoring Centre

Refs: 8464, 19073

\section{Cleistanthus malabaricus}

Euphorbiaceae

YU Bl $+2 c$

India (Karnataka, Kerala)

Known from a few reports and even fewer herbarium specimens, the species occurs in low to medium altitude forest in scattered locations in the Western Ghats. Assessor: World Conservation Monitoring Centre Refs: 19144

\section{Cleistanthus membranaceus}

Euphorbiaceae

Malaysia (Peninsular Malaysia)

A lowland rainforest tree, occurring between 90 and $150 \mathrm{~m}$ in Penang and Perak. The species has been collected few times.

Assessor: World Conservation Monitoring Centre

Refs: 8464, 19073

\section{Cleistanthus parvifolius}

Euphorbiaceae

VU D2

Malaysia (Peninsular Malaysia)

A small tree of limestone forest in Gopeng, Perak. It has been collected only once.

Assessor: Kochummen, K.M.

Refs: 19073

\section{Cleistanthus petelotii}

Euphorbiaceae

VU D2

Viet Nam

A scarce tree, which appears to be known only from Hda Binh (Muòng Thôn, Luong Son: Lâm Son) in north Viet Nam.

Assessor: World Conservation Monitoring Centre Refs: 848

\section{Cleistanthus robustus}

Euphorbiaceae

$\mathrm{CR} \mathrm{B} 1+2 \mathrm{c}$

Sri Lanka

A tree restricted to lowland wet evergreen forests in south-west Sri Lanka. This species was not found during the recent National Conservation Review forest surveys, indicating that it is either extremely rare or possibly extinct. Previously a population was known from Kanneliya Forest Reserve.

Assessor: World Conservation Monitoring Centre Refs: 17195,19112

\section{Cleistanthus travancorensis}

Euphorbiaceae

$\mathrm{EN} \mathrm{B1}+2 \mathrm{c}$

India (Kerala, Tamil Nadu)

Two collections of the species have been gathered from widely separated localities of submontane evergreen forest at the southern end of the Western Ghats.

Assessor: World Conservation Monitoring Centre

Refs: 19144

\section{Clermontia arborescens ssp. arborescens}

Campanulaceae

EN Alce

USA (Hawaii)

One of two subspecies. An epiphytic or terrestrial tree or shrub restricted to southern West Maui, where it occurs in montane rainforest. It has been estimated that as much as $90 \%$ of the habitat has been logged and converted into pastureland. Remaining areas are affected by grazing feral pigs. The genus is endemic to the Hawaii Islands.

Assessor: World Conservation Monitoring Centre

\section{Clermontia drepanomorpha}

Campanulaceae

EN B $1+2 c, C 2 a, D 1$

USA (Hawaii)

A terrestrial or epiphytic tree which is known only from the summits of the Kohala Mountains on Hawaii, where it is found in low boggy forest within an area of $26 \mathrm{~km}^{2}$. 
A survey in 1995 identified 200 individuals in five different populations. The area is state-owned and the only site to harbour this unique habitat. The major threats come from ditch management, invasive plants, feral pigs and rats. The species is protected by the US Endangered Species Act.

Assessor: World Conservation Monitoring Centre

Refs: 3372, 19037

\section{Clermontia grandiflora \\ Campanulaceae}

$\mathrm{LR} / \mathrm{nt}$

USA (Hawaii)

The species occurs in rainforest or the margins of bogs up to $1975 \mathrm{~m}$ on Molokai, Lanai and Maui Islands. Two subspecies are sometimes recognised, of which the type subspecies is locally common but confined to West Maui.

Assessor: World Conservation Monitoring Centre

Refs: 3372

\section{Clermontia hawaiiensis}

Campanulaceae

VUAlce

USA (Hawaii)

A terrestrial or epiphytic species confined to Hawaii Island, where it occurs in Puna and Kau Districts in rainforest from low to high altitudes. Much of the habitat has been logged and converted into pastureland. Remaining areas are strongly affected by grazing feral pigs.

Assessor: World Conservation Monitoring Centre

Refs: 3372

\section{Clermontia lindseyana}

Campanulaceae

$\mathrm{EN} \mathrm{B} 1+2 \mathrm{c}, \mathrm{C} 2 \mathrm{a}$

USA (Hawaii)

An uncommon terrestrial or epiphytic species occurring in montane rainforest up to $2150 \mathrm{~m}$ altitude. A single population remains on Maui on the southern slopes of Haleakala. About 14 populations are known from Hilo, Kau and South Kona Districts on Hawaii. The total population has been estimated to lie between 225 and 325 individuals. The major threats to the species are invading alien plants, grazing and damage caused by domesticated animals and the feral pig. The species is protected by the US Endangered Species Act.

Assessor: World Conservation Monitoring Centre

Refs: 3372, 19039

\section{Clermontia oblongifolia ssp. brevipes}

\section{Campanulaceae \\ CR B1+2c, C2ab, DI}

USA (Hawaii)

This subspecies is known from a single population of about 20 individuals located in the south-eastern part of Kamakou Preserve, on Molokai, where it grows on forested slopes between 1100 and $1200 \mathrm{~m}$ altitude. Feral pigs are an immediate threat to the population and rats may be predating the fruit and other plant parts. The taxon is protected by the US Endangered Species Act. Assessor: World Conservation Monitoring Centre Refs: 3372,19040

\section{Clermontia oblongifolia ssp. mauiensis}

\section{Campanulaceae \\ $\mathrm{CR} B 1+2 \mathrm{c}, \mathrm{C} 2 \mathrm{~b}, \mathrm{D} 1$}

USA (Hawaii)

This subspecies is restricted to one locality on West Maui, populations on Lanai and East Maui having become extinct in 1913 and 1927 respectively. On West Maui the taxon was first collected in the 1980 s and is presently known from a single individual within a protected area of montane wet forest. There still exist areas of rainforest on East Maui where a population may yet be discovered. Attempts at propagation have so far failed. The taxon is protected by the US Endangered Species Act.

Assessor: World Conservation Monitoring Centre Refs: 3372,19087

\section{Clermontia oblongifolia ssp. oblongifolia Campanulaceae \\ USA (Hawaii)}

VU Alce

This subspecies is confined to lowland rainforest on Oahu Island.

Assessor: World Conservation Monitoring Centre Refs: 3372

\section{Clermontia peleana}

Campanulaceae

USA (Hawaii)

CR C2a, D1

A shrub or tree which is epiphytic on tree ferns, Metrosideros, Acacia or Cheirodendron species. It occurs in rainforest on the slopes of Mauna Kea and Mauna Loa on Hawaii. A population on East Maui along with another population on the northem slope of Mauna Kea have been referred to as ssp. singulifera but both are now extinct. There are four remaining populations of the species, numbering no more than a few individuals. There is evidence of damage to the habitat caused by feral pigs, rats and the illegal cultivation of cannabis. The species is protected by the US Endangered Species Act.

Assessor: World Conservation Monitoring Centre Refs: 3372,19039

\section{Clermontia persicifolia}

Campanulaceae

USA (Hawaii)

LR/nt

This terrestrial or epiphytic species is found in lowland rainforest on Oahu. It is recorded from both the Koolau and Waianae Mountains, more commonly from the latter.

Assessor: World Conservation Monitoring Centre Refs: 3372

\section{Clermontia pyrularia \\ Campanulaceae \\ USA (Hawaii)}

A small tree restricted to Hawaii, where a single wild population of three plants remains. Two populations have been planted in exclosures at Hakalau, nearby. Invasive plants and the damage caused by feral pigs are thought to have contributed significantly to the species decline. It is protected by the US Endangered Species Act.

Assessor: World Conservation Monitoring Centre Refs: 3372, 19039

\section{Clermontia tuberculata}

Campanulaceae

USA (Hawaii)

Confined to East Maui, this terrestrial species occurs in montane rainforest, primarily along stream beds. Assessor: World Conservation Monitoring Centre Refs: 3372 
Clerodendrum calcicolum

Verbenaceae

VU A $1 \mathrm{c}, \mathrm{B} 1+2 \mathrm{c}$

Cuba

A shrub or small tree up to $8 \mathrm{~m}$ tall, endemic to the coastal dry evergreen forests of western Cuba. Habitat declines have been great in the past decades; overcutting and clearing for urbanisation continue to be threats.

Assessor: Areces-Mallea, A.E.

Refs: 19149

\section{Clerodendrum denticulatum}

Verbenaceae

VU B I $+2 \mathrm{c}$

Cuba

A small tree, of up to $10 \mathrm{~m}$ in height, inhabiting semideciduous forest on eroded limestone in eastern Cuba. The habitat in this region has been heavily degraded in places.

Assessor: Areces-Mallea, A.E.

Refs: $16327,18485,19149$

\section{Clerodendrum galeatum}

Verbenaceae

VU D2

Yemen (Socotra)

A small tree or shrub which is scattered in woodland areas throughout the island. Its timber is exploited at a local level. Populations are stable at present.

Assessor: Miller, A.G.

Refs: 2354, 19083

\section{Clerodendrum glabrum ssp. minutiflorum}

\section{Verbenaceae}

VU D2

Seychelles (Aldabra)

A small tree or shrub of inland scrub communities on the islands of Malabar, Polymnie, Picard, Grand Terre, Assumption, Cosmoledo and Astove. It provides an important food for tortoises. The Aldabran Islands are under protection within a Strict Nature Reserve. Some disturbance has occurred on Assumption because of strip-mining for phosphate or guano, and on Cosmoledo and Astove, where areas have been cleared for the establishment of coconut and Casuarina plantations.

Assessor: World Conservation Monitoring Centre

Refs: 19027,19062

\section{Clerodendrum leucophloeum}

Verbenaceae

VU D2

Yemen (Socotra)

A small tree or shrub which is scattered in woodland areas throughout the island. Its timber is exploited at a local level. Populations are stable at present.

Assessor: Miller, A.G.

Refs: 2354, 19083

\section{Clethra alexandri}

Clethraceae

LR/nt

Jamaica

This species appears to be common to abundant, especially above $1800 \mathrm{~m}$. The largest population occurs in forest on the Grand Ridge, also in forest margins and gaps. Hybridisation takes place between this species and C. occidentalis. The forest at lower altitudes has suffered more serious degradation because of logging and the ensuing soil erosion and invasion of aggressive exotic plants.

Assessor: World Conservation Monitoring Centre

Refs: $6057,7980,12564$
Clethra coloradensis

Clethraceae

CR B $1+2 b c$

Panama

The species is known from a few collections all taken from a small area of cloud forest around Cerro Colorado in Chiriqui. There is much activity in the area, particularly copper and gold mining.

Assessor: Mitré, M.

Refs: 6067,16772

\section{Clethra crispa}

Clethraceae

VU B $1+2 c$

\section{Ecuador}

An endemic of Ecuador, currently known to occur only in areas of montane and upper montane cloud forest in Azuay and Loja.

Assessor: World Conservation Monitoring Centre Refs: 19119

\section{Clethra hendersonii}

Clethraceae

$\mathrm{LR} / \mathrm{cd}$

Malaysia (Peninsular Malaysia)

An uncommon shrub to small tree which resides in the understorey or in gaps of montane rainforest, also occuring in secondary fo-ests at high elevation. It is given a degree of protection within the permanent forest estate.

Assessor: Chua, L.S.L.

Refs: 8464,19073

\section{Clethra javanica}

Clethraceae

VU A1c, D2

Indonesia (Java)

The species is known only from a forested area near the lake at Taman Hidup in Dataran Tinggi Yang or the Yang Plateau. The area is relatively isolated, although logging has occurred in the past and commercial plantations have been established. Proposals to give the area national park status have failed. A variety may possibly occur on Lombok.

Assessor: World Conservation Monitoring Centre

Refs: 1011,9078

Clethra parallelinervia

Clethraceae

VU $B 1+2 c$

\section{Ecuador}

An endemic of Ecuador, found only in the provinces of Loja and Azuay where it occurs in montane and upper montane cloud forest.

Assessor: World Conservation Monitoring Centre

Refs: 19119,19120

\section{Clethra tutensis}

Clethraceae

Panama

The species is known only from the type specimen collected in 1975 from Cerro Tute in Verguas. It is not known whether the species still exists and the area is little explored.

Assessor: Mitré, M.

Refs: 6067,16772

\section{Cleyera bolleana}

Theaceae

VU BI+2c

Dominican Republic, Hait

A cloud forest species which has been collected from only six localities in Hispaniola. The two collections from Haiti from the Massif de la Selle date back over 50 years. There is considerable pressure exerted on these 
small forests because of the demand for farming land and wood. It is unknown whether the populations remain intact.

Assessor: World Conservation Monitoring Centre

Refs: 13574

\section{Cleyera cernun}

Theaceae

Mexico (Oaxaca)

A montane forest species known only from the Oaxaca region of Mexico. Several localities are known but most are not definite and more fieldwork is necessary to confirm the distribution of this rare species.

Assessor: World Conservation Monitoring Centre Refs: 13574

\section{Cleyera japonica var. grandiflora}

Theaceae

$\mathrm{EN} \mathrm{B1}+2 \mathrm{c}$

India (Meghalaya)

A taxon known only from a few localities in Meghalaya. How many of the localities harbour extant populations is not known. No record of the taxon has been made since 1935 despite explorations in the area. The forest in Meghalaya has been seriously fragmented and reduced to sacred groves in many places.

Assessor: World Conservation Monitoring Centre Refs: 4799

\section{Cleyera vaccinioides}

Theaceae

Dominican Republic, Haiti

VU B $1+2 \mathrm{c}$

A species known only from five localities within cloud and pine forests of Hispaniola. The two Haitian localities occur in the Massif de la Selle and Massif de la Hotte and date back the 1920s. Considerable pressure is exerted upon these small areas of forest because of the demand for farming land and wood. It is unknown whether these populations remain intact.

Assessor: World Conservation Monitoring Centre

Refs: 197,13574

\section{Clianthus puniceus}

Leguminosae

New Zealand (North Is.)

EN D 1

Occurring in scattered populations from Northland to Hawkes Bay, the species occurs as a shrub or small tree in scrubby forest margins and flaxland. About 200 plants exist in total, most of these occurring within the boundaries of Urewera National Park. Browsing by goats, pigs, deer and possums and the illegal collecting of seedlings have caused more recent declines in numbers. A popular ornamental plant with large bright red flowers, it is possible that the Maori were partly responsible for previously known occurrences on offshore islands, the East Cape and other parts of the North Island.

Assessor: de Lange, P.J.

Refs: 902, 4253, 15251, 17637, 19133, 19134

Clidemia crossosepala var. adamsii

Melastomataceae

$\mathrm{EN} \mathrm{B1}+2 \mathrm{c}$

Jamaica

This variety occurs very locally in thickets on limestone, only in Trelawny at about $680 \mathrm{~m}$.

Assessor: Kelly, D.L

Refs: 401, 5653, 7980, 19085

\section{Cliffortia arborea}

Rosaceae

South Africa (Northem Cape, Western Cape)

VU Aled

A * fynbos relic which occurs in *karroid vegetation along the Great Escarpment from Beaufort West in the east to near Sutherland in the west and northwards to Calvinia. Information from local farmers indicated that it was once very common along the edge of the escarpment. However, being the only woody plant in the area, it was heavily used for firewood and reduced to five remnant subpopulations. Two of the extant subpopulations are healthy, with a range of size classes present; one is also contained within a national park and the other occurs in a local authority nature reserve. There is no evidence of any further declines in recent years.

Assessor: Hilton-Taylor, C. et al.

Refs: 689,19218

\section{Clinostigma haerestigma}

Palmae

Solomon Islands (South Solomon)

A palm tree of lowland Casuarina forest on ultrabasic soils, restricted to south-east Santa Isabel.

Assessor: Dowl, J.L.

Refs: 19118

\section{Clinostigma harlandii}

Palmae

$\mathrm{LR} / \mathrm{nt}$

Vanuatu

Endemic to Vanuatu, this palm tree occurs in wet rainforest on ridge tops and the adjacent steep slopes. The population is extensive with 100,000 s of mature trees. Regeneration is good.

Assessor: Dowl, J.L.

Refs: 19118

\section{Clinostigma samoense}

Palmae

EN Alc

Western Samoa

A palm confined to Upolu Island, Western Samoa. The major part of the broadleaved lowland forest habitat is now destroyed. Remaining populations appear to be healthy and stable, the species occasionally being quite common.

Assessor: Whistler, A. \& D. Johnson

Refs: 19118

\section{Clinostigma savoryana}

Palmae

Japan (Ogasawara-shoto)

A rare palm tree of wet forest endemic to the Bonin Islands. Very little has been published on this species.

Assessor: Johnson, D.

Refs: 19118

\section{Clitoria mayobambensis}

Leguminosae

VU D2

Peru

Known only from the type, the species occurs in lowland rainforest in San Martin Department.

Assessor: World Conservation Monitoring Centre Refs: 1984 
Clitoria woytkowskii

Leguminosae

VU D2

Peru

Known only from the type collection, the species occurs in lowland rainforest in San Martin Department.

Assessor: World Conservation Monitoring Centre

Refs: 1984

\section{Clusia carinata}

Guttiferae

Peru

VU D2

A lowland rainforest species which is known only from the type collected in the department of Loreto.

Assessor: World Conservation Monitoring Centre

Refs: 1984

\section{Clusia clarendonensis}

Guttiferae

VU B $1+2 \mathrm{c}$

Jamaica

An uncommon tree occurring in woodland on limestone in Clarendon, St James and Trelawny.

Assessor: World Conservation Monitoring Centre

Refs: 401, 6057, 7980

\section{Clusia croatii}

\section{Guttiferae}

Colombia, Panama

VU A2c

Occurring in semi-deciduous rainforest above $500 \mathrm{~m}$, the species is found throughout Panama from Darien, extending into Colombia, to the border with Costa Rica, possibly extending over that border as well. In places it is relatively common but never abundant. Some populations are protected in national parks, but elsewhere the species is under pressure from mining for copper and gold, as in Cerro Colorado, and from increasing settlement of the land in Cocle. The only known Colombian population is restricted to a very small area.

Assessor: Mitré, $\mathrm{M}$.

Refs: 7980, 15037, 16772

\section{Clusia cupulata}

Guttiferae

VUAlc

Panama

Principally known from the centre-north of Panama, the species continues to be in found new sites, increasing its range so that it almost stretches from the border with Costa Rica to the border with Colombia. No record of the species has been made in either of the latter countries so far. It occurs almost exclusively in undisturbed rainforest up to $1200 \mathrm{~m}$. There are small populations in Volcán Barú and Chagres National Parks and Kunayala Indigenous Reserve. Outside these areas the habitat is frequently threatened by settlement, logging and extensive agriculture.

Assessor: Mitré, M.

Refs: $7272,7980,16772$

\section{Clusia dukei}

Guttiferae

VUAlc

Panama

Largely growing epiphytically, the species is scattered diffusely in areas of moist forest from low elevation to $1800 \mathrm{~m}$. It is recorded from localities throughout Panama. Some populations are protected in national parks, others are seriously exposed to increasing habitat clearance for settlement and agriculture.

Assessor: Mitré, M.

Refs: $7272,7980,16772$
Clusia havetioides var. havetioides

Guttiferae

Jamaica

Assessor: World Conservation Monitoring Centre

Refs: 7980

Clusia havetioides var. pauciflora

Guttiferae

$\mathrm{EN} \mathrm{Bl+2c}$

Jamaica

This variety is known from only a single locality on a steep densely wooded hillside on Croft's Mountain. Clarendon.

Assessor: Kelly, D.L.

Refs: 401, 7980, 19085

Clusia havetioides var. stenocapa

Guttiferae

LR/nt

Jamaica

Assessor: World Conservation Monitoring Centre

Refs: 7980

\section{Clusia longipetiolata}

Guttiferae

VU B $1+2 c$

Panama

At present, the species is known only from the Caribbean coast in Bocas del Toro and Colon, where it is scattered in lowland semi-evergreen or evergreen forest. The area is not well explored but available information suggests the species is uncommon. A small population in Santa Rita, Colón, is in grave danger of being cut down.

Assessor: Mitre, $\mathrm{M}$.

Refs: $7272,7980,16772$

\section{Clusia osseocarpa}

Guttiferae

VU Cl

Colombia, Panama

Occurring in rainforest from low elevation to $1500 \mathrm{~m}$, the species ranges from the Canal region in Panama to an area just over the border with Colombia in the Chocó. Population numbers are not large but several of the localities are within protected areas. Increasing agriculture, settlement and logging threaten areas of unprotected forest.

Assessor: Mitré, M.

Refs: $7272,7980,16772$

Clusia portlandiana

Guttiferae

VU B $1+2 c$

Jamaica

An epiphytic tree or shrub confined to mossy forest on limestone in Portland between 450 and $750 \mathrm{~m}$.

Assessor: World Conservation Monitoring Centre Refs: $401,5653,7980$

Clusia pseudomangle

Guttiferae

VU D2

Peru

A cloud forest species which is endemic to the Peruvian Andes and has been collected only once, from the department of San Martin.

Assessor: World Conservation Monitoring Centre Refs: 1984 


\section{Clusia tarmensis \\ Guttiferae \\ Peru}

Known only from the type, the species occurs in lowland rainforest in the department of Junín.

Assessor: World Conservation Monitoring Centre

Refs: 1984

\section{Cnidoscolus fragrans}

Euphorbiaceae

EX

Cuba

Apparently endemic to the site where the capital city of Cuba was built, this tree was described from the area of Regla at the eastem side of Habana Bay more than a century and a half ago. A wide area of several kilometres around the harbour has been cleared and urbanised. There is very little chance of rediscovering the species.

Assessor: Areces-Mallea, A.E.

Refs: 11403, 18485, 19149

\section{Cnidoscolus matosii}

Euphorbiaceae

$\mathrm{EN} \mathrm{B1}+2 \mathrm{c}$

Cuba

This tree is locally restricted to coastal, dry, evergreen forests on limestone terraces in Maisf, eastern Cuba.

Assessor: Areces-Mallea, A.E.

Refs: 16327, 18485, 19149

\section{Cnidoscolus rangel}

Euphorbiaceae

$\mathrm{EN} \mathrm{B} 1+2 \mathrm{c}$

Cuba

Confined to Pinar del Rio Province, this small tree occurs infrequently in semi-deciduous forest on shallow soils or on bare, deeply eroded limestone rocks.

Assessor: Areces-Mallea, A.E.

Refs: $16327,18485,19149$

\section{Coccoloba cholutecensis}

Polygonaceae

CR C2a

Honduras

A scarce species of lowland dry forest, occurring on the Pacific coast where fires and encroaching agriculture are frequent threats.

Assessor: Nelson, C.

Refs: 13995

\section{Coccoloba coriacea}

Polygonaceae

VU D2

Cuba

Endemic to a relatively small area in the north of Pinar del Rio Province, this shrub or small tree is confined to sclerophyllous evergreen scrub and woodland on serpentine-derived soils in the Cajalbana range.

Assessor: Areces-Mallea, A.E.

Refs: 19149

\section{Coccoloba dariensis}

Polygonaceae

$\mathrm{LR} / \mathrm{nt}$

Colombia, Panama

A relatively common species of lowland seasonal rainforest, in Panama occurring in Darién Province, Valle de Antón in Coclé, and the Canal area. Much of the range lies within protected areas, outside which occurrences are less common. In Colombia, there are populations in the Chocó and Valle de Cauca.

Assessor: Mitré, M.

Refs: 16772
Coccoloba lindaviana

Polygonaceae

CR C2a

Honduras

A tree restricted to the Atlantic drainage, occurring at low to middle elevations.

Assessor: Nelson, C.

Refs: 13995

\section{Coccoloba matudae}

Polygonaceae

VU Alc

Mexico

A rainforest species with a distribution confined to high precipitation forests in the Gulf region and from the Pacific slope.

Assessor: World Conservation Monitoring Centre

Refs: 5993

Coccoloba plumieri

Polygonaceae

LR/nt

Jamaica

A tree of moist savannas, thickets and woodlands on limestone in the central and western parishes. General habitat declines have been considerable.

Assessor: World Conservation Monitoring Centre

Refs: 6057,7980

\section{Coccoloba proctorii}

Polygonaceae

$\mathrm{EN} B 1+2 \mathrm{c}$

Jamaica

A large tree with a local distribution on limestone hills in St Elizabeth and St James. Population numbers are very low. The habitat is severely degraded in places and under constant threat from cutting and encroaching agriculture.

Assessor: Kelly, D.L.

Refs: 401, 5653, 7980, 19085

\section{Coccoloba retirensis}

Polygonaceae

CR B $1+2 \mathrm{c}$

Cuba

A small tree described from a single locality in El Retiro, Santa Cruz, Pinar del Rio Province. The habitat in the area has been severely degraded.

Assessor: Areces-Mallea, A.E.

Refs: 19149

\section{Coccoloba rugosa}

Polygonaceae

EN C2a

Puerto Rico, Virgin Islands (US) (ex)

Originally described from a cultivated specimen, this beautiful tree occurs in the wild in semi-dry woodland on coastal hills in the north-east and east of Puerto Rico. The record from St Thomas in the US Virgin Islands dates from over 100 years ago and the habitat there has largely been destroyed. The main extant population consists of 121 plants in Palmas de Mar, Puerto Rico. There are thought to be a further three populations, making the population total $400-500$ plants. Threats of quarrying and development, especially of houses, tourist facilities and roads, are apparent.

Assessor: World Conservation Monitoring Centre Refs: 7980,17124

\section{Coccoloba tiliacea}

Polygonaceae

VU B1+2ac

Argentina (Jujuy, Salta), Bolivia

Endemic to the piedmont forest of north-west Argentina and Bolivia, the species is confined to an unprotected 
ecosystem which is being rapidly replaced by agricultural systems.

Assessor: Prado, D.

Refs: 19122

\section{Coccoloba troyana}

Polygonaceae

VU Bl+2c

Jamaica

Populations occur in two main areas, Trelawny and St James, and Portland and St Thomas. They are confined to remaining areas of woodland on limestone and serpentine soils. Deforestation has occurred extensively in the latter two parishes.

Assessor: World Conservation Monitoring Centre

Refs: $6057,7980,19116$

\section{Cocconerion minus}

Euphorbiaceae

VU Bl $+2 c$

New Caledonia

Assessor: Jaffré, T. et al.

Refs: 10351

\section{Coccothrinax borhidiana}

Palmae

CR B $1+2 \mathrm{c}$

Cuba

Occurring on raised limestone beaches near the sea, this palm is restricted to Matanzas. The area of occupancy is less than $10 \mathrm{~km}^{2}$

Assessor: Moya, C.

Refs: 19118

\section{Coccothrinax crinita ssp. brevicrinis}

Palmae

$\mathrm{EN} \mathrm{B} 1+2 \mathrm{e}, \mathrm{C} 2 \mathrm{a}$

Cuba

A Cuban endemic found in lowland, seasonally flooded savanna up to $500 \mathrm{~m}$. Habitat destruction and local exploitation of the plant parts are causing population reductions. The species is traded locally as an ormamental.

Assessor: Moya, C.

Refs: 19118

\section{Coccothrinax crinila ssp. crinila}

Palmae

$\mathrm{EN} \mathrm{B} 1+2 \mathrm{c}, \mathrm{C} 2 \mathrm{a}$

Cuba

A Cuban endemic of lowland, seasonally-flooded savanna up to $500 \mathrm{~m}$. Habitat destruction and local exploitation of the plant parts are causing population reductions. The species is traded locally as an ornamental.

Assessor: Moya, C.

Refs: 19118

\section{Coccothrinax ekmanii}

Palmae

Dominican Republic, Haiti

A palm tree found in dry scrub forest on limestone on rocky hills or near the sea. Little is known about the species status in Dominican Republic but it is very likely to be threatened in Haiti.

Assessor: Johnson, D.

Refs: 19118

\section{Coccothrinax inaguensis}

Palmae

DD limestone soils in coastal areas. Little information is available on its conservation status.

Assessor: Johnson, D.

Refs: 19118

\section{Coccothrinax pauciramosa}

Palmae

VU B $1+2 e$

Cuba

Confined to Camagiey, Holguin and Oriente in Cuba, this small tree grows in open forest on limestone hills or on serpentine savanna between 200 and $250 \mathrm{~m}$. The area of occupancy is small and populations are declining.

Assessor: Moya, C.

Refs: 19118

\section{Cochlospermum tetraporum}

Cochlospermaceae

$\mathrm{EN} \mathrm{B1+2a}$

Argentina (Jujuy, Salta), Bolivia

Within the genus, the species appears to have evolved in isolation. It is endemic to the subandean piedmont forest in north-west Argentina and Bolivia and appears to be restricted to gypsum-based soils. The ecosystem remains entirely unprotected and threatened by agriculture, logging and pastoralism.

Assessor: Prado, D

Refs: $1262,5112,7980,11140,19122$

\section{Coffea costatifructa}

Rubiaceae

VU D2

Tanzania

This species was first described in 1994. It is known from two localities: Mafia Island and the Selous Game Reserve, where it occurs in patches of forest, woody savanna or Brachystegia thicket.

Assessor: World Conservation Monitoring Centre Refs: 17153

\section{Coffea fadenii}

Rubiaceae

VU B1+2c, D2

Kenya

Endemic to the Taita Hills, the species is scattered to scarce in areas of moist montane forest. Populations are known from Mbololo, a protected reserve, and Ngangao. There is some habitat encroachment by local farmers and settlers.

Assessor: World Conservation Monitoring Centre

Refs: 6396, 17859

\section{Coffea lemblinii}

Rubiaceae

Côte d'Tvoire

Known only from a single herbarium specimen, the species is believed to be extinct.

Assessor: Assi, A.

Refs: 2773, 12822

\section{Coffea mongensis}

Rubiaceae

VU B $1+2 b$

Tanzania

Known from the East Usambara, North Udzungwa and also probably the Ngun Mountains, this species is found in moist evergreen forest at altitudes of 1150 to $1400 \mathrm{~m}$. Assessor: Lovett, J. \& G.P. Clarke Refs: 3356, 8814

Bahamas, Turks and Caicos Islands

This rare palm species occurs in scrub on sandy or 
Coffea mufindiensis ssp. mufindiensis Rubiaceae

$\mathrm{VU} B 1+2 \mathrm{~b}$

Tanzania

A Tanzania endemic, this subspecies is restricted to moist montane forests in the Kiboriani and Udzungwa Mountains.

Assessor: Lovett, J. \& G.P. Clarke

Refs: 3356,8814

\section{Coffea pocsii}

Rubiaceae

VU B1 $+2 c, D 2$

Tanzania

Described in 1994, this small tree is confined to dry evergreen forest, characterised by the frequency of Euphorbia and Encephalartos, in Kitulanghalo Forest Reserve in the Morogoro region.

Assessor: World Conservation Monitoring Centre

Refs: 17153

\section{Coffea pseudozanguebariae}

Rubiaceae VU B $1+2 b$

Kenya, Tanzania

A shrubby tree which is known from remnant dry forest patches occurring in the Taita Hills in Kenya, and further south in Tanzania and Zanzibar.

Assessor: Lovett, J. \& G.P. Clarke

Refs: 3356, 10961

\section{Coffea togoensis}

Rubiaceae

VUAlc

Ghana, Togo

A small tree which is common but restricted to the southern dry forests of Ghana, from Tain II Forest Reserve to the Volta region and extending into Togo. Dry forests have suffered the most serious losses of all the forest types in this area. They continue to decline because of fire, felling and agricultural expansion.

Assessor: Hawthome, W.

Refs: $2773,8369,12061$

\section{Coffea zanguebariae}

Rubiaceae

VU B $1+2 b$

Mozambique, Tanzania

Ranging in a relatively unexplored area from southem Tanzania in the Kilwa District to northern Mozambique, this species is confined to patches of dry coastal forest. The species is possibly cultivated in Madagascar.

Assessor: Lovett, J. \& G.P. Clarke

Refs: $1308,3356,8814$

\section{Cola attiensis}

Sterculiaceae

Côte d'Ivoire

EN Alc, B1+2c

At one time widespread, this species has become rare because of the extent of deforestation in the country. It occurs in remaining moist semi-deciduous forest, the large part of which now exists only in protected areas. Assessor: Assi, A.

Refs: 2773,12822

\section{Cola boxiana}

Sterculiaceae

$E N B 1+2 c$

Ghana

Endemic to Ghana, this tree is generally rare and confined to upland evergreen forest. It is most common in the Atewa range and occurs in neighbouring forest reserves. Farming, fire, forest management and large- scale mining continue to put pressure on the species habitat. Its status could prove to be more threatened after necessary survey work.

Assessor: Hawthome, W.

Refs: $6127,8369,12061$

\section{Cola bracteata}

Sterculiaceae

VU Bl+2c

Uganda

An endemic to Uganda, occurring relatively commonly in Kalinzu and Malamagambo Forest Reserve but scarce in Itwara Forest Reserve and elsewhere.

Assessor: *MUIENR

Refs: $5654,9605,9837,14667$

\section{Cola clavata}

Sterculiaceae

Mozambique

Assessor: Bandeira, S.

Refs: 5117,18965

\section{Cola duparquetiana}

Sterculiaceae

VU D2

Gabon

This species has been collected only from Lastoursville, where logging has been intensive and the forest is degraded. The species may be found to be more widespread in the country's relatively unexplored forests, which, although extensive, are largely under concession to logging companies.

Assessor: World Conservation Monitoring Centre

Refs: 14958,15790

\section{Cola gigas}

Sterculiaceae

VU B $1+2 c$

Nigeria

Only recorded in south-eastern Nigeria, the largest, if not only, population of this species occurs in the Oban Division of the Cross River National Park. The areas outside the park have been largely deforested and planted with commercial or subsistence crops. Assessor: World Conservation Monitoring Centre Refs: $2773,4977,11504$

\section{Cola glabra}

Sterculiaceae

Nigeria

A small tree confined to the few remaining forested areas in south-west Nigeria. Large-scale logging, encroaching agriculture and the planting of commercial crops have resulted in large declines in the habitat. Assessor: World Conservation Monitoring Centre Refs: 2773, 11504

\section{Cola hypochrysea}

Sterculiaceae

VUAlc

Cameroon, Nigeria

A species with a scattered occurrence in lowland rainforest, especially in swampy areas or along river banks. Its range extends from south-eastern Nigeria, (although it does not appear to occur in Cross River National Park), to Cameroon, where it has been recorded from Japoma, Dibamba, Eseka, Kribi, Ebolowa and Campo. Unprotected areas have been extensively logged and cleared for agriculture.

Assessor: World Conservation Monitoring Centre Refs: 11504, 12597 
Cola letestui

Sterculiaceae

Gabon

Apparently the species is known only from the vicinity of Lastoursville, where the habitat is largely disturbed. Further collecting is likely to uncover additional occurrences, but there is concern over the extent to which forest in Gabon is now under concession to logging companies.

Assessor: World Conservation Monitoring Centre

Refs: 14958, 15790

\section{Cola lizae}

Sterculiaceae

LR/nt

Gabon

A common species confined to Lopé Forest Reserve and a $50 \mathrm{~km}$ radius around the northem boundary. Part of the range is under concession to logging companies and there is concem over future plans for intensive logging. The species is notable in being wholly dependent on the lowland gorilla for seed dispersal.

Assessor: World Conservation Monitoring Centre Refs: 14958

\section{Cola lourougnonis}

Sterculiaceae

EN Alc, Bl+2c

Cameroon, Côte d'Ivoire

The sites of moist semi-deciduous forest where this species was found in Côte d'Ivoire have been felled. The habitat in Cameroon has also declined because of logging operations.

Assessor: Assi, A.

Refs: 12822

\section{Cola mossambicensis}

Sterculiaceae

Malawi, Mozambique, Zimbabwe?

VU $B 1+2 c$

Occurring mainly in central Mozambique in areas of lowland forest, this species is severely threatened by the decline in quality and conversion of its habitat for agricultural purposes. Populations may also exist in southern Malawi.

Assessor: Bandeira, S.

Refs: $5117,5654,18965$

\section{Cola nigerica}

Sterculiaceae

Nigeria

VU Alc

Records suggest the species is confined to the remaining areas of lowland rainforest in southem Nigeria. Although it is said to occur frequently in parts of Shasha and Omo Forest Reserves, most of the latter forest has been felled and replanted with exotic timber species. A protected population exists in the Oban Division of the Cross River National Park. Forests outside protected areas are almost completely cleared and taken over by commercial and subsistence crops. Assessor: World Conservation Monitoring Centre Refs: 2773, 4977, 11504

\section{Cola octoloboides}

Sterculiaceae

$\mathrm{EN} \mathrm{Bl+2c}$

Kenya

A shrub or small tree, confined to a few forest patches or shady crevices, including localities in Cha Simba, Gongoni, Muhaka and Dzombo.

Assessor: World Conservation Monitoring Centre Refs: 6396,9198

\section{Cola philipi-jonesii}

Sterculiaceae

EN B $1+2 c$

Nigeria

A shrubby species, which has to date been recorded in only a small area near Ikom which lies between the northem and southem division of the Cross River National Park. Unprotected forest has been almost completely felled up to the park boundaries.

Assessor: World Conservation Monitoring Centre

Refs: 2773, 11504

\section{Cola porphyrantha}

Sterculiaceae

$\mathrm{EN} B \mathrm{~B}+2 \mathrm{C}$

Kenya

A tree of dense evergreen forest, collected only a few times from Pangani, Longo and Magandi forests.

Assessor: World Conservation Monitoring Centre

Refs: 6396,9198

\section{Cola reticulata}

Sterculiaceae

Côte d'Ivoire, Ghana, Guinea

VU Alc, Bl+2c

An uncommon small evergreen tree which is confined to areas of upland evergreen forest in Côte d'Ivoire, Ghana, and also on Mount Nzo in Guinea. These areas are under pressure from farming, fire, forest management activities and large-scale mining.

Assessor: Hawthome, W.

Refs: $2773,8369,12061$

\section{Cola scheffleri}

Sterculiaceae

VU B $1+2 b$

Tanzania

A species of moist semi-deciduous submontane forests occurring only in the Nguru Mountains and in the south of the Udzungwa Mountains at Kihanzi.

Assessor: Lovett, J. \& G.P. Clarke

Refs: 3356,8814

\section{Cola semecarpophylla}

Sterculiaceae

LR/cd

Cameroon, Nigeria

A small tree of lowland rainforest and secondary forest. The range extends from south-east Nigeria, including the Oban Hills in Cross River National Park, to Cameroon, where it is krown from several localities including Mount Cameroon, Korup National Park, Kribi, Kompina, Mamfe, Kumba and Campo. Unprotected forested areas have been heavily logged and cleared for agriculture.

Assessor: World Conservation Monitoring Centre

Refs: 11504, 12597, 19092

\section{Cola umbratilis}

Sterculiaceae

Côte d'Ivoire, Ghana

VU Alc, B1+2c

Known only from Ghana but expected in Côte d'Ivoire. this specie: is confined to remaining patches of wet evergreen forest. Declines in this habitat type because of mining, logging and commercial forestry activities have been significant in the last few decades.

Assessor: Hawthome, W.

Refs: 2773, 8369, 12061

\section{Cola usambarensis}

Sterculiaceae

Tanzania

Assessor: Lovett, J. \& G.P. Clarke

Refs: 3356,8814 


\section{Colea colei}

Bignoniaceae

Mauritius

Assessor: Strahm, W.

Refs: $9120,16426,19208$

\section{Colea seychellarum}

Bignoniaceae

VU D2

Seychelles

Endemic to the Seychelles, the species qualifies as threatened by virtue of its restricted distribution. Populations are healthy and stable.

Assessor: World Conservation Monitoring Centre

Refs: 9859,17229

\section{Colona poilanei}

Tiliaceae

LR/nt

Viet Nam

A small pioneer tree found in areas of lowland secondary, disturbed and recolonising forest in Viet Nam. Occurrences are recorded from several provinces. Assessor: World Conservation Monitoring Centre Refs: 848,15357

\section{Colpothrinax wrightii}

Palmae

VU B $1+2 e$

Cuba

A palm tree of lowland savanna on quartzine soils, restricted to Pinar del Rio and Isla de Pinos. It is suffering from excessive exploitation of trunk wood, leaves and fruit for local use. Regeneration is poor.

Assessor: Moya, C.

Refs: 19118

\section{Colubrina anomala}

Rhamnaceae

VU B $1+2 c$

Malaysia (Peninsular Malaysia)

A primary species of lowland evergreen rainforest, confined to the state of Perak. Habitat reductions have been caused by logging and conversion to agriculture.

Assessor: Chua, L.S.L.

Refs: 8464, 19073

\section{Colubrina hondurensis}

Rhamnaceae

CR C2a

Honduras

An endemic species found along rocky streams in dry forest at middle elevations.

Assessor: Nelson, C.

Refs: 13995

\section{Colubrina nicholsonii}

Rhamnaceae

EN C2a, D1

South Africa (Eastern Cape)

A palaeoendemic confined to riverine forest patches along the Transkei coast in close proximity to, or overhanging the water. It grows in shallow acidic soils derived from sandstones. Initially, only three very small subpopulations were known, each containing between 10 and 15 plants. Additional subpopulations have since been found, the largest of which is near Port St John's where the species is described as locally common. No seedlings have ever been recorded and, although plants flower prolifically, fruits are rarely seen. A population is found in Mkambati Game Reserve and in demarcated forest reserves, although protection measures in the latter have largely collapsed since 1994.

Assessor: Hilton-Taylor, C. et al.

Refs: 689,19218

\section{Colubrina obscura}

Rhamnaceae

VU B1+2c

Jamaica

Confined to thickets and woodlands in limestone areas in the Cockpit Country, the species has experienced widespread clearance of its habitat.

Assessor: World Conservation Monitoring Centre

Refs: 5653,7980

\section{Colubrina oppositifolio}

Rhamnaceae

$\mathrm{EN} \mathrm{B1}+2 \mathrm{c}, \mathrm{C} 2 \mathrm{a}$

USA (Hawaii)

One of the hardest native woods, the species was heavily harvested by ancient Hawaiians and is now only rarely found in dry to moist forest up to $920 \mathrm{~m}$ altitude. There are 10 extant populations in the Waianae Mountains on Oahu, in the Kohala Mountains, Muana Loa and Hualalai on Hawaii and a recently discovered individual on Maui. It has been estimated that there are approximately 300 individuals. The spread of alien plants, damage caused by feral pigs and the black twig borer are among the major threats to remaining populations. The species is protected by the US Endangered Species Act.

Assessor: World Conservation Monitoring Centre Refs: 3372, 19039

\section{Colvillea racemosa}

Leguminosae

Madagascar

This species is found in the north-west and south-west in Antsiranana, and from Morondava to Toliary in lowland areas of primary *tropophilic forest, wooded savanna and clearings. The wood is useful and the species is the focus of silvicultural studies.

Assessor: World Conservation Monitoring Centre Refs: 6161

\section{Combretocarpus rotundatus}

Anisophylleaceae

VUAlcd

Brunei, Indonesia (Kalimantan, Sumatra), Malaysia (Peninsular Malaysia, Sabah, Sarawak)

This monotypic genus is restricted to all types of peatswamp forest throughout Borneo, Sumatra and Peninsular Malaysia. Larger trees occur in the wetter swamp forests. The timber is used for railway sleepers and heavy construction.

Assessor: World Conservation Monitoring Centre Refs: 19017

\section{Combretum hartmannianum}

Combretaceae

VU A1c+2c

Eritrea, Ethiopia, Sudan

A distinctive species with long drooping leaves. It is a dominant component of Combretum-Terminalia woodland and wooded grassland in the region of west Eritrea, Tigray and Gonder. Factors of agricultural expansion and increasing human activities are causing declines and degradation of the habitat. The situation of $C$. rochetianum is the same.

Assessor: World Conservation Monitoring Centre Refs: 5941

\section{Combretum mkuzense}

Combretaceae

Mozambique, South Africa (KwaZulu-Natal)

LR/nt

A species of mixed woodland and sand forests in northern Zululand and southern Mozambique. It grows in deep sand on the Maputaland coastal plain within 
$60 \mathrm{~km}$ of the coast. Plants have been recorded from Mkuze Game Reserve and the species may also occur within Ndumu and Kosi Bay cnservation areas. Sand forest is under threat from cutting for firewood and timber. The area is also increasingly threatened by settlement and agricultural activities. There is some debate over the specific status of the taxon.

Assessor: Hilton-Taylor, C. et al.

Refs: 689,19218

\section{Combretum petrophilum}

\section{Combretaceae}

LR/nt

South Africa (Mpumalanga, Northern Province)

The species occurs on north-western or southern slopes in mixed savanna. Specimens are often found growing between rocks, in fissures or along ledges in hilly and mountainous terrain. Populations are recorded from a number of localities, some of which are protected areas. Outside protected areas, the species is showing some decline because of wood-cutting activities.

Assessor: Hilton-Taylor, C. et al.

Refs: $689,15561,19218$

\section{Combretum rochetianum}

\section{Combretaceae}

VUAlc+2c

Eritrea, Ethiopia, Sudan

Reported to be often common, this species is confined to Combretum-Terminalia woodland in a relatively small range covering west Eritrea, north-west Ethiopia and adjacent areas of Sudan. Agricultural expansion and human activities are causing declines in the extent of this habitat in the area.

Assessor: World Conservation Monitoring Centre Refs: 5941

\section{Combretum tenuipetiolatum}

Combretaceae

CR B $1+2 \mathrm{c}$

Kenya, Tanzania

A small tree collected from Rabai and Mombasa over 70 years ago and also apparently from Potwe forest in adjacent Tanzania. The Rabai forest is sacred. The other occurrences, if they still exist, are far less secure.

Assessor: World Conservation Monitoring Centre

Refs: 6396,9198

\section{Commidendrum robustum ssp. gummiferum}

Compositae

St Helena

Although it is doubtful whether any pure material of this subspecies still exists, its characters are frequently seen in hybrid populations at Peak Dale. The taxon was at one lime distributed on the central ridge between 400 and $700 \mathrm{~m}$. There is also a tree of questionable identity found in Deep Valley. The genus consists of four species, all endemic to St Helena.

Assessor: Cronk, Q.C.B

Refs: 19081

\section{Commidendrum robustum ssp. robustum}

\section{Compositae}

$\mathrm{EN} \mathrm{B} 1+2 \mathrm{c}$

St Helena

Gumwood woodland covered over $60 \%$ of St Helena in the 16th century. Extensive cutting of trees for their fine timber in the following centuries led to their reduction to a few small stands. Only two viable populations now remain in Peak Dale and Deep Valley, accounting for less than 2500 trees. Recent evidence indicates that sheep grazing and competition with introduced plants may be a problem. Biological control appears to have helped get rid of infestations of the homopteran pest, Orthezia insignis. The genus consists of four species, all endemic to St Helena.

Assessor: Cronk, Q.C.B.

Refs: 11891, 19071, 19081

\section{Commidendrum rotundifolium}

Compositae

EW

St Helena

Formerly one of the common gumwoods occurring in dry areas. By the end of the 18th century stands were reduced to a few isolated localities and the species was considered extinct at the end of the $19^{\text {t }}$ century. A tree was rediscovered on an inaccessible cliff at the southern edge of Horse Pasture in 1982 but by 1986 it had blown down in a gale. Some trees have been planted at Pounceys. The genus consists of four species, all endemic to St Helena.

Assessor: Cronk, Q.C.B.

Refs: $9954,11891,19081$

\section{Commidendrum rugosum}

Compositae

VU D1

St Helena

A low-domed shrub of the crown wastes. At one time it became entirely confined is cliff localities. Since the extirpation of goats, population numbers are believed to be expanding. The total population size exceeds 1000 individuals, but most subpopulations are very small and restricted geographically, making them vulnerable to stochastic events. The species is able to tolerate severe drought and saline conditions. There is evidence of hybridisation. The genus consists of four species, all endemic to St Helena.

Assessor: Cronk, Q.C.B.

Refs: $9954,11891,19081$

\section{Commidendrum spurium}

Compositae

CR D1

St Helena

A small tree, known from just six individuals in the wild: one at Coles Rock, one old plant with three young ones at Mount Vesey and one fenced individual on a ridge between Cason's Gate and Oaklands. The species has been brought into cultivation. In the past, trees were recorded as growing on the tops of the highest mountains. The wood was used chiefly as a source of fuel. The genus consists of four species, all endemic to St Helena.

Assessor: Cronk, Q.C.B.

Refs: 9954, 11891, 19081

\section{Commiphora alata}

Burseraceae

VU D2

Somalia

This species is confined to bushland on sand over limestone in a small area in the south-west of Somalia. The habitat is under pressure from degradation and overcutting for charcoal production.

Assessor: Thulin, $\mathbf{M}$.

Refs: 7620,18665

\section{Commiphora albiflora}

Burseraceae

$\mathrm{LR} / \mathrm{nt}$

Ethiopia, Somalia

Occurring in Acacia-Commiphora bushland on limestone substrate, this small tree is known from scattered localities from northern and south-central Somalia to Sidamo, southern Ethiopia. Habitat is being 
degraded in places where there is overcutting for charcoal production and the expansion of agriculture. Assessor: Thulin, $\mathbf{M}$.

Refs: 1330,7620

\section{Commiphora campestris ssp. campestris} Burseraceae

LR/nt

Kenya

A tree of Acacia-Commiphora bushland or open woodland, which is found in two varieties, vars. campestris and heterophylla. It occurs in abundance in the Kibwezi-Taita area, where the two varieties coexist and interbreed.

Assessor: World Conservation Monitoring Centre

Refs: $6396,10961,17859$

\section{Commiphora chaetocapa}

Burseraceae

VU D2

Kenya, Somalia

A rare spiny shrub or tree. The only viable population occurs in central Somalia in a few localities of bushland on gypsum soils. A collection was also made from a male plant, near Garissa in Kenya in open bushland on sandy soil. The habitat is under threat of degradation from overgrazing and overcutting for charcoal production.

Assessor: Thulin, M.

Refs: $6396,7620,12067,13058,18665$

\section{Commiphora ciliata}

Burseraceae

$\mathrm{LR} / \mathrm{nt}$

Ethiopia, Kenya, Somalia

Known from central and southern Somalia, parts of the Ogaden in Ethiopia and two localities in north-east Kenya in Acacia-Commiphora woodland, this species is restricted in range and rare. In places, the habitat is degraded because of farming activities and overcutting for charcoal production.

Assessor: Thulin, $\mathrm{M}$.

Refs: $1330,6396,7620,12067,13058,18665$

\section{Commiphora corrugata}

Burseraceae

Ethiopia, Kenya, Somalia

$\mathrm{LR} / \mathrm{nt}$

An unusual species on account of the characteristics of its bark, leaves and stamens. Only a few localities are known in central and southern Somalia, in the Ogaden in Ethiopia and a small area in north-east Kenya. The Acacia-Commiphora bushland habitat is vulnerable to overcutting for charcoal production and the expansion of agricultural activities.

Assessor: Thulin, M.

Refs: $1330,7620,18665$

\section{Commiphora guidottii}

Burseraceae

LR/nt

Ethiopia, Somalia

A species which is fairly widespread in Somalia and also in adjacent parts of the Ogaden in Ethiopia. It is found in Acacia-Commiphora bushland, always on gypsum soils. Habitat is being degraded in places where there is overcutting for charcoal production and also an expansion of agricultural activities.

Assessor: Thulin, $\mathrm{M}$.

Refs: 1330,7620
Commiphora hodai

Burseraceae

LR/nt

Ethiopia, Somalia

Although the species has a very restricted range in the Ogaden in Ethiopia, it is widespread in Somalia. Its resin is used locally for myrrh.

Assessor: Thulin, M.

Refs: 1330,7620

\section{Commiphora mafaidoha}

Burseraceae

LR/nt

Madagascar

A species confined to the south-west in areas of *tropophilic forest up to $600 \mathrm{~m}$. A useful timber tree and the focus of silvicultural studies.

Assessor: World Conservation Monitoring Centre

Refs: 6161

\section{Commiphora monoica \\ Burseraceae \\ Ethiopia}

VU D2

A species known from only five collections made in the vicinity of the Sof Omar caves in dense woodland on rocky limestone slopes. It is the only wholly monoecious species in the genus.

Assessor: World Conservation Monitoring Centre

Refs: $1330,13058,18523$

\section{Commiphora obovata}

Burseraceae

LR/nt

Ethiopia, Kenya, Somalia

A small tree with a fragmented range restricted to parts of the Ogaden in Ethiopia, central and northem Somalia and eastern Kenya. The habitat has been degraded in places because of farming activities and overcutting for charcoal production.

Assessor: Thulin, M.

Refs: $1330,7620,10961,18665$

\section{Commiphora ornifolia}

Burseraceae

VU D2

Yemen (Socotra)

Although widespread on coastal plains and foothills, the populations are generally scattered and small. Leaves are used as fodder for livestock. Increasing goat numbers could cause the species to become more seriously threatened.

Assessor: Miller, A.G.

Refs: 2354, 19083

\section{Commiphora planifrons}

Burseraceae

VU D2

Yemen (Socotra)

Collected only a few times, the species has a very scattered distribution in moist woodland on limestone and granite hills. There are no immediate threats.

Assessor: Miller, A.G.

Refs: 2354, 19083

\section{Commiphora pseudopaolii}

Burseraceae

LR/nt

Kenya, Somalia

A spreading tree known from central and southern Somalia and from central Kenya in open bushland, often on alluvium soils. Overcutting and grazing of this habitat are threats.

Assessor: Thulin, M.

Refs: 6396, 7620, 13058, 18665 
Commiphora socotrana

Burseraceae

VU D2

Yemen (Socotra)

A species of dry shrubland on the low-lying foothills and plains. The gum is tapped for use as incense. At present the rates of exploitation are sustainable, since it is restricted to the local level, but increased demand could potentially put the species at risk.

Assessor: Miller, A.G.

Refs: 2354,19083

\section{Commiphora sphaerophylla}

Burseraceae

LR/nt

Ethiopia, Somalia

Fairly widespread in Somalia extending into Harerge in Ethiopia, this tree occurs in wooded grassland and bushland overlying limestone. There is some suggestion that the species could be a form of the variable $C$. erythraea.

Assessor: Thulin, M.

Refs: 1330,7620

\section{Commiphora sulcata}

Burseraceae

LR/nt

Somalia

Only a few localities where this species occurs are known. All are confined to northern and central Somalia in bushland which is vulnerable to degradation.

Assessor: Thulin, M.

Refs: 7620,18665

\section{Commiphora truncata}

Burseraceae

LR/nt

Ethiopia, Somalia

A species of Acacia-Commiphora bushland overlying limestone. It is fairly widespread in Somalia but known only from Harerge in Ethiopia. In places there is a threat to the habitat from overcutting for charcoal production and from expanding agricultural activities. The resin is used locally as myrrh.

Assessor: Thulin, $\mathrm{M}$.

Refs: 1330,7620

\section{Commiphora unilobata}

Burseraceae

LR/nt

Ethiopia, Kenya, Somalia

Relatively wide-ranging, the species is found in central eastern parts of Kenya, central and southern Somalia and Sidamo in Ethiopia. In some areas the habitat is vulnerable to degradation from agricultural expansion and charcoal production.

Assessor: Thulin, $\mathrm{M}$.

Refs: $1330,7620,18665$

\section{Commiphora wighti}

Burseraceae

India (Gujarat, Rajasthan), Pakistan

A small tree occurring in dry zones from the Deccan and west India to the north-west and Karachi, Sind and Balochistan in Pakistan. The gum is of importance in international trade and it appears to be being extracted at unsustainable rates, causing declines, particularly in the southern populations. In the northern parts of its distribution it remains relatively common. The government of India has banned the export of the species.

Assessor: CAMP Workshops on Medicinal Plants in India

Refs: 561, 7147
Comocladia cordata

Anacardiaceae

VU B $1+2 c$

Jamaica

Known only in Trelawny, the species is confined to areas of woodland on limestone.

Assessor: World Conservation Monitoring Centre

Refs: 401, 5653, 7980

\section{Comocladia parvifoliola}

Anacardiaceae

CR Bl+2c

Jamaica

Endemic to Dolphin Head, the species is confined to an area of woodland.

Assessor: World Conservation Monitoring Centre

Refs: 401,5653

\section{Comocladia velutina}

Anacardiaceae

$\mathbf{L R} / \mathrm{nt}$

Jamaica

This species is found along the south coast on dry limestone. It is locally common in places.

Assessor: World Conservation Monitoring Centre

Refs: 6057,7980

\section{Conceveiba macrostachys}

Euphorbiaceae

LR/nt

Gabon

A common tree confined to the central part of Lopé Forest Reserve, extending a few kilometres to the south. Part of the range is under concession to logging companies and there is concern over future plans for intensive logging.

Assessor: World Conservation Monitoring Centre

Refs: 14958

\section{Condaminea glabrata}

Rubiaceae

VU D2

Peru

A species which has been collected only once from the department of Huanuco. There is some doubt as to the taxonomic status of this Andean genus of just three species.

Assessor: World Conservation Monitoring Centre

Refs: 1984

\section{Condaminea macrocarpa}

Rubiaceae

VU D2

Peru

A species which is recorded only from the type in Huánuco Department. There is some doubt as to the taxonomic status of this Andean genus of just three species.

Assessor: World Conservation Monitoring Centre Refs: 1984

\section{Condaminea microcapa}

Rubiaceae

VU D2

Peru

A species which is recorded only from the type in Huánuco Department. There is some doubt as to the taxonomic status of this Andean genus of just three species.

Assessor: World Conservation Monitoring Centre

Refs: 1984 


\section{Connarus agamae}

Connaraceae

VU D2

Malaysia (Sabah)

To date this small tree is known only from Sandakan and Mostyn of Sabah, where it is restricted to primary mixed dipterocarp forest

Assessor: World Conservation Monitoring Centre

Refs: 19017

\section{Connarus brachybotryosus}

Connaraceae

EN C2a

Guatemala, Honduras

A scarce species of the Atlantic wet lowlands of Guatemala and Honduras. Continuing conversion of the habitat for agriculture has caused population reductions. Assessor: Nelson, C.

Refs: 7980,13995

\section{Connarus popenoei}

Connaraceae

CR C2a

Honduras

Restricted to the Altantic wet lowlands of Honduras, the species occurs in low numbers in Lancetilla Biological Reserve.

Assessor: Nelson, C.

Refs: 7980, 13995, 14911

\section{Connarus williamsii var. williamsii}

Connaraceae

VU B $1+2 \mathrm{c}$

Colombia, Panama

The main population of this variety is concentrated in the province of Darién in Panama, with additional occurrences in the Canal area in Panama, and also just over the border into Colombia, in the Serrania del Darién in the Chocó, and Urabá. Occurring in lowland, sometimes inundated, forest up to $300 \mathrm{~m}$, the species is scarce throughout much of its range and only in Darién National Park is there a well-protected population.

Assessor: Mitré, M

Refs: 7980,16772

\section{Conocarpus lancifolius}

Combretaceae

LR/nt

Somalia, Yemen

A small tree from a genus of just two species. The natural distribution is thought to be restricted to populations in the region of Wogooyi Galbeed, Togdheer, Bari and Nugaal in Somalia and in Hadramaut in South Yemen. It occurs in cultivation elsewhere in East and North Africa and Arabia. Wild populations are confined to localities along water courses in the semi-desert coastal zone. The wood of the damas tree provides excellent timber and charcoal. Assessor: World Conservation Monitoring Centre Refs: $9059,19083,19108$

\section{Conostegia chiriquensis}

Melastomataceae

VU Cl

Panama

For a short period, this cloud forest species was known only from the mountains of Chiriquí. Populations have now been found in Bocas del Toro and the high mountains in the Canal region. There are occurrences in Volcán Bań and La Amistad National Parks, one within $3 \mathrm{~km}$ of the border with Costa Rica.

Assessor: Mitré, M.

Refs: $7272,7980,14873,16772$
Conostegia extinctoria

Melastomataceae

$\mathrm{EN} \mathrm{B} 1+2 \mathrm{c}$

Colombia

An endemic to Tolima.

Assessor: Calderon, E.

Refs: 19069

\section{Conostegia grisebachi}

Melastomataceae

Jamaica

The species is apparently known only from specimens which originated from John Crow Mountains in St Thomas. This area has since been almost comprehensively deforested and no living populations are known. There is some question as to the taxonomy of the species as it closely resembles $C$. balbisiana. Assessor: World Conservation Monitoring Centre Refs: $401,5653,7980$

\section{Conostegia subprocera}

Melastomataceae

$\mathrm{EN} \mathrm{B} 1+2 \mathrm{c}$

Jamaica

An uncommon species, confined to moist thickets on limestone in Portland.

Assessor: Kelly, D.L.

Refs: 401, 5653, 7980, 19085

\section{Conostegia superba}

Melastomataceae

VU B $1+2 \mathrm{c}$

Jamaica

A small tree of moist woodland areas below $750 \mathrm{~m}$, found only in St Mary, Portland and St Thomas. The habitat, especially in the latter parish, has been extensively destroyed and degraded.

Assessor: World Conservation Monitoring Centre

Refs: $6057,7980,19116$

\section{Copaifera epunctata}

Leguminosae

VU D2

Suriname

A rare endemic of rainforest on iron-capped hills in Brownsberg.

Assessor: World Conservation Monitoring Centre

Refs: 6493,19196

\section{Copaifera panamensis}

Leguminosae

VU A2cd

Panama

Endemic to Panama, the species ranges from Cocle towards the east, to Darién and San Blas. It occurs in low numbers in lowland semi-deciduous rainforest, sometimes inundated forest. Only in the Canal area does the species occur a little more frequently. Seedlings are notably scarce, indicating that regeneration may be poor. The wood and resin are of commercial value but are less commonly traded because the species has become rare.

Assessor: Mitré, $M$.

Refs: $3156,7272,7980,16772$

\section{Copaifera salikounda}

Leguminosae

VUAId

Côte d'Ivoire, Ghana, Guinea, Liberia, Sierra Leone An Upper Guinea endemic, most abundant in moist evergreen forests. It can occur commonly and regeneration appears to be good. Exploitation of the timber, as well as habitat loss, throughout its range are causing population declines.

Assessor: African Regional Workshop

Refs: $2362,2773,6128$ 


\section{Copernicia brittonorum}

Palmae

Cuba

VU B1+2e

Las Villas and Pinar del Rio are the only known localities of this palm tree. It occurs in lowland woodlands and in open wetlands. Local overexploitation of the timber and leaf fibre is causing a decline in population number and few individuals remain in the wild.

Assessor: Moya, C.

Refs: 19118

\section{Copernicia ekmanï}

Palmae

Haiti

EN C1

Restricted to north-west Haiti, this palm tree occurs in lowland scrub on rocky shores near the sea. In 1996, a field survey found about 1200 individuals in four populations, ranging from a single relict tree to healthy populations numbering around 500 . The leaves are used locally for thatching and the trunks are used for construction; this exploitation is the major threat to this species.

Assessor: Johnson, D.

Refs: 19118

\section{Copernicia gigas}

Palmae

VU B $1+2 \mathrm{e}$

Cuba

A palm tree confined to seasonally flooded woodland and savanna in eastem Cuba. It is suffering from excessive local exploitation of the trunk wood and leaves.

Assessor: Moya, C.

Refs: 19118

\section{Coprosma cookei}

Rubiaceae

French Polynesia (Tubuai Is.)

An endemic to Rapa.

Assessor: Florence, J.

Refs: 14513

\section{Coprosma esulcata}

Rubiaceae

French Polynesia (Marquesas Is.)

Populations are recorded on Nuku Hiva and Ua Pou.

Assessor: Florence, J.

Refs: 14513

\section{Coprosma oliveri}

Rubiaceae

Chile (Juan Fernández Is)

A characteristic species of lower montane forest, a good example of which is found at Quebrada Villagra. Preliminary data indicate the species is confined to less than $100 \mathrm{~km}^{2}$. More detailed information on the species should become available to confirm this evaluation. The islands are designated as a national park and biosphere reserve and work is being carried out by * CONAF to save the native plants.

Assessor: World Conservation Monitoring Centre

Refs: $3241,5651,7980,14140$

\section{Coprosma pyrifolia}

Rubiaceae

VU D2

Chile (Juan Fernández Is)

A characteristic species of lower montane forest, a good example of which is found at Quebrada Villagra.
Preliminary data indicate the species is confined to less than $100 \mathrm{~km}^{2}$. More detailed information on the species should become available to confirm this evaluation. The islands are designated as a national park and biosphere reserve and work is being carried out by ${ }^{*}$ CONAF to save the native plants.

Assessor: World Conservation Monitoring Centre

Refs: 3241, 5651, 7980, 14140

\section{Coprosma rapensis var. benefica}

Rubiaceae

CR D 1

Pitcaim Islands

A small dioecious tree, endemic to Pitcaim. Only 10 individuals of flowering size were seen in 1997, and these are mostly well scattered in the eastern half of the island in degraded areas of forest. Evidence of natural regeneration is limited to a single sapling.

Assessor: Waldren, S. \& N. Kingston

Refs: 19154

\section{Coprosma taitensis var. glabrata}

Rubiaceae

DD

French Polynesia (Society Is.)

A shrub or small tree which is known only from the island of Raiatea in the Society Group.

Assessor: Florence, J.

Refs: 14513

\section{Coprosma lailensis var, oliveri}

Rubiaceae

DD

French Polynesia (Society Is.)

The rarer of two varieties of the species occurring on Tahiti. This taxon is also recorded from Moorea.

Assessor: Florence, J.

Refs: 14513

\section{Coprosma taitensis var. raiateensis}

Rubiaceae

French Polynesia (Society Is.)

As with var. glabrata, the taxon is confined to the island of Raiatea.

Assessor: Florence, J.

Refs: 14513

\section{Coprosma wallii}

Rubiaceae

New Zealand (North Is., South Is.)

VU B1 $+2 c, D 2$ A small tree with divaricating branches, found in lowland *kahikatea/matai forest, frost flats and clearings. In the North Island only three localities are known and occurrences have been recorded from Nelson, Westland and Canterbury in the South Island. There is evidence suggesting the species to be a poor competitor, suffering from the lack of periodic disturbance and sites available for recolonisation.

Assessor: de Lange, P.J.

Refs: $9800,19133,19134$

\section{Cordeauxia edulis}

Leguminosae

VU A2cd

Ethiopia, Somalia

An important shrub or small tree species confined to semi-desert bushland from eastern Ogaden to central Somalia. The seeds are highly nourishing and are exploited to such levels that regeneration may be hampered. The tree also provides valuable dry-season 
browse as well as fuel and dye. The potential of the plant as a food crop is being studied. The genus is monotypic. Assessor: World Conservation Monitoring Centre Refs: 1330,18665

\section{Cordia anisophylla}

Boraginaceae

VU A2cd

Panama

Ranging from the centre of Panama to the border with Colombia, the species occurs in lowland evergreen forest. It is found in areas which are experiencing increasing urbanisation. Only the populations within Chagres National Park and Kunayala Indigenous Reserve are given some form of protection.

Assessor: Mitré, M.

Refs: 14407, 16772, 18039

\section{Cordia cicatricosa}

Boraginaceae

VU D2

Peru

This lowland rainforest species is known only from its type, which was collected from the department of Loreto.

Assessor: World Conservation Monitoring Centre Refs: 1984

\section{Cordia clarendonensis}

Boraginaceae

VU B1+2c

Jamaica

A Cockpit Country endemic which occurs rarely in open woodland on arid limestone between 400 and $760 \mathrm{~m}$, only in Clarendon and Trelawny Parishes.

Assessor: Kelly, D.L.

Refs: 5653, 19085

\section{Cordia correae}

Boraginaceae

EN A2c, E

Panama

Described in 1988, this species is known only from a few collections taken from areas of evergreen rainforest between 800 and $1000 \mathrm{~m}$ in central Panama. There is a population within Chagres National Park, in Cerro Jefe. Other locations in Cerro Tute and in the Valle de Antón, which harbours the largest population, are strongly affected by urban development and tourism.

Assessor: Mitré, $\mathrm{M}$.

Refs: $4072,16772,18039$

\section{Cordia croatii}

Boraginaceae

VU A2c

Costa Rica, Panama

A species first described in 1988 and known only from a few scattered localities in Veraguas and Coclé in Panama and from larger populations in Costa Rica, principally located in San Ramón Forest Reserve. It is restricted to cloud forest between 800 and $1200 \mathrm{~m}$.

Assessor: Mitré, M.

Refs: $4072,16772,18039$

\section{Cordia elliptica}

Boraginaceae

$\mathrm{LR} / \mathrm{nt}$

Jamaica

An uncommon species occurring in secondary rainforest on limestone hills in central and eastem parishes.

Assessor: World Conservation Monitoring Centre Refs: 6057,7980

\section{Cordia harrisii}

Boraginaceae

VU B $1+2 c$

Jamaica

A Cockpit Country endemic with a disjunct population at the summit of Dolphin Head. Populations occur in areas of woodland on limestone.

Assessor: World Conservation Monitoring Centre

Refs: 401, 5653, 7980

\section{Cordia leslieae}

Boraginaceae

CR B I+3bc

Panama

The area from which this relatively newly described species has been collected is geographically and altitudinally very restricted. The entire population is contained within Chagres National Park and is somewhat threatened by encroaching settlement and tourist activities.

Assessor: Mitré, M.

Refs: $4072,16772,18039$

\section{Cordia mandimbana}

Boraginaceae

VU D2

Mozambique

Known only from the type specimen, the species was collected in 1941 from open woodland in the Ngami valley.

Assessor: World Conservation Monitoring Centre Refs: 5117,18965

\section{Cordia mukuensis}

Boraginaceae

VU D2

Democratic Republic of Congo

A species found only in rocky areas of savanna on Mont Mukuen. The area is vulnerable to fire and overcutting.

Assessor: Ndjele, M.B.

Refs: 17185,17951

\section{Cordia obovata}

Boraginaceae

Oman, Somalia, Yemen (Socotra)

LR/nt

A species known from north-eastern Somalia and also Socotra and Oman. Its habitat type is vulnerable to overcutting for wood especially for charcoal production. Assessor: Thulin, $\mathbf{M}$.

Refs: 8697,18665

\section{Cordia platythyrsa}

Boraginaceae

VUAld

Cameroon, Côte d'Ivoire, Ghana, Liberia, Nigeria, Sierra Leone

A timber species occurring in closed forest and secondary formations. It regenerates well in disturbed forest; e.g. along logging roads. Exploitation is moderate and the current threatened status of the species should be kept under review.

Assessor: African Regional Workshop

Refs: $2362,2773,6128,6718$

\section{Cordia protracta}

Boraginaceae

EN B1+2bde

Colombia, Panama

Current information indicates that populations of this shrubby species are very scarce, occurring in lowland evergreen forest in Kunayala Indigenous Reserve and the Serranía del Darién in Panama, and in the Chocó in Colombia.

Assessor: Mitré, M.

Refs: $7980,15037,16772$ 
Cordia ramirezii

Boraginaceae

VU B $1+2 c$

Colombia

An endemic to Nariño.

Assessor: Calderon, E.

Refs: 19069

\section{Cordia sebestena var, caymanensis}

Boraginaceae

$\mathrm{LR} / \mathrm{nt}$

Cayman Islands

Occurring in dry habitats on all three islands, this variety is widespread and well represented in protected areas. There is potential for hybridisation to occur with the type variety, which is being brought onto the islands for landscaping. Import restrictions and growing interest in the propagation of native trees may help to avoid the problem. Habitat destruction is also extensive, but trees are often retained for landscaping.

Assessor: World Conservation Monitoring Centre

Refs: 17038,19137

\section{Cordia stuhlmannii}

Boraginaceae

VU D2

Mozambique

Two collections of this species were made from northern parts of Mozambique 30 years ago, one from the Reserva Florestal do Mucheve. The species occurs in thicket on sandy soils and termite hills.

Assessor: World Conservation Monitoring Centre

Refs: 5117,18965

\section{Cordia suckertii}

Boraginaceae

$\mathrm{LR} / \mathrm{nt}$

Ethiopia, Somalia

Scattered in central Somalia and adjacent parts of Ethiopia, the species is not widely spread. It is exploited locally for the seeds, which are a good source of fat and protein.

Assessor: Thulin, $\mathrm{M}$.

Refs: 1330,18665

\section{Cordia tacarcunensis}

Boraginaceae

Panama

The species has been collected only once, from an area of lowland rainforest near the Colombian border in Darien National Park. It is possible the population extends into Colombia but no record of the species has been made since 1975 . The locality has been opened up for agriculture somewhat.

Assessor: Mitré, M.

Refs: $4072,16772,18039$

\section{Cordia troyana}

Boraginaceae

VU B $1+2 c$

Jamaica

A Cockpit Country endemic recorded from Peckham and Douglas Castle Woods and other areas of woodland on limestone. There is evidence of cutting and agricultural encroachment at both these sites.

Assessor: World Conservation Monitoring Centre

Refs: 401, 5653, 7980

\section{Cordia urticacea}

Boraginaceae

Honduras, Mexico (Guerrero)

Assessor: Nelson, C.

Refs: 3952, 3977, 13995, 18039
Cordia valenzuelana

Boraginaceae

VU B $1+2 e$

Cuba

An uncommon shrub or small tree confined to Rangel, a small area in eastern Pinar del Rio Province. The species has been overcut for its valuable timber.

Assessor: Areces-Mallea, A.E

Refs: $16327,18485,19149$

\section{Cordia wagnerorum}

Boraginaceae

Puerto Rico

CR DI

A straggling tree or woody vine of moist forest, known from no recent sitings but recorded in 1991 from the type locality on the El Toro Trail.

Assessor: World Conservation Monitoring Centre

Refs: $3786,5988,7980,17124$

\section{Cordyla haraka}

Leguminosae

VU A2cd

Madagascar

An emergent tree confined to low-altitude evergreen humid forest in north-east Madagascar. The forest is being degraded by exploitation and agriculture. Its estimated range covers $20000 \mathrm{~km}^{2}\left({ }^{*} \mathrm{AOO}\right)$ and includes some protected areas.

Assessor: Du Puy, D. \& H. Labat

Refs: 12353

\section{Cordyla madagascariensis}

Leguminosae

LR/nt

Madagascar

A deciduous tree, widespread in western and northern Madagascar. Its distribution is estimated to be 200,000 $\mathrm{km}^{2}\left({ }^{*} \mathrm{EOO}\right)$ but is confined to highly fragmented areas of native vegetation. Several protected areas fall within its distribution.

Assessor: Du Puy, D. \& H. Labat

Refs: 6161

\section{Cordyla richardii}

Leguminosae

Sudan, Uganda

VU B $1+2 c$

A savanna species known only from northern Uganda and neighbouring Sudan.

Assessor: *MUIENR

Refs: $9605,9837,10961,16021$

\section{Cordyla somalensis}

Leguminosae

LR/nt

Somalia

One of the subspecies, ssp. littoralis, is confined to the coastal dunes in southern Somalia and would be categorised as vulnerable (VU D2). However, the differences between it and the type subspecies are not thought to be significant. The species occurs more widely from southern Somalia up to the eastern Ogaden. It is not common and its habitat is vulnerable to degradation.

Assessor: Thulin, $\mathrm{M}$.

Refs: $1330,7550,18665$

\section{Cornus disciflora}

Comaceae VU Alcd

Costa Rica, Guatemala, Honduras, Mexico (Chiapas, Guerrero, Jalisco, Michoacan, Nayarit, Oaxaca, Sonora, Tamaulipas, Veracruz), Panama

A cloud forest species with a wide range, extending from northem Mexico through Central America. It is 
mainly found in the upper ranges of cloud forest, penetrating into pine-oak forest, between 1900 and $2250 \mathrm{~m}$. The timber is exploited and the habitat has declined significantly.

Assessor: Ramirez-Marcial, N. \& M. González-Espinosa Refs: 19203, 19206

\section{Cornus monbeigï}

Comaceae

VU B $1+2 c$

China (Yunnan)

A species of mixed montane forest or cloud forest, occurring between 2800 and $3200 \mathrm{~m}$. Populations are known from Weixi, Lijiang and Degin in north-west Yunnan. Rapid declines in numbers have been recorded, largely because of extensive habitat loss and degradation in the last few years. No protection or conservation measures appear to be in place. The species is in cultivation as an omamental plant.

Assessor: Sun, W.

Refs: 19055

\section{Cornutia obovata}

Verbenaceae

CR D1

Puerto Rico

A small tree of dry serpentine or moist limestone locations. A total population of eight individuals is thought to be divided between three or four sites: Río Abajo, Aricedo Observatory, Barrenquitas and possibly in the state forest at Susua.

Assessor: World Conservation Monitoring Centre

Refs: $6107,7980,17124$

\section{Cornutia thyrsoidea}

Verbenaceae

LR/nt

Jamaica

Occurring in woodland margins on limestone hills, the species is uncommon and exposed to frequent habitat degradation.

Assessor: World Conservation Monitoring Centre

Refs: 6057,7980

\section{Corokia macrocarpa}

Escalloniaceae

LR/nt

New Zealand (Chatham Is.)

This small tree actually occurs quite commonly on the Chatham Islands, to which it is confined. Populations are, however, under great pressure from the continuous damage caused by browsing possums.

Assessor: de Lange, P.J.

Refs: $902,5563,19133,19134$

\section{Corylopsis pauciflora}

Hamamelidaceae

DD

Japan, Taiwan

In Taiwan populations are few and restricted to isolated localities in broadleaved submontane forest in Chingshuishan and Bashienshan. They are unprotected and regenerating poorly. Information is needed on the population in Japan.

Assessor: World Conservation Monitoring Centre

Refs: $6469,19050,19053$

\section{Corylus chinensis}

Corylaceae

China (Henan, Hubei, Hunan, Shaanxi, Sichuan, Yunnan)

A relatively widely occurring component of middle elevation broadleaved forest. Trees are fast-growing and provide various commercially useful products, most importantly a good-quality timber. Declines in the number of mature individuals have been reported, caused largely by overexploitation. Habitat loss and poor regeneration, apparently caused by the decimation of seed crops by birds, are also thought to have contributed to the present status of the species.

Assessor: Sun, W

Refs: $1818,11847,19055$

\section{Corypha macropoda}

Palmae

DD

India (Andaman and Nicobar Is. - Andaman Is.)

A palm tree known only from the middle and south Andaman Islands. Its present status is unknown.

Assessor: Johnson, D.

Refs: 19118

\section{Corypha microclada}

Palmae

VU A1c, D2

Philippines

The species distribution is not confirmed. It appears to be confined to lowland rainforest in Biliran Island.

Assessor: Madulid, D.

Refs: 19118

\section{Corypha taliera}

Palmae

India

This monocarpic palm tree is not known in the wild. Specimens are growing in the Indian Botanic Garden and the Fairchild Tropical Garden.

Assessor: Johnson, D.

Refs: 19118

\section{Corypha umbraculifera}

Palmae

DD

India (Kamataka, Kerala)

A monocarpic palm of moist forest, restricted to Kamataka and the Malabar coast of Kerala. It is difficult to distinguish between wild and semi-wild populations. Assessor: Johnson, D.

Refs: 19118

\section{Corythophora labriculato}

Lecythidaceae

VU D2

Suriname

A relatively small tree of non-flooded rainforest, riverine or swamp forest, known from about 15 collections. The genus is made up of four species.

Assessor: World Conservation Monitoring Centre Refs: $3791,7980,9263,19196$

\section{Cossinia trifoliata}

Sapindaceae

VU Bl+2c

New Caledonia

Assessor: Jaffré, T. et al.

Refs: 10351

\section{Cotoneaster granatensis}

Rosaceae

LR/cd

Spain

Endemic to the Andalusian sierras, this shrubby species occurs on calcareous and ultrabasic rocks. Most of the population is contained within protected sites. It is a useful coloniser and stabiliser of eroding slopes.

Assessor: Vivero, J.L. et al.

Refs: 7222,7741 


\section{Cotylelobium burckii}

Dipterocarpaceae

EN Alcd+2cd

Brunei, Malaysia (Sarawak)

A tree that is locally common on giant podzols and poor sandy soils, often near the coast and in lowland heath forest. The wood is used for boat making. Some populations occur within reserves.

Assessor: Ashton, $\mathrm{P}$.

Refs: 7673,9169, 13857

\section{Cotylelobium lanceolatum}

Dipterocarpaceae

VU Alcd, B1+2c

Brunei, Indonesia, Malaysia (Peninsular Malaysia,

Sabah, Sarawak), Singapore, Thailand

This species is restricted to a declining habitat on sandy low hills. It is widespread but local, and recorded within some reserves.

Assessor: Ashton, P.

Refs: $5550,7673,9169,9199,13857,18327$

\section{Cotylelobium lewisianum}

Dipterocarpaceae

CR Alacd, $\mathrm{B} 1+2 \mathrm{c}$

Sri Lanka

A tree restricted to rocky ridges of highland evergreen forest. Its wood is collected locally. This species was not found during the extensive National Conservation

Review forest surveys.

Assessor: Ashton, $\mathrm{P}$.

Refs: $15431,13857,19112$

\section{Cotylelobium melanoxylon}

Dipterocarpaceae

EN Alcd $+2 c d$

Indonesia (Sumatra), Malaysia (Peninsular Malaysia), Singapore

Some populations of the species are known to occur in forest reserves.

Assessor: Ashton, P.

Refs: 7673, 9169, 13857

\section{Cotylelobium scabriusculum}

Dipterocarpaceae

CR Alcd, B1+2c

Sri Lanka

A tree restricted to lowland wet evergreen forest, a habitat type that is found only in the south-westem comer of the island. This species was not found in the extensive forest surveys conducted for the National Conservation Review.

Assessor: Ashton, P.

Refs: $15431,17195,13857,19112$

\section{Couepia joaquinae}

Chrysobalanaceae

CR D1

Brazil (Amapá)

The species was described in 1991 from collections originating from Jari. So far only four individuals are known.

Assessor: Pires O'Brien, J.

Refs: 19095

\section{Couepia schottii}

Chrysobalanaceae

Brazil (Bahia, Espírito Santo, Rio de Janeiro)

VU Alc+2c

Little of the * restinga vegetation, to which the species is confined, remains. The expansion of the tourist industry and holiday homes, as well as exploitation for fuelwood, threatens the species survival. It is included in the official list of threatened Brazilian plants compiled by *IBAMA

Assessor: Varty, N.

Refs: $5901,7980,8815,15539,16123$

\section{Couepia scottmorï}

Chrysobalanaceae

CR B1+2bd

Panama

A scarce species which is confined to a small area of cloud forest between 800 and $1000 \mathrm{~m}$ in the region of Cerro Jefe, in the province of Panama. The whole species' range is within the boundaries of Chagres National Park. Before the area was granted this status, a large part of the original forest was destroyed for housing and industrial developments. A single collection from Valle del Cauca in Colombia could possibly be included under this species.

Assessor: Mitré, M.

Refs: $5970,7501,7980,16772$

\section{Couratari asterophora}

Lecythidaceae

$\mathrm{CR} B 1+2 \mathrm{C}$

Brazil (Bahia)

This species is known only from the type collection, which was taken from farming land.

Assessar: Pires O'Brien, J.

Refs: $3791,5942,7980,9632$

\section{Couratari asterotricha}

Lecythidaceae

CR B $1+2 d$

Brazil (Espírito Santo)

A species known only from the type locality in Linhares Forest Reserve.

Assessor: Pires O'Brien, J.

Refs: $3791,7980,9632$

\section{Couratari atrovinosa}

Lecythidaceae

$\mathrm{EN} \mathrm{B} 1+2 \mathrm{~d}$

Brazil (Amazonas)

Confined to non-flooded forests in the vicinity of Manaus, the species is threatened by fires and urban expansion. An occurrence is recorded from INPA Experimental Reserve.

Assessor: Pires O'Brien, J.

Refs: $3791,7980,9632$

\section{Couratari calycina}

Lecythidaceae

VU D2

Guyana

This rainforest tree has been collected only once, along the Bartica-Potaro road in 1933.

Assessor: World Conservation Monitoring Centre

Refs: 3791,7980

\section{Couratari guianensis}

Lecythidaceae

VU A2bcde

Brazil (Acre, Amazonas, Pará, Rondônia), Colombia, Costa Rica, French Guiana, Guyana, Panama, Penu, Suriname, Venezuela

A widespread timber species which has suffered serious population declines because of overexploitation and habitat loss, most particularly in Central America and Brazil.

Assessor: Pires O'Brien, J.

Refs: 4616, 4870, 5134, 5942, 9632, 10686, 12109 14717,17854 


\section{Couratari longipedicellata}

Lecythidaceae

VU B $1+2 c, D 1$

Brazil (Amazonas)

This species is known only from areas of non-flooded forest in the vicinity of Manaus. Fires, felling and cutting the buttresses are the most major threats.

Assessor: Pires O'Brien, J.

Refs: $3791,7980,9632$

\section{Couratari prancei}

Lecythidaceae

$\mathrm{CR} \mathrm{B1+2d}$

Brazil (Acre), Peru

A rarely collected species of non-flooded forest, occurring in Acre and eastern Peru. The area is threatened by increasing land settlement.

Assessor: Pires O'Brien, J.

Refs: $3791,7980,9632$

\section{Couratari pyramidata}

Lecythidaceae

$\mathrm{EN} \mathrm{B} 1+2 \mathrm{c}$

Brazil (Rio de Janeiro)

At one time the species may have represented a commonly occurring tree. It is now confined to forested areas around Rio de Janeiro.

Assessor: Pires O'Brien, J.

Refs: $3791,7980,9632$

\section{Couratari sandwithii}

Lecythidaceae

VU D2

Suriname, Venezuela

A poorly known species, collected only twice from areas of lowland non-flooded rainforest in the Venezuelan Guyana and Suriname.

Assessor: World Conservation Monitoring Centre

Refs: $3791,6493,7980$

\section{Couratari scottmori}

Lecythidaceae

VU B $1+2 \mathrm{c}$

Costa Rica, Panama

A large buttressed tree of evergreen lowland rainforest, known from about four collections taken from a locality in the Osa Peninsula in Costa Rica and from single localities in San Blás and Darién in Panama.

Assessor: World Conservation Monitoring Centre

Refs: $3791,4616,7980,14717$

\section{Couratari tauari}

Lecythidaceae

Brazil (Amazonas, Pará)

An infrequent species known from a few widely geographically separated collections from non-flooded forest.

Assessor: Pires O'Brien, J.

Refs: $3791,5942,7980,9632$

\section{Couroupita nicaraguensis}

Lecythidaceae

LR/nt

Colombia, Costa Rica, Ecuador, El Salvador, Nicaragua, Panama

Although widely occurring from El Salvador to Ecuador, the species is scattered sparsely in lowland semideciduous rainforest, sometimes in swampy areas. It is noted as common in Nicaragua and in Darién National Park in Panama. The habitat, especially where unprotected, is under pressure from increasing settlement, logging and agriculture.

Assessor: Mitré, M.

Refs: $1984,7980,16772$

\section{Coursetia brachyrachis}

Leguminosae

VU B1+2ac

Argentina (Jujuy, Salta), Bolivia

Endemic to the piedmont forest of north-west Argentina and Bolivia, the species is confined to an unprotected ecosystem which is being rapidly replaced by agricultural systems.

Assessor: Prado, D.

Refs: 19122

\section{Coursetia hypoleuca}

Leguminosae

VU B1+2ac

Argentina (Jujuy, Salta, Tucumán), Bolivia

A tree or shrub, endemic to the subandean piedmont forest of north-west Argentina and Bolivia. The ecosystem is unprotected and, at least in Argentina, the habitat is constantly declining because of encroaching agriculture and other human activities. The species acts as a pioneer and is reported to be regenerating sufficiently. There is considerable interest in it as a source for compounds which attack the AIDS virus.

Assessor: Prado, D.

Refs: 1262,13295

\section{Coussapoa curranii}

Cecropiaceae

VU Alc

Brazil

A scarce species of Atlantic forest in the north-east and south-east of Brazil

Assessor: Carauta, J.P.P.

Refs: 7980, 10481, 15717, 19101

\section{Coussapoa floccosa}

Cecropiaceae

VU B $1+2 a b$

Brazil (Minas Gerais)

Assessor: Pereira, J.P. et al.

Refs: 7980, 10481, 15717

\section{Coussapoa tolimensis}

Cecropiaceae

EN B $1+2 c$

Colombia

An endemic to Tolima.

Assessor: Calderon, E.

Refs: 7980, 19069

\section{Coussarea klugii}

Rubiaceae

Peru

Occurring in Amazon forest, the only record of the species is its type collection taken from the department of Loreto. There is uncertainty over the taxonomy. It may be treated as a variety of $C$. longiflora or a synonym of $C$. benensis.

Assessor: World Conservation Monitoring Centre Refs: 1984

\section{Coussarea mexicana}

Rubiaceae

VU Alc

Mexico (Chiapas, Oaxaca, Veracruz)

This canopy tree is restricted to the remaining rainforest in the Gulf region, from southern Veracruz to the adjacent states further south.

Assessor: World Conservation Monitoring Centre

Refs: 5993

\section{Craibia atlantica}

Leguminosae VU Alc

Cameroon, Côte d'Ivoire, Ghana, Nigeria

The distribution of this species is irregular from Côte 
d'Ivoire to Cameroon. Although generally uncommon, it can occur in some abundance at certain sites, e.g. along river banks. In Ghana it is best known from the Shai Hills. In Cameroon it is known only from an area along the banks of Sanaga River. Its forest habitat, particularly dry forest in Ghana, has experienced serious reductions in extent, mainly because of agricultural expansion, settlement and fires.

Assessor: Hawthome, W.

Refs: $2773,8369,12061,12597$

\section{Craibia brevicaudata ssp. brevicaudata \\ Leguminosae \\ Tanzania}

$\mathrm{LR} / \mathrm{nt}$

Relatively widespread in Kenya extending into northeast Tanzania, this subspecies occurs in evergreen coastal forest and rocky woodland or bushland along rivers.

Assessor: World Conservation Monitoring Centre

Refs: $3356,6396,10961$

\section{Craibia brevicaudata ssp. burttii}

Leguminosae

$\mathrm{EN} \mathrm{B} 1+2 \mathrm{c}$

Kenya

Most specimens of the species in Kenya are ssp. brevicaudata. This subspecies survives only in coastal forest patches near Kibwezi and on Emali Hill.

Assessor: World Conservation Monitoring Centre

Refs: 6396, 10961

\section{Craibia brevicaudata ssp. schliebenii}

Leguminosae

Mozambique, Tanzania

VU B $1+2 b$

This subspecies occurs in dry evergreen forest at elevations between 1100 and $1800 \mathrm{~m}$ in east Tanzania and the Gorongosa Mountains in Mozambique.

Assessor: Lovett, J. \& G.P. Clarke

Refs: 3356, 10961

\section{Craibiodendron scleranthum}

Ericaceae

VU B $1+2 c$

Viet Nam

Endemic to central Viet Nam, this large tree is scattered sparsely or found in dominant stands in dense evergreen broadleaved and mixed forest in Gia Lai, Kon Tum, Phu Yen and Khanh Hoa Provinces. The wood is used in construction work and furniture-making.

Assessor: World Conservation Monitoring Centre

Refs: $848,15357,19060$

\section{Craigia kwangsiensis}

Tiliaceae

CR D1

China (Guangxi)

This species has been found at only a single locality in Langping, growing in forest on limestone hills at $1400 \mathrm{~m}$. An extensive search in 1982 failed to relocate the species. There are only two species in this somewhat taxonomically unresolved genus.

Assessor: World Conservation Monitoring Centre

Refs: $1818,11725,11847$

\section{Craigia yunnanensis}

Tiliaceae

$\mathrm{EN} \mathrm{B} 1+2 c$

China (Guangxi, Guizhou, Yunnan), Viet Nam

Small populations are scattered in Ruili, Malipo, Xichou and Lushui in Yunnan, in westem Guangxi and Dushan County in southem Guizhou, and in north Viet Nam. The species habitat is monsoon forest between 500 and $1000 \mathrm{~m}$. It has been extensively cleared and degraded throughout the range. Only two species have been described in this somewhat taxonomically unresolved genus.

Assessor: Sun, W.

Refs: $1818,11847,19055$

\section{Crateranthus talbotii}

\section{Lecythidaceae}

VUB $1+2$ ac

Cameroon, Nigeria

An unusual small tree, which occurs in swamp forests in an area extending from south-east Nigeria into Cameroon. The largest, if not the only, remaining populations occur in the Oban Division of the Cross River National Park in Nigeria and the contiguous Korup National Park in Cameroon. Forests outside protected areas have largely been logged and cleared for commercial crops and subsistence farming. This is the only member of the genus.

Assessor: World Conservation Monitoring Centre

Refs: $2773,4977,11504$

\section{Craterispermum longipedunculatum}

Rubiaceae

VU B $1+2 b$

Tanzania

Endemic to southem parts of the Nguru Mountains and northern parts of the Udzungwa Mountains, this species is confined to moist evergreen montane forest within a very narrow altitudinal band.

Assessor: Lovett, J. \& G.P. Clarke

Refs: 3356,5204

\section{Craterispermum microdon}

Rubiaceae

VU D2

Seychelles

Endemic to the Seychelles, the species qualifies as threatened by virtue of its restricted distribution. Populations are healthy and stable.

Assessor: World Conservation Monitoring Centre

Refs: 16212,17229

\section{Craterispermum montanum}

Rubiaceae

VU B1 $+2 c, D 2$

São Tomé \& Príncipe (Príncipe, Sāo Tomé)

A small tree, which was relatively well collected on expeditions at the turn of the century and before. In the present day it appears to be localised to a number of primary forest sites at high altitudes $(>1000 \mathrm{~m})$. The bark is an important ingredient in a fortifying drink for swordfish hunters and also in an aphrodisiac drink. There is evidence that some trees are dying from overcollection of the bark.

Assessor: World Conservation Monitoring Centre

Refs: 2724, 10080, 19042, 19111

\section{Cratylia bahiensis}

Leguminosae

VU B1+2c

Brazil (Bahia)

Known from six sites, this newly described species is confined to a small area of semi-deciduous forest in central-southem Bahia. It can occur as a climbing shrub or a treelet.

Assessor: World Conservation Monitoring Centre

Refs: 16095 


\section{Cremastosperma longicuspe Annonaceae \\ Peru}

VU D2

A genus endemic to the Andes. This species is known only from the type, collected in Loreto.

Assessor: World Conservation Monitoring Centre Refs: 1984

\section{Cremastosperma megalophyllum Annonaceae \\ Peru}

VU D2

A genus endemic to the Andes. This species is known only from the type, which was collected in Loreto. Assessor: World Conservation Monitoring Centre Refs: 1984

\section{Cremastosperma panamense}

\section{Annonaceae}

Panama

Although reported from Panama, there is no information in the literature or in herbaria in Panama to indicate where the species is located.

Assessor: Mitré, M.

Refs: 6247,16772

\section{Cremastosperma peruvianum}

Annonaceae

VU D2

Peru

A genus endemic to the Andes. This species is known only from the type, which was collected in Loreto. Assessor: World Conservation Monitoring Centre Refs: 1984

\section{Critoniopsis sevillana}

Compositae

VU $B 1+2 c$

Ecuador

A tree species which is endemic to the High Andes of Ecuador. It is apparently restricted to montane forest in a narrow altitudinal range.

Assessor: World Conservation Monitoring Centre Refs: 19119,19120

\section{Critoniopsis sodiroi}

Compositae

VU B $1+2 c$

Ecuador

A tree or shrub which is endemic to the montane forest zone of the Ecuadorean High Andes.

Assessor: World Conservation Monitoring Centre

Refs: 19119,19120

\section{Crossopetalum parviflorum}

Celastraceae

Costa Rica, Guatemala, Mexico, Nicaragua, Panama

A widely distributed species in Costa Rica, Nicaragua and Guatemala, also reported from Mexico, and in small populations in the provinces of Bocas del Toro, Panamá and the Canal zone in Panama. Scattered in lowland semi-deciduous forest, the species is found in areas which are experiencing high rates of settlement and human population growth.

Assessor: Mitré, M.

Refs: 15037,16772

\section{Crotalaria exaltata}

Leguminosae

LR/nt

Ethiopia

From the Kefa, Shewa, Bale and Sidamo regions this small tree occurs in the margins of upland forest or bamboo thicket above $3000 \mathrm{~m}$. It is not known elsewhere.

Assessor: World Conservation Monitoring Centre

Refs: $1330,11191,18523$

\section{Croton alienus}

Euphorbiaceae

$\mathrm{EN} \mathrm{B} 1+2 \mathrm{c}$

Kenya

Endemic to central Kenya, this shrub or small tree is restricted to humid areas of upland evergreen or secondary forest. Loss of habitat to create land for agriculture and land settlement is the greatest threat to the species. There are protected populations in some reserves, such as Mount Kenya and Kakamega forest, although some of these areas are being actively logged. The Plant Conservation Programme in Kenya has raised seedlings.

Assessor: World Conservation Monitoring Centre Refs: $6396,9198,17859$

\section{Croton aubrevillei}

Euphorbiaceae

VU Alc, Bl+2c

Côte d'Ivoire, Ghana

A rare species of wet evergreen forests. Reductions in this habitat, caused by mining and forestry activities over the last few decades, have been significant.

Assessor: Hawthorne, W.

Refs: $4108,8369,11530,12061$

\section{Croton cordatulus}

Euphorbiaceae

$\mathrm{EN} \mathrm{Bl}+2 \mathrm{c}$

New Caledonia

Assessor: Jaffré, $\mathrm{T}$, et al.

Refs: 10351

\section{Croton dictyophlebodes}

Euphorbiaceae

VU B $1+2 b$

Tanzania

Restricted to the West Usambara Mountains, this species occurs within dry montane forest. It has a close affinity with $C$. sylvaticus.

Assessor: Lovett, J. \& G.P. Clarke

Refs: $2074,3356,11631$

\section{Croton jatrophoides}

Euphorbiaceae

VU $B 1+2 b$

Tanzania

A dry coastal forest species from eastem Tanzania, also said to occur in south-east Kenya.

Assessor: Lovett, J. \& G.P. Clarke

Refs: 3356, 10961

\section{Croton kelantanicus}

Euphorbiaceae VUD2

Malaysia (Peninsular Malaysia)

A small tree of primary evergreen rainforest, collected only a single time from Kelantan.

Assessor: Kochummen, K.M.

Refs: 8464, 19073

\section{Croton laurinus}

Euphorbiaceae

$\mathrm{LR} / \mathrm{nt}$

Jamaica

Populations are confined to areas of woodland on craggy limestone.

Assessor: World Conservation Monitoring Centre Refs: 6057,7980 
Croton lawianus

Euphorbiaceae

India (Kamataka)

A small tree of stunted montane forest, collected only once in the Bababudan range.

Assessor: World Conservation Monitoring Centre

Refs: 19144

\section{Croton longipedicellatus ssp. austrotanzanicus}

Euphorbiaceae

VU B $1+2 b$

Tanzania

A Tanzanian endemic which occurs in deciduous coastal thicket and open woodland. It is known from two sites: Nakilala in Kilwa District and Lake Lutamba. Areas around the latter were extensively cleared 50 years ago for the cultivation of commercial crops, leaving only a small area of forest contained within Litipo Forest Reserve.

Assessor: Lovett, J. \& G.P. Clarke

Refs: 3356,8814

\section{Croton lucidus}

Euphorbiaceae

VU D2

Malaysia (Peninsular Malaysia)

A small tree of primary evergreen rainforest, known only from a single collection, gathered from Gunung Pulai in Johore.

Assessor: Kochummen, K.M.

Refs: 8464,19073

\section{Croton macrocaspus}

Euphorbiaceae

$\mathrm{CR} B 1+2 \mathrm{C}$

Malaysia (Peninsular Malaysia)

Recorded by a single collection, the species was known from an area of peat swamp forest at Telok in Selangor which has since been developed for agriculture.

Assessor: World Conservation Monitoring Centre

Refs: 17140,19073

\section{Croton megalocarpoides}

Euphorbiaceae

LR/nt

Kenya, Mozambique, Somalia, Tanzania

At the north of the species range two populations occur in rocky places of semi-evergreen woodland and scrub in southem Somalia extending into Kenya near Kiunga. Further south new locations have been found in remaining patches of forest in Lindi and coastal Tanzania, possibly extending into northem Mozambique.

Assessor: Lovett, J. \& G.P. Clarke

Refs: $3356,5654,6396,8697,9198,12067,18665$

\section{Croton phuquocensis}

Euphorbiaceae

VU D2

Viet Nam

This species appears to be endemic to Viet Nam, where it is known from only a single locality in Kien Giang Province.

Assessor: World Conservation Monitoring Centre

Refs: 848

\section{Croton sarcocarpus}

Euphorbiaceae

VU D2

Yemen (Socotra)

The species is scattered, although occasionally common in areas of moist submontane woodland. There are no immediate threats.

Assessor: Miller, A.G.

Refs: 2354, 19083

\section{Croton socotranus}

Euphorbiaceae

Yemen (Socotra)

This is one of the commonest trees on Socotra. It dominates all types of vegetation over much of the coastal plains and foothills. Trees are cut for constructing roofs. Current rates of exploitation are sustainable but increasing development of the island may place the species under greater risk.

Assessor: Miller, A.G.

Refs: 2354, 19083

\section{Croton stellulifer}

Euphorbiaceae

São Tomé \& Príncipe (Príncipe, São Tomé)

VU B1 $+2 c, D 2$

An upland tree with a relatively wide altitudinal range, principally occurring in secondary forest. Populations are recorded from Oquê Pipi on Príncipe and Lagoa Amelia, Morro Miguel Angelo and Esperanca on São Tomé. Although trees have been seen to set fruit, no regeneration is evident. The wood is valued as a timber. Areas on both islands remain to be inventoried and it is hoped there are regenerating populations in existence. Assessor: World Conservation Monitoring Centre Refs: 2724, 10080, 19042, 19111

\section{Croton sulcifructus}

Euphorbiaceae

VU D2

Yemen (Socotra)

The species is scattered, although occasionally common in areas of moist submontane woodland. There are no immediate threats.

Assessor: Miller, A.G.

Refs: 2354,19083

\section{Croton talaeporos}

Euphorbiaceae

Kenya, Somalia

LR/nt

A species confined to bushland or woodland on the coast of Kenya and southem Somalia. It occurs in abundance near Kiunga.

Assessor: Thulin, M.

Refs: $6396,8697,10961,18665$

\section{Croton touranensis}

Euphorbiaceae

VU D2

Viet Nam

This species appears to be endemic to Viet Nam, where it is known from only a single locality in Da Nang. Assessor: World Conservation Monitoring Centre Refs: 848, 11530

\section{Croton vaughanii}

Euphorbiaceae

CR Alc, B1+2e, C2ab, D1

Mauritius

Only five individuals remain.

Assessor: Strahm, W.

Refs: $9120,16426,19208$

\section{Crotonogyne manniana}

Euphorbiaceae

LR/nt

Cameroon, Equatorial Guinea (Bioko), Gabon, Ghana, Nigeria

An understorey shrubby tree restricted to but locally abundant in wet evergreen forest. The species is relatively wide-ranging from Ghana to Gabon. Mining, logging and other forestry activities, particularly in 
Ghana, Nigeria and Cameroon, have caused the general decline and degradation of these forests.

Assessor: World Conservation Monitoring Centre

Refs: 450, 2773, 12061, 12597, 15251, 19043

\section{Crudia balachandrae}

Leguminosae

VU D2

India (Andaman and Nicobar Is. - Nicobar Is.)

This is the only species of the genus in India. It is rare and endemic to Great Nicobar Island where it is found on forested slopes on the north to south road near South Bay. There is evidence of insect damage on the flowers. Assessor: World Conservation Monitoring Centre

Refs: 2609

\section{Crudia brevipes}

Leguminosae

VU D2

Malaysia (Peninsular Malaysia)

A tree of lowland rainforest, confined to Tasek Glugor, Wellesley Province, Penang. Only one collection of the species has been made. The area is under increasing settlement.

Assessor: World Conservation Monitoring Centre

Refs: 8464,19073

\section{Crudia glauca}

Leguminosae

Malaysia (Peninsular Malaysia)

This rare tree occurs in open forest on limestone hills, confined to Gopeng in the state of Perak. The area is experiencing mining activities and increasing settlement. Assessor: Chua, L.S.L.

Refs: 8464,19073

\section{Crudia lanceolata}

Leguminosae

VU B $1+2 \mathrm{c}$

Malaysia (Peninsular Malaysia), Thailand

This tree is found in both Peninsular Malaysia and Peninsular Thailand, inhabiting primary hill rainforest.

Assessor: Chua, L.S.L.

Refs: 8464, 19073

\section{Crudia penduliflora}

\section{Leguminosae}

VU D2

Malaysia (Peninsular Malaysia)

This lowland rainforest species is confined to Mount Ophir in Johore. Only one collection has been made. The area is experiencing some logging and increasing settlement.

Assessor: World Conservation Monitoring Centre

Refs: 8464, 19073

\section{Crudia scortechinii}

Leguminosae

Malaysia (Peninsular Malaysia)

VU B $1+2 c$

An endemic tree of Peninsular Malaysia known only

from lowland and hill rainforest in the state of Perak.

Assessor: Chua, L.S.L.

Refs: 8464,19073

\section{Crudia splendens}

Leguminosae

VU D2

Indonesia (Kalimantan)

This species is only known from the type collection.

Assessor: World Conservation Monitoring Centre

Refs: 1766
Crudia zeylanica

Leguminosae

EX

Sri Lanka

A large tree of the wet lowlands endemic to Sri Lanka. The species has been considered on the verge of extinction for over a decade, and as it was not found in the recent National Conservation Review forest survey it is likely to be extinct. A single tree was supposed to exist in the Peradeniya Botanical Garden. However, it has not been refound in the garden despite an intensive search.

Assessor: World Conservation Monitoring Centre

Refs: 8203, 12129, 18796

\section{Cryosophila bartlettii}

Palmae

EN A1c, B1+2c, C2a

Panama

Occurring in lowland areas, the species is known only from a few small scattered populations in the vicinity of Lago Alajuela. Much of the original habitat was flooded by the construction of this artificial lake. Logging and increasing agriculture and settlements are the principal threats to remaining populations. One small population is protected within Chagres National Park. The fibre is locally traded.

Assessor: Evans, R.

Refs: 19118

\section{Cryosophila cookii}

Palmae

CR Alc, B1+2a, C2a

Costa Rica

The most morphologically distinct species in the genus. Individuals or small groups are scattered in Atlantic lowland rainforest near Limon. The present adult population is estimated to number less than 100 individuals. The range of the species is presumed to have been larger in the past. Habitat conversion to agriculture has caused major population declines. Logging, increasing settlements and decline in dispersal/pollination agent populations have also contributed to losses. The palm heart is eaten locally for medicinal purposes. A few plants are protected in Tortu Guero National Park.

Assessor: Evans, R.

Refs: 19118

Cryosophila grayumii

Palmae

CR Alc

Costa Rica

A single-stemmed palm of lowland rainforest, occurring on limestone on the Pacific slope. Populations are small, widely scattered and threatened by increasing agriculture and settlement and logging. There is a protected population in Carava Biological Reserve.

Assessor: Evans, $\mathrm{R}$.

Refs: 19118

\section{Cryosophila guagara}

Palmae

LR/nt

Costa Rica, Panama

A palm tree of lowland rainforest, a habitat which has greatly declined through conversion to agriculture. Large populations still exist in protected areas in Costa Rica, including Corcorado National Park, Carava Biological Reserve and Golfito Wildlife Reserve. The heart of the palm is eaten locally for medicinal purposes. Assessor: Evans, R.

Refs: 19118 
Cryosophila kalbreyeri

Palmae

Colombia, Panama

A single-stemmed palm of lowland to submontane rainforest, ranging from eastern Panama to western Madalena, Colombia. The Colombian populations have been divided into two subspecies, both of which are considered endangered by the Instituto de Investigacion de Recursos Biologicos Alexander von Humboldt. Much of the original habitat has been converted for agriculture and the species has become rare or absent in places. In remote, undisturbed areas the species remains relatively common.

Assessor: Evans, R.

Refs: 19069,19118

\section{Cryosophila nana}

Palmae

LR/nt

Mexico (Chiapas, Colima, Guerrero, Jalisco, Michoacan, Nayarit, Sinaloa)

Occurring on the Pacific coast, the species is found in areas of dry deciduous forest, often pine-oak woodland, up to $1700 \mathrm{~m}$. Much of the original dry forest along the coast is cleared or greatly altered as a result of logging and conversion to agriculture and settlements. Populations have become scarce or have completely disappeared at lower elevations. In relatively undisturbed areas in upper altitudinal limits, the species can be common.

Assessor: Evans, $\mathrm{R}$.

Refs: 19118

\section{Cryosophila williamsii}

\section{Palmae}

Honduras

The species is confined to two widely-separated populations on the west side of Lago Yojoa, occurring in lowland rainforest on steep slopes. The population at Lago Yojoa is known to be reproducing and is given some protection within a forest reserve. Increasing agricuture, settlement and logging have caused population declines in the past. The leaves are used locally for thatching and the palm heart is eaten for medicinal purposes. The flowers are unique in the genus in their ascending rather than arching position.

Assessor: Evans, $\mathrm{R}$.

Refs: $7645,7724,19118$

\section{Cryptocarya anamallayano \\ Lauraceae}

$\mathrm{EN} \mathrm{BI}+2 \mathrm{c}$

India (Kerala, Tamil Nadu)

A poorly known species of submontane forest, collected three or four times from three widely separated localities.

Assessor: World Conservation Monitoring Centre

Refs: 19144

\section{Cryptocarya beddomei}

Lauraceae

$\mathrm{VU} \mathrm{B} 1+2 \mathrm{C}$

India (Karnataka, Kerala, Tamil Nadu)

Rarely collected, the species occurs in widely scattered localities of submontane forest along the Westem Ghats, from Kodachadri to the Agastyamalai Hills.

Assessor: World Conservation Monitoring Centre Refs: 19144

\section{Cryptocarya bitriplinerva}

Lauraceae

$\mathrm{EN} \mathrm{B1}+2 \mathrm{C}$

New Caledonia

A single locality is known in the Kalouéholo valley where the species occurs in lowland forest on ultramafic soils.

Assessor: Jaffré, T. et al.

Refs: 10351,12630

\section{Cryptocarya elliptifolia}

Lauraceae

Philippines, Taiwan

In Taiwan, the population is confined to areas of lowland broadleaved forest on Lanyu Island. The number of mature individuals is very small $(<250)$. Poor regeneration and housing developments cause the most serious concern for remaining populations. Information is needed on the populations in Philippines.

Assessor: Lu, S.Y. \& F.J. Pan

Refs: 6469, 7933, 19050, 19051

\section{Cryptocarya ferrarsii}

Lauraceae

CR B1+2c

India (Andaman and Nicobar Is. - Andaman Is.)

A small forest tree, known o.ly from the type collection on Middle Andaman Island. The forests here have declined significantly through large-scale logging. Intact forest remains in Jarwa Reserve, which is unexplored and may harbour further populations of the species.

Assessor: World Conservation Monitoring Centre

Refs: 4799,7147

\section{Cryptocarya mannii}

Lauraceae

LR/nt

USA (Hawaii)

A rarely collected species known only from Kauai and Oahu, where it occurs in various forest types.

Assessor: World Conservation Monitoring Centre

Refs: 3372

\section{Cryptocarya membranacea}

Lauraceae

$\mathrm{EN} \mathrm{B1}+2 \mathrm{c}$

\section{Sri Lanka}

A rare species confined to lowland wet evergreen forest in south-west Sri Lanka. During the extensive National Conservation Review forest surveys, this species tumed up in only four forest localities.

Assessor: World Conservation Monitoring Centre Refs: 8203, 17195, 19112

\section{Cryptocarya palawanensis}

Lauraceae

Philippines

This Palawan endemic occurs in forest next to mangrove stands at sea level. Mangrove areas continue to be depleted by local people collecting firewood and construction timber, despite their forest reserve status. The main island is declared a biosphere reserve.

Assessor: World Conservation Monitoring Centre Refs: 4986,18088

\section{Cryptocarya stocksii}

Lauraceae

VU B $1+2 c$

India (Karnataka, Kerala, Tamil Nadu)

A medium-sized tree of submontane forest. Little is known about its habitat. It has been collected just four times from four widely separated locations, from 
Bababudan in the Kamataka to the Agastyamalai Hills in Tamil Nadu.

Assessor: World Conservation Monitoring Centre

Refs: 19144

\section{Cryptocarya wightiana}

Lauraceae

VU Alc

Sri Lanka

A common tree occurring in the lowland wet evergreen forests of south-west Sri Lanka.

Assessor: World Conservation Monitoring Centre

Refs: 9176, 17195

\section{Cryptosepalum diphyllum}

Leguminosae

$\mathrm{EN} \mathrm{B} 1+2 \mathrm{ac}$

Nigeria

Records of this forest species are known only from south-east Nigeria. It is not known from the Oban Division of the Cross River National Park. Forest outside protected areas is almost completely cleared and planted with commercial or subsistence crops.

Assessor: World Conservation Monitoring Centre Refs: 2773, 7550, 11504

\section{Cryptosepalum tetraphyllum}

Leguminosae

VU Alc, Bl+2c

Côte d'Ivoire, Ghana, Guinea, Liberia, Sierra Leone

A rare tree which occurs in wet evergreen forests and along riversides in more deciduous forests. It ranges from Guinea to Sierra Leone. A general decline in this habitat type has been caused by mining, logging and the establishment of commercial plantations.

Assessor: Hawthome, W.

Refs: $7550,8369,12061$

\section{Cullenia ceylanica}

Bombacaceae

VU Alc

Sri Lanka

A species occurring in the lowland wet evergreen forests of south-west Sri Lanka.

Assessor: World Conservation Monitoring Centre

Refs: 15431, 17195

\section{Cullenia rosayroana}

Bombacaceae

$\mathrm{LR} / \mathrm{cd}$

Sri Lanka

A subcanopy tree, restricted to the wet lowlands of Sri Lanka. It is commonly found in the Sinharaja Biosphere Reserve.

Assessor: World Conservation Monitoring Centre

Refs: 15431, 17195, 18515

\section{Cuminia eriantha}

Labiatae

CR B $1+2 \mathrm{c}$

Chile (Juan Fernández Is)

An arborescent species of Labiatae, confined to remaining upper montane forest. Preliminary data indicate the species is confined to less than $100 \mathrm{~km}^{2}$ and declining in numbers through the effects of grazing by feral animals and spread of introduced weeds. More detailed information on the species should become available to confirm this evaluation. The islands are designated as a national park and biosphere reserve and work is being carried out by ${ }^{*}$ CONAF to save the native plants. The genus contains two species, endemic to Juan Fernandez.

Assessor: World Conservation Monitoring Centre Refs: 3241,5651

\section{Cuminia fernanderia}

Labiatae

CR B1+2c

Chile (Juan Fernández Is)

An arborescent species of Labiatae, confined to remaining upper montane forest. Preliminary data indicate the species is confined to less than $100 \mathrm{~km}^{2}$ and declining in numbers through the effects of grazing by feral animals and spread of introduced weeds. More detailed information on the species should become available to confirm this evaluation. The islands are designated as a national park and biosphere reserve and work is being carried out by *CONAF to save the native plants. The genus contains two species, endemic to Juan Fernandez.

Assessor: World Conservation Monitoring Centre

Refs: 3241,5651

\section{Cunninghamia konishü}

Taxodiaceae

VU Alac

Laos, Taiwan, Viet Nam

A good-quality timber tree, which is mainly known from occurrences in evergreen submontane forest in northem and central Taiwan. Many stands have been destroyed by felling and replaced with commercial plantations in Taiwan. There is a protected population in Yushan National Park. More recently the species has apparently been found in two small stands in the wild, in Houa Phan Province in northem Laos and at Bu Huong Mountain in Viet Nam. The species is sometimes known as a variety or form of C. lanceolata.

Assessor: Pan, F.J.

Refs: 374, 11191, 15357, 19050, 1905

\section{Cunonia aoupiniensis}

Cunoniaceae VU D2

New Caledonia

Assessor: Jaffré, T. et al.

Refs: 10351

\section{Cunonia ouaiemensis}

Cunoniaceae

VU D2

New Caledonia

Assessor: Jaffré, T. et al.

Refs: 10351

\section{Cunonia rotundifolia}

Cunoniaceae

$\mathrm{LR} / \mathrm{cd}$

New Caledonia

Assessor: Jaffré, T. et al.

Refs: 10351

\section{Cupania mollis}

Sapindaceae

LR/cd

El Salvador, Guatemala

A fairly abundant species of primary forest up to an altitude of $1200 \mathrm{~m}$ in El Salvador. The habitat is under great pressures from logging, fires, the growing human population and agriculture. The species regenerates well and is represented in protected areas.

Assessor: World Conservation Monitoring Centre Refs: 4862, 4974, 19030

\section{Cupaniopsis acuticarpa}

Sapindaceae

VU D2

Papua New Guinea

A small tree or shrub known only from the type collection from Central Province.

Assessor: World Conservation Monitoring Centre Refs: 18389,19047 


\section{Cupaniopsis bullata}

Sapindaceae

Papua New Guinea

A small tree found in secondary vegetation in Central Province, known only from the type collection.

Assessor: World Conservation Monitoring Centre

Refs: 18389,19047

\section{Cupaniopsis crassivalvis}

Sapindaceae

New Caledonia

A species once collected from an area north-east of La Conception near Nouméa. It has not been found since 1869 despite this being the botanically best known region of Grand Terre.

Assessor: Jaffré, T. et al.

Refs: 4492, 10351

\section{Cupaniopsis euneura}

Sapindaceae

VU D2

Papua New Guinea

This species is only known from the type collection, gathered from West Highlands Province.

Assessor: World Conservation Monitoring Centre

Refs: 18389,19047

\section{Cupaniopsis glabra}

Sapindaceae

New Caledonia

$\mathrm{EN} \mathrm{BI+2c}$

Assessor: Jaffré, T. et al.

Refs: 10351

\section{Cupaniopsis globosa}

Sapindaceae

New Caledonia

VU B $1+2 c$

Assessor: Jaffré, T, et al.

Refs: 4492,10351

\section{Cupaniopsis mouana}

Sapindaceae

New Caledonia

$\mathrm{EN} \mathrm{Bl}+2 \mathrm{c}$

Assessor: Jaffré, T. et al.

Refs: 10351

\section{Cupaniopsis napaensis}

Sapindaceae

VU D2

Papua New Guinea

This species is known only from the type collection, which was located in scrub near a dry creek in Central Province.

Assessor: World Conservation Monitoring Centre

Refs: 18389,19047

\section{Cupaniopsis phanerophleibia}

Sapindaceae

VU D2

Papua New Guinea

An understorey tree from Western Province, known only

from a single collection.

Assessor: World Conservation Monitoring Centre

Refs: 18389,19047

\section{Cupaniopsis rosea}

Sapindaceae

New Caledonia

$\mathrm{EN} \mathrm{B} 1+2 \mathrm{c}$
Cupaniopsis rotundifolia

Sapindaceae

$\mathrm{EN} \mathrm{B1+2c}$

New Caledonia

Assessor: Jaffré, T, et al.

Refs: 10351

\section{Cupaniopsis squamosa}

Sapindaceae

New Caledonia

EN B $1+2 c$

Assessor: Jaffré, T. et al.

Refs: 10351

Cupaniopsis strigosa

Sapindaceae

VU D2

Indonesia (Sulawesi)

This species is known only from the type collection from Mount Bonthain.

Assessor: Adema, F.

Refs: 18389,19047

Cupaniopsis subfalcata

Sapindaceae

$\mathrm{EN} \mathrm{B} 1+2 \mathrm{c}$

New Caledonia

Assessor: Jaffré, T. et al.

Refs: 10351

\section{Cupaniopsis tontoutensis}

Sapindaceae

$\mathrm{EN} \mathrm{Bl+2c}$

New Caledonia

Assessor: Jaffré, T. et al.

Refs: 10351

\section{Cupheanthus microphyllus}

Myrtaceae

VU Bl+2c

New Caledonia

Assessor: Jaffré, T. et al.

Refs: 10351

\section{Cupressus arizonica var. montana}

\section{Cupressaceae}

Mexico (Baja Califomia)

VU D2

Very few trees remain in the area where the variety was described. They are confined to steep slopes in San Pedro Martír. Large herds of cattle appear to be allowed to graze indiscriminately even though the area has national park status.

Assessor: SSC Conifer Specialist Group

Refs: $6972,11886,13041,18751$

\section{Cupressus arizonica var. nevadensis}

Cupressaceae

VU D2

USA (Califomia)

This variety is known from four localities in the Piute Mountains and their vicinity. Some risk occurs from fires, grazing and mining. Several occurrences are contained within protected areas.

Assessor: SSC Conifer Specialist Group

Refs: $374,3786,6972,13041,19193$

\section{Cupressus arizonica var. stephensoniu}

Cupressaceae

USA (California)

VU D2

Only two populations, approximately 1000 individuals, exist in fire-prone areas within Cleveland National Forest and Cuyamaca Rancho State Park. The Conejo fire of 1950 extirpated part of the population. Species management guidelines are adopted in Cleveland 
National Forest. There is a lack of agreement over the variety's taxonomic status, it commonly being considered to hold species status.

Assessor: SSC Conifer Specialist Group

Refs: 374, 3786, 6972, 11886, 13041, 19193

\section{Cupressus atlantica}

Cupressaceae

EN Alabc, Bl+2b, Cl+2a, D1

Morocco

One or two small groves remain in dry woodland on steep scree slopes in Oued n'Fiss Valley south of Marakech in the Atlas Mountains. Estimates of the area of occupancy have declined from 5500 ha in 1950 to 1460ha in 1986, largely because of habitat degradation, overgrazing and to some extent exploitation. Observations during a visit to the site in 1997 indicated a complete absence of natural regeneration. One subpopulation is fenced and attempts are being made to replant the species but the rates of success are very low. Assessor: SSC Conifer Specialist Group

Refs: 374, 4506, 13041, 19191

\section{Cupressus bakeri}

Cupressaceae

USA (Califomia, Oregon)

VU $B 1+2 b d$

This species is known from nine scattered sites in north California and the extreme south of Oregon. Only one of them extends as far as two miles in length. Locations once known have been lost. Although fire-adapted, it is vulnerable to intense fires, which break out when the fuel load has built up.

Assessor: SSC Conifer Specialist Group

Refs: 13041, 18751, 19193

\section{Cupressus cashmeriana}

Cupressaceae

VU B $1+2 c$

Bhutan, India (Arunachal Pradesh)

The natural distribution of the species is probably confined to west central Bhutan and Arunachal Pradesh but it is obscured by the widespread cultivation of the plant. Populations do not appear to be large.

Assessor: SSC Conifer Specialist Group

Refs: 4237, 13041, 18751

\section{Cupressus chengiana}

Cupressaceae

VUAlcd

China (Gansu, Sichuan)

A few locations are known where the species dominates in mid-elevation coniferous forest on the flanks of gorges and arid valleys. Constant overcutting has eliminated the species in accessible sites and it is being replaced by thickets of other species.

Assessor: SSC Conifer Specialist Group

Refs: $374,1818,11847$

\section{Cupressus chengiana var. jiangeensis}

Cupressaceae

CR D1

China (Sichuan)

This variant of the threatened $C$. chengiana is restricted to a single tree in Sichuan. It is monoecious.

Assessor: SSC Conifer Specialist Group

Refs: 374

\section{Cupressus duclouxiana}

Cupressaceae

China (Sichuan, Xizang, Yunnan)

The native range of the species has not been resolved.

Large trees are known to occur in a remote part of "Tibet.

The largest population occurs in Yunnan, where it is widely distributed, especially along a historic trade route to Sikkim. These trees may have been planted.

Assessor: SSC Conifer Specialist Group

Refs: 374

\section{Cupressus dupreziana}

Cupressaceae

$\mathrm{CR} \mathrm{A2c}, \mathrm{Cl}$

Algeria

Three populations, containing 153 individuals and covering 200sq.km, are thought to exist. The main concentration is in Tassili N'Ajjer National Park, which has been designated a World Heritage Site. There is no regeneration in the wild. It is believed that the water table has sunk to an extent that impedes regeneration. The species has been successfully established in cultivation.

Assessor: SSC Conifer Specialist Group

Refs: 374,12567

\section{Cupressus gigantea}

Cupressaceae

VU Ald

China (Xizang)

Confined to eastern Tibet, the species forms sparse pure stands along rivers on sheltered dry slopes. The largest individuals are said to be in a cemetery. Little regeneration is apparent except in the Yarlungzangbo River basin but the tree coppices well.

Assessor: SSC Conifer Specialist Group

Refs: $1818,11847,13041$

\section{Cupressus goveniana var. abramsiana}

Cupressaceae

EN C2a

USA (California)

Commonly recognised as $A$. abramsiana, this variety is rare and confined to fewer than 10 groves in the Santa Cruz Mountains. Each population is thought to have fewer than 100 individuals. There are threats from residential and agricultural developments, alteration of fire regimes and introgression of conifer species, which may also increase the risk from fires. None of the populations is officially protected.

Assessor: SSC Conifer Specialist Group

Refs: 11886, 13041, 18751, 19193

\section{Cupressus goveniana var. goveniana}

Cupressaceae

VU D1

USA (California)

Less than 1000 individuals are thought to exist in five popuations, in S.F.B. Morse Botanical Reserve, Point Lobos Reserve, where the species is protected, and along the coast in Mendocin and north-west Sonoma Counties. The coastal populations are sometimes known as var. pygmaea. There are some pressures from local development, altered fire regimes and possibly from non-native plants.

Assessor: SSC Conifer Specialist Group

Refs: 11886, 13041, 19193

\section{Cupressus guadalupensis var. forbesii}

Cupressaceae

VU B $1+2 c$

Mexico (Baja Califomia), USA (Califomia)

Fewer than five occurrences are known in Califomia. One of them is relatively inaccessible but the others are susceptible to frequent wildfires and development. Individuals can be found along roadsides. Mexico also harbours few, perhaps two, populations. Assessor: SSC Conifer Specialist Group Refs: 6972, 11886, 13041, 18751, 19193 


\section{Cupressus guadalupensis var. guadalupensis}

Cupressaceae

Mexico (Guadalupe Is.)

A population of 200 is thought to exist in two small stands. Regeneration is seriously hampered by goats.

Assessor: SSC Conifer Specialist Group

Refs: 374

\section{Cupressus lusitanica var, benthamii}

Cupressaceae

Mexico (Hidalgo, Puebla, Veracruz)

The species occurs in montane forest, in oak and mesophillous formations, in the border regions of several Mexican states.

Assessor: SSC Conifer Specialist Group

Refs: $374,6541,19161$

\section{Cupressus macrocarpa}

Cupressaceae

VU D2

USA (California)

A widely planted and naturalised species which, in the wild, is restricted to two healthy subpopulations occurring in Point Lobos and Point Cypress. The former is thought to contain between 500 and 1000 individuals. Both are protected.

Assessor: SSC Conifer Specialist Group

Refs: 7222, 11886, 13041, 19193

\section{Cupressus sempervirens}

Cupressaceae

Greece (Crete), Iran, Turkey

The species is sometimes referred to in different varieties. Only var, horizontalis is believed to originate from the wild and therefore is the only taxon considered in this context. The type specimen was collected from Crete. Populations which are questionably wild are also known from southern Turkey and northem Iran, where it is very vulnerable. It is planted all over the Mediterranean.

Assessor: SSC Conifer Specialist Group

Refs: $3489,4508,5519,7222,16111$

\section{Cupressus torulosa}

Cupressaceae

$\mathrm{LR} / \mathrm{nt}$

Bhutan, China (Xizang), India (Jammu-Kashmir), Nepal, Pakistan

Assessor: SSC Conifer Specialist Group

Refs: $374,848,7222,11530,13041,16781,18710$

\section{Cussonia bancoensis}

Araliaceae

VUAlc

Ghana

The only natural populations appear to occur in Ghana. Occurrences in Côte d'Ivoire are reported to be planted. The species regenerates freely in a wide ecological range, but is best established in upland evergreen forest, where there are threats from farming, fires, forest management activities and mining.

Assessor: Hawthorne, W.

Refs: 6127,12061

\section{Cussonia gamtoosensis}

Araliaceae

VU DI+2

South Africa (Eastem Cape)

Occurring in thicket vegetation on stony hill sides, the species, for many years, was only known from the type locality. Three localities are now known. The species does not appear to be very abundant, but it is difficult to spot in the dense thickets where it grows. Large tracts of the habitat have been cleared for agriculture, settlement and industrial development, possibly resulting in the species becoming fragmented and the subpopulations becoming isolated. Any developments at the type locality could seriously affect the species.

Assessor: Hilton-Taylor, C. et al.

Refs: 689,19218

\section{Cussonia ostinii}

Araliaceae

LR/nt

Ethiopia

An Ethiopian endemic, occurring abundantly in upland savanna in the west. Increasing human population and their activities threaten the habitat to some extent, especially in the north.

Assessor: World Conservation Monitoring Centre Refs: 1330,18523

\section{Cuviera migeodii}

Rubiaceae

VU B1+2b, D2

Tanzania

A species of dry forest or open woodland, known only from Tendagurs.

Assessor: Lovett, J. \& G.P. Clarke

Refs: 3356,8814

\section{Cuviera schliebenii}

Rubiaceae

$\mathrm{EN} B 1+2 \mathrm{bc}$

Tanzania

Known only from Litipo $\left(10 \mathrm{~km}^{2}\right)$ and Rondo $\left(140 \mathrm{~km}^{2}\right)$ Forest Reserves, this species is relatively well protected. Both forests have been extensively logged and other activities have contributed to large areas being disturbed.

The demand for land for commercial and subsistence agriculture is also strongly felt but local activities and encroachment are discouraged by the presence of forest management operations.

Assessor: Lovett, J. \& G.P. Clarke

Refs: 3356,8814

\section{Cuviera tomentosa}

Rubiaceae

Mozambique, Tanzania

VU BI+2b

A species confined to relatively unexplored areas of dry coastal forest in Kingupira in Tanzania and northern Mozambique.

Assessor: Lovett, J. \& G.P. Clarke

Refs: $1308,3356,8814$

\section{Cyanea aculeatiflora}

Campanulaceae

VU D2

USA (Hawaii)

A palm-like tree restricted to East Maui, where it occurs in rainforest between 945 and $1450 \mathrm{~m}$ altitude on the windward slopes of Haleakala.

Assessor: World Conservation Monitoring Centre Refs: 3372

\section{Cyanea arborea}

Campanulaceae

USA (Hawaii)

A palm-like tree formerly known from a narrow altitudinal band in montane forest on the slopes of Haleakala on East Maui. It was last collected in 1928. Assessor: World Conservation Monitoring Centre Refs: 3372 


\section{Cyanea giffardii}

Campanulaceae

EX

USA (Hawaii)

This species is known only from the type material, which was collected in 1917 from a locality of rainforest near Glenwood on Hawaii.

Assessor: World Conservation Monitoring Centre Refs: 3372

\section{Cyanea hamatiflora ssp. carlsonii}

Campanulaceae

CR C2a, D1 USA (Hawaii)

A montane rainforest taxon which is known to have occurred at only three sites on the western slopes of Hualalai on Hawaii. One population is found at Honuaulu Forest Reserve and another at Keokea, $45 \mathrm{~km}$ away. In addition two populations have been planted within the native range, taking the total population size to possibly more than 50 individuals. Invasive plants and grazing are a persistent problem. The subspecies is protected by the US Endangered Species Act.

Assessor: World Conservation Monitoring Centre

Refs: 3372, 19039

\section{Cyanea hamatiflora ssp. hamatiflora}

Campanulaceae

VU D2

USA (Hawaii)

A palm-like tree which occurs in rainforest between 1200 and $1400 \mathrm{~m}$ altitude on the windward slopes of Haleakala on East Maui.

Assessor: World Conservation Monitoring Centre

Refs: 3372,3786

\section{Cyanea hardyi}

Campanulaceae

USA (Hawaii)

VU D2

Restricted to an area in the south of Kauai, the species occurs in forested valleys up to an altitude of $790 \mathrm{~m}$. Assessor: World Conservation Monitoring Centre Refs: 3372

\section{Cyanea horrida}

Campanulaceae

USA (Hawaii)

VU D2

A palm-like tree known only from East Maui, where it is restricted to rainforest and the margins of subalpine forest between altitudes of 1520 and $2000 \mathrm{~m}$.

Assessor: World Conservation Monitoring Centre

Refs: 3372

\section{Cyanea leptostegia}

Campanulaceae

VU D2

USA (Hawaii)

This palm-like tree is confined to westem Kauai, where it is found in moist forest 1000 and $1300 \mathrm{~m}$.

Assessor: World Conservation Monitoring Centre Refs: 3372

\section{Cyanea macrostegia ssp. gibsonii}

Campanulaceae

EN Alce USA (Hawaii)

The species is known from two subspecies, this one being the rarer. It is restricted to rainforest only on Lanai and has been collected very rarely in the last 50 years. The type subspecies is endemic to Maui.

Assessor: World Conservation Monitoring Centre Refs: 3372

\section{Cyanea marksii}

Campanulaceae

USA (Hawaii)

EX

A small palm-like tree recorded in rainforest in Kona District on Hawaii. No adult trees have been found this century, although a population was located of what appeared to be precociously flowering juvenile individuals.

Assessor: World Conservation Monitoring Centre Refs: 3372

\section{Cyanea pohaku \\ Campanulaceae}

USA (Hawaii)

EX

This species has not been seen since it was first collected in 1910. It was found in subalpine shrubland on Puunianiau, a small cinder cone on the north-west slopes of Haleakala on East Maui.

Assessor: World Conservation Monitoring Centre Refs: 3372

\section{Cyanea procera}

Campanulaceae

USA (Hawaii)

CR C2a, D1

A palm-like tree formerly found in the Kamalo region on Molokai and thought to be extinct until it was recently rediscovered at Puu O Kaeha, west of Kamalo. A total of eight individuals have been found in three populations in an area known to harbour feral goats. The species is protected by the US Endangered Species Act. Assessor: World Conservation Monitoring Centre Refs: 3372, 19040

\section{Cyanea pycnocarpa}

Campanulaceae

USA (Hawaii)

EX

Now presumed extinct, this species is known only from the type material. It was collected on the Kohala Mountains on Hawaii.

Assessor: World Conservation Monitoring Centre Refs: 3372

\section{Cyanea quercifolia}

Campanulaceae

EX

USA (Hawaii)

A poorly known species which is recorded only from the type collection taken from an area between 915 and $1220 \mathrm{~m}$ on the leeward slopes of Haleakala on East Maui. Assessor: World Conservation Monitoring Centre Refs: 3372

\section{Cyanea solenocalyx}

Campanulaceae

VU D2

USA (Hawaii)

Confined to Molokai, the species is found in rainforest at medium elevation in the east of the island.

Assessor: World Conservation Monitoring Centre Refs: 3372

\section{Cyanea stictophylla}

Campanulaceae

USA (Hawaii)

CR C2a

A shrub or tree of montane rainforest restricted to the slopes of Mauna Loa, where it is now known from fewer than 20 individuals in three populations near Keauhou, Kohae and on Puuwaawaa. Another 46 individuals have been planted in exclosures at Puuwaawaa and Kau 
Forest Reserve. Cattle grazing and trampling are major causes for the species decline. It is protected by the US Endangered Species Act.

Assessor: World Conservation Monitoring Centre Refs: 19039

\section{Cyanea superba ssp. regina \\ Campanulaceae \\ USA (Hawaii)}

A subspecies recorded from the Southem Koolau Mountains on Oahu, where it was last found in 1932 in lowland rainforest. It is protected by the US Endangered Species Act.

Assessor: World Conservation Monitoring Centre

Refs: 3372

\section{Cyanea superba ssp. superba}

Campanulaceae

CR C2a, D1

USA (Hawaii)

This subspecies is still extant, as opposed to ssp, regina. It is known from two small populations, totalling fewer than 10 plants, in the Waianae Mountains, one on federal property in Kahanahaiki valley and the other on state land in Pahole Gulch. Habitat degradation by the spread of introduced plants is the most serious threat to remaining populations. Protective measures and planting are being carried out at Pahole. The taxon is protected by the US Endangered Species Act.

Assessor: World Conservation Monitoring Centre

Refs: 3372, 19168

\section{Cyanea tritomantha}

Campanulaceae

VU Alce

USA (Hawaii)

A palm-like tree occurring in rainforest up to $1080 \mathrm{~m}$ altitude in Waipio valley, Mauna Kea and the windward side of Mauna Loa on Hawaii. Damage by feral pigs has been recorded at a number of sites where the species is known.

Assessor: World Conservation Monitoring Centre

Refs: 3372

\section{Cyathocalyx olivaceus}

Annonaceae

$\mathrm{LR} / \mathrm{cd}$

Malaysia (Peninsular Malaysia)

A tree locally common in the lowland and hill forests of Maxwell's Hill, Perak, which is a protected area.

Assessor: Kochummen, K.M.

Refs: 19073

\section{Cyathocalyx scortechinü}

Annonaceae

$\mathrm{LR} / \mathrm{cd}$

Malaysia (Peninsular Malaysia)

A tree, restricted to lowland and submontane forest, known only from the states of Perak and Pahang. The locality in Perak is no longer forested. It does, however, occur in Taman Nagara National Park and the protected forest of Mentigi in the Cameron Highlands.

Assessor: Kochummen, K.M.

Refs: 19073

\section{Cybianthus cogolloi}

Myrsinaceae

VU B $1+2 c$

Colombia

An endemic to Antioquia.

Assessor: Calderon, E.

Refs: 19069

\section{Cyclobalanopsis repandifolia}

Fagaceae

$\mathrm{CR} B \mathrm{~B}+2 \mathrm{~b}, \mathrm{C} 2 \mathrm{a}$

Taiwan

A tree with a scarce distribution in areas of lowland broadleaved forest in Chinshuiying on the Hengchun Peninsula. In the few populations known, regeneration is poor, seed crops appear to be frequently decimated by squirrels and other animals. No protection or conservation measures are in place.

Assessor: Pan, F.J.

Refs: 3295,19050

\section{Cyclobalanopsis rex}

Fagaceae

DD

China (Yunnan), Laos, Myanmar

In China the main populations are found at Mengla and Tengchong. They are extremely small and largely made up of senescing trees in areas of monsoon forest on limestone hills. Regeneration is poor and the habitat degraded. Information is needed on the populations in Laos and Myanmar.

Assessor: World Conservation Monitoring Centre

Refs: $1818,11847,19055$

\section{Cyclophyllum tenuipes}

Rubiaceae

VU D1

New Caledonia

Assessor: Jaffré, T, et al.

Refs: 10351

\section{Cymbopetalum baillonii}

Annonaceae

Mexico (Chiapas, Oaxaca, Veracruz)

VUAlc

Confined to the Gulf region, the species occurs in most areas of remaining rainforest, extending as far north as northern Veracruz.

Assessor: World Conservation Monitoring Centre

Refs: 5993, 19124

\section{Cymbopetalum mayanum}

Annonaceae

EN C2a

Guatemala, Honduras

Populations are small and scattered in the Atlantic lowlands in areas of varying humidity. The habitat continues to diminish through conversion to agriculture. Assessor: Nelson, C.

Refs: 13228,13995

\section{Cymbopetalum torulosum}

Annonaceae

VU A2c

Costa Rica, Panama

The main part of the species range occurs in areas of lowland rainforest in Costa Rica, concentrated in the region of Río San Juan and La Selva Biological Station in the north-west. In Panama collections have been made in Chiriquí, near the border with Costa Rica. The populations here appear to be very restricted and under some threat from cattle ranching and commercial banana cultivation.

Assessor: Mitré, M.

Refs: $5125,7980,16772$

\section{Cynometra beddomei}

\section{Leguminosae}

India (Kerala)

A large tree, which has only ever been recorded from Tambacherry Ghat, where it was found in submontane streamside forest. It has not been found since 1870 , 
despite intensive explorations. Forestry plantations are now widely established where there was once primary forest.

Assessor: World Conservation Monitoring Centre

Refs: 4799, 8483, 19144

\section{Cynometra bourdillonii}

Leguminosae

$\mathrm{EN} \mathrm{B} 1+2 \mathrm{c}$

India (Kamataka, Kerala)

A lowland forest tree which appears to occur in two main areas: in South Kanara, Karnataka, and in the Agastyamalai range in Kerala. Widespread and indiscriminate cutting and expansion of commercial agriculture have resulted in a significant reduction in the extent of these forests.

Assessor: World Conservation Monitoring Centre

Refs: 2538,19144

\section{Cynometra brachyrrhachis}

Leguminosae

$\mathrm{VU} \mathrm{B} 1+2 \mathrm{bc}, \mathrm{D} 2$

Tanzania

The species is locally dominant in three patches of coastal forest in the Pangani River basin. Two of them are contained within forest reserves: Gendagenda Forest Reserve $\left(27 \mathrm{~km}^{2}\right)$, and Tongwe Forest Reserve $\left(12 \mathrm{~km}^{2}\right)$, the remaining population occurs in the Pangani Falls forest $\left(1 \mathrm{~km}^{2}\right)$, where a hydroelectric dam has been built. The demand for agricultural land puts pressure on all these sites. The species is also reported to occur in lowland forest in the East Usambara Mountains *FTEA notes this may be a species of Scorodophloeus.

Assessor: Lovett, J. \& G.P. Clarke

Refs: $3925,5654,16796$

\section{Cynometra cubensis}

Leguminosae

EN B $1+2 c$

Cuba

An uncommon tree endemic to semi-deciduous forests, mainly in gallery communities along rivers and creeks in Pinar del Rio Province. Its habitat has suffered intense degradation from logging and the ensuing invasion of exotic or secondary vegetation.

Assessor: Areces-Mallea, A.E.

Refs: $16327,18485,19149$

\section{Cynometra engleri}

Leguminosae

VU B $1+2 b, D_{2}$

Tanzania

A species found only in lowland semi-deciduous forest in Sigi valley at the foot of the East Usambara Mountains.

Assessor: Lovett, J. \& G.P. Clarke

Refs: 3356, 3925, 5204, 5654

\section{Cynometra falcata}

Leguminosae

Fiji

CR D1

A slender tree, endemic to Fiji and known only from the two collections: the type was gathered from Viti Levu in 1840 and the second collection was from Vanua Levu in 1950.

Assessor: World Conservation Monitoring Centre Refs: 18818

\section{Cynometra filifera}

Leguminosae

CR BI+2abcde

Tanzania

The species is locally dominant in a 0.25 ha patch of forest near Lindi and elsewhere only from a single forest patch located $40 \mathrm{~km}$ away. The latter site has not been visited recently and the forest may have disappeared.

Assessor: Lovett, J. \& G.P. Clarke

Refs: 3925,16796

\section{Cynometra gillmanii}

Leguminosae

CR Bl+2abcde, $\mathrm{C} 2 \mathrm{~b}$

Tanzania

The species is known from coastal forest near Mkoe from a single collection made in the $1940 \mathrm{~s}$. It is possible the species habitat has been destroyed.

Assessor: Lovett, J. \& G.P. Clarke

Refs: 3925,16796

\section{Cynometra inaequifolia}

Leguminosae

VU Ald

Malaysia (Peninsular Malaysia, Sabah), Philippines, Thailand?

A small tree of lowland forest which is used as a source of kekatong timber.

Assessor: World Conservation Monitoring Centre

Refs: $4919,12937,14573$

\section{Cynometra longipedicellata}

Leguminosae

$\mathrm{VU} B 1+2 \mathrm{~b}$

Tanzania

This species is largely known from areas of moist lowland forest reaching $900 \mathrm{~m}$ in the East Usambara Mountains. A population may also occur in the Pugu Forest Reserve $\left(22 \mathrm{~km}^{2}\right)$ near Dar es Salaam.

Assessor: Lovett, J. \& G.P. Clarke

Refs: $3356,3925,5204,5654$

\section{Cynometra lukei}

Leguminosae

$\mathrm{EN} \mathrm{Bl}+2 \mathrm{c}$

Kenya, Tanzania

Formerly known only from Kenya, this riverine forest tree has recently been found in Selous National Park in Tanzania. The Kenya population is small and confined to the seasonally flooded banks of the Tana River, near Wenje, where it is under some threat from increasing human settlement and agriculture.

Assessor: World Conservation Monitoring Centre Refs: $5654,6396,17859$

\section{Cynometra suaheliensis}

Leguminosae

$\mathrm{VU} B \mathrm{Bl}+2 \mathrm{~b}$

Kenya, Tanzania

The range of this dry coastal forest species extends from Kwale and Kilifi Districts in Kenya into northern Tanzania in the Pangani River basin.

Assessor: Lovett, J. \& G.P. Clarke

Refs: $3356,3925,5204,6396,7550$

\section{Cynometra travancorica}

Leguminosae

India (Kamataka, Kerala, Tamil Nadu)

EN Bl $+2 c$

A tall tree reported from about four scattered locations in the Western Ghats, occurring in lowland evergreen forest on rocky slopes. In Karnataka the species occurs in Sollekallu in Chikmagalur and in Kerala there are records from the Palghat area and also apparently from the Travancore range. There has been much loss of habitat because of road building, expanding agriculture and other developments.

Assessor: World Conservation Monitoring Centre Refs: 14276,19144 


\section{Cynometra ulugurensis}

Leguminosae

EN C2b, D1

Tanzania

This tree is endemic to Kimboza Forest Reserve $\left(4 \mathrm{~km}^{2}\right)$ at the foot of the Uluguru Mountains. The forest is disturbed because of previous logging and the planting of exotic species, including a Cedrela species which has become invasive. The surrounding area is densely populated and the demand for land to cultivate is strong. There are now two forest guards to stop illegal cutting and encroachment.

Assessor: Lovett, J. \& G.P. Clarke

Refs: 3925,16796

\section{Cynometra webberi}

Leguminosae

VU BI+2b

Kenya, Tanzania

A shrubby tree occurring in dry coastal forest patches within an area ranging from Kwale and Kilifi Districts in Kenya into Tanzania. In some forest types it forms the dominant canopy element. Soils with impeded drainage and unpredictable water supply are especially favoured by the species.

Assessor: Lovett, J. \& G.P. Clarke

Refs: 3356, 6396, 10961

\section{Cyphophoenix elegans}

Palmae

VU Bl+2c

New Caledonia

This species is localised to the north-east on low-lying areas of schistose rocks.

Assessor: Jaffré, T, et al.

Refs: 10351,19118

\section{Cyphophoenix nucele}

Palmae

$\mathrm{CR} \mathrm{B} 1+2 \mathrm{c}$

New Caledonia

The entire population is reduced to a small area of forest on raised coral on the north-east coast of Lifou in the Loyalty Islands. Regeneration is poor. The only other species in the genus is also threatened and confined to north-east New Caledonia.

Assessor: Jaffré, T, et al.

Refs: 10351,19118

\section{Cyphosperma tanga}

Palmae

CR Alc

Fiji

Only a few populations are known, confined to areas of dense forest on Viti Levu. Cutting by the Forestry Department resulted in the serious depletion of one population in 1970 and also continues to affect another more recently discovered population. Seed crops of reasonable size appear to be extremely infrequent.

Assessor: Fuller, D.

Refs: 6053,19118

\section{Cyphosperma trichospadix}

Palmae

VU Alc

Fiji

A few small populations are known from areas of dense forest between 600 and $760 \mathrm{~m}$ on Vanua Levu and Taveuni. Some areas are being cleared for coconut plantations.

Assessor: Fuller, D.

Refs: 6053,19118

\section{Cyphosperma voutmelensis}

Palmae

EN D 1

Vanuatu

A small palm tree scattered in rainforest on volcanic soils. It is restricted to the Cumberland Peninsula and Espírito Santo. Less than 100 mature individuals are known.

Assessor: Dowl, J.L.

Refs: 19118

\section{Cyrtandra denhami}

Gesneriaceae

VU D2

Fiji

The species appears to be highly localised. It is confined to the island of Ngau in Loma-i Viti, where it has been collected only twice from lowland forest in the hills around Herald Bay.

Assessor: World Conservation Monitoring Centre Refs: 18818

\section{Cyrtandra elbertii}

Gesneriaceae

VU B1 $+2 c, D 2$

Indonesia (Java)

The only known location of this species is on Mount Lawu, where it occurs in an area of forest from 1500 to $1700 \mathrm{~m}$. An area of $60 \mathrm{~km}^{2}$ on Mount Lawu is being proposed as a nature reserve. Pressures of encroachment and cutting are severe.

Assessor: World Conservation Monitoring Centre Refs: 9078

\section{Cyrtandra feaniana}

Gesneriaceae

LR/nt

French Polynesia (Marquesas Is.)

A shrub or small tree known from occurrences on Fatu Hiva, Hiva Oa, Nuku Hiva, Tauhata and Ua Huka.

Assessor: Florence, J.

Refs: 14513

\section{Cyrtandra giffardii}

Gesneriaceae

EN C2a

USA (Hawaii)

A small shrubby tree which is now known from 11 populations in montane rainforest on the north-eastern slopes of Mauna Kea south to the eastern siopes of Mauna Loa, including several populations in Volcanoes National Park. The species has disappeared from previously known sites and habitat damage caused by feral pigs, along with the invasion of introduced plants, continues to threaten remaining populations. Estimates of the total population size lie in the region of 1000 individuals. The species is protected by the US Endangered Species Act.

Assessor: World Conservation Monitoring Centre Refs: 3372, 19039

\section{Cyrtandra kandavuensis}

\section{Gesneriaceae}

VU D2

Fiji

A spreading tree or shrub, which is confined to the island of Kandavu, where it occurs on the summit and slopes of Mount Mbuke Levu.

Assessor: World Conservation Monitoring Centre Refs: 18818 


\section{Cyrtandra natewaensis}

Gesneriaceae

VU D2

Fiji

A shrub or small tree, which occurs infrequently in dense forest between 400 and $820 \mathrm{~m}$. It is rarely collected and, so far, known only from eastem Vanua Levu and a site in Taveuni.

Assessor: World Conservation Monitoring Centre

Refs: 18818

\section{Cyrtandra spathacea}

Gesneriaceae

VU D2

Fiji

A scarce but distinct tree species of dense forest between 500 and $750 \mathrm{~m}$. It has been collected just twice, once in 1933 on the slopes of Mount Mbuke Levu, on the island of Kandavu, and once from near Lautoka, Mba, on Viti Levu.

Assessor: World Conservation Monitoring Centre

Refs: 18818

\section{Cyrtandra tavinunensis}

Gesneriaceae

VU D2

Fiji

A shrub or tree which is endemic to the island of Taveuni. Collections have been made from the regions of Wairiki and Somosomo in dense forest between 700 and $850 \mathrm{~m}$ altitude.

Assessor: World Conservation Monitoring Centre

Refs: 18818

\section{Cyrtandra tempestii}

Gesneriaceae

VU D2

Fiji

An uncommon species restricted to Taveuni in dense forest up to $900 \mathrm{~m}$.

Assessor: World Conservation Monitoring Centre

Refs: 18818

\section{Cyrtostachys kisu}

Palmae

DD

Solomon Islands (South Solomon)

A palm endemic to the islands of Choiseul and Baga, where it is scattered in lowland to submontane rainforest.

Assessor: Dowl, J.L.

Refs: 19118

\section{Dacrycarpus kinabaluensis}

Podocarpaceae

Malaysia (Sabah)

$\mathrm{LR} / \mathrm{cd}$

A shrub or small tree, which is known only from elevations above $2100 \mathrm{~m}$ on Mount Kinabalu. Populations are protected within the national park. The species is thought to be susceptible to periodic droughts, but populations appear to have successfully survived recent dry spells.

Assessor: SSC Conifer Specialist Group

Refs: 6851, 13041, 19125

\section{Dacrycarpus steupii}

Podocarpaceae

Indonesia (Irian Jaya, Kalimantan, Sulawesi)

LR/nt

A tree of submontane swamp or disturbed forest, where it can form pure stands. In Kalimantan it was known from a now extinct population near Balikpapan. In Sulawesi it is confined to the Latimodjong Mountains, where lower slopes have been cleared in places for agriculture. Populations in New Guinea are thought to be widespread.

Assessor: SSC Conifer Specialist Group

Refs: 374, 6851, 13041, 18751

\section{Dacrydium comosum}

Podocarpaceae

Malaysia (Peninsular Malaysia)

$\mathrm{EN} \mathrm{Bl}+2 \mathrm{c}$

A relatively rarely collected shrub or small tree, which grows on exposed ridges in stunted mossy montane forest. Populations occurring on the Gunung Tahan Massif are protected within a national park. In the southern part of the species range, however, the habitat is threatened by infrastructural development.

Assessor: SSC Conifer Specialist Group

Refs: 6851, 13041, 15966, 19073, 19192

\section{Dacrydium cornwalliana}

Podocarpaceae

Indonesia (Irian Jaya), Papua New Guinea

The species grows in some abundance in confined patches of cloud forest or mossy heath forest above $1430 \mathrm{~m}$. Collections are few, largely because the area is poorly explored.

Assessor: SSC Conifer Specialist Group

Refs: 374,6851

\section{Dacrydium ericioides}

Podocarpaceae

VU D2

Malaysia (Sarawak)

A locally abundant tree of primary mossy forest, occurring on exposed ridges in two locations on Mount Dulit and Meruong Plateau. It appears to be confined to ultrabasic soils. The area could possibly come under the heavy logging regimes which have occured throughout the country.

Assessor: SSC Conifer Specialist Group

Refs: $374,6851,19192$

\section{Dacrydium gibbsiae}

Podocarpaceae

LR/cd

Malaysia (Sabah, Sarawak)

A shrub or small tree, known only from Mount Kinabalu and the summit ridge on Mount Murud in Sarawak. In the former location the species appears to be common at high elevations, particularly on ultramafic substrates. The population here is protected within the national park.

Assessor: SSC Conifer Specialist Group

Refs: $374,6851,12121,19125$

\section{Dacrydium gracilis}

Podocarpaceae

VU D2

Malaysia (Sabah, Sarawak)

A large tree with a distribution which appears to be highly localised within a narrow altitudinal range on Mount Kinabalu, the Crocker range and adjacent parts of Sarawak. It is an integral part of the lower montane oaklaurel forest. Trees are hard to distinguish from other Dacrydium species and so are likely to be cut wherever accessible for construction timber. Populations on Mount Kinabalu are almost entirely contained within the national park and so are relatively well protected.

Assessor: SSC Conifer Specialist Group

Refs: $374,6851,12121,19125$ 
Dacrydium guillauminii

Podocarpaceae

CR B $1+2 \mathrm{c}$

New Caledonia

A rare rheophyte confined to a single river basin where it grows in a restricted area of moist woodland. The largest population occurs at Chûtes de la Madeleine, which, although given the status of a botanical reserve, is inadequately managed. The area is fire-prone, the shrub layer has regressed with increasing numbers of visitors and there is a threat of pollution from mining operations upstream.

Assessor: SSC Conifer Specialist Group

Refs: 10351, 12630

\section{Dacrydium lycopodioides}

Podocarpaceae

LR/cd

New Caledonia

A New Caledonian endemic confined to a few sites of cloud forest in the southern massif, e.g. Mont Mou, Mont Humboldt and Mont Ningua. Populations are small and confined to high, usually inaccessible, mountain ridges. Regeneration does not appear to be good.

Assessor: SSC Conifer Specialist Group

Refs: 9631,12630

\section{Dacrydium magnum}

Podocarpaceae

Indonesia (Moluccas), Papua New Guinea, Solomon Islands

Populations are known from the islands of Guadalcanal, Choiseul and Santa Ysabel in the Solomons, from the Louisades in Papua New Guinea and Obi Island in the Moloccas. The species is scattered to locally common in areas of lowland rainforest, especially on ridge crests. Forest management activities and agricultural pressures could cause rapid population losses to most or all parts of the range.

Assessor: SSC Conifer Specialist Group

Refs: $374,6851,19192$

\section{Dacrydium nausoriense}

\section{Podocarpaceae}

EN Alcd, Bl $+2 \mathrm{ce}, \mathrm{Cl}$

Fiji

Endemic to the Nausori Highlands in western Viti Levu, the species occurs in small stands within a closely confined area. There is evidence that regeneration is poor. The area is unprotected and the stands are open to cutting, buming, agricultural and pastoral activities.

Assessor: SSC Conifer Specialist Group

Refs: $374,9631,18818$

\section{Dacrydium spathoides}

Podocarpaceae

Indonesia (Irian Jaya)

A poorly-collected species, known only from a small area in a remote locality along the Idenburg River in Westem Irian Jaya. Further field work could reveal a more substantial distribution.

Assessor: SSC Conifer Specialist Group

Refs: 374, 6851, 19192

\section{Dacryodes breviracemosa}

Burseraceae

VU D2

Malaysia (Peninsular Malaysia)

Known from a single collection this lowland rainforest species is confined to Terengganu .

Assessor: Chua, L.S.L

Refs: 19073

\section{Dacryodes colombiana}

Burseraceae

EN B $1+2 c$

Colombia

An endemic to Boyacá.

Assessor: Calderon, E

Refs: 15343, 19069

\section{Dacryodes elmeri}

Burseraceae

Brunei, Malaysia (Sabah)

VU D2

This very rare tree is known only from a single collection taken from lowland forest in Tawau, Sabah and from Brunei.

Assessor: World Conservation Monitoring Centre

Refs: 18327,19017

\section{Dacryodes expansa}

Burseraceae

VU D2

Brunei, Malaysia (Sarawak)

A small tree of lowland forest known from a single collection from Kuching, Sarawak and from Brunei.

Assessor: World Conservation Monitoring Centre

Refs: 18327, 19017

\section{Dacryodes igaganga}

Burseraceae

VUAlcd+2cd

Cameroon, Congo?, Gabon

A timber species which is confined to localities of lowland rainforest in Cameroon, Ngounié and Lopé Forest Reserve in Gabon and possibly Congo. There is concern over the rate at which logging has taken place and the decline in the habitat. Lopé is proposed for designation as a national park.

Assessor: World Conservation Monitoring Centre

Refs: $2773,5595,12509$

\section{Dacryodes kingii}

Burseraceae

$\mathrm{LR} / \mathrm{cd}$

Malaysia (Peninsular Malaysia)

A small tree of late secondary and primary forest of up to $600 \mathrm{~m}$ altitude. This species is protected in Taman Negara National Park.

Assessor: Chua, L.S.L.

Refs: 19073

\section{Dacryodes macrocarpa var. kostermansii}

Burseraceae

VU B1+2c

Indonesia (Kalimantan), Malaysia (Sabah)

Restricted to coastal mixed swamp forest, this variety is known only from Kalimantan and from a single collection from Sabah.

Assessor: World Conservation Monitoring Centre Refs: 7673

Dacryodes macrocarpa var. patentinervia

Burseraceae

VU Bl+2c

Brunei, Malaysia (Sabah, Sarawak)

Occurring in lowland to submontane forest, the variety is known only from Bukit Hampuan in Ranau District, in Sabah, and from scattered populations in the 3rd, 4th and 5th Districtsin Sarawak. It is also found in Brunei.

Assessor: World Conservation Monitoring Centre Refs: 7673

\section{Dacryodes multijuga}

Burseraceae

VU D2

Malaysia (Peninsular Malaysia)

Known only from the type collection, gathered at 
Pehang in Jerantut, this rare species occurs in moist forest at $60 \mathrm{~m}$.

Assessor: World Conservation Monitoring Centre Refs: 8464,19073

\section{Dacryodes puberula}

Burseraceae

VU BI+2a

Malaysia (Peninsular Malaysia)

A tree of moist forest up to $1000 \mathrm{~m}$ altitude in the states of Perak, Pahang, Negeri Sembilan and Malacca.

Assessor: Chua, L.S.L.

Refs: 8464, 19073

\section{Dactyladenia dinklagei}

Chrysobalanaceae

VU Alc, Bl+2c

Ghana

An uncommon species restricted to wet evergreen forest in Upper Guinea. General losses to this habitat have been caused by mining activities, logging and commercial planting.

Assessor: Hawthome, W.

Refs: 8369, 12061

\section{Dactyladenia hirsuta}

Chrysobalanaceae

$\mathrm{EN} \mathrm{B1}+2 \mathrm{c}$

Côte d'Ivoire, Ghana

Rare and confined to remaining areas of wet evergreen forest in Ghana and largely confined to Tai National Park in south-west Côte d'Ivoire, this species has suffered extensive logging of its habitat, the effects of mining and the establishment of commercial plantations. Assessor: Assi, A.

Refs: 8369, 12061, 12822

\section{Dactyladenia laevis}

Chrysobalanaceae

VU D2

Gabon

A small tree found only in the vicinity of Libreville. Logging has taken place in the area and nearly all the remaining forest is under concession to logging companies. It is possible, with further exploration, that the species may be found to be more widespread.

Assessor: World Conservation Monitoring Centre Refs: 19043

\section{Dahlgrenodendron natalense}

Lauraceae

$\mathrm{EN} \mathrm{B1+2ae,} \mathrm{C2a,} \mathrm{D1}$

South Africa (Eastern Cape, KwaZulu-Natal)

A palaeoendemic usually found on forest margins, both next to and away from stream banks. A few individuals have been recorded from within climax forest, but these were invariably very old and senescent. The species is known from a number of localities; it has not been found again at Ngoye forest, despite several searches and it is probably extinct at this locality; there are at least two plants in the Nqutu area; a single large tree, which is dying of old age, is in Umdoni Park; the largest number of trees are found in the remnant forest patches between the Msikaba and Umtamvuna Rivers. The total number of mature individuals is estimated to be less than 200 . Regeneration from seed has not been recorded and plants in fruit are seldom recorded. This may be the result of the synchronised dichogamy, where male and female flowers are produced at different times. Their isolated occurrence then provides little chance of pollination. There is some debate about the taxonomic placement of this species, it is maintained here as a monotypic genus.

Assessor: Hilton-Taylor, C. et al.

Refs: 689,19218

\section{Dalbergia abrahamii}

Leguminosae

EN B1+2abcd

Madagascar

A tree known only from a few localities around Autsiranana and the Ankarana Massif in areas of limestone outcrops. Populations are fragmented and much of the range is decreasing through forest destnuction. The main threat comes from selective felling for timber and charcoal. Some localities are protected in Ankarana Reserve.

Assessor: Du Puy, D.

Refs: 12353,19115

Dalbergia acariantha

Leguminosae

VU B $1+2 b$

Tanzania

This species is restricted to dry coastal forest patches in east and south-east Tanzania.

Assessor: Lovett, J. \& G.P. Clarke

Refs: $2459,3356,7550$

Dalbergia albiflora ssp. echinocarpa

Leguminosae

VU B1+2c

Nigeria

A subspecies endemic to forest areas in southem Nigeria. The extent of the habitat has unquestionably declined as there has been large-scale deforestation in the last three decades.

Assessor: World Conservation Monitoring Centre Refs: 2773, 5651, 7550, 11504

\section{Dalbergia andapensis}

Leguminosae

$\mathrm{EN} \mathrm{B1}+2 \mathrm{abc}$

Madagascar

A species confined to north-east Madagascar in humid, broadleaved evergreen forest between the altitudes of 400 and $500 \mathrm{~m}$. This rare species is poorly known, apparently having a restricted distribution in an area of declining forest.

Assessor: Du Puy, D.

Refs: 19115

\section{Dalbergia annamensis \\ Leguminosae}

EN Alcd

Viet Nam

Endemic to Viet Nam, this small tree is scattered in lowland dry open forest in Phú Yên and Khánh Hòa Provinces. This species is endangered by overexploitation for its valuable wood.

Assessor: Nghia, N.H.

Refs: 848,19091

\section{Dalbergia aurea}

Leguminosae

VU D2

Madagascar

A submontane, rainforest tree which has been collected only once from an area between the Marivorahona Massif north of the Tsaratanana Massif. This restricted area is little known but is suffering from a decline in natural vegetation.

Assessor: Du Puy, D.

Refs: 19115 


\section{Dalbergia balansae}

Leguminosae

VU Alcd

China, Viet Nam

Scattered in northern Viet Nam and China, this pioneer species grows in lowland and submontane moist forest. Its distribution has been reduced by shifting cultivation. Natural regeneration is strong on fallow land. It is grown on a small scale in mixed plantations as a host plant for lac insects.

Assessor: Nghia, N.H.

Refs: 6125,19091

\section{Dalbergia bariensis}

Leguminosae

Cambodia, Laos, Thailand, Viet Nam

EN Alcd

A tree widely distributed and scattered in lowland and submontane broadleaved forest in Indo-China. There has been a rapid decline in the number of large trees because of overexploitation of the precious timber. It is protected from illegal cutting in Viet Nam and occurs in protected areas.

Assessor: Nghia, N.H.

Refs: 848, 6125, 19091

\section{Dalbergia baronii}

Leguminosae

VUAlcd $+2 \mathrm{~cd}$

Madagascar

A widespread species confined to the lowland plains of eastem Madagascar; these forests have been greatly reduced. This fine rosewood timber species grows in lowland rainforest, often in marshy areas and near mangroves. Large individuals are rare because of overexploitation.

Assessor: Du Puy, D.

Refs: $6161,9090,12353,19115$

\section{Dalbergia bathiei}

Leguminosae

Madagascar

EN Alcd, $\mathrm{B} 1+2 \mathrm{abcd}, \mathrm{Cl}+2 \mathrm{a}$

A tree confined to a few small areas of lowland, evergreen, humid forest, mainly along river margins to the north and south of Toamasina, eastern Madagascar. As a result of selective exploitation, this species is now very rare. Very few adult specimens have been recorded and the population is severely fragmented. This species is a fine rosewood and is traded nationally and locally.

Assessor: Du Puy, D.

Refs: 19115

\section{Dalbergia bojeri}

Leguminosae

Madagascar

EN B1+2abcde

A rare climbing species known from very few collections in an area of eastem Madagascar largely cleared of lowland forest. The total population is fragmented and few mature individuals remain.

Assessor: Du Puy, D.

Refs: 19115

\section{Dalbergia boniana}

Leguminosae

DD

Viet Nam

Assessor: Nghia, N.H.

Refs: 19091

\section{Dalbergia brachystachya}

Leguminosae

EN B $1+2 a b c d e$

Madagascar

This species occurs in evergreen, humid forest between
1000 and $1500 \mathrm{~m}$. Currently the only population known can be found north of Lake Aloatra in a region with only a few patchy forest remnants; these remnants are still in decline. This species is traded locally and nationally as fuel and timber.

Assessor: Du Puy, D.

Refs: 19115

\section{Dalbergia bracteolata}

Leguminosae

LR/nt

Kenya, Madagascar, Mozambique, Tanzania

A lowland tree or scandent shrub, occurring in deciduous, seasonally dry forest and woodland. It is widespread and quite common throughout western and northern Madagascar, as well as in localised forest patches in eastem Africa. However, this species distribution is highly fragmented largely because of extensive deforestation. A $20-50 \%$ population decline is expected over the next 100 years in Madagascar.

Assessor: Du Puy, D.

Refs: $6396,7550,12353,19115$

\section{Dalbergia cambodiana}

Leguminosae

EN Alcd

Cambodia, Viet Nam

Widely distributed but scattered, this tree occurs in moist lowland forest. Its wood is valuable and continues to be exploited illegally.

Assessor: Nghia, N.H.

Refs: 19091

\section{Dalbergia capuronii}

Leguminosae

EN B 1+2abcde

Madagascar

A rare species known from only four collections from two localities in remnants of evergreen forest in central Madagascar between $1200 \mathrm{~m}$ and $1300 \mathrm{~m}$. These forest fragments are seriously threatened and declining.

Assessor: Du Puy, D.

Refs: 19115

\section{Dalbergia catipenonii}

\section{Leguminosae}

VU B1+2abcde

Madagascar

A species restricted to remnants of evergreen forest around the capital, Antananarivo, and Lake Aloatra. Some localities lie within the Manakambahin Natural Reserve, but other areas are exposed to exploitation and clearance.

Assessor: Du Puy, D.

Refs: 19115

\section{Dalbergia chapelieri}

Leguminosae

VU Alcd $+2 c d$

Madagascar

This species occurs in humid, evergreen forest up to $1000 \mathrm{~m}$ altitude. Although widespread, it occurs mainly in lowland forest which has been and continues to be extensively cleared. This species is traded in minor international, national and local markets.

Assessor: Du Puy, D.

Refs: 19115

\section{Dalbergia chlorocarpa}

Leguminosae

VU Alacd $+2 c d$ Madagascar

A Madagascan endemic occurring in lowland, seasonally dry deciduous forest. Although fairly widespread in western Madagascar, the primary 
vegetation in this area has been extensively destroyed and is still decreasing. The species is selectively felled for timber and fuel for export. Protected populations are known from Ankarafantsika Natural Reserve, Namoroka Reserve and Bemaraha Reserve.

Assessor: Du Puy, D.

Refs: 19115

\section{Dalbergia cochinchinensis}

Leguminosae

Cambodia, Laos, Thailand, Viet Nam

VUAlcd

A large evergreen tree of open semi-deciduous forests. It is considered threatened in Viet Nam because of the rates of exploitation of the prime timber. In Thailand the pressures on the species have also caused concern. The species is the focus of an ongoing *IPGRI study of the distribution of genetic resources.

Assessor: Asian Regional Workshop

Refs: $848,6125,11530,15357,19063$

\section{Dalbergia cultrata var. cultrata} Leguminosae

EN Alcd

Laos, Myanmar, Thailand, Viet Nam

This variety occurs in moist forests up to $1500 \mathrm{~m}$. In Viet Nam, it is scattered from Dac Lac to Dong Nai. The population has declined through overexpoitation of the timber.

Assessor: Nghia, N.H.

Refs: $6125,9090,19091$

\section{Dalbergia davidii}

Leguminosae

EN B $1+2 d e, C 1$

Madagascar

Known only from a single locality, this tree occurs in lowland, seasonally dry, deciduous forest in an area where Dalbergia species are being selectively felled for the export market. Despite its presence in Ankarafantsika Natural Reserve, the species is still under threat from logging.

Assessor: Du Puy, D.

Refs: 19115

\section{Dalbergia delphinensis}

Leguminosae

EN A2cd, B1+2bcde

Madagascar

This species occurs in lowland, evergreen, humid forest in south-east Madagascar, near Taolanaro. Selective felling for export, coupled with the fragmented and declining state of the habitat has brought the species into danger. Its restricted distribution coincides with a proposed site for titanium mining, which threatens all the remaining forest in the area.

Assessor: Du Puy, D.

Refs: 19115

\section{Dalbergia emirnensis}

\section{Leguminosae}

$\mathrm{LR} / \mathrm{nt}$

Madagascar

A widespread species, mainly found in rapidly-declining areas of deciduous, dry vegetation in southern Madagascar. The species is relatively common but selectively felled for minor timber trade. Some localities are protected within Andohahela Natural Reserve.

Assessor: Du Puy, D.

Refs: 19115
Dalbergia entadoides

Leguminosae

DD

Cambodia, Laos, Thailand, Viet Nam

Assessor: Nghia, N.H.

Refs: 19091

\section{Dalbergia eremicola}

Leguminosae

LR/nt

Kenya, Somalia

The largest population of this small tree occurs in Kenya where it appears to be quite common in bushland near Wajir. It also extends into a small area of southem Somalia.

Assessor: Thulin, $\mathrm{M}$.

Refs: $1308,6396,7550,18665$

\section{Dalbergia erubescens}

Leguminosae

EN B 1+2abcde

Madagascar

A species known from two remnants of submontane, evergreen forest in a very restricted area of Ivohibe. Trees are selectively felled and the habitat is in decline. Assessor: Du Puy, D.

Refs: 19115

\section{Dalbergia funera}

Leguminosae

El Salvador, Guatemala

In El Salvador the species is confined to Santa Ana and Chalatenango, where it occurs in pine-oak forest up to $2000 \mathrm{~m}$. There have been no recent reports of its occurrence and the area is unprotected and susceptible to logging and expanding agricultural development. The wood is of wide importance in carpentry and constuction. Information is needed on the Guatemalan population.

Assessor: World Conservation Monitoring Centre Refs: 4862, 4974, 10395, 19030

\section{Dalbergia fusca var. enneandra}

Leguminosae

VU B1+2c

China (Yunnan)

This variety is confined to localities of lowland semideciduous forest at Simao, Meijiang, Jianchen and Jinghong in southern Yunnan. Overcutting of the timber, encroaching cultivation and habitat degradation have caused population reductions. The taxon has been observed to occur quite frequently in scrub, regenerating after the destruction of forested areas.

Assessor: Sun, W.

Refs: $1818,11847,19055$

\section{Dalbergia glaberrima}

Leguminosae

VU B $1+2 d e$

Madagascar

Two subspecies are recognised. Both have a restricted range within declining areas of seasonally dry forest and woodland on limestone outcrops. Trees are selectively felled to supply local and national markets. Populations are recorded in Ankarana and Bemaraha Reserves.

Assessor: Du Puy, D.

Refs: 19115

\section{Dalbergia glaucocarpa}

Leguminosae

EN B $1+2 a b c d e$

Madagascar

Currently this species is known only from the Sambrino margins of north-west Madagascar where it is selectively felled for the local and national timber 
markets. The deciduous, seasonally dry, sandstone forest habitat of this species is severely fragmented.

Assessor: Du Puy, D.

Refs: 19115

\section{Dalbergia glomerata}

Leguminosae

VUAlc

Mexico (Chiapas, Oaxaca, Veracruz)

A species, endemic to remaining rainforest in the Gulf region, occurring as far north as southem Veracruz.

Assessor: World Conservation Monitoring Centre

Refs: 5993, 19124

\section{Dalbergia greveana}

Leguminosae

LR/nt

Madagascar

This species occurs in deciduous, seasonally dry forest and woodland up to $800 \mathrm{~m}$. Although widespread in western Madagascar, trees are sought-after and selectively felled for the high-quality wood which forms the bulk of timber wood exports from western Madagascar. Population numbers have declined over the entire range. Some localities are protected in Ankarafantsika Nature Reserve and in Ankarana Special Reserve.

Assessor: Du Puy, D.

Refs: 19115

\section{Dalbergia hildebrandtii}

Leguminosae

VU Alcd+2cd

Madagascar

The lowland dry forest and woodland habitat of this species is being gradually reduced and fragmented. Although widespread, the species is uncommon and selectively felled for the valuable rosewood timber.

Assessor: Du Puy, D.

Refs: 19115

\section{Dalbergia hirticalyx}

\section{Leguminosae}

Madagascar

EN B1+2bce

Found in evergreen, seasonally dry forest between $900 \mathrm{~m}$ and $1100 \mathrm{~m}$, this species is known only from a single forest remnant at Tsiroanomandidy. The total population is selectively felled and the entire forest exploited.

Assessor: Du Puy, D.

Refs: 19073,19115

\section{Dalbergia humbertii \\ Leguminosae \\ Madagascar}

A deciduous tree known only from two locations within a very restricted area north of Morondava. It covers an estimated $1500 \mathrm{~km}^{2}$ ( $\left.{ }^{*} \mathrm{EOO}\right)$ within a region of fragmented and declining native vegetation.

Assessor: Du Puy, D. \& H. Labat

Refs: 12353

\section{Dalbergia hupeana var. laccifera}

Leguminosae

$\mathrm{LR} / \mathrm{nt}$

Laos, Viet Nam

This species occurs along rivers and streams and on slopes in lowland and submontane moist forest in northwest Viet Nam and Laos. Forest fragmentation and shifting cultivation are the main reasons for the decline of this variety.

Assessor: Nghia, N.H.

Refs: 6125,19091

\section{Dalbergia hutibertii}

Leguminosae

VU Alcd $+2 c d$

Madagascar

A tree restricted to deciduous, seasonally dry forest and woodland on a few isolated limestone massifs in west and north Madagascar. Although these areas are largely protected, selective felling still takes place and populations are declining. Protected areas in which the species is found are Ankarana Special Reserve and Bemeraha.

Assessor: Du Puy, D.

Refs: 19115

\section{Dalbergia intibucana}

Leguminosae

CR C2a

Honduras

There is some doubt over the nomenclature of the species. It is confined to areas of medium-to highelevation humid forest in Honduras.

Assessor: Nelson, C.

Refs: 13995, 14311

\section{Dalbergia Latifolia}

Leguminosae

VU Alcd

India (Andhra Pradesh, Kamataka, Sikkim, Tamil Nadu, Uttar Pradesh), Indonesia (Java), Nepal

Indian rosewood is principally a species of monsoon forests. Its timber is of high commercial value and wild populations are widely overexploited. The species is protected under the Indian Forest Act, the export of logs or sawn timber being banned, but considerable pressure continues to be exerted by illegal felling.

Assessor: Asian Regional Workshop

Refs: $6431,8483,11145,14573,16458,17286,19064$

\section{Dalbergia lemurica}

Leguminosae

Madagascar

VU Alcd $+2 c d$

A tree confined to deciduous, seasonally dry forest on sand in western Madagascar. Although apparently widespread, most records are from near Morondava, where the habitat is being rapidly reduced and the trees are selectively felled.

Assessor: Du Puy, D.

Refs: 19115

\section{Dalbergia louvelii \\ Leguminosae}

EN Alcd $+2 c d$

Madagascar

A species confined to the drastically reduced lowland, humid forests of eastem Madagascar. Populations of this rare rosewood species are now severely fragmented and it is selectively felled for the export market.

Assessor: Du Puy, D.

Refs: 19115

\section{Dalbergia madagascariensis Leguminosae \\ Madagascar}

VU Alcd+2cd

A widespread species found along river margins in the humid, evergreen forest of north and east Madagascar. The extent of the forest is in decline and trees are selectively felled for the timber.

Assessor: Du Puy, D.

Refs: 19115 
Dalbergia malacophylla

Leguminosae

$\mathrm{EN} \mathrm{B} 1+2 \mathrm{bc}$

Madagascar

Known only from a single locality, this deciduous species is found in Mikea forest in south-west Madagascar and covers an estimated $2000 \mathrm{~km}^{2}\left({ }^{*} \mathrm{EOO}\right)$. The native forest in this restricted locality is undergoing gradual decline and selective exploitation for timber.

Assessor: Du Puy, D. \& H. Labat

Refs: 12353

\section{Dalbergia mammosa}

Leguminosae

EN Alcd

Viet Nam

A tree scattered throughout broadleaved forest in central and southern Viet Nam up to $800 \mathrm{~m}$. The entire population has declined through overexploitation of the valuable timber. The species is now legally protected, but continues to be cut illegally.

Assessor: Nghia, N.H.

Refs: $848,6125,15357,19091$

\section{Dalbergia maritima}

Leguminosae

EN Alcd+2cd

Madagascar

A lowland tree restricted to humid, evergeen, coastal forest which has been almost completely destroyed. The remaining forests are seriously threatened by exploitation and clearing. Selective felling for export, fragmented populations and titanium mining activities threaten this endemic species.

Assessor: Du Puy, D.

Refs: 19115

\section{Dalbergia melanoxylon}

Leguminosae

LR/nt

Angola, Botswana, Burkina Faso, Cameroon, Central African Republic, Chad, Côte d'Ivoire, Democratic Republic of Congo, Ethiopia, Kenya, Malawi, Mali, Mozambique, Nigeria, Senegal, South Africa, Sudan, Tanzania, Uganda, Zambia, Zimbabwe

This species occurs in a range of woodland habitats in at least 26 sub-Saharan countries. Its timber, mpingo, is widely used in the wood carving industry and in musical instrument manufacture. Levels of exploitation are very high and larger or suitably exploitable individuals are becoming increasingly scarce. There is cause for concern over genetic erosion in many populations. However, as a species there is no imminent threat of extinction.

Assessor: World Conservation Monitoring Centre

Refs: $6396,7550,13370,13947,14418,16021,17335$

\section{Dalbergia mollis}

Leguminosae

Madagascar

LR/nt

This widely distributed tree inhabits lowland, deciduous forest and woodland in western Madagascar. It occurs in regions of rapidly declining fragmented forest. It is also selectively felled for the high-quality rosewood timber. Some populations lie within the boundaries of Ankarafantsika Strict Nature Reserve.

Assessor: Du Puy, D.

Refs: 19115

\section{Dalbergia monticola}

Leguminosae

Madagascar

VU Alcd+2cd

A tree of evergreen, humid forest with an extensive distribution along the eastem escarpment of Madagascar, including areas with extensive forest cover. However, this much sought-after rosewood is selectivey felled for export and mature trees are considered rare. Many localities receive protection in Perinet/Andasibe, Zahamena, and Ranomafana Protected Areas.

Assessor: Du Puy, D.

Refs: 19115

\section{Dalbergia neoperrieri \\ Leguminosae}

VU Alcd+2cd

Madagascar

This species occurs in the lowland, seasonally dry, deciduous forests of western Madagascar. Only a few isolated populations are known, mainly confined to specialised limestone habitats. The area of forest is declining and the species is selectively felled, although good populations are recorded at Bemaraha Reserve. Assessor: Du Puy, D.

Refs: 19115

\section{Dalbergia nigra}

Leguminosae

VU Alcd

Brazil (Bahia, Espírito Santo, Minas Gerais, Rio de Janeiro, Sāo Paulo)

Brazilian rosewood is one of the most highly prized woods in Brazil. The timber has been harvested since colonial times for high-quality furniture and musical instruments. The highest concentrations of the species are located in hygrophilous forest on rich soils in southern Bahia and northen Espírito Santo, where rates of deforestation are great. Regeneration appears to be poor, possibly because of seed predation by rodents. It is found in a number of protected areas and it is listed on the official list of threatened Brazilian plants by *IBAMA. Listed in *CITES Appendix I.

Assessor: Varty, N.

Refs: $4506,7980,8815,13947,15539$

\section{Dalbergia normandii}

Leguminosae

Madagascar

EN Alcd $+2 c d, B 1+2 a b c d e$

A very rare species known from only two localities, Antalaha and the Isle Sainte Marie in north-east Madagascar, where it inhabits very fragmented humid, evergreen, coastal forest. This tree has been severely exploited for the excellent quality of its rosewood. Assessor: Du Puy, D.

Refs: 19115

\section{Dalbergia odorifera}

Leguminosae

China (Guangdong - Hainan)

VU Ald

Confined to Hainan Island, the species is known only from stands of coppiced individuals in secondary forest and scrub up to $600 \mathrm{~m}$ altitude. Trees have been heavily harvested for the timber and scented wood.

Assessor: World Conservation Monitoring Centre Refs: $1660,1818,11847$

\section{Dalbergia oliveri}

Leguminosae

Myanmar, Thailand, Viet Nam

EN Alcd

Scattered in dense evergreen and semi-deciduous forest up to $1200 \mathrm{~m}$, the species occurs within a restricted 
distribution. Its beautiful red wood is overexploited. A protected population occurs in Nam Cát Tiên National Park.

Assessor: Nghia, N.H.

Refs: $3090,6125,18802,19091$

\section{Dalbergia orientalis}

Leguminosae

VU Alcd $+2 c d$

Madagascar

A little-known species distributed through eastem Madagascar. This rare species natural habitat is evergreen humid forest between $100 \mathrm{~m}$ and $1200 \mathrm{~m}$ altitude. Such forest is decreasing and this species is selectively felled for timber. It is most frequently recorded around Fort Carnot, east of Fianarantsoa.

Assessor: Du Puy, D.

Refs: 19115

\section{Dalbergia peltieri \\ Leguminosae \\ Madagascar}

LR/nt

A widespread species of deciduous, seasonally dry, lowland forest on sand in western Madagascar. The species is still relatively common and less sought-after than other rosewoods because of its softer wood. It is mainly used for local construction purposes.

Assessor: Du Puy, D.

Refs: 19115

\section{Dalbergia pervillei}

Leguminosae

LR/nt

Madagascar

A tree occurring in broadleaved, deciduous, seasonally dry forest and woodland, usually between $50 \mathrm{~m}$ and $300 \mathrm{~m}$ altitude. This locally common species is very widespread in southern, western and northern Madagascar. However, the vegetation in this zone is fragmented and the species is selectively felled. Some localities fall within protected area boundaries.

Assessor: Du Puy, D.

Refs: 19115

\section{Dalbergia pseudobaronii}

Leguminosae

VU Alcd+2cd

Madagascar

Occurring in evergreen, humid forest between 50 and $1000 \mathrm{~m}$, the species is mainly recorded from northem Madagascar. Little is known about its frequency, but population reductions have been caused by selective felling for the high-quality timber, which is sold on national and local markets.

Assessor: Du Puy, D.

Refs: 19115

\section{Dalbergia purpurascens}

Leguminosae

VU Alcd+2cd

Madagascar

Widespread in east, west and south-west Madagascar, where it is locally common. However, this species produces a notably attractive high-quality rosewood which is selectively felled, seriously reducing populations. Some localities are in the protected areas of Ankarana, Namoroka and Bemaraha.

Assessor: Du Puy, D.

Refs: 19115

\section{Dalbergia retusa}

Leguminosae

VU Alacd

Belize, Costa Rica, El Salvador, Guatemala, Honduras, Mexico, Nicaragua, Panama

A dry forest species of the Pacific side of Central America and Mexico. Exploitation as a timber is intense and areas where the species was formerly widespread are almost completely exhausted. This is most notable in Costa Rica. There is a limited occurrence of the species north of the canal in Panama and reasonably sized populations are reported to be found still in Mexico. The habitat has been exploited for $\mathbf{4 0 0}$ years and continuing reductions are caused through cattle ranching and burning. The species responds well to periodic buming. Assessor: Americas Regional Workshop

Refs: $7980,14717,15037,19179$

\section{Dalbergia sambesiaca}

Leguminosae

Mozambique

Assessor: Bandeira, $\mathrm{S}$.

Refs: 5117,7550

\section{Dalbergia setifera}

Leguminosae

Ghana

$\mathrm{EN} \mathrm{B} 1+2 \mathrm{c}$

Endemic to Ghana, this species is confined to areas of dry forest at Sekondi. Habitat degradation has been extensive, although the species' preference for rocky sites lessens the threat of agricultural encroachment.

Assessor: Hawthorne, W.

Refs: 2773,12061

\section{Dalbergia simpsonii}

Leguminosae

Peru

A lowland forest species known only from the type collection taken from the department of Loreto.

Assessor: World Conservation Monitoring Centre

Refs: 1984

\section{Dalbergia suaresensis}

Leguminosae

EN B1+2abcde

Madagascar

A tree occurring in lowland deciduous forest in the northern tip of Madagascar, around Antsiranana. The extent of occurrence is very small, and the forest very fragmented within it. Selective felling of this species has drastically reduced the population.

Assessor: Du Puy, D.

Refs: 19115

\section{Dalbergia tonkinensis}

Leguminosae

VU Alcd

China (Guangdong - Hainan), Viet Nam

A tree known from scattered populations in areas of primary and secondary forest in Viet Nam and Hainan Island in Cnina. In Viet Nam heavy exploitation of the beautiful timber has led to considerable population declines. Habitat loss on Hainan Island through logging has also been significant.

Assessor: Ban, N.T.

Refs: $848,6125,11530,15357,19060,19091$

\section{Dalbergia tricolor}

Leguminosae

VU Alcd $+2 c d$

Madagascar

A tree occurring in lowland deciduous, seasonally dry forest and woodland. This uncommon species has a 
distinct distribution. Selective felling in fragmented vegetation is causing a reduction in the total population. Assessor: Du Puy, D.

Refs: 19115

\section{Dalbergia tsaratananensis}

\section{Leguminosae}

Madagascar

EN B1+2abcde

Few populations are known and all are confined to broadleaved, submontane, moist forest in the Tsaratanana Massif in Madagascar. Trees are selectively felled and the habitat is in rapid decline because of increasing cultivation.

Assessor: Du Puy, D.

Refs: 19115

\section{Dalbergia tsiandalana}

Leguminosae

EN B1+2abcde

Madagascar

Very restricted, this poorly known species occurs around Soalala and Mahajanga in western Madagascar. The coastal, lowland, moist forest habitat of this species is very reduced and fragmented. This good-quality rosewood is selectively felled.

Assessor: Du Puy, D.

Refs: 19115

\section{Dalbergia urschii}

Leguminosae

EN B $1+2 a b c d e$

Madagascar

A tree known from only one locality in lowland, deciduous, seasonally dry forest near Antsiranana. This rare species is easily accessible, selectively felled and in an area of forest degradation and clearance.

Assessor: Du Puy, D.

Refs: 19115

\section{Dalbergia vaccinuifolia}

Leguminosae

VU Bl+2b

Kenya, Tanzania

A relatively wide-ranging species which occurs as a scandent shrub in places. It is known from patches of dry coastal forest in south-east Kenya, at unusually high altitudes in the Shimba Hills and at Taru. The range extends south through coastal Tanzania to Zanzibar Island.

Assessor: Lovett, J. \& G.P. Clarke

Refs: $3356,6396,7550$

\section{Dalbergia viguieri}

Leguminosae

VU Alcd+2cd

Madagascar

A poorly known rosewood tree, restricted to broadleaved transition forest in north-east Madagascar. The species is known from only three rapidly diminishing sites, all of which are fragmented and isolated.

Assessor: Du Puy, D.

Refs: 19115

\section{Dalbergia xerophila}

Leguminosae

EN B $1+2$ abcde

Madagascar

This species has a very restricted distribution in woodland and scrubland on sand, in south-east Madagascar. A shrubby species, not of expon-quality rosewood, but the stems are very sought-after locally for construction and tool making. The vegetation in this area is very fragmented.

Assessor: Du Puy, D.

Refs: 12353,19115

\section{Daniellia klainei}

Leguminosae

LR/nt

Cameroon, Gabon

Populations in Cameroon have become reduced with increasing exploitation of the timber. There are intact stands in Gabon, where large tracts of forest have remained undisturbed. This trend, however, is rapidly changing as almost all forest areas in Gabon are now under concession to timber companies.

Assessor: World Conservation Monitoring Centre

Refs: 14958,19132

\section{Daniellia oblonga}

Leguminosae VU Alc

Benin, Cameroon, Equatorial Guinea (Bioko), Nigeria

A large tree from Atlantic forest. Populations have been recorded in Benin, on the Nigerian border at Oueme, in Ikom in Nigeria, extending into Cameroon and Bioko. Although information on the extent of the species range and its status is incomplete, the habitat is known to have declined severely.

Assessor: World Conservation Monitoring Centre Refs: 2773, 7111, 11504

\section{Daphnopsis calcicola}

Thymelaeaceae

VU D2

Cuba

A small, endemic tree locally restricted to the deeply eroded limestone mountains called the mogotes complex in Viñales, Pinar del Rio Province.

Assessor: Areces-Mallea, A.E.

Refs: 11403, 18485, 19149

\section{Daphnopsis macrophylla}

Thymelaeaceae

VU B $1+2 c$

Ecuador

A tree of montane and upper montane cloud forest in the Ecuadorean High Andes.

Assessor: World Conservation Monitoring Centre

Refs: 19119,19120

\section{Daphnopsis pavonii}

Thymelaeaceae

VU D2

Pens

Known only from the type collected in the department of Junin, the species occurs in forest between 2500 and $3000 \mathrm{~m}$.

Assessor: World Conservation Monitoring Centre Refs: 1984

\section{Dasylepis integra}

Flacourtiaceae

Kenya, Tanzania

$\mathrm{VU} B 1+2 \mathrm{~b}$

An upland moist forest species known from the Taita Hills in Kenya, the West Usambara Mountains and Pare Mountains in Tanzania. There is also an unusual record of occurrence at Nou in Mbulu based on a single collection.

Assessor: Lovett, J. \& G.P. Clarke

Refs: $3356,6396,8814$ 


\section{Dasymaschalon scandens}

Annonaceae

VU B $1+2 c$

Philippines

This tree is endemic to Palawan, found on forested slopes at low and medium altitudes. The main island is declared a biosphere reserve.

Assessor: World Conservation Monitoring Centre Refs: 4986

\section{Davidia involucrata var. involucrata}

Comaceae

LR/Cd

China (Guizhou, Hubei, Hunan, Shaanxi, Sichuan, Yunnan)

One of the two varieties in this monospecific genus. It occurs in small pure stands scattered over a fairly wide range in broadleaved forest between 1000 and $2200 \mathrm{~m}$. It is a valuable omamental tree and seed collecting coupled with high levels of habitat destruction, have caused the species to disappear from parts of its range.

Assessor: Sun, W.

Refs: $1818,11847,19055$

\section{Davidia involucrata var. vilmoriniana}

Comaceae

VUAlcd

China (Guizhou, Hubei, Hunan, Shanxi, Sichuan, Yunnan)

The more threatened of the two varieties in this monospecific genus. Occurring in montane or cloud forest with a distribution similar to as the type variant, populations appear to be less common. There is also a keener demand for the seeds and plants in the horticultural trade, and overcollection from wild populations has reduced natural regeneration severely. Assessor: Sun, W.

Refs: i818, 19055

\section{Debregeasia ceylanica}

\section{Urticaceae}

Sri Lanka

CR B $1+2 \mathrm{~cd}$

A tree occurring in the lowland wet evergreen forests of south-west Sri Lanka. This species was not recorded during the extensive National Conservation Review forest surveys conducted between 1991 and 1996, indicating that it is extremely rare or possibly extinct. Assessor: World Conservation Monitoring Centre

Refs: 17195, 19112

\section{Decatropis paucijuga}

\section{Rutaceae}

EN C2a

Guatemala, Honduras

A scarce species, collected only once in Honduras from a locality in the Atlantic wet lowlands.

Assessor: Nelson, C.

Refs: 13995

\section{Decazyx esparzae}

Rutaceae

CR C2b

Honduras, Mexico

Assessor: Nelson, C.

Refs: 13995

\section{Decezyx macrophyllus}

Rutaceae

EN C2a

Guatemala, Honduras

A species known from small populations, in lowland wet mixed forest.

Assessor: Nelson, C.

Refs: 13995

\section{Deckenia nobilis}

Palmae

$E N B 2 e+3 d$

Seychelles

A palm tree, reaching up $1040 \mathrm{~m}$ in height, scattered in lowland forest up to $600 \mathrm{~m}$. Population numbers are declining as result of exploitation of the edible palm hearts. Some stands are naturally protected on rocky, inaccessible cliffs. The species is legally protected and seedlings, raised in nurseries, are distributed to the public for planting.

Assessor: Nature Protection Tnust of Seychelles

Refs: 19025,19118

\section{Degeneria roseiflora}

Degeneriaceae

LR/nt

Fiji

An endemic family of just two species. This species is endemic to Viti Levu, Vanua Levu and Taveuni. It is relatively abundant but being logged extensively.

Assessor: World Conservation Monitoring Centre Refs: $5515,6053,18818$

\section{Degeneria vitiensis}

Degeneriaceae

VU D1

Fiji

An endemic family of just two species. This is the rarer taxon, occurring on Vanua Levu and Taveuni in small, scattered populations.

Assessor: World Conservation Monitoring Centre

Refs: $1736,5515,6053,18818$

\section{Dehasia acuminato}

Lauraceae

Indonesia (Java)

$\mathrm{CR} A \mathrm{~A}+2 \mathrm{c}, \mathrm{B} 1+2 \mathrm{c}$

A lowland forest species known from populations near Pelabuhan Ratu and a formerly forested area near Pringombo. The current status of these populations is unknown but they are bound to be affected by the almost complete clearance of their habitat.

Assessor: World Conservation Monitoring Centre

Refs: 9078

\section{Dehaasia chatacea}

Lauraceae

CR C2b, Dl

Indonesia (Java)

Little is known about this species other than that it was collected only once before 1850 , probably from forest in west Java. Given the extent of habitat clearance, it is very likely this species is now extinct.

Assessor: World Conservation Monitoring Centre

Refs: 9078

\section{Dehaasia lancifolia}

Lauraceae

LR/cd

Malaysia (Peninsular Malaysia)

This rare species is confined to the mountain forests of Perak and Pahang.

Assessor: Kochummen, K.M.

Refs: 8464, 19073

\section{Dehaasia pugerensis}

Lauraceae CR C2b, D1

Indonesia (Java)

This species has not been collected since the last century, when it occurred in lowland forest near Meru Betiri National Park. Given the extent of habitat loss, it is very likely that the species is now extinct. Assessor: World Conservation Monitoring Centre Refs: 9078 


\section{Deinbollia longiacuminata} Sapindaceae

LR/cd

Democratic Republic of Congo

A species endemic to the Forestier Central in the region of Ofala.

Assessor: Ndjele, M.B.

Refs: 17185,17951

\section{Deinbollia molliuscula}

Sapindaceae

Côte d'Ivoire?, Ghana

VU Alc, B1+2c

Confined to wet evergreen forest in Upper Guinea, this species has experienced general losses in habitat caused by mining, logging and the establishment of commercial plantations.

Assessor: Hawthome, W.

Refs: 12061

\section{Deinbollia nyasica}

Sapindaceae

$\mathrm{EN} B 1+2 \mathrm{ac}$

Malawi

A large tree, apparently known only from the type locality near Mboma stream in the Thyolo region. Most of the original forest in this area has been supplanted by tea estates and Eucalyptus plantations. In more recent years remaining forest areas have been steadily encroached upon for farming.

Assessor: World Conservation Monitoring Centre

Refs: 7058, 18965

\section{Deinbollia rambaensis}

Sapindaceae

VU D2

Gabon

Apparently known only from Ramba, the species may be found to be more widespread as large areas have yet to be explored. The future of Gabon's forest is uncertain as it is now almost completely under concession to logging companies. The taxonomic status of the genus is held in question.

Assessor: World Conservation Monitoring Centre

Refs: 15790,19043

\section{Deinbollia saligna}

Sapindaceae

VU Alc, Bl+2c

Cameroon, Ghana, Nigeria

An understorey species, a borderline shrub or tree. It occurs in rocky streamside forest in a few localities in Nigeria and Cameroon and is recently recorded in Ghana. Populations in unprotected forest have been exposed to extensive logging and clearing for agriculture.

Assessor: World Conservation Monitoring Centre

Refs: $450,8369,11504$

\section{Delissea undulata ssp. kauaiensis}

Campanulaceae

EX

USA (Hawaii)

One of three subspecies. It was known to occur in rainforest near Hanapepe Falls on Kauai, but no record of it has been made since 1895. The genus is endemic to the Hawaiian Islands.

Assessor: World Conservation Monitoring Centre Refs: 19034,19039

\section{Delissea undulata ssp. nühauensis}

This subspecies was known only from a population occurring on the island of Nihau. It has not been collected since 1870. The genus is endemic to Hawaii. Assessor: World Conservation Monitoring Centre Refs: 19034,19039

\section{Delissea undulata ssp. undulata}

Campanulaceae

CR B 1+2c, C2ab, D1

USA (Hawaii)

The only extant form of this species. It is represented by a single tree at Puuwaawaa on Hawaii. All other populations on West Maui, and on the slopes of Hulalai and Mauna Loa on Hawaii are believed extinct. The tree occurs in an area leased for ranching where it is under immediate threat from grazing, fire and also from invasive plants. Seeds have been propagated and planted out in the area, increasing the population to approximately 50 plants. The species is protected by the US Endangered Species Act.

Assessor: World Conservation Monitoring Centre

Refs: 19034,19039

\section{Delonix baccal}

Leguminosae

LR/nt

Ethiopia, Kenya, Somalia

Occurring in Acacia-Commiphora bushland or riverine woodland, often on limestone, the species is confined to an area extending from central and southern Somalia to north-east Kenya and the Ogaden in Ethiopia. It is not common and, in places, the habitat is severely degraded by encroaching agriculture and overcutting for charcoal production.

Assessor: Thulin, $\mathbf{M}$.

Refs: 1308, 1330, 6396, 8697, 10961, 13072, 18665

\section{Delonix boiviniana}

Leguminosae

LR/nt

Madagascar

A deciduous woodland and forest species that occurs throughout north, south and west regions of Madagascar. It is locally common and exists within protected areas that are not imminently threatened.

Assessor: Du Puy, D, et al.

Refs: 13856

\section{Delonix brachycarpa}

Leguminosae

LR/nt

Madagascar

This deciduous woodland species has a scattered and widespread distribution across west, south-west and south-east areas of Madagascar. Its distribution is similar to that of $D$. boiviniana and indeed it may not qualify as a separate species.

Assessor: Du Puy, D. et al.

Refs: 13856

\section{Delonix decaryi}

Leguminosae

Madagascar

Restricted to a narrow strip near the coast of south and south-west Madagascar, this deciduous woodland species is extensive but occurs in areas under increasing threat from charcoal production. It is highly utilised locally.

Assessor: Du Puy, D. et al. Refs: 13856 
Delonix floribunda

Leguminosae

Madagascar

A deciduous woodland species that occurs commonly in the south-west and west of Madagascar. Its main populations are in areas of the south-west that are being increasingly reduced for charcoal production.

Assessor: Du Puy, D. et al.

Refs: 13856

\section{Delonix leucantha ssp. bemarahensis}

Leguminosae

VU D2

Madagascar

Known only from a single herbarium specimen collected from Tsingy de Bemaraha in west Madagascar, this deciduous woodland species occurs within a reserve where exploitation is limited because of the area's remoteness.

Assessor: World Conservation Monitoring Centre

Refs: 13856

\section{Delonix leucantha ssp. gracilis}

Leguminosae

VU B2c

Madagascar

Restricted mainly to south-west Madagascar, this deciduous woodland species is uncommon where it occurs and is threatened by charcoal buming.

Assessor: Du Puy, D, et al.

Refs: 13856

\section{Delonix leucantha ssp. leucantha}

Leguminosae

VU D2

Madagascar

Known only from a small population in west Madagascar, this lowland deciduous woodland species occurs in a fairly inaccessible location within a reserve where it is not threatened. However, in a recent botanical survey it was not recorded.

Assessor: Du Puy, D. et al.

Refs: 13856

\section{Delonix pumila}

Leguminosae

EN B $1+2$ cde

Madagascar

Known only from two populations in south-west Madagascar, this species is restricted to areas of xerophytic scrubland on La Table Hill, with a smaller population on the plateau above St Augustin. Threats to the former population exist from road widening and the collection of mature individuals for the omamental trade. Both populations are susceptible to fires and neither is protected.

Assessor: Du Puy, D. et al.

Refs: 13856

\section{Delonix regia}

Leguminosae

VU BI $+2 c$

Madagascar

This deciduous species is native to west and north Madagascar but is cultivated throughout this and many other tropical countries. The main native populations found around Antsiranana occur in areas that are threatened from charcoal production. It is used widely as an omamental tree.

Assessor: Du Puy, D. et al.

Refs: $559,1833,13856$

\section{Delonix tomentosa}

Leguminosae

Madagascar

This deciduous species, previously known only from the type collected from the Ankara Plateau in the Boina, has recently been reported from a small population on the Ankarana Massif. Periodic fires on the Ankara Plateau are a threat. Its location is very inaccessible and no recent survey has been done.

Assessor: Du Puy, D. et al.

Refs: 13856

\section{Delonix velutina}

Leguminosae

Madagascar

CR A2c

Known from only a few small populations in north Madagascar, the main locality of this rare deciduous species is Orangea Peninsula, where it is severely threatened by charcoal buming. It has been recorded once from a protected site at Ankarana.

Assessor: Du Puy, D. et al.

Refs: 13856

\section{Delpydora macrophylla}

Sapotaceae

VU D2

Gabon

From a genus of only two species, this tree is apparently confined to the Libreville area. Its range may prove to be wider as the forest is further explored. There is concern about the extent to which logging concessions have been made throughout the country.

Assessor: World Conservation Monitoring Centre

Refs: 14958,15790

\section{Dendropanax alberti-smithü}

Araliaceae

Vu C2a

Colombia, Costa Rica, Panama

The species is scattered in areas of evergreen rainforest up to about $1200 \mathrm{~m}$, principally on the Atlantic side of Panama, and on the Pacific coast in Colombia. There are also reports of occurrences in Costa Rica. None of the populations appears to be large and they occur in areas which are largely unprotected and prone to logging.

Assessor: Mitré, M.

Refs: 16772

\section{Dendropanax blakeanus}

Araliaceae

VU B $1+2 c$

Jamaica

Apparently confined to John Crows Mountains, the species has been recorded in few localities, one above Ecclesdown and another at Proctor's Pool (a single individual), in *elfin or moist forest on limestone. Assessor: World Conservation Monitoring Centre Refs: 5653,7980

\section{Dendropanax cordifolius}

Araliaceae

CR B $1+2 \mathrm{c}$

Jamaica

The species has been collected from wooded limestone hillsides at the summit of Dolphin Head. Thorough searches for the species in 1989 failed to locate it. Apart from habitat declines and degradation, it is possible that Hurricane Gilbert in 1988 caused serious damage. Assessor: World Conservation Monitoring Centre Refs: $401,5653,7980$ 


\section{Dendropanax darienensis}

Araliaceae

DD

Panama

The type collection for this species was supposedly taken from the province of Darien but the herbarium specimen lacks details on the specific locality and the collection number. There has also been a claim that the specimen originated from Cabo Corrientes in Colombia. Assessor: Mitré, $M$.

Refs: $7272,7980,16772$

\section{Dendropanax filipes}

Araliaceae

$\mathrm{CR} \mathrm{BI}+2 \mathrm{c}$

Jamaica

A small tree or straggling shrub, endemic to the Cockpit Country, where it occurs locally in woodland on limestone rocks. Originally recorded from four locations, attempts to find the species at three of these sites, Peckham Woods, Mango Tree Hill and Miss Laura's Hill, have failed. These areas suffer frequent cutting and agricultural encroachment.

Assessor: World Conservation Monitoring Centre

Refs: $401,5653,7980$

\section{Dendropanax grandiflorus}

Araliaceae

$\mathrm{CR} \mathrm{B} 1+2 \mathrm{C}$

Jamaica

The species is known from four localities. At two of them, Peckham and Douglas Castle Woods, attempts to find the species have failed. Another location on a ridge south of Sunbury is severely degraded by cutting and intensive cultivation. The last site, on jagged limestone on White Rock Hill, appears to harbour a population which is in good condition.

Assessor: World Conservation Monitoning Centre

Refs: $401,5653,7980$

\section{Dendropanax grandis}

Araliaceae

$\mathrm{CR} \mathrm{B} 1+2 \mathrm{C}$

Jamaica

A single sterile specimen is known from a ridge of woodland south of Sunbury, where the habitat has been severely degraded by cutting and intensive agriculture. Another population is known in forest in St Ann Parish. Assessor: World Conservation Monitoring Centre Refs: $401,5653,7980$

\section{Dendropanax hondurensis}

Araliaceae

Honduras, Mexico

A tree of high-elevation cloud forest.

Assessor: Nelson, C

Refs: 13995

\section{Dendropanax lanceifolius}

Araliaceae

Malaysia (Peninsular Malaysia)

VU $B 1+2 c$

A small tree of hill rainforest, confined to the state of Perak.

Assessor: Chua, L.S.L.

Refs: 19073

\section{Dendropanax marginiferus}

Araliaceae

VU D2

Pers

A lowland forest species known only from the type collected in the department of San Martin in the Peruvian Andes.

Assessor: World Conservation Monitoring Centre Refs: 1984

\section{Dendropanax nutans var. nutans}

Araliaceae

LR/nt

Jamaica

One of the two varieties of a species which is endemic to the Blue Mountains and John Crow Mountains. It grows as a shrub or gnarled tree below $1700 \mathrm{~m}$ on ridges, especially the Grand Ridge.

Assessor: World Conservation Monitoring Centre Refs: 7980,12564

Dendropanax nutans var. obtusifolius

Araliaceae

LR/nt

Jamaica

This variety occurs in montane forest at higher altitudes, above $1700 \mathrm{~m}$, in the Blue Mountains and John Crow Mountains.

Assessor: World Conservation Monitoring Centre Refs: $7980,12564,17743$

\section{Dendropanax ovalifolius}

Araliaceae

$\mathrm{VU} B 1+2 c$

Jamaica

Recorded from the parishes of St Elizabeth and St James, populations occur locally in woodlands on limestone, between 400 and $610 \mathrm{~m}$.

Assessor: Kelly, D.L.

Refs: $401,5653,7980,17743,19085$

\section{Dendropanax pendulus}

Araliaceae

LR/nt

Jamaica

A species which occurs as a shrub or small tree, mostly on ridge crests, especially the Grand Ridge in the Blue Mountains. It is locally common below $1850 \mathrm{~m}$. Assessor: World Conservation Monitoring Centre Refs: 7980,12564

\section{Dendropanax portlandianus}

Araliaceae

VU $B 1+2 c$

Jamaica

A shrub or small tree which has only been recorded from Portland Parish in localised areas of moist mossy limestone forest between 450 and $600 \mathrm{~m}$.

Assessor: Kelly, D.L.

Refs: 401, 5653, 7980, 19085

\section{Dendropanax sessiliflorus}

Araliaceae

VU C2a

Costa Rica, Panama

A species of rainforest or cloud forest, occurring from low altitude to $2000 \mathrm{~m}$. Its range extends from Costa Rica through Panama to the Kunayala Indigenous Reserve, close to the border with Colombia. In Panama most of the collections originate from Chiriquí. Only a few populations are in protected areas and elsewhere the species is threatened by logging and buming.

Assessor: Mitré, M.

Refs: $7272,7980,16772$ 
Dendropanax swartzii

Araliaceae

DD

Jamaica

A taxon of doubtful validity, recorded from woodlands and thickets in wet areas in the John Crow Mountains.

Assessor: World Conservation Monitoring Centre

Refs: $401,5653,7980$

\section{Dendroseris berteriana}

\section{Compositae}

CR B $1+2 c$

Chile (Juan Fernández Is)

A genus of palm-like pachycaul trees, endemic to Juan Fernández. Most of the species in the genus are now reduced to a few individuals, largely through the effects of grazing by feral animals and spread of introduced weeds. More detailed information on the species should become available to confirm this evaluation. The islands are designated as a national park and biosphere reserve and work is being carried out by *CONAF to save the native plants.

Assessor: World Conservation Monitoring Centre

Refs: $3241,5651,14140$

\section{Dendroseris gigantea}

Compositac

Chile (Juan Fernández Is)

$\mathrm{CR} B 1+2 \mathrm{C}$

A genus of palm-like pachycaul trees, endemic to Juan Fernandez. Most of the species in the genus are now reduced to a few individuals, largely through the effects of grazing by feral animals and spread of introduced weeds. More detailed information on the species should become available to confirm this evaluation. The islands are designated as a national park and biosphere reserve and work is being carried out by *CONAF to save the native plants.

Assessor: World Conservation Monitoring Centre Refs: $3241,5651,14140$

\section{Dendroseris litoralis}

\section{Compositae}

$\mathrm{CR} \mathrm{Bl}+2 \mathrm{C}$

Chile (Juan Fernández Is)

A genus of palm-like pachycaul trees, endemic to Juan Fernández. Most of the species in the genus are now reduced to a few individuals, largely through the effects of grazing by feral animals and spread of introduced weeds. This species has been successfully cultivated and thrives in some places where it has been planted. More detailed information on the species should become available to confirm this evaluation. The islands are designated as a national park and biosphere reserve and work is being carried out by *CONAF to save the native plants.

Assessor: World Conservation Monitoring Centre

Refs: $3241,5651,7980,14140$

\section{Dendroseris macrantha}

\section{Compositae}

CR B $1+2 \mathrm{c}$

Chile (Juan Fernández Is)

A genus of palm-like pachycaul trees, endemic to Juan Femández. Most of the species in the genus are now reduced to a few individuals, largely through the effects of grazing by feral animals and spread of introduced weeds. More detailed information on the species should become available to confirm this evaluation. The islands are designated as a national park and biosphere reserve and work is being carried out by *CONAF to save the native plants.

Assessor: World Conservation Monitoring Centre

Refs: $3241,5651,14140$

\section{Dendroseris macrophylla}

Compositae

Chile (Juan Femández Is)

CR BI+2C

A genus of palm-like pachycaul trees, endemic to Juan Fernandez. Most of the species in the genus are now reduced to a few individuals, largely through the effects of grazing by feral animals and spread of introduced weeds. More detailed information on the species should become available to confirm this evaluation. The islands are designated as a national park and biosphere reserve and work is being carried out by *CONAF to save the native plants.

Assessor: World Conservation Monitoring Centre

Refs: $3241,5651,14140$

\section{Dendroseris marginata}

Compositae

$\mathrm{CR} B 1+2 \mathrm{C}$

Chile (Juan Fernández Is)

A genus of palm-like pachycaul trees, endemic to Juan Fernández. Most of the species in the genus are now reduced to a few individuals, largely through the effects of grazing by feral animals and spread of introduced weeds. More detailed information on the species should become available to confirm this evaluation. The islands are designated as a national park and biosphere reserve and work is being carried out by ${ }^{*}$ CONAF to save the native plants.

Assessor: World Conservation Monitoring Centre

Refs: $3241,5651,14140$

\section{Dendroseris micrantha}

Compositae

Chile (Juan Fernández Is)

CR B $1+2 \mathrm{c}$

A genus of palm-like pachycaul trees, endemic to Juan Femández. Most of the species in the genus are now reduced to a few individuals, largely through the effects of grazing by feral animals and spread of introduced weeds. More detailed information on the species should become available to confirm this evaluation. The islands are designated as a national park and biosphere reserve and work is being carried out by ${ }^{*}$ CONAF to save the native plants.

Assessor: World Conservation Monitoring Centre

Refs: 3241,5651

\section{Dendroseris neriifolia}

Compositae

$\mathrm{CR} B 1+2 \mathrm{C}$

Chile (Juan Fernández Is)

A genus of palm-like pachycaul trees, endemic to Juan Fernandez. Most of the species in the genus are now reduced to a few individuals, largely through the effects of grazing by feral animals and spread of introduced weeds. More detailed information on the species should become available to confirm this evaluation. The islands are designated as a national park and biosphere reserve and work is being carried out by *CONAF to save the native plants.

Assessor: World Conservation Monitoring Centre

Refs: $3241,5651,7980,14140$

\section{Dendroseris pinnata}

\section{Compositae}

Chile (Juan Fernández Is)

CR B $1+2 c$

A genus of palm-like pachycaul trees, endemic to Juan Fernández. Most of the species in the genus are now reduced to a few individuals, largely through the effects of grazing by feral animals and spread of introduced weeds. More detailed information on the species should become available to confirm this evaluation. The islands 
are designated as a national park and biosphere reserve and work is being carried out by * CONAF to save the native plants.

Assessor: World Conservation Monitoring Centre

Refs: $3241,5651,14140$

\section{Dendroseris pruinata}

Compositae

CR B $1+2 \mathrm{c}$

Chile (Juan Fernández Is)

A genus of palm-like pachycaul trees, endemic to Juan Fernández. Most of the species in the genus are now reduced to a few individuals, largely through the effects of grazing by feral animals and spread of introduced weeds. More detailed information on the species should become available to confirm this evaluation. The islands are designated as a national park and biosphere reserve and work is being carried out by ${ }^{*}$ CONAF to save the native plants.

Assessor: World Conservation Monitoring Centre

Refs: $3241,5651,14140$

\section{Dendroseris regia}

Compositae

CR B $1+2 \mathrm{c}$

Chile (Juan Fernández Is)

A genus of palm-like pachycaul trees, endemic to Juan Femández. Most of the species in the genus are now reduced to a few individuals, largely through the effects of grazing by feral animals and spread of introduced weeds. More detailed information on the species should become available to confirm this evaluation. The islands are designated as a national park and biosphere reserve and work is being carried out by *CONAF to save the native plants.

Assessor: World Conservation Monitoring Centre

Refs: $3241,5651,14140$

\section{Dendrosicyos socotrana}

Cucurbitaceae

VU A2d

Yemen (Socotra)

One of the very few species in Cucurbitaceae to grow to the stature of a tree, it is also notable for its characteristic swollen trunk. Trees are fairly common on the coastal plains and foothills, mainly on limestone but also in granite areas. The whole plant is cut and pulped for livestock fodder. Although current levels of use are sustainable, there is a potential risk of increasing livestock numbers placing populations under severe pressure.

Assessor: Miller, A.G.

Refs: 2354, 19083

\section{Dennettia tripetala}

Annonaceae

VU Alc, Bl+2c

Ghana, Nigeria

A small tree found in dry forest in Upper Guinea. Its habitat is most vulnerable to agricultural expansion and the effects of high population growth and fires.

Assessor: Hawthorne, W.

Refs: 8369, 11504, 12061

\section{Desmopsis dolichopetala}

Annonaceae

CR C2a

Honduras

Assessor: Nelson, C.

Refs: 13995
Desmostachys vogelii

Icacinaceae

Cameroon, Ghana, Nigeria

VU Alc, Bl+2c

A wet evergreen forest tree ranging from Ghana to Cameroon. The species habitat has declined because of mining and logging activities and the establishment of commercial plantations.

Assessor: Hawthome, W.

Refs: 2773, 12061

\section{Deutzianthus tonkienensis}

Euphorbiaceae

China (Guangxi, Yunnan), Viet Nam

$\mathrm{LR} / \mathrm{nt}$

A species which occurs sparsely in the lower storey of primary or slightly disturbed forest. Its distribution in China is restricted to a small area of south-east Yunnan and south-west Guangxi. In Viet Nam populations are found in a number of northem provinces. Indiscriminate cutting and degradation of the habitat has caused declines in the mature population. It is the only species in the genus.

Assessor: World Conservation Monitoring Centre

Refs: $1818,10013,11847,15357,19055$

\section{Dialium bipindense}

Leguminosae

LR/nt

Cameroon, Gabon

A large canopy timber tree found in abundance in lowland rainforest in Kribi, Ebolowa and Bipindi in Cameroon and Ogoue and Njole in Gabon. The rates of harvesting of the timber are a primary concern throughout its range. Agricultural encroachment upon the habitat is also common.

Assessor: World Conservation Monitoring Centre

Refs: $12509,12597,15251,15790$

\section{Dialium cochinchinense}

Leguminosae

LR/nt

Cambodia, Laos, Malaysia (Peninsular Malaysia), Myanmar, Thailand, Viet Nam

A large deciduous tree, highly valued for the timber. Occurring in various forest types throughout Indo-China south into Peninsular Thailand and Malaysia, the species is becoming rarer in many places because of overexploitation. In Viet Nam, it is listed as threatened. A protected population occurs in Kon Cha Rang Nature Reserve.

Assessor: World Conservation Monitoring Centre Refs: $848,11530,14573,15357$

\section{Dialium excelsum}

Leguminosae

$\mathrm{EN} B 1+2 \mathrm{c}$

Democratic Republic of Congo, Uganda

The species occurs in Ituri forest in DR Congo, where the species is fairly common but scattered. Elsewhere it is found uncommonly in small populations in a few localities in Uganda. General threats of mining, overcutting for charcoal production and expansive agriculture affect unprotected parts of the range.

Assessor: *MUIENR

Refs: $7550,9605,9837,14667$

\section{Dialium holtzii \\ Leguminosae}

Kenya, Mozambique, Tanzania

VU Bl+2b

A moist forest species which can occur in wetter or riverine areas of dry forests. It is found in remaining forest patches in east and south-east Tanzania into Mozambique. It has also been collected further north in 
limestone areas at Buda, Gongoni and Pangani in Kenya. Assessor: Lovett, J. \& G.P. Clarke

Refs: $3356,6396,10961$

\section{Dialium lopense}

Leguminosae

$\mathrm{LR} / \mathrm{nt}$

Gabon

An endemic species to Lopé Forest Reserve, extending about $100 \mathrm{~km}$ outside the reserve's boundaries. Part of the range is under concession to logging companies and there is concern over future plans for intensive logging. Assessor: World Conservation Monitoring Centre Refs: 14958, 15790

\section{Dialium orientale}

Leguminosae

LR/nt

Kenya, Somalia, Tanzania

This species ranges along the coast in semi-evergreen forest or bushland from north-east Tanzania, through Kenya into southem Somalia. The fruits are edible and the wood is used to make dhow ribs. Much of the habitat is threatened with overcutting and clearing.

Assessor: Lovett, J. \& G.P. Clarke

Refs: $2361,3356,3925,7550,18665$

\section{Dialium travancoricum}

Leguminosae

$\mathrm{CR} \mathrm{Bl}+2 \mathrm{c}$

India (Kerala)

A large tree of lowland forest, endemic to a small area in the Travancore range, occurring at Ponmudi and Ariankavu. It appears to have become extremely scarce. No collections have been made in the last 100 years. Only small remnants of forest now exist within its former range.

Assessor: World Conservation Monitoring Centre

Refs: 4799, 19144

\section{Dicellostyles axillaris}

Malvaceae

Sri Lanka

CR D1

An extremely rare lowland tree. No records were made during the recent forest surveys by the National Conservation Review, but there is a possibility that a population is located in the dry zone, which was not extensively surveyed. The only cultivated specimen, located in the Peradeniya Botanical Garden, died in 1992.

Assessor: World Conservation Monitoring Centre

Refs: $8203,12129,18796$

\section{Dichapetalum bocageanum}

Dichapetalaceae

Sāo Tomé \& Principe (Sāo Tomé)

VU D2

Little is known about the species. It has been collected twice. Large areas of the island remain to be explored, although most of the forest below $1500 \mathrm{~m}$ was felled in the first half of the century.

Assessor: World Conservation Monitoring Centre Refs: 2724

\section{Dichapetalum costaricense}

Dichapetalaceae

VU D2

Costa Rica, Nicaragua

A newly described species occurring in cloud forest in the Monteverde and Heredia Biological Reserve in Costa Rica and from areas along Río San Juan near Caño Chontaleño in Nicaragua.

Assessor: World Conservation Monitoring Centre

Refs: 13112
Dichilanthe zeylanica

Rubiaceae

EN B $1+2 \mathrm{c}$

Sri Lanka

A tree confined to the lowland wet evergreen forests of south-west Sri Lanka. This species was recorded from only five forest localities during the extensive National Conservation Review forest surveys conducted between 1991 and 1996.

Assessor: World Conservation Monitoring Centre

Refs: 8203, 17195, 19112

\section{Dichrostachys dehiscens}

Leguminosae

Yemen (Socotra)

VU D2

A fairly common small tree or shrub, occurring in submontane woodland. Leaves provide good livestock fodder, and trees are frequently damaged to obtain them. Although under no current threat, there is a potential for livestock numbers to increase and put the species at greater risk.

Assessor: Miller, A.G.

Refs: 19083

\section{Dichrostachys kirkii}

Leguminosae

LR/nt

Ethiopia, Somalia

A variable species known from central and southern Somalia extending to the eastern Ogaden in Ethiopia, where it occurs in dry deciduous bushland. In places the habitat is suffering from degradation caused by overcutting for charcoal production and by expanding agricultural activities.

Assessor: Thulin, $\mathbf{M}$.

Refs: 1330,18665

\section{Dicraeopetalum capuroniana}

Leguminosae

VU B $1+2 a b c$

Madagascar

Recorded from only a few scattered localities in a restricted area of southern Madagascar, this deciduous tree occurs on sand near the coast. Its range is estimated to be $16,000 \mathrm{~km}^{2}\left({ }^{*} \mathrm{EOO}\right)$ in areas that are subjected to continuing degradation. It is selectively felled for timber, with little or no conservation measures in existence.

Assessor: Du Puy, D. \& H. Labat

Refs: 12353

\section{Dicraeopetalum mahafaliensis}

Leguminosae

VU B1+2abc

Madagascar

A xerophytic species restricted to the limestone Mahafaly Plateau of southern Madagascar, covering an estimated $18,000 \mathrm{~km}^{2}\left({ }^{*} \mathrm{EOO}\right)$. The area is already fragmented and grazed and is continuing to be cleared. A small area is protected beside Lake Tsimanampetsotsa.

Assessor: Du Puy, D. \& H. Labat

Refs: 12353

\section{Dicraeopetalum stipulare}

Leguminosae

VU A2cd

Ethiopia, Kenya, Somalia

There are reports of many trees in the Somalian population, but they are threatened by overcollection for charcoal production and also by habitat degradation. The species is also known from a single record in the eastern Ogaden and one in an area of bushland on limestone 
north-east of Wajir in Kenya. It is the only species in the genus.

Assessor: World Conservation Monitoring Centre

Refs: 1308, 1330, 6396, 13072, 18665

Dictyosperma album var. album

Palmae

CR D1

Mauritius

A palm tree of submontane forest known only from Florin Reserve in south-west Mauritius. Less than 10 mature individuals remain and there are no authenticated reports of natural regeneration. The trees are protected in a managed, weeded and fenced reserve. Seed production is monitored.

Assessor: Page, W.

Refs: 19118

\section{Dictyosperma album var. conjugatum}

Palmae

CR D1

Mauritius

Restricted to lile Ronde off the north-east coast of Mauritius, this palm tree has been reduced to a single wild individual. Two trees survived until 1994, when a cyclone killed one of them. Seeds were obtained from the tree before it died and 25 offspring were raised. These individuals have been introduced to a $25 \mathrm{ha}$ island reserve called Ile aux Aigrettes. The remaining wild tree produced seeds for the first time in December 1996.

Assessor: Page, W.

Refs: 19118

\section{Dicypellium caryophyllaceum}

Lauraceae

VU Alcd

Brazil (Amazonas, Maranháo, Pará)

Most recent collections have come from non-flooded forest in Tapajós in Pará. In the past, the species was known from Maranhâo further north. Intense exploitation of the bark to make essential oils has caused the species to become rare; there is $95.5 \%$ eugenol contained in the oil. The epithet is commonly spelled caryophyllatum.

Assessor: Pedralli, G

Refs: $7144,7145,15539,16123,19142$

\section{Didelotia idae}

Leguminosae

LR/nt

Benin, Cameroon, Côte d'Ivoire, Ghana, Liberia, Nigeria, Sierra Leone, Togo

This species ranges from Sierra Leone to Cameroon but it is confined to wet evergreen and swampy forest. It occurs commonly in parts of its range but the effects of mining, logging and commercial forestry activities have caused significant losses in the extent of its occurrence. Assessor: World Conservation Monitoring Centre Refs: $7550,8369,12061$

\section{Didelotia unifoliolata}

Leguminosae LR/nt Cameroon, Côte d'Ivoire?, Democratic Republic of Congo, Gabon, Ghana, Liberia?, Sierra Leone?

A relatively wide-ranging species, occurring from $D R$ Congo to Ghana and possibly further west. It is confined and scarce in wet evergreen forest, which has experienced general declines in its extent because of mining, logging and commercial forestry activities.

Assessor: World Conservation Monitoring Centre

Refs: 2773, 5595, 8369, 12061, 12597, 19092
Dillenia ferruginea

Dilleniaceae

VU D2

Seychelles

Endemic to the Seychelles, the species qualifies as threatened by virtue of its restricted distribution. Populations are healthy and stable.

Assessor: World Conservation Monitoring Centre

Refs: 9859,17229

\section{Dillenia fischeri}

Dilleniaceae

VUAlcd

Philippines

A timber species, endemic to the Philippines. Rates of habitat loss through logging and shifting cultivation have led to considerable population declines.

Assessor: World Conservation Monitoring Centre

Refs: $4919,5651,12937$

\section{Dillenia luzoniensis}

Dilleniaceae

VUAlcd

Philippines

A timber species, endemic to the Philippines. Rates of habitat loss through logging and shifting cultivation have led to considerable population declines.

Assessor: World Conservation Monitoring Centre

Refs: $2072,4919,5651$

\section{Dillenia megalantha}

Dilleniaceae

VUAld

Philippines

A timber species of primary lowland forest.

Assessor: World Conservation Monitoring Centre

Refs: $4919,11145,12937$

\section{Dillenia philippinensis}

Dilleniaceae

VU Ald

Philippines

An evergreen tree which occurs in primary and secondary forests throughout the Philippines. It provides a useful timber and the fruits are edible and also have a medicinal value.

Assessor: World Conservation Monitoring Centre

Refs: $4919,11145,12937$

\section{Dillenia reifferscheidtia}

Dilleniaceae

VU Ald

Philippines

A species of primary and secondary lowland forests. It is exploited for its timber and edible fruits.

Assessor: World Conservation Monitoring Centre

Refs: $4919,11145,12937$

\section{Dillenia triquetra}

Dilleniaceae

CR B $1+2$ cd

Sri Lanka

A tree restricted to the lowland rainforests of south-west Sri Lanka. This species was scattered but fairly widespread in the lowland rainforests according to a survey in the late 1980 s, but it was not recorded at any of the forest sites during the extensive National Conservation Review forest surveys conducted between 1991 and 1996, suggesting that this species is either extremely rare or possibly extinct.

Assessor: World Conservation Monitoring Centre Refs: 17195,19112 
Dimocapus longan

Sapindaceae

LR/nt

China (Guangdong - Hainan)

One of the common and important components of lowelevation monsoon forests in the south-west of Hainan Island. Large-scale logging has taken out a considerable proportion of the population but trees are resprouting where allowed.

Assessor: World Conservation Monitoring Centre

Refs: 1818,11847

\section{Dimorphocalyx beddomei}

Euphorbiaceae

India (Kerala, Tamil Nadu)

$\mathrm{EN} B 1+2 \mathrm{C}$

An understorey tree, recorded only from the Agastymalai range in submontane evergreen forest. Large areas have been exposed to fires, grazing, the establishment of commercial plantations and cutting for fuelwood, but almost $1000 \mathrm{~km}^{2}$ of forest is now under protection within sanctuaries.

Assessor: World Conservation Monitoring Centre

Refs: 19144

\section{Diospyros acuminata}

Ebenaceae

VU Alc

Sri Lanka

A tree scattered in the lowland rainforests of south-west Sri Lanka.

Assessor: World Conservation Monitoring Centre

Refs: 15431,17195

\section{Diospyros acuta}

Ebenaceae

$E N B 1+2 c$

Sri Lanka

A very rare tree restricted the lowland wet evergreen forests of south-west Sri Lanka. This species is known from four localities: Kanneliya, Kottawa, Badullakele and Dediyagala.

Assessor: World Conservation Monitoring Centre

Refs: 15431, 16943, 17195

\section{Diospyros albiflora}

Ebenaceae

VU Alc

Sri Lanka

A tree confined to the lowland rainforests of south-west Sri Lanka.

Assessor: World Conservation Monitoring Centre

Refs: 15431,17195

\section{Diospyros amaniensis}

Ebenaceae

VU B $1+2 b c$

Kenya, Tanzania

A coastal forest species, often a shrub, known from populations in the Shimba Hills in Kenya and in northeast Tanzania. It is closely related to the West African species $D$. gabunensis.

Assessor: Lovett, J. \& G.P. Clarke

Refs: 556, 3356, 6396

\section{Diospyros angulata}

Ebenaceae

CR D1

Mauritius

A species now known from just a single female tree in lowland forest at Magenta. The tree fruited for the first time in five years in 1996 and again in 1997, which suggests there is a male individual in the vicinity. Neither natural regeneration nor ex situ propagation have been successful. The species is believed to have been a popular timber in colonial times.

Assessor: Page, W.

Refs: $1411,9120,16426$

\section{Diospyros atrate}

Ebenaceae

$\mathrm{VUB} 1+2 \mathrm{c}$

India (Kerala, Tamil Nadu), Sri Lanka

In Sri Lanka, a recent survey identified a total of three populations, occurring in wet evergreen forests in Ratnapura and Kalutara Districts. In India populations are restricted to submontane forest at the southernmost end of the Western Ghats, including the Agastyamalai Hills, where forest has declined in extent but is now protected within sanctuaries.

Assessor: World Conservation Monitoring Centre Refs: 12129, 15431, 18796, 19112, 19144

\section{Diospyros attenuata}

Ebenaceae

$\mathrm{EN} \mathrm{Bl}+2 \mathrm{c}$

Sri Lanka

This tree was found to occur in only three forest reserves during the extensive National Conservation Review forest surveys.

Assessor: World Conservation Monitoring Centre Refs: $15431,18796,19112$

\section{Diospyros barberi}

Ebenaceae

India (Kerala, Tamil Nadu)

VU BI $+2 \mathrm{c}$

One of the trees endemic to the Agastyamalai Hills. Large parts of the forest here have been affected by fires, grazing, the incursion of commercial plantations and cutting for fuelwood. However, almost $1000 \mathrm{~km}^{2}$ of forest are relatively well protected within sanctuaries. Assessor: World Conservation Monitoring Centre Refs: 5651, 19144

\section{Diospyros barteri}

Ebenaceae

VUAlc

Cameroon, Ghana, Nigeria

A species which can be found in a variety of moist forest formations in populations on either side of the Dahomey Gap. General forest loss has been high in all three countries where it is found because of logging, mining, oil exploration and commercial forestry activities.

Assessor: Hawthome, W.

Refs: 6197, 11504, 12061

\section{Diospyros benstonei}

Ebenaceae

CR C2b

Papua New Guinea

Apparently confined to Misima Island in Milne Bay Province, this small rare tree occurs in streamside rainforest in a gorge. The population is threatened by mining and cutting for local use.

Assessor: Eddowes, P.J.

Refs: 19114,19147

\section{Diospyros blancoi}

Ebenaceae

VU Aled

Philippines

A timber species, endemic to the Philippines. Rates of habitat loss through logging and shifting cultivation have led to considerable population declines. Assessor: World Conservation Monitoring Centre Refs: 5651, 10938 


\section{Diospyros blumutensis}

Ebenaceae

VU D2

Malaysia (Peninsular Malaysia)

A tree known from a single collection taken from hill forest on Gunung Belumut, Johore. The area is classified as a protected forest.

Assessor: World Conservation Monitoring Centre Refs: 19073

\section{Diospyros boutoniana}

Ebenaceae

VU B I $+2 \mathrm{c}$

Mauritius

A relatively common species of upland and mid elevation forest in the south-west and occasionally in the east and northem ranges. The spread of invasive species and habitat degradation are causing considerable concern. The species responds poorly to disturbance and appears to be regenerating insufficiently.

Assessor: Page, W.

Refs: $1411,9120,16426$

\section{Diospyros capricornuta}

Ebenaceae

DD

Tanzania

Assessor: Lovett, J. \& G.P. Clarke

Refs: 556,3356

\section{Diospyros celebica}

Ebenaceae

VU Alcd

Indonesia (Sulawesi)

Occuming in lowland rainforest, the species is found only in central and northem Sulawesi. It has been heavily exploited for its fine streaked ebony timber which is used for carving, inlay, fumiture and musical instruments. The number of mature trees has declined and large parts of the habitat have been converted to crops. Felling of the species is now only allowed by quota but continues illegally.

Assessor: World Conservation Monitoring Centre

Refs: 4329, 11145, 12937, 19048, 19065

\section{Diospyros chaetocarpa}

Ebenaceae

VU Alc, Bl+2c

\section{Sri Lanka}

A rare tree endemic to the lowland wet evergreen forests of south-west Sri Lanka. In the extensive surveys conducted for the National Conservation Review, this species was discovered in six localities in Galle and Kalutara Districts.

Assessor: World Conservation Monitoring Centre

Refs: $15431,17195,19112$

\section{Diospyros chrysophyllos}

\section{Ebenaceae}

$\mathrm{EN} \mathrm{B} 1+2 \mathrm{c}, \mathrm{C} 2 \mathrm{a}$

Mauritius

A small tree found extremely rarely in lowland to intermediate evergreen forest in the south-west, east and northern mountain ranges. The largest populations occur at Bel Ombre and at Femey, Mount Creole. Natural regeneration is rarely observed and there are significant pressures caused by the spread of invasive species and habitat degradation.

Assessor: Page, W.

Refs: $1411,9120,16426$

\section{Diospyros conformis}

Ebenaceae

VU B $1+2 c$

Malaysia (Peninsular Malaysia)

Known only from a single collection, this tree of lowland forest was collected from Lenggong, Perak. It is hoped that the species will be found in Piah Forest Reserve.

Assessor: Chua, L.S.L.

Refs: 19073,19182

\section{Diospyros crassiflora}

Ebenaceae

EN Ald

Cameroon, Central African Republic, Congo, Democratic Republic of Congo, Gabon, Nigeria

Virtually all large trees of this lowland rainforest species have been felled for the ebony wood, except perhaps in the most remote parts of its range.

Assessor: African Regional Workshop

Refs: $2362,2773,6718,17408$

\section{Diospyros crumenata}

Ebenaceae

$\mathrm{EN} \mathrm{B1}+2 \mathrm{c}$

Sri Lanka

This species was discovered in only two forest localities during the extensive surveys conducted for the National Conservation Review.

Assessor: World Conservation Monitoring Centre Refs: 15431,19112

\section{Diospyros daemona}

Ebenaceae

VU D2

Malaysia (Peninsular Malaysia)

A lowland forest tree, known from four collections from northern Peninsular Malaysia. Populations may be conserved in the permanent forest reserves of Kedah, Kelantan and north Pahang.

Assessor: World Conservation Monitoring Centre Refs: 19073

\section{Diospyros ebenoides}

Ebenaceae

EN B1+2c

Sri Lanka

In the extensive surveys conducted for the National Conservation Review, this tree was found in only three forest localities in Kandy and Ratnapura Districts. Assessor: World Conservation Monitoring Centre Refs: $15431,17759,19112$

\section{Diospyros ebenum}

Ebenaceae

DD

India, Sri Lanka

An understorey tree of dry evergreen forests. Since ancient times the species has been renowned for its black wood and it is still regarded as the best commercial black ebony. Both India and Sri Lanka have banned the export of this species.

Assessor: Asian Regional Workshop

Refs: $11145,15431,16031$

\section{Diospyros egrettarum}

Ebenaceae

CR B $1+2 \mathrm{c}$

Mauritius

Once a dominant coastal ebony, the species is now reduced to fewer than 10 individuals on the mainland and a larger viable population on lle aux Aigrettes, a coral island off the east coast. It was heavily harvested in the past for timber and firewood. The trees on lle aux Aigrettes are now benefiting from a number of protective measures, such as the eradication of exotic plants and rats.

Assessor: Page, W.

Refs: $1411,2000,9120,16426$ 


\section{Diospyros elegantissima}

Ebenaceae

LR/cd

Malaysia (Peninsular Malaysia)

A rare tree of Perak and Pahang found in lowland and hill forest up to $700 \mathrm{~m}$. The habitat is threatened by agricultural expansion and other developments, but it is possible the species is conserved within the permanent forest reserves.

Assessor: Kochummen, K.M.

Refs: 19073

\section{Diospyros fastidiosa}

Ebenaceae

VU D2

New Caledonia

Apparently only collected once in 1972 on the eastern slopes of Mont Aoupinie in an area of humid forest at $600 \mathrm{~m}$ occurring on an unusual and highly restricted substrate.

Assessor: Jaffre, T. et al.

Refs: 10351,12630

\section{Diospyros feliciana}

Ebenaceae

VU B $1+2 c$

Guinea

Endemic to Guinea, the species is confined to remaining areas of upland forest.

Assessor: World Conservation Monitoring Centre

Refs: 10090

\section{Diospyros gambleana}

\section{Ebenaceae}

VU D2

Malaysia (Peninsular Malaysia)

A rare species, confined to hill forest in the Keledang range, in the state of Perak. Only two collections are known, both of them from the same locality. The forest in the region is classified as protected.

Assessor: World Conservation Monitoring Centre

Refs: 19073

\section{Diospyros gillisonii}

Ebenaceae

Papua New Guinea

EN Alcd $+2 c d, C 2 a$

A tree scattered throughout the small coral islands in the Kiriwina (Trobriand) Group and the Louisiade Archipelago, where it occurs in beach scrub on coral limestone at sea level. It is heavily exploited by the local people for its black heartwood, which is used in carvings, native hair combs and ceremonial pieces. Very few mature trees, if any, remain.

Assessor: Eddowes, P.J.

Refs: 19114

\section{Diospyros greenwayi}

Ebenaceae

VU B $1+2 c$

Kenya, Somalia, Tanzania

A shrub or tree confined to remaining patches of forest. Occurrences in Kenya are recorded from the Shimba Hills, Buda and Witu. It is known from a number of forest reserves in Tanzania and is apparently newly found in Somalia in the Jubbada Hoose region. The demand for agricultural land exerts heavy pressure throughout the range.

Assessor: Lovett, J. \& G.P. Clarke

Refs: $556,2361,3356,6396$

\section{Diospyros hemiteles}

Ebenaceae

CR C2a, D1

Mauritius

A species, probably a timber in the distant past, now confined to a few sites of lowland evergreen forest in the south-west and also recently recorded on the east coast at Mont Brisée. The total population is estimated to be less than 60 , although only 42 trees are known at present. No regeneration is apparent. There are plans to plant trees from cultivation into managed reserves.

Assessor: Page, W.

Refs: $1411,4506,9120,16426$

\section{Diospyros hirsuta}

Ebenaceae

VUAlc

Sri Lanka

Endemic to Sri Lanka, this species is scattered in the lowland wet evergreen forests.

Assessor: World Conservation Monitoring Centre

Refs: 15431, 17195

\section{Diospyros impolita}

Ebenaceae

VU B $1+2 c$

New Caledonia

Confined to sclerophyllous forest, the species occurs in a few locations on the west coast. The habitat is fragmented and much reduced in extent, largely because of agricultural activities, grazing and fires.

Assessor: Jaffré, T. et al.

Refs: $4492,10351,12630$

\section{Diospyros insidiosa}

Ebenaceae

VU B1+2c

Malaysia (Peninsular Malaysia)

A lowland forest tree confined to Pulau Tioman. Only two collections have been made. The island is being developed into a resort and the chances of the conserving the species are remote.

Assessor: Kochummen, K.M.

Refs: 19073

\section{Diospyros insularis}

Ebenaceae

EN A $1 \mathrm{~cd}+2 \mathrm{~cd}, \mathrm{~B} 1+2 \mathrm{c}$

Papua New Guinea (Bismarck Archipelago, North Solomons), Solomon Islands (South Solomon)

A tree of primary lowland rainforest found in only a few localities in the Solomon Islands and New Ireland of the Bismarck Archipelago. Overexploitation and logging have resulted in the species becoming highly endangered, possibly critically endangered.

Assessor: Eddowes, P.J.

Refs: 19114

\section{Diospyros johorensis}

Ebenaceae

Malaysia (Peninsular Malaysia)

VU D2

Known only from a single collection, this lowland forest tree occurs in Gunong Panti Forest Reserve, which is now considered a conservation area by the Johore Forest Department.

Assessor: World Conservation Monitoring Centre Refs: 19073

\section{Diospyros katendei}

Ebenaceae

CR B $1+2 c e, C 2 b, D 1$

Uganda

At present the species is known from a single population of about 20 trees in upland evergreen rainforest in central Kasyoha-Kitomi. The area is designated as a forest reserve and timber is being extracted.

Assessor: Katende, A.B.

Refs: 5525, 5654 


\section{Diospyros kingỉ}

Ebenaceae

VU D2

Malaysia (Peninsular Malaysia)

A species confined to hill forest in Perak, where it has been collected three times. It is thought that the species receives a degree of protection within permanent forest reserves.

Assessor: World Conservation Monitoring Centre Refs: 19073

\section{Diospyros kotoensis}

Ebenaceae

EN A1 ad, B $1+2 a b, C 2 a$

Taiwan

An endemic to Lanyu Island off the south-east coast of Tawan. It occurs in lowland broadleaved forest and has attracted considerable attention as an ornamental tree. The populations are unprotected and under some threat from encroaching settlements and agriculture.

Assessor: Pan, F.J.

Refs: 3295,19050

\section{Diospyros leucomelas}

Ebenaceae

VU B1+2ce

Mauritius

A relatively common species in lowland forests in the south-west and occasionally found in the eastern mountain ranges. Natural regeneration is poor and appears to be hampered by the spread of exotic plants and predation of the seeds by monkeys.

Assessor: Page, W.

Refs: $1411,9120,16426$

\section{Diospyros littorea}

Ebenaceae

VU B $1+2 \mathrm{c}$

Papua New Guinea

This tree is endemic to Motupore Island, where it is found in scrub vegetation. It was not found in the 1990 expedition to Motupore Island. It is a segregate species of the widespread $D$. ferrea.

Assessor: World Conservation Monitoring Centre

Refs: 19140

\section{Diospyros lolinopsis}

Ebenaceae

$\mathrm{CR} \mathrm{B} 1+2 \mathrm{c}, \mathrm{C} 2 \mathrm{~b}$

Papua New Guinea

The only recorded occurrence of this tree is located in open hillside forest at Usino near the Bigei River in Madang Province. The population may no longer exist. Assessor: Eddowes, P.J.

Refs: 19114

\section{Diospyros macrocarpa}

Ebenaceae

$\mathrm{LR} / \mathrm{cd}$

New Caledonia

Relatively widespread on the Grand Terre and also occurring on lle des Pins, the species has been found in diverse habitats including humid forest and degraded maquis on ultramafic or schist substrates.

Assessor: Jaffré, T. et al.

Refs: 10351,12630

\section{Diospyros magogoana}

Ebenaceae

$\mathrm{EN} \mathrm{Bl}+2 \mathrm{bc}$

Tanzania

The range of the species now appears to be confined to undisturbed areas within the Rondo Forest Reserve $\left(140 \mathrm{~km}^{2}\right)$. Activities in the past resulting from logging and planting commercial timbers, shifting cultivation and wood collection have caused extensive damage to the forest. Forest management operations are now discouraging any illegal encroachment or exploitation. Assessor: Lovett, J. \& G.P. Clarke

Refs: 556, 5654, 16796

\section{Diospyros margaretae}

Ebenaceae

VU D1

New Caledonia

A species known from two small populations. At the type locality in Kouaoua it occurs commonly in the rainforest understory on serpentine soils. In the second location at Petit Koum it occurs with Agathis lanceolata in rainforest on granite.

Assessor: Jaffré, T et al.

Refs: 10351,12630

\section{Diospyros melanida}

Ebenaceae

VU B $1+2 c d e$

Mauritius

A likely timber of past centuries this species is commonly found in dry deciduous lowland forest mostly in the south-west but also on the east coast and eastern mountain ranges. Regeneration appears to be poor because of the invasion of exotic plants and also exotic animals which destroy the seeds. In many places the populations are reduced to scattered individuals or small subpopulations.

Assessor: Page, W.

Refs: $1411,9120,16426$

\section{Diospyros minimifolia}

Ebenaceae

VU B $1+2 c$

New Caledonia

Several scattered localities occur on the west coast confined to sclerophyllous forest. This habitat is fragmented and massively reduced in extent because of the effects of fire, grazing and habitat clearance.

Assessor: Jaffré, T. et al.

Refs: $4492,10351,12630$

\section{Diospyros molissima}

Ebenaceae

CR C2b

Indonesia (Irian Jaya)

Confined to Adi Island in Kaimana District, this tree occurs in rainforest below altitudes of $15 \mathrm{~m}$

Assessor: Eddowes, P.J.

Refs: 19114

\section{Diospyros moonii}

Ebenaceae

CR B $1+2 \mathrm{c}$

Sri Lanka

Apparently restricted to a small conservation forest reserve in Matara District, only a single tree was found in the comprehensive forest surveys for the National Conservation Review.

Assessor: World Conservation Monitoring Centre Refs: 15431, 18796, 19112

\section{Diospyros mun}

Ebenaceae

CR Alcd

Laos, Viet Nam

A small, slow-growing tree endemic to Viet Nam, although there are reports of occurrences in Laos. Stands are found in the northern provinces of $\mathrm{Ha}$ Giang, Tuyen Quang, Lang Son, Hoa Binh, Ha Tinh and Quang Binh, where the species occurs on limestone mountains below $800 \mathrm{~m}$, and in the south in Cam Thinh Dong and Cam Thinh Tay communes. The glossy black timber is highly valued and has been in great demand. Export is now 
banned. Populations in the wild are much reduced, but some are protected in areas, such as Cuc Phuong National Park.

Assessor: Nghia, N.H.

Refs: 848,11530

\section{Diospyros nebulosa}

Ebenaceae

VU D2

New Caledonia

The species appears to be known from just two collections taken from cloud forest on Mont Panié. The area is given some protection as a special botanical reserve.

Assessor: Jaffré, T. et al.

Refs: 10351,12630

\section{Diospyros neraudï}

Ebenaceae

VU B1+2cde

Mauritius

A small tree of moist evergreen submontane forest confined to the south-west and a few localities in the east. Regeneration is observed to be poor, especially in areas to which exotic species have spread.

Assessor: Page, W.

Refs: $1411,9120,16426$

\section{Diospyros nodosa}

Ebenaceae

CR C2a, D1

Mauritius

The population is estimated to be very small, possibly numbering less than 10 individuals. The species occurs in upland moist evergreen forest in the mountains in the south-west and has also recently been found in northern and eastern ranges. Regeneration is rarely apparent and is adversely affected by the spread of exotic invasives, especially in the north. The species has not yet become established in ex situ collections.

Assessor: Page, W.

Refs: $1411,9120,16426$

\section{Diospyros nummularifolia}

Ebenaceae

$\mathrm{EN} \mathrm{Bl}+2 \mathrm{c}$

Sri Lanka

A dry zone tree found in only five forest localities during the extensive forest surveys for the National Conservation Review.

Assessor: World Conservation Monitoring Centre

Refs: 19112

\section{Diospyros oblongifolia}

Ebenaceae

VU Alc

Sri Lanka

A tree found in $\mathbf{1 2}$ forest localities during the National Conservation Review.

Assessor: World Conservation Monitoring Centre

Refs: 15431, 19112

\section{Diospyros occulata}

Ebenaceae

DD

Tanzania

This species is almost indistinguishable from the West African species $D$. troupinii.

Assessor: Lovett, J. \& G.P. Clarke

Refs: 556,3356

\section{Diospyros oppositifolia}

Ebenaceae

$\mathrm{EN} \mathrm{B} 1+2 \mathrm{c}$

Sri Lanka

An uncommon species of lowland rainforest in south- west Sri Lanka. Until recently, it was known only from Hinidumkanda Biosphere Reserve. Single collections were made in both Sinharaja Biosphere Reserve and in Kanneliya Forest Reserve.The forest on the southeastem slopes of Hinidumkanda is threatened by encroaching slash-and-bum cultivation and illegal logging, resulting from increases in human population numbers in the surrounding area.

Assessor: World Conservation Monitoring Centre

Refs: $15431,16916,16943,17195$

\section{Diospyros perplexa}

Ebenaceae

VU BI+2c

New Caledonia

A shrub or small tree confined to five or six localities of sclerophyllous forest in the west of Grand Terre. The habitat is fragmented and massively reduced because of the effects of fire, grazing and agricultural encroachment.

Assessor: Jaffré, T. et al.

Refs: 4492, 10351, 12630

\section{Diospyros philippinensis}

Ebenaceae

Indonesia? (Java?), Malaysia?, Philippines

A timber species occurring in primary lowland forest up to $200 \mathrm{~m}$. In the Philippines exploitation of the ebony has caused the species to become rare; very little lowland forest remains and records of Philippine ebony are often from forest fragments smaller than $50 \mathrm{~km}^{2}$. Despite a ban on log exports which came into force in 1989, there have been reports of an illegal trade.

Assessor: Asian Regional Workshop

Refs: $11145,12888,19066$

\section{Diospyros pterocalyx}

Ebenaceae

VU B $1+2$ cde

Mauritius

An occasional species of upland moist evergreen forest found mainly in the south-west, but also in the eastern and northem ranges. As field surveys are carried out, the species continues to be found in new locations. Regeneration is not good and is hampered, especially in the north, by invasive plants.

Assessor: Page, W.

Refs: $1411,9120,16426$

\section{Diospyros pulgarensis}

Ebenaceae

Philippines

$\mathrm{VUBI}+2 \mathrm{c}$

A species of primary lowland forest in Palawan, ascending to $500 \mathrm{~m}$. The main island is declared a biosphere reserve.

Assessor: World Conservation Monitoring Centre

Refs: 4986, 5651

\section{Diospyros pustulata}

Ebenaceae

VU B1 $+2 \mathrm{c}$

New Caledonia

A species restricted to sclerophyllous forest on the west coast of Grand Terre. The habitat is fragmented and massively reduced in extent because of the effects of fires, grazing and encroaching agriculture. It is a conspicous species and derives its names from blisters on its leaves.

Assessor: Jaffré, T. et al.

Refs: 4492, 10351, 12630 


\section{Diospyros quaesita}

Ebenaceae

VU Alcd

Sri Lanka

Endemic to Sri Lanka, this large tree occurs infrequently in lowland wet evergreen forest and in dry forest. The species is threatened by overexploitation of its valuable variegated timber and by poor regeneration. In addition, the heartwood is used medicinally to heal wounds. It was found at 25 forest sites during the National Conservaton Review forest surveys.

Assessor: World Conservation Monitoring Centre

Refs: $15431,17195,19110,19112$

\section{Diospyros revaughanii}

Ebenaceae

VU B $1+2$ cde

Mauritius

Generally found on exposed ridges and plateaux, the species is relatively common where it occurs in the south-west. less so in the northem ranges. Although the trees fnit regularly and in abundance, regeneration appears to be poor and populations are declining where the habitat is susceptible to degradation.

Assessor: Page, W.

Refs: $1411,9120,16426$

\section{Diospyros rheophytica}

Ebenaceae

$\mathrm{CR} \mathrm{B} 1+2 \mathrm{c}$

Sri Lanka

A tree apparently restricted to a single locality of forest in Ratnapura District. Only two trees were discovered during the extensive fieldwork carried out for the National Conservation Review.

Assessor: World Conservation Monitoring Centre

Refs: 15431, 17759, 19112

\section{Diospyros riojae}

Ebenaceae

$\mathrm{EN} \mathrm{B1}+2 \mathrm{C}$

Mexico (Hidalgo, Tamaulipas, Veracruz)

The largest concentration of the species is confined to cloud forest on steep scarp slopes in the Sierra de Tantima and Plan de las Hayas in Veracruz. There a few individuals existing in Tamaulipas and Hidalgo. The population at the type locality in the Sierra de Chiconquiaco is now extinct and less than 500 individuals are suspected to exist in the two remaining Veracruz localities. The decline has taken place largely because of deforestation and agricultural expansion. There is no evidence of regeneration in one of the localities and attempts at propagation have so far failed. Assessor: World Conservation Monitoring Centre

Refs: 81, 10480, 19206

\section{Diospyros rumphii}

Ebenaceae

Indonesia (Moluccas, Sulawesi)

A lowland forest tree exploited as an important source of black and streaked ebony.

Assessor: Asian Regional Workshop

Refs: 4734,11145

\section{Diospyros selangorensis}

\section{Ebenaceae}

Malaysia (Peninsular Malaysia)

Found in montane forest on Gunong Ulu Semongkok in Selangor, this tree has been collected only once.

Assessor: Kochummen, K.M.

Refs: 19073

\section{Diospyros seychellarum}

Ebenaceae

VU D2

Seychelles

Occurring on Mahé, Praslin, Silhouette and Felicite, this tree or shrub does not have a uniform distribution but exists in numerous small populations in forest on exposed rocky outcrops or in well-drained places. Regeneration appears to be fairly good and some populations are protected in national parks. Branches are frequently cut for the leaves and flowers, which have a medicinal value.

Assessor: World Conservation Monitoring Centre Refs: $9859,16212,17229,19023$

\section{Diospyros shimbaensis}

Ebenaceae

$\mathrm{EN} \mathrm{B1}+2 \mathrm{c}$

Kenya, Tanzania

In Kenya this small tree occurs in moist semi-deciduous forest in the Shimba Hills National Reserve, Gongoni Forest Reserve and Buda Mafisini Forest Reserve. Habitat loss and degradation has caused population declines. More information is needed on the populations in Zaraninge forest in Bagamoyo and in Mrora forest on Mafia Island, Tanzania.

Assessor: CAMP Workshop in Kenya

Refs: $556,3356,5654,6396,19181$

\section{Diospyros tessellaria}

Ebenaceae

VU B $1+2$ cde

Mauritius

Once heavily harvested as a timber, this canopy tree forms a dominant component of lowland evergreen forest and upland rainforest in the south-west and eastern mountain ranges. The habitat is declining and regeneration is poor in areas which are degraded.

Assessor: Page, W.

Refs: $1411,9120,16426$

\section{Diospyros thwaitesii}

\section{Ebenaceae}

VU Alc, Bl+2c

Sri Lanka

A species confined to the lowland wet evergreen forests of south-west Sri Lanka. During the extensive forest surveys conducted for the National Conservation Review, the species was found in six forest localities including the Sinharaja and Haycok Biosphere Reserves. Assessor: World Conservation Monitoring Centre Refs: $15431,17195,19112$

\section{Diospyros trichophylla}

Ebenaceae

VU A1c, B1+2c

India, Sri Lanka

A rare tree, restricted to the lowland wet evergreen forests of south-west Sri Lanka. This species was found in nine localities during the extensive fieldwork carried out for the Sri Lankan National Conservation Review.

Assessor: World Conservation Monitoring Centre Refs: $1065,15431,17195,19112$

\section{Diospyros trisulca}

Ebenaceae

VU D1

New Caledonia

Only a single location is known where the species occurs in dense forest on Mont Mandjelia at $600 \mathrm{~m}$. Of the New Caledonian taxa in the genus, this species is noted for its unique flower form.

Assessor: Jaffré, T. et al.

Refs: $4492,10351,12630$ 


\section{Diospyros vaccinioides}

Ebenaceae CR Al ad+2bd, Bl+2abc, Cl+2ab, D1 China (Guangdong), Hong Kong, Taiwan

A heavily-exploited omamental species. Overcollecting in Taiwan, has led to the complete absence of mature trees in the wild. A population of unproductive individuals, however, is believed to exist on a wooded hillside in Fengkang. Populations are also recorded from Chuhai and Huiyang in China, and Hong Kong.

Assessor: Lu, S.Y. \& F.J. Pan

Refs: $3295,6469,8142,19050,19051$

\section{Diospyros veillonii}

Ebenaceae

CR D1

New Caledonia

A shrub or small tree known from only about 20 plants at Gadji, near Paita. It is confined to sclerophyllous forest, which has been in serious decline because of fire, grazing by cattle and deer and vegetation clearance.

Assessor: Jaffré, T, et al.

Refs: 4492, 10351, 12630

\section{Diospyros wajïrensis}

Ebenaceae

$\mathrm{LR} / \mathrm{nt}$

Kenya, Somalia

Occurring in dry bushland, this small tree is restricted in range from north-eastem Kenya to neighbouring Somalia. It is very common near Wajir and is locally used for making walking sticks. The habitat is threatened with degradation through grazing and overcutting for charcoal production.

Assessor: Thulin, $\mathrm{M}$.

Refs: 6396, 18665

\section{Diospyros walkeri}

Ebenaceae

VU Alc

Sri Lanka

A tree confined to the lowland rainforests of south-west Sri Lanka. This species was discovered in $\mathbf{2 0}$ localities during the extensive National Conservation Review forest surveys.

Assessor: World Conservation Monitoring Centre

Refs: $15431,17195,19112$

\section{Diphasiopsis fadenï}

Rutaceae

VU $B 1+2 c$

Kenya

A rarely collected species of moist forest or thickets on rocky hills. Populations are recorded from Chyulu, Mbololo, Kasigau, near Murka and Ngulia. There are only two species in the genus.

Assessor: World Conservation Monitoring Centre

Refs: 1308, 6396

\section{Diplodiscus hookerianus}

Tiliaceae

$\mathrm{EN} \mathrm{Bl}+2 \mathrm{c}$

Malaysia (Peninsular Malaysia)

A very rare tree known only from a single herbarium specimen which was collected in lowland rainforest on the bank of the Kinta River, Perak.

Assessor: Chung, R.C.K.

Refs: 17140,19073

\section{Diplodiscus paniculatus}

Tiliaceae

VU Alcd

Philippines

A timber species, endemic to the Philippines. Rates of habitat loss through logging and shifting cultivation have led to considerable population declines.

Assessor: World Conservation Monitoring Centre

Refs: 2072, 4919

\section{Diplodiscus scortechinï}

Tiliaceae

LR/cd

Brunei, Malaysia (Peninsular Malaysia, Sarawak)

A lowland forest tree known only from Keledang Saiong Forest Reserve in Perak, Peninsular Malaysia, Lambill Hill, Sarawak and the Andulau Forest Reserve, Brunei. Assessor: Chung, R.C.K.

Refs: 8464,19073

\section{Diplokeleba herzogi}

Sapindaceae

VU B $1+2 \mathrm{ac}$

Bolivia

Endemic to the piedmont forest in Bolivia, the species is confined to an unprotected ecosystem which is being rapidly replaced by agricultural systems.

Assessor: Prado, D.

Refs: 19122

\section{Diplopanax stachyanthus}

Comaceae VUAlc China (Guangdong, Guangxi, Guizhou, Hunan, Yunnan), Viet Nam

A small tree, widespread in submontane broadleaved forest on limestone mountains in southern China and in several localities in secondary forest in northern Viet Nam. In China, declines in population numbers have been recorded in the last decade, caused largely by habitat destruction. Traditional medicine may be harvested from the bark, otherwise the tree is only cut for fuelwood. The genus is monospecific.

Assessor: Sun, W.

Refs: $1818,11847,15357,19055$

\section{Diplycosia pilosa}

Ericaceae

VU B $1+2 c$

Indonesia (Java)

From Banten to Preanger the species is locally common in montane forest remnants between 1200 and $2200 \mathrm{~m}$. Its high-altitude distribution avoids the worst levels of habitat clearance and cutting but the species habitat is nevertheless under severe pressure.

Assessor: World Conservation Monitoring Centre

\section{Dipterocarpus alatus}

Dipterocarpaceae

EN Alcd $+2 c d, B 1+2 c$

Bangladesh, Cambodia, India (Andaman and Nicobar Is. - Andaman Is., Assam), Myanmar, Philippines, Thailand, Viet Nam

In Indo-China and Thailand the species occurs gregariously along river banks, and in the Philippines it is found in mixed dipterocarp forest. It is one of the main species of keruing timber in Indo-China and Thailand. Recently $D$. philippinensis has been discovered to be conspecfic. The conservation status is based on the rate of habitat loss.

Assessor: Ashton, $\mathrm{P}$.

Refs: $3998,9169,10013,13857,15754,18243$

\section{Dipterocarpus applanatus}

Dipterocarpaceae

CR Alcd, B1+2c

Indonesia (Kalimantan)

A large tree endemic to Kalimantan.

Assessor: Ashton, P.

Refs: $7673,9169,13857$ 
Dipterocarpus baudii

Dipterocarpaceae CR Alcd+2cd

Cambodia, Indonesia (Sumatra), Malaysia, Myanmar, Thailand, Viet Nam

A species found scattered in the greatly reduced lowland evergreen forests of South East Asia.

Assessor: Ashton, P.

Refs: $3998,6646,7673,9169,13857$

\section{Dipterocarpus bourdilloni}

Dipterocarpaceae

India (Karnataka, Kerala, Tamil Nadu)

A large tree endemic to the Western Ghats, occurring principally in lowland evergreen forest in Kerala, with one or two occurrences extending into Karnataka and Tamil Nadu. The timber is used to make plywood.

Assessor: Ashton, P.

Refs: $3998,13857,19144$

\section{Dipterocarpus caudatus ssp. caudatus}

Dipterocarpaceae

Philippines, Viet Nam

CR Alcd $+2 \mathrm{~cd}, \mathrm{Bl}+2 \mathrm{c}$

A lowland subspecies found locally in permanently wet zones. The timber is strong and used in heavy construction. Wood-oil was also of commercial value in the past.

Assessor: Ashton, P.

Refs: $7673,9169,13857$

\author{
Dipterocarpus caudatus ssp. penangianus \\ Dipterocarpaceae EN Alcd+2cd, B1+2c \\ Indonesia (Sumatra), Malaysia (Peninsular Malaysia, \\ Sabah, Sarawak), Singapore \\ A lowland subspecies found on well-drained land in \\ humid areas. The strong timber is utilised for heavy \\ construction and the wood-oil once had commercial \\ value. \\ Assessor: Ashton, P. \\ Refs: $7673,9169,9199,13857$
}

\section{Dipterocarpus chartaceus}

Dipterocarpaceae

CR Alcd $+2 c d, B 1+2 c$

Malaysia (Peninsular Malaysia), Thailand

A large tree of lowland dipterocarp forest or semiswamp forest.

Assessor: Ashton, $\mathrm{P}$.

Refs: $5550,6206,6646,7673,9169,13857$

\section{Dipterocarpus cinereus}

Dipterocarpaceae

Indonesia (Sumatra)

Assessor: Ashton, P.

Refs: $7673,9169,13857$

\section{Dipterocarpus concavus}

Dipterocarpaceae CR Alcd+2cd, B 1+2c Indonesia (Sumatra), Malaysia (Peninsular Malaysia)

Assessor: Ashton, P.

Refs: $5550,7673,9169,13857$

\section{Dipterocarpus conformis ssp. borneensis}

Dipterocarpaceae VU Alcd, B1+2c

Brunei, Malaysia (Sabah, Sarawak)

This subspecies is restricted to northern Bomeo, where it grows in mixed dipterocarp forest up to $800 \mathrm{~m}$.

Assessor: Ashton, $\mathrm{P}$.

Refs: 13857,14573
Dipterocarpus conformis ssp. conformis

Dipterocarpaceae

CR Alcd $+2 c d, B 1+2 c$

Indonesia (Sumatra)

This variety is confined to lowland and hill dipterocarp forests in north-west Sumatra.

Assessor: Ashton, P.

Refs: $7673,9169,13857$

Dipterocarpus coriaceus

Dipterocarpaceae

CR Alcd $+2 c d, B 1+2 c$

Indonesia (Kalimantan, Sumatra), Malaysia (Peninsular Malaysia)

Assessor: Ashton, $\mathrm{P}$.

Refs: $5550,7673,9169,13857,17140$

\section{Dipterocarpus cornutus}

Dipterocarpaceae

CR Alcd $+2 \mathrm{~cd}$

Indonesia (Kalimantan, Sumatra), Malaysia (Peninsular Malaysia), Singapore

The conservation status of this species is based on the rate of habitat loss and conversion.

Assessor: Ashton, $\mathrm{P}$.

Refs: $7673,9169,9199,13857,17140$

\section{Dipterocarpus costatus}

Dipterocarpaceae

EN Alcd $+2 c d$

Bangladesh, Cambodia, India (Andaman and Nicobar Is.

- Andaman Is.), Laos, Malaysia (Peninsular Malaysia), Myanmar, Thailand, Viet Nam

This species is widely scattered in lowland, hill and upper dipterocarp forest. Natural hybrids are formed with $D$. obtusifolius in Thailand and with $D$. gracilis in Thailand and Peninsular Malaysia. Populations are found within reserves.

Assessor: Ashton, P.

Refs: $3998,7673,9169,10013,13857,15754,16925$

\section{Dipterocarpus costulatus}

Dipterocarpaceae

CR Alcd $+2 c d, B 1+2 c$ Indonesia (Kalimantan, Sumatra), Malaysia (Peninsular Malaysia, Sarawak)

A large tree exploited for the keruing timber. The conservation status is based upon the rate of habitat loss. Assessor: Ashton, P.

Refs: $7673,9169,13857,17140$

\section{Dipterocarpus crinitus}

Dipterocarpaceae

EN Alcd $+2 c d$

Malaysia (Peninsular Malaysia), Thailand

A large tree of mixed dipterocarp forest, important as a source of keruing timber and also for various other uses. Conservation status of the species is based upon the rate of habitat loss and conversion. Populations are found within forest reserves.

Assessor: Ashton, $\mathrm{P}$.

Refs: 11295, 13857

\section{Dipterocarpus cuspidatus}

Dipterocarpaceae

CR Alcd+2cd, B1+2c

Malaysia (Sarawak)

Assessor: Ashton, P.

Refs: $7673,9169,13857$

\section{Dipterocarpus dyeri}

Dipterocarpaceae

CR Alcd $+2 c d, B 1+2 c$

Cambodia, Malaysia (Peninsular Malaysia), Myanmar, Thailand, Viet Nam

A lowland tree of semi-evergreen dipterocarp forest and 
Schima/bamboo forest. The conservation status is based on rates of habitat loss.

Assessor: Ashton, P.

Refs: $3998,5550,7673,9169,10013,13857$

\section{Dipterocarpus elongatus}

Dipterocarpaceae

CR Alcd $+2 c d, B 1+2 c$

Indonesia (Kalimantan, Sumatra), Malaysia (Peninsular

Malaysia, Sarawak), Singapore

A large tree of secondary and primary forest and freshwater swamp forest. The conservation status is based on rates of habitat loss.

Assessor: Ashton, P.

Refs: $7673,9169,13857,18243$

\section{Dipterocarpus eurynchus}

Dipterocarpaceae

CR Alcd+2cd, Bl+2c

Brunei, Indonesia (Kalimantan, Sumatra), Malaysia (Peninsular Malaysia, Sarawak), Philippines

A species with a localised distribution in mixed dipterocarp forest on leached clay soils.

Assessor: Ashton, $\mathrm{P}$.

Refs: $7673,9169,10547,13857$

\section{Dipterocarpus fagineus}

Dipterocarpaceae CR Alcd+2cd Indonesia (Sumatra), Malaysia (Peninsular Malaysia, Sarawak)

Assessor: Ashton, $\mathrm{P}$.

Refs: $9169,10547,13857$

\section{Dipterocarpus fusiformis}

Dipterocarpaceae

Indonesia (Kalimantan)

Assessor: Ashton, $\mathrm{P}$.

Refs: $7673,9169,13857$

\section{Dipterocarpus glabrigemmatus}

Dipterocarpaceae CR Alcd +2cd, Bl+2c Indonesia (Kalimantan), Malaysia (Sarawak)

Assessor: Ashton, P.

Refs: $7673,9169,13857$

\section{Dipterocarpus glandulosus}

Dipterocarpaceae

CR Alcd, $\mathrm{B} 1+2 \mathrm{c}$

\section{Sri Lanka}

An emergent species found only in restricted lowland wet evergreen forests on well-drained deep soils. Populations have been eliminated from many areas because of excessive tapping for resin. Regeneration is also observed to be poor. Some populations are known to occur in forest reserves.

Assessor: Ashton, P.

Refs: 13857, 15431, 17195

\section{Dipterocarpus globosus}

Dipterocarpaceae CR Alcd $+2 \mathrm{~cd}, \mathrm{~B} 1+2 \mathrm{c}$

Brunei, Indonesia (Kalimantan), Malaysia (Sarawak)

This species is locally abundant in mixed dipterocarp forest and heath forest.

Assessor: Ashton, P.

Refs: $7673,9169,13857$

\section{Dipterocarpus gracilis}

Dipterocarpaceae

CR Alcd+2cd

Bangladesh, India (Andaman and Nicobar Is. - Andaman Is., Arunachal Pradesh, Assam, Tripura), Indonesia (Java, Kalimantan, Sumatra), Malaysia (Peninsular Malaysia), Myanmar, Philippines, Thailand
A large tree found in lowland semi-evergreen and evergreen dipterocarp forest. It is one of the important sources of keruing timber in Indo-China and is often used as a commercial grade plywood. The conservation status is based on rates of habitat loss. Some populations are known to occur in forest reserves.

Assessor: Ashton, P.

Refs: $5550,7673,9169,13857,15754$

\section{Dipterocarpus grandiflorus}

Dipterocarpaceae

CR Alcd+2cd

India (Andaman and Nicobar Is. - Andaman Is.), Indonesia (Sumatra), Malaysia (Peninsular Malaysia, Sabah), Myanmar, Philippines, Singapore, Thailand, Viet Nam

A relict species of the Pleistocene Sundaland, occurring in primary semi-evergreen and evergreen dipterocarp forest. Substantial amounts of keruing timber and also large quantities of oleo-resin are harvested. The conservation status of the species is based on rates of habitat loss and conversion. Some populations are known to exist within reserves.

Assessor: Ashton, P.

Refs: $848,3998,6646,9169,9199,13857,17140$

\section{Dipterocarpus hasseltii}

Dipterocarpaceae

CR Alcd $+2 \mathrm{~cd}$

Indonesia (Bali, Java, Kalimantan, Sumatra), Malaysia (Peninsular Malaysia, Sabah), Philippines, Thailand, Viet Nam

A large tree of lowland dipterocarp forest, cut for keruing timber. It is recorded in the sacred forest of Sanggen, Bali, and some forest reserves. The conservation status of the species is based on the rate of habitat conversion and loss.

Assessor: Ashton, P.

Refs: $5054,5550,7673,9169,13857$

\section{Dipterocarpus hispidus \\ Dipterocarpaceae}

CR Alcd

Sri Lanka

A species of the restricted lowland wet evergreen forest in south-west Sri Lanka. It is reported to regenerate well. There are populations in some forest reserves.

Assessor: Ashton, $\mathrm{P}$.

Refs: $13857,15431,17195$

\section{Dipterocarpus indicus}

Dipterocarpaceae

India (Karnataka, Kerala, Tamil Nadu)

A species found in lowland humid evergreen forests in southem India. It regenerates prolifically in disturbed areas. It is an important plywood species.

Assessor: Ashton, P.

Refs: $3998,8483,9169,13857,15754,19144$

\section{Dipterocarpus insignis}

Dipterocarpaceae

CR Albcd, $\mathrm{B} 1+2 \mathrm{c}$

Sri Lanka

The species occurs in an area that has been proposed as a reserve.

Assessor: Ashton, $\mathrm{P}$.

Refs: 13857, 15431, 17195

\section{Dipterocarpus kerrii}

Dipterocarpaceae

CR Alcd+2cd, B1+2c

India (Andaman and Nicobar Is. - Andaman Is.), Indonesia (Kalimantan, Sumatra), Malaysia (Peninsular Malaysia), Myanmar, Philippines, Thailand, Viet Nam 
A species which is locally common in lowland semievergreen and evergreen dipterocarp forest. It is cut for keruing timber and is the main source of damar minyak or gurjun balsam in the region.

Assessor: Ashton, P.

Refs: $3998,5550,7673,9169,13857,17140,19093$

\section{Dipterocarpus kunstleri}

Dipterocarpaceae

CR Alcd+2cd

Indonesia (Sumatra), Malaysia (Sarawak), Philippines

The conservation status is based on rates of habitat loss.

Assessor: Ashton, $\mathrm{P}$.

Refs: $7673,9169,13857$

\section{Dipterocarpus lamellatus}

Dipterocarpaceae

CR Alcd+2cd, B1+2c, Cl, D1

Malaysia (Sabah)

Endemic to Sabah, the species is found in mixed dipterocarp forest on low coastal hills.

Assessor: Ashton, P.

Refs: $7673,9169,13857$

\section{Dipterocarpus littoralis}

Dipterocarpaceae

$\mathrm{CR} B 1+2 \mathrm{c}, \mathrm{C} 2 \mathrm{a}$

Indonesia (Java)

Confined to Nusa Kambangan Island, Java, this species is locally common in lowland mixed rainforest covering an area of about $80 \mathrm{~km}^{2}$. Despite the presence of three high-security prisons and armed guards patrolling a $20 \mathrm{~km}^{2}$ reserve, the tree is illegally harvested.

Assessor: Ashton, P.

Refs: $7673,9169,13857$

\section{Dipterocarpus lowii}

Dipterocarpaceae

CR Alcd $+2 \mathrm{~cd}, \mathrm{Bl}+2 \mathrm{c}$

Brunei, Indonesia (Sumatra), Malaysia (Peninsular Malaysia, Sabah, Sarawak)

A large tree which is an important source of keruing timber. Some populations of the species are found in forest reserve.

Assessor: Ashton, P.

Refs: $7673,9169,13857,17140$

\section{Dipterocarpus perakensis}

Dipterocarpaceae CR Alcd+2cd, B1+2c, Cl, Dl Malaysia (Peninsular Malaysia)

A very localised species found in lowland dipterocarp forest on coastal hills.

Assessor: World Conservation Monitoring Centre

Refs: $7673,9169,13857$

\section{Dipterocarpus retusus}

Dipterocarpaceae

VU Alcd $+2 c d, B 1+2 c$

China (Yunnan), India (Arunachal Pradesh, Assam, Manipur, Meghalaya, Nagaland, Tripura, West Bengal), Indonesia (Java, Lesser Sunda Is., Sumatra), Malaysia (Peninsular Malaysia), Myanmar, Thailand, Viet Nam

A large timber tree which is widespread in moist evergreen, sometimes semi-deciduous, montane forest. In China, the species is confined to an area of $30 \mathrm{~km}^{2}$ in Yingjiang, where a nature reserve has been set up. The populations in Viet Nam, restricted to northem evergreen or monsoon forests, have been reduced to at least half their original size.

Assessor: Ashton, P.

Refs: $1818,3998,5550,7673,9169,11847,13857$, 15754

\section{Dipterocarpus rigidus}

Dipterocarpaceae

CR Alcd $+2 \mathrm{~cd}, \mathrm{Bl}+2 \mathrm{c}$

Indonesia (Sumatra), Malaysia (Sarawak)

A large tree which occurs locally in dry forest on coastal

hills. Some populations are found within forest reserves.

Assessor: Ashton, P.

Refs: $7673,9169,13857$

Dipterocarpus rotundifolius

Dipterocarpaceae

Malaysia (Peninsular Malaysia)

CR Alcd $+2 c d, B 1+2 c$

A large tree endemic to Peninsular Malaysia and found on coastal hills.

Assessor: Ashton, P.

Refs: $5550,11647,13857$

\section{Dipterocarpus semivestitus}

Dipterocarpaceae CR Alcd +2cd, B1+2c, C1, D1

Indonesia (Kalimantan), Malaysia (Peninsular Malaysia)

A tree of lowland forest on almost swampy land. It is very close to extinction because of the loss and degradation of its habitat.

Assessor: Ashton, $\mathrm{P}$.

Refs: $7673,9169,13857,17140$

\section{Dipterocarpus sublamellatus}

Dipterocarpaceae

EN Alcd +2 cd

Indonesia (Sumatra), Malaysia (Peninsular Malaysia, Sarawak), Singapore

In Peninsular Malaysia, this very large tree is an important source of keruing timber.

Assessor: World Conservation Monitoring Centre

Refs: $7673,9169,9199,13857,17140$

\section{Dipterocarpus tempehes}

Dipterocarpaceae

CR Alcd $+2 c d, B 1+2 c$

Indonesia (Kalimantan)

A lowland species, which is locally abundant near freshwater swamps and streams. It is often used as keruing timber in Sabah and parts of Sarawak, but is mainly threatened by habitat loss.

Assessor: Ashton, $\mathrm{P}$.

Refs: $7673,13857,18327$

\section{Dipterocarpus turbinatus}

Dipterocarpaceae

CR Alcd $+2 c d$

Bangladesh, Cambodia, India (Andaman and Nicobar Is. - Andaman Is., Arunachal Pradesh, Assam, Manipur, Meghalaya, Tripura), Laos, Myanmar, Thailand, Viet Nam

A large tree found in mixed deciduous, evergreen and semi-evergreen forest. It is exploited for the manufacture of commercial-grade plywood. The conservation status is based on the rate of habitat loss. Some populations are protected in reserves.

Assessor: Ashton, $\mathrm{P}$.

Refs: $3998,6646,9169,13857,15754$

\section{Dipterocarpus validus}

Dipterocarpaceae

CR Alcd $+2 c d$

Indonesia (Kalimantan), Malaysia (Sabah), Philippines

This species occurs in both primary and secondary forest, especially along rivers and in freshwater swamps. Its wood is used as keruing timber and large quantities of wood-oil are extracted.

Assessor: Ashton, $\mathrm{P}$.

Refs: $7673,9169,13857$ 


\section{Dipterocarpus zeylanicus}

Dipterocarpaceae

Sri Lanka

A canopy tree scattered in restricted areas of lowland wet evergreen forest. It is also found as an emergent in semi-evergreen moist forest. Regeneration is noted to be good. The conservation status is based on the rate of habitat loss and conversion. Some populations are also known to exist in forest reserves. The wood is an important source of plywood in Sri Lanka.

Assessor: Ashton, $\mathrm{P}$.

Refs: $13857,15431,17195$

\section{Dipteronia dyeriana}

Aceraceae

$\mathrm{EN} B 1+2 \mathrm{c}$

China (Yunnan)

Known only from the counties of Mengzi and Wenshan in the south-east of Yunnan, the species occurs at the edges of broadleaved evergreen forest between 1800 and $2400 \mathrm{~m}$. The habitat has declined in extent because of logging and clearing for agriculture, but the area is now under protection. It is a prized omamental plant and one of just two species in the genus.

Assessor: Sun, W.

Refs: $1818,11847,19055$

\section{Dipteronia sinensis}

Aceraceae

$\mathrm{LR} / \mathrm{nt}$

China (Gansu, Guizhou, Henan, Hubei, Hunan, Shaanxi, Sichuan)

The more widespread of the two species in the genus. It occurs in small stands scattered in mountainous moist forest areas in the centre and south-west of China. Mature trees are said to be becoming scarcer because of cutting.

Assessor: World Conservation Monitoring Centre

Refs: 1818,11847

\section{Dipteryx alata}

Leguminosae

VU Alcd

Brazil

This tree, confined to *cerrado, is widespread in Brazil. The species has suffered from habitat conversion for agriculture. In addition, exploitation of its excellent quality timber and medicinal seeds has led to massive declines in population numbers.

Assessor: World Conservation Monitoring Centre Refs: 4506

\section{Dipteryx charapilla \\ Leguminosae \\ Peru}

VU D2

Known only from the type locality, the species occurs in Amazon forest in the department of Loreto.

Assessor: World Conservation Monitoring Centre Refs: 1984

\section{Dirachma socotrana}

Geraniaceae

VU D2

Yemen (Socotra)

A small tree or shrub which is restricted to a few valleys in the Eastern Haggier Mountains and adjacent limestone hills. The total population was formerly thought to consist of no more than 30 individuals. Although severely geographically restricted, the species actually occurs commonly in places and appears to be regenerating healthily. There are no immediate threats to populations. The only other member of the genus is in Somalia.

Assessor: Miller, A.G.

Refs: $2354,7334,19083$

Dirachma somalensis

Geraniaceae

EN C2b, D1

Somalia

The best known population, observed to have fewer than 10 individuals, occurs in bushland in Gawen Gorge, near Hobyo. Although few pressures threaten this population, it remains unprotected. Other populations are thought to exist. The species is taxonomically isolated. The only other member of the genus is endemic to Socotra.

Assessor: Thulin, $\mathbf{M}$.

Refs: 9059,18665

\section{Discoclaoxylon occidentale}

Euphorbiaceae

VU D2

São Tomé \& Príncipe (São Tomé)

A forest tree, known only from a few herbarium specimens and thought to be extinct until it was rediscovered in 1968. Populations have been located at a range of altitudes in Pico, Angolares and Monte Café in two locations, one in Esperanca. The remaining populations are now confined to higher altitudes which have evaded deforestation.

Assessor: World Conservation Monitoring Centre

Refs: 2724, 10080

\section{Distylium gracile}

Hamamelidaceae

EN A1d, C2a

Taiwan

A species localised in wooded limestone areas in Taroko National Park, Hualien, eastem Taiwan. There is some threat from mining activities and regeneration does not appear to be good.

Assessor: Lu, S.Y. \& F.J. Pan

Refs: $3295,19050,19051$

\section{Doerpfeldia cubensis}

Rhamnaceae

$\mathrm{EN} \mathrm{B1}+2 \mathrm{c}$

Cuba

A very uncommon tree found in coastal and subcoastal areas of eastem and south-central Cuba. The dry evergreen forests where this species thrives have experienced severe degradation in many places.

Assessor: Areces-Mallea, A.E.

Refs: 9522, 11403, 19149

\section{Dombeya aethiopica}

Sterculiaceae

LR/nt

Ethiopia

A tree of dry Juniperus forest, forest margins and secondary forest. It is endemic to Ethiopia and is found in various localities in the western and south-west highlands.

Assessor: World Conservation Monitoring Centre Refs: 2361, 5941

\section{Dombeya amaniensis}

Sterculiaceae

VU B $1+2 b$

Tanzania

Three localities are known where the species is found in moist forest within a narrow altitudinal belt, between 900 and $1000 \mathrm{~m}$ : the East Usambara Mountains, Makuyuni and Mahenge.

Assessor: Lovett, J. \& G.P. Clarke

Refs: 3356,8814 


\section{Dombeya longebracteolata}

Sterculiaceae

VU D2

Ethiopia

Three localities in Kefa, Gamo Gofa and Sidamo regions are known, where the species occurs in CombretumTerminalia woodland.

Assessor: World Conservation Monitoring Centre

Refs: 5941

\section{Dorstenia gigas}

Moraceae

VU D2

Yemen (Socotra)

The largest species in the genus, attaining a height of $3.7 \mathrm{~m}$. The trunks are succulent and in drought years the whole plant is cut and pulped as fodder for goats. During years of average rainfall populations are largely untouched and unthreatened as they are confined to vertical cliff faces and areas inaccessible to grazing goats. The species is found only on the Haggier Mountains. It is of great horticultural interest and could potentially come under risk from overcollection by enthusiasts.

Assessor: Miller, A.G.

Refs: 2354,19083

\section{Dovyalis xanthocarpa}

Flacourtiaceae

VU B $1+2 b$

Tanzania

A species, endemic to Tanzania, occurring in lowland dry forest in northern and central eastern areas.

Assessor: Lovett, J. \& G.P. Clarke

Refs: 3356,5020

\section{Dracaena cinnabari}

Dracaenaceae

$\mathrm{EN} \mathrm{B} 1+2 \mathrm{c}$

Yemen (Socotra)

The dragon tree of Socotra. Occurring only at altitudes above $500 \mathrm{~m}$ in the centre and east of the island, the species is widespread and dominant in areas of woodland. Regeneration is very limited and generally confined to cliffs and boulders. Of its various uses it is most famously known as a commercial source of dragon's blood. Current exploitation is small-scale but there is potential for more harmful exploitation to take place.

Assessor: Miller, A.G.

Refs: 2354,19083

\section{Dracaena concinna}

Dracaenaceae

EN Alce

Mauritius

The remaining populations of this species are now managed in reserves, which should halt previous declines in numbers. The populations are very small and confined to a few tiny islands.

Assessor: Strahm, W.

Refs: $9120,16426,19208$

\section{Dracaena draco}

Dracaenaceae

VU Alabcde

Cape Verde, Morocco, Portugal (Madeira), Spain (Canary Is.)

The wild populations of the dragon tree have been in decline for a long time. The species is present in five of the seven islands in the Canaries and the total population is reduced to a few hundred trees. In Madeira and Porto Santo, it was once an important component of the vegetation in more arid areas but is reduced today to two individuals in the wild. A survey in 1996 revealed new populations in North Africa, in the Anezi region of the Anti-Atlas Mountains in Morocco. Thousands of individuals exist on steep quartzite cliffs in inaccessible gorges. These populations are likely to represent a distinct variant of the species. The species is listed in regional, govemmental and international legislation. It is widespread in cultivation, long-living and reaches maturity in 30 years. Dragon's blood had a wide range of uses as a medicine, for staining violins and for embalming the dead. Its closest relative is the dragon tree endemic to Socotra.

Assessor: Bañares, A. et al.

Refs: 7228, 13121, 19022, 19131, 19199

Dracaena floribunda

Dracaenaceae

EN Alce+2ce

Mauritius

Assessor: Strahm, W.

Refs: $9120,16426,19208$

Dracaena ombet

Dracaenaceae

EN Alcd

Djibouti, Egypt, Ethiopia, Saudi Arabia, Somalia, Sudan, Uganda

A once widespread and abundant species known as the Nubian dragon tree, it has experienced population declines throughout its range. Scattered individuals remain in inaccessible areas. The populations on the Red Sea Hills and Jebel Elba in Sudan and Egypt are particularly threatened. Overgrazing, overcutting and droughts have contributed to these declines.

Assessor: World Conservation Monitoring Centre

Refs: $2361,5165,6988,16021$

\section{Dracaena serrulata}

Dracaenaceae

EN A labcd

Oman, Saudi Arabia, Yemen

This taxon represents the populations of the dragon tree in the southern escarpments of the Arabian Peninsula. The species, however, is likely to be taxonomically indistinct from $D$. ombet. The Arabian populations are restricted to high altitudes in drier areas. In Oman trees on Jabal Samhan have been severely damaged in the last 10 years because of the cutting of leaves for camel fodder. No regeneration is apparent anywhere within its distribution in Oman.

Assessor: World Conservation Monitoring Centre Refs: 16380,19083

\section{Dracaena umbraculifera}

Dracaenaceae

Mauritius

It is possible there are complications in the taxonomy of the species.

Assessor: Strahm, W.

Refs: $9120,16426,19208$

\section{Drimys confertifolia}

Winteraceae

VU D2

Chile (Juan Fernández Is)

A dominant species of lowland dry forest and lower montane forest on Masatierra and Masafuera Islands. The extent of the forest has declined through the effects of grazing by feral animals, spread of introduced weeds and soil erosion. Trees were cut in large numbers for lumber in the past. Preliminary data indicate the species is confined to less than $100 \mathrm{~km}^{2}$. More detailed information on the species should become available to confirm this evaluation. The islands are designated as a 
national park and biosphere reserve and work is being carried out by ${ }^{*}$ CONAF to save the native plants.

Assessor: World Conservation Monitoring Centre

Refs: $3241,5651,14140$

\section{Drymophloeus lepidotus}

Palmae

Solomon Islands (South Solomon)

A rainforest palm, occurring up to $600 \mathrm{~m}$, restricted to the Solomon Islands. The genus is in need of taxonomic revision.

Assessor: Dowl, J.L.

Refs: 19118

\section{Drymophlocus oliviformis}

Palmae

DD

Indonesia (Moluccas)

A single-stemmed palm of lowland rainforest, confined to Ambon Island. The genus is in need of taxonomic revision.

Assessor: Johnson, D.

Refs: 19118

\section{Drymophloeus pachycladus}

Palmae

Solomon Islands (South Solomon)

Confined to Makira Island, this palm tree is located inland in moist lowland forest up to $600 \mathrm{~m}$. The genus is in need of taxonomic revision.

Assessor: Dowl, J.L.

Refs: 19118

\section{Drymophloeus samoensis}

Palmae

CR D1

Westem Samoa

A rare palm of montane cloud forest on Savai'i and Upolu Islands. Natural disasters pose the most serious threat.

Assessor: Whistler, A. \& D. Johnson

Refs: 19118

\section{Drymophloeus subdistichus}

Palmae

Solomon Islands (South Solomon)

A palm tree, scattered in lowland rainforest. The genus is in need of taxonomic revision.

Assessor: Dowl, J.L.

Refs: 19118

\section{Dryobalanops aromatica}

Dipterocarpaceae

CR Alcd $+2 \mathrm{~cd}, \mathrm{Bl}+2 \mathrm{c}$ Indonesia (Sumatra), Malaysia (Peninsular Malaysia, Sabah, Sarawak)

A very large gregarious tree, which provides most of the kapur timber and camphor for Peninsular Malaysia and Sumatra. Small populations of the species have been found in forest reserves. It has recently been determined that $D$. sumatrensis is synonymous.

Assessor: Ashton, P.

Refs: $3738,10547,13857$

\section{Dryobalanops beccari}

Dipterocarpaceae

EN Alcd+2cd

Brunei, Indonesia (Kalimantan), Malaysia (Sabah. Sarawak)

Distributed within Bomeo, this locally abundant tree occurs on leached sandy soils, sometimes in periodically inundated areas or along streams. In Brunei the wood is considered to be the best-quality kapur timber.

Assessor: Ashton, P.

Refs: 7673, 13857

\section{Dryobalanops fusca}

Dipterocarpaceae

CR Alcd $+2 c d, B 1+2 c, C l, D I$

Indonesia (Kalimantan)

This species occurs locally on sandy, podzolic soils in heath forest.

Assessor: Ashton, $\mathrm{P}$

Refs: 7673,13857

\section{Dryobalanops keithii}

Dipterocarpaceae

CR Alcd $+2 \mathrm{~cd}, \mathrm{Bl}+2 \mathrm{c}, \mathrm{Cl}, \mathrm{Dl}$

Indonesia (Kalimantan)

A lowland species always found near water.

Assessor: Ashton, $\mathrm{P}$

Refs: 7673,13857

\section{Dryobalanops lanceolata}

Dipterocarpaceae

Indonesia (Kalimantan), Malaysia (Sabah)

EN Alcd

This is the tallest recorded dipterocarp tree. Its kapur timber fetches the highest prices in Bomeo and the species is also a major source of Bomeo camphor. The conservation status of this tree is based upon the rate of habitat loss and conversion. Some populations are known to occur within forest reserves.

Assessor: Ashton, $\mathrm{P}$.

Refs: 7673,13857

\section{Dryobalanops oblongifolia ssp. oblongifolia}

Dipterocarpaceae

EN Alcd

Indonesia (Kalimantan), Malaysia (Sarawak)

Some populations are known to occur in forest reserves.

Assessor: Ashton, P.

Refs: $7673,9169,13857$

\section{Dryobalanops oblongifolia ssp. occidentalis}

Dipterocarpaceae EN Alcd, Bl+2c

Indonesia (Sumatra), Malaysia (Peninsular Malaysia)

A large tree restricted to shallow acidic soils.

Assessor: Ashton, P.

Refs: $7673,9169,13857$

\section{Drypetes afzelii}

Euphorbiaceae

Côte d'Ivoire, Ghana, Liberia, Sierra Leone

Extending from Sierra Leone to Ghana, this species occurs only in a restricted wet evergreen forest habitat, generally along rivers. It is uncommon and has suffered from general declines in this habitat because of mining, logging and commercial forestry activities.

Assessor: Hawthorne, W.

Refs: $2773,8369,12061$

\section{Drypetes andamanica}

Euphorbiaceae

India (Andaman and Nicobar Is. - Andaman Is.)

Endemic to South Andaman Island, the species occurs in areas of evergreen forest which have declined severely in extent through logging activities. A relatively intact tract of forest remains in the Jarwa Reserve where it is possible the species occurs.

Assessor: World Conservation Monitoring Centre

Refs: 4799,7147 


\section{Drypetes caustica}

Euphorbiaceae

Mauritius, Réunion

Assessor: Strahm, W.

Refs: $2046,12470,16426,19208$

\section{Drypetes cockburnii}

Euphorbiaceae

LR/cd

Malaysia (Peninsular Malaysia)

A relatively recently discovered species, known from areas of rainforest between 500 and $700 \mathrm{~m}$ in Pahang and Johore. The full distribution and abundance of the species is still unknown. One locality in Ulu Endau is protected within Endau Rompin National Park and the other in Gunung Panti is also a conserved area.

Assessor: Kochummen, K.M.

Refs: 8464, 19073

\section{Drypetes detersibilis}

Euphorbiaceae

Malaysia (Peninsular Malaysia)

VU D2

Known only from Kuala Triang in Pahang, the species has been collected only a single time from forest on the banks of the Pahang River.

Assessor: Kochummen, K.M.

Refs: 8464, 19073

\section{Drypetes gerrardinoides}

Euphorbiaceae

$\mathrm{VUB} 1+2 \mathrm{c}$

Tanzania

An endemic species of dry montane forests within the Udzungwa Forest Reserve and Lulanda. It is abundant but confined to a $70 \mathrm{~m}$ elevation band. These forests have been heavily exploited and disturbed in the past but active conservation programmes are now in place.

Assessor: Lovett, J. \& G.P. Clarke

Refs: 3356,8814

\section{Drypetes glabra}

Euphorbiaceae

VU D2

São Tomé \& Príncipe (São Tomé)

Endemic to Sāo Tomé this tree is known from collections, both recent and old, from Ilheu das Rolas, Angolares, Ribeira Peixe, Lagoa Amalia, Bombaim and Jou. The lowland localities are likely to have been lost in the first half of the century when forest at these altitudes was extensively cleared.

Assessor: World Conservation Monitoring Centre

Refs: $2724,10080,19042$

\section{Drypetes henriquesii}

Euphorbiaceae

VU D $1+2$

São Tomé \& Príncipe (São Tomé)

A tree of secondary forest, collected only twice, in the last century from $\mathrm{S}$. Nicaolau and more recently from $\mathrm{S}$. Carlos. Areas remain to be explored, although most of the forest below $1500 \mathrm{~m}$ was cleared in the first half of the century.

Assessor: World Conservation Monitoring Centre

Refs: 2724,10080

\section{Drypetes laciniata}

Euphorbiaceae

$\mathrm{LR} / \mathrm{nt}$

Cameroon, Côte d'Ivoire, Gabon

A species with a fragmented distribution, which is sparse and confined to remaining areas of lowland moist forest, mostly in protected areas. It is found between the rivers of Sassandra and Cavally in south-west Côte d'Ivoire, including Tai National Park. In Cameroon populations are harboured in Konu National Park and Abong-Mbang. It is relatively widespread in Gabon, where large tracts of forest remain but are under concession to logging companies.

Assessor: World Conservation Monitoring Centre

Refs: $12590,12597,12822,19043$

Drypetes natalensis var. leiogyna

Euphorbiaceae

VU B1+2b

Kenya, Somalia, Tanzania

A riverine forest tree, occurring in coastal areas from eastem Tanzania and Zanzibar just into Somalia. It is threatened by localised habitat degradation. The type variety occurs from Sudan to KwaZulu-Natal and differs in having hairy fruit.

Assessor: Lovett, J. \& G.P. Clarke

Refs: 3356, 9059

\section{Drypetes nervosa}

Euphorbiaceae

Malaysia (Peninsular Malaysia)

VU D2

A primary species of lowland rainforest, recorded only from limestone hills in Perak.

Assessor: World Conservation Monitoring Centre Refs: 19073

\section{Drypetes obanensis}

Euphorbiaceae

$\mathrm{VU} B \mathrm{~B}+2 \mathrm{c}$

Nigeria

Endemic to the Oban Division of the Cross River National Park, this small forest tree is relatively well protected. Pressures from commercial logging and agriculture are very strong outside the park.

Assessor: World Conservation Monitoring Centre

Refs: 2773, 4977, 11504

\section{Drypetes oxyodonta}

Euphorbiaceae

Malaysia (Peninsular Malaysia)

VU D2

A species of lowland forest on limestone in Pahang.

Assessor: World Conservation Monitoring Centre

Refs: 19073

\section{Drypetes palawanensis}

Euphorbiaceae

VU B1+2c

Philippines

Endemic to Palawan, the species occurs in primary forest at low and medium altitude. The main island is declared a biosphere reserve.

Assessor: World Conservation Monitoring Centre Refs: 4986

\section{Drypetes pellegrinii}

Euphorbiaceae

Côte d'Ivoire, Ghana

VUAlc

Occurring only in Ghana and Côte d'Ivoire, this species is found in areas of upland evergreen forest where it can be common in some areas. The effects of fire, overgrazing, forest management activities and mining have caused declines in the extent of the species' habitat. Assessor: Hawthorne, W.

Refs: $6127,8369,12061$

\section{Drypetes perakensis}

Euphorbiaceae

VU D2

Malaysia (Peninsular Malaysia)

A primary forest species, known only by a single 
collection from Perak. The exact locality remains unknown.

Assessor: Kochummen, K.M.

Refs: 19073

\section{Drypetes porteri}

Euphorbiaceae

India (Tamil Nadu)

Recorded only a few times, the species occurs in scattered localities in low to medium elevation evergreen forest at the southern end of the Western Ghats.

Assessor: World Conservation Monitoring Centre Refs: 19144

\section{Drypetes preussii}

Euphorbiaceae

VU B $1+2 c$

Cameroon, Nigeria

A rare species confined to forest patches in south-east Nigeria and neighbouring parts of Cameroon. The largest remaining forested area is contained within Oban Hills in Cross River National Park in Nigeria and the contiguous Korup National Park in Cameroon. Outside these protected areas forest has been comprehensively logged and cleared for agriculture.

Assessor: World Conservation Monitoring Centre

Refs: 4977, 11504

\section{Drypetes riseleyi}

Euphorbiaceae

CR D1

Seychelles

A Seychelles endemic confined to the islands of Mahe. Praslin and Silhouette, where it occurs sparsely in the understorey of primary and secondary upland forest. The total population contains fewer than 50 trees. Overexploitation of the wood and loss of habitat are the main contributors to the historical decline in the species. Habitat degradation and low recruitment continue to have an impact on remaining trees. Parts of the species range are contained in Mome Seychellois and Praslin National Parks and forest areas protected by the Nature Protection Trust of Seychelles.

Assessor: Nature Protection Trust of Seychelles

Refs: $9859,17229,19023,19025,19062$

\section{Drypetes sclerophylla}

Euphorbiaceae

VU B $1+2 b$

Tanzania

A species of dry forest or woodland formations, endemic to the coastal forests of Tanzania. Populations have been recorded at four localities: Lake Lutamba, which has been cleared except for the $10 \mathrm{~km}^{2}$ of Litipo Forest Reserve, Namatogoro, Mpangapanga Ridge and Nahomba Valley.

Assessor: Lovett, J. \& G.P. Clarke

Refs: 3356, 10961

\section{Drypetes singroboensis}

Euphorbiaceae

VU Alc

Côte d'Ivoire, Ghana

A species which, although common in places, is found only in dry forest areas in southern Ghana and in moist semi-deciduous forest between the rivers Bandama and Nzi in Côte d'Ivoire. Declines in this habitat have been severe, mainly because of the effects of human population growth, but also because of fires.

Assessor: Assi, A.

Refs: $6127,12061,12590,12822$

\section{Drypetes travancoria}

Euphorbiaceae

$\mathrm{EN} \mathrm{B} 1+2 \mathrm{c}$

India (Kerala)

Known from a single collection, the species occurs on the Tamil Nadu/Kerala border in lowland evergreen forest.

Assessor: World Conservation Monitoring Centre Refs: 19144

Drypetes usambarica var. mrimae

Euphorbiaceae

VU B $1+2 c$

Kenya

Endemic to Kenya, this variety is confined to a few remaining patches of lowland coastal forest.

Assessor: World Conservation Monitoring Centre Refs: 6396,9198

Drypetes usambarica var. rugulosa

Euphorbiaceae

CR B $1+2 \mathrm{c}$

Tanzania

The species as a whole is confined to a region covering eastem Tanzania and south-east Kenya. This variety is restricted to the Lulanda forest in the Udzungwa range, where an active conservation programme is in place.

Assessor: Lovett, J. \& G.P. Clarke

Refs: 3356,8814

\section{Drypetes usambarica var. stylosa}

Euphorbiaceae

EN C2b, D1

Tanzania

Confined to moist coastal forest within Kimboza Forest Reserve $\left(4 \mathrm{~km}^{2}\right)$, this variety is similarly restricted in range as other varieties of the species. The forest is disturbed, mainly from previous logging activities, and contained within a densely populated area where the demand for land is strong. Two forest guards are employed under the Tanzanian Catchment Forest Project to prevent illegal encroachment.

Assessor: Lovett, J. \& G.P. Clarke

Refs: 3356,8814

\section{Drypetes usambarica var. trichogyna}

Euphorbiaceae

VU B1+2b, D2

Tanzania

As with other varieties of this East African endemic, this taxon is restricied in range. It occurs from lowland to submontane elevations in areas of moist forest on two separate mountains. In the Udzungwa range there are populations at Mwanihana and Chita and to the east in Malundwe National Park.

Assessor: Lovett, J. \& G.P. Clarke

Refs: 3356,10961

\section{Drypetes usambarica var. usambarica}

Euphorbiaceae

VU $B 1+2 b$

Kenya, Tanzania

Restricted to south-east Kenya and eastern Tanzania, this variant occurs within moist forest at high elevations. It is contained within reserves over most of its range. Assessor: Lovett, J. \& G.P. Clarke

Refs: 3356,10961

\section{Drypetes wightii}

Euphorbiaceae

India (Kerala, Tamil Nadu)

VU B $1+2 c$ A species of submontane evergreen forest, occurring in two main areas: in the west of the Nilgiri range and in 
the Anaimalai range. Only a few collections are known. Assessor: World Conservation Monitoring Centre Refs: 19144

\section{Dubautia arborea \\ Compositae \\ USA (Hawaii)}

EN Alce

A shrub or small tree of subalpine shrubland, woodland and also alpine desert on Hawaii. It was once common around the flanks of Mauna Kea but the impact of grazing feral animals has severely restricted its distribution. It remains locally abundant above Puulaau. Assessor: World Conservation Monitoring Centre Refs: 3372

\section{Dubautia knudsenii ssp. filiformis}

Compositae

$\mathrm{EN} \mathrm{B} 1+2 \mathrm{c}$

USA (Hawaii)

One of three subspecies confined to Kauai. This one appears to be the rarest, known from just two collections.

Assessar: World Conservation Monitoring Centre

Refs: 3372

\section{Dubautia knudsenü ssp. knudsenü}

Compositae

EN Alce

USA (Hawaii)

One of three subspecies confined to Kauai.

Assessor: World Conservation Monitoring Centre

Refs: 3372

\section{Dubautia knudsenii ssp. nagatae}

Compositae

EN Alce

USA (Hawaii)

One of three subspecies confined to Kauai Island.

Assessor: World Conservation Monitoring Centre

Refs: 3372

\section{Dubautia microcephala}

Compositae

USA (Hawaii)

EN Alce, C2a

Confined to Kauai Island, this shrub or small tree is infrequently collected and scattered in small numbers in moist forest between 825 and $1275 \mathrm{~m}$.

Assessor: World Conservation Monitoring Centre

Refs: 3372

\section{Dubautia reticulata}

Compositae VU Alce

USA (Hawaii)

A montane rainforest species confined to Maui Island. It appears to have been eliminated from the vicinity of Puunianiau but remains locally abundant on the east side of Koolau Gap.

Assessor: World Conservation Monitoring Centre

Refs: 3372

\section{Duguetia peruviana}

Annonaceae

Peru

A poorly known species. It has been collected just once from an unspecified location.

Assessor: World Conservation Monitoring Centre Refs: 1984

\section{Duguetio schulzi}

Annonaceae

VU D2

Suriname

Endemic to Jodensavanna, the species is rare and confined to areas of rainforest or savanna forest.

Assessor: World Conservation Monitoring Centre

Refs: $942,6493,19196$

\section{Dulacia crassa}

Olacaceae

VU D2

Guyana

This species is known from only two collections: one from forest on the slopes of Mount Roraima and the other from Kaieteur Savanna.

Assessor: World Conservation Monitoring Centre Refs: 7980,19158

\section{Duranta armato}

Verbenaceae

LR/nt

Peru

Relatively widely ranging, the species occurs in forest up to $4000 \mathrm{~m}$ in the Peruvian Andes.

Assessor: World Conservation Monitoring Centre Refs: 1984

\section{Durio acutifolius}

Bombacaceae VU Alc

Indonesia (Kalimantan), Malaysia (Sabah, Sarawak)

This understorey tree occurs on poor sandy and clay-rich yellow soils, often in periodically inundated areas in lowland rainforest. Wild specimens flower annually and could contribute significantly to the development of a reliably flowering durian cultivar.

Assessor: World Conservation Monitoring Centre

Refs: 11145,18327

\section{Durio dulcis}

Bombacaceae

Indonesia (Kalimantan), Malaysia (Sabah, Sarawak)

A large tree found scattered in lowland mixed dipterocarp forest. The fruit is sold in local and urban markets, but the species is rarely planted because of its short fruiting period. The wood is probably one of the most important sources of durian timber in Sarawak. Forest clearance and degradation because of agriculture and logging are major threats to the habitat. In addition this species is suffering from some genetic erosion. Assessor: World Conservation Monitoring Centre Refs: 11145,18327

\section{Durio grandiflorus}

Bombacaceae

VUAlc

Brunei, Malaysia (Sabah, Sarawak)

Restricted to the lowland mixed dipterocarp rainforests of northern Borneo, this species has edible fruits which are collected for consumption. It is only occasionally cultivated e.g. in Brunei. The species is suffering from some genetic erosion.

Assessor: World Conservation Monitoring Centre Refs: 11145,18327

\section{Durio kutejensis}

Bombacaceae

VU Alc

Brunei, Indonesia (Kalimantan), Malaysia (Sabah, Sarawak)

Wild trees are confined to mixed dipterocarp forest on the foothills of the mountains in central Bomeo. The natural habitat of this species is threatened by forest degradation due to logging and shifting agriculture and 
in Indonesia there is evidence of genetic erosion within populations. The species is cultivated for its popular fnits throughout Malesia and are the most similar to those of $D$. zibethinus.

Assessor: World Conservation Monitoring Centre

Refs: 11145,18327

\section{Durio pinangianus}

Bombacaceae

VU B $1+2 \mathrm{c}$

Malaysia (Peninsular Malaysia)

A species of lowland hill forest on steep slopes. The habitat has declined through logging and increasing settlement.

Assessor: Chua, L.S.L.

Refs: 19073

\section{Durio testudinarum}

Bombacaceae

VUAIc

Brunei, Indonesia (Kalimantan), Malaysia (Sabah, Sarawak)

A species restricted to the lowland mixed dipterocarp forests. It is occasionally cultivated for its edible fruit and the wood is thought to be used as durian timber. It is possible that the species is conspecific with $D$. affinis. Assessor: World Conservation Monitoring Centre Refs: $11145,18327,19073$

\section{Durio wyatt-smithii}

Bombacaceae

Malaysia (Peninsular Malaysia)

The possible wild progenitor of cultivated durian, the only differences from the cultivated form being a shorter calyx and more slender fruit spines. The species can be locally common. There are possible occurrences in Sarawak and Brunei.

Assessor: World Conservation Monitoring Centre

Refs: 11145

\section{Dussia foxii}

Leguminosae

VU D2

Peru

Known only from the type, the species occurs in lowland forest in the department of Loreto.

Assessor: World Conservation Monitoring Centre

Refs: 1984

\section{Dutaillyea amosensis}

Rutaceae

VU Dl

New Caledonia

Assessor: Jaffré, T. et al.

Refs: 10351

\section{Dyera polyphylla}

Apocynaceae

VUAlcd

Brunei, Indonesia (Kalimantan, Sumatra), Malaysia (Sabah, Sarawak)

Less well-known than the more common $D$. costata, this species is scattered in swamp forest, peat-swamp forest and *kerangas on groundwater podzols. The wood is traded as jelutong timber and trees are tapped for the valuable latex. The risk of extinction from overexploitation was recognised 60 years ago. Populations in Sarawak are considered endangered. Assessor: World Conservation Monitoring Centre Refs: $11145,12937,17214,19117$

\section{Dyerophytum pendulum}

Plumbaginaceae

VU D2

Yemen (Socotra)

The species occurs as a scattered solitary small tree or shrub in dry woodland or shrubland. At present populations are under no threat.

Assessor: Miller, A.G.

Refs: 19083

\section{Dyerophytum socotrano}

Plumbaginaceae

Yemen (Socotra)

VU D2

A newly described species, which, like $D$. pendulum, occurs as a scattered solitary small tree or shrub in dry woodland or shrubland. At present populations are under no threat.

Assessor: Miller, A.G.

Refs: 19083

\section{Dypsis ambanjae}

Palmae

CR D I

Madagascar

This endemic of the Madagascan rainforest has not been collected for over 80 years and is possibly extinct.

Assessor: Johnson, D.

Refs: 19118

\section{Dypsis ambositrae}

Palmae

CR D1

Madagascar

Currently only known to occur in the central region near Ambositra, the species is found among rocks and in remnant of riverine forest between $1300 \mathrm{~m}$ and $1500 \mathrm{~m}$.

Assessor: Dransfield, J. \& H.J. Beentje

Refs: 18986,19118

Dypsis ampasindavae

Palmae

EN Alcd

Madagascar

This Madagascan endemic is known from only two locations in Nosy Be and Manongarivo Mountains on steep slopes in moist lowland forest. Both sites are protected within Lokobe Special Reserve. However, tree poaching does occur.

Assessor: Dransfield, J. \& H.J. Beentje

Refs: 18986,19118

Dypsis andrianatonga

Palmae

$\mathrm{LR} / \mathrm{nt}$

Madagascar

A small branching palm, restricted to Manangarivo and the Marojejy Massif in north Madagascar. Its habitat is open montane forest or heath, although occasionally it is found on rocks in denser forest.

Assessor: Johnson, D.

Refs: 18986, 19118

Dypsis antanambensis

Palmae

EN D1

Madagascar

A tree confined to Mananara Avaratra Biosphere Reserve, where it inhabits open rainforest on ultramafic soils. There are fewer than 50 individuals in total, scattered between 250 and $290 \mathrm{~m}$ on steep slopes and ridge tops.

Assessor: Johnson, D.

Refs: 19118 


\section{Dypsis arenarum}

Palmae

CR B $1+2 \mathrm{c}$

Madagascar

A littoral forest species, found near fresh water. It is confined to an area lying between Soanierana-Ivango and Vatomandry. Population numbers are thought to be very low. Various developments and fires continue to threaten the habitat.

Assessor: Dransfield, J. \& H.J. Beentje

Refs: 18986, 19118

\section{Dypsis basilonga}

Palmae

EN C2b

Madagascar

This tree is confined to small crown submontane forest on gneiss in Vatovavy, Madagascar.

Assessor: Dransfield, J. \& H.J. Beentje

Refs: 18986,19118

\section{Dypsis bejofo}

Palmae

EN Alc

Madagascar

An endemic of Madagascar, known from only two sites of moist lowland forest in the bay of Antongil.

Assessor: Dransfield, J. \& H.J. Beentje

Refs: 18986, 19118

\section{Dypsis boiviniana}

Palmae

EN D1

Madagascar

This palm of forest undergrowth inhabits open lowland rainforest or sand forest next to black water and peat swamps. It is known only from three sites in northeastem Madagascar, only one of which is protected. The population is estimated to consist of $\mathbf{5 0}$ individuals.

Assessor: Dransfield, J. \& H.J. Beentje

Refs: 18986,19118

\section{Dypsis canaliculata}

Palmae

CR D1

\section{Madagascar}

The species has not been seen since 1951 and may possibly be extinct. Its flowers remain unknown to science. The two known collections were gathered from lowland forest on sandstone in locations which are geographically far apart, one in the Manongarivo area and another from Ampasimanolotra.

Assessor: Johnson, D.

Refs: 18986,19118

\section{Dypsis canescens}

Palmae

CR D1

Madagascar

This species has not been seen for over 50 years and may now be extinct. There is confusion over the type locality, which could either be at Ambaliha on the Ampasindava Peninsula or Ambaliha on the left bank of the Sambirano River. The habitat is defined as lowland moist forest on sandstone.

Assessor: Johnson, D.

Refs: 18986,19118

\section{Dypsis ceracea}

Palmae

CR D1

Madagascar

This species is known only from moist lowland forest in the Marojejy area and Betampona. It has not been seen since 1949.

Assessor: Johnson, D.

Refs: 18986,19118

\section{Dypsis commersoniana}

Palmae

CR B1+2c

Madagascar

A little known Madagascan endemic from the southeastern lowland rainforest. Most of the habitat has been cleared and the remainder is under intense pressure from the expanding human population.

Assessor: Dransfield, J. \& H.J. Beentje

Refs: 18986,19118

Dypsis confusa

Palmae

LR/nt

Madagascar

A Madagascan endemic of lowland rainforest in peat swamps, on ridge tops or flat ground. Populations are confined to Masoala, Mananara and Betampona. One site is protected.

Assessor: Johnson, D.

Refs: 18986, 19118

\section{Dypsis coursii}

Palmae

VU D1

Madagascar

A palm of moist montane forest or dense sclerophyll forest on ridges, usually found on gneiss and quartzite between 900 and $1850 \mathrm{~m}$. The global population is confined to the Marojejy area, which is restricted in size but protected.

Assessor: Johnson, D.

Refs: 19118

Dypsis crinita

Palmae

LR/nt

Madagascar

An endemic palm of Madagascar, confined to areas of lowland open forest in Manongarivo, Masoala Peninsula and Mananara Biosphere Reserve. Seedlings require frequent submerging in water, which may explain the species' common occurrence by streamsides.

Assessor: Johnson, D.

Refs: 18986, 19118

\section{Dypsis decaryi}

Palmae

VU D1

Madagascar

This species is confined to a small area of southem Madagascar, in dry forest or bush on stony soils. About 1000 individuals are thought to exist in the wild. Fire is a major threat and nearly all the seeds are harvested for export. In cultivation the species is widespread and grown in a wide variety of climates. It is listed in * CITES Appendix II.

Assessor: Dransfield, J. \& H.J. Beentje

Refs: 18986,19118 


\section{Dypsis decipiens}

Palmae

EN D1

Madagascar

This species is restricted to central Madagascar, between Ankazobe and Fianarantsoa, an area prone to forest destruction and fire. The number of individuals in the wild is estimated at about100. They inhabit remnant forest near streams or on rocky sites between 1400 and $2000 \mathrm{~m}$. Cultivation of the palm remains small-scale and the species is listed in * CITES Appendix II.

Assessor: Dransfield, J. \& H.J. Beentje

Refs: 18986,19118

\section{Dypsis dransfieldii}

Palmae

EN C2b

Madagascar

This species inhabits a single site of littoral forest on coastal white sand on the western side of Masoala Peninsula in north-east Madagascar. The habitat is fragile and prone to grazing and clearance for agriculture or settlements.

Assessor: Dransfield, J. \& H.J. Beentje

Refs: 18986,19118

\section{Dypsis faneva}

Palmae

EN Alc, Cl

\section{Madagascar}

An endemic species confined to areas of littoral forest or lowland moist forest in Maroantsetra, Mananara and near Fenoarivo. The lowland rainforest in these areas is not well protected. Fewer than 50 individuals are estimated to exist in total.

Assessor: Dransfield, J. \& H.J. Beentje

Refs: 18986,19118

\section{Dypsis fasciculata}

Palmae

VU Alc

\section{Madagascar}

A coastal forest palm, rarely extending inland, within an area stretching from Antalaha and Marojejy to Betampona in the north-east of Madagascar. The habitat is often affected by fires.

Assessor: Dransfield, J. \& H.J. Beentje

Refs: 18986, 19118

\section{Dypsis heteromorpha}

Palmae

Madagascar

A palm of moist montane forest, confined to Tsaratanana, Marojejy and Anjanaharibe in northern Madagascar. The area is not botanically well known.

Assessor: Dransfield, J. \& H.J. Beentje

Refs: 19118

\section{Dypsis hovomantsina}

Palmae

Madagascar

An impressive rainforest tree growing on steep slopes or ridge crests, known only from Maroantsetra and Mananara. Both sites are under pressure from increasing agriculture. The known populations consist of few individuals.

Assessor: Dransfield, J. \& H.J. Beentje

Refs: 18986,19118

\section{Dypsis ifanadianae}

Palmae

CR D1

Madagascar

A slender palm, known only from lowland rainforest in the Ifanadiana area, which is undergoing continuous deforestation. Fewer than 50 individuals are known in total.

Assessor: Dransfield, J. \& H.J. Beentje

Refs: 19118

\section{Dypsis intermedia}

Palmae

CR D1

Madagascar

Fewer than 50 individuals are confined to a single locality of steadily dwindling lowland rainforest in Manombo in Madagascar.

Assessor: Dransfield, J. \& H.J. Beentje

Refs: 18986,19118

\section{Dypsis interrupta}

Palmae

CR B $1+2 \mathrm{c}$

\section{Madagascar}

An omamental palm of hill forest undergrowth, currently known only from a single collection in the south-east of Madagascar around Ifanadiana and Ambinanindrano. The forests of Ambinanindrano are gradually being destroyed by shifting cultivation.

Assessor: Dransfield, J. \& H.J. Beentje

Refs: 18986,19118

\section{Dypsis lanceolata}

Palmae

VUD2

Comoros

This species is restricted to Grande Comore and Moheli in the Comoro Islands. It inhabits rainforest between 500 and $1000 \mathrm{~m}$. Information is lacking on the current population status and the species may be more seriously threatened.

Assessor: World Conservation Monitoring Centre

Refs: 18986,19118

\section{Dypsis ligulata}

Palmae

CR D1

Madagascar

A tree last seen over 70 years ago in the lowland moist forest of north-west Madagascar.

Assessor: Johnson, D.

Refs: 18986,19118

\section{Dypsis madagascariensis}

Palmae

$\mathrm{LR} / \mathrm{nt}$

Madagascar

Although rare, the species is widespread in north-west and westem Madagascar. It occurs in moist rainforest and semi-deciduous dry or plateau forest up to $650 \mathrm{~m}$. Populations are also found rarely in palm grassland, dry bushland and coastal forest. The total population consists of several thousand individuals. Habitat destruction is reducing the number of populations. Harvesting of palm heart and wood continues, even in the single protected location in Lokobe Special Reserve. Assessor: Johnson, D.

Refs: 18986, 19118

Dypsis malcomberi

Palmae

VU D2

Madagascar

This palm is known only from Andohahela Special Reserve, where it inhabits submontane moist forest on 
slight or steep slopes, occasionally near forest streams. Assessor: Johnson, D.

Refs: 18986, 19118

\section{Dypsis mananjarensis}

Palmae

Madagascar

VU D1

This species is confined to lowland moist and dry forest remnants between Vatomandry and Talanaro in eastern Madagascar. The entire area suffers high levels of habitat destruction as a result of various anthropogenic activities.

Assessor: Dransfield, J. \& H.J. Beentje

Refs: 18986,19118

\section{Dypsis mangorensis}

Palmae

Madagascar

CR D 1

A Madagascan endemic, confined to littoral or lowland rainforest in Mananara Biosphere Reserve. There is an old collection from the lower Mangoro River. Only a single sighting has been made recently, consisting of fewer than 20 individuals in a forest patch surrounded by agriculture and under threat of agricultural conversion.

Assessor: Dransfield, J. \& H.J. Beentje

Refs: 18986,19118

\section{Dypsis medonaldiana}

Palmae

VU A2c

Madagascar

A Madagascan endemic, confined to the mountains in the south-east, where it is found at rainforest edges between 300 and $1100 \mathrm{~m}$. The area of occurrence is small but partially protected.

Assessor: Dransfield, J. \& H.J. Beentje

Refs: 18986,19118

\section{Dypsis nauseosa}

Palmae

Madagascar

CR DI

A Madagascan endemic known only from two recent collections, gathered in coastal lowland forest in Fianarantsoa Province. Fewer than 20 trees are known to exist and the area is being rapidly cut down.

Assessor: Dransfield, J. \& H.J. Beentje

Refs: 18986,19118

\section{Dypsis nossibensis}

Palmae

CR D1

\section{Madagascar}

A timber species, confined to Lokobe forest in the northwest, where a number of palm species are felled for timber. Fewer than 25 trees have been counted.

Assessor: Dransfield, J. \& H.J. Beentje

Refs: 18986,19118

\section{Dypsis onilahensis}

Palmae VU D1

Madagascar

A palm confined to north-west, west and south-central Madagascar, inhabiting riverine forest and evergreen forest. Total numbers are estimated to be less than 1000 . The species is most abundant within the flood level on the rocky banks of the Analabe River. The area of occurrence is fairly large, but the habitat is prone to outbreaks of fire.

Assessor: Dransfield, J. \& H.J. Beentje

Refs: 18986,19118

\section{Dypsis oreophila}

Palmae

Madagascar

An endemic palm of Madagascar confined to areas of moist montane forest in Tsaratanana, Marojejy, high ground near Maroansterta and Mandritsara. The distribution is limited and the palm heart is highly esteemed, putting the species under considerable pressure.

Assessor: Dransfield, J. \& H.J. Beentje

Refs: 18986, 19118

\section{Dypsis oropedionis}

Palmae

CR C2a

Madagascar

This palm is known only from two sites on the western side of Madagascar's central plateau, inhabiting relict dry evergreen forest on steep-sided valleys between 1100 and $1450 \mathrm{~m}$. Neither population is protected and their habitat is under severe threat from cutting and annual fires.

Assessor: Dransfield, J. \& H.J. Beentje

Refs: 18986, 19118

\section{Dypsis ovobontsira}

Palmae

CR D1

Madagascar

A Madagasacan endemic, known from a single population of fewer than 10 individuals contained within Mananara Biosphere Reserve. It is found in moist submontane forest on ultramafic soil with a deep humus layer.

Assessor: Dransfield, J. \& H.J. Beentje

Refs: 18986,19118

\section{Dypsis paludosa}

Palmae

VUAlc

Madagascar

An endemic palm, occurring along the east coast in small pockets of peat swamp developed on white sand adjacent to the beach zone and also found in swampy areas further inland. Although the coastal lowland forest, which the species inhabits, is widespread it is threatened Assessor: Dransfield, J. \& H.J. Beentje

Refs: 18986, 19118

Dypsis pembana

Palmae

VU C2b

Tanzania

An endemic palm of Tanzania, confined to lowland moist and littoral forest in Ngezi forest on Pemba Is. The population is estimated at 3000 individuals.

Assessor: Dransfield, J. \& H.J. Beentje

Refs: 18986, 19118

\section{Dypsis perrieri}

Palmae

VU Alc

Madagascar

An endemic palm of Madagascar, inhabiting moist forest between 150 and $800 \mathrm{~m}$, in Marojejy, Masoala and Mananara Avaratra. Despite its fairly wide distribution, the species is uncommon wherever it is found. Overexploitation of the palm heart is a major threat.

Assessor: Johnson, D

Refs: 18986, 19118 


\section{Dypsis pilulifera}

Palmae

VU B I $+2 \mathrm{C}$

Madagascar

This endemic palm of Madagascar is confined to moist montane forest in the Sambirano region, Marojejy and Mantady. Harvesting of the palm heart continues even within Marojejy and Mantady protected areas.

Assessor: Dransfield, J. \& H.J. Beentje

Refs: 18986,19118

\section{Dypsis prestoniana}

Palmae

VU D1

Madagascar

The entire population does not exceed 200 individuals, confined to the Midongy area. The former population in Mahanoro appears to be extinct. In no part of its range is it protected.

Assessor: Dransfield, J. \& H.J. Beentje

Refs: 18986,19118

\section{Dypsis procero}

Palmae

VU Alc

Madagascar

A Madagascan endemic, confined to the area around Antongil. The lowland rainforest habitat in this area is under threat from shifting cultivation.

Assessor: Dransfield, J. \& H.J. Beentje

Refs: 18986,19118

\section{Dypsis psammophila}

Palmae

CR C2a

Madagascar

A palm confined to east Madagascar, between Soanierana Ivongo and Ambila-Lemaitso. The area of occupancy is small, containing fewer than 100 trees and the lowland coastal forest habitat is being destroyed.

Assessor: Dransfield, J. \& H.J. Beentje

Refs: 18986,19118

\section{Dypsis rivularis}

Palmae

EN D1

Madagascar

A palm confined to Mananjeba River, at Manongarivo and Ankarafantsika, where it inhabits streamside forest between 130 and $300 \mathrm{~m}$. The total population is estimated to contain less than 100 individuals.

Assessor: Dransfield, J. \& H.J. Beentje

Refs: 18986, 19118

\section{Dypsis sahanofensis}

Palmae

EN Alc

Madagascar

Formerly known only from the type collection of 1911 , the species has now been found in an area of submontane rainforest on Mount Vatovavy, eastern Madagascar. Population numbers are low and the forest is unprotected, although local taboos do provide some form of protection. The status will become critical in the next few years if forest clearance continues.

Assessor: Dransfield, J. \& H.J. Beentje

Refs: 18986,19118

\section{Dypsis saintelucei}

Palmae

CR DI

Madagascar

Confined to a single site in Sainte-Luce forest, the species is known from a total population of $\mathbf{5 0}$ individuals. The area is threatened by proposed mining operations for mineral sand (ilmenite ore).

Assessor: Dransfield, J. \& H.J. Beentje

Refs: 18986,19118

\section{Dypsis scottiana}

Palmae

VU DI

Madagascar

An endemic palm of south-east Madagascar, inhabiting forest and heath scrub on white sand between 10 and $515 \mathrm{~m}$. The species range is small and the habitat is under threat from mining operations and fire.

Assessor: Dransfield, J. \& H.J. Beentje

Refs: 19118

\section{Dypsis serpentina}

Palmae

VU D2

Madagascar

A palm confined to Mananara Biosphere Reserve in Madagascar, where it is locally abundant in lowland rainforest on steep slopes and ridgetops on ultramafic soils, between 240 and $280 \mathrm{~m}$.

Assessor: Dransfield, J. \& H.J. Beentje

Refs: 18986,19118

Dypsis singularis

Palmae

Madagascar

Confined to Manombo forest, the species inhabits lowland rainforest at the base of slopes. Shifting cultivation, fire and logging have gradually destroyed the forest. The number of trees remaining is estimated to be less than 100

Assessor: Dransfield, J. \& H.J. Beentje

Refs: 18986,19118

\section{Dypsis tsaratananensis}

Palmae

Madagascar

This palm, endemic to Madagascar, has not been seen for 70 years. Mount Tsaratanana, where the species occurs, has not been visited for a long time. The palm heart is edible and highly esteemed.

Assessor: Dransfield, J. \& H.J. Beentje

Refs: 18986,19118

\section{Dypsis tsaravotsira}

Palmae

Madagascar

EN Alcd

This endemic palm is confined to Marojejy, Maroantsetra and Mananara, where it occurs in submontane primary woodland on steep slopes or ridgetop hollows. Population numbers are low and two of the sites are under pressure from agriculture.

Assessor: Dransfield, J. \& H.J. Beentje

Refs: 19118

\section{Dypsis utilis}

Palmae

VU Alcd

Madagascar

This gregarious palm is restricted to eastem Madagascar, where it is restricted to only a few streamside sites of swamp or moist forest between 950 and $1000 \mathrm{~m}$. Numbers are thought to be small.

Assessor: Dransfield, J. \& H.J. Beentje

Refs: 18986,19118 


\section{Dysosma versipellis}

Berberidaceae

VU Alcd

China (Anhui, Fujian, Guangxi, Guizhou, Henan, Hubei, Hunan, Jiangxi, Shaanxi, Sichuan, Yunnan, Zhejiang)

Although the species has a wide distribution, populations are small and declining. It has a wide altitudinal range within moist seasonal forest, sometimes bamboo forest. Roots and seeds are commonly collected for medicinal use, mostly at a local level.

Assessor: World Conservation Monitoring Centre

Refs: $1818,11847,19055$

\section{Dysoxylum angustifolium}

Meliaceae

VU B $1+2 c$

Philippines

A species of primary forest, only found in Palawan. The main island is declared a biosphere reserve.

Assessor: World Conservation Monitoring Centre

Refs: 4986,18088

\section{Dysoxylum beddomei}

Meliaceae

EN B $1+2 \mathrm{c}$

India (Kerala)

Occurring in evergreen forest between 250 and $1200 \mathrm{~m}$, the species has been recorded from only a few localities in northern Kerala.

Assessor: World Conservation Monitoring Centre

Refs: 19144

\section{Dysoxylum ficiforme}

Meliaceae

VU B $1+2 c$

India (Kerala)

At present five collections are known from scattered localities in the Anamalai and Travancore ranges. The species occurs in the canopy of submontane evergreen forest.

Assessor: World Conservation Monitoring Centre

Refs: 19144

\section{Dysoxylum pachypodum}

Meliaceae

New Caledonia

Collected very rarely and only recently from an area near Sarraméa, the species has a precarious existence in cultivated fields and also on river borders.

Assessor: Jaffré, T, et al.

Refs: 10351,12630

\section{Dysoxylum palawanensis}

Meliaceae

VU B $1+2 \mathrm{c}$

Philippines

A primary forest species, endemic to Palawan at low altitudes. The main island is declared a biosphere reserve.

Assessor: World Conservation Monitoring Centre

Refs: 4986

\section{Dysoxylum peerisi}

Meliaceae

$\mathrm{CR} B 1+2 \mathrm{c}$

Sri Lanka

This rare tree is restricted to lowland rainforest in southwest Sri Lanka. It was not found during the extensive forest surveys conducted for the National Conservation Review, indicating that it is extremely rare or possibly extinct. Earlier surveys located a population in Sinharaja Biosphere Reserve.

Assessor: World Conservation Monitoring Centre Refs: 17195,19112
Dysoxylum turczaninowii

Meliaceae

VU Alcd

Philippines

A timber species, endemic to the Philippines. Rates of habitat loss through logging and shifting cultivation have led to considerable population declines.

Assessor: World Conservation Monitoring Centre

Refs: $2072,4919,18088$

Ecclinusa lancifolia

Sapotaceae

VU Bl+2c

Brazil (Amazonas)

A shrub or tree known from very few collections originating from permanently flooded forest in central Brazilian Amazonia.

Assessor: Pires O'Brien, J.

Refs: $1983,7980,8816$

\section{Ecclinusa orinocoensis}

Sapotaceae

VU D2

Venezuela

A treelet with a distribution confined to a small area of periodically flooded sandy savanna in Amazonas. Assessor: World Conservation Monitoring Centre Refs: 7980,8816

\section{Ecclinusa parviflora}

Sapotaceae

Venezuela

VU D2

A newly described species, currently known from just two collections taken from a site of low forest over granitic rocks near Puerto Ayacucho.

Assessor: World Conservation Monitoring Centre

Refs: 7980,8816

\section{Ehretia glandulosissima}

Boraginaceae

$\mathrm{EN} \mathrm{B1}+2 \mathrm{c}$

Tanzania

The species range now appears to be confined to the undisturbed areas of Rondo Forest Reserve $\left(140 \mathrm{~km}^{2}\right)$.

Logging, planting of commercial timbers, shifting cultivation and wood collection in the past have caused disturbance to much of the forest. Current forestry management activities are discouraging illegal activities. Assessor: Lovett, J. \& G.P. Clarke

Refs: 10961, 16796

\section{Ehretia scrobiculata}

Boraginaceae

VU D2

São Tomé \& Príncipe (Príncipe)

It appears that only two collections have been made, one being from the coast where just one tree was located. More detailed information is lacking. There have been no recent botanical surveys of the island.

Assessor: World Conservation Monitoring Centre Refs: 2724

\section{Ekmanianthe longiflora}

Bignoniaceae

Cuba, Dominican Republic, Haiti

EN Alc, Bl+2cd

A tree confined to semi-deciduous forest in Cuba and Hispaniola. In Cuba and Haiti, the species has disappeared from most places where logging, settlement and agricultural expansion have taken place. In the Dominican Republic it has been reported only from Sierra de Barahona.

Assessor: Areces-Mallea, A.E.

Refs: $7980,8451,19149$ 


\section{Elaeagia ecuadorensis}

Rubiaceae

VU B1+2c

Ecuador

This Ecuadorean endemic inhabits cloud forest between 2250 and $3500 \mathrm{~m}$. Currently it is known to occur in the High Andean regions of Morona-Santiago and Loja.

Assessor: World Conservation Monitoring Centre

Refs: 19119,19120

\section{Elaeagia pastoensis}

Rubiaceae

VU B $1+2 c$

Colombia

An endemic to Putumayo.

Assessor: Calderon, E.

Refs: 19069

\section{Elacagia uxpanapensis}

Rubiaceae

EN A1c

Mexico (Chiapas)

A relatively common tree of evergreen hill forest. confined to the Uxpananpa-Chimalapa region.

Assessor: World Conservation Monitoring Centre

Refs: $5651,5993,14953,19124$

\section{Elaeagnus conferta ssp. dendroidea}

Elaeagnaceae

CR B $1+2 c$

India (Meghalaya)

This subspecies is confined to the Khasi Hills, where it occurs in hill forest. Only a single occurrence is known and numbers are believed to be very small.

Assessor: World Conservation Monitoring Centre

Refs: 4799

\section{Elaeagnus mollis}

Elaeagnaceac

VU Aled

China (Shaanxi, Shanxi)

Restricted to Xiangning, Hejin and Yicheng Counties in Shanxi and Huxian County in Shaanxi, the species is scattered on mountain slopes between 800 and $1500 \mathrm{~m}$. The numbers of large individuals and the overall natural extent of the species is declining because of overcutting. Assessor: World Conservation Monitoring Centre Refs: 1818,11847

\section{Elaeagnus tarokoensis}

Elaeagnaceae

Taiwan

Endemic to Taiwan, the species occurs in lowland forest in a small area to the east around Tienshiang.

Assessor: Lu, S.Y. \& F.J. Pan

Refs: 19053

\section{Elaeocarpus acmosepalus}

Elaeocarpaceae

Malaysia (Peninsular Malaysia), Singapore VU B $1+2 c$

A medium-sized tree scattered throughout the freshwater and peat-swamp forest in Pehang, Selangor and Johore in Peninsular Malaysia, and parts of Singapore.

Assessor: Chua, L.S.L.

Refs: 9199, 19073

\section{Elaeocarpus apiculatus}

Elaeocarpaceae

VU B $1+2 a$

Malaysia (Peninsular Malaysia), Viet Nam

A large tree of primary forest, on valley and mountain slopes up to $330 \mathrm{~m}$. Regeneration under the canopy of wet forests is reported to be profuse in Viet Nam, where it is known from Ninh Binh (Cuc Phuong National Park), Thanh Hoa and Lam Dong Provinces. Populations are localised in Peninsular Malaysia in Kelantan, Terengganu and Perak.

Assessor: Chua, L.S.L.

Refs: 8464, 15357, 19073

Elaeocarpus beccarii ssp. beccarii

Elaeocarpaceae

VU B $1+2 c$

Malaysia (Sarawak)

A few localities are known in the region of Kuching. The taxon occurs in primary lowland forest. All forms of this species are restricted in range.

Assessor: World Conservation Monitoring Centre Refs: 4074

\section{Elaeocarpus beccari ssp. nitens}

Elaeocarpaceae

VU B I + 2 c

Malaysia (Sarawak)

A tree of Sarawak hill forest occurring in a number of localities in Lundu District. All the forms of this species are restricted in range.

Assessor: World Conservation Monitoring Centre Refs: 4074

\section{Elaeocarpus beccari ssp. sumatrana}

Elaeocarpaceae

VU B1 $+2 \mathrm{c}, \mathrm{D} 2$

Indonesia (Sumatra)

Known only from the type collection, this newly described subspecies is found in lowland ridge forest in Sumatra.

Assessor: World Conservation Monitoring Centre

Refs: 4074

\section{Elaeocarpus blascoi}

Elaeocarpaceae

$\mathrm{EN} \mathrm{B1+2c}$

India (Tamil Nadu)

Occurring on the fringes of moist evergreen forest at an altitude of $2150 \mathrm{~m}$, the species is confined to the Palni and Kodaikanal HIlls. It has not been found in recent years and may have suffered the conversion of its habitat to agricultural land.

Assessor: World Conservation Monitoring Centre

Refs: 4799,19144

\section{Elaeocarpus bojeri}

Elaeocarpaceae

CR D1

Mauritius

Fewer than 10 dwarfed trees are found in degraded cloud forest close to an Indian temple in the Grand Bassin. They are being closely monitored.

Assessor: Page, W.

Refs: $1411,9120,16426$

\section{Elaeocarpus brigittae}

Elaeocarpaceae

VU D2

Indonesia (Sumatra)

A newly described species known from montane rainforest and mossy forest in Gunung Leuser National Park in Sumatra.

Assessor: World Conservation Monitoring Centre Refs: 4074

\section{Elaeocarpus calomala var. pustulatus}

Elaeocarpaceae

VU Alc, B1+2c

Philippines

A tree found in remaining upland forest in Mindanao, Mindoro, Luzon and possibly Sibuyan.

Assessor: World Conservation Monitoring Centre

Refs: 4074 
Elaeocarpus calomala var. villosiusculus

Elaeocarpaceae

Philippines

This variety is very poorly known and the status of any remaining populations in the wild is completely unknown. It was collected from Tayabas on Luzon.

Assessor: World Conservation Monitoring Centre

Refs: 4074

\section{Elaeocarpus ceylanicus}

Elaeocarpaceae

$\mathrm{EN} \mathrm{Bl+2c}$

Sri Lanka

A species found only at three localities during the extensive National Conservation Review forest surveys. Assessor: World Conservation Monitoring Centre Refs: 8203, 18796, 19112

\section{Elaeocarpus colnettianus}

Elaeocarpaceae

VU D1

New Caledonia

A species known only from locations on Mont Colnett and Mont Ignambi in the north-east of Grand Terre, where it occurs in some abundance in forest between 1000 and $1350 \mathrm{~m}$

Assessor: Jaffré, T. et al.

Refs: 10351,12630

\section{Elaeocarpus cordifolius}

Elaeocarpaceae

LR/cd

Indonesia (Kalimantan), Malaysia (Sarawak)

Occurring in open shrubland, this small tree is recorded in Gunung Mulu National Park in Sarawak and one location in Kalimantan.

Assessor: World Conservation Monitoring Centre Refs: 4074

\section{Elaeocarpus coriaceus}

Elaeocarpaceae

$\mathrm{EN} \mathrm{B1}+2 \mathrm{C}$

Sri Lanka

During the extensive National Conservation Review forest surveys, this species was found in only two sites: Horton Plains National Park and the Peak Wilderness Sanctuary.

Assessor: World Conservation Monitoring Centre

Refs: 19112

\section{Elaeocarpus cruciatus}

Elaeocarpaceae

Malaysia (Peninsular Malaysia)

Occurring in montane and submontane rainforest, this uncommon species is found in Gunung Padang, Gunung Mandi Angin in Terengganu and Fraser's Hill, Gunung Ulu and the Kali/Genting Highlands in Pahang. It receives protection within a national park and the permanent forest estate.

Assessor: Chua, L.S.L.

Refs: 8464, 19073

\section{Elaeocarpus dinagatensis}

Elaeocarpaceae

VU D2

Philippines

Little is known about the present status of this lowland species. It was collected in 1919 from two small islands, Bucas Grande and Dinagrat, off the north-east tip of Mindanao.

Assessor: World Conservation Monitoring Centre Refs: 4074

\section{Elaeocarpus eriobotryoides}

Elaeocarpaceae

Malaysia (Peninsular Malaysia)

VU $B 1+2 c$

This endemic tree occurs in montane forests of southern Peninsular Malaysia, up to $1510 \mathrm{~m}$. Its known localities are under threat from infrastructural development.

Assessor: Chua, L.S.L.

Refs: 8464, 19073

\section{Elaeocarpus fraseri}

Elaeocarpaceae

VU D2

Malaysia (Peninsular Malaysia)

Known only from Peninsular Malaysia, this montane forest species is probably endemic to Fraser's Hill in Pahang. A more serious threat category may be appropriate pending further information.

Assessor: World Conservation Monitoring Centre

Refs: 4074

\section{Elaeocarpus gaussenii}

Elaeocarpaceae

$\mathrm{CR} B 1+2 \mathrm{c}$

India (Tamil Nadu)

Little is known about this species. It has been collected just once or twice from a single locality of evergreen forest at about $1500 \mathrm{~m}$ in the Westem Ghats.

Assessor: World Conservation Monitoring Centre Refs: 4799,19144

\section{Elaeocarpus gigantifolius}

Elaeocarpaceae

VU D2

Philippines

A tree only definitely known from the 1909 type collection from steep sloping forest on Mount Apo on Mindanao. The mountain has been relatively wellvisited. It also has national park status, although shifting cultivation and illegal logging continue to take place. Other specimens from Leyte Island are similar but more material is needed to confirm they are same species.

Assessor: World Conservation Monitoring Centre Refs: 4074

\section{Elaeocarpus glabrescens}

Elaeocarpaceae

Malaysia (Peninsular Malaysia)

LR/cd

A species found between 450 and $1830 \mathrm{~m}$ within a range extending from the Cameron Highlands to Gunung Angsi and Gunung Panti in Johore. It is locally common on Gunung Inas and Gunung Jerai in Kedah. Some areas receive a degree of protection within the permanent forest estate.

Assessor: Chua, L.S.L.

Refs: 8464,19073

\section{Elaeocarpus glandulifer}

Elaeocarpaceae

VU Alc

Sri Lanka

A tree occurring in the lowland wet evergreen forests of south-west Sri Lanka.

Assessor: World Conservation Monitoring Centre

Refs: $9176,17195,17759$

\section{Elaeocarpus homalioides}

Elaeocarpaceae

DD

Indonesia (Irian Jaya), Papua New Guinea

A New Guinea endemic recorded from a few locations.

It has not been collected in recent years.

Assessor: World Conservation Monitoring Centre

Refs: 4074 


\section{Elaeocarpus inopinatus}

Elaeocarpaceae

VU D2

Malaysia (Sabah)

A small tree known from one location in scrubby forest in Mount Kinabalu National Park.

Assessor: World Conservation Monitoring Centre

Refs: 4074

\section{Elaeocapus integrifolius}

Elaeocarpaceae

CR D1

Mauritius

The most recent population estimate, in March 1997, is 51 individuals. Trees are found in small groups or as isolated individuals in upland evergreen forest in the Black River Gorges, Macchabe and Brise Fer. There are also isolated trees in the northern mountain ranges. No natural regeneration has been observed.

Assessor: Page, W.

Refs: $1411,9120,16426$

\section{Elaeocarpus miriensis}

Elaeocarpaceae

VU D2

Brunei

Known from just two collections, this species occurs near river banks in valley forest in Tutong District in Bnunei and in Sarawak.

Assessor: World Conservation Monitoring Centre

Refs: 4074

\section{Elaeocarpus moratü}

Elaeocarpaceae

VUDI

New Caledonia

A species described in 1982 and known only from the location where the type specimen was collected on Mont Ignambi.

Assessor: Jaffré, T. et al.

Refs: 10351,12630

\section{Elaeocarpus munronii}

Elaeocarpaceae

$\mathrm{LR} / \mathrm{nt}$

India (Kamataka, Maharashtra, Tamil Nadu)

An uncommon tree occurring in evergreen and *shola forest between 600 and $2000 \mathrm{~m}$ over a wide range at the southern end of the Western Ghats.

Assessor: World Conservation Monitoring Centre

Refs: 4799, 19144

\section{Elaeocarpus nanus}

Elaeocarpaceae

$\mathrm{LR} / \mathrm{cd}$

Malaysia (Peninsular Malaysia)

Scattered in moist forest between 1000 and $2000 \mathrm{~m}$, the species is found in Perak, Pahang, Selangor and Johore. Some localities receive a degree of protection within the permanent forest estate.

Assessor: Chua, L.S.L.

Refs: 8464, 19073

\section{Elaeocarpus prunifolius}

Elaeocarpaceae

VU BI+2c

Bangladesh, India (Manipur, Meghalaya)

This species appears to be restricted to remaining sacred groves of moist evergreen or semi-evergreen forest in the Khasi Hills and Manipur.

Assessor: World Conservation Monitoring Centre

Refs: 4799

\section{Elaeocarpus pseudopaniculatus}

Elaeocarpaceae

LR/cd

Malaysia (Peninsular Malaysia)

Occurring in primary submontane to montane rainforest in the state of Pahang, the species is protected within the boundaries of Taman Negara National Park and within the permanent forest estate.

Assessor: Chua, L.S.L.

Refs: 8464, 19073

\section{Elaeocarpus recurvatus}

Elaeocarpaceae

VU B $1+2 c$

India (Tamil Nadu)

Occurring in evergreen forest and *shola forest above $1800 \mathrm{~m}$, the species is endemic to the Anamalai range and parts of the Nilgiris. Its habitat has been strongly affected by fire and conversion to commercial plantations.

Assessor: World Conservation Monitoring Centre

Refs:" 4799, 19144

\section{Elaeocarpus reticosus}

Elaeocarpaceae

LR/cd

Malaysia (Peninsular Malaysia)

A shrubby tree, inhabiting moist forest between 1000 and $2000 \mathrm{~m}$ on Gunung Rabong in Kelantan, Gunung

Bubu in Perak, Gunung Tahan in Pahang and on Gunung

Blumut in Johore. Populations are protected in the Taman Negara National Park and in the permanent forest estate.

Assessor: Chua, L.S.L

Refs: 8464,19073

\section{Elaeocarpus royenii}

Elaeocarpaceae

VU D2

Indonesia (Irian Jaya)

A newly described species known only from the type collection. It occurs along Bot River in Merauke District.

Assessor: World Conservation Monitoring Centre

Refs: 4074

\section{Elaeocarpus rugosus}

Elacocarpaceae

VU B $1+2 c$

Malaysia (Peninsular Malaysia), Singapore

A tall tree up to $39 \mathrm{~m}$, inhabiting moist lowland and hill forest. This tree can be found in Perak, Terengganu, Pahang, Selangor, Johore and Singapore. It is protected in Cameron Highlands Wildlife Sanctuary.

Assessor: Chua, L.S.L.

Refs: 9199, 19073

\section{Elaeocarpus sallehiana}

Elaeocarpaceae

LR/cd

Malaysia (Peninsular Malaysia)

A species inhabiting hill and mountain rainforest up to $1070 \mathrm{~m}$ in Pahang and Terengganu. It receives a degree of protection within the permanent forest estate.

Assessor: Chua, L.S.L.

Refs: 8464,19073

\section{Elaeocarpus simaluensis}

Elaeocarpaceae

VU D2

Indonesia (Sumatra)

A species known from one location in swamp forest on Simalue Island, north-west Sumatra.

Assessor: World Conservation Monitoring Centre

Refs: 4074 
Elaeocarpus submonoceras ssp. collinus

Elacocarpaceae

Indonesia (Kalimantan), Malaysia (Sabah)

A montane forest tree found in Kalimantan and the Mount Kinabalu region in Sabah.

Assessor: World Conservation Monitoring Centre

Refs: 4074

Elacocarpus submonoceras ssp. fusicarpus

Elaeocarpaceae

VU Alc, B1+2c

Philippines

A tree that is found in damp montane forest habitats in Mindoro, Negros and Mindanao.

Assessor: World Conservation Monitoring Centre

Refs: 4074

\section{Elaeocarpus submonoceras ssp. oliganthus}

Elaeocarpaceae

$\mathrm{CR} B 1+2 \mathrm{c}$

Philippines

This subspecies is known only from its type locality in Zamboanga District in Mindanao, from where it was collected at the beginning of the century. The monsoon forest here has been almost completely degraded.

Assessor: World Conservation Monitoring Centre

Refs: 4074

\section{Elaeocarpus submonoceras ssp. oxypyren}

Elaeocarpaceae

VU B $1+2 \mathrm{c}$

Indonesia (Bali, Java)

A forest tree restricted to a few locations in Java and

Bali.

Assessor: World Conservation Monitoring Centre

Refs: 4074

\section{Elaeocarpus submonoceras ssp. procerus}

Elaeocarpaceae

VU D2

Philippines

A subspecies known only from the type locality in the Cuemos Mountains, from where it was collected in 1908. New information may indicate that the species is extinct or that a more serious threat category is appropriate.

Assessor: World Conservation Monitoring Centre

Refs: 4074

\section{Elaeocarpus submonoceras ssp. submonoceras}

Elaeocarpaceae

VU B $1+2 c$

Indonesia (Sumatra), Malaysia (Peninsular Malaysia)

A tree known from primary forest in Sumatra and

Peninsular Malaysia, where it has not been collected since 1929.

Assessor: World Conservation Monitoring Centre

Refs: 4074

\section{Elaeocarpus subvillosus}

Elaeocarpaceae

VUAlc

Sri Lanka

A tree occurring in the lowland wet evergreen forests of south-west Sri Lanka.

Assessor: World Conservation Monitoring Centre

Refs: 9176, 17195, 18515

\section{Elaeocapus symingtonü}

Elaeocarpaceae

LR/cd

Malaysia (Peninsular Malaysia)

A small tree of montane rainforest, distributed between 1400 and $2200 \mathrm{~m}$ at Perak in Gunung Bubu, Terengganu in Gunung Mandi Angin and Pahang in the Cameron
Highlands, Gunung Berebun. Protected populations are found within Taman Negara National Park and the permanent forest estate.

Assessor: Chua, L.S.L.

Refs: 8464,19073

\section{Elaeocarpus teysmannü ssp. domatiferus}

Elaeocarpaceae

VU D2

Indonesia (Sulawesi)

Recently found and described, this tree is known only from lower montane forest in Dumoga Bone National Park.

Assessor: World Conservation Monitoring Centre Refs: 4074

\section{Elaeocarpus teysmannii ssp. moluccensis}

Elaeocarpaceae

VU D2

Indonesia (Moluccas)

A variant known only from the type locality in the Moluccas. It is said to be common where it occurs in thinned-out forest at the sides of a river.

Assessor: World Conservation Monitoring Centre

Refs: 4074

\section{Elaeocarpus teysmannii ssp. morowalensis}

Elaeocarpaceae

VU D2

Indonesia (Sulawesi)

A lowland tree known only from a relatively recent collection made on a ridge top in Morowali in north-east Sulawesi.

Assessor: World Conservation Monitoring Centre

Refs: 4074

\section{Elaeocarpus teysmannii ssp. rhizophorus}

Elaeocarpaceae

VU D2

Indonesia (Sulawesi)

A tree known only from one collection from Minahasa, north Sulawesi. There are reports from the early part of the century that it was planted and protected as a sacred tree. New information may indicate that a more serious threat category is appropriate.

Assessor: World Conservation Monitoring Centre

Refs: 4074

\section{Elaeocarpus teysmannii ssp. teysmannii}

Elaeocarpaceae

Indonesia (Sulawesi)

A Sulawesi endemic known only from Minahasa.

Assessor: World Conservation Monitoring Centre Refs: 4074

\section{Elaeocarpus venustus}

Elaeocarpaceae

India (Kerala, Tamil Nadu)

VU B $1+2 c$

A large tree of submontane evergreen forest. It is narrowly distributed in the southern end of the Western Ghats, occurring in Chimunji and Muthukuzhivayal and nearby areas, where the forest has been extensively cleared for a hydroelectric project.

Assessor: World Conservation Monitoring Centre

Refs: 10733, 14276, 19144

\section{Elaeodendron Laneanum}

Celastraceae

VU D2

Bermuda

Occurring, sometimes commonly, on rocky upland hillsides throughout the eastem end of the island, Harrington Sound, Walsingham and Abbotts Cliff, the species is under no immediate threat. It is also widely 
planted in gardens and within its native range as part of a conservation initiative.

Assessor: World Conservation Monitoring Centre

Refs: 19143

\section{Elaeoluma crispa}

Sapotaceae

LR/nt

Venezuela

The rarest of the four species in the genus. It occurs in areas of periodically or permanently flooded forest confined to Amazonas State.

Assessor: World Conservation Monitoring Centre

Refs: 7980,8816

\section{Elattostachys aiyurensis}

Sapindaceae

VU D2

Papua New Guinea

A small palmoid tree known only from the type collection from Madang Province.

Assessor: World Conservation Monitoring Centre

Refs: 18389

\section{Elattostachys dzumacensis}

Sapindaceae

VU DI

New Caledonia

Assessor: Jaffré, T. et al.

Refs: 10351

\section{Elattostachys erythrocarpum}

Sapindaceae

VU D2

Indonesia (Sulawesi)

Endemic to Sulawesi, this small palmoid tree has been collected only a few times.

Assessor: World Conservation Monitoring Centre

Refs: 18389

\section{Elattostachys goropuensis}

Sapindaceae

VU D2

Papua New Guinea

Known only from the type collection, this small palmoid tree occurs in Euphorbia-Ficus forest in the Northern Province.

Assessor: World Conservation Monitoring Centre

Refs: 18389

\section{Elattostachys rubrofructus}

Sapindaceae

VU BI+2c

Papua New Guinea

A rare understorey tree of lowland rainforest, often found on riverbanks and near swamps.

Assessor: World Conservation Monitoring Centre

Refs: 18389

\section{Elingamita johnsoni}

Myrsinaceae

VU D2

New Zealand (North Is.)

A shrub or small tree, representing a monotypic genus, endemic to the Three Kings Islands. The 1981 Red Data Book of New Zealand records a colony of about 12 small trees in an isolated area of windswept scrub on West Island. A precise population estimate is not presently available, but the species is no longer dangerously low in numbers.

Assessor: World Conservation Monitoring Centre

Refs: 902, 17637, 19133
Ellipanthus beccari var. beccarii

Connaraceae

VU B $1+2 c$

Indonesia (Kalimantan), Malaysia (Sarawak)

A small dioecious tree which occurs in mixed dipterocarp forest on leached yellow soils in westem Borneo. In Sarawak, the only known occurrence is in the Kuching region.

Assessor: World Conservation Monitoring Centre

Refs: 18327,19017

\section{Ellipanthus hemandradenioides}

Connaraceae

LR/nt

Kenya, Tanzania

This species has a broken distribution, extending $700 \mathrm{~km}$ along the coastline. It is known from numerous localities of coastal vegetation on white sands usually associated with rivers or wetter areas.

Assessor: World Conservation Monitoring Centre

Refs: $1308,5654,6396,14719$

\section{Ellipanthus madagascariensis}

Connaraceae

Madagascar

The type collection was made a century ago in the northwest of the country. The species has not been collected again. Taxonomically, it strongly resembles $E$. hemandradenioides, but until further material is available no conclusions can be drawn as to the status of the species.

Assessor: World Conservation Monitoring Centre Refs: 14719

\section{Embelia upembensis}

Myrsinaceae

VU B $1+2 c$

Democratic Republic of Congo, Zambia

Occurring in Brachystegia woodland on lake shores or river terraces, often on termite hills, this species is restricted to a small area stretching from northem Zambia to Shaba Province in DR Congo.

Assessor: World Conservation Monitoring Centre

Refs: 18965

\section{Embolanthera spicata}

Hamamelidaceae

VU D2

\section{Philippines}

An endemic genus to Palawan. The species is confined to Mount Victoria, where it is found along streams at about $150 \mathrm{~m}$.

Assessor: World Conservation Monitoring Centre

Refs: 4986

\section{Emmenosperma pancherianum}

Rhamnaceae

VU Bl+2c

New Caledonia

A species confined to a few localities in sclerophyllous forest. The habitat is fragmented and massively reduced in extent because of the effects of fire, grazing and encroaching agriculture.

Assessor: Jaffré, T. et al.

Refs: 4492, 10351

\section{Enantia kummeriae}

Annonaceae

VU B $1+2 b$

Tanzania

Untul recently this species was known only from the East Usambara Mountains. Fallen fruits have now been found in the Mwanihana forest, Udzungwa Mountains, where the species is considered to be very rare. The forest in 
both areas has suffered severe declines and encroachment but is now relatively well protected.

Assessor: Lovett, J. \& G.P. Clarke

Refs: 3356, 5204, 9302

\section{Endiandra lecardii}

Lauraceae

VU D2

New Caledonia

A species known from two upland locations on the Plateau de Dogny and in Baakin, Canala.

Assessor: Jaffré, T. et al.

Refs: 10351,12630

\section{Endiandra scrobiculata}

Lauraceae

VU D2

Malaysia (Peninsular Malaysia)

Found at $1200 \mathrm{~m}$, this montane forest tree is known only from Fraser's Hill, Pahang. The area is under threat from rapid development as a tourist resort. It is hoped that the species will survive in remnant forest.

Assessor: Kochummen, K.M.

Refs: 19073

\section{Endocomia canarioides}

Myristicaceae

VU Alc

Indonesia (Sumatra), Malaysia (Peninsular Malaysia), Singapore, Thailand, Viet Nam?

A fairly widespread tree found in evergreen forest, open bamboo forest and lowland rainforest below $300 \mathrm{~m}$

Assessor: World Conservation Monitoring Centre Refs: $9199,9603,19078$

\section{Endocomia rufirachis}

Myristicaceae

Indonesia (Kalimantan), Malaysia (Sabah, Sarawak)

A tree found in lowland primary and logged-over forest.

Assessor: World Conservation Monitoring Centre

Refs: 1766,9603

\section{Endocomia virello}

Myristicaceae

VU D2

Malaysia (Sabah, Sarawak)

A primary forest tree very localised within the Fourth Division, Sarawak and Beaufort Hill, Sabah.

Assessor: World Conservation Monitoring Centre

Refs: $1766,9603,19078$

\section{Engelhardia danumensis}

Juglandaceae

Malaysia (Sabah)

This tree of lowland mixed dipterocarp forest is known only from the type collection found in the Ulu Segama Forest Reserve.

Assessor: World Conservation Monitoring Centre Refs: 19017

\section{Engelhardia kinabaluensis}

Juglandaceae

VU D2

Malaysia (Sabah)

A rare tree of lowland mixed dipterocarp and submontane forest, known only from the Mamut Copper Mine and the Mesilau area in Kundasang, Mount Kinabalu.

Assessor: World Conservation Monitoring Centre Refs: 19017

\section{Engelhardia mendalomensis}

Juglandaceae

VU D2

Malaysia (Sarawak)

This uncommon tree is known only from the type specimen, which was collected in an area of primary mixed dipterocarp forest in Mendalom Forest Reserve.

Assessor: World Conservation Monitoring Centre Refs: 19017

\section{Englerodendron usambarense}

Leguminosae

VU B $1+2 c$

Tanzania

This monospecific genus is restricted to the East and possibly the West Usambara Mountains. Occurring in moist forest at elevations of $760-1000 \mathrm{~m}$, the species has suffered severe habitat losses and degradation in the past.

Assessor: Lovett, J. \& G.P. Clarke

Refs: $3356,3925,7550$

\section{Enicosanthum acuminata}

Annonaceae

VU Alc

Sri Lanka

A rare species restricted to the lowland wet evergreen forests of south-west Sri Lanka.

Assessor: World Conservation Monitoring Centre

Refs: 15431,17195

\section{Enicosanthum congregatum}

Annonaceae

LR/cd

Malaysia (Peninsular Malaysia)

A very rare tree scattered in lowland forest. So far it has only been collected from Perak and the Bukit Lagong Forest Reserve, Selangor.

Assessor: Kochummen, K.M.

Refs: 8464, 19073

\section{Enicosanthum cupulare}

Annonaceae

VU D2

Malaysia (Peninsular Malaysia)

The species is known only from lowland forest in Larut in Maxwell's Hills, Perak, and Bukit Kajong in Terengganu. Maxwell's Hills is a protected resort area. Assessor: Kochummen, K.M.

Refs: 8464,19073

\section{Enicosanthum fuscum}

Annonaceae

LR/nt

Malaysia (Peninsular Malaysia)

Although few collections have been made, the species is expected to be more widespread in areas of lowland and submontane forest. It occurs in Kanching Forest Reserve in Selangor and Gunung Bubu in Perak, where some protection is provided.

Assessor: Kochummen, K.M.

Refs: $8464,11449,19073$

\section{Enicosanthum macranthum}

Annonaceae

VU B $1+2 \mathrm{c}$

Malaysia (Peninsular Malaysia)

This tree of lowland forest is known only from Lanut in the Maxwell's Hills mountain range in Perak. This area, home to many endemic plants, is currently conserved and protected; however, with increasing tourism Maxwell's Hills are likely be developed further. Assessor: Kochummen, K.M.

Refs: 19073 
Enicosanthum praestigiosum

Annonaceae

VU D2

Malaysia (Peninsular Malaysia)

A tree restricted to the lowland swamp forests of southeast Johore. A large part of the area is now being developed.

Assessor: Kochummen, K.M.

Refs: 17140,19073

\section{Entandrophragma angolense}

Meliaceae

VU Alcd

Angola, Cameroon, Central African Republic, Congo, Côte d'Ivoire, Democratic Republic of Congo, Equatorial Guinea (Bioko), Gabon, Ghana, Guinea, Kenya, Liberia, Nigeria, Sierra Leone, Sudan, Tanzania, Uganda

One of the main sources of African mahogany. The commercial exploitation of this timber species has resulted in the large-scale extraction of mature individuals throughout its range. Significant genetic erosion has been reported in some countries. It has the potential to occur commonly and regenerates well after logging damage but not after buming. The seed does not appear to disperse over great distances and regeneration is poor away from parent trees. A slow-growing species. There are protected populations and felling limits in various countries.

Assessor: Hawthome, W.

Refs: 450, 2773, 3479, 4506, 6128, 6396, 6718, 10961 , $12061,15017,16021,17408$

\section{Entandrophragma candollei}

Meliaceae

VU Alcd

Angola, Cameroon, Congo, Côte d'Ivoire, Democratic Republic of Congo, Ghana, Guinea, Liberia, Nigeria

One of the major sources of African mahogany. The species is widespread and heavily exploited throughout its range. Population densities are comparatively low and seed production is erratic, but regeneration appears to be good where parent trees remain and may also occur to some degree after buming. There are protected populations and felling limits in various countries.

Assessor: Hawthome, W.

Refs: $2362,2773,6128,6718,12061,17408$

\section{Entandrophragma cylindricum}

Meliaceae

VU Alcd

Angola, Cameroon, Congo, Côte d'Ivoire, Democratic Republic of Congo, Gabon, Ghana, Nigeria, Sierra Leone, Togo, Uganda

A major source of African mahogany, this species is scattered in semi-deciduous forests and exploited heavily throughout its range. Genetic erosion caused by the large-scale depletion of mature individuals from populations has taken place in some countries. In comparison with other species of Entandrophragma, this species can occur in drier habitats, including abandoned fields, but it does not respond well to burning. Growth rates are amongst the slowest in the genus. There are protected populations and felling limits in various countries.

Assessor: Hawthome, W.

Refs: 2362, 2773, 3479, 6128, 6718, 12061, 15017, 16021,17408

\section{Entandrophragma utile}

Meliaceae

VUAlcd

Angola, Cameroon, Congo, Côte d'Ivoire, Democratic Republic of Congo, Gabon, Ghana, Liberia, Nigeria, Sierra Leone, Uganda

An important source of African mahogany, this widespread species is heavily exploited throughout its range. Genetic erosion caused by the depletion of mature individuals from populations has taken place in most countries. Local overcutting is also common in parts of West Africa. Regeneration is good after disturbance and the species is generally noted to be more lightdemanding and tolerant of dry conditions. Growth rates are amongst the slowest in the genus and the seeds and seedlings suffer high mortality rates because of insect attack. There are protected populations and felling limits in various countries.

Assessor: Hawthome, W.

Refs: $2773,6128,6718,12061,13250,14667,16822$, 17408

\section{Eribroma oblonga}

Sterculiaceae

VU Alc

Cameroon, Côte d'Ivoire, Equatorial Guinea (Bioko), Gabon, Ghana, Liberia, Nigcria, Sierra Leone

A species of various rainforest types, locally common in places. Levels of exploitation for its timber are moderate and are contributing to the declines in population numbers. The current category applied should be kept under review.

Assessor: African Regional Workshop

Refs: $2773,8369,11504,13013,13947$

\section{Erica scoparia ssp. platycodon}

Ericaceae

LR/cd

Spain (Canary Is.)

A species known from Tenerife, Gomera and Hierro, where it occurs in areas of woodland from low to medium elevation. It is listed in government legislation of 1991.

Assessor: Bañares, A. et al.

Refs: 19022

\section{Eriocoelum oblongum}

Sapindaceae

DD

Gabon, Nigeria

A little-known forest tree that occurs in south-east Nigeria and also in Gabon. The Nigerian population to date appears to be unprotected. Forest outside protected areas has been extensively logged and cleared for agriculture. In Gabon the species is found in Lopé Forest Reserve and most probably in other forest areas which have yet to be explored. There is concern about the degree to which forest is now under concession in Gabon

Assessor: World Conservation Monitoring Centre Refs: 2773,11504

\section{Eriocoelum pungens var. inermis}

Sapindaceae

EN Alc, Bl+2c

Nigeria

This variety has, until now, been recorded only from the coastal forests in the Eket and Degema area in the southeast. The habitat of the Eket population has been degraded, if not completely destroyed, by oil exploration operations. The other population is unprotected and its habitat is vulnerable to severe degradation.

Assessor: World Conservation Monitoring Centre Refs: $450,2773,11504$ 


\section{Eriolaena lushingtonü}

Sterculiaceae

India (Andhra Pradesh, Tamil Nadu)

VU B $1+2 c$

Populations appear to be few and fragmented. The species occurs in lowland hill forest in various localities in the Eastern Ghats. There have been steady declines in the extent of the habitat.

Assessor: World Conservation Monitoring Centre Refs: 4799

\section{Eriotheca peruviana}

Bombacaceae

VU D2

Peru

Known only from the type collection, the species occurs in lowland forest in the department of La Libertad.

Assessor: World Conservation Monitoring Centre Refs: 1984

\section{Erithalis harrisii}

Rubiaceae

LR/nt

Jamaica

Known from the central parishes, the species is locally common in woodland margins on rough limestone. General habitat declines have been considerable. Assessor: World Conservation Monitoring Centre Refs: 6057,7980

\section{Erithalis quadrangularis}

Rubiaceae

VU B $1+2 c$

Jamaica

Known from Clarendon, Manchester and St Ann, the species is confined to woodland on limestone. General habitat declines have been considerable.

Assessor: World Conservation Monitoring Centre Refs: 6057,7980

\section{Erythrina ankaranensis}

Leguminosae

$\mathrm{EN} \mathrm{B1+2abc}$

Madagascar

An uncommon tree of limestone outcrops in the Ankarana Massif, north Madagascar. Its area of occupancy covers an estimated $500 \mathrm{~km}^{2}$ and is contained within a protected reserve.

Assessor: Du Puy, D. \& H. Labat

Refs: 12353

\section{Erythrina burana}

Leguminosae

LR/nt

Ethiopia

Known only from an area of bushland between 1350 and $2100 \mathrm{~m}$ in Harerge, the species is relatively restricted in distribution but fast growing and under no present threat. Cultivated specimens are found elsewhere in Ethiopia. Assessor: World Conservation Monitoring Centre Refs: $1330,4505,18523$

\section{Erythrina eggersii}

Leguminosae EN D1

Puerto Rico, Virgin Islands (US)

Occurring as a vine or tree, the species is known from a small population of about 12 individuals in Nevarez, Puerto Rico, and from three to six isolated trees and a core population of 30-50 trees in Virgin Islands National Park on St John. Plants elsewhere are believed to be cultivated. The main population on St John is under little threat. Populations elsewhere are potentially threatened by grazing and quarrying. In cultivation there is some indication that the plants die before reaching reproductive maturity.

Assessor: World Conservation Monitoring Centre

Refs: $3786,7980,17124$

\section{Erythrina elenae}

Leguminosae

VU B $1+2 \mathrm{c}$

Cuba

A small tree, up to $10 \mathrm{~m}$ tall, confined to shrubwoods and forests on the southem slopes of the Guamuhaya Massif of Escambray in Cienfuegos Province. Its habitat has declined through logging and cutting.

Assessor: Areces-Mallea, A.E.

Refs: 11403, 18485, 19149

\section{Erythrina euodiphylla}

Leguminosae

VU D2

Indonesia (Java, Lesser Sunda Is.)

A rare species, known only from a few herbarium specimens, the last of which was collected in 1975. It occurs in savanna areas in east Java and was once collected on Timor in 1968. The Bali specimen is now thought to belong to $E$. variegata. The species is recorded in Baluran National Park, where it is potentially threatened by human encroachment and competition with the introduced tree Acacia nilotica. Assessor: World Conservation Monitoring Centre Refs: 9078

\section{Erythrina haerdii}

Leguminosae

VU B $1+2 b, D 2$

Tanzania

The species occurs in one locality of dry lowland forest, at the eastem foot of the Udzungwa range. The forest is under some pressure from agricultural encroachment and local exploitation.

Assessor: Lovett, J. \& G.P. Clarke

Refs: 2459,3356

\section{Erythrina hazomboay}

Leguminosae

VU D2

Madagascar

Currently known from only four localities, this submontane species is uncommon and localised in stands of primary vegetation. Its range is broad, extending over $1000 \mathrm{~km}^{2}$ and it is likely that further localities exist. Populations are found in Andasibe/Perinet Reserve.

Assessor: Du Puy, D. \& H. Labat

Refs: 12353

\section{Erythrina perrieri}

Leguminosae

Madagascar

CR C2a

Known only from a single location in an area of highly fragmented vegetation on Ankara Plateau, this species occupies an area of approximately $100 \mathrm{~km}^{2}$. Trees are very rare, scattered and low in numbers. The remaining vegetation is declining rapidly as a result of buming and encroachment.

Assessor: Du Puy, D. \& H. Labat

Refs: 12353

\section{Erythrina sacleuxii}

Leguminosae

VU $B 1+2 b$

Kenya, Tanzania

Ranging from south-east Kenya, through Tanzania to 
Zanzibar and Pemba Islands, the species is restricted to pockets of dry coastal forest.

Assessor: Lovett, J. \& G.P. Clarke

Refs: 3356, 6396, 10961

\section{Enthrina schliebenü}

Leguminosae

EX

Tanzania

Repeated searches for this species at its type locality have failed to rediscover it. It was collected in the 1930 s in an area of forest on the sides of Lake Lutamba, which has since been cleared.

Assessor: Lovett, J. \& G.P. Clarke

Refs: 2459,16796

\section{Erythrina tahitensis \\ Leguminosae}

French Polynesia (Society Is.)

CR B $1+2 \mathrm{C}$

An endemic to Tahiti.

Assessor: Florence, J.

Refs: 14513

\section{Erythrina turtlana}

Leguminosae

VUAlc

Mexico (Chiapas, Oaxaca, Veracruz)

A tree of high precipitation rainforest, occurring in the regions of Los Tuxtlas, Tuxtepec and UxpanapaChimalapa

Assessor: World Conservation Monitoring Centre

Refs: 5993, 19124

\section{Erythrococca columnaris}

Euphorbiaceae

Sāo Tomé \& Príncipe (Príncipe)

VU DI+2

A tree which is known from a single collection. More detailed information is lacking. There have been no recent botanical surveys of the island.

Assessor: World Conservation Monitoring Centre

Refs: 2724

\section{Erythrococca molleri}

Euphorbiaceae

LR/nt

Sāo Tomé \& Príncipe (São Tomé)

A relatively well-collected shrub or small tree, found in wet and shady places in secondary forest between 500 and $1000 \mathrm{~m}$.

Assessor: World Conservation Monitoring Centre

Refs: 2724, 10080

\section{Erythrophleum fordii}

Leguminosae

China (Guangdong, Guangxi), Taiwan, Viet Nam

A valuable timber tree. The Chinese populations are largely reduced to trees left standing around living areas. The species' range in Viet Nam extends from the border with China to Quang Nam-Da Nang Province. Occurring in monsoon or rainforest up to $800 \mathrm{~m}$, it can form a scattered or dominant component. Plantations were established in the 1950 s to increase supplies of the hardwood but demands are still in excess of what can be sustainably provided.

Assessor: Nghia, N.H.

Refs: $1818,5054,11530,11847$

\section{Erythrophysa septentrionalis}

Sapindaceae

LR/nt

Ethiopia

A species of dry Acacia-Commiphora bushland with a rich shrub and forb layer in the eastern Ogaden. It has been collected five times within an area of $2500 \mathrm{~km}^{2}$. Although the habitat is affected by overgrazing and agricultural activities in some places, the area is not obviously threatened.

Assessor: World Conservation Monitoring Centre

Refs: $1330,4505,18523$

\section{Erythroxylum acranthum}

Erythroxylaceae

VU D2

Seychelles (Aldabra)

A frequent constituent of inland mixed scrub occurring on the islands of Malabar, Polymnie, Picard, Grande Terre, Michel, Assumption and Menai. The Aldabran Islands are under protection within a Strict Nature Reserve and only Picard is inhabited with a research station. Areas of Assumption have been disturbed by strip mining for phosphate or guano.

Assessor: World Conservation Monitoring Centre Refs: 19027

\section{Erythroxylum echinodendron}

Erythroxylaceae

EW

Cuba

Assessor: World Conservation Monitoring Centre

Refs: 11403, 18485

\section{Erythroxylum incrassatum}

Erythroxylaceae

VU B1+2c

Jamaica

An uncommon tree confined to woodland on limestone in Manchester and St Ann.

Assessor: World Conservation Monitoring Centre

Refs: 401, 5653, 7980

\section{Erythroxylum jamaicense}

Erythroxylaceae

VU B $1+2 \mathrm{c}$

Jamaica

Known from Clarendon and St Ann, the species is confined to woodland on limestone hills.

Assessor: World Conservation Monitoring Centre

Refs: $401,5653,7980$

\section{Erythroxylum kochummenii}

Erythroxylaceae

VU Bl+2c

Malaysia (Peninsular Malaysia)

A very rare species, known only from three collections from Ulu Gombak Forest Reserve in Selangor, Merlimau Forest Reserve in Malacca and Ulu Lebir Forest Reserve in Kelantan. Stricter conservation measures are required to secure these populations.

Assessor: Chung, R.C.K.

Refs: 8464,19073

\section{Enythroxylum obtusifolium}

Erythroxylaceae

VU Alc, B1+2c

Sri Lanka

A tree occurring in the lowland wet evergreen forests of south-west Sri Lanka. This species was found at 10 localities during the extensive National Conservation Review forest surveys.

Assessor: World Conservation Monitoring Centre Refs: $9176,17195,19112$ 


\section{Erythroxylum pacificum}

Erythroxylaceae

VU D2

Peru

A species from the coast in the department of Tumbes. It is known only from the type collection.

Assessor: World Conservation Monitoring Centre

Refs: 1984

\section{Erythroxylum sechellarum}

Erythroxylaceae

VU D2

Seychelles

A species with a widespread distribution within the Seychelles, occurring in rainforest on Mahé, Praslin, $\mathrm{La}$ Digue, Silhouette and several smaller islands. There are no obvious threats and populations appear to be healthy. Assessor: World Conservation Monitoring Centre Refs: $9859,17229,19023$

\section{Eschweilera alvimii}

Lecythidaceae

VU B1+2c

Brazil (Alagoas, Bahia, Pemambuco)

A species which is found scattered in lowland rainforest in north-east Brazil.

Assessor: Pires O'Brien, J.

Refs: $3791,5942,7980,9632$

\section{Eschweilera amazonicaformis}

Lecythidaceae

VU B1+2c, D2

Brazil (Amazonas)

A species which has been collected several times from non-flooded forest around Manaus. It is present in Ducke Forest Reserve, but elsewhere populations are under pressure from urban expansion and fires.

Assessor: Pires O'Brien, J.

Refs: $3791,7980,9632$

\section{Eschweilera amplexifolia}

Lecythidaceae

CR Alc, E

Panama

The species is restricted to just three neighbouring localities of lowland semi-deciduous rainforest on the Atlantic side of Panama. The largest population occurs in Santa Rita, where increasing settlement of the area has destroyed much of the remaining forest. The same pressures are affecting the population along the highway from El Lano to Cartí. A specimen collected in 1984 from Valle del Cauca in Colombia has also been included in this species.

Assessor: Mitré, $\mathrm{M}$

Refs: $3791,7980,16772$

\section{Eschweilera atropetiolata}

Lecythidaceae

$\mathrm{LR} / \mathrm{cd}$

Brazil (Amazonas)

Although the species is restricted in range, occurring in non-flooded forest in the vicinity of Manaus, it is known from many localities, including the Ducke Forest Reserve.

Assessor: Pires O'Brien, J.

Refs: $3791,7980,9632$

\section{Eschweilera baguensis}

Lecythidaceae

VU D2

Perv

A medium-sized tree, relatively newly described. It is known only from the type locality of lower montane cloud forest, occurring between 1700 and $2100 \mathrm{~m}$ in the department of Amazonas.

Assessor: World Conservation Monitoring Centre

Refs: 3791, 7980

\section{Eschweilera beebei}

Lecythidaceae

VU B1+2c, D2

Venezuela

Known only from Henri Pittier National Park, this cloud forest species has been collected about three times, each specimen probably from the same tree.

Assessor: World Conservation Monitoring Centre

Refs: 3791,7980

\section{Eschweilera bogotensis}

Lecythidaceae

VU B $1+2 c$

Colombia

A small tree of non-flooded forest from sea level to $1100 \mathrm{~m}$. About 10 collections have been taken from localities in Valle and Cundinamarca.

Assessor: World Conservation Monitoring Centre

Refs: 3791, 7980

\section{Eschweilera boltenï}

Lecythidaceae

VU D2

Suriname, Venezuela

A small tree, known only from the type locality in the floodplain of the Zuid River in the Kayser Mountains.

Assessor: World Conservation Monitoring Centre

Refs: 3791,7980

\section{Eschweilera carinata}

Lecythidaceae

VU B1 $+2 c, D 2$

Brazil (Amazonas)

This species is confined to non-flooded forest in southcentral and south-west Amazonas.

Assessor: Pires O'Brien, J.

Refs: $3791,7980,9632$

\section{Eschweilera compressa}

Lecythidaceae

CR Bl+2cd

Brazil (Rio de Janeiro)

Confined to non-flooded forests around Rio de Janeiro, the species range has been extensively reduced through urban expansion and exploitation.

Assessor: Pires O'Brien, J.

Refs: $3791,5942,7980,9632$

\section{Eschweilera cyathiformis}

Lecythidaceae

LR/cd

Brazil (Amazonas)

A canopy tree of non-flooded forest, known only from the vicinity of Manaus, including occurrences in INPA Biological Reserve and Ducke Forest Reserve.

Assessor: World Conservation Monitoring Centre Refs: $3791,7980,9632$

\section{Eschweilera fanshawei}

Lecythidaceae

VU D2

Guyana

This tree has been collected only once, in 1947, from an area of lowland non-flooded rainforest along the Bartica-Potaro road.

Assessor: World Conservation Monitoring Centre

Refs: 3791,7980 
Eschweilera integricalyx

Lecythidaceae

VU B $1+2 c$

Colombia

A large canopy or emergent tree, occurring commonly in places, but collected rarely from Pacific coastal Colombia in the departments of Choco and Valle. Assessor: World Conservation Monitoring Centre Refs: 3791,7980

\section{Eschweilera jacquelyniae}

Lecythidaceae

$\mathrm{EN} \mathrm{Cl}+2 \mathrm{a}$

Panama

A species largely confined to cloud forest on the summits of mountains in the Cordillera Central in central-eastem Panama. In localised areas it may be common, but on the whole it is not frequent. In Santa Rita and along the road from El Llano to Carti, in the Kunayala Indigenous Reserve, a large part of the forest has been destroyed. Small populations are protected in Chagres National Park.

Assessor: Mitré, M.

Refs: 7980, 16772

\section{Eschweilera longirachis}

Lecythidaceae

Costa Rica, Panama

The species is known from the type specimen taken from Veraguas in 1974 and from a recent collection from Costa Rica. Similar specimens in the area have been identified as $E$. panamensis.

Assessor: Mitré, M.

Refs: 7980,16772

\section{Eschweilera mexicana}

Lecythidaceae

VUAlc

Mexico (Oaxaca, Veracruz)

This rainforest tree is endemic to the UxpanapaChimalapa region, occurring in large but isolated populations. The Chimalapa area still harbours large tracts of relatively undisturbed forest, but is under potential threat from proposed large-scale forestry and development projects. Uxpanapa has suffered from substantial habitat clearance for agriculture and settlement in the government relocation scheme. This is the only member of Lecythidaceae in Mexico.

Assessor: World Conservation Monitoring Centre

Refs: $3791,5651,5993,7980,18150$

\section{Eschweilera obversa}

Lecythidaceae

$\mathrm{LR} / \mathrm{cd}$

Brazil (Amazonas, Maranháo, Pará)

Populations are small but relatively widely scattered. An occurrence is recorded in Jari Genetic Reserve.

Assessor: Pires O'Brien, J.

Refs: $3791,5942,7980,9632$

\section{Eschweilera piresii ssp. piresii}

Lecythidaceae

$\mathrm{EN} \mathrm{B1+2c}$

\section{Brazil (Pará)}

Currently known only from one location on the BelémBrasilia highway, this tree of periodically flooded forest has experienced serious habitat loss over the last two decades.

Assessor: Pires O'Brien, J.

Refs: $3791,7980,9632$
Eschweilera piresui ssp. viridipetala

Lecythidaceae

French Guiana

This subspecies is known solely from the type locality in lowland moist forest surrounding Saül. To date only two individuals have been located.

Assessor: World Conservation Monitoring Centre

Refs: 3791, 7980

\section{Eschweilera potaroensis}

Lecythidaceae

Guyana

A poorly known species, recorded only from the type specimen, which was collected in 1943 from westcentral Guyana. More collections of flowering material are needed to consolidate the taxonomy.

Assessor: World Conservation Monitoring Centre

Refs: 3791,7980

\section{Eschweilera punctata}

Lecythidaceae

Brazil (Acre), Colombia

LR/nt

This species occurs in periodically flooded forests of the Amazon in Acre and Colombia.

Assessor: Pires O'Brien, J.

Refs: $3791,7980,9632$

\section{Eschweilera rabeliana}

Lecythidaceae

Brazil (Amapá)

EN B $1+2 c, D 1$

A species known only from the type locality in nonflooded forest.

Assessor: Pires O'Brien, J.

Refs: $3791,7980,9632$

\section{Eschweilera rhododendrifolia}

Lecythidaceae

Brazil (Amazonas)

VU D2

This species has been collected from the roadside in non-flooded forests near Manaus. It is not known to occur elsewhere.

Assessor: Pires O'Brien, J.

Refs: 3791, 7980,9632

\section{Eschweilera rimbachii}

Lecythidaceae

VU B $1+2 \mathrm{C}$

Colombia, Ecuador

This species is known only from a few collections, gathered in western Ecuador and south-west Colombia from rainforest between 500 and $2000 \mathrm{~m}$.

Assessor: World Conservation Monitoring Centre

Refs: 3791, 7980, 10965

\section{Eschweilera rionegrense}

Lecythidaceae

Brazil (Amazonas)

VU D2

This species is known from a single location in the upper Rio Negro basin.

Assessor: Pires O'Brien, J.

Refs: $3791,7980,9632$

\section{Eschweilera rodriguesiana}

Lecythidaceae

Brazil (Amazonas)

VU D2

A species of non-flooded forest known only from the vicinity of Manaus. It occurs in the Ducke Forest Reserve.

Assessor: Pires O'Brien, J.

Refs: 3791, 7980, 9632 


\section{Eschweilera roraimensis}

Lecythidaceae

VU D2

Brazil (Roraima), Venezuela

A canopy tree, unusual in the genus in occurring at submontane elevation. It has only been collected from cloud forest between 700 and $1500 \mathrm{~m}$ on the Serra Parima.

Assessor: Pires O'Brien, J.

Refs: $3791,7980,9632$

\section{Eschweilera sclerophylla}

Lecythidaceae

VU B1+2c

Colombia

A medium-sized tree, known from a few localities of lowland non-flooded forest in the departments of Valle and Chocó.

Assessor: World Conservation Monitoring Centre

Refs: 3791, 7980

\section{Eschweilera squamata}

Lecythidaceae

French Guiana

A canopy or emergent tree of non-flooded forest, endemic to French Guiana. It has been collected from two localities, one being in Saül.

Assessor: World Conservation Monitoring Centre

Refs: 3791,7980

\section{Eschweilera subcordata}

Lecythidaceae

Brazil (Pará)

The species has been collected twice from forest margin and savanna areas on Marajo Island. It is not known elsewhere.

Assessor: Pires O'Brien, J.

Refs: $3791,7980,9632$

\section{Eschweilera tetrapetala}

Lecythidaceae

VU D2

Brazil (Bahia)

So far the species is known from three populations in non-flooded forests and roadsides in southern Bahia.

Assessor: Pires O'Brien, J.

Refs: $3791,5942,7980,9632$

\section{Eschweilera venezuelica}

Lecythidaceae

VU B $1+2 c$

Venezuela

A small tree, restricted to the lowland forest on the Caribbean slopes of the mountains of north-central Venezuela, from where it has been collected about four times.

Assessor: World Conservation Monitoring Centre

Refs: 3791,7980

\section{Esenbeckia alata}

Rutaceae

$\mathrm{EN} \mathrm{B} 1+2 \mathrm{c}$

Colombia

Endemic to Colombia, the species is restricted to

Cundinamarca, Tolima and Valle.

Assessor: Calderon, E.

Refs: 19069

\section{Esenbeckia berlandieri ssp. litoralis}

Costa Rica, El Salvador, Honduras, Nicaragua, Panama

A lowland tree of dry rocky hillsides.

Assessor: Nelson, C.

Refs: 13995

\section{Esenbeckia leiocarpa}

Rutaceae Brazil (Bahia, Goiás, Mato Grosso do Sul, Rio de Janeiro, Sāo Paulo)

The habitat of this species has been greatly reduced because of massive forest conversion over the last century for agriculture, livestock and plantations. The heavy, decay-resistant wood is of commercial value and the last stands are gradually being cut down.

Assessor: World Conservation Monitoring Centre Refs: 4506,7980

\section{Esenbeckia pentaphylla ssp. australensis}

Rutaceae

Colombia, Panama

Assessor: Calderon, E.

Refs: 7980,19069

VU Bl+2c

\section{Esenbeckia pentaphylla ssp. pentaphylla}

Rutaceae

LR/nt

Jamaica

The Jamaican subspecies of a Central American taxon, occurring in woodlands, most commonly in the westem parishes.

Assessor: World Conservation Monitoring Centre Refs: 6057,7980

\section{Eucalyptopsis papuana}

Myrtaceae

LR/nt

Indonesia (Irian Jaya, Moluccas), Papua New Guinea This tree is locally common, sometimes forming pure stands, in scattered areas of rainforest up to $1500 \mathrm{~m}$. It occurs in a small patch on Woodlark Island, in the headwaters of the Watut River in the Morobe Province and in lower montane forest in the Westem and East Sepik Provinces. The species has been logged and exported from Woodlark Island and occurs in areas subject to further exploitation.

Assessor: Eddowes, P.J.

Refs: 19114

\section{Eucalyptus morrisbyi}

Myrtaceae

Australia (Tasmania)

$\mathrm{EN} \mathrm{B1+2ce}$

Only four stands survive, all in southern Tasmania, largely on private land. Calverts Hill harbours the largest population of 2000 trees. East Risdon Nature Reserve has fewer than 20 trees and the other populations are small and near roads. Agricultural expansion is the main reason for the species' decline.

Assessor: World Conservation Monitoring Centre Refs: 17200

\section{Eucalyptus recurva}

Myrtaceae

CR D1

Australia (New South Wales)

A shrub known only from two localities near Mongarlowe in New South Wales. Apparently six individuals remain and are genetically very similar. The species has proved very difficult to cultivate.

Assessor: World Conservation Monitoring Centre Refs: 17200

\section{Euchorium cubense}

Sapindaceae

$\mathrm{EN} \mathrm{Bl}+2 \mathrm{c}$

Cuba

A monotypic genus endemic to the deepley eroded 'haystack' karstic hills of Viñales in the limestone range 
of Sierra de Los Organos, Pinar del Rio Province. Assessor: Areces-Mallea, A.E.

Refs: 11403, 18485, 19149

\section{Euclea balfourii}

Ebenaceae

VU D2

Yemen (Socotra)

This is likely to to be taxonomically indistinct from $E$. laurina. Both species are endemic to Socotra and scattered in montane and submontane vegetation in both granite and limestone areas. There are no immediate threats to populations.

Assessor: Miller, A.G.

Refs: 2354, 19083

\section{Euclea laurina}

Ebenaceae

VU D2

Yemen (Socotra)

This is likely to to be taxonomically indistinct from $E$. balfourii. Both species are endemic to Socotra and scattered in montane and submontane vegetation in both granite and limestone areas. There are no immediate threats to populations.

Assessor: Miller, A.G.

Refs: 2354,19083

\section{Eucommia ulmoides}

Eucommiaceae

LR/nt

China (Anhui, Gansu, Guizhou, Henan, Hubei, Hunan, Jiangxi, Shanxi, Sichuan, Zhejiang)

A species of a monotypic family, known from scattered populations occurring over a relatively wide range, altitudinally, ecologically and geographically. Its range is not clearly defined because it has been widely utilised and cultivated for the medicinal properties of its bark. Plantations are being established with some difficulties. Assessor: World Conservation Monitoring Centre Refs: 1818,11847

\section{Eucryphia cordifolia}

Eucryphiaceae LR/nt

Argentina, Chile (Biobio, La Araucania, Los Lagos)

A highly exploited species of broadleaved evergreen forest. The largest populations are in Chile and are considered to be under some threat because of the tree's use as the major source of fuelwood and charcoal for southern Chile. The species is also used as a timber and in the tannery industry.

Assessor: González, M.

Refs: $11140,13947,16328$

\section{Eucryphia glutinosa}

Eucryphiaceae

LR/nt

Chile (Bíobio, La Araucania, Maule)

Occurring at riversides or in swampy areas, the species occupies a relatively small area of subandean forest in central Chile. It does not appear to be common or well known.

Assessor: González, M.

Refs: 4893, 7980, 16328

\section{Eugenia abbreviata}

Myrtaceae

$\mathrm{EN} \mathrm{B} 1+2 \mathrm{c}$

Jamaica

The species is apparently scarce, occurring in Westmoreland, Manchester and St Catherine. The most recent collection was taken in 1965 from an area of damp thicket at the base of a wooded limestone hill.

Assessor: Kelly, D.L.

Refs: 401, 5653, 7980, 19085

\section{Eugenia aboukirensis}

Myrtaceae

CR B $1+2 c$

Jamaica

This species appears to be known only from the vicinity of Aboukir in St Ann Parish, where it occurs in woodland on a rocky limestone hilltop.

Assessor: World Conservation Monitoring Centre

Refs: 401, 5653, 7980

\section{Eugenia aceitillo}

Myrtaceae

$\mathrm{EN} \mathrm{B1}+2 \mathrm{c}$

Cuba

An endemic tree confined to dry evergreen forest on the limestone terraces of Cabo Cruz in Gramna Province. The species is very uncommon and parts of Cabo Cruz have been degraded by logging and cutting.

Assessor: Areces-Mallea, A.E.

Refs: 11403, 18485, 19149

\section{Eugenia acunai}

Myrtaceae

EN B1+2c

Cuba

A shnub or small tree locally restricted to the rainforests of Loma del Gato in the province of Santiago de Cuba.

Assessor: Areces-Mallea, A.E.

Refs: $11403,18485,19149$

\section{Eugenia acutisepala}

Myrtaceae

$\mathrm{EN} \mathrm{B1}+2 \mathrm{c}$

Jamaica

A small tree or shrub found only in the parish of St Catherine, where it is confined to wooded limestone hills.

Assessor: World Conservation Monitoring Centre

Refs: 401, 5653, 7980

\section{Eugenia acutissima}

Myrtaceae

CR B $1+2 \mathrm{C}$

Cuba

An imperfectly known species, described from a specimen without flowers and fruits. It is a small tree, apparently restricted to the type locality, Toscano in Pinar del Rio Province. Much of the area has been cleared for settlement and agriculture. No recent collections have been made.

Assessor: Areces-Mallea, A.E.

Refs: 11403, 18485, 19149

\section{Eugenia amoena}

Myrtaceae

VU Alc, B1+2c

Sri Lanka

Apparently restricted to the lowland wet evergreen forests of Ratnapura District, the species was found in six sites during the extensive forest surveys of the National Conservation Review. Asian Eugenia are now included in Syzygium.

Assessor: World Conservation Monitoring Centre

Refs: $15431,17195,19112$ 


\section{Eugenia amplifolia}

Myrtaceae

LR/nt

Jamaica

A shrub or small tree, uncommon and confined to areas of woodland on limestone hillsides.

Assessor: World Conservation Monitoring Centre Refs: 6057,7980

\section{Eugenia arianae}

Myrtaceae

CR B1+2abcde

Brazil

The species is known only from the type collection.

Assessor: Pires O'Brien, J.

Refs: 19097

\section{Eugenia bayatensis}

Myrtaceae

$\mathrm{EN} \mathrm{Bl+2c}$

Cuba

Known only from a few localities on karstic hills and limestone plateaux, this uncommon shrub or small tree occurs on the border of Santiago de Cuba with Holguin. Assessor: Areces-Mallea, A.E.

Refs: 11403, 18485, 19149

\section{Eugenia benjamina}

\section{Myrtaceae}

VU D1

Malaysia (Peninsular Malaysia)

Found only in hill and montane forest in Perak, this tree is threatened by the increasing settlement of the area. It is hoped the species is present in the protected forest reserves. Asian Eugenia are now included in Syzygium. Assessor: Kochummen, K.M.

Refs: 8464,19073

\section{Eugenia bojeri}

Myrtaceae

CR D1

Mauritius

A species which has only recently been rediscovered since the $1960 \mathrm{~s}$, when the single known individual died. A total of two trees have been found in the last two years in a single locality of cloud forest on the southern slopes of Mount Cocotte. They are being closely monitored.

Assessor: Page, W.

Refs: $1411,9120,16426$

\section{Eugenia brachythrix}

Myrtaceae

VU Bl+2c

Jamaica

A tree confined to submontane forest in the western Blue Mountains. It has been reported from the headwaters of the Mabess River and also, very rarely, from the Grand Ridge.

Assessor: World Conservation Monitoring Centre

Refs: 401, 5653, 7980, 12564

\section{Eugenia brownei}

Myrtaceae

VU B $1+2 c$

Jamaica

Only known from the parish of St Elizabeth, the species is very localised along riverbanks at sea level.

Assessor: Kelly, D.L.

Refs: 401, 5653, 7980, 19085

\section{Eugenia burkilliana}

Myrtaceae

VU D2

Malaysia (Peninsular Malaysia)

Confined to the lowland forests of Perak, this tree is known only from a few collections in an area which is experiencing forest clearance and increasing agriculture. Asian Eugenia are now included in Syzygium.

Assessor: Kochummen, K.M.

Refs: 8464,19073

\section{Eugenia calcadensis}

Myrtaceae

VU B $1+2 c$

India (Tamil Nadu)

Collections have been made from areas of evergreen forest along the Tamil Nadu/Kerala border at the southem end of the Western Ghats. Asian Eugenia are now included in Syzygium.

Assessor: World Conservation Monitoring Centre Refs: 19144

\section{Eugenia camptophylla}

Myrtaceae

$\mathrm{CR} \mathrm{B} 1+2 \mathrm{C}$

Malaysia (Peninsular Malaysia)

A species known only by a single collection from Gopeng District in Perak gathered in the 18 th century. It is unknown whether the species exists today. Asian Eugenia are now included in Syzygium.

Assessor: World Conservation Monitoring Centre

Refs: 8464, 19073

\section{Eugenia caudata}

Myrtaceae

VU B $1+2 c$

Malaysia (Peninsular Malaysia)

Confined to montane forest between 600 and $1500 \mathrm{~m}$, the species has been reported from Penang, Perak, Selangor and Pahang. Despite montane forest being considered protected by the govemment, increasing developments in the region are threatening the species. Asian _Eugenia_are now included in_Syzygium_. Assessor: Kochummen, K.M.

Refs: 8464, 19073

\section{Eugenia colipensis}

Myrtaceae VU Alc

Mexico (Chiapas, Oaxaca, Veracruz)

Endemic to the Gulf region, the species occurs in remaining rainforest, ranging as far north as northem Veracruz.

Assessor: World Conservation Monitoring Centre Refs: 5993

\section{Eugenia conglomerata}

Myrtaceae

VU D2

Malaysia (Peninsular Malaysia), Singapore

A rare tree of lowland rainforest known only from three collections from Selangor, Malacca and Johore. The species is threatened by increasing settlement and agriculture. Asian Eugenia are now included in Syzygium.

Assessor: Kochummen, K.M.

Refs: $9199,11647,19073$

\section{Eugenia cordifoliolata}

Myrtaceae

VU D2

Malaysia (Peninsular Malaysia)

A tree known only from the type locality in Perak. The exact location has not been recorded. Asian Eugenia are now included in Syzygium.

Assessor: World Conservation Monitoring Centre Refs: 8464,19073 
Eugenia cotinifolia ssp. codyensis Myrtaceae

India (Karnataka, Kerala, Tamil Nadu)

$\mathrm{EN} \mathrm{B1}+2 \mathrm{c}$

This subspecies is known only from a single collection in the south of Kamataka, an additional collection, imprecisely located in the Nilgiris, and a record from the Agastyamalai Hills. Asian Eugenia are now included in Syzygium.

Assessor: World Conservation Monitoring Centre

Refs: 19144

\section{Eugenia coyolensis}

Myrtaceae

CR C2b

Honduras

A species of the dry Atlantic lowlands. There are doubts surrouding the nomenclature.

Assessor: Nelson, C.

Refs: 13995

\section{Eugenia crassicaulis}

Myrtaceae

$\mathrm{EN} \mathrm{BI}+2 \mathrm{c}$

Jamaica

Endemic to Portland, the species occurs at altitudes of $600-900 \mathrm{~m}$. Much of the habitat has been affected by forestry activities and logging.

Assessor: World Conservation Monitoring Centre

Refs: 401, 5653, 7980

\section{Eugenia crenata}

Myrtaceae

VU B $1+2 c$

\section{Jamaica}

A shrub or small tree found uncommonly on steep wooded hillsides in Manchester, St Andrew and St Thomas Parishes. It may represent a form of $E$ harrisii. The habitat in the latter two parishes has been almost completely cleared or severely degraded.

Assessor: World Conservation Monitoring Centre Refs: $6057,7980,19116$

\section{Eugenia cyrtophylloides}

Myrtaceae

VU D2

Malaysia (Peninsular Malaysia)

Although the species is known only from a single collection in Gunong Tahan in Pahang, it is expected to be locally frequent at the type locality within Taman Negara National Park. Asian Eugenia are now included in Syzygium.

Assessor: World Conservation Monitoring Centre Refs: 8464,19073

\section{Eugenia daenikeri}

Myrtaceae

$\mathrm{EN} \mathrm{B1}+2 \mathrm{c}$

New Caledonia

Asian Eugenia are now contained within Syzygium.

Assessor: Jaffré, T. et al.

Refs: 10351

\section{Eugenia discifera}

Myrtaceae

$\mathrm{ENB} 1+2 c$

India (Kerala, Tamil Nadu)

Known from two locations, Chimunji and the Sethur Hills, the species occurs very sparsely in evergreen forest between 1300 and $1400 \mathrm{~m}$. The location in the Sethur Hills has been converted into cardamom plantations. Asian Eugenia are now contained within Syzygium.

Assessor: World Conservation Monitoring Centre

Refs: $1237,2538,19144$
Eugenia discors

Myrtaceae

Peru

VU D2

A species known only from its type collected in San

Martin Department.

Assessor: World Conservation Monitoring Centre

Refs: 1984

\section{Eugenia eperforata}

Myrtaceae

$\mathrm{EN} \mathrm{B1}+2 \mathrm{c}$

Jamaica

A tree of wooded limestone hillsides, found only in St

Ann Parish.

Assessor: World Conservation Monitoring Centre

Refs: 401, 5653

\section{Eugenia ericoides}

Myrtaceae

VU $B 1+2 c$

New Caledonia

Asian Eugenia are now contained within Syzygium.

Assessor: Jaffré, T. el al.

Refs: 10351

\section{Eugenia erythrophylla}

Myrtaceae

LR/nt

South Africa (Eastem Cape, KwaZulu-Natal)

A coastal forest species confined to sandstone formations in southem KwaZulu-Natal and the Pondoland area of the Eastern Cape, usually found in rocky situations near streams or along the upper edge of sandstone cliffs. It is recorded in two provincial nature reserves, a local authority reserve and a number of demarcated forests. The latter forest patches do not receive as much protection as they did prior to 1994, and they are increasingly being used as a source of firewood and timber. Some forest patches are also threatened by expanding settlement.

Assessor: Hilton-Taylor, C. et al.

Refs: 689,19218

\section{Eugenia excisa}

Myrtaceae

$\mathrm{EN} \mathrm{B1+2c}$

Cuba

A small tree confined to the karstic hill comolex of Sierra de Nipe on the border of Santiago de Cuba and Holguin Provinces. Habitat degradation has occurred in the accessible areas.

Assessor: Areces-Mallea, A.E.

Refs: $11403,18485,19149$

\section{Eugenia floccosa}

Myrtaceae

$\mathrm{EN} \mathrm{B1+2c}$

India (Tamil Nadu)

A forest tree endemic to the Agastyamalai Hills in southem India. Large areas have been exposed to fires, grazing, the establishment of commercial plantations and cutting for fuelwood, but almost $1000 \mathrm{~km}^{2}$ of forest are now under protection within sanctuaries. Asian Eugenia are now contained within Syzygium.

Assessor: World Conservation Monitoring Centre Refs: 5651, 10733, 19144

\section{Eugenia fulva}

Myrtaceae

VU Alc, B1+2c

Sri Lanka

This species was found at nine localities during the extensive National Conservation Review forest surveys. 
Asian Eugenia are now included in Syzygium. Assessor: World Conservation Monitoring Centre Refs: $15431,18796,19112$

\section{Eugenia gageana \\ Myrtaceae}

CR B $1+2 \mathrm{c}$

Malaysia (Peninsular Malaysia)

The single collection of this species, made last century, is probably from Maxwell's Hill in Taiping. The hill is now being developed into a resort area. Asian Eugenia are now included in Syzygium.

Assessor: World Conservation Monitoring Centre

Refs: 8464, 19073

\section{Eugenia gatopensis}

Myrtaceae

VU B $1+2 \mathrm{c}$

New Caledonia

Asian Eugenia are now contained within Syzygium.

Assessor: Jaffré, T. et al.

Refs: 10351

\section{Eugenia glabra \\ Myrtaceae \\ Sri Lanka}

$\mathrm{EN} \mathrm{B} 1+2 \mathrm{c}$

A species found at only three localities during the extensive forest surveys carried out for the National Conservation Review. Asian Eugenia are now included in Syzygium.

Assessor: World Conservation Monitoring Centre

Refs: 15431, 18796, 19112

\section{Eugenia goniocalyx}

Myrtaceae

VU D2

Malaysia (Peninsular Malaysia)

A tree confined to montane forest at about $1500 \mathrm{~m}$ in the Cameron Highlands and Fraser's Hill, Pahang. Both localities are hill stations which are being developed. However, it is likely the species occurs in the highaltitude protected forests. Asian Eugenia are now included in Syzygium.

Assessor: World Conservation Monitoring Centre

Refs: 8464, 19073

\section{Eugenia haematocarpa}

Myrtaceae

EN D1

Puerto Rico

The main population occurs in two colonies, totalling $50-100$ plants, in submontane rainforest in El Verde. A population of about nine adults is found at the edge of Carite forest. There are no obvious threats to the El Verde colonies.

Assessor: World Conservation Monitoring Centre Refs: $7980,17124,17540$

\section{Eugenia haniffii}

Myrtaceae

VU D2

Malaysia (Peninsular Malaysia)

A tree scattered in moist hill forest between 300 and $450 \mathrm{~m}$ in parts of Penang and Selangor. Both localities are under plans for development. Asian Eugenia are now included in Syzygium.

Assessor: Kochummen, K.M.

Refs: 8464, 19073

\section{Eugenia hanoverensis}

Myrtaceae

CR B $1+2 \mathrm{c}$

Jamaica

This species is confined to Hanover Parish, where it was collected in 1965 from a glade between limestone hills west of Hillsbrook.

Assessor: World Conservation Monitoring Centre

Refs: $401,5653,7980$

\section{Eugenia harrisü var. grandifolia}

Myrtaceae

CR B $1+2 \mathrm{C}$

Jamaica

The locality of this variety is unconfirmed. It was last reported in Egnor Gap in 1893. The species as a whole is local in distribution and confined to Jamaica.

Assessor: World Conservation Monitoring Centre

Refs: $401,5653,7980$

\section{Eugenia harrisii var. hamisii}

Myrtaceae

VU BI $+2 c$

Jamaica

A tree confined to the Blue Mountains, where it occurs occasionally to commonly on wooded slopes below $1650 \mathrm{~m}$, mostly in the southem catchments, where the disturbance from encroaching agriculture has been most severe.

Assessor: World Conservation Monitoring Centre Refs: 7980,12564

\section{Eugenia heterochroa}

Myrtaceae

VU B $1+2 c$

Jamaica

Known only from the parish of Clarendon, the species occurs on wooded rocky limestone hilltops at about $760 \mathrm{~m}$.

Assessor: Kelly, D.L.

Refs: $401,5653,7980,19085$

\section{Eugenia hexovulata}

Myrtaceae

VU D2

Peru

Occurring in forest up to $1500 \mathrm{~m}$, the species is known only from its type collected in the department of Loreto. Assessor: World Conservation Monitoring Centre Refs: 1984

\section{Eugenia hypoleuca}

Myrtaceae

$\mathrm{EN} \mathrm{Bl+2c}$

Sri Lanka

A tree recorded only twice in a single locality in Knuckles State Forest, which covers $300 \mathrm{~km}^{2}$, during the extensive forest surveys by the National Conservation Review. Asian Eugenia are now included in Syzygium. Assessor: World Conservation Monitoring Centre Refs: 19112

\section{Eugenia indica}

Myraceae

$\mathrm{EN} B 1+2 \mathrm{c}$ India (Tamil Nadu)

An understorey tree of evergreen forest, known from single records from three different locations at the southem end of the Western Ghats. Asian Eugenia are now included in Syzygium.

Assessor: World Conservation Monitoring Centre Refs: 19144

\section{Eugenia insignis}

Myrtaceae

$\mathrm{CR} B 1+2 \mathrm{C}$

Sri Lanka

A tree restricted to lowland rainforest in south-west Sri Lanka. Previously recorded in Sinharaja and Haycock Biosphere Reserves, this extremely rare species was not found during the extensive forest surveys conducted for the National Conservation Review, suggesting that it 
might be extinct. Asian Eugenia are now included in Syzygium.

Assessor: World Conservation Monitoring Centre

Refs: 17195,19112

\section{Eugenia isosticta}

Myrtaceae

LR/nt

Jamaica

This is an uncommon species found on lowland wooded limestone hillsides.

Assessor: World Conservation Monitoring Centre

Refs: 6057,7980

\section{Eugenia johorensis}

\section{Myrtaceae}

EN B $1+2 c$

Malaysia (Peninsular Malaysia)

A very rare tree known from a single collection from moist submontane forest on Gunong Pulai. This area is being developed into a holiday resort. Asian Eugenia are now included in Syzygium.

Assessor: Kochummen, K.M.

Refs: 8464,19073

\section{Eugenia jutiapensis}

\section{Myrtaceae}

DD

El Salvador, Guatemala

Restricted to the Pacific coast, the species occurs in lowland forest. It is recorded in El Imposible National Park in El Salvador. The habitat has been widely logged and also affected by tourism and industrial developments in places. More information is needed on the Guatemalan populations.

Assessor: World Conservation Monitoring Centre

Refs: $4862,4974,19030$

\section{Eugenia kaalensis}

Myrtaceae

VU B $1+2 c$

New Caledonia

Asian Eugenia are now contained within Syzygium.

Assessor: Jaffré, $T$, et al.

Refs: 10351

\section{Eugenia kellyana}

Myrtaceae

CR B $1+2 \mathrm{C}$

Jamaica

The species has been reported in recent years from two locations, Hog House Hill and Holland Mountain, in submontane forest on limestone in the John Crow Mountains.

Assessor: World Conservation Monitoring Centre

Refs: $401,5653,7980$

\section{Eugenia klossii}

Myrtaceae

Malaysia (Peninsular Malaysia)

A tree known from a single collection from lowland rainforest in Rantau Panjang in Selangor. The present existence of the collection locality is doubtful and the species may be extinct. Asian Eugenia are now included in Syzygium.

Assessor: Kochummen, K.M.

Refs: 8464, 19073

\section{Eugenia koolauensis}

Myrtaceae

EN C2a, D1

USA (Hawaii)

A small tree which, in the past, has been collected from lowland dry forest in the north of the Koolau Mountains on Oahu and from Maunaloa on Molokai. The only extant populations are now restricted to Oahu, the Molokai populations being replaced by fields of pineapples. Fewer than 220 individuals now remain in eight populations in the Koolau Mountains, where they are threatened mainly by the destructive activities of feral pigs and by invasions of introduced plants. The species is protected by the US Endangered Species Act. Assessor: World Conservation Monitoring Centre Refs: $3372,19041,19168$

\section{Eugenia lamprophylla}

Myrtaceae

VU BI+2c

Jamaica

Confined to areas of woodland on rocky hillsides along the base of limestone cliffs, this tree is uncommon in a habitat that is constantly vulnerable to cutting.

Assessor: World Conservation Monitoring Centre

Refs: 401, 5653, 7980

\section{Eugenia lancetillae}

Myrtaceae

CR C2b

Honduras

Endemic to the wet Atlantic lowlands of Honduras, the species has a rare occurrence in Lancetilla Biological Reserve.

Assessor: Nelson, C.

Refs. 4974, 13995

\section{Eugenia laurae}

Myrtaceae

$\mathrm{EN} \mathrm{B} 1+2 c$

Jamaica

A Cockpit Country endemic, known from localities in Trelawny and Clarendon Parishes. The woodland in Warsop, where the type specimen was collected, has been severely degraded and attempts to find the species have failed.

Assessor: World Conservation Monitoring Centre

Refs: 401, 5653, 7980

\section{Eugenia linocieroidea}

Myrtaceae

LR/nt

Malaysia (Peninsular Malaysia), Singapore

The collection localities of this lowland rainforest tree are being developed for agriculture and settlement. It is expected the species will be found in the nearby production forest reserves in Perak and Selangor. Asian Eugenia are now included in Syzygium.

Assessor: Kochummen, K.M.

Refs: 9199, 19073

\section{Eugenia longicuspis}

Myrtaceae

VU D2

Peru

An Amazon forest species known only from the type collection taken from the department of Loreto. Assessor: World Conservation Monitoring Centre Refs: 1984

\section{Eugenia mabaeoides ssp. mabaeoides}

Myrtaceae

$\mathrm{EN} \mathrm{B} 1+2 \mathrm{c}$

Sri Lanka

The species as a whole was found in only five forest sites curring the extensive surveys carried out for the National Conservation Review. Asian Eugenia are now included in Syzygium.

Assessor: World Conservation Monitoring Centre

Refs: $15431,17759,19112$ 
Eugenia mabaeoides ssp. pedunculata Myrtaceae

Sri Lanka

The species as a whole was found in only five forest sites during the extensive surveys carried out for the National Conservation Review. Asian Eugenia are now included in Syzygium.

Assessor: World Conservation Monitoring Centre

Refs: 15431,18796

\section{Eugenia mackeeana}

Myrtaceae

VU B $1+2 \mathrm{c}$

New Caledonia

Asian Eugenia are now contained within Syzygium.

Assessor: Jaffré, T. et al.

Refs: 10351

\section{Eugenia mandevillensis var. mandevillensis}

Myrtaceae

VU B $1+2 \mathrm{c}$

Jamaica

A shrub or small tree confined to areas of woodland on limestone hillsides in Manchester Parish.

Assessor: World Conservation Monitoring Centre

Refs: 401, 5653, 7980

\section{Eugenia mandevillensis var. perratonii}

Myrtaceae

VU B $1+2 c$

Jamaica

Slightly more widespread than the type variety, this taxon occurs in St Catherine and St Elizabeth, where it is uncommon and confined to woodland on limestone.

Assessor: World Conservation Monitoring Centre

Refs: 6057,7980

\section{Eugenia marchiana}

Myrtaceae

LR/nt

Jamaica

In the western Blue Mountains, the species is scattered but moderately common in submontane rainforest, especially on steep slopes in the relatively extensive forests of the northem catchments.

Assessor: World Conservation Monitoring Centre

Refs: 7980,19116

\section{Eugenia mexicana}

Myrtaceae

VUAlc

Mexico (Chiapas, Oaxaca, Veracruz)

Endemic to the Gulf region, the species occurs in remaining rainforest, ranging as far north as northem Veracruz.

Assessor: World Conservation Monitoring Centre

Refs: 3467,5993

\section{Eugenia micranthoides}

Myrtaceae

VU D2

Peru

Known only from the type collection, this species occurs in Amazon forest in the Loreto Department.

Assessor: World Conservation Monitoring Centre Refs: 1984

\section{Eugenia microcarpa}

Myrtaceae

VU B1+2acd

Brazil (Espínto Santo, Rio de Janeiro)

A rarely occurring species of Atlantic forest. It is recorded from only two states.

Assessor: Pires O'Brien, J.

Refs: 19097

\section{Eugenia millsii}

Myrtaceae

Malaysia (Peninsular Malaysia)

LR/nt

Although scattered and rare in lowland rainforest in

Kedah, Pahang and Selangor, the species does not yet qualify as threatened. It is hoped there are populations within the production forest reserves of these states. Asian_Eugenia_are now included in _Syzygium_.

Assessor: Kochummen, K.M.

Refs: 8464,19073

\section{Eugenia mozomboensis}

Myrtaceae

Mexico (Veracruz)

EN C2b

This shrub or small tree is now confined to a single locality near Mozomboa in the Sierra de Manuel Diaz, where about 500 individuals survive on rocky shallow soils. The only evident regeneration is vegetative from stolons. There is great interest in the species as an ornamental and cuttings have been propagated at Xalapa Botanic Garden.

Assessor: Vovides, A.P.

Refs: 19206

\section{Eugenia myriantha}

Myrtaceae

DD

Malaysia (Peninsular Malaysia)

This species is known by a single collection from Perak, probably from hill forest, made during the last century. It is uncertain whether the species still exists. The exact locality has not been specified. Asian Eugenia are now included in Syzygium.

Assessor: Kochummen, K.M.

Refs: 8464, 19073

\section{Eugenia ngadimaniana}

Myrtaceae

VU Bl+2c

Malaysia (Peninsular Malaysia), Singapore

A tree confined to freshwater swamp and lowland forest in Kelantan and Johore. 'The species' localities are vulnerable to development, especially the swamp forests of Johore which are being rapidly settled. It is possible a population exists in the productive forest reserves in Kelantan. Asian Eugenia are now included in Syzygium. Assessor: Chua, L.S.L.

Refs: 9199, 19073, 19182

\section{Eugenia nicholsii}

Myrtaceae

$\mathrm{EN} \mathrm{B1+2c}$

Jamaica

A poorly known species of Portland and St Andrews Parishes. Populations are found at an altitude of about $1500 \mathrm{~m}$, where they are largely safe from high levels of disturbance and human activity.

Assessor: Kelly, D.L.

Refs: $401,5653,7980,19085$

\section{Eugenia nitidula}

Myrtaceae

$L R / n t$

Malaysia (Peninsular Malaysia)

A locally abundant tree confined to montane forest on Gunong Ines, Perak and the Cameron Highlands and Fraser's Hill, Pahang. The expansion of agriculture and settlement both threaten the habitat. Populations are expected to be found in protected forest reserves in Perak and Pahang. Asian Eugenia are now included in Syzygium.

Assessor: Kochummen, K.M.

Refs: 8464, 19073 


\section{Eugenia noumeensis}

Myrtaceae

VU D2

New Caledonia

A species of sclerophyllous forest. It is known from only a few locations and its habitat is severely threatened by fires, grazing and encroaching agriculture. Asian Eugenia are now contained within Syzygium.

Assessor: Jaffre, T. et al.

Refs: 4492, 10351

\section{Eugenia orites}

Myrtaceae

Malaysia (Peninsular Malaysia)

LR/cd

A montane forest tree, restricted to Gunung Tapis, Pahang, and Gunung Belumut, Johore, at $900 \mathrm{~m}$. The habitat is generally threatened by the development of resorts, but some areas are given a degree of protection within protected forests. Asian _Eugenia_ are now included in Syzygium.

Assessor: Kochummen, K.M.

Refs: 8464, 19073

\section{Eugenia pachychlamys}

Myrtaceae

DD

El Salvador, Guatemala

A shade-loving tree which, in El Salvador, is confined to Chalatenango in various upland habitats from closed forest to pastureland. More information is needed on the Guatemalan population. The fruits are edible and both livestock and humans are believed to help in seed dispersal.

Assessor: World Conservation Monitoring Centre Refs: 4862, 4974, 19030

\section{Eugenia pahangensis}

Myrtaceae

LR/cd

Malaysia (Peninsular Malaysia)

Occurring in montane and alpine forest, this tree is known only from Fraser's Hill and Gunung Tahan, Pahang, at about $1500 \mathrm{~m}$. The species is protected in Taman Negara National Park. Asian Eugenia are now included in Syzygium.

Assessor: Kochummen, K.M.

Refs: 8464, 19073

\section{Eugenia pallidula}

Myrtaceae

VU B $1+2 \mathrm{c}$

Malaysia (Peninsular Malaysia)

This species is very rare, known only from a few cullections from Perak and Pahang. It occurs in areas of lowland rainforest, which are threatened by encroaching agriculture and increasing settlement. The area around Pondok Tanjong Forest Reserve in Perak, where a collection has been made, is now fully developed. It is hoped that the population here has survived along with a second population located along the banks of Semarang River near Temerloh, Pahang. Asian Eugenia are now included in Syzygium.

Assessor: Chua, L.S.L.

Refs: 8464, 19073, 19182

\section{Eugenia pearsoniana}

Myrtaceae

LR/cd

Malaysia (Peninsular Malaysia)

A tree of lowland and hill rainforest, recorded from Maxwell's Hill, Perak, and Gunong Panti, Johore. Both localities are now ecotourist destinations and as such it is hoped these forests will be preserved. Asian Eugenia are now included in Syzygium.

Assessor: Kochummen, K.M.

Refs: 8464, 19073

\section{Eugenia plumbea}

Myrtaceae

VU D2

Malaysia (Peninsular Malaysia)

A single collection of this species was made in submontane rainforest on Gunong Batu Puteh in Perak. The locality is thought to be contained within the protected forests of Perak State. Asian Eugenia are now included in Syzygium.

Assessor: World Conservation Monitoring Centre

Refs: 8464,19073

\section{Eugenia polypore}

Myrtaceae

Jamaica

A tree of up to $20 \mathrm{~m}$, confined to a small area on the Dolphin Head

Assessor: World Conservation Monitoring Centre

Refs: $401,5653,7980$

\section{Eugenia porphyrantha}

Myrtaceae

Malaysia (Peninsular Malaysia)

VU D2

A tree of lowland and hill rainforest, known from Bukit Kutu, Selangor, and Raka Hill Forest Reserve, Pahang. Both localities lie within the boundaries of protected forest reserves. Asian Eugenia are now included in Syzygium.

Assessor: World Conservation Monitoring Centre

Refs: 8464, 19073

\section{Eugenia praestigiosa}

Myrtaceae

Malaysia (Peninsular Malaysia)

A lowland rainforest species, known only from a single collection from Perak. The exact locality is unknown. Asian Eugenia are now included in Syzygium.

Assessor: Kochummen, K.M.

Refs: $3467,8464,19073$

\section{Eugenia prasina}

Myrtaceae

VU B1+2acd

Brazil (Rio de Janeiro)

Assessor: Pires O'Brien, J.

Refs: 19097

\section{Eugenia pseudoclaviflora}

Myrtaceae

Malaysia (Peninsular Malaysia)

VU D2

A lowland rainforest tree known only from a single collection gathered along the track to Gunung Tahan in Taman Negara National Park. Asian Eugenia are now included in Syzygium.

Assessor: World Conservation Monitoring Centre Refs: 8464, 19073

\section{Eugenia pycnoneura}

Myrtaceae

$\mathrm{EN} \mathrm{B} 1+2 \mathrm{c}$

Jamaica

Endemic to the John Crow Mountains in Portland, the species is uncommon and confined to areas of montane forest at about $1000 \mathrm{~m}$.

Assessor: World Conservation Monitoring Centre

Refs: $401,5653,7980$ 


\section{Eugenia quadrata}

Myrtaceae

VU D2

Malaysia (Peninsular Malaysia)

Confined to a single locality, this species was found in Larut in Maxwell's Hills, Perak. This area, although protected as a nature reserve and water catchment, is under development as a resort. Asian Eugenia are now included in Syzygium.

Assessor: World Conservation Monitoring Centre Refs: 17140,19073

\section{Eugenia rendlei}

Myrtaceae

CR B $1+2 \mathrm{C}$

Jamaica

Confined to parts of the John Crow Mountains in St Thomas Parish, the species is uncommon and restricted to remaining areas of moist forest at about $500 \mathrm{~m}$. Almost all of the forest in this parish have been destroyed or severely degraded.

Assessor: World Conservation Monitoring Centre

Refs: $401,5653,7980,19116$

\section{Eugenia rheophytica}

Myrtaceae

$\mathrm{CR} \mathrm{Bl+2c}$

Sri Lanka

During the extensive National Conservation Review forest surveys, only one individual was found in a single forest site in Ratnapura District. Asian Eugenia are now included in Syzygium.

Assessor: World Conservation Monitoring Centre

Refs: 19112

\section{Eugenia rhomboidea}

Myrtaceae

Malaysia (Peninsular Malaysia)

VU D2

This tree is known from a single collection from Gunung Mengkueng in Selangor; it was found in moist montane forest at $1300 \mathrm{~m}$. The locality is within a protected forest. Asian Eugenia are now included in Syzygium.

Assessor: World Conservation Monitoring Centre

Refs: 8464,19073

\section{Eugenia rivulorum \\ Myrtaceae}

VU Alc

Sri Lanka

During the extensive National Conservation Review forest surveys, this species was found in 13 localities. Asian Eugenia are now included in Syzygium.

Assessor: World Conservation Monitoring Centre

Refs: $15431,18796,19112$

\section{Eugenia rostadonis}

Myrtaceae

Malaysia (Peninsular Malaysia)

A species known only from a single collection from Terengganu. Its exact locality is unknown. Asian Eugenia are now included in Syzygium.

Assessor: Kochummen, K.M.

Refs: 8464, 19073

\section{Eugenia rottleriana}

Myrtaceae

VU B $1+2 c$

India (Tamil Nadu)

A small tree, known largely from field data and a few collections, occurring along the Tamil Nadu/Kerala border in submontane evergeen forest. Asian Eugenia are now included in Syzygium.

Assessor: World Conservation Monitoring Centre

Refs: 19144

\section{Eugenia rotundata}

Myrtaceae

Sri Lanka

During the extensive National Conservation Review forest surveys, this species was found in seven sites. Asian Eugenia are now included in Syzygium.

Assessor: World Conservation Monitoring Centre Refs: $15431,17759,19112$

\section{Eugenia rufo-fulva}

Myrtaceae

VUAlc

Sri Lanka

During the extensive National Conservation Review forest surveys, this species was found in 14 localities. Asian Eugenia are now included in Syzygium. Assessor: World Conservation Monitoring Centre Refs: 15431, 18796, 19112

\section{Eugenia sachetae}

Myrtaceae

$\mathrm{EN} B 1+2 c$

Jamaica

Occurring only in Trelawny, the species is known from populations found on wooded limestone hills, between 450 and $600 \mathrm{~m}$.

Assessor: Kelly, D.L.

Refs: 401, 5653, 7980, 19085

\section{Eugenia salamancana}

Myrtaceae

DD

Panama

Known only from the type collection of 1938, the species remains poorly known. Other taxa of the same genus have been collected in the same area.

Assessor: Mitré, M.

Refs: $7272,7980,16772$

\section{Eugenia salamensis}

Myrtaceae EN C2a

Costa Rica, El Salvador, Honduras, Mexico, Nicaragua A species of moist wooded ravines or rocky hills and dense wet mixed forest at medium to high altitudes. It may be divided up into subspecies.

Assessor: Nelson, C.

Refs: 8100,13995

\section{Eugenia scalarinervis}

Myrtaceae

CR B $1+2 c$

Malaysia (Peninsular Malaysia)

A lowland forest tree known by a few collections in two separate localities in Perak. The species is threatened by encroaching agriculture but it is expected to be found in permanent forest reserves. Asian Eugenia are now included in Syzygium.

Assessor: Chua, L.S.L

Refs: $8464,19073,19182$

\section{Eugenia schulziana}

Myrtaceae

VU B $1+2 c$

Jamaica

A small tree confined to wooded banks and hillsides in Hanover and Westmoreland Parishes.

Assessor: World Conservation Monitoring Centre Refs: 401,5653 


\section{Eugenia schunkei}

Myrtaceae

VU D2

Peru

Known only from the type collection, the species occurs in Amazon forest in the department of Loreto.

Assessor: World Conservation Monitoring Centre Refs: 1984

\section{Eugenia setosa}

\section{Myrtaceae}

Malaysia (Peninsular Malaysia)

Confined to Perak and Selangor, this tree occurs in peatswamp forest and sometimes in freshwater swamps. Since the peat-swamp forests are no longer being converted for agriculture, the species is considered to be less threatened than in the past. Asian Eugenia are now included in Syzygium.

Assessor: Chua, L.S.L.

Refs: 17140, 19073, 19182

\section{Eugenia singampattiana}

Myrtaceae

CR Alc

India (Tamil Nadu)

The only collections of the species were made over 100 years ago in the Singampatti and Papanasam Hills. Dam construction at the latter locality and clearing for tea and other plantations at the former may have destroyed both populations. The species may now be extinct. Asian Eugenia are now placed within the genus Syzygium. Assessor: World Conservation Monitoring Centre Refs: 2538, 19144

\section{Eugenia sripadaense}

Myrtaceae

$\mathrm{EN} \mathrm{Bl}+2 \mathrm{c}$

Sri Lanka

During the extensive National Conservation Review forest surveys, only five individuals were found in the Peak Wilderness Wildlife Sanctuary. Asian Eugenia are now included in Syzygium.

Assessor: World Conservation Monitoring Centre

Refs: 19112

\section{Eugenia sulcivenia}

Myrtaceae

$\mathrm{EN} \mathrm{B} 1+2 \mathrm{c}$

Jamaica

This small tree was known to occur in montane forests at about $1200 \mathrm{~m}$ in St Andrew Parish. Almost all the forest below $1400 \mathrm{~m}$ has been cleared or severely degraded.

Assessor: World Conservation Monitoring Centre

Refs: 401, 5653, 7980, 19116

\section{Eugenia swettenhamiana}

Myrtaceae

VUD2

Malaysia (Peninsular Malaysia)

A single herbarium specimen of this species exists, collected from lowland forest in Gunung Pondok, Perak.

Asian Eugenia are now included in Syzygium.

Assessor: World Conservation Monitoring Centre

Refs: 8464, 19073

\section{Eugenia tabouensis}

\section{Myrtaceae}

VU B $1+2 \mathrm{c}$

\section{Côte d'Ivoire}

An endemic to lowland evergreen forests of Côte d'Ivoire. It is known solely from remaining forested areas between the rivers of Sassandra and Cavally, largely contained within Tai National Park. Over the last few decades the effects of logging have been extensive. An influx of people into the area also threatens the integrity of the forest.

Assessor: Assi, A.

Refs: 2773,12822

\section{Eugenia tahanensis}

Myrtaceae

Malaysia (Peninsular Malaysia)

LR/cd

A tree confined to montane forest in Gunung Tahan in Pehang. The area is protected within Taman Negara National Park. Asian Eugenia are now included in Syzygium.

Assessor: Kochummen, K.M.

P.efs: 8464, 19073

\section{Eugenia taipingensis}

Myrtaceae

Malaysia (Peninsular Malaysia)

$\mathrm{EN} \mathrm{B1}+2 \mathrm{c}$

Found in lowland forest in Taiping, the only known locality of this species has probably been cleared for agriculture and human habitation. Asian Eugenia are now included in Syzygium.

Assessor: Kochummen, K.M.

Refs: 8464, 19073

\section{Eugenia tecta}

Myrtaceae

LR/cd

Malaysia (Peninsular Malaysia)

Mainly occurring in the mountain forests of Perak and

Pahang, the exact range of this species is uncertain as it is poorly represented in herbarium collections. However, the mountain forests are considered protected. Asian Eugenia are now included in Syzygium.

Assessor: Kochummen, K.M.

Refs: 8464, 19073

\section{Eugenia tekuensis}

Myrtaceae

Malaysia (Peninsular Malaysia)

LR/cd

This lowland forest tree is known only from Kuala Teku in Pahang, where it is contained within a national park. Asian Eugenia are now included in Syzygium.

Assessor: Kochummen, K.M.

Refs: 8464,19073

\section{Eugenia terpnophylla}

Myrtaceae

$\mathrm{EN} \mathrm{BI}+2 \mathrm{c}$

Sri Lanka

A tree restricted to lowland rainforest in south-west Sri Lanka. During the extensive National Conservation Review forest surveys, this species was found at three localities. Asian Eugenia are now included in Syzygium. Assessor: World Conservation Monitoring Centre

Refs: $15431,17195,19112$

\section{Eugenia tiumanensis}

Myrtaceae VU B $1+2 c$

Malaysia (Peninsular Malaysia)

The species is known only from two collections from Pulau Tioman. The island is developing rapidly into a tourist resort. Asian Eugenia are now included in Syzygium.

Assessor: Chua, L.S.L.

Refs: $8464,19073,19182$ 


\section{Eugenia umtamvunensis}

Myrtaceae

South Africa (Eastem Cape, KwaZulu-Natal)

VU D2

A coastal forest species confined to sandstone formations in southern KwaZulu-Natal and the Pondoland area of the Eastern Cape, usually found on forest margins but very scarce and scattered in occurrence. It is not encountered as frequently as $E$. erythrophylla and regeneration appears to be poor, although the seed set is viable. There are protected populations in at least two nature reserves and two demarcated forests. In places, it is threatened by cutting for firewood and timber, and increasing settlement.

Assessor: Hilton-Taylor, C. et al.

Refs: 689,19218

\section{Eugenia uxpanopensis}

Myrtaceae

EN Alc, B1+2c

Mexico (Veracruz)

A species confined to rainforest in the Uxpanapa region of Veracruz. The habitat is greatly reduced through deforestation and clearance for crops, especially in the south where there are deep soils.

Assessor: World Conservation Monitoring Centre

Refs: $3905,5651,5993$

\section{Eugenia verdoorniae}

Myrtaceae

L.R/nt

South Africa (Eastem Cape, KwaZulu-Natal)

A coastal forest species and attractive omamental tree, confined to sandstone formations in southem KwaZuluNatal and the Pondoland area of the Eastern Cape. It is found on forest margins and in the open on the banks and islands of some of the larger rivers, where in places it is locally common. There are recorded populations within three nature reserves and a few demarcated forests, but threats of increasing settlement and cutting for firewood and timber continue to put pressure on these remaining forest patches.

Assessor: Hilton-Taylor, C. et al.

Refs: 689,19218

\section{Eugenia virgultosa}

Myrtaceae

LR/nt

Jamaica

A widespread common component of most forest types confined to the Blue Mountains and John Crow Mountains. Two varieties have been described but they commonly intergrade.

Assessor: World Conservation Monitoring Centre

Refs: 7980,19116

\section{Eugenia virotii}

Myrtaceae

VU $B 1+2 c$

New Caledonia

Asian Eugenia are now contained within Syzygium.

Assessor: Jaffré, T. et al.

Refs: 10351

\section{Eugenia watsoniana}

Myrtaceae

Malaysia (Peninsular Malaysia)

Restricted to lowland forest in Selangor, the species is experiencing rapid habitat loss through agricultural development and increasing settlement. Kanching Forest Reserve, where the species has been recorded, is now largely a recreational area. Asian Eugenia are now included in Syzygium.

Assessor: Kochummen, K.M.

Refs: 8464, 19073

\section{Eugenia woodburyana}

Myrtaceae

CR D1

Puerto Rico

A slender tree with unusual winged fruit. A total of 45 plants are contained within three populations. Threats from fire, mining, grazing and road building are evident. Assessor: World Conservation Monitoring Centre Refs: 3786, 7980, 17124

\section{Eugenia zeyheri}

Myrtaceae

South Africa (Eastem Cape)

There is considerable confusion in the literature about the identity of this taxon and its correct distribution. More recent accounts indicate that it is confined to the Eastem Cape but absent from KwaZulu-Natal and Mpumalanga as recorded previously. Herbarium specimens are also misidentified and there is little field knowledge of the species.

Assessor: Hilton-Taylor, C. et al.

Refs: 689,19218

\section{Euodia lunuankenda}

Rutaceae

$\mathrm{EN} \mathrm{B1}+2 \mathrm{c}$

India (Tamil Nadu)

A poorly known species of forest margins, recorded from restricted areas of forest between 1400 and $1600 \mathrm{~m}$ in the Agastyamalai Hills and Elamalai Hills.

Assessor: World Conservation Monitoring Centre Refs: 19144

\section{Euodia macrocarpa}

Rutaceae

VUAlc

Malaysia (Peninsular Malaysia)

An uncommon tree found in moist lowland and submontane forest in Kedah, Penang, Perak, Pahang and Selangor. Increasing settlement of the area is the greatest threat to the species.

Assessor: Chua, L.S.L.

Refs: $1892,8464,14541,19073$

\section{Euodia robusta}

Rutaceae

$\mathrm{LR} / \mathrm{cd}$

Malaysia (Peninsular Malaysia), Singapore

A small tree of moist forest up to $1300 \mathrm{~m}$ in Kedah, Perak and Singapore. Populations receive a degree of protection within the permanent forest estate.

Assessor: Chua, L.S.L.

Refs: 8464,9199, 14541, 19073

\section{Euonymus acanthocarpa}

Celastraceae

LR/nt

China (Anhui, Guangxi, Guizhou, Henan, Hubei, Shanxi, Yunnan)

A species of omamental interest. It is widely scattered in moist semi-deciduous forest between 1200 and $3000 \mathrm{~m}$. Assessor: Sun, W.

Refs: 19055

\section{Euonymus angulatus}

Celastraceae

VU $B 1+2 c$

India (Karnataka, Kerala, Tamil Nadu)

A small tree of evergreen forest on slopes and river banks, collected in the past from a number of locations 
in the Nilgiri Hills and apparently also from two locations in southem Kamataka. It is thought to have disappeared from a number of sites, mainly because of habitat conversion and possibly also fires.

Assessor: World Conservation Monitoring Centre Refs: 2538, 19144

\section{Euonymus assamicus}

Celastraceae

$\mathrm{EN} \mathrm{B1}+2 \mathrm{c}$

\section{India (Assam)}

Recorded from the Delei Valley in north Assam in 1928 , the species occurred in thickets on a steep rocky slope but has not been found since.

Assessor: World Conservation Monitoring Centre

Refs: 2538

\section{Euonymus glandulosus}

Celastraceae

$\mathrm{LR} / \mathrm{cd}$

Malaysia (Sabah, Sarawak), Philippines

A small tree found in hill and montane forest in northem Borneo and the Philippines. It is widely distributed in Sarawak, but restricted to Mount Kinabalu National Park in Sabah.

Assessor: World Conservation Monitoring Centre

Refs: 19017

\section{Euonymus lanceifolia}

\section{Celastraceae}

VU $B 1+2 c$

China (Yunnan)

The taxonomic status of the species is not resolved; it may represent a variety of $E$. hamiltonianus. It is confined to Mengzi in the south-east, where it is scattered in areas of semi-deciduous forest between 2100 and $3000 \mathrm{~m}$. In places the habitat has become degraded in the last few years and population numbers are reported to be declining.

Assessor: Sun, W.

Refs: 19055

\section{Euonymus morrisonensis}

Celastraceae

VU DI+2

Taiwan

A species which is restricted to a narrow altitudinal range, occurring in open rocky habitats between 2700 and $2900 \mathrm{~m}$. Populations are found at distant localities, in Tatachia, Nengkaoyueh and Tienchin. There is little sign of regeneration.

Assessor: Lu, S.Y. \& F.J. Pan

Refs: $3295,6469,19050,19051$

\section{Euonymus pallidifolia}

\section{Celastraceae}

CR A $1 a+2 d$

Taiwan

A potentially valuable ornamental shrub, which is restricted to areas of evergreen forest on raised coral reef in the Hengchun Peninsula at the southem tip of Taiwan. Populations are very small and suffering from poor regeneration. The entire species' range is contained within Kenting National Park.

Assessor: Lu, S.Y. \& F.J. Pan

Refs: $3295,6469,19050,19051$

\section{Euonymus paniculatus}

Celastraceae

$\mathrm{EN} \mathrm{B} 1+2 \mathrm{c}$

India (Tamil Nadu)

A small tree, so far only collected twice from submontane evergreen forest at two widely separated localities.

Assessor: World Conservation Monitoring Centre

Refs: 19144

\section{Euonymus serratifolius}

Celastraceae

$\mathrm{EN} \mathrm{B1}+2 \mathrm{c}$

India (Kerala, Tamil Nadu)

A small understorey tree, recorded only three times: once from an imprecisely recorded site in the Agastyamalai Hills and elsewhere from isolated localities in the Wyanad area.

Assessor: World Conservation Monitoring Centre

Refs: 2538, 19144

\section{Euonymus thwaitesii}

Celastraceae

$\mathrm{EN} \mathrm{BI+2c}$

Sri Lanka

A species found twice only in the extensive forest surveys conducted between 1991 and 1996 for the National Conservation Review.

Assessor: Worid Conservation Monitoring Centre Refs: $8203,18796,19112$

\section{Euonymus walkeri}

Celastraceae

VUAlc

Sri Lanka

A species occurring in the lowland wet evergreen forests of south-west Sri Lanka.

Assessor: World Conservation Monitoring Centre Refs: 17195

\section{Euphorbia abdelkuri}

Euphorbiaceae

EN D1

Yemen (Socotra)

Approximately 15 small populations, each of about 10 mature individuals, are known, all confined to Jebel Saleh on the western side of Abd al Kuri, an island to the west of Socotra. They occur in dry semi-desert and are unthreatened at present. The species is subject to *CITES Appendix II controls.

Assessor: Miller, A.G.

Refs: 19083,19197

\section{Euphorbia ammak}

Euphorbiaceae

VU Alc

Saudi Arabia, Yemen

A succulent tree, once an important component of the succulent shrubland between 1000 and $1500 \mathrm{~m}$. It has now become scarce, particularly in Saudi Arabia and South Yemen, although it remains common in places in North Yemen.The species is subject to ${ }^{*}$ CITES Appendix II controls.

Assessor: Miller, A.G.

Refs: 19083,19197

\section{Euphorbia apurimacensis}

Euphorbiaceae

VU B $1+2 c$

Peru

Apparently confined to the department of Apurimac, the species occurs in forest roughly between 1500 and $2000 \mathrm{~m}$.

Assessor: World Conservation Monitoring Centre Refs: 1984 


\section{Euphorbia arbuscula}

Euphorbiaceae

VU D2

Yemen (Socotra)

The species is fairly widespread, occurring on coastal plains and foothills in areas of dry woodland and shrubland. Trees are planted near settlements as dry season fodder for livestock. There is also a doubtfully distinct variety which is rare and confined to higher altitudes. The species is subject to ${ }^{*}$ CITES Appendix II controls.

Assessor: Miller, A.G.

Refs: 19083,19197

\section{Euphorbia bwambensis}

Euphorbiaceae

Congo, Uganda

VU B1+2c

A tree with drooping branches which, in Uganda, is confined to Cynometra forest in Semuliki, Bundibugyo District. Regeneration appears to be poor. It is protected within Rwenzori Mountain National Park. The species is subject to *CITES Appendix II controls.

Assessor: *MUIENR

Refs: $1308,9605,10961,16021,19197$

\section{Euphorbia cussonioides}

Euphorbiaceae

VU B1+2c

Kenya

A tree with succulent branches. It is endemic to localised areas of dry or riverine upland forest. The species is subject to *CITES Appendix II controls.

Assessor: World Conservation Monitoring Centre Refs: $1546,6396,9198,19197$

\section{Euphorbia doloensis}

Euphorbiaceae

Ethiopia

This species is known only from the type collection which occurs in open Commiphora-Boswellia bushland on steep rocky slopes in the Sidamo region.

Assessor: World Conservation Monitoring Centre

Refs: 5941,18523

\section{Euphorbia epiphylloides}

Euphorbiaceae EN C2a, D1

India (Andaman and Nicobar Is. - Andaman Is.)

An unarmed succulent tree which was recorded, up to 1977 , as locally common in several localities. Recent surveys have been less successful in locating the species. In total no more than 250 plants exist around Saddle Peak on North Andaman, representing a serious decline from original population numbers. There are no known reasons for the decline as the area is relatively isolated and unthreatened.

Assessor: World Conservation Monitoring Centre Refs: 19029

\section{Euphorbia haeleeleana \\ Euphorbiaceae \\ USA (Hawaii)}

EN C2a

A small dioecious tree occurring on two Hawaiian islands in lowland forest, both moist and dry. At present 15 populations, containing between 450 and 625 individuals, are recorded from the Waianae Mountains on Oahu and on the north-west coast of Kauai. All but one of the localities are on state-owned land. The habitat is steadily being degraded by feral goats, pigs and also deer and the spread of introduced plants is causing a decline in native flora. The species is protected by the US Endangered Species Act.

Assessor: World Conservation Monitoring Centre

Refs: 3372, 19035

\section{Euphorbia lividiflora}

Euphorbiaceae

VU D2

Malawi, Mozambique, Tanzania, Zimbabwe

Populations are few and disjunct. One is known in Mikindani in Tanzania and another in a protected area in south-east Zimbabwe. Coastal populations in Mozambique may be extensive but more information is needed to confirm their status and extent.This species is subject to ${ }^{*}$ CITES Appendix II controls.

Assessor: World Conservation Monitoring Centre

Refs: $1546,5108,5117,10961,17190,19172,19197$

\section{Euphorbia mayurnathanii}

Euphorbiaceae

India

The species was described in 1940 from three old specimens growing on a rocky ledge on the eastem spur of a hill in Pallasana situated in the Palghat Gap. The vegetation is monsoon forest and succulent plants are absent apart from this single species. It has been postulated that the climate in the past was drier and this small remnant of a previously xerophytic community survived because of its exposed position. Thorough searches have failed to locate any living wild specimens today, although the species has been successfully cultivated. The species is subject to *CITES Appendix II controls.

Assessor: World Conservation Monitoring Centre Refs: 19029,19197

\section{Euphorbia meuleniana}

Euphorbiaceae

VU D2

Yemen

Known only from the Mahra region of South Yemen, the species is scarce and scattered in a few dry valleys. Further fieldwork is needed to estimate population sizes. Assessor: Miller, A.G.

Refs: 19083

\section{Euphorbia nigrispinioides \\ Euphorbiaceae}

LR/nt

Ethiopia

A species which is locally common on lava flows in open deciduous woodland. It is known from Shewa but its distribution may extend into Harerge and possibly Somalia.The species is subject to *CITES Appendix II controls.

Assessor: World Conservation Monitoring Centre Refs: 5941, 18523, 19197

\section{Euphorbia noxia \\ Euphorbiaceae \\ Somalia}

VU D2

A laxly branched, slender tree confined to a few localities on rocky limestone soils with sparse bushland south of Bosaso and Qandala in north-eastern Somalia. The habitat is under some threat from overcutting and overgrazing.

Assessor: Thulin, M.

Refs: $1546,8697,18665$ 


\section{Euphorbia obcordata}

Euphorbiaceae

VU D2

Yemen (Socotra)

A small tree or shrub, which has been collected on only a few occasions and is thought to be rare. Populations occur on wooded limestone cliffs on the east of the island. They are under no immediate threat.

Assessor: Miller, A.G.

Refs: 2354,19083

\section{Euphorbia santapauii}

Euphorbiaceae

$\mathrm{EN} \mathrm{Bl+2cd}$

India (Tamil Nadu)

A succulent species localised to the sward-covered summit of Mount Agasthya on the Kerala-Tamil Nadu border. Individuals survive in sheltered and moist places. Most localities have apparently been destroyed, frequently because of accidental and intentional fires. Trees are also cut and dried to be used as firewood by pilgrims trekking up to the temple on the summit of Mount Agasthya.This species is subject to *CITES Appendix II controls.

Assessor: World Conservation Monitoring Centre

Refs: 5651, 19028, 19029, 19197

\section{Euphorbia sekukuniensis}

Euphorbiaceae

LR/nt

South Africa (Mpumalanga, Northern Province)

A small spiny succulent tree with a restricted distribution on a range of hills northwest of Lydenburg. Plants are found on rocky slopes and cliffs in shallow sandy and turfy soils, associated with mixed savanna vegetation. The species is not threatened but it is listed as protected. Any changes in land use could have some impact. None of the localities are contained-within conservation areas. The species is subject to ${ }^{*}$ CITES Appendix II controls.

Assessor: Hilton-Taylor, C. et al.

Refs: $689,14002,19218$

\section{Euphorbia smithï}

Euphortiaceae

LR/nt

Oman, Yemen

Endemic to the escarpment mountains from Dhofar in Oman to neighbouring south-east Yemen, this species is a common component of woodlands at lower altitudes. There has been an influx of people into the area in Oman since 1975 and a subsequent rise in grazing pressure and cutting of wood.

Assessor: Ghazanfar, S.A.

Refs: 16380

\section{Euphorbia socotrana}

Euphorbiaceae

VU D2

Yemen (Socotra)

Populations appear to be scattered and relatively rare in areas of dry woodland and shrubland on granite and limestone. They are under no immediate threat.

Assessor: Miller, A.G.

Refs: 19083

\section{Euphorbia tanaensis}

Euphorbiaceae

CR B1+2c, Dl

Kenya

A medium-sized tree of semi-deciduous swamp forest, confined to Witu Forest Reserve. The present population estimate includes 20 mature individuals. Although the area is legally protected, civil insecurity has led to a lack of research and enforcement of protective measures. The species is subject to *CITES Appendix II controls.

Assessor: CAMP Workshop in Kenya

Refs: 1546, 6396, 12067, 19181, 19197

Euphorbia thulinii

Euphorbiaceae

VU D2

Somalia

A imall tree known only from a limestone escarpment, vegetated with sparse low bushes, south of Dhurbo in north-east Somalia. The area is vulnerable to degradation.

Assessor: Thulin, $\mathrm{M}$

Refs: 8697, 18665

\section{Euphorbia uniglans}

Euphorbiaceae

VU D2

Ethiopia

A species recorded only from a small area in Sidamo in high Commiphora bushland.

Assessor: World Conservation Monitoring Centre

Refs: 5941,18523

\section{Euphorbia vajravelui}

Euphorbiaceae

VU D2

India (Tamil Nadu)

Endemic to Tamil Nadu, this small succulent tree or shrub occurs in submontane forest. Populations occur in Kalakkad Forest, Kodyar, Sinumalai and Highwavys. More detailed information is needed on their status. This species is subject to the provisions of *CITES Appendix II.

Assessor: World Conservation Monitoring Centre

Refs: 19029,19197

\section{Euphorbia wakefieldii}

Euphorbiaceae

$\mathrm{EN} \mathrm{B} 1+2 \mathrm{c}$

Kenya, Tanzania?

A succulent tree, best known from a population confined to coral cliffs and limestone outcrops in the MombassaKilifi area in Kenya. There is also a record of an occurrence in the South Pare Mountains in Tanzania. The species is subject to *CITES Appendix II controls. Assessor: World Conservation Monitoring Centrc Refs: 1546, 6396

\section{Euphorbia zoutpansbergensis}

Euphorbiaceae

LR/nt

South Africa (Northem Provine)

A small spiny succulent tree restricted to the Zoutpansberg and Blouberg mountain ranges, where it grows in sandy soils on rocky, sandstone slopes of ridges and hills with a north and north-east aspect in mixed savanna vegetation. Apart from slight pressure from succulent-collectors, no immediate threats exist. Any change in land use, however, would have a serious impact because of the species' restricted range. The species is listed as protected, but it is not recorded from any conservation areas. It is also subject to ${ }^{*}$ CITES Appendix II controls. Assessor: Hilton-Taylor, C. et al. Refs: $689,14002,19218$ 


\author{
Euplassa isernü \\ Proteaceae \\ VU D2 \\ Peru \\ This species is known only from its type collection taken \\ from the department of Junin. \\ Assessor: World Conservation Monitoring Centre \\ Refs: 1984
}

\section{Euroschinus aoupiniensis}

Anacardiaceae

New Caledonia

Assessor: Jaffré, T. er al.

Refs: 10351

\section{Euroschinus jaffrei}

Anacardiaceae

New Caledonia

VU B $1+2 \mathrm{c}$

Assessor: Jaffré, T, et al.

Refs: 10351

\section{Eurya rengechiensis}

Theaceae

$\mathrm{EN} \mathrm{B} 1+2 \mathrm{~b}$

Taiwan

Only a few small populations are known in areas of lowland broadleaved forest at Lienhunchi in the centre of Taiwan. There is little evidence of regeneration. None of the populations is protected.

Assessor: Pan, F.J.

Refs: 3295,19050

\section{Eurya sandwicensis}

Theaceae

VU Alce

USA (Hawaii)

Apparently the species is uncommon and scattered on forested ridges between 450 and $1600 \mathrm{~m}$ on Kauai, Oahu, Molokai, Maui and Hawaii.

Assessor: World Conservation Monitoring Centre

Refs: 3372

\section{Eurycorymbus cavaleriei}

Sapindaceae

LR/nt

China (Fujian, Guangdong, Guangxi, Guizhou, Hubei, Hunan, Jiangxi, Yunnan), Taiwan

A wide-ranging tree, and important fuelwood, of lowland semi-deciduous forest, occurring up to $1600 \mathrm{~m}$. Habitat declines have been extensive throughout the range. Some populations exist within protected forest.

Assessor: World Conservation Monitoring Centre

Refs: $1818,11847,19055$

\section{Euryodendron excelsum}

Theaceae

China (Guangdong, Guangxi)

CR D1

The species has been reduced to two localities, Yangchong in Guangdong and Pingnan in Guangxi, and very few individuals which are found in open forest on hilly slopes between 50 and $150 \mathrm{~m}$. The remaining trees do not appear to be protected and are close to villages, where they are susceptible to cutting. The genus is monospecific.

Assessor: World Conservation Monitoring Centre Refs: 1818,11847

\section{Eusideroxylon zwageri}

Lauraceae

VU Alcd $+2 c d$

Brunei, Indonesia (Java, Kalimantan, Sumatra), Malaysia (Sabah, Sarawak), Philippines

Generally a species of lowland primary forest. Belian or ironwood is one of the most renowned timbers of
Bomeo, the decline of which was first noted in 1955. Population reduction caused by overexploitation and shifting agriculture has been noted in the following regions: Kalimantan, Sumatra, Sabah, Sarawak and the Philippines. Indonesia has banned the export of belian and Sarawak has placed restrictions on export; Sabah and Kalimantan continue to export it. Regeneration in logged-over forests is limited. So far the species is only planted on a small scale because the supply of seeds and seedlings is inadequate.

Assessor: Asian Regional Workshop

Refs: 898, 3122, 7087, 7461, 12937, 13395, 14573, 17235,19026

\section{Euterpe luminosa}

Palmae

VU B $1+2 c$

Peru

A clustered palm tree of great taxonomic interest, restricted to Cordillera Yanachaga. It occurs in the understorey of moist cloud forest between 2000 and $2500 \mathrm{~m}$. The species range is extremely small and threatened by forest clearance.

Assessor: Henderson, A.

Refs: 19118

\section{Excoecaria benthamiana}

Euphorbiaceae

VU D2

Seychelles

Endemic to the Seychelles, the species occurs within a very restricted area $(<1000 \mathrm{ha})$, on Mahé and Praslin. Populations are healthy and stable.

Assessor: Nature Protection Trust of Seychelles

Refs: $16212,17229,19025$

\section{Exocarpos gaudichaudii}

Santalaceae

USA (Hawaii)

EN Alce

This species is uncommon and scattered primarily on forested ridges or in shrubland at medium elevations on all the main islands except Kauai.

Assessor: World Conservation Monitoring Centre Refs: 3372

\section{Exostema brachycarpum}

Rubiaceae

LR/nt

Jamaica

Occurring in central and western parishes, this tree has a local distribution confined to remaining areas of woodland on limestone. General declines in the habitat have been considerable.

Assessor: World Conservation Monitoring Centre Refs: 6057,7980

\section{Exostema orbiculatum}

Rubiaceae

CR B $1+2 \mathrm{C}$

Jamaica

An uncommon species confined to Crown Lands in Troy in Trelawny.

Assessor: World Conservation Monitoring Centre Refs: $401,5653,7980$

\section{Exostema triflorum}

Rubiaceae

VU $B 1+2 c$

Jamaica

A tree known only from St Ann and Portland Parishes, where it is restricted to sheltered moist woodland on 
limestone at about $450 \mathrm{~m}$. Many areas have been logged or taken over by commercial plantations.

Assessor: World Conservation Monitoring Centre

Refs: 401, 5653, 7980

\section{Fagara externa}

Rutaceae

VU D2

Chile (Juan Fernández Is)

A characteristic species of lower montane forest, endemic to Masafuera Island. Preliminary data indicate the species is confined to less than $100 \mathrm{~km}^{2}$. More detailed information on the species should become available to confirm this evaluation. The islands are designated as a national park and biosphere reserve and work is being carried out by *CONAF to save the native plants.

Assessor: World Conservation Monitoring Centre

Refs: $3241,5651,14140$

\section{Fagara mayu}

Rutaceae

VU D2

Chile (Juan Fernández Is)

A characteristic species of lower montane forest, a good example of which is found at Quebrada Villagra. Preliminary data indicate the species is confined to less than $100 \mathrm{~km}^{2}$. More detailed information on the species should become available to confirm this evaluation. The islands are designated as a national park and biosphere reserve and work is being carried out by *CONAF to save the native plants. Fagara is now included in Zanthoxylum.

Assessor: World Conservation Monitoring Centre

Refs: $3241,5651,7980,14140$

\section{Fagara mezoneurospinosa}

Rutaceae

$\mathrm{EN} \mathrm{B1}+2 \mathrm{C}$

Côte d'Ivoire

A rare species, known only from coastal forest in Côte D'Ivoire. This forest type has been severely degraded and depleted. Zanthoxylum is now the accepted name for this genus.

Assessor: Assi, A.

Refs: 12590,12822

\section{Fagraea carstensensis}

Loganiaceae

DD

Papua New Guinea

A poorly understood species, collected twice from forest between 200 and $860 \mathrm{~m}$ on Mount Carstensz and Mount

Tamrau, Mimika District.

Assessor: World Conservation Monitoring Centre

Refs: 19031

\section{Fagraea gracilipes}

Loganiaceae

LR/nt

Fiji

A desirable timber, used for house posts and marine constructions. It is sometimes locally abundant, occurring in dry dense forest and occasionally on the inner edges of mangroves on four of the high islands. Cutting of trees in Mathuata and Mbua is restricted. It has become rare on Viti Levu because of cutting and coastal developments. The populations on the north coast of Vanua Levv are probably the least disturbed. Assessor: World Conservation Monitoring Centre Refs. 5515, 6053, 6433, 18818
Fagus hayatae

Fagaceae

VU D2

Taiwan

The Taw wan beech is found in broadleaved submontane forest in the northern and southem parts of Chatienshan and in smaller populations in Tungshan and Agushan in Ilan County. Populations are largely made up of old individuals. Trees are slow-growing and regeneration is poor, depending on the creation of gaps which are currently being invaded by alpine bamboo and broadleaved species. The species is morphologically similar to and may turn out to be synonymous with $F$. lucida from the central provinces of China.

Assessor: Lu, S.Y. \& F.J. Pan

Refs: $1818,3295,11847,19050,19051,19054$

\section{Fagus longipetiolata}

Fagaceae

China, Viet Nam

In Viet Nam this slow-growing tree is known only from Sapa and Moc Chau, where it is sometimes the dominant species in dense subtropical broadleaved forest. Regeneration is thought to be hampered by a thick layer of leaf litter on the forest floor. The wood is used to make furniture, implements and musical instruments.

Assessor: Nghia, N.H.

Refs: 848, 4506, 11530, 15357

\section{Falcatifolium angustum}

Podocarpaceae

VU D2

Malaysia (Sarawak)

A rare tree of lowland rainforest, collected four times from just two localities of rainforest near the coast at Bintulu and Kuching. Its diminutive size and scarcity render it unlikely to be exploited.

Assessor: SSC Conifer Specialist Group

Refs: $374,6851,19192$

\section{Faramea exemplaris}

Rubiaceae

VU D2

Peru

Known only from the type collection, the species occurs in lowland Amazon forest in the department of Loreto. Assessor: World Conservation Monitoring Centre Refs: 1984

\section{Fatsia polycarpa}

Araliaceae

LR/nt

Taiwan

Occurring in broadleaved forest up to $2800 \mathrm{~m}$, the species is confined to the central mountain range. Habitat destruction has been extensive but most intense at lower elevations. The only other member of the genus is confined to Japan.

Assessor: World Conservation Monitoring Centre

Refs: $1818,6469,11847$

\section{Faurea macnaughtonii}

Proteaceae

South Africa (Eastem Cape, Westem Cape, KwaZuluNatal, Mpumalanga), Swaziland

A very widespread but scattered species occurring in forests and on forest margins from near Knysna in the Western Cape to Mariepskop in Mpumalanga (approx. 13 localities in South Africa). It is also recorded from a single forest in Swaziland. All the subpopulations are very small, except for a comparatively large and vigorous subpopulation in Lilyvlei forest at Gouna near Knysna in the Western Cape. Regeneration in all except 
the latter subpopulation is non-existent, despite trees fruiting plentifully and the seed being viable. At one time trees were harvested for their timber, but this is now strictly controlled. It is a protected species over much of its range and efforts are being made to improve the potential of recruitment. More research is needed to establish the relationship between this species and other Faurea species in East Africa, Madagascar and Zimbabwe.

Assessor: Hilton-Taylor, C. et al.

Refs: $689,16730,19218$

\section{Fernandoa lutea \\ Bignoniaceae \\ Tanzania}

An endemic species of the Rondo Forest Reserve $\left(140 \mathrm{~km}^{2}\right)$, limited to areas which remain undisturbed. Logging, planting of commercial timbers, shifting cultivation and wood collection have all contributed to the disturbance of forested areas within the reserve. The stability of the remaining forest is maintained by the presence of forest management activities which discourage local exploitation.

Assessor: Lovett, J. \& G.P. Clarke

Refs: 5654, 16796

\section{Ficus aguaraguensis}

Moraceae

VU B $1+2 \mathrm{ac}$

Bolivia

Endemic to the piedmont forest in Bolivia, the species is confined to an unprotected ecosystem which is being rapidly replaced by agricultural systems.

Assessor: Prado, D.

Refs: 19122

\section{Ficus andamanica}

Moraceae

EN B1+2c

India (Andaman and Nicobar Is. - Andaman Is.)

A fig tree endemic to South Andaman Island where it is sparsely distributed in remaining areas of evergreen forest. Large declines in extent of the forest have been caused by logging.

Assessor: World Conservation Monitoring Centre

Refs: 4799,7147

\section{Ficus angladei}

Moraceae

CR B $1+2 \mathrm{c}$

India (Tamil Nadu)

A poorly known species which has been recorded just the once from an unspecified locality in the Palni Hills.

Assessor: World Conservation Monitoring Centre Refs: 19144

\section{Ficus aripuanensis}

Moraceae

Brazil (Mato Grosso, Pará)

Assessor: Pereira, J.P. et al.

Refs: 2562

\section{Ficus bizanae}

Moraceae

South Africa (Eastem Cape, KwaZulu-Natal)

$\mathrm{EN} \mathrm{B} 1+2 \mathrm{bc}$

A species of coastal and riverine forest, mainly found in the Transkei, Eastern Cape, but also in southem KwaZulu-Natal and in a disjunct subpopulation in Ngoye forest, northem KwaZulu-Natal. It is known from approximately six localities and does not seem to be common anywhere. Although a number of localities are in demarcated forest reserves, these reserves have not been effectively protected since 1994. Many forest patches are under threat from people collecting firewood and timber and expanding settlements.

Assessor: Hilton-Taylor, C. et al.

Refs: 689,19218

Ficus blepharophylla

Moraceae

$\mathrm{EN} B 1+2 \mathrm{bc}$

Brazil (Roraima)

Assessor: Pereira, J.P. et al.

Refs: 2562

\section{Ficus bojeri}

Moraceae

Seychelles

A species of the granitic islands, endemic to the Seychelles.

Assessor: World Conservation Monitoring Centre

Refs: 16212,17229

Ficus calyptroceras

Moraceae

$\mathrm{VU} B 1+2 \mathrm{bc}$

Brazil (Bahia, Goiás, Mato Grosso do Sul, Minas Gerais, Piaun)

Assessor: Pereira, J.P. et al.

Refs: 2562

Ficus chlamydocarpa ssp. fernandesiana

Moraceae

VU D2

São Tomé \& Príncipe (São Tomé)

A tree of secondary forest, occurring up to $1000 \mathrm{~m}$. It has been collected from four locations, $S$. Vicente, Jou, a site between Nova Moka and Bom Sucesso and also Monte Café

Assessor: World Conservation Monitoring Centre Refs: $2421,2724,10080$

\section{Ficus cotinifolia var, hondurensis}

Moraceae

EN C2a

Costa Rica, El Salvador, Honduras, Nicaragua

This variety occurs in mixed forest types of varying humidity.

Assessor: Nelson, C

Refs: 2652, 13995

\section{Ficus cyclophylla}

Moraceae

EN Alc

Brazil (Maranháo, Minas Gerais, Pararba, Pernambuco, Pernambuco - Fernando de Noronha, Rio de Janeiro, Rondônia)

In the past the species has been confused with $F$. catappifolia or $F$. longifolia. It has a scattered distribution in areas of Atlantic forest in the north-east and south-east. Loss and degradation of habitat and poor regeneration have resulted in population reductions.

Assessor: Carauta, J.P.P.

Refs: $2562,15717,19101$

\section{Ficus faulkneriana}

Moraceae

CR C2a, D1

Kenya, Tanzania

A strangler fig of coastal dry open bushland. Populations of extremely small size are known from Gongoni Forest Reserve and Dzirihini in Kenya. It was also recorded in Langoya Nwaganid in 1968. In Tanzania there are records from sisal estates in Pangani and Korogwe. These areas are in danger of being completely cleared. Assessor: CAMP Workshop in Kenya

Refs: 6396, 19181 


\section{Ficus hirsuta}

\section{Moraceae}

LR/nt

Brazil (Bahia, Mato Grosso do Sul, Minas Gerais, Rio de Janeiro, Sāo Paulo)

A species which was once thought to be near extinction. Assessor: Pereira, J.P. et al.

Refs: 2562

\section{Ficus lapathifolia}

Moraceae

VUAlc

Mexico (Chiapas, Oaxaca, Veracruz)

Endemic to the Gulf region, the species occurs in remaining areas of rainforest, ranging as far north as northem Veractuz.

Assessor: World Conservation Monitoring Centre Refs: 5993

\section{Ficus lateriflora}

Moraceae

CR C2a, D1

Mauritius, Réunion

The Mauritian population consists of fewer than 10 individuals, only three of which have been identified with complete confidence. Individuals are confined to extremely wet areas in forest in the south-west uplands. There is no available information on the population which apparently exists on Réunion

Assessor: Page, W.

Refs: $1411,2000,3476,12646$

\section{Ficus meizonochlamys}

Moraceae

$\mathrm{EN} \mathrm{B1}+2 \mathrm{c}$

Cuba

Confined to the karstic hill complex of Sierra de Nipe on the border of the provinces of Santiago de Cuba and Holguin, this endemic tree is not well collected and its habitat has been degraded in accessible areas.

Assessor: Areces-Mallea, A.E.

Refs: $11403,18485,19149$

Ficus mexiae

Moraceae

Brazil (Bahia, Minas Gerais)

Assessor: Pereira, J.P. et al.

Refs: 2562

\section{Ficus muelleriana}

Moraceae

EN D1

Mozambique

A shrub or small tree of moist deciduous woodland at about $600 \mathrm{~m}$, known only from two localities immediately to the east and south of the Chimanimani Mountains in westem Mozambique. This woodland type is being extensively destroyed throughout south and central Africa. Although this area is largely unexplored and further populations may be found, the species distribution is very restricted and the populations are unprotected and small, one locality containing in the region of 20 individuals.

Assessor: World Conservation Monitoring Centre

Refs: 11085,19172

\section{Ficus mutabilis}

Moraceae

VU Bl+2c

New Caledonia

Assessor: Jaffré, T, et al.

Refs: 10351
Ficus pakkensis

Moraceae

VU $B 1+2 b c$

Brazil (Maranháo, Pará), Guyana

The Brazilian population is confined and declining.

Assessor: Pereira, J.P. et al.

Refs: 2562

Ficus pulchello

Moraceae

VU B $1+2 b c$

Brazil (Maranháo, Pará, Paraná, Rio de Janeiro, Santa Catarina)

An Atlantic forest species which is threatened by loss and degradation of the habitat and poor regeneration.

Assessor: Carauta, J.P.P.

Refs: 15717,19101

\section{Ficus ramiflora}

Moraceae

$\mathrm{EN} \mathrm{Bl+2bc}$

Brazil (Acre, Amapá, Amazonas, Roraima)

Assessor: Pereira, J.P. er al.

Refs: 2562

\section{Ficus reflexa ssp. seychellensis}

Moraceae

VU D2

Seychelles

Endemic to the Seychelles, the species qualifies as threatened by virtue of its restricted distribution. Populations are healthy and stable.

Assessor: World Conservation Monitoring Centre

Refs: 16212,17229

\section{Ficus roraimensis}

Moraceae

$\mathrm{EN} \mathrm{B1}+2 \mathrm{bc}$

Brazil (Roraima)

Assessor: Pereira, J.P. et al.

Refs: 2562

\section{Ficus salzmanniana}

Moraceae

$\mathrm{EN} \mathrm{BI+2bc}$

Brazil (Bahia)

Assessor: Pereira, J.P. et al.

Refs: 2562

\section{Ficus ulmifolia}

Moraceae

VU Alcd

Philippines

An endemic to the Philippines. Rates of habitat loss through logging and shifting cultivation have led to considerable population declines.

Assessor: World Conservation Monitoring Centre Refs: $2072,4919,18088$

\section{Ficus ursino}

Moraceae

$\mathrm{EN} \mathrm{B} 1+2 \mathrm{bc}$

Brazil (Acre)

Assessor: Pereira, J.P. et al.

Refs: 2562

\section{Firmiana hainanensis}

Sterculiaceae

VU BI+2c

China (Guangdong - Hainan)

The southermmost member of the genus. The few populations known are confined to Hainan Island, where they occur in seasonal rainforest between 400 and $900 \mathrm{~m}$. Extensive declines in the habitat because of logging and agricultural expansion have caused populations to decline throughout the species' range.

Assessor: World Conservation Monitoring Centre Refs: 1818,11847 


\section{Firmiana major}

Sterculiaceae

China (Yunnan)

The only remaining trees are those which have been planted around temples and villages. Wild populations were once believed to have existed in central and westem Yunnan between 1700 to $2500 \mathrm{~m}$. The forests here have been replaced by crops. The species remains in cultivation, frequently planted as an ornamental tree. Assessor: Sun, W.

Refs: $1818,11847,19055$

\section{Fitchia cordata}

Compositae

French Polynesia (Society Is.)

$\mathrm{CR} B 1+2 \mathrm{c}$

A small genus endemic to East Polynesia. This species is recorded only on Bora Bora.

Assessor: Florence, J.

Refs: 14513

\section{Fitchia cuneata ssp. cuneata}

Compositae

French Polynesia (Society Is.)

CR B $1+2 \mathrm{C}$

A small genus endemic to East Polynesia. This taxon represents one of two subspecies. It is confined to Raiatea.

Assessor: Florence, J.

Refs: 14513

\section{Fitchia mangarevensis}

Compositae

French Polynesia (Tuamotu Is.)

Occurring as either a shrub or small tree, the species was only ever known from Taravai in the Gambier Islands. The genus is endemic to East Polynesia.

Assessor: Florence, J.

Refs: 14513

\section{Fitchia nutans}

Compositae

French Polynesia (Society Is.)

VU D2

This species comes from a small genus, endemic to East Polynesia. It has been found only on Tahiti.

Assessor: Florence, J.

Refs: 14513

\section{Fitchia tahitensis}

Compositae

VU D2

French Polynesia (Society Is.)

One of the six species in the genus, which is endemic to East Polynesia. It occurs only on Tahiti.

Assessor: Florence, J.

Refs: 14513

\section{Fitzroya cupressoides}

Cupressaceae

EN Alcd

Argentina (Chubut, Neuquén, Rio Negro), Chile (Los Lagos)

Alerce has been logged since the middle of the 17th century. The largest concentration of the species, at the southem end of the Chilean depression, was exploited in the 18th and 19th centuries, leaving no remains except blackened stumps. By the early 1900 s a third of the Fitzroya forests had been removed. In the 1930s motorised transport and the building of roads allowed access to the stands in the Coastal Cordillera and High Cordillera. Exploitation continued in both of these areas at such intensities that chances of regrowth and regeneration are anihalated. Present estimates of the area taken up by remaining stands lie at $20,000 \mathrm{ha}, 15 \%$ of their original size. Restrictions laid down by the Chilean Government have not been adhered to and illegal logging in remote areas has been impossible to halt. Today the best stands may be found between latitudes of $41^{\circ}$ and $42^{\circ} \mathrm{S}$ in the High Cordillera. Elsewhere populations are small. The species is listed in ${ }^{*}$ CITES Appendix I.

Assessor: González, $\mathbf{M}$.

Refs: $5112,7980,11147,13041,16328,19214$

\section{Fleurydora felicis}

Ochnaceae

VU B $1+2 c$

Guinea

Information on the population status is not available. The species is endemic to upland forest. The pressure on these few small remaining areas exerted by a dense human population is great. It is the only species in the genus.

Assessor: World Conservation Monitoring Centre Refs: 2773

\section{Flindersia amboinensis}

Rutaceae

LR/nt

Indonesia (Moluccas), Papua New Guinea

A large tree, widespread but of sporadic occurrence throughout lowland and submontane rainforest on mainland Papua New Guinea, Seram Island and Tanimbar Islands of the Moluccas. The main threat to the species is logging. The wood has commercial value as a veneer and is used to make high-class furniture.

Assessor: Eddowes, P.J.

Refs: 19114

\section{Flindersia ifflaina}

Rutaceae

Australia (Queensland), Papua New Guinea

In Papua New Guinea, this tree is found in monsoon and gallery forest up to $50 \mathrm{~m}$. The species occurs in the Oriomo River ecosystem in Western Province, which is relatively restricted, fragile and threatened by logging activities. The above threat category applies only to the population in Papua New Guinea. More information is needed from Queensland.

Assessor: Eddowes, P.J.

Refs: 19114

\section{Flindersia laevicarpa}

Rutaceae

VU C $1+2 a$

Australia (Queensland), Indonesia (Irian Jaya), Papua New Guinea

Found in monsoon, gallery and hill forest on elevated ground, this large tree is threatened in New Guinea by exploitation and logging activities. It has a sporadic occurrence in hill forest in Varirata National Park, Central Province, where it is hoped populations will survive. Its status in Australia is not considered in this evaluation.

Assessor: Eddowes, P.J.

Refs: 19114

\section{Flindersia pimenteliana}

Rutaceae

Australia (Queensland), Indonesia (Irian Jaya), Papua New Guinea

A large tree found mainly in lower montane rainforest or in foothill rainforest. In Papua New Guinea, the species is widespread but uncommon and sporadic. It has been heavily exploited in the Bulolo/Wau region of Morobe 
Province. Populations on spurs and ridges of mountain ranges may be spared from future exploitation. The population status in Australia is not taken into consideration in this evaluation.

Assessor: Eddowes, P.J.

Refs: 19114

\section{Flindersia schottiana}

Rutaceae

$\mathrm{LR} / \mathrm{nt}$

Australia, Indonesia (Irian Jaya), Papua New Guinea

This species is widespread in monsoon, hill and lower montane forest. In Papua New Guinea, it was subject to exploitation in two major logging areas in Morobe and Westem Provinces. Populations in the rugged mountains of Owen Stanley range may be spared from exploitation. The above threat category refers to the species' situation in New Guinea.

Assessor: Eddowes, P.J.

Refs: 19114

\section{Flueggea anatolica}

Euphorbiaceae

EN D1

Turkey

A recently described shrub known from just a single locality in the Kadincik Valley north of Mersin. About 100 individuals have been estimated to exist in an area of one hectare within the grounds of a dam. The site has been declared a nature reserve.

Assessor: Güner, A. \& J. Zielinski

Refs: 3736

\section{Flueggea neowawraea}

Euphorbiaceae

USA (Hawaii)

CR DI

A large forest tree known from approximately 13 populations in north-west Kauai, the Waianae Mountains on Oahu, Molokai, where the one specimen known has died, the south-west slope of Haleakala on Maui and the Kona coast on Hawaii. The total population comprises of fewer than 50 individuals. The decline in numbers has mainly been caused by the black twig borer (Xylosandrus compactus). The species is protected by the US Endangered Species Act.

Assessor: World Conservation Monitoring Centre

Refs: 3372

\section{Fokienia hodginsii}

Cupressaceae

LR/nt

China (Fujian, Guangdong, Guangxi, Guizhou, Hunan, Jiangxi, Sichuan, Yunnan, Zhejiang), Laos, Viet Nam A common species with a wide range, although the exact extent of the truly wild populations is obscured by those which have been planted. Large-scale logging has resulted in the species disappearing or becoming scarce in parts of its range, notably in northern Viet Nam and southem China. Regeneration is fire-dependent and appears to be good. The genus is monospecific.

Assessor: SSC Conifer Specialist Group

Refs: $374,848,1818,11847,16925$

\section{Fordia incredibilis}

Leguminosae

VU B $1+2 c$

Malaysia (Peninsular Malaysia)

Confined to the state of Johore, this small tree occurs in lowland forest up to $240 \mathrm{~m}$. Increasing agriculture and settlement are causing habitat declines.

Assessor: Chua, L.S.L.

Refs: 19073
Fordia lanceolata

Leguminosae

Malaysia (Peninsular Malaysia)

The species is scattered in lowland hill forest between 500 and $700 \mathrm{~m}$. Continued settlement of the area has resulted in habitat declines.

Assessor: Chua, L.S.L.

Refs: 19073

\section{Fordia ophirensis}

Leguminosae

Malaysia (Peninsular Malaysia)

VU D2

Occurring in hill forest, this small tree is confined to Mount Ophir, Johore. Only two collections have been made, gathered from localities between 300 and $400 \mathrm{~m}$.

The area is being increasingly settled.

Assessor: World Conservation Monitoring Centre

Refs: 19073

\section{Fordia pauciflora}

Leguminosae

Malaysia (Peninsular Malaysia), Thailand

VU B $1+2 c$

A small tree found in hill forests in Perak, between 150 and $300 \mathrm{~m}$. Main threats to the species include logging activities and increasing settlement of the area. Populations are protected within forest reserves.

Assessor: Chua, L.S.L.

Refs: 19073

\section{Forestiera hondurensis}

Oleaceae

Honduras

A tree of submontane oak woodland and thicket.

Assessor: Nelson, C.

Refs: 8805, 13995

\section{Frangula azorica}

Rhamnaceae

$\mathrm{LR} / \mathrm{nt}$

Portugal (Azores, Madeira)

An endemic to the Azores, now probably extinct in Madeira. It occurs on all the Azorean Islands, except Graciosa and Corvo, in laurel-juniper forest up to $1000 \mathrm{~m}$. It appears to be a vigorous species which is little affected by habitat degradation.

Assessor: World Conservation Monitoring Centre Refs: $5287,7222,19131$

\section{Franklinia alatamaha}

Theaceae

USA (Georgia)

A multi-stemmed shrub or small tree which has not been seen in the wild since 1803 . Originally occurring along the banks of Alatahama River in McIntosh County on the coastal plain of Georgia, the only known colony occurred in acidic bogs at the heads of sand-hill branches and was thought to have been brought to extinction largely through overcollection by nurserymen. Numerous expeditions to relocate the plant have failed. It is now a popular garden plant.

Assessor: World Conservation Monitoring Centre Refs: 2276,19200

\section{Fraxinus caroliniana ssp. cubensis}

Oleaceae VU D2

Cuba

A subspecies restricted to fenwoods and swamp forests on peat on the Zapata Peninsula in Matanzas Province. 
The habitat has been degraded by logging and charcoal production.

Assessor: Areces-Mallea, A.E.

Refs: 19149

\section{Fraxinus hondurensis}

Oleaceae

CR C2b

Honduras

A rarely collected tree, found in groves near river banks and on forested plains at medium elevation.

Assessor: Nelson, C.

Refs. 13995

\section{Freycinetia auriculata}

Pandanaceae

VU $B 1+2 c$

Philippines

This tree is an endemic of Palawan, found in forests at low or medium altitudes. The main island is a biosphere reserve.

Assessor: World Conservation Monitoring Centre

Refs: 4986

\section{Freziera alato}

Theaceae

VU B1+2c, D2

Bolivia

Records of three localities have been made within a small area of cloud forest in the department of La Paz. Two of these are over 100 years old. The extent of the forest in this area has declined because of widespread fires, encroaching farming activities and cutting for wood and charcoal production.

Assessor: World Conservation Monitoring Centre Refs: 5070

\section{Freziera angulosa}

Theaceae

$\mathrm{VU} B 1+2 \mathrm{~b}$

Bolivia

A river or submontane forest species known from seven localities in Beni and $\mathrm{La} \mathrm{Paz}$. Forests in the area have declined because of encroaching farming activities and curting for wood and charcoal production.

Assessor: World Conservation Monitoring Centre

Refs: 5070,13661

\section{Freziera biserrata}

Theaceae

VU D2

Costa Rica

An *elfin forest species known only from a single collection made in 1984, from the Cordillera de Talamanca.

Assessor: World Conservation Monitoring Centre

Refs: 5070, 13574

\section{Freziera caesariata}

Theaceae

VU $B 1+2 c$

Bolivia

A cloud forest species confined to a small number of localities, all from the $\mathrm{La} \mathrm{Paz}$ region, where the extent of forest has been reduced by increasing fires, encroaching farming activities and cutting for wood and charcoal production.

Assessor: World Conservation Monitoring Centre

Refs: 5070

\section{Freziera caloneura}

Theaceae

VU B $1+2 c$

Bolivia, Peru

A cloud forest species known from several localities in $\mathrm{La} \mathrm{Paz}$ and Cochabamba in Bolivia, extending into
Cuzco, Peru. Of the six Bolivian collections four were made in 1866. Agricultural expansion and local exploitation and burning of forested areas have caused a decline in the habitat.

Assessor: World Conservation Monitoring Centre

Refs: 5070

\section{Freziera campanulata}

Theaceae

VU D2

Ecuador, Pen

A montane or *elfin forest species known only from two localities: Huánuco in Peru and Loja-Zamora, Ecuador.

The Ecuadorean population is located within Podocarpus National Park but the Penvian one is unprotected and vulnerable to habitat degradation.

Assessor: World Conservation Monitoring Centre Refs: 5070,13574

\section{Freziera ciliata}

Theaceae

VU B1+2c, D2

Peru

A cloud forest species known only from two localities in Tumango in Huánuco and Oxapampa in Pasco. Collections have been few, illustrating that the species may be very rare.

Assessor: World Conservation Monitoring Centre

Refs: 5070,13574

\section{Freziera cordata}

Theaceae

VU B1+3abcd, D2

Dominica, Guadeloupe, Martinique

Known from only three localities, this species is found in montane forests near volcanic summits. Populations occur on Mome Anglais in Dominica, on Mount Pelée in Martinique and Guanacaste in Rincón de la Vieja National Park in Costa Rica. Although it has been expected to become extinct at more than one of its localities after volcanic eruptions, it continues to recover.

Assessor: World Conservation Monitoring Centre Refs: $5070,10754,14883$

\section{Freziera dudleyi}

Theaceae

EN B $1+2$ cd

Bolivia, Peru

A cloud forest species known from only two localities: Cordillera Vilcabamba in Peru and Sandillani in Bolivia. There have been no collections from Bolivia since 1866 and the original populations may now be extinct. Agricultural expansion, cutting for wood and charcoal production and fires have caused extensive degradation and loss of this forest habitat.

Assessor: World Conservation Monitoring Centre Refs: 5070,13574

\section{Freziera echinata}

Theaceae

Colombia

Known only from the type specimen, this morphologically distinctive species occurs within cloud forest in Munchique National Park.

Assessor: World Conservation Monitoring Centre Refs: 5070,13574

\section{Freziera euryoides}

Theaceae

CR B I+2abcde

Colombia

This species is poorly known. The locality of the type collection dating back to the 18 th century is unknown. 
Another locality in Valle is tentative. The species has not been definitely collected for over 100 years and may now be extinct.

Assessor: World Conservation Monitoring Centre Refs: 5070, 13574

\section{Freziera ferruginea}

Theaceae

VU D2

\section{Peru}

This species is known from only two localities in San Martin and Loreto. No habitat information is available. Assessor: World Conservation Monitoring Centre Refs: 5070, 13574

\section{Freziera forerorum}

\section{Theaceae}

CR D1

\section{Panama}

A cloud forest species, known only from the type locality on the summit of Cerro Tacarcuna in Darién. In the late 1970 s only three trees were counted. It appears that the summit vegetation is dying of natural causes. Assessor: World Conservation Monitoring Centre Refs: 4246, 5070, 7272, 12963

\section{Freziera friedrichsthailana}

Theaceae

Costa Rica, Nicaragua

A relatively common species occurring in cloud forest on Mount Mombacho and Ometepe in Nicaragua and various localities in Costa Rica. In parts of its range, especially in Costa Rica its habitat has declined and populations are threatened.

Assessor: World Conservation Monitoring Centre

Refs: 5070,8100

\section{Freziera glabrescens}

Theaceae

VU $B 1+2 b c$

Bolivia

Probably only two localities exist where this species occurs in deciduous forest. One is in Chuquisaca and the other in Santa Cruz, mainly in Samaipata. Forest in this area has declined or become degraded because of heavy exploitation for wood and the encroachment of farming activities.

Assessor: World Conservation Monitoring Centre

Refs: 5070

\section{Freziera inaequilatera}

Theaceae

CR B $1+2 c$

Bolivia

A species known from a single locality near Mapiri in $\mathrm{La} \mathrm{Paz}$, most recently collected in 1939. Fieldwork is needed to ascertain whether it is now extinct.

Assessor: World Conservation Monitoring Centre

Refs: 5070, 13661

\section{Freziera incana}

Theaceae

VU D2

Peru

An *elfin or cloud forest species known from three localities: Cordillera Vilcabamba in Cuzco, Pan de Azúcar and Tumango. Encroachment of farming activities, buming and overcutting for wood and charcoal production are causing widespread degradation of forested areas.

Assessor: World Conservation Monitoring Centre

Refs: 5070

\section{Freziera jaramilloi}

Theaceae

VU D2

Colombia

Known only from the type, this species was collected in 1976 from the Choco, between Alto del Galápago and San José del Palmar. Fieldwork is needed to ascertain the current status of the population.

Assessor: World Conservation Monitoring Centre

Refs: 5070,13574

\section{Freziera longipes}

Theaceae

LR/nt

Colombia

Occurring in cloud forest, this species is known from five localities in Magdalena, Risaralda, Cundinamarca and Valle regions of Columbia.

Assessor: World Conservation Monitoring Centre

Refs: $\mathbf{5 0 7 0}$

\section{Freziera obovata}

Theaceae

VU B1+2c, D2

Ecuador

A small cloud forest species known from four localities in the Azuay and Loja regions of Ecuador. The populations may be more seriously threatened but fieldwork is needed to give an accurate assessment of their status.

Assessor: World Conservation Monitoring Centre Refs: 5070

\section{Freziera parva}

Theaceae

VU B1 $+2 c, D 2$

Peru

An *elfin forest species known from only two localities in Peru; Bongara in the Amazonas region (collected in 1915) and the Cordillera Vilcabamba in Cuzco. The forest in these areas has suffered from the encroachment of farming activities, buming and cutting for charcoal production. These populations may be more seriously threatened but fieldwork is needed to give an accurate assessment of their status.

Assessor: World Conservation Monitoring Centre

Refs: 5070,13574

\section{Freziera punctata}

Theaceae

$\mathrm{VU} B 1+2 c, \mathrm{D} 2$

Colombia

Occurring in cloud forest, this species has been collected in various localities in central Antioquia. Nowhere is it found to be common.

Assessor: World Conservation Monitoring Centre Refs: 5070

\section{Freziera retinveria}

Theaceae

VU D2

Colombia

A poorly known species recorded only from the type specimen, which was collected in Alto de Santo Inés in 1941.

Assessor: World Conservation Monitoring Centre

Refs: 5070,13574

\section{Freziera revoluta}

Theaceae

$\mathrm{EN} \mathrm{B} 1+2 \mathrm{c}$

Bolivia, Peru

A large tree of primary cloud forest. It has been collected from just three localities. In Peru populations are known from Cordillera Vilcabamba in Cuzco and Oxapampa in Pasco. In Bolivia it was collected over 50 
years ago in the Mapiri region of La Paz. Forests in these areas have been extensively degraded by encroaching farming activities, fires and overcutting for fuelwood and charcoal production.

Assessor: World Conservation Monitoring Centre

Refs: 5070,13574

\section{Freziera roraimensis}

Theaceae

CR B $1+2 c$

Venezuela

The exact location of this species is not known. The only collections date back to 1842 and are likely to have been taken from forests to the south of Roraima. Reports suggest that this area is no longer forested because of heavy buming. Surrounding forests have not been botanically well explored.

Assessor: World Conservation Monitoring Centre

Refs: 5070,13574

\section{Freziera rufescens}

Theaceae

VU Alc

Ecuador

A species noted for the good-quality charcoal it produces. It is known from five localities in areas of primary or secondary cloud forest in Carchi, Imbabura, Pichincha (Pululahua Geobotanical Reserve) and Tangurahua. Some of these collections date back over 100 years and fieldwork is needed to evaluate the current situation.

Assessor: World Conservation Monitoring Centre

Refs: 5070

\section{Freziera sessiliflora}

Theaceae

VU D2

Colombia

Occurring in cloud forest, this tree is confined to three localities: Las Orquideas Natural National Park, between Alto del Galápago, San José del Palmar in Chocó and La Argentina in Huila.

Assessor: World Conservation Monitoring Centre

Refs: 5070, 13574

\section{Freziera smithiana}

Theaceae

EN C2b

Colombia

A poorly known species once collected in 1926 in thickets in the vicinity of Las Vegas, Santander.

Assessor: World Conservation Monitoring Centre

Refs: 5070,13574

\section{Freziera spathulifolia}

Theaceae

EN C2b

Peru

Little information on this species is available. It has been collected only once in 1923 from Huánuco.

Assessor: World Conservation Monitoring Centre

Refs: 5070,13574

\section{Freziera stuebelii}

Theaceae

Colombia

Known only from the type collection in Cerro Patascoy in Putumayo, this species has not been seen in the wild since 1869.

Assessor: World Conservation Monitoring Centre

Refs: 5070, 13574

\section{Freziera suberosa}

Theaceae

Colombia, Ecuador

A cloud forest species occurring in three localities:

Tolima in Colombia and from Cantón Montúfar in Carchi and Playón de San Francisco in Napo in Ecuador. The Colombian collection dates back over 100 years and its present status is unknown, possibly extinct.

Assessor: World Conservation Monitoring Centre

Refs: 5070, 13574

\section{Freziera subintegrifolia}

Theaceae

CR B $1+2 c$

Bolivia

Collections of this species have not been made for over 100 years since it was found in the Yungas, $\mathrm{La} \mathrm{Paz}$. The present status of its population is unknown but likely to be seriously threatened, possibly extinct.

Assessor: World Conservation Monitoring Centre Refs: 5070,13661

\section{Freziera tomentosa}

Theaceae

Colombia, Ecuador, Peru, Venezuela

LR/nt

Although relatively widespread in areas of cloud forest, this species is rare wherever it occurs. In most of its range the habitat has been degraded or destroyed through burning and encroaching agriculture.

Assessor: World Conservation Monitoring Centre Refs: 5070

\section{Freziera uncinata}

Theaceae

VU Alc $+2 c$

Bolivia

Several localities, all in the department of La Paz, exist where this species can be found in areas of cloud forest. This habitat has suffered from the encroachment of agriculture and farming activities, burning and overcutting for wood or charcoal production.

Assessor: World Conservation Monitoring Centre Refs: 5070

\section{Freziera uniauriculata}

Theaceae

$\mathrm{CR} \mathrm{C} 2 \mathrm{~b}$

Bolivia

Collected over 140 years ago in the department of $\mathrm{La}$ $\mathrm{Paz}$ from forests above Sandillani, the current status of this species is not known but is likely to be seriously threatened, possibly extinct. These areas have been seriously degraded by encroaching farming activities, buming and overcutting for wood and charcoal production.

Assessor: World Conservation Monitoring Centre Refs: 5070,13574

\section{Freziera varibrateata}

Theaceae

CR C2b

Bolivia

This species is known only from the type collection located in Suri-Negracota, in the department of La Paz in 1928. The current status of the population is not known and it is likely to be seriously threatened, possibly extinct. Forested areas have been seriously degraded because of encroaching farming activities, fire and overcutting for wood and charcoal production. Assessor: World Conservation Monitoring Centre Refs: 5070,13574 


\section{Freziera velutina}

Theaceae

VU D2

Colombia

A small tree from the edge of secondary forest in an area north-east of Carmen del Atrato, Chocó.

Assessor: World Conservation Monitoring Centre

Refs: 5070,13574

\section{Gaertnera rosea}

Rubiaceae

VUAlc

Sri Lanka

A tree occurring in the lowland wet evergreen forests of south-west Sri Lanka.

Assessor: World Conservation Monitoring Centre

Refs: 9176, 17195

\section{Gaertnera ternifolia}

Rubiaceae

$\mathrm{EN} \mathrm{Bl}+2 \mathrm{c}$

Sri Lanka

During the extensive National Conservation Review forest surveys, this species was found in only two forest localities. It appears to be fairly common in the Peak Wilderness wildlife sanctuary.

Assessor: World Conservation Monitoring Centre

Refs: 19112

\section{Gaertnera walkeri}

Rubiaceae

VU Alc, B1+2c

Sri Lanka

During the extensive National Conservation Review forest surveys, this species was found in only four forest localities.

Assessor: World Conservation Monitoring Centre

Refs: 19112

\section{Galipea ossana}

Rutaceae

Cuba

Discovered in the early 19th century in the area of San Diego. Pinar del Rio Province, another record of this species was made in Habana. No collections or records have been made since.

Assessor: Areces-Mallea, A.E.

Refs: 11403, 18485, 19149

\section{Garcia nutans}

Euphorbiaceae

$\mathrm{EN} \mathrm{Bl}+2 \mathrm{c}$

Colombia

A small tree, endemic and relatively widely scattered in moist forest in Colombia.

Assessor: Calderon, E.

Refs: 19069

\section{Garcinia acutifolia}

Guttiferae

VU B $1+2 c$

Mozambique, Tanzania

A dry coastal forest species which appears to be known from relatively widely separated localities. The Tanzanian population is restricted to the highly disturbed $22 \mathrm{~km}^{2}$ patch of forest at the Pugu Forest Reserve, near Dar es Salaam. There are also occurrences within the restricted coastal forests of Mozambique, where further fieldwork is needed to consolidate whether the status of the species is more seriously threatened.

Assessor: Lovett, J. \& G.P. Clarke

Refs: $3356,5204,7089$

\section{Garcinia afzelii}

\section{Guttiferae}

Côte d'Ivoire, Ghana

VU Alcd

A species from dry forest fringes and forest outliers. It is locally common but widely exploited as a source of chewsticks.

Assessor: Hawthorne, W.

Refs: $1609,8369,12061$

\section{Garcinia bifasciculata}

Guttiferae

EN C2b, D1

Tanzania

A species endemic to Kimboza Forest Reserve, which covers just $4 \mathrm{~km}^{2}$ of dry coastal forest in the foothills of the Uluguru Mountains. Disturbance has been caused by logging and planting of commercial timbers in the past. The surrounding area is densely populated and the demand for land is strong. Illegal activities and encroachment are currently prevented by two forest guards employed under the Catchment Forestry Project. Assessor: Lovett, J. \& G.P. Clarke

Refs: 7089,16796

\section{Garcinia brevipedicellata}

Guttiferae

VU Alc, Bl+2c

Cameroon, Nigeria

The range of this small lowland rainforest tree extends from south-east Nigeria to Cameroon. Populations are recorded in the Oban Hills of Cross River National Park in Nigeria and in Korup National Park, Masaka-Batanga and the Douala area in Cameroon. Outside protected areas there has been extensive deforestation.

Assessor: World Conservation Monitoring Centre

Refs: 11504, 19092

\section{Garcinia cadelliana}

Guttiferae

CR B $1+2 \mathrm{C}$

India (Andaman and Nicobar Is. - Andaman Is.)

A small tree endemic to South Andaman Island apparently occurring in evergreen rainforest. It has not been found since it was first collected and large areas of the species' habitat have been logged and cleared. Intact forest remains in Jarwa Reserve, where it is possible the species may still be found.

Assessor: World Conservation Monitoring Centre

Refs: 4799,714 ?

\section{Garcinia clusiaefolia}

Guttiferae

Malaysia (Peninsular Malaysia)

A tree so far only known from Wray's Camp at Gichon, Pahang at $900 \mathrm{~m}$. Only two collections have been made but they are located within the boundaries of Taman Negara National Park.

Assessor: World Conservation Monitoring Centre Refs: 8464,19073

\section{Garcinia costata}

Guttiferae

Malaysia (Peninsular Malaysia)

VU D2

Little information is available on this species. It is known from two localities, one from Ulu Merala Forest Reserve, Kedah, and the other from Maxwell's Hill, Perak, where it is protected.

Assessor: World Conservation Monitoring Centre Refs: 8464,19073 


\section{Garcinia decussata}

Guttiferae

VU B $+2 c$

Jamaica

The distribution is disjunct, with occurrences in Clarendon, Manchester and Portland Parishes. The species is confined to damp shady woodlands on limestone. The habitat has been severely degraded and converted into commercial plantations in many places.

Assessor: World Conservation Monitoring Centre

Refs: 6057,7980

\section{Garcinia diversifolia}

Guttiferae

$\mathrm{LR} / \mathrm{cd}$

Malaysia (Peninsular Malaysia)

A tree widely distributed but scattered in lowland to montane forest, where it is protected within permanent forest reserves.

Assessor: Kochummen, K.M.

Refs: 8464,19073

\section{Garcinia epunctata}

Guttiferae

VU Aled

Ghana

A species of evergreen Guineo-Congolian forests. Apart from serious habitat losses the species is heavily exploited, with $G$. afzelit, as a source of chewsticks.

Assessor: Hawthome, W.

Refs: 8369,12061

\section{Garcinia eugeniaefolia}

Guttiferae

LR/ed

Malaysia (Peninsular Malaysia)

Widely distributed, this species occurs in lowland and submontane forest. Populations are conserved in production and protected forests throughout the country. The species might be synonymous with $G$. rostrata.

Assessor: Kochummen, K.M.

Refs: 8464, 19073

\section{Garcinia hermonii}

Guttiferae

$\mathrm{LR} / \mathrm{cd}$

Sri Lanka

An understorey tree confined to wet lowland evergreen forest. It is frequent in many forest reserves including Sinharaja Biosphere Reserve.

Assessor: World Conservation Monitoring Centre

Refs: $15431,17195,18515$

\section{Garcinia holttumii}

Guttiferae

VU D2

Malaysia (Peninsular Malaysia)

Confined to the summit of Gunung Belumut in Johore, this forest species is so far known from only three collections, all from the same locality. Gunung Belumut falls within protected forest.

Assessor: World Conservation Monitoring Centre

Refs: 8464, 19073

\section{Garcinia imberti}

Guttiferae

$\mathrm{EN} \mathrm{Bl}+2 \mathrm{c}$

India (Kerala)

Collected only once, the species occurs in submontane evergreen forest in the Agastyamalai Hills. Large areas have been exposed to fires, grazing, the establishment of commercial plantations and cutting for fuelwood, but almost $1000 \mathrm{~km}^{2}$ oi forest are now under protection within sanctuaries.

Assessor: World Conservation Monitoring Centre

Refs: 19144

\section{Garcinia kingii}

Guttiferae EN B I +2c

India (Andaman and Nicobar Is. - Andaman Is.)

A small tree of evergreen rainforest endemic to the Andaman Islands. Very little is known about the species as it has not been collected since it was first discovered. Deforestation has been carried out on a large scale and few intact tracts of forest now remain.

Assessor: World Conservation Monitoring Centre

Refs: 4799,7147

\section{Garcinia kola}

Guttiferae

VUAlcd

Democratic Republic of Congo, Ghana

A widespread tree of evergreen forest. It is probably the most important source of chewsticks. Overexploitation has caused population declines. Seedlings are uncommon and slow-growing.

Assessor: Hawthome, W.

Refs: $5651,8369,12061$

\section{Garcinia linii}

Guttiferae

$\mathrm{EN} \mathrm{B1+2b}$

Taiwan

Restricted to Lanyu Island, the species occurs in lowland broadleaved forest. The population appears to be healthy but it is unprotected and under considerable threat from the expansion of housing and agriculture in the area.

Assessor: Pan, F.J.

Refs: 3295,19050

\section{Garcinia montana}

Guttiferae VU D2

Malaysia (Peninsular Malaysia)

Known only from a single collection from Mount Oplur in Johore, this species was found in submontane forest. Mount Oplur falls within the protected forests of Johore. Assessor: Kochummen, K.M.

Refs: 8464, 19073

\section{Garcinia paucinervis}

Guttiferae

$\mathrm{EN} \mathrm{B1}+2 \mathrm{e}$

China (Guangxi, Yunnan), Viet Nam

A timber species distributed in forest on limestone, rarely above $600 \mathrm{~m}$. Populations are confined to central Guangxi and to Malipo in south-east Yunnan, extending into northem Viet Nam. Large trees have been cut; very few remain. Regeneration also appears to be insufficient. Assessor: Sun, W.

Refs: $1818,11847,19055$

\section{Garcinia quaesita}

Guttiferae

VUAlc

Sri Lanka

A species confined to the lowland wet evergreen forests of south-west Sri Lanka.

Assessor: World Conservation Monitoring Centre Refs: 15431,17195

\section{Garcinia rubro-echinata}

Guttiferae

VU B $1+2 c$

India (Kerala, Tamil Nadu)

The species is largely contained within the Agastyamalai range. Large areas have been exposed to fires, grazing, the establishment of commercial plantations and cutting for fuelwood, but almost $1000 \mathrm{~km}^{2}$ of forest are now under protection within sanctuaries.

Assessor: World Conservation Monitoring Centre Refs: 19144 


\section{Garcinia semseii}

Guttiferae

VU B1+2b, D2

Tanzania

A widely varying species known only from three localities of moist forest. An occurrence is recorded from the Kimboza Forest Reserve, where $4 \mathrm{~km}^{2}$ of forest within a densely populated area are protected by two forest guards. There are also populations in the south of the Nguru Mountains and possibly at Chita and Kihansi within the Udzungwa Mountains. The latter occurrence is strange for its high elevation and may be a distinct taxon.

Assessor: Lovett, J. \& G.P. Clarke

Refs: 3356, 5204, 11631, 15251

\section{Garcinia staudrï}

Guttiferae

VU Alc, Bl+2c

Cameroon, Nigeria

A morphologically distinctive species. It is confined to forested areas extending from south-east Nigeria to Cameroon. Populations are recorded in the Oban Hills of Cross River National Park in Nigeria and from Douala, Edea and Korup National Park in Cameroon. Outside protected areas large-scale deforestation has taken place. Assessor: World Conservation Monitoring Centre Refs: 11504, 19092

\section{Garcinia terpnophylla var, acuminata}

Guttiferae

VU Alc

Sri Lanka

This variety occurs in the lowland wet evergreen forests of south-west Sri Lanka.

Assessor: World Conservation Monitoring Centre

Refs: 17195,18796

\section{Garcinia terpnophylla var. terpnophylla}

Guttiferae

VUAlc

Sri Lanka

A variety occurring in the lowland wet evergreen forests of south-west Sri Lanka.

Assessor: World Conservation Monitoring Centre

Refs: 15431, 17195

\section{Garcinia thwaitesii}

Guttiferae

$\mathrm{EN} \mathrm{B1}+2 \mathrm{c}$

Sri Lanka

During the extensive forest surveys by the National Conservation Review, this species was found in only five localities.

Assessor: World Conservation Monitoring Centre

Refs: 15431, 19112

\section{Garcinia travancorica}

\section{Guttiferae}

VU Bl $+2 \mathrm{c}$

India (Kerala, Tamil Nadu)

Endemic to the Agastyamalai Hills at the southern end of the Western Ghats, the species occurs in the margins of submontane evergreen forest. Large areas have been exposed to fires, grazing, the establishment of commercial plantations and cutting for fuelwood, but almost $1000 \mathrm{~km}^{2}$ of forest are now under protection within sanctuaries.

Assessor: World Conservation Monitoring Centre

Refs: 5651,19144

\section{Garcinia wighti}

Guttiferae

VU $B 1+2 c$ occurrences in the Westem Ghats between Anamalai and Travancore.

Assessor: World Conservation Monitoring Centre

Refs: 19144

\section{Garcinia zeylanica}

Guttiferae

$\mathrm{EN} \mathrm{B1+2c}$

Sri Lanka

This species was discovered in only three forest localities during the extensive surveys conducted for the National Conservation Review.

Assessor: World Conservation Monitoring Centre

Refs: 15431, 19112

\section{Gardenia anapetes}

Rubiaceae

CR D1

Fiji

A small tree of lowland dense forest, confined to southwest Vanua Levu. Only two localities are known: one on Mount Kasi where about 12 plants exist and the type locality on Mount Seatura.

Assessor: World Conservation Monitoring Centre

Refs: 5515, 6053, 18818

\section{Gardenia brighamii}

Rubiaceae

CR C2a

USA (Hawaii)

A small tree occurring in a once widespread but unique dry forest type. Although it must have been present on all of the main islands, the population is now reduced to single or small numbers of trees at Honouliuli, Puukuua and Nanahuli on Oahu, Mauna Loa on Molokai, Kanepuu on Lanai, Olowalu on West Maui and Puuwaawaa on Hawaii. Deer and invasive plants have contributed to the damage and loss of habitat. The species is protected by the US Endangered Species Act. Assessor: World Conservation Monitoring Centre Refs: 3372

\section{Gardenia candida}

Rubiaceae

CR D1

Fiji

The species is known only from the type collection, gathered in 1947 from the Seanggangga Plateau in the vicinity of Natua, Vanua Levu. Trees were reported to exist in patches of forest in open rolling country. Assessor: World Conservation Monitoring Centre Refs: $5515,6053,18818$

\section{Gardenia gordonii}

Rubiaceae

LR/nt

Fiji

Occurring in dense or open forest or on forest edges, this shrub or small tree is known from numerous collections from the two largest islands and from Rambi.

Assessor: World Conservation Monitoring Centre Refs: $5515,6053,18818$

\section{Gardenia grievei}

Rubiaceae

EN C2a

Fiji

A shrub or small tree of lowland open forest and thickets. It has been reported to be locally abundant, but presently appears to be confined to a few small populations in the west and north of Vanua Levu. Assessor: World Conservation Monitoring Centre Refs: 5515, 6053, 18818

A lowland forest species, known from scattered 


\section{Gandenia hillii}

Rubiaceae

VU B $1+2 c$

Fiji

This lowland shrub or slender tree is recorded from open slopes in dry areas of Mathuata Province on Vanua Levu, from forest on Kandavu and from Rambi Island. Assessor: World Conservation Monitoring Centre Refs: $5515,6053,18818$

\section{Gardenia mannii}

Rubiaceae

CR C2a

USA (Hawaii)

This species is known from scattered populations along the length of the Koolau Mountains, from Kaunala Gulch and Kaunala-Waimea Ridge to Palolo, and in the Waianae Mountains, ranging from Haleauau Valley to Kaluaa Gulch on Oahu. The number of populations has steadily decreased. Of the remaining 27 populations, the large majority consist of fewer than five plants and the total number of individuals is thought not to exceed 100 . The major threats come from feral pigs and invasive plants. The species is protected by the US Endangered Species Act.

Assessor: World Conservation Monitoring Centre

Refs: $3372,12359,19168$

\section{Gardenia remyi}

Rubiaceae

VUAlce

USA (Hawaii)

A lowland rainforest tree with an occasional distribution on Kauai, Molokai, Maui and Hilo and Puna Districts on Hawaii.

Assessor: World Conservation Monitoring Centre

Refs: 3372

\section{Gardenia storckii}

Rubiaceae

LR/nt

Fiji

Confined to south-east Viti Levu, this slender tree occurs below $150 \mathrm{~m}$ in areas of dense, dry or secondary forest.

Assessor: World Conservation Monitoring Centre

Refs: 5515,18818

\section{Gardenia transvenulosa}

Rubiaceae

$\mathrm{VUB} 1+2 \mathrm{~b}$

Kenya, Tanzania

In Kenya this shrubby species is known from the Arabuko-Sokoke forest. It ranges south to south-east Tanzania within dry coastal forest.

Assessor: Lovett, J. \& G.P. Clarke

Refs: $3356,6396,8814$

\section{Gardenia vitiensis}

Rubiaceae

CR D1

Fiji

A tree or shrub of lowland areas near the sea, occurring in open forest or on open slopes. It has only been collected from the eastern part of Mathuata Province in Vanua Levu, where a few small populations are known. Assessor: World Conservation Monitoring Centre Refs: 5515, 6053, 18818

\section{Gastonia crassa}

Araliaceae

VU D2

Seychelles

A typical understorey component of mist forests on the islands of Mahé, Praslin and Silhouette. Trees are locally abundant and recruitment is good, but the species is sensitive to habitat disturbance. The main populations are contained within protected areas.

Assessor: Nature Protection Trust of Seychelles

Refs: 9859, 17229, 19023, 19025, 19062

\section{Gastonia lionnetii}

Araliaceae

CR A2c, D1

Seychelles

At present the species is known from two mature individuals in Mission Casse Dent on Mahé Island. One is found in secondary forest, the other in a tea estate. There is evidence of seed germination but no young plants are surviving. It has been suggested that the species is the result of a cross between $G$. sechellarum and $G$. crassa and that may provide the reason why recruitment is low. The results of research into the genetic profiles of these species is soon to be made available.

Assessor: Nature Protection Trust of Seychelles

Refs: $10610,19023,19025,19062$

\section{Gastonia mauritiana}

Araliaceae

CR C2a, D1

Mauritius

The known populations of this succulent heterophyllous tree are very small. They occur in forest on the east coast and in Yemen on the mainland and also on Ile aux Aigrettes, where active management of exotic species is aiding regeneration of native species.

Assessor: Page, W

Refs: $1411,8106,9120,16426$

\section{Gastonia rodriguesiana}

Araliaceae

CR Alc, B1+2e, D1 Mauritius (Rodrigues)

Less than 50 individuals exist in the wild as isolated specimens on calcarenite and basalt, mainly on Plaine Corail. Attempts at propagation have been successful and young specimens have been planted in the wild.

Assessor: Strahm, W.

Refs: 9426, 16426, 19208

Gastonia sechellarum var. contracta

Araliaceae

CR B $1+2 \mathrm{de}$

Seychelles

Found only in a single patch of moist forest near Mission Casse Dent, this variety is presently protected in Mome Seychellois National Park. The most serious threats come from invasive plants and encroaching housing developments. Work is being carried out to consolidate the taxonomic status of the three varieties, although material for var. curiosae is insufficient.

Assessor: Carlstrom, A

Refs: 10610,19023

\section{Gastonia sechellarum var. curiosae}

Araliaceae

CR Ale, Bl+2e, Dl

Seychelles

The species is known from a single small tree confined to a rocky crevice on the island of Curieuse. Regeneration is not evident and infestations of weevils and other insects are a problem. Work is being carried out to consolidate the taxonomic status of the three varieties, although material from this variety is insufficient.

Assessor: Carlstrom, A

Refs: $10610,19023,19025$ 


\section{Gastonia sechellarum var, sechellarum}

Araliaceae

VU A1c, D2 Seychelles

An understorey tree confined to remnant populations in moist forest on the islands of Mahé, Praslin, Silhouette and Felicite. Most populations are contained within areas which are protected. However, poor recruitment and the continuing marginalisation and degradation of the habitat continue to cause declines. Work is being carried out to consolidate the taxonomic status of the three varieties, although material for var. curiosae is insufficient.

Assessor: Carlstrom, A.

Refs: $17229,19023,19025$

\section{Gaussia attenuata}

Palmae

VU B $1+2 c$

Puerto Rico

A palm tree confined to steep-sided, extremely welldrained limestone hills in Puerto Rico.

Assessor: Henderson, A.

Refs: 19118

\section{Gaussia gomez-pompae}

Palmae

VUAIC

Mexico (Oaxaca, Tabasco, Veracruz)

An endemic palm of Mexico scattered in forest in steep, rocky places on limestone soils.

Assessor: Quero, H.J.

Refs: $7980,12985,15251,16516,19118$

\section{Gaussia maye}

Palmae

VU D2

Belize, Guatemala, Mexico

A forest species, scattered in rocky places on limestone soils at low elevations. The population size is small.

Assessor: Quero, H.J.

Refs: 19118

\section{Gaussia spirituana}

Palmae

EN C2a, D1

Cuba

An endemic to Jatibonico, a limestone plateau in central Cuba. Fewer than 150 mature trees remain in five populations.

Assessor: Moya, C.

Refs: 19118

\section{Geijera salicifolia}

Rutaceae

$\mathrm{LR} / \mathrm{nt}$

Australia (New South Wales, Queensland), New Caledonia, Papua New Guinea

A timber species, which in New Guinea is mainly confined to the Bulolo/Wau region of Morobe Province. This region was once heavily exploited, logged and converted into Araucaria plantations. It is not known exactly how many mature specimens remain here and this subpopulation is considered to be critically endangered.

Assessor: World Conservation Monitoring Centre

Refs: 19114

\section{Geissanthus challuayacus}

Myrsinaceae

VU D2

Ecuador

Known only from Volcán Sumaco in Napo Province, on the eastern slopes of the Andes, the species occurs in a very restricted area of lower montane forest. The province has experienced considerable forest destruction but it is not known how this population has been affected.

Assessor: World Conservation Monitoring Centre

Refs: 2909, 6362

\section{Geissanthus ecuadorensis}

Myrsinaceae

VU BI+2c

Ecuador

An endemic tree of Ecuador, currently only known to occur in cloud forest between 2200 and $2600 \mathrm{~m}$ in

Bolivar and Loja Provinces.

Assessor: World Conservation Monitoring Centre

Refs: 19119,19120

\section{Geissanthus pichinchae}

Myrsinaceae

VU B $1+2 c$

\section{Ecuador}

Endemic to Ecuador, the species is currently known only from areas of cloud forest between 2700 and $3400 \mathrm{~m}$ in Napo, Pichincha and Cotopaxi Provinces.

Assessor: World Conservation Monitoring Centre

Refs: 19119,19120

\section{Geissanthus vanderwerffi}

Myrsinaceae

LR/cd

Ecuador

A small understorey tree endemic to the south-central Andes in Ecuador. It is locally common in areas of *elfin forest and scrub cloud forest. A sizeable population is protected in a national park.

Assessor: World Conservation Monitoring Centre

Refs: 2909,6362

\section{Geissois imthurni}

Cunoniaceae

EN D1

Fiji

A small sturdy tree, usually found in dense forest between 500 and $900 \mathrm{~m}$, only in northem Viti Levu, principally in the vicinity of Nandarivatu. A single collection has also been taken from the Nausori Highlands. Each locality harbours about 40-50 individuals, the total population probably not exceeding 200 individuals.

Assessor: World Conservation Monitoring Centre

Refs: $5515,6053,18818$

\section{Geissois stipularis}

Cunoniaceae

EN D1

Fiji

Known only with certainty from Viti Levu, the species is restricted to a few localities of dense, open or dry forest. each containing 30-40 plants.

Assessor: World Conservation Monitoring Centre

Refs: 5515, 6053, 18818

\section{Geissois superba}

Cunoniaceae

VU D1

Fiji

A small tree of dense forest or forest edges, only in Viti Levu. The total population consists of a few hundred plants.

Assessor: World Conservation Monitoring Centre

Refs: 5515, 6053, 18818

\section{Geissois ternata var. minor}

Cunoniaceae

EN D1

Fiji

This small gnarled tree is known from the two major Fijian islands. It occurs in dense forest and thickets on 
exposed ridges and open slopes at comparatively high elevations. Three or four populations are known, containing 50 plants each.

Assessor: World Conservation Monitoring Centre

Refs: $5515,6053,18818$

\section{Geissois ternata var. serrata}

Cunoniaceae

CR D1

Fiji

The only known collection was made in 1937 from Waya Island, Yasawas. It was said to be locally common and used in house-building, but no additional material has been gathered.

Assessor: World Conservation Monitoring Centre

Refs: $5515,6053,18818$

\section{Geniostoma astylum}

Loganiaceae

LR/nt

French Polynesia (Society Is.)

Populations occur on Moorea and Tahiti.

Assessor: Florence, J.

Refs: 14513

\section{Geniostoma clavigerum}

Loganiaceae

CR D1

Fiji

So far known only from north-west Viti Levu, the species occurs in dense wet forest between 800 and $1190 \mathrm{~m}$ on Mount Evans and Mount Lomalagi. Each population consists of between 12 and 20 individuals. Assessor: World Conservation Monitoring Centre Refs: $5515,6053,18818$

\section{Geniostoma gagneae}

Loganiaceae

French Polynesia (Marquesas Is.)

An endemic to Fatu Hiva.

Assessor: Florence, $J$.

Refs: 14513

\section{Geniostoma hallei var. fatuivense}

Loganiaceae

French Polynesia (Marquesas Is.)

An endemic to Fatu Hiva.

Assessor: Florence, J.

Refs: 14513

\section{Geniostoma hallei var. hallei}

Loganiaceae

French Polynesia (Marquesas Is.)

DD

An endemic to Tahuata.

Assessor: Florence, J.

Refs: 14513

\section{Geniostoma hallei var, hivaoense}

Loganiaceae

French Polynesia (Marquesas Is.)

An endemic to Hiva Oa.

Assessor: Florence, J.

Refs: 14513

\section{Geniostoma macrophyllum}

Loganiaceae

Fiji

A shrub or slender tree of lowland forest, thickets, rocky areas or sea cliffs on limestone. Populations are rare on the six islands where it is known in Fiji. It may be more abundant on Tonga.

Assessor: World Conservation Monitoring Centre

Refs: $5515,6053,18818$

\section{Geniostoma rupestre var. rouffaeranum}

\section{Loganiaceae}

VU D2

Papua New Guinea

This variety is known from a single site, where it occurs commonly, on the banks of the Rouffaer River in Jayapura District.

Assessor: World Conservation Monitoring Centre

Refs: 19031

\section{Geniostoma stipulare}

Loganiaceae

Fiji

EN DI

Known only from four localities, this slender tree or shrub is confined to areas of undisturbed dense forest on Viti Levu and Vanua Levu. Each site harbours about 2030 plants.

Assessor: World Conservation Monitoring Centre Refs: $5515,6053,18818$

\section{Geniostoma umbellatum}

Loganiaceae

VU D2

Papua New Guinea (North Solomons)

A small semi-erect tree found only once on Guadalcanal in hillside secondary forest on well-drained soil.

Assessor: World Conservation Monitoring Centre Refs: 19031

\section{Gentlea molinae}

Myrsinaceae

Honduras

A species of submontane forest.

Assessor: Nelson, C.

Refs: 8553, 13995

\section{Gentlea vafteri}

Myrsinaceae

El Salvador, Guatemala

In $\mathrm{El} \mathrm{Salvador} \mathrm{the} \mathrm{species} \mathrm{is} \mathrm{confined} \mathrm{to} \mathrm{cloud} \mathrm{forest,}$ where it ranges from 1500 to $3000 \mathrm{~m}$. Threats are posed mainly by fires and tourism. More information is required on the population status in Guatemala.

Assessor: World Conservation Monitoring Centre Refs: 19030

\section{Geoffroea decorticans var. subtropicalis}

Leguminosae

VU B $1+2$ ac

Argentina (Jujuy, Salta), Bolivia

Endemic to the piedmont forest of north-west Argentina and Bolivia, the species is confined to an unprotected ecosystem which is being rapidly replaced by agricultural systems.

Assessor: Prado, D.

Refs: 19122

\section{Gesneria calycina}

Gesneriaceae

LR/nt

Jamaica

Known only from the northern parts of John Crow Mountains, the species is found in areas of moist shady woodland on limestone.

Assessor: World Conservation Monitoring Centre Refs: $401,5653,7980$ 


\section{Gesneria calycosa}

Gesneriaceae

LR/nt

Jamaica

A small tree or shrub with populations occurring occasionally in westem parishes in shaded guilies and on sheltered banks.

Assessor: World Conservation Monitoring Centre

Refs: 6057,7980

\section{Gesneria scabra var. fawcettii}

Gesneriaceae

CR C2b

Jamaica

Once recognised as a distinct species, this variety is known from just one collection on a damp shady limestone bank in Westmoreland.

Assessor: World Conservation Monitoring Centre Refs: 5653

\section{Gigasiphon macrosiphon}

Leguminosae

EN Bl+2abcde

Kenya, Tanzania

A species of ornamental interest, known from moist coastal forest in Mrima Forest Reserve, Marenje Forest

Reserve, Kaya Muhaka National Monument and Gongoni Forest Reserve in Kenya and the Rondo Plateau in Tanzania. Destruction and degradation of coastal forest is ongoing.

Assessor: CAMP Workshop in Kenya

Refs: $3356,3925,5654,6396,19181$

\section{Gilbertiodendron bilinearum}

Leguminosae

VU A1c, B $1+2 c$

Côte d'Ivoire, Ghana, Liberia, Sierra Leone

Scattered along riversides in wet evergreen forest from Sierra Leone to Ghana, this species is very rare and has disappeared from previously recorded localities. Habitat losses have been caused by mining, logging and commercial forestry activities.

Assessor: Hawthorne, W.

Refs: $7550,8369,12061$

\section{Gilbertiodendron klainei}

Leguminosae

VU D2

Gabon

This species has been collected only from Libreville. The habitat has been extensively logged. Much of the forest in the country remains unexplored and relatively intact, although large parts of it are now under concession to logging companies.

Assessor: World Conservation Monitoring Centre

Refs: 14958,15790

\section{Gilbertiodendron pachyanthum}

Leguminosae

VU D2

Cameroon

A large canopy tree endemic to Bipindi, where it occurs sparsely in lowland rainforest. The habitat is frequently cleared for agriculture and settlements.

Assessor: World Conservation Monitoring Centre

Refs: 12597

\section{Gilbertiodendron robynsianum}

Leguminosae

VU B $1+2 \mathrm{c}$

Côte d'Ivoire

A species of swampy areas. It is endemic to the remaining forest between the rivers Sassandra and Cavally. The largest part of the population is contained within the $3300 \mathrm{~km}^{2}$ of Tai National Park, outside which deforestation and habitat degradation have been severe in the past three decades.

Assessor: Assi, A.

Refs: 2773,12822

\section{Gilbertiodendron splendidum}

Leguminosae

VU Alc, B1+2c

Côte d'Ivoire, Ghana, Sierra Leone

A gregarious tree, occurring in swamps in the restricted wet evergreen forest habitat in the Upper Guinea region. Habitat declines have been caused by mining, logging and commercial forestry activites.

Assessor: Hawthome, W.

Refs: 8369,12061

\section{Gilletiodendron glandulosum}

Leguminosae

$\mathrm{VU} A 2 \mathrm{c}, \mathrm{B} 1+2 \mathrm{c}$

Mali

This tree is confined to rocky wooded areas which are sheltered from fire in a region in the south-west defined by three points, Kita, Bafoulabé and Kéméba. It is a significant component of Kololo forest. The present population is a remnant of what was once a widespread species, which has declined because of climatic reasons and fire. Although it flowers and fruits abundantly and germinates well, there is no evidence of colonisation in new areas.

Assessor: World Conservation Monitoring Centre Refs: 3640,7439

\section{Ginkgo biloba}

Ginkgoaceae

$\mathrm{EN} \mathrm{B} 1+2 \mathrm{c}$

China (Zhejiang)

The wild populations of this widely planted omamental are apparently confined to Xitianmu Mountain, Zhejiang, where they are scattered in broadleaved forests up to $1100 \mathrm{~m}$. This is the only species in the genus. It is long-living and has an ancient geological record, appearing in the Jurassic. The species has been widespread in cultivation for several centuries.

Assessor: Sun, W.

Refs: 1818,11847

\section{Ginoria nudiflora}

Lythraceae

VU Alc

Mexico (Chiapas, Oaxaca, Veracruz)

A relatively widespread rainforest tree, endemic to Mexico. It occurs in both Gulf and Pacific regions, sometimes in drier forest types.

Assessor: World Conservation Monitoring Centre

Refs: 1966, 5993, 19124

\section{Gleditsia assamica}

Leguminosae

VU B $1+2 c$

India

Occurring in the Aka Hills, Naga Hills and Garo Hills, the species is found in open situations in evergreen forest. No recent collections have been made and the species is believed to have become scarce. Encroaching agriculture has caused declines in the species' habitat. Assessor: World Conservation Monitoring Centre Refs: 4799

\section{Gleditsia rolfei}

Leguminosae

EN D1

Taiwan

A species which is confined to the Hengchun Peninsula, south of Fengkang. It occurs in lowland dry forest in 
small populations, all of which are contained within Kenting National Park. Local people frequently collect wood for charcoal production. The habitat is also believed to be declining because of encroaching settlements and grazing.

Assessor: Lu, S.Y. \& F.J. Pan

Refs: $3295,9379,19050,19053$

\section{Gleditsia vestita \\ Leguminosae \\ China (Hunan)}

CR D1

A species reduced to two surviving individuals on the south-east slopes of Mount Hengshan, where it reaches the lower limit of mixed forest. The two trees are protected and attempts to propagate the species are under way.

Assessor: World Conservation Monitoring Centre

Refs: 1818, 11847

\section{Glenniea penangensis}

Sapindaceae

VU $B 1+2 c$

Malaysia (Peninsular Malaysia)

A species which occurs throughout Peninsular Malaysia in lowland and hill forests up to $900 \mathrm{~m}$.

Assessor: Chua, L.S.L.

Refs: 8464, 19073

\section{Glenniea unijuga}

Sapindaceae

VU Alc, B1+2c

Sri Lanka

A tree found mainly in the lowland wet evergreen forests of south-west Sri Lanka. This rare species was discovered in nine sites during the extensive forest surveys conducted for the National Conservation Review.

Assessor: World Conservation Monitoring Centre

Refs: 9176, 17195, 19112

\section{Glionnetia sericea}

Rubiaceae

VU D2

Seychelles

Endemic to the Seychelles, the species occurs within a very restricted area $(<1000 \mathrm{ha})$ on Mahé and Silhouette.

Populations are healthy and stable.

Assessor: Nature Protection Trust of Seychelles

Refs: 16212,17229

\section{Glochidion bourdillonii}

Euphorbiaceae

India (Kerala)

VU B $1+2 c$

A rarely collected species of forest margins, occurring from low to medium altitudes at the southern end of the Western Ghats.

Assessor: World Conservation Monitoring Centre

Refs: 19144

\section{Glochidion carrickii}

Euphorbiaceae

VU D2

Malaysia (Peninsular Malaysia)

Known only from two collections from a single locality, the species is confined to lowland forest in Gombak Forest Reserve, a permanent reserve in Selangor.

Assessor: World Conservation Monitoring Centre

Refs: 8464, 19073

\section{Glochidion comitum}

Euphorbiaceae

EN C2b

Pitcaim Islands

A newly described species, apparently endemic to
Pitcaim Island, where it is widespread in disturbed scrub and open forest. There are relatively few large individuals, but many shrubby specimens which appear to have reached flowering age. Probably 500-1000 mature individuals exist. The timber was heavily exploited in the past for making into joists in construction. There has also been considerable habitat loss and degradation with the spread of exotic plants.

Assessor: Waldren, S. \& N. Kingston

Refs: 13604, 19154

\section{Glochidion ellipticum var. ralphü}

Euphorbiaceae

$\mathrm{EN} \mathrm{B} 1+2 \mathrm{c}$

India (Kerala)

Known from two collections, this variety appears to be endemic to the Travancore range, occurring in submontane evergreen forest.

Assessor: World Conservation Monitoring Centre Refs: 19144

\section{Glochidion grantii}

Euphorbiaceae

VU B1+2c

French Polynesia (Society Is.)

Occurring in the same lagoon on the sister islands of Tahaa and Raiatea, the species is localised on the summital crest of Mount Ohiri on the former and scattered on the plateaux of Temehani Rahi and Temehani Ute Ute on the latter. The populations are fragmented and reduced in extent.

Assessor: Florence, J.

Refs: 19169

\section{Glochidion insulare}

Euphorbiaceae

VU $B 1+2 c$

Malaysia (Peninsular Malaysia)

The exact locality of the species remains unknown. It has been collected only once from primary forest in Penang. Most of the forest in the area has been cleared for development.

Assessor: Kochummen, K.M.

Refs: 8464, 19073

\section{Glochidion johnstonei}

Euphorbiaceae

VU B $1+2 c$

India (Goa, Kerala)

Although relatively wide-ranging, the species is known from only a few collections taken from areas of submontane evergreen forest.

Assessor: World Conservation Monitoring Centre Refs: 19144

\section{Glochidion manono}

Euphorbiaceae

VU B $1+2 c$

French Polynesia (Society Is.)

Populations occur on Moorea and Tahiti, where the species is most seriously threatened.

Assessor: Florence, J.

Refs: 14513

\section{Glochidion nadeaudi}

Euphortiaceae

French Polynesia (Society Is.)

VU B $1+2 c$

A small tree, endemic to Moorea, occurring in the north between 420 and $800 \mathrm{~m}$. It is usually found in local abundance in mesophyllous open forest on crests. The populations are small and fragmented.

Assessor: Florence, J.

Refs: 19169 


\section{Glochidion papenooense}

\section{Euphorbiaceae}

French Polynesia (Society Is.)

$\mathrm{CR} \mathrm{Bl+2c}$

A shrub or tree at the edge of riverine forest, confined to a single locality in the Papenoo Valley. A hydroelectric project has been responsible for the destruction of large parts of the natural vegetation in the valley and the invasion of Miconia calvescens also presents a threat to the survival of the species.

Assessor: Florence, J.

Refs: 19169

\section{Glochidion pauciflorum}

Euphorbiaceae

$\mathrm{EN} \mathrm{B} 1+2 \mathrm{c}$

India (Kamataka, Tamil Nadu)

A poorly known species of montane forest, which has been collected once from the Bababudan range and twice from the Nilgiri range. It has also been recorded from an unspecified location in the Palni area.

Assessor: World Conservation Monitoring Centre

Refs: 19144

\section{Glochidion pitcaimense}

Euphorbiaceae

VU D2

Pitcairn Islands

A small tree known only from Henderson and Pitcaim Islands. On Henderson the species is relatively common, numbering about 20,000 individuals in plateau and beach forest. The population is smaller, with fewer than 500 individuals, on Pitcaim, confined to remnant forest and scrub, where it is threatened with cutting and the spread of the invasive Syzygium jambos. No regeneration has been observed. Henderson Island is a World Heritage Site.

Assessor: Waldren, S. \& N. Kingston

Refs: $5123,12900,14513,16427,19154$

\section{Glochidion raivavense}

\section{Euphorbiaceae}

$\mathrm{EN} \mathrm{B} 1+2 \mathrm{c}$

French Polynesia (Tubuai Is.)

Known only from the Tubuai Islands, the species is recorded from Raivavae, Rurutu and Tubuai.

Assessor: Florence, J.

Refs: 12900,14513

\section{Glochidion rapaense}

Euphorbiaceae

LR/nt

French Polynesia (Tubuai Is.)

A shrub or very small tree of mesophyllous or riverine forest, humid rocks or cliffs in mountain or littoral areas. It appears to be relatively common but never abundant.

Assessor: Florence, J.

Refs: 19169

\section{Glochidion sisparense}

Euphorbiaceae

India (Tamil Nadu)

The species occurs in a single locality of montane forest in the Nilgiris.

Assessor: World Conservation Monitoring Centre

Refs: 19144

\section{Glochidion stylosum}

Euphorbiaceae

VU D2

Malaysia (Peninsular Malaysia)

The species is known from a single collection, gathered from submontane forest at the base of Fraser's Hill in

Pahang.

Assessor: Kochummen, K.M

Refs: 8464,19073

\section{Glochidion symingtoni}

Euphorbiaceae

VU D2

Malaysia (Peninsular Malaysia)

Confined to Gunung Peninjau in Perak, the species has been collected twice from a single locality of forest at $840 \mathrm{~m}$. The area is contained within the protected forests of Perak.

Assessor: World Conservation Monitcring Centre Refs: 8464, 19073

\section{Glochidion tomentosum}

Euphorbiaceae

$\mathrm{EN} \mathrm{B} 1+2 \mathrm{c}$

India (Kamataka, Tamil Nadu)

Occurring on forest margins, the species has been collected only rarely from sites at medium elevation in southern Karnataka. It has also apparently been found in the Travancore range.

Assessor: World Conservation Monitoring Centre

Refs: 19144

\section{Glochidion toovilanum}

Euphorbiaceae

$\mathrm{LR} / \mathrm{nt}$

French Polynesia (Marquesas Is.)

A small tree confined to the Toovii Plateau in the central part of Nuku Hiva. It has been collected between 710 and $1000 \mathrm{~m}$ from primary riverine forest, on moist forested crests, in secondary forest and relict forest within pasture land. Although restricted in range, the species is relatively common.

Assessor: Florence, J.

Refs: 19169

\section{Gloeocarpus patentivalvis}

Sapindaceae

EN Alc

Philippines

A rare tree restricted to the primary dipterocarp forests of Mindanao, Samar, Leyte and Luzon.

Assessor: van Welzen, P.C.

Refs: 18389

\section{Gloeospermum boreale}

Violaceae

CR C2b

Honduras

Only a small population is known, occurring in the wet Atlantic lowlands.

Assessor: Nelson, C

Refs: 13995

\section{Gluema ivorensis}

Sapotaceae

VU B1 $+2 c$

Cameroon, Côte d'Ivoire, Gabon, Ghana

This is a rare species confined to wet places in wet evergreen forest on either side of the Dahomey Gap. Its habitat has been severely degraded through mining, logging and commercial forestry activities throughout its range. It is the only member of the genus.

Assessor: Hawthome, W.

Refs: $2773,8369,12061,12509$

\section{Gluta papuana}

Anacardiaceae

VUAlcd $+2 c d$

Indonesia? (Irian Jaya?), Papua New Guinea

Endemic to New Guinea, this tree grows in seasonally inundated forest along rivers, in freshwater swamps and 
on well-drained soils up to $50 \mathrm{~m}$. In Papua New Guinea it is restricted to Gulf and Western Provinces, which are now subject to heavy logging activities. The timber is sought-after for its decorative grain.

Assessor: Eddowes, P.J.

Refs: 19114

\section{Gluta travancorica}

Anacardiaceae

LR/nt

India (Kerala, Tamil Nadu)

A well-collected species, endemic to submontane forest running the length of the Agastyamalai Hills.

Assessor: World Conservation Monitoring Centre

Refs: 19144

\section{Glycosmis chlorosperma var. bidiensis}

Rutaceae

VU D2

Malaysia (Sarawak)

Known only from the type locality, this variety is found on limestone near the Bidi Cave, Kuching.

Assessor: World Conservation Monitoring Centre

Refs: 19017

\section{Glycosmis crassifolia}

Rutaceae

CR B $1+2 \mathrm{c}$

Malaysia (Peninsular Malaysia)

Confined to the state of Malacca this very rare tree of lowland rainforest is under threat from increasing settlement of the area.

Assessor: Chua, L.S.L.

Refs: $8464,14541,19073$

\section{Glycosmis decipiens}

Rutaceae

LR/cd

Malaysia (Peninsular Malaysia)

A species of rainforest and swamp forest, distributed in the states of Terengganu, Pahang, Negeri Sembilan and Johore. A protected population is found in Taman Negara National Park.

Assessor: Chua, L.S.L.

Refs: $8464,14541,19073$

\section{Glycosmis longisepala}

Rutaceae

VU D2

Malaysia (Sarawak)

A small forest tree known only from Mount Pueh.

Assessor: World Conservation Monitoring Centre

Refs: 19017

\section{Glycosmis monticola}

Rutaceae

EN D1

Malaysia (Peninsular Malaysia)

A shrub or small tree confined to hill forest on Mount Oplur in Johore State.

Assessor: Chua, L.S.L.

Refs: 8464, 19073

\section{Glycosmis perakensis}

Rutaceae

VU D2

Malaysia (Peninsular Malaysia)

A small tree of hill forest, confined to Bubu Forest Reserve, Perak.

Assessor: Chua, L.S.L.

Refs: 14541, 19073
Glycosmis tomentella

Rutaceae

Malaysia (Peninsular Malaysia)

$\mathrm{EN} B 1+2 \mathrm{c}$

A very rare shrub or small tree confined to a single locality in Selangor.

Assessor: Chua, L.S.L.

Refs: 14541,19073

\section{Glyphaea tomentosa}

Tiliaceae

DD

Mozambique

The range of this species is small and confined to central Mozambique. Information is too limited to evaluate the species.

Assessor: Bandeira, $\mathbf{S}$.

Refs: 5117, 18965

\section{Glyptopetalum lawsonü}

Celastraceae

VU B $1+2 c$

India (Tamil Nadu)

Confined to the Western Ghats within an area stretching from the Nilgiri Hills to a site at the north of Shencottah, this understorey tree has been rarely collected from scattered sites within submontane evergreen forest. Assessor: World Conservation Monitoring Centre Refs: 19144

\section{Glyptopetalum palawanense}

Celastraceae

VU B $1+2 c$

Malaysia (Sabah), Philippines

This small tree is known only from primary forest in Palawan in the Philippines and a single sterile collection from a coastal limestone ridge on Balambangan Island, Sabah. The main island of Palawan is a biosphere reserve.

Assessor: World Conservation Monitoring Centre

Refs: 4986, 19017

\section{Glyptostrobus pensilis}

Taxodiaceae

China (Fujian, Guangdong, Guangdong - Hainan, Guangxi, Jiangxi, Sichuan, Yunnan), Viet Nam

The only extant species of a genus which was speciesrich in the Tertiary period. It is a prime timber tree, scattered in south and south-east China in areas which are densely populated. Primary localities exist in the Zhujiang Delta and the lower reaches of the Minjiang River. Populations in Viet Nam were once common but are now reduced to fewer than 100 individuals in a few sites of swamp forest in Dac Lac Province (CR Alcd). The population in Krong Bak Nature Reserve is protected, but regeneration is reported to be nonexistent.

Assessor: SSC Conifer Specialist Group

Refs: $374,848,2901,11191,11530,11847,15357$

\section{Gmelina hainanensis}

Verbenaceae

VU B $1+2 c$

China (Guangdong - Hainan), Viet Nam

In China the species is known only from rainforest in the mountain ranges of the south and west of Hainan Island. In Viet Nam it is recorded from Quanh Ninh Province, where it occurs in lowland evergreen monsoon forest. Although parts of the range are designated nature reserves, the habitat is generally subject to logging and clearance.

Assessor: World Conservation Monitoring Centre Refs: $1818,11530,11847,15357$ 
Gmelina lignum-vitreum

Verbenaceae

CR D1

New Caledonia

Assessor: Jaffré, T et al.

Refs: 10351

\section{Gmelina vitiensis}

Verbenaceae

LR/nt

Fij

A relatively tall tree which supplies good fumiture wood. It has been well collected from dense forest between 90 and $900 \mathrm{~m}$ in Viti Levu, Kandavu, Ngau and Vanua Levu.

Assessor: World Conservation Monitoring Centre

Refs: 18818

\section{Goetzea elegans}

Goetzeaceae

EN C2a

Puerto Rico

A small understory tree of limestone forest, recorded from eight populations of between 100 and 125 individuals. They are unprotected and experiencing various pressures. Road widening destroyed six individuals, which have since been replaced by numerous root suckers. Construction of a hotel complex, pipe-laying and predation of flowers are amongst the major concerns.

Assessor: World Conservation Monitoring Centre

Refs: $7980,17124,17540$

\section{Gomidesia cambessedeana}

Myrtaceae

Brazil (Rio de Janeiro)

The species was collected twice in the early part of the 19 th century, but since then it has not been found.

Assessor: Pires O'Brien, J.

Refs: 19097

\section{Gomidesia mugnifolia}

Myrtaceae

EN B1+2abcd

Brazil (Rio de Janeiro)

First described in 1857 , the species has only recently been rediscovered from a population in the Poça d'Antas Biological Reserve.

Assessor: Pires O'Brien, J.

Refs: 19097

\section{Gomortega keule}

Gomortegaceae

EN Alcd

Chile (Bíobío, Maule)

A species of taxonomic interest, belonging to an ancient monotypic family. It is known from a very restricted distribution in the Coastal Cordillera of central Chile, occurring in forest on the south-facing slopes of humid ravines. The populations are unprotected and under threat from logging and forest management activities, fire and agricultural encroachment.

Assessor: González, M.

Refs: $7980,13628,16328$

\section{Gomphandra comosa}

Icacinaceae

VU B $1+2 \mathrm{c}$

India (Andaman and Nicobar Is. - Andaman Is., Andaman and Nicobar Is. - Nicobar Is.)

A small tree of evergreen forest confined to the Nicobar and Andaman Islands. Large areas of forest have been logged and lost to increasing agriculture and settlement. Assessor: World Conservation Monitoring Centre

Refs: 4799, 7147
Gongrospermum philippinense

Sapindaceae

CR Alc

Philippines

This forest species is endemic to Luzon and known only

from one or two collections.

Assessor: van Welzen, P.C

Refs: 18389

\section{Goniothalamus calycinus}

Annonaceae

VU D2

Malaysia (Peninsular Malaysia)

Confined to Terengganu in lowland forest, this tree is mainly found on Bukit Kajong, which is a protected forest.

Assessor: Kochummen, K.M.

Refs: 8464,19073

\section{Goniothalamus gardneri}

Annonaceae

$\mathrm{EN} \mathrm{BI}+2 \mathrm{c}$

Sri Lanka

This species was discovered in only four forest localities during the extensive surveys conducted for the National Conservation Review.

Assessor: World Conservation Monitoring Centre

Refs: 15431, 19112

\section{Goniothalamus holttumii}

Annonaceae

VU D2

Malaysia (Peninsular Malaysia)

Confined to Fraser's Hill by the Selangor border, this montane forest tree is known from a single locality. The main threat to the area is tourism. It is hoped that the proposed route of a new highway which is planned will not affect the population.

Assessor: Kochummen, K.M

Refs: 8464,19073

\section{Goniothalamus hookeri}

Annonaceae

VUAlc, BI+2c

Sri Lanka

A tree confined to the lowland wet evergreen forests of south-west Sri Lanka. This species was discovered in only six forest localities during the extensive surveys conducted for the National Conservation Review.

Assessor: World Conservation Monitoring Centre

Refs: 15431, 17195, 19112

\section{Goniothalamus macrocalyx}

Annonaceae

VU Ala

Viet Nam

The species appears to be endemic to a restricted area in the north, confined to the provinces of Ha Tay, Hoa Binh and Thanh Hoa.

Assessor: Ban, N.T.

Refs: 848,19060

\section{Goniothalamus majestatis}

Annonaceae

VU D2

Indonesia (Sulawesi)

A treelet restricted to the coralline limestone or serpentine soils of central and south-east Sulawesi. The species is only recently described and is known from three collections.

Assessor: World Conservation Monitoring Centre

Refs: 11509 
Goniothalamus montanus Annonaceae

VU D2

Malaysia (Peninsular Malaysia)

Confined to montane forest in Ulu Brang in Terengganu and the Cameron Highlands in Pahang, this tree is known only from two collections. Both localities fall within protected forest.

Assessor: Kochummen, K.M.

Refs: 8464, 19073

\section{Goniothalamus rhynchantherus}

Annonaceae

India (Kerala, Tamil Nadu)

$\mathrm{EN} \mathrm{B1}+2 \mathrm{c}$

A species confined to the Agastyamalai Hills at the southern end of the Westem Ghats, where it is scattered in a few localities of evergreen forest. Large areas have been exposed to fires, grazing, the establishment of commercial plantations and cutting for fuelwood, but almost $1000 \mathrm{~km}^{2}$ of forest are now under protection within sanctuaries.

Assessor: World Conservation Monitoring Centre

Refs: 2538, 5651, 19144

\section{Goniothalamus salicina}

Annonaceae

VUAlc

Sri Lanka

This species was discovered in 13 forest localities during the extensive surveys conducted for the National Conservation Review

Assessor: World Conservation Monitoring Centre

Refs: 15431,19112

\section{Goniothalamus simonsii}

Annonaceae

$\mathrm{EN} \mathrm{B1}+2 \mathrm{c}$

India (Meghalaya)

A small tree of the Khasi Hills. It is known only from the Lailad area of Nongkyllen Forest Reserve in Meghalaya.

Assessor: World Conservation Monitoring Centre

Refs: 7147

\section{Goniothalamus wynaadensis}

Annonaceae

LR/nt

India (Kerala, Tamil Nadu)

Occurring in the understorey of lowland evergreen forest up to $900 \mathrm{~m}$, the species has been collected from scattered localities along the Westem Ghats from Wayanad to Anaimalai.

Assessor: World Conservation Monitoring Centre

Refs: 19144

\section{Gonystylus bancanus}

Thymelaeaceae

VUAlcd

Brunei, Indonesia (Kalimantan, Sumatra), Malaysia (Peninsular Malaysia, Sabah, Sarawak)

A gregarious, often dominant tree of lowland freshwater swamp and peat-swamp forest. Populations have been heavily depleted as the most important source of ramin timber. The species is also threatened in parts of its range by habitat loss. A recent investigation by Dutch and Malaysian experts, following ${ }^{*}$ CITES debates on the species, concluded that $\boldsymbol{G}$. bancanus is not threatened with extinction in Malaysian swamp forests although regeneration in overexploited forests may be a cause for concern.

Assessor: World Conservation Monitoring Centre

Refs: $7673,14448,14573,17140,19202$
Gonystylus calophylloides

Thymelaeaceae

VU Alc+2c

Malaysia (Sarawak)

A small tree found growing on the banks of rocky streams. It is endemic to north-east Sarawak.

Assessor: World Conservation Monitoring Centre Refs: 1766

\section{Gonystylus consanguineus}

Thymelaeaceae

VU Alcd $+2 c d$

Indonesia (Kalimantan), Malaysia (Sabah, Sarawak)

A lowland species, of primary or old secondary forest up to $400 \mathrm{~m}$ altitude, which is exploited for its ramin timber. Assessor: World Conservation Monitoring Centre Refs: 1766,14573

\section{Gonystylus costalis}

Thymelaeaceae

Malaysia (Sarawak)

VU Alc+2c

A small tree endemic to the lowlands of Sarawak.

Assessor: World Conservation Monitoring Centre Refs: 1766

\section{Gonystylus decipiens}

Thymelaeaceae

VUAlc+2c Sarawak

A small tree endemic to Sarawak up to $500 \mathrm{~m}$.

Assessor: World Conservation Monitoring Centre Refs: 1766

\section{Gonystylus glaucescens}

Thymelaeaceae

VU Alc+2c

Indonesia (Kalimantan)

A small tree endemic to East Kalimantan. It has been recorded on a sandstone ridge at $400 \mathrm{~m}$.

Assessor: World Conservation Monitoring Centre Refs: 1766

\section{Gonystylus keithii}

Thymelaeaceae VU Alcd $+2 c d$ Indonesia (Kalimantan), Malaysia (Sabah, Sarawak) A tree scattered in the evergreen, non-inundated rainforests of Bomeo. The wood is used as ramin timber. Assessor: World Conservation Monitoring Centre Refs: 1766, 14573

\section{Gonystylus lucidulus}

Thymelaeaceae

VU Alc+2c

Brunei, Malaysia (Sarawak)

A tree confined to the lowlands of Brunei and Sarawak. Assessor: World Conservation Monitoring Centre Refs: 1766

\section{Gonystylus macrophyllus}

Thymelaeaceae

VU Alcd

Indonesia (Bali, Irian Jaya, Kalimantan, Moluccas, Sulawesi, Sumatra), Malaysia (Peninsular Malaysia), Papua New Guinea (North Solomons, Papua New Guinea), Philippines?, Solomon Islands (South Solomon)

A widespread tree occurring in primary forest reaching an altitude of $1500 \mathrm{~m}$ in some areas. The species is extremely rare in Papua New Guinea and occurs only on New Georgia and Choiseul in the Solomon Islands, where it is locally common. It is one of the important ramin timber species and the heartwood is used as 
incense. This species might eventually be split into several distinct species, as the present species concept might be too wide.

Assessor: World Conservation Monitoring Centre Refs: $1766,4919,12937,14573,17140,19147$

\section{Gonystylus nervosus}

\section{Thymelaeaceae}

VUAlc+2c

Malaysia (Sarawak)

Apparently restricted to limestone hills, this small tree is endemic to Sarawak.

Assessor: World Conservation Monitoring Centre Refs: 1766

\section{Gonystylus nobilis}

Thymelaeaceae

VUAlc+2c

Malaysia (Sarawak)

A lowland species endemic to Sarawak.

Assessor: World Conservation Monitoring Centre

Refs: 1766

\section{Gonystylus pendulus}

Thymelaeaceae

VU Alc $+2 c$

Malaysia (Sarawak)

A small tree confined to the lowlands of south-west Sarawak.

Assessor: World Conservation Monitoring Centre Refs: 1766

\section{Gonystylus spectabilis}

Thymelaeaceae

VUAlc+2c

Malaysia (Sarawak)

A lowland tree endemic to Sarawak.

Assessor: World Conservation Monitoring Centre Refs: 1766

\section{Gonystylus stenosepalus}

Thymelaeaceae

VUAlc+2c

Malaysia (Sarawak)

A small tree endemic to Sarawak.

Assessor: World Conservation Monitoring Centre Refs: 1766

\section{Gonystylus xylocarpus}

Thymelaeaceae

VU Alcd $+2 c d$

Indonesia (Kalimantan), Malaysia (Sarawak)

A tree of primary rainforest and heath forest up to $100 \mathrm{~m}$, confined to western Borneo. The species is exploited for its ramin timber.

Assessor: World Conservation Monitoring Centre

Refs: 14573

\section{Gordonia hirtella}

Theaceae

VU B $1+2 \mathrm{a}$

Malaysia (Peninsular Malaysia)

A tree species occurring scattered in hill forest.

Assessor: Chua, L.S.L.

Refs: $5550,11647,19073$

\section{Gordonia maingayi}

Theaceae

VU D2

Malaysia (Peninsular Malaysia)

This tree species is scattered on the ridge tops and hillsides of rainforests within a national park.

Assessor: Chua, L.S.L.

Refs: 8464, 19073

\section{Gordonia multinervis}

Theaceae

VU Bl+2a

Malaysia (Peninsular Malaysia), Singapore

This tree occurs in lowland and hill forest of Perak, Kelantan, Terengganu, Pahang, Penang, Malacca, Johore and Singapore. Encroaching settlements are the largest threat to the species.

Assessor: Chua, L.S.L.

Refs: $9199,17140,19073$

\section{Gordonia penangensis}

Theaceae

VU B1+2a

Malaysia (Peninsular Malaysia), Singapore

A small tree inhabiting open rainforest between 20 and

$500 \mathrm{~m}$ in Penang, Perak, Pahang and Singapore.

Assessor: Chua, L.S.L.

Refs: 9199,19073

\section{Gordonia scortechinii}

Theaceae

Malaysia (Peninsular Malaysia)

VU B1+2c

A very rare tree occurring scattered in the hill forest of

Perak and Pehang.

Assessor: Chua, L.S.L.

Refs: 8464, 19073

\section{Gordonia singaporeana}

Theaceae

VU $B 1+2 c$

Malaysia (Peninsular Malaysia), Singapore

A tree of moist forest up to $1300 \mathrm{~m}$, found in Perak, Pahang, Penang, Negeri Sembilan, Malacca, Johore and Singapore. Some areas receive a degree of protection within the permanent forest estate.

Assessor: Chua, L.S.L.

Refs: $5550,8464,9199,11647,17140,19073$

\section{Gordonia taipingensis}

Theaceae

VU BI+2a

Malaysia (Peninsular Malaysia)

This rare, medium-sized tree is confined to the hills of one forest reserve in the state of Perak. Tourism presents the main threat to the species.

Assessor: Chua, L.S.L.

Refs: 8464,19073

\section{Gordonia villosa}

Theaceae

$\mathrm{EN} \mathrm{B1+2c}$

Jamaica

A recent taxonomic revision includes this species in the relatively common $G$. haematoxylon but this arrangement is disputed. The plant is stunted and seldom exceeds $2 \mathrm{~m}$ in height because it grows in nutrientstarved conditions on deep acid mor humus. Endemic to the Blue Mountains, small populations are restricted to a very small range in montane rainforests between 1550 and $1700 \mathrm{~m}$.

Assessor: Bellingham, $\mathrm{P}$.

Refs: 19116

\section{Gossweilerodendron balsamiferum}

Leguminosae EN Alcd Angola, Cameroon, Congo, Democratic Republic of Congo, Equatorial Guinea, Gabon, Nigeria

Endemic to the Guineo-Congolian region, this timber species is declining in population numbers because of heavy exploitation and habitat loss. It grows in mature 
little-disturbed lowland rainforest. In the main DR Congo/Nigeria forest block it is generally rare or absent. Assessor: African Regional Workshop Refs: 2362, 2773, 6718, 15790, 17408

\section{Graffenrieda bella}

Melastomataceae

LR/nt

Panama

One of the most common cloud forest trees, the species occurs above $800 \mathrm{~m}$ in all provinces of Panama. It is less common in Coclé, Panamá and Bocas del Toro. There are several occurrences in protected areas. Elsewhere populations come under pressure from increasing habitat encroachment.

Assessor: Mitré, M.

Refs: $3913,7980,15037,16772$

\section{Graffenrieda caudata}

Melastomataceae

VU D2

Guyana

A tree known only from the type collection, gathered in rainforest on the Pakaraima Mountains.

Assessor: World Conservation Monitoring Centre

Refs: 9867

Graffenrieda grandifolia

Melastomataceae

EN B $1+2 c$

Colombia

An endemic to Antioquia.

Assessor: Calderon, E.

Refs: 19069

\section{Graffenrieda robusta}

Melastomataceae

Peru

This species is known only from forest between 1500 and $2000 \mathrm{~m}$ in the department of Huanuco region. Assessor: World Conservation Monitoring Centre Refs: 1984

\section{Graffenrieda trichanthera}

Melastomataceae

VU D2

Peru

Known only from the type collection, the species occurs in lowland rainforest in the department of Loreto. Assessor: World Conservation Monitoring Centre Refs: 1984

\section{Graptophyllum repandum}

Acanthaceae

$\mathrm{LR} / \mathrm{nt}$

Fiji

Apparently this shrub or small tree is endemic to Fiji, where it is known from dense forest in rocky places up to $1130 \mathrm{~m}$ on the two largest islands and Ovaluau.

Assessor: World Conservation Monitoring Centre Refs: 18818

\section{Greenwayodendron suaveolens ssp. usambaricum Annonaceae \\ $\mathrm{VU} B 1+2 \mathrm{~b}$ \\ Tanzania}

A distinct form of a tropical African taxon, this subspecies occurs rarely within a $100 \mathrm{~m}$ altitudinal belt of moist submontane forest on the East Usambara Mountains. Although forest loss and disturbance have been severe and the surrounding area is densely populated, an active conservation programme is now in place.

Assessor: Lovett, J. \& G.P. Clarke

Refs: $3356,5204,9302$

\section{Grewia aldabrensis}

Tiliaceae

VU D2

Seychelles (Aldabra)

A small slender tree with an occasional distribution in mixed scrub. It is endemic to the Aldabras, where it occurs only on Malabar, the east of Grand Terre and Michel Island. The islands are protected within a Strict Nature Reserve and are uninhabited.

Assessor: World Conservation Monitoring Centre Refs: 19027

\section{Grewia bilocularis}

Tiliaceae

VU D2

Yemen (Socotra)

Populations appear to be very scattered and scarce, but under no current threat.

Assessor: Miller, A.G.

Refs: 2354, 19083

\section{Grewia goetzeana}

Tiliaceae

Tanzania

Assessor: Lovett, J. \& G.P. Clarke

Refs: 3356,8814

\section{Grewia limae}

Tiliaceae

Mozambique

Assessor: Bandeira, S.

Refs: 5117,18965

\section{Grewia salicifolia}

Tiliaceae

Seychelles (Aldabra)

An occasional constituent of mixed scrub found only on Malabar, the west of Picard, the east of Grand Terre in the Aldabras and Menai on Cosmoledo. The Aldabran Islands are protected within a Strict Nature Reserve and only Picard is inhabited with a research station.

Assessor: World Conservation Monitoring Centre Refs: 19027

\section{Grewia transzambesica}

Tiliaceae

Mozambique

Assessor: Bandeira, $\mathrm{S}$.

Refs: 5117,18965

\section{Grewia turbinata}

Tiliaceae

VUD2

Yemen (Socotra)

Populations appear to be very scattered and scarce, but under no current threat.

Assessor: Miller, A.G.

Refs: 2354,19083

\section{Greyia flanaganü}

Greyiaceae

South Africa (Eastem Cape)

A shrub or small tree which grows on rocky, grassy hillsides in only a few restricted localities, all on private land. No information is available on the size of the populations or degree of threat. The roots are reportedly used for traditional medicinal and magical purposes.

Assessor: Hilton-Taylor, C. et al.

Refs: $689,17410,19218$ 
Grias colombiana

Lecythidaceae

VU B1 $+2 \mathrm{c}, \mathrm{D} 2$

Colombia

A small of lowland non-flooded forest, known only from three collections from the Pacific coast.

Assessor: World Conservation Monitoring Centre

Refs: 3791, 7980

Grias haughtii

Lecythidaceae

VU B $1+2 c$

Colombia

A Colombian endemic, collected relatively few times from non-flooded lowland forest in Antioquia, Caldas and Santander.

Assessor: Calderon, E.

Refs: 3791, 7980, 19069

\section{Grias multinervia}

Lecythidaceae

VU B $1+2 \mathrm{c}$

Colombia, Ecuador

Known only from two collections, the species occurs in Cauca in coastal Colombia and in Los Ríos in coastal

Ecuador.

Assessor: World Conservation Monitoring Centre

Refs: 3791,7980

\section{Grimmeodendron jamaicense}

Euphorbiaceae

VU BI+2c

Jamaica

Local and uncommon, this Cockpit Country endemic is distributed in forest on craggy limestone in St Elizabeth and Trelawny.

Assessor: World Conservation Monitoring Centre

Refs: 5653,7980

\section{Grisollea thomasseti}

Icacinaceae

Seychelles

A tree endemic to the Seychelles, which was reported in 1910 to be locally common on Mahé and Silhouette. The population on Mahé is now reduced to a single tree on Mount Simpson, having declined through forest clearance at medium altitudes and degradation at higher altitudes. The species remains relatively common on Silhouette and is present in forest areas protected by the Nature Protection Trust of Seychelles.

Assessor: Nature Protection Trust of Seychelles

Refs: $16212,17229,19025$

\section{Grossera elongata}

Euphorbiaceae

VU D1+2

São Tomé \& Príncipe (Príncipe)

This tree is known from a site above Neves Ferrieira. More detailed information is lacking. There have been no recent botanical surveys of the island.

Assessar: World Conservation Monitoring Centre Refs: 2724

\section{Grosvenoria rimbachï}

Compositae

VU B1+2c

Ecuador

A species which is endemic to the High Andes of Ecuador.

Assessor: World Conservation Monitoring Centre

Refs: 19119,19120
Guaiacum coulteri

Zygophyllaceae

Mexico (Jalisco)

Assessor: Ramirez-Marcial, N. \& M. González-Espinosa

Refs: 81, 7588, 19203

\section{Guaiacum officinale}

Zygophyllaceae

EN C2a

Anguilla, Antigua and Barbuda, Bahamas, Barbados, Colombia, Cuba, Dominica, Dominican Republic, Grenada, Guadeloupe (Guadeloupe, St Martin-St Barthelemy), Haiti, Jamaica, Martinique, Montserrat, Netherlands Antilles, Puerto Rico, St Vincent, Turks and Caicos Islands, Venezuela, Virgin Islands (British), Virgin Islands (US)

A slow-growing species of lowland dry forest, woodland and thicket, frequently growing in coastland areas. The timber and medicinal resin have been traded for several centuries as lignum-vitae and overexploitation has taken place throughout the species' range. Populations are now severely reduced in the Lesser Antilles, Puerto Rico, Barbados, Virgin Islands and Colombia and extinct or almost extinct in Antigua, Anguilla and Barbuda. Regeneration is good but growth is very slow. The species is listed in Appendix II of *CITES.

Assessor: Americas Regional Workshop

Refs: 4082, 6602, 7630, 14301, 16327, 16987, 17678, 19069,19179

\section{Guaiacum sanctum}

Zygophyllaceae

EN C2a

Bahamas, Belize, Costa Rica, Cuba, Dominican Republic, El Salvador (ex), Guatemala, Haiti, Honduras, Mexico (Quintana Roo), Nicaragua, Panama, Puerto Rico, USA (Florida)

A less valuable but rarely distinguished source of lignum-vitae than $G$. officinale. Occurring in lowland dry forest, the species is now extinct or extremely rare on most of the Caribbean islands. In Central America and Florida remaining populations are confined to restricted areas and continue to be threatened with habitat loss or exploitation, e.g. in Guancaste in Costa Rica, El Salvador, Florida Keys. As with $G$. officinale, both the timber and medicinal resin are of commercial use and have been traded for several centuries. Regeneration is good but growth is very slow. The species is listed in Appendix II of *CITES.

Assessor: Americas Regional Workshop

Refs: $197,4147,4974,9254,10197,14717,15037$ 16327, 19179

\section{Guapira rotundifolia}

Nyctaginaceae

LR/nt

Jamaica

Assessor: World Conservation Monitoring Centre

Refs: 7980

\section{Guarea carapoides}

Meliaceae

VU D2

Peru

Apparently known only from the type collection, the species is confined to the Peruvian Amazon at the mouth of Río Santiago.

Assessor: World Conservation Monitoring Centre

Refs: 7980, 12281 


\section{Guarea cartaguenya}

Meliaceae

VU B $1+2 c$

Colombia, Ecuador

This species is known from few collections, gathered from rainforest flanking the base of the Pacific slopes of the Andes, occurring at the type locality in Valle, Colombia, and in Los Ríos, Ecuador.

Assessor: Calderon, E.

Refs: 7980, 12281, 19069

\section{Guarea casimiriana}

Meliaceae

VU D2

Penu

Apparently known only from the type collection, this small tree is confined to the Peruvian Amazon at Yurimaguas in the department of Loreto.

Assessor: World Conservation Monitoring Centre

Refs: 7980,12281

\section{Guarea caulobotrys}

Meliaceae

VU B $1+2 \mathrm{c}$

Colombia

Endemic to Colombia, the species is known only from a few collections from the department of Valle on the Pacific coast, probably occurring in rainforest.

Assessor: Calderon, E

Refs: 7980, 12281, 19069

\section{Guarea cedrata}

Meliaceae

VU Alc

Cameroon, Congo, Côte d'Ivoire, Democratic Republic of Congo, Ghana, Liberia, Nigeria, Sierra Leone, Uganda

A timber species found in some abundance in moist semi-deciduous forest and in the drier undisturbed areas of moist evergreen forest. Levels of exploitation are moderate and the species often suffers from its similarity to Entandrophragma angolense, resulting in it being harvested with the same intensity. Regeneration is more successful in undisturbed areas where there has been no burning.

Assessor: World Conservation Monitoring Centre

Refs: 2773, 6128, 12061, 13250, 14667, 16021, 17408

\section{Guarea convergens}

Meliaceae

VU D2

Brazil (Amazonas)

This species is known only from non-flooded forest in central Amazonia.

Assessor: Pires O'Brien, J.

Refs: $5942,7980,12281$

\section{Guarea corrugata}

Meliaceae

$\mathrm{EN} \mathrm{B1+2c}$

Colombia

A poorly known species, occurring in Valle, recorded only from the type locality.

Assessor: Calderon, E.

Refs: $7980,12281,19069$

\section{Guarea crispa}

Meliaceae

EN D1

Brazil (Amazonas)

Confined to non-flooded forest in central Amazonia, the species is known from rare collections on the ManausPorto Vello road.

Assessor: Pires O'Brien, J.

Refs: $5942,7980,12281$

\section{Guarea cristata}

Meliaceae

VU $B 1+2 c$

Brazil (Amazonas), Peru

A species which is confined to forested areas from the Javari River area between Brazil and Peru.

Assessor: Pires O'Brien, J.

Refs: 5942, 7980, 12281

\section{Guarea guentheri}

Meliaceae

VU B $1+2 c$

Brazil (Amazonas), Peru

A species of western Amazonia, occurring in nonflooded forest from sea level to $600 \mathrm{~m}$.

Assessor: Pires O'Brien, J.

Refs: $5942,7980,12281$

\section{Guarea humaitensis}

Meliaceae

VU B $1+2 c$

Brazil (Amazonas)

The species is confined to non-flooded forest in southwest Amazonia.

Assessor: Pires O'Brien, J.

Refs: $5942,7980,12281$

\section{Guarea jamaicensis}

Meliaceae

VU Bl+2c

Jamaica

Known only from disjunct limestone localities in $\mathrm{St}$ Andrew and St James, the species is uncommon and, particularly in St Andrew, has experienced almost complete destruction or degradation of its habitat.

Assessor: Bellingham, $\mathrm{P}$.

Refs: $401,5653,7980,19116$

\section{Guarea juglandiformis}

Meliaceae

VU B $1+2 c$

Brazil (Acre), Peru

Occurring in non-flooded forest, the species appears to be restricted to the extreme westem part of Amazonia.

Assessor: Pires O'Brien. J.

Refs: $1984,5942,7980,12281$

\section{Guarea macropetala}

Meliaceae

VU A2c

Panama

This scarce species has been collected throughout Panama, but only in areas of undisturbed forest of low to medium elevation. There are occurrences within protected areas, but elsewhere the habitat is under severe pressures. A site on the El Llano-Cartí highway to the north-east of Panamá city is under threat of deforestation.

Assessor: Mitré, M.

Refs: 7980, 15037, 16772

\section{Guarea macrophylla ssp. macrophylla}

Meliaceae

VU BI+2c

Antigua and Barbuda, Dominica, Grenada, Guadeloupe. Martinique, Montserrat, St Vincent, Virgin Islands (US) Only known with certainty from the Lesser Antilles, the species occurs in remaining areas of lowland rainforest, often at riversides. The other subspecies are widespread in the Amazon.

Assessor: World Conservation Monitoring Centre Refs: 7980, 12281 
Guarea mayombensis

Meliaceae

VU Alc

Democratic Republic of Congo, Gabon, Uganda

A tree of mid-altitude rainforest. In Uganda it occurs in Ishasha Gorge and Kayonza forest in Bwindi Impenetrable National Park. There are reports that regeneration is poor because seed dispersal agents are lacking. There is no information on populations elsewhere. If it is assumed that the species occurs in Mayombe, populations there are under heavy pressure from logging and overcutting for charcoal.

Assessor: *MUIENR

Refs: $1308,9605,10961,16021$

\section{Guarea polymera}

Meliaceae

VU B $1+2 c$

Colombia, Ecuador

A tree of Pacific coastal forest, known from only a few collections taken from the department of Valle in Colombia and Esmeraldas in Ecuador.

Assessor: Calderon, $\mathrm{E}$.

Refs: 7980, 12281, 19069

\section{Guarea pyriformis}

Meliaceae

VU B $1+2 c$

Costa Rica

A medium-sized tree of lowland evergreen rainforest, confined to the Golfo Dulce area of south-eastern Pacific Costa Rica. The few collections made so far have all come from streamsides or river banks.

Assessor: World Conservation Monitoring Centre

Refs: 7980,12281

\section{Guarea sphenophylla}

Meliaceae

VU B I +2c

Dominican Republic, Haiti

A shrub or small tree of forested limestone hills, collected from the Massif de la Hotte in Haiti and near Rincón in Dominican Republic.

Assessor: World Conservation Monitoring Centre

Refs: 197, 7980, 12281

\section{Guarea sprucei}

Meliaceae

CR C2b

Brazil (Amazonas)

This species is known only from the type collection in the Rio Negro basin.

Assessor: Pires O'Brien, J.

Refs: $5942,7980,12281$

\section{Guarea thompsonii}

Meliaceae

VUAlc

Cameroon, Congo, Côte d'Ivoire, Democratic Republic of Congo, Gabon, Ghana, Liberia, Nigeria

Although moderately exploited, this species is less commercially important than $G$. cedrata. It occurs commonly in hilly moist evergreen forest. Growth is slow, reaching only $9 \mathrm{ft}$. DBH in 200 years.

Assessor: World Conservation Monitoring Centre

Refs: $2773,6128,6718,12061,13250,17408$

\section{Guarea trunciflora}

Meliaceae

VU Bl+2c

Brazil (Amazonas, Pará), Peru

Despite its wide distribution in Amazonian Peru, Brazil, and the border area between Brazil and Guyana, this tree is scattered in non-flooded forest and has been collected rarely.

Assessor: Pires O'Brien, J.

Refs: 5942, 7980, 12281

\section{Guarea velutina}

Meliaceae

VU BI+2c

Brazil (Amazonas, Pará, Roraima)

A species occurring in the middle and upper Rio Negro and adjacent Roraima territory. It has also been collected once south of the Amazon in Pará.

Assessor: Pires O'Brien, J.

Refs: $5942,7980,12281$

\section{Guarea venenata}

Meliaceae

LR/cd

Brazil (Amazonas), Colombia

This understorey species, although locally abundant in places, is confined to westem and south-westem Amazonia.

Assessor: Pires O'Brien, J.

Refs: $5942,7980,12281$

\section{Guatteria alutacea var. angustifolia}

Annonaceae

VU D2

Peru

A variety known only from the type collected from the department of San Martin.

Assessor: World Conservation Monitoring Centre

Refs: 1984

\section{Guatteria anomala}

Annonaceae

LR/nt

El Salvador, Guatemala, Mexico (Campeche, Chiapas, Tabasco, Veracruz)

A timber tree and dominant component of lowland seasonal rainforest. In Mexico, populations are restricted to the Gulf Region, occurring commonly in remaining rainforest in the Lacandon region, and the UxpanapaChimalapa region. Rates of deforestation have been very high in all parts of the range.

Assessor: World Conservation Monitoring Centre

Refs: $4862,4974,5651,7588,19161$

\section{Guatteria atabapensis}

Annonaceae

LR/nt

Venezuela

A treelet which occurs in shrub islands in white-sand savanna in a number of localities in Amazonas.

Assessor: World Conservation Monitoring Centre

Refs: 19128

\section{Guatteria augusti}

Annonaceae

VU D2

Peru

A species of submontane forest, known only from the type collection from the department of La Libertad. Assessor: World Conservation Monitoring Centre Refs: 1984

\section{Guatteria calliantha}

Annonaceae

VU D2

Peru

This species is known only from the type collection from the department of Loreto.

Assessor: World Conservation Monitoring Centre Refs: 1984 
Guatteria diospyroides ssp. hondurensis Annonaceae

CR C2b

Honduras

Assessor: Nelson, C.

Refs: 13995

\section{Guatteria dura}

Annonaceae

$\mathrm{LR} / \mathrm{nt}$

Venezuela

This species occurs along smaller rivers and creeks, probably in seasonally flooded sites, ranging from central to south-westem Amazonas.

Assessor: World Conservation Monitoring Centre

Refs: 19128

\section{Guatteria eriopoda}

Annonaceae

VU D2

Peru

A species known only from the type collection from the department of Huánuco.

Assessor: World Conservation Monitoring Centre

Refs: 1984

\section{Guatteria excelsa}

Annonaceae

VU D2

Peru

This species is known only from the type collection from the department of Huánuco.

Assessor: World Conservation Monitoring Centre Refs: 1984

\section{Guatteria ferruginea}

Annonaceae

$\mathrm{DD}$

Suriname

A species of no recorded locality, endemic to Suriname. Assessor: World Conservation Monitoring Centre Refs: 19196

\section{Guatteria geminiflora}

Annonaceae

VU D2

Peru

This species is known only from the type collection from the department of Amazonas.

Assessor: World Conservation Monitoring Centre

Refs: 1984

\section{Guatteria glauca}

Annonaceae

VU D2

Peru

This species is known only from the type collection from the department of Huánuco.

Assessor: World Conservation Monitoring Centre

Refs: 1984

\section{Guatteria guentheri}

Annonaceae

VU D2

Peru

Known only from the type collection, the species occurs in the department of Loreto.

Assessor: World Conservation Monitoring Centre Refs: 1984

\section{Guatteria insignis}

Annonaceae

Suriname

A species of no recorded locality, endemic to Suriname. Assessor: World Conservation Monitoring Centre Refs: 19196

\section{Guatteria jefensis}

Annonaceae

EN B $1+2 b d$

Panama

Only small populations are known, confined to areas of lowland rainforest in Cerro Jefe. Several are contained within Chagres National Park, but those elsewhere are increasingly threatened by encroaching agriculture, settlements and industrial developments.

Assessor: Mitré, $\mathrm{M}$.

Refs: $7980,12226,16772$

\section{Guatteria juninensis}

Annonaceae

VU D2

Penu

This species is known only from the type collection from the department of Junín.

Assessor: World Conservation Monitoring Centre Refs: 1984

\section{Guatteria liesneri}

Annonaceae

LR/nt

Venezuela

A tree of riverine forests, with occurrences in Serrania de los Pijiguaos in Bolívar and in western Amazonas.

Assessor: World Conservation Monitoring Centre Refs: 19128

\section{Guatteria modesta}

Annonaceae

VU D2

Peru

This species is known only from the type collection from the department of Loreto.

Assessor: World Conservation Monitoring Centre Refs: 1984

\section{Guatteria panamensis}

Annonaceae

VU B1+2de

Panama

Occurring in lowland evergreen forest, the species is known from a few populations in the provinces of Los Santos and Bocas del Toro. There may be other occurrences, possibly in Costa Rica. No specific protection or conservation measures are in place and the habitat is susceptible to logging and clearing in many areas.

Assessor: Mitre, M.

Refs: $7272,7980,16772$

\section{Guatteria stenopetala}

Annonaceae

VU D2

Venezuela

Endemic to the Sierra de la Neblina in Amazonas, the species occurs within a restricted altitudinal range in lower montane Clusia forest. The area is protected but has suffered from fires and illegal mining.

Assessor: World Conservation Monitoring Centre Refs: 19128

\section{Guatteria tonduzi}

Annonaceae

$\mathrm{LR} / \mathrm{nt}$

Colombia, Costa Rica, Panama

Ranging from Costa Rica to Colombia, the species is relatively widespread in areas of evergreen rainforest up to $1500 \mathrm{~m}$. Populations in Panama are reported to be healthy; certain areas are threatened with logging, while others are protected within national parks. In Costa Rica 
the species is common at medium elevations. In

Colombia the species distribution appears to be concentrated in the Chocó, especially the Urabá area.

Assessor: Mitré, M.

Refs: $7272,15037,16772$

Guatteria williamsii

Annonaceae

LR/nt

Venezuela

A tree of non-flooded evergreen forest, occurring along

Río Casiquiare in Amazonas.

Assessor: World Conservation Monitoring Centre

Refs: 19128

\section{Guatteriopsis ramiflora}

Annonaceae

VU D2

Peru

This species is known only from the type collection from lowland Amazon rainforest in the department of San Martin.

Assessor: World Conservation Monitoring Centre

Refs: 1984

\section{Guettarda comata}

Rubiaceae

VU D2

Peru

Known only from the type collection, the species occurs

in lowland Amazon rainforest in the department of

Loreto. There is uncertainty over its taxonomic status, as it may be conspecific with $G$. comosa or $G$. sericea.

Assessor: World Conservation Monitoring Centre

Refs: 1984

\section{Guettarda frangulifolia}

Rubiaceae

VU Bl $+2 \mathrm{C}$

Jamaica

This species is likely to be a minor variant of $G$. argentea. It is uncommon and local in its distribution, apparently confined to St Catherine, Hanover and Trelawny,

Assessor: World Conservation Monitoring Centre

Refs: 6057,7980

\section{Guettarda longiflora}

Rubiaceae

CR B $1+2 c$

Jamaica

There is little information about this species and no recent collection material. It is, apparently, confined to St Ann and St Thomas Parishes and is evidently very uncommon. Almost all forested areas below $1400 \mathrm{~m}$ in the latter parish have been destroyed or severely degraded.

Assessor: World Conservation Monitoring Centre

Refs: 401, 5653, 19116

\section{Guettarda noumeano}

Rubiaceae

VU B $1+2 c$

New Caledonia

A species confined to a restricted area of sclerophyllous forest in the region of Nouméa. Fires, grazing and encroaching agriculture are continual problems and have caused a severe reduction in the habitat.

Assessor: Jaffré, T. et al.

Refs: 4492,10351

\section{Guettarda ochreata}

Rubiaceae

LR/nt

Peru

This species is relatively widespread but confined to the
Peruvian Andes up to $2500 \mathrm{~m}$.

Assessor: World Conservation Monitoring Centre Refs: 1984

\section{Guettarda retuso}

Rubiaceae

EX

Cuba

An endemic tree discovered in the mid 19th century in Loma Pelada, Los Palacios, Pinar del Rio Province. Thorough searches for the species over the past 25 years have been unable to locate it. Its habitat has been severely degraded by cutting and clearing.

Assessor: Areces-Mallea, A.E.

Refs: 19149

\section{Guibourtia ehie}

Leguminosae

VU Alc

Cameroon, Côte d'lvoire, Gabon, Ghana, Liberia, Nigeria

A West African timber which occurs in moderate densities in different forest types, from closed rainforest to drier semi-deciduous forest. Exploitation rates of the wood are high and causing population declines. The timber acts as a popular substitute for rosewood.

Assessor: African Regional Workshop

Refs: 2773, 6128, 8369, 12061, 12509, 19132

\section{Guibourtia schliebenii}

Leguminosae

VU $B 1+2 b$

Mozambique, Tanzania

A dry coastal forest species ranging from south-east Tanzania into little-known areas of Mozambique.

Assessor: Lovett, J. \& G.P. Clarke

Refs: 3356, 10961

\section{Guibourtia sousae}

Leguminosae

DD

Mozambique

No information is available on the location and habitat of this species.

Assessor: Bandeira, S.

Refs: 5117,7550

\section{Guioa acuminata}

Sapindaceae

EN Alc

Philipoines

A smill tree found in secondary forest on Luzon and Polillo. It is known only from five collections.

Assessor: van Welzen, P.C.

Refs: 18389

\section{Guioa asquamosa}

Sapindaceae

VU Bl $+2 c$

Indonesia (Lesser Sunda Is.)

Restricted to Timor and Flores, this small tree is known only from six collections.

Assessor: van Welzen, P.C.

Refs: 18389

Guioa bicolor

Sapindaceae

VU Al, Bl+2c

Philippines

This species is only known from a total of seven collections from Luzon, Mindanao and Sabtang. It has been recorded in logged-over forest.

Assessor: World Conservation Monitoring Centre Refs: 18389 


\section{Guioa discolor}

Sapindaceae

Philippines

Known only from four herbarium specimens, this small tree is confined to the primary dipterocarp forests of Luzon and Samar.

Assessor: van Welzen, P.C.

Refs: 18389

\section{Guioa grandifoliola}

Sapindaceae

$\mathrm{CR} B 1+2 \mathrm{c}$

Papua New Guinea

An extremely localised species known only from four collections from lowland rainforest and advanced secondary forest near the Buso River. Large areas of lowland forest in Papua New Guinea are threatened by increased logging activity.

Assessor: van Welzen, P.C.

Refs: 18389

\section{Guioa hospita}

Sapindaceae

CR D1

Papua New Guinea

The only record of this species is the type specimen collected in 1890 in Gulf Province. Despite the area being relatively well studied, it has not been recorded since.

Assessor: van Welzen, P.C.

Refs: 18389

\section{Guioa malukuensis}

Sapindaceae

VU D2

Indonesia (Moluccas)

A tree known from two collections, both from Morotai Island.

Assessor: van Welzen, P.C.

Refs: 18389

\section{Guioa melanopoda}

Sapindaceae

VU D2

Indonesia (Irian Jaya)

A very localised tree, collected twice in the 1940 s, found in rainforest on river banks in Jayapura.

Assessor: van Welzen, P.C.

Refs: 18389

\section{Guioa molliuscula}

Sapindaceae

VU D2

Papua New Guinea

To date there are just two collections from the 1950-'60s of this understorey tree of alluvial swamp. The area is not under threat but it is not well visited by botanists.

Assessor: van Welzen, P.C.

Refs: 18389

\section{Guioa multijuga}

Sapindaceae

Indonesia (Irian Jaya)

VU D2

Known only from two collections from the early 1900 s, this small tree is found in the rainforest/savanna transition zone on steep ground and in old secondary forest.

Assessor: van Welzen, P.C.

Refs: 18389
Guioa myriadenia

Sapindaceae

EN Alc

Philippines

Endemic to Luzon, this forest species, known from 19 specimens, has not been collected since the 1940 s.

Assessor: van Welzen, P.C.

Refs: 18389

\section{Guioa normanbiensis}

Sapindaceae

VU D2

Papua New Guinea

Confined to the Milne Bay Province on Normanby Island, this tree is known from only four collections to date.

Assessor: van Welzen, P.C.

Refs: 18389

\section{Guioa novobritannica}

Sapindaceae

VU D2

Papua New Guinea

A tree known only from the type specimen, collected in Casuarina rumphiana-dominated montane forest in west New Britain.

Assessor: van Welzen, P.C.

Refs: 18389

\section{Guioa oligotricha}

Sapindaceae

VU D2

Indonesia (Irian Jaya), Papua New Guinea

A small tree, known only from three collections, found in lowland secondary forest in the Southem Division of Irian Jaya and the Westem Province of Papua New Guinea. These areas are underexplored.

Assessor: van Welzen, P.C

Refs: 18389

Guioa palawanica

Sapindaceae

CR Alc

Philippines

A small tree or shrub endemic to Palawan, where it has been collected only a few times in lowland forest on ultrabasic rock and in stunted montane rainforest.

Assessor: van Welzen, P.C.

Refs: 18389

\section{Guioa parvifoliola}

Sapindaceae

CR Alc

Philippines

This species was found only once on the dry slopes of the Ilocos Norte Province of Luzon.

Assessor: van Welzen, P.C

Refs: 18389

\section{Guioa patentinervis}

Sapindaceae

VU D2

Indonesia (Moluccas)

A small tree confined to the transitional area between coral sand beach and open forest on nickel-rich soils. It is known from a total of seven collections from the islands of Ambon, Buru, Ceram and Obi.

Assessor: van Welzen, P.C.

Refs: 18389 
Guioa pauciflora

Sapindaceae

VU D2

Indonesia (Irian Jaya), Papua New Guinea

A shrubby tree only known from three disjunct collections in an area which is underexplored.

Assessor: van Welzen, P.C.

Refs: 18389

\section{Guioa plurinervis}

Sapindaceae

VU D2

Papua New Guinea

To date this species is known only from three collections from secondary hill rainforest in Milne Bay Province in

Rossel Island. There has been little collecting from this island.

Assessor: van Welzen, P.C.

Refs: 18389

\section{Guioa reticulata}

Sapindaceae

CR Alc

Philippines

A secondary forest tree confined to the dimishing forests of Luzon. It has not been collected since the 1960s-70s.

Assessor: van Welzen, P.C.

Refs: 18389

\section{Guioa scalariformis}

Sapindaceae

VUD2

Papua New Guinea

A shrub or small tree restricted to primary montane forest of Morobe Province. It has been collected only twice.

Assessor: World Conservation Monitoring Centre

Refs: 18389,19189

\section{Guioa truncata}

Sapindaceae

EN Alc

Philippines

A tree of dense moist mossy forest found only on Mindanao Island. Collected only twice, it has not been recorded since the 1960 s.

Assessor: van Welzen, P.C.

Refs: 18389

\section{Guioa unguiculata}

Sapindaceae

VU D2

Papua New Guinea

A small tree known only from four collections.

Assessor: World Conservation Monitoring Centre

Refs: 18389,19189

\section{Guioa venusto}

Sapindaceae

Indonesia (Irian Jaya)

Restricted to secondary scrubby vegetation on Schouten and Japen Islands, this small tree has been collected three times, most recently in 1945.

Assessor: van Welzen, P.C.

Refs: 18389

\section{Guioa waigeoensis}

Sapindaceae

VU D2

Indonesia (Irian Jaya)

Known only from the type specimen, this small tree is endemic to Waigeo Island, which is an undercollected area.

Assessor: van Welzen, P.C.

Refs: 18389

\section{Gulubia hombronii}

Palmae

DD

Solomon Islands (South Solomon)

Endemic to the Solomon Islands, this palm tree is scattered in broadleaved, swamp and cloud forest on ultrabasic soils from 100 to $1500 \mathrm{~m}$.

Assessor: Dowl, J.L.

Refs: 19118

\section{Gulubia microcarpa}

Palmae

VUAlc

Fiji

A scarce species of steep forested slopes, occurring between 180 and $260 \mathrm{~m}$, only on the islands of Viti Levu and Vanua Levu. Some areas have been lost to agriculture and logging.

Assessor: Fuller, D.

Refs: 6053,19118

\section{Gustavia acuminato}

Lecythidaceae

Brazil (Roraima), Venezuela

VU D2

This species appears to be restricted to non-flooded forest between 1250 and $1300 \mathrm{~m}$ in Amazonian Brazil and adjacent parts of Venezuela.

Assessor: Pires O'Brien, J.

Refs: $1503,7980,9632$

\section{Gustavia dodsonii}

Lecythidaceae

VU B $1+2 c$

Ecuador

Known only from north-west Ecuador, this middlestorey tree has been collected about five times from areas of lowland non-flooded forest. It is apparently uncommon. The high tensile strength of the trunk has resulted in the species being popular for local use as a lever to lift heavy objects.

Assessor: World Conservation Monitoring Centre

Refs: 1503, 3791, 7980

\section{Gustavia erythrocarpa}

Lecythidaceae

VU D2

Brazil (Pará)

An understorey tree, locally common but confined to the vicinity of the type locality in non-flooded forest in the Tapajós River region.

Assessor: Pires O'Brien, J.

Refs: $1503,7980,9632$

\section{Gustavia excelsa}

Lecythidaceae

$\mathrm{EN} \mathrm{B1}+2 \mathrm{c}$

Colombia

An endemic to the Magdalena Valley in Santander. Although it is a relatively common understorey tree in lowland non-flooded forest, it remains poorly known and rarely collected.

Assessor: Calderon, $\mathrm{E}$

Refs: $1503,3791,4460,7980,19069$

\section{Gustavia foliosa}

Lecythidaceae

VU B $1+2 c$

Colombia, Ecuador

Occurring on the Pacific coast, the species has been collected twice from areas of lowland non-flooded forest in Valle in Colombia and Esmeraldas in Ecuador. Assessor: World Conservation Monitoring Centre Refs: $1503,3791,7980$ 


\begin{abstract}
Gustavia fosteri
Lecythidaceae

Panama

VU C2a

Occurring in semi-deciduous rainforest on seasonally flooded plains, the species is restricted to Barro Colorado Island $(\mathrm{BCl})$ and the surrounding area. The populations are small but almost every one is contained within a protected area, including one in Soberanía National Park. Only a population on the Gigante Peninsula at the south of $\mathrm{BCl}$ is under serious pressure because of the expanding human population.

Assessor: Mitré, M.
\end{abstract}

Refs: $1503,7980,16772$

\section{Gustavia gracillima}

Lecythidaceae

$\mathrm{EN} \mathrm{B1+2c}$

Colombia

A small slender tree with an unconfirmed distribution in lowland non-flooded rainforest in western Colombia, possibly occurring also in Antioquia, Chocó or Narino. It has been collected about four times. Cultivated specimens are found in Rio de Janeiro Botanic Garden, Singapore Botanical Garden and in Chelsea, UK.

Assessor: Calderon, E.

Refs: $1503,3791,7980,19069$

\section{Gustavia latifolia}

Lecythidaceae

CR B $1+2 \mathrm{c}$

Colombia

Now possibly extinct, the species is known only from the type specimen, which was collected from Cundinamarca.

Assessor: Calderon, E.

Refs: 1503, 3791, 7980, 19069

\section{Gustavia longepetiolata}

Lecythidaceae

EN D1

Brazil (Pará)

A very small tree, known only from the type locality in non-flooded lowland rainforest in the Rio CuminaMirim region.

Assessor: Pires O'Brien, J.

Refs: $1503,3791,7980$

\section{Gustavia longifuniculata}

Lecythidaceae

CR B $1+2 \mathrm{c}$

Colombia

A poorly known species, recorded from approximately seven collections from lowland non-flooded rainforest in Santander.

Assessor: Calderon, E.

Refs: 1503, 3791, 7980, 19069

\section{Gustavia monocaulis}

Lecythidaceae

Colombia, Panama

$\mathrm{EN} \mathrm{Cl}+2 \mathrm{a}$

In Panama, the species is known from forest along the highway running from El Llano to Carti-Tupile in Kunayala Indigenous Reserve. It is easily confused with G. grandibracteata, which may explain why there have been no recent collections in this region. The forest is rapidly disappearing and being colonised by campesinos. The species has also been identified from recent collections in Antioquia in Colombia, and in Darién in Panama.

Assessor: Mitré, M.

Refs: $1503,7980,16772$
Gustavia nana ssp. nana

Lecythidaceae

DD

Colombia, Panama

A subspecies which is known in Panama solely from a collection from Darién made in 1962. Similar collections in the area have been identified as ssp. rhodantha. In Colombia there is a collection of the subspecies from the Choco but no further information is available.

Assessor: Mitré, M.

Refs: 7980,16772

\section{Gustavia nana ssp. rhodantha}

Lecythidaceae

VU C2a

Colombia, Panama

This subspecies is recorded from low to medium elevation rainforest, often along streamsides, occurring largely in Colombia and extending into Darien and the Kunayala Indigenous Reserve in Panama. The greater part of the range is in protected areas and the taxon is reported to relatively common and regenerating well in places.

Assessor: Mitré, M.

Refs: 7980,16772

\section{Gustavia petiolata}

Lecythidaceae

$\mathrm{EN} \mathrm{Bl}+2 \mathrm{c}$

Colombia

In Colombia, the species is recorded from the type locality in lowland non-flooded rainforest in the Chocó.

Assessor: Calderon, E

Refs: 1503, 3791, 7980, 19069

\section{Gustavia pubescens}

Lecythidaceae

VU B $1+2 c$

Colombia, Ecuador

A rarely collected species of lowland non-flooded rainforest, confined to Pacific coastal Colombia and Ecuador.

Assessor: World Conservation Monitoring Centre Refs: $1503,3791,7980$

\section{Gustavia santanderiensis}

Lecythidaceae

VU B $1+2 \mathrm{c}, \mathrm{D} 2$

Brazil (Amazonas), Colombia

Occurring in areas of non-flooded forest, the species is distributed disjunctly with occurrences in the Magdalena Valley in Córdoba, Cundinamarca, Santander and Vaupés Departments in Colombia and in north-west Amazonia in Brazil.

Assessor: Calderon, E.

Refs: $1503,5942,7980,19069$

\section{Gustavia serrata}

Lecythidaceae

VU D2

Ecuador

Known only from the type locality, the species occurs in lowland non-flooded rainforest on the road from Chone to Pichincha in Manabi. The area is contained within Pedro Franco Davila Biological Station.

Assessor: World Conservation Monitoring Centre Refs: $1503,3791,7980$

\section{Gustavia sessilis}

Lecythidaceae

VU Bl+2c

Colombia

Presently known only from the type collection, the species is confined to dense forest in Chocó.

Assessor: World Conservation Monitoring Centre

Refs: 1503, 3791, 7980 
Gustavia speciosa ssp. occidentalis

Lecythidaceae

VU B $1+2 c$

Colombia

A large tree, confined to the type locality on the Pacific slopes of Valle.

Assessor: World Conservation Monitoring Centre

Refs: $1503,3791,7980,8869$

\section{Gustavia verticillata}

Lecythidaceae

VU B $1+2 c$

Colombia, Panama

The species has been collected relatively rarely from localities of lowland non-flooded rainforest in Cundinamarca and Tolima in Colombia and parts of neighbouring Panama in Darién Province.

Assessor: Calderon, E.

Refs: $1503,3791,7980,19069$

\section{Gyminda orbicularis}

Celastraceae

VU B $1+2 c$

Cuba

A shrub which sometimes attains the size of a small tree up to $5 \mathrm{~m}$ tall. It is very restricted in the dry shrubwoods and shrublands on limestone terraces near the coast between Cajobabo and Jauco in Guantánamo Province. Assessor: Areces-Mallea, A.E.

Refs: $11403,18485,19149$

\section{Gymnacranthera canarica}

Myristicaceae

VU B1 $+2 c, D 2$

India (Karnataka, Kerala)

A large tree found in the lowland moist dense forests of Kerala, just extending into South Kanara in Karnataka. Collected from widely scattered locations in the 19th century, the species had not been collected for almost a century and was suspected of being extinct until recently. Remaining populations appear to be extremely rare and restricted. Further detailed information may indicate that a more serious threat category is appropriate. The seeds have been mistaken for nutmeg. Assessor: World Conservation Monitoring Centre

Refs: 8295, 12114, 19144

\section{Gymnacranthera maliliensis}

Myristicaceae

LR/nt

Indonesia (Sulawesi)

This tree is restricted to primary and degraded forest on ultrabasic soils in central Sulawesi, east of Malili. Sulawesi has the largest tract of forest on ultrabasic rock in the tropics. It is, at least relatively, secure from conversion to agriculture because of the ultramafic nature of the soil.

Assessor: World Conservation Monitoring Centre

Refs: 4329,8295

\section{Gymnosporia bachmannü}

Celastraceae

VU A2c

South Africa (Eastem Cape, KwaZulu-Natal)

A shrub or rarely a small straggling tree, endemic to Pondoland in southern KwaZulu-Natal and the eastern Transkei area of the Eastern Cape. It occurs on sandstone outcrops on the rocky banks and beds of rivers and streams. It is present in most of the protected areas in the region and also many of the demarcated forest areas in the Transkei, which are ineffectively protected and under threat of losing their habitat through cutting for firewood and timber and increasing settlement. Agricultural activities upstream have also caused habitat loss through the siltation of rivers.

Assessor: Hilton-Taylor, C. et al.

Refs: 19218,19220

\section{Gymnostemon zaizou}

Simaroubaceae

VU BI+2c

Côte d'Ivoire

A Côte d'Ivoire endemic, confined to remaining patches of forest between Cavally and Sassandra Rivers. The largest and most stable forest is contained within Tai National Park. Logging and the influx of people have caused the rapid decline and degradation of forests elsewhere.

Assessor: Assi, A.

Refs: 2773,12822

\section{Gynoxys azuayensis}

Compositae

VU $B 1+2 c$

Ecuador

A tree species endemic to montane forest of the Ecuadorean High Andes.

Assessor: World Conservation Monitoring Centre

Refs: 19119,19120

\section{Gynoxys chimborazensis}

Compositae

VU Bl+2c

Ecuador

A species which is endemic to the High Andes of Ecuador.

Assessor: World Conservation Monitoring Centre

Refs: 19119,19120

\section{Gynoxys colanensis}

Compositae

VU D2

Peru

Known only from the type collection, the species is found in *terra firme forest above $2000 \mathrm{~m}$ in the department of Amazonas.

Assessor: World Conservation Monitoring Centre Refs: 1984

\section{Gynoxys cuicochensis}

Compositae

VU B $1+2 c$

Ecuador

A tree or shrub species which is endemic to the High Andes of Ecuador.

Assessor: World Conservation Monitoring Centre

Refs: 19119,19120

\section{Gynoxys dielsiana}

Compositae

VU B $1+2 c$

Ecuador

A tree or shrub species which is endemic to the High Andes of Ecuador.

Assessor: World Conservation Monitoring Centre

Refs: 19119,19120

\section{Gynoxys laurifolia}

Compositae

VU $B 1+2 c$

Ecuador

A tree species which is endemic to the High Andes of Ecuador.

Assessor: World Conservation Monitoring Centre

Refs: 19119,19120 


\section{Gynoxys rimbachüi \\ Compositae \\ Ecuador}

A tree or shrub species restricted to the montane or upper montane forest zones of the Ecuadorean High Andes.

Assessor: World Conservation Monitoring Centre Refs: 19119,19120

\section{Gyranthera darienensis \\ Bombacaceae}

EN C2a

Panama

Originally known only from Kunayala Indigenous Reserve and Darién near the border with Colombia, the species has now been collected from Veraguas, in central Panama. Future collecting may reveal the species in between these areas. Populations are few and small and the habitat is frequently cleared for settlements, agriculture and ranching. There is a protected population within the Darién National Park. Only two species exist in the genus.

Assessor: Mitré, M

Refs: $3156,7272,7980,16772$

\section{Gyrotaenia microcarpa}

Urticaceae

LR/nt

Jamaica

An occasional species of the eastern parishes, where it occurs in moist woodlands on limestone.

Assessor: World Conservation Monitoring Centre Refs: 6057,7980

\section{Gyrotaenia spicata}

Urticaceae

LR/nt

Jamaica

Abundant where it occurs, the species is distributed in central and western parishes in areas of woodlands on limestone.

Assessor: World Conservation Monitoring Centre Refs: 6057,7980

\section{Halesia macgregorii}

Styracaceae

VU Alcd

China (Fujian, Guangdong, Guangxi, Hunan, Jiangxi, Zhejiang)

A tree with a scattered occurrence in south-east China. It is found in remaining areas of mid-elevation broadleaved forest on slopes and valleys. Throughout its range the species has been exposed to severe rates of habitat clearance and logging.

Assessor: World Conservation Monitoring Centre

Refs: 1818,11847

\section{Halfordia papuana}

Rutaceae

CR C2a

Papua New Guinea

This tree is scattered in submontane and montane rainforest between 1200 and $2700 \mathrm{~m}$, mostly confined to the Bulolo/Wau region in Morobe Province. The region has been heavily exploited, logged and converted into Araucaria plantations. It is not certain how many mature specimens remain but it is certainly less than 250 .

Assessor: Eddowes, P.J.

Refs: 19114

\section{Hallea ledermannii}

Rubiaceae

VU Alc

Angola, Benin, Cameroon, Congo, Côte d'Ivoire, Democratic Republic of Congo, Equatorial Guinea, Gabon, Ghana, Liberia, Nigeria

A gregarious forest species restricted to swampy areas, rivers and also coastal regions. Regeneration is good in wet areas. It is able to reproduce vegetatively. Overexploitation of the general-purpose timber and habitat degradation in large parts of its range are causing population declines.

Assessor: African Regional Workshop

Refs: 2036, 6127, 7791, 8369, 12061, 15251, 17408

\section{Hallea stipulosa}

Rubiaceae

VU Alcd

Angola, Cameroon, Central African Republic, Congo, Gabon, Ghana, Guinea, Nigeria, Senegal, Sierra Leone, Sudan, Uganda, Zambia

A widespread and important source of timber which occurs most commonly in swampy areas. In many places it suffers from overexploitation.

Assessor: World Conservation Monitoring Centre Refs: 2773, 6127, 8369, 12061, 15251, 16021, 17408

\section{Halocarpus kirkii}

Podocarpaceae

New Zealand (North Is.)

VU Ala+2b

Only a few populations are known, occurring in areas of forest up to $700 \mathrm{~m}$ between the North Cape and the Coromandel Peninsula. Few seedlings and juvenile plants are apparent and the species appears to be dependent on disturbance (e.g. volcanic disturbance) for regeneration. Most populations are within protected areas.

Assessor: SSC Conifer Specialist Group

Refs: $374,8032,13041,19126$

\section{Hamelia papillosa}

Rubiaceae

VU B $1+2 c$

Jamaica

A Cockpit Country endemic occurring in the westcentral parishes on exposed craggy limestone cliffs and woodland margins.

Assessor: World Conservation Monitoring Centre

Refs: 5653,7980

\section{Hampea breedlovei}

Malvaceae

$\mathrm{VU} B 1+2 \mathrm{c}$

Mexico

Assessor: Ramirez-Marcial, N. \& M. González-Espinosa Refs: 4105,6308

\section{Hampea dukei}

Malvaceae

DD

Panama

Known only from Kunayala Indigenous Reserve, the species has not been collected since the type collection was made in 1966. However, H. punctulala, a very similar species, has been collected in the surrounding area and other parts of Panama.

Assessor: Mitré, M.

Refs: $7980,15037,16772$

\section{Hampea micrantha}

Malvaceae

VU B $1+2 d$

Panama

Recorded from the provinces of Colon and Panama, the species occurs in rainforest to $1000 \mathrm{~m}$, mainly in the 
central region of Panama and slightly to the east. The major part of the range is contained within protected areas, outside which the species occurs very rarely and is under severe threat from habitat clearance.

Assessor: Mitré, M.

Refs: 7980, 13315, 16772

\section{Hampea montebellensis}

Malvaceae

$\mathrm{EN} \mathrm{B1}+2 \mathrm{c}$

Mexico

Assessor: Ramirez-Marçal, N. \& M. González-Espinosa Refs: 6308, 12985

\section{Hampea reynae}

Malvaceae

VU D2

El Salvador

A rarely collected species, endemic to El Salvador and confined to cloud forest in Monte Cristo, Metapán, Santa Ana.

Assessor: World Conservation Monitoring Centre

Refs: 4105, 6150, 19030

\section{Hampea sphaerocarpa}

Malvaceae

EN C2a

Guatemala, Honduras

A tree confined to the wet Atlantic lowlands, where it has experienced gradual habitat loss to encroaching agriculture.

Assessor: Nelson, C.

Refs: 13995

\section{Hampea thespesioides}

Malvaceae

$\mathrm{CR} B 1+2 \mathrm{c}$

Colombia

Possibly now extinet, the species was known from a locality in Tolima.

Assessor: Calderon, E.

Refs: 19069

\section{Hannoa ferruginea}

Simaroubaceae

VUAlc

Cameroon, Nigeria

A poorly known species, occurring only on Mount Koloishe, Cross River State, in Nigeria and in Cameroon. Updates on the taxonomy and species distribution will help to consolidate its status.

Assessor: World Conservation Monitoring Centre

Refs: 11504

\section{Hannoa kitombetombe}

Simaroubaceae

Democratic Republic of Congo

A tree from upland gallery forest at the source of the Muye River. It is known only from a single locality. The area is vulnerable to overcutting, fire and agricultural encroachment.

Assessor: Ndjele, M.B.

Refs: 17185,17951

\section{Haplocoelopsis africana}

Sapindaceae

Angola? (Angola?), Kenya, Tanzania

In Kenya the species is rare and confined to groundwater forest in Witu, Mangea, Shimba Hills and Marenji. It has been suggested that the range of the species is more widespread, extending to Angola.

Assessor: Lovett, J. \& G.P. Clarke

Refs: 3356, 5654, 6396, 12067

\section{Haplocoelum trigonocarpum}

Sapindaceae

LR/nt

Kenya, Mozambique, Somalia, Tanzania

A rare species with disparate populations confined to pockets of forest, especially coastal forest. In Kenya it is confined to the Taita Hills. In neighbouring Tanzania the species is thought to be less rare than originally suspected. The population in Mozambique is very poorly known.

Assessor: World Conservation Monitoring Centre

Refs: $3356,6396,12067,18665$

\section{Haplolobus beccarii}

Burseraceae

VU D2

Malaysia (Sarawak)

Endemic to Sarawak, this tree is known only from the type specimen collected in lowland forest on Mount Matang.

Assessor: World Conservation Monitoring Centre

Refs: 18327

\section{Haplolobus bintuluensis}

Burseraceae

VU D2

Malaysia (Sarawak)

Endemic to Sarawak, this small tree has only been collected once in a site of mixed dipterocarp forest in the Nyabau catchment area, Bintulu.

Assessor: World Conservation Monitoring Centre Refs: 19017

\section{Haplolobus inaequifolius}

Burseraceae

VU D2

Malaysia (Sarawak)

Known only from the type collection, this tree was found in Sabal Forest Reserve in hill forest at an altitude of $360 \mathrm{~m}$.

Assessor: World Conservation Monitoring Centre Refs: 19017

\section{Haplolobus kapitensis}

Burseraceae

VU D2

Malaysia (Sabah, Sarawak)

A rare emergent tree of lowland hill forest, so far known from only four collections, two from Kapit in Sarawak and two from Ranau in Sabah.

Assessor: World Conservation Monitoring Centre Refs: 19017

\section{Haplolobus leenhoutsii}

Burseraceae

VU D2

Malaysia (Sarawak)

Known only by the type specimen, the species occurs in mixed dipterocarp forest at $500 \mathrm{~m}$ in Ulu Balleh, Kapit. Assessor: World Conservation Monitoring Centre Refs: 19017

\section{Haplolobus sarawakanus}

Burseraceae

VU D2

Malaysia (Sabah, Sarawak)

A small tree of mixed dipterocarp forest, known only from the type collected from Ulu Balleh of Kapit. Another collection from Sabah might also be identified as this species.

Assessor: World Conservation Monitoring Centre Refs: 19017 
Haplorhus peruviana

Anacardiaceae

Chile (Tarapacá), Peru

Occurring as isolated individuals or in small groups, the species is found in dry hot ravines in lowland areas, ranging from south-east Peru to the Ariza Province of Chile.

Assessor: González, M

Refs: $4893,7980,12268,16328$

\section{Haplormosia monophylla}

\section{Leguminosae}

VU Ald $+2 d$

Cameroon, Côte d'Ivoire, Liberia, Nigeria, Sierra Leone A lowland swamp forest species exploited for its timber. There is little information on the status of populations or their regeneration but it is expected that overexploitation and habitat degradation are resulting in population declines.

Assessor: African Regional Workshop

Refs: $2773,6128,12590$

\section{Harpalyce maisiana}

Leguminosae

VU D2

Cuba

A small tree reaching $5 \mathrm{~m}$ in height, confined to a small area of arid evergreen shrubwoods and scrub on the Maisí coastal plain, at the easternmost end of Cuba.

Assessor: Areces-Mallea, A.E.

Refs: 11403, 18485, 19149

\section{Hebe barkeri}

Scrophulariaceae

New Zealand (Chatham Is.)

Once a significant component of forests in the Chatham Islands, this small tree is now reduced to four populations and scattered isolated individuals. The species is severely browsed by livestock and more recently by possums.

Assessor: de Lange, P.J.

Refs: $902,5563,17637,19133,19134$

\section{Heberdenia excelsa}

Myrsinaceae

$\mathrm{VUCl}$

Portugal (Madeira), Spain (Canary Is.)

An uncommon species of *laurisilva and, at higher altitudes, cloud forest. Past exploitation of its habitat has resulted in the reduction and fragmentation of populations. *Laurisilva in Madeira is now said to be increasing in extent, although areas close to habitations are still under the threat of fire. The species occurs in protected areas and regional legislation.

Assessor: Bañares, A. et al.

Refs: 19022, 19131

\section{Hederopsis maingayi}

Araliaceae

VU B1+2a

Malaysia (Peninsular Malaysia)

A tree of lowland and hills up to $610 \mathrm{~m}$ in the states of Pahang, Kelantan, Kedah, Perak and Selangor.

Assessor: Chua, L.S.L.

Refs: 8464,19073

\section{Hederopsis major}

Araliaceae

VU D2

Malaysia (Peninsular Malaysia)

This rare species, known only from a single collection, is confined to rainforest in Kelantan.

Assessor: World Conservation Monitoring Centre

Refs: 8464, 19073
Hedyosmum burgerianum

Chloranthaceae

$\mathrm{EN} B 1+2 \mathrm{~cd}$

Panama

Current information suggests the species is confined to Cerro Colorado and Cerro Horqueta in the province of

Chiriquí. The populations are large in places but confined to a narrow altitudinal range, between 1500 and $1900 \mathrm{~m}$. The area is unprotected and parts of Cerro Colorado, in particular, are affected by mining for copper and gold, and the impact of an expanding human population.

Assessor: Mitre, $\mathrm{M}$.

Refs: $6724,7980,8999,16772$

\section{Hedyosmum correanum}

Chloranthaceae

$\mathrm{EN} \mathrm{B} 1+2 \mathrm{bcd}$

Panama

A shrubby species which occurs in small populations up to $3000 \mathrm{~m}$ in cloud forest only in the mountains in the west. Each collecting trip appears to uncover a new population in a more remote area. There is also a report of a population in La Amistad National Park on the border with Costa Rica. The habitat is generally declining in extent, over much of the range, mainly because of logging and mining for copper and gold. Assessor: Mitré, M.

Refs: $6724,7980,8999,16772$

\section{Hedyosmum mexicanum}

Chloranthaceae

VUAlc

Guatemala, Mexico (Chiapas)

A scarce species of cloud forest or mesophyllous montane forest.

Assessor: World Conservation Monitoring Centre

Refs: 19161

\section{Hedyosmum purpurascens}

Chloranthaceae

VU Bl+2c

Ecuador

An Ecuadorean endemic, currently known only from the High Andes in Loja Province. The altitudinal range of the species extends between 2300 and $2900 \mathrm{~m}$.

Assessor: World Conservation Monitoring Centre

Refs: $6724,7980,8999,19119$

\section{Hedyscepe canterburyana}

Palmae

VU D2

Australia (New South Wales - Lord Howe Is.)

Endemic to Lord Howe Island, this palm tree dominates palm forest on the slopes of Mount Glower and Mount Lidgbird. Lord Howe Island is a World Heritage Site, most of which is a permanent park reserve.

Assessor: Johnson, D.

Refs: 19118

\section{Heinsenia diervilleiodes ssp. mufindiensis}

Rubiaceae

VU $B l+2 b$

Tanzania

A moist montane forest tree, occurring at elevations exceeding $1500 \mathrm{~m}$ in three localities: Nyumbanitu, Lulanda and west Mufindi.

Assessor: Lovett, J. \& G.P. Clarke

Refs: 3356,8814 


\section{Helicia acutifolia}

Proteaceae

VU D2

Papua New Guinea

A small tree of secondary forest at $2040 \mathrm{~m}$, confined to

Mount Victoria in the central district.

Assessor: World Conservation Monitoring Centre

Refs: 7673, 19031

\section{Helicia albiflora}

\section{Proteaceae}

LR/nt

Papua New Guinea

A tree often found in Castanopsis-Nothofagus rainforest from 900 to $2000 \mathrm{~m}$. Known from the East and Western Highlands, Morobe, Northern and Central Provinces of Papua New Guinea. Its conservation is dependent upon the conservation of its montane habitat. The attractive wood has a decorative grain.

Assessor: Eddowes, P.J.

Refs: $7673,19031,19114$

\section{Helicia amplifolia}

Proteaceae

$\mathrm{LR} / \mathrm{nt}$

Papua New Guinea

A tree occurring in primary or secondary rainforest or submontane forest from 600 to $1300 \mathrm{~m}$. It is known from the Eastem, Western and Southem Highlands, Madang and Morobe Provinces. The wood is very attractive.

Assessor: Eddowes, P.J.

Refs: 7673, 19031, 19114

\section{Helicia australasica}

Proteaceae

VU $\mathrm{C} 2 \mathrm{~b}$

Australia (Northern Territory), Papua New Guinea

A tree usually found in patches of rainforest along rivers and streams. In Papua New Guinea, it is known only from the Westem Province. Its restricted occurrence renders it vulnerable. The status of this species in Northem Australia has not been considered in this threat category.

Assessor: Eddowes, P.J.

Refs: 19031, 19114

\section{Helicia calocoma}

Proteaceae

VUBI+2c

Papua New Guinea

Confined to the Morobe District, this tree is restricted to a small area of Nothofagus- dominated forest on ridges up to $1800 \mathrm{~m}$. The wood is considered attractive and has a decorative grain.

Assessor: Eddowes, P.J.

Refs: 19031,19114

\section{Helicia grandifolia}

Proteaceae

VU D2

Viet Nam

Apparently endemic to Viet Nam, this small to mediumsized tree is known only from $\mathrm{Ba} \mathrm{Vi}$, a number of localities in Hoa Binh and Cuc Phuong in Ninh Binh.

Assessor: World Conservation Monitoring Centre

Refs: 848,15357

\section{Helicia insularis}

Proteaceae

EN B1+2abcde

Papua New Guinea

A small tree found in mossy forest on ridge crests at 800 to $950 \mathrm{~m}$ on Normanby and Fergusson Islands of the D'Entrecasteaux Group.

Assessor: Eddowes, P.J.

Refs: 19031,19114

\section{Helicia latifolia}

Proteaceae

LR/nt

Papua New Guinea (Bismarck Archipelago, Papua New Guinea)

A tree scattered on slopes and ridges in primary and secondary rainforest up to $800 \mathrm{~m}$ in the Gulf, Central, Milne Bay and Northern Provinces of Papua New Guinea and New Britain of the Bismarck Archipelago. This species has attractive wood.

Assessor: Eddowes, P.J.

Refs: 19031,19114

\section{Helicia neglecta}

Proteaceae

VU Alcd, C2a

Papua New Guinea (Bismarck Archipelago)

A tree of primary and secondary forest up to $400 \mathrm{~m}$, which occurs only on New Britain and New Ireland in the Bismarck Archipelago. It is potentially threatened by ongoing and future logging activities and encroaching agriculture.

Assessor: Eddowes, P.J.

Refs: 19031, 19114

\section{Helicia peekelii}

Proteaceae

VU D2

Papua New Guinea (Bismarck Archipelago)

This lowland tree is known only from Namatanai, New Ireland, where it is thought to occur in coastal forest. Assessor: World Conservation Monitoring Centre Refs: 19031

\section{Helicia peltata}

Proteaceae

Papua New Guinea

CR Bl+2abcde

Known only from a single location. Bisiatabu in the Central Province, this tree occurs in forest at $450 \mathrm{~m}$. The habitat is threatened by logging and the increasing settlement.

Assessor: Eddowes, P.J.

Refs: $7673,19031,19114$

\section{Helicia polyosmoides}

Proteaceae

Papua New Guinea (Bismarck Archipelago)

This small tree, restricted to Manus Island in the Bismarck Archipelago, occurs in ridge forest between the elevations of 100 and $550 \mathrm{~m}$. This species may face extinction through the commercial logging of its habitat. Assessor: Eddowes, P.J.

Refs: 19031, 19114

\section{Helicia retusa}

Proteaceae

VU D2

Papua New Guinea

Occurring in ridge forest between 1600 and $1900 \mathrm{~m}$, this small tree found is known only from Milne Bay District. Assessor: World Conservation Monitoring Centre Refs: 19031

\section{Helicia rostrata}

Proteaceae

VU D2

Papua New Guinea

A small tree, so far known only from lower montane forest on Mount Dayman, occurring between 2000 and $2200 \mathrm{~m}$.

Assessor: World Conservation Monitoring Centre

Refs: 19031 
Helicia shweliensis

Proteaceae

$\mathrm{EN} \mathrm{B1}+2 \mathrm{c}$

China (Yunnan)

Confined to south-west and west Yunnan, the species occurs in areas of monsoon forest between 1800 and $2150 \mathrm{~m}$. The extensive loss of habitat caused by logging and conversion to agriculture has incurred losses in population numbers and brought the species into serious risk of extinction.

Assessor: Sun, W.

Refs: 1818,11847

\section{Helicia subcordata}

Proteaceae

CR B 1+2abcde

Papua New Guinea

A tall tree found only once in mid-montane open forest at $1350 \mathrm{~m}$ near Wagau in the Morobe Province.

Assessor: Eddowes, P.J.

Refs: 19031, 19114

\section{Heliciopsis cockburnii}

Proteaceae

VU B1+2c

Malaysia (Peninsular Malaysia)

A rare tree scattered in lowland and hill forest. So far it is known only from Keledang Saiong Forest Reserve in Perak, and Gunung Tapis in Pahang.

Assessor: Chung, R.C.K.

Refs: 19073

\section{Heliciopsis lanceolata}

Proteaceae

Indonesia (Kalimantan), Malaysia (Sarawak)

$\mathrm{EN} \mathrm{B} 1+2 \mathrm{c}$

A species distributed in remnant hill forests in the vicinity of Bogor. It is unknown how much of the original population remains but the extent of habitat clearance and cutting has been extremely high.

Assessor: World Conservation Monitoring Centre

Refs: 1766,15417

\section{Heliciopsis montana}

Proteaceae

$\mathrm{LR} / \mathrm{cd}$

Malaysia (Peninsular Malaysia)

A montane forest tree confined to Gunung Korbu, the Cameron Highlands and Fraser's Hill. This region is threatened by the expansion of human habitation and tourism.

Assessor: Chung, R.C.K.

Refs: 19073

\section{Heliciopsis rufidula}

Proteaceae

VU B $1+2 c$

Malaysia (Peninsular Malaysia, Sarawak)

A species of seasonal lowland and montane forest known only from Perak, Selangor, Trennganu and Pahang in Peninsular Malaysia. A single collection has been made from mixed dipterocarp forest near Belaga, Sarawak.

Assessor: Chung, R.C.K.

Refs: 19073

\section{Heliciopsis whitmorei}

Proteaceae

$\mathrm{LR} / \mathrm{cd}$

Malaysia (Peninsular Malaysia)

Rarely found, this forest species is known only from Gunung Mandi Angin, Ulu Sungai Terengganu and Ulu Bendong Kemaman in Terengganu.

Assessor: Chung, R.C.K.

Refs: 19073
Helicostylis heterotricha

Moraceae

EN B $1+2 b c$

Brazil (Amazonas)

A tree of non-flooded forest in the upper Amazon.

Assessor: Pereira, J.P. et al.

Refs: 7980,15717

\section{Helietta glaucescens}

Rutaceae

$\mathrm{EN} \mathrm{B1}+2 \mathrm{c}$

Cuba

A small tree restricted to the karstic block mountains and limestone cliffs in the northem Sierra Maestra mountain range, province of Santiago de Cuba.

Assessor: Areces-Mallea, A.E.

Refs: $11403,18485,19149$

\section{Hemandradenia chevalieri}

Connaraceae

$\mathrm{EN} \mathrm{B} 1+2 \mathrm{c}$

Côte d'Ivoire, Ghana

Occurring in wet evergreen forest, this species is known from few localities in coastal Côte d'Ivoire and Ghana. In these areas, the forest has severely declined in extent through logging, commercial forestry and mining activities.

Assessor: Assi, A

Refs: 2773, 12061, 12822, 14719

\section{Hemandradenia mannii}

Connaraceae

Cameroon, Central African Republic, Congo, Côte d'Ivoire, Democratic Republic of Congo, Equatorial Guinea, Gabon, Ghana, Nigeria

A small tree which is very rare in places but ranges widely from Côte d'Ivoire to DR Congo in moist evergreen or semi-deciduous forest.

Assessor: World Conservation Monitoring Centre

Refs: $8369,12822,14719$

\section{Henriettea granularis}

Melastomataceae

CR B $1+2 \mathrm{c}$

Cuba

An imperfectly known species found in semi-deciduous forests on acid substrate, mainly along rivers and creeks. Degradation of the habitat has resulted in soil erosion and the invasion of exotic species.

Assessor: Areces-Mallea, A.E.

Refs: $9522,11403,19149$

\section{Henriettea membranifolia}

Melastomataceae

CR A2c, D1

Puerto Rico

A small tree of wet montane forest, with questionable records dating back to the 1960 s from two sites in the Cordillera Central. The populations have not been recently located.

Assessor: World Conservation Monitoring Centre Refs: $3786,7980,17124$

\section{Henriettea punctato}

Melastomataceae

VU D2

Cuba

A shrub, less often a small tree, locally confined to the karstic limestone range of Monteverde in the NipeYateras area of eastem Cuba.

Assessor: Areces-Mallea, A.E.

Refs: $11403,18485,19149$ 


\section{Henriettea squamata}

Melastomataceae

VU D2

Cuba

An uncommon tree, up to $10 \mathrm{~m}$ tall, restricted to the Moa mountain group in eastern Cuba where it grows in montane rainforest on serpentine-derived soils between 400 and $900 \mathrm{~m}$

Assessor: Areces-Mallea, A.E.

Refs: 11403, 18485, 19149

\section{Henriettella goudotiana}

Melastomataceae

$\mathrm{EN} \mathrm{B} 1+2 \mathrm{c}$

Colombia

Endemic to Colombia, the species is recorded from

Cundinamarca, Huila, Meta and Tolima.

Assessor: Calderon, $\mathrm{E}$.

Refs: 19069

\section{Henriettella ininensis}

Melastomataceae

VU D2

French Guiana

Described in 1988, this small tree is known only from the type specimen collected in Montagne Bellevue de l'Inini.

Assessor: World Conservation Monitoring Centre

Refs: 9867

\section{Heptacodium miconioides}

Caprifoliaceae

VU Alcd

China (Anhui, Hubei, Zhejiang)

A prized omamental occurring in two main areas. It has not been found recently in the westernmost site in Xingshan, Hubei. In the east it is found in small numbers in woodlands or on the edge of evergreen broadleaved forest. Population declines through indiscriminate cutting have been recorded. It is the only member of the genus.

Assessor: World Conservation Monitoring Centre

Refs: 1818,11847

\section{Heritiera longipetiolata}

Sterculiaceae

VU D2

Federated States of Micronesia?, Guam, Northern Marianas

A medium-sized tree of moist forest on limestone cliffs and coastal windblown sites. The species is known from occurrences on Guam, Tinian, Saipan and Rota in the Mariana Islands, and also possibly on Pohnpei in the Caroline Islands. There are about 1000 trees on Guam, several hundred on Tinian and fewer than 100 on Saipan. The Rota population has not been found recently. There is strong evidence to suggest that the species is not regenerating. Seedlings and seeds are predated by ungulates and crabs. The species is listed as endangered by the Guam government and two populations are effectively protected within military bases.

Assessor: Wiles, G.

Refs: $2474,2627,15533,16676,19175$

\section{Heritiera parvifolia}

Sterculiaceae

VU $B 1+2 c$

China (Guangdong - Hainan)

A species restricted to small areas of remaining forest below $500 \mathrm{~m}$ in the south of Hainan Island. It is a common component of this habitat type and sometimes occurs in pure stands. Regeneration is good. However, the rates of decline of the habitat have been considerable and the species has disappeared from parts of its range. Assessor: World Conservation Monitoring Centre

Refs: 1818,11847

\section{Heritiera percoriacea}

Sterculiaceae

$\mathrm{EN} \mathrm{B1}+2 \mathrm{c}$

Indonesia (Java)

This species is known only from Ujung Kulon and Sukawayana, a remnant of forest near Pelabuhan Ratu. The former population occurs in a national park but continues to be threatened by illegal logging, fuelwood collection and agricultural encroachment. The latter is unprotected and under intense pressure.

Assessor: World Conservation Monitoring Centre Refs: 9078

\section{Heritiera utilis}

Sterculiaceae

VU Alcd

Côte d'Ivoire, Gabon, Ghana, Liberia, Sierra Leone

A timber species which occurs commonly, especially in evergreen forests. Exploitation rates are high and likely to be unsustainable.

Assessor: Hawthome, W.

Refs: $2773,6127,12061$

\section{Hernandia beninensis}

Hernandiaceae

LR/nt

Sāo Tomé \& Príncipe

Relatively well collected, most recently in Diogo Vaz in 1972, the species occurs on cultivated or abandoned plantations. The original forest habitat was extensively felled and cleared for agriculture in the first half of the century.

Assessor: World Conservation Monitoring Centre

Refs: 2724, 10080

\section{Hernandia catalpifolia}

Hernandiaceae

VU B $1+2 c$

Jamaica

A tree which is locally common in the parishes of Portland and St Thomas by streams and in damp ravines in submontane woodland. Deforestation has almost completely removed the habitat in the latter parish, areas in ravines probably representing the only remaining fragments.

Assessor: World Conservation Monitoring Centre Refs: 6057,7980

\section{Hernandia cubensis}

Hernandiaceae

$\mathrm{CR} B 1+2 \mathrm{c}$

Cuba

Known only from forests near the conical karst complex of Monteverde in Guantanamo Province, this rare tree has not been collected recently. Disturbance has been heavy where logging and agricultural encroachment have occurred.

Assessor: Areces-Mallea, A.E.

Refs: $11403,18485,19149$

\section{Hernandia didymantho}

Hernandiaceae LR/nt

Colombia, Costa Rica, Honduras, Nicaragua, Panama

This species occurs in lowland evergreen rainforest in Punta Mona, La Selva, Golfo Duce in Costa Rica, near Almirante, Bocas del Toro in Panama and in an increasing number of of other countries.

Assessor: World Conservation Monitoring Centre

Refs: $730,1881,3156,3977,7272,14487$ 


\section{Hernandia drakeana}

Hernandiaceae

French Polynesia (Society Is.)

An exinct species, originally known from Moorea.

Assessor: Florence, J.

Refs: 14513

\section{Hernandia hammelii \\ Hernandiaceae}

\section{Panama}

Known only from the type locality, the species is found in an area of Cocle which is not well explored botanically but is rapidly being colonised by an increasing number of settlers. It has been suggested that the species is actually a variety of $H$. didymantha, which is more widespread in Central and South America.

Assessor: Mitré, M.

Refs: $7980,15037,16772$

\section{Hermandia jamaicensis}

Hernandiaceae

LR/nt

Jamaica

Known from western and north-western parishes, the tree is confined to areas of woodland on limestone.

Assessor: World Conservation Monitoring Centre

Refs: 6057,7980

\section{Hernandia mascarenensis}

Hernandiaceae

EN Alc

Mauritius, Réunion

The population on Mauritius is extinct and remaining populations on Réunion have experienced severe declines.

Assessor: Strahm, W.

Refs: $9120,12470,16426,19208$

\section{Hernandia moerenhoutiana ssp. elliptica}

Hemandiaceae

$\mathrm{EN} \mathrm{Bl}+2 \mathrm{c}$

French Polynesia (Tubuai Is.)

Endemic to the Tubuai Group, the subspecies is recorded only from the islands of Raivave and Tubuai. The latter population is poorly known.

Assessor: Florence, J.

Refs: 14513

\section{Hernandia stenura}

Hemandiaceae

$\mathrm{LR} / \mathrm{nt}$

Costa Rica, Nicaragua, Panama

Closely related to $H$. didymantha, the species occurs in lowland wet evergreen forest from Guatemala to Coclé in Panama.

Assessor: World Conservation Monitoring Centre

Refs: $730,3156,7272,14487$

\section{Hernandia stokesii}

Hernandiaceae

VU D2

French Polynesia (Tubuai Is.), Pitcaim Islands

In the Pitcaim Group the species occurs only on Henderson Island. It is commonly found rooted in deep crevices within a restricted range in the north-west of the island. There are estimated to be 500 individuals here. It has been postulated that the Polynesian pigeon, now extinct on the island, alone was responsible for dispersing the seed. The population on Rapa Iti is poorly known. Henderson Island is a World Heritage Site. Assessor: Waldren, $\mathbf{S}$.

Refs: $2818,8306,13604,14513,17122$

\section{Hernandia tahütensis}

Hernandiaceae

French Polynesia (Society Is., Tubuai Is.)

Little is known about the populations of this species, which are recorded from the island of Tubuai in the Tubuai Group and from Raiatea and Tahiti in the Society Islands.

Assessor: Florence, J.

Refs: 14513

\section{Hernandia temarii}

Hemandiaceae

French Polynesia (Society Is.)

CR B $1+2 \mathrm{C}$

An endemic to Tahiti.

Assessor: Florence, J.

Refs: 14513

\section{Herrania laciniifolia}

Sterculiaceae

CR B1+2c

Colombia

Endemic to Colombia, the species is restricted to localities in the departments of Cundinamarca and Tolima.

Assessor: Calderon, E.

Refs: 19069

\section{Herrania umbratica}

Sterculiaceae

$\mathrm{EN} \mathrm{B1+2c}$

Colombia

Endemic to Colombia, the species is restricted to localities in the departments of Norte de Santander and Santander.

Assessor: Calderon, E.

Refs: 19069

\section{Hesperomannia arborescens}

Compositae

CR C2a

USA (Hawaii)

A small shrubby tree, occurring in scattered tiny populations on forested slopes and ridges in the Koolau Mountains, on Oahu, in Olokui Reserve on Molokai and in West Maui Reserve on Maui. In total fewer than 100 individuals exist in 14 populations. Goats threaten the Molokai population and in other areas feral pigs and invasive plants pose immediate problems. The species is protected by the US Endangered Species Act.

Assessor: World Conservation Monitoring Centre

Refs: 19041,19168

\section{Hesperomannia arbuscula}

Compositae

USA (Hawaii)

CR C2a

A small shrubby tree or shrub, known from scattered populations in lowland rainforest in the central and southem Waianae Mountains in Oahu and from a single individual on West Maui. There are four populations on Oahu, containing about 90 individuals. Feral pigs and introduced plants pose the most serious threats. The species is protected by the US Endangered Species Act. Assessor: World Conservation Monitoring Centre Refs: 3372,19168

\section{Hesperomannia lydgatei}

Compositae

$\mathrm{CR} B 1+2 \mathrm{c}, \mathrm{C} 2 \mathrm{~b}$

USA (Hawaii)

A small tree of dense wet forest known only from a site along Wahiawa Stream on Kauai Island. It is protected 
by the US Endangered Species Act.

Assessor: World Conservation Monitoring Centre

Refs: 3372

\section{Hexalobus mossambicensis}

Annonaceae

DD

Mozambique

A species of northern Mozambique. Information on the species' range and habitat are inadequate.

Assessor: Bandeira, $\mathrm{S}$.

Refs: 5117,18965

\section{Hexalobus salicifolius}

Annonaceae

$\mathrm{EN} B 1+2 \mathrm{c}$

Cameroon, Côte d'Ivoire

Two isolated populations are known. In Côte d'Ivoire, the species is confined to swampy areas within remaining forest patches between the rivers Cavally and Sassandra. The largest patch is contained within Tai National Park. Logging and the influx of people have caused a rapid decline and degradation of the habitat. More information is needed on the other population in Cameroon.

Assessor: Assi, A.

Refs: 12590,12822

\section{Hexapora curtisii}

Lauraceae

Malaysia (Peninsular Malaysia)

$\mathrm{CR} B 1+2 \mathrm{c}$

Known only from Penang Hill, this rare lowland forest species may be extinct as most of Penang has been developed.

Assessor: World Conservation Monitoring Centre

Refs: 8464, 19073

\section{Hibiscadelphus bombycinus}

Malvaceae

USA (Hawaii)

Collected just once before 1868, the species is now presumed extinct. It was thought to occur in rainforest at Kawaihae on Hawaii. The genus is endemic to the Hawaiian Islands and is known from species which are either extinct or critically endangered.

Assessor: World Conservation Monitoring Centre

Refs: 3372

\section{Hibiscadelphus crucibracteatus}

Malvaceae

USA (Hawaii)

A single tree was discovered on a dry slope of Puhielelu Ridge in 1981. It has since died. Seeds were collected but none have germinated. The genus is endemic to the Hawaiian Islands and is known from either extinct or critically endangered species.

Assessor: World Conservation Monitoring Centre

Refs: 3372

\section{Hibiscadelphus distans}

Malvaceae

CR D1

USA (Hawaii)

Occurring as a shrub or small tree, the species is known from a single population of fewer than 20 individuals in a dry forest patch on the bluff above Koaie Stream in Waimea Canyon on Kauai. It is protected by the US Endangered Species Act. The genus is endemic to the Hawaiian Islands and is known from species which are either extinct or critically endangered.

Assessor: World Conservation Monitoring Centre

Refs: 3372
Hibiscadelphus giffardianus

Malvaceae

CR D1

USA (Hawaii)

The last of the original wild specimens on Mauna Loa, Hawaii, died in 1930. Since then cuttings from the species in cultivation have been reintroduced into a fenced area at Kipuka Puaulu, in Volcanoes National Park. Nine individuals remain here. They show some signs of damage by rats and pests. The establishment of a viable population in the wild may be hampered by the decline of the plants' likely pollinator, the Haiwaiian honey-creeper species. The species is protected by the US Endangered Species Act.. The genus is endemic to the Hawaiian Islands and is known from species which are extinct or critically endangered.

Assessor: World Conservation Monitoring Centre

Refs: 3372,19037

\section{Hibiscadelphus hualalaiensis}

Malvaceae

CR D1

USA (Hawaii)

Originally known from three populations in Puwwaawaa on Hawaii, the last known wild tree died in 1992. A small number of cultivated trees have been reintroduced into two fenced sanctuaries. The species' natural habitat is dry to moist forest on lava fields between 915 and $1020 \mathrm{~m}$. The only remaining patches are heavily threatened by fire, grazers, invasive plants and ranching activities. The species is protected by the US Endangered Species Act. The genus is endemic to the Hawaiian Islands and is known from species which are extinct or critically endangered.

Assessor: World Conservation Monitoring Centre

Refs: 3372, 19037

\section{Hibiscadelphus wilderianus}

Malvaceae

USA (Hawaii)

A single tree was found in 1910 on the dry forest lava fields of Auwahi on Maui. It has since died and the species is presumed extinct. The genus is endemic to the Hawaiian Islands and is known only from either extinct or critically endangered species.

Assessor: World Conservation Monitoring Centre Refs: 3372

\section{Hibiscadelphus woodii}

Malvaceae

CR D1

USA (Hawaii)

A small tree found in 1991. It is known only from the site of discovery in Kalalau Valley in Napali Coast State Park on Kauai. Only four trees have been found growing on cliff walls in montane rainforest. The main threats to the population come from feral goats and pigs and invasive plants. The species is protected by the US Endangered Species Act. The genus is endemic to the Hawaiian Islands and is only known from species which are extinct or critically endangered.

Assessor: World Conservation Monitoring Centre Refs: 19036,19086

\section{Hibiscus arnottianus ssp. immaculatus}

\section{Malvaceae}

$\mathrm{EN} \mathrm{B1+2c,C2a,D1}$

USA (Hawaii)

Formerly ranging from Waihanau Valley to Papalaua Valley on East Molokai, the taxon is now reduced to an area stretching for $5 \mathrm{~km}$ on the northern coast, where three populations occur along the steep cliffs. There are no more than 100 individuals in the area. Feral goats are 
a major cause of damage to the habitat. The taxon is protected by the US Endangered Species Act.

Assessor: World Conservation Monitoring Centre

Refs: 3372,19040

\section{Hibiscus brackenridgei ssp. brackenridgei}

Malvaceae

USA (Hawaii)

$\mathrm{EN} \mathrm{C2a}$

A sprawling to erect shrub or tree known from small populations restricted to dry forest and shrubland up to $350 \mathrm{~m}$ on Molokai, Lanai, Maui and Hawaii.

Assessor: World Conservation Monitoring Centre

Refs: 3372

\section{Hibiscus brackenridgei ssp. mokuleianus}

Malvaceae

$\mathrm{EN} \mathrm{B1}+2 \mathrm{c}, \mathrm{C} 2 \mathrm{a}$

USA (Hawaii)

A tree of dry forest and shrubland known from three localised populations, two on Kauai at Lihue and Olokele Canyon, and in the Waianae Mountains between Kawaihapai and Puupane on Oahu.

Assessor: World Conservation Monitoring Centre

Refs: 3372

\section{Hibiscus clayi}

Malvaceae

CR D1

USA (Hawaii)

Occurring as a shrub or tree, the species is endemic to Kauai where it has been recorded from a number of locations in dry forest up to $350 \mathrm{~m}$. A group of four trees in the Nounou Mountains appears to be the only remaining population. The damage caused by cattle was realised in 1928 when the species was first brought into cultivation. That threat has been removed but the habitat continues to be steadily degraded by the spread of invasive plants, by feral pigs and potentially recreational activities. A small number of individuals have been planted to augment the population in the wild. The species is protected by the US Endangered Species Act. Assessor: World Conservation Monitoring Centre

Refs: 3372,19038

\section{Hibiscus kokio ssp. kokio}

Malvaceae

VUAlce

USA (Hawaii)

A variable subspecies known from scattered populations in dry to moist forest up to $800 \mathrm{~m}$ on Kauai, Oahu, Molokai and Maui. It is also presumed to be present on Hawaii.

Assessor: World Conservation Monitoring Centre

Refs: 3372

\section{Hibiscus kokio ssp. saintjohnianus}

Malvaceae

EN C2a

USA (Hawaii)

This subspecies is confined to forest in north-west Kaui, occurring up to $1100 \mathrm{~m}$.

Assessor: World Conservation Monitoring Centre

Refs: 3372

\section{Hibiscus waimeae ssp. hannerae}

Malvaceae

USA (Hawaii)

$\mathrm{EN} \mathrm{B1+2c,C2a,D1}$

A rainforest tree confined to Kauai, where two remaining populations occur in adjacent valleys, Limahuli and Hanakapiai, on the north coast. An additional population in Kalihiwai appears to be extinct and after Hurricane Iniki the population in Hanakapiai Valley was halved to about 25 plants. The second population consists of between 50 and 100 plants. The lowland rainforest habitat is frequently damaged by feral pigs and invaded by introduced plants. The species is protected by the US Endangered Species Act.

Assessor: World Conservation Monitoring Centre Refs: 3372, 19036, 19086

\section{Hibiscus waimeae ssp. waimeae}

Malvaceae

$\mathrm{LR} / \mathrm{nt}$

USA (Hawaii)

This subspecies is distributed from Waimea Canyon to the ocean-facing valleys in the west and south-west on Kauai.

Assessor: World Conservation Monitoring Centre Refs: 3372

\section{Hieronima crassistipula \\ Euphorbiaceae}

CR B $1+2 \mathrm{C}$

Cuba

A very rare tree of natural pine forest along ravines and creeks in Pinar del Rio Province and on Isla de Pinos. Population numbers are probably too low to ensure the species' survival without intervention.

Assessor: Areces-Mallea, A.E.

Refs: $11403,18485,19149$

\section{Hieronima macrocarpa}

Euphorbiaceae

Colombia, Ecuador

VU B $1+2 c$

Assessor: Calderon, E.

Refs: 4217,19069

\section{Hildegardia cubensis}

Sterculiaceae

VU B1+2c

Cuba

A tree found in lowland semi-deciduous forest on rocky limestone soils in eastem Cuba. Populations have declined substantially in the past decades through habitat clearance and buming for logging, grazing and agricultural encroachment.

Assessor: Areces-Mallea, A.E.

Refs: 19149

\section{Hildegardia gillettii}

Sterculiaceae

EN C2b, D1

Somalia

In the last 10 years fewer than 10 individuals have been found, most of them in the vicinity of El Ellan. Although the true population size is likely to be greater, the tree and its habitat are threatened with overcutting and grazing. The population is unprotected but local inhabitants are aware of its uniqueness.

Assessor: Thulin, M.

Refs: 18665

\section{Hildegardia populifolia}

Sterculiaceae

India (Andhra Pradesh, Tamil Nadu)

CR D1

Endemic to the Eastern Ghats in Andra Pradesh and Tamil Nadu, the species is believed to have disappeared from all its recorded localities except for one on the forested eastern slopes of the Kalrayans Hills, where about 20 trees survive.

Assessor: World Conservation Monitoring Centre Refs: 4799 
Himalanthus stenophyllus

Apocynaceae

DD

Suriname

No locality is recorded for the species.

Assessor: World Conservation Monitoring Centre

Refs: 19196

\section{Hirtella enneandro}

Chrysobalanaceae

Colombia

$\mathrm{EN} \mathrm{B1}+2 \mathrm{c}$

An endemic to Valle.

Assessor: Calderon, E.

Refs: 5970, 7980, 19069

\section{Hirtella megacarpa}

Chrysobalanaceae

VU $B 1+2 b$

Tanzania

Rarely occurring in moist evergreen montane forest in two mountain ranges, this species is thought to be sufficiently ecologically and geographically distinct from the related $H$. zanzibaricc to keep it taxonomically separate, although morphological differences are not substantial. In the West Usambaras a population is known in Shagai and in the Udzungwas there are occurrences in Mwanihana and Nyumbanitu.

Assessor: Lovett, J. \& G.P. Clarke

Refs: $1308,3356,11631$

\section{Holarrhena pubescens}

Apocynaceae

Pakistan

A small tree, once occurring in Nurpur, Tret, Murree Hills up to $1200 \mathrm{~m}$, now apparently extinct.

Assessor: World Conservation Monitoring Centre

Refs: 4013,5995

\section{Holmskioldia gigas}

Verbenaceae

CR Bl+2abcde, Dl

Kenya, Tanzania

Formerly known from a single individual in Kenya, which was felled in the 1980 's, the species is now known to occur in a 0.1 ha patch of forest near Ngarama Forest Reserve in Tanzania. Only a single individual exists.

Assessor: Lovett, J. \& G.P. Clarke

Refs: 5654, 6396, 16796

\section{Homalanthus polyandrus}

Euphorbiaceae

VU D2

New Zealand (Kermadec Is.)

A small pioneer tree found only on Raoul Island in the Kermadec Group. By the early 1970 s only a few small groups of trees had survived the damage caused by feral goats. A spectacular recovery in numbers has since been made following the removal of goats.

Assessor: World Conservation Monitoring Centre

Refs: $5563,9800,17637$

\section{Homalium betulifolium}

Flacourtiaceae

$\mathrm{EN} \mathrm{B1}+2 \mathrm{c}$

New Caledonia

Assessor: Jaffré, T. et al.

Refs: 10351

\section{Homalium buxifolium}

Flacourtiaceae

$\mathrm{EN} \mathrm{B1}+2 \mathrm{c}$

\section{Homalium dalzielii}

Flacourtiaceae

Benin, Nigeria

A small tree recorded in Lagos in Nigeria and from Dja and Kpoguidi in Benin.

Assessor: World Conservation Monitoring Centre

Refs: 2773, 7111, 11504

\section{Homalium gracilipes}

Flacourtiaceae

VU B1 $+2 c, D 2$

Tanzania

Known only from the type collection in Liwiri-Kiteza forest at Songea, southem Tanzania, the species occurs in moist semi-deciduous montane forest.

Assessor: Lovett, J. \& G.P. Clarke

Refs: $3356,5020,5204$

\section{Homalium henriquesi}

Flacourtiaceae

LR/nt

São Tomé \& Principe (Príncipe, São Tomé)

This species is present in all high altitude sites. Regeneration is reported to be good. The wood is used as a construction timber.

Assessor: World Conservation Monitoring Centre

Refs: 2724, 10080, 19042, 19111

\section{Homalium jainii}

Flacourtiaceae

$\mathrm{EN} \mathrm{B} 1+2 \mathrm{C}$

India (Tamil Nadu)

Known only from the type collection, this canopy tree occurs in a restricted area of submontane forest in the Agastyamalai Hills. Large areas have been exposed to fires, grazing, the establishment of commercial plantations and cutting for fuelwood, but almost $1000 \mathrm{~km}^{2}$ of forest are now under protection within sanctuaries.

Assessor: World Conservation Monitoring Centre

Refs: 19144

Homalium juxtapositum

Flacourtiaceae

$\mathrm{EN} \mathrm{B1}+2 \mathrm{c}$

New Caledonia

Assessor: Jaffré, T. et al.

Refs: 10351

\section{Homalium kunstleri}

Flacourtiaceae VU D2 Malaysia (Peninsular Malaysia)

A very rare species of lowland rainforest, scattered in limestone areas in Kinta, Perak.

Assessor: Chua, L.S.L.

Refs: 8464,19073

\section{Homalium Lacticum var. glabratum}

Flacourtiaceae

VU B $1+2 c e$

China (Yunnan)

Remaining stands of this large tree are small and restricted to Jinghong, Mengla and Gengma Counties in Yunnan. The variety is a scattered component of the upper canopy in monsoon or subtropical rainforest. Large trees are increasingly scarce and continue to be cut for the timber. Regeneration, too, is insufficient. Protected populations exist in Xishuangbanna Nature Reserve.

Assessor: Sun, W.

Refs: $1818,11847,19055$

Assessor: Jaffré, T. et al.

Refs: 10351 
Homalium mathieuanum

Flacourtiaceae

New Caledonia

Assessor: Jaffré, T. et al.

Refs: 10351

\section{Homalium ogoouense}

Flacourtiaceae

VU D2

Gabon

A species known from collections made around Lastoursville in 1929-1930. A collection in Wageningen comes from Echira. The area has been heavily logged and, although the species may be more widespread in Gabon's relatively unexplored forests, most areas are now under concession to logging companies.

Assessor: World Conservation Monitoring Centre

Refs: 8415,19043

\section{Homalium patoklaense}

Flacourtiaceae

VU B1+2c

Côte d'Ivoire, Gabon

Also known under the synonym, $\boldsymbol{H}$. lastoursvillense, this species occurs in two disjunct populations. The threatened Côte d'Ivoire population is restricted largely to Tai National Park. Forested areas outside the park have been heavily logged and degraded. In Gabon the species has been collected only from Lastoursville, where logging has been intensive. Although it may be more widespread, most forest areas are now under concession to logging companies.

Assessor: Assi, A.

Refs: $2773,8415,12822$

\section{Homalium polystachyum}

Flacourtiaceae

$\mathrm{EN} \mathrm{B1}+2 \mathrm{c}$

New Caledonia

Assessor: Jaffré, T. et al.

Refs: 10351

\section{Homalium rubiginosum}

Flacourtiaceae

New Caledonia

Assessor: Jaffré, T, et al.

Refs: 10351

\section{Homalium rubrocostatum}

Flacourtiaceae

New Caledonia

$\mathrm{EN} \mathrm{B1+2c}$

Assessor: Jaffré, T. et al.

Refs: 10351

\section{Homalium sleumerianum}

Flacourtiaceae

$\mathrm{VU} B 1+2 \mathrm{C}$

New Caledonia

Assessor: Jaffré, T. et al.

Refs: 10351

\section{Homalium smythei}

Flacourtiaceae

Côte d'Ivoire, Guinea, Liberia, Sierra Leone

This species is confined to moist forest in the Upper Guinea region, from Guinea to Côte d'Ivoire. In the latter country the population is mainly contained within Tai National Park. Forested areas outside the park have been widely logged and degraded.

Assessor: Assi, A.

Refs: 12822

\section{Homalium spathulatum}

Flacourtiaceae

Malaysia (Peninsular Malaysia)

EN D1

A very rare species confined to lowland rainforest on the island of Pangkor, Perak. The habitat is threatened by the encroaching settlements and tourism.

Assessor: Chua, L.S.L.

Refs: 19073

\section{Homalium taypau}

Flacourtiaceae

VU D2

Pitcairn Islands

Restricted to hillsides and valleys on Pitcaim Island, the species is still common and often dominates the vegetation that remains. The population probably consists of at least 2000 mature individuals. Loss of habitat and spread of invasive plants have caused the populations to be reduced to their present extent. In the past the timber was also frequently cut for use in construction work. Regeneration is strong from cut stumps but rare from the seed.

Assessor: World Conservation Monitoring Centre Refs: $5658,13604,19154$

\section{Homalium travancoricum}

Flacourtiaceae

India (Kerala, Tamil Nadu)

VU B $1+2 c$

Collections are recorded from the Travancore range down to the Agastyamalai Hills and field data have identified further populations to the south of the Nilgiris. The species occurs in the lower storey of evergreen forest, mainly at low altitudes.

Assessor: World Conservation Monitoring Centre Refs: 19144

\section{Homalium undulatum}

Flacourtiaceae

VU B1+2a

Malaysia (Peninsular Malaysia)

A small to medium-sized tree occurring mainly in limestone hill forest in Kedah (Langkawi) and Perak, where it is threatened by increasing settlement and logging. It is unclear whether the species occurs in Peninsular Thailand or not.

Assessor: Chua, L.S.L.

Refs: 8464,19073

\section{Hopea acuminata}

CR Alcd, B1+2c Philippines

A widespread species in the greatly diminished evergreen and semi-evergreen forests of the Philippines. The lightweight merawan timber is used for the construction of bridges, ships and houses.

Assessor: Ashton, $\mathrm{P}$.

Refs: $7673,9169,13857$

\section{Hopea aequalis}

Dipterocarpaceae

Malaysia (Sabah, Sarawak)

CR Alc, B1+2c, C1

An endemic tree found in mixed dipterocarp forest on low hills, where the demand for agricultural land exerts a strong pressure on remaining forest.

Assessor: Ashton, P.

Refs: $7673,9169,13857$

\section{Hopea altocollina}

Dipterocarpaceae

Malaysia (Sabah, Sarawak)

EN Alcd, B $1+2 c$

A large tree which is locally common on clay-rich 
hillsides and spurs. An occurrence is recorded in a site proposed as a reserve.

Assessor: Ashton, $\mathrm{P}$.

Refs: $7673,9169,13857$

Hopea andersoni ssp. basalticola

Dipterocarpaceae

CR Alcd, $\mathrm{B} 1+2 \mathrm{c}$

Malaysia (Sabah, Sarawak)

This subspecies, endemic to Bomeo, occurs throughout mixed dipterocarp forest on rich clay soils.

Assessor: Ashton, P.

Refs: $7673,9169,13857$

\section{Hopea apiculata}

Dipterocarpaceae

CR Alc, Bl+2c

Malaysia (Peninsular Malaysia), Myanmar, Thailand

The species is probably a synonym of $H$. oblongifolia. Some populations are known within forest reserves.

Assessor: Ashton, P.

Refs: $7673,9169,13857$

\section{Hopea aptera}

Dipterocarpaceae

Papua New Guinea

Endemic to Papua New Guinea, this species forms pure stands in secondary forest and is a locally important timber species.

Assessor: Ashton, $\mathrm{P}$.

Refs: 7673, 13857

\section{Hopea auriculata}

Dipterocarpaceae

Malaysia (Peninsular Malaysia)

EN Alc, Bl+2c

This tree is restricted to hill forests in Peninsular Malaysia. It is a small tree, that is not exploited.

Assessor: Ashton, $\mathrm{P}$.

Refs: $5550,7673,9169,13857$

\section{Hopea bancana}

Dipterocarpaceae

Indonesia (Sumatra)

Endemic to Sumatra, this species is seriously threatened by the loss of its forest habitat.

Assessor: Ashton, P.

Refs: 7673, 13857

\section{Hopea basilanica}

Dipterocarpaceae

Philippines

A species of primary lowland forest, seriously threatened by the loss of its habitat.

Assessor: Ashton, P.

Refs: $7673,9169,13857$

\section{Hopea beccariana}

Dipterocarpaceae

Indonesia (Sumatra), Malaysia, Thailand

CR Alcd $+2 c d$

Widespread on coastal hills and inland ridges, this tree is an important source of heavy merawan timber and dammar resin. Some populations are known to occur in forest reserves.

Assessor: Ashton, $\mathrm{P}$.

Refs: $7673,9169,13857$

\section{Hopea bilitonensis}

Dipterocarpaceae

CR Alc $+2 \mathrm{c}, \mathrm{B} 1+2 \mathrm{c}$

Indonesia (Sumatra), Malaysia (Peninsular Malaysia)

This species is locally common on the sandy islands of
Billiton and Banka.

Assessor: Ashton, $\mathrm{P}$.

Refs: $7673,9169,13857$

\section{Hopea brachyptera}

Dipterocarpaceae

$\mathrm{CR} \mathrm{Alc}+2 \mathrm{c}, \mathrm{B} 1+2 \mathrm{c}, \mathrm{Cl}, \mathrm{Dl}$

Philippines

A species which occurs in lowland primary forests on Mindanao Island. It is seriously threatened by the loss of its habitat.

Assessor: Ashton, P.

Refs: $7673,9169,13857$

\section{Hopea brevipetiolaris}

Dipterocarpaceae

CR Alcd, $\mathrm{B} 1+2 \mathrm{c}, \mathrm{Cl}, \mathrm{Dl}$

Sri Lanka

A species with an extremely restricted distribution, scattered in the remnants of lowland semi-evergreen rainforest in the south-west corner of Sri Lanka. It was discovered in only three forest localities within Kurunegala District, during the extensive surveys conducted for the National Conservation Review. The tree has little value as a timber because of its warped bole.

Assessor: Ashton, P.

Refs: $15431,13857,19112$

\section{Hopea cagayanensis}

Dipterocarpaceae

CR Alcd $+2 c d, B 1+2 c$

Philippines

This locally abundant species is restricted to the diminishing lowland primary forest of north-east Luzon. Assessar: Ashton, $\mathrm{P}$.

Refs: $7673,9169,13857$

\section{Hopea canarensis}

Dipterocarpaceae

India (Karnataka)

A lowland forest species, collected only once from a site near Kudremukh.

Assessor: Ashton, P.

Refs: $3998,13857,19144$

\section{Hopea celebica}

Dipterocarpaceae

Indonesia

$\mathrm{EN} \mathrm{Alcd}+2 \mathrm{~cd}, \mathrm{Bl}+2 \mathrm{c}$

A species which is locally common in lowland semievergreen forest.

Assessor: Ashton, P.

Refs: $7673,9169,13857$

\section{Hopea centipeda}

Dipterocarpaceae

Brunei, Malaysia (Sarawak)

EN A $1 c+2 c$

Occurs locally on river banks.

Assessor: Ashton, P.

Refs: $7673,9169,13857$

\section{Hopea chinensis}

Dipterocarpaceae

China (Guangxi), Viet Nam

CR Alcd+2cd, Cl, Dl

A relatively small evergreen tree restricted to monsoon forest in the Shiwan Mountains. It provides a valuable timber, renowned as 'ten-thousand year wood'. Overcutting is a serious problem.

Assessor: Ashton, P.

Refs: $1818,11847,13857,15754$ 


\section{Hopea cordata}

Dipterocarpaceae

Viet Nam

Assessor: Ashton, $\mathrm{P}$.

Refs: $848,7673,9169,13857$

\section{Hopea cordifolia}

Dipterocarpaceae

EN Alcd, Bl+2c, Dl

Sri Lanka

No evidence of the species was found during the extensive forest surveys conducted between 1991 and 1996 for the National Conservation Review, suggesting that the species is either extremely rare or possibly extinct.

Assessor: Ashton, $\mathrm{P}$

Refs: $13857,15431,18796,19112$

\section{Hopea coriacea}

Dipterocarpaceae CR Alcd+2cd, B1+2c, Cl, D1 Indonesia (Kalimantan), Malaysia (Peninsular Malaysia) Found scattered on low hills and ridges, this slowgrowing tree is exploited locally for house supports and boat hulls. It is unlikely to survive logging activities because it doesn't reach reproductive age within a logging cycle.

Assessor: Ashton, $\mathrm{P}$.

Refs: $7673,9169,13857,17140$

\section{Hopea dasyrrhachio}

Dipterocarpaceae

EN Alcd $+2 c d, B 1+2 c$

Brunei, Indonesia (Kalimantan), Malaysia (Sabah, Sarawak)

The species is locally abundant on limestone slopes.

Assessor: Ashton, $\mathrm{P}$.

Refs: 11295,13857

\section{Hopea depressinerva}

Dipterocarpaceae

Malaysia (Sarawak)

Restricted to *granodiorite hill slopes in western Sarawak, this tree may already be extinct.

Assessor: Ashton, P.

Refs: $7673,9169,13857$

\section{Hopea discolor}

Dipterocarpaceae

EN Albcd, B1+2c, Cl, D1

Sri Lanka

This species' distribution is extremely restricted, occurring in pure stands on ridges in lowland wet evergreen forests. It apparently regenerates sufficiently in its natural habitat. This species was found in seven forests during the surveys conducted for the National Conservation Review.

Assessor: Ashton, $\mathrm{P}$

Refs: $13857,15431,17195,19112$

\section{Hopea enicosanthoides}

Dipterocarpaceae

CR Alc, Bl+2c

Malaysia (Sarawak)

This small tree species is locally frequent in Sarawak.

Assessor: Ashton, $\mathrm{P}$.

Refs: $7673,9169,13857$

\section{Hopea erosa}

Dipterocarpaceae

CR Ald $+2 \mathrm{~d}, \mathrm{Bl}+2 \mathrm{e}, \mathrm{Cl}, \mathrm{D} 1$

India (Karnataka, Kerala, Tamil Nadu)

Known only from very few scattered records, the species is confined to lowland evergreen forest at the southem end of the Westem Ghats.

Assessor: SSC Conifer Specialist Group

Refs: 13857,19144

\section{Hopea exalata}

Dipterocarpaceae

China (Guangdong - Hainan)

VU Ald, B1+2e

A small tree of monsoon forest, only recently discovered in Yaxian County of Hainan Province. The degree of habitat disturbance suggests that most of the trees are secondary growth. The species has a good regenerative capacity in its natural habitat. The population on Ganshi Mountain is contained within a designated nature reserve. The species presents several primitive features which are of phylogenetic interest.

Assessor: Ashton, $\mathrm{P}$.

Refs: $1818,11847,13857$

\section{Hopea ferrea}

Dipterocarpaceae

EN Alcd $+2 \mathrm{~cd}, \mathrm{Bl}+2 \mathrm{c}$

Cambodia, Malaysia (Peninsular Malaysia), Myanmar, Thailand, Viet Nam

A commercially important timber tree, which is commonly traded in isolation from other members of the genus under the name malut.

Assessor: Ashton, P.

Pefs: $7673,9169,10013,13857$

\section{Hopea ferruginea}

Dipterocarpaceae CR Alc+2c Brunei, Indonesia (Kalimantan, Sumatra), Malaysia (Peninsular Malaysia, Sabah, Sarawak)

Assessor: Ashton, P.

Refs: 13857,16104

\section{Hopea fuvialis}

Dipterocarpaceae

Sarawak)

This tree is recorded in sites proposed for reserve status. The species is locally abundant, by streams.

Assessor: Ashton, P.

Refs: $7673,9169,13857$

\section{Hopea foxworthyi}

Dipterocarpaceae

Philippines

Assessor: Ashton, $\mathrm{P}$.

Refs: $7673,9169,13857$

\section{Hopea glabra}

Dipterocarpaceae

India (Kamataka, Kerala, Tamil Nadu)

EN Alcd $+2 \mathrm{~cd}$

Confined to the southem end of the Western Ghats, the species has been collected from scattered localities in low to medium altitude evergreen forest. The most northerly occurrence is recorded in the Nilgiri Hills, the most southerly in the Agastyamalai range

Assessor: Ashton, P.

Refs: $3998,9169,13857,19144$

\section{Hopea glabrifolia}

Dipterocarpaceae

Papua New Guinea

Assessor: Ashton, P.

Refs: 7673, 9169, 13857 


\section{Hopea glaucescens}

Dipterocarpaceae

Malaysia (Peninsular Malaysia)

CR Alc $+2 c, B l+2 c$

Assessor: Ashton, $\mathrm{P}$.

Refs: $5550,7673,13857$

Hopea gregaria

Dipterocarpaceae

Indonesia

Assessor: Ashton, P.

Refs: $7673,9169,13857$

\section{Hopea griffithii}

Dipterocarpaceae

VU Alcd +2cd

Malaysia (Peninsular Malaysia, Sarawak), Myanmar, Singapore, Thailand

This species is locally common on leached soils, with some populations known to occur within forest reserves.

Assessor: Ashton, $\mathrm{P}$.

Refs: $3998,9169,9199,13857$

\section{Hopea hainanensis}

Dipterocarpaceae

CR Alcd $+2 \mathrm{~cd}, \mathrm{Bl}+2 \mathrm{c}$

China (Guangdong - Hainan), Viet Nam

A slow-growing tree, occurring in remaining areas of lowland rainforest on Hainan Island in China and Nghia Dan, Quy Chau, Quy Hop and Nhu Xuan and a few smaller localities in Viet Nam. The Chinese population consists of several hundred mature trees, which are now protected from cutting. The timber is highly valued in both China and Viet Nam.

Assessor: Ashton, $\mathrm{P}$.

Refs: $848,1818,11847,13857,15357,15754$

\section{Hopea helferi}

Dipterocarpaceae

CR Alcd $+2 \mathrm{~cd}, \mathrm{BI}+2 \mathrm{c}$

Cambodia, India (Andaman and Nicobar Is. - Andaman

Is.), Malaysia (Peninsular Malaysia), Myanmar. Thailand

A large tree found in semi-evergreen and evergreen forests. The timber is valuable in the construction industry.

Assessor: Ashton, $\mathrm{P}$.

Refs: $2430,9169,13857$

\section{Hopea hongayanensis}

Dipterocarpaceae

CR Alcd, B1+2c, Cl, D1

Viet Nam

Endemic to Viet Nam, this slow-growing tree is valued highly for its hard, heavy timber, which is included in Viet Nam's 'precious timber' group. Occurrences are known from mixed forest at about $950 \mathrm{~m}$ in Quang Ninh. Lang Son, Tuyen Quang, Ninh Binh and Nghe An Provinces.

Assessor: Ashton, $\mathrm{P}$.

Refs: $9169,13857,15357$

\section{Hopea inexpectata}

Dipterocarpaceae

Papua New Guinea

CR Alcd, B1+2c

Assessor: Ashton, P.

Refs: $7673,9169,13857$

\section{Hopea jacobi}

Dipterocarpaceae

India (Karnataka)

A relatively small dipterocarp found only once in evergreen forest in Kodugu in the Westem Ghats. It may now be extinct.

Assessor: Ashton, P.

Refs: 4799, 13857, 19144

\section{Hopea johorensis}

Dipterocarpaceae

Malaysia (Peninsular Malaysia)

CR Alcd, $B 1+2 c$

A tree which is restricted to eastern Johore, often on hill ridges. Some populations are found within forest reserves.

Assessor: Ashton, $\mathrm{P}$

Refs: $5550,7673,9169,13857$

Hopea jucunda ssp. jucunda

Dipterocarpaceae

CR A1cd

Sri Lanka

Some populations are known to occur in forest reserves.

Assessor: Ashton, $\mathrm{P}$.

Refs: 13857, 15431

Hopea jucunda ssp. modesta

Dipterocarpaceae

CR Alcd

Sri Lanka

Some populations are known to occur in forest reserves. Assessor: Ashton, $\mathrm{P}$

Refs: 13857

\section{Hopea kerangasensis}

Dipterocarpaceae

CR Alc, B1+2c

Indonesia (Sumatra), Malaysia (Peninsular Malaysia, Sarawak)

This species is locally abundant in Sarawak, with some populations occurring in forest reserves.

Assessor: Ashton, P.

Refs: $7673,9169,13857$

\section{Hopea latifolia}

Dipterocarpaceae

CR Alc, Bl+2c

Brunei, Cambodia, Malaysia (Peninsular Malaysia, Sarawak), Thailand?

This tree is locally common in lowland mixed dipterocarp forest. It is widely distributed in Peninsular Malaysia and is known to occur in a number of forest reserves.

Assessor: Ashion, $\mathbf{P}$.

Refs: $7673,9169,13857$

\section{Hopea longirostrata}

Dipterocarpaceae

Malaysia (Sarawak)

CR Alcd, B1+2c, Cl, D1

This species is restricted to mixed dipterocarp forests in Sarawak.

Assessor: Ashton, $\mathrm{P}$.

Refs: $7673,9169,13857$

\section{Hopea malibato}

Dipterocarpaceae

CR Alcd, Bl+2c

Philippines

A widespread and locally common species.

Assessor: Ashton, P.

Refs: $7673,9169,13857$ 
Hopea megacarpa

Dipterocarpaceae

Malaysia (Sarawak)

EN Alc, B1+2c

This species is locally frequent in mixed dipterocarp forest.

Assessor: Ashton, $\mathrm{P}$.

Refs: $7673,9169,13857$

\section{Hopea mengerawan}

Dipterocarpaceae

CR Alcd, $\mathrm{Bl}+2 \mathrm{c}$

Indonesia (Sumatra), Malaysia (Peninsular Malaysia,

Sarawak), Singapore

Scattered throughout lowland mixed dipterocarp forest, this species is an important source of merawan timber and also produces a good-quality dammar resin. It is also contained within a number of forest reserves in Peninsular Malaysia.

Assessor: Ashton, $\mathrm{P}$.

Refs: $7673,9169,9199,13857$

\section{Hopea mesuoides}

Dipterocarpaceae

Brunei, Malaysia (Sarawak)

EN Alc, B $1+2 c$

A species of mixed dipterocarp and heath forest. The habitat is threatened by clearance and degradation.

Assessor: Ashton, $\mathrm{P}$.

Refs: $7673,9169,13857$

\section{Hopea micrantha}

Dipterocarpaceae

CR Alc, Bl+2c, Cl, DI

Brunei, Indonesia (Kalimantan), Malaysia (Sabah,

Sarawak)

A tree found in heath forest, where it is severely threatened by habitat conversion and degradation.

Assessor: Ashton, $\mathrm{P}$.

Refs: $7673,9169,13857$

\section{Hopea mindanensis}

Dipterocarpaceae

Philippines

This lowland primary species may already be extinct.

Assessor: Ashton, $\mathrm{P}$.

Refs: $7673,9169,13857$

\section{Hopea mollissima}

Dipterocarpaceae

China (Yunnan), Viet Nam

Only recently discovered, the species occurs in evergreen rainforest in south Yunnan and northern Viet Nam. In China populations are disappearing because of deforestation and habitat degradation. Small stands still exist in a number of provinces in Viet Nam.

Assessor: Ashton, $\mathrm{P}$.

Refs: $9169,11847,13857,15357$

\section{Hopea montana}

Dipterocarpaceae

CR B 1+2c, D1

Indonesia (Sumatra), Malaysia (Peninsular Malaysia, Sabah)

This tree is found infrequently on hill slopes in dipterocarp forest.

Assessor: Ashton, $\mathrm{P}$.

Refs: $5550,7673,9169,13857$

\section{Hopea nervosa}

Dipterocarpaceae

CR Alc, B1+2c

Indonesia (Kalimantan, Sumatra), Malaysia (Peninsular Malaysia, Sabah, Sarawak)

This species is locally common on lowland clay-rich fertile soil.

Assessor: Ashton, $\mathrm{P}$.

Refs: $5550,7673,9169,13857$

\section{Hopea nigra}

Dipterocarpaceae

CR Alc, B $1+2 c$

Indonesia (Sumatra)

A tree endemic to the lowland forests of Sumatra, where it is severely threatened by the loss and degradation of the habitat.

Assessor: Ashton, $\mathrm{P}$.

Refs: $7673,9169,13857$

\section{Hopea nutans}

Dipterocarpaceae

CR A $1 c d+2 c d, B 1+2 c$

Brunei, Indonesia (Kalimantan), Malaysia (Peninsular Malaysia, Sabah, Sarawak)

A species of periodically inundated sandy soils, used for its good-quality giam timber.

Assessor: Ashton, $\mathrm{P}$.

Refs: $5550,7673,9169,13857$

\section{Hopea oblongifolia}

Dipterocarpaceae

Myanmar, Thailand

This species is very rare and restricted in range.

Assessor: Ashton, P.

Refs: $3998,9169,13857$,

18243

\section{Hopea odorata}

Dipterocarpaceae

VU Alcd+2cd

Bangladesh, Cambodia, India (Andaman and Nicobar Is.

- Andaman Is.?), Laos, Malaysia (Peninsular Malaysia), Myanmar, Thailand, Viet Nam

This widespread tree usually occurs in lowland riparian forest on deep rich soils. The Indian population, however, occurs in moist evergreen forest at higher altitudes, away from streams. It provides merawan timber and the resin has economic value. In Viet Nam a long period of selective logging has reduced the size of stands to small groups of trees or isolated individuals.

Assessor: Ashton, $\mathrm{P}$.

Refs: $3619,3998,5550,7673,10013,11727,13857$, $15357,15754,16925,17140$

\section{Hopea ovoidea}

Dipterocarpaceae

CR Alcd $+2 c d, B 1+2 c, C l, D 1$

Indonesia (Kalimantan)

Assessor: Ashton, P.

Refs: $7673,9169,13857$

Hopea pachycarpa

Dipterocarpaceae

VU Alc+2c

Brunei, Indonesia (Sumatra), Malaysia (Peninsular Malaysia, Sarawak)

A tree found in mixed dipterocarp forest. It is known to occur in an area proposed as a reserve.

Assessor: Ashton, $\mathbf{P}$.

Refs: $7673,9169,13857,17140$ 


\section{Hopea parviflora}

Dipterocarpaceae

India (Kamataka, Kerala, Tamil Nadu)

Endemic to the south-west, the species is common and has a relatively wide distribution in evergreen, semideciduous and deciduous moist forest from sea level to about $900 \mathrm{~m}$. It appears to be regenerating well in the wild and provides a popular construction timber.

Assessor: Ashton, P.

Refs: 3998, 8483, 13857, 19144

\section{Hopea paucinervis \\ Dipterocarpaceae}

DD

Indonesia (Sumatra)

This species is possibly extinct.

Assessor: Ashton, P.

Refs: $7673,9169,13857$

\section{Hopea pedicellata}

Dipterocarpaceae

EN Alc+2c

Cambodia, Indonesia (Kalimantan), Malaysia (Peninsular Malaysia, Sabah, Sarawak), Thailand

A tree found in mixed dipterocarp forest. It is contained within productive and protected forests in Peninsular Malaysia.

Assessor: Ashton, P.

Refs: $5550,7673,9169,13857,18243$

\section{Hopea pentanervia}

Dipterocarpaceae

Brunei, Malaysia (Sabah, Sarawak)

A species which occurs in highly threatened mixed peatswamp forests in northern Borneo. It is a popular timber for heavy construction. Some populations are known to occur in forest reserves.

Assessor: Ashton, P.

Refs: $7673,9169,13857$

\section{Hopea philippinensis}

Dipterocarpaceae

CR Alcd, B1+2c

Philippines

This species occurs in the much-diminshed, nonseasonal evergreen forests of the Philippines. The tree's small size allows only for small-scale exploitation of the merawan timber.

Assessor: Ashton, P.

Refs: $7673,9169,13857$

\section{Hopea pierrei}

Dipterocarpaceae

$\mathrm{EN} \mathrm{Alc}+2 \mathrm{c}, \mathrm{B} 1+2 \mathrm{c}, \mathrm{C} 1, \mathrm{D} 1$

Cambodia, Indonesia (Sumatra), Laos, Malaysia (Peninsular Malaysia), Thailand, Viet Nam

A relatively small dipterocarp, which is found mainly in lowland evergreen rainforest on sandy soils, and also in heath forest in parts of Indo-China. The timber is highly valued in Viet Nam and Cambodia. Populations in the former are seriously reduced by past chemical warfare, exploitation and habitat reduction. In Peninsular Malaysia the species is reported in several forest reserves.

Assessor: Ashton, $\mathrm{P}$.

Refs: $848,7673,9169,13857,14573,15357$

\section{Hopea plagata}

Dipterocarpaceae

CR Alcd, $\mathrm{B} 1+2 \mathrm{c}$

Malaysia (Sarawak), Philippines

The preferred habitat of the species is semi-evergreen forest and sometimes evergreen forest. It is one of the most popular timbers for heavy construction work in the Philippines.

Assessor: Ashton, $\mathrm{P}$.

Refs: $7673,9169,13857$

\section{Hopea polyallhioides}

Dipterocarpaceae

$\mathrm{CR} \mathrm{Alc}+2 \mathrm{c}, \mathrm{Bl}+2 \mathrm{c}, \mathrm{Cl}, \mathrm{DI}$

Malaysia (Peninsular Malaysia)

Endemic to south Johore and under severe threat of extinction, this dipterocarp species occurs on welldrained lowland forest.

Assessor: Ashton, $\mathrm{P}$

Refs: $7673,9169,13857$

\section{Hopea ponga}

Dipterocarpaceae

EN Alcd+2cd, B $1+2 c$

India (Goa, Karnataka, Kerala, Maharashtra, Tamil Nadu)

A gregarious tree, widely occurring in low to medium altitude evergreen forest, especially along riversides.

Assessor: Ashton, $\mathrm{P}$.

Refs: $8483,13857,15754,19144$

\section{Hopea pterygota}

Dipterocarpaceae

Malaysia (Sarawak)

VU Alc+2c, Bl+2c, Cl, Dl

Locally common in Perak forests, populations are also known to occur in forest reserves.

Assessor: Ashton, P.

Refs: $7673,9169,13857$

\section{Hopea pubescens}

Dipterocarpaceae

CR Alc, Bl+2c

Malaysia (Peninsular Malaysia)

Endemic to Peninsular Malaysia, this tree is often found on flat and hilly well-drained land. The species is relatively abundant in Pahang.

Assessor: Ashton, $\mathrm{P}$.

Refs: $5550,7673,9169,13857$

\section{Hopea quisumbingiana}

Dipterocarpaceae

$\mathrm{CR} \mathrm{Bl+2c}$

Philippines

A species known only from a single collection from Samar Island.

Assessor: World Conservation Monitoring Centre

Refs: 9501

\section{Hopea racophloea}

Dipterocarpaceae

India (Kamataka, Kerala)

EN Alcd $+2 c d, B l+2 c$

This tree is known from scarce and scattered collections from evergreen forests at the southern end of the Western Ghats.

Assessor: Ashton, P.

Refs: $3998,9169,13857,19144$

\section{Hopea recopei}

Dipterocarpaceae

Cambodia, Laos, Thailand, Viet Nam

The species is known to occur in forest reserves.

Assessor: Ashton, P.

Refs: 6206, 13857 


\section{Hopea reticulata}

Dipterocarpaceae

Thailand, Viet Nam

A species of seasonal evergreen forest.

Assessor: Ashton, P.

Refs: 7673,13857

\section{Hopea samarensis}

Dipterocarpaceae

Philippines

CR Alcd, Bl+2c, Cl, D1

The species is under severe threat from the loss of its forest habitat.

Assessor: Ashton, $\mathrm{P}$.

Refs: $7673,9169,13857$

\section{Hopea sangal}

Dipterocarpaceae

CR Alcd, Bl+2c, Cl, D1

Indonesia (Java, Lesser Sunda Is., Sumatra), Malaysia (Peninsular Malaysia), Myanmar, Singapore, Thailand

This tree is widely distributed, and locally common by rivers. It is commonly cut as merawan timber.

Assessor: Ashton, $\mathrm{P}$.

Refs: $3998,5550,7673,9169,9199,13857,17140$

\section{Hopea scabra}

Dipterocarpaceae

Papua New Guinea

Assessor: Ashton, P.

Refs: $7673,9169,13857$

\section{Hopea semicuneata}

\section{Dipterocarpaceae}

CR Alcd, Bl+2c

Indonesia (Kalimantan, Sumatra), Malaysia (Peninsular Malaysia)

A tree of lowland dipterocarp forest on clay-rich alluvium. It is cut for its giam timber.

Assessor: Ashton, $\mathrm{P}$.

Refs: $5550,7673,9169,13857$

\section{Hopea shingkeng}

Dipterocarpaceae

India (Arunachal Pradesh)

A small tree once locally exploited for house posts and now thought to be extinct.

Assessor: Ashton, $\mathrm{P}$.

Refs:13857, 15754

\section{Hopea siamensis}

Dipterocarpaceae

Cambodia, Thailand, Viet Nam

CR Alc, B $1+2 c$

Assessor: Ashton, $\mathrm{P}$.

Refs: 9169,13857

\section{Hopea sphaerocarpa}

Dipterocarpaceae

CR A $1 \mathrm{c}, \mathrm{B} 1+2 \mathrm{c}$

Indonesia (Kalimantan), Malaysia (Sarawak)

A tree of mixed dipterocarp forest, suffering from forest degradation.

Assessor: Ashton, $\mathrm{P}$.

Refs: $7673,9169,13857$

\section{Hopea subalata}

Dipterocarpaceae

Malaysia (Peninsular Malaysia)

A small tree, which is locally common but confined to a single locality in Selangor Province within the Kanching Forest Reserve.

Assessor: Ashton, $\mathbf{P}$.

Refs: $7673,9169,13857$
Hopea sublanceolata

Dipterocarpaceae

CR Alc, Bl+2c

Malaysia (Peninsular Malaysia)

A locally abundant tree found on undulating land and low spurs up to $150 \mathrm{~m}$. The species is common along river basins by Gunung Perak and Gunung Pahang.

Assessor: Ashton, P.

Refs: $5550,7673,9169,13857$

\section{Hopea sulcata}

Dipterocarpaceae

Malaysia (Peninsular Malaysia)

CR Alc, B1+2c

A gregarious tree which is locally common but restricted to forested ridges.

Assessor: Ashton, P.

Refs: $7673,9169,13857$

\section{Hopea tenuivervula}

Dipterocarpaceae

CR Alc, B1+2c

Brunei, Malaysia (Sabah, Sarawak)

A tree of northern Borneo found growing in mixed dipterocarp forest on low hills.

Assessor: Ashton, P.

Refs: $7673,9169,13857$

\section{Hopea thorelii}

Dipterocarpaceae

Laos, Thailand

Assessor: Ashton, $\mathrm{P}$.

Refs: 13857

\section{Hopea ultima}

Dipterocarpaceae

Papua New Guinea

There is a possibility that this dipterocarp is extinct in the wild.

Assessor: Ashton, $\mathrm{P}$.

Refs: $7673,9169,13857$

\section{Hopea utilis}

Dipterocarpaceae

EN C2a, D1

India (Kerala, Tamil Nadu)

This slow-growing species is restricted to a small area of semi-evergreen forest, usually near large rivers, in Thenmala and the Silent Valley in Kerala, and in Tirunelveli and Courtallam in Tamil Nadu. It regenerates copiously around the parent tree. Locally, the wood is used in construction work.

Assessor: Ashton, $\mathrm{P}$.

Refs: $3998,13857,19144$

\section{Hopea vaccinifolia}

Dipterocarpaceae

Brunei, Malaysia (Sarawak)

EN Alc, B1+2c, C2a

A tree which occurs in remaining patches of *kerangas vegetation in Brunei and Sarawak. It is locally abundant in heath forest.

Assessor: Ashton, P.

Refs: $7673,9169,13857$

\section{Hopea wightiana}

Dipterocarpaceae

India (Kamataka, Kerala, Tamil Nadu)

EN Alc $+2 c, B l+2 c$

A relatively small tree, locally used for construction. It can occur frequently and regeneration is observed to be good.

Assessor: Ashton, P.

Refs. 3998, 9169, 13857 
Hopea wyatt-smithii

Dipterocarpaceae

$\mathrm{CRAl}+2 \mathrm{c}, \mathrm{Bl}+2 \mathrm{c}$

Indonesia (Kalimantan)

A species of mixed dipterocarp forest, under severe threat from habitat degradation.

Assessor: Ashton, P.

Refs: $7673,9169,13857$

\section{Horsfieldia ampla}

Myristicaceae

VU D2

Papua New Guinea

A small tree known only from the type collection which was found in dense humid forest in Sepik Province.

Assessor: World Conservation Monitoring Centre

Refs: 18674

\section{Horsfieldia ampliformis}

Myristicaceae

VU D2

Papua New Guinea

A small tree of lower montane rainforest, known from two collections, one from Sepik Province and the other from Morobe Province.

Assessor: World Conservation Monitoring Centre

Refs: 18674

\section{Horsfieldia amplomontana}

Myristicaceae

VU D2

Malaysia (Sabah)

Endemic to Mount Kinabalu, the species is known from four collections taken from primary and secondary forest.

Assessor: World Conservation Monitoring Centre

Refs: 1766,3597

\section{Horsfieldia androphora}

Myristicaceae

VU D2

Malaysia (Sabah, Sarawak)

A montane forest tree, collected once from Sabah and three times from Sarawak.

Assessor: World Conservation Monitoring Centre

Refs: 1766,3597

\section{Horsfieldia ardisiifolia}

Myristicaceae

VUAlc

Philippines

A Philippines endemic found in lowland forests in moist valleys on the islands of Luzon, Mindoro, Sibuyan, Samar and Leyte.

Assessor: World Conservation Monitoring Centre

Refs: 18674

\section{Horsfieldia atjehensis}

Myristicaceae

VU D2

Indonesia (Sumatra)

A montane forest species known from a single collection from North Aceh.

Assessor: World Conservation Monitoring Centre

Refs: 319,10547

\section{Horsfieldia borneensis}

Myristicaceae

Indonesia (Kalimantan), Malaysia (Sabah, Sarawak)

This species is apparently specific to primary lowland dipterocarp forests.

Assessor: World Conservation Monitoring Centre

Refs: 1766,3597

\section{Horsfieldia camosa}

Myristicaceae

LR/nt

Brunei, Indonesia (Kalimantan), Malaysia (Sabah, Sarawak)

Restricted to lowland areas of Bomeo, this is a small tree that grows in heath forest, wet *kerangas forest, peat-swamp forest and Agathis-Casuarina forest.

Assessor: World Conservation Monitoring Centre

Refs: 319,1766

\section{Horsfieldia clavata}

Myristicaceae

VU D2

Papua New Guinea

A shrub or small tree which, although locally common, has been collected only three times from tall lowland forest on well-drained soils in the Northern Province.

Assessor: World Conservation Monitoring Centre

Refs: 18674

\section{Horsfieldia coriacea}

Myristicaceae

LR/nt

Indonesia (Sulawesi)

Endemic to central Sulawesi, the species is restricted to primary and disturbed forest on ultrabasic soil.

Assessor: World Conservation Monitoring Centre

Refs: 3597

\section{Horsfieldia crassifolia}

Myristicaceae

Brunei, Indonesia (Kalimantan, Sumatra), Malaysia (Peninsular Malaysia, Sabah, Sarawak), Singapore

A lowland tree which is fairly widespread in marshy forest and freshwater peat-swamp forest.

Assessor: World Conservation Monitoring Centre

Refs: 319,9199

\section{Horsfieldia crux-melitensis}

Myristicaceae

Papua New Guinea

A small tree or shrub, which is restricted to mixed lowland rainforest in Morobe Province. It has been collected only six times.

Assessor: World Conservation Monitoring Centre Refs: 18674

\section{Horsfieldia decalvata}

Myristicaceae

VU D2

Indonesia (Moluccas)

A lowland forest tree known from single collections from each of the following islands: Morotai, Halmaheira, Ceram and Ambon.

Assessor: World Conservation Monitoring Centre Refs: 17232,18674

\section{Horsfieldia discolor}

Myristicaceae

Indonesia (Kalimantan), Malaysia? (Sabah?, Sarawak?)

This species is known from the type collection, gathered in East Kalimantan, and from some doubtful specimens from Sabah, Sarawak and Brunei.

Assessor: World Conservation Monitoring Centre Refs: 8148

\section{Horsfieldia disticha}

Myristicaceae

VU D2

Brunei

A species of lowland rainforest, known from the type 
collection in Andulau Forest Reserve and from another specimen from Kuala Belait District.

Assessor: World Conservation Monitoring Centre

Refs: 1766,3597

\section{Horsfieldia elongata}

Myristicaceae

VU D2

Malaysia (Peninsular Malaysia)

A small tree known only from the type collection from Fraser's Hill.

Assessor: World Conservation Monitoring Centre

Refs: 8148

\section{Horsfieldia flocculosa}

Myristicaceae

VU B $1+2 c$

Malaysia (Peninsular Malaysia)

Endemic to Peninsular Malaysia, this tree is known only from lowland rainforest and swamp forest in Selangor, Negri Sembilan, Pahang and Johore. No recent collections have been made of this species and it is threatened by expanding settlements and logging activities.

Assessor: Chua, L.S.L.

Refs: $319,19073,19078$

\section{Horsfieldia fragillima}

Myristicaceae

VU Alc

Brunei, Indonesia (Kalimantan), Malaysia (Sabah,

Sarawak)

This tree is restricted to primary lowland dipterocarp forest and riverine forests.

Assessor: World Conservation Monitoring Centre

Refs: 1766,3597

\section{Horsfieldia fulva}

Myristicaceae

VU Alc

Indonesia (Sumatra), Malaysia (Peninsular Malaysia)

A rare tree occurring in lowland rainforest up $10200 \mathrm{~m}$ in

Jambi Province, Sumatra, and Peninsular Malaysia. In

Peninsular Malaysia the species is threatened by urban expansion and logging activities.

Assessor: de Wilde, W.J.J.O

Refs: $319,11647,19073,19078$

\section{Horsfieldia glabra var. javanica}

Myristicaceae

VU D2

Indonesia (Java)

This variety is known from only two collections.

Assessor: World Conservation Monitoring Centre

Refs: 3597

\section{Horsfieldia glabra var. oviflora}

Myristicaceae

Indonesia (Java)

Restricted to west and central Java, this variety has been collected just five times from submontane forest.

Assessor: World Conservation Monitoring Centre Refs: 3597

\section{Horsfieldia gracilis}

Myristicaceae

Brunei, Malaysia (Sarawak)

A small tree found only once in primary lowland forest in Sarawak. In addition, three slightly different collections have been identified as this species. They may represent intermediates between $H$. paucinervis and H. gracilis.

Assessor: World Conservation Monitoring Centre

Refs: 319,2147
Horsfieldia hellwigii var. brachycarpa

Myristicaceae

VU D2

Papua New Guinea

This variety is known from only four collections from northern Papua New Guinea.

Assessor: World Conservation Monitoring Centre

Refs: 18674

\section{Horsfieldia hirtiflora}

Myristicaceae

VU D2

Indonesia (Sumatra)

A small tree which is known from just three collections from Tapanuli and the east coast.

Assessor: World Conservation Monitoring Centre

Refs: 3597,10547

\section{Horsfieldia iriana}

Myristicaceae

VU D2

Indonesia (Irian Jaya)

This tree is known only from the type collection, which was gathered from a site in south-west New Guinea. Assessor: World Conservation Monitoring Centre Refs: 18674

\section{Horsfieldia iryaghedhi}

Myristicaceae

CR B $1+2 \mathrm{c}$

Sri Lanka

Endemic to Sri Lanka, this tree occurs in lowland wet evergreen forest and disturbed forest. It is cultivated in Singapore, Penang and Java. This species was not found during the extensive forest surveys conducted for the National Conservation Review, indicating that it is either extremely rare or possibly extinct.

Assessor: World Conservation Monitoring Centre Refs: $15919,17195,19112$

\section{Horsfieldia lancifolia}

Myristicaceae

LR/nt

Indonesia (Sulawesi)

A tree endemic to forest areas on ultrabasic soils in central and south Sulawesi. Sulawesi has the largest tract of forest over ultrabasic soils in the tropics. The nature of the soil renders it unattractive to agriculture. Assessor: World Conservation Monitoring Centre Refs: 10148,18674

\section{Horsfieldia leptantha}

Myristicaceae

Indonesia (Irian Jaya), Papua New Guinea

This tree is known from six or seven collections from primary and secondary forest areas in Vogelkop in Irian Jaya and West Sepik in Papua New Guinea.

Assessor: World Conservation Monitoring Centre Refs: 18674

\section{Horsfieldia longiflora}

Myristicaceae

VU D2

Viet Nam

Collected only five times, the species appears to be restricted to submontane evergreen forests in Annam. Assessor: World Conservation Monitoring Centre Refs: 15919

\section{Horsfieldia macilenta}

Myristicaceae

VUAlc Indonesia (Sumatra), Malaysia (Peninsular Malaysia, Sabah, Sarawak)

A rare tree found growing in lowland primary mixed dipterocarp forest and swamp forest. There are eight 
collections in total.

Assessor: World Conservation Monitoring Centre Refs: 3597

\section{Horsfieldia macrothyrsa}

Myristicaceae

LR/nt

Indonesia (Sumatra)

A small tree of submontane and riverine forest apparently restricted to Mount Sago, central and northem Sumatra.

Assessor: World Conservation Monitoring Centre

Refs: 3597, 10547

\section{Horsfieldia moluccana var. moluccana}

Myristicaceae

$\mathrm{LR} / \mathrm{nt}$

Indonesia (Moluccas)

This variety is found in well-drained forest on Obi and Morotai Islands.

Assessor: World Conservation Monitoring Centre

Refs: 18674

\section{Horsfieldia moluccana var. pubescens}

Myristicaceae

VU D2

Indonesia (Irian Jaya)

This variety is common in primary and secondary forest on limestone, so far known from four collections from the Vogelkop Peninsula.

Assessor: World Conservation Monitoring Centre

Refs: 18674

\section{Horsfieldia moluccana var. robusta}

Myristicaceae

VU D2

Indonesia (Irian Jaya)

Known from three collections from the Vogelkop Peninsula and Batanta Island, the variety grows in lowland secondary and coastal forest on limestone. Assessor: World Conservation Monitoring Centre Refs: 18674

\section{Horsfieldia montana}

Myristicaceae

LR/nt

Brunei, Malaysia (Sabah, Sarawak)

A small to medium-sized tree found in montane and *kerangas forest in northem Borneo. All the specimens from Sabah were collected from the vicinity of Mount Kinabalu and they differ from the collections from Brunei and Sarawak.

Assessor: World Conservation Monitoring Centre

Refs: 1766, 3597

\section{Horsfieldia motleyi}

Myristicaceae VU Alc

Indonesia (Kalimantan), Malaysia (Sabah, Sarawak)

An uncommon species found throughout Bomeo in primary and disturbed lowland forest up to $600 \mathrm{~m}$.

Assessor: de Wilde, W.J.J.O.

Refs: 319,1766

\section{Horsfieldia nervosa}

Myristicaceae

VU D2

Malaysia (Sarawak)

To date this species is known from just two collections from primary forest in the First Division of Sarawak. Assessor: World Conservation Monitoring Centre Refs: 1766,3597

\section{Horsfieldia obscura}

Myristicaceae VU D2

Indonesia (Kalimantan), Malaysia? (Sarawak?)

A species restricted to East Kalimantan (two collections). It grows in lowland dipterocarp forest and in ridge forest on limestone.

Assessor: World Conservation Monitoring Centre Refs: 1766,3597

\section{Horsfieldia obscurineria}

Myristicaceae

EN B $1+2 c$

Philippines

A small tree restricted to Luzon, where it has been collected just three times.

Assessor: World Conservation Monitoring Centre Refs: 18674

\section{Horsfieldia obtusa}

Myristicaceae

Malaysia (Sarawak)

This species is known from a single herbarium specimen collected from Sarawak. Nothing is known of its ecology or the specific location of the collection. Assessor: World Conservation Monitoring Centre Refs: 1766,3597

\section{Horsfieldia oligocarpa}

Myristicaceae

Brunei, Malaysia (Sarawak)

LR/nt

A tree of *kerangas and forest on poor soils confined to Sarawak and Brunei up to $50 \mathrm{~m}$.

Assessor: World Conservation Monitoring Centre Refs: $1766,3597,19078$

\section{Horsfieldia pachyrachis}

Myristicaceae VU D2

Indonesia (Kalimantan)

A tree known only from the type specimen, which was collected in Bukit Kelawai in West Kalimantan in 1939. The area is relatively unexplored.

Assessor: World Conservation Monitoring Centre Refs: 1766,3597

\section{Horsfieldia palauensis}

Myristicaceae

LR/nt

Palau

This tree is locally common in primary lowland forest and is found only on the Palau Islands.

Assessor: World Conservation Monitoring Centre Refs: 18674

\section{Horsfieldia pallidicaula var. macrocarya}

Myristicaceae

VU D2

Malaysia (Sarawak)

A variety found in lowland mixed dipterocarp forest and known from just two collections.

Assessor: World Conservation Monitoring Centre Refs: 319

\section{Horsfieldia pallidicaula var. microcarya}

Myristicaceae

VU D2

Indonesia? (Kalimantan?), Malaysia (Sabah)

This variety is known only from the type collected in lowland forest in west Sabah and one other dubious collection from East Kalimantan.

Assessor: World Conservation Monitoring Centre Refs: 319 


\section{Horsfieldia pallidicaula var. pallidicaula} Myristicaceae

VU A1c Indonesia? (Kalimantan?), Malaysia (Sabah, Sarawak)

A variety found in primary lowland and lower montane forests in Sarawak and west Sabah. The collection from West Kalimantan is doubtful.

Assessor: World Conservation Monitoring Centre Refs: 319

\section{Horsfieldia pandurifolia}

Myristicaceae

$\mathrm{EN} \mathrm{B1+2c}$

China (Yunnan)

Endemic to southern Yunnan, occurring in Mengling, Xishuangbanna and Gengma, the species is scattered sparsely in lowland monsoon forest. Most of the range is contained within nature reserves. Overcollection of the seeds, which provide a commercial oil, and of the timber have caused declines in population numbers, particularly in the number of fertile female trees.

Assessor: Sun, W.

Refs: $1818,11847,19005,19055$

\section{Horsfieldia paucinervis}

Myristicaceae

VU D2

Malaysia (Sarawak)

A small slender tree apparently endemic to Sarawak and known from just four collections. It grows in coastal *kerangas and secondary forest on eroded white sand.

Assessor: World Conservation Monitoring Centre

Refs: 319, 1766

\section{Horsfieldia penangiana ssp. obtusifolia}

Myristicaceae

VU D2

Indonesia (Kalimantan), Malaysia (Sarawak)

This subspecies is known from four collections from Borneo. It is found in forest on hills and ridges.

Assessor: World Conservation Monitoring Centre

Refs: 2147

\section{Horsfieldia penangiana ssp. penangiana}

Myristicaceae

VU Alc

Indonesia (Sumatra), Malaysia (Peninsular Malaysia)

A tree found in primary dry montane forest. It is known from seven collections from Peninsular Malaysia and Sumatra.

Assessor: World Conservation Monitoring Centre

Refs: 2147

\section{Horsfieldia perangusta}

Myristicaceae

VU D2

Malaysia (Peninsular Malaysia)

A small slender tree known only from the type collection from the Ulu Endau Forest Reserve.

Assessor: World Conservation Monitoring Centre

Refs: 2147

\section{Horsfieldia polyspherula var. maxima}

Myristicaceae VUAlc

Indonesia (Kalimantan), Malaysia (Sabah, Sarawak)

This variety is found in lowland mixed forest in Sarawak, Sabah and East Kalimantan.

Assessor: World Conservation Monitoring Centre Refs: 3597

\section{Horsfieldia pulcherrima}

Myristicaceae

Indonesia (Sumatra), Malaysia (Peninsular Malaysia)

A rare tree of lowland primary forest and swamp forest.
It is known from five collections from Pahang and Johore and from a single sterile collection from Jambi, Sumatra.

Assessor: World Conservation Monitoring Centre Refs: 319

\section{Horsfieldia punctata}

Myristicaceae

Malaysia (Peninsular Malaysia)

VU D2

This species is apparently endemic to the Cameron Highlands, from where it has been collected three times in areas of lower montane forest on granite and in ridge forest.

Assessor: World Conservation Monitoring Centre Refs: 3597,15919

\section{Horsfieldia reticulata}

Myristicaceae

LR/nt

Indonesia (Kalimantan), Malaysia (Sarawak)

This lowland forest tree occurs throughout much of Borneo, although it has not yet been collected in Sabah. Assessor: World Conservation Monitoring Centre Refs: 319,1766

\section{Horsfieldia rufo-lanata}

Myristicaceae

VU D2

Malaysia (Sabah, Sarawak)

Found in upper dipterocarp forest, the species has been collected just four times from Sarawak and Sabah.

Assessor: World Conservation Monitoring Centre Refs: 319,1766

\section{Horsfieldia sabulosa}

Myristicaceae

VUD2

Brunei, Malaysia (Sabah, Sarawak)

A tall tree found in lowland mixed forest, Agathis forest and ridge forest with a restricted distribution. No recent collections have been made.

Assessor: de Wilde, W.J.J.O.

Refs: $319,1766,19078$

\section{Horsfieldia samarensis}

Myristicaceae

VU D2

Philippines

This small tree is known only from the type, which was collected on Samar Island.

Assessor: World Conservation Monitoring Centre Refs: 18674

\section{Horsfieldia sepikensis}

Myristicaceae

VU D2

Papua New Guinea

A tree found in both primary and secondary forest. So far it is only known from three collections from East Sepik Province.

Assessor: World Conservation Monitoring Centre Refs: 18674

\section{Horsfieldia sessilifolia}

Myristicaceae

CR Alc, Bl+2c

Malaysia (Sarawak)

Collected only once in 1971 from a threatened swamp forest in Sarawak. Most of the peat-swamp forest in Sarawak has been licensed for timber extraction. Assessor: World Conservation Monitoring Centre Refs: $319,1766,3597,18088$ 


\section{Horsfieldia sparsa}

Myristicaceae

LR/nt

Indonesia (Sumatra), Malaysia (Peninsular Malaysia),

Singapore, Thailand

An uncommon tree found in both primary and secondary dryland forest, as well as periodically inundated forest up to $350 \mathrm{~m}$. It is relatively widely distributed in Peninsular Malaysia, but known only from a single collection in Peninsular Thailand, two collections from northem Sumatra and one from Singapore.

Assessar: de Wilde, W.J.J.O.

Refs: 319,9199

\section{Horsfieldia splendida}

Myristicaceae

$\mathrm{LR} / \mathrm{nt}$

Brunei, Indonesia (Kalimantan), Malaysia (Sabah, Sarawak)

A species, endemic to Borneo, found in lowland mixed dipterocarp forest, *kerangas forest and montane forest usually below $600 \mathrm{~m}$ but occasionally found at altitudes up to $1500 \mathrm{~m}$. The species has not been collected recently.

Assessor: de Wilde, W.J.J.O.

Refs: $319,1766,19078$

\section{Horsfieldia squamulosa}

Myristicaceae

VU D2

Papua New Guinea

A locally common understorey shrub or small tree restricted to the Western Province and known only from three collections.

Assessor: World Conservation Monitoring Centre Refs: 8148

\section{Horsfieldia sterilis}

Myristicaceae

VU D2

Malaysia (Sabah)

Locally endemic to Tawau, this small tree or shrub is known only from four specimens.

Assessor: World Conservation Monitoring Centre

Refs: 319, 1766

\section{Horsfieldia subalpina ssp. kinabaluensis}

Myristicaceae

$\mathrm{LR} / \mathrm{cd}$

Malaysia (Sabah, Sarawak?)

This subspecies is found in montane forest on Mount Kinabalu and the surrounding area. A collection which is doubtfully this species was taken from east Sarawak. Assessor: World Conservation Monitoring Centre Refs: 1766,3597

\section{Horsfieldia subtilis var, rostrata}

Myristicaceae

VU D2

Papua New Guinea

A variety of mossy montane forest, known only from the type collection from Etappenberg, Sepik Province.

Assessor: World Conservation Monitoring Centre Refs: 18674

\section{Horsfieldia sucosa ssp. bifissa}

Myristicaceae

VU Alc

Indonesia (Kalimantan), Malaysia (Sabah)

A subspecies found in lowland forest and Shorea laevifolia forest in east Sabah and east and south Kalimantan.

Assessor: World Conservation Monitoring Centre

Refs: 319

\section{Horsfieldia superba}

Myristicaceae LR/nt

Indonesia (Sumatra), Malaysia (Peninsular Malaysia), Singapore

A tree scattered in lowland, hill and swamp forest. This species has not been collected recently and it is threatened by increasing settlement and logging of the area.

Assessor: Chua, L.S.L.

Refs: $319,9199,17140,19073,19078$

\section{Horsfieldia talaudensis}

Myristicaceae

VU D2

Indonesia (Sulawesi)

A tree collected four or five times in old forest at low altitudes on mountain slopes in the Talaud Islands. There is a collection from mainland Sulawesi, but it is held in some doubt.

Assessor: World Conservation Monitoring Centre

Refs: 4329,18674

\section{Horsfieldia tenuifolia}

Myristicaceae

Malaysia (Sabah, Sarawak)

VU D2

An understorey tree of lowland dipterocarp forest restricted to the Beaufort Hill and Jesselton in Sabah and the First Division of Sarawak.

Assessor: de Wilde, W.J.J.O.

Refs: 1766, 3597

\section{Horsfieldia tomentosa}

Myristicaceae

LR/nt

Indonesia (Sumatra), Malaysia (Peninsular Malaysia), Singapore?, Thailand

A tree of lowland and hill forest found up to $300 \mathrm{~m}$.

Assessor: de Wilde, W.J.J.O.

Refs: 319,9199

\section{Horsfieldia triandra}

Myristicaceae

VU D2

Indonesia (Sumatra)

A tree known from two collections in central and south Sumatra.

Assessor: World Conservation Monitoring Centre Refs: 319,10547

\section{Horsfieldia tristis}

Myristicaceae VU D2

Indonesia (Kalimantan, Sumatra), Malaysia (Sarawak)

A species known from five localities in lowland forest. Assessor: World Conservation Monitoring Centre Refs: 319

\section{Horsfieldia tuberculata var. crassivalva}

Myristicaceae

VU D2

Papua New Guinea

A subcanopy tree known from three or four collections from Misima, Tagula and Rossel Islands. The collection from San Cristobal is doubtful.

Assessor: World Conservation Monitoring Centre Refs: 18674

\section{Horsfieldia urceolata}

Myristicaceae

VU D2

Papua New Guinea

A small tree or shrub which has been collected two or three times from lowland primary rainforest.

Assessor: World Conservation Monitoring Centre Refs: 8148 


\section{Horsfieldia valida}

Myristicaceae

Indonesia (Kalimantan?, Sumatra)

This tree is known from five collections taken from primary and ravine forest on the east and west coast of Sumatra. A collection, which is only doubtfully this species, was taken from Mount Damoes, West Kalimantan.

Assessor: World Conservation Monitoring Centre Refs: 3597,10547

\section{Horsfieldia xanthina ssp. macrophylla}

Myristicaceae

VU D2

Malaysia (Sabah, Sarawak)

Only three collections of this montane forest species are known, two from east Sarawak and one from Mount Kinabalu, Sabah.

Assessor: World Conservation Monitoring Centre Refs: 3597

\section{Horsfieldia xanthina ssp. xanthina}

Myristicaceae

VU D2

Malaysia (Sarawak)

This subspecies is known from only four collections from Mount Dulit, Sarawak.

Assessor: World Conservation Monitoring Centre

Refs: 1766, 3597

\section{Hortonia angustifolia}

Monimiaceae

$\mathrm{CR} B 1+2 \mathrm{c}$

Sri Lanka

A tree restricted to lowland rainforest in south-west Sri Lanka. Previously the species was found at a single locality within Sinhararja Biosphere Reserve. However, it was not found during the extensive forest surveys conducted for the National Conservation Review, indicating that it is either extremely rare or possibly extinct.

Assessor: World Conservation Monitoring Centre

Refs: $9176,17195,19112$

\section{Howea belmoreana}

Palmae

VU D2

Australia (New South Wales - Lord Howe Is.)

A palm tree, endemic to Lord Howe Island, found in lowland and submontane moist forest between 100 and $300 \mathrm{~m}$. A valuable omamental, the seeds of wild trees are collected and germinated, and the seedlings are exported. The seed industry is strictly regulated. Lord Howe Island is a World Heritage Site, most of which is a permanent park reserve.

Assessor: Johnson, D.

Refs: 19118

\section{Howea forsteriana}

Palmae

VU D2

Australia (New South Wales - Lord Howe Is.)

A palm tree endemic to Lord Howe Island, a World Heritage Site. It occurs in lowland and submontane moist forest up to $300 \mathrm{~m}$. The seeds of wild trees are collected and germinated, and the seedlings are exported. The seed industry is strictly regulated.

Assessor: Johnson, D.

Refs: 19118

\section{Huberodendron patinoi}

Bombacaceae

Colombia, Ecuador, Panama?

The species occurs in forest types of varying humidity.
There is an unconsolidated report that the species has been found in Panama. Otherwise populations are confined to Chocó, Córdoba, Valle del Cauca and other parts of Colombia and also Ecuador. Population numbers do not appear to be large and much of the habitat is under threat from increasing settlement, logging and agriculture.

Assessor: Mitré, $\mathbf{M}$.

Refs: 16772

\section{Huertea cubensis}

Staphyleaceae

VU B1 $+2 c$

Cuba, Dominican Republic, Haiti

A rare tree found in the remaining stands of semideciduous forest on limestone-derived soils. Its habitat has been severely degraded in most places in Cuba. It is infrequently found on Hispaniola.

Assessor: Areces-Mallea, A.E.

Refs: 19149

\section{Huilaea kirkbridei}

Melastomataceae

$\mathrm{EN} \mathrm{B1}+2 \mathrm{c}$

Colombia

An endemic to Magdalena.

Assessor: Calderon, E.

Refs: 19069

\section{Huilaea macrocarpa}

Melastomataceae

$\mathrm{EN} \mathrm{B} 1+2 \mathrm{c}$

Colombia

An endemic to Boayaca.

Assessor: Calderon, E.

Refs: 19069

\section{Huilaea minor}

Melastomataceae

$\mathrm{EN} \mathrm{B1}+2 \mathrm{c}$

Colombia

An endemic species known to occur in Santander and possibly also Boyaca.

Assessor: Calderon, E.

Refs: 19069

\section{Huilaea mutisiana}

Melastomataceae

EN B $1+2 c$

Colombia

Endemic to Colombia, the species is recorded from Boyaca and Santander.

Assessor: Calderon, E.

Refs: 19069

Huilaea occidentalis

Melastomataceae

VU B1+2c

Colombia

An endemic to Cauca.

Assessor: Calderon, E. Refs: 19069

\section{Huilaea penduliflora}

Melastomataceae

EN B $1+2 c$

Colombia

An endemic to Huila.

Assessor: Calderon, E.

Refs: 19069

\section{Humboldtia bourdillonii}

Leguminosae

$\mathrm{EN} \mathrm{B1+2c}$

India (Kerala, Tamil Nadu)

Collections of the species were made at the tum of the century from Peermade and Courtallum at the southern 
end of the Westem Ghats. There do not appear to be any more recent records and there is concem that extensive forest clearance and the spreading cultivation of cardamom have caused serious declines in population numbers.

Assessor: World Conservation Monitoring Centre Refs: 2538, 19144

\section{Humboldtia decurrens}

Leguminosae

India (Kerala)

LR/nt

A common species of low to medium elevation evergreen forest, confined to southem parts of the Western Ghats, ranging from the Anamalai Hills to the Travancore range.

Assessor: World Conservation Monitoring Centre

Refs: 2538, 19144

\section{Humboldtia laurifolia}

Leguminosae

VU Alc, B1+2cd

India (Kerala), Sri Lanka

A shrub or small tree recorded from two localities in the Western Ghats and throughout Sri Lanka. In India it was originally known to occur in shady places along streamsides up to $600 \mathrm{~m}$, but there have been no records of it since 1874. It appears to be fairly common in Sri Lanka, occurring in 66 forest sites according to surveys conducted for the National Conservation Review.

Assessor: World Conservation Monitoring Centre Refs: 14276,19112

\section{Humboldtia unijuga var. trijuga}

Leguminosae

India (Kerala)

CR Bl+2c

A small tree of submontane evergreen forest in the Travancore range, which is known only from the type collection dating to the 19 th century.

Assessor: World Conservation Monitoring Centre

Refs: $2538,6925,19144$

\section{Humboldtia unijuga var, unijuga}

Leguminosae

$\mathrm{EN} \mathrm{B} 1+2 \mathrm{c}$

India (Kerala, Tamil Nadu)

This variety is sympatric with var. trijuga, occurring in a small area of submontane forest in the Travancore range. Since the type specimen was collected in the last century, a second record of the species has been made in an area close by.

Assessor: World Conservation Monitoring Centre

Refs: 2538,19144

\section{Humiriastrum melanocarpum}

Humiriaceae

$\mathrm{EN} \mathrm{Bl}+2 \mathrm{C}$

Colombia

An endemic to Valle.

Assessor: Calderon, E

Refs: 19069

\section{Hunga cordata}

Chrysobalanaceae

New Caledonia

Assessor: Jaffré, T. et al.

Refs: 10351

\section{Hunga gerontogea}

Chrysobalanaceae

New Caledonia

$\mathrm{VU} B 1+2 \mathrm{C}$

Assessor: Jaffré, T. et al.

Refs: 10351
Hunga guillauminii

Chrysobalanaceae

New Caledonia

VU B I +2c

Assessor: Jaffre, $T_{\text {. et al }}$

Refs: 10351

\section{Hunga mackeeana}

Chrysobalanaceae

New Caledonia

VU BI+2c

Assessor: Jaffré, T. et al.

Refs: 10351

\section{Hunteria ghanensis}

Apocynaceae

EN Alc, $\mathrm{Bl}+2 \mathrm{c}$

Ghana

Officially this is a Ghanaian endemic but it may have been overlooked elsewhere. It is confined to extreme dry forest in the south, where the effects of human population growth and the expansion of agriculture have caused severe declines in the habitat. Most recorded occurrences are in forest which is unprotected and has since disappeared.

Assessor: Hawthome, W.

Refs: 8369,12061

\section{Huodendron parviflorum}

Styracaceae

VU D2

Viet Nam

So far recorded only from Viet Nam, this small tree appears to be restricted to Mong Cai in Quang Ninh, on the border with China.

Assessor: World Conservation Monitoring Centre

Refs: 848

\section{Hydnocarpus cucurbitina}

Flacourtiaceae

Malaysia (Peninsular Malaysia)

Occurring in rainforest below $210 \mathrm{~m}$, the species is protected in Taman Negara National Park.

Assessor: Chua, L.S.L.

Refs: 8464,19073

\section{Hydnocarpus filipes}

Flacourtiaceae

Malaysia (Peninsular Malaysia)

VU B1+2a

A medium to large species inhabiting the moist lowland and hill forests of Terengganu, Perak, Selangor and Pahang.

Assessor: Chua, L.S.L.

Refs: 17140,19073

\section{Hydnocarpus hainanensis}

Flacourtiace

VU Alcd

China (Guangdong - Hainan, Guangxi), Viet Nam

A tree of monsoon forest occurring at low elevation in mountainous regions. The Chinese population is largely found on Hainan Island, where levels of deforestation at this altitude have been very high. In Viet Nam there has also been extensive declines in the habitat and the species is reported to be regenerating poorly. The timber is used in industry and agriculture.

Assessor: World Conservation Monitoring Centre Refs: $1818,11847,15357$

\section{Hydnocarpus humei}

Flacourtiaceae

VU D2

Malaysia (Peninsular Malaysia)

A small tree known from only two collections in 
lowland open quartzite forest in Laut, Perak, and Klang Gates, Selangor.

Assessor: Chua, L.S.L.

Refs: 8464,19073

\section{Hydnocarpus kurzii}

\section{Flacourtiaceae}

India, Myanmar

Information from India indicates the species has declined by $50 \%$ in population numbers in the last 10 years. Fewer than 20 locations are known in northeastem India, where the species is found in areas of evergreen forest between 200 and $800 \mathrm{~m}$. Oil is harvested from the fruits and traded locally. More information is needed on the population status in Myanmar.

Assessor: CAMP Workshops on Medicinal Plants in India

Refs: 19209

\section{Hydnocarpus macrocarpa ssp. macrocarpa}

Flacourtiaceae

VU B $1+2 c$

India (Kerala, Tamil Nadu)

The main concentration of populations occurs near Muthukuzhivayal in evergreen hill forest. Large areas of forest have been destroyed for the Kodayar Hydroelectric Project and also for the establishment of plantation crops. Outlying populations exist further north towards Anamalai. Fruits have been overcollected. Assessor: CAMP Workshops on Medicinal Plants in India

Refs: $561,4799,5651,19144$

\section{Hydnocarpus nana}

Flacourtiaceae

LR/nt

Malaysia (Peninsular Malaysia)

A shrub or small tree of lowland and hill rainforest. Populations are found in Selangor and Terengganu, where they are protected within the boundaries of Taman Negara National Park.

Assessor: Chua, L.S.L.

Refs: 8464,19073

\section{Hydnocarpus octandra}

Flacourtiaceae

VU Alc

Sri Lanka

A tree occurring in the lowland wet evergreen forests of south-west Sri Lanka.

Assessor: World Conservation Monitoring Centre

Refs: 8203, 17195

\section{Hydnocarpus scortechinii}

Flacourtiaceae

$\mathrm{EN} \mathrm{Bl+2c}$

Malaysia (Peninsular Malaysia)

A primary lowland forest species, found in two coastal localities in Peninsular Malaysia. Increasing tourism and settlement in the vicinity are the main pressures faced by the species.

Assessor: Chua, L.S.L.

Refs: 8464, 19073

\section{Hydrochorea acreana}

Leguminosae

Brazil (Acte)

A tree known from non-inundated Amazonian forest in Acre. Until the fruit is discovered, there will be some doubt as to the taxonomic placement of the species.

Assessor: World Conservation Monitoring Centre Refs: 5994
Hydrochorea marginata var. scheryi

Leguminosae

LR/nt

Venezuela

A small tree or shrub so far found only along the Orinoco River between Pto Ayacucho and Sanariapo, Amazonas.

Assessor: World Conservation Monitoring Centre Refs: 5994

\section{Hyeronima clusioides}

Euphorbiaceae

DD

Puerto Rico

A species of moist hills and mountain forests in central and westem Puerto Rica. The wood is good quality and used as lumber.

Assessor: World Conservation Monitoring Centre Refs: 7931,7980

\section{Hyeronima jamaicensis}

Euphorbiaceae

VU $B 1+2 c$

Jamaica

An uncommon tree, confined to moist woodlands on limestone between 700 and $900 \mathrm{~m}$ in St Andrew, Clarendon, St Ann and Portland Parishes. The loss of habitat has been particularly severe in St Andrew. Assessor: World Conservation Monitoring Centre Refs: $6057,7980,19116$

\section{Hymenaea torrei}

Leguminosae

VU B $1+2 \mathrm{c}$

Cuba

A tall shrub or tree restricted to the dry evergreen forests and dry lowland shrubwoods of eastern Cuba. Habitat declines have been considerable in both communities; logging activities, agriculture and urban development are resulting in land clearance and habitat degradation Assessor: Areces-Mallea, A.E.

Refs: $9522,11403,19149$

\section{Hymenostegia aubrevillei}

Leguminosae

Côte d'Ivoire, Ghana, Nigeria

VU Alc, Bl+2c

In Ghana this species occurs in the region of the Krokosua Hills. It is also known in upland evergreen forest on the other side of the Dahomey Gap and in Côte d'Ivoire. Farming, fire, forest management and mining are causes of habitat decline.

Assessor: Hawthome, W.

Refs: 2773, 8369, 12061

\section{Hymenostegia bakeriana}

Leguminosae

VU B $1+2 c$

Cameroon, Nigeria

Populations of this small forest tree are protected but confined to the Oban Division of the Cross River National Park and the adjacent Korup National Park in Cameroon. Large-scale deforestation has taken place in surrounding areas.

Assessor: World Conservation Monitoring Centre Refs: $2773,4977,7550,11504$

\section{Hymenostegia gracilipes}

Leguminosae

$\mathrm{EN} \mathrm{B1}+2 \mathrm{c}$

Ghana

Endemic to Ghana, this species is rare within a restricted wet evergreen forest habitat, which has declined in 
extent because of mining, logging and commercial forestry activities.

Assessor: Hawthome, W.

Refs: 2773, 8369, 12061

\section{Hymenostegia talbotii}

Leguminosae

CR B $1+2 c$

Nigeria

A little-known species, which has been recorded only from Eket in south-east Nigeria. Oil exploration operations in this area have caused the destruction of most if not all the forest habitat.

Assessor: World Conservation Monitoring Centre

Refs: $450,2773,11504$

\section{Hyophorbe amaricaulis}

\section{Palmae}

CR D1

\section{Mauritius}

Only a single individual remains in Curepipe, south-west central Mauritius, where it is now contained within a botanical garden. It is unlikely further individuals exist in the wild. The tree is monitored regularly. Attempts at propagation have been unsuccessful. There is some likelihood of hybridisation with other Hyophorbe species native to the Mascarenes, which are grown in the area.

Assessor: Page, W.

Refs: 19118

\section{Hyophorbe indica}

Palmae

EN D1

Réunion

A palm tree of moist primary forest between 175 and $600 \mathrm{~m}$, persisting in low numbers only. It is threatened by the expansion of agriculture and human habitation. Assessor: Johnson, D.

Refs: 19118

\section{Hyophorbe lagenicaulis}

Palmae

CR D1

Mauritius

A palm tree with a bottle-shaped bole, confined to lowland palm savanna on Round Island. Fewer than 10 mature trees remain in the wild. Regeneration is sporadic in situ, but is increasing since rabbits and goats were eradicated from the island. The island is a managed reserve.

Assessor: Page, W.

Refs: 19118

\section{Hyophorbe vaughanii}

\section{Palmae}

CR D1

Mauritius

A tree of submontane evergreen forest. Only three wild individuals are known from Mare Longue Plateau, Fixon, south-west Mauritius. The seed from wild specimens have produced numerous plants, which have been re-introduced into a managed forest.

Assessor: Page, W.

Refs: 19118

\section{Hyophorbe verschaffeltii}

Palmae

CR C2a

Mauritius (Rodrigues)

Fewer than 60 individuals remain in the wild, occurring in limestone areas of Grand Montagne, Anse Quitor and Ravine de la Cascade, St Louis. There is no evidence of regeneration and grazing pressures are strong. There is also a threat of hybridisation with the introduced $H$. lagenicaulis. The species is of commercial interest as an ormamental.

Assessor: Johnson, D.

Refs: 19118

\section{Hyperbaena allenii}

Menispermaceae

Costa Rica, Panama

VU C2a

A lowland rainforest tree, occurring fairly commonly in the Valle de Antón area in Coclé and in populations of just a few individuals from Darien Province, close to the Colombian border in Panama, and in Puntarenas in Costa Rica. Although it is possible larger populations will be discovered, the species is poorly known in the latter two areas and under threat of habitat loss.

Assessor: Mitré, M.

Refs: $7272,7980,16772$

\section{Hyperbaena jalcomulcensis}

Menispermaceae

Mexico (Veracruz)

VU B $1+2 c$

Occurring in a range of forest types from evergreen rainforest to more deciduous forest, the species is confined to the central region of Jalcomulco, Rinconada, Plan del Río and Sierra de Manuel Diaz on karst topography. The forest is fragmented and widely disturbed. There is evidence of natural regeneration. Attempts at propagation have failed.

Assessor: World Conservation Monitoring Centre Refs: 19206

\section{Hyperbaena prioriana}

Menispermaceae

LR/nt

Jamaica

Known only from central parishes, the species is confined to rocky limestone woodland.

Assessor: World Conservation Monitoring Centre

Refs: 6057,7980

\section{Hyperbaena valida}

Menispermaceae

$\mathrm{LR} / \mathrm{nt}$

Jamaica

A species confined to coastal vegetation on limestone. It is thought to be endemic.

Assessor: World Conservation Monitoring Centre

Refs: 6057,7980

\section{Hypericum balfourii}

Guttiferae

VU D2

Yemen (Socotra)

A shrub or small tree found in low montane shrubland and dwarf Hypericum-Crotonopsis shrubland. The populations are believed to be stable and under no immediate threat.

Assessor: Miller, A.G.

Refs: 2354, 19083

\section{Hypericum gnidiifolium}

Guttiferae

VU D2

Ethiopia

A bushy tree known only from two disjunct localities beside streams, one in Wogera, on the Maye-Borhha Plateau in Tigray, and another in Choa in Shewa. It has not been collected recently.

Assessor: World Conservation Monitoring Centre Refs: 5941 


\section{Hyphaene dichotoma \\ Palmae}

LR/nt

India (Gujarat, Maharashtra)

A palm tree restricted to the coastal areas of Gujarat and Maharashtra between the latitudes of $18^{\circ}$ and $23^{\circ}$. The area is mainly threatened by increasing settlement and development.

Assessor: Johnson, D.

Refs: 19118

\section{Ilex abscondita}

Aquifoliaceae

VU D2

Venezuela

A shrub or low tree, which is endemic to upper montane forest on the Sierra de la Neblina. The area is protected within a national park.

Assessor: World Conservation Monitoring Centre

Refs: 19128

\section{Ilex acutidenticulata}

Aquifoliaceae

VU D2

Venezuela

The species is so far known from two disjunct populations both occurring in upper montane forest, one on Cerro Marahuaka and the second further south on the border with Brazil on the Sierra de la Neblina. Both areas are contained within national parks.

Assessor: World Conservation Monitoring Centre

Refs: 19128

\section{Ilex altiplana}

Aquifoliaceae

Venezuela

LR/nt

Endemic to the Gran Sabana within Canaima National Park, the species is found in riparian forest on sandstone plateaux. The tourist industry is rapidly growing, with some damaging consequences.

Assessor: World Conservation Monitoring Centre

Refs: 19128

Ilex anonoides

Aquifoliaceae

VU D2

Peru

This species is known only from the type collection from the department of Puno.

Assessor: World Conservation Monitoring Centre

Refs: 1984

\section{Ilex aracamuniana}

Aquifoliaceae

VU D2

Venezuela

A tree so far only known from a restricted zone of semiopen montane forest on Cerro Aracamuni in Amazonas. The area is protected within a national park.

Assessor: World Conservation Monitoring Centre

Refs: 19128

\section{Ilex arisanensis}

Aquifoliaceae

$\mathrm{EN} \mathrm{B1+2b}$

Taiwan

The species is restricted to the Arishan area, where it is scattered in mixed evergreen forest between 1500 and $2200 \mathrm{~m}$. Populations are unprotected and the area susceptible to forest management activities and expanding settlement.

Assessor: Pan, F.J.

Refs: $3295,6469,19050$

\section{Ilex attenuata}

Aquifoliaceae

VUD2

Brazil (Amazonas)

So far the species has been found in only a small area of montane forest in the Serra Pirapucu in Brazil, near the

Venezuelan border.

Assessor: World Conservation Monitoring Centre

Refs: 19128

\section{Ilex brevipedicellate}

Aquifoliaceae

VU D2

Venezuela

Occurring in montane forest bordering streams between 1100 and $1200 \mathrm{~m}$, the species is known from Cerro Marahuaka in Amazonas. The area is contained within a national park.

Assessor: World Conservation Monitoring Centre

Refs: 19128

\section{Ilex canariensis}

Aquifoliaceae

LR/nt

Portugal (Madeira), Spain (Canary Is.)

Occurring sporadically but in local abundance, the species is found mainly at lower altitudes in scrub and *laurisilva. The latter habitat type may be increasing in Madeira, but throughout much of the range there are pressures, particularly from grazing and fires. Populations occur within protected areas.

Assessor: World Conservation Monitoring Centre Refs: 19131

\section{llex caniensis}

Aquifoliaceae

VU D2

Peru

A species which is known only from the type collection found in the department of Huánuco.

Assessor: World Conservation Monitoring Centre Refs: 1984

\section{Ilex ciliolata}

Aquifoliaceae

LR/nt

Venezuela

The species is endemic to Bolivar, where it occurs in semi-deciduous to evergreen submontane forest in an area stretching from El Paují to Uaiparú near Kavanayén.

Assessor: World Conservation Monitoring Centre Refs: 19128

\section{Ilex cookii}

Aquifoliaceae

CR C2a, D1

Puerto Rico

A small tree of cloud forest, known from a single tree with four root sprouts on Cerro de Punta and a few small plants and seedlings scattered along ridge tops on Monte Jayuya in Toro Negro State Forest. The construction of communication towers is likely to have destroyed a large part of the original population on Cerro de Punta. Further development, road building and trampling threaten remaining plants. The species is thought to be dioecious, although male flowers have never been observed. It is protected by the US Endangered Species Act.

Assessor: World Conservation Monitoring Centre Refs: 17124,19167 
llex costaricensis

Aquifoliaceae

Costa Rica, Nicaragua, Panama

VU A2c

A species of evergreen moist montane forest or cloud forest. The largest populations are in the Cordillera de Talamanca between west Panama and east Costa Rica, where they are contained entirely within protected areas. Other smaller populations exist elsewhere, including one in the Volcán Mombacho in Nicaragua. In most of these sites the species is locally abundant. Unprotected forest is under some threat from logging and encroaching agriculture.

Assessor: Mitré, M.

Refs: $7272,14487,16772$

\section{Ilex cowanii}

Aquifoliaceae

VU D2

Venezuela

Known only from Cerro Huachamacari in Amazonas, the species occurs in a site of dense montane forest along a creek at about $1800 \mathrm{~m}$. The area is contained within Duida Marahuaca National Park.

Assessor: World Conservation Monitoring Centre

Refs: 19128

\section{Ilex davidsei}

Aquifoliaceae

$\mathrm{LR} / \mathrm{nt}$

Venezuela

A slender tree, found only in the Río Pasimoni basin in Amazonas State, where it occurs in periodically flooded riparian forest.

Assessor: World Conservation Monitoring Centre

Refs: 19128

\section{Ilex ericoides}

Aquifoliaceae

Peru

VU D2

A tree which is known only from the type collection from the department of Puno.

Assessor: World Conservation Monitoring Centre

Refs: 1984

\section{Ilex florifera}

Aquifoliaceae

Jamaica

VU B $1+2 c$

A tree confined to areas of woodland on limestone in St

Ann Parish.

Assessor: World Conservation Monitoring Centre

Refs: $401,5653,7980$

\section{Ilex gardneriana}

Aquifoliaceae

India (Tamil Nadu)

This species is known only from the type collection made in 1859 from * shola forest on Sispara Ghat in the Nilgiri Hills. The area has been repeatedly explored but no specimens have been found in the last few decades.

Assessor: World Conservation Monitoring Centre

Refs: 4799, 19144

\section{Ilex glabella}

Aquifoliaceae

VU D2

Venezuela

Endemic to the Sierra de la Neblina, the species occurs on forested slopes along streams between 700 and $800 \mathrm{~m}$. The area is protected within a national park. Assessor: World Conservation Monitoring Centre Refs: 19128
Ilex gleasoniana

Aquifoliaceae

LR/nt

Venezuela

A shrub or small tree, which is found in dwarf forests on *tepui summits, namely Cerro Coro Coro, Cerro Duida and Cerro Marahuaka in Amazonas. The latter two are contained within a national park.

Assessor: World Conservation Monitoring Centre

Refs: 19128

\section{Ilex grandiflora}

Aquifoliaceae

LR/cd

Malaysia (Peninsular Malaysia)

A shrub or small tree of montane rainforest found in the states of Perak (on Gunung Korbu), Pahang and Johore. Populations receive a degree of protection within the permanent forest estate

Assessor: Chua, L.S.L.

Refs: 8464,19073

\section{Ilex guaiguinimae}

Aquifoliaceae

VUD2

Venezuela

A species of seasonally dry evergreen forest, occurring between 700 and $900 \mathrm{~m}$ on Cerro Guaiquinima in Bolivar State.

Assessor: World Conservation Monitoring Centre

Refs: 19128

Ilex harrisii

Aquifoliaceae

LR/nt

Jamaica

A montane woodland species found in the Blue Mountains, sometimes in abundance, on the Grand Ridge and on steep slopes in the headwaters of the Clyde, Green and Mabess Rivers.

Assessor: World Conservation Monitoring Centre Refs: $6057,7980,12564$

\section{Ilex holstii}

Aquifoliaceae

VU D2

Venezuela

A species which is very similar to I. oliveriana and may prove to be conspecific. It is known only from a restricted area of submontane forest on Cerro Marahuaka in Amazonas State. The Duida Marahuaka National Park covers the locality.

Assessor: World Conservation Monitoring Centre Refs: 19128

\section{Ilex huachamacariana}

Aquifoliaceae

LR/nt

Venezuela

A shrub or tree of shrubby meadows and dwarf riparian and mossy forest, generally on sandy soils. Disjunct populations, both of which are protected within national parks, are known from Auyán-tepui in Bolivar, and Cerro Huachamacari in Amazonas. The former may prove to be a distinct taxon.

Assessor: World Conservation Monitoring Centre

Refs: 19128

\section{Ilex ignicola}

Aquifoliaceae

Venezuela

Occurring on Serranía de los Pijiguaos in Bolívar State and Cerro Aratitiyope in Amazonas State, the species is 
found in submontane semi-deciduous and evergreen forest on igneous rock.

Assessor: World Conservation Monitoring Centre

Refs: 19128

\section{Ilex illustris}

Aquifoliaceae

Malaysia (Peninsular Malaysia)

LR/cd

A shrub or small tree inhabiting rainforest up to $2000 \mathrm{~m}$ in Pahang,Terengganu and Perak. A protected population is found in Taman Negara National Park.

Assessor: Chua, L.S.L.

Refs: 8464,19073

\section{Ilex jamaicana}

Aquifoliaceae

Jamaica

$\mathrm{EN} \mathrm{B1+2c}$

A rare tree, occurring in moist mossy montane forest in Portland, with a recently discovered population at a lower altitude above Ecclesdown. The vegetation has been heavily cleared for agriculture and forestry activities.

Assessor: World Conservation Monitoring Centre

Refs: $401,5653,7980$

\section{Ilex jauaensis}

Aquifoliaceae

$\mathrm{LR} / \mathrm{nt}$

Venezuela

A small tree of montane riparian forests, occurring on Cerro Jáua and Serranía Marutaní in Bolívar State. The former is contained within a national park.

Assessor: World Conservation Monitoring Centre

Refs: 19128

\section{Ilex jelskii}

Aquifoliaceae

VU D2

Peru

A species which is known only from the type collection from the department of Cajamarca.

Assessor: World Conservation Monitoring Centre Refs: 1984

\section{Ilex karuaiana}

Aquifoliaceae

VU D2

Venezuela

Occurring in dense riparian forest and semi-deciduous and evergreen forest on sandstone, the species appears to be endemic to the lower slopes of Ptari-tepui, near Rio Caruay in Canaima National Park.

Assessor: World Conservation Monitoring Centre Refs: 19128

\section{Ilex khasiana}

Aquifoliaceae

India (Meghalaya)

$\mathrm{CR} B 1+2 \mathrm{c}, \mathrm{C} 2 \mathrm{~b}, \mathrm{D} 1$

An endemic of the Khasi Hills, occurring in mixed evergreen forest between 1000 and $1500 \mathrm{~m}$. Only three of four trees are known, confined to Shillong Peak. Regeneration is reported to be poor and the habitat has declined in extent and quality.

Assessor: CAMP Workshops on Medicinal Plants in India

Refs: 7147,19209

\section{Ilex lasseri}

Aquifoliaceae

VU D2

Venezuela

Known only from the vicinity of Kavanayén, the species is found on slopes in semj-deciduous and evergreen forest.

Assessor: World Conservation Monitoring Centre

Refs: 19128

\section{llex lechleri}

Aquifoliaceae

VU D2

Peru

A species which is known only from the type collection from the department of Puno.

Assessor: World Conservation Monitoring Centre

Refs: 1984

\section{Ilex magnifructa}

Aquifoliaceae

LR/nt

Venezuela

The species is known from localities of gallery forest or semi-deciduous to evergreen forest up to $1800 \mathrm{~m}$ on Cerro Parú, Cerro Ualipano, Cerro Yutajé, Río Coro Coro and Rio Parucito in Amazonas State.

Assessor: World Conservation Monitoring Centre Refs: 19128

\section{llex maingayi}

Aquifoliaceae

Malaysia (Peninsular Malaysia)

VU Bl+2c

A small to medium tree inhabiting lowland forest in swampy (peat swamp or the edge of mangroves), limestone areas (e.g. in Gopeng). The species is widely distributed along the west coast and in the south. Assessor: Chua, L.S.L.

Refs: $7673,8464,9199,17140,19073$

\section{Ilex marahuacae}

Aquifoliaceae

$\mathrm{LR} / \mathrm{nt}$

Venezuela

The species is endemic to montane slope forest on Cerro Huachamacari and Cerro Marahuaka in Amazonas State. Both areas are contained within Duida Marahuaka National Park.

Assessor: World Conservation Monitoring Centre Refs: 19128

\section{Ilex marginata}

Aquifoliaceae

Venezuela

$\mathrm{LR} / \mathrm{nt}$

A shrub or tree of dwarf cloud forest and Bonnetia shrublands, occurring on Auyán-tepui and Macizo del Chimantá in Bolívar State. Both areas are contained within Canaima National Park. Tourism is a rapidly growing industry with some damaging consequences. Assessor: World Conservation Monitoring Centre Refs: 19128

\section{Ilex mathewsii}

Aquifoliaceae

VU D2

Peru

A species which is known only from the type collection from the department of Amazonas.

Assessor: World Conservation Monitoring Centre Refs: 1984

\section{Ilex mitis var. schliebenii}

Aquifoliaceae

VU $B 1+2 d$

Tanzania

A distinct variant of a widely distributed and variable montane tree. It is localised on forested ridge tops in the Uluguru Mountains and on the Lukwangule Plateau.

Assessor: Lovett, J. \& G.P. Clarke

Refs: $3356,5204,13207$ 


\section{Nex neblinensis}

Aquifoliaceae

Brazil (Amazonas), Venezuela

VU D2

A shrub or tree, endemic to the Sierra de la Neblina on the Venezuela-Brazilian border, where it is found on steep forested slopes along sandstone escarpments. The area is protected within a national park.

Assessor: World Conservation Monitoring Centre Refs: 19128

\section{Ilex palawanica}

Aquifoliaceae

VU B1+2c, D2

Philippines

An endemic tree to Palawan, occurring in dense thickets on exposed ridges of Mount Pulgar at about $1200 \mathrm{~m}$. The main island is a biosphere reserve.

Assessor: World Conservation Monitoring Centre Refs: 4986

\section{Ilex pallida}

Aquifoliaceae

VU B $1+2$ bd

Costa Rica, Nicaragua, Panama

A species of high-altitude cloud forest, occurring between 2000 and $3000 \mathrm{~m}$ or higher. Populations are rare and isolated. Regeneration appears to be good and large fruit crops are reported. Most of the areas which the species occupies are under protection within national parks. However, there are increasing threats of habitat clearance for agriculture and logging.

Assessor: Mitré, M.

Refs: $7272,14487,16772$

\section{Ilex paraguariensis}

Aquifoliaceae

$\mathrm{LR} / \mathrm{nt}$

Argentina, Bolivia, Brazil (Rio Grande do Sul, Santa Catarina), Colombia, Ecuador, Paraguay, Uruguay

An understorey tree of mixed Araucaria forest, occurring in the subtropical and temperate regions of South America. For centuries the leaves have been used to make a tonic and stimulant drink. The rates of exploitation, in some areas, are believed to have caused a significant decline in population numbers. Plantations have been set up, but the demand for leaves is still, apparently, greater than the supply from cultivated stands.

Assessor: World Conservation Monitoring Centre

Refs: 4506, 7906, 9173, 11374, 11936

\section{Ilex parvifructa}

Aquifoliaceae

VU D2

Venezuela

A shrub or tree of broadleaved meadows and riparian montane forests between 1600 and $1700 \mathrm{~m}$ on Cerro Guaiquinima in Bolivar State. It is similar to and may be conspecific with $I$. steyermarkii.

Assessor: World Conservation Monitoring Centre

Refs: 19128

\section{Ilex patens}

Aquifoliaceae

Malaysia (Peninsular Malaysia)

LR/cd

A small tree of montane and submontane rainforest in Pahang, Kedah and Selangor. It is protected in Taman Negara National Park and within the permanent forest estate.

Assessor: Chua, L.S.L.

Refs: 8464,19073
Ilex pauciflora

Aquifoliaceae

Malaysia (Peninsular Malaysia)

EN D 1

A small tree confined to the hill forest of Penang Hill,

Penang.

Assessor: Chua, L.S.L.

Refs: 18840,19073

\section{llex paujiensis}

Aquifoliaceae

Venezuela

A small tree of savanna and forest margins, found in the Río Icabarú basin and along Río Paragua at the base of Cerro Guaiquinima.

Assessor: World Conservation Monitoring Centre

Refs: 19128

\section{llex perado ssp. azorica}

Aquifoliaceae

$\mathrm{LR} / \mathrm{nt}$

Portugal (Azores)

A subspecies endemic to the Azores, where it is one of the dominant components of remaining laurel forest on all the islands, except Graciosa. On Corvo only one specimen has been reported and the population on Santa Maria is under threat.

Assessor: World Conservation Monitoring Centre Refs: 7222,19131

\section{llex perado ssp. iberica}

Aquifoliaceae

CR B1+2de

Portugal, Spain

A species occurring within a restricted area of the Sierras de Algeciras in the south of Spain, where it is largely confined to forest patches in humid ravines and inaccessible places. It is possibly also found in Portugal. Of the various threats to the remaining plants, fire appears to be the most significant. The Cordoba Botanic Garden is carrying out work on the wild populations in order to determine their status and to establish the species in cultivation.

Assessor: Vivero, J.L. et al.

Refs: 7741

\section{Ilex perado ssp. lopezlilloi}

Aquifoliaceae

CR C2a, D1

Spain (Canary Is.)

This species is restricted to just two populations in cloud forest in Garajonay National Park on Gomera, both consisting of very few individuals. A recovery plan has been devised and the species is listed in government legislation of 1991.

Assessor: Bañares, A. et al.

Refs: 8716, 19022

\section{Ilex perado ssp. perado}

Aquifoliaceae

$\mathrm{LR} / \mathrm{nt}$

Portugal (Madeira)

Endemic to Madeira, this is a common tree of *laurisilva and forest at higher altitudes. There is evidence to suggest that *laurisilva is expanding. The taxon occurs within protected areas and is also covered by regional legislation.

Assessor: World Conservation Monitoring Centre Refs: 7222,19131

Ilex perado ssp. platyphylla

Aquifoliaceae

VU C2a

Spain (Canary Is.)

A cloud forest species confined to parts of Tenerife and 
Gomera, where it can be found in Garajonay National Park. The populations are small and fragmented. The species is listed in government legislation of 1991.

Assessor: Bañares, A. et al.

Refs: 8716,19022

\section{Ilex polita}

Aquifoliaceae

LR/nt

Venezuela

A shrub or tree which occurs in forest and shrubby savanna on tepui summits and slopes in several localities in Bolívar State.

Assessor: World Conservation Monitoring Centre

Refs. 19128

\section{Ilex praetermissa}

Aquifoliaceae

VU B $1+2 c$

Malaysia (Peninsular Malaysia)

Known from only one locality, this uncommon shrub or small tree inhabits quartzite ridge in the hill forest of Selangor.

Assessor: Chua, L.S.L.

Refs: 19073

\section{Ilex puberula}

Aquifoliaceae

Jamaica

VU B1+2c

This species is found in exposed montane thickets and woodland on steep slopes, 1200 to $1500 \mathrm{~m}$, in St Andrew and Portland Parishes. Disturbance and clearing of the habitat has been extensive but mostly at lower altitudes in more accessible sites.

Assessor: World Conservation Monitoring Centre

Refs: 401, 5653

\section{Hex quercetorum}

Aquifoliaceae

VU AIc

Guatemala, Mexico (Chiapas)

A montane forest tree, occurring in oak forest and mesophyllous formations. It is known mainly from the populations in Guatemala but also occurs in the northern mountains of Chiapas, where the species is considered to be vulnerable.

Assessor: World Conservation Monitoring Centre

Refs: 4974,19161

\section{Ilex savannarum var. morichei}

Aquifoliaceae

VU D2

Venezuela

Endemic to Cerro Moriche in Amazonas State, the variety occurs in shrublands and broadleaved meadows between 1200 and $1300 \mathrm{~m}$.

Assessor: World Conservation Monitoring Centre Refs: 19128

\section{Ilex savannarum var, savannarum}

Aquifoliaceae

Venezuela

LR/nt

This variety is known from areas of white-sand savanna, bordering streams or forests or in shrub islands. Occurrences have been recorded from Caño Yagua and the basins of Rio Atabapo, Río Guainía and Río Pasimoni in Amazonas State.

Assessor: World Conservation Monitoring Centre Refs: 19128

\section{Ilex sclerophylla}

Aquifoliaceae

Malaysia (Peninsular Malaysia)

A small tree which is distributed rarely in montane rainforest on Gunung Ledang in Johore and Ulu Brang in Terengganu. Populations receive a degree of protection within the permanent forest estate.

Assessor: Chua, L.S.L.

Refs: 8464,19073

\section{Ilex sessilifructa}

Aquifoliaceae

LR/nt

Venezuela

A shrub or tree which occurs in savannas and submontane forest in the Rio Erebato basin in Bolivar State and in the Sierra de la Neblina in Amazonas State. The latter is contained within a national park. Assessor: World Conservation Monitoring Centre Refs: 19128

\section{llex sideroxyloides var. occidentalis}

Aquifoliaceae

LR/nt

Jamaica, Puerto Rico

In Jamaica the variety occurs in thickets and woodlands in the eastem parishes and also Clarendon.

Assessor: World Conservation Monitoring Centre Refs: 6057,7980

\section{Ilex sintenisüi}

Aquifoliaceae

EN C2a, D1

Puerto Rico

Occurring in dwarf or *elfin forest on mountain summits, the species is known only from a restricted area of the Luquillo Mountains within Toro Negro State Forest. A total of 150 individuals exist within three populations. The forest has been cut through various forest management activities and also in the development of communication facilities. The species is protected by the US Endangered Species Act.

Assessor: World Conservation Monitoring Centre

Refs: $7980,17124,19167$

\section{Ilex sipapoana}

Aquifoliaceae

LR/nt

Venezuela

A montane forest and shrubland species, occurring in a locality east of Los Pijiguaos in Bolivar State and elsewhere on Cerro Guanay and Cerro Sipapo in Amazonas State.

Assessor: World Conservation Monitoring Centre Refs: 19128

\section{Ilex spruceana}

Aquifoliaceae

LR/nt

Venezuela

A lowland shrub or tree, which occurs in white-sand savannas on exposed igneous rock and in riparian forest in a number of localities in Amazonas State.

Assessor: World Conservation Monitoring Centre Refs: 19128

\section{Ilex steyermarkii}

Aquifoliaceae

$\mathrm{LR} / \mathrm{nt}$

Venezuela

The species may prove to be conspecific with $I$. parvifructa. It is known from Bolivar State, where it occurs in forest from mid to high elevation at the base of sandstone escarpments, such as those on Auyan-tepui, 
Gran Sabana and Torono-tepui in Macizo del Chimanta. Much of the range is contained within a national park. Assessor: World Conservation Monitoring Centre Refs: 19128

\section{Ilex subrotundifolia}

Aquifoliaceae

LR/nt

Venezuela

Known from various localities in Bolivar State, including the Gran Sabana and Macizo del Chimantá, and on Cerro Sipapo in Amazonas State, the species occurs in shrublands, swampy depressions in meadows or savannas and at the margins of gallery forest between 500 and $2200 \mathrm{~m}$. It is possible that the specimens from high elevations on the Macizo del Chimantá represent a distinct species. Much of the range is contained within protected areas.

Assessor: World Conservation Monitoring Centre

Refs: 19128

\section{Ilex subtriflore}

Aquifoliaceae

$\mathrm{CR} B 1+2 \mathrm{C}$

Jamaica

An extremely rare species, which is poorly known. It is confined to St Ann Parish and has not been recently collected.

Assessor: World Conservation Monitoring Centre

Refs: 401, 5653, 7980

\section{llex sulcata}

Aquifoliaceae

LR/nt

Venezuela

A shrub or tree of shrubland, gallery forest and swampy depressions in meadows at mid to high elevation. Collections have been made on Auyán-tepui, Cerro Venama, Gran Sabana and Macizo del Chimantá in Bolivar State. Much of the range is contained within a national park.

Assessor: World Conservation Monitoring Centre

Refs: 19128

\section{Ilex tahanensis}

Aquifoliaceae

Malaysia (Peninsular Malaysia)

LR/cd

A montane species found on Gunung Tahan in Pahang and on Gunung Rabong in Kelantan. This small tree is protected in Taman Negara National Park and within the permanent forest estate.

Assessor: Chua, L.S.L.

Refs: 8464,19073

\section{Ilex tateana}

Aquifoliaceae

LR/nt

Venezuela

A shrub or tree which has been collected from riparian and semi-open forest between 1400 and $1500 \mathrm{~m}$ on Cerro Aracamuni, Cerro Duida and Sierra de la Neblina in Amazonas State. All the localities are contained within national parks.

Assessor: World Conservation Monitoring Centre

Refs: 19128

\section{Ilex ternatiflora}

Aquifoliaceac

Cuba

Described in the mid-1800s, this species was apparently restricted to a single locality in Las Pozas, Pinar del Rio Province. The type locality has been completely destroyed and the species has not been collected again despite thorough searches.

Assessor: Areces-Mallea, A.E.

Refs: 11403, 12801, 19149

\section{Ilex tiricae}

Aquifoliaceae

LR/nt

Venezuela

A shrub or small tree of montane thicket and riparian forest on sandstone. Collections have been made from Auyán-tepuj and Macizo del Chimantá in Bolívar State, both contained within Canaima National Park. Assessor: World Conservation Monitoring Centre Refs: 19128

\section{Mex tolucano}

Aquifoliaceae

Mexico

VUAlc

A tree of oak forest or mesophyllous montane forest, so far known only from Mexico but possibly also occurring in Guatemala. The wood is used locally as a source of fuel and timber. There is an occurrence in El Triunfo Biosphere Reserve.

Assessor: Ramirez-Marcial, N. \& M. González-Espinosa Refs: 19161

\section{Ilex trachyphylla}

Aquifoliaceae

VU D2

Peru

A species which is known only from type collection from the department of Cajamarca.

Assessor: World Conservation Monitoring Centre

Refs: 1984

\section{Ilex vaccinoides}

Aquifoliaceae

VU Bl+2c

Jamaica

A locally common species, confined to primary and secondary montane forest at the headwaters of Green River in St Andrews Parish. Occurring above $1800 \mathrm{~m}$, the species' habitat has largely escaped the forest destruction and degradation which have been extensive at lower altitudes.

Assessor: World Conservation Monitoring Centre

Refs: $5653,7980,19116$

Ilex venezuelensis

Aquifoliaceae

LR/nt

Venezuela

Occurring in various localities in Bolivar and Amazonas States, the species is found in *tepui meadows, dwarf riparian forests, forested slopes and on the edges of escarpments.

Assessor: World Conservation Monitoring Centre Refs: 19128

Ilex venulosa

Aquifoliaceae

India (Arunachal Pradesh)

$\mathrm{EN} \mathrm{B1+2c}$

Endemic to the Khasi Hills, the species is known mainly from populations in Sohrarim and Laaitlyngkot. These areas have been drastically cleared and the species is believed to be very scarce now.

Assessor: World Conservation Monitoring Centre

Refs: 7147 
Ilex vomitoria ssp. chiapensis

Aquifoliaceae

VU $B 1+2 c$

Mexico (Chiapas)

A medicinal plant, found scattered in dry montane forest above $1500 \mathrm{~m}$ in the high areas of Chiapas. The taxonomic status of the subspecies may need confirmation. The species is widespread in eastern North America.

Assessor: Ramirez-Marcial, N. \& M. González-Espinosa Refs: 9312, 19161

\section{Ilex vulcanicola}

Aquifoliaceae

VU A2c

Costa Rica, Panama

A more common species than I. costaricensis. Although it, too, occurs in high-altitude cloud forest, populations are also found below $1000 \mathrm{~m}$ in Cerro Jefe and Cerro Campana in Panama. In Costa Rica, the species is reported to be abundant above $1500 \mathrm{~m}$, always within areas which receive some level of protection. Populations within Panama are also entirely contained within national parks or reserves. Despite this level of apparent protection, there still remain potential threats from logging and habitat clearance.

Assessor: Mitré, M.

Refs: $7272,14487,16772$

\section{Ilex williamsii}

Aquifoliaceae

CR C2b

Honduras

A seldom-collected species of cloud forest.

Assessor: Nelson, C.

Refs: 8805,13995

\section{Illicium kinabaluensis}

Illiciaceae

VU D2

Malaysia (Sabah)

A small tree restricted to Mount Kinabalu, where it is found in primary forest between 1200 and $2000 \mathrm{~m}$.

Assessor: World Conservation Monitoring Centre

Refs: 19017

\section{Illicium peninsulare}

Illiciaceae

$\mathrm{LR} / \mathrm{cd}$

Malaysia (Peninsular Malaysia)

A primary species of submontane rainforest, occurring between 800 and $1500 \mathrm{~m}$. Populations are found in a Wildlife Sanctuary and in the protective forests within the permanent forest estate.

Assessor: Chua, L.S.L.

Refs: 19073

\section{Illicium tenuifolium}

Illiciaceae

$\mathrm{LR} / \mathrm{cd}$

Malaysia (Peninsular Malaysia), Thailand

A species of hill forest and cloud forest, scattered in Peninsular Thailand and Malaysia. Populations in Peninsular Malaysia are contained in a national park and protective forests within the permanent forest estate.

Assessor: Chua, L.S.L.

Refs: 19073

\section{Illicium ternstroemioides}

Illiciaceae

VU D2

China, Viet Nam

A small tree, restricted to Hainan Island in China and high mountains in north Viet Nam: Son La, Tuan Giao and Dien Bien.

Assessor: World Conservation Monitoring Centre

Refs: $848,11530,15357$

\section{Indigofera rothii}

Leguminosae

VU Alc

Ethiopia

An Indigofera species which reaches the stature of a small tree. It is confined to upland scrub and forest margins in an area where the majority of the Ethiopian population lives.

Assessor: World Conservation Monitoring Centre

Refs: 1330,18523

\section{Indigofera socotrana}

Leguminosae

VU D2

Yemen (Socotra)

One of the few arborescent Indigofera species. It is scattered relatively sparsely in areas of submontane and montane woodland.

Assessor: Miller, A.G.

Refs: 2354, 19083

\section{Inga allenii}

Leguminosae

VU A2c

Colombia, Costa Rica, Panama

In Panama, a large number of the original species' localities have been converted into fields, especially banana plantations, ranches and farms. A few collections are known from Coclé and some more doubtful ones from Darien. In Costa Rica the species is fairly common in the south-east and there are small populations in $\mathrm{La}$ Selva and Limón. Recently the species has been recorded in Valle del Cauca, Colombia.

Assessor: Mitré, M.

Refs: $7980,15037,16772,19123$

\section{Inga amboroensis}

Leguminosae

VU D2

Bolivia

A tree known only from the type locality in the Amboro National Park, Santa Cruz. It occurs in montane rainforest at $1380 \mathrm{~m}$.

Assessor: World Conservation Monitoring Centre Refs: 19123

\section{Inga andersonii}

Leguminosae

VU D2

Mexico (Jalisco)

A small tree, known only from the type locality in forest in a humid ravine.

Assessor: World Conservation Monitoring Centre

Refs: 17165,19123

\section{Inga approximata}

Leguminosae

VU D2

Bolivia

Known only from three localities in Cochabamba and Santa Cruz, this small tree occurs in cloud forest between 2000 and $2500 \mathrm{~m}$.

Assessor: World Conservation Monitoring Centre Refs: 19123

\section{Inga aptera}

Leguminosae

Brazil (Bahia)

VU B $1+2 c$

Found below $100 \mathrm{~m}$, this small tree occurs in secondary 
vegetation derived from wet lowland rainforest in Bahia. Assessor: World Conservation Monitoring Centre Refs: 19123

\section{Inga arenicolo}

Leguminosae

Brazil (Rio de Janeiro)

$\mathrm{EN} \mathrm{B} 1+2 \mathrm{C}$

This treelet, up to $4 \mathrm{~m}$ tall, is restricted to dense low arboreal *restinga near the coast of Rio de Janeiro.

Assessor: World Conservation Monitoring Centre

Refs: 19123

\section{Inga augusti \\ Leguminosae}

Peru

VUD2

Collected only twice, this small tree occurs in sclerophyllous bush in Huánuco between 1800 and $2500 \mathrm{~m}$.

Assessor: World Conservation Monitoring Centre

Refs: 1984, 19123

\section{Inga balsapambensis}

Leguminosae

VU Alc, Bl+2c

Ecuador

Restricted to the western slopes of the Ecuadorean Andes between 1550 and $1770 \mathrm{~m}$, this small tree occurs on steep slopes in remnant forest fragments and disturbed areas. This region was formerly covered in cloud forest.

Assessor: World Conservation Monitoring Centre

Refs: 19123

\section{Inga bella}

Leguminosae

$\mathrm{EN} \mathrm{Bl}+2 \mathrm{c}$

Costa Rica

A small tree found in gallery forest and secondary vegetation. It appears to be restricted to the Osa Peninsula.

Assessor: World Conservation Monitoring Centre

Refs: 19123

\section{Inga bicoloriflora}

Leguminosae

VU B $1+2 \mathrm{c}$

Brazil (Amazonas)

Apparently restricted to central Amazonas, this tree is known only from a few collections from non-flooded lowland rainforest near Manaus.

Assessor: World Conservation Monitoring Centre

Refs: 19123

\section{Inga bijuga}

Leguminosae

VU D2

Venezuela

A tree known only from the type collection found at $2200 \mathrm{~m}$ on Sororopán-tepui in southern Venezuela.

Assessor: World Conservation Monitoring Centre Refs: 19123

\section{Inga blanchetiana}

Leguminosae

$\mathrm{EN} \mathrm{B1+2c}$

Brazil (Bahia)

A tree restricted to the threatened Atlantic coastal lowland rainforest of Bahia.

Assessor: World Conservation Monitoring Centre

Refs: 19123

\section{Inga bollandii}

Leguminosae

VU D2

Brazil (Ceará, Rio de Janeiro?, Sergipe)

A species of hill forest occurring between 900 and $1000 \mathrm{~m}$. A collection labelled Rio de Janeiro is suspected to be misidentified.

Assessor: World Conservation Monitoring Centre

Refs: 19123

\section{Inga bracteifera}

Leguminosae

Costa Rica

$\mathrm{EN} \mathrm{B1}+2 \mathrm{c}$

An understorey tree in high rainforest endemic to the

Osa Peninsula in south-eastern Costa Rica.

Assessor: World Conservation Monitoring Centre

Refs: 19123

\section{Inga bullata}

Leguminosae

Brazil (Rio de Janeiro, Sảo Paulo)

VU $B \mid+2 c$

So far known only from a few collections from Rio de Janeiro and São Paulo, the species occurs in lowland secondary forest and swampy areas.

Assessor: World Conservation Monitoring Centre

Refs: 19123

\section{Inga bullatorugosa}

Leguminosae

VU D2

Brazil (Pará)

Known only from three collections from the River Tapajoz in Pará, this small tree occurs in non-flooded lowland forest.

Assessor: World Conservation Monitoring Centre Refs: 19123

\section{Inga cabelo}

Leguminosae

Brazil (Espírito Santo, Rio de Janeiro)

$\mathrm{EN} \mathrm{Bl}+2 \mathrm{c}$

A small tree of coastal rainforest confined to the states of Espírito Santo and Rio de Janeiro.

Assessor: World Conservation Monitoring Centre

Refs: 19123

\section{Inga calantha}

Leguminosae

Brazil (Pará)

VU D2

A small tree of secondary forest on non-flooded land, known from just two collections from the middle Tapajoz River.

Assessor: World Conservation Monitoring Centre

Refs: 19123

\section{Inga calanthoides}

Leguminosae

VU D2

Suriname

A tree known only from the type collection, gathered from forest on Tafelberg in 1944.

Assessor: World Conservation Monitoring Centre Refs: 15188, 19123, 19196

\section{Inga calcicola}

Leguminosae

VU D2

Mexico (Oaxaca)

Confined to the Tuxtepec District of Oaxaca, this understorey tree occurs in lowland evergreen rainforest on limestone. Although there has been extensive 
deforestation, this area is perhaps less susceptible to development and clearance because of the difficulty of working on the karst substrate.

Assessor: World Conservation Monitoring Centre

Refs: 19123, 19124

Inga canonegrensis

Leguminosae

VU D2

Costa Rica

A small tree known only from the type locality. It grows on poorly drained flat land in rainforest near sea level in Alajuela.

Assessor: World Conservation Monitoring Centre

Refs: 19123

\section{Inga caudata}

Leguminosae

VU D2

Brazil (Amazonas)

A species known only from the type collection from Rio

Maturacá in Amazonas.

Assessor: World Conservation Monitoring Centre

Refs: 19123

\section{Inga chiapensis}

Leguminosae

VU Alc

Mexico (Chiapas, Veracruz)

A tree of deciduous forest on the northern edge of the Central Depression in Chiapas and of high evergreen rainforest in Uxpanapa in Veracruz. Half of the forest in the Uxpanapa has disappeared through land clearance for a government relocation scheme. This population is similar to and may prove to be $I$. dasycarp.

Assessor: World Conservation Monitoring Centre

Refs: $5651,5993,19123$

\section{Inga coragypsea}

Leguminosae

VU D2

Colombia

Apparently restricted to the department of Santander del Sur in Colombia, this small tree is known from two collections, which were gathered between 1800 and $1900 \mathrm{~m}$. There is no available information on the species habitat type.

Assessor: World Conservation Monitoring Centre

Refs: 19123

\section{Inga cuspidata}

Leguminosae

VUB $1+2 \mathrm{c}$

Panama

A small tree confined to a restricted area of lowland rainforest near rivers in central Panama.

Assessor: World Conservation Monitoring Centre

Refs: 19123

\section{Inga cynometrifolia}

Leguminosae

Peru

A small tree known from only two collections from rainforest at $250 \mathrm{~m}$ in Juan Guerra in Loreto and from Río Huallaga in San Martin.

Assessor: World Conservation Monitoring Centre Refs: 19123

\section{Inga dominicensis \\ Leguminosae}

VU D2

Dominica

A small tree up to $4 \mathrm{~m}$ tall, confined to montane rainforest between 700 and $800 \mathrm{~m}$. The $40 \mathrm{~km}^{2}$ of montane forest on Dominica has largely escaped deforestation.

Assessor: World Conservation Monitoring Centre

Refs: 7424, 19123, 19124

\section{Inga dwyeri}

Leguminosae

VU B $1+2 c$

Panama

A small tree of wet lowland and montane forest up to $900 \mathrm{~m}$, known only from central Panama.

Assessor: World Conservation Monitoring Centre

Refs: 19123

\section{Inga enterolobioides}

Leguminosae

CR B $1+2 c$

Brazil (Rio de Janeiro)

Known only from the type collection from Rio de Janeiro, this tree is likely to have occurred in rainforest but its present status and location, if it is still in existence, are unknown.

Assessor: World Conservation Monitoring Centre Refs: 19123

\section{Inga exalata ssp. umbilicata}

Leguminosae

$\mathrm{EN} \mathrm{B1}+2 \mathrm{c}$

Costa Rica

A poorly collected subspecies known only from mixed lowland rainforest up to $500 \mathrm{~m}$ from the Osa Peninsula and from a single collection from montane forest in San José.

Assessor: World Conservation Monitoring Centre

Refs: 19123

\section{Inga exfoliata}

Leguminosae

Brazil (Espírito Santo)

EN B $1+2 c$

An understorey tree, found in rainforest on the coastal plains and in hill forest up to $800 \mathrm{~m}$, endemic to Espirto Santo.

Assessor: World Conservation Monitoring Centre

Refs: 19123

\section{Inga exilis}

Leguminosae

VU D2

Brazil (Amazonas)

A small tree of lowland forest on *terra firme, known only from the type collection from westem Amazonas. Assessor: World Conservation Monitoring Centre Refs: 19123

\section{Inga extra-nodis}

Leguminosae

VU B1+2c

Ecuador

Found between 1700 and $2000 \mathrm{~m}$, this tree is restricted to the upper Amazonian slopes of the Ecuadorean Andes in disturbed areas, roadsides and pastures. This region was formerly covered in montane rainforest.

Assessor: World Conservation Monitoring Centre Refs: 19123

\section{Inga fosteriana}

Leguminosae

Peru

Known only from the type collection, this small tree was found in lowland rainforest between Shintuya and Manu in Madre de Dios in 1974.

Assessor: World Conservation Monitoring Centre Refs: 19123 
Inga gereauana

Leguminosae

VU D2

Peru

A small tree of undisturbed lowland rainforest on nonflooded land between 120 and $150 \mathrm{~m}$, known only from a small area of Amazonian Pen near Iquitos.

Assessor: World Conservation Monitoring Centre

Refs: 19123

\section{Inga golfodulcensis}

Leguminosae

Colombia?, Costa Rica

A tree found in lowland evergreen forest up to $200 \mathrm{~m}$. In

Costa Rica, populations are restricted to the Osa Peninsula and it is also apparently reported from Colombia.

Assessor: World Conservation Monitoring Centre

Refs: 19123

\section{Inga goniocalyx}

Leguminosae

Colombia

A species known only from two collections without exact locality.

Assessor: World Conservation Monitoring Centre

Refs: 19123

\section{Inga grazielae}

Leguminosae

VU B $1+2 \mathrm{c}$

Brazil (Bahia)

Found below $100 \mathrm{~m}$, this small tree occurs in wet lowland rainforest and associated secondary vegetation in Bahia.

Assessor: World Conservation Monitoring Centre

Refs: 19123

\section{Inga hayesii}

Leguminosae

LR/nt

Colombia, Costa Rica, Ecuador, Nicaragua, Panama,

Peru

Although for many years the species was thought to be endemic to Panama, it is now known to range from Nicaragua to Peru, occurring in lowland semi-deciduous rainforest, often at the edges of roads and in secondary forest. In Panama and Costa Rica, and probably in other countries, trees are found only in small numbers outside protected areas.

Assessor: Mitre, M.

Refs: $7272,7980,16772,19123$

\section{Inga herrerae}

Leguminosae

$\mathrm{EN} B 1+2 \mathrm{c}$

Costa Rica

Endemic to Guanacaste Province, this localised tree is found in forest at around $400 \mathrm{~m}$. It is present in Rincon de la Vieja National Park.

Assessor: World Conservation Monitoring Centre

Refs: 19123

\section{Inga hispida}

Leguminosae

Brazil (Espírito Santo, Minas Gerais, Rio de Janeiro)

A small tree found in wet forest between 400 and $800 \mathrm{~m}$

from Minas Gerais to Rio de Janeiro.

Assessor: World Conservation Monitoring Centre

Refs: 19123
Inga interfluminensis

Leguminosae

VU D2

Colombia

A tall tree known only from the type collection, gathered at $2100 \mathrm{~m}$ in Antioquia.

Assessor: World Conservation Monitoring Centre

Refs: 19123

\section{Inga ismaelis}

Leguminosae

VU Alc, B1+2c

Mexico (Oaxaca, Veracruz)

A tree of lowland evergreen rainforest in the Uxpanapa region of Veracnuz and the Tuxtepec area of Oaxaca. It grows on deep soils on limestone outcrops below $200 \mathrm{~m}$. The forest at Uxpanapa has been severely reduced through clearance for a government relocation scheme. Assessor: World Conservation Monitoring Centre Refs: 5651, 5993, 19123

\section{Inga jaunechensis}

Leguminosae

CR Bl+2c

Ecuador

A small understorey tree of seasonal lowland mixed forest, confined to the 100ha Jauneche Reserve in Los Rios Province. The area is in a precarious position, threatened by fires and encroachment.

Assessor: Pennington, T.D.

Refs: 19123,19217

\section{Inga jimenezii}

Leguminosae

EN B $1+2 c$

Costa Rica

A understorey tree of seasonal semi-deciduous rainforest, restricted to a small area of San José Province. It occurs within the Carará Biological Reserve.

Assessor: World Conservation Monitoring Centre Refs: 19123

\section{Inga lacustris}

Leguminosae

EN Alc, B $1+2 c$

Mexico (Veracruz)

A small tree, restricted to an area of rainforest adjacent to mangroves in the Los Tuxtlas region of southem Veracruz.

Assessor: World Conservation Monitoring Centre Refs: 5993, 19123, 19124

\section{Inga lanceifolia}

Leguminosae

Brazil (Rio de Janeiro)

$\mathrm{EN} B 1+2 \mathrm{c}$

A tree occuring in rainforest on hills between 900 and $1200 \mathrm{~m}$ in Rio de Janeiro.

Assessor: World Conservation Monitoring Centre Refs: 19123

\section{Inga latipes}

Leguminosae

$\mathrm{EN} \mathrm{B1}+2 \mathrm{c}$

\section{Costa Rica}

Restricted to Limón and Cartago, this tree occurs in montane rainforest between 450 and $1400 \mathrm{~m}$. Rates of habitat loss have been severe.

Assessor: World Conservation Monitoring Centre

Refs: 14487, 19123

\section{Inga lenticellata}

Leguminosae

VU Alc

Brazil (Rio de Janeiro, São Paulo)

Apparently restricted to the states of Rio de Janeiro and 
São Paulo, the tree is found in rainforest on hills and along riversides up to $1000 \mathrm{~m}$.

Assessor: World Conservation Monitoring Centre

Refs: 19123

\section{Inga lentiscifolia}

Leguminosae

VU Alc

Brazil (Rio Grande do Sul, Santa Catarina)

Apparently restricted to Santa Caterina and Rio Grande do Sul, this species occurs in cloud forest and Araucaria forest between 900 and $1000 \mathrm{~m}$.

Assessor: World Conservation Monitoring Centre

Refs: 19123

\section{Inga leptantha}

Leguminosae

Brazil (Bahia, Espírito Santo, Rio de Janeiro)

VU Alc

A tree, reaching $6 \mathrm{~m}$ in height, found in disturbed lowland wet forest from Bahia to Rio de Janeiro.

Assessor: World Conservation Monitoring Centre

Refs: 19123

\section{Inga leptingoides}

Leguminosae

VU D2

Suriname

Restricted to Tafelberg Mountain, this small tree is known from a few locations of low bush or Clusia bush. Assessor: World Conservation Monitoring Centre Refs: 19123,19196

\section{Inga lisoralis}

Leguminosae

$\mathrm{EN} B 1+2 \mathrm{c}$

Costa Rica

Endemic to the Pacific drainage region of Costa Rica, this tree occurs in semi-deciduous forest extending into evergreen forest near the Pacific coast.

Assessor: World Conservation Monitoring Centre Refs: 19123

\section{Inga macarenensis \\ Leguminosae}

VU D2

Colombia

A small tree known only from the type collection found at $1700 \mathrm{~m}$ in dense mossy forest in Sierra de la Macarena Natural National Park.

Assessor: World Conservation Monitoring Centre

Refs: 19123

\section{Inga macrantha}

Leguminosae

VU D2

Venezuela

This small tree is restricted to Isla Margarita off the north coast of Venezuela. It grows in windswept evergreen cloud forest between 400 and $850 \mathrm{~m}$.

Assessor: World Conservation Monitoring Centre Refs: 19123

\section{Inga maritima}

Leguminosae

Brazil (Rio de Janeiro, Rio Grande do Sul?)

$\mathrm{EN} \mathrm{B} 1+2 \mathrm{c}$

A shrub or small tree confined to * restinga, mainly in Rio de Janeiro, but also from Rio Grande do Sul, where a single collection has been made and provisionally included in this species.

Assessor: World Conservation Monitoring Centre Refs: 19123
Inga martinicensis

Leguminosae

VU D2

Martinique

A shrub or small tree restricted to a small area of rainforest between 600 and $700 \mathrm{~m}$.

Assessor: World Conservation Monitoring Centre

Refs: 19123

\section{Inga megalobotrys}

Leguminosae

$\mathrm{LR} / \mathrm{cd}$

Peru

Confined to flood plain forest between 350 and $400 \mathrm{~m}$, this treelet, up to $3.5 \mathrm{~m}$ tall, is known only from Manu National Park in Madre de Dios.

Assessor: World Conservation Monitoring Centre

Refs: 19123

\section{Inga mendoncaei}

Leguminosae

Brazil (Rio de Janeiro)

$\mathrm{EN} \mathrm{B1+2c}$

A small tree of coastal forest between 500 and $1000 \mathrm{~m}$, restricted to the state of Rio de Janeiro.

Assessor: World Conservation Monitoring Centre

Refs: 19123

\section{Inga microcalyx}

Leguminosae

Brazil (Pará)

VU D2

A small tree up to $8 \mathrm{~m}$ tall, found only along the flooded banks of the Amazon River in Para.

Assessor: World Conservation Monitoring Centre

Refs: 19123

\section{Inga mortoniana}

Leguminosae

$\mathrm{EN} B 1+2 \mathrm{c}$

Costa Rica

A small tree, endemic to Costa Rica, confined to wet montane forest between 900 and $1750 \mathrm{~m}$. An estimated total of $1037 \mathrm{~km}^{2}$ montane forest remain in Costa Rica.

Assessor: World Conservation Monitoring Centre

Refs: 19123,19124

\section{Inga mucuna}

Leguminosae

Colombia, Panama

VUAlc

Populations occur in lowland semi-deciduous rainforest, rarely in secondary forest, throughout Panama and in Chocó and Antioquia in Colombia. The species is generally scarce except in the Canal area and in Darién National Park, Panama. Much of the unprotected forest at these low altitudes is exposed to increasing settlement, farming and agriculture.

Assessor: Mitre, $\mathrm{M}$.

Refs. 7980,16772

\section{Inga multijuga ssp. aestuariorum}

Leguminosae

$\mathrm{EN} \mathrm{B1}+2 \mathrm{c}$

Costa Rica, Panama

A dry forest tree found along rivers and the Pacific coast at low altitudes.

Assessor: World Conservation Monitoring Centre

Refs: 19123

\section{Inga neblinensis}

Leguminosae

VU D2

Venezuela

This small tree is known from two localities on periodically flooded gravel bars and in swamp forest up 
to $800 \mathrm{~m}$ on the lower slopes of Cerro Neblina. Assessor: World Conservation Monitoring Centre Refs: 19123

\section{Inga pallida}

Leguminosae

VU D2

Bolivia

Information on the species is somewhat limited. It is thought to be a tree of montane forest and is currently known only from the type collection from eastern Bolivia.

Assessor: World Conservation Monitoring Centre

Refs: 19123

\section{Inga pauciflora}

Leguminosae

VU Alc

Panama

So far the species has been found only in Panama. It occurs, nowhere in abundance, in lowland rainforest throughout the country. The larger part of its distribution coincides with areas experiencing an influx of people and increasing agricultural and farming activities. It is most common in the Canal area, where it occurs in a number of protected areas.

Assessor: Mitré, M.

Refs: $7272,7980,16772,19123$

\section{Inga pedunculata}

Leguminosae

Brazil (Bahia)

$\mathrm{EN} \mathrm{B} 1+2 \mathrm{c}$

A treelet known from only two collections, one gathered from * restinga and the other from disturbed wet lowland forest.

Assessor: World Conservation Monitoring Centre

Refs: 19123

\section{Inga platyptera}

Leguminosae

$\mathrm{EN} \mathrm{B} 1+2 \mathrm{c}$

Brazil (Rio de Janeiro)

A tree known from several collections from Rio de Janeiro, where it occurs in rainforest on hills at approximately $1200 \mathrm{~m}$.

Assessor: World Conservation Monitoring Centre

Refs: 19123

\section{Inga pleiogyna \\ Leguminosae}

Brazil (Bahia)

Apparently endemic to Bahia, this treelet is confined to * restinga over white sand at sea level.

Assessor: World Conservation Monitoring Centre

Refs: 19123

\section{Inga pluricarpellata}

Leguminosae

VU D2

Peru

A small tree known only from two collections from eastern Peru. It occurs in wet forest between 200 and $300 \mathrm{~m}$.

Assessor: World Conservation Monitoring Centre

Refs: 19123

\section{Inga porcata}

Leguminosae

Peru

$\mathrm{LR} / \mathrm{cd}$

Found between 350 and $400 \mathrm{~m}$ in lowland flood plain forest, this recently described species is known only from Cuzco and Manu National Park and Río Sotileja in Madre de Dios.

Assessor: World Conservation Monitoring Centre

Refs: 19123

\section{Inga portobellensis}

Leguminosae

VU $B 1+2 c$

Panama

Confined to central Panama, this tree occurs in gallery forest along rivers and sandbars below $100 \mathrm{~m}$.

Assessor: World Conservation Monitoring Centre

Refs: 19123

\section{Inga praegnans}

Leguminosae

VU B $1+2 \mathrm{c}$

Brazil (São Paulo)

Restricted to the state of Sāo Paulo, this treelet occurs in lowland rainforest.

Assessor: World Conservation Monitoring Centre

Refs: 19123

\section{Inga saffordiana}

Leguminosae

VU Alc

Colombia, Panama

In Panama, the species is known from a few forest localities in Darién, including Darién National Park. Recent reports indicate the species also exists in the Chocó and Antioquia in Colombia. It doesn't appear to be common at any of these sites and where the habitat is unprotected it suffers increasing encroachment.

Assessor: Mitré, M.

Refs: $7272,7980,16772,19123$

\section{Inga salicifoliola}

Leguminosae

Brazil (Amazonas)

VU D2

Known only from the type collection, the species is locally common in forest on the lower slopes of the Cerro Neblina near the Brazilian Venezuelan border.

Assessor: World Conservation Monitoring Centre

Refs: 19123

\section{Inga saltensis}

Leguminosae

Argentina (Jujuy, Salta), Bolivia

VU B1+2c

Endemic to piedmont forest of north-west Argentina and Bolivia, the species occurs in an unprotected ecosystem, which is rapidly being replaced by agricultural systems.

Assessor: Prado, D.

Refs: 19122, 19123

\section{Inga santaremnensis}

Leguminosae

Brazil (Pará)

VU D2

Apparently confined to the state of Para, only a few collections of this small tree have been found in disturbed rainforest on non-flooded sites.

Assessor: World Conservation Monitoring Centre Refs: 19123

\section{Inga sellowiana}

Leguminosae

$\mathrm{EN} \mathrm{B1}+2 \mathrm{c}$

Brazil (Sāo Paulo)

A shrub or small tree up to $2.5 \mathrm{~m}$ in height, found on sand dunes and in beach scrub, apparently only in São Paulo.

Assessor: World Conservation Monitoring Centre

Refs: 19123 
Inga sinacae

Leguminosae

Mexico (Veracruz)

Restricted to the Los Tuxtlas region of Veracruz, this tree is found in evergreen rainforest up to $200 \mathrm{~m}$. Most collections of this species were made near the Los Tuxtlas Biological Station.

Assessor: World Conservation Monitoring Centre

Refs: 5993, 19123

\section{Inga skutchü}

Leguminosae

VU $B 1+2 c$

\section{Costa Rica}

Known only from south-east Costa Rica, this tree is found in disturbed lowland to montane rainforest up to $1300 \mathrm{~m}$.

Assessor: World Conservation Monitoring Centre

Refs: 19123

\section{Inga spiralis}

Leguminosae

Panama

VU D2

This tree of wet lowland forest is restricted to central Panama. It is known only from four collections.

Assessor: World Conservation Monitoring Centre Refs: 19123

\section{Inga stenophylla}

Leguminosae

$\mathrm{EN} \mathrm{B1}+2 \mathrm{c}$

Costa Rica

A treelet, up to $2 \mathrm{~m}$ in height, confined to montane and cloud forest in central Costa Rica between 600 and $1200 \mathrm{~m}$. Only an estimated $1037 \mathrm{~km}^{2}$ of montane forest remain in Costa Rica.

Assessor: World Conservation Monitoring Centre

Refs: 14487, 19123, 19124

\section{Inga suberosa}

Leguminosae

Brazil (Amazonas)

$\mathrm{EN} \mathrm{B} 1+2 \mathrm{c}$

Apparently restricted to Manaus, this recently described tree grows in mixed rainforest on non-flooded sites. It is known from two collections.

Assessor: World Conservation Monitoring Centre

Refs: 19123

\section{lnga subnuda ssp. subnuda}

Leguminosae

Brazil (Alagoas, Bahia, Mato Grosso,

Pernambuco, Sergipe)

A tree of arboreal * restinga on sand, distributed near the coast from Parafba to Espirito Santo. In Espirito Santo, the species is also found in lowland rainforest near sea level.

Assessor: World Conservation Monitoring Centre

Refs: 19123

\section{Inga suborbicularis}

Leguminosae

Brazil (Bahia, Minas Gerais)

VU Alc

An understorey tree of lowland rainforest up to $600 \mathrm{~m}$, restricted to Minas Gerais and the coastal zone of Bahia. Assessor: World Conservation Monitoring Centre Refs: 19123
Inga tenuicalyx

Leguminosae

VU D2

Peru

Restricted to the Tarapoto region of San Martin, this small tree or shrub grows in dry low forest between 200 and $300 \mathrm{~m}$.

Assessor: World Conservation Monitoring Centre

Refs: 19123

\section{Inga tenuilobe}

Leguminosae

Costa Rica

$\mathrm{EN} B 1+2 \mathrm{c}$

A tree of undisturbed lowland rainforest between 50 and $150 \mathrm{~m}$, endemic to the Osa Peninsula in south-eastem Costa Rica.

Assessor: World Conservation Monitoring Centre

Refs: 19123

\section{Inga unica}

Leguminosae

VU B $1+2 c$

Brazil (Bahia, Espirito Santo)

A tree known from a few collections gathered from rainforest in Bahia and Espírito Santo.

Assessor: World Conservation Monitoring Centre

Refs: 19123

\section{Inga xinguensis \\ Leguminosae \\ Brazil (Pará)}

VU D2

A recently described species known only from the type collection found in non-flooded lowland forest on the bank of the River Xingu in Pará.

Assessor: World Conservation Monitoring Centre Refs: 19123

\section{Inga yasuniana \\ Leguminosae}

Ecuador

An understorey tree, known only from non-flooded lowland rainforest in Yasunf National Park.

Assessor: World Conservation Monitoring Centre

Refs: 19123

\section{Intsia acuminata}

Leguminosae

VUAld Philippines

A species which occurs in coastal forest. It yields valuable merbau timber used for high-quality fumiture. Assessor: World Conservation Monitoring Centre Refs: 4919, 12937

\section{Intsia bijuga}

Leguminosae

VU Alcd

American Samoa, Australia, British Indian Ocean Territory (Chagos Archipelago), Cambodia, India, Indonesia (Irian Jaya, Kalimantan, Lesser Sunda Is.), Japan, Madagascar, Malaysia (Peninsular Malaysia, Sabah, Sarawak), Myanmar, Papua New Guinea (Bismarck Archipelago, Papua New Guinea), Philippines, Seychelles, Singapore, Solomon Islands (South Solomon), Tanzania, Thailand, Vanuatu, Viet Nam

A lowland rainforest tree which produces one of the most valuable timbers of South East Asia. The species has been exploited so intensively for merbau timber that few sizeable natural stands remain. Few plantations are 
established. In Peninsular Malaysia, trees are never common and rarely reach a commercial size. There are apparently good stands still in Indonesia and Papua New Guinea.

Assessor: World Conservation Monitoring Centre

Refs: 559, 2625, 4919, 5054, 6156, 6161, 8058, 8865, $9199,10571,12779,12937,13662,14011,14573$. 16765,17140

\section{Iochroma lehmannii}

Solanaceae

VU B $1+2 c$

Ecuador

An endemic of Ecuador, inhabiting cloud forest at $2850 \mathrm{~m}$, in Chimborazo Province in the High Andes. Assessor: World Conservation Monitoring Centre Refs: 19119,19120

\section{Iochroma longipes}

Solanaceae

VU $B 1+2 c$

Ecuador

An endemic tree of Ecuador, inhabiting upper montane cloud forest in the High Andean regions of Carchi and Pichincha.

Assessor: World Conservation Monitoring Centre

Refs: 19119,19120

\section{Ipomoea pulcherrima}

Convolvulaceae

VU D2

Peru

An arborescent Ipomoea species, known only from the type collection which was taken from a savanna area above $1000 \mathrm{~m}$.

Assessor: World Conservation Monitoring Centre

Refs: 1984

\section{Irvingia gabonensis}

Irvingiaceae

LR/nt

Angola, Congo, Côte d'Ivoire, Democratic Republic of Congo, Ghana, Guinea, Nigeria, São Tomé \& Principe (Príncipe), Senegal, Sierra Leone, Sudan, Uganda Tropical evergreen rainforest is the optimal habitat for this species. However, it occurs also in gallery forest and semi-deciduous forest and is often found in towns or on the outskirts of villages. It is restricted to fairly wet, well-drained loamy to clayey soils. Population numbers have declined through logging operations, the expansion of human settlements and poor natural regeneration.

Assessor: World Conservation Monitoring Centre

Refs: $2773,4506,6127,8369,10961,16021,17408$

\section{Iryanthera campinae}

Myristicaceae

$\mathrm{EN} \mathrm{B} 1+2 \mathrm{~d}$

Brazil

Assessor: Rodrigues, W.A.

Refs: 19198

\section{Iryanthera megistocarpa}

\section{Myristicaceae}

$\mathrm{CR} \mathrm{B1+2bc}$

Panama

Recorded very rarely, the species is known only from the vicinity of the highway which runs from El Llano to Cartí in the Kunayala Indigenous Reserve. This area has been well covered botanically and the low number of collections of the species is a reasonable indication of its scarcity. Moreover, in recent years the major part of the forest here has been cleared and the land colonised by campesinos.

Assessor: Mitré, $\mathrm{M}$.

Refs: $233,7980,16772$

\section{Iryanthera obovate}

Myristicaceae

VU B1+2de

Brazil

Assessor: Rodrigues, W.A.

Refs: 19198

\section{Isoberlinia scheffleri}

Leguminosae

VU $B 1+2 b$

Tanzania

A species of moist forest at a wide altitudinal range.

Assessor: Lovett, J. \& G.P. Clarke

Refs: $1308,3356,3925,7550$

\section{Isolona congolana}

Annonaceae

Democratic Republic of Congo, Uganda

LR/nt

A useful tree occurring in areas of closed forest, often along rivers, largely in DR Congo, extending into Uganda.

Assessor: Ndjele, M.B.

Refs: 1308, 10961, 16021, 17951

\section{Isolona deightonii}

Annonaceae

VU Alc, $B 1+2 c$

Ghana, Sierra Leone

This species is uncommon and confined to the wet evergreen forest in Upper Guinea. The forest has declined over the past decades as a result of logging, mining and commercial forestry activities.

Assessor: Hawthome, W.

Refs: 4108, 8369, 12061

\section{Isolona dewevrei}

Annonaceae

VU $B 1+2 b c, D 2$

Democratic Republic of Congo

A Mayombe endemic known from two localities in the Luki Forest Reserve. The habitat has been greatly reduced by logging, charcoal production and agriculture. Assessor: Ndjele, M.B.

Refs: 17951

\section{Isolona heinsenü}

Annonaceae

$\mathrm{EN} \mathrm{Bl}+2 \mathrm{~b}$

Tanzania

Restricted to low-elevation forests, the species occurs in the East Usambara Mountains and Magombera.

Assessor: Lovett, J. \& G.P. Clarke

Refs: 3356,9302

\section{Isonandra perakensis var. perakensis}

Sapotaceae

LR/cd

Malaysia (Peninsular Malaysia)

A small tree of lowland rainforest, known under two varieties. This variety is confined to the state of Perak. A population is protected in Taman Negara National Park. Assessor: Chua, L.S.L.

Refs: 19073

\section{Isonandra stocksii}

Sapotaceae

EN B $1+2 c$

India

A small tree scattered in forest remnants in the Western Ghats. Several occurrences recorded from the turn of the century no longer appear to exist. The most recent collections are from Bangare in Upper Bisle Ghat and the Bababudan Hills.

Assessor: World Conservation Monitoring Centre Refs: 4799 


\section{Isonandra villosa}

Sapotaceae

$\mathrm{EN} \mathrm{B1+2c}$

India (Kerala, Tamil Nadu)

A species with a disjunct distribution, occurring in the Velligonda Hills in the south of the Eastern Ghats and in Quilon in coastal Kerala. Little is known of the present status of the populations as no record of them has been made since 1923.

Assessor: World Conservation Monitoring Centre Refs: 4799

\section{Itaya amicorum}

Palmae

\section{Brazil, Colombia, Peru}

An understorey palm of lowland rainforest, confined to the western Amazon regions of Brazil, Colombia and Peru. In Colombia it is known from a remote locality in a national park. At a local level the trunk is bumed for the production of salt and leaves are used for thatch.

Assessor: Bernal, $\mathbf{R}$.

Refs: 19118

\section{Iteiluma pinifolium}

Sapotaceae

$\mathrm{EN} \mathrm{B} 1+2 \mathrm{c}$

New Caledonia

The genus has now been moved to Pouteria. The taxon has been collected from Mont Poume and from maquis in Koumea and a few localities in the vicinity.

Assessor: Jaffré, T. et al.

Refs: $10351,10781,12630$

\section{Ixonanthes chinensis}

Ixonanthaceae

VUAlcd

China (Fujian, Guangdong, Guangxi, Guizhou, Hunan, Yunnan), Viet Nam

A small to medium-sized tree, which is widely scattered in China, crossing the border into northem Viet Nam. Occurring in lowland monsoon forest, the species has suffered extensive habitat loss. One of the major populations is found on Hainan Island, which has experienced large-scale habitat destruction over the last 30 years. Other areas of forest are given protection.

Assessor: Sun, W

Refs: $1818,11847,15357,19055$

\section{Ixonanthes khasiana}

Ixonanthaceae

India (Assam, Meghalaya)

VU B $1+2 c$

Occurrences are known from the Syreyngam, Khasi and the Jaintea Hills in Meghalaya and Bhutan Hill in Assam. The species is found in rainforest over $1000 \mathrm{~m}$. High rates of habitat loss have affected the entire range and no collections appear to have been made more recently than 1937.

Assessor: World Conservation Monitoring Centre

Refs: 2538

\section{Ixora albersii}

Rubiaceae

VU $B 1+2 b$

Tanzania

A moist montane forest species confined to the West Usambara Mountains at Shagayu and Shuwe-Magamba. Assessor: Lovett, J. \& G.P. Clarke

Refs: 3356, 10961

\section{Ixora brevipedunculasa}

Rubiaceae

French Polynesia (Tubuai Is.)

An endemic to Tubuai Island.

Assessor: Florence, J.

Refs: 14513

\section{Ixora calycina}

Rubiaceae

$\mathrm{EN} \mathrm{B} 1+2 \mathrm{c}$

Sri Lanka

Apparantly restricted to the wet zone of Sri Lanka, this species was collected in five forests during the extensive fieldwork carried out for the recent National Conservation Review.

Assessor: World Conservation Monitoring Centre

Refs: 19112

\section{Ixora degemensis}

Rubiaceae

$\mathrm{EN} \mathrm{B} 1+2 \mathrm{c}$

Nigeria

A shrubby tree endemic, confined to an area on the coast at Degema.

Assessor: World Conservation Monitoring Centre

Refs: 2773,11504

\section{Ixora johnsonï}

Rubiaceae

India (Kerala)

Known only from an imprecisely recorded location in the vicinity of Ernakulam on the Kerala coast, it is not known whether the species is still extant.

Assessor: World Conservation Monitoring Centre

Refs: 19144

\section{Ixora jucunda}

Rubiaceae

VUAlc

Sri Lanka

A tree restricted to the lowland wet evergreen forests of south-west Sri Lanka.

Assessor: World Conservation Monitoring Centre

Refs: 9176, 17195

\section{Ixora lawsoni}

Rubiaceae

$\mathrm{EN} \mathrm{B} 1+2 \mathrm{c}$

India (Kamataka, Kerala)

A small tree of submontane evergreen forest, known from two reconds close to the Kerala-Karnataka border.

Assessor: World Conservation Monitoring Centre

Refs: 19144

\section{Ixora malabarica}

Rubiaceae

VU B $1+2 c$

India (Kamataka, Kerala)

A small tree, recorded from scattered localities of lowland forest along the coast.

Assessor: World Conservation Monitoring Centre

Refs: 19144

\section{Ixora marquesensis}

Rubiaceae

DD

French Polynesia (Marquesas Is.)

Populations are recorded from Fatu Hiva, Mohotani and Nuku Hiva.

Assessor: Florence, J.

Refs: 14513 
Ixora nigerica

Rubiaceae

VU B $1+2 c$

Nigeria

This shrubby tree is endemic to southern Nigeria.

Assessor: World Conservation Monitoring Centre

Refs: 2773, 11504

\section{Ixora ooumuensis}

Rubiaceae

French Polynesia (Marquesas Is.)

An endemic to Nuku Hiva.

Assessor: Florence, J.

Refs: 14513

\section{Ixora pudica}

Rubiaceae

Seychelles

Endemic to the Seychelles, the species qualifies as threatened by virtue of its restricted distribution. Populations are healthy and stable.

Assessor: World Conservation Monitoring Centre

Refs: 16212,17229

\section{Ixora raiateensis}

Rubiaceae

LR/nt

French Polynesia (Society Is.)

An endemic to Raiatea.

Assessar: Florence, J.

Refs: 14513

\section{Ixora raivavaensis}

Rubiaceae

$\mathrm{LR} / \mathrm{nt}$

French Polynesia (Tubuai Is.)

An endemic to Raivavae.

Assessor: Florence, J.

Refs: 14513

\section{Ixora saulierei}

Rubiaceae

$\mathrm{EN} \mathrm{B} 1+2 \mathrm{c}$

India (Tamil Nadu)

A poorly recorded tree, occurring in the understorey of montane forest in the Palni Hills.

Assessor: World Conservation Monitoring Centre

Refs: 19144

\section{Ixora scheffleri ssp. keniensis}

Rubiaceae

CR B $1+2 \mathrm{c}$

Kenya

A shrub or tree which is possibly extinct, originally known from the north-east, east and south slopes of Mount Kenya between 1900 and $2100 \mathrm{~m}$ in areas of moist Ocotea forest.

Assessor: World Conservation Monitoring Centre

Refs: 6396

\section{Ixora scheffleri ssp. scheffleri}

Rubiaceae

VU $B 1+2 b$

Malawi, Tanzania

A subspecies which appears to extend from Tanzania into Malawi, confined to the remaining moist forest areas at submontane to montane elevations. In Tanzania records are known from the East Usambara Mountains, North Uluguru Mountains, Udzungwa Mountains and Rungwe Mountain.

Assessor: Lovett, J. \& G.P. Clarke

Refs: 3356, 6396, 10961
Ixora st-johnü

Rubiaceae

DD

French Polynesia (Society Is.)

An endemic to Huahine.

Assessor: Florence, J.

Refs: 14513

\section{Ixora temehaniensis}

Rubiaceac

DD

French Polynesia (Society Is.)

An endemic to Rajatea.

Assessor: Florence, J.

Refs: 14513

\section{Ixora umbellata}

Rubiaceae

French Polynesia (Society Is.)

An endemic to Tahiti.

Assessor: Florence, J.

Refs: 14513

\section{Jacaranda arborea}

Bignoniaceae

VU B $1+2 c$

Cuba

A small tree found in pine forests, serpentine shrubwoods and shrublands of the Sagua-Baracoa range in eastern Cuba. The habitat has been degraded in places. Logging and mining activities are constant threats.

Assessor: Areces-Mallea, A.E.

Refs: 7980,19149

\section{Jacaranda mimosifolia}

Bignoniaceae VU B $1+2 a c$

Argentina (Catamarca, Jujuy, Salta), Bolivia

The species is reported to be endemic to the endangered piedmont forest of north-west Argentina and Bolivia, an ecosystem which is rapidly being coverted to agriculture.

Assessor: Prado, D.

Refs: $5112,8451,14040,15037,19122$

\section{Jacqueshuberia loretensis}

Leguminosae

VU D2

Peru

This species occurs in *terra firme forest in the department of Loreto. It has been recorded only from the type collection.

Assessor: World Conservation Monitoring Centre

Refs: 1984

\section{Jacquinia macrantha var. clarendonensis}

Theophrastaceae

CR B $1+2 c$

Jamaica

This small tree is known from a rocky limestone hilltop above $730 \mathrm{~m}$, and possibly from Peckham Woods in Clarendon Parish.

Assessor: World Conservation Monitoring Centre Refs: 5653,7980

\section{Jacquinia macrantha var. macrantha}

Theophrastaceae

VU B $1+2 c$

Jamaica

The species is endemic to Jamaica. The type variety is found in crevices of precipitous rocks, where it is relatively well protected from the extensive clearance which has taken place in more accessible habitats. Assessor: World Conservation Monitoring Centre Refs: 5653,7980 
Jatropha bullockii

Euphorbiaceae

Mexico (Jalisco)

VU D2

A relatively recently described species, occurring as a small tree in deciduous forest in La Huerta on the coast of Jalisco. It is known only from the type locality. Assessor: World Conservation Monitoring Centre Refs: 7980,19068

Jatropha chamelensis

Euphorbiaceae

VU D2

Mexico (Jalisco)

Described in 1982, the species is found in deciduous forest in the Chamela Biological Station in La Huerta. Assessor: World Conservation Monitoring Centre Refs: 153, 15346, 19068

\section{Jatropha unicostata}

Euphorbiaceae

LR/nt

Yemen (Socotra)

Endemic to Socotra, this species is one of its commonest plants, co-dominating low-altitude succulent shrubland.

Assessor: Miller, A.G.

Refs: 2354, 19083

\section{Joannesia princeps}

Euphorbiaceae

VU Alcd

Brazil

A rainforest tree found in east Minas Gerais, north Espirito Santo to the south of Bahia. The species has been in decline through forest conversion for agriculture, livestock and plantation projects. In addition, it is exploited for the valuable boleira wood.

Assessor: World Conservation Monitoring Centre Refs: 4506, 7980

\section{Jollydora glandulosa}

Connaraceae

$\mathrm{VU} \mathrm{B} 1+2 \mathrm{c}, \mathrm{D} 2$

Cameroon, Nigeria

A rainforest treelet which is known from four localities. In Nigeria, it exists only on the Obudu Plateau in Cross Rivers National Park, where it is confined to forested valleys. Damage to the habitat is incurred from frequent fires and also from encroaching agriculture, especially banana plantations but also subsistence farming. In Cameroon, the species is restricted to the west, at sites near Obang, Limbe and Ediki.

Assessor: World Conservation Monitoring Centre Refs: 14719

\section{Jollydora pierrei}

Connaraceae

VU D2

Gabon

This treelet has been collected in rainforest near Libreville. The habitat is degraded where there has been logging. The species distribution may be more extensive given that Gabon's forests are relatively unexplored. However most areas are under concession to timber companies and their future remains uncertain.

Assessor: World Conservation Monitoring Centre Refs: 14719,14958

\section{Joosia standleyana}

Rubiaceae

VU B $1+2 \mathrm{C}$

Ecuador

An endemic tree of the Ecuadorean High Andes, currently known only from an area of montane cloud forest between 2000 and $2700 \mathrm{~m}$ in Zamora-Chinchipe. Assessor: World Conservation Monitoring Centre Refs: 19119,19120

Joseanthus chimborazensis

Compositae

VU B $1+2 c$

Ecuador

A tree species which is endemic to the High Andes of Ecuador.

Assessor: World Conservation Monitoring Centre

Refs: 19119

Joseanthus cuatrecasasii

Compositae

VU B $1+2 c$

Ecuador

A tree species which is endemic to the High Andes of Ecuador.

Assessor: World Conservation Monitoring Centre

Refs: 19119,19120

Juania australis

Palmae

VU D2

Chile (Juan Femández Is)

Restricted to the Masatierra Island, this palm tree occurs on steep slopes and ridges in lowland rainforest between 190 and $900 \mathrm{~m}$. Felling of the tree has been prohibited. The Juan Fernandez islands are designated as a national park and biosphere reserve and work is being carried out by *CONAF to save the native plants.

Assessor: World Conservation Monitoring Centre

Refs: 5651,19118

\section{Jubaea chilensis}

Palmae

VUAlcd

Chile

A palm tree of dry river valleys in the Andean foothills and of open hillsides in seasonally dry regions. Populations were once relatively common between the latitudes of $32^{\circ}$ and $35^{\circ}$ south, but they are now confined to a few small areas. This species is felled as a source of palm wine, which is reduced to make honey.

Assessor: González, M.

Refs: 19118

\section{Jubaeopsis caffra}

Palmae

VU D2

South Africa (Eastern Cape)

A multi-stemmed palm confined to the north banks of the Msikaba and Mtentu Rivers on the Transkei coast. Records from the Mzintlava River near Manteku have not been confirmed and it is possible that this subpopulation was destroyed by deforestation. The species grows from just above the water level to the tops of steep forested sandstone cliffs, even in the salt spray zone. Reproduction from seed is poor, but plants sucker vigorously. Both localities have been declared as national monuments and although they are in a designated protected area, there is no management and enforcement to ensure effective protection. This species is traded internationally on a small scale as an ornamental and overexploitation is a potential threat. The miniature coconut fruits are favoured by the local people and baboons.

Assessor: Hilton-Taylor, C. et al.

Refs: $389,689,19118,19218$ 
Juglans australis

Juglandaceae

LR/nt

Argentina (Catamarca?, Jujuy, Salta, Tucumán), Bolivia

A vigorous pioneer species, which is valued as a source of timber, medicine, fodder and food. It occurs in moist montane forest in an area extending from north-west Argentina to Tarya and Chuquisaca in Bolivia. Bolivian populations are facing heavy exploitation.

Assessor: World Conservation Monitoring Centre

Refs: 1262, 13295, 19170

\section{Juglans californica}

Juglandaceae

VU Alc

USA (California)

The species may be divided into two varieties, vars. californica and hindsii, both endemic to Califomia. Walnut forest is a much fragmented and decling habitat, threatened in several counties by urbanisation, grazing and possibly by the lack of natural reproduction. There are just two or three stands remaining of var. hindsii, although it is widely naturalised in parts of Califomia and was formerly cultivated as a rootstock for J. regia, with which it readily hybridises.

Assessor: World Conservation Monitoring Centre

Refs: 19163, 19183, 19193

\section{Juglans insularis}

Juglandaceae

VU B $1+2 \mathrm{c}$

Cuba

An endemic tree, up to $30 \mathrm{~m}$ tall, occurring in all types of seasonal forest, transitional between rainforest and semideciduous forest. The species is typical of pristine communities and acts as an indicator of minimal disturbance. The habitat, however, is one of the most suitable for tropical agriculture. Undisturbed stands are very rare.

Assessor: Areces-Mallea, A.E.

Refs: 16327, 18485, 19149

\section{Juglans jamaicensis}

Juglandaceae

VU Alc, B1+2c

Cuba, Dominican Republic, Haiti, Puerto Rico

A large tree, occurring on all islands of the Greater Antilles except for Jamaica, where it was reported once but probably in error. In Puerto Rico, 10 trees exist in La Silla de Calderon at $1000 \mathrm{~m}$. It is similarly uncommon on Cuba and Hispaniola but may be recorded under the name $J$. insularis. The wet montane forest habitat has been extensively destroyed and degraded.

Assessor: World Conservation Monitoring Centre

Refs: $6057,7980,8915,17124$

\section{Juglans neotropica}

Juglandaceae

EN Alacd $+2 \mathrm{~cd}$

Colombia, Ecuador, Peru

A highland species, with a scattered distribution on the periphery of the Andes and in inter-Andean valleys, often as isolated individuals in agricultural land. Declines in habitat have been considerable and the species continues to be exploited for its timber, which is often used for decorative purposes. Its presence in the international timber trade is thought to be increasing. No commercial plantations have been established. The seeds are also edible and marketed locally.

Assessor: Americas Regional Workshop

Refs: $3014,4217,4870,12109,16093,18432,19069$,

19179,19183

\section{Juglans olanchana}

Juglandaceae

EN C2a

Guatemala, Honduras, Mexico, Nicaragua

A species of the Atlantic lowlands, occurring as distinct varieties.

Assessor: Nelson, C.

Refs: 13995,18136

Juglans peruviana

Juglandaceae

VU D2

Peru

This species has been collected just once, from Lima.

Assessor: World Conservation Monitoring Centre

Refs: 1984

\section{Julbernardia magnistipulata}

Leguminosae

VU B $1+2 b$

Kenya, Tanzania

This species is restricted to moist forest areas from south-east Kenya to eastern Tanzania.

Assessor: Lovett, J. \& G.P. Clarke

Refs: 3356, 6396, 10961

\section{Julostylis polyandra}

Malvaceae

EN B $1+2 c$

India (Kerala)

Apparently collected only twice, the species is known from two forest localities to the north and south of the Travancore range.

Assessor: World Conservation Monitoring Centre

Refs: 19144

\section{Juniperus barbadensis}

Cupressaceae

CR D1

St Lucia

Overcutting in the past and overgrazing today have led to the confinement of the species to an inaccessible rocky outcrop, where it occurs in a dwarfed form. It is thought that forms growing to $15 \mathrm{~m}$ were more frequent at one time.

Assessor: SSC Conifer Specialist Group

Refs: 374

\section{Juniperus bermudiana}

Cupressaceae

CR B $1+2 \mathrm{C}$

Bermuda

Overexploitation in the past, as with $J$. barbadensis, has caused population reductions. However, the cause of more recent declines is an infestation of two accidentally introduced scale insects. This species is marginally more common than $J$. barbadensis. A few stands remain in undisturbed areas. Protection measures are helping in its recovery, but the development of the island ensures that the species will never take up its former range.

Assessor: SSC Conifer Specialist Group

Refs: $374,4506,9836$

\section{Juniperus blancoi}

Cupressaceae

Mexico (Durango, México State, Sonora)

Very similar to J. scopulorum, this species is known from three locations, generally along streamsides in montane pine-oak forest. It is locally common in Durango.

Assessor: SSC Conifer Specialist Group

Refs: 13041,13205 


\section{Juniperus brevifolia}

Cupressaceae

$\mathrm{EN} \mathrm{B} 1+2 \mathrm{c}$

Portugal (Azores)

A shrub or small tree which forms a typical component of remaining laurel forest, mostly above $500 \mathrm{~m}$. It is found on all the Azores, except Santa Maria and Graciosa. Continuous cutting of old stands for their high-quality wood has caused significant reductions in the population. Sizeable trees are now rare and the species is represented largely by shrub-sized individuals. Assessor: SSC Conifer Specialist Group

Refs: $374,7222,13041$

\section{Juniperus cedrus}

Cupressaceae

VU C1

Portugal (Madeira), Spain (Canary Is.)

Remaining populations are confined to dry woodland in inaccessible rocky areas of La Palma and Tenerife in the Canary Islands and only at higher altitudes on Madeira, where a total of 39 specimens have been counted in the wild. The species is dioecious and dispersal between the isolated populations is apparently failing because of declines in numbers in the avian-disperser population. It is listed in regional legislation and populations are also protected within national parks.

Assessor: Bañares, A. et al.

Refs: $374,13041,19022,19131$

\section{Juniperus centrasiatica}

Cupressaceae

LR/nt

China (Xinjiang)

An endemic to the Kuen Luen Mountains.

Assessor: SSC Conifer Specialist Group

Refs: 374,13041

\section{Juniperus comitana}

Cupressaceae

Guatemala, Mexico (Chiapas)

VU Bl $+2 \mathrm{C}$

Although relatively widespread within its range, stretching from Comitán in Mexico to north Guatemala, the species has suffered population losses from deforestation. It occurs on rocky hills in dry forests.

Assessor: SSC Conifer Specialist Group

Refs: $374,4974,13205,19161$

\section{Juniperus convallium var. convallium}

Cupressaceae

China (Sichuan, Xizang)

The species is found in an area extending from northwest Sichuan into east Tibet.

Assessor: SSC Conifer Specialist Group

Refs: 374,13041

\section{Juniperus convallium var. microsperme}

Cupressaceae

China (Xizang)

A species which is endemic to the south-east of Tibet.

Assessor: SSC Conifer Specialist Group

Refs: 374, 13041

\section{Juniperus deppeana var. patoniane}

Cupressaceae

VU B $1+2 \mathrm{ce}$

Mexico (Durango)

This taxon is widely scattered on agricultural land in six main locations. Trees can be coppiced and large individuals are left for shade, leading to an unbalanced population structure. The variety may be dubiously separated by bark characteristics.

Assessor: SSC Conifer Specialist Group

Refs: 13041, 13205

Juniperus deppeana var. robusta

Cupressaceae

VU B $1+2 c e$

Mexico (Chihuahua, Durango, Jalisco)

Assessor: SSC Conifer Specialist Group

Refs: 374,13205

Juniperus deppeana var. zacatecensis

Cupressaceae

Mexico (Durango, Zacatecas)

VU B1+2ce

This taxon is restricted, in the same way as var. patoniana, to areas where stands have been left to serve as shade trees. The population structure is poor. The variety is dubiously separated by bark characteristics.

Assessor: SSC Conifer Specialist Group

Refs: 13041, 13205

\section{Juniperus durangensis}

Cupressaceae

VU B1+2c

Mexico (Aguascalientes, Chihuahua, Durango, Jalisco, Sonora, Zacatecas)

A scarce species which favours openings in montane pine-oak forest. Up to 10 localities are known, but more are likely to be found. It is possible the scarcity of collections is a reflection of the species being overlooked rather than low in numbers.

Assessor: SSC Conifer Specialist Group

Refs: 374

\section{Juniperus ekmanii}

Cupressaceae

CR D1

Haiti

A taxonomically questionable species. Occurrences are recorded from Mome la Selle and Morne la Visite, although the latter population is now thought to be extinct.

Assessor: SSC Conifer Specialist Group

Refs: $374,9836,13041$

\section{Juniperus gamboana}

Cupressaceae

VU $B 1+2 c$

Guatemala, Mexico (Chiapas)

A tree of pine-oak forest, restricted to limestone hillsides. Deforestation continues to occur on a large scale. The timber is used on a local scale.

Assessor: SSC Conifer Specialist Group

Refs: 374, 13041, 13205, 19161

\section{Juniperus gaussenii}

Cupressaceae

LR/nt

China (Yunnan)

A Yunnan endemic with a relatively restricted range. Overcutting is a threat.

Assessor: SSC Conifer Specialist Group

Refs: 374

\section{Juniperus gracilior}

Cupressaceae

$\mathrm{EN} \mathrm{B} 1+2 \mathrm{c}$

Dominican Republic

Known from a locality near Constanza, Valle del Jaque, the increasing settlement of the area has reduced populations of this species to less accessible or attractive areas.

Assessor: SSC Conifer Specialist Group

Refs: $374,13041,13205$ 
Juniperus jaliscana

Cupressaceae

Mexico (Durango, Jalisco)

This species is restricted to two populations in montane pine-oak forest in Pueblo Nuevo, the Sierra Madre Occidental and Cuale in Jalisco. These forests are experiencing rapid deforestation rates.

Assessor: SSC Conifer Specialist Group

Refs: $374,6541,13041$

\section{Juniperus komarovii}

Cupressaceae

LR/nt

China (Sichuan)

Assessor: SSC Conifer Specialist Group

Refs: 374, 13041

\section{Juniperus lucayana}

Cupressaceae

Bahamas, Cuba, Haiti, Jamaica

VU BI+2c

This species is now rare in Cuba because of past overexploitation. It is technically extinct in Haiti and is rarely seen in the Bahamas. Of all tree species in the Blue Mountains in Jamaica, this is considered to be under the most direct threat because of its value as a fuelwood and a timber. It has a local and scattered distribution, mostly on steep slopes. In the Blue Mountains it occurs most commonly on southern slopes, where deforestation is prevalent and once remote populations are now accessible by road. Regeneration is spasmodic and young trees frequently colonise exposed sites and landslides.

Assessor: SSC Conifer Specialist Group

Refs: $374,9836,16327,19116,19149$

\section{Juniperus martinezii}

Cupressaceae

Mexico (Aguascalientes, Guanajuato, Jalisco)

Assessor: SSC Conifer Specialist Group

Refs: $4311,6541,13041$

\section{Juniperus pingii}

Cupressaceae

China (Sichuan, Yunnan)

LR/nt

A very rare species but apparently not under threat of extinction. Deforestation is taking place extensively in north-west Yunnan. There are some taxonomic queries about the boundary between this species and other Chinese junipers.

Assessor: SSC Conifer Specialist Group

Refs: 374,13041

\section{Juniperus procera}

Cupressaceae

LR/nt

Democratic Republic of Congo, Djibouti, Ethiopia, Kenya, Malawi, Saudi Arabia, Somalia, Sudan, Tanzania, Uganda, Yemen (Former North Yemen), Zimbabwe

Widespread from Arabia to Zimbabwe, this large tree is found in mountainous areas on rocky ground, mostly between 1750 and $2500 \mathrm{~m}$. Existing populations in the Arabian Peninsula represent a small fragment of the woodlands that once existed. At lower elevations populations appear to be regenerating extremely poorly, possibly because of climatic changes. Trees continue to be cut for fuelwood and timber at a local level, and in some places also for export. Changing land-use patterns, browsing, particularly by buffalo and elephants, and the increase in plantations of fast-growing exotic species are also contributing to the species' decline. Outlying populations in Zimbabwe, the Republic of Congo and Malawi are extremely small and threatened.

Assessor: World Conservation Monitoring Centre

Refs: $2361,4506,5108,6079,7222,14667$

\section{Juniperus przewalskii}

Cupressaceae

China (Gansu, Qinghai, Sichuan)

LR/nt

As with $J$. pingii, the species is relatively rare but apparently not overly threatened.

Assessor: SSC Conifer Specialist Group

Refs: 374, 13041

\section{Juniperus recurva var. coxï}

Cupressaceae

China (Yunnan), Myanmar

VUAlc

A fairly widespread variety of moist montane woodland in Yunnan and north-west Myanmar. It has been harvested heavily in Yunnan but appears to regenerate well.

Assessor: SSC Conifer Specialist Group

Refs: 374,13041

\section{Juniperus saxicola}

Cupressaceae

Cuba

VU D2

A tree up to $10 \mathrm{~m}$ tall, restricted to submontane forest on the rocky ridges of Pico Turquino and adjacent peaks in the Sierra Maesra mountain range in south-east Cuba. Population numbers are low.

Assessor: SSC Conifer Specialist Group

Refs: $16327,18485,19149$

\section{Juniperus standleyi}

Cupressaceae

Guatemala, Mexico (Chiapas)

$\mathrm{EN} \mathrm{Bl+2bc}$

An uncommon tree or prostrate shrub, occurring in forest above $3000 \mathrm{~m}$. Less than a third of the original $700 \mathrm{~km}^{2}$ extent of occurrence remains. The wood is heavily exploited for local construction work and fuel, and the scarcity of the tree has now led to municipal boundary disputes. Trees are legally protected but the law is not well respected. In the rainy season grazing by sheep is heavy.

Assessor: SSC Conifer Specialist Group

Refs: $374,536,4974,13205$

\section{Juniperus urbaniana}

\section{Cupressaceae}

Haiti

$\mathrm{EN} \mathrm{B} 1+2 \mathrm{c}$

Viable populations were recorded in 1984 in Pic la Selle. Since then attempts to find this shrubby species have failed. It appears to be reduced to inaccessible areas. Much of its habitat has been destroyed.

Assessor: SSC Conifer Specialist Group

Refs: 374,9836

\section{Kageneckia lanceolato}

Rosaceae

Bolivia, Peru

VUAlcd

This species is located at elevations in the dry Andean valleys and transition zones to the *puna, where agricultural activity is most intense. Grazing, habitat clearing and collection as a fuelwood is affecting remaining populations. In areas where it was once noted as abundant, the species is almost extinct. The hard wood is also popular for making ploughs, etc. Assessor: World Conservation Monitoring Centre Refs: 19180 


\section{Kalappia celebica}

Leguminosae

$\mathrm{VUB} 1+2 \mathrm{c}$

Indonesia (Sulawesi)

A monotypic genus, known only from a few collections, restricted to lowland forest in the vicinity of Malili. This large tree is locally valuable for its timber, especially for building ships and bridges.

Assessor: World Conservation Monitoring Centre

Refs: 4329, 6426, 19072

\section{Kayea coriacea}

Guttiferae

VU D2

Papua New Guinea

This tree is found in Westem District and has recently been discovered on Sudest Island. It occurs in lowland seasonally flooded or ridge forest. The taxonomic limits of the species are presently unknown. It could represent more than one taxon.

Assessor: Stevens, P.F.

Refs: 19031, 19113

\section{Kayea macrophylla}

Guttiferae

VU D2

Indonesia (Irian Jaya), Papua New Guinea

A small tree of lowland rainforest, known from two collections: one from Geelvink Bay, Irian Jaya, and the other from an area near Angoram in the East Sepik District of Papua New Guinea.

Assessor: Stevens, P.F.

Refs: 19031

\section{Keetia koritschaneri}

Rubiaceae

VU B1+2b, D2

Tanzania

A dry forest species confined to the Mombo Forest Reserve, Makuyuni.

Assessor: Lovett, J. \& G.P. Clarke

Refs: 3356, 10961

\section{Keetia purpurascens}

Rubiaceae

VU $B 1+2 b$

Tanzania

A Tanzanian endemic restricted to areas of dry forest in the east and south-east.

Assessor: Lovett, J. \& G.P. Clarke

Refs: 3356,10961

\section{Kentiopsis oliviformis}

Palmae

$\mathrm{EN} \mathrm{Bl}+2 \mathrm{c}$

New Caledonia

Occurring in the lowlands, the species is restricted to a small area of the south-west and centre of the island.

Assessor: Jaffré, T. et al.

Refs: 10351, 19118

\section{Kermadecia pronyensis}

Proteaceae

VU D2

New Caledonia

A species known from four localities. One is in the south near Prony and more recently the species has been recorded from the Boulinda Massif, where it is found in diverse habitat types of maquis and forest up to an altitude of $850 \mathrm{~m}$.

Assessor: Jaffré, T. et al.

Refs: 10351, 12630

\section{Keteleeria davidiane var. formosana}

Pinaceae

Taiwan

$\mathrm{CRBl}+2 \mathrm{c}$

A close relative of $K$. davidiana in Yunnan, known from localities in the north and south, separated by $300 \mathrm{~km}$.

The populations are small, numbering fewer than 150 mature trees, and the lowland forest habitat is commonly invaded by broadleaved species, leading to very poor regeneration. A reserve has been set up specifically to help conserve the taxon. It is also protected under the Cultural Heritage Preservation Law.

Assessor: Lu, S.Y. \& F.J. Pan

Refs: 2106, 11191, 13041, 19050, 19051

\section{Keteleeria fortunei}

Pinaceae

LR/nt

China (Fujian, Guangdong, Guangxi, Guizhou, Hunan, Jiangxi, Yunnan, Zhejiang), Hong Kong, Viet Nam

Assessor: SSC Conifer Specialist Group

Refs: 1818, 13041

\section{Khay anthotheca}

Meliaceae

VU Alcd

Angola, Cameroon, Congo, Côte d'Ivoire, Democratic Republic of Congo, Ghana, Liberia, Malawi, Mozambique, Nigeria, Sierra Leone, Tanzania, Uganda, Zambia, Zimbabwe

An important source of African mahogany, this species is widespread in areas of evergreen forest. It is heavily exploited, particularly in East and West Africa. Regeneration is poor in places, especially where parent trees are scarce, and serious genetic erosion is believed to have occurred. This species is commonly confused with $K$. grandifoliola. There are protected populations, log export bans and felling limits in various countries. Assessor: Hawthome, W.

Refs: $2773,6128,6725,10961,12061,13250,13370$, $16021,16822,17408$

\section{Khaya grandifoliola}

Meliaceae VU Alcd

Benin, Côte d'Ivoire, Democratic Republic of Congo, Ghana, Guinea, Nigeria, Sudan, Togo, Uganda

An important timber species, commonly confused with

$K$. anthotheca but less widespread, occurring more frequently in dry semi-deciduous forest and forest outliers. Exploitation is heavy: extraction of mature individuals from populations has been comprehensive. Regeneration is poor away from parent individuals and is best at the savanna-forest boundary. Protected populations and $\log$ export bans are in place in various countries.

Assessor: Hawthome, W.

Refs: 2036, 2773, 6127, 11504, 12061, 14667, 16021

\section{Khaya ivorensis}

Meliaceae

VUAlcd

Angola, Cameroon, Côte d'Ivoire, Gabon, Ghana, Liberia, Nigeria

The most important Khaya species for providing African mahogany. It is found in various habitat types in West and Central Africa but is most abundant in wet undisturbed evergreen forest. Levels of exploitation are very high. Little regeneration takes place after disturbance. Individuals reach a seed-producing age at 
30 years, although large seed crops appear only at three to four year intervals. Log export bans and legal protection exist in various countries.

Assessor: African Regional Workshop

Refs: $2773,6128,6718,8785,12061,13250$

\section{Khaya madagascariensis}

Meliaceae

Comoros, Madagascar

In the north-west, the species occurs in Mahajanga, Port-

Berge, Mitsinjo, Ambilobe and also on the Comoros: further east on the mainland in Vohémas, Ambila and Mananjary. Populations are found in rainforest, along rivers, salt-water marshes and also in degraded forest. Both habitat and trees have been heavily exploited. Assessor: World Conservation Monitoring Centre Refs: 6161

\section{Khaya senegalensis}

Meliaceae

VU Alcd

Benin, Burkina Faso, Cameroon, Central African Republic, Chad, Côte d'Ivoire, Gabon, Gambia, Ghana, Guinea, Guinea-Bissau, Mali, Niger, Nigeria, Senegal, Sierra Leone, Sudan, Togo, Uganda

A mahogany species, widespread in high-rainfall savanna woodland. Logging and local exploitation are largely uncontrolled and poorly monitored. In northern parts of the range exploitation may be leading to genetic erosion. Natural regeneration from the seed is poor but does occur from suckers. Legal protection exists in various countries. Many uses of the tree, particularly the medicinal properties of the bark, are documented.

Assessor: World Conservation Monitoring Centre

Refs: 2036, 2773, 4506, 5003, 11504, 14667

\section{Kibatalia borneensis}

\section{Apocynaceae}

Malaysia (Sarawak)

EN Alc

A small tree or shrub found in swamp forest and heath forest near Kuching, Sarawak. The vegetation surrounding Kuching is extremely threatened by urban encroachment.

Assessor: World Conservation Monitoring Centre

Refs: 18327,18388

\section{Kibatalia elmeri}

Apocynaceae

VU D2

Philippines

A montane forest species known only from a single locality, Mount Bulusan on Luzon.

Assessor: World Conservation Monitoring Centre

Refs: 18388

\section{Kibatalia gitingensis}

Apocynaceae

VU Alc, B1+2c

Philippines

A tree of hill forest between 150 and $525 \mathrm{~m}$, found on the islands of Catanduances, Luzon, Leyte and Surigao. Trees are cut for timber.

Assessor: World Conservation Monitoring Centre

Refs: 18388

\section{Kibatalia longifolia}

Apocynaceae

CR B $1+2 c$

Philippines

A tree, known only from the type collection, found in forest on deep rich soils at an altitude of $40 \mathrm{~m}$. It is apparently endemic to Davao Province of Mindanao Island.

Assessor: World Conservation Monitoring Centre

Refs: 18388

Kibatalia macgregori

Apocynaceae

VU D2

Philippines

Apparantly endemic to Sibuyan Island, this tree has been collected only once in montane forest.

Assessor: World Conservation Monitoring Centre

Refs: 18388

Kibatalia merrilliana

Apocynaceae

VU D2

Philippines

A small tree endemic to the Philippines, so far found only on Samar and Leyte Islands.

Assessor: World Conservation Monitoring Centre

Refs: 18388

\section{Kibatalia puberula}

Apocynaceae

$\mathrm{EN} \mathrm{B1}+2 \mathrm{C}$

Philippines

Restricted to Samar Island, this small evergreen tree occurs in dipterocarp forest on river banks between altitudes of 100 and $250 \mathrm{~m}$. It has been collected only three times.

Assessor: World Conservation Monitoring Centre Refs: 18388

\section{Kibatalia stenopetala}

Apocynaceae

$\mathrm{EN} \mathrm{B1+2c}$

Philippines

Found in forest in the foothills of mountains in Luzon and Mindanao, this tree is known only from three herbarium specimens.

Assessor: World Conservation Monitoring Centre Refs: 18388

\section{Kibatalia villosa}

Apocynaceae

VU B $1+2 \mathrm{C}$

Indonesia (Kalimantan), Malaysia (Peninsular Malaysia, Sarawak)

An evergreen tree of swamp and montane forest, found in Johore in Peninsular Malaysia, Kalong and Manundi in Sarawak and in west, east and south Kalimantan. Assessor: World Conservation Monitoring Centre Refs: 18388

\section{Kibatalia wigmani}

Apocynaceae

VU D2

Indonesia (Sulawesi)

Endemic to north-east Sulawesi, the species has been collected several times from evergreen forest on volcanic soils.

Assessor: World Conservation Monitoring Centre Refs: 4329,18388

\section{Kielmeyera peruviana}

Guttiferae

VU D2

Peru

Known only from the type collection, this species occurs in *terra firme forest over $1000 \mathrm{~m}$ in the department of San Martin.

Assessor: World Conservation Monitoring Centre Refs: 1984 


\section{Kingiodendron pinnatum}

Leguminosae

India (Karnataka, Kerala, Tamil Nadu)

EN Alcd

A large tree sparesely distributed in evergreen hill forest and deciduous forest, occurring up to $1000 \mathrm{~m}$ over a range extending from South Kanara in Karnataka to the southern tip of the Western Ghats in Tamil Nadu. The species yields useful timber, bark and resin. The population has declined considerably because of overexploitation and habitat degradation. Regeneration appears to be very poor.

Assessor: CAMP Workshops on Medicinal Plants in India

Refs: 561, 4799, 19144

\section{Kirkia burgeri ssp. somalensis}

Simaroubaceae

LR/nt

Somalia

Confined to northern Somalia, the subspecies is threatened by habitat degradation caused by general overcutting and grazing.

Assessor: Thulin, $\mathrm{M}$.

Refs: 8697,18665

\section{Kirkia dewinteri}

Simaroubaceae

VU D2

Namibia

A species of very arid savanna, confined to dolomite mountain slopes in Damaraland, northern Namibia. There is possibly a new locality further to the east. The population size is small and overutilisation of the area or a natural disaster could result in its demise. There are threats from increasing settlement and grazing by livestock. It is protected by forestry legislation and to a certain extent by the inaccessible terrain in which it occurs. If this new locality is confirmed, it will lie within a newly-formed conservancy.

Assessor: Hilton-Taylor, C. et al.

Refs: 689,19218

\section{Knema alvarezii}

Myristicaceae

Philippines

VU D2

This species is known from only two collections from the Province of Nueva Ecija in the Philippines.

Assessor: World Conservation Monitoring Centre Refs: 10460

\section{Knema andamanica ssp. andamanica}

Myristicaceae

VU B $1+2 \mathrm{c}$

India (Andaman and Nicobar Is. - Andaman Is., Andaman and Nicobar Is. - Nicobar Is.)

A rainforest tree found only on the Andaman and Nicobar Islands.

Assessor: World Conservation Monitoring Centre

Refs: 10460

\section{Knema andamanica ssp. nicobarica}

Myristicaceae

VU D2

India (Andaman and Nicobar Is. - Nicobar Is.), Indonesia (Sumatra), Malaysia (Peninsular Malaysia) A total of six collections are known of this rainforest tree, taken from Nicobar Island, Pinang Island in Peninsular Malaysia and Atjeh in Sumatra.

Assessor: World Conservation Monitoring Centre Refs: 10460

\section{Knema andamanica ssp. peninsularis}

Myristicaceae

VU D2

Thailand

This subspecies has been collected only four times from rainforest in Thailand, including some island localities. Assessor: World Conservation Monitoring Centre Refs: 10460

\section{Knema ashtonii var. ashtonii}

Myristicaceae

VU Alc

Brunei, Malaysia (Sabah, Sarawak)

This variety is found in primary forest in northem Bomeo.

Assessor: World Conservation Monitoring Centre

Refs: 10460

\section{Knema ashtonii var. cinnamomea}

Myristicaceae

Indonesia (Kalimantan), Malaysia (Sarawak)

A primary forest variety found in central-east Kalimantan and Sarawak.

Assessor: World Conservation Monitoring Centre

Refs: 10460

\section{Knema austrosiamensis}

Myristicaceae

VU D2

Thailand

Known only from four collections, this tree is found in evergreen forest in south-east Thailand.

Assessor: World Conservation Monitoring Centre Refs: 10460

\section{Knema bengalensis}

Myristicaceae

VU D2

Bangladesh

This tree is known only from the type collected in the Chittagong District of Bangladesh.

Assessor: World Conservation Monitoring Centre Refs: 5626, 10460

\section{Knema celebica}

Myristicaceae

VU D2

Indonesia (Sulawesi)

This species is confined to lowland forest on ultrabasic soils in central Sulawesi, south of Lake Matano. There are no occurrences north of the lake, where the soils have a different origin. It is known from four collections.

Assessor: World Conservation Monitoring Centre Refs: 4329,10460

\section{Knema communis}

Myristicaceae

Malaysia (Peninsular Malaysia), Singapore

VU Alc

Apparently endemic to Peninsular Malaysia, this scattered species grows in lowland and hill rainforest up to $270 \mathrm{~m}$. Expansion of settlements and forest clearance are the main threats.

Assessor: Chua, L.S.L.

Refs: $9199,17140,19073$

\section{Knema conica}

Myristicaceae

VU D2

Thailand

A small tree found in evergreen forest; known only from the type collected in Chantabun, south-east Thailand in 1930.

Assessor: World Conservation Monitoring Centre Refs: 10460 


\section{Knema curtisui var, amoena}

Myristicaceae

VU D2

Brunei

Very localised, this variety is known only from the type collected from lowland forest in Brunei.

Assessor: de Wilde, W.J.J.O.

Refs: 10460,19078

\section{Knema curtisii var. arenosa}

Myristicaceae

VU D2

Indonesia (Kalimantan), Malaysia (Sabah, Sarawak)

Endemic to Bomeo, this uncommon variety is restricted to sandy ridges. It has not been collected recently.

Assessor: World Conservation Monitoring Centre

Refs: 10460, 19078

\section{Knema curtisii var. paludosa}

Myristicaceae

VUAlc

Indonesia (Sumatra), Malaysia (Peninsular Malaysia, Sarawak), Singapore

A variety found predominantly in freshwater swamp forest, where it has been collected only infrequently. Assessor: World Conservation Monitoring Centre Refs: 9199,10460

\section{Knema emmae}

Myristicaceae

Indonesia (Kalimantan), Malaysia (Sabah)

VUD2

A small tree of hillside forest, recently described and known only from three collections from Bukit Tawau and Keningau in Sabah and Gunung Maeru Tagal in north-east Kalimantan.

Assessor: World Conservation Monitoring Centre

Refs: 2147

\section{Knema glauca var. riparia}

Myristicaceae

VUAlc

Malaysia (Sarawak)

This tree is usually found in lowland primary riverine forest.

Assessor: World Conservation Monitoring Centre

Refs: 875

\section{Knema hirtella var. pilocarpa}

Myristicaceae

VU B $1+2 c$

Indonesia (Kalimantan), Malaysia (Sabah)

This variety is known from occurrences in east Kalimantan, east Sabah and from a collection in Sarawak

Assessor: World Conservation Monitoring Centre

Refs: 10460

\section{Knema hookerana}

Myristicaceae VUAlc

Indonesia (Sumatra), Malaysia (Peninsular Malaysia),

Singapore, Thailand

A distinctive species which occurs from southern Peninsular Thailand to Sumatra; no recent collections have been made.

Assessor: de Wilde, W.J.J.O.

Refs: 9199,10460

\section{Knema intermedia}

\section{Myristicaceae}

$\mathrm{LR} / \mathrm{nt}$

Indonesia (Java, Kalimantan, Sumatra), Malaysia (Peninsular Malaysia, Sabah, Sarawak), Singapore

Although fairly widespread in west Malesia, the species has been collected only twice in recent years.

Assessor: de Wilde, W.J.J.O.

Refs: 9199, 10460, 17140

Knema kinabaluensis

Myristicaceae

Malaysia (Sabah)

A montane species locally common and endemic to Mount Kinabalu and the surrounding area.

Assessor: World Conservation Monitoring Centre Refs: 1766, 10460

Knema korthalsii ssp. rimosa

Myristicaceae

Malaysia (Sabah)

VU B $1+2 c$

A small tree of lowland primary dipterocarp forest endemic to east Sabah.

Assessor: World Conservation Monitoring Centre

Refs: 19082

\section{Knema kostermansiana}

Myristicaceae

Indonesia (Kalimantan), Malaysia (Sabah)

VU D2

A tree found in logged forest and riverine forest; it is known from two collections from Sabah, a single collection from Sarawak and another from north-east Kalimantan.

Assessor: World Conservation Monitoring Centre Refs: $875,1766,10460$

\section{Knema krusemaniana}

Myristicaceae

Indonesia (Kalimantan)

VU D2

A recently described small tree, which has been collected four times in the upper reaches of Katingan and Kahayan Rivers. It is locally common in secondary forest.

Assessor: World Conservation Monitoring Centre Refs: 2147

\section{Knema kunstleri ssp. alpina}

Myristicaceae

Indonesia (Kalimantan), Malaysia (Sabah, Sarawak)

A subspecies of submontane to montane forest in Sarawak, Sabah and west and south Kalimantan.

Assessor: World Conservation Monitoring Centre Refs: 10460

\section{Knema kunstleri ssp. coriacea}

Myristicaceae

VUAlc

Brunei, Malaysia (Sabah, Sarawak)

A subspecies usually found in the threatened peatswamp forests of northern Bomeo.

Assessor: World Conservation Monitoring Centre Refs: 10460

\section{Knema kunstleri ssp. leptophylla}

Myristicaceae

VU D2

Indonesia (Kalimantan)

This recently described subspecies is known only from the type collection. It was found in primary hill dipterocarp forest in west Kalimantan.

Assessor: World Conservation Monitoring Centre Refs: 2147

\section{Knema kunstleri ssp. macrophylla}

Known only from the type collection from the Irdragiri 
Uplands, the subspecies occurs in lowland swamp forest. Assessor: World Conservation Monitoring Centre Refs: 10460,10547

\section{Knema kunstleri ssp. pseudostellata}

Myristicaceae

VU D2

Indonesia (Kalimantan)

A small tree known only from a single collection found in primary dipterocap forest at $1200 \mathrm{~m}$ in Serawai, west Kalimantan.

Assessor: World Conservation Monitoring Centre

Refs: 19082

\section{Knema lamellaria}

Myristicaceae

VU D2

Malaysia (Peninsular Malaysia)

A species known only from a collection from Terengganu and another from Pahang.

Assessor: World Conservation Monitoring Centre

Refs: 10460

\section{Knema lampongensis}

Myristicaceae

VU D2

Indonesia (Kalimantan, Sumatra)

A total of five collections have been found on the east coast and Riouw Island off Sumatra and the Anambas Islands off Bomeo.

Assessor: World Conservation Monitoring Centre Refs: 10460

\section{Knema latericia ssp. latericia}

Myristicaceae

VU B $1+2 c$

Philippines

This subspecies is endemic to Palawan; it has been further divided into two varieties: var. latericia and var. subtilis. The variety subtilis grows in primary and logged dipterocarp forest.

Assessor: World Conservation Monitoring Centre

Refs: 10460,19082

\section{Knema longepilosa}

Myristicaceae

VU D2

Indonesia (Kalimantan), Malaysia (Sarawak)

Known only from three collections, this small tree is found in hillside forest and occasionally mixed dipterocarp forest in Fourth Division of Sarawak and west-central Kalimantan.

Assessor: World Conservation Monitoring Centre

Refs: 2147

\section{Knema losirensis}

Myristicaceae

LR/cd

Indonesia (Sumatra)

This tree has been found only in northern Sumatra. It is present in the Gunung Leuser Nature Reserves.

Assessor: World Conservation Monitoring Centre

Refs: 10460,10547

\section{Knema mamillata}

Myristicaceae

VU D2

Indonesia (Kalimantan)

Found in lowland Agathis forest on sand ridges in peat forest, this tree is known only from three collections from south Kalimantan.

Assessor: World Conservation Monitoring Centre Refs: 1766,10460
Knema matanensis

Myristicaceae

VU D2

Indonesia (Sulawesi)

A tree, endemic to central Sulawesi, known only from four collections.

Assessor: World Conservation Monitoring Centre Refs: 4329

\section{Knema minima}

Myristicaceae

VU D2

Brunei

Known only from a restricted area in south Brunei, this small tree occurs in mixed dipterocarp forest on ridges between 50 and $350 \mathrm{~m}$.

Assessor: World Conservation Monitoring Centre Refs: 19082

\section{Knema mixta}

Myristicaceae

VU D2

Viet Nam

A montane forest tree that has been collected only once in Annam.

Assessor: World Conservation Monitoring Centre Refs: 10460

\section{Knema mogeana}

Myristicaceae

Indonesia (Kalimantan), Malaysia (Sabah, Sarawak)

A small tree found in primary forest and mixed dipterocarp forest.

Assessor: World Conservation Monitoring Centre Refs: 875,1766

\section{Knema muscosa}

Myristicaceae

VU D2

Malaysia (Sarawak)

This species is restricted to two collections from Mount Majau, Sarawak.

Assessor: World Conservation Monitoring Centre

Refs: 1766,10460

\section{Knema oblongata ssp. parviflora}

Myristicaceae

VU D2

Malaysia (Sabah)

Known only from the type, this subspecies occurs in primary forest in Sabah.

Assessor: World Conservation Monitoring Centre

Refs: 10460

Knema oblongata ssp. pedunculata

Myristicaceae

VU D2

Malaysia (Sabah)

Known from three collections, this subspecies is found in lowland primary forests in Sabah.

Assessor: World Conservation Monitoring Centre

Refs: 10460

\section{Knema oblongifolia}

Myristicaceae

LR/Cd

Malaysia (Peninsular Malaysia)

A rare tree found in moist forest up to $1700 \mathrm{~m}$. Although populations are generally threatened by increasing settlement and logging activities, the species is conserved in Taman Negara National Park, wildlife reserves and forest reserves.

Assessor: Chua, L.S.L.

Refs: $10460,11647,19073,19078$ 
Knema pachycarpa

Myristicaceae

VU D2

Viet Nam

Known only from the type collection, this tree is found in evergreen montane forest near Da Nang in Annam.

Assessor: World Conservation Monitoring Centre

Refs: 10460

\section{Knema pectinata ssp. pectinata}

Myristicaceae

Malaysia (Sabah, Sarawak)

This lower montane subspecies is locally common in Sarawak and Sabah.

Assessor: World Conservation Monitoring Centre

Refs: $1766,10460,17176,19078$

\section{Knema pectinata ssp. vestita}

Myristicaceae

VU D2

Malaysia (Sarawak)

This subspecies appears to be restricted to the Fifth Division, where it has been collected only three times.

Assessor: World Conservation Monitoring Centre

Refs: 17176

\section{Knema pedicellata}

Myristicaceae

Malaysia (Sabah, Sarawak)

VUAlc

A tree restricted to mixed dipterocarp forest up to an altitude of $700 \mathrm{~m}$.

Assessor: World Conservation Monitoring Centre

Refs: 1766,10460

\section{Knema percoriacea for. fusca}

Myristicaceae

VU D2

Brunei

This form is known only from the type collected in Brunei.

Assessor: World Conservation Monitoring Centre

Refs: 10460

\section{Knema pierrei}

Myristicaceae

Viet Nam

VU D2

This tree is confined to Cochinchina, south Viet Nam, where it is known from five collections from lower montane forest.

Assessor: World Conservation Monitoring Centre

Refs: 10460

\section{Knema piriformis}

Myristicaceae

$\mathrm{LR} / \mathrm{cd}$

Malaysia (Sabah, Sarawak)

The species is found in montane forest especially on and around Mount Kinabalu. A single collection has also been recorded from Sarawak.

Assessor: World Conservation Monitoring Centre

Refs: 1766,10460

\section{Knema plumulosa}

Myristicaceae

Malaysia (Peninsular Malaysia)

Found throughout Peninsular Malaysia, this species of lowland and hill rainforest is declining through the expansion of human habitation and logging activities. There are no recent collections of this species.

Assessor: Chua, L.S.L.

Refs: $17140,19073,19078$
Knema poilanei

Myristicaceae

VU D2

Viet Nam

Known only from type collection from Annam, this tree was found in montane forest in 1939.

Assessor: World Conservation Monitoring Centre

Refs: 10460

\section{Knema psilantha}

Myristicaceae

Indonesia (Kalimantan), Malaysia (Sabah, Sarawak)

A tree known from two collections from the Third

Division, Sarawak, a single collection from the Beaufort

District, Sabah, and a recent collection from east

Kalimantan.

Assessor: World Conservation Monitoring Centre

Refs: $1766,2147,10460$

\section{Knema pubiflora}

Myristicaceae

LR/nt

Indonesia (Kalimantan), Malaysia (Sabah, Sarawak)

A forest tree found in the Third Division of Sarawak, Sabah and Kalimantan (including Nunukan Island).

Assessor: World Conservation Monitoring Centre

Refs: 1766, 10460

\section{Knema retusa}

Myristicaceae

VU D2

Malaysia (Peninsular Malaysia)

A tree known only from four collections from Perak. The species is very rare and has not been collected recently. It is not known whether it still exists.

Assessor: World Conservation Monitoring Centre

Refs: 10460, 19073, 19078

\section{Knema riangensis}

Myristicaceae

Indonesia (Kalimantan), Malaysia? (Sarawak?)

VU D2

Known from three or four collections, the tree is known from primary riverine forest in Bukit Raya, central Kalimantan, and from a slightly different collection from Sarawak.

Assessor: World Conservation Monitoring Centre Refs: 875

\section{Knema ridsdaleana}

Myristicaceae

VU D2

Philippines

A small tree, known only from the type collection, found growing by a stream on ultrabasic soil in Palanan, northeast Luzon. The area receives limited protection as a wildemess area, but continues to be threatened by illegal logging and expansion of settlements.

Assessor: World Conservation Monitoring Centre Refs: 2147

\section{Knema rigidifolia ssp. camerona}

Myristicaceae

VU D2

Malaysia (Peninsular Malaysia)

A subspecies of montane forest known only from a single locality in the Cameron Highlands. The locality is under pressure from infrastructural development.

Assessor: de Wilde, W.J.J.O.

Refs: 10460,19073

Knema rigidifolia ssp. rigidifolia

Myristicaceae

LR/nt

Malaysia (Peninsular Malaysia)

This subspecies is restricted to the mountains of Pahang 
and Selangor. The known localities are under pressure from infrastructural development. Some populations are contained within a wildlife sanctuary and protected forests within the permanent forest estate.

Assessor: Chua, L.S.L.

Refs: 10460,19073

\section{Knema rufa}

Myristicaceae

VU D2

Brunei, Malaysia (Sarawak)

This species occurs in Sarawak and Brunei.

Assessor: de Wilde, W.J.J.O.

Refs: 10460

\section{Knema saxatilis}

Myristicaceae

VU D2

Viet Nam

This tree is found in montane forest near Da Nang, Annam.

Assessor: World Conservation Monitoring Centre Refs: 10460

\section{Knema sericea}

Myristicaceae

Brunei, Indonesia (Kalimantan), Malaysia (Sarawak)

Known from five collections, the tree is found at the foot of limestone mountains.

Assessor: World Conservation Monitoring Centre

Refs: 1766, 2147, 10460

\section{Knema sessiflora}

Myristicaceae

VU D2

Viet Nam

A montane forest species collected only twice, in Annam, Viet Nam.

Assessor: World Conservation Monitoring Centre

Refs: 10460

\section{Knema squamulosa}

Myristicaceae

VU D2

Viet Nam

A tree, known only from the type collection, which was found growing in montane forest on rocky clay soil in Annam in 1923.

Assessor: World Conservation Monitoring Centre Refs: 10460

\section{Knema steenisii}

Myristicaceae

Indonesia (Lesser Sunda Is.)

A tree only known from west Flores at about $800 \mathrm{~m}$.

Assessor: World Conservation Monitoring Centre

Refs: 1011,17176

\section{Knema stellata ssp. minahassae}

Myristicaceae

VU D2

Indonesia (Sulawesi)

This subspecies is endemic to north and central Sulawesi, from where it has been collected four times. It occurs on poor soils north of Lake Matano. There are no occurrences south of the lake, where the soils have a different origin.

Assessor: World Conservation Monitoring Centre Refs: 4329,10460
Knema stellata ssp. stellata

Myristicaceae

VU D2

Philippines

This subspecies is known from only five collections on the Samar Islands.

Assessor: World Conservation Monitoring Centre

Refs: 10460

\section{Knema stenocarpa}

Myristicaceae

VU B $1+2 c$

Philippines

This rare species is found on Sulu and Mindanao Islands.

Assessor: World Conservation Monitoring Centre

Refs: 10460,19078

\section{Knema stylosa}

Myristicaceae

VU Alc

Malaysia (Sabah, Sarawak)

This primary forest tree is found in north-east Sarawak and Sabah.

Assessor: World Conservation Monitoring Centre

Refs: 875,1766

\section{Knema subhirtella}

Myristicaceae

VU Alc

Malaysia (Sabah, Sarawak)

An understorey tree found in mixed dipterocarp forest in west Sabah and Sarawak.

Assessor: World Conservation Monitoring Centre Refs: 875,1766

\section{Knema tenuinervia ssp. Kanburiensis}

Myristicaceae

VU D2

Thailand

Found in mixed deciduous forest, this tree appears to be restricted to Kanchanaburi Province.

Assessor: World Conservation Monitoring Centre Refs: 10460

\section{Knema tonkinensis}

Myristicaceae

Laos, Viet Nam

This tree occurs in montane forest in Upper Laos and Tonkin, Viet Nam.

Assessor: World Conservation Monitoring Centre Refs: 10460

\section{Knema tridactyla ssp. pachydactyla}

Myristicaceae

VU D2

Malaysia (Sabah)

Known only from the type collection, this small tree was found on a ridge at $400 \mathrm{~m}$ in the Sugud Recreation Park, Penampang District.

Assessor: World Conservation Monitoring Centre Refs: 19082

\section{Knema tridactyla ssp. salicifolia}

Myristicaceae

VU D2

Malaysia (Sabah)

Known only from the type collection found south of Tabilong in north Sabah, this subspecies was found on a hill at $650 \mathrm{~m}$.

Assessor: World Conservation Monitoring Centre Refs: 19082 


\section{Knema tridactyla ssp. sublaevis \\ Myristicaceae}

VU Alc

Brunei?, Malaysia (Sarawak)

This subspecies is apparently restricted to the primary lowland dipterocarp forests of the First Division, Sarawak. A collection from Brunei possibly belongs to it.

Assessor: World Conservation Monitoring Centre

Refs: 10460,19082

\section{Knema tridactyla ssp. tridactyla \\ Myristicaceae}

VUAlc

Brunei, Malaysia (Sabah, Sarawak)

This subspecies occurs in the Forth Division in Sarawak, Brunei and west Sabah.

Assessor: World Conservation Monitoring Centre

Refs: 10460,19082

\section{Knema uliginosa}

Myristicaceae

VU D2

Indonesia (Kalimantan), Malaysia (Sarawak)

This species appears to be restricted to Sarawak and west Kalimantan. It is known only from three collections.

Assessor: World Conservation Monitoring Centre

Refs: 1766,10460

\section{Knema viridis}

Myristicaceae

VU D2

Malaysia (Sarawak)

This species is based on four specimens, all found in the Fourth and Fifth Divisions of Sarawak in lowland and hill mixed dipterocarp forest.

Assessor: World Conservation Monitoring Centre

Refs: 875, 1766

\section{Koanophyllon panamensis}

Compositae

$\mathrm{EN} \mathrm{Cl}$

Panama

Originally the species was thought to be restricted to rainforest along rivers and lakesides in the central parts of Panama, including Altos de Campana National Park. Recent reports indicate that the species occurs in Bocas del Toro andl La Amistad National Park on the border with Costa Rica. Occurrences are uncommon and outside protected areas populations are severely threatened by habitat loss.

Assessor: Mitré, M.

Refs: 16772

\section{Koilodepas calycinum}

Euphorbiaceae

$\mathrm{EN} \mathrm{Bl}+2 \mathrm{c}$

India (Tamil Nadu)

Known from just two collections, the species occurs in widely separated localities of submontane evergreen forest.

Assessor: World Conservation Monitoring Centre

Refs: 11373,19144

\section{Koilodepas ferrugineum}

Euphorbiaceae

$\mathrm{CR} B 1+2 \mathrm{c}$

Malaysia (Peninsular Malaysia)

There is some doubt over the continued existence of the species. It has been collected only once from lowland evergreen forest in Malacca. Most of the forest here has been cleared for plantations or colonisation.

Assessor: World Conservation Monitoring Centre

Refs: 8464, 19073

\section{Koilodepas wallichianum}

Euphorbiaceae

LR/cd

Malaysia (Peninsular Malaysia)

The species is confined to Penang Hill, where it is scattered in submontane rainforest. The locality is a conserved area.

Assessor: Kochummen, K.M.

Refs: 5550, 11647, 19073

\section{Kokia cookei}

Malvaceae

EW

USA (Hawaii)

When first discovered in the 1860 s, only three small trees were found in relictual dryland forest near Mahana in western Molokai. The site was central to a sheep run and the population was directly affected by browsing and trampling domestic and feral stock. By 1918 all the specimens in the wild had died. Some years after, the only known cultivated tree died without producing viable offspring and the species was thought extinct. However, living material has been obtained from the branch of a cultivated specimen discovered in 1970, and grafted onto $K$. kavaiensis. The genus consists of four species, all endemic to Hawaii and either extinct or critically endangered. The species is protected by the US Endangered Species Act.

Assessor: World Conservation Monitoring Centre

Refs: 3372,19089

\section{Kokia drynarioides}

Malvaceae

CR D1

USA (Hawaii)

A species from a small genus endemic to the Hawaiian Islands, reduced to a few individuals in dry forest on lava fields at Puuwaawaa and Huehue on Hawaii. It persists in cultivation. The species is protected by the US Endangered Species Act.

Assessor: World Conservation Monitoring Centre Refs: 3372

\section{Kokia kauaiensis}

Malvaceae

CR C2a

USA (Hawaii)

At one time this species was known only from a single tree in Koaloha Canyon. It is now the most numerous member of the genus. At present six populations are known from rainforest in Paaiki, Kuia, Mahanaloa, Kalalau, Pohakuao and Koaie Valleys in the west of Kauai. All of these are on state land. Estimates of the total population size range from 105 to 145 , the largest containing no more than $\mathbf{5 0}$ individuals. Invasive plants and the activities of feral goats, deer and rats are the major threats to remaining populations. The species is protected by the US Endangered Species Act. Assessor: World Conservation Monitoring Centre Refs: $3372,19036,19086$

\section{Kokia lanceolata}

Malvaceae

USA (Hawaii)

A species from a small genus endemic to the Hawaiian Islands. Originally known from the hills of Makaku, Koko Head and Wailupe Valley on Oahu, it was first recorded in 1888 and became extinct shortly afterwards. The species is protected by the US Endangered Species Act.

Assessor: World Conservation Monitoring Centre Refs: 3372 


\section{Kokoona coriacea}

Celastraceae

Malaysia (Peninsular Malaysia, Sarawak)

VU D2

This lowland forest species is known from the type collected from Perak, Peninsular Malaysia, and another recent collection from Niah Cave National Park, Sarawak. Trees of this genus are cut for mata ulat timber which is used locally. The species is threatened by the large-scale clearance of the forest.

Assessor: World Conservation Monitoring Centre

Refs: 5550, 11145, 11647, 19017, 19073

\section{Kokoona leucoclada}

Celastraceae

VU D2

Malaysia (Sabah)

Endemic to Sabah, the species has been collected only once from Ranau and once from Sandakan in lowland forest. Trees of the genus are cut for mata ulat timber, which is used locally. The species is threatened by the large-scale clearance of the forest.

Assessor: World Conservation Monitoring Centre Refs: 11145, 19017

\section{Kokoona littoralis var, bakoensis}

Celastraceae

VU D2

Malaysia (Sarawak)

Locally abundant in Bako National Park, this variety is found in heath forest. The species is cut for mata ulat timber.

Assessor: World Conservation Monitoring Centre

Refs: 11145, 19017

\section{Kokoona littoralis var. longifolia}

Celastraceae

VU D2

Malaysia (Sarawak)

This variety is known only from the type collection found in lowland forest in Limbang. The species is cut for mata ulat timber for local use.

Assessor: World Conservation Monitoring Centre

Refs: 11145,19017

\section{Kokoona sabahana}

Celastraceae

VU D2

Malaysia (Sabah)

Occurring infrequently in lowland swamp and hill forest, this small tree is known only from three collections from Nabawan, Tawau and Sandakan.

Assessor: World Conservation Monitoring Centre Refs: 11145,19017

\section{Kokoona sessilis}

Celastraceae

VUA1c+2c, D2

Malaysia (Peninsular Malaysia)

A rare tree inhabiting rainforest between 60 and $730 \mathrm{~m}$ in the states of Kelantan, Terengganu and east Johore. It is protected in Taman Negara National Park, but elsewhere is threatened by large-scale forest clearance.

Assessor: World Conservation Monitoring Centre

Refs: 5550, 8464, 11145, 11647, 19073

\section{Koompassia excelsa}

Leguminosae

$\mathrm{LR} / \mathrm{cd}$

Indonesia (Kalimantan, Sumatra), Malaysia (Peninsular Malaysia, Sabah, Sarawak), Philippines, Thailand?

One of the tallest rainforest trees ever reported, reaching up to $85 \mathrm{~m}$, found along rivers and in valleys in lowland primary forest and often in secondary growth. The trees are protected from cutting in Kalimantan because wild bees often build nests in the branches. It is also protected in Sarawak under the Wildlife Protection Bill of 1990. There is concem over its conservation status in Sabah. However, Koompassia timber is currently gaining importance in trade because of the shortage of heavy hardwood timber.

Assessor: Asian Regional Workshop

Refs: 4919, 12937, 14573, 17214, 19026, 19072

\section{Koompassia grandiflora}

Leguminosae VU Alcd $+2 c d$

Indonesia (Irian Jaya), Papua New Guinea

A primary rainforest tree occurring on coastal plain foothills and stony low hills in Vogelkop, Irian Jaya and the Morobe, Gulf and Central Provinces of Papua New Guinea. Observations of active exploitation for the timber of this species in Papua New Guinea were made in the 1960s; the timber continues to be in high demand and is heavily exploited in areas subject to logging. As it occurs in primary forest and in readily accessible areas, the species is considered highly vulnerable.

Assessor: Eddowes, P.J.

Refs: 14573, 19057, 19072, 19114

\section{Koompassia malaccensis}

Leguminosae

LR/cd

Brunei, Indonesia (Kalimantan, Sumatra), Malaysia (Peninsular Malaysia, Sabah, Sarawak), Singapore, Thailand

This very large tree is found in freshwater peat-swamp forest, usually below $150 \mathrm{~m}$. It is a useful timber species for heavy construction. Koompassia timber is currently gaining importance in trade because of the shortage of heavy hardwood timber. It is protected in Sarawak under the Wildlife Protection Bill of 1990.

Assessor: Asian Regional Workshop

Refs: $2422,9199,12827,12937,14573,17140,17214$, 19057,19072

\section{Kopsia lancifolia}

Apocynaceae

VU D2

Malaysia (Sabah)

A tree known by only a single collection from Sabah. The taxonomy of this genus is in need of revision. Assessor: World Conservation Monitoring Centre Refs: 19117

\section{Kopsia larutensis}

Apocynaceae

Malaysia (Peninsular Malaysia, Sarawak), Thailand A rare shrub to small tree found in lowland rainforest. In Peninsular Malaysia it is apparently restricted to the Kledang Saiong range in Perak. The taxonomy of this genus is in need of revision.

Assessor: World Conservation Monitoring Centre Refs: 19073,19117

\section{Kopsia profunda}

Apocynaceae

Malaysia (Peninsular Malaysia)

This species is known only from three herbarium collections. The taxonomy of the genus is in need of revision.

Assessor: World Conservation Monitoring Centre Refs: 19117

\section{Kopsia scortechinii}

Apocynaceae

Malaysia (Peninsular Malaysia)

A medium-sized tree of rainforest in Perak. It has been 
collected only once in 1878 . The taxonomy of this genus is in need of revision.

Assessor: Chua, L.S.L.

Refs: 8464, 19073, 19117

\section{Kopsia singaporensis}

Apocynaceae

VU B $1+2 c$

Malaysia (Peninsular Malaysia), Singapore

A tree of up to $5 \mathrm{~m}$ height, occurring in lowland rainforests and swamp forests of Perak, Selangor, Pahang. Negeri Sembilan, Malacca, Johore and Singapore. The main threat is encroaching settlements.

Assessor: Chua, L.S.L.

Refs: 8464, 9199,17140, 19073

\section{Kopsia sleesiana}

Apocynaceae

VU D2

Malaysia (Sarawak)

This species is known from the type collection only. However, the taxonomy of this genus is in need of revision.

Assessor: World Conservation Monitoring Centre

Refs: 19117

Kopsia tenuis

Apocynaceae

Malaysia (Sarawak)

VU D2

A species known only from the type collection. However, the taxonomy of this genus is in need of revision.

Assessor: World Conservation Monitoring Centre

\section{Kostermansia malayana}

Bombacaceae

Malaysia (Peninsular Malaysia)

VU Bl+2c

This species occurs in areas of swampy hill forest. Habitat reductions have resulted from logging and increasing agriculture and settlement.

Assessor: Chua, L.S.L.

Refs: 17140,19073

\section{Kostermanthus malayus}

Chrysobalanaceae

$\mathrm{EN} \mathrm{Bl}+2 \mathrm{c}$

Malaysia (Peninsular Malaysia)

Confined to a single locality on the Kedah-Perak border, this species occurs in lowland rainforest, where it is under pressure from increasing settlement of the area. Assessor: Chua, L.S.L.

Refs: 19073

\section{Kotchubaea montana}

Rubiaceae

VU D2

Peru

This forest species is recorded only from the type collection below $2000 \mathrm{~m}$ in the department of San Martin. There is some question about whether it is synonymous with $K$. semisericea.

Assessor: World Conservation Monitoring Centre

Refs: 1984

\section{Kotschya platyphylla}

Leguminosae

VU B $1+2 b$

Tanzania

A gregarious species, occurring in forest or grassland on upland exposed ridges in the vicinties of Udzungwa and Njombe in east Tanzania.

Assessor: Lovett, J. \& G.P. Clarke

Refs: 1308, 3356
Kraussia speciosa

Rubiaceae

VU B $1+2 b$

Kenya, Tanzania

A species confined to areas of moist coastal forest from the Shimba Hills, Dzombo and Witu in Kenya to eastern

Tanzania.

Assessor: Lovett, J. \& G.P. Clarke

Refs: $3356,6396,8814$

Krokia pilotoana

Myrtaceae

VU D2

Cuba

Very rare, this small tree is locally confined to parts of the Sierra de Nipe mountain range in Holguin and Santiago de Cuba Provinces.

Assessor: Areces-Mallea, A.E.

Refs: 18485,19149

Labordia hirtella

Loganiaceae

LR/nt

USA (Hawaii)

A species which is highly variable. Scattered individuals are found in various forest types up to $1830 \mathrm{~m}$ on eastern Kauai, the Koolau Mountains on Oahu, Molokai, Lanai, Maui and Hawaii.

Assessor: World Conservation Monitoring Centre Refs: 3372

\section{Labordia kadae}

Loganiaceae

USA (Hawaii)

EN C2a

A shrub or small tree restricted to the Waianae Mountains on Oahu, where it is found in diverse forest types at altitudes between 450 and $950 \mathrm{~m}$.

Assessor: World Conservation Monitoring Centre

Refs: 3372

\section{Labordia lydgatei}

Loganiaceae

USA (Hawaii)

EN C2a

Known from few collections, the species is restricted to the Wahiawa Mountains on Kauai. It is protected by the US Endangered Species Act.

Assessor: World Conservation Monitoring Centre

Refs: 3372

\section{Labordia tinifolia var. lanaiensis}

Loganiaceae

USA (Hawaii)

EN C2a

One of three varieties. Populations are known from rainforest on Lanai and from Mapulehu Valley on Molokai.

Assessor: World Conservation Monitoring Centre

Refs: 3372

\section{Labordia tinifolia var. wahiawaensis}

Loganiaceae

$\mathrm{CR} \mathrm{B} 1+2 \mathrm{c}, \mathrm{C} 2 \mathrm{ab}, \mathrm{D} 1$

The total population is restricted to private land along forested streamsides in the Wahiawa drainage on Kauai. Once estimated to contain 100 plants, only 20 or 30 plants survived Hurricane Iniki. Feral pigs and invasive plants are the primary threats to the habitat. The species is protected by the US Endangered Species Act.

Assessor: World Conservation Monitoring Centre Refs: 19036, 19086 


\section{Lachanodes arborea}

Compositae

CR D1

St Helena

Once a common tree, occurring on the central ridge between 600 and $800 \mathrm{~m}$, the species was thought to have become extinct until three old trees and some seedlings were discovered in 1976 in pastureland above Osbome's Cottage. Seedlings have since been raised and planted out. It is a short-lived tree, which takes considerable effort to conserve in cultivation. The genus is monotypic.

Assessor: Cronk, Q.C.B.

Refs: 9954, 16700, 19081

\section{Lacistema lucidum}

Lacistemataceae

Brazil (Pará, São Paulo)

An Atlantic forest species which is closely related to $L$ pubescens, also an endemic to Brazilian Atlantic forest but more widely ranging in five states. The separation of the two taxa in São Paulo poses such difficulty that it is possible they may be considered taxonomically the same species. This taxon is recorded in Itha do Cardosa State Park in São Paulo.

Assessor: World Conservation Monitoring Centre Refs: 7980, 19099

\section{Lacunaria panamensis}

Quiinaceae

EN C2a

Costa Rica, Honduras, Panama

Assessor: Nelson, C.

Refs: $7272,7980,13995,14873$

\section{Ladenbergia acutifolia}

Rubiaceae

VU D2

Peru

A species which is known only from the type collected in the department of Huánuco.

Assessor: World Conservation Monitoring Centre

Refs: 1984

\section{Ladenbergia ferruginea}

Rubiaceae

VU D2

Peru

Known only from the type collection, the species occurs in lowland rainforest along a riverside in the department of Puno.

Assessor: World Conservation Monitoring Centre

Refs: 1984

\section{Ladenbergia gavanensis}

Rubiaceae

VU D2

Peru

The taxonomic status of the species is uncertain. It is known only from the type collection from the department of Puno.

Assessor: World Conservation Monitoring Centre

Refs: 1984

\section{Ladenbergia pavonii}

Rubiaceae

VU B $1+2 \mathrm{c}$

Ecuador

An Ecuadorean endemic of the High Andean regions in Imbabura, Morona-Santiago and Azuay. The habitat of this species is cloud forest between $2260 \mathrm{~m}$ and $3450 \mathrm{~m}$. Assessor: World Conservation Monitoring Centre Refs: 19119,19120

\section{Ladenbergia stenocarpa}

Rubiaceae

VU D2

Peru

The species is known only from the type collection from the department of Cajamarca.

Assessor: World Conservation Monitoring Centre

Refs: 1984

\section{Ladenbergia ulei}

Rubiaceae

VU D2

Peru

A lowland grassland species which has been recorded just a single time from the department of Loreto.

Assessor: World Conservation Monitoring Centre Refs: 1984

\section{Laetia micrantha}

Flacourtiaceae

VU D1

Panama

The species is known only from a narrow strip of lowland semi-evergreen rainforest running the length of the province of Darién. A large part of the population runs close to the border with, and is likely to extend into, Colombia. The species is uncommon but utilised locally as a source of fuel and edible fruit. All known populations are within Darién National Park, where they are officially protected but under some threat from gold mining and localised logging.

Assessor: Mitré, $\mathrm{M}$.

Refs: $7272,7980,16772$

\section{Lafoensia replicata}

Lythraceae

VU Alact $2 \mathrm{~d}$

Brazil (Bahia, Brazilia Distrito Federal, Goias, Minas Gerais, São Paulo)

A rainforest species with sparse distribution. Populations in Atlantic forest have declined extensively, especially in Bahia, as the habitat has been cleared and logged.

Assessor: Cavalcanti, T.B.

Refs: 19096

\section{Lagarostrobos franklinii}

Podocarpaceae

VU B1+2ce

Australia (Tasmania)

Huon pine, one of the longest living trees in the world, is found mostly in small stands in rainforest associated with the river systems of south-west Tasmania. Populations retreated during the Last Glacial and were heavily logged in the more recent past. Whilst most of the range is protected within a World Heritage Site, significant areas are open to the persistent threats of mining, logging, hydroelectric schemes and fire regimes. A small proportion of trees are sexually reproductive in one season, a disproportionate number of them being the oldest trees. Regrowth by vegetative reproduction is, however, very strong.

Assessor: SSC Conifer Specialist Group

Refs: $374,8032,18833$

\section{Lagerstroemia anisoptera}

Lythraceae

VU B $1+2 c$

Malaysia (Peninsular Malaysia)

This rare species is a small tree confined to the lowland tropical rainforests of north-west Peninsular Malaysia. Assessor: Chua, L.S.L.

Refs: 8464,19073 


\section{Lagerstroemia intermedia}

Lythraceae

China (Yunnan), Thailand

VU B $1+2 \mathrm{ce}$

A species found at forest edges and along roadsides between 800 to $1500 \mathrm{~m}$ in south and south-west Yunnan and north Thailand. In Yunnan, populations are scattered and very small. It appears to be naturally rare but loss of habitat and cutting for fuelwood has contributed significantly to the present scarcity.

Assessor: Sun, W.

Refs: $1818,11847,19055$

\section{Lagerstroemia langkawiensis}

Lythraceae

Malaysia (Peninsular Malaysia)

$\mathrm{EN} \mathrm{B} 1+2 c$

A rare species found in areas of limestone, quartzite and shale on Langkawi Island, Kedah. This small tree is scattered in open lowland rainforest, in an area which continues to be developed for tourism and other land uses.

Assessor: Chua, L.S.L.

Refs: 8464, 19073

\section{Lagerstroemia minuticarpa}

Lythraceae

India (Assam, Sikkim)

$\mathrm{EN} \mathrm{B} 1+2 \mathrm{c}$

Known from just two forest localities in Kerempani, Assam, and Singtam, Sikkim, the species was last collected in 1938.

Assessor: World Conservation Monitoring Centre

Refs: 4799

\section{Lagynias pallidiflora}

Rubiaceae

VU $B 1+2 b$

Kenya, Tanzania

A species confined to areas of moist coastal forest from the Shimba Hills, Buda and Arabuko-Sokoke in Kenya to eastern Tanzania and Pemba Island.

Assessor: Lovett, J. \& G.P. Clarke

Refs: $3356,6396,8814$

\section{Lagynias rufescens ssp. angustiloba}

Rubiaceae

VU B1+2b, D2

Tanzania

Occurring in moist submontane forest, this subspecies is known only from Mwanihana in the North Udzungwa Mountains.

Assessor: Lovett, J. \& G.P. Clarke

Refs: 3356,8814

\section{Lannea schweinfurthï var. acutifoliolata}

Anacardiaceae

Kenya, Tanzania

$\mathrm{LR} / \mathrm{nt}$

A coastal forest taxon located in pockets of remaining forest in a range stretching from south-east Kenya to eastern Tanzania, Zanzibar and the Pemba Islands. The type variety is widespread.

Assessor: Lovett, J. \& G.P. Clarke

Refs: $3356,6396,8814$

\section{Lannea transulto}

Anacardiaceae

VU D2

Yemen (Socotra)

Scattered small populations occur in dry woodland and shrubland in mountain areas. They are under no immediate threat.

Assessor: Miller, A.G.

Refs: 2354,19083
Lannea welwitschü var. cilliolata

Anacardiaceae

Kenya, Tanzania

LR/nt

A forest tree existing in remaining areas of moist lowaltitude forest in south-east Kenya and eastem to southwest Tanzania. It is reported to be common in Diani in Kenya. The type variety is distributed from Central to West Africa.

Assessor: Lovett, J. \& G.P. Clarke

Refs: 2361,3356

\section{Laplacea curtyana}

Theaceae

CR Bl+2c

Cuba

A very uncommon tree, up to $15 \mathrm{~m}$ tall, occurring in lowland and hill semi-deciduous forest of Pinar del Rio and the Isla de Pinos. The area is under constant pressure from cutting and clearing. The accepted genus of the taxon is now Gordonia.

Assessor: Areces-Mallea, A.E.

Refs: $9522,11403,19149$

\section{Laportea urentissima}

Urticaceae

$\mathrm{EN} \mathrm{B1}+2 \mathrm{c}$

China (Guangxi, Yunnan), Viet Nam

Ranging in stature from a small shrub to a tree of $15 \mathrm{~m}$, this fast-growing species is a prominent component of monsoon forest on limestone hills between 700 and $1000 \mathrm{~m}$. Its range is concentrated in the border region of Guangxi, Yunnan and Viet Nam. Additional populations exist in the south-west of Yunnan. Continuous declines and degradation of the habitat have caused the species to disappear from large parts of its range.

Assessor: Sun, W.

Refs: $1818,11847,19055$

\section{Larix decidua var. polonica}

Pinaceae

VU B $1+2 c$

Poland, Romania, Ukraine

A variety with a patchy distribution confined to remaining areas of natural forest. Young individuals were noted as being rare as early as 1930 . The forest does not appear to be healthy and has been degraded by war and exploitative activities. Populations in the Carpathians may fare better.

Assessor: SSC Conifer Specialist Group

Refs: $374,2162,6858,7222,9887$

\section{Larix griffithiana var. speciosa}

Pinaceae

LR/nt

China (Sichuan?, Xizang?, Yunnan), Myanmar

Assessor: SSC Conifer Specialist Group

Refs: 374, 11191, 13041

\section{Larix mastersiana}

Pinaceae

VUAlcd

China (Sichuan)

Once occurring in large stands, the species has been reduced to isolated sparse woodlands and mixed forest at $2300-3500 \mathrm{~m}$ along various river systems. The habitat continues to deteriorate because of overcutting and logging.

Assessor: SSC Conifer Specialist Group

Refs: $11242,11847,13041$

\section{Larix potaninii var. himalaica}

Pinaceae

VU D2

China (Xizang), Nepal?

A taxon restricted to the Himalayas in Xizang Zizhiqu, 
apparently extending into Langtang Khola in Nepal. Assessor: SSC Conifer Specialist Group

Refs: $374,13041,18751$

\section{Lasianthus ciliatus}

Rubiaceae

VU D2

India (Tamil Nadu)

A small tree, mainly known from areas of submontane forest in the Nilgiris, but also recorded from a single locality in the Anaimalai Hills.

Assessor: World Conservation Monitoring Centre Refs: 19144

\section{Lasianthus gardneri}

Rubiaceae

VU Bl+2c

Sri Lanka

During the extensive National Conservation Review forest surveys, this species was recorded in seven forests.

Assessor: World Conservation Monitoring Centre

Refs: 19112

\section{Lasianthus grandifolius}

Rubiaceae

VU B1+2b, D2

Tanzania

The only population known occurs at $2050 \mathrm{~m}$ elevation in moist evergreen forest on the North Udzungwa Mountains at Bandwa

Assessor: Lovett, J. \& G.P. Clarke

Refs: 3356,8814

\section{Lasianthus kilimandscharicus ssp. laxinervis}

Rubiaceae

VU B $1+2 b$

Tanzania

Confined to the Uluguru Mountains, this subspecies occurs in moist evergreen montane forest. It is not, in fact, thought to descend from $L$. kilimandscharicus and may attain full species status.

Assessor: Lovett, J. \& G.P. Clarke

Refs: 3356,8814

\section{Lasianthus oliganthus}

Rubiaceae

LR/cd

Sri Lanka

A small tree or shnub, restricted to lowland wet evergreen forest in south-west Sri Lanka. It is a dominant component in areas of Sinharaja Biosphere Reserve.

Assessor: World Conservation Monitoring Centre

Refs: $9176,17195,18515$

\section{Lasianthus pedunculatus}

Rubiaceae

VU B $1+2 b$

Tanzania

Assessor: Lovett, J. \& G.P. Clarke

Refs: 3356,8814

\section{Lasianthus rhinophyllus}

Rubiaceae

CR B $1+2 \mathrm{C}$

Sri Lanka

During the extensive National Conservation Review forest surveys, only two individuals were found within a single forest reserve in Ratnapura District.

Assessor: World Conservation Monitoring Centre Refs: 8203, 18796, 19112

\section{Lasianthus rostratus}

Rubiaceae

VU B $1+2 c$

India (Kerala)

A small tree, known only from a few collections taken from forest between 600 and $1000 \mathrm{~m}$ between the Anaimalai Hills and the Travancore range.

Assessor: World Conservation Monitoring Centre Refs: 19144

\section{Lasianthus tomentosus}

Rubiaceae

$\mathrm{EN} \mathrm{B} 1+2 \mathrm{c}$

Indonesia (Java), Singapore

A species confined to Mount Salak near Bogor city in Java. The population occurs at $1700 \mathrm{~m}$. There are intense pressures of habitat clearance, degradation and cutting. The Singapore record needs confirmation.

Assessor: World Conservation Monitoring Centre Refs: 9078,9199

\section{Lasianthus varians}

Rubiaceae

$\mathrm{EN} \mathrm{B1}+2 \mathrm{c}$

Sri Lanka

During the extensive forest surveys conducted between 1991 and 1996 for the National Conservation Review, this species was found in three forest localities including the Peak Wildemess Wildlife Sanctuary.

Assessor: World Conservation Monitoring Centre Refs: 19112

\section{Lasianthus wallacei}

Rubiaceae

VU Bl+2b

Tanzania

An endemic of the Uluguru Mountains, occurring in moist evergreen montane forest.

Assessor: Lovett, J. \& G.P. Clarke

Refs: 3356,8814

\section{Lasiochlamys hurlimannii}

Flacourtiaceae

$\mathrm{EN} \mathrm{B1+2c}$

New Caledonia

Assessor: Jaffré, T. et al.

Refs: 10351

\section{Lasiochlamys mandjeliana}

Flacourtiaceae

New Caledonia

Assessor: Jaffré, T. et al.

Refs: 10351

\section{Lasiochlamys pseudocoriacea}

Flacourtiaceae

VU D2

New Caledonia

Assessor: Jaffré, T. et al

Refs: 10351

\section{Lasiochlamys trichostemona}

Flacourtiaceae

New Caledonia

Assessor: Jaffré, T. et al.

Refs: 10351

Lasiococca malaccensis

Euphorbiaceae

VU D2

Malaysia (Peninsular Malaysia)

A species of lowland evergreen rainforest, known only from a single collection from Batang Malaka Permanent Forest Reserve in Malacca.

Assessor: Kochummen, K.M.

Re's: 8464,19073 


\section{Lasiocroton fawcettii}

Euphorbiaceae

VU B $1+2 \mathrm{c}$

Jamaica

Occurrences are known from Westmoreland, Hanover and Trelawny Parishes. The species has a local distribution, confined to areas of thickets and woodlands on limestone.

Assessor: World Conservation Monitoring Centre

Refs: 6057,7980

\section{Lasiocroton harrisii}

Euphorbiaceae

VU BI+2c

Jamaica

Similar in many respects to $L$ fawcettii, the species occurs in thickets on limestone hills in a narrow altitudinal band in the parishes of Clarendon and St Ann. Assessor: World Conservation Monitoring Centre

Refs: $401,5653,7980$

\section{Lasiocroton macrophyllus}

Euphorbiaceae

LR/nt

Jamaica

Frequently common, the species occurs in dry thickets on limestone along the south coast.

Assessor: World Conservation Monitoring Centre

Refs: 6057,7980

\section{Lasiocroton trelawniensis}

Euphorbiaceae

$\mathrm{EN} \mathrm{Bl+2c}$

Jamaica

Confined to Trelawny, this species has a localised distribution on a wooded limestone hilltop.

Assessor: Kelly, D.L.

Refs: 5653, 19085

\section{Lasiodiscus mildbraedii ssp. ferrugineus}

Rhamnaceae

VU B $1+2 c$

Kenya

A shrub or tree of lowland dry evergreen forest, known from localities in Witu, Mangea and Arabuko-Sokoke.

Assessor: World Conservation Monitoring Centre

Refs: 6396,12067

\section{Lasiodiscus rozeirae}

Rhamnaceae

VU D2

São Tomé \& Príncipe (São Tomé)

The species has not been found since it was collected in 1954 in the south-east of the island. It is not known whether there is still an extant population. Extensive areas of remote forest remain to be explored. There are no obvious threats to the habitat at present.

Assessor: World Conservation Monitoring Centre

Refs: 2421,18501

\section{Latania loddigesii}

\section{Palmae}

EN C2a

Mauritius

Remaining wild populations are confined to offshore islands, in coastal savanna. Regeneration has been good since the eradication of goats and rabbits. The species is widely cultivated as an omamental.

Assessor: Johnson, D.

Refs: 19118

\section{Latania lontaroides}

Palmae

EN Alc

\section{Réunion}

Occurring on the coast between Petite Ile and SaintPhilippe, the species was once common but has declined in extent through increasing agriculture and settlement It is traded internationally as an omamental.

Assessor: Johnson, D.

Refs: 19118

\section{Latania verschaffeltii}

Palmae

EN C2a

Mauritius (Rodrigues)

Confined to Fond la Bonté, Baie aux Huîtres, remaining populations account for about 500 individuals. There is almost no evidence of regeneration and the harvesting of leaves for use as thatch is not controlled, despite regulations.

Assessor: Johnson, D.

Refs: 19118

\section{Laurelia sempervirens}

Monimiaceae

$\mathrm{LR} / \mathrm{nt}$

Chile (Bíobío, La Araucania, Los Lagos, Maule, O'Higgins)

Restricted to central Chile, the species occurs in moist seasonal forest in the Coastal Cordillera, subandean range and central plains. It is of some importance as a timber and is under threat from overexploitation in the north of its range

Assessor: González, M

Refs: 11449,16328

\section{Laurus azorica}

Lauraceae

LR/nt

Morocco, Portugal (Azores, Madeira), Spain (Canary Is.)

One of the major components of *laurisilva, occurring over a wide altitudinal range. Threats exist from grazing. fires and habitat conversion, but recent evidence suggests the *laurisilva is now expanding.

Assessor: World Conservation Monitoring Centre

Refs: 19131, 19199

\section{Lavoixia macrocarpa}

Palmae

CR D1

New Caledonia

An endemic to Mont Panié, occurring in wet forest on a steep rocky slope at $500 \mathrm{~m}$.

Assessor: Jaffré, T. el al.

Refs: $10351,1911 \varepsilon$

\section{Lebronnecia kokioides}

Malvaceae

EN D1

French Polynesia (Marquesas Is.)

A small tree which at one time was thought to be reduced to a single individual surrounded by a few seedlings on Tahuata. A small colony covering a few hectares has now been found on Mohotane, a nature reserve. Although feral sheep are present on the island, they appear to find the plant unpalatable.

Assessor: Florence, $\mathrm{J}$.

Refs: 14513,15251

\section{Lecaniodiscus punctatus}

Sapindaceae

$\mathrm{EN} \mathrm{B} 1+2 \mathrm{c}$

Cameroon, Ghana

Little is known about this unusual species. It is usually found near stream banks in moist semi-deciduous forest. In Ghana, few localities are known, all contained within the vicinity of Baku and Supong Forest Reserves, where deforestation has been severe.

Assessor: Hawthome, W.

Refs: $8369,12061,15251$ 


\section{Lecointea ovalifolia \\ Leguminosae \\ Peru}

VUD2

Recorded only from the type collection, the species occurs in lowland Amazon forest in the department of San Martin.

Assessor: World Conservation Monitoring Centre Refs: 1984

\section{Lecomtedoxa nogo}

Sapotaceae

VU D2

Gabon

A species so far collected only from Feman Vaz. Forests in Gabon have not been well explored botanically and it is possible the species is more widespread. Most areas, however, are under concession to logging companies. Assessor: World Conservation Monitoring Centre Refs: 14958,15790

\section{Lecythis barnebyi \\ Lecythidaceae}

VU D2

Brazil (Amazonas)

Several collections have been made of this species, but it is thought only to exist in three populations in open forest on white sand in central Amazonia.

Assessor: Pires O'Brien, J.

Refs: $3791,7980,9632$

\section{Lecythis brancoensis}

Lecythidaceae

VU B $1+2 c$

Brazil (Roraima), Guyana

A small savanna tree, known from a few collections from the Roraima territory of Brazil and adjacent Guyana.

Assessor: World Conservation Monitoring Centre

Refs: 3791,7980

\section{Lecythis lanceolata}

Lecythidaceae

$\mathrm{LR} / \mathrm{cd}$

Brazil (Bahia, Espírito Santo, Goiás, Pernambuco, Rio de Janeiro)

A relatively widely occurring species of Atlantic coastal forest. It is known to occur in Linhares Forest Reserve.

Assessor: Pires O'Brien, J.

Refs: $3791,7980,9632,9866$

\section{Lecythis lurida}

Lecythidaceae

Brazil (Amazonas, Bahia, Espírito Santo, Pará, Pernambuco, Piauí, Rio de Janeiro, Sergipe)

Although the species is wide-ranging, its habitat has undergone serious deterioration and declines. It is known to occur in the Jari Genetic Reserve and in Linhares Forest Reserve.

Assessor: Pires O'Brien, J.

Refs: $3204,3791,9632$

\section{Lecythis parvifructo}

Lecythidaceae

VU D2

Brazil (Amazonas)

A canopy tree, known only from central Amazonia, occurring in non-flooded forest.

Assessor: Pires O'Brien, J.

Refs: $3791,7980,9632$

\section{Lecythis prancei}

Lecythidaceae

EN D 1

Brazil (Amazonas)

Confined to non-flooded forests in the vicinity of
Manaus, this species is under some pressure from urban expansion. It is known to occur in the Ducke Forest Reserve.

Assessor: Pires O'Brien, J.

Refs: $3791,7980,9632$

\section{Lecythis retusa}

Lecythidaceae

Brazil (Amazonas)

LR/nt

A canopy tree confined to non-flooded forest in central Amazonia. It is found in the Ducke Forest Reserve and INPA Experimental Reserve.

Assessor: World Conservation Monitoring Centre Refs: $3791,7980,9632$

\section{Lecythis schomburgki}

Lecythidaceae

VU B $1+2 c$

Brazil (Roraima), Guyana

A small savanna tree, rarely collected and restricted to Roraima territory in Brazil and adjacent Guyana.

Assessor: Pires O'Brien, J.

Refs: $3791,7980,9632$

\section{Lecythis schwackei}

Lecythidaceae

VU D2

Brazil (Minas Gerais, Rio de Janeiro)

Known from few localities, the species is scattered in secondary deciduous forest and savanna-like vegetation. Assessor: Pires O'Brien, J.

Refs: $3791,7980,9632$

\section{Lecythis serrata}

Lecythidaceae

LR/nt

Brazil (Amazonas, Pará, Rondônia)

Evidence from collections indicate that this is a wideranging species, scattered in non-flooded forest.

Assessor: Pires O'Brien, J.

Refs: 3791, 7980, 9632

\section{Leea tinctoria}

Leeaceae

LR/nt

São Tomé \& Príncipe (São Tomé)

This shrub or small tree is common and well known for its various local uses. It occurs in secondary forest up to $1060 \mathrm{~m}$.

Assessor: World Conservation Monitoring Centre Refs: $2421,2724,10080$

\section{Leitneria floridana}

Leitneriaceae

USA (Arkansas, Florida, Georgia, Missouri, Texas)

A shrub or small tree with a very scaltered distribution in three widely separated areas. Occurring along muddy riverbanks or in sawgrass marshes, usually within reach of seawater inundations, the species is known from south-east Missouri and eastern Arkansas, where it is locally common, south-east Texas, southem Georgia and northern Florida. There is no evidence of any serious declines in the population. The family is monotypic. Assessor: World Conservation Monitoring Centre Refs: 9254, 19163

\section{Lemurophoenix halleuxi}

Palmae

EN Alc, D1

Madagascar

An endemic palm of Madagascar known only from two populations, totalling an estimated 50 individuals. They occur in submontane primary forest on steep slopes and in a deep narrow valleys at elevations between $200 \mathrm{~m}$ 
and $450 \mathrm{~m}$. This species is used as an ornament for minor intemational, national and local trade.

Assessor: Dransfield, J. \& H.J. Beentje

Refs: 18986,19118

\section{Lennea viridiflora}

Leguminosae

VU A2c

Costa Rica, El Salvador, Mexico, Nicaragua, Panama

The distribution of this species apparently extends the length of Central America from the border with Colombia to Mexico. The species occurs in lowland rainforest and is generally scarce outside protected areas. Logging, encroaching agriculture and settlements have caused the habitat to decline.

Assessor: Mitré, M.

Refs: $2965,7980,15037,16772$

\section{Lepidothamnus fonkii}

Podocarpaceae

VU B1+2c Argentina (Chubut, Neuquén, Rio Negro), Chile (Aisén, Los Lagos, Magallanes)

A dwarf conifer and the only member of the genus on the continent. Its nearest relatives are in New Zealand. It occurs as a pioneer in upland scrub in acidic bogs, often with Fitzroya and Pilgerodendron. The area is vulnerable to fires and habitat degradation.

Assessor: SSC Conifer Specialist Group

Refs: 278, 374, 5112, 8032, 15415

\section{Lepinia taitensis}

Apocynaceae

French Polynesia (Society Is.)

$\mathrm{CRB}$ B $+2 \mathrm{c}$

An endemic to Tahiti and Moorea.

Assessor: Florence, J.

Refs: 14513

\section{Leptactina delagoensis ssp. bussei}

Rubiaceae

$\mathrm{EN} \mathrm{B} 1+2 \mathrm{~b}$

Tanzania

Occurring in dry coastal forest, this subspecies is known from two populations confined to the remaining forested areas on the Rondo Plateau and Lake Lutamba. The forest on the Rondo Plateau has been heavily disturbed by previous activities, especially logging and shifting cultivation. It is thought that only $5 \mathrm{~km}^{2}$ of the original undisturbed forest remains. Forest management work in the forest reserve is discouraging further illegal activities and encroachment. Lake Lutamba has been largely cleared of forest except for $10 \mathrm{~km}^{2}$ contained within the Litipo Forest Reserve.

Assessor: Lovett, J. \& G.P. Clarke

Refs: 3356,10961

\section{Leptactina papyrophloea}

\section{Rubiaceae}

$\mathrm{EN} \mathrm{B} 1+2 \mathrm{c}$

Tanzania

A coastal forest species, which is now thought to be confined to undisturbed areas of the Rondo Forest Reserve $\left(140 \mathrm{~km}^{2}\right)$. Disturbance in the past has been severe as a result of logging, planting of exotic timbers, shifting cultivation and wood collection. The presence of active forestry measures is helping to discourage local exploitation.

Assessor: Lovett, J. \& G.P. Clarke

Refs: 3356, 10961, 16796
Leptostylis gatopensis

Sapotaceae

EN B $1+2 c$

New Caledonia

Assessor: Jaffré, T. et al.

Refs: 10351

\section{Leptostylis goroensis}

Sapotaceae

New Caledonia

Assessor: Jaffré, T. et al.

Refs: 10351

\section{Leptostylis multiflora}

Sapotaceae

New Caledonia

VU B $1+2 \mathrm{c}$

Assessor: World Conservation Monitoring Centre

Refs: 10351

\section{Leptostylis petiolata}

Sapotaceae

VU B $1+2 \mathrm{c}$

New Caledonia

Assessor: World Conservation Monitoring Centre

Refs: 10351

\section{Lettowianthus stellatus}

Annonaceae

VU $B 1+2 b$

Kenya, Tanzania

A monotypic genus, known from the Shimba Hills and Miongoni in Kenya and areas of dry coastal forest in eastern Tanzania. The taxonomy of the Kenyan population is not confirmed.

Assessor: Lovett, J. \& G.P. Clarke

Refs: $3356,9198,9302$

\section{Leucadendron argenteum}

Proteaceae

VU D2

South Africa (Western Cape)

Scattered subpopulations are known from the slopes of Table Mountain from Lion's Head to Orange Kloof, Cape Peninsula. There are also several subpopulations, which have probably been planted, including those on the Helderberg, Simonsberg and Paarl Mountain These are excluded from the evaluation. The species grows on moist, usually south-facing slopes, on granite clays in mountain *fynbos and on the margins of afromontane forest patches. Population counts indicate that there are more than 10,000 mature individuals. The expansion of Cape Town and the establishment of tree plantations continue to cause reductions in population numbers. There is also concern in the mixing of genetic pools by the extensive planting of the species and increased fire frequency in some areas. Only about $10 \%$ of the subpopulations are considered to be viable and are showing signs of active recruitment at present. Almost half of the entire population occurs within protected areas, all of which suffer from invasions by alien plant species. Alien eradication programmes are in place.

Assessor: Hilton-Taylor, C. et al.

Refs: 689,19218

\section{Leucadendron discolor}

Proteaceae

$\mathrm{EN} \mathrm{Bl+2abc}$

South Africa (Western Cape)

A tall shrub, sometimes growing to the size of a tree, confined to the western side of the Piketberg range. It grows on rocky soils derived from sandstone in mountain *fynbos. The total population of between 1000 and 5000 mature individuals is fragmented into three or four major subpopulations and a number of scattered 
individuals, occurring within an area of $20 \mathrm{~km}^{2}\left({ }^{*} \mathrm{AOO}\right)$. The species is threatened in the eastem parts of its range by agricultural activities, particularly the planting of fruit orchards. Frequent fires could also be a problem, as they may not allow the species sufficient time to regenerate from seed. The only form of protection received is within private nature reserves.

Assessor: Hilton-Taylor, C. ef al.

Refs: 689,19218

\section{Leucadendron strobilinum}

Proteaceae

$\mathrm{LR} / \mathrm{cd}$

South Africa (Westem Cape)

A shrub or small tree confined to the Cape Peninsula, where it occurs from Table Mountain to Kommetjie. It grows on south-facing, damp, rocky slopes in mountain * fynbos. The larger dense subpopulations occur mainly on the Table Mountain and Constantiaberg ranges, with the southern Peninsula subpopulations being small and scattered. The area of occupancy is only about $150 \mathrm{~km}^{2}$ and the estimated population is 5000 mature plants. More than $50 \%$ of the subpopulations are protected in nature reserves and there is no evidence for decline. Invasive alien species could pose a threat as scattered pine trees have been recorded from a number of localities. Frequent fires could also be a problem, as they may not allow the species sufficient time to regenerate from seed.

Assessor: Hilton-Taylor, C. el al.

Refs: 689,19218

\section{Leucaena confertiflora var. adenotheloidea}

Leguminosae

EN B $1+2 c$

Mexico

The more restricted in range of the two varieties of this Mexican endemic. Few wild populations are known and there are strong pressures from grazing and collection of the pods for their edible seeds. Trees are occasionally cultivated for the production of pods.

Assessor: Hughes, C.

Refs: 10207

\section{Leucaena confertiflora var, confertiflora}

Leguminosae VUAlc, B1+2c

Mexico

Geographically restricted, both the varieties of this species are known from only a few wild populations. Grazing pressure and the harvesting of pods for their edible seeds put considerable pressure on the remaining populations. Trees are occasionally cultivated for the production of pods.

Assessor: Hughes, C.

Refs: 10207

\section{Leucaena cuspidata}

Leguminosae

VU Alc, B1+2c

Mexico

A species confined to the forest understorey within a restricted range. It is only occasionally found outside forest areas. Grazing pressures have reduced the species distribution to less accessible areas. Trees are often protected within the traditional agricultural system. Assessor: Hughes, $\mathrm{C}$.

Refs: 10207

\section{Leucaena greggii}

Leguminosae

VU Alc, Bl+2c

Mexico

A species restricted in range, low in numbers and generally reduced to inaccessible areas because of the pressures of constant grazing.

Assessor: Hughes, C.

Refs: 10207

\section{Leucaena involucrata}

Leguminosae

$\mathrm{EN} \mathrm{B1}+2 \mathrm{c}$

Mexico (Sonora)

This species is poorly known but seemingly very restricted in range. During the last 50 years it has been recorded from a single site in central Sonora.

Assessor: Hughes, C.

Refs: 10207

\section{Leucaena lempirana}

Leguminosae

VU B $1+2 \mathrm{c}$

Honduras

A highly localised species confined to northem Honduras in areas of degraded forest. The protection afforded the species within traditional agroforestry systems mitigates the threats to remaining stands.

Assessor: Hughes, C.

Refs: 10207

Leucaena leucocephala ssp. ixlahuacana

Leguminosae

LR/cd

\section{Guatemala}

This subspecies is uncommon and confined to a habitat which is restricted in extent and severely degraded. However, trees are protected and also cultivated in local agroforestry systems for the production of pods bearing edible seeds.

Assessor: Hughes, C.

Refs: 10207

\section{Leucaena magnifica}

Leguminosae

$\mathrm{EN} \mathrm{B1}+2 \mathrm{c}, \mathrm{Cl}+2 \mathrm{a}$

Guatemala

The total population is restricted to fewer than 400 individuals, occupying an area of less than $400 \mathrm{~km}^{2}$ in south-eastem Chiquimula. The species is unprotected and exposed to pressures of grazing and habitat degradation.

Assessor: Hughes, C.

Refs: 10207

\section{Leucaena matudae}

Leguminosae

$\mathrm{EN} \mathrm{B} 1+2 \mathrm{c}$

Mexico

A species which is confined to a very small area of remaining $\mathrm{dry}$ forest. The stands are exposed to pressures from grazing and habitat degradation.

Assessor: Hughes, C.

Refs: 10207

\section{Leucaena pueblana}

Leguminosae

VU B1+2c

Mexico (Puebla)

An endemic species of the Tehuacan Valley. It is never found in abundance. Populations have been largely reduced to areas which escape from the pressure of grazing

Assessor: Hughes, C.

Refs: 10207

\section{Leucaena salvadorensis}

Leguminosae

LR/cd

El Salvador, Honduras, Nicaragua

The species occurs relatively commonly across southern 
Honduras and northem Nicaragua with a very restricted population in eastem El Salvador. The habitat is severely degraded in places but the species is frequently protected within traditional agroforestry systems.

Assessor: Hughes, C.

Refs: 10207

\section{Leucochloron foederale}

Leguminosae

Brazil (Brazilia Distrito Federal)

VU D2

Known only from Chapada do Contagem, Distrito Federal, the species is found in cerrado and gallery woodland.

Assessor: World Conservation Monitoring Centre

Refs: 5994

\section{Leucochloron minarum}

Leguminosae

Brazil (Minas Gerais)

A tree known only from two collections, the most recent dated 1906, taken from *campo in an unspecified location in Minas Gerais.

Assessor: World Conservation Monitoring Centre

Refs: 5994

\section{Leucomeris decora}

\section{Compositae}

China (Yunnan), Myanmar, Thailand, Viet Nam

A small composite tree scattered in hot dry valleys. The populations in China are confined to south and west Yunnan and are steadily being reduced by local exploitation of the wood for fuel and the bark for medicine. The distribution in Viet Nam is not known.

Assessor: World Conservation Monitoring Centre

Refs: 11847, 19055, 19061

\section{Leucostegane latistipulata}

Leguminosae VU B $1+2 c$

Malaysia (Peninsular Malaysia)

Confined to the lowlands of Perak, this small understorey species is principally threatened by increasing settlement.

Assessor: Chua, L.S.L.

Refs: 8464, 19073

\section{Libocedrus austro-caledonica}

Cupressaceae

LR/ed

New Caledonia

Usually a shrub, the species occurs in small populations in cloud forest on a few of the higher mountains in the south and on Mont Pafoua in the north. Regeneration is evident in places but not on Mont Paéoua where mining and fires threaten the population. There are effectively protected populations in Rivière Bleue Provincial Park and Montagne des Sources Nature Reserve.

Assessor: SSC Conifer Specialist Group

Refs: $9631,12630,14508$

\section{Libocedrus chevalieri}

Cupressaceae

$\mathrm{EN} \mathrm{B1+2de}$

New Caledonia

Known only from the summits of Mont Humboldt and Mont Kouakoue, the species grows in high-altitude maquis shrubland, where there is a high fire risk. Rates of growth and regeneration are slow. Both sites are within botanic reserves.

Assessor: SSC Conifer Specialist Group

Refs: $10351,12630,14508$

\section{Libocedrus plumosa}

Cupressaceae

LR/nt

New Zealand (North Is., South Is.)

A lowland forest species with a wide but local distribution, occurring from the North Cape to East Cape in the North Island and in north-west Nelson in the South Island. Regeneration occurs in disturbed sites. Many populations are found in protected areas. Others are exposed to forestry, agriculture and mining activities.

Assessor: SSC Conifer Specialist Group

Refs: $374,13041,13930,19126$

\section{Libocedrus yateensis}

Cupressaceae

VU B1+3d, C2a

New Caledonia

The species is sparsely distributed in small areas of lowland woodland or scrub, often on rocky slopes. Populations are restricted to two river valleys in the southem ultramafic massifs and a single location in Roche Ouaieme. The populations in Rivière Bleue Provincial Park are well protected, although situated closely to the tourist facilities. Fire is a hazard throughout its range.

Assessor: SSC Conifer Specialist Group

Refs: $9631,12630,14508$

\section{Licania caldasiana}

Chrysobalanaceae

EX

Colombia

Assessor: Calderon, $\mathrm{E}$.

Refs: 5970, 7501, 7980, 19069

\section{Licania chiriquiensis}

Chrysobalanaceae

Panama

Only three collections of this cloud forest species exist: one from Cerro Colorado and two from Cerro Jefe. Mining for copper and gold threatens the population in Cerro Colorado. Cerro Jefe is contained within Chagres National Park.

Assessor: Mitre, M.

Refs: $7501,7980,16772$

\section{Licania conferruminata}

Chrysobalanaceae

VU B $1+2 c$

Brazil (Rondônia)

A newly described forest species, known only from Rondônia in Brazil.

Assessor: World Conservation Monitoring Centre

Refs: 13176

\section{Licania fasciculata}

Chrysobalanaceae

EN Alac

Panama

A species of lowland semi-evergreen rainforest, which occurs in two neighbouring areas. One, in Santa Rita, Colón, has experienced an influx of people in recent years, which has resulted in almost loss of the forest. The other, in Kunayala Indigenous Reserve, consists of a very small population. There is a considerable area of relatively unexplored forest and other populations possibly exist.

Assessor: Mitré, M.

Refs: 7980, 15037, 16772 
Licania intrapetiolaris var. brevis Chrysobalanaceae

VU D2

Peru

This variety is known only from lowland Amazon rainforest in the department of Loreto.

Assessor: World Conservation Monitoring Centre Refs: 1984

\section{Licania morï}

Chrysobalanaceae

Panama

The species has been collected only once, in 1975 , although a second collection found almost $90 \mathrm{~km}$ away was once thought to be the same species. The type locality has not been revisited and it is not known whether the species still exists. If it does, it should be considered to be seriously threatened.

Assessor: Mitré, $\mathrm{M}$.

Refs: 7501, 7980, 15037, 16772

\section{Licania salicifolia}

Chrysobalanaceae

Colombia

$\mathrm{EN} \mathrm{B} 1+2 \mathrm{c}$

An endemic to Antioquia.

Assessor: Calderon, E.

Refs: 5970, 7501, 7980, 19069

\section{Licania vasquezii}

Chrysobalanaceae

VU D2

Peru

Known only from the type collection, the species occurs in swamp forest in the department of Loreto.

Assessor: World Conservation Monitoring Centre

Refs: 1984

\section{Licaria cubensis}

Lauraceae

VU D2

Cuba

A small, aromatic tree occurring in montane rainforests. This rare species is confined to the Sierra Maestra range. Assessor: Areces-Mallea, A.E.

Refs: 19149

\section{Licaria velutina}

Lauraceae

Mexico (Chiapas, Oaxaca, Tabasco, Veracruz)

A large tree of high precipitation rainforest, occurring in the areas of Uxpanapa-Chimalapa and Los Tuxtlas.

Assessor: World Conservation Monitoring Centre Refs: 5993, 15719

\section{Ligustrum microcarpum}

Oleaceae

$\mathrm{EN} \mathrm{B1+2a}$

Taiwan

This species is confined to coniferous scrub at elevations above $2400 \mathrm{~m}$ in the central mountain range. Populations are fragmented and suffering from poor regeneration.

Assessor: Pan, F.J.

Refs: 3295,19050

\section{Ligustrum pricei}

Oleaceae

Taiwan

Assessor: Pan, F.J.

Refs: 3295, 19050

\section{Lijndenia brenanü}

Melastomataceae

Tanzania

A tree of moist evergreen forest endemic to a narrow altitudinal range in the East Usambara Mountains.

Assessor: Lovett, J. \& G.P. Clarke

Refs: 3356,8814

\section{Lijndenia greenwayï}

Melastomataceae

VU B1+2b, D2

Tanzania

Populations are known from the East Usambara Mountains and Mount Mlinga, where they are confined to a narrow aftitudinal range in moist evergreen submontane forest.

Assessor: Lovett, J. \& G.P. Clarke

Refs: 3356,8814

\section{Limnocitrus littoralis}

\section{Rutaceae}

$\mathrm{EN} \mathrm{B} 1+2 \mathrm{c}$

Indonesia (Java)

Little is known about this species which is endemic to central Java, but it is believed to be seriously endangered. There are intense pressures on remaining areas of natural vegetation.

Assessor: World Conservation Monitoring Centre Refs: 9078

\section{Linociera albidiflora}

Oleaceae

CR B I +2cd

Sri Lanka

A tree restricted to lowland rainforest in south-west Sri Lanka. Previously found in Kottawa, Hinidumkanda, Sinharaja and Gilimale. This species was not found during the extensive forest surveys conducted for the National Conservation Review, indicating that it is either extremely rare or possibly extinct.

Assessor: World Conservation Monitoring Centre

Refs: 17195,19112

\section{Linociera ramiflora}

Oleaceae

Philippines, Taiwan

In Taiwan the species is restricted to Lanyu Island, where it occurs in very small numbers $(<250)$.

Assessor: World Conservation Monitoring Centre

Refs: $2072,4919,19050,19053$

\section{Linospadix microcarya}

Palmae

LR/nt

Australia (Queensland)

Confined to north-east Queensland, this small palm tree, up to $2 \mathrm{~m}$ in height, is commonly found in lowland to montane rainforest near the coast. It is adequately represented in national parks and World Heritage areas. Assessor: Dowl, J.L.

Refs: 19118

\section{Lippia salicifolia}

Verbenaceae VU C2b

Ecuador (Galápagos)

Endemic to the island of Floreana, the species was reported to occur in some abundance in the first half of the century. Large numbers of trees were felled for constructing houses during a period of settlement of the island and the total population is now estimated to include 2600 adult trees, most of which are located on 
the Cerro de Pampa Bola. Regeneration is reasonable but there is a potential threat of colonization by Lantana camara and Psidium guajava.

Assessor: Mauchamp, A. el al.

Refs: $9651,14556,18411,19155,19204$

\section{Liquidambar orientalis var. integriloba} Hamamelidaceae

VU Alcd Turkey

The Liquidambar forests have been reduced from $63 \mathrm{~km}^{2}$ to $13.5 \mathrm{~km}^{2}$ since 1945 . Much of the land has been converted for agriculture. Trees are cut for firewood and the resin is collected for the production of fixative in the perfume industry. The species is now the target of a special conservation programme. There is some uncertainty in the taxonomy.

Assessor: World Conservation Monitoring Centre Refs: 3489,4863

\section{Liquidambar orientalis var. orientalis}

Hamamelidaceae

VU Alcd

Greece (East Aegean Is), Turkey

In Turkey the Liquidambar forests have been reduced from $63 \mathrm{~km}^{2}$ to $13.5 \mathrm{~km}^{2}$ since 1945 . Much of the land has been converted for agriculture. Trees are cut for firewood and the resin is collected for the production of fixative in the perfume industry. The species is now the target of a special conservation programme.

Assessor: Güner, A.

Refs: $1890,3489,19165$

\section{Liriodendron chinense}

Magnoliaceae

LR/nt

China (Anhui, Fujian, Guangxi, Guizhou, Hubei, Hunan, Jiangxi, Shaanxi, Sichuan, Yunnan, Zhejiang), Viet Nam The species is widely scattered in montane evergreen broadleaved forest in the Yangtze River valley and further south to northem Viet Nam. Poor regeneration, extensive logging and clearing of the habitat have affected populations throughout the range. It is a relict species from a once widespread and species-rich genus. Assessor: Ban, N.T.

Refs: $848,1818,9274,11530,11847,19060$

\section{Litchi chinensis var. euspontanea}

Sapindaceae

VU B $1+2 c$

China (Guangdong, Guangdong - Hainan)

A canopy tree of middle elevation rainforest known from several localities in the south-west of Hainan Island, and also from a single locality in Xuwen County, Guangdong. It is found below $800 \mathrm{~m}$ in a habitat which has experienced severe declines in extent over much of the taxon's range.

Assessor: World Conservation Monitoring Centre

Refs: 1818,11847

\section{Lithocarpus burkillii}

Fagaceae

VU D2

Malaysia (Peninsular Malaysia)

This tree is known from only one collection in the hill forest of Fraser's Hill, Pahang, where it is reported as being common.

Assessor: Chua, L.S.L

Refs: 19073

\section{Lithocarpus crassinervius}

Fagaceae

$\mathrm{EN} \mathrm{B1}+2 \mathrm{c}$

Indonesia (Java)

Occurring only in areas of primary forest in west and central regions, both the species and the habitat are uncommon. The pressures on remaining forest patches are very high, especially at elevations below $1400 \mathrm{~m}$, where the forest is almost completely cleared.

Assessor: World Conservation Monitoring Centre

\section{Lithocarpus curtisüi}

Fagaceae

Malaysia (Peninsular Malaysia)

Populations are known from areas of lowland rainforest in Penang, Kelantan, Pahang, Terengganu, Perak and Selangor. The species is also protected in Taman Negara National Park.

Assessor: Chua, L.S.L

Refs: 19073

\section{Lithocarpus erythrocarpus}

Fagaceae

VU B $1+2 c$

Malaysia (Peninsular Malaysia)

A rainforest species, occurring up to an altitude of $900 \mathrm{~m}$ in Terengganu, Pahang, Selangor, Negeri Sembilan. Much of the lowland forest has been converted for nonforest land use.

Assessor: Chua, L.S.L.

Refs: 19073

\section{Lithocarpus hendersonianus}

Fagaceae

VU Alc Malaysia (Peninsular Malaysia)

A medium-sized tree inhabiting montane rainforest. Some localities are being cleared for agniculture despite being contained within the permanent forest estate.

Assessor: Chua, L.S.L.

Refs: 8464, 19073

\section{Lithocarpus indutus}

Fagaceae

Indonesia (Java)

VU B $1+2 \mathrm{c}$

A relatively common species where it occurs in patches of remaining submontane forest up to $1800 \mathrm{~m}$ on Mount Slamet and further west. This habitat has been almost completely cleared below $1400 \mathrm{~m}$ and at higher elevations it is under severe pressure from the activities of surrounding human populations.

Assessor: World Conservation Monitoring Centre

\section{Lithocarpus kingianus}

Fagaceae

LR/cd

Malaysia (Peninsular Malaysia)

A tree of submontane and montane rainforest, found in the states of Pahang. Terengganu and Selangor. The species is protected in Taman Negara National Park and in protective forest within the permanent forest estate.

Assessor: Chua, L.S.L.

Refs: 8464,19073

\section{Lithocarpus kingï}

Fagaceae

Malaysia (Peninsular Malaysia)

VU B $1+2 c$

A tree of moist forest up to an altitude of $1200 \mathrm{~m}$, in the states of Perak, Terengganu, and Johore.

Assessor: Chua, L.S.L

Refs: $8464,17140,19073$

\section{Lithccarpus kostermansii}

Fagaceae

EN Alc, B1+2c Indonesia (Java)

A species confined to the west, where it occurs in scattered remnants of hill forest up to $1000 \mathrm{~m}$. This 
habitat has been almost completely cleared and remaining patches are under extremely severe pressure from the activities of local populations.

Assessor: World Conservation Monitoring Centre

\section{Lithocarpus kunstleri}

Fagaceae

Malaysia (Peninsular Malaysia)

A tree of primary and secondary forest, and also swamps, up to an altitude of $300 \mathrm{~m}$. This species is recorded in Kedah, Kelantan, Perak, Selangor, Negeri Sembilan and Johore. Some localities are protected within Taman Negara National Park.

Assessor: Chua, L.S.L.

Refs: 8464, 17140, 19073

\section{Lihocapus maingayi}

\section{Fagaceae}

Malaysia (Peninsular Malaysia)

VU B1+2c

A hill forest tree species from Kedah, Selangor, Negeri

Sembilan, Malacca and Johore.

Assessor: Chua, L.S.L.

Refs: 8464, 19073

\section{Lithocarpus neorobinsonii}

\section{Fagaceae}

Malaysia (Peninsular Malaysia)

LR/nt

A tree of moist submontane and hill forest. Most localities are in protected forests within the permanent forest estate.

Assessor: Chua, L.S.L.

Refs: 19073

\section{Lithocarpus ovalis}

Fagaceae

VU Alcd

Philippines

A timber species, endemic to the Philippines. Rates of habitat loss through logging and shifting cultivation have led to considerable population declines.

Assessor: World Conservation Monitoring Centre Refs: 2072,4919

\section{Lithocarpus platycarpus}

Fagaceae

Indonesia (Java)

EN Alc, B1+2c

Populations are confined to remnants of lowland forest in the south-west corner of Java and to Nusa Kambangan. The population on the Kambangan is relatively well protected by the presence of three highsecurity prisons. A reserve of $20 \mathrm{~km}^{2}$ is also patrolled by armed guards. However, illegal logging continues. On the mainland the habitat is also under extreme pressure from local activities.

Assessor: World Conservation Monitoring Centre

\section{Litosanthes capitulatus}

Rubiaceae

VU B1 $+2 \mathrm{c}$

India (Karnataka, Kerala, Tamil Nadu)

A small tree, poorly collected but recorded from a few scattered localities of submontane forest from the Pushpagiri Hills to the Nilgiris and Anaimalai range. Assessor: World Conservation Monitoring Centre Refs: 19144

\section{Litsea auriculata}

Lauraceae

LR/nt

China (Anhui, Jiangxi, Zhejiang)

A species with a scattered distribution in a few mountain locations. It occurs in deciduous or mixed forest in mountain valleys between 800 and $1100 \mathrm{~m}$. There have been reports of population declines caused by largescale logging and habitat degradation.

Assessor: World Conservation Monitoring Centre Refs: 1818,11847

\section{Litsea beddome}

Lauraceae

India (Kerala, Tamil Nadu)

$\mathrm{EN} B 1+2 \mathrm{c}$

The species has been collected twice from forest between 1200 and $1350 \mathrm{~m}$, only in the Agastyamalai Hills. Large areas have been exposed to fires, grazing, the establishment of commercial plantations and cutting for fuelwood, but almost $1000 \mathrm{~km}^{2}$ of forest are now under protection within sanctuaries.

Assessor: World Conservation Monitoring Centre Refs: 19144

\section{Litsea claviflora}

Lauraceae

Malaysia (Peninsular Malaysia)

Known only by a single collection from Perak, the species was found in lowland forest in Taiping, Perak. Assessor: Kochummen, K.M.

Refs: 8464, 19073

\section{Litsea dilleniifolia}

Lauraceae

$\mathrm{EN} \mathrm{B1+2ce}$

China (Yunnan)

Endemic to south and south-west Yunnan, the species occurs in dense monsoon forest in mountain valleys below $800 \mathrm{~m}$. It is relatively uncommon and large trees have been cut for their valuable timber. The most substantial remaining populations are confined to nature reserves.

Assessor: Sun, W

Refs: $1818,11847,19050,19055$

\section{Litsea foxiana}

Lauraceae

LR/cd

Malaysia (Peninsular Malaysia)

Known only from Penang Hill, a conservation area, this tree occurs in lowland forest.

Assessor: Kochummen, K.M.

Refs: 8464, 19073

\section{Litsea gardneri}

Lauraceae

VUAlc

Sri Lanka

A tree occurring in the lowland wet evergreen forests of south-west Sri Lanka.

Assessor: World Conservation Monitoring Centre Refs: 9176,17195

\section{Litsea glaberrima}

Lauraceae

$\mathrm{EN} \mathrm{B1+2c}$

Sri Lanka

The comprehensive forest surveys conducted for the National Conservation Review located this wet-zone species in four forest localities in Ratnapura and in a population consisting of five individuals in Rammalakanda Biosphere Reserve.

Assessor: World Conservation Monitoring Centre Refs: 19112

\section{Litsea gracilis}

Lauraceae

VU D2

Malaysia (Peninsular Malaysia)

A single collection of this species has been made in 
lowland forest in Temengor, Perak. There has been much forest conversion for agriculture and it is uncertain whether the species still exists. However, some forest remains around Temengor, in which the species may survive.

Assessor: Kochummen, K.M.

Refs: 8464,19073

\section{Litsea hirsutissima}

Lauraceae

$\mathrm{LR} / \mathrm{cd}$

Malaysia (Peninsular Malaysia)

Confined to the states of Perak and Kelantan, this hill forest species has been collected only a few times. It does, however, occur in Taiping near Maxwell's Hills, which is a conservation area. Agriculture is a threat.

Assessor: Kochummen, K.M.

Refs: 8464, 19073

\section{Litsea imbricata}

Lauraceae

$\mathrm{EN} \mathrm{B1+2c}$

New Caledonia

A species occurring in two upland locations, one on Mont Humboldt and the other near Ngoye. Mont Humboldt is a well-visited and tramped botanical reserve.

Assessor: Jaffré, $T$, et al.

Refs: 10351,12630

\section{Litsea iteodaphne}

Lauraceae

VUAlc

Sri Lanka

A tree occurring in the lowland wet evergreen forests of south-west Sri Lanka. This species was found in 25 localities during the forest surveys conducted for the National Conservation Review.

Assessor: World Conservation Monitoring Centre Refs: 9176, 17195, 19112

\section{Litsea leiantha}

Lauraceae

EN B $1+2 c$

India (Andaman and Nicobar Is. - Andaman Is.)

Endemic to South Andaman Island, the species occurs in scattered small populations in remnant patches of evergreen forest. Large-scale logging has caused significant population declines.

Assessor: World Conservation Monitoring Centre

Refs: 4799, 7147

\section{Litsea leytensis}

Lauraceae

VU Ald

Philippines

An important source of medang timber, this forest species has become rare.

Assessor: World Conservation Monitoring Centre

Refs: 2072, 4919

\section{Litsea ligustrina}

\section{Lauraceae}

VU B $1+2 \mathrm{c}$

India (Kerala, Tamil Nadu)

Occurring in submontane forest, the species is known from only a few collections from scattered localities in Wayanad and the Nilgiris, the Palni Hills and Elamalai range.

Assessor: World Conservation Monitoring Centre

Refs: 19144

\section{Litsea longifolia}

Lauraceae

VU Alc

Sri Lanka

A tree occurring in the lowland wet evergreen forests of south-west Sri Lanka.

Assessor: World Conservation Monitoring Centre Refs: 17195

\section{Litsea nemoralis \\ Lauraceae}

Sri Lanka

$\mathrm{EN} \mathrm{B1}+2 \mathrm{c}$

This uncommon tree is confined to the lowland wet evergreen forests of south-west Sri Lanka. The species was found in three of the sites surveyed by the National Conservation Review, none of which is protected. Assessor: World Conservation Monitoring Centre Refs: 8203, 17195, 19112

\section{Litsea nigrescens}

Lauraceae

EN B1 $+2 \mathrm{c}$

India (Tamil Nadu)

A medium-sized tree, known only from the type collection taken from submontane forest near Shencottah.

Assessor: World Conservation Monitoring Centre Refs: 19144

\section{Litsea pierrei var, szemois}

Lauraceae

EN B $1+2$ ce

China (Yunnan)

A variety restricted to areas of monsoon forest between 800 and $1500 \mathrm{~m}$ in the counties of Menghai, Jinghong and Mengla. The timber and oil, which goes to make perfume, are commercially valuable but population numbers are very low for large-scale exploitation. The loss and degradation of the habitat now appear to be the more serious threat.

Assessor: Sun, W.

Refs: $1818,11847,19055$

\section{Litsea scortechinii}

Lauraceae

CR B I +2c

Malaysia (Peninsular Malaysia)

A lowland forest tree collected only once in Perak. The locality is no longer forested but there is a possibility that populations have survived in surrounding areas. Assessor: World Conservation Monitoring Centre Refs: 8464,19073

\section{Litsea travancorica}

\section{Lauraceae}

$\mathrm{EN} \mathrm{B} 1+2 \mathrm{c}$

India (Kerala)

A medium-sized tree known only from three collections taken from lowland forest at the base of the Western Ghats in Travancore.

Assessor: World Conservation Monitoring Centre Refs: 19144

\section{Livistona alfredii}

Palmae

LR/cd

Australia (Western Australia)

Endemic to Westem Australia, this palm tree is scattered in dry open forest between 100 and $150 \mathrm{~m}$. Potential threats include fires, natural disasters and tourism. The population is conserved within Millstream National Park.

Assessor: Dowl, J.L.

Refs: 19118 


\section{Livistona carinensis}

Palmae

Djibouti, Somalia, Yemen (Former South Yemen)

VU B $1+2 c$

A palm tree occurring in lowland deserts. In Somalia, only 38 trees in two localities are known and there are no signs of regeneration. There are approximately 2000 trees in three villages in Wadi Hadjen in the Jol, South Yemen, where regeneration is apparent but limited by an excessive number of goats. The South Yemen populations are additionally threatened by local overexploitation of the wood because of timber shortages. There is no information regarding the population status in Djibouti.

Assessor: Johnson, D.

Refs: 3768, 16980, 18665, 19118

\section{Livistona drudei}

Palmae

Australia (Queensland)

EN Alc

A palm tree of moist open forest up to an altitude of $150 \mathrm{~m}$, confined to an area extending from Kurramine Beach and Hinchin Island southward to Conway Beach. The main cause of population declines is land clearance. The species is mainly found on privately owned land. It is listed in the Nature Conservation Act (Queensland) 1994.

Assessor: Dowl, J.L.

Refs: 19118

\section{Livistona endauensis}

Palmae

LR/nt

Malaysia (Peninsular Malaysia)

A lowland palm tree of open and closed forest, existing in two disjunct populations. One population is in Endau Rompin State Park and the other is found in the coastal hills of south Terengganu.

Assessor: Saw, L.G

Refs: 19118

\section{Livistona mariae}

Palmae

LR/cd

Australia (Northem Territory)

The entire range of this palm tree falls within Finke Gorge National Park, where it occurs in dry sparsely vegetated habitats along creeks and watercourses.

Assessor: Johnson, D.

Refs: 19118

\section{Livistona robinsoniana}

Palmae

VU Alc, D2

Philippines

Endemic to the island of Palillo, the species has been little studied. Its lowland rainforest habitat is under pressure from logging and increasing agriculture and settlement.

Assessor: Madulid, D.

Refs: 19118

\section{Livistona tahanensis}

\section{Palmae}

LR/cd

Malaysia (Peninsular Malaysia)

A locally common palm tree of upper montane forest on peat soils between 1000 and $1200 \mathrm{~m}$, restricted to Gunung Tahan within the boundaries of Taman Negara National Park.

Assessor: Saw, L.G.

Refs: 19118

\section{Livistona tonkinensis}

Palmae

DD

Viet Nam

The description on which the species is based in insufficient.

Assessor: Johnson, D.

Refs: 19118

\section{Livistona woodfordii}

Palmae

VU D2

Solomon Islands (South Solomon)

A palm tree of lowland rainforest and swamp forest, restricted to Nggela Island.

Assessor: World Conservation Monitoring Centre Refs: 19118

\section{Lerasia assuensis}

Compositae

VU $B 1+2 c$

Ecuador

A species which is endemic to the High Andes of Ecuador.

Assessor: World Conservation Monitoring Centre

Refs: 19119,19120

\section{Lodoicea maldivica}

Palmae

VU Alcd

Seychelles

Famous for its distinctively large double nut, the cocode-mer occurs naturally only on Praslin and Curieuse Islands and is now extinct on St Pierre, Chauve-Souris and Round Islands. Planted populations occur on Mahé and Silhouette Islands. The long-term overexploitation of the unusual nuts has virtually wiped out natural recruitment. Fire is another major threat to the species. An important population at Fond Ferdinand has been burnt repeatedly and the only significant adult population left is at Vallée de Mai. The species is now protected and the nut trade is legally controlled by the coco-de-mer Management Decree of 1995.

Assessor: Nature Protection Trust of Seychelles Refs: 19025,19118

\section{Loesenera kalantha}

Leguminosae

Côte d'Ivoire, Liberia

VUAlc

A lowland forest species, confined to remaining forested areas in Liberia and Côte d'Ivoire.

Assessor: World Conservation Monitoring Centre

Refs: 7550,12590

\section{Loesenera talbotii}

Leguminosae

VU Alc, B1+2c

Cameroon, Nigeria

In Nigeria this rare forest tree is known only from the Oban Hills, where the population is protected within Cross River National Park. The population in Cameroon appears to be confined to Korup National Park. Areas outside protected areas have suffered serious habitat declines.

Assessor: World Conservation Monitoring Centre

Refs: 2773, 5595, 19092

\section{Lonchocarpus calcaratus}

Leguminosae

VU C1

Costa Rica, Panama

In Panama, this cloud forest species is just known from Valle de Antón in Coclé, where it appears to be very scarce and in some danger from industrial developments 
and other human activities. The species is more common in Costa Rica in the Cordillera de Tilarán in Alajuela, where it less affected by external pressures and protected by law.

Assessor: Mitré, M.

Refs: $7272,7980,16772$

\section{Lonchocarpus chiricanus}

Leguminosae

VU D2

Panama

Until recently the species was known only from the type specimen collected on a 1911 expedition to Chiriqui. Last year the species was identified on the Isla de Coiba in Coiba National Park, where it occurs commonly in rainforest along beaches and is protected.

Assessor: Mitré, M.

Refs: $7272,7980,16772$

\section{Lonchocarpus guatemalensis var. proteranthus} Leguminosae

DD

Panama

Although, $L$ guatemalensis extends from Mexico to Panama, var. proteranthus has been collected only once, from Cocle in Panama. There have been no reports of the taxon for almost 90 years and it is possible that it is now extinct.

Assessor: Mitré, M.

Refs: $7272,7980,16772$

\section{Lonchocarpus kanurii}

Leguminosae

LR/nt

Kenya, Somalia

A species known from southem Somalia and adjacent parts of Kenya in Acacia-Commiphora bushland on sand. The habitat is frequently degraded because of overcutting and grazing.

Assessor: Thulin, $M$.

Refs: $6396,8697,18665$

\section{Lonchocarpus miniflorus}

Leguminosae

EN C2b

Costa Rica, El Salvador, Guatemala, Honduras, Mexico, Nicaragua

A relatively widely ranging tree of dry scrub on plains and hillsides, often in rocky areas.

Assessor: Nelson, C.

Refs: 8100,13995

\section{Lonchocarpus molinae}

Leguminosae

CR C2b

Honduras

A tree of low elevations, occurring in moist thickets along streams within areas of dry forest.

Assessor: Nelson, C.

Refs: 13995, 18427

\section{Lonchocarpus phaseolifolius}

Leguminosae

CR C2b

Costa Rica, El Salvador, Guatemala, Honduras, Nicaragua

A tree found in thicket on lowland plains, sometimes along rocky creeks or on hillsides.

Assessor: Nelson, C

Refs: 13995
Lonchocarpus phlebophyllus

Leguminosae

EN C2a

Costa Rica, Guatemala, Honduras, Nicaragua

A tree of rocky dry hillsides in lowland regions.

Assessor: Nelson, C.

Refs: 4974, 13995

\section{Lonchocarpus retiferus}

Leguminosae

EN C2a

Honduras, Nicaragua

This species occurs in humid areas or near streams in dry forest.

Assessor: Nelson, C.

Refs: 9076, 13995, 18427

\section{Lonchocarpus sanctuarii}

Leguminosae

CR C2b

Honduras

Occurring in thicket and forest, often near streams, the species is reduced to remnant populations because of habitat loss.

Assessor: Nelson, C.

Refs: 13995,18427

\section{Lonchocarpus santarosanus}

Leguminosae

VU B $1+2 c$

El Salvador, Guatemala

There is no recent information on the status of the populations in either El Salvador or Guatemala. The species occurs in montane forest where it is evidently very scarce and under some threat from logging, agriculture, fires and forest management activities. Assessor: World Conservation Monitoring Centre Refs: $4862,4974,19030$

\section{Lonchocarpus trifolius}

Leguminosae

Honduras

A seldom collected tree, found in pine-oak forest.

Assessor: Nelson, C.

Refs: 8805, 13995

\section{Lonchocarpus yoroensis}

Leguminosae

Honduras, Mexico, Nicaragua

A rarely collecteci tree of dry forest.

Assessor: Nelson, C.

Refs: 13995

\section{Lophira alata}

Ochnaceae

VU Alcd

Cameroon, Congo, Côte d'Ivoire, Democratic Republic of Congo, Equatorial Guinea, Gabon, Ghana, Liberia, Nigeria, Sierra Leone, Sudan, Uganda

Azobe is a pioneer species and occurs abundantly in wet evergreen forest, which continues to experience largescale destruction. Slow growth rate, poor regeneration in less than optimum conditions and overexploitation as a timber species are contributing to the decline in population numbers through most of its range.

Assessor: African Regional Workshop

Refs: $2773,6718,9605,12061,17408,19043$

\section{Lophopetalum sessilifolium}

Celastraceae

VUAlcd+2cd

Malaysia (Sarawak)

A small tree, endemic to Sarawak, found in lowland forest near rivers. It is locally frequent in west Baram. 
All members of the genus are commercially valuable as perupok timber.

Assessor: World Conservation Monitoring Centre

Refs: 14573, 18327, 19017

\section{Lovoa swynnertonï}

Meliaceae

EN Alcd

Democratic Republic of Congo, Kenya, Mozambique,

Tanzania, Uganda, Zimbabwe

This timber species occurs sparsely in small patches of remaining wet evergreen forest in East and Southem Africa. Populations in Mozambique and Zimbabwe are confined to single localities: Garuso forest and Chirinda Forest Reserve, respectively. Habitat loss and excessive exploitation of the seed-producing individuals are resulting in poor regeneration and a global population decline. Plantations have been unsuccessful because of infestation by $H y p s i p y l a$.

Assessor: African Regional Workshop

Refs: 4506, 5117, 6396, 6725, 10961, 14667, 17335

\section{Lovoa trichilioides}

Meliaceae

VU Alcd

Angola, Cameroon, Congo, Côte d'Ivoire, Democratic Republic of Congo, Gabon, Ghana, Liberia, Nigeria, Sierra Leone, Tanzania, Uganda

African walnut or dibetou occurs in evergreen and deciduous forest, generally in moist sites. Regeneration occurs only in canopy gaps. Germination success is somewhat limited by short-lived seeds which are heavily predated. Exploitation rates are high. It is one of the two principal timber species in Congo.

Assessor: African Regional Workshop

Refs: $2362,2773,6128,6718,8369,10961,12061$, $13250,16021,17408$

\section{Loxococcus rupicola}

Palmae

CR Alc

Sri Lanka

A palm tree, occurring in moist closed forest between 300 and $742 \mathrm{~m}$. This monotypic genus is present within the national omamental trade and the seeds are used locally as a betel nut substitute. It occurs within Sinharaja Biosphere Reserve.

Assessor: Johnson, D.

Refs: 19118

\section{Loxopterygium grisebachü}

Anacardiaceae

VU B $1+2 c$

Argentina, Bolivia

Endemic to the piedmont forest of north-west Argentina and Bolivia, the species occurs in an unprotected ecosystem, which is rapidly being replaced by agricultural systems.

Assessor: Prado, D.

Refs: 12837,19122

\section{Ludwigia anastomosans}

Onagraceae

VU B $1+2 c$

Brazil

Morphologically a very distinct species from a monotypic section of Ludwigia. It is rare and restricted to a few scattered individuals in black water streams of the ancient Planalto habitat of central Brazil, where it stands above associated tree species and bamboo canes. Assessor: World Conservation Monitoring Centre Refs: 2744
Lunania cubensis

Flacourtiaceae

VU D2

Cuba

Populations of this tree are uncommon. The species is restricted to areas of montane semi-deciduous forest in the Sierra Maestra mountain range.

Assessor: Areces-Mallea, A.E.

Refs: 7980,19149

\section{Lunania dodecandra}

Flacourtiaceae

$\mathrm{EN} \mathrm{B1}+2 \mathrm{c}$

Cuba

An endemic tree apparently restricted to the Baracoa area of Guantanamo Province. The species has not been collected recently.

Assessor: Areces-Mallea, A.E.

Refs: $7980,11403,18485,19149$

\section{Lunania elongata}

Flacourtiaceae

$\mathrm{EN} \mathrm{B} 1+2 \mathrm{c}$

Cuba

This uncommon shrub or small tree is confined to montane forest in the Guamuhaya Massif, Sancti Spiritus Province. Cutting and logging are threats to the habitat of this species.

Assessor: Areces-Mallea, A.E.

Refs: 11403, 18485, 19149

\section{Lunania polydactyla}

Flacourtiaceae

VU B $1+2 c$

Jamaica

An uncommon tree of hillside woodlands in Clarendon, Portland and St Thomas, occurring at altitudes of 480 to $900 \mathrm{~m}$. Logging and encroaching agriculture have caused extensive disturbance, causing almost complete loss or severe degradation of forest in St Thomas in particular. Assessor: World Conservation Monitoring Centre Refs: 6057,7980

\section{Lunania racemosa}

Flacourtiaceae

VU $B 1+2 c$

Jamaica

An uncommon tree found in woodland at about $600 \mathrm{~m}$ in St Ann, St Mary and St Thomas. Almost all forested areas at this altitude have been removed or severely degraded in the latter parish.

Assessor: World Conservation Monitoring Centre

Refs: 6057, 7980, 19116

\section{Lupinus macbrideanus}

Leguminosae

VU D2

Peru

A small tree which is known only from the type collection along a riverside in shrubland above $3000 \mathrm{~m}$ in the department of Huánuco.

Assessor: World Conservation Monitoring Centre Refs: 1984

\section{Lyonia elliptica \\ Ericaceae}

$\mathrm{EN} B 1+2 \mathrm{c}$

Cuba

Occurring only in rainforest on ferralitic soils near Monte Verde in the Nipe-Baracoa Massif, Guantánamo, this rare shrub or small tree is very localised. Its habitat is susceptible to cutting and logging.

Assessor: Areces-Mallea, A.E.

Refs: 7980,19149 
Lyonia jamaicensis

Ericaceae

$\mathrm{LR} / \mathrm{nt}$

Jamaica

Confined to the Blue Mountains, mostly in secondary montane forest at altitudes below $1650 \mathrm{~m}$, the species is relatively common in southem catchments at forest margins. It colonises exposed well-drained sites.

Assessor: World Conservation Monitoring Centre Refs: 7980,12564

\section{Lyonia maestrensis \\ Ericaceae}

$\mathrm{EN} \mathrm{Bl}+2 \mathrm{c}$

Cuba

A rare shrub or small tree found in cloud forest on the highest peaks of the western Sierra Maestra mountain range, Santiago de Cuba Province.

Assessor: Areces-Mallea, A.E.

Refs: 19149

\section{Lyonia octandra}

Ericaceae

$\mathrm{LR} / \mathrm{nt}$

Jamaica

Endemic to the Blue Mountains, the species is generally rare, although locally dominant in a few sites on ridge tops, especially on the Grand Ridge.

Assessor: World Conservation Monitoring Centre

Refs: $7980,12564,19116$

\section{Lyonothamnus floribundus ssp. asplenifolius}

Rosaceae

VU D2

USA (California)

Restricted to the islands of Santa Cruz, Santa Rosa and San Clemente, the subspecies is limited in occurrence and threatened in parts of its range by damage caused by grazing animals. Feral herbivores have been removed from San Clemente and stump-sprouting has now been observed.

Assessor: World Conservation Monitoring Centre

Refs: 19193

\section{Lyonothamnus floribundus ssp. floribundus}

Rosaceae

USA (Califormia)

Endemic to Santa Catalina Island, this subspecies occurs in groves in moist humid areas of canyons and mountain sides, mainly on the Channel slopes. Increased control of feral pigs and deer has brought about improved regenerative capacity. Stump sprouting and seedlings have recently been observed. The introduced Acom Woodpecker may also be causing damage by drilling into tree trunks. The species' range has shown historical declines, presumably as a consequence of climate changes.

Assessor: World Conservation Monitoring Centre

Refs: 19193,19194

\section{Maackia taiwanensis}

Leguminosae

$\mathrm{EN} B 1+2 \mathrm{ab}, \mathrm{C} 2 \mathrm{a}$

Taiwan

A relict species confined to a small area of broadleaved evergreen forest in the Yangmingshan area, northern Taiwan. The area is partially protected as a national park.

Assessor: Lu, S.Y. \& F.J. Pan

Refs: 19050,19051

\section{Macadamia neurophylla}

Proteaceae

VU B $1+2 c$

New Caledonia

A species found rarely and confined to the southem massifs of Grand Terre, where it occurs largely on the coast in various types of moderate to dry habitats. Observations of hyper accumulation of nickel and manganese have led to considerable scientific interest in the species.

Assessor: Jaffré, T, et al.

Refs: 10351,12630

\section{Macaranga beillei}

Euphorbiaceae

VU B $1+2 c$

Côte d'Ivoire

A Côte d'Ivoire endemic confined to coastal forests. The species also occurs in Banco National Park, near Abidjan, but it could have been introduced there. There has been widespread degradation and loss of these forests.

Assessor: Assi, A.

Refs: 2773,12822

\section{Macaranga bicolor}

Euphorbiaceae

VUAlcd

Philippines

An endemic species to the Philippines. Rates of habitat loss through logging and shifting cultivation have led to considerable population declines.

Assessor: World Conservation Monitoring Centre

Refs: 2072, 4919

\section{Macaranga caudatifolia}

Euphorbiaceae

VUAled

Philippines

An endemic species to the Philippines. Rates of habitat loss through logging and shifting cultivation have led to considerable population declines.

Assessor: World Conservation Monitoring Centre Refs: $2072,4919,5651$

\section{Macaranga cogostiflora}

Euphorbiaceae

VU BI+2c

Philippines

An endemic to Palawan, surviving in old clearings. The main island is a biosphere reserve.

Assessor: World Conservation Monitoring Centre Refs: 4986,5651

\section{Macaranga conglomerata}

Euphorbiaceae

VU $B 1+2 b$

Kenya, Tanzania

A local offshoot of the $M$. capensis- $M$. kilimandscharica complex, this species is restricted to two montane forests. A small population is known from the Taita Hills and another is found in the West Usambara Mountains. It has been recorded as common in the past, but recent tree plots suggest it is rare. The explosive increase in the human population in the surrounding area has exerted a heavy demand for wood and land.

Assessor: Lovett, J. \& G.P. Clarke

Refs: $3356,6396,9198,12067$

\section{Macaranga grandifolia}

Euphorbiaceae

VU Alcd

Philippines

An endemic species to the Philippines. Rates of habitat 
loss through logging and shifting cultivation have led to considerable population declines.

Assessor: World Conservation Monitoring Centre

Refs: 2072, 4919, 5651

\section{Macaranga huahineensis}

Euphorbiaceae

French Polynesia (Society Is.)

A dioecious tree, restricted to the central crest of Huahine Nui, on Mount Mato Ereere and Turi. It is common or co-dominant in ridge forest between 390 and $669 \mathrm{~m}$. There are signs of a spreading invasion of Merremia peltata.

Assessor: Florence, J.

Refs: 19169

\section{Macaranga mauritiana}

Euphorbiaceae

EN Alce

Mauritius

A pioneer species, which grows well in managed reserves where weeding is carried out. Regeneration is poor outside managed areas.

Assessor: Strahm, W.

Refs: 9120, 16426, 19208

\section{Macaranga paxii}

Euphorbiaceae

VU B1+2c

Cameroon, Nigeria

Extending from south-eastem Nigeria to Cameroon, the species is found sparsely distributed in patches of old secondary and disturbed forest. There is a population in the Oban Division of the Cross River National Park in Nigeria and in Cameroon the species is recorded in Ebone, Mantoum and Mount Cameroon. Unprotected forests have been heavily logged and cleared for agriculture.

Assessor: Lovett, J. \& G.P. Clarke

Refs: 4977, 11504, 12597

\section{Macaranga quadricornis}

Euphorbiaceae

$\mathrm{LR} / \mathrm{cd}$

Malaysia (Peninsular Malaysia)

A species of lowland to submontane closed and open forest, with an interesting distribution. There are two main populations; one in mountain forest at Gunong Nuong in Selangor and the other in lowland seasonal swamp in south-east Johore. The Johore population is being deforested for the construction of resorts and it is doubtful that the species will survive there. The forest at Gunong Nuong is protected.

Assessor: Kochummen, K.M.

Refs: 8464, 19073

\section{Macaranga raivavaeensis}

Euphorbiaceae

$\mathrm{CR} B 1+2 \mathrm{c}$

French Polynesia (Tubuai Is.)

An endemic to Raivavae.

Assessor: Florence, J.

Refs: 14513

\section{Macaranga taitensis}

Euphorbiaceae

French Polynesia (Society Is.)

LR/nt

An endemic to Tahiti.

Assessor: Florence, J.

Refs: 14513
Machaerium chambersü

Leguminosae

VU D2

Panama

The species is known from a collection taken from the province of Panamá. No further records of the species have been made.

Assessor: World Conservation Monitoring Centre

Refs: $7272,7980,16772$

\section{Machaerium cuzcoense}

Leguminosae

VU D2

Per

A species of semi-deciduous forest, known only from the type collection in the department of Cuzco.

Assessar: World Conservation Monitoring Centre

Refs: 1984

\section{Machaerium glabripes}

Leguminosae

VU D2

Panama

This species was described from a collection made in 1908. No reports of the species have been made since.

Assessor: World Conservation Monitoring Centre

Refs: $7272,7980,16772$

\section{Machaerium nicaraguense}

Leguminosae

EN C2a

Honduras, Nicaragua

This tree occurs on rocky wooded river banks and open areas in pine-oak forest.

Assessor: Nelson, C.

Refs: 13995

\section{Machaerium villosum}

Leguminosae

VUAlcd

Brazil

Fairly widespread within Brazil from Minas Gerais to Paraná, this species is grows in highland dry forests. Deforestation in this region has been severe. This species is exploited for its timber which is used to make fine fumiture and veneer.

Assessor: World Conservation Monitoring Centre

Refs: 4506

\section{Mackeea magnifica}

Palmae

VU BI+2c

New Caledonia

Restricted to north-east New Caledonia, the species occurs in wet montane forest or gallery forest on schistose rocks.

Assessor: Jaffré, T. et al.

Refs: 10351,19118

\section{Macleania loeseneriana}

Ericaceae

Ecuador

VU B $1+2 c$

An Ecuadorean endemic of montane and upper montane cloud forest in the High Andes, known from the provinces of Carchi, Imbabura, Pichincha and Cotopaxi. Assessor: World Conservation Monitoring Centre Refs: 19119,19120

\section{Maclurodendron parviflorum}

Rutaceae

VU D2

Malaysia (Sarawak)

Endemic to the Kuching District, this small lowland tree is known from only four collections found in primary 
* kerangas forest and secondary forest.

Assessor: World Conservation Monitoring Centre

Refs: 19017

\section{Maclurodendron pubescens}

Rutaceae

VU D2

Malaysia (Sabah)

Endemic to Sabah, this tree is found in primary forest on ridges and hillsides up to $140 \mathrm{~m}$. It is found in Sandakan,

Keningau and Lamag Districts.

Assessor: World Conservation Monitoring Centre

Refs: 10348,19017

\section{Macrocarpaea harti}

Gentianaceae

VU B $1+2 \mathrm{c}$

Jamaica

A species confined to moist montane and submontane forest, 1000 to $1400 \mathrm{~m}$, in St Andrew and Portland Parishes. Forest areas, in the former parish in particular, have been extensively destroyed or severely degraded.

Assessor: World Conservation Monitoring Centre

Refs: $6057,7980,19116$

\section{Macrocnemum cinchonoides}

Rubiaceae

VU D2

Peru

Known only from the type specimen, this forest species was collected from Puno.

Assessor: World Conservation Monitoring Centre

Refs: 1984

\section{Macrocnemum jamaicense}

Rubiaceae

LR/nt

Jamaica

This species occurs in rocky rainforest and in pasture margins mostly in the north-central and eastem parishes.

It is not common and habitat degradation has been severe in places.

Assessor: World Conservation Monitoring Centre

Refs: 6057,7980

\section{Macrocnemum pilosinervium}

Rubiaceae

VU D2

Peru

This species is known only from the type collection which was taken from a site in the department of Amazonas. It possibly represents a variety of $M$. roseum. Assessor: World Conservation Monitoring Centre Refs: 1984

\section{Macrolobium amplexans}

Leguminosae

VU D2

Suriname

The species is known from the type locality on forested slopes in central Suriname and the Nassau Mountains. Assessor: World Conservation Monitoring Centre Refs: 19196

\section{Macrolobium pittieri}

Leguminosae

Colombia, Panama

Originally known only from a few records, all from Kunayala Indigenous Reserve, in recent years the species has also been found in the Chocó, Valle del Cauca and Antioquia in Colombia. There is a possibility that there are populations in similar forest in Darién Province, Panama. Where it is known, the species is uncommon and under some pressure of habitat loss, although the area remains relatively under developed.

Assessor: Mitré, M.

Refs.: $3969,7272,7980,16772$

\section{Macrolobium stenopetalum \\ Leguminosae}

VU D2

Suriname

This species is known only from the type locality at Tafelberg.

Assessor: World Conservation Monitoring Centre

Refs: 19196

\section{Macrolobium taylori}

Leguminosae

VU D2

Peru

Known only from the type collection, the species is recorded from forest in the department of Huánuco.

Assessor: World Conservation Monitoring Centre Refs: 1984

\section{Macropanax concinnus}

Araliaceae

VU BI+2c

Indonesia (Java)

A widespread but uncommon species of damp montane forests above $400 \mathrm{~m}$. At lower elevation the species habitat has been almost completely cleared.

Assessor: World Conservation Monitoring Centre

\section{Macrosamanea macrocalyx}

Leguminosae

VU D2

Brazil (Pará)

A shrub or small tree, known only from Rio Xingú, near Altamira, growing on the margins of flooded forest.

Assessor: World Conservation Monitoring Centre

Refs: 5994

\section{Macrosamanea prancei}

Leguminosae

Brazil (Amazonas)

Only know from sites along the Rio Araca in north Amazonas, this shrubby tree is found growing on seasonally inundated white sand savanna and on sandy riverbanks.

Assessor: World Conservation Monitoring Centre Refs: 5994

\section{Madhuca aristulata}

Sapotaceae

Malaysia (Peninsular Malaysia)

VU D2

A small tree of rainforest, known from two collections: one from Perak and the other from Kedah.

Assessor: World Conservation Monitoring Centre

Refs: 8464, 19073

\section{Madhuca betis}

Sapotaceae

Indonesia (Sulawesi), Philippines

VUAlcd

This primary lowland forest species is a source of bitis timber and also medicinal extracts. In the Philippines stands have been depleted by logging and shifting agriculture.

Assessor: World Conservation Monitoring Centre Refs: $4919,12937,14573$

\section{Madhuca boerlageana}

Sapotaceae

CR Alcd, C2ab, D1

Indonesia (Irian Jaya, Moluccas), Papua New Guinea

A tree of primary lowland forest in New Guinea and the 
Moluccas. In Papua New Guinea, this species is extremely rare and known from a single sterile collection made from the Vanimo area, West Sepik Province. This part of Papua New Guinea is heavily logged and there is grave doubt as to its continuing existence in this country. The above threat category applies to the situation in Papua New Guinea only.

Assessor: Eddowes, P.J.

Refs: 19114

\section{Madhuca bourdillonii}

Sapotaceae

EN Alcd, $\mathrm{B} 1+2 \mathrm{c}$

India (Kerala)

The only collections of this large tree were made in lowland rainforest in Ariankavu and Shendumi Valley in Quilon District and from further north in the Trissur vicinity. It is not known to what extent the species has survived the continued exploitation of the habitat and of the trees for timber. Repeated searches have failed to find living specimens.

Assessor: World Conservation Monitoring Centre

Refs: 4799,19144

\section{Madhuca calcicola}

Sapotaceae

$\mathrm{EN} \mathrm{B1+2c}$

Malaysia (Peninsular Malaysia)

This rare tree is scattered in lowland limestone forests at Tasik Dayong Bunting in Langkawi, Kedah. The area is under intense pressure for development.

Assessor: Chua, L.S.L.

Refs: 19073

\section{Madhuca cuprea}

Sapotaceae

Malaysia (Peninsular Malaysia)

The species is confined to rainforest in Perak.

Assessor: Chua, L.S.L.

Refs: 19073

\section{Madhuca diplostemon}

Sapotaceae

$\mathrm{EN} \mathrm{Bl}+2 \mathrm{c}$

India

The only record of the species comes from a imprecisely located collection in the Deccan Peninsula. Botanical explorations in the Eastern and Western Ghats have failed to find the species.

Assessor: CAMP Workshops on Medicinal Plants in India

Refs: 4799, 18325

\section{Madhuca fulva}

Sapotaceae

Sri Lanka

VU Alc

A tree restricted to the lowland wet evergreen forests of south-west Sri Lanka.

Assessor: World Conservation Monitoring Centre

Refs: 9176, 17195

\section{Madhuca hainanensis}

Sapotaceae

China (Guangdong - Hainan)

VU B $1+2$ cde

A canopy tree of rainforest on the upper part of mountain slopes usually above $600 \mathrm{~m}$ on Hainan Island and in Quang Ninh Province in Viet Nam where it is found in forest below 1000 to $1200 \mathrm{~m}$. It provides a useful timber and overexploitation of both the tree and its habitat has caused considerable population declines. Assessor: World Conservation Monitoring Centre Refs: 1818,11847

\section{Madhuca insignis}

Sapotaceae

EX

India (Karnataka)

The species is recorded from a single locality in Mangalore in South Kanara District, Karnataka. It has not been found this century despite thorough searches. Only fragments of the original forest now remain. Assessor: World Conservation Monitoring Centre Refs: 561,4799

\section{Madhuca longistyla}

Sapotaceae

Malaysia (Peninsular Malaysia)

VU B $1+2 c$

A large tree inhabiting lowland rainforest and occasionally freshwater swamps. This species is confined to the state of Perak.

Assessor: Chua, L.S.L.

Refs: 17140,19073

\section{Madhuca microphylla}

Sapotaceae

$\mathrm{EN} \mathrm{B} 1+2 \mathrm{c}$

Sri Lanka

A rare species which was found in only two wet zone forests during the extensive forest surveys conducted for the National Conservation Review.

Assessor: World Conservation Monitoring Centre

Refs: 19112

\section{Madhuca moonü}

Sapotaceae

Sri Lanka

VUAlc

A rare tree restricted to the lowland wet evergreen forests of south-west Sri Lanka. During the recent National Conservation Review, this species was found in 14 forest localities.

Assessor: World Conservation Monitoring Centre

Refs: 8203, 17195, 19112

\section{Madhuca neriifolia}

Sapotaceae

$\mathrm{EN} \mathrm{B} 1+2 \mathrm{c}$

Sri Lanka

This rare species turned up in only four localities in Kalutara and Ratnapura during the comprehensive forest surveys conducted for the recent National Conservation Review.

Assessor: World Conservation Monitoring Centre Refs: 19112

\section{Madhuca oblongifolia}

Sapotaceae

Philippines

VUAld

This species occurs in primary lowland forest on the island of Luzon. The wood is a source of bitis timber but has very limited availability.

Assessor: World Conservation Monitoring Centre

Refs: 14573

\section{Madhuca obovarifolia}

Sapotaceae

Philippines

VU Ald

A species of primary lowland forest on Luzon. The timber is used as bitis but is very limited in supply. Assessor: World Conservation Monitoring Centre Refs: 12937, 14573 
Madhuca obtusifolia

Sapotaceae

DD

Malaysia (Peninsular Malaysia)

A very rare tree confined to the state of Perak.

Assessor: Chua, L.S.L.

Refs: 8464,19073

\section{Madhuca pasquieri}

Sapotaceae

VUAlcd

China (Guangdong, Guangxi, Yunnan), Viet Nam

A large timber tree with a scattered distribution in lowland primary forest in south-west Guangdong, southern Guangxi, Malipo and Pingbian in Yunnan and northem provinces of Viet Nam. Few large trees remain. Populations have been heavily exploited throughout the range. The species' range coincides with protected areas in both countries.

Assessor: World Conservation Monitoring Centre Refs: 848, 1818, 11530, 11847, 15357, 19055, 19061

\section{Madhuca penangiana}

Sapotaceae

LR/cd

Malaysia (Peninsular Malaysia)

A tree inhabiting rainforest between 150 and $1100 \mathrm{~m}$ in Kedah, Penang and Perak. This species receives a degree of protection within the permanent forest estate.

Assessor: Chua, L.S.L.

Refs: 8464, 14573, 19073

\section{Madhuca penicillata}

Sapotaceae

VU B $1+2 a$

Malaysia (Peninsular Malaysia)

A large tree up to $33 \mathrm{~m}$ tall, inhabiting lowland and hill forest in the states of Kelantan, Terengganu, Perak, Selangor and Negeri Sembilan.

Assessor: Chua, L.S.L.

Refs: $8464,11647,19073$

\section{Madhuca ridleyi}

Sapotaceae

VU B $1+2 a$

Malaysia (Peninsular Malaysia)

A tree inhabiting late secondary and primary forests on limestone areas at altitudes of 150 to $390 \mathrm{~m}$. This species, occasionally growing on seasonally swampy land, can be found in Perlis, Kedah, Upper Perak, Kelantan and Pahang.

Assessor: Chua, L.S.L.

Refs: $8464,14573,17140,19073$

\section{Madhuca rufa}

Sapotaceae

VU B $1+2 c$

Malaysia (Peninsular Malaysia)

This species is found in the lowland, primary forest of Perak. Populations are unprotected and threatened by increasing settlement and logging.

Assessor: Chua, L.S.L.

Refs: 19073

\section{Madhuca selangorica}

Sapotaceae

$\mathrm{LR} / \mathrm{cd}$

Malaysia (Peninsular Malaysia)

A tree of moist forest up to an altitude of $300 \mathrm{~m}$, occurring only in the state of Selangor.

Assessor: Chua, L.S.L.

Refs: 19073
Madhuca sessiliflora

Sapotaceae

VU B $1+2 c$

Malaysia (Peninsular Malaysia)

This is an uncommon small tree confined to shady, lowlying, seasonally swampy forests in north-eastem Johore.

Assessor: Chua, L.S.L.

Refs: 17140,19073

\section{Madhuca tomentosa}

Sapotaceae

LR/nt

Malaysia (Peninsular Malaysia)

Occurring in freshwater swamps and near streams in lowland and hill rainforest up to $480 \mathrm{~m}$, the species is recorded from Temerloh in Pahang and east Johore. The populations are protected within state parks and Taman Negara National Park.

Assessor: Chua, L.S.L.

Refs: 8464, 11647, 17140, 19073

\section{Madhuca tubulosa}

Sapotaceae

LR/cd

Malaysia (Peninsular Malaysia)

A small tree inhabiting the primary rainforest up to an altitude $540 \mathrm{~m}$ in Johore and Terengganu. This species is protected in state parks, wildlife reserves and forest reserves.

Assessor: Chua, L.S.L.

Refs: 11647, 19073

Maerua acuminata

Capparaceae

DD

Mozambique, Tanzania

Assessor: Bandeira, S.

Refs: 5117, 5654, 18965

\section{Maerua andradae}

Capparaceae

DD

Mozambique

Assessor: Bandeira, S.

Refs: 5117,18965

\section{Maerua angolensis var. socotranum}

Capparaceae

EN B $1+2 c$

Yemen (Socotra)

An important timber tree with a scattered distribution. declining in some areas. Recent rapid development could result in a building boom which would put certain pressure on remaining populations.

Assessor: Miller, A.G.

Refs: 19083

\section{Maerua brunnescens}

Capparaceae

Mozambique

It is likely that the species is confined to central Mozambique but more fieldwork, especially in northern regions, is required to consolidate the distribution and status of the species.

Assessor: Bandeira, S.

Refs: 5117,18965

\section{Maerua elegans}

Capparaceae

VU D2

Democratic Republic of Congo

The only known locality of this forest species is in Upemba National Park, east of Lake Upemba. The density of the human population is low and the threats 
from agricultural encroachment and logging are at a relatively low level. The crushed leaves are used to wash infants.

Assessor: Ndjele, M.B.

Refs: 17185, 17951

\section{Maerua scandens}

Capparaceae

Mozambique

Assessor: Bandeira, $\mathrm{S}$

Refs: 5117,18965

\section{Maesa velutina}

Myrsinaceae

India (Kamataka, Kerala)

EN B $1+2 c$

A small tree of lowland evergreen forest, very poorly known and collected only once from North Kanara in Kamataka and once from an imprecise locality in the Wayanad area in Kerala.

Assessor: World Conservation Monitoring Centre Refs: 19144

\section{Magnistipula butayei var. greenwayi}

Chrysobalanaceae

VU $B l+2 b$

Democratic Republic of Congo, Tanzania

The entire population of this variant is believed to be restricted to moist evergreen forest at relatively low elevations in the East Usambara Mountains. A population reported from the Katanga range in DR Congo is considered to be distinct but the taxonomy is not yet published. Heavy declines and exploitation of the forest have occurred in the past. There is continued pressure from the growing human population but an active conservation programme is now in place.

Assessor: Lovett, J. \& G.P. Clarke

Refs: $1308,3356,10961$

\section{Magnistipula butayei var. sargosii}

Chrysobalanaceae

Ghana

VU $B 1+2 c$

Although the species is widespread in Africa, from east to west, this subspecies is very rare. Few records of it exist in Ghana, where it is believed to occur in a range of forest types.

Assessor: Hawthorne, W.

Refs: $2773,8369,12061$

\section{Magnolia amoena}

Magnoliaceae

VU B $1+2 c$

\section{China (Anhui, Jiangsu, Jiangxi, Zhejiang)}

A species known from small scattered stands, occurring in hilly lowland mixed forest in a restricted area just south of the mouth of the Yangtze River. The species is found nowhere in large numbers and collection of flower buds for medicinal purposes is believed to be affecting the regeneration of the plant.

Assessor: World Conservation Monitoring Centre

Refs: $1818,9274,11847$

\section{Magnolia boliviana}

Magnoliaceae

VU B1+2c

Bolivia

Originally described under the genus Talauma, the species is known only from forest in the foothills of Amboro Park and the Chapare region. Deforestation is ongoing

Assessor: Ibisch, P.L. \& I. Vargas

Refs: 19138,19180
Magnolia calimaensis

Magnoliaceae

EN B $1+2 c$

Colombia

The accepted name for Dugandiodendron calimaense. It is recorded only from Valle.

Assessor: Calderon, E.

Refs: 19069,19138

\section{Magnolia calophylla}

Magnoliaceae

VUB $1+2 c$

Colombia

The accepted name for Dugandiodendron calophyllum. The species is recorded from Naraiño.

Assessor: Calderon, E.

Refs: 19069,19138

\section{Magnolia cararensis}

Magnoliaceae

$\mathrm{EN} \mathrm{B} 1+2 \mathrm{c}$

Colombia

The accepted name for Dugandiodendron cararense. The species is recorded only from Norte de Santander.

Assessor: Calderon, E.

Refs: 19069,19138

\section{Magnolia caricifragrans}

Magnoliaceae

$\mathrm{EN} \mathrm{B} 1+2 \mathrm{c}$

Colombia

The accepted name for Talauma caricifragrans. The species is recorded from localities in Boyaca, Cundinamarca and Norte de Santander.

Assessor: Calderon, E.

Refs: 19069,19138

\section{Magnolia cespedesủi}

Magnoliaceae

Colombia

CR B $1+2 c$

The accepted name for Talauma cespedesii. The species is recorded from Cundinamarca and from a less definite record in Boyaca.

Assessor: Calderon, E.

Refs: 19069,19138

\section{Magnolia colombiana}

Magnoliaceae

VU B $1+2 c$

Colombia

The accepted name for Dugandiodendron colombianum. The species has been recorded only from Huila.

Assessor: Calderon, E.

Refs: 19069

\section{Magnolia cubensis ssp. cacuminicola Magnoliaceae}

VU D2

Cuba

A rare tree of montane rainforest and cloud forest, restricted to Baracoa in eastern Cuba.

Assessor: Areces-Mallea, A.E.

Refs: 9522, 19138, 19149

\section{Magnolia cylindrica}

Magnoliaceae

VU $B 1+2 c$

China (Anhui, Fujian, Jiangxi, Zhejiang)

A tree known from a restricted area in the lower reaches of the Yangtze River, where it occurs in thickets and open forest up to $1700 \mathrm{~m}$. Collection of the flower buds for medicinal use and general forest clearance are believed to be having detrimental effects throughout the species range.

Assessor: World Conservation Monitoring Centre Refs: $1818,9274,11847$ 


\section{Magnolia dealbata}

Magnoliaceae

Mexico (Hidalgo, Oaxaca, Veracruz)

$\mathrm{EN} \mathrm{B} 1+2 \mathrm{c}, \mathrm{C} 2 \mathrm{~b}$

About four or five relict populations exist in areas of cloud forest between 600 and $1600 \mathrm{~m}$. The largest consists of between 80 and 100 individuals in disturbed cloud forest at Ixhuacan de los Reyes, Veracruz. Numbers are very small in Oaxaca and Hidalgo. The reasons for declines have largely been habitat destruction, timber production and poor regeneration. Approximately 1000 saplings have been produced ex situ, some of which are being planted at Jardin Botánico Francisco Javier Clavijero.

Assessor: Vovides, A.P.

Refs: 81, 4301, 16907, 19206

\section{Magnolia delavayi}

Magnoliaceae

China (Sichuan, Yunnan)

$\mathrm{EN} \mathrm{B} 1+2 \mathrm{c}$

Assessor: Sun, W.

Refs: 19138,19174

\section{Magnolia espinalï \\ Magnoliaceae}

CR B $1+2 \mathrm{c}$

Colombia

The accepted name for Talauma espinalii. The species is recorded only from Antioquia.

Assessor: Calderon, E.

Refs: 19069,19138

\section{Magnolia georgii}

Magnoliaceae

$\mathrm{EN} \mathrm{B} 1+2 \mathrm{c}$

Colombia

The accepted name for Talauma georgii. The species has been recorded only from localities in Boyaca and Santander.

Assessor: Calderon, E.

Refs: 19069,19138

\section{Magnolia gilbertoi \\ Magnoliaceae}

$\mathrm{EN} \mathrm{B1}+2 \mathrm{c}$

Colombia

The accepted name for Talauma gilbertoi. The species is restricted to Risaralda and Valle.

Assessor: Calderon, E.

Refs: 19069,19138

\section{Magnolia griffuthï}

Magnoliaceae

India (Assam), Myanmar

Assessor: World Conservation Monitoring Centre

Refs: 19138

\section{Magnolia guatapensis}

Magnoliaceae

CR B $1+2 \mathrm{c}$

Colombia

The accepted name for Dugandiodendron guatapense.

The species is recorded only from Antioquia.

Assessor: Calderon, E.

Refs: 19069,19138

\section{Magnolia guatemalensis ssp. hondurensis}

Magnoliaceae

EN C2a

El Salvador, Honduras

A species of medium- to high-altitude mixed forest.

Assessor: Nelson, C.

Refs: 13995,15892
Magnolia gustavi

Magnoliaceae

India (Assam)

A large tree confined to Makum forest in Assam.

Assessor: World Conservation Monitoring Centre

Refs: 16640,19138

\section{Magnolia henaoi}

Magnoliaceae

$\mathrm{EN} \mathrm{B1+2c}$

Colombia

The accepted name for Talauma henaoi. The species is recorded only from Huila.

Assessor: Calderon, E.

Refs: 19069,19138

\section{Magnolia henryi}

Magnoliaceae

DD

China (Yunnan), Laos, Myanmar, Thailand

Ranging from south-east Yunnan to north-east Myanmar, Thailand and north Laos, the species is found in dry monsoon forest on limestone at low to medium elevations. The extensive clearing and destruction of the forest in China has resulted in populations there becoming scarce and threatened.

Assessor: World Conservation Monitoring Centre

Refs: $1818,9274,11847$

\section{Magnolia hernandezii}

Magnoliaceae

$\mathrm{EN} \mathrm{B1}+2 \mathrm{c}$

Colombia

The accepted name for Talauma hemandezii. The species is recorded from localities in Antioquia, Oiomdio, Risaralda and Valle.

Assessor: Calderon, E.

Refs: 19069,19138

\section{Magnolia iltisiana}

Magnoliaceae

VU B $1+2 c$

Mexico (Guerrero, Jalisco)

A majestic tree which forms part of the mesophyllous montane forest in the Sierra de Manantlán and Cacoma in Jalisco. There is also a disjunct population in Guerrero.

Assessor: World Conservation Monitoring Centre Refs: 7980,19068

\section{Magnolia kachirachirai}

Magnoliaceae

EN Ald, C2a

Taiwan

A species at the most southerly limit of the family's range, in southern Taiwan from Taitung to the Hengchun Peninsula. Populations are healthy but fragmented, occurring in areas of lowland broadleaved forest. Kenting National Park covers part of the range, but elsewhere encroaching settlements are causing loss of habitat.

Assessor: Lu, S.Y. \& F.J. Pan

Refs: $2428,3295,19050,19051$

\section{Magnolia katiorum}

Magnoliaceae

$\mathrm{EN} \mathrm{B} 1+2 \mathrm{c}$

Colombia is known only from Antioquia.

Assessor: Calderon, E.

Refs: 19069,19138 


\section{Magnolia lenticellatum}

Magnoliaceae

VU B $1+2 \mathrm{c}$

Colombia

The accepted name for Dugandiodendron lenticellatum.

The species is recorded only from Antioquia.

Assessor: Calderon, E.

Refs: 19069,19138

\section{Magnolia macrophylla ssp. ashei \\ Magnoliaceae \\ USA (Florida) \\ Endemic to Florida, the species ranges from Leon and Wakulla Counties westward to Santa Rosa County along the southern half of the Florida Panhandle. A record in Texas appears to be a misidentification. Occurring in broadleaved or mixed forest on ravine slopes and bluffs, the species is sporadic and scarce in distribution. It doesn't respond well to disturbance and competition with more aggressive plants.}

Assessor: World Conservation Monitoring Centre

Refs: 9254, 19138, 19163

\section{Magnolia mahechae}

Magnoliaceae

$\mathrm{CR} B 1+2 \mathrm{c}$

Colombia

The accepted name for Dugandiodendron mahechae.

The species is recorded only from Valle.

Assessor: Calderon, E.

Refs: 19069,19138

\section{Magnolia minor}

Magnoliaceae

$\mathrm{EN} \mathrm{Bl}+2 \mathrm{c}$

Cuba

A scarce tree of lower montane rainforest, confined to the Sierra Maestra. The habitat has been disturbed by logging and overcutting.

Assessor: Areces-Mallea, A.E.

Refs: 19138,19149

\section{Magnolia narinensis}

Magnoliaceae

$\mathrm{EN} \mathrm{Bl}+2 \mathrm{c}$

Colombia

The accepted name for Talauma narinensis. The species is known only from Nariño.

Assessor: Calderon, E.

Refs: 19069,19138

\section{Magnolia nitida var. Lotungensis}

Magnoliaceae

LR/nt

China (Fujian, Guangdong, Guangdong - Hainan, Guizhou, Hunan, Jiangxi, Zhejiang)

Previously considered to belong to a separate genus Parakmeria, this variety is scattered over parts of central and southem China and Tawan. It occurs in broadleaved evergreen forest below $1000 \mathrm{~m}$. The species is thought to be scarcer now because of the affects of logging and habitat degradation.

Assessor: World Conservation Monitoring Centre

Refs: $1818,9274,11847$

\section{Magnolia nitida var. nitida}

Magnoliaceae

VUAlcd

China (Guangxi, Guizhou, Xizang, Yunnan), Myanmar

The taxon occurs in montane broadleaved evergreen forest between 1400 and $1500 \mathrm{~m}$ on Damiao Mountain in northern Guangxi, Rongjiang in south-east Guizhou, various mountain localities in Yunnan extending into Tibet and Myanmar. It provides a useful timber and its exploitation as well as general habitat loss have caused considerable population declines. There is some concern that the androdioecious nature of the flowering system may be contributing to poor regeneration.

Assessor: World Conservation Monitoring Centre

Refs: $1818,2428,9274,11847$

\section{Magnolia officinalis}

Magnoliaceae

LR/nt

China (Anhui, Fujian, Gansu, Guangdong, Guangxi, Guizhou, Hubei, Hunan, Jiangxi, Shaanxi, Sichuan, Zhejiang)

A very widespread tree endemic to China. It generally occurs in broadleaved deciduous forest up to $2000 \mathrm{~m}$ but the rate of decline of forest and also the levels of barkstripping of the tree have led to the species becoming rare outside cultivation. The species is frequently divided into subspecies but the differences between the two forms are not thought to be sufficient for taxonomic distinction.

Assessor: World Conservation Monitoring Centre Refs: $1818,9274,11847$

\section{Magnolia omeiensis}

Magnoliaceae

China (Guizhou, Sichuan)

CR D1

A species closely resembling $M$. nitida var. nitida, confined to Emei Mountain, where only male individuals have been found in an area of broadleaved evergreen forest between 1000 and $1200 \mathrm{~m}$. It is unknown whether further localities and female individuals exist. Logging appears to be continuing in the area and no special protection is yet in place to ensure that the population remains intact.

Assessor: World Conservation Monitoring Centre

Refs: 1818, 2428, 9274, 11725

\section{Magnolia pacifica ssp. pacifica}

Magnoliaceae

VU D2

Mexico (Jalisco)

A variety which appers to be known only from a few localities in ravines and gorges from Zapopan and San Cristóbal.

Assessor: World Conservation Monitoring Centre Refs: 7980,19068

\section{Magnolia panamensis \\ Magnoliaceae}

$\mathrm{EN} \mathrm{B1+2c}$

Panama

Recently described, the species is presently known from forest between 2000 and $2600 \mathrm{~m}$ on the Cordillera Central in Bocas del Toro and Chiriquí Provinces, right up to the border with Costa Rica. There is almost no doubt that the species continues into Costa Rica on the Cordillera de Talamanca, although it has yet to be collected here. There is a protected population in $\mathrm{La}$ Amistad National Park.

Assessor: Mitré, M.

Refs: 7980,16772

\section{Magnolia phanerophlebia}

Magnoliaceae

$\mathrm{EN} \mathrm{B1+2c}$

China (Yunnan)

The species is endemic to Maguan in the south-east.

Assessor: Sun, W.

Refs: 19138, 19174 


\section{Magnolia polyhypsopylla}

Magnoliaceae

Colombia

The accepted name for Talauma polyhypsophylla. The species is recorded only from Antioquia.

Assessor: Calderon, E.

Refs: 19069,19138

\section{Magnolia rostrata}

Magnoliaceae

China (Xizang, Yunnan), Myanmar

VU Bl $+2 \mathrm{c}$

A montane forest tree, occurring between 2100 and $3000 \mathrm{~m}$ within a small area encompassing westem Yunnan, Mêdog County in Tibet and north-east Myanmar. Overexploitation and detrimental harvesting of the bark are believed to have caused considerable population declines.

Assessor: World Conservation Monitoring Centre

Refs: $1818,9274,11847$

\section{Magnolia sambuensis}

Magnoliaceae

VU C2a

Colombia, Panama

Known under the genus Talauma in Panama, the species occurs in small sporadic populations, usually in inundated forest, in Darién National Park and slightly more frequently in the Serrania de Pirre, both in Panama. In Colombia, populations are recorded in Antioquia and more recently in Valle del Cauca. Outside protected areas the habitat has been extensively cleared for settlement and agriculture.

Assessor: Mitré, M.

Refs: 16772,19138

\section{Magnolia santanderiana}

Magnoliaceae

$\mathrm{EN} \mathrm{Bl}+2 \mathrm{c}$

Colombia

The accepted name for Talauma sanderiana. The species is recorded only from Santander.

Assessor: Calderon, E.

Refs: 19069,19138

\section{Magnolia sargentiana \\ Magnoliaceae \\ China (Sichuan, Yunnan) \\ Assessor: Sun, W \\ Refs: $9274,19138,19174$}

\section{Magnolia schiedeana}

Magnoliaceae

$\mathrm{EN} B 1+2 \mathrm{c}$

Mexico (Guerrero, Hidalgo, Nayarit, Oaxaca, Querétaro,

Sinaloa, Veracruz)

Remaining stands show signs of disturbance or cutting. Regeneration is primarily vegetative, by resprouting from the roots and trunk bases. There appears to be low fertility.

Assessor: Ramirez-Marcial, N. \& M. González-Espinosa Refs: 81, 15892, 16907, 19171, 19203

\section{Magnolia sinensis}

Magnoliaceae

VU B1+2c, D2

China (Sichuan)

A species known only in Tianquan, Lushan and Wenchuan Counties in Sichuan, occurring on the edges of forest and in scrub. The habitat has been cleared in places and the trees may be detrimentally affected by frequent bark-stripping. The bark contains a medicinal extract often used as a substitute for that of $M$. officinalis.

Assessor: World Conservation Monitoring Centre

Refs: $1818,9274,11847$

\section{Magnolia sororum ssp. sororum \\ Magnoliaceae \\ Panama}

VU A2c

This subspecies is recorded from Chiriqui and Cocle Provinces, where it occurs in cloud forest between 1000 and $2600 \mathrm{~m}$. It is fairly common in Volcán Barú National Park and is expected to be found in other protected areas. The populations in Coclé are facing significant increase in the human population, and in industrial and tourist activities. The other subspecies is endemic to Costa Rica.

Assessor: Mitré, M.

Refs: 7980,16772

\section{Magnolia urraoense}

Magnoliaceae

VU B $1+2 c$

Colombia

The accepted name for Dugandiodendron urraoense. The species is recorded only from Antioguia.

Assessor: Calderon, E.

Refs: 19069,19138

\section{Magnolia virolinensis}

Magnoliaceae

VU Bl+2c

Colombia

The accepted name for Talauma virolinensis. The species is recorded from localities in Boyaca and Santander.

Assessor: Calderon, E.

Refs: 19069,19138

\section{Magnolia wilsonii}

Magnoliaceae

$\mathrm{EN} \mathrm{Bl+2c}$

China (Guizhou, Sichuan, Yunnan)

These are scattered populations within the range of western Sichuan, northem Yunnan and western Guizhou in montane forest and thicket between 2000 and $3300 \mathrm{~m}$. The forest has been extensively cleared and the bark of the tree is also exploited to a considerable degree. Although it contains the same medicinal extract as $M$. officinalis, it makes a relatively poor substitute.

Assessor: Sun, W.

Refs: $1818,9274,11847,19174$

\section{Magnolia wolfii}

Magnoliaceae

CR B $1+2 c$

Colombia

The accepted name for Talauma wolfii. The species is recorded only from Risaralda.

Assessor: Calderon, E.

Refs: 19069,19138

\section{Magnolia yarumalense}

Magnoliaceae

CR B1+2c

Colombia

The accepted name for Dugandiodendron yarumalense. The species is recorded only from Antioquia.

Assessor: Calderon, E.

Refs: 19069,19138 
Magnolia yoroconte

Magnoliaceae

Belize, Guatemala, Honduras, Mexico (Chiapas, Veracruz)

The species is mainly known from the critically endangerd population in Honduras, occurring in medium to high elevation mixed forest. The distribution apparently extends to southern Mexico.

Assessor: World Conservation Monitoring Centre

Refs: 13995, 19138

Magnolia zenü

Magnoliaceae

China (Jiangsu)

CR D1

Apparently only a single population exists containing 18 individuals at the type locality on the north slopes of Baohua Mountain in mixed forest at an altitude of $220 \mathrm{~m}$. The area is a provincial reserve but no specific protection is given to these trees. No natural regeneration has been observed.

Assessor: World Conservation Monitoring Centre

Refs: $1818,9274,11847$

Mahonia oiwakensis

Berberidaceae

VU B $1+2 a b$

Taiwan

Endemic to the central mountain range on Taiwan, the species occurs in scattered populations in montane coniferous forest and woodland scrub. Regeneration is reported to be poor and no conservation or protection measures are in place.

Assessor: Pan, F.J.

Refs: $3295,6469,19050$

\section{Maillardia pendula}

Moraceae

CR B $1+2 \mathrm{c}$

Seychelles (Aldabra)

A small tree known from just a few individuals in Takamaka Grove on Grand Terre, in the Aldabras. It was once locally common but changes in the vegetation appear to have reduced the population significantly. The island is protected within a Strict Nature Reserve and is uninhabited.

Assessor: World Conservation Monitoring Centre

Refs: 19027

\section{Maingaya malayana}

Hamamelidaceae

Malaysia (Peninsular Malaysia)

VU $B 1+2 c$

An endemic species of Peninsular Malaysia, known only from Perak and Penang. This species inhabits primary rainforest up to $960 \mathrm{~m}$.

Assessor: Chua, L.S.L.

Refs: 15251,19073

\section{Malania oleifera}

Olacaceae

VU $B 1+2 c$

China (Guangxi, Yunnan)

An uncommon tree scattered in western Guangxi and eastern Yunnan on limestone mountains up to $1640 \mathrm{~m}$. Wild populations are much reduced as a result of continued logging and habitat clearance. A large population is under protection in Longzhou Nature Reserve. The genus is monotypic. It has long been cultivated as a source of oil for cooking and soapmaking.

Assessor: Sun, W.

Refs: $1818,11847,19055$

\section{Malleastrum leroyi}

Meliaceae

VU D2

Seychelles (Aldabra)

This shrub or small tree is found infrequently in mixed scrub on Polymnie, the east of Picard and the east of Grand Terre. The islands are protected within a Strict Nature Reserve and only Picard has a population of staff from a research station.

Assessor: World Conservation Monitoring Centre Refs: 19027

\section{Mallotus atrovirens}

Euphorbiaceae

India (Tamil Nadu)

VU B1+2c

A lowland forest species which has been collected rarely from scattered localities along the coast and base of the Westem Ghats.

Assessor: World Conservation Monitoring Centre

Refs: 19144

\section{Mallotus fuscescens}

Euphorbiaceae

VUAlc

Sri Lanka

A tree occurring in the lowland wet evergreen forests of south-west Sri Lanka.

Assessor: World Conservation Monitoring Centre

Refs: 9176,17195

\section{Mallotus odoratus}

Euphorbiaceae

VU D2

Philippines

An endemic species to the island of Camiguin. The present population status is not known and may be more seriously threatened.

Assessor: World Conservation Monitoring Centre Refs: 4986

\section{Mallotus oppositifolius var. lindicus}

Euphorbiaceae

VU B $1+2 b$

Mozambique, Tanzania

This variety occurs in south-east Tanzania and Mozambique within remaining areas of dry coastal forest.

Assessor: Lovett, J. \& G.P. Clarke

Refs: $1308,3356,8814$

\section{Mallotus smilaciformis}

Euphorbiaceae

CR B $1+2 c$

Malaysia (Peninsular Malaysia)

It is questionable whether the species still exists. It has been collected only once from primary areas of lowland evergreen rainforest in Perak.

Assessor: World Conservation Monitoring Centre

Refs: 8464,19073

\section{Malmea cuspidata}

Annonaceae

VU D2

Per

This species is known only from the type collection, which was taken from the department of Loreto.

Assessor: World Conservation Monitoring Centre Refs: 1984

\section{Malmea gaumeri}

Annonaceae

EN Alc

Guatemala, Mexico (Chiapas)

A species with a restricted range, occurring in remaining 
areas of lowland seasonal rainforest. The timber is of local use.

Assessor: Ramirez-Marcial, N. \& M. González-Espinosa Refs: $13228,19151,19161$

\section{Malmea leiophylla}

Annonaceae

CR C2b

Honduras

This species is known from a single collection dating from 1890. It was discovered in Allantic dry forest.

Assessor: Nelson, C.

Refs: 13995

\section{Malmea pachiteae}

Annonaceae

VU D2

Peru

Known only from the type collection, the species is found in lowland Amazon forest in the department of Huánuco.

Assessor: World Conservation Monitoring Centre Refs: 1984

\section{Malouetia isthmica}

Apocynaceae

VU Cl

Colombia, Panama

The species is distributed relatively widely in areas of lowland evergreen rainforest throughout the centre and east of Panama and is also reported from San José del Palmar in Colombia. Populations do not appear to be large and some areas are threatened by deforestation.

Assessor: Mitre, M.

Refs: $7980,15037,16772$

\section{Malpighia cauliflora}

Malpighiaceae

$\mathrm{EN} \mathrm{BI}+2 \mathrm{c}$

Jamaica

Only three localities are known, containing small populations in St Catherine and St Thomas. Deforestation has almost removed all forest areas below $1400 \mathrm{~m}$ in the latter parish.

Assessor: World Conservation Monitoring Centre

Refs: 401, 5653, 7980, 19116

\section{Malpighia harrisii}

Malpighiaceae

VU $B 1+2 c$

Jamaica

A slender shrub or tree, known only from populations in woodland on limestone in Clarendon and St Ann. Assessor: World Conservation Monitoring Centre Refs: $401,5653,7980$

\section{Malpighia obtusifolia}

Malpighiaceae

VU B $1+2 c$

Jamaica

A small tree or shrub from Clarendon, St James and Trelawny, where it occurs in woodland on limestone. Assessor: World Conservation Monitoring Centre Refs: $5653,6057,7980$

\section{Malpighia proctorii}

Malpighiaceae

CR B $1+2 c$

Jamaica

The type locality of the species appears to have been cleared for charcoal production. It is not known whether the species occurs elsewhere or whether it is now extinct.

Assessor: World Conservation Monitoring Centre

Refs: $401,5653,7980$
Malus hupehensis

Rosaceae

Japan, Taiwan

In Taiwan the species has been found in a very restricted area to the north of the island in the boundary area between Taipei and llan Counties. The population here consists of fewer than 50 individuals, in forest between 1700 and $1900 \mathrm{~m}$.

Assessor: World Conservation Monitoring Centre

Refs: 12135,19053

Malus komarovii

Rosaceae

China (Jilin), North Korea

VU B $1+2 c$

In China the species is confined to the Changbai Mountains, where it occurs infrequently in thickets between 1000 and $1300 \mathrm{~m}$. Clearing and altering of the habitat are believed to have affected regeneration and caused population declines. Observations of the species' resistance to cold has causer some interest in its potential as an apple cultivar.

Assessor: World Conservation Monitoring Centre

Refs: 1818,11847

Malus sieversii

Rosaceae

China (Xinjiang), Former USSR

VU B $1+2 \mathrm{c}$

In China pure stands of the species occur in the Ili River Valley in the westem part of the Tianshan Mountains and on hillsides in western Junggar between 1100 and $1600 \mathrm{~m}$.

Assessor: World Conservation Monitoring Centre

Refs: 1818,11847

\section{Mammea grandifolia}

Guttiferae

VU D2

Papua New Guinea

This small tree, known only from the type collection, was found along Pinini Creek in the Gulf Province. The taxonomic limits of this species are unclear.

Assessor: Stevens, P.F.

Refs: 19031, 19113

\section{Mammea immansueta}

Guttiferae

EN Alac

Panama

Almost all of the few existing collections of this species have come from an area of lowland rainforest along the highway running from Panamá Province to the Kunayala Indigenous Reserve. The species is relatively common where forest remains, but in the last 10 years an influx of campesinos into the area has resulted in extensive deforestation.

Assessor: Mitré, M.

Refs: $7980,15037,16772$

\section{Mammea malayana}

Guttiferae VU D2

Malaysia (Peninsular Malaysia)

This lowland forest tree is known only from two localities, one in north-east Pahang and the other in Perak. It is not certain that these localities are still forested, as the area is threatened by land conversion for agriculture.

Assessor: Kochummen, K.M.

Refs: 19073 


\section{Mammea novoguineensis}

Guttiferae

Indonesia (Irian Jaya), Papua New Guinea

A tree that occurs in primary well-drained forest between 60 and $420 \mathrm{~m}$. It is known from a few scattered localities in an area that is poorly known.

Assessor: Stevens, P.F.

Refs: 19031, 19113

\section{Mammea papuana}

Guttiferae

VU D2

Papua New Guinea

A rainforest tree known only from two collections from East Sepik. The taxonomic limits of this species are unclear.

Assessor: Stevens, P.F.

Refs: 19031, 19113

\section{Mammea papyracea}

Guttiferae

VU D2

Papua New Guinea

A small tree, known only from the type collection, found in Buso, south of Lae in the Morobe District.

Assessor: Stevens, P.F.

Refs: 19031

\section{Mammea timorensis}

Guttiferae

VU D2

Indonesia (Lesser Sunda Is.)

A species confined to the island of Komodo, a national park, and to West Timor.

Assessor: World Conservation Monitoring Centre

Refs: 1011

\section{Mammea usambarensis}

Guttiferae

$\mathrm{VU} \mathrm{B} 1+2 \mathrm{~b}$

Tanzania

The distinctness of this species from the West African species, $M$. africana, is considered to be doubtful. Populations in Tanzania occur in moist montane forest in the West Usambara and South Pare Mountains.

Assessor: Lovett, J. \& G.P. Clarke

Refs: 3356, 5204, 7089, 10961, 11631

\section{Mammea veimauriensis}

Guttiferae

VU D2

Papua New Guinea

The description of this species is based on two herbarium specimens. This tree is found along the Veimauri River in lowland rainforest, where it is reported to be quite common.

Assessor: Stevens, P.F

Refs: 19031

\section{Mangifera acutigemma}

Anacardiaceae

DD

India (Sikkim)

The species is based on a sterile herbarium specimen collected from a mountain locality in Sikkim.

Assessor: World Conservation Monitoring Centre

Refs: 11278

\section{Mangifera altissima}

Anacardiaceae

VU Ald

Indonesia (Irian Jaya, Lesser Sunda Is., Moluccas, Sulawesi), Malaysia (Sabah), Papua New Guinea (Bismarck Archipelago, Papua New Guinea), Philippines, Solomon Islands (South Solomon)

A timber species of lowland evergreen forest. It is nowhere abundant and the timber is available only in small quantities.

Assessor: World Conservation Monitoring Centre

Refs: $2698,4919,9570$

\section{Mangifera andamanica}

Anacardiaceae

India (Andaman and Nicobar Is. - Andaman Is.)

$\mathrm{EN} \mathrm{B1}+2 \mathrm{c}$

A tree endemic to Andaman and Nicobar Islands and restricted to wet evergreen forests. Many of the forests of the Andaman Islands have been affected in recent decades by overexploitation.

Assessor: World Conservation Monitoring Centre

Refs: 4799,9570

\section{Mangifera austro-indica}

Anacardiaceae

India (Tamil Nadu)

VU D2

A small tree noted for its conspicuous mass of flowers.

The species occurs commonly in remnants of *shola forest in Salem and Coorg Districts.

Assessor: World Conservation Monitoring Centre

Refs: 11278

\section{Mangifera austro-yunnanensis}

Anacardiaceae

DD

China (Yunnan)

There is very little known about this species on the basis of a collection found in south-western Yunnan at $1500 \mathrm{~m}$. It is even doubtful that the specimen fits the limits of the genus.

Assessor: World Conservation Monitoring Centre Refs: 11278

\section{Mangifera blommesteinii}

Anacardiaceae

EN Alc

Indonesia (Kalimantan), Malaysia (Peninsular Malaysia,

Sabah, Sarawak)

A rare tree known from only three collections in Sabah, two from Sarawak, and single collections from Nunukan Island off east Kalimantan and Rotan Tunggal Forest Reserve in Peninsular Malaysia. It is usually found in wet evergreen forest. The species has been reported to be in immediate danger of extinction.

Assessor: World Conservation Monitoring Centre Refs: $4377,8969,16394$

\section{Mangifera bullata}

Anacardiaceae

Indonesia (Sumatra), Malaysia? (Peninsular Malaysia?, Sabah?)

A tree known from two sterile herbarium collections from northem Sumatra and from dubious collections from Peninsular Malaysia and Sabah. It is reported to be fairly common in well-drained rainforest at $900 \mathrm{~m}$. Assessor: World Conservation Monitoring Centre Refs: 11278

\section{Mangifera campnospermoides}

Anacardiaceae

$\mathrm{CR} B 1+2 \mathrm{c}$

Indonesia (Kalimantan)

A distinctive tree, which superficially looks like a Campnosperma species. It is known from only a single sterile specimen collected in well-drained wet evergreen forest in Purukcau near Kelaseh in south Kalimantan at $260 \mathrm{~m}$. The forest near Purukacau has been destroyed and the species may already be extinct.

Assessor: World Conservation Monitoring Centre Refs: 11278 


\section{Mangifera casturi}

Anacardiaceae

EW

Indonesia (Kalimantan)

Endemic to Kalimantan, mostly in the south, this tree produces delicious fruit but it is known only in cultivation.

Assessor: World Conservation Monitoring Centre Refs: 4377, 16394

\section{Mangifera collina \\ Anacardiaceae \\ Thailand \\ Restricted to Chiang Mai region in north Thailand, this uncommon tree is found in montane, wet evergreen and deciduous forests. \\ Assessor: World Conservation Monitoring Centre Refs: 11278}

DD

\section{Mangifera dewildei}

Anacardiaceae

VU D2

Indonesia (Sumatra)

Found in lowland rainforest, this massive tree is known only from the type locality in North Sumatra Leuser Nature Reserve at $400 \mathrm{~m}$.

Assessor: World Conservation Monitoring Centre Refs: 11278

\section{Mangifera dongnaiensis \\ Anacardiaceae \\ EN Alc \\ Viet Nam \\ A small tree, endemic to southern Viet Nam, restricted to the diminishing submontane wet evergreen forests. Assessor: World Conservation Monitoring Centre Refs: 9570}

\section{Mangifera flava}

Anacardiaceae

VU $B 1+2 c$

Cambodia, Viet Nam

A rare species of mid-elevation wet evergreen forest, dry deciduous forest and bamboo thicket, occurring in Thailand and southem Viet Nam. Only a single collection from 1918 is known from Cambodia.

Assessor: World Conservation Monitoring Centre

Refs: 9570

\section{Mangifera hiemalis}

Anacardiaceae

China (Guangxi)

This evergreen tree is so far only known from a region in south-west Guangxi Province.

Assessor: World Conservation Monitoring Centre

Refs: 9570

\section{Mangifera indica}

Anacardiaceae

India

The common mango has been cultivated for thousands of years and now has a pantropical distribution. Wild populations can be found in Assam, India and Myanmar, especially the Assam-Chittagong Hills. There is a protected population in the biosphere reserve on the Mysore Plateau, India. The timber is also traded as machang.

Assessor: World Conservation Monitoring Centre

Refs: 4919, 5550, 9570, 11479, 12937, 15431, 16121, 17759,18327

\section{Mangifera lalijiwa}

Anacardiaceae

DD

Indonesia (Bali, Java, Sumatra?)

There is some question over the existence of this large forest tree in the wild. A population is known from an area between Semarang and Yogyakarta in central Java. There are also possible occurrences in Madura, Java, Bali and Sumatra and perhaps further afield. In Java encroaching agriculture and logging have almost completely eradicated lowland forest. This species is obviously highly valued for its fruit, which appears in large quantities in local markets.

Assessor: World Conservation Monitoring Centre

Refs: 9078,11278

\section{Mangifera macrocarpa}

Anacardiaceae

VU Alc

Indonesia (Java, Kalimantan, Sumatra), Malaysia (Peninsular Malaysia, Sabah), Singapore, Thailand

A large tree, extremely scattered and localised within lowland wet evergreen rainforest. The species is rarely found in cultivation as it flowers and fruits infrequently and the fruit is rarely, if ever, eaten. It is possibly extinct in Java. The lowland rainforests of Peninsular Malaysia and Bomeo are threatened by conversion to agriculture and forest degradation through logging.

Assessor: World Conservation Monitoring Centre

Refs: $7215,9199,9328,9570,11479$

\section{Mangifera minutifolia}

Anacardiaceae

VU D2

Viet Nam

So far this species is known only from the type specimen collected near Nhatrang, Annam.

Assessor: World Conservation Monitoring Centre

Refs: 9570

\section{Mangifera monandra}

Anacardiaceae

EN Alcd

Philippines

A very scattered and uncommon tree found in wet evergreen lowland forest on the islands of Luzon, Samar, Lete, Ticae and Quimaras. The fruit has little flesh and is eaten unripe. The timber is used for interior finish and making fumiture.

Assessor: World Conservation Monitoring Centre Refs: 9570

\section{Mangifera nicobarica}

Anacardiaceae

$\mathrm{EN} \mathrm{B} 1+2 \mathrm{c}$

India (Andaman and Nicobar Is. - Nicobar Is.)

A scarce species which is known only from the type locality in lowland mixed dense rainforest on the island of Great Nicobar.

Assessor: World Conservation Monitoring Centre Refs: 11278

\section{Mangifera odorato}

Anacardiaceae

Thailand?, Viet Nam?

This species has never been found in the wild and its origin remains a mystery. The fruit is popular and trees are commonly cultivated in eastern Asia in areas of high rainfall, especially where $M$. indica can't be grown. Assessor: World Conservation Monitoring Centre Refs: 4377, 5054, 5550, 9199, 9570, 11278, 12937 


\section{Mangifera orophila}

Anacardiaceae

Malaysia (Peninsular Malaysia)

One of the only mango species and one of the few tropical fruit trees that can grow at high altitudes, up to $1700 \mathrm{~m}$. It grows in wet evergreen forest in mountainous areas. This unique species opens up the possibility of cultivating mangoes in more temperate regions.

Assessor: World Conservation Monitoring Centre Refs: 4377

\section{Mangifera pajang}

Anacardiaceae

VU Alc

Brunei, Indonesia (Kalimantan), Malaysia (Sabah, Sarawak), Singapore

Restricted to primary lowland dipterocarp forests in Bomeo, this tree is rare within its natural habitat type. The only area where it is common is on the west coast plains of Sabah. It is found both wild and cultivated in Dayak gardens in the north-east and west of Kalimantan, but it is very rarely found in the south. It has not yet been cultivated widely outside its natural range, although, given the economic value and quality of the fruit, there is potential for more widespread cultivation in South East Asia. It may hybridise with M. foetida. Assessor: World Conservation Monitoring Centre Refs: $7215,8969,9199,9570$

\section{Mangifera paludosa}

Anacardiaceae

$\mathrm{EN} \mathrm{A} 1 \mathrm{c}+2 \mathrm{c}$

Indonesia (Sumatra), Malaysia (Peninsular Malaysia), Singapore

A tree found in freshwater marshy areas and mangrove swamp in southern Peninsular Malaysia, Riau Islands, Bangka Islands, Jambi and Palembang, Sumatra. It is thought to be extinct in Singapore because of the destruction of mangrove areas for urban growth. Elsewhere it is suspected to be in real danger of extinction. An occurrence is recorded in Berbak Nature Reserve in Sumatra.

Assessor: World Conservation Monitoring Centre Refs: 4377,16394

\section{Mangifera pedicellata}

Anacardiaceae

Indonesia (Java)

This species is found on the Karimun Djawa Islands, north of Java. It is cultivated in south Sulawesi.

Assessor: World Conservation Monitoring Centre Refs: 11278

\section{Mangifera pentandra}

Anacardiaceae

VU Alc, B1+2c

Malaysia (Peninsular Malaysia, Sabah), Singapore, Thailand?

The natural distribution of this species is possibly confined to wet evergreen lowland forest in the north of Peninsular Malaysia. It was once a common village tree in Peninsular Malaysia and old orchards are found in Peninsular Thailand. It is suspected that the interest in the species is declining in favour of $M$. indica, although it is still useful in improving the genetic stock of the common mango.

Assessor: World Conservation Monitoring Centre Refs: $8969,9570,11278,11479$

\section{Mangifera persiciformis}

Anacardiaceae

China (Yunnan)

A small tree found in the district of Funing in south-east Yunnan, south-west Guizhou and south Guangxi. It is frequently found or planted near villages.

Assessor: World Conservation Monitoring Centre

Refs: 11278

\section{Mangifera rubropetala}

Anacardiaceae

EW

Indonesia? (Sumatra?), Malaysia (Sabah, Sarawak)

Yet to be found in the wild, this species is cultivated widely in Sabah, Sarawak and also south Kalimantan and probably Sumatra. Its tasty fruit is similar to the common mango. It is adapted to wet lowland conditions and is best grown in areas without a pronounced dry season.

Assessor: World Conservation Monitoring Centre Refs: 11278

\section{Mangifera rufocostata}

Anacardiaceae

VU Alc

Indonesia (Kalimantan, Sumatra), Malaysia (Peninsular Malaysia, Sabah)

One of the tallest trees in the genus, reaching $53 \mathrm{~m}$ in height, it is found scattered in lowland wet evergreen forest in Peninsular Malaysia, Sumatra and Bomeo. The species produces a sour-tasting fruit after a long dry spell when other food is scarce.

Assessor: World Conservation Monitoring Centre Refs: $4377,8969,11278$

\section{Mangifera similis}

Anacardiaceae

VUAlc

Indonesia (Sumatra)

Restricted to south Kalimantan and Palembang in Sumatra, this rare tree is found in lowland rainforests. It was introduced to Java, where it is now cultivated. The specimen from Sumatra is slightly different.

Assessor: World Conservation Monitoring Centre Refs: 15991

\section{Mangifera sumbawaensis}

Anacardiaceae

VU D2

Indonesia (Lesser Sunda Is.)

Restricted to montane wet evergreen rainforest, this large tree is known only from the islands of Sumbawa and Flores. On the Lesser Sunda Islands, only small isolated patches of tropical rainforests remain and only an estimated total of $210 \mathrm{~km}^{2}$ of montane rainforest is left. The original forests have been degraded by human activity or converted for agriculture.

Assessor: World Conservation Monitoring Centre Refs: 16394

\section{Mangifera superba}

Anacardiaceae

EN Alc

Malaysia (Peninsular Malaysia)

So far this species is known only from the lowland wet evergreen forests in Peninsular Malaysia. It is one of the most threatened mango species. A large part of the habitat has been lost through clearance for agriculture, especially for large-scale cash crops.

Assessor: World Conservation Monitoring Centre Refs: $9570,11278,19073$ 


\section{Mangifera taipa}

Anacardiaceae

Indonesia? (Moluccas?)

Very little is known about this species.

Assessor: World Conservation Monitoring Centre

Refs: 11278

\section{Mangifera transversalis}

Anacardiaceae

VU D2

Indonesia (Moluccas)

The species was originally described in 1755 as a remarkable species with fruit hanging transversely off the stalks. It is recorded as being endemic to BandaNeira Island and introduced to Amboina Island. In 1993, this species was described by Kostermans based on a small cultivated tree, which is reputed to be common on Banda-Neira Island.

Assessor: World Conservation Monitoring Centre Refs: 11278

\section{Mangifera zeylanica}

Anacardiaceae

VU Alc

Sri Lanka

This Sri Lankan endemic is very rare and scattered in both the wet and dry zones, in some places in designated reserves. The tree produces tasty fruits but is not yet in cultivation. It could potentially contribute to the improvement of mango varieties. The bark is also collected for its medicinal properties.

Assessor: World Conservation Monitoring Centre Refs: 9570, 11278, 17195, 19110

\section{Manglietia aromatica}

Magnoliaceae

VU Alcd, Bl+2cde

China (Guangxi, Yunnan)

Only a few scattered stands of this important timber tree remain. The species is found in monsoon forest on limestone hills between 800 and $1550 \mathrm{~m}$ in a range stretching from south-east Yunnan to south-west Guangxi. Several populations are reported to have become extinct in both provinces, largely because of overexploitation of the timber.

Assessor: World Conservation Monitoring Centre

Refs: $1818,9274,11847$

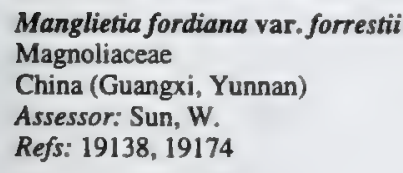

VU B $1+2 c$

\section{Manglietia grandis}

Magnoliaceae

VU B $1+2 c$

China (Guangxi, Yunnan)

Ranging from south-west Guangxi to south-east Yunnan, the species occurs in forested valleys on limestone mountains between 800 and $1500 \mathrm{~m}$. The habitat has been extensively cleared and degraded, and population declines have been reported as a result. Assessor: World Conservation Monitoring Centre Refs: $1818,9274,11847$

\section{Manglietia megaphylla}

Magnoliaceae

VU Bl +2 cde

China (Guangxi, Yunnan)

The remaining populations are believed to be small. They are restricted to broadleaved evergreen forest between altitudes of 450 and $1500 \mathrm{~m}$ on Mount Caoguo, where the species occurs with $M$. sinica, Mount Laojun in south-east Yunnan and in Jingxi and Napo Counties in Guangxi. The forests are unprotected and heavily exploited for firewood and timber. This species provides a construction timber given particular preference by local inhabitants.

Assessor: World Conservation Monitoring Centre Refs: $1818,9274,11847$

\section{Manglietia ovoidea}

Magnoliaceae

China (Yunnan)

Assessor: Sun, W.

Refs: 19138,19174

\section{Manglietia sinica}

Magnoliaceae

China (Yunnan)

CR D1

A species known from a single population, which consists of just seven mature individuals on forested slopes between 1300 and $1550 \mathrm{~m}$ on Caoguo Mountain and Nanchang Mountain. No effective protective measures are in place and the area is open to cutting and clearance. Regeneration is non-existent. The species was previously known under the monospecific genus Manglietiastrum.

Assessor: World Conservation Monitoring Centre Refs: 9274, 11847

\section{Manilkara bella}

Sapotaceae

$\mathrm{EN} \mathrm{B} !+2 \mathrm{c}$

Brazil (Espírito Santo, Rio de Janeiro)

A primary forest tree, restricted to an altitudinal range between 600 and $700 \mathrm{~m}$ on the Brazilian Atlantic coast. It provides an excellent timber. Overexploitation of both the tree and the habitat as a whole has caused the species to become scarce.

Assessor: Pires O'Brien, J.

Refs: $1983,7980,8816$

\section{Manilkara bolivarensis}

Sapotaceae

Venezuela

The species was found some 30 years ago at the headwaters of Río Pacairao in the Gran Sabana in Bolivar, where it was confined to gallery forest at $1100 \mathrm{~m}$. It has apparently not been found since, but the area is protected within Canaima National Park. Assessor: World Conservation Monitoring Centre Refs: 7980

\section{Manilkara cavalcantei}

\section{Sapotaceae}

VU $B 1+2 c$

Brazil (Amazonas, Pará)

Occurring in the non-flooded lowland forests of northern Brazil, this species is threatened primarily by logging activities. It is present in the Duke Forest Reserve near Manaus.

Assessor: Pires O'Brien, J.

Refs: $1983,7980,8816$

\section{Manilkara dardanoi \\ Sapotaceae}

Brazil (Pernambuco)

$\mathrm{EN} \mathrm{B1}+2 \mathrm{c}$

A small tree restricted to a small area of coastal forest and old secondary forest in Pernambuco. The habitat is threatened by felling and increasing settlement. Assessor: Pires O'Brien, J.

Refs: $1983,7980,8816$ 


\author{
Manilkara decrescens \\ Sapotaceae \\ $\mathrm{EN} \mathrm{B1+2c}$ \\ Brazil (Bahia) \\ A treelet which has been collected only once in 1982 \\ from the *restinga on the roadside between Maraú and \\ Campinhos. \\ Assessor: Pires O'Brien, J. \\ Refs: $1983,7980,8816$

\section{Manilkara clata} \\ Sapotaceae \\ EN Alc, Bl $+2 c$ \\ Brazil (Bahia, Espírito Santo) \\ The type collection originates from Bahia. The only \\ other record was made in 1965, when the species was \\ reported to be relatively abundant in Linhares in Espirito \\ Santo. No recent collections in either location have since \\ been made and the species is reported to have suffered \\ population declines. \\ Assessor: Pires O'Brien, J. \\ Refs: $1983,7980,8816$
}

\section{Manilkara excelsa}

Sapotaceae

Brazil (Amazonas, Mato Grosso, Pará)

VU B $1+2 \mathrm{c}$

A large tree confined to periodically flooded forest on the banks of the Tapajos River. It occurs within the boundaries of the Tapajós National Forest.

Assessor: Pires O'Brien, J.

Refs: $1983,7980,8816$

\section{Manilkara excisa}

Sapotaceae

$\mathrm{EN} \mathrm{BI}+2 \mathrm{C}$

Jamaica

A Cockpit Country endemic, confined to areas of woodland on limestone hills in Trelawny and St James.

It is a large tree, valuable for its timber.

Assessor: World Conservation Monitoring Centre

Refs: $401,5653,7980$

\section{Manilkara gonavensis}

Sapotaceae

$\mathrm{CR} \mathrm{B} 1+2 \mathrm{C}$

Haiti

An imperfectly known species. The only information available comes from the type collection, which was taken from Gonâve Island in Haiti in the first part of the century.

Assessor: World Conservation Monitoring Centre Refs: 7980,8816

\section{Manilkara jaimiqui ssp. haitensis}

Sapotaceae

VU B $1+2 c$

Dominican Republic, Haiti, Puerto Rico?

A shrub or small tree of forest on rocky limestone hills up to $400 \mathrm{~m}$. Collections have been made from two sites in Haiti and two from the Dominican Republic. There are also unconfirmed reports of an occurrence in Puerto Rico. The timber is exploited locally but the destruction of the habitat is the main cause of concern.

Assessor: World Conservation Monitoring Centre Refs: 8816

\section{Manilkara jaimiqui ssp. jaimiqui}

Sapotaceae

VU Bl+2c

Cuba, Jamaica

The subspecies occurs in lowland semi-deciduous forest, which for the most part has been heavily degraded in
Cuba. It is also native to Jamaica. Although it is a small tree, it has been overexploited for its valuable timber. Assessor: Areces-Mallea, A.E.

Refs: $7980,8816,19149$

\section{Manilkara jaimiqui ssp. wrightiana}

Sapotaceae

VU $B 1+2 c$

Cuba

This small tree is found in various sites throughout Cuba, both in coastal dry evergreen forests on limestone and in dry serpentine woodland. The habitat has suffered severe degradation in many places and continues to be threatened with cutting and buming.

Assessor: Areces-Mallea, A.E.

Refs: $7980,8816,19149$

\section{Manilkara kanosiensis}

Sapotaceae

EN Alcd $+2 c d, C 2 a$

Indonesia (Moluccas), Papua New Guinea (Bismarck

Archipelago, Papua New Guinea)

Relatively widespread but uncommon, this timber tree is scattered in primary lowland rainforest. It occurs mainly in areas where intense logging is being carried out, such as New Britain and New Ireland in the Bismarck Archipelago and the north-west of Papua New Guinea.

Assessor: Eddowes, P.J.

Refs: 19114

\section{Manilkara longifolia}

Sapotaceae

EN Alc, B1+2c

Brazil (Bahia, Espírito Santo)

A lowland rainforest species, recorded to be abundant in Espirito Santo in 1965. This area has been heavily cleared since and recent collections of the species have been rare.

Assessor: Pires O'Brien, J.

Refs: $1983,7980,8816$

\section{Manilkara maxima}

Sapotaceae

VU B $1+2 c$

Brazil (Bahia)

The species is confined to * restinga vegetation.

Assessor: Pires O'Brien, J.

Refs: $1983,7980,8816$

\section{Manilkara mayarensis}

Sapotaceae

$\mathrm{EN} \mathrm{B} 1+2 \mathrm{c}$

Cuba

A shrub or small tree confined to the province of Oriente, where it occurs in montane serpentine shrubwoods, mainly along creeks, ravines and watercourses. Mining is a constant threat to its habitat. Assessor: Areces-Mallea, A.E.

Refs: $7980,8816,19149$

\section{Manilkara multifida}

Sapotaceae

$\mathrm{EN} \mathrm{B} 1+2 \mathrm{c}$

Brazil (Bahia)

The species has only been found once at Belmonte Experimental Station in 1970.

Assessor: Pires O'Brien, J.

Refs: $1983,7980,8816$

\section{Manilkara nicholsonii}

Sapotaceae

South Africa (Eastem Cape, KwaZulu-Natal)

A Pondoland endemic confined to sandstone outcrops in southern KwaZulu-Natal around Port Edward and in the eastem Transkei in the Eastem Cape. It occus as 
scattered single individuals on sandy soils among rocks on forest margins or streambanks. The few remaining patches of forest are under threat from cutting for firewood and timber, agricultural activities and coastal development. This species is used as firewood and for stick making. There are populations in two provincial nature reserves and a local authority reserve in KwaZulu-Natal, also in a game reserve and a few demarcated forest areas in the Transkei.

Assessor: Hilton-Taylor, C. et al.

Refs: 689,19218

\section{Manilkara paraensis}

Sapotaceae

Brazil (Maranháo, Mato Grosso, Para)

LR/cd

The range of this species is restricted to non-flooded forest. Much of its range has been affected by largescale deforestation. The species occurs in the Caxiuana National Forest.

Assessor: Pires O'Brien, J.

Refs: $1983,7980,8816$

\section{Manilkara pleeana}

Sapotaceae

$\mathrm{VU} B 1+2 \mathrm{c}$

Puerto Rico

A shrub or small tree of coastal woodlands on limestone only in Puerto Rico. A record of the species from St John in the US Virgin Islands requires confirmation. Assessor: World Conservation Monitoring Centre Refs: $7980,8816,16898$

\section{Manilkara pubicarpa}

Sapotaceae

Guyana

A tall tree, known solely from the type collection, gathered 50 years ago from rainforest in the Kanuku Mountains.

Assessor: World Conservation Monitoring Centre

Refs: 7980,8816

\section{Manilkara rufula}

Sapotaceae

LR/nt

Brazil (Bahia, Ceará, Paraiba, Pernambuco, Piauŕ, Sergipe)

Populations of this submontane forest species are numerous. However, recent collections have suggested a decline in the numbers of individuals.

Assessor: Pires O'Brien, J.

Refs: $1983,7980,8816$

\section{Manilkara spectabilis}

Sapotaceae

$\mathrm{CR} \mathrm{B1+2c}$

Costa Rica

Recorded only from a single site, the species occurs in Atlantic coastal forest near Limon. The area was once covered with lowland rainforest but is now largely disturbed.

Assessor: World Conservation Monitoring Centre

Refs: 7980,8816

\section{Manilkara subsericea}

Sapotaceae

LR/cd

Brazil (Paraná, Rio de Janeiro, Santa Catarina, São Paulo)

The extent of occurrence of this species is relatively wide. It is found in both * restinga vegetation and lowland rainforest, also in Ilha do Cardosa Forest Reserve in Sāo Paulo.

Assessor: Pires O'Brien, J.

Refs: $1983,7906,7980,8816$

\section{Manilkara valenzuelana}

Sapotaceae VU B $1+2 c$

Cuba, Dominican Republic, Haiti, Puerto Rico?

Populations of this tall shrub or tree are found in areas of coastal and subcoastal semi-deciduous forest in Pinar del Rio and Oriente in Cuba. Two localities are recorded in both Haiti and the Dominican Republic. There are also unconfirmed reports of occurrences in Puerto Rico. Declines in the habitat have been large-scale because of logging, charcoal production and increasing settlement. Assessor: Areces-Mallea, A.E.

Refs: $7980,8816,19149$

\section{Maniltoa schefferi var. peekelii}

Leguminosae

VU Alcd $+2 c d, C 2 a$

Papua New Guinea (Bismarck Archipelago, Papua New Guinea)

Restricted to East Sepik Province, New Britain and New Ireland in the Bismarck Archipelago, this tree grows in lowland rainforest mainly in areas under siege from intensive logging activities. Its long-term survival is highly questionable.

Assessor: Eddowes, P.J.

Refs: 19114

\section{Maniltoa vestita}

Leguminosae

$\mathrm{LR} / \mathrm{nt}$

Fiji

A forest tree of rocky slopes, occurring relatively infrequently on Viti Levu and Vanua Levu.

Assessor: World Conservation Monitoring Centre Refs: 18818

\section{Mansonia altissima var. altissima}

Sterculiaceae

EN Alcd

Benin, Cameroon, Congo, Côte d'Ivoire, Ghana, Nigeria A moderately exploited timber tree. It occurs particurlarly in disturbed areas or light gaps in lowland moist forest. Regeneration is good after disturbance. Assessor: African Regional Workshop Refs: $2773,6718,7111,17408$

\section{Mappia racemosa}

Icacinaceae VUAlcd

Cuba, Dominican Republic, Guatemala, Haiti, Jamaica, Panama, Puerto Rico

A relatively widespread tree of semi-deciduous forest. It has been overexploited for its valuable timber in the West Indies and is now reduced to very small populations on most islands: one tree on Jamaica, five trees on Puerto Rico. Logging and habitat destruction continue to pose a serious threat. More information is needed on the Central American populations.

Assessor: Areces-Mallea, A.E.

Refs: 17124,19149

\section{Margaritaria anomala var. cheloniphorbe}

Euphorbiaceae

VU D2

Seychelles (Aldabra)

Occurring in inland scrub, this small tree or shrub is found on most of the Aldabran islands and also Menai and Astove. The fruits are eaten and the seeds dispersed by the blue pigeon. The Aldabras are protected within a Strict Nature Reserve. Areas of Cosmoledo and Astove 
have been cleared for the establishment of coconut and Casuarina plantations.

Assessor: World Conservation Monitoring Centre

Refs: 19027,19062

\section{Marila saramaccana}

Guttiferae

VU D2

Suriname

This species is endemic to an area around the upper Saramacca River.

Assessor: World Conservation Monitoring Centre

Refs: 19196

\section{Marila spiciformis}

Guttiferae

VU D2

Peru

Known only from the type collection, the species is recorded from lowland forest in the department of Amazonas.

Assessor: World Conservation Monitoring Centre

Refs: 1984

\section{Marlierea sintenisï}

Myrtaceae

VU D2

Puerto Rico

An endemic to upper wet ridges in the Luquillo Mountains. More information may indicate a more serious threat category is appropriate.

Assessor: World Conservation Monitoring Centre

Refs: 3786, 7931, 7980, 17124, 17540

\section{Marojejya darianii}

Palmae

$\mathrm{CR} \mathrm{B} 1+2 \mathrm{c}, \mathrm{C} 2 \mathrm{~b}$

Madagascar

This solitary species is known only from a single site near Maroantsetra, in upland swamp in a valley bottom between $400 \mathrm{~m}$ and $450 \mathrm{~m}$.

Assessor: Dransfield, J, \& H.J. Beentje

Refs: 18986,19118

\section{Marojejya insignis}

Palmae

VU C2a

Madagascar

An endemic palm of Madagascar, inhabiting rainforest on ridge tops or steep slopes. Despite its wide distribution, ranging from Marojejy to Andohahela, the size of individual populations is small. The total number of individuals is estimated at less than 2000. Harvesting of the palm heart continues.

Assessor: Dransfield, J. \& H.J. Beentje

Refs: 18986,19118

\section{Masoala kona}

Palmae

EN Alc

Madagascar

A newly described species, currently known only from the Ifanandiana area, where it inhabits rainforest on sandy/quartz soils between 450 and $550 \mathrm{~m}$. The forest and the populations in this small area are steadily disappearing because of shifting cultivation.

Assessor: Dransfield, J. \& H.J. Beentje

Refs: 18986, 19118

\section{Masoala madagascariensis}

Palmae

VU Alc

Madagascar

This endemic palm is known only from Marojejy, Masoala and Mananara, inhabiting lowland rainforest on dry hillside or swampy valley bottoms, occasionally on ultramafic soils. The number of individuals in all known sites is low.

Assessor: Dransfield, J. \& H.J. Beentje

Refs: 18986, 19118

\section{Mastixia glauca}

Comaceae

VU D2

Malaysia (Sarawak)

Endemic to Sarawak, this species is known only from Mount Santubong in mixed dipterocarp forest at an elevation of $90 \mathrm{~m}$.

Assessor: World Conservation Monitoring Centre Refs: 18327,19017

\section{Mastixia macrocarpa}

Cornaceae

VU Alc

Malaysia (Sarawak), Philippines

This tree is known only from Luzon in the Philippines and from Miri in Sarawak, where it grows in mixed dipterocarp forest at $75 \mathrm{~m}$.

Assessor: World Conservation Monitoring Centre Refs: 19017

\section{Mastixia macrophylla}

Cornaceae

VU Alc, B1+2c

Sri Lanka

During the recent National Conservation Review, this species was discovered in eight of the surveyed forest sites.

Assessor: World Conservation Monitoring Centre Refs: 19112

\section{Mastixia nimali}

Cornaceae

VU Alc, B1+2c

Sri Lanka

A tree confined to the lowland rainforests of south-west Sri Lanka. This species was found in only 10 localities during the comprehensive forest surveys conducted for the recent National Conservation Review.

Assessor: World Conservation Monitoring Centre Refs: 17195,19112

\section{Mastixia tetrandra}

Cornaceae

VUAlc

Sri Lanka

A tree occurring in the lowland rainforests of south-west Sri Lanka.

Assessor: World Conservation Monitoring Centre Refs: 9176,17195

\section{Mastixiodendron plectocarpum}

Rubiaceae

LR/nt

Indonesia (Irian Jaya), Papua New Guinea

Confined to south-west Papua New Guinea and southeast Irian Jaya, this large tree grows in lowland seasonal moist forest. This species occurs in a large forest logging concession area of Papua New Guinea which is subject to ongoing exploitation for log exports; continued exploitation will render it vulnerable.

Assessor: Eddowes, P.J.

Refs: 19114,19147

\section{Mastixiodendron stoddardii}

Rubiaceae VU Alcd+2cd, B1+2abcde Papua New Guinea (Bismarck Archipelago, North Solomons), Solomon Islands (South Solomon)

A large timber tree of primary lowland rainforest. restricted to New Britain in the Bismarck Archipelago and the Solomon Islands. New Britain is one of the most 
intensively logged islands in the Bismarck Archipelago, thereby threatening this species with habitat destruction. The Solomon Islands population is also at risk from logging activities.

Assessor: Eddowes, P.J.

Refs: 19114

\section{Matisia exalata}

Bombacaceae

EN C2a

Panama

The species is restricted to areas of evergreen rainforest between 650 and $1000 \mathrm{~m}$ in the Central Cordillera. Populations are reported to be healthy, although much of the area has been altered by cattle ranching and increasing urbanisation. There is a record from $\mathrm{La}$ Yeguada Forest Reserve, which lies just to the west of the principal population.

Assessor: Mitré, M.

Refs: 7980,16772

\section{Matisia stenopetala}

Bombacaceae

VU D2

Peru

Known only from the type collection, the species occurs in lowland Amazon forest in the department of Loreto.

Assessor: World Conservation Monitoring Centre

Refs: 1984

\section{Matudaea trinervia}

Hamamelidaceae

VU B $1+2 c$

Mexico

Assessor: Ramirez-Marcial, N. \& M. González-Espinosa Refs: 12985

\section{Mauria killipii}

Anacardiaceae

VU D2

Peru

The species has been recorded only from the type collection, which occurs above $1500 \mathrm{~m}$ in the department of Junín.

Assessor: World Conservation Monitoring Centre

Refs: 1984

\section{Mauria trichothyrsa}

Anacardiaceae

VU D2

Peru

Known only from the type collection, the species occurs in shrubland above $2500 \mathrm{~m}$ in the department of Cajamarca.

Assessor: World Conservation Monitoring Centre

Refs: 1984

\section{Mauritia carana}

Palmae

LR/cd

Brazil (Amazonas), Colombia, Peru, Venezuela

Widespread but uncommon, this palm tree occurs in lowland forest on poorly drained white sand soils in the Amazon region.

Assessor: Henderson, A.

Refs: 19118

\section{Mayna pubescens}

Flacourtiaceae

Colombia

$\mathrm{EN} \mathrm{B1+2c}$

A small tree or shrub, endemic to Colombia, recorded only in Cundinamarca.

Assessor: Calderon, E.

Refs: 7980,19069

\section{Mayna suaveolens}

Flacourtiaceae

EN B1+2c

Colombia

Endemic to Colombia, the species is recorded in Antioquia, Cundinamarca and Tolima.

Assessor: Calderon, E.

Refs: 7980,19069

\section{Maytenus abbottii}

Celastraceae

VU C2a

South Africa (Eastern Cape, KwaZulu-Natal)

A Pondoland endemic found in remnant evergreen forest patches between Durban in KwaZulu-Natal and Port St John's in the Transkei, Eastem Cape. It occurs in isolated groups as an understorey shrub or slender tree in coastal scarp forest, often on river banks. In two of the known localities, trees have been chopped down at an alarming rate for local use as firewood and timber and the habitat cleared for agriculture and settlement. A large subpopulation is protected in the Umtamvuna Nature Reserve and plants also occur in the Mkambati Game Reserve and a number of demarcated reserves in the Transkei. However, little protection is afforded to these forests in the Eastern Cape. The species was previously confused with $M$. acuminata and could be more widespread than is currently known.

Assessor: Hilton-Taylor, C. et al.

Refs: 689,19218

\section{Maytenus addat \\ Celastraceae \\ Ethiopia}

LR/nt

A tree of Afromontane forest, especially along forest margins, and also secondary formations. It ranges throughout the highlands. In the north the expanding human population and agricultural activities have caused a decline in the extent of the forest and continue to put pressure on the remaining habitat. Where the forest is cleared the tree is often left standing because of its usefulness as a timber and firewood.

Assessor: World Conservation Monitoring Centre

Refs: 1330,18523

\section{Maytenus arbutifolia var. sidamoensis}

Celastraceae

VU D2

Ethiopia

A variety known only from Afromontane forest and forest margins in Sidamo and adjacent parts of Shewa. The type variety is not ecologically distinct and is widely spread from DR Congo and Tanzania to Saudi Arabia.

Assessor: World Conservation Monitoring Centre

Refs: 1330

\section{Maytenus canariensis}

Celastraceae

Spain (Canary Is.)

A shrub or small tree, locally common in scrub on steep cliffs and in rocky areas. Endemic to the Canary Islands, populations are found on all the main islands except for Lanzarote. The extent of its known occurrence appears to be expanding. The species is listed in government legislation of 1991.

Assessor: Bañares, A. et al.

Refs: 19022 


\section{Maytenus clarendonensis \\ Celastraceae}

LR/nt

Jamaica

Occurring in central parishes, the species has a local distribution confined to woodland on limestone hills.

Assessor: World Conservation Monitoring Centre

Refs: 6057,7980

\section{Maytenus crassipes}

Celastraceae

LR/nt

Jamaica

Known only from central and westem parishes, the species is found in woodland on rough limestone.

Assessor: World Conservation Monitoring Centre

Refs: 6057,7980

\section{Maytenus curtissii}

Celastraceae

VU B $1+2 c$

Malaysia (Peninsular Malaysia), Thailand

This species, confined to Thailand and the northern states of Peninsular Malaysia, inhabits open and closed rainforest below $300 \mathrm{~m}$. It is accasionally found in coastal and limestone forest.

Assessor: Chua, L.S.L.

Refs: 8464,19073

\section{Maytenus cymoso}

Celastraceae

EN D1

Puerto Rico, Virgin Islands (British), Virgin Islands (US)

A species of dry coastal woodland. The greatest concentration is on Gorda Peak in the British Virgin Islands, where at least 100 plants exist. Elsewhere there are single trees, which may possibly have suffered in Hurricane Hugo, on St Croix and St Thomas in the US Virgin Islands and a population of about 52 plants in two sites in Puerto Rico.

Assessor: World Conservation Monitoring Centre

Refs: 7980,17124

\section{Maytenus dhofarensis}

Celastraceae

$\mathrm{LR} / \mathrm{nt}$

Oman, Yemen (Former South Yemen)

Occurring in escarpment woodlands and the drier summit plateau, this species is endemic to the mountains extending from the Dhofar region in Oman to south-east Yemen. It is quite common but at risk from overcutting for domestic use, especially in Oman, where there has been a sharp rise in the population since 1975.

Assessor: Ghazanfar, S.A.

Refs: 16380

\section{Maytenus harenensis}

Celastraceae

VU D2

Ethiopia

A small tree endemic to Harena forest, an Afromontane remnant of forest on the Bale Mountain. The forest is disturbed by logging activities and the building of sawmills in the area has made the activity more intense. Assessor: World Conservation Monitoring Centre Refs: 1330,18523

\section{Maytenus harrisi}

\section{Celastraceae}

Jamaica

This small tree is known only from the type specimen, which was collected in montane woodland in St Ann. Assessor: World Conservation Monitoring Centre Refs: $401,5653,7980$
Maytenus jefeana

Celastraceae

EN B $1+2 b$ Panama

Only a few records of this species are known, all from the same region from Cerro Jefe and Cerro Azul towards the north-east of Panama city. The species appears to be rare and present in small numbers, threatened by a growing urban population and various industrial developments.

Assessor: Mitré, M.

Refs: $7980,15037,16772$

\section{Maytenus matudai}

Celastraceae

VU B1+2c

Mexico

Assessor: Ramirez-Marcial, N. \& M. González-Espinosa Refs: 4974

Maytenus microcapa

Celastraceae

VU B1+2c

Jamaica

A Cockpit Country endemic which is found in Clarendon and Trelawny Parishes in woodland on limestone.

Assessor: Kelly, D.L.

Refs: 5653, 19085

\section{Maytenus oleosa}

Celastraceae

VU A2c

South Africa (Eastern Cape, KwaZulu-Natal)

A willow-like tree found along streams and rivers in southem KwaZulu-Natal and eastem Transkei in the Eastern Cape. It is often associated with Gymnosporia bachmannii on the rocky banks and beds of rivers and streams, confined to sandstone outcrops. The species has been recorded in fair numbers along several rivers in the Transkei. It is protected in the Umtamvuna Nature Reserve, Mkambati Game Reserve and several demarcated forest areas in the Transkei. In the latter, the lack of effective protection, combined with rapid human population increases and proposed developments threaten this and many of the other sandstone endemics in the region. There are also threats from agricultural activities and increasing settlement in southem KwaZulu-Natal.

Assessor: Hilton-Taylor, C. et al.

Refs: 689,19218

\section{Maytenus ponceano}

Celastraceae

VU B $1+2 c$

Puerto Rico

A small tree of moist areas near Florida and Río Portugués, north of Ponce. The habitat is degraded and destroyed in places.

Assessor: World Conservation Monitoring Centre

Refs: 5988, 7931, 7980, 17124

\section{Maytenus stipitata}

Celastraceae VU B $1+2 c$

Mexico (Chiapas)

Assessor: Ramirez-Marcial, N. \& M. González-Espinosa Refs: 642 
Maytenus williamsii

Celastraceae

CR C2b

Honduras

A cloud forest species of somewhat dubious nomenclature.

Assessor: Nelson, C.

Refs: 2260, 13995

\section{Medemia abiadensis}

Palmae

Sudan

A taxonomically-unresolved species restricted to desert oases along the White Nile. There is some indication the species is a small-fruited form of $M$. argun. No recent collections exist.

Assessor: Johnson, D.

Refs: $5165,18839,19118$

\section{Medemia argun}

Palmae

CR B $1+2 \mathrm{c}$

Egypt, Sudan

Found in desert oases, this palm tree was rediscovered in Sudan in 1995 in small fragmented populations. There are signs of regeneration and seeds have been collected for cultivation. The populations in Egypt are assumed to be similarly small and fragmented.

Assessor: Johnson, D.

Refs: $6988,9920,19118$

\section{Medusagyne oppositifolia}

Medusagynaceae

CR A2be, D1

Seychelles

The jellyfish tree comes from a monospecific family endemic to the Seychelles. The species is confined to Mahé Island, where it occurs as scattered individuals or in small groups on massive granitic outcrops at Bernica, Mount Sebert, Copolia and Mount Jasmin. The seeds appear unable to germinate in the wild. It has been suggested that the species requires more humid conditions than are found in the vegetated rocky fissures where it is growing.

Assessor: Nature Protection Trust of Seychelles

Refs: 19023,19025

\section{Medusandra richardsiana}

Medusandraceae

$\mathrm{LR} / \mathrm{cd}$

Cameroon

Endemic to the foothills of Mount Cameroon, the species occurs commonly in lowland rainforest in relatively well-protected areas: Mokoko Forest Reserve, Korup National Park, Bamuko Forest Reserve and the Rumpi Hills Forest Reserve. Where populations are unprotected they are exposed to encroaching agriculture and land settlement.

Assessor: World Conservation Monitoring Centre Refs: 12597

\section{Megalopanax rex}

Araliaceae

$\mathrm{CR} \mathrm{Bl+2c,Dl}$

Cuba

A monotypic genus endemic to Cuba. Collections have been made in western Cuba but now this tall tree appears to be locally confined to the montane forests of central Cuba, where only a few individuals have been seen. Fieldwork is needed to verify the number of remaining trees to assess whether the population is capable of recovery.

Assessor: Areces-Mallea, A.E.

Refs: 11403, 18485, 19149

\section{Meiogyne hainanensis}

Annonaceae

VU Alcd

China (Guangdong - Hainan, Guangxi)

Recorded under the name Oncodostigma hainanensie in the China Plant Red Data book, the species is endemic to Hainan Island, with the exception of a population which apparently can be found at Hepu in Guangxi. It occurs in dense montane forest in the Guoling, Limu, Bawang and Jianfeng Mountains and also other localities. Rapid population declines have taken place because of increasing habitat loss through logging and clearing for cultivation.

Assessor: World Conservation Monitoring Centre

Refs: 11847, 19090

\section{Melanochyla fasciculiflora}

Anacardiaceae

Malaysia (Peninsular Malaysia)

VU D2

A species of lowland forest, known from only two collections, both from Rengom Forest Reserve, a permanent forest reserve in Johore.

Assessor: Kochummen, K.M.

Refs: 19073

\section{Melanochyla longipetiolata}

Anacardiaceae

VUBI+2c

Malaysia (Peninsular Malaysia)

A lowland forest tree known only from three collections from Terengganu and Pahang. Populations are given a degree of protection within permanent forest reserves although there is still a threat from logging.

Assessor: Kochummen, K.M.

Refs: 19073

\section{Melanodendron integrifolium \\ Compositae}

VU DI

St Helena

The most abundant of the endemic cabbage trees. A total of probably more than 1000 individuals grow in various localities on the central ridge, principally Diana's Peak, Actaeon, Cabbage Tree Road, near Sandy Bay, High Peak and the Depot. Populations are healthy, appearing to regenerate well, although under competitive pressure from invading introduced species. The genus is monotypic.

Assessor: Cronk, Q.C.B.

Refs: 9954, 11891, 19081

\section{Melicope balloui}

Rutaceae

$\mathrm{EN} \mathrm{B} 1+2 \mathrm{c}, \mathrm{C} 2 \mathrm{~b}$

USA (Hawaii)

A small tree of montane wet forest on north-west Haleakala, Maui. Sites where the species was historically known to occur no longer appear to harbour populations. Only a relatively recently discovered locality in the Kipahulu Valley in Haleakala National Park still holds a population, which is estimated to consist of fewer than 300 individuals. Feral pigs, although presently controlled, require constant vigilance. The spread of introduced plants also presents a serious threat to the long-term survival of the species. It is protected by the US Endangered Species Act. Assessor: World Conservation Monitoring Centre Refs: 3372, 19087

\section{Melicope christophersenii}

Rutaceae

EN C2a

USA (Hawaii)

Known only from the Waianae Mountains on Oahu, the 
species is uncommon and restricted to rainforest between 910 and $1220 \mathrm{~m}$ from Puukaua to Mount Kaala. Assessor: World Conservation Monitoring Centre Refs: 3372

\section{Melicope cinerea}

Rutaceae EN C2a

USA (Hawaii)

The main population occurs in the Waianae Mountains in lowland rainforest. There are also collections from Manoa and Palolo Valleys in the Koolau Mountains and a tentative specimen from Maui.

Assessor: World Conservation Monitoring Centre Refs: 3372

\section{Melicope cruciata}

Rutaceae

USA (Hawaii)

A small tree known only from a few collections, thought to be taken from boggy rainforest above $1000 \mathrm{~m}$, in Kaholuamanu and Mount Waialeale on Kauai. It is now probably extinct.

Assessor: World Conservation Monitoring Centre

Refs: 3372

\section{Melicope fatuhivensis}

Rutaceae

CR B $1+2 \mathrm{c}$

French Polynesia (Marquesas Is.)

The species is known only from Fatu Hiva in the Marquesas. The leaves are highly esteemed for their fragrance.

Assessor: Florence, J.

Refs: 14513

\section{Melicope haleakalae}

Rutaceae

USA (Hawaii)

A small tree or shrub last seen in 1919 at Ukuele, on Maui, where it was found in rainforest at $1220 \mathrm{~m}$.

Assessor: World Conservation Monitoring Centre

Refs: 3372

\section{Melicope haupuensis}

Rutaceae

$\mathrm{CR} B 1+2 \mathrm{c}, \mathrm{C} 2 \mathrm{~b}$

USA (Hawaii)

Originally known only from the type locality on the north side of Haupu, on Kauai, the species has now been found in Waimea Canyon. The first population no longer exists and at the second site there are two trees $1.6 \mathrm{~km}$ apart. The habitat is frequently degraded by feral goats and the invasion of alien plants. The species is protected by the US Endangered Species Act.

Assessor: World Conservation Monitoring Centre Refs: 3372,19038

\section{Melicope hawaiensis}

Rutaceae

VUAlce

USA (Hawaii)

A variable species of $\mathrm{dry}$, and occasionally moist, forest up to $1220 \mathrm{~m}$ on Molokai, Lanai, Maui and Hawaii. The habitat is extensively degraded because of the impact of cattle, feral herbivores and introduced plants.

Assessor: World Conservation Monitoring Centre Refs: 3372

\section{Melicope indica}

Rutaceae

$\mathrm{EN} \mathrm{B1}+2 \mathrm{c}$

India (Tamil Nadu)

A small tree of montane forest, occurring between 1800 and $2400 \mathrm{~m}$ in a single locality in the Nilgiris.

Assessor: World Conservation Monitoring Centre

Refs: 4799, 19144

\section{Melicope jugosa}

Rutaceae

VU B1+2c

Malaysia (Sabah)

Confined to forest between 2250 and $2400 \mathrm{~m}$, this shrub or tree is endemic to Sabah.

Assessor: World Conservation Monitoring Centre

Refs: 19017

\section{Melicope kaalaensis}

Rutaceae

VU Alce

USA (Hawaii)

The species is endemic to the Waianae Mountains on Oahu, where it has been collected from lowland rainforest in an area extending from Puukaua to Piko Trail.

Assessor: World Conservation Monitoring Centre Refs: 3372

\section{Melicope knudsenii}

Rutaceae

CR C2a, D1

USA (Hawaii)

On Kauai a total of four isolated individuals are known from Olokele Valley and Waimea. On Maui, at one time locally common, the species has been reduced to 20 or 30 plants in two populations at Auwahi and Kanaio. The habitat has been steadily degraded by grazing and the invasion of introduced plants. The species is protected by the US Endangered Species Act.

Assessor: World Conservation Monitoring Centre Refs: 3372,19038

\section{Melicope macropus}

Rutaceae

$\mathrm{EN} \mathrm{B} 1+2 \mathrm{c}$

USA (Hawaii)

Endemic to Kauai, the species is known from just a few collections from two localities, the Robinson's summer house and Kaholuamanu.

Assessor: World Conservation Monitoring Centre Refs: 3372

\section{Melicope makahae}

Rutaceae

EN C2a

USA (Hawaii)

This shrubby tree is endemic to Oahu, where it occurs in rainforest up to an altitude of $1220 \mathrm{~m}$ in the Waianae Mountains from Palawai to Makaha Valley.

Assessor: World Conservation Monitoring Centre Refs: 3372

\section{Melicope mucronulata}

Rutaceae

CR B1+2c, C2b, D1 USA (Hawaii)

A small tree of dryland forest, known from three collections taken in 1920 from the southem slope of Haleakala on East Maui, and from a single collection of 1985 from Kupaia Gulch on Molokai. The Maui population is likely to be extinct. The population on Molokai consists of just three individuals. Goats are evidently browsing the trees and there is an immediate threat of invasion by molasses grass. It is protected by the US Endangered Species Act.

Assessor: World Conservation Monitoring Centre Refs: 3372,19087 


\section{Melicope nukuhivensis}

Rutaceae

LR/nt

French Polynesia (Marquesas Is.)

A small glabrous tree or shrub, endemic to Nuku Hiva.

Assessor: Florence, J.

Refs: 14513

\section{Melicope obovata}

Rutaceae

USA (Hawaii)

Presumed to be extinct, this species is known only from the type, of unknown locality but thought to originate from Maui.

Assessor: World Conservation Monitoring Centre

Refs: 3372

\section{Melicope orbicularis}

Rutaceae

EN C2a

USA (Hawaii)

A small tree endemic to Maui, where it is restricted to medium-elevation rainforest from Pohakea to Honokahua in the west and from Makawao to Koolau Gap in the east.

Assessor: World Conservation Monitoring Centre

Refs: 3372

\section{Melicope ovalis}

Rutaceae

$\mathrm{EN} \mathrm{BI}+2 \mathrm{cde}$

USA (Hawaii)

A species which once grew in the mountains above Hana, on Maui, from where the type specimen was collected. Recent observations suggest that the taxon occurs over an area of several hundred hectares in Kipahulu Valley, where it is said to be more common than $M$. balloui. The species is particularly vulnerable to seed predation by rats and insects. Invasive plants are also prevalent in the area. It is protected by the US Endangered Species Act.

Assessor: World Conservation Monitoring Centre Refs: 3372,19087

\section{Melicope pallida \\ Rutaceae}

EN C2a, D1

USA (Hawaii)

Originally known from localities on Oahu and Kauai, the species has been reduced to six populations confined to the latter island. About 156 individuals have been counted. The habitat continues to be damaged by grazing feral animals and invasive plants. The species is protected by the US Endangered Species Act.

Assessor: World Conservation Monitoring Centre

Refs: $3372,7274,19038$

\section{Melicope paniculata}

Rutaceae

USA (Hawaii)

Only three collections have been made of this small tree. These have been taken from populations on the upper Lihue Ditch Trail at $875 \mathrm{~m}$ and from Waihiawa Bog at $580 \mathrm{~m}$. The species has not been found in recent years and is now probably extinct.

Assessor: World Conservation Monitoring Centre

Refs: 3372

\section{Melicope puberula}

Rutaceae

$\mathrm{EN} \mathrm{B} 1+2 \mathrm{c}$

USA (Hawaii)

A shrub or small tree reported to be scarce and restricted to rainforest above $1070 \mathrm{~m}$, from Kalalau and Puuokila Look-outs.

Assessor: World Conservation Monitoring Centre

Refs: 3372

\section{Melicope quadrangularis}

Rutaceae

USA (Hawaii)

CR D1

Known only from the type material collected in 1909 from Wahiawa Bog on Kauai, the species had been presumed extinct when a small population of 13 individuals was discovered in 1991. Potential threats of overcollecting and invading alien plants are present. The species is protected by the US Endangered Species Act. Assessor: World Conservation Monitoring Centre Refs: $3372,7274,19038$

\section{Melicope saint-johnii}

Rutaceae

EN C2a, Dl

USA (Hawaii)

Endemic to Oahu, eight populations, containing fewer than 150 individuals, are found in an area between Puu Kaua and Puu Kanehoa to Mauna Kapu in the Waianae and Koolau Mountains. The species grows to an elevation of $853 \mathrm{~m}$ on forested ridges. feral goats, pigs and invasive plants are continuing threatS to the native flora. The species is protected by the US Endangered Species Act.

Assessor: World Conservation Monitoring Centre

Refs: $3372,12359,19168$

\section{Melicope sandwicensis}

Rutaceae

EN C2a

USA (Hawaii)

A species confined to Oahu, where it is known from populations occurring in lowland rainforest in the Waianae Mountains and from Kahana Iki to Waimalu in the Koolau Mountains.

Assessor: World Conservation Monitoring Centre Refs: 3372

\section{Melicope sororia}

Rutaceae

VU B $1+2 c$

Malaysia (Sabah)

A shrub or small tree endemic to Sabah. It is restricted to forest between the altitudes of 1500 and $2400 \mathrm{~m}$.

Assessor: World Conservation Monitoring Centre Refs: 19017

\section{Melicope subunifoliolata}

Rutaceae

Malaysia (Sabah)

VU B $1+2 c$

Endemic to Sabah, this shrub or tree occurs in primary montane forest between 1200 and $2600 \mathrm{~m}$, descending occasionally to as low as $180 \mathrm{~m}$.

Assessor: World Conservation Monitoring Centre

Refs: 19017

\section{Melicope tahitensis}

Rutaceae

French Polynesia (Society Is.)

Populations are recorded from Moorea and Tahiti.

Assessor: Florence, J.

Refs: 14513

\section{Melicope waialealae}

Rutaceae

USA (Hawaii)

A many-branched shrub or tree which occurs in open 
bogs and bog hummocks, including Wahiawa Bog and an area ranging from Alakai Swamp to Mount Waialeale on Kauai.

Assessor: World Conservation Monitoring Centre

Refs: 3372

\section{Melicope wawraeane}

Rutaceae

VU D2

USA (Hawaii)

A small forest tree known primarily from occurrences in the Koolau Mountains and an occasional appearance in the Waianae Mountains on Oahu. A single collection has also been made from Wahiawa Bog on Kauai.

Assessor: World Conservation Monitoring Centre

Refs: 3372

\section{Melicope zahlbruckneri}

Rutaceae

$\mathrm{CR} \mathrm{B} 1+2 \mathrm{c}, \mathrm{C} 2 \mathrm{ab}, \mathrm{D} 1$

USA (Hawaii)

To date the species has been found in three locations on Hawaii. Only one of them, a fenced site at Kipuka Pualu, still harbours an extant population, containing 30 to 35 individuals. Regeneration appears to be taking place. There are threats of leafhopper infestations, invasive plants and rat damage. The species is protected by the US Endangered Species Act.

Assessor: World Conservation Monitoring Centre

Refs: 3372, 19037

\section{Melicytus flexuosus}

Violaceae

LR/nt

New Zealand (North Is., South Is.)

A shrub or small tree, occurring in scattered localities in the North and South Islands. It appears to be a poor competitor and has suffered from the lack of periodic disturbance and available sites to recolonise.

Assessor: de Lange, P.J.

Refs: 19133,19134

\section{Meliosma cordato}

Meliosmaceae

Panama

A poorly known species, recorded only from the original collection from Cerro Tute in Verguas. It is possible that a population still exists there.

Assessor: Mitré, M.

Refs: $7980,15037,16772$

\section{Meliosma linearifolia \\ Meliosmaceae}

EN C2a

Panama

A species of lowland semi-evergreen rainforest, known from two geographically close locations: one in Santa Rita in Colón and the other in Cerro Azul in Panamá Province. The population in Santa Rita is threatened by increasing encroachment of the forest. More moderate pressures affect the larger Cerro Azul population.

Assessor: Mitré, M.

Refs: $7980,15037,16772$

\section{Meliosma sirensis}

Meliosmaceae

Peru

Known only from the type collection, the species occurs in *elfin forest in Huánuco.

Assessor: World Conservation Monitoring Centre Refs: 1984

\section{Meliosma youngi}

Meliosmaceae

Peru

Known only from the type collection, the species occurs in forest in the department of San Martin.

Assessor: World Conservation Monitoring Centre Refs: 1984

\section{Memecylon acuminatum var. acuminatum}

Melastomataceae

LR/cd

Malaysia (Peninsular Malaysia), Singapore

A primary hill forest species, which is not restricted in range and occurs in protective forest within the permanent forest estate.

Assessor: Chua, L.S.L.

Refs: 9199, 11647, 19073

\section{Memecylon arnottianum}

Melastomataceae

CR B $1+2 \mathrm{c}$

Sri Lanka

A tree occurring in lowland wet evergreen forest in south-west Sri Lanka. In the past it has been found in Kottawa, Hinidumkanda and Kanneliya Forest Reserves and in Sinharaja Biosphere Reserve. The recent forest surveys conducted for the National Conservation Review failed to find these or any other populations. Assessor: World Conservation Monitoring Centre Refs: 9176, 17195, 19112

\section{Memecylon bequaertii}

Melastomataceae

Democratic Republic of Congo, Uganda

Assessor: *MUIENR

Refs: $1308,9605,9837,10961,16021$

\section{Memecylon candidum}

Melastomataceae

VU B $1+2 c$

Cameroon, Nigeria

Confined to an area extending from south-east Nigeria to Cameroon, this understorey tree is not uncommon. It occurs and is protected in the Oban Hills in Cross River National Park. Outside protected areas deforestation has occurred on a large scale.

Assessor: World Conservation Monitoring Centre Refs: 4977,11504

\section{Memecylon cinereum}

Melastomataceae

VU B $1+2 c$

Malaysia (Peninsular Malaysia), Singapore

A species of lowland hill forest, occurring along streams throughout Peninsular Malaysia and Singapore. The habitat is under pressure from logging.

Assessor: Chua, L.S.L.

Refs: 9199,19073

\section{Memecylon clarkeanum}

Melastomataceae

VU Alc

Sri Lanka

A tree scattered in the lowland wet evergreen forests of south-west Sri Lanka.

Assessor: World Conservation Monitoring Centre Refs: 17195

\section{Memecylon corticosum}

Melastomataceae

$\mathrm{LR} / \mathrm{cd}$

Malaysia (Peninsular Malaysia)

A hill forest species, which is not restricted in range and 
occurs in protected areas, such as national parks and forest reserves.

Assessor: Chua, L.S.L.

Refs: 8464, 19073

\section{Memecylon cuneatum}

Melastomataceae

$\mathrm{EN} \mathrm{B} 1+2 \mathrm{c}$

Sri Lanka

This rare species turned up in only four forest localities, including the Peak Wilderness wildlife sanctuary, during the comprehensive forest surveys conducted for the recent National Conservation Review.

Assessor: World Conservation Monitoring Centre Refs: 19112

\section{Memecylon discolor}

Melastomataceae

$\mathrm{EN} B 1+2 \mathrm{c}$

Sri Lanka

A rare species found in only two forest localities in the wet zone during the comprehensive forest surveys conducted for the recent National Conservation Review. Assessor: World Conservation Monitoring Centre Refs: 19112

\section{Memecylon eleagni}

Melastomataceae

VUD2

Seychelles

Endemic to the Seychelles, the species qualifies as threatened by virtue of its restricted distribution. Populations are healthy and stable.

Assessor: World Conservation Monitoring Centre

Refs: 16212,17229

\section{Memecylon elegantulum}

Melastomataceae

CR B $1+2 \mathrm{C}$

Sri Lanka

A species confined to lowland wet evergreen forest in south-west Sri Lanka. Although previously found at a single site in Sinharaja Biosphere Reserve, it was not found again during the extensive forest surveys conducted between 1991 and 1996 for the National Conservation Review, suggesting that the species is either extremely rare or possibly extinct.

Assessor: World Conservation Monitoring Centre

Refs: 9176, 17195, 19112

\section{Memecylon ellipticum}

Melastomataceae

$\mathrm{EN} \mathrm{Bl}+2 \mathrm{c}$

Sri Lanka

Endemic to south-west Sri Lanka, this rare tree is scattered in the lowland wet evergreen forests. This species was found in only four of the National Conservation Review surveyed forest sites.

Assessor: World Conservation Monitoring Centre

Refs: 8203, 17195, 19112

\section{Memecylon flavescens}

Melastomataceae

$\mathrm{EN} \mathrm{B1}+2 \mathrm{c}$

India (Tamil Nadu)

A species of high-altitude evergreen *shola forest known only from Kundha and Avalanche in the Nilgiri Hills. It appears to have become extremely scarce and has not been found in more recent decades despite repeated searches.

Assessor: World Conservation Monitoring Centre

Refs: 4799,16438

\section{Memecylon floridum}

Melastomataceae

$\mathrm{VU} B 1+2 \mathrm{c}$

Malaysia (Peninsular Malaysia), Singapore

This species inhabits open and closed rainforest up to an altitude of $1200 \mathrm{~m}$, in Peninsular Malaysia and Singapore.

Assessor: Chua, L.S.L.

Refs: 9199,19073

\section{Memecylon gardneri}

Melastomataceae

$\mathrm{CR} \mathrm{B} 1+2 \mathrm{c}$

Sri Lanka

An extremely rare tree, occurring in lowland wet evergreen forest in south-west Sri Lanka. In the past populations were known from Kanneliya and Gilimale Forest Reserves and Sinharaja Biosphere Reserve, but the species was not found in the recent forest surveys conducted for the National Conservation Review. Assessor: World Conservation Monitoring Centre Refs: $9176,17195,19112$

\section{Memecylon giganteum}

Melastomataceae

$\mathrm{EN} \mathrm{B} 1+2 \mathrm{c}$

Sri Lanka

A rare species which was found in only four wet zone forests during the extensive forest surveys conducted for the National Conservation Review.

Assessor: World Conservation Monitoring Centre

Refs: 19112

\section{Memecylon gracillimum}

Melastomataceae

EN B $1+2 c$

Sri Lanka

Only four trees of this species were discovered in a single forest site during the recent forest surveys conducted for the National Conservation Review. Assessor: World Conservation Monitoring Centre Refs: $8203,18796,19112$

\section{Memecylon grande}

Melastomataceae

VU Alc, B1+2c

Sri Lanka

A rare tree confined to the lowland wet evergreen forests of south-west Sri Lanka. This species was found in eight forest sites during the extensive forest surveys conducted for the National Conservation Review.

Assessor: World Conservation Monitoring Centre Refs: 17195, 19112

\section{Memecylon hookeri}

Melastomataceae

Sri Lanka

VU Alc, Bl+2c

A species found in only 10 localities during the extensive forest surveys conducted for the National Conservation Review.

Assessor: World Conservation Monitoring Centre Refs: 19112

\section{Memecylon hullettii}

Melastomataceae VU BI+2c

Malaysia (Peninsular Malaysia)

An endemic species of Peninsular Malaysia, where it is confined to the lowland and hill rainforests of Johore.

Assessor: Chua, L.S.L.

Refs: 17140,19073 


\section{Memecylon kunstleri}

Melastomataceae

VU $B 1+2 c$

Malaysia (Peninsular Malaysia)

An endemic tree of Peninsular Malaysia, inhabiting primary rainforest.

Assessor: Chua, L.S.L.

Refs: 8464, 19073

\section{Memecylon lawsonii}

Melastomataceae

VU B1+2c

India (Kerala, Tamil Nadu)

A small tree of submontane forest. It has been collected only seldom from localities in the Anamalai Hills, the Nilgiris and Wayanad area.

Assessor: World Conservation Monitoring Centre Refs: 832, 19144

\section{Memecylon leucanthemum}

Melastomataceae

VU Alc, B1+2c

Sri Lanka

A species found in only eight localities in the districts of Kurunegala, Badulla and Monarangala during the extensive forest surveys conducted for the National Conservation Review.

Assessor: World Conservation Monitoring Centre Refs: 19112

\section{Memecylon macrocarpum}

Melastomataceae

VU Alc, Bl+2c

Sri Lanka

A tree occurring in tropical wet lowland and montane forest. In the extensive surveys conducted for the National Conservation Review, this species was discovered in eight localities.

Assessor: World Conservation Monitoring Centre

Refs: 8203, 12129, 18796, 19112

\section{Memecylon macrophyllum}

Melastomataceae

$\mathrm{EN} \mathrm{Bl}+2 \mathrm{c}$

Sri Lanka

During the extensive surveys conducted for the National Conservation Review between 1991 and 1996, this species was discovered in only three forest localities.

Assessor: World Conservation Monitoring Centre

Refs: 19112

\section{Memecylon orbiculare}

Melastomataceae

$\mathrm{CR} \mathrm{B} 1+2 \mathrm{c}$

Sri Lanka

Only a single individual was found during the extensive forest surveys conducted for the National Conservation Review.

Assessor: World Conservation Monitoring Centre Refs: $8203,18796,19112$

\section{Memecylon ovoideum}

Melastomataceae

VU Alc, B1+2c

Sri Lanka

A tree occurring in the lowland wet evergreen forests of south-west Sri Lanka. During the extensive National Conservation Review forest surveys, this species was recorded in seven localities.

Assessor: World Conservation Monitoring Centre

Refs: $8203,17195,18796,19112$

\section{Memecylon revolutum}

Melastomataceae

$\mathrm{EN} \mathrm{B1}+2 \mathrm{c}$

Sri Lanka

A species apparently restricted to the wet zone. During the extensive National Conservation Review forest surveys, this species was recorded in five forest localities.

Assessor: World Conservation Monitoring Centre Refs: 8203, 18796, 19112

\section{Memecylon rhinophyllum \\ Melastomataceae \\ Sri Lanka}

CR B $1+2 c$

A tree restricted to lowland wet evergreen forest in south-west Sri Lanka. It is apparently locally common but confined to a single forest reserve. Only nine individuals were discovered in at a single site during the extensive National Conservation Review forest surveys. Assessor: World Conservation Monitoring Centre Refs: 17195,19112

\section{Memecylon rostratum}

Melastomataceae

VU Alc

Sri Lanka

A tree occurring in the lowland wet evergreen forests of south-west Sri Lanka.

Assessor: World Conservation Monitoring Centre Refs: 9176, 17195

\section{Memecylon rotundatum}

Melastomataceae

VU Alc, B $1+2 c$

Sri Lanka

During the extensive National Conservation Review forest surveys, this species was found in only six of the sites.

Assessor: World Conservation Monitoring Centre Refs: 8203, 18796, 19112

\section{Memecylon royenii}

Melastomataceae

VU Alc, B1+2c

Sri Lanka

A species found in only six forest localities in Ratnapura District and in a single locality in Kalutara District during the extensive forest surveys conducted for the National Conservation Review.

Assessor: World Conservation Monitoring Centre Refs: 19112

\section{Memecylon sessilicarpum}

Melastomataceae

Mozambique

Assessor: Bandeira, S.

Refs: 5117,18965

\section{Memecylon sisparense}

Melastomataceae

India (Tamil Nadu)

$\mathrm{CR} \mathrm{B} 1+2 \mathrm{c}$

The type locality is in Sispara in the Nilgiri Hills. The species has not been found there since it was first discovered. It is possible the population has been wiped out by the large-scale conversion of forest to plantation crops. Elsewhere there is an occurrence further south in submontane forest in the Palni Hills.

Assessor: World Conservation Monitoring Centre Refs: 4799,19144

\section{Memecylon subramanii}

Melastomataceae

$\mathrm{EN} \mathrm{B1}+2 \mathrm{c}$ India (Tamil Nadu)

A small tree of submontane forest, collected only from the Agastyamalai range. Large areas have been exposed to fires, grazing, the establishment of commercial plantations and cutting for fuelwood, but almost 
$1000 \mathrm{~km}^{2}$ of forest are now under protection within sanctuaries.

Assessor: World Conservation Monitoring Centre

Refs: 19144

\section{Memecylon sylvaticum}

Melastomataceae

VU Alc

Sri Lanka

A tree occurring in the lowland wet evergreen forests of south-west Sri Lanka.

Assessor: World Conservation Monitoring Centre

Refs: 17195

\section{Memecylon teitense}

Melastomataceae

VU B $1+2 c$

Kenya

A shrub or tree, endemic to forest at Ngangao and Mbololo in the Teita Hills.

Assessor: World Conservation Monitoring Centre

Refs: $1308,6396,13072$

\section{Memecylon urceolatum}

Melastomataceae

VU Alc, Bl+2c

Sri Lanka

This species was found in seven forest sites during the extensive forest surveys conducted for the National

Conservation Review.

Assessor: World Conservation Monitoring Centre

Refs: 19112

\section{Memecylon varians}

Melastomataceae

VU Alc

Sri Lanka

A tree confined to the lowland wet evergreen forests of south-west Sri Lanka.

Assessor: World Conservation Monitoring Centre

Refs: 17195

\section{Memecylon wallichii}

Melastomataceae

Malaysia (Peninsular Malaysia)

VU B $1+2 \mathrm{c}$

An endemic tree of Peninsular Malaysia, inhabiting primary rainforest up to $330 \mathrm{~m}$.

Assessor: Chua, L.S.L

Refs: 8464,19073

\section{Meriania ampla}

Melastomataceae

Ecuador

VU B $1+2 c$

A tree endemic to the High Andes of Ecuador. Currently the species is known only from montane and upper montane cloud forest in Morona-Santiago Province. Assessor: World Conservation Monitoring Centre Refs: 2989, 6596, 19119, 19120

\section{Meriania campii}

Melastomataceae

$\mathrm{VU} B 1+2 \mathrm{c}$

Ecuador

An endemic of the High Andes of Morona-Santiago Province in Ecuador. The habitat of this species is cloud forest between 1800 and $3350 \mathrm{~m}$.

Assessor: World Conservation Monitoring Centre Refs: $2989,6596,19119$

\section{Meriania crassiramis}

Melastomataceae

$\mathrm{LR} / \mathrm{nt}$

Guyana, Venezuela

A tree restricted to upland rainforest on Mount Roraima on the Venezuela-Guyana border. The area is protected but affected to some extent by tourism.

Assessor: World Conservation Monitoring Centre

Refs: 5651, 9867

Meriania cuneifolia ssp. cuneifolia

Melastomataceae

VUBI+2c

Ecuador

This subspecies is endemic to Ecuador, where it inhabits cloud forest between 1100 and $2200 \mathrm{~m}$ in Zamora. Chinchipe

Assessor: World Conservation Monitoring Centre

Refs: $2989,6596,19119$

\section{Meriania cuneifolia ssp. subandina}

Melastomataceae

VU B $1+2 c$

Ecuador

An endemic tree of Ecuador, occurring in montane cloud forest between 1100 and $2400 \mathrm{~m}$ in Zamora-Chinchipe. Assessor: World Conservation Monitoring Centre Refs: $2989,6596,19119$

\section{Meriania drakei ssp. chontalensis}

Melastomataceae

VU B $1+2 c$

Ecuador

An endemic of the Ecuadorean High Andes, this small tree inhabits montane cloud forest between 1600 and $2700 \mathrm{~m}$ in Morona-Santiago, Loja, and ZamoraChinchipe

Assessor: World Conservation Monitoring Centre

Refs: $2989,6596,19119$

\section{Meriania drakei ssp. drakei}

Melastomataceae

VU B $1+2 c$

Ecuador

An endemic tree of the Ecuadorean High Andes. This subspecies inhabits montane cloud forest between 1600 and $2700 \mathrm{~m}$ in Morona-Santiago, Loja, and ZamoraChinchipe.

Assessor: World Conservation Monitoring Centre Refs: $2989,6596,19119$

\section{Meriania furvanthera}

Melastomataceae

VU B $1+2 c$

Ecuador

A small tree of montane cloud forest, endemic to the Ecuadorean High Andes and currently only known from the provinces of Loja and Zamora-Chinchipe.

Assessor: World Conservation Monitoring Centre Refs: $2989,6596,19119$

\section{Meriania grandiflora}

Melastomataceae

VU C2a

Costa Rica, Panama

A few collections have recently been made between 1800 and $2000 \mathrm{~m}$ on the Cordillera de Talamanca, mostly within La Amistad National Park, Costa Rica. Elsewhere the species is known from Panama in the Cordillera Central in Coclé towards the west, where it occurs fairly commonly in cloud forest above $800 \mathrm{~m}$. A number of populations here are in reserves of various kinds. Where no protection exists the habitat is susceptible to clearance and conversion into agriculture.

Assessor: Mitré, M

Refs: 16772

\section{Meriania leucantha}

Melastomataceae

LR/nt

Jamaica

The species occurs in the eastern half of the island in 
moist thickets and forested areas. A variety is reported in Cuba.

Assessor: World Conservation Monitoring Centre

Refs: 6057, 7980

\section{Meriania panamensis}

Melastomataceae

$\mathrm{EN} \mathrm{BI}+2 \mathrm{c}$

Panama

Up to the present, the species has been found only in Chiniquí around Volcán Barú, where it occurs in the highest part of the country in cloud forest between 1800 and $3300 \mathrm{~m}$. There are tourism and agricultural developments in the area which may affect certain populations. Only part of the total population is contained within Banu National Park.

Assessor: Mitré, M.

Refs: $3913,7272,7980,16772$

\section{Meriania peltata}

Melastomataceae

$\mathrm{EN} \mathrm{B1+2c}$

Colombia

Endemic to Colombia, the species is recorded to Cundinamarca and Valle.

Assessor: Calderon, E.

Refs: 19069

\section{Meriania pichinchensis}

Melastomataceae

VU B $1+2 c$

Ecuador

A small tree, up to $6 \mathrm{~m}$ tall, endemic to Ecuador. This species inhabits cloud forest at an altitude of $2750 \mathrm{~m}$, and at present is only known from Sucumbíos Province. Assessor: World Conservation Monitoring Centre Refs: 2989, 19119

\section{Meriania rigida}

Melastomataceae

Ecuador

VU B $1+2 c$

An endemic tree of montane and upper montane cloud forest in the High Andes of Ecuador. The species is currently known only from the provinces of Azuay, Loja and Zamora-Chinchipe.

Assessor: World Conservation Monitoring Centre Refs: $2989,6596,19119$

\section{Meriania versicolor}

Melastomataceae

$\mathrm{CR} B 1+2 \mathrm{c}$

Colombia

Possibly now extinct, the species has been recorded only from Cundinamarca.

Assessor: Calderon, E.

Refs: 19069

\section{Merrillia caloxylon}

Rutaceae

Indonesia (Sumatra), Malaysia (Peninsular Malaysia (ex), Sabah), Thailand

Solitary trees of this monotypic genus are scattered in lowland moist primary and secondary forest on stream banks and hill sides. It has been collected only once, in Sabah from a stream bank in secondary forest in Sandakan. The durable, handsome wood has been used in the past in Peninsular Malaysia to make small implements. It is now presumed to be extinct in this region.

Assessor: World Conservation Monitoring Centre Refs: $1685,5550,17140,19017$

\section{Meryta brachypoda}

Araliaceae

$\mathrm{CR} \mathrm{B} 1+2 \mathrm{c}, \mathrm{C} 2 \mathrm{a}$

French Polynesia (Tubuai Is.), Pitcaim Islands

A shrub or tree recorded from Raivavae, Tubuai and Rapa Iti in the Tubuai Group and Henderson Island in the Pitcaim Group. The Raivavae population is in a critical state and the population on Henderson consists of fewer than six adult plants in tall forest on the northwest beach. Henderson Island is a World Heritage Site. Assessor: Florence, J.

Refs: 13604,14513

\section{Meryta choristanthe}

Araliaceae

French Polynesia (Tubuai Is.)

An endemic to Rapa Iti.

Assessor: Florence, J.

Refs: 14513

\section{Meryta drakeana}

Araliaceae

French Polynesia (Society Is.)

An endemic to Tahiti.

Assessor: Florence, J.

Refs: 14513

\section{Meryta lanceolato}

Araliaceae

LR/nt

French Polynesia (Society Is.)

Populations are recorded from Moorea and Tahiti.

Assessor: Florence, J.

Refs: 14513

\section{Meryta lucida}

Araliaceae

French Polynesia (Society Is.)

An endemic to Raiatea.

Assessor: Florence, J.

Refs: 14513

\section{Meryta mauruensis}

Araliaceae

French Polynesia (Society Is.)

An endemic to Tahiti.

Assessor: Florence, J.

Refs: 14513

\section{Meryta raiateensis}

Araliaceae

French Polynesia (Society Is.)

Populations are recorded from Bora Bora, Huahine, Raiatea and Tahaa.

Assessor: Florence, J.

Refs: 14513

\section{Meryta salicifolia}

Araliaceae

French Polynesia (Society Is.)

An endemic to Tahiti.

Assessor: Florence, J.

Refs: 14513

\section{Meryta sinclairi}

Araliaceae

VU D2

New Zealand (North Is.)

The species occurs in localised populations on the Three

Kings Islands and Whatupuke Island.

Assessor: World Conservation Monitoring Centre

Refs: 902,19133 
Meryta sonchifolia

Araliaceae

New Caledonia

VU BI $+2 \mathrm{c}$

Assessor: Jaffre, T. et al.

Refs: 10351

\section{Mesogyne insignis}

Moraceae

VU B $1+2 b$

São Tomé \& Príncipe (São Tomé), Tanzania

The bulk of the population is found in areas of moist evergreen forest on the eastem mountains of Tanzania. Another population, which shows some morphological distinctness and was originally published under the name of $M$. henriquesii, occurs on the island of Sāo Tome. The population here is small and found in areas which were forest at the tum of the century but are now cultivated or secondary forest. The genus is monospecific.

Assessor: World Conservation Monitoring Centre

Refs: $8814,10080,11631$

\section{Mesua kochummenia}

Guttiferae

VU B $1+2 \mathrm{c}$

Malaysia (Peninsular Malaysia)

Confined to lowland forest in south-east Johore and south-east Pahang, the species occurs in areas which are earmarked for development. It is also reported to be present in Endau Rompin National Park.

Assessor: Kochummen, K.M.

Refs: 17140,19073

\section{Mesua manii}

Guttiferae

India (Andaman and Nicobar Is. - Andaman Is.)

A small tree of evergreen rainforest, endemic to South Andaman Island.The habitat has been severely deforested and no living specimens have been found since the type collection. It is possible that a population exists in the relatively intact Jarwa Reserve.

Assessor: World Conservation Monitoring Centre

Refs: 4799,7147

\section{Mesua purseglovei}

Guttiferae

Malaysia (Peninsular Malaysia)

A montane forest tree known only from a single collection from $1500 \mathrm{~m}$ in the Cameron Highlands, Pehang. The species is thought to be locally common. There are protected forests in the Cameron Highlands, but some areas are also given over to tea plantations.

Assessor: World Conservation Monitoring Centre

Refs: 8464, 19073

\section{Mesua rosea}

Guttiferae

$\mathrm{LR} / \mathrm{cd}$

Malaysia (Peninsular Malaysia)

A lowland forest species, known from only a few localities in south-east Johore. Lowland areas in this state have largely been converted to agriculture. Protected populations are found in Gunong Panti Forest Reserve and Gunung Belumut. The genus is currently undergoing revision.

Assessor: Kochummen, K.M.

Refs: 17140,19073

\section{Mesua stylosa}

Guttiferae

CR Alc, B1+2c, D1

Sri Lanka

Restricted to swamp forest in the westem lowlands of
Sri Lanka, this ironwood tree is threatened because its habitat is being converted for rice cultivation. In the recent National Conservation Review forest survey, only four individuals were discovered in a single locality. Assessor: World Conservation Monitoring Centre Refs: 15431, 18796, 19104, 19112

\section{Metaporana obtusa \\ Convolvulaceae}

Yemen (Socotra)

An unusually arborescent member of Convolvulaceae. Populations are confined to scattered individuals along wadis in the dry west side of the island. It is one of the only trees to remain green during the dry season and the leaves provide an important browse for livestock.

Assessor: Miller, A.G.

Refs: 2354,19083

\section{Metasequoia glyptostroboides}

Taxodiaceae

China (Hubei, Hunan, Sichuan)

Confined to slightly waterlogged areas of open forest, the species is known from sites in Shizhu in Sichuan, Lichuan in Hubei and Longshan and Sangzhi in Hunan. The subpopulations appear to have been reduced to a few mature individuals. Surrounding areas are heavily cultivated and there are poor prospects for natural regeneration. All large trees are protected but the habitat is not.

Assessor: SSC Conifer Specialist Group

Refs: 1818,11847

\section{Metatrophis margaretae}

Moraceae

DD

French Polynesia (Tubuai Is.)

Assessor: Florence, J.

Refs: 14513

\section{Meteoromyrtus wynaadensis}

Myrtaceae

$\mathrm{CR} B 1+2 \mathrm{C}$

India (Tamil Nadu)

A small tree from a monotypic genus. The only remaining population apparently occurs at Theerthundamala in Cannanore District, where its habitat is steadily declining. The populations in Wynnad and Nilgiri Hills in Tamil Nadu are thought to have been destroyed.

Assessor: World Conservation Monitoring Centre

Refs: 4799,19144

\section{Metrosideros bartlettii}

Myrtaceae

EN D1

New Zealand (North Is.)

A large tree, first discovered in 1975 near Cape Reinga. At present, the entire known population comprises 30 trees at three sites. The species is associated with streamsides or wetlands, a distribution which probably reflects land clearance pattems rather than a genuine preference. It favours dense forest, where it germinates in the the crowns of canopy trees such as Vitex lucens and Beilschmiedia taraire. Further occurrences are expected to be discovered and recovery work is under way to ensure the survival of known populations. There is particular pressure from browsing pigs, possums and livestock. Although widely cultivated, most ex situ plantings are derived from a single tree.

Assessor: de Lange, P.J.

Refs: $902,9800,19133,19134$ 


\section{Metrosideros humboldriana}

Myrtaceae

LR/cd

New Caledonia

A bushy shrub or tree occurring in the high-altitude maquis of various ultramafic massifs in the south, including Mont Humboldt, Pic du Rocher, Montagne des Sources. The latter is a Strict Nature Reserve and provides effective protection for the population.

Assessor: Jaffré, T. et al.

Refs: 10351,12630

\section{Metrosideros ochrantha}

Myrtaceae

VU D2

Fiji

This small tree is restricted to Mount Kasi and its vicinity, Vanua Levu. Only the type collection is known. It occurs in dense low forest between 300 and $430 \mathrm{~m}$. Assessor: World Conservation Monitoring Centre Refs: 18818

\section{Metrosideros polymorpha var. newellii} Myrtaceae

VU Alce

USA (Hawaii)

This variety represents the most threatened of about eight varieties of this widely dominating and variable Hawaiian endemic. It is restricted to remaining forms of forest and shrubland, usually along watercourses, from low to middle elevation on Hawaii.

Assessor: World Conservation Monitoring Centre

Refs: 3372

\section{Metrosideros punctata}

Myrtaceae

New Caledonia

VU $B 1+2 c$

A bushy shrub or small tree which is well represented in the southern ultramafic massifs and also on isolated massifs in the north. It occurs in low forest or maquis. In many places the habitat is degraded and exposed to threats of mining, fires and clearance.

Assessor: Jaffré, T. et al.

Refs: 10351,12630

\section{Metroxylon amicarum}

Palmae

VU D2

Federated States of Micronesia

A palm tree endemic to Ponape and Truk in the Caroline Islands. This scarce species is found in moist forest up to $550 \mathrm{~m}$ in mountainous areas which are remote and unattractive for settlement.

Assessor: Johnson, D.

Refs: 19118

\section{Metteniusa cundinamarcensis}

Icacinaceae

VU $B 1+2 c$

Colombia

Metteniusa is a small genus of trees, endemic to northwest South America. This species is recorded from Cundinamarca.

Assessor: Calderon, E.

Refs: 19069

\section{Metteniusa edulis}

Icacinaceae

VU B $1+2 c$

Colombia

Metteniusa is a small genus of trees, endemic to northwest South America. This species is recorded from Guajira.

Assessor: Calderon, E.

Refs: 19069

\section{Metteniusa huilensis}

Icacinaceae

VU B1 $+2 c$

Colombia

Metteniusa is a small genus of trees, endemic to northwest South America. This species is recorded from Huila.

Assessor: Calderon, E.

Refs: 19069

\section{Metteniusa santanderensis}

Icacinaceae

VU $B 1+2 c$

Colombia

Metteniusa is a small genus of trees, endemic to northwest South America. This species is recorded from Santander

Assessor: Calderon, E.

Refs: 19069

\section{Mezilaurus itauba}

Lauraceae

VU Ala

Bolivia, Brazil, Ecuador, French Guiana, Peru, Suriname Assessar: Americas Regional Workshop Refs: $6493,7957,12109,14291,15478,15714,19179$

\section{Mezilaurus navalium}

Lauraceae

Brazil

VU Alac

Assessor: Pedralli, G.

Refs: 19098,19142

\section{Mezzettia herveyana}

Annonaceae

$\mathrm{CR} B 1+2 \mathrm{c}$

Malaysia (Peninsular Malaysia)

Known only from a single collection found in lowland forest in Malacca, it is uncertain if this species still exists.

Assessor: Kochummen, K.M

Refs: 19073

\section{Michelia aenea}

Magnoliaceae

China (Yunnan), Viet Nam

Assessor: Sun, W.

Refs: $9274,11530,19174$

\section{Michelia coriacea}

Magnoliaceae

China (Yunnan)

$\mathrm{EN} \mathrm{Bl}+2 \mathrm{c}$

The species is known only from Xichou in the southeast.

Assessor: Sun, W

Refs: 19138,19174

\section{Michelia hypolampra}

Magnoliaceae VUAlc

China (Guangdong - Hainan, Guangxi, Yunnan)

Scattered occurrences are known from Hainan Island, southern Yunnan and south-west Guangxi. They are restricted to remaining areas of lowland monsoon forest, which have been severely reduced by high rates of habitat clearance and logging. The species has some value as a source of medicine and condiment. Assessor: World Conservation Monitoring Centre Refs: $1818,9274,11847$ 


\section{Michelia ingrata}

Magnoliaceae

$\mathrm{EN} \mathrm{B1}+2 \mathrm{c}$

China (Yunnan)

Assessor: Sun, W.

Refs: 19138,19174

\section{Michelia odora}

Magnoliaceae

LR/nt

China (Fujian, Guangdong, Guangdong - Hainan, Guangxi, Guizhou, Hunan, Jiangxi, Yunnan), Viet Nam

Previously known under the monotypic genus Tsoongiodendron, this species is relatively widespread in lowland moist forest within an area extending from southern China to northern Viet Nam. Population declines have occurred because of extensive logging and habitat clearance. Mature trees are said to be only rarely encountered.

Assessor: World Conservation Monitoring Centre

Refs: $1818,9274,11530,11847$

\section{Michelia punduana}

Magnoliaceae

VU $B 1+2 c$

India (Meghalaya, Nagaland)

A species of open sunny places in moist forest in northeast India. There have been no recent collections and both the species and its habitat are in decline because of overexploitation of the timber resources.

Assessor: World Conservation Monitoring Centre Refs: 2538

\section{Michelia wilsoni}

Magnoliaceae

China (Hubei, Sichuan)

$\mathrm{EN} B$

A species restricted to mountainous areas on the south to west fringe of the Sichuan basin and Lichuan in western Hubei. It occurs in moist broadleaved forest between 700 and $1600 \mathrm{~m}$. Uncontrolled logging and habitat clearance are believed to have caused considerable population declines.

Assessor: World Conservation Monitoring Centre

Refs: $1818,9274,11242,11847$

\section{Michelia xanthantha}

Magnoliaceae

$\mathrm{EN} \mathrm{B} 1+2 \mathrm{c}$

China (Yunnan)

An endemic to Xishuangbanna.

Assessor: Sun, W.

Refs: 19138,19174

\section{Miconia abbreviata}

Melastomataceae

$\mathrm{LR} / \mathrm{nt}$

Peru

Relatively widespread, the species is endemic to lowland forests of Peru.

Assessor: World Conservation Monitoring Centre

Refs: 1984

\section{Miconia aligera}

Melastomataceae

Peru

VU B $1+2 \mathrm{c}$

This species appears to be confined to Andean cloud forest above $2000 \mathrm{~m}$ in the department of Cuzco.

Assessor: World Conservation Monitoring Centre Refs: 1984

\section{Miconia alpina}

Melastomataceae

VU Bl $+2 c$

Peru

Occurring above $3500 \mathrm{~m}$, the species is recorded from areas of forest in the departments of Ancash, Cuzco and Huánuco.

Assessor: World Conservation Monitoring Centre Refs: 1984

\section{Miconia aspratilis}

Melastomataceae

VU B $1+2 c$

Ecuador

This small tree is endemic to the High Andes of Ecuador, currently known only from areas of cloud forest, between 2700 and $3400 \mathrm{~m}$, in Azuay Province. Assessor: World Conservation Monitoring Centre Refs: 19119,19120

\section{Miconia ayacuchensis \\ Melastomataceae \\ Pen \\ A species which is known from *elfin forest in the department of Ayacucho. \\ Assessor: World Conservation Monitoring Centre \\ Refs: 1984}

VU B $1+2 c$

\section{Miconia bailloniana}

Melastomataceae

Peru

Endemic to Peru, the species occurs relatively widely in forest up to $2000 \mathrm{~m}$.

Assessor: World Conservation Monitoring Centre Refs: 1984

\section{Miconia barbipilis}

Melastomataceae

Ecuador

A shrub or tree up to $3 \mathrm{~m}$ tall, endemic to the High Andes of Ecuador and currently known from cloud forest, between 2250 and $3450 \mathrm{~m}$, in the province of Morona-

Santiago.

Assessor: World Conservation Monitoring Centre

Refs: $2989,6596,19119$

\section{Miconia beneolens}

Melastomataceae

$\mathrm{VU} B 1+2 \mathrm{c}$

Ecuador

An endemic tree to Loja Province in the Ecuadorean

High Andes, inhabiting cloud forest between $1500 \mathrm{~m}$ and $3000 \mathrm{~m}$.

Assessor: World Conservation Monitoring Centre

Refs: $2989,6596,19119,19120$

\section{Miconia bipatrialis}

Melastomataceae

VU B1+2c

Ecuador

A shrub or tree endemic to Azauy Province in the High Andes of Ecuador, where it inhabits montane cloud forest between 2400 and $3000 \mathrm{~m}$.

Assessor: World Conservation Monitoring Centre Refs: $2989,6596,19119,19120$

\section{Miconia brevistylis}

Melastomataceae

VU B $1+2 \mathrm{c}$

Peru

Presently known only from the department of Huánuco, the species occurs in forest and shrubland between 1500 and $2000 \mathrm{~m}$.

Assessor: World Conservation Monitoring Centre Refs: 1984 
Miconia caesariata

Melastomataceae

Ecuador

A species of tree or shrub, endemic to the Ecuadorean

Andes, where it is confined to the area of the Sangay

National Park. The development of a road through the park threatens the integrity of the forest habitats.

Assessor: World Conservation Monitoring Centre

Refs: 5651,19119

\section{Miconia cajanumana}

Melastomataceae

VU B $1+2 c$

Ecuador

An endemic of the Ecuadorean High Andes, currently known to occur in areas of cloud forest, between 2200 and $3200 \mathrm{~m}$, in the provinces of El Oro, Loja and Zamora-Chinchipe.

Assessor: World Conservation Monitoring Centre

Refs: $2989,6596,19119,19120$

\section{Miconia calophylla}

Melastomataceae

VU B $1+2 c$

Peru

A species recorded from forest between 2000 and $2500 \mathrm{~m}$ in the department of Pasco.

Assessor: World Conservation Monitoring Centre

Refs: 1984

\section{Miconia campii}

Melastomataceae

VU B $1+2 \mathrm{c}$

Ecuador

A shrub or tree endemic to the High Andes of Ecuador. Currently the species is known only from the montane and upper montane cloud forest of Morona-Santiago and Azuay.

Assessor: World Conservation Monitoring Centre

Refs: $2989,6596,19119,19120$

\section{Miconia castillensis}

Melastomataceae

VU $B 1+2 c$

Ecuador

An endemic of the Ecuadorean High Andes, occurring in montane and upper montane cloud forest in MoronaSantiago, Azuay and Loja.

Assessor: World Conservation Monitoring Centre

Refs: $2989,6596,19119,19120$

\section{Miconia castrensis}

Melastomataceae

VU B $1+2 \mathrm{c}$

Ecuador

A species of montane cloud forest, confined to Azuay

Province in the Ecuadorean High Andes.

Assessor: World Conservation Monitoring Centre

Refs: 19119,19120

\section{Miconia centrosperma}

Melastomataceae

Panama

EN C1

Occurring in lowland forest or woodlands, the species is found in small localities along the road from El Llano to Cartí-Tupile in Kunayala Indigenous Reserve. Other undetermined collections, suspected to be this species, come from the east, including some from Chagres National Park and Kunayala Indigenous Reserve. Within the confirmed range the forest continues to be destroyed by settlement, agriculture, farming and buming.

Assessor: Mitré, $\mathrm{M}$.

Refs: $6626,7980,16772$

\section{Miconia cuprea}

Melastomataceae

VU $B 1+2 c$

Ecuador

This endemic tree of Ecuador inhabits montane and upper montane cloud forest in the High Andean areas of Azuay Province.

Assessor: World Conservation Monitoring Centre

Refs: 19119,19120

\section{Miconia demissifolia}

Melastomataceae

VU $B 1+2 c$

Peru

A tree of montane forest above $3000 \mathrm{~m}$, recorded in the departments of Cuzco and Pasco.

Assessor: World Conservation Monitoring Centre Refs: 1984

\section{Miconia dissimulans}

Melastomataceae

VU B $1+2 c$

Ecuador

An Ecuadorean endemic of the High Andes, inhabiting cloud forest between 2300 and $2800 \mathrm{~m}$ in the provinces of Loja and Zamora-Chinchipe.

Assessor: World Conservation Monitoring Centre Refs: $2989,6596,19119,19120$

\section{Miconia dodsoni}

Melastomataceae

VU B1+2c

\section{Ecuador}

A tree or shrub which is narrowly endemic to the southern High Andes of Ecuador.

Assessor: World Conservation Monitoring Centre Refs: $2989,6596,19119,19120$

\section{Miconia floccosa \\ Melastomataceae}

VU Bl+2c

Pen

This species occurs in grassland areas between 2500 and $3500 \mathrm{~m}$ in the departments of Junin and Pasco.

Assessor: World Conservation Monitoring Centre Refs: 1984

\section{Miconia glandulistyla}

Melastomataceae

VU B1+2c

Ecuador

This Ecuadorean endemic inhabits cloud forest between 1600 and $3350 \mathrm{~m}$, in the High Andean areas of MoronaSantiago and Zamora-Chinchipe.

Assessor: World Conservation Monitoring Centre Refs: $2989,6596,19119,19120$

\section{Miconia glyptophylla}

Melastomataceae

VU B $1+2 c$

Ecuador

An endemic tree of the Ecuadorean High Andes. The species can be found in cloud forest between 2550 and $2750 \mathrm{~m}$ in the province of Azuay.

Assessor: World Conservation Monitoring Centre Refs: 19119,19120

\section{Miconia griffisii}

Melastomataceae

VU B1+2c

Peru

A species occurring in montane forest above $3500 \mathrm{~m}$ in the departments of Huánuco and San Martin.

Assessor: World Conservation Monitoring Centre Refs: 1984 


\section{Miconia hexamera}

Melastomataceae

Ecuador

An endemic tree of the Ecuadorean High Andes, inhabiting cloud forest between $2550 \mathrm{~m}$ and $3350 \mathrm{~m}$ in Morona-Santiago, Cañar, Azuay and Zamora-Chinchipe. Assessor: World Conservation Monitoring Centre Refs: 19119,19120

\section{Miconia huigrensis}

Melastomataceae

$\mathrm{VU} \mathrm{Bl}+2 \mathrm{c}$

Ecuador

Endemic to Ecuador this species inhabits cloud forest between $1500 \mathrm{~m}$ and $3400 \mathrm{~m}$. Currently it is known only from the High Andean areas of Bolivar, Chimborazo and Azuay.

Assessor: World Conservation Monitoring Centre Refs: $2989,6596,19119,19120$

\section{Miconia lachnoclada}

Melastomataceae

$\mathrm{VU} B 1+2 \mathrm{c}$

Peru

Known only from the department of Ayacucho, the species occurs in forest on rocky slopes above $3500 \mathrm{~m}$. Assessor: World Conservation Monitoring Centre Refs: 1984

\section{Miconia mediocris}

Melastomataceae

Ecuador

VU B $1+2 c$

An endemic of the Ecuadorean High Andes, inhabiting cloud forest between 1000 and $3350 \mathrm{~m}$ in Pichincha and Azuay Provinces.

Assessor: World Conservation Monitoring Centre

Refs: $2989,6596,19119,19120$

\section{Miconia monzoniensis ssp. cuzcoensis}

Melastomataceae

VU B $1+2 c$

Peru

This subspecies occurs in forest roughly between 2500 and $3000 \mathrm{~m}$ in the departments of Cuzco and Pasco. Assessor: World Conservation Monitoring Centre Refs: 1984

\section{Miconia namandensis}

Melastomataceae

VU B $1+2 c$

Ecuador

An endemic tree of the Ecuadorean High Andes, inhabiting cloud forest between 1500 and $3200 \mathrm{~m}$ in Loja and Zamora-Chinchipe Provinces.

Assessor: World Conservation Monitoring Centre

Refs: $2989,6596,19119,19120$

\section{Miconia nubicola}

Melastomataceae

Jamaica

$\mathrm{EN} \mathrm{B} 1+2 \mathrm{c}$

A small tree or shrub of mossy montane woodland. It is recorded only from St Thomas Parish between 1830 and $2000 \mathrm{~m}$.

Assessor: Kelly, D.L.

Refs: 401, 5653, 7980, 19085

\section{Miconia pausana}

Melastomataceae

VU B $1+2 c$

Ecuador

A small tree, 5-6m tall, endemic to the High Andes of
Ecuador, where it is confined to cloud forest at $2400 \mathrm{~m}$ in Azuay Province.

Assessor: World Conservation Monitoring Centre

Refs: 19119,19120

\section{Miconia penningtonii}

Melastomataceae

VU B $1+2 c$

Ecuador

An endemic tree of the Ecuadorean High Andes, inhabiting cloud forest between 2800 and $3500 \mathrm{~m}$ in Napo and Pichincha Provinces.

Assessor: World Conservation Monitoring Centre

Refs: 19119,19120

\section{Miconia perelegans}

Melastomataceae

VU Bl+2c

Cuba

An uncommon endemic shrub or small tree, restricted to savanna in northem Isla de Pinos. Most of the original habitat in Pinus tropicalis forest has been converted into pastures.

Assessor: Areces-Mallea, A.E.

Refs: 11403, 18485, 19149

\section{Miconia poecilantha}

Melastomataceae

$\mathrm{EN} B 1+2 \mathrm{c}$

Colombia

An endemic to Cundinamarca.

Assessor: Calderon, E.

Refs: 19069

\section{Miconia poortmannii}

Melastomataceae

VU B1+2c

Ecuador

Endemic to Ecuador, this species is found in areas of cloud forest between 1000 and $2400 \mathrm{~m}$ in the High Andes of El Oro Province.

Assessor: World Conservation Monitoring Centre Refs: $2989,6596,19119,19120$

\section{Miconia pseudorigida}

Melastomataceae

$\mathrm{EN} \mathrm{B1}+2 \mathrm{c}$

Jamaica

A very uncommon small tree or shrub of mossy woodlands on limestone, recorded only from Portland Parish between 450 and $760 \mathrm{~m}$.

Assessor: Kelly, D.L.

Refs: 5653, 19085

\section{Miconia quadrangularis var. glandulosa}

Melastomataceae

EN B $1+2 c$ Jamaica

The species is endemic to Jamaica. This variety is confined to Portland Parish, where it occurs in mossy woodland on limestone between 450 and $600 \mathrm{~m}$. Assessor: World Conservation Monitoring Centre Refs: $401,5653,7980$

\section{Miconia rimbachii}

Melastomataceae

VU B $1+2 c$

Ecuador

Currently known to occur only in the High Andean areas of Bolivar Province, Ecuador. The habitat of this species is cloud forest between 2400 and $2600 \mathrm{~m}$.

Assessor: World Conservation Monitoring Centre Refs: $2989,6596,19119,19120$ 


\section{Miconia santaritensis}

Melastomataceae

Panama

Confined to the central region of Panama, extending a little to the east, the species occurs in lowland semideciduous rainforest. It appears to be fairly common in Santa Rita, Colón, becoming rarer in other localities. Parts of the range come under heavy pressure from increasing settlement of the area and related activities.

Assessor: Mitré, M.

Refs: $6626,7980,16772$

\section{Miconia setulosa}

Melastomataceae

VU Bl $+2 c$

Peru

Apparently restricted to the departments of Cuzco and Puno, the species occurs in forest between roughly 2500 and $4000 \mathrm{~m}$.

Assessor: World Conservation Monitoring Centre Refs: 1984

\section{Miconia silicicola}

Melastomataceae

Guyana, Venezuela

$\mathrm{LR} / \mathrm{nt}$

Confined to south Venezuela and south Guyana, this species is found in scrub forest and on the summit of sandstone mountains in the vicinity of Roraima. The area is protected but under some pressure from tourism. Assessor: World Conservation Monitoring Centre Refs: 9867

\section{Miconia sodiroi}

Melastomataceae

Ecuador

An endemic of Ecuador's High Andean region, at present known oniy to occur in Pichincha Province. The habitat of this species is cloud forest between 1800 and $2600 \mathrm{~m}$.

Assessor: World Conservation Monitoring Centre

Refs: 2989, 6596, 19119, 19120

\section{Miconia superba}

Melastomataceae

Guyana, Venezuela

A montane species found in rainforest on the slopes of Mount Roraima on the border of Venezuela and Guyana. The area is protected but under some pressure from tourism.

Assessor: World Conservation Monitoring Centre Refs: 9867

\section{Miconia thaminantha ssp. thaminantha}

Melastomataceae

VU B $1+2 c$

Peru

A subspecies of cloud forest to $2500 \mathrm{~m}$, known only from the department of Cuzco.

Assessor: World Conservation Monitoring Centre Refs: 1984

\section{Miconia villonacensis}

Melastomataceae

VU Bl+2c

Ecuador

An endemic to Loja Province in the Ecuadorean High Andes, inhabiting cloud forest between 2600 and $2950 \mathrm{~m}$.

Assessor: World Conservation Monitoring Centre

Refs: $2989,6596,19119,19120$
Microberlinia bisulcata

Leguminosae

CR Alc

Cameroon, Nigeria

A valuable timber species endemic to remaining areas of coastal evergreen forest in Cameroon, apparently extending to the Oban Hills in south-east Nigeria. Largescale habitat decline and exploitation have caused population declines. Populations are protected in Korup National Park, Cameroon and Cross River National Park, Nigeria. The species has ectomycorrhizal properties.

Assessor: African Regional Workshop

Refs: $2773,4977,5595,6718,13013$

\section{Microberlinia brazzavillensis}

Leguminosae

VU Alc

Cameroon, Congo, Gabon

A speciality timber tree, restricted to areas of coastal forest in Gabon, and neighbouring Congo. Populations in many places are small and scattered, with less than one individual per $\mathrm{km}^{2}$. Logging is currently not heavy and populations appear to be stable in areas of Gabon.

The Cameroon occurrence is doubtful.

Assessor: World Conservation Monitoring Centre

Refs: $1332,7550,15790,17408,19043$

\section{Microbiota decussata}

Cupressaceae

DD

Former USSR (Khabarovsk, Primorski)

The present limited data suggest the species is endemic to an area near the Suchan River in Skihote Alin Province.

Assessor: SSC Conifer Specialist Group

Refs: 1956, 13041

\section{Micrococca scariosa}

Euphorbiaceae

VU B $1+2 b$

Kenya, Tanzania

Restricted to dry coastal forest in limestone areas, the species ranges from Pangani and Gongoni in south-east Kenya, through eastern Tanzania to Zanzibar.

Assessor: Lovett, J. \& G.P. Clarke

Refs: $3356,5654,6396$

\section{Microcos erythrocarpa}

Tiliaceae

Malaysia (Peninsular Malaysia)

VU D2

An uncommon tree in the lowland and hill forests of Fraser's Hill and the Genting Highlands. Both areas are threatened by the encroachment of settlements and tourism.

Assessor: Chung, R.C.K.

Refs: 19073

\section{Microcos globulifera}

Tiliaceae

Malaysia (Peninsular Malaysia)

VU B1+2c

Confined to lowland moist forest on the west coast from Perak to Johore, this tree is threatened by urban encroachment and habitat clearance.

Assessor: Chung, R.C.K.

Refs: 19073 


\section{Microcos laurifolia}

Tiliaceae

Malaysia (Peninsular Malaysia)

A tree of lowland rainforest widespread within Peninsular Malaysia.

Assessor: Chung, R.C.K.

Refs: 19073

\section{Micropholis brochidodroma}

Sapotaceae

$\mathrm{VUB} 1+2 \mathrm{c}$

Peru

A newly described tree known only from Loreto, where it occurs in forest over white sand at altitiudes between 150 and $200 \mathrm{~m}$.

Assessor: World Conservation Monitoring Centre

Refs: 7980,8816

\section{Micropholis casiquiarensis}

Sapotaceae

LR/nt

Brazil (Amazonas, Pará), Venezuela

Only a few collections have been made of this species, which appears to be scattered sparsely from southem Venezuela to central Brazilian Amazonia in non-flooded forest over clay up to medium elevation.

Assessor: World Conservation Monitoring Centre Refs: 7980,8816

\section{Micropholis caudata}

Sapotaceae

CR B I+2d, D

Brazil (Amazonas)

A newly described species of non-flooded Amazonian forest, so far known only from the Manaus to Porto Velho road where the type was collected.

Assessor: Pires O'Brien, J.

Refs: $1983,7980,8816$

\section{Micropholis compta}

Sapotaceae

VU B $1+2 c$

Brazil (Bahia, Rio de Janeiro)

A tree known from a few scattered sites of coastal rainforest.

Assessor: Pires O'Brien, J.

Refs: $1983,7980,8816$

\section{Micropholis crassipedicellata}

Sapotaceae

LR/cd

Brazil (Bahia, Espínto Santo, Rio de Janeiro, São Paulo)

A coastal forest species, ranging from Bahia southwards

to São Paulo. The species habitat has suffered greatly

from intensive logging. A population occurs in Linhares

Forest Reserve.

Assessor: Pires O'Brien, J.

Refs: 1983, 7980, 8816

\section{Micropholis cylindrocapa}

Sapotaceae

LR/nt

Brazil (Amazonas), Peru

Ranging from western Brazilian Amazonia to Loreto in Peru the species occurs in lowland forest, usually in areas which are not flooded.

Assessor: World Conservation Monitoring Centre

Refs: 7980,8816

\section{Micropholis emarginata}

Sapotaceae

$\mathrm{EN} \mathrm{B} 1+2 \mathrm{c}$

Brazil (Bahia)

A shrub or small tree, restricted in distribution to areas of * campo rupestre on sandstone outcrops. Overcutting is a particular threat.

Assessor: Pires O'Brien, J.

Refs: $1983,7980,8816$

\section{Micropholis garciniifolia}

Sapotaceae

LR/nt

Puerto Rico

Endemic to Puerto Rico, the species is a common upper storey component of old secondary and undisturbed submontane forest in the Sierra de Naguabo and Luquillo Mountains.

Assessor: World Conservation Monitoring Centre Refs: 7980,8816

\section{Micropholis gnaphaloclados}

Sapotaceae

LR/nt

Brazil (Bahia, Espírito Santo, Mato Grosso, Pernambuco)

A tree of submontane ${ }^{*}$ cerrado, ${ }^{*}$ caatinga and rocky outcrops. It ranges from Pernambuco to Mato Grosso but the populations appear to be highly fragmented.

Assessor: Pires O'Brien, J.

Refs: $1983,7980,8816$

\section{Micropholis grandiflora}

Sapotaceae

CR B $1+2 c$

Brazil (Amazonas)

A single collection of the species is known, originating from Neblina National Park on the Brazilian side.

Assessor: Pires O'Brien, J.

Refs: $1983,7980,8816$

\section{Micropholis humboldtiana}

Sapotaceae

LR/nt

Brazil (Amazonas), Venezuela

A species of *igapó forest and periodically flooded savanna from the lower Rio Negro in Amazonas.

Assessor: World Conservation Monitoring Centre Refs: 7980,8816

\section{Micropholis macrophylla}

Sapotaceae

CR B $1+2 \mathrm{c}$

Perv

The type, which was collected in the first part of the century from an altitude of $1200 \mathrm{~m}$ in Loreto, is the only record of this species.

Assessor: World Conservation Monitoring Centre Refs: 7980,8816

\section{Micropholis madeirensis}

Sapotaceae

LR/nt

Brazil (Amazonas), Peru

A lowland rainforest species distributed in central and western Amazonian Brazil and in Loreto in Peru. Assessor: World Conservation Monitoring Centre Refs: 7980,8816

\section{Micropholis maguirei}

Sapotaceae

LR/nt

Brazil (Amazonas), Venezuela

Occurring in non-flooded lowland rainforest, the species is confined to a small area of southern Amazonas in Venezuela and neighbouring Brazil.

Assessor: World Conservation Monitoring Centre Refs: 7980,8816 


\section{Micropholis polita}

Sapotaceae

VU B $1+2 \mathrm{c}$

Cuba

A Cuban endemic confined to montane rainforests in Oriente Province. This species has suffered from overcutting.

Assessor: Areces-Mallea, A.E.

Refs: $7980,8816,19149$

\section{Micropholis resinifera}

Sapotaceae

VU $B l+2 b$

Brazil (Amazonas)

Possibly not distinct from $M$. guyanensis, the species is known only from a few collections which have come from non-flooded highland and lowland forest. The wood is said to be good quality but in too small a quantity to be commercially valuable.

Assessor: Pires O'Brien, J.

Refs: $1983,7980,8816$

\section{Micropholis retusa}

Sapotaceae

EN B1+2b

Brazil (Amazonas)

A lowland rainforest tree, known only from the type collection from the north-west of the Brazilian Amazon. Assessor: Pires O'Brien, J.

Refs: $1983,7980,8816$

\section{Micropholis rugosa}

Sapotaceae

LR/nt

Jamaica

Occurring in central and western parishes, the species has a sporadic distribution, mostly in open situations on limestone hills.

Assessor: World Conservation Monitoring Centre

Refs: $6057,7980,8816$

\section{Micropholis spectabilis}

Sapotaceae

VU D2

Venezuela

So far this species has been recorded only from the site where it was first collected in submontane rainforest north-east of Luepa in Bolívar.

Assessor: World Conservation Monitoring Centre

Refs: 7980,8816

\section{Micropholis splendens}

Sapotaceae

LR/nt

Brazil (Amazonas), Venezuela

A species known only with certainty from southem Amazonas in Venezuela and adjacent Brazil. Tentative occurrences have been recorded from French Guiana and Amapá in Brazil.

Assessor: World Conservation Monitoring Centre Refs: 7980,8816

\section{Micropholis submarginalis}

Sapotaceae

$\mathrm{EN} \mathrm{B} 1+2 \mathrm{~b}$

Brazil (Amazonas)

A newly described tree, so far known only from the type collection in non-flooded forest over sand in central Brazilian Amazonia.

Assessor: World Conservation Monitoring Centre Refs: 7980,8816

\section{Micropholis suborbicularis}

Sapotaceae

$\mathrm{LR} / \mathrm{nt}$

Venezuela

In Bolívar and Amazonas, this small tree or shrub occurs in bush islands in the savanna or dwarf forest along watercourses between 1300 and $2000 \mathrm{~m}$.

Assessor: World Conservation Monitoring Centre

Refs: 7980,8816

\section{Micropholis venamoensis}

Sapotaceae

Venezuela

VU D2

This species is respresented by two herbarium specimens, collected from wet montane mossy forest on or near Cerro Venamo in Bolívar.

Assessor: World Conservation Monitoring Centre

Refs: 7980,8816

\section{Micropholis williami}

Sapotaceae

LR/cd

Brazil (Amazonas, Pará)

A species of scattered occurrence in non-flooded forest on clay soil. It is known to occur in the Ducke Forest

Reserve.

Assessor: Pires O'Brien, J.

Refs: $1983,8816,12109$

\section{Microstrobos fitzgeraldit}

Podocarpaceae

Australia (New South Wales)

EN C2a

A dwarf conifer, usually decumbent, confined to moist montane scrub in an area between Wentworth Falls and Katoomba Falls in the Blue Mountains. A count has been made of seven populations containing $\mathbf{4 5 5}$ individuals. Populations are declining because of a number of factors, including competition with invasive plants and poor recruitment prospects on the sheltered unstable cliffs and waterfall ledges where the species occurs. Urban development is also threatening the catchment area of the site. The genus contains only one other species, which is endemic to Tasmania.

Assessor: SSC Conifer Specialist Group

Refs: 10808,17200

\section{Microtropis argentea}

Celastraceae

VU D2

Malaysia (Sarawak)

Found in *kerangas forest on a plateau in Belaga, this small tree is known only from a single collection.

Assessor: World Conservation Monitoring Centre Refs: 19017

\section{Microtropis borneensis}

Celastraceae

VU D2

Malaysia (Sabah, Sarawak)

A shrub or small tree locally abundant on Mount Kinabalu, Sabah, where it grows in *kerangas and montane forest up to an altitude of $2400 \mathrm{~m}$. In Sarawak, it is known only from a single collection found in the Lambir National Park.

Assessor: World Conservation Monitoring Centre Refs: 19017

\section{Microtropis densiflora}

Celastraceae

EN B $1+2 c$

India (Tamil Nadu)

A small tree, known only from a single imprecisely recorded location in the Nilgiri Hills.

Assessor: World Conservation Monitoring Centre Refs: 19144 
Microtropis fascicularis

Celastraceae

VU D2

Malaysia (Sarawak)

Known only from five collections, this uncommon small tree is found in mixed dipterocarp forest and *kerangas forest, usually growing near streams, up to $500 \mathrm{~m}$.

Assessor: World Conservation Monitoring Centre

Refs: 19017

\section{Microtropis grandifolia var. grandifolia}

Celastraceae

VU D2

Malaysia (Sarawak)

Endemic to Sarawak, this variety of lowland and hill forest is so far known from only two specimens, one collected from Bukit Panjo of Lundu and the other from Lubok Antu.

Assessor: World Conservation Monitoring Centre

Refs: 19017

\section{Microtropis grandifolia var. Longipetiolatus}

\section{Celastraceae}

VU D2

Malaysia (Sarawak)

A variety known from the type collection only.

Assessor: World Conservation Monitoring Centre

Refs: 19017

\section{Microtropis keningauensis}

Celastraceae

VU D2

Malaysia (Sabah)

This uncommon shrub or small tree is known only from the lowland forest of Lanas, Keningau.

Assessor: World Conservation Monitoring Centre

Refs: 19017

\section{Microtropis rigida}

Celastraceae

VU D2

Malaysia (Sarawak)

Endemic to Sarawak, this small tree of lowland and submontane forest is known only from Bako National Park, Gunung Santubong and Mulu National Park. Assessor: World Conservation Monitoring Centre

Refs: 19017

\section{Microtropis sabahensis}

Celastraceae

Malaysia (Sabah)

Endemic to Sabah, this small tree is known only from the type specimen collected from Kinabatangan in lowland and seasonal swamp forest.

Assessor: World Conservation Monitoring Centre

Refs: 19017

\section{Microtropis sarawakensis}

Celastraceae

VU D2

Malaysia (Sarawak)

Endemic to Sarawak, this small tree has been collected only once in lowland forest near streams.

Assessor: World Conservation Monitoring Centre

Refs: 19017

\section{Microtropis tenuis}

Celastraceae

VU D2

Malaysia (Peninsular Malaysia)

Known from only a single collection, this small tree is confined to hill forest in Mount Tapis in the state of

Pahang.

Assessor: World Conservation Monitoring Centre

Refs: 8464,19073
Mildbraedia carpinifolia

Euphorbiaceae

VU B $1+2 b$

Kenya, Mozambique, Tanzania

A shrub or tree of dry coastal forest or open woodland, ranging from south-east Kenya to eastem Tanzania and Zanzibar Island and possibly Mozambique.

Assessor: Lovett, J. \& G.P. Clarke

Refs: 3356,8814

\section{Milicia excelsa}

Moraceae LR/nt

Angola, Benin, Burundi, Cameroon, Central African Republic, Congo, Côte d'Ivoire, Democratic Republic of Congo, Equatorial Guinea (Bioko), Ethiopia, Gabon, Ghana, Kenya, Malawi, Mozambique, Nigeria, Rwanda, São Tomé \& Príncipe (São Tomé), Sierra Leone, Sudan, Tanzania, Togo, Uganda, Zimbabwe

Iroko, although common and widely distributed in different forest types throughout tropical Africa, suffers from heavy exploitation. East Africa was once a major source of the timber, which was used as a teak substitute until supplies became short. West Africa continues to export large quantities of it. Some populations suffer from gall attacks, especially in plantations, and its seed loses viability quickly. Trees are often left standing after land clearance and natural regeneration is good in open places.

Assessor: World Conservation Monitoring Centre

Refs: 2036, 2361, 4506, 6127, 6244, 6396, 6718, 7791 , $9605,15251,16021,17335,17408,19172$

\section{Milicia regia}

Moraceae

VUAlcd

Benin, Cameroon, Côte d'Ivoire, Gambia, Ghana, Guinea, Guinea-Bissau, Liberia, Senegal

Logging companies do not distinguish this species from $M$. excelsa. The rates of timber exploitation have a more serious impact on this species, with its narrower distribution within a region which has experienced large-scale forest destruction.

Assessor: African Regional Workshop

Refs: $2773,12061,15251$

\section{Miliusa nilagirica}

Annonaceae

VU B $1+2 c$ India (Kamataka, Kerala, Tamil Nadu)

A poorly known species, which occurs in the understorey of stunted evergreen forest between 900 and $1600 \mathrm{~m}$. Occurrences are sparsely scattered; three records have been made in the Agastyamalai Hills and three from sites further north, including the Nilgiri Hills and the Karnataka and Kerala border.

Assessor: World Conservation Monitoring Centre

Refs: 19144

\section{Miliusa parviflora}

Annonaceae

Malaysia (Peninsular Malaysia)

VU D2

A species known from four localities in the Langkawi Islands and Perlis State. It is restricted to forest on limestone hills. These areas are rapidly being developed and destroyed by urban expansion.

Assessor: Kochummen, K.M.

Refs: 19073

\section{Miliusa zeylanica}

Annonaceae

VU Alc

Sri Lanka

Until recently this endemic tree had gone uncollected for 
over a century. This species tumed up in 13 forest sites during the extensive forest surveys conducted for the National Conservation Review.

Assessor: World Conservation Monitoring Centre

Refs: 15431, 16943, 18796, 19112

\section{Millettia aurea}

Leguminosae

EN Alc

Madagascar

A deciduous woodland species that is restricted and uncommon. Its range extends $40,000 \mathrm{~km}^{2}$ ( ${ }^{*} \mathrm{EOO}$ ) but is highly fragmented as a result of agriculture and burning. Recent cotton plantations have had a strong impact and it is likely that at least $50 \%$ of the forest has been cleared or degraded in the last 100 years. This decline is continuing although this species is included within Ankarafantsika Reserve.

Assessor: Du Puy, D. \& H. Labat

Refs: 12353

\section{Millettia bussei}

Leguminosae

Mozambique, Tanzania

VU $B 1+2 b$

This species is restricted to areas of dry coastal forest in

Niassa Province, Mozambique, and south-east and east

Tanzania

Assessor: Lovett, J. \& G.P. Clarke

Refs: 3356, 10961

\section{Millettia capuronii}

Leguminosae

VU D2

Madagascar

Known from only three localities, this coastal forest species is confined to eastern Madagascar. Its range is estimated to lie between 500 and $1000 \mathrm{~km}^{2}$ (*AOO), but it is uncommon and the habitat is almost entirely destroyed, with only small vestiges remaining.

Assessor: Du Puy, D. \& H. Labat

Refs: 12353

\section{Millettia conraui}

Leguminosae

VU Alc, BI+2c

Cameroon, Nigeria

A small forest tree, similar to $M$. macrophylla, with a range extending from south-east Nigeria into Cameroon. Unprotected forest has been heavily logged and cleared for agriculture.

Assessor: World Conservation Monitoring Centre

Refs: 11504

\section{Millettia decipiens}

Leguminosae

VU D2

Malaysia (Peninsular Malaysia)

This lowland rainforest species is known from only two collections from Kuala Dipong, Perak. The area is under increasing conversion to agriculture.

Assessor: World Conservation Monitoring Centre

Refs: 17140,19073

\section{Millettia elongistyla}

Leguminosae

VU Bl+2b

Tanzania

Two populations are known. One is restricted to Kimboza Forest Reserve, which covers $4 \mathrm{~km}^{2}$ of moist semi-deciduous coastal forest within a densely populated area. The demand for land and wood is high but the forest is protected by two forest guards, employed in the
Catchment Forest Project. The other is restricted to low elevations in the Udzungwa Mountains.

Assessor: Lovett, J. \& G.P. Clarke

Refs: $1308,3356,5204$

\section{Millettia eriocarpa}

Leguminosae

Tanzania

VU $B 1+2 b$

A species of dry coastal forest endemic to south-east Tanzania.

Assessor: Lovett, J. \& G.P. Clarke

Refs: 3356, 5204, 10961

\section{Millettia galliflagrans}

Leguminosae

Malaysia (Peninsular Malaysia)

VU B $1+2 c$

A tree of lowland moist areas, confined to the Kluang Forest Reserve in the state of Johore. The principal threat to remaining populations is logging.

Assessor: Chua, L.S.L.

Refs: 8464,19073

\section{Millettia hitsika}

Leguminosae

EN B 1+2abc

Madagascar

Recorded from only two sites, this eastern coastal forest species is confined to a forest remnant at AmbilaLemaitsu which extends less than $500 \mathrm{~km}^{2}$ (*AOO) and suffers continual degradation.

Assessor: Du Puy, D. \& H. Labat

Refs: 12353

\section{Millettia lacus-alberti}

Leguminosae

VU B $1+2 c$

Democratic Republic of Congo, Uganda

An endemic to the Albertine Rift, confined to upland forest margins along the Waki River in Uganda and Lake Albert in DR Congo.

Assessor: *MUIENR

Refs: $1308,9605,10961,16021$

\section{Millettia laurentii}

Leguminosae

EN Alcd

Cameroon, Congo, Democratic Republic of Congo, Equatorial Guinea, Gabon

A species of Central African semi-deciduous, sometimes swampy, forest. In much of its range it is threatened with overexploitation for its decorative timber.

Assessor: African Regional Workshop

Refs: $7142,11449,12509,17408$

\section{Millettia macrophylla}

Leguminosae

VUAlc, B $1+2 c$

Cameroon, Nigeria

A small forest tree which occurs in areas of remaining forest, ranging from south-east Nigeria to Cameroon. Unprotected forest has been heavily logged and cleared for agriculture.

Assessor: World Conservation Monitoring Centre Refs: 11504

\section{Millettia micans}

Leguminosae

VU $B 1+2 b$

Tanzania

A small tree restricted to remaining areas of dry coastal forest and open woodland in east and south-east Tanzania.

Assessor: Lovett, J. \& G.P. Clarke

Refs: 1308, 3356 
Millettia mossambicensis

Leguminosae

DD

Mozambique

A poorly known species of Zanzibar-Inhambane woodland.

Assessor: Bandeira, $\mathrm{S}$.

Refs: 5117,7550

\section{Millettia nathaliae}

Leguminosae

Madagascar

A deciduous woodland species known only from two localities restricted to the Ankarana-Analamerana Massif of north Madagascar. It is uncommon, covering an estimated area of $500 \mathrm{~km}^{2}\left({ }^{*} \mathrm{AOO}\right)$, within which the forests are declining. It is included within Ankarana and Analamerana Reserves.

Assessor: Du Puy, D. \& H. Labat

Refs: 12353

\section{Millettia oblata ssp. intermedia}

Leguminosae

VU B $1+2 b$

Tanzania

A montane taxon confined to moist forests on the West Usambara Mountains, Ulugun Mountains and at Lupembe in the Kipengere range.

Assessor: Lovett, J. \& G.P. Clarke

Refs: $1308,3356,7550$

\section{Millettia oblata ssp. oblata}

Leguminosae

VU $B I+2 b$

Tanzania

A subspecies confined to moist evergreen forest at submontane altitudes in the East and West Usambara Mountains. A doubtful record also originates from the Udzungwa Mountains.

Assessor: Lovett, J. \& G.P. Clarke

Refs: $1308,3356,7550$

\section{Millettia oblata ssp. stolzii}

Leguminosae

VU $B 1+2 b$

Tanzania

A tree of moist montane forest at altitudes of between 1400 and $1500 \mathrm{~m}$ on Mount Rungwe and along Mkenja River. It is also apparently cultivated in Zambia.

Assessor: Lovett, J. \& G.P. Clarke

Refs: $1308,3356,5204$

\section{Millettia oblata ssp. teitensis}

\section{Leguminosae}

VU B $1+2 b c d . D 2$

Kenya

This subspecies is known only from the Taita Hills, occurring in remnants of moist evergreen forest. The tree has many local uses and illegal exploitation of the wood continues. The habitat is also reduced through encroaching agriculture, settlement, the planting of commercial species and road building. Seed and living stocks are maintained under the Plant Conservation Programme in Kenya.

Assessor: World Conservation Monitoring Centre Refs: $1308,6396,17859$

\section{Millettia orientalis}

Leguminosae

$\mathrm{EN} \mathrm{B1}+2 \mathrm{abc}$

Madagascar

A coastal forest species known only from two restricted sites: Nosy Mangabe \& Antongil and Taolanaro. The southern population extends less than $500 \mathrm{~km}^{2}$ (*AOO)

and is threatened by mining.

Assessor: Du Puy, D. \& H. Labat

Refs: 12353

\section{Milletria pterocarpa}

Leguminosae

VU D2

Malaysia (Peninsular Malaysia)

A tree of primary lowland forest, confined to the state of

Perak, from where it has been collected three times.

Assessor: World Conservation Monitoring Centre

Refs: 8464,19073

Millettia saclewxü

Leguminosae

VU B $1+2 b$

Tanzania

A species that occurs in the lowland forests in the East Usambara and south Nguru Mountains.

Assessor: Lovett, J. \& G.P. Clarke

Refs: 1308, 3356, 5204, 10961

\section{Millettia schliebenii}

Leguminosae

VU $B 1+2 b$

Tanzania

A species endemic to south-east Tanzania, where it is confined to remaining areas of dry coastal forest.

Assessor: Lovett, J. \& G.P. Clarke

Refs: 1308, 3356, 7550

\section{Milletria semsei}

Leguminosae

VU $B l+2 b$

Tanzania

A moist forest species of low elevation, endemic to east and south-east Tanzania.

Assessor: Lovett, J. \& G.P. Clarke

Refs: 1308,3356

\section{Millettia sericantha}

Leguminosae

VU B1+2b, D2

Tanzania

Two populations are known, both in moist lowland forest. One occurs at the foot of the Ulugur Mountains and the other at Turiani.

Assessor: Lovett, J. \& G.P. Clarke

Refs: $1308,3356,5204,10961$

\section{Millettia taolanaroensis}

Leguminosae

EN B $1+2 a b c$

Madagascar

A transitional forest species between dry and humid vegetation, it is confined to an area of less than $500 \mathrm{~km}^{2}$ (*AOO) in south-east Madagascar. The area is under threat from development, exploitation and mining, and the remaining forest is already highly fragmented.

Assessor: Du Puy, D. \& H. Labat

Refs: 12353

\section{Millettia unifoliata}

Leguminosae

VU B $1+2 c$

Malaysia (Peninsular Malaysia)

A lowland rainforest species, confined to the state of Perak, where it is principally threatened by encroaching settlements, agriculture and logging activities.

Assessor: Chua, L.S.L.

Refs: 8464, 19073 
Millettia usaramensis var. parvifolia

Leguminosae

VU B $1+2 b$

Tanzania

A shrub or tree from two locations in south-east Tanzania, one in Kilwa and the other near Lindi. It is restricted to areas of dry coastal forest.

Assessor: Lovett, J. \& G.P. Clarke

Refs: 1308,5204

\section{Millettia warnecke}

Leguminosae

Ghana, Guinea, Liberia, Sierra Leone, Togo

VUAlc

More information is needed on this species to confirm the status. It is not common and occurs in dry forests only in the Upper Guinea region. This type of vegetation has suffered extensively from the effects of human population growth, agricultural expansion and fire.

Assessor: Hawthorne, W.

Refs: 2773, 8369, 12061

\section{Mimetes arboreus}

Proteaceae

VU D1+2

South Africa (Westem Cape)

The species is confined to the Kogelberg range, where it occurs on the upper south slopes in seeps growing in wet mountain *fynbos. It is usually encountered as single plants, although small subpopulations, never exceeding 100 individuals, are also known. There is a total of approximately 500 mature plants within an area of 10 $\mathrm{km}^{2}$ (*AOO). Populations may have been more extensive in the past and declined because of frequent fires, to which the species is susceptible as it is a reseeder and takes eight years to reach maturity. All the present localities are now in a strictly protected conservation area, with a clear management policy which controls the occurrence of fire and presence of alien invasives. However, this deliberate exclusion of fire for many years may not have had a totally beneficial effect because periodic fires are needed to ensure recruitment.

Assessor: Hilton-Taylor, C. et al.

Refs: 689,19218

\section{Mimosa caesalpiniaefolia}

Leguminosae

Brazil (Bahia, Ceará, Maranháo)

VU B1+2c

A xerophytic species found growing mainly in deep alluvial soils. It is suffering a slow decline through its use as a timber, fuelwood and charcoal and through habitat loss and degradation.

Assessor: World Conservation Monitoring Centre Refs: 4506

\section{Mimosa nothacacia}

Leguminosae

Peru

VU D2

Known only from the type collection, the species occurs in shrubland in the department of Piura.

Assessor: World Conservation Monitoring Centre

Refs: 1984

\section{Mimosa verrucosa}

Leguminosae

LR/nt

Brazil (Bahia, Ceará, Pararba, Pemambuco, Rio Grande do Norte)

Common on hillsides, this shrubby tree is found on
* caatinga in north-east Brazil. It is slowly declining as a result of exploitation for timber and fuel.

Assessor: World Conservation Monitoring Centre

Refs: 4506, 7980, 9902

\section{Mimusops acutifolia}

Sapotaceae

VU B $1+2 b$

Tanzania

This small tree or shrub is mainly known from a dry forest habitat around Lake Lutamba. It may also be found in the East Usambara Mountains. The area around the lake has been completely cleared, with the exception of a $10 \mathrm{~km}^{2}$ patch of forest protected as Litipo Forest Reserve.

Assessor: Lovett, J. \& G.P. Clarke

Refs: 3356, 5204

\section{Mimusops angel}

Sapotaceae

LR/nt

Somalia

A rare evergreen tree of dry and open riverine forest. restricted to the north-eastern tip of Somalia. Overexploitation and degradation of the forest threaten the species.

Assessor: Thulin, $\mathrm{M}$.

Refs: $2361,8697,18665$

\section{Mimusops penduliflora}

Sapotaceae

$\mathrm{EN} B 1+2 \mathrm{~d}$

Tanzania

The type specimen is the only record of this species. It was collected from the bank of the Mbakana River in the southem Uluguru Mountains. It could represent a form of a more widespread species.

Assessor: Lovett, J. \& G.P. Clarke

Refs: 3356, 10961

\section{Mimusops riparia}

Sapotaceae

VU B $1+2 b$

Kenya, Tanzania

Two localities in Kenya are known, where the species occurs in forest along the Luma and Tana Rivers. The range extends to eastern Tanzania, where populations are restricted to remaining areas of moist forest.

Assessor: Lovett, J. \& G.P. Clarke

Refs. 3356, 6396, 10961

\section{Mimusops sechellarum}

Sapotaceae

VU D2

Seychelles

A once important timber tree now restricted to scattered stunted individuals in exposed rocky areas on the islands of Mahé, Praslin, Silhouette, Ile Longue and Felicite. The population on Curieuse is now extinct because of a fire. Seed predation by rats hampers regeneration in localised areas. The species is a good candidate for reforestation projects.

Assessor: World Conservation Monitoring Centre

Refs: 9859, 17229, 19023, 19062

\section{Minquartia guianensis}

Olacaceae

LR/nt

Bolivia, Brazil, Colombia, Costa Rica, Ecuador, French Guiana, Guyana, Nicaragua, Panama, Peru, Suriname, Venezuela

A monotypic species, widespread in lowland moist forest types from Nicaragua to Bolivia and Pen. It is locally common in the Guianas and other countries but it has become rarer in some areas where the wood is 
intensively harvested for local use, notably in Brazil and Colombia. Seed-producing trees are sometimes low in numbers but regeneration does not appear to be inadequate. The timber is scarce in international trade. Assessor: Americas Regional Workshop Refs: $730,6317,9867,14717,15037,15478,19069$, 19158,19179

\section{Mitranthes clarendonensis}

Myrtaceae

VU B $1+2 c$

Jamaica

Occurring in areas of wooded rocky limestone at about $760 \mathrm{~m}$, the species appears to be scarce and confined to Clarendon Parish.

Assessor: Kelly, D.L.

Refs: $401,5653,7980,19085$

\section{Mitranthes macrophylla}

\section{Myrtaceae}

$\mathrm{CR} \mathrm{B} 1+2 \mathrm{C}$

Jamaica

A small tree or shrub, which appears to have been found in only two locations in Trelawny. One is near a road extension west of Troy and the other is in woodland on a rocky limestone hilltop.

Assessor: World Conservation Monitoring Centre

Refs: $401,5653,7980$

\section{Mitranthes nivea}

Myrtaceae

$\mathrm{EN} \mathrm{B} 1+2 \mathrm{c}$

Jamaica

A small tree or shrub found only in woodland areas on limestone hilltops in St Ann Parish.

Assessor: World Conservation Monitoring Centre

Refs: $401,5653,7980$

\section{Mitrephora caudata}

Annonaceae

VU B $1+2 c$

Philippines

This tree is found at low and medium altitudes in forest in Palawan. The main island is a biosphere reserve. Assessor: World Conservation Monitoring Centre Refs: 4986

\section{Mitrephora fragrans}

Annonaceae

VU BI+2c

Philippines

This tree is endemic to Palawan, found in forest at low altitudes. The main island is a biosphere reserve.

Assessor: World Conservation Monitoring Centre

Refs: 4986

\section{Mitrephora grandiflora}

Annonaceae

India (Kamataka, Kerala)

A poorly collected species, known from a few scattered localities of lowland evergreen forest. In Kerala records have been made to the north of the Agastyamalai Hills, near Trissur, and in the Vavulmalai Hills. A single collection also originates from central Karnataka. Assessor: World Conservation Monitoring Centre Refs: 19144

\section{Mitrephora lanota}

Annonaceae

VUAlcd

Philippines

A timber species, endemic to the Philippines. Rates of habitat loss through logging and shifting cultivation have led to considerable population declines. Assessor: World Conservation Monitoring Centre Refs: $2072,4919,565$

\section{Mkilua fragrans}

Annonaceae

VU B $1+2 b$

Kenya, Tanzania

A species from a monotypic genus, commercially important for the fragrance of its flowers. The historical interest and trade in the species may have caused its range to be artificially expanded. In Kenya it occurs in evergreen forest in two separate localities along the coast. Populations also occur in north-east Tanzania and Zanzibar and Pemba Islands.

Assessor: Lovett, J. \& G.P. Clarke

Refs: $2418,3356,6396,8814$

\section{Molinadendron hondurense}

Hamamelidaceae

CR C2b

Honduras

A tree of high-altitude mixed humid forest.

Assessor: Nelson, C.

Refs: 10147,13995

\section{Mollia glabrescens}

Tiliaceae

VU D2

Guyana

Described in 1842, this species has not been recorded since the type collection from the Kwitaro River. Assessor: World Conservation Monitoring Centre Refs: 7951

\section{Mollinedia argyrogyna}

Monimiaceae

LR/nt

Brazil

Although widely distributed in Allantic forest in the south and south-east of Brazil, the species occurs sparsely and populations are in decline because of extensive habitat loss and degradation.

Assessor: Peixoto, A.L.

Refs: 19102

\section{Mollinedia butleriana}

Monimiaceae

CR C2b

Honduras

A rainforest tree of the Atlantic lowlands.

Assessor: Nelson, C.

Refs: 13995

\section{Mollinedia engleriana}

Monimiaceae

VU B1+2C

Brazil (Rio de Janeiro, São Paulo)

Occurring in areas of montane evergreen rainforest, the species is known from few localities and populations are believed to be small.

Assessor: Peixoto, A.L.

Refs: 19098,19102

\section{Mollinedia gilgiana}

Monimiaceae

CR B1+2C

Brazil (Rio de Janeiro)

An understorey species which is confined to Allantic forest in Serra de Macaé in Nova Friburgo. It is believed to be naturally rare and only a few collections have been made, dating from the 1800 s and more recently between 1987 and 1988. The locality is contained within a 
protected area and the species is included in the official list of threatened Brazilian plants compiled by *IBAMA. Assessor: Varty, N.

Refs: $8815,16123,19102$

\section{Mollinedia glabra}

Monimiaceae

VU B1+2c

Brazil (Espírito Santo, Rio de Janeiro)

A tree of potential horticultural interest. It occurs sparsely in remnant areas of *restinga woodland. The habitat has been widely destroyed by urban expansion. The species is also suspected to suffer from habitat fragmentation because of its dioecious nature. It occurs on the official list of threatened Brazilian plants compiled by *IBAMA.

Assessor: Peixoto, A.L.

Refs: $8815,16123,19102$

\section{Mollinedia lamprophylla}

Monimiaceae

CR C2a, D1

Brazil (Rio de Janeiro)

Formerly known along streamsides, this understorey species appears to have become extremely scarce. Extensive searches have located only two female specimens restricted to forest in Corcovado. One specimen has, however, set seed, suggesting there is at least a pollen-producing male individual in the vicinity. The species is included in the official list of threatened Brazilian plants compiled by *IBAMA.

Assessor: Varty, N.

Refs: 8815,16123

\section{Mollinedia longicuspidata}

Monimiaceae

$\mathrm{EN} \mathrm{B1+2c}$

Brazil (Rio de Janeiro)

This rare understorey species is confined to streamsides in areas of humid forest in Alto Macaé, in Nova Friburgo. The locality is now protected and the species is included in the official list of threatened Brazilian plants compiled by *IBAMA.

Assessor: Varty, N.

Refs: 8815,16123

\section{Mollinedia marquetiana}

Monimiaceae

VU B $1+2 c$

Brazil (Bahia, Espírito Santo)

An Atlantic forest species which is restricted to localities in the Linhares Reserve in Espirito Santo and to forest on Mussununga. The subpopulations are reported to be small.

Assessor: Peixoto, A.L.

Refs: 19102

\section{Mollinedia ruae}

Monimiaceae

CR C2b

Honduras, Nicaragua

Assessor: Nelson, C.

Refs: 13995

\section{Mollinedia stenophylla}

Monimiaceae

$\mathrm{EN} \mathrm{B} 1+2 \mathrm{ac}$

Brazil (Rio de Janeiro)

Known from a restricted area of Atlantic forest in Nova Friburgo, this species has yet to be collected or recorded this century. The forest continues to be rapidly destroyed and recent surveys have failed to locate living populations. The species is on the official list of threatened Brazilian plants compiled by *IBAMA.

Assessor: Varty, N.

Refs: 8815,16123

\section{Monadenium arborescens}

Euphorbiaceae

VU D2

\section{Tanzania}

Originally described from a cultivated plant, the wild population was discovered in 1990 , confined to an area of scrub on limestone in the Ruaha Valley. The area measures little more than a square kilometre and is situated a short distance from the main road. There is no current threat from collecting, but grazing and loss of habitat may be a problem.

Assessor: Carter-Holmes, $\mathbf{S}$.

Refs: 19160

\section{Monadenium elegans}

Euphorbiaceae

VU D2

Tanzania

Occurring in the same area as $M$. arborescens in the Ruaha Valley, this species is more abundant and not restricted to limestone but more widely distributed on hillsides and the summits of the surrounding mountains. Assessor: Carter-Holmes, $\mathbf{S}$.

Refs: 19160

\section{Monanthocitrus oblanceolata}

Rutaceae

VU B1+2c

Malaysia (Sabah)

Endemic to Sabah, this rather uncommon tree or shrub is found in the understorey of lowland forest, usually on slopes and ridges of low hills. Often this species is solitary or in small populations.

Assessor: World Conservation Monitoring Centre Refs: 19017

\section{Monocyclanthus vignei}

Annonaceae

$\mathrm{EN} \mathrm{B1}+2 \mathrm{c}$

Ghana, Liberia

Once thought to be endemic to Ankasa in Ghana, this understorey tree has now been found in Liberia. It occurs, but rarely, in wet evergreen forest.

Assessor: Hawthorne, W.

Refs: $8369,8854,12061$

\section{Monodora junodii var. macrantha}

Annonaceae

DD

Mozambique

Endemic to northern Mozambique. More fieldwork is required to consolidate the range and status of this variety.

Assessor: Bandeira, S.

Refs: 5117,14416

\section{Monodora unwini}

Annonaceae

VU A1c, B 1+2c

Nigeria

A forest tree, endemic to western Nigeria. Only a small area of forest remains and the extent of it continues to decline because of logging pressures and the demand for land for commercial crops and subsistence farming. Assessor: World Conservation Monitoring Centre Refs: 2773, 11504 
Monopetalanthus compactus

Leguminosae

VU Alc

Côte d'Ivoire, Liberia, Sierra Leone

The largest part of the species' range lies in Liberia. It extends from the south-west tip of Côte d'Ivoire towards the Nimba region of Liberia extending into Sierra Leone.

Assessor: World Conservation Monitoring Centre Refs: 2773, 4979

\section{Monopetalanthus durandii}

Leguminosae

VU B $1+2 \mathrm{c}$

Gabon

Populations are known from Lopé Forest Reserve and the relatively isolated Cristal Mountains, possibly extending into the remnant coastal forest in Cameroon. The habitat is degraded where logging has taken place. A large part of Gabon's forest is now under concession to logging companies.

Assessor: World Conservation Monitoring Centre Refs: $1332,7550,14958,15790$

\section{Monopetalanthus hedinii}

Leguminosae

CR Bl+2abcd, $\mathrm{Cl}+2 \mathrm{ab}$

Cameroon

This is the most endangered member of the genus. Recorded from small localities at Muyuka, Eseka, Kribi, Maleke and Lolodorf in Cameroon, the species may already be extinct from most of these sites. One location is converted to agricultural land. Another remains forested but attempts to find the species have failed and the third location appears now have been planted with bananas. It is closely related to $M$. heitzii but appears to grow to larger proportions and at a relatively rapid rate. There is considerable interest in its potential as a plantation tree.

Assessor: World Conservation Monitoring Centre

Refs: 1332, 5595, 12597

\section{Monopetalanthus heitzi}

Leguminosae

Cameroon?, Gabon

$\mathrm{LR} / \mathrm{nt}$

A species confined to dry forest along the coast of Gabon following the Oguooé valley inland to Lopé Forest Reserve. Suggestions that it occurs in Cameroon have not been consolidated. It ranges over an area covering at least $70,000 \mathrm{~km}^{2}$ in extent. The species is being felled for its timber, but the threat is not believed to be substantial at present. The long-term survival of the tree and its habitat is uncertain given the extent to which logging concessions have been made

Assessor: World Conservation Monitoring Centre

Refs: 1332,7550

\section{Monotes lutambensis}

\section{Dipterocarpaceae}

$\mathrm{EN} \mathrm{B} 1+2 \mathrm{c}, \mathrm{C} 2 \mathrm{~b}$

Tanzania

An African dipterocarp. It is cited as occurring at Lake Lutamba, where the only remaining forest is contained within Litipo Forest Reserve $\left(10 \mathrm{~km}^{2}\right)$. Logging, clearing of the forest for agriculture and wood collection have taken place in the past and continue to put pressure on the reserve.

Assessor: Lovett, J. \& G.P. Clarke

Refs: 10961,16796

\section{Montrouziera cauliflora}

Guttiferae

New Caledonia

Assessor: Jaffré, T. et al

Refs: 10351

\section{Moratia cerifera}

Palmae

LR/cd

New Caledonia

Restricted to north-east New Caledonia, the species occurs in wet forest on schistose soils between 500 and $800 \mathrm{~m}$.

Assessor: Jaffré, T. et al.

Refs: 10351,19118

\section{Morinda asteroscepa}

Rubiaceae

VU B $1+2 b$

Malawi, Tanzania

From Nchisi forest in Malawi to eastern Tanzania, the species is restricted to areas of moist forest at medium elevations.

Assessor: Lovett, J. \& G.P. Clarke

Refs: 3356, 10961

\section{Morinda trimera}

Rubiaceae

LR/nt

USA (Hawaii)

Not an uncommon species. It is scattered, sometimes dominating lowland rainforest in the Waianae Mountains and Koolau Mountains on Oahu, and also Lanai and Maui.

Assessor: World Conservation Monitoring Centre

Refs: 3372

\section{Moringa arborea}

Moringaceae

Kenya

This species has been found only once in a site southeast of Malka Mari.

Assessor: World Conservation Monitoring Centre

Refs: $1308,6396,9198$

\section{Mouretia tonkinensis}

Rubiaceae

Viet Nam

VU D2

Apparently endemic to Viet Nam, where the species is restricted to a single locality in $\mathrm{Ba} \mathrm{Vi,} \mathrm{Ha} \mathrm{Tay} \mathrm{Province.}$ Assessor: World Conservation Monitoring Centre

Refs: 848,11530

\section{Mouriri completens}

Melastomataceae

Colombia, Panama

$\mathrm{EN} \mathrm{B1}+2 \mathrm{c}$

Assessor: Calderon, E

Refs: 7980, 19069

\section{Mouriri emarginata var. rostrata}

Melastomataceae

$\mathrm{EN} \mathrm{B} 1+2 \mathrm{c}$

Cuba

This variety occurs very occasionally in dry serpentine woodland, mostly on deeper soils near ravines in Holguín, Pinar del Rio and Habana. Its habitat has been severely degraded in most places.

Assessor: Areces-Mallea, A.E.

Refs: 7980,19149 


\begin{abstract}
Mouriri panamensis
Melastomataceae

Colombia, Panama

Originally known only from Cerro Jefe, to the north-east of Panamá city, the species has now been reported from Kunayala Indigenous Reserve and from Darién Province in Panama, and also Valle del Cauca and the Chocó in Colombia. It is sparsely scattered in lowland, often inundated, forest, mostly within protected areas. Unprotected forest is exposed to logging and development.

Assessor: Mitré, $\mathbf{M}$.
\end{abstract}

Refs: $7588,7980,10218,16772$

\section{Mozartia emarginata}

Myrtaceae

$\mathrm{EN} \mathrm{B1}+2 \mathrm{c}$

Cuba

A rare shrub or small tree restricted to parts of the serpentine range, Sierra de Moas, in Holguín Province. Disturbance has been heavy in places.

Assessor: Areces-Mallea, A.E.

Refs: $11403,18485,19149$

\section{Mozartia maestrensis}

Myrtaceae

$\mathrm{EN} \mathrm{B1}+2 \mathrm{c}$

Cuba

A tree known only from montane rainforest on Sierra Maestra in eastern Cuba. It occurs mainly along creeks and watercourses.

Assessor: Areces-Mallea, A.E.

Refs: 9522, 16327, 19149

\section{Mozartia manacalensis \\ Myrtaceae \\ Cuba and rocky outcrops. \\ Assessor: Areces-Mallea, A.E. \\ Refs: 16327, 18485, 19149}

$\mathrm{EN} B 1+2 \mathrm{c}$

Confined to the montane rainforests of Sierra Maestra range in eastern Cuba, this tree thrives on shallower soils

\section{Multidentia castaneae}

Rubiaceae

VU B $1+2 b$

Tanzania

A shrub or small tree of dry coastal forest, endemic to eastern Tanzania.

Assessor: Lovett, J. \& G.P. Clarke

Refs: 3356,8814

\section{Multidentia sclerocarpa}

Rubiaceae

VU B1+2b, D2

Kenya, Tanzania

Two localities are known where the species occurs in moist forest. One is in Kenya in Mkongani North and the other is in the East Usambara Mountains.

Assessor: Lovett, J. \& G.P. Clarke

Refs: $1308,3356,8814$

\section{Munroidendron racemosum}

Araliaceae

CR C2a

USA (Hawaii)

Endemic to Kauai, the species, once widely scattered, is now confined to 15 populations mostly found on steep forested cliffs or slopes at low elevation. It is restricted to the Napali coast, Haupu range and Nounou Mountain, each population amounting to only one or two individuals, with the biggest one containing fewer than 50 individuals. Invasive plants and animals, including a longhorned beetle, rats and goats, pose serious threats to the survival of the species. There has been some success with propagation and plants have been reintroduced at Kauhao Ridge. The species is protected by the US Endangered Species Act.

Assessor: World Conservation Monitoring Centre Refs: 19038

\section{Mussaenda microdonta var. microdonta}

Rubiaceae

VU B $1+2 b$

Tanzania

A small tree known from moist evergreen forest at medium elevations at Shagayu in the West Usambara Mountains and Binduki in the Uluguru Mountains.

Assessor: Lovett, J. \& G.P. Clarke

Refs: 3356,8814

\section{Mussaenda monticola var. glabrescens \\ Rubiaceae}

VU B $1+2 b$

Tanzania

A small tree confined to three patches of moist lowland forest: Mvuma, Kiberege and Mohenge.

Assessor: Lovett, J. \& G.P. Clarke

Refs: 3356, 5204

\section{Mussaenda monticola var, monticola}

Rubiaceae

VU B $1+2 b$

Kenya, Tanzania

The nominate variant of an East African endemic. Populations occur in moist forest in the Shimba Hills, Gongoni and Pangani rocks in Kenya. They extend into remaining forest patches in eastern Tanzania.

Assessor: Lovett, J. \& G.P. Clarke

Refs: 6396,8814

\section{Myodocarpus angustialatus}

Araliaceae

VU B1+2c

New Caledonia

Assessor: Jaffré, T. et al.

Refs: 10351

\section{Myoporum rimatarense}

Myoporaceae

French Polynesia (Tubuai Is.)

A species which has been recorded only from Rimatara Island in the Tubuai Group.

Assessor: Florence, J.

Refs: 14513

\section{Myoporum stokesii}

Myoporaceae

French Polynesia (Tubuai Is.)

$\mathrm{CR} \mathrm{B} 1+2 \mathrm{c}$

The species has been recorded from Matotea and Maunganui on the island of Raivavae in the Tubuai Group.

Assessor: Florence, J.

Refs: 14513

\section{Myrceugenia bracteosa}

Myrtaceae

VU B1+2acd

Brazil

The main centre of distribution of the genus is in Chile and Argentina. The Brazilian species are localised, $1000 \mathrm{~km}$ further north, in the south-eastern states, where their occurrence is scarce.

Assessor: Pires O'Brien, J.

Refs: 7980,19097 
Myrceugenia brevipedicellata

Myrtaceae VU B1+2acd

Brazil

The main centre of distribution of the genus is in Chile and Argentina. The Brazilian species are localised, $1000 \mathrm{~km}$ further north, in the south-eastem states, where their occurrence is scarce.

Assessor: Pires O'Brien, J.

Refs: 7980,19097

\section{Myrceugenia campestris}

Myrtaceae

VU Bl+2acd

Brazil

The main centre of distribution of the genus is in Chile and Argentina. The Brazilian species are localised, $1000 \mathrm{~km}$ further north, in the south-eastern states, where their occurrence is scarce.

Assessor: Pires O'Brien, J.

Refs: 19097

\section{Myrceugenia fernandeziana}

Myrtaceae

Chile (Juan Fernández Is)

VU D2

A dominant species of lowland dry forest and lower montane forest on Masatierra Island The extent of the forest has declined through the effects of grazing by feral animals, spread of introduced weeds and soil erosion. Trees were also cut in large numbers for lumber in the past. Preliminary data indicate the species is confined to less than $100 \mathrm{~km}^{2}$. More detailed information on the species should become available to confirm this evaluation. The islands are designated as a national park and biosphere reserve and work is being carried out by *CONAF to save the native plants.

Assessor: World Conservation Monitoring Centre

Refs: $3241,5651,7980,14140$

\section{Myrceugenia franciscensis}

Myrtaceae

VU B1+2acd

Brazil

The main centre of distribution of the genus is in Chile and Argentina. The Brazilian species are localised, $1000 \mathrm{~km}$ further north, in the south-eastern states, where their occurrence is scarce.

Assessor: Pires O'Brien, J.

Refs: 7980,19097

\section{Myrceugenia kleinii}

Myrtaceae

VU B $1+2$ acd

Brazil

The main centre of distribution of the genus is in Chile and Argentina. The Brazilian species are localised, $1000 \mathrm{~km}$ further north, in the south-eastern states, where their occurrence is scarce.

Assessor: Pires O'Brien, J.

Refs: 7980,19097

\section{Myrceugenia miersiana}

Myrtaceae

LR/nt

Brazil

The main centre of distribution of the genus is in Chile and Argentina. The Brazilian species are localised, $1000 \mathrm{~km}$ further north, in the south-eastern states, where their occurrence is scarce.

Assessor: Barroso, G.M.

Refs: 19097
Myrceugenia myrcioides

Myrtaceae

LR/nt

Brazil

The main centre of distribution of the genus is in Chile and Argentina. The Brazilian species are localised, $1000 \mathrm{~km}$ further north, in the south-eastern states, where their occurrence is scarce.

Assessor: Barroso, G.M.

Refs: 19097

\section{Myrceugenia pilotantha}

Myrtaceae

VU B1+2acd

Brazil

The main centre of distribution of the genus is in Chile and Argentina. The Brazilian species are localised, $1000 \mathrm{~km}$ further north, in the south-eastem states, where their occurrence is scarce.

Assessor: Pires O'Brien, J.

Refs: 7980,19097

\section{Myrceugenia rufescens}

Myrtaceae

VU B1+2acd

Brazil

The main centre of distribution of the genus is in Chile and Argentina. The Brazilian species are localised, $1000 \mathrm{~km}$ further north, in the south-eastern states, where their occurrence is scarce.

Assessor: Pires O'Brien, J.

Refs: 7980,19097

\section{Myrceugenia schulzei}

Myrtaceae

VU D2

Chile (Juan Fernández Is)

A dominant species of lowland dry forest on Masafuera Island. The extent of the forest has declined through the effects of grazing by feral animals, spread of introduced weeds and soil erosion. Preliminary data indicate the species is confined to less than $100 \mathrm{~km}^{2}$. More detailed information on the species should become available to confirm this evaluation. The islands are designated as a national park and biosphere reserve and work is being carried out by *CONAF to save the native plants. Assessor: World Conservation Monitoring Centre Refs: $3241,5651,14140$

\section{Myrceugenia scutellata}

Myrtaceae

VU B1+2acd Brazil

The main centre of distribution of the genus is in Chile and Argentina. The Brazilian species are localised, $1000 \mathrm{~km}$ further north, in the south-eastem states, where their occurrence is scarce.

Assessor: Pires O'Brien, J.

Refs: 7980,19097

\section{Myrcia albobrunnea}

Myrtaceae

VU D2

Peru

Known only from the type collection, the species occurs in lowland rainforest in the department of Loreto. Assessor: World Conservation Monitoring Centre Refs: 1984

\section{Myrcia almasensis}

Myrtaceae

VU D2

Brazil (Bahia)

Endemic to Bahia in Brazil, the species is presently known from just two locations in *campo rupestre or in 
sandy grassland. Evidence suggests that the species is unusual for its family in possibly being dioecious. Assessor: World Conservation Monitoring Centre Refs: 849

\section{Myrcia calcicola}

Myrtaceae

VU B1+2c

Jamaica

Reported to occur in abundance, the species is confined to areas of moist forest on limestone in Portland between 450 and $600 \mathrm{~m}$. Many areas have experienced logging and conversion to commercial plantations.

Assessor: World Conservation Monitoring Centre

Refs: $401,5653,6057,7980$

\section{Myrcia crassimarginata}

Myrtaceae

VU D2

Peru

Apparently the species is known only from the type collection, which was taken from lowland Amazon forest near Yurimaguas in the department of Loreto.

Assessor: World Conservation Monitoring Centre

Refs: 1984, 15371

\section{Myrcia fosteri \\ Myrtaceae}

VU C2a

Panama

Ranging from the Canal area towards Darién National Park in the east, the species is very common in places, such as Barro Colorado Island and the forest around the Canal. There are almost no populations outside protected areas or in disturbed forest.

Assessor: Mitré, M.

Refs: 7980,16772

\section{Myrcia grandiflora}

Myrtaceae

VU B 1+2acd

Brazil

A rare species of Brazilian Atlantic forest.

Assessor: Pires O'Brien, J.

Refs: 19097,19098

\section{Myrcia lineata \\ Myrtaceae}

VU B1+2acd

Brazil

A rare species of Brazilian Atlantic forest.

Assessor: Pires O'Brien, J.

Refs: 19098

\section{Myrcia paganii}

Myrtaceae

CR D1

Puerto Rico

Only two populations, accounting for 10 individuals in total, are known from areas of moist limestone forest in the west. No evidence of flowering or fruiting is apparent. Both sites are on private land. Attempts at cultivation have been unsuccessful.

Assessor: World Conservation Monitoring Centre

Refs: $3786,7980,17124,17540$

\section{Myrcia pentagona}

Myrtaceae

VU D2

Peru

Known only from the type collection, the species occurs in lowland rainforest species in the department of Loreto.

Assessor: World Conservation Monitoring Centre Refs: 1984
Myrcia skeldingï

Myrtaceae

EX

Jamaica

A population was once located in streamside thickets along the Mason River on the Clarendon-St Ann border. No individuals have been seen or recorded since 1972 and the species is presently presumed extinct.

Assessor: Kelly, D.L.

Refs: 401, 5653, 7980, 19085

Myrcia splendens var. chrysocoma

Myrtaceae

VU D2

Peru

This variety is known only from the type collection, which originates from lowland rainforest in the department of San Martin.

Assessor: World Conservation Monitoring Centre Refs: 1984

\section{Myrcianthes callicoma}

Myrtaceae

VU $B 1+2 c$

Argentina (Tucumán), Bolivia

Originally thought to be endemic to Tucumán in Argentina, the species has recently been discovered in a small area in Bolivia.

Assessor: World Conservation Monitoring Centre

Refs: 5112,19180

\section{Myrcianthes oreophila}

Myrtaceae

VU $B l+2 c$

Peru

A cloud forest species of the Peruvian Andes, recorded from disturbed areas in the departments of Apurimac and Cuzco.

Assessor: World Conservation Monitoring Centre

Refs: 1984

\section{Myrcianthes pungens}

Myrtaceae

$\mathrm{EN} \mathrm{Bl}+2 \mathrm{c}$

Brazil

Assessor: Barroso, G.M.

Refs: 19097, 19098

\section{Myrciaria cuspidata}

Myrtaceae

VU B1+2acd

Brazil, Paraguay

A rare species of Brazilian Atlantic forest.

Assessor: Pires O'Brien, J.

Refs: 7980,19097

\section{Myrciaria pliniodes}

Myrtaceae

VU B1+2acd

Brazil

A rare species of Brazilian Atlantic forest.

Assessor: Pires O'Brien, J.

Refs: 19097, 19098

\section{Myrciaria silveirana}

Myrtaceae

VU B $1+2$ acd

Brazil

A rare species of Brazilian Atlantic forest.

Assessor: Pires O'Brien, J.

Refs: 19097

\section{Myrica rivas-martinezii}

Myricaceae

CR C2a

Spain (Canary Is.)

A dioecious species which is found scattered mainly as isolated individuals in cloud forest on the islands of $\mathrm{La}$ 
Palma, Gomera and Hierro. The total population size is small and regeneration is poor. There is also evidence of hybridisation occurring with $\boldsymbol{M}$. faya. The species is listed in government legislation of 1991.

Assessor: Bañares, A et al.

Refs: 451, 16500, 19022

\section{Myristica agusanensis ssp. squamulosa}

Myristicaceae

VU D2

Philippines

This subspecies is newly described, based on three herbarium specimens. It is found in lower montane forest on the islands of Luzon and Sibuyan.

Assessor: World Conservation Monitoring Centre

Refs: 18022

\section{Myristica alba}

Myristicaceae

VU D2

Indonesia (Moluccas)

A small tree, found on limestone from four collections in Bacan, Obi and Buru Islands.

Assessor: World Conservation Monitoring Centre

Refs: 8013

\section{Myristica ampliata}

Myristicaceae

VU D2

Australia (Queensland)

Known only from four collections, this small tree is found locally in the lowland rainforest of the Mission Beach area of north-east Queensland.

Assessor: World Conservation Monitoring Centre Refs: 10378

\section{Myristica andamanica}

Myristicaceae

VU B $]+2 c$

India (Andaman and Nicobar Is.- Andaman Is., Andaman and Nicobar Is. - Nicobar Is.)

The only species in the genus to be found in the Andaman and Nicobar Islands. A handsome tree of evergreen hill forest, rainforest or mixed forest, it has been collected a total of eight times, three times in the $19^{\text {th }}$ century.

Assessor: World Conservation Monitoring Centre

Refs: 18022

\section{Myristica arfakensis}

Myristicaceae

VU D2

Indonesia (Irian Jaya)

A small montane forest tree known only from two collections from the Arfak Mountains in north-east Vogelkop Peninsula.

Assessor: World Conservation Monitoring Centre Refs: 1493

\section{Myristica atresens}

Myristicaceae

VU D2

Papua New Guinea

The type specimen is the only known collection of the tree. It was gathered from lowland forest near the border of Papua New Guinea in south-eastern Irian Jaya.

Assessor: World Conservation Monitoring Centre Refs: 1493

\section{Myristica basilanica}

Myristicaceae

VU D2

Philippines

A newly described tree known only from the type collected from Basilan Island in 1912

Assessor: World Conservation Monitoring Centre Refs: 18022

\section{Myristica beddomei ssp. sphaerocarpa}

Myristicaceae

$\mathrm{EN} \mathrm{Bl}+2 \mathrm{c}$

India (Kerala, Tamil Nadu)

A small tree restricted to the eastern slopes of the Western Ghats in the Tinnevelly District. This subspecies has been collected only twice, in areas of wet evergreen forest.

Assessor: World Conservation Monitoring Centre

Refs: 10148,18022

\section{Myristica beddomei ssp. ustulata}

Myristicaceae

$\mathrm{EN} \mathrm{B1}+2 \mathrm{c}$

India (Kerala, Tamil Nadu)

This tree is found in montane wet and relatively dry evergreen forest in Kerala and East Madras. Only five collections are known.

Assessor: World Conservation Monitoring Centre

Refs: 10148,18022

\section{Myristica bifurcata ssp. bifurcata}

Myristicaceae

Indonesia (Irian Jaya, Moluccas)

LR/nt

This subspecies is locally common in forest on Morotai Island of the Moluccas and is also known from the Vogelkop Peninsula, Irian Jaya. It has been collected five times. The wood of the species is likely to be traded as penarahan.

Assessor: World Conservation Monitoring Centre Refs: 8013, 11145

\section{Myristica bifurcata ssp. sulaica}

Myristicaceae

Indonesia (Moluccas)

$\mathrm{LR} / \mathrm{nt}$

This subspecies is locally common in lowland welldrained forest on the northern Moluccan Islands (Sula, Halmaheira and $\mathrm{Obi}$ ). The wood of the species is likely to be traded as penarahan.

Assessor: World Conservation Monitoring Centre Refs: 8013,11145

\section{Myristica brachypoda}

Myristicaceae

Papua New Guinea

The type species was gathered in 1955 in logged-over forest near the Seribi River in the Gulf Province. It is the only known collection of the species.

Assessor: World Conservation Monitoring Centre Refs: 1493

\section{Myristica brevistipes}

Myristicaceae

Papua New Guinea

A small tree collected only on one occasion in tall foothill forest in the Central Province.

Assessor: World Conservation Monitoring Centre Refs: 1493

\section{Myristica buchneriana}

Myristicaceae

Indonesia (Inian Jaya), Papua New Guinea

Frequently found on ridge tops between 300 and $1300 \mathrm{~m}$, this tree is an important source of penarahan timber. Assessor: World Conservation Monitoring Centre Refs: 1493, 11145 


\section{Myristica byssacea}

Myristicaceae

VU D2

Papua New Guinea

A small tree of montane forest, known from only two collections from the Northem Province.

Assessor: World Conservation Monitoring Centre

Refs: 1493

\section{Myristica ceylanica}

Myristicaceae

VU B $1+2 c$

Sri Lanka

A rare tree confined to remnants of intermediate forest and in drier gallery forest. It has recently been found in seven forest sites during the extensive forest surveys conducted for the National Conservation Review.

Assessor: World Conservation Monitoring Centre

Refs: $9176,17195,19112$

\section{Myristica coacta}

Myristicaceae

VU D2

Papua New Guinea

Known only from the type collection of 1968, this species occurs in degraded Fagaceous forest of West Sepik Province.

Assessor: World Conservation Monitoring Centre

Refs: 1493

\section{Myristica colinridsdalei}

Myristicaceae

VU D2

Philippines

Endemic to the Palanan area of north-east Luzon, this recently described tree has been collected three times from lowland forest over ultrabasic soil.

Assessor: World Conservation Monitoring Centre

Refs: 18022

\section{Myristica conspersa}

Myristicaceae

DD

Indonesia (Irian Jaya)

A species which provisionally unites three collections until further material becomes available. So far its distribution is restricted to primary forest in the Vogelkop Peninsula.

Assessor: World Conservation Monitoring Centre

Refs: 1493

\section{Myristica corticata}

Myristicaceae

Brunei, Malaysia (Sabah)

A tree of lowland primary forest and logged-over forest, known only from a single collection from Brunei and four collections from Sabah.

Assessor: World Conservation Monitoring Centre

Refs: 18022

\section{Myristica crassa}

Myristicaceae

Indonesia (Kalimantan), Malaysia (Peninsular

Malaysia), Singapore

This species is uncommon in lowland and hill forest.

The wood has been used as penarahan timber.

Assessor: World Conservation Monitoring Centre

Refs: $9199,11145,11647,17140,18022,19073,19078$

Myristica crassipes ssp. marronia

Myristicaceae

VU D2

Papua New Guinea

This subspecies is found in open montane Araucaria forest near creeks on Mount Suckling. Milne Bay
Province. It is known from only two collections. Assessor: World Conservation Monitoring Centre Refs: 1493

\section{Myristica dactyloides}

Myristicaceae

LR/cd

Sri Lanka

This Sri Lankan endemic is restricted to the wetter region of the island, where remaining rainforest covers an area of less than $1440 \mathrm{~km}^{2}$. The species is locally common in lowland and montane rainforest and has been collected many times. It is one of the dominant subcanopy species in Sinharaja Biosphere Reserve. Assessor: World Conservation Monitoring Centre Refs: $17195,17759,18515,19112$

\section{Myristica dasycarpa}

Myristicaceae

VU D2

Papua New Guinea

Known only from the type collection, this subcanopy tree was found growing on a ridge at approximately $50 \mathrm{~m}$ in the Waskuk Hills, East Sepik Province. Another collection from Irian Jaya might belong to this recently described species.

Assessor: World Conservation Monitoring Centre Refs: 19084

\section{Myristica depressa}

Myristicaceae LR/nt Indonesia (Kalimantan, Sumatra), Malaysia (Peninsular Malaysia, Sabah, Sarawak)

A tree restricted to lowland primary mixed dipterocarp forest.

Assessor: World Conservation Monitoring Centre Refs: 18022

\section{Myristica devogelï}

Myristicaceae

VU D2 Indonesia (Sulawesi)

Endemic to forest on ultrabasic rock in central Sulawesi, this tree has been collected three times from the area north of Lake Matano.

Assessor: World Conservation Monitoring Centre Refs: 18022

\section{Myristica duplopunctata ssp. duplopunctata}

Myristicaceae

VU D2

Indonesia (Irian Jaya)

A primary forest subspecies, known only from three collections from the coastal mountains of northern Irian Jaya.

Assessor: World Conservation Monitoring Centre Refs: 1493

\section{Myristica duplopunctata ssp. versteeghii}

Myristicaceae

VU D2 Indonesia (Irian Jaya), Papua New Guinea

A tree of primary montane forest, occurring on the northern side of the main range. It is known from four collections.

Assessor: World Conservation Monitoring Centre Refs: 1493

\section{Myristica extensa}

Myristicaceae

VU Alc

Brunei, Indonesia (Kalimantan), Malaysia (Sarawak)

A species of lowland primary forest. Five collections have been gathered from Sarawak, a single collection is 
known from Brunei and two collections have come from central and east Kalimantan.

Assessor: World Conservation Monitoring Centre

Refs: 18022

\section{Myristica fasciculata}

Myristicaceae

VU D2

Papua New Guinea

Collected three times, this species is locally common in primary and secondary forest in the upper Sepik River region of Sepik Province.

Assessor: World Conservation Monitoring Centre Refs: 1493, 19084

\section{Myristica filipes}

Myristicaceae

Papua New Guinea

This tree is locally endemic to the Buso River area of the Morobe Province. It has been collected six times in coastal swamp forest, river flat forest and lowland secondary forest.

Assessor: World Conservation Monitoring Centre Refs: 1493

\section{Myristica fissurata}

Myristicaceae

VU D2

Indonesia (Moluccas)

A lowland forest tree, known only from three collections from Bacan Island.

Assessor: World Conservation Monitoring Centre Refs: 8013

\section{Myristica flavovirens}

Myristicaceae

VU D2

Indonesia (Irian Jaya)

This tree, found in old primary forest, is known only from the type collection taken from the Kebar Valley in the Vogelkop Peninsula.

Assessor: World Conservation Monitoring Centre

Refs: 1493

\section{Myristica fragrans}

Myristicaceae

Indonesia (Moluccas)

The original source of nutmeg. It is thought to occur naturally in the lowland forests of Banda Island in the Moluccas, but it is now widely cultivated in the tropics, becoming naturalised in many areas.

Assessor: World Conservation Monitoring Centre

Refs: $3738,8915,18022$

\section{Myristica frugifera}

Myristicaceae

VUAlc

Philippines

An understorey tree, of primary and disturbed lowland forest, found on the islands of Luzon, Leyte and Mindoro. It is known from five collections.

Assessor: World Conservation Monitoring Centre Refs: 18022

\section{Myristica fugax ssp. fugax}

Myristicaceae

VU D2

Papua New Guinea

A subspecies of primary and secondary montane forest, collected four times from localities near Isuarava and Lala, Central Province.

Assessor: World Conservation Monitoring Centre Refs: 1493
Myristica fugax ssp. septentrionalis

Myristicaceae

VU D2

Papua New Guinea

A tree occurring in foothill and montane forest in East Sepik, Gulf and Madang Provinces, known only from four collections.

Assessor: World Conservation Monitoring Centre

Refs: 1493

\section{Myristica fusiformis ssp. fusiformis}

Myristicaceae

VU D2

Indonesia (Irian Jaya)

A small tree found only once in Nothofagus forest in west Irian Jaya.

Assessor: World Conservation Monitoring Centre

Refs: 1493

\section{Myristica fusiformis ssp. pseudostipitata}

Myristicaceae

VU D2

Indonesia (Irian Jaya)

This subspecies is known only from the type specimen, collected from the lower Lorentz River in south-west Irian Jaya.

Assessor: World Conservation Monitoring Centre

Refs: 1493

\section{Myristica gigantea}

Myristicaceae

LR/nt

Indonesia (Kalimantan, Sumatra), Malaysia (Peninsular Malaysia, Sabah, Sarawak)

A large tree found on flat land and hillsides up to $700 \mathrm{~m}$ altitude. The wood is used as penarahan timber.

Assessor: World Conservation Monitoring Centre Refs: 11145

\section{Myristica globosa}

Myristicaceae

Papua New Guinea (North Solomons, Papua New Guinea), Solomon Islands

Confined to evergreen rainforest up to $1200 \mathrm{~m}$, this tree is cut for its penarahan timber.

Assessor: World Conservation Monitoring Centre Refs: 11145

\section{Myristica guadalcanalensis}

Myristicaceae

LR/nt

Solomon Islands (South Solomon)

A tree found in well-drained primary and secondary forest endemic to the islands of Guadalcanal, Rennell and Malaita.

Assessor: World Conservation Monitoring Centre Refs: 18252

\section{Myristica inaequalis}

Myristicaceae

VU D2

Indonesia (Irian Jaya)

A recently described species of ridge forest, known only from the type specimen gathered in the Arfak Mountains.

Assessor: World Conservation Monitoring Centre Refs: 19082

\section{Myristica incredibilis}

Myristicaceae

VU D2

Papua New Guinea

A tree known only from the type specimen collected on

Rossel Island. This island has a fragile ecosystem, with 
very poor soils, which is possibly threatened by gold and copper mining and logging.

Assessor: World Conservation Monitoring Centre

Refs: 1493, 19032

\section{Myristica inundata}

Myristicaceae

VU D2

Papua New Guinea

Known only from the type specimen, this species occurs in seasonally inundated swamp forest in Kiunga, Western Province.

Assessor: World Conservation Monitoring Centre

Refs: 1493

\section{Myristica kajewski ssp. kajewski}

Myristicaceae

LR/nt

Solomon Islands (South Solomon)

A tree locally common in well-drained forest, restricted to Guadalcanal and San Cristobal.

Assessor: World Conservation Monitoring Centre

Refs: 18252

\section{Myristica kajewski ssp. robusta}

Myristicaceae

VU D2

Solomon Islands (South Solomon)

A primary forest tree, possibly restricted to ultrabasic soils. It is known from only two collections, both from Choiseul.

Assessor: World Conservation Monitoring Centre

Refs: 18252

\section{Myristica kjellbergii}

Myristicaceae

VU D2

Indonesia (Sulawesi)

A primary forest tree found in central and south-west

Sulawesi, known only from four collections.

Assessor: World Conservation Monitoring Centre

Refs: 18022

\section{Myristica laevis ssp. badia}

Myristicaceae

VU D2

Philippines

A small tree known only from the type collection found in hillside forest from south Surigao, north-east Mindanao.

Assessor: World Conservation Monitoring Centre Refs: 18022

\section{Myristica laevis ssp. laevis}

Myristicaceae

VU D2

Philippines

This subspecies is known from only two collections from forest on Mount Sohoton, Samar Island.

Assessor: World Conservation Monitoring Centre

Refs: 18022

\section{Myristica lancifolia ssp. australiana}

Myristicaceae

VU D2

Australia (Northem Territory)

A locally common subspecies, described recently, found in lowland rainforest, monsoon forest and riparian evergreen vine forest of the north-west Northern Territory, including Melville Island.

Assessor: World Conservation Monitoring Centre

Refs: 18251

\section{Myristica lancifolia ssp. kutubuensis}

Myristicaceae

Papua New Guinea

A tentative new subspecies described from one specimen. It occurs in primary forest over limestone in Southern Highlands Province.

Assessor: World Conservation Monitoring Centre Refs: 1493

\section{Myristica lasiocarpa}

Myristicaceae

VU D2

Papua New Guinea

A subcanopy species, occurring as solitary trees in Nothofagus forest. It has only been collected only twice from the Kuper range area of the Morobe Province. Assessor: World Conservation Monitoring Centre Refs: 1493

\section{Myristica lepidota ssp. lepidota}

Myristicaceae

Indonesia (Irian Jaya, Moluccas)

This subspecies, known from five collections, is found in lowland rainforest in south-west New Guinea and in Aru and Pulau Wokam Islands of the Moluccas. Assessor: World Conservation Monitoring Centre Refs: 8013, 11145

\section{Myristica leptophylla}

Myristicaceae

VU D2

Papua New Guinea

Known only from the type locality, near Busilmin, West Sepik Province, the species occurs in secondary regrowth at medium elevation.

Assessor: World Conservation Monitoring Centre Refs: 1493

\section{Myristica longipetiolata}

Myristicaceae

VU D2

Philippines

This forest tree is known only from three collections from the islands of Luzon and Biliran.

Assessor: World Conservation Monitoring Centre Refs: 18022

\section{Myristica lowiana}

Myristicaceae

Indonesia (Kalimantan, Sumatra), Malaysia (Peninsular Malaysia, Sabah, Sarawak), Singapore

This tree is mainly found in peat-swamp forest; it is rarely found on dry land. Trees are cut for penarahan timber.

Assessor: World Conservation Monitoring Centre Refs: $9199,11145,12937,18022$

\section{Myristica magnifica}

Myristicaceae

$\mathrm{EN} \mathrm{Bl}+2 \mathrm{c}$

India (Kamataka, Kerala)

A large tree and dominant component of a restricted area of lowland evergreen swamp forest in the Agastyamalai Hills. There are also two records of the species occurring in northern Kerala and North Kanara in Karnataka. Very little of the habitat remains.

Assessor: World Conservation Monitoring Centre

Refs: $10148,18022,19144$

\section{Myristica maingayi}

Myristicaceae

LR/nt

Malaysia (Peninsular Malaysia), Singapore

This lowland species is found on hillsides and crests in 
Peninsular Malaysia up to $300 \mathrm{~m}$. Trees are cut for penarahan timber. There is also a single deviating collection from Sumatra.

Assessor: World Conservation Monitoring Centre

Refs: 9199, 11145, 17140

\section{Myristica malabarica}

Myristicaceae

VU B $1+2 \mathrm{c}$

India (Karnataka, Kerala, Maharashtra, Tamil Nadu)

A tree of swamp forest and other lowland forest types, occurring in scattered localities in the Western Ghats. The swamp habitat has been extensively drained for agriculture. There is additional evidence of low seed viability because of unfavourable soil conditions and pollination difficulties. The seed was once used as an adulterant of nutmeg and the plant is often grown as an omamental.

Assessor: CAMP Workshops on Medicinal Plants in India

Refs: 561, 18022, 18325, 19144

\section{Myristica malaccensis ssp. papillosa}

Myristicaceae

VU D2

Malaysia (Sarawak)

A newly described subspecies, known only from three collections from Sarawak.

Assessor: World Conservation Monitoring Centre

Refs: 11145,18022

\section{Myristica mediovibex var. kosteriana}

Myristicaceae

VU D2

Indonesia (Irian Jaya), Papua New Guinea

A variety known from two collections, occurring in primary forest along the Bodem River, Irian Jaya and East Sepik Province, Papua New Guinea.

Assessor: World Conservation Monitoring Centre

Refs: 1493

\section{Myristica mediovibex var. mediovibex}

Myristicaceae

VU D2

Indonesia (Irian Jaya)

A single locality exists on mainland Irian Jaya and three collections come from Japen Island. The species is reported to be locally common in primary forest.

Assessor: World Conservation Monitoring Centre

Refs: 1493

\section{Myristica mediterranea}

Myristicaceae

VU D2

Indonesia (Irian Jaya), Papua New Guinea

Known only from three collections from the southern border between Irian Jaya and Papua New Guinea, this small tree occurs in disturbed forest or semi-swamp in valley forest.

Assessor: World Conservation Monitoring Centre

Refs: 1493

\section{Myristica millepunctata}

Myristicaceae

VU D2

Indonesia (Irian Jaya)

A large tree known from two collections from montane forest in south-east Irian Jaya.

Assessor: World Conservation Monitoring Centre

Refs: 1493

\section{Myristica nana}

Myristicaceae

VU D2

Papua New Guinea

A small tree, known from four collections, locally endemic to forest in the Central and Milne Bay Provinces.

Assessor: World Conservation Monitoring Centre

Refs: 1493

\section{Myristica olivacea}

Myristicaceae

VU D2

Papua New Guinea

An understorey rainforest tree known only from four collections from near Amazon Bay, Central Province.

Assessor: World Conservation Monitoring Centre

Refs: 1493

\section{Myristica ornata}

Myristicaceae

VU D2

Papua New Guinea

Known only from the type specimen, the tree was discovered in lowland rainforest in the Kiunga area,

Western Province.

Assessor: World Conservation Monitoring Centre

Refs: 1493

\section{Myristica ovicarpa}

Myristicaceae

Papua New Guinea

VU D2

This tree is known only from the type collection. It was found in lowland hill forest on Mount Don of Rossel Island. Rossel Island has quite a fragile ecosystem with very poor soils; possible threats include mining and logging.

Assessor: World Conservation Monitoring Centre Refs: 1493, 19032

\section{Myristica pachycarpidia}

Myristicaceae

VU D2

Papua New Guinea

A tree known only from the type locality in oak forest on Mount Dayman, Milne Bay Province.

Assessor: World Conservation Monitoring Centre Refs: 1493

\section{Myristica papillatifolia}

Myristicaceae

VU D2

Indonesia (Irian Jaya), Papua New Guinea

A small tree found only once in valley forest near Ingambit in the Western Province, near the border with lrian Jaya.

Assessor: World Conservation Monitoring Centre

Refs: 1493

\section{Myristica perlaevis}

Myristicaceae

VU D2

Indonesia (Moluccas)

Discovered in 1990, this tree is known only from the type collection found in the Ruwa catchment area of Ceram.

Assessor: World Conservation Monitoring Centre Refs: 18022

\section{Myristica petiolata}

Myristicaceae

Solomon Islands (South Solomon)

VU D2

A forest tree known only from two collections: Santa Ysabel and Big Nggela Island.

Assessor: World Conservation Monitoring Centre Refs: 18252 


\section{Myristica philippensis}

Myristicaceae

VU Alc

Philippines

A small tree restricted to the lowlands of Luzon. No recent collections of this species have been made.

Assessor: World Conservation Monitoring Centre

Refs: 11145,19078

\section{Myristica pilosella}

Myristicaceae

VU D2

Papua New Guinea

A small tree known only from a site of Castanopsis forest at the junction of the Ugat and Mayu Rivers in Milne Bay Province.

Assessor: World Conservation Monitoring Centre

Refs: 1493

\section{Myristica pilosigemma}

Myristicaceae

VU Alc, D2

Philippines

A tree restricted to Samar and Mindanao and known from only two herbarium specimens.

Assessor: World Conservation Monitoring Centre

Refs: 18022

\section{Myristica polyantha}

Myristicaceae

VU D2

Papua New Guinea

A canopy or subcanopy tree restricted to Goodenough

Island, where it has been collected twice. The

D'Entrecasteaux Islands harbour many locally endemic species and require botanical investigation.

Assessor: World Conservation Monitoring Centre

Refs: 1493, 19032

\section{Myristica psilocarpa}

Myristicaceae

VU D2

Papua New Guinea

An endemic to Manus Island, this tree has been collected twice in areas of lowland rainforest.

Assessor: World Conservation Monitoring Centre

Refs: 1493

\section{Myristica pubicarpa}

Myristicaceae

VU D2

Indonesia (Moluccas)

So far the species is known from four collections, all from Halmaheira and Obi. Solitary trees are found in both open and dense primary forest.

Assessor: World Conservation Monitoring Centre

Refs: 8013

\section{Myristica pygmaea}

Myristicaceae

Papua New Guinea

A small tree, endemic to Morobe Province, where it has been collected twice in lowland rainforest and logged forest.

Assessor: World Conservation Monitoring Centre

Refs: 1493

\section{Myristica robusta}

Myristicaceae

VU D2

Indonesia (Moluccas)

A distinctive solitary tree, known only from the type collection, found in disturbed lowland forest with little undergrowth. The lowland forest in Bacan is rapidly disappearing.

Assessor: World Conservation Monitoring Centre Refs: 8013

\section{Myristica rosselensis ssp. minutiflora}

Myristicaceae

VU D2

Papua New Guinea

A tree occurring in rainforest on ridge crests between 100 and $300 \mathrm{~m}$. It is known from two collections, one from Sudest Island and the other from Rossel Island. Assessor: World Conservation Monitoring Centre Refs: 19082

\section{Myristica rubrinervis var, duplex}

Myristicaceae

VU Alc, D2 Philippines

A newly described variety found in rainforest, montane and ridge forest on the islands of Palawan, Mindoro and Leyte. It is known from a total of only five collections. Assessor: World Conservation Monitoring Centre Refs: 18022

\section{Myristica rubrinervis var. rubrinervis \\ Myristicaceae}

VU D2

Philippines

So far this variety is known only from three collections from Palawan, where it occurs in stunted montane rainforest, sometimes on ultrabasic rock. The main island is a biosphere reserve.

Assessor: World Conservation Monitoring Centre Refs: 18022

\section{Myristica rumphii var. florentis}

Myristicaceae

$\mathrm{VU} B \mathrm{~B}+2 \mathrm{c}$

Indonesia (Lesser Sunda Is.)

This variety is confined to montane forest on Flores Island. It has been collected a total of nine times.

Assessor: World Conservation Monitoring Centre Refs: 18022

\section{Myristica sarcantha}

Myristicaceae

VU D2

Indonesia (Irian Jaya)

An understorey tree known only from the type collection from mixed primary lowland forest in Sarmi, northem Irian Jaya.

Assessor: World Conservation Monitoring Centre Refs: 3641,19084

\section{Myristica schlechteri}

Myristicaceae

VU D2

Papua New Guinea

The only specimen of this understorey tree was collected in 1908 in forest near Pema, Morobe Province. Assessor: World Conservation Monitoring Centre Refs: 1493

\section{Myristica simiarum ssp. calcarea}

Myristicaceae VU D2 Indonesia (Kalimantan), Malaysia (Sarawak)

A forest tree, usually found on limestone; to date it is known from west and north-east Kalimantan and west Sarawak.

Assessor: World Conservation Monitoring Centre Refs: 18022 


\section{Myristica simulans}

Myristicaceae

VU D2

Papua New Guinea

The sole collection of this tree was gathered from riverine rainforest at Modewa Bay, Milne Bay Province. Assessor: World Conservation Monitoring Centre Refs: 1493

\section{Myristica sinclairi}

Myristicaceae

VU D2

Papua New Guinea

A total of five collections of this understorey tree have been gathered from Castanopsis forest, restricted to Morobe Province.

Assessor: World Conservation Monitoring Centre Refs: 1493

\section{Myristica sogeriensis \\ Myristicaceae}

VU D2

Papua New Guinea

Endemic to the Sogeri region of Central Province, this shrub or small tree has been collected twice in foothill forest.

Assessor: World Conservation Monitoring Centre Refs: 1493

\section{Myristica subalulata var, hagensis}

Myristicaceae

VU D2

Papua New Guinea

This variety is found in montane Noshofagus or Castanopsis forest. It is known from five collections. Assessor: World Conservation Monitoring Centre Refs: 1493

\section{Myristica subalulata var. leptantha}

Myristicaceae

VU D2

Indonesia (Irian Jaya), Papua New Guinea

A variety known from three disjunct localities of forest in the Vogelkop Peninsula, Irian Jaya, and Western and Sepik Provinces, Papua New Guinea.

Assessor: World Conservation Monitoring Centre

Refs: 1493,19084

\section{Myristica subalulata var. pedunculata}

Myristicaceae

VU D2

Papua New Guinea

A small tree, known only from the type locality at a streamside in lowland rainforest in the Gulf Province. Assessor: World Conservation Monitoring Centre Refs: 1493, 19084

\section{Myristica subcordata var. rimosa}

Myristicaceae

VU D2

Indonesia (Irian Jaya)

This variety is known from only four collections, gathered in forest on bedrock on the Vogelkop peninsula.

Assessor: World Conservation Monitoring Centre

Refs: 3641

\section{Myristica succadanea}

Myristicaceae

LR/nt

Indonesia (Moluccas)

A small tree of lowland and montane primary forest, found on the islands of Ternate, Tidore and Bacan. Assessor: World Conservation Monitoring Centre Refs: 8013,17232

\section{Myristica tamrauensis}

Myristicaceae

VU D2

Indonesia (Irian Jaya)

A small tree restricted to the Tamrau range of the northern Vogelkop Peninsula, where it has been collected twice in primary oak forest.

Assessor: World Conservation Monitoring Centre Refs: 1493

\section{Myristica teijsmannii}

Myristicaceae

$\mathrm{EN} \mathrm{Bl+2c}$

Indonesia (Java)

From Pacitan to Kawi the species occurs in mixed lowland forest up to $700 \mathrm{~m}$. The habitat has been almost completely cleared at this altitude and there is intense pressure on remaining forested areas. There have been no recent collections.

Assessor: de Wilde, W.J.J.O.

Refs: $9078,18022,19078$

\section{Myristica tenuivenia ssp. lignosa}

Myristicaceae

VU D2

Papua New Guinea

A subspecies of hill forest, known only from a single collection from Fergusson Island and a single collection from Rossel Island.

Assessor: World Conservation Monitoring Centre

Refs: 1493

\section{Myristica trianthera}

Myristicaceae

VU D2

Indonesia (Irian Jaya)

Restricted to the Jayapura area, this small tree has been collected twice from lowland periodically flooded forest. Assessor: World Conservation Monitoring Centre Refs: 1493

\section{Myristica tristis ssp. ingambitense}

Myristicaceae

VU D2

Indonesia (Irian Jaya), Papua New Guinea

This subspecies is known from two collections from two localities of secondary forest, one in south-east Irian Jaya and the other in south-west Papua New Guinea.

Assessor: World Conservation Monitoring Centre Refs: 1493

\section{Myristica tristis ssp. Louisiadensis}

Myristicaceae

VU D2

Papua New Guinea

A subcanopy tree of lowland forest, known from a single collection from Sudest (Tagula) Island and from one or two collections from Rossel Island.

Assessor: World Conservation Monitoring Centre

Refs: 1493

\section{Myristica tristis ssp. sessilifructa}

Myristicaceae

VU D2

Indonesia (Moluccas)

A solitary species, known from a single collection from lowland forest on Bacan Island.

Assessor: World Conservation Monitoring Centre

Refs: 18022

\section{Myristica ultrabasica}

Myristicaceae

VU D2

Indonesia (Sulawesi)

A tree restricted to forest over ultrabasic (nickel) soils of 
central Sulawesi. It has been collected four times. Assessor: World Conservation Monitoring Centre Refs: 18022

\section{Myristica velutina ssp. breviflora}

Myristicaceae

VU D2

Papua New Guinea

This subspecies is restricted to the West Sepik and Westem Provinces, where it has been collected five times in montane forest.

Assessor: World Conservation Monitoring Centre

Refs: 1493

\section{Myristica verruculosa}

Myristicaceae

VU D2

Indonesia (Irian Jaya)

Known from five collections, this tree occurs in secondary forest on limestone from the Vogelkop and Bombarai Peninsulas.

Assessor: World Conservation Monitoring Centre

Refs: 3641

\section{Myristica warburgii ssp. hybrida}

Myristicaceae

VU D2

Papua New Guinea

This subspecies is restricted to mixed primary montane forest in the East Highlands Province, where it has been collected twice, and possibly Sepik Province.

Assessor: World Conservation Monitoring Centre

Refs: 1493

\section{Myristica warburgii ssp. siphonantha}

Myristicaceae

VU D2

Indonesia (Irian Jaya), Papua New Guinea

This subspecies has been collected five times from the northem slopes of New Guinea.

Assessor: World Conservation Monitoring Centre

Refs: 1493

\section{Myristica xylocarpa}

Myristicaceae

LR/nt

Solomon Islands (South Solomon)

A tree that occurs in well-drained forest and ridge forest up to $250 \mathrm{~m}$ on the islands of Santa Ysabel, San Cristóbal and Guadalcanal.

Assessor: World Conservation Monitoring Centre

Refs: 18252

\section{Myristica yunnanensis}

Myristicaceae

CR D1

China (Yunnan)

A species recorded from four small localities in Mengla, in Xishuangbanna, where it occurs in low-elevation humid monsoon forest. The species is extinct from two of these localities and approximately 20 trees have been recorded in remaining populations. They appear to be unhealthy and rarely set seed.

Assessor: World Conservation Monitoring Centre

Refs: $1818,11847,19055$

\section{Myrocarpus frondosus}

Leguminosae

DD

Argentina (Corrientes, Misiones), Brazil (Minas Gerais, Paraná, Rio de Janeiro, Rio Grande do Sul, Santa Catarina, São Paulo), Paraguay

A good-quality commercial timber tree, which is widely occurring within an area of seasonally dry forest extending from the south-east coast of Brazil to
Paraguay and northern Argentina. The expansion of agriculture has caused severe habitat loss in Argentina. Assessor: Prado, D.

Refs: $1262,5112,7906,9173,12837$

\section{Myrrhinium atropurpureum var. atropurpureum}

Myrtaceae

$\mathrm{CR} \mathrm{B} 1+2 \mathrm{c}$

Brazi

A monotypic genus which is divided into two varieties. This variety is restricted to * restinga vegetation in Rio de Janeiro. It does not appear to have been collected recently. This habitat is in serious danger of disappearing. The other variety is widespread in temperate and subtropical South America.

Assessor: World Conservation Monitoring Centre Refs: 5435,7980

\section{Myrsine adamsonii}

Myrsinaceae

French Polynesia (Marquesas Is.)

An endemic to Nuku Hiva.

Assessor: Florence, J.

Refs: 14513

\section{Myrsine andersonii}

Myrsinaceae

$\mathrm{CR} B 1+2 \mathrm{c}$

French Polynesia (Tubuai Is.)

Although little is known about the populations on Rapa, the species is in a critical state on the islands of Raivavae and Tubuai.

Assessor: Florence, J.

Refs: 14513

\section{Myrsine brownii}

Myrsinaceae

CR B $1+2 c$

French Polynesia (Tubuai Is.)

Little is known about the population on Tubuai, but the species is critically threatened on the island of Raivavae. Assessor: Florence, J.

Refs: 14513

\section{Myrsine bullata}

Myrsinaceae

VU D2

Peru

A cloud forest species, known only from the department of San Martin, occurring roughly between 3000 and $3500 \mathrm{~m}$

Assessor: World Conservation Monitoring Centre Refs: 1984

\section{Myrsine degeneri}

Myrsinaceae

USA (Hawaii)

A small rainforest tree restricted to populations in Puukeahiakahoe and Kawai Nui on the summit of Koolau Mountains.

Assessor: World Conservation Monitoring Centre Refs: 3372

\section{Myrsine diazii}

Myrsinaceae

VU D2

Peru

Known only from the type collection, this cloud forest species occurs in the department of Amazonas. Assessor: World Conservation Monitoring Centre Refs: 1984 
Myrsine fernseei

Myrsinaceae

USA (Hawaii)

This is a shrub or small tree of bogs and streamsides endemic to Kauai and known from several localities, Wahiawa, Powerline Trail, the headwaters of Hanalei River and Kaloko Reservoir.

Assessor: World Conservation Monitoring Centre Refs: 3372

\section{Myrsine fosbergï}

Myrsinaceae

VU C2a

USA (Hawaii)

An uncommon species confined to Oahu, where it is known from populations in cloudswept forest along the crest of the Koolau Mountains from the south-eastern end to Castle Trail.

Assessor: World Conservation Monitoring Centre

Refs: 3372

\section{Myrsine gracilissima}

Myrsinaceae

French Polynesia (Marquesas Is.)

The species is known only from Hiva $\mathrm{Oa}$.

Assessor: Florence, J.

Refs: 14513

\section{Myrsine grantii var. tobiiensis}

Myrsinaceae

LR/nt

French Polynesia (Marquesas Is.)

The species is known only from Nuku Hiva.

Assessor: Florence, J.

Refs: 14513

\section{Myrsine hartii}

Myrsinaceae

French Polynesia (Socjety Is.)

$\mathrm{CR} B 1+2 \mathrm{c}$

An endemic to Tahiti.

Assessor: Florence, J.

Refs: 14513

\section{Myrsine hosakae \\ Myrsinaceae}

VU D2

Pitcairn Islands

One of the least common of the Henderson Island endemics. Up to 7000 individuals may exist, scattered in the plateau forest. The species is dioecious and may be suffering from the heavy predation of fnits, often before they are ripe, by doves. Ex situ germination tests have failed so far as many seeds appear to lack embryos. Henderson Island is a World Heritage Site.

Assessor: Waldren, $\mathbf{S}$.

Refs: 12900,13604

\section{Myrsine knudseni}

Myrsinaceae

EN C2a

USA (Hawaii)

Endemic to Kauai, the species occurs in rainforest between 1060 and $1220 \mathrm{~m}$ in altitude in Kokee and Hanapepe Valley.

Assessor: World Conservation Monitoring Centre

Refs: 3372

\section{Myrsine longifolia}

Myrsinaceae

French Polynesia (Society Is.)

CR B $1+2 \mathrm{c}$

An endemic to Tahiti.

Assessor: Florence, J.

Refs: 14513
Myrsine mezii

Myrsinaceae

USA (Hawaii)

A small tree known from the ridge west of Hanapepe River on Kauai. It has been postulated that the species represents a hybrid between $M$. kavaiensis and $M$. wawraea, although the distribution of the latter does not coincide closely with that of $M$. mezii.

Assessor: World Conservation Monitoring Centre

Refs: 3372

\section{Myrsine obovata}

Myrsinaceae

French Polynesia (Society Is.)

The species is known only from Raiatea.

Assessor: Florence, J.

Refs: 14513

\section{Myrsine oliveri}

Myrsinaceae

New Zealand (North Is.)

VU D2 An endemic to the Three Kings Islands. Information from the Red Data Book in 1981 indicated that very few individuals remained in coastal forest on Great Island. Current population figures are not available but are no longer believed to be at a critical low.

Assessor: World Conservation Monitoring Centre Refs: 902, 17637, 19133

\section{Myrsine orohenensis}

Myrsinaceae

French Polynesia (Society Is.)

The species is known only from Tahiti.

Assessor: Florence, J.

Refs: 14513

Myrsine ovalis var, ovalis

Myrsinaceae

French Polynesia (Society Is.)

$\mathrm{LR} / \mathrm{nt}$

Populations are recorded from Huahine, Raiatea and Tahiti.

Assessor: Florence, J.

Refs: 14513

\section{Myrsine pearce}

Myrsinaceae

Peru

VU B $1+2 c$

This cloud forest species is endemic to Cuzco, where it occurs within the altitudinal range of 2500 to $4000 \mathrm{~m}$. Assessor: World Conservation Monitoring Centre Refs: 1984

\section{Myrsine petiolata}

Myrsinaceae

USA (Hawaii)

$\mathrm{EN} \mathrm{C2a}$

Normally a shrub but occasionally a small tree the species mainly occurs in boggy shrubland and forest in the eastem half of Kauai and along Alakai Swamp Trail. Assessor: World Conservation Monitoring Centre Refs: 3372

\section{Myrsine raiateensis}

Myrsinaceae DD

\section{An endemic to Raiatea}

Assessor: Florence, J.

Refs: 14513 


\section{Myrsine reyneli \\ Myrsinaceae}

VU B I +2c

Peru

A cloud forest species, known only from the department of Piura.

Assessor: World Conservation Monitoring Centre

Refs: 1984

\section{Myrsine rivularis \\ Myrsinaceae}

VU D2

Peru

Recorded only from the type collection, the species occurs in forest up to about $2000 \mathrm{~m}$ in the department of Puno.

Assessor: World Conservation Monitoring Centre

Refs: 1984

\section{Myrsine romuiensis}

Myrsinaceae

$\mathrm{CR} B 1+2 \mathrm{c}$

French Polynesia (Society Is.)

The species is known only from Tahiti.

Assessor: Florence, J.

Refs: 14513

\section{Myrsine sodiroana}

Myrsinaceae

VU B1+2c

Ecuador

An endemic tree of Ecuador currently known only to occur in Pichincha and Cotopaxi. The habitat of this species is High Andean cloud forest between 1500 and $3500 \mathrm{~m}$.

Assessor: World Conservation Monitoring Centre

Refs: 19119,19120

\section{Myrsine tahuatensis}

Myrsinaceae

DD

French Polynesia (Marquesas Is.)

An endemic to Tahuata.

Assessor: Florence, J.

Refs: 14513

\section{Myrtus claraensis \\ Myrtaceae \\ Cuba}

CR B $1+2 \mathrm{C}$

Very uncommon, this shrub, sometimes a small tree, is confined to the coastal areas of Casilda in Sancti Spiritus Province. Housing development and the expansion of tourism have caused extremely severe habitat decline.

Assessor: Areces-Mallea, A.E.

Refs: 11403, 18485, 19149

\section{Nageia maxima}

Podocarpaceae

VU D2

Malaysia (Sarawak)

An understorey tree of peat-swamp forest. Present information suggests the species is confined to the Mujong River drainage and Bako National Park, but it is possible other populations exist in nearby localities. The area is vulnerable to disturbance from logging and habitat clearance for agriculture.

Assessor: SSC Conifer Specialist Group

Refs: $374,2226,6851,19192$

\section{Nageia nagi}

Podocarpaceae

China, Japan (Japan, Ryukyu Is.), Taiwan

An important timber species occurring in moist forest at various elevations in southem China. Taiwan and the southern islands of Japan. There is concem for populations on Shikoku and Kyushu Islands in Japan because of the levels of exploitation. In Taiwan the species is known under the name $N$. formosensi. It is also known under the name of $N$. nagi, the species appears in populations in the northern end and southern tip of Taiwan, separated by the central range of mountains. Occurring in lowland mixed evergreen forest, the species has come under threat from habitat declines. Whole plants are also dug up for the horticultural trade. The species is recorded in Kenting and Yangmingshan National Parks.

Assessor: SSC Conifer Specialist Group

Refs: 374, 6469, 11380, 18751, 19050, 19051

\section{Napoleonaea lutea}

Lecythidaceae

CR Alc, Bl+2c

Nigeria

This species, along with $N$. reptans, is poorly documented and apparently confined to Eket in southeast Nigeria. Oil exploration operations in the area are causing extensive damage, to the habitat, if not it's complete destruction.

Assessor: World Conservation Monitoring Centre Refs: $450,2773,11504$

\section{Napoleonaea reptans}

Lecythidaceae

CR B1+2c

Nigeria

This species, along with $N$. lutea, is poorly documented and confined to the Eket area in south-east Nigeria. Oil exploration operations are causing extensive damage, if not complete destruction of the habitat.

Assessor: World Conservation Monitoring Centre Refs: 450, 2773, 11504

\section{Nargedia macrocarpa}

Rubiaceae

VU Alc

Sri Lanka

A tree restricted to the lowland wet evergreen forests of south-west Sri Lanka.

Assessor: World Conservation Monitoring Centre Refs: 8203, 17195

\section{Nauclea diderrichii}

Rubiaceae

VUAlcd

Angola, Cameroon, Central African Republic, Congo, Côte d'Ivoire, Democratic Republic of Congo, Gabon, Ghana, Liberia, Mozambique, Nigeria, Sierra Leone, Uganda

A widespread species which is found in low densities in the wild. It is heavily exploited for its timber, which is used in general construction work. Regeneration is good in large canopy gaps but the species is outcompeted by other pioneers after clear-felling.

Assessor: African Regional Workshop

Refs: 2773, 6718, 10961, 12061, 14667, 17408

\section{Nauclea gageana}

Rubiaceae

$\mathrm{CR} B 1+2 \mathrm{c}$

India (Andaman and Nicobar Is. - Andaman Is.)

A large tree collected from Middle and South Andaman Islands in the $19^{\text {th }}$ century. No record of the species has been made since and little is known of its present status, if it still exists.

Assessor: World Conservation Monitoring Centre Refs: 4799,7147 
Naucleopsis oblongifolia

Moraceae

VU B $1+2 b c$

Brazil

Assessor: Carauta, J.P.P.

Refs: 15717,19101

Necepsia castaneifolia ssp. chirindica

Euphorbiaceae

EN D1

Zimbabwe

Endemic to Chirinda forest, this subspecies occupies an area of just $0.5 \mathrm{~km}^{2}$. The forest has been logged in the past and is most heavily disturbed at the perimeter, where it is at risk from invasive species, drought and fire. It is otherwise well protected and the population is healthy. Other subspecies of this taxon are known from Tanzania and Madagascar.

Assessor: World Conservation Monitoring Centre

Refs: 6725

\section{Necepsia castaneifolia ssp. kimbozensis}

Euphorbiaceae

EN C2b, D1

Tanzania

The East African form of a taxon also occurring as a distinct subspecies in Chirinda forest, Zimbabwe, and thereafter only in Madagascar. This subspecies is confined to a $4 \mathrm{~km}^{2}$ patch of moist forest on limestone contained within Kimboza Forest Reserve. The surrounding area is densely populated but two forest guards are employed by the Tanzanian Catchment Forest Project to prevent illegal activities.

Assessor: Lovett, J. \& G.P. Clarke

Refs: 3356, 10961

\section{Nectandra angusta}

Lauraceae

VU D2

Bolivia

A species known from just three locations on the eastern slopes of the Andes from central and southern parts of Bolivia. One of the most important timber trees in the area, it is being heavily exploited in at least one of these sites. It is closely related to $N$. longifolia, a more widespread species in the same region.

Assessor: Rohwer, J.G.

Refs: $7980,9262,12663$

\section{Nectandra apiculata}

Lauraceae

VU D2

Bolivia

Restricted to cloud forest, this species has been collected from just one site on the Cochabamba to Santa Cruz road. More material is needed to ascertain whether similar collections nearby are the same species.

Assessor: World Conservation Monitoring Centre

Refs: 7980,9262

\section{Nectandra astyla}

Lauraceae

VU D2

Peru

A montane species, which is known only from the type collection near Moyobamba.

Assessor: World Conservation Monitoring Centre

Refs: 7980,9262

\section{Nectandra aurea}

Lauraceae

LR/nt

Venezuela

A gallery forest tree from the banks of the Orinoco. Its range covers an area greater than $20,000 \mathrm{~km}^{2}$. It is possible that this will increase as additional undetermined material is studied.

Assessor: World Conservation Monitoring Centre

Refs: 7980,9262

\section{Nectandra baccans}

Lauraceae

Venezuela

LR/cd

An evergreen species known from a few locations in dry forest or cloud forest, between 750 and $2400 \mathrm{~m}$. Although there is considerable population pressure in much of its range, it is well represented in protected areas.

Assessor: Rohwer, J.G.

Refs: 9262, 12663

\section{Nectandra barbellata}

Lauraceae

VU B1+2c, D2

Brazil (Espírito Santo, São Paulo)

This forest species is known from just a few collections in south-east Brazil, where the rates of deforestation have been considerable. Doubts as to its being a separate entity from the variable species $N$. puberula have been expressed.

Assessor: World Conservation Monitoring Centre

Refs: 7980,9262

\section{Nectandra bartlettiana}

Lauraceae

LR/nt

Venezuela

A relatively wide-ranging tree from lowland moist forest on both sides of the Cordillera de Mérida in Venezuela. This includes records from forest reserves, Ticoporo and Caparo.

Assessor: World Conservation Monitoring Centre

Refs: 7980,9262

\section{Nectandra bicolor}

Lauraceae

EN B $1+2 c$

Panama

The species is known from just a small population confined to a unique low-altitude cloud forest on the Cerro Jefe. The area is well protected and essential as a watershed. Very little is actually known about the species.

Assessor: Mitré, $\mathrm{M}$.

Refs: $7950,7980,9262,16772$

\section{Nectandra brittonii}

Lauraceae

VU D2

Bolivia, Pen

An understorey species, which occurs in disjunct populations. The 1886 type collection is from $\mathrm{La} \mathrm{Paz}$. In Peru, the tree has been collected in pastures and in tall forest.

Assessor: Rohwer, J.G.

Refs: $7980,9262,12663$

\section{Nectandra brochidodrome}

Lauraceae

VU D2

Peru

A striking species on account of the leaf venation. It is known only from the type collection in Manu National Park. The park protects $15,328 \mathrm{~km}^{2}$ of forest, although there are threats from oil exploitation.

Assessor: World Conservation Monitoring Centre

Refs: 7980,9262 


\section{Nectandra canaliculata}

Lauraceae

VU D2

Ecuador

A tree which is known only from the type collection from Limonococha.

Assessor: World Conservation Monitoring Centre

Refs: 7980, 9262

\section{Nectandra caudatoacuminata}

Lauraceae

CR B1+2c

Haiti

This species is even less well collected than its close relative $N$. pulchra. It is known only from the type collection, which was made in 1929 on the Massif de la Hotte. These forests are under considerable pressure from local exploitation and encroaching agriculture. Fieldwork is needed to confirm whether the population is still intact.

Assessor: World Conservation Monitoring Centre

Refs: 197, 7980, 9262

\section{Nectandra cerifolia}

Lauraceae

VU D2

Ecuador

A collection in *elfin forest on the western slopes of the Cordillera de Cutucú was made in 1976. No other record of the small tree species is known.

Assessor: World Conservation Monitoring Centre

Refs: 7980,9262

\section{Nectandra citrifolia}

Lauraceae

VUD2

Bolivia, Peru

This shrubby tree was originally described from an 1892 collection in Bolivia. Since then another population has been found along the banks of Rio Mayo in Peru.

Assessor: World Conservation Monitoring Centre Refs: 7980,9262

\section{Nectandra coeloclada}

Lauraceae

VU D2

Ecuador

An unusual Nectandra species on account of its hollow twigs. It occurs in humid forest in Jatun Sacha Biological Reserve. Collections from Morona Santiago also seem to concur with this species.

Assessor: World Conservation Monitoring Centre

Refs: 7980, 9262

\section{Nectandra cordata}

Lauraceae

Peru

A tree known only from the type specimen, which was collected in 1933. Information on its ecology and habitat are lacking.

Assessor: World Conservation Monitoring Centre Refs: 7980, 9262

\section{Nectandra crassiloba}

Lauraceae

VU D2

Ecuador

Occurring as a tall tree in primary and secondary rainforest, this species is apparently confined to two adjacent localities.

Assessor: World Conservation Monitoring Centre Refs: 7980,9262

\section{Nectandra cufodontisii}

Lauraceae

LR/nt

Costa Rica, Nicaragua, Panama

A distinctive tree found only in montane and cloud forests from Palmira and Poás through the Cordillera de Talamanca to the Chiriquí highlands in Panama. It has also recently been collected from the Central Cordilleral of Nicaragua. Much of its distribution lies in protected areas but there is still some threat of deforestation. It yields a hard yellow-wood.

Assessor: World Conservation Monitoring Centre

Refs: 9262,12587

\section{Nectandra dasystyla}

Lauraceae

VU C2a

Bolivia, Ecuador? (Ecuador?), Peru

Occurring in moist lowland forest, this large-flowered and conspicuous species is known from only a few locations in Loreto, including Alexander von Humboldt National Forest, and in Beni and Pando. A collection of doubtful identity has also been found in Manabi in Ecuador.

Assessor: Rohwer, J.G.

Refs: 9262,12663

\section{Nectandra debilis}

Lauraceae

Brazil (Espírito Santo, Rio de Janeiro)

CR Alc

An Atlantic forest species, which hasn't been collected for over 100 years. A tiny fraction of these forests has survived the past centuries of deforestation.

Assessor: World Conservation Monitoring Centre

Refs: 7980,9262

\section{Nectandra embirensis}

Lauraceae

Brazil (Amazonas), Ecuador, Peru

So far only three locations are known where the species occurs in *várzea forest or rainforest at the mouth of rivers. These include Río Zubineta in Loreto, Peru, and Rio Envira in Amazonas, Brazil. Each population in each country is notably distinct.

Assessor: Rohwer, J.G.

Refs: 9262, 12663

\section{Nectandra filiflora}

Lauraceae

VU D2

Peru

A species which is known only from the type collection in the Alexander von Humboldt National Forest, which extends to $5708 \mathrm{~km}^{2}$. Its inflorescence and pedicels are unlike any other in the genus.

Assessor: World Conservation Monitoring Centre Refs: 7980,9262

\section{Nectandra fragrans}

Lauraceae

VU D2

Ecuador

A species known only from a collection, in 1989 , from the Cordillera de Cutucu.

Assessor: World Conservation Monitoring Centre

Refs: 7980,9262

\section{Nectandra fulva}

Lauraceae

VU D2

Venezuela

Only one population is known. It occurs on the Río Mawarinuma near the Neblina Base Camp. The area is protected within a national park but disturbances have 
been caused by gold mining, and pressures also exist from the influx of people.

Assessor: World Conservation Monitoring Centre

Refs: 7980,9262

\section{Nectandra gracilis}

Lauraceae

LR/nt

Ecuador, Peru

A newly described Amazon tree species, occurring in seasonally inundated forest. The number of sites where it is found continues to increase.

Assessor: Rohwer, J.G.

Refs: $7980,9262,12663$

\section{Nectandra grisea}

Lauraceae

VU D2

Brazil (Amazonas)

Known only from one locality on the banks of Rio

Japurá, this species occurs in *várzea forest.

Assessor: World Conservation Monitoring Centre

Refs: 7980,9262

\section{Nectandra guadaripo}

Lauraceae

VU D2

Colombia, Ecuador

A tall tree of primary lowland rainforest, recorded from three localities along the western part of the Colombian/Ecuadorean border. The species is considered threatened by *INEFAN.

Assessor: World Conservation Monitoring Centre Refs: $7980,9262,19135$

\section{Nectandra herrerae}

Lauraceae

$\mathrm{EN} \mathrm{Bl}+2 \mathrm{c}$

Peru

A small tree discovered near Aguas Calientes train station in Machupicchu Historical Sanctuary. The cloud forest extends c. $3260 \mathrm{~km}^{2}$ and is heavily visited by tourists on foot and by train. Aguas Calientes is expanding rapidly as a tourist town. However, regular buming of the forest, including a very serious fire in 1997, remains the greatest threat to the area.

Assessor: World Conservation Monitoring Centre Refs: 7980,9262

\section{Nectandra heterotricha}

Lauraceae

VU D2

Peru

A tree species confined to a small area of forest in the Iquitos region.

Assessor: World Conservation Monitoring Centre

Refs: 7980,9262

\section{Nectandra hirtella}

Lauraceae

VU D2

Peru

A newly described species which has been recorded from two sites in submontane forest.

Assessor: World Conservation Monitoring Centre Refs: 7980,9262

\section{Nectandra hypoleuca}

Lauraceae

VU D2

Costa Rica

A Central American Nectandra species which is most closely related to Amazonian species. This tree is known with certainty from La Selva Biological Station from secondary woodlands and alluvial forest along the Río Puerto Viejo. The area is protected but occupies a small corridor of forest now surrounded by pastureland and crops. More material is needed to confirm the species' occurrence in the Sirena Field Station in Puntarenas. Assessor: World Conservation Monitoring Centre Refs: 7980,9262

\section{Nectandra impressa}

Lauraceae

Brazil

This species is known only from the type specimen collected in the last century. It has not been found since and its locality in the wild remains unknown.

Assessor: Rohwer, J.G.

Refs: $7980,9262,12663$

\section{Nectandra japurensis}

Lauraceae

Brazil (Amazonas), Peru

The complete distribution of the species is not consolidated. It occurs for certan in lowland forest sites in the western Amazon. In Peru populations have been recorded in Iparía in Huánuco National Forest, near Vitoc in Junin, and in three locations near rivers in Loreto. A population occurs along Rio Japurá in Amazonas in Brazil. Specimans with some similarities have been collected in two locations in the Peruvian Andes.

Assessor: Rohwer, J.G.

Refs: 9262,12663

\section{Nectandra krugii}

Lauraceae

EN Alcd $+2 c, B 1+2 c d$

Antigua and Barbuda, Dominica, Dominican Republic, Guadeloupe, Martinique, Netherlands Antilles, Puerto Rico

This Caribbean forest tree ranges from Dominica (and possibly Martinique) to western Dominican Republic. The forest in most of these areas has been heavily exploited. The species was noted in 1896 as becoming rare as a result of excessive exploitation and in the last 70 years it has only been collected in Puerto Rico.

Assessor: Rohwer, J.G.

Refs: $197,7424,7980,9262,12663$

\section{Nectandra Latissima}

Lauraceae

VU D2

Bolivia

Occurring as a small tree or shrub, this species is confined to islands of forest in savanna in the province of Beni.

Assessor: World Conservation Monitoring Centre Refs: 7980,9262

\section{Nectandra leucocome}

Lauraceae

$\mathrm{EN} \mathrm{B} 1+2 \mathrm{c}$

Mexico (Chiapas)

A seriously restricted species, which with the more widespread $N$. ambigens, is the only species of the genus to produce pink flowers. It is recorded only from tall evergreen forest in Chiapas. These forests, in particular, have suffered dramatic declines in extent, largely because of land settlement and cattle ranching. Assessor: World Conservation Monitoring Centre Refs: 7980,9262

\section{Nectandra longipetiolata}

Lauraceae

EN B $1+2 c d$

Costa Rica

This small tree is known from three collections from 
lower ridges in remnant primary forest near Limón. There has been large-scale conversion of these forests over the last 50 years into pastureland.

Assessor: World Conservation Monitoring Centre

Refs: 7950, 7980, 9262

\section{Nectandra matogrossensis}

Lauraceae

Brazil (Bahia, Mato Grosso)

VU D2

Closely related to $N$. globosa, this species is known from southern coastal Bahia and adjacent Mato Grosso in gallery forest and also in secondary vegetation and cocoa plantations, where it is used as a shade tree. A disjunct and doubtful locality also exists $1800 \mathrm{~km}$ inland. Assessor: Rohwer, J.G.

Refs: $7980,9262,12663$

\section{Nectandra matudai}

Lauraceae

VU B $1+2 c$

Mexico (Chiapas, Oaxaca)

Restricted to deciduous or secondary forests. There have been considerable declines in the extent of the forest, largely because of land settlement and cattle ranching. Assessor: World Conservation Monitoring Centre Refs: $7950,7980,9262$

\section{Nectandra micranthera}

Lauraceae

VUAlc+2c

Brazil (Bahia)

This tree species is restricted to the remnants of coastal rainforest and the cocoa plantations which have taken the place of forest. With more up-to-date information a more serious threat category might apply.

Assessor: World Conservation Monitoring Centre

Refs: 7980,9262

\section{Nectandra microcarpa}

Lauraceae

LR/nt

Colombia, Peru

Occurring in lowland rainforest often along rivers, this shrubby tree is known from the edges of Río Huallaga in Pen and from a more doubtful collection in Colombia. A record which may be erroneous has also been made in Argentina.

Assessor: World Conservation Monitoring Centre Refs: $7134,7980,9262$

\section{Nectandra minima \\ Lauraceae \\ $\mathrm{CRB} \mathrm{B}+2 \mathrm{C}$ \\ Cuba \\ The only collections of this shrub or small tree, from Isla de Pinos and the adjacent mainland, were made over 50 years ago. Natural vegetation remains only where land is unsuitable for agriculture. Fieldwork is necessary to determine how many individuals exist. \\ Assessor: Areces-Mallea, A.E.}

Refs: $7950,7980,9262,19149$

\section{Nectandra mirafloris}

Lauraceae

Nicaragua

VU D2

A tree which is known solely from montane and cloud forests in Nicaragua.

Assessor: World Conservation Monitoring Centre

Refs: $7980,9262,15719$

\section{Nectandra obtuscta}

Lauraceae

Colombia, Ecuador

LR/nt

A tree species collected from southernmost Colombia to Ecuador in Andean cloud and montane forests. The number of collections in Ecuador appears to be increasing and part of the population is in Rio Guajalito Floristic Reserve.

Assessor: Rohwer, J.G.

Refs: $7980,9262,12663$

\section{Nectandra olida}

Lauraceae

Ecuador, Peru

VUB $1+2 c$

A rainforest tree restricted to a fairly small range from southem Ecuador to northern Peru on the eastern slopes of the Andes. Threats exist from fires and encroaching farming activities.

Assessor: Rohwer, J.G.

Refs: $7980,9262,12663$

\section{Nectandra paranaensis}

Lauraceae

VU Alc+2c

Brazil (Paraná, São Paulo)

A tree which is confined to primary rainforest in southeast Brazil. In São Paulo it is restricted to Carlos Botelho State Park.

Assessor: World Conservation Monitoring Centre Refs: 7980,9262

\section{Nectandra parviflora}

Lauraceae

Ecuador, Pen?

VU D2

This is a primary forest species, which is largely known from the region of Río Pastaza. Another slightly different collection has been made in Loreto. Despite intensive collecting in Ecuador the species has not been found to be more widespread.

Assessor: Rohwer, J.G.

Refs: $7980,9262,12663$

\section{Nectandra psammophila}

Lauraceae EN Alc Brazil (Bahia, Espírito Santo, Minas Gerais, Rio de Janeiro)

The *restinga vegetation to which the species is confined is being rapidly destroyed, especially in the region of Rio de Janeiro. Only four collections have been made in the last 50 years.

Assessor: Rohwer, J.G.

Refs: $7980,9262,12663$

\section{Nectandra pseudocotea}

Lauraceae

VUAlc+2c

Peru

This species is restricted to forest in the foothills of the Peruvian Andes where fires are frequent. It is one of the most distinctive species of its genus on account of the pattem of glands in the stamens and staminodes.

Assessor: World Conservation Monitoring Centre Refs: 7980,9262

\section{Nectandra pulchra}

Lauraceae

CR B $1+2 c$

Haiti

The species has not been collected since 1927, when it occurred in the vicinity of Miragoane on limestone crags. Forest areas in Haiti have declined rapidly in the 
past century and the demand for land to cultivate continues to put pressure on remaining areas.

Assessor: World Conservation Monitoring Centre Refs: $197,7980,9262$

\section{Nectandra ramonensis \\ Lauraceae}

VU $B 1+2 c$

Costa Rica, Panama

This tree species is confined to drier montane forests from central Costa Rica to Cocle in Panama. Much of the area is covered by La Amistad Biosphere Reserve but forest destruction in the past decades has been considerable and pressures are still exerted by various activities: expanding agriculture, logging, industrial plantations, oil exploration, hydroelectric projects. Assessor: World Conservation Monitoring Centre Refs: 7980,9262

\section{Nectandra reflexa \\ Lauraceac}

VU D2

Ecuador, Peru

This species is known from a few collections, each so different that they may be worthy of distinction. Populations are found in pastureland or primary forest. In Ecuador the species is found in the Cordillera de Cutucu. In Peru it has been collected from a location near Quebrada, from Cajamarca and from three locations in Pasco.

Assessor: Rohwer, J.G.

Refs: 9262, 12663

\section{Nectandra rudis}

Lauraceae

VUAlc+2c

El Salvador, Guatemala, Mexico (Chiapas)

This species occurs in montane forests, which have declined in extent and continue to be under serious threat of deforestation.

Assessor: World Conservation Monitoring Centre

Refs: 7980,9262

\section{Nectandra ruforamula}

Lauraceae

$\mathrm{LR} / \mathrm{nt}$

Venezuela

A tree species which is restricted to the lowland link between the Orinoco and Amazon basins in Venezuela. Its extent of occurrence covers in the region of $50,000 \mathrm{~km}^{2}$.

Assessor: World Conservation Monitoring Centre

Refs: 7980,9262

\section{Nectandra salicina}

Lauraceae

LR/nt

Costa Rica, Panama

In Costa Rica and Panama the species is confined to montane forests, between 370 and $2000 \mathrm{~m}$. One collection made in Mexico is probably a new species. This species does not appear to be rare where it occurs but the dramatic declines in the habitat may qualify it for a threat category. It occurs in Rincón de la Vieja National Park

Assessor: Rohwer, J.G.

Refs: $7950,8100,9262,12663$

\section{Nectandra smithü}

Lauraceae

VU Alc, B1+2c

Costa Rica, Panama

Originally recorded only from Costa Rican cloud forest, this tree may now have been found in Panama. It occurs in submontane forest.

Assessor: World Conservation Monitoring Centre

Refs: 7980, 9262

\section{Nectandra sordida}

\section{Lauraceae}

VUAlc+2c

Peru

This species is relatively widespread, but restricted to remnant primary forest, mostly in coffee plantations. The potentially unbalanced structure of the populations and their location put the species at risk.

Assessor: World Conservation Monitoring Centre Refs: 7980,9262

\section{Nectandra spicata}

Lauraceae

Brazil (Rio de Janeiro)

A species known only from the surroundings of Rio de Janeiro city, where it is under serious threat from habitat destruction. Additional material is required to confirm its taxonomic status as separate from $N$. hihua and $N$. leucantha.

Assessor: World Conservation Monitoring Centre Refs: 7980,9262

\section{Nectandra subbullata}

Lauraceae

VU D2

Venezuela

A tree species which is known only from the type taken on the road from Mérida to La Azulita in 1982. It is very closely related to the more widespread $N$. cissiflora. Assessor: World Conservation Monitoring Centre Refs: 7980,9262

\section{Nectandra truxillensis}

Lauraceae

LR/nt

Venezuela

A small tree known from several locations on the Cordillera de Mérida in Venezuela.

Assessor: World Conservation Monitoring Centre Refs: 9262

\section{Nectandra utilis}

Lauraceae

$\mathrm{EN} \mathrm{B}++2 \mathrm{~cd}$

Peru

This tree occurs in Andean forests in northem Peru. It is known from only two locations and has not been collected again for some years, which may indicate that there has been a serious decline in the population. It apparently has the reputation of being the most-used general-purpose timber in the Chachapoyas area. Assessor: World Conservation Monitoring Centre Refs: $7980,9262,12663$

\section{Nectandra venulosa}

\section{Lauraceae}

Brazil (Minas Gerais)

This is a poorly known tree species from Serra do Frio in Minas Gerais. It is known from only herbarium specimens, the most recent of which is from 1864. Assessor: World Conservation Monitoring Centre Refs: 7980,9262

\section{Nectandra warmingü}

Lauraceae

LR/nt

Brazil (Bahia, Minas Gerais)

An easily overlooked tree of gallery forest and dry forest 
in the savanna regions of central Brazil. It is planted in Brasflia Federal District.

Assessor: World Conservation Monitoring Centre Refs: 9262

\section{Nectandra weddellii}

Lauraceae

$\mathrm{EN} \mathrm{B} 1+2 \mathrm{c}$

Brazil (Rio de Janeiro)

A species collected only from within a $250 \mathrm{~km}$ radius of Rio de Janeiro city.

Assessor: World Conservation Monitoring Centre

Refs: 7980,9262

\section{Nectandra wurdackii}

Lauraceae

VU D2

Peru

A little-known species with only one recorded location, in Amazon rainforest along Rio Marañon near Teniente Pingo in Loreto.

Assessor: Rohwer, J.G.

Refs: $7980,9262,12663$

\section{Nectandra yarinensis}

Lauraceae

Peru

A species known solely from two collections in the Río Ucayali, one being in the Iparia National Forest. More material would help determine its taxonomic position. Assessor: World Conservation Monitoring Centre Refs: 7980,9262

\section{Neea acuminatissima}

Nyctaginaceae

EN C2a

Guatemala, Honduras

Confined to the wet Caribbean lowlands, the species is scattered in sparse populations, including a rare occurrence in Lancetilla Biological Reserve.

Assessor: Nelson, C.

Refs: 13995

\section{Neea amplexicaulis}

Nyctaginaceae

EN C2a

\section{Panama}

Known only from a few records, the species is endemic to areas of lowland rainforest in Darién Province. It appears to be uncommon and only in Darién National Park is it relatively well protected. Elsewhere the threats of habitat clearance are great. There are no recent records of the species but much of the forest remains under-studied.

Assessor: Mitré, M.

Refs: $7980,14453,16772$

\section{Neea darienensis \\ Nyctaginaceae}

VU A2c

\section{Panama}

Originally known from just Darien Province, the species now appears to have a sparse occurrence in lowland rainforest, ranging from Darién National Park up to the Canal area. Its distribution extends very close to the border with Colombia. Most populations are contained within protected areas, outside which habitat loss has been extensive.

Assessor: Mitré, M.

Refs: $7980,14453,16772$

\section{Neea ekmanii}

Nyctaginaceae

$\mathrm{EN} \mathrm{B1+2c}$

Cuba

A tree up to $5 \mathrm{~m}$ tall confined to Hanabanilla River valley in south-central Cuba; this area is severely degraded by logging, agriculture, settlement and the construction of a river dam.

Assessor: Areces-Mallea, A.E.

Refs: $11403,18485,19149$

\section{Neisosperma brevituba}

Apocynaceae

VU D2

New Caledonia

A species occurring in the north-east of Grand Terre.

Assessor: Jaffré, $T$. et al.

Refs: 10351,12630

\section{Neisosperma brownï}

Apocynaceae

EX

French Polynesia (Marquesas Is.)

A species originally known from Nuku Hiva.

Assessor: Florence, J.

Refs: 14513

\section{Neisosperma sevenetii}

Apocynaceae

New Caledonia

$\mathrm{EN} \mathrm{B1+2c}$

This species is known from two recorded sites, one on the summit of Mont Tiebaghi and the other from an unknown locality labelled Wagap on the east coast. Both sites are unprotected and exposed to fires and encroaching activities.

Assessor: Jaffré, T. et al.

Refs: 10351,12630

\section{Neisosperma thiollierei}

Apocynaceae

CR B $1+2 \mathrm{c}$

New Caledonia

Found only in a small area of forest on Mont Koghi in the south-west of Grand Terre the species is unprotected and exposed to various threats, including tourist activities.

Assessor: Jaffré, T. et al.

Refs: 10351, 12630

\section{Neobalanocarpus heimii}

Dipterocarpaceae

VU Alc,d

Malaysia (Peninsular Malaysia), Singapore (ex), Thailand (ex?)

A large tree now only extant in Peninsular Malaysia. Populations in the southernmost part of Thailand and Singapore are believed to be extinct. Chengal is a valuable timber species. The export of logs has been banned. The species is found in numerous protected areas.

Assessor: Chua. L.S.L.

Refs: $5550,7673,9169,9199,13857,17140$

\section{Neoboutonia mannii}

Euphorbiaceae

LR/nt

\section{Cameroon, Equatorial Guinea, Nigeria}

The species ranges from south-east Nigeria to Equatorial Guinea. Although habitat clearance and logging have caused declines in the extent of lowland forest throughout its range, the species appears to be abundant in secondary and disturbed forest.

Assessor: World Conservation Monitoring Centre Refs: 11504,12597 


\section{Neocallitropsis pancheri}

Cupressaceae

VU Alc, B $1+2 b$

New Caledonia

A useful tree prone to overexploitation and confined to a few populations in southem maquis, with a single northem location on Mont Pafoua. Most populations occur in areas which are officially although frequently not effectively protected. Fire is a constant threat and the population on Mont Paéoua is also threatened by mining exploits.

Assessor: Jaffre, T. et al.

Refs: $9631,12630,14508$

\section{Neoharmsia baronii}

Leguminosae

CR B1+2abc

Madagascar

An important coastal forest species known from only two highly restricted localities in the northern tip of Madagascar near Irodo village. Its entire range is estimated to be just $10 \mathrm{~km}^{2}\left({ }^{*} \mathrm{AOO}\right)$ and only one site has been confirmed recently, on a small patch of highly specialised vegetation that is threatened by disturbance and exploitation. The site is not protected.

Assessor: Du Puy, D. \& H. Labat

Refs: 12353

\section{Neoharmsia madagascariensis \\ Leguminosae \\ Madagascar}

VU D2

A deciduous species known only from the Bemaraha Massif and Namoroka in west Madagascar, where it occurs on exposed limestone. It is confined to this very specialised habitat, which is of little interest for agriculture or exploitation. Both areas are reserves.

Assessor: Du Puy, D. \& H. Labat

Refs: 12353

\section{Neohemsleya usambarensis}

Sapotaceae

VU B1+2b

Tanzania

Known from the West Usambara Mountains and also sighted in the South Nguru Mountains, this species is locally common within a $200 \mathrm{~m}$ altitudinal range in moist forest. A monotypic genus.

Assessor: Lovett, J. \& G.P. Clarke

Refs: $3356,8814,11631$

\section{Neolemonniera clitandrifolia}

Sapotaceae

$\mathrm{EN} \mathrm{B} 1+2 \mathrm{C}$

Ghana, Liberia, Nigeria, Sierra Leone

From an unusual genus of five species, this tree is found at low densities in a few localities from Upper and Lower Guinea. In Ghana, it occurs in Atewa and also Cape Three Points and Ankasa Game Park Reserves. Much of its habitat has been lost to agriculture, mining and logging. Population numbers have been observed to decline rapidly.

Assessor: Hawthome, W.

Refs: 8369,12061

\section{Neolitsea daibuensis}

Lauraceae

EN C2a

Taiwan

A shrub to small tree, which occurs in the understorey of broadleaved forest between 1100 and $1300 \mathrm{~m}$ in Nanfengshan and Chinshuiying. The populations are small and unprotected, in areas which are susceptible to housing developments. Regeneration is poor.

Assessor: Lu, S.Y. \& F.J. Pan

Refs: 19050,19051

\section{Neolitsea fischeri}

Lauraceae

VU BI+2c

India (Kerala, Tamil Nadu)

Occurring from $1000 \mathrm{~m}$ to $2500 \mathrm{~m}$, the species is endernic to the Anamalai and Palni Hills.

Assessor: World Conservation Monitoring Centre

Refs: 19144

\section{Neolitsea kedahense}

Lauraceae

LR/cd

Malaysia (Peninsular Malaysia)

Confined to Gunung Terai in Kedah, this tree is scattered in montane forest at $1000 \mathrm{~m}$.

Assessor: Kochummen, K.M.

Refs: 8464,19073

\section{Neolitsea mollissima}

Lauraceae

VU D2

Malaysia (Peninsular Malaysia)

Known only from Gunong Batu Puteh in Perak, this montane forest tree is known from a single collection. The locality is within a protected forest.

Assessor: Kochummen, K.M.

Refs: 8464,19073

\section{Neolitsea vidali}

Lauraceae

Philippines

VU Aled

An endemic species to the Philippines. Rates of habitat loss through logging and shifting cultivation have led to considerable population declines.

Assessor: World Conservation Monitoring Centre

Refs: $2072,4919,4986$

\section{Neomitranthes cordifolia}

Myrtaceae

VU BI+2acd

Brazil (Santa Catarina)

Assessor: Pires O'Brien, J.

Refs: 19097,19098

\section{Neomitranthes langsdorfii}

Myrtaceae

VU B $1+2$ acd

Brazil (Santa Catarina)

Assessor: Pires O'Brien, J.

Refs: 19097

\section{Neosprucea sararensis}

Tiliaceae

$\mathrm{EN} \mathrm{B1}+2 \mathrm{c}$

Colombia

A Colombian endemic, found in Cundinamarca and Norte de Santander.

Assessor: Calderon, E.

Refs: 7980,19069

\section{Neostenanthera hamata}

Annonaceae

VU Alc, BI+ $2 c$

Côte d'Ivoire, Ghana, Liberia, Sierra Leone

Ranging from Sierra Leone to Ghana, this species is largely confined to lowland wet evergreen forest. Loss of its habitat over the past decades has been caused by mining, logging and the establishment of commercial plantations.

Assessor: Hawthome, W

Refs: 2773, 8369, 12061 


\section{Neostenanthera robsonü}

Annonaceae

LR/nt

Gabon

Collections are known from Lopé Forest Reserve, Lastoursville and Moumba. Logging has taken place in these areas and is expected to continue over the large areas of forest which are now under concession to logging companies.

Assessor: World Conservation Monitoring Centre

Refs: 14958,15790

\section{Neoveitchia storckii}

Palmae

EN Alc

Fiji

Endemic to Viti Levu, the species is reduced to a small area of secondary forest in Naitasiri Province. Over the past few decades the decline in population numbers has been rapid as the habitat has been logged and cleared for cultivation of commercial crops, such as bananas. It is the only species in the genus.

Assessor: Fuller, D.

Refs: 6053,19118

\section{Nephelium costatum}

Sapindaceae

VU B $1+2 c$

Malaysia (Peninsular Malaysia)

A late secondary and primary species found in the lowland open rainforest of Perak, Pahang, Selangor, Negeri Sembilan and Malacca.

Assessor: Chua, L.S.L.

Refs: 8464,19073

\section{Nephelium hamulatum}

Sapindaceae

VU B $1+2 \mathrm{c}$

Malaysia (Peninsular Malaysia)

A species of lowland open and closed rainforest on sandy soils. This tree can be found in Kedah, Perak, Pahang, Selangor, Negeri Sembilan, Malacca and Johore. Some localities lie within the wildlife sanctuary in the Cameron Highlands.

Assessor: Chua, L.S.L

Refs: 8464, 19073

\section{Nephrosperma vanhoutteanum}

Palmae

LR/nt

Seychelles

A palm tree endemic to Mahé, Silhouette, Praslin, Curieuse and Ste Anne, where it grows abundantly in lowland moist forest. Presently there is no threat to the species.

Assessor: Murugaiyan, P.

Refs: 19118

\section{Neraudia melastomifolia}

Urticaceae

VU Alce

USA (Hawaii)

A genus endemic to the Hawaiian Islands. This is the most common of the species and the only one that attains the stature of a tree. Populations are found in rainforest up to an altitude of $1160 \mathrm{~m}$ on Kauai, Oahu, and in Olowalu and Lao Valley on Maui. A single collection was also taken from Olokui Plateau on Molokai.

Assessor: World Conservation Monitoring Centre

Refs: 3372
Neraudia ovata

Urticaceae

USA (Hawaii)

CR C2a, D1

Originally occurring from North Kona to Kau on Hawaii, this dry forest species is now known from two populations of five and six individuals on privately owned land in Kaloko and a US Army training area at Pohakuloa. There are persistent threats from browsing and habitat damage by feral goats and sheep, and invasions of introduced plants. The species is classified as endangered on the US Federal Register.

Assessor: World Conservation Monitoring Centre

Refs: 3372, 19037

\section{Nesiota elliptica}

Rhamnaceae

St Helena

A small tree, once known from localised populations on the highest parts of the eastern central ridge. It became noticeably rare in the $19^{\text {t }}$ century, when the population was recorded as consisting of only 12 to 15 trees on the northem side of Diana's Peak. A single tree was discovered on a precipitous cliff near Diana's Peak but died in 1994. Of the many attempts to propagate cuttings from the tree, all but one have failed. The one cutting is now a tree of $2 \mathrm{~m}$ high in Scotland. It is suffering from a fungal infection but has provided a limited source of seed for further propagation. In St Helena, the species was known to be pollinated by an endemic syrphid fly, which also visits other endemic trees. The genus is monotypic.

Assessor: Cronk, Q.C.B.

Refs: 11891, 19081

\section{Nesogordonia papaverifera}

Sterculiaceae

VUAlcd

Benin, Cameroon, Central African Republic, Congo, Côte d'Ivoire, Gabon, Ghana, Liberia, Nigeria, Sierra Leone

A timber species, which grows in dense stands, commonly in areas where savanna has been replaced by forest. Regeneration is good in disturbed forest but genetic impoverishment is reported in outlying parts of the species' range. Exploitation is moderate. Sometimes large individuals are left after logging.

Assessor: African Regional Workshop

Refs: 2036, 2773, 4506, 6127, 6718, 12061, 17408

\section{Nesohedyotis arborea}

Rubiaceae

EN D1

St Helena

One of the commoner and keystone endemic trees of St Helena, with 132 adult trees growing in damp tree-fern thickets on the central ridge. The 24 subpopulations are small and clumped because of human land-use patterns. The species is dioecious, although males can set seed occasionally, and a small part of the population is currently reproductively isolated. It is pollinated by an endemic syrphid fly, which is also known to visit other endemic trees. The genus is monotypic.

Assessor: Cronk, Q.C.B.

Refs: 5556, 11891, 16700, 19081 


\section{Nesoluma nadeaudii}

Sapotaceae

French Polynesia (Society Is.)

The genus is made up of the three poorly defined species. This represents the taxon endemic to Tahiti.

Assessor: Florence, J.

Refs: 14513

\section{Nesoluma polynesicum}

Sapotaceae

VUAlce

Cook Islands, French Polynesia (Tubuai Is.), USA

(Hawaii)

Populations, which are sometimes recognised as separate varieties, have been recorded in the Tubuai Group, on Raivavae, Rurutu and Rapa, apparently on Mauke in the Cook Islands and on all the main Hawaiian Islands with the exception of Niihau and Kahoolawe. On Raivavae and Rurutu populations are in a critical state, but on Rapa they are unthreatened. In Hawaii the species once formed a significant component of lowland dry forest. It has become rare because of habitat loss, and is now restricted to remnant patches of forest on lava flows and slopes which are less attractive for cultivation or grazing.

Assessor: World Conservation Monitoring Centre

Refs: 434, 3372, 14513, 16551

\section{Nesoluma st.-johnianum}

Sapotaceae

VU D2

Pitcaim Islands

A common tree endemic to Henderson Island and codominant in the plateau forest with Xylosma suaveolens. It also occurs in scrub vegetation and on cliff slopes. The total population is estimated to number between 20,000 and 40,000 individuals and is under no threat at present. Henderson Island is a World Heritage Site.

Assessor: Waldren, S.

Refs: 12900,13604

\section{Neuburgia alata}

Loganiaceae

$\mathrm{LR} / \mathrm{nt}$

Fiji

Occurring within a restricted area of south-east Viti Levu, the species is found in dense or secondary forest up to $400 \mathrm{~m}$.

Assessor: World Conservation Monitoring Centre

Refs: 5515,18818

\section{Neuburgia macrocarpa}

Loganiaceae

LR/nt

Fiji

A tree with a compact crown, occurring in dense or open forest or forest edges up to $400 \mathrm{~m}$. So far populations are known only from Vanua Levu at the type locality and Viti Levu.

Assessor: World Conservation Monitoring Centre Refs: 5515, 18818

\section{Neuburgia macroloba}

Loganiaceae

EN D1

Fiji

A dense forest species, endemic to Taveuni. Small populations of about 20 plants are known from each of six sites.

Assessor: World Conservation Monitoring Centre

Refs: $5515,6053,18818$

\section{Neuburgia tubiflora}

Loganiaceae

VU D2

Papua New Guinea

A shrub or small tree, so far known only from two collections taken in the Vogelkop District. It is reported to be common in young secondary lowland forest. Assessor: World Conservation Monitoring Centre Refs: 19031

\section{Newtonia erlangeri}

Leguminosae

LR/nt

Kenya, Somalia, Tanzania

A tree of riverine or groundwater forest, extending into periodically flooded bushland. A few localities are known in southemmost Somalia and from the Tana River in Kenya, where it can be locally dominant. It also extends into north-east Tanzania. The habitat is reduced and degraded through overcutting. The timber of this species is used for construction work.

Assessor: Thulin, $\mathbf{M}$.

Refs: 9151, 12067, 18665

\section{Newtonia paucijuga}

Leguminosae

VU BI+2b

Kenya, Tanzania

Fairly common in places, e.g. Shimba Hills, this tree is restricted to pockets of moist coastal forest from southeast Kenya to south Tanzania.

Assessor: Lovett, J. \& G.P. Clarke

Refs: $3356,6396,10961$

\section{Nicotiana africana}

Solanaceae

VU Dl+2

Namibia

An unusual wild tobacco species confined to the Brandberg, Erongo and Spitzkuppe Mountains in northern Namibia. It occurs as a shrub or small tree of $2.5 \mathrm{~m}$ in very arid *karroid shrubland in a semideservdesert environment, usually in inaccessible, shady areas between huge granite boulders where there is some protection from human activities and browsing by livestock. The subpopulations are so small that any natural disaster or human impact like mining could easily wipe them out. Nothing is known about its reproductive strategy and few young plants have been seen. Cross-pollination between the isolated localities appears to be impossible, but there are no signs of any genetic decline. Research is being carried out to assess the potential of the species to improve cultivated tobacco forms. Although not used today, it may have been used as tobacco by early inhabitants.

Assessor: Hilton-Taylor, C. et al.

Refs: 689,19218

\section{Normanbya normanbyi}

Palmae

VUAlc

Australia (Queensland)

An omamental palm tree of coastal rainforest up to $300 \mathrm{~m}$, restricted to north-east Queensland. This uncommon species is in decline because of land clearance. It is listed in the Nature Conservancy Act (Queensland) 1994.

Assessor: Dowl, J.L.

Refs: 19118

\section{Northea hornei}

Sapotaceae

VU D2

A common component of forest areas on Mahe, Praslin, 
Silhouette, Curieuse and Felicite Islands. It occurs in Morne Seychelloise National Park and seedlings are being used in a reforestation programme. The timber is of high quality and diverse use. The main threat to populations comes from the pervasive spread of introduced plants. The genus is monotypic.

Assessor: World Conservation Monitoring Centre

Refs: 9859, 16212, 17229, 19023

\section{Nostolachma crassifolia}

Rubiaceae

$\mathrm{EN} \mathrm{B} 1+2 \mathrm{c}$

India (Kerala, Tamil Nadu)

A small tree of submontane forest, known only from a few collections and field records in the Anamalai Hills and an imprecisely recorded location in the Agastyamalai Hills.

Assessor: World Conservation Monitoring Centre

Refs: 19144

\section{Nothaphoebe condensa}

Lauraceae

VU B $1+2 c$

Malaysia (Peninsular Malaysia)

Endemic to Langkawi Island, this species is known only from a single collection found in lowland seasonal forest. Langkawi Island is being rapidly developed as a tourist resort.

Assessor: Kochummen, K.M.

Refs: 8464, 19073

\section{Nothaphoebe javanica}

Lauraceae

CR C2b, D1

Indonesia (Java)

A species known from a single specimen, collected from Mount Payung in Ujung Kulon National Park. It is not known whether the species is now extinct.

Assessor: World Conservation Monitoring Centre

Refs: 9078

\section{Nothaphoebe pahangensis}

Lauraceae

Malaysia (Peninsular Malaysia)

$\mathrm{LR} / \mathrm{cd}$

A montane forest species confined to the Cameron Highlands in Pahang. Mountain forests are protected forests in Peninsular Malaysia.

Assessor: Kochummen, K.M.

Refs: 8464,19073

\section{Nothocestrum breviflorum}

Solanaceae

CR C2a, D1

USA (Hawaii)

A stout tree which occurs only rarely, generally confined to dry forest up to an altitude of $1830 \mathrm{~m}$ in the southern part of the Kohala Mountains, the northern slopes of Hualalai and Mauna Loa on Hawaii. Fewer than 50 individuals remain in six populations. Habitat conversion for residential and recreational purposes, the invasion of introduced plants, fire and grazing have all contributed to the decline in the species. It is protected by the US Endangered Species Act. The genus consists of four species, all endemic to the Hawaiian Islands.

Assessor: World Conservation Monitoring Centre

Refs: 3372,19039

\section{Nothocestrum latifolium}

Solanaceae

EN C2a

USA (Hawaii)

This small tree occurs in various forest types between 460 and $1530 \mathrm{~m}$ on Kauai, Oahu, Molokai, Lanai and
Maui. The genus consists of four species, all endemic to the Hawaiian Islands.

Assessor: World Conservation Monitoring Centre Refs: 3372

\section{Nothocestrum longifolium}

Solanaceae

LR/nt

USA (Hawaii)

A small tree or shrub, the commonest in the genus, occurring in rainforest up to $1620 \mathrm{~m}$ on all the main islands except Niihau and Kahoolawe. The genus consists of four species, all endemic to the Hawaiian Islands.

Assessor: World Conservation Monitoring Centre

Refs: 3372

\section{Nothocestrum peltatum}

Solanaceae

CR C2a, D1

\section{USA (Hawaii)}

A species of montane rainforest endemic to Kauai, where it is known from seven populations located at Kalalau Lookout, Awaawapuhi and Makaha Valleys, Nualolo, Kawaiula and Waimea Canyon. The number of individuals has declined to about 23 in total, largely because of the impact of invasive plants, feral goats, pigs, deer and jungle fowl. It is protected by the US Endangered Species Act. The genus consists of four species all endemic to the Hawaiian Islands. Assessor: World Conservation Monitoring Centre Refs: 3372, 19038

\section{Nothofagus alessandri}

Fagaceae

EN Alcde, B2cd

Chile (Maule)

Endemic to Maule region, the species was once more widespread but is now restricted to eight scattered localities in a small area of deciduous forest in the Coastal Cordillera. These stands all represent secondary growth from stump sprouts and between 1983 and 1991 their extent of occurrence was reduced by almost $60 \%$ as a result of the establishment of plantations of Pinus radiata. About $13 \%$ of the species range is covered by protected areas. It is recognised as a very primitive member of the genus.

Assessor: González, M.

Refs: $4893,11147,16328,19153$

\section{Nothofagus alpina}

Fagaceae

LR/nt

Argentina (Neuquén), Chile (Bíobío, Maule)

The species occurs in moist seasonal forest up to $1900 \mathrm{~m}$ in both the Coastal Cordillera and Andes in Chile, extending into Argentina. Most of the lower elevation forest has been logged and converted to agriculture, especially in the northern part of the range, and also to Pinus radiata plantations. There are still extensive areas of intact forest. The species is little represented in Chilean protected areas.

Assessor: González, M.

Refs: $331,5112,16328$

\section{Nothofagus baumanniae}

Fagaceae

LR/cd

New Caledonia

This species is a dominant component of stunted cloud forest on ultramafic soils, restricted to three mountain peaks. The species' range is not believed to have been 
any more extensive in the past. It is effectively protected within Rivière Bleue National Park.

Assessor: Jaffré, T. et al.

Refs: 5300, 10351

\section{Nothofagus discoidea}

Fagaceae

VU D2

New Caledonia

This species is confined to a few small populations on ultramafic soils in the lowlands of the far south.

Assessor: Jaffré, T. et al.

Refs: 5300, 10351

\section{Nothofagus glauca}

Fagaceae

VU Alcd, B1+2c

Chile (Bíobio, Maule, O'Higgins, Santiago, Valparaiso)

The species is endemic to central Chile, occurring on thin or rocky soils up to $1500 \mathrm{~m}$ in both the Coastal Cordillera and the Andes. Almost all the pure stands in the coastal range, known as Maule forest, have been logged and converted into Pinus radiata plantations. The Andean populations are presently under conversion. Since 1985 the woodchip industry has increased the demand for timber. Regeneration in old growth stands is very good. The species is rarely contained within protected areas.

Assessor: González, M.

Refs: $4893,11147,16328,19153$

\section{Nothofagus $\times$ leonii}

Fagaceae

EN Alcd, B2c

Chile

A hybrid between $N$. obliqua and $N$. glauca. It is found only in areas where the two parent species meet in the Coastal Cordillera and the Andes in Chile. Its occurrence in protected areas is rare and most areas have experienced logging and clearing.

Assessor: González, M.

Refs: 4893, 11147, 16328

\section{Nothofagus nuda}

Fagaceae

CR D 1

Papua New Guinea

A tree known from a single collection found in mixed lower montane forest near the Tauri River in the Gulf Province, which is outside the general range of Nothofagus in New Guinea. A future taxonomic revision may change the status of this species.

Assessor: Eddowes, P.J.

Refs: 5300,19114

\section{Nothofagus stylosa}

Fagaceae

VU D2

Indonesia (Irian Jaya)

A species known from a single locality in the central mountain range of Irian Jaya.

Assessor: World Conservation Monitoring Centre

Refs: 5300,7154

\section{Nothofagus womersleyi}

Fagaceae

$\mathrm{EN} \mathrm{B1+2c}$

Indonesia (Irian Jaya)

A locally common species, restricted to a single locality of primary rainforest on Bukit Irau in the Kebar Valley of the Vogelkop Peninsula. Its restricted occurrence and narrow genetic base place the species in a precarious state.

Assessor: Eddowes, P.J.

Refs: 5300,19114

\section{Nothopegia aureo-fulva}

Anacardiaceae

CR B $1+2 \mathrm{c}$

India (Tamil Nadu)

Recorded only from the Tirunelveli Hills, this small tree has not been found this century despite botanical surveys of the area. Various developments have encroached upon and degraded the forest but there is still a possibility that the species may be rediscovered.

Assessor: World Conservation Monitoring Centre Refs: 14276,19144

\section{Nothopegia beddomei var, wynaadica}

Anacardiaceae

$\mathrm{EN} B 1+2 \mathrm{c}$

India (Kerala)

This taxon is poorly recorded, known only from a single site of submontane forest in Wynaad near the border with Karnataka.

Assessor: World Conservation Monitoring Centre

Refs: 19144

\section{Nothopegia castanaefolia}

Anacardiaceae

India (Maharashtra)

A poorly known tree from an imprecisely recorded localition on the border between Kamataka and Maharashtra.

Assessor: World Conservation Monitoring Centre

Refs: 19144

\section{Nothopegia heyneana}

Anacardiaceae

LR/nt

India (Karnataka, Kerala, Orissa, Tamil Nadu)

A widely but sparsely scattered species, occurring in areas of low- to medium-altitude forest in the Westem Ghats.

Assessor: World Conservation Monitoring Centre

Refs: 7147,19144

\section{Nothospondias staudtii}

Simaroubaceae

Cameroon, Côte d'Ivoire, Gabon, Ghana, Nigeria

Extending from Côte d'Ivoire to Gabon, the species is relatively widespread but rare within a rapidly declining habitat. It occurs in semi-deciduous forest, which has been heavily logged everywhere. It is the sole member of the genus.

Assessor: Hawthome, W.

Refs: $2773,8369,12061,12590$

\section{Nothotsuga longibracteata}

Pinaceae EN Alc

China (Fujian, Guangdong, Guangxi, Guizhou, Hunan, Jiangxi)

Although the species is widespread, it appears to be very rare and poorly collected. Deforestation is a threat in most of its range.

Assessor: SSC Conifer Specialist Group

Refs: $374,1818,11242,13041,18751$

\section{Notospartium carmichaeliae}

Leguminosae

LR/nt

New Zealand (South Is.)

A small tree, known only from Marlborough, where it occurs in valleys between the Wairau and Awatere Rivers. The genus consists of three species, endemic to New Zealand.

Assessor: de Lange, P.J.

Refs: 902, 17637, 19133 


\section{Notospartium glabrescens}

Leguminosae

LR/nt

New Zealand (South Is.)

A small tree, confined to Marlborough, where it is found between Awatere and Kowhai Rivers. The genus consists of three species endemic to New Zealand.

Assessor: de Lange, P.J.

Refs: 19133

\section{Notospartium torulosum}

Leguminosae

LR/nt

New Zealand (South Is.)

Confined to Canterbury, this small tree is found in one main population near Peel forest and a few smaller populations, occurring on steep rocky slopes in riparian scrub or on forest margins. An increase in farming has caused a retraction of the species'. The total population consists of a few hundred individuals. Reproduction is sufficient in the main population. The genus consists of three species endemic to New Zealand.

Assessor: de Lange, P.J.

Refs: 17637,19133

\section{Nouelia insignis}

Compositae

LR/nt

China (Sichuan, Yunnan)

Shrubs or small trees are found singly or in small clumps, restricted largely to the lower reaches of the Anning and Yalong Rivers and Jinsha River Valley between $900 \mathrm{~m}$ and $2800 \mathrm{~m}$. The main threat comes from firewood collection, but populations frequently occur in inaccessible places in rock crevices and on steep cliffs. Assessor: World Conservation Monitoring Centre Refs: 1818,11847

\section{Nuria glomerulata}

Buddlejaceae

$\mathrm{LR} / \mathrm{nt}$

South Africa (Guateng, North-West Province)

A straggling shrub or small tree which occurs on ridges and hills between Pretoria and Zeerust in mixed savanna. There may have been some decline in numbers and the extent of occurrence because of agricultural activities and other developments. Its restricted distribution also renders it vulnerable to any future developments in the area. It occurs in a privately owned nature reserve and a local authority reserve.

Assessor: Hilton-Taylor, C. et al.

Refs: 689,19218

\section{Nyssa yunnanensis}

Comaceae

$\mathrm{CR} \mathrm{B} 1+2 \mathrm{c}, \mathrm{C} 2 \mathrm{a}$

China (Yunnan)

A species known from a small population restricted to Jinghong County in the region of Xishuangbanna. It occurs infrequently as a component of the upper canopy of monsoon forest between 540 and $850 \mathrm{~m}$. Logging has contributed significantly to the decline in the extent of the species' range. The area is now under protection.

Assessor: Sun, W.

Refs: $1818,11847,19055$

\section{Ochanostachys amentacea}

Olacaceae

Indonesia (Kalimantan, Sumatra), Malaysia (Peninsular Malaysia, Sabah, Sarawak), Singapore

A monotypic genus found scattered in the understorey, occasionally reaching the canopy, of primary and secondary lowland rainforest, often mixed dipterocarp forest. Natural regeneration is sparse and scattered, but it can be good under favourable conditions. The tree is slow-growing; taking about 150 years to reach a diameter of $50 \mathrm{~cm}$. The petaling timber is too scarce to be of commercial importance. However, it is often traded with other medium and hard woods in mixed consignments. The wood is used for house posts and heavy construction.

Assessor: Asian Regional Workshop

Refs: $5550,9199,9328,11145,12937,17140,19017$

Ochna angustata

Ochnaceae

DD

Mozambique

A species confined to central coastal areas of Mozambique. More fieldwork is required to consolidate the status of the population.

Assessor: Bandeira, $\mathbf{S}$

Refs: 5117,18965

Ochna beirensis

Ochnaceae

DD

Mozambique

Along with $O$. angustata, this species is confined to the central coastal area of Mozambique. More fieldwork is required to consolidate the status of the species.

Assessor: Bandeira, S.

Refs: 5117,18965

\section{Ochna rufescens}

Ochnaceae

CR B1+2cd

Sri Lanka

A tree restricted to lowland rainforest in south-west Sri Lanka. This species was previously found in Kottawa and Kanneliya Forest Reserves. However, it was not again found during the extensive forest surveys conducted between 1991 and 1996 for the National Conservation Review, suggesting that the species is either extremely rare or possibly extinct.

Assessor: World Conservation Monitoring Centre

Refs: 17195,19112

\section{Ochreinauclea missionis}

Rubiaceae

VU BI+2c

India (Kerala)

Endemic to the Western Ghats in Kerala, the species occurs in scattered pockets of evergreen forest along streamsides. It is believed to have been wiped out from several locations where there has been logging, clearing for commercial agriculture or other projects. The bark has medicinal value and the leaves are fed to livestock. The genus is monotypic.

Assessor: CAMP Workshops on Medicinal Plants in India

Refs: $561,4799,19144$

\section{Ochrosia borbonica}

Apocynaceae

EN Alct2ce

Mauritius, Réunion

Less than $\mathbf{5 0}$ individuals are known on Mauritius. The species is also rare and scaltered in forest on Reunion. More information may indicate Critically Endangered is a more appropriate category.

Assessor: Strahm, W.

Refs: $9120,12470,16426,19208$ 
Ochrosia fatuhivensis

Apocynaceae

French Polynesia (Marquesas Is.)

The species has been recorded only from Fatu Hiva.

Assessor: Florence, J.

Refs: 14513

\section{Ochrosia grandiflora}

Apocynaceae

New Caledonia

VU B $1+2 c$

Occurring in lowland gallery forest on schist or calcareous substrates, the species is known from four main localities in the regions of Koumac, Néavin and Col d'Amien, and also on the lle de Pins. All sites are unprotected and exposed to threats, such as fire and agricultural encroachment.

Assessor: Jaffré, T. et al.

Refs: 10351,12630

\section{Ochrosia haleakalae}

Apocynaceae

EN C2a

USA (Hawaii)

A tree scattered in dry to moist forest, often on lava, between 700 and $1200 \mathrm{~m}$ on East Maui. Two collections have also been made, from Pololu Valley and Kalopa Gulch on Hawaii. It is reported to be in cultivation on Hawai.

Assessor: World Conservation Monitoring Centre Refs: 3372,15251

\section{Ochrosia kauaiensis}

\section{Apocynaceae}

EN C2a

USA (Hawaii)

This tree is uncommon and confined to Kauai Island, where it is found in lowland moist forest up to $350 \mathrm{~m}$ on the Napali coast and on the slopes of Mount Kahili. Assessor: World Conservation Monitoring Centre Refs: 3372

\section{Ochrosia kilaueaensis}

\section{Apocynaceae}

USA (Hawaii)

CR B $1+2 c, C 2 b, D 1$

Originally collected only from Puuwaawaa and Kipuka Puaulu on Hawaii, the species has not been recorded since the 1940s. It is possible that a population remains in the former site but recent surveys in the latter failed to uncover any remnant of a population. The montane rainforest habitat has been degraded by introduced plants, goats and fire. The species is protected by the US Endangered Species Act.

Assessor: World Conservation Monitoring Centre Refs: 3372,19039

\section{Ochrosia nukuhivensis}

Apocynaceae

French Polynesia (Marquesas Is.)

The species has been recorded only from Nuku Hiva. Assessor: Florence, J.

Refs: 14513

\section{Ochrosia tahitensis}

Apocynaceae

French Polynesia (Society Is.)

The species has been recorded only from Tahiti.

Assessor: Florence, J.

Refs: 14513

\section{Ochrothallus blanchoni}

Sapotaceae

$\mathrm{EN} \mathrm{B} 1+2 \mathrm{c}$

New Caledonia

The genus is now included in Niemeyera.

Assessor: Jaffré, T. et al.

Refs: 10351

\section{Ochrothallus francei}

Sapotaceae

VU $B 1+2 c$

New Caledonia

The genus is now included in Niemeyera.

Assessor: Jaffré, T. et al.

Refs: 10351

\section{Ocotea argylei}

Lauraceae

VU D2

Kenya

The species is possibly synonymous with $O$. kenyensis. It is endemic to areas of moist forest above $2200 \mathrm{~m}$ at Posta Hill, Mau.

Assessor: World Conservation Monitoring Centre Refs: 6396, 9198, 17859

\section{Ocotea basicordatifolia}

Lauraceae

EN B $1+2 c$

Brazil (Sāo Paulo)

This species is confined to a restricted area of Atlantic forest on the Serra de Paranapiacaba in Santo André. There is a biological reserve here within the Serra do Mar State Park. However, it is under serious threat from uncontrolled industrial pollution. The species is included in the official list compiled by *IBAMA of threatened Brazilian plants.

Assessor: Varty, N

Refs: 8815,16123

\section{Ocotea benthamiana}

Lauraceae

VU $B 1+2 c$

Ecuador

An endemic tree of Ecuador, inhabiting montane cloud forest, between 2000 and $3000 \mathrm{~m}$ in the High Andes. Assessor: World Conservation Monitoring Centre Refs: 19119,19120

\section{Ocotea catharinensis}

Lauraceae

VU Alcd

Brazil (Paraná, Rio de Janeiro, Rio Grande do Sul, Santa Catarina, São Paulo)

Formerly abundant, this slow-growing species has become rare because of the levels of exploitation of its timber. Essential oil is also harvested from the bark for the perfume industry. Its habitat also continues to to decline, although several localities are protected within state parks and biological reserves. The species is included in the official list compiled by *IBAMA of threatened Brazilian plants. There is also a suggestion that populations exist in Misiones in Argentina and in Paraguay.

Assessor: Varty, N. \& D.L. Guadagnin

Refs: $8815,15539,16123$

\section{Ocotea clarkei}

Lauraceae

LR/cd

Mexico (Chiapas)

Assessor: Ramirez-Marcial, N. \& M. González-Espinosa Refs: 8553 


\section{Ocotea foetens}

Lauraceae

LR/nt

Portugal (Madeira), Spain (Canary Is.)

One of the major components of *laurisilva. Populations in both island groups are scattered and fragmented as a result of past habitat loss and timber exploitation. The most serious threat in the present day is fire. The population in the Canary Islands has not been properly censored but probably contains fewer than 10,000 individuals in total. It is listed in government legislation of 1991. In Madeira it is possible that population numbers are increasing with the expansion of laursilva. Assessor: World Conservation Monitoring Centre Refs: 1512, 19022, 19131

\section{Ocotea gabonensis}

Lauraceae

LR/nt

Gabon

A Gabon endemic, so far found at Lopé Forest Reserve and near Lastoursville. The habitat is degraded where logging has taken place. The species may be more widespread, given that Gabon's forests are relatively unexplored. These areas, however, are now largely under concession to logging companies.

Assessor: World Conservation Monitoring Centre

Refs: 14958,15790

\section{Ocotea glaucosericea}

Lauraceae

LR/nt

Costa Rica, Panama

Occurring in montane forest, this species is found only in the Cordillera de Talamanca in Costa Rica and in the Chiriquí Highlands in Panama, where it is fairly abundant

Assessor: World Conservation Monitoring Centre

Refs: 8381,12587

\section{Ocotea harrisii}

Lauraceae

$\mathrm{CR} B 1+2 \mathrm{c}$

Jamaica

A species known only from the type locality in Peckham Woods. Much of the area is degraded by cutting and lower slopes are planted with Pinus caribaea.

Assessor: World Conservation Monitoring Centre

Refs: $401,5653,7980$

\section{Ocotea jorge-escobarii}

Lauraceae

EN C2a

Honduras, Nicaragua

A species of mixed dry forest, occurring at middle elevations.

Assessor: Nelson, C.

Refs: $1080,6703,7534$

\section{Ocotea kenyensis}

\section{Lauraceae}

VU Alcd

Democratic Republic of Congo, Ethiopia, Kenya, Malawi, Mozambique, Rwanda, South Africa (Eastern Cape, KwaZulu-Natal, Mpumalanga, Northem Province), Sudan, Swaziland, Tanzania, Uganda, Zimbabwe

A timber species found in areas of moist forest in East and South Africa extending into Central Africa. In some areas the populations are very small, e.g. the Zimbabwean population consists of four immature individuals. The populations in South Africa are all contained within protected areas, but usually comprise of only isolated individuals or small groups of trees. It yields a superior hardwood which is heavily exploited through most of its range.

Assessor: World Conservation Monitoring Centre

Refs: 689, 2361, 6396, 6725, 10536, 10961, 16021, 19218

\section{Ocotea langsdorffii}

Lauraceae

Brazil (Minas Gerais)

VU Alcd

This species occurs in low densities in a restricted area of * campo rupestre in the Serra do Cipo. Trees are indiscriminately cut for timber resources, at levels of exploitation that are unsustainable. Laws to set up the Serra do Cipó State Botanical Park and to protect the species are not yet well established. This species is included on the official list of threatened Brazilian plants compiled by *IBAMA.

Assessor: Varty, N.

Refs: $7144,8815,16123$

\section{Ocotea otuzcensis}

Lauraceae

VU D2

Peru

A cloud forest species, which is known only from the type collection from the department of La Libertad. Assessor: World Conservation Monitoring Centre Refs: 1984

\section{Ocotea porosa}

Lauraceae

VU Alcd Argentina? (Misiones?), Brazil (Paraná, Rio de Janeiro, Rio Grande do Sul, Santa Catarina, São Paulo), Paraguay?

One of the dominant species of Araucaria forest, also occurring in various other habitat types. The largest populations occur in south Paraná and north Santa Catarina, where the species occurs in almost pure stands. Although present in large numbers, the species is slowgrowing and declining in numbers through timber exploitation. In rates of extraction, the species is second only to Paraná pine. Several localities are protected and the species occurs on the official list of threatened Brazilian plants compiled by *IBAMA. Suggestions that populations exist in Argentina and Paraguay need verification.

Assessor: Varty, N. \& D.L. Guadagnin

Refs: $4506,8815,14355,15539,16123,19179$

\section{Ocotea pretiosa}

Lauraceae

VU Alcd

Argentina? (Misiones?), Brazil (Bahia, Minas Gerais, Paraná, Rio de Janeiro, Rio Grande do Sul, Santa Catarina, São Paulo), Paraguay?

Commonly known under the name of $\boldsymbol{O}$. odorifera, the species is an important source of timber and essential oil. The species' distribution is discontinuous, occurring in coastal forests which continue to be cleared despite legislative measures, and also in small woods and forest formations on the southern Brazilian plateau. There is also some indication that it may be found in Misiones in Argentina and also Paraguay. Exploitation of the species as a source of sassafras oil has been uncontrolled but largely confined to Santa Catarina, which is the only area to contain trees with sufficiently high safrole content. Remaining stands are no longer capable of sustaining high levels of utilization and no replanting has taken place. Natural sources of safrole are still the preferred source and it is likely that the market will tum 
to alternative plant species to replace $O$. pretiosa. The species is included in the official list of threatened Brazilian plants compiled by *IBAMA.

Assessor: Varty, N.

Refs: $7144,8815,15539,16123$

\section{Ocotea raimondii}

Lauraceae

VU D2

Peru

Known only from the type collection, the species occurs in the department of Cajamarca.

Assessor: World Conservation Monitoring Centre

Refs: 1984

\section{Ocotea rivularis}

Lauraceae

VU D2

Costa Rica

A lowland rainforest species, known from the type locality near Esquinas, where it was once said to be common, and also from Rincón.

Assessor: World Conservation Monitoring Centre Refs: 12587, 14311

\section{Ocotea robertsoniae}

Lauraceae

VU B $1+2 c$

Jamaica

The species is found in St Ann, St Elizabeth and Clarendon Parishes in areas of woodland on limestone. Assessor: World Conservation Monitoring Centre Refs: 6057,7980

\section{Ocotea rotundato}

Lauraceae

VUBl+2c

Ecuador

A tree, growing up to $8 \mathrm{~m}$, endemic to the High Andes of Ecuador. It inhabits cloud forest between 2640 and $3200 \mathrm{~m}$ in Loja and Zamora-Chinchipe Provinces. Assessor: World Conservation Monitoring Centre Refs: 19119

\section{Ocotea staminoides}

Lauraceae

$\mathrm{EN} \mathrm{B} 1+2 \mathrm{c}$

Jamaica

An uncommon species found only in St Ann Parish.

Assessor: World Conservation Monitoring Centre

Refs: $401,5653,7980$

\section{Ocotea uxpanapana}

Lauraceae

VU Alc, Bl+2c

Mexico (Veracruz)

A common tree of riparian forest in the regions of Uxpanapa and Los Tuxtlas. Half of the forest in Uxpanapa has disappeared through resettlement projects in the 1970s. The forests of Los Tuxtlas are rapidly disappearing and are considered to be extremely threatened.

Assessor: World Conservation Monitoring Centre

Refs: 5651, 5993, 7980

\section{Ocotea viridiflora}

Lauraceae

VU D2

Costa Rica?, Panama

Confined to the Chiriqur Highlands in cloud forest, this species is poorly understood. Undetermined specimens from Costa Rica may also represent this taxon. Assessor: World Conservation Monitoring Centre Refs: $7144,7980,13228$

\section{Octoknema orientalis}

Olacaceae

VU B $1+2 b$

Tanzania

This species is restricted to moist evergreen forest between 1000 and $1200 \mathrm{~m}$ in the South Nguru Mountains, North Udzungwa Mountains and Mahenge.

Assessor: Lovett, J. \& G.P. Clarke

Refs: $3356,5204,10961,11631$

\section{Oenocarpus circumtextus}

Palmae

VU B1+2c

Colombia

This endemic Colombian palm is found in lowland scrub in Amazonas, often in white sand areas or on rocky outcrops. The species is restricted to two remote localities, where few pressures are evident.

Assessor: Bernal, $\mathbf{R}$.

Refs: 19118

\section{Oenocarpus makeru}

Palmae

Colombia

A palm of lowland rainforest, bordering areas of white sand. The species is known only from one location in a remote area of north-western Amazonia.

Assessor: Bemal, $\mathbf{R}$.

Refs: 19118

\section{Oenocarpus simplex}

Palmae

DD

Colombia

An understorey species of lowland rainforest, known only from an undisturbed remote area in the north-west Amazon.

Assessor: Bernal, R.

Refs: 19118

\section{Olax psittacorum}

Olacaceae

Mauritius, Réunion

In Mauritius occurrences are known in seasonal forest in Simonet and Morne Seche. Around 50 individuals have been counted and regeneration is observed to be occasional. Information on the Réunion population is required. The fruits of the tree are believed to be a food for a rare endemic parrot.

Assessor: Page, W.

Refs: $1411,9120,12470,16426,19199$

\section{Oldenburgia grandis}

Compositae

South Africa (Eastem Cape)

LR/nt

A shrub or small tree of potential omamental interest, found along the Suurberg inland from Port Elizabeth to the mountains around Grahamstown. The species always occurs on outcrops of quartzite in grassy *fynbos. Its extent of occurrence is only about $500 \mathrm{~km}^{2}$. Although there are threats from invasive alien species, especially *wattles, and agricultural activities in places, there is no evidence of population declines. Most of the subpopulations occur on privately owned farms. Some plants are found in a national park and a few provincial and private nature reserves.

Assessor: Hilton-Taylor, C. et al.

Refs: 689,19218 


\section{Olea chimanimani}

Oleaceae

VU D2

Mozambique, Zimbabwe

A species known only from the Chimanimani Mountains on the Zimbabwe-Mozambique border. It occurs fairly commonly on quartzite soils within a well-protected area of $600 \mathrm{~km}^{2}$.

Assessor: World Conservation Monitoring Centre

Refs: 18965

\section{Olea europaea ssp. cerasiformis}

\section{Oleaceae}

$\mathrm{LR} / \mathrm{nt}$

Portugal (Madeira), Spain (Canary Is.)

This taxon now includes subspecies from both the Canary Islands and Madeira, the latter previously being known as ssp. maderensis. It is relatively abundant at low and medium elevation in dry woodland on most Canary Islands, on the south coast and some areas of north Madeira and on Desertas and Porto Santo Islands, where it is rare. The species is covered in regional legislation and occurs in protected areas, but the habitat continues to experience general degradation and declines through increasing house-building, fires and invasive species.

Assessor: World Conservation Monitoring Centre

Refs: 6729, 19022, 19131

\section{Olearia angulata}

Compositae

New Zealand (North Is.)

The taxonomic status of this species is dubious.

Assessor: World Conservation Monitoring Centre

Refs: $902,9800,19134$

\section{Olearia chathamica}

\section{Compositae}

LR/nt

New Zealand (Chatham Is.)

The coastal forests of the Chatham Islands were once dominated by this small tree. The comprehensive destruction of the forest type has reduced populations to scrubland on exposed cliffs, largely confined to the south shore of Chatham Island, and on Pitt and South East Islands.

Assessor: de Lange, P.J.

Refs: $902,19133,19134$

\section{Olearia fragrantissima}

Compositae

$\mathrm{LR} / \mathrm{nt}$

New Zealand (South Is.)

Occurring in lowland forest and scrub in the east of South Island, this small tree appears to be common in most areas but is showing little regeneration. In the southern parts of its range it occurs on high-fertility soils, which are highly sought-after by agriculturists and colonised by aggressive pasture grass.

Assessor: de Lange, P.J.

Refs: 902, 9800, 19133, 19134

\section{Olearia hectorii}

Compositae

EN C2a

New Zealand (North Is., South Is.)

Approximately 1000 individuals remain of this small tree, occurring in isolated populations in forest and scrub on fertile soils. Regeneration is almost absent.

Assessor: de Lange, P.J.

Refs: 902, 9800, 19133, 19134

\section{Olearia polita}

Compositae

New Zealand (South Is.)

$\mathrm{EN} \mathrm{C2b}$

A tree restricted to a population of about 500 trees in lowland beech forest in Nelson.

Assessor: World Conservation Monitoring Centre

Refs: 902,9800

\section{Olearia traversi}

Compositae

LR/nt

New Zealand (Chatham Is.)

Once one of the major components of forest on the Chatham Islands. Complete destruction of the forest type has led to the species becoming rare and largely confined to paddocks. There is evidence of some regeneration.

Assessor: de Lange, P.J.

Refs: $902,5563,19133,19134$

\section{Omalanthus stokesii}

Euphorbiaceae

LR/nt

French Polynesia (Tubuai Is.)

An endemic to Rapa.

Assessor: Florence, J.

Refs: 14513

\section{Oncosperma fasciculatum}

Palmae

$\mathrm{LR} / \mathrm{nt}$

Sri Lanka

A palm tree of the wet lowlands, endemic to Sri Lanka.

Assessor: Johnson, D.

Refs: 19118

Oncosperma platyphyllum

Palmae

VU Alc

Philippines

A species of primary forest at low to medium elevations, confined to the island of Negros.

Assessor: Madulid, D.

Refs: 19118

Ophrypetalum odoratum ssp. longipedicellatum

Annonaceae

$\mathrm{EN} \mathrm{B} 1+2 \mathrm{~d}, \mathrm{C} 2 \mathrm{~b}, \mathrm{D} 1$

Tanzania

An endemic to the Kimboza Forest Reserve, which covers $4 \mathrm{~km}^{2}$ of moist coastal forest on limestone. The surrounding area is densely populated and there is a strong demand for land for cultivation. Two forest guards are employed by the Tanzanian Catchment Forest Project to prevent illegal activities or encroachment. The type subspecies is the only other member of the genus and is similarly restricted.

Assessor: Lovett, J. \& G.P. Clarke

Refs: $3356,5204,9302$

\section{Ophrypetalum odoratum ssp. odoratum}

Annonaceae

VU $B 1+2 b$

Kenya, Tanzania

Ranging more widely than ssp. longipedicellatum, this small tree is often locally dominant within pockets of dry coastal forest, often on coral. Populations are known from Diani, Jadini and Vipingo in south-east Kenya as well as further south in eastern Tanzania. The genus is monotypic.

Assessor: Lovett, J. \& G.P. Clarke

Refs: $3356,6396,8814$ 


\section{Orania decipiens}

Palmae

LR/nt

Philippines

A primary forest species, endemic to Mindoro.

Assessor: Madulid, D.

Refs: 19118

\section{Orania longisquama}

Palmae

Madagascar

A rare palm endemic to Madagascar, known only in the north-west and east. This species inhabits lowland and submontane rainforest between 40 and $550 \mathrm{~m}$.

Assessor: Dransfield, J. \& H.J. Beentje

Refs: 19118

\section{Orania ravaka}

Palmae

VU $B 1+2 c$

Madagascar

This Madagascan endemic is known only from lowland rainforest at three sites in the north-east. The total population is estimated to consist of 500 individuals.

Assessor: Dransfield, J. \& H.J. Beentje

Refs: 18986,19118

\section{Orania sylvicola}

Palmae

LR/nt

Indonesia (Java, Sumatra), Malaysia (Peninsular

Malaysia, Sarawak), Singapore (ex)

This palm tree is confined to coastal rainforest up to $200 \mathrm{~m}$. The population in West Java has been reduced to fewer than 200 individuals in a single locality. The species is extinct in Singapore.

Assessor: Johnson, D.

Refs: 9199,19118

\section{Orania trispatha}

Palmae

CR Alcd

Madagascar

Fewer than 50 individuals are known from three locations of lowland rainforest, all of which are under threat of destruction.

Assessor: Dransfield, J. \& H.J. Beentje

Refs: 18986,19118

\section{Oreomunnea pterocarpa}

Juglandaceae

$\mathrm{EN} \mathrm{C2a}$

Costa Rica, Mexico, Panama

Although previously considered to be a Costa Rican endemic, it appears the species is also recorded in Mexico and Chiriqui in Panama and hence could be distributed throughout Central America. It is sparse in occurrence, usually found as isolated individuals in areas of moist and wet evergreen forest. Little is known of the regenerative capacity of the species, although it does not appear to be strong. The timber is not heavily exploited, although it is traded to some extent domestically. The species is listed in Appendix II of * CITES.

Assessor: Americas Regional Workshop

Refs: $7980,14487,14717,19179,19185,19186$

\section{Oreopanax arcanus}

Araliaceae

Guatemala, Mexico (Chiapas)

Occurring in montane forest in oak and mesophyllous

formations, the species is found in the Chiapas Highlands in Mexico, between 2000 and $2300 \mathrm{~m}$, and in mountainous parts of Guatemala. The population in Mexico is considered endangered.

Assessor: World Conservation Monitoring Centre

Refs: 4974, 19161

\section{Oreopanax candamoanus}

Araliaceae

VU D2

Peru

Known only from the type collection, this species occurs in forest between roughly 2000 and $3500 \mathrm{~m}$ in the department of Cajamarca.

Assessor: World Conservation Monitoring Centre Refs: 1984

\section{Oreopanax cissoides}

Araliaceae

VU D2

Peru

Recorded only from the type collection, the species occurs in forest above $2500 \mathrm{~m}$ in the department of Cajamarca.

Assessor: World Conservation Monitoring Centre

Refs: 1984

\section{Oreopanax echinops}

Araliaceae

VU Alc

Guatemala, Honduras, Mexico

A species of oak forest occurring at medium elevations. Its distribution extends from Sierra Madre in Chiapas, Mexico to Honduras.

Assessor: World Conservation Monitoring Centre Refs: 19161

\section{Oreopanax ischnolobus}

Araliaceae

VU D2

Peru

A species of forest above $2500 \mathrm{~m}$, known only from the type collection from the department of Junin.

Assessor: World Conservation Monitoring Centre Refs: 1984

\section{Oreopanax jelskii}

Araliaceae

VU D2

Peru

Recorded only from the type collection, the species occurs in forest above $2500 \mathrm{~m}$ in Cajamarca.

Assessor: World Conservation Monitoring Centre Refs: 1984

\section{Oreopanax klugii}

Araliaceae

DD

Peru

A lowland forest species which is recorded only from the department of Loreto. There are doubts over its taxonomic status and it is not included in the Flora of Peru.

Assessor: World Conservation Monitoring Centre Refs: 1984

\section{Oreopanax lempiranus}

Araliaceae

Honduras

Endemic to Honduras, the species is, so far, known only from an area of wet montane forest in Celaque National Park.

Assessor: Nelson, C.

Refs: 2935, 10147 


\section{Oreopanax oerstediana}

Araliaceae

VU C2a

Costa Rica, Panama

A species of cloud forest, occurring between 1000 and $2500 \mathrm{~m}$ in small, restricted populations. Despite the entire range coinciding with protected areas, there are increasing threats of habitat logging and clearance.

Assessor: Mitré, $\mathrm{M}$.

Refs: $7272,14487,15037,16772$

\section{Oreopanax peltatus}

Araliaceae

VU Alc

Guatemala, Mexico

Occurring from the Gulf region of Mexico to Guatemala, the species is found in areas of moist seasonal forest from medium to high elevations.

Assessor: World Conservation Monitoring Centre

Refs: 5993, 19161

\section{Oreopanax raimondii}

Araliaceae

VU D2

Peru

Recorded only from the type collection, the species occurs in forest above $2500 \mathrm{~m}$ in the department of La Libertad.

Assessor: World Conservation Monitoring Centre Refs: 1984

\section{Oreopanax sanderianus}

Araliaceae

VU Alc

Guatemala, Honduras, Mexico

A scarce species of pine-oak forest and mesophyllous montane forest.

Assessor: Ramirez-Marcial, N. \& M. González-Espinosa Refs: 19161

\section{Oreopanax stenophyllus}

Araliaceae

VUB $1+2 c$

Peru

This cloud forest species occurs in forest between 3000 and $3500 \mathrm{~m}$, in the departments of Cuzco and Puno.

Assessor: World Conservation Monitoring Centre

Refs: 1984

\section{Oricia suaveolens}

Rutaceae

Côte d'Ivoire, Democratic Republic of Congo, Ghana,

Guinea, Nigeria, Sierra Leone

Widely occurring from Sierra Leone to DR Congo, this species is confined to the more restricted wetter evergreen forests, which in certain areas have been heavily logged and destroyed by oil exploration, mining and commercial forestry operations.

Assessor: World Conservation Monitoring Centre Refs: 2773, 8369, 11504, 12061

\section{Oricia trifoliolata}

Rutaceae

VU $B 1+2 c$

Cameroon

A small forest tree confined to Korup National Park and the Mount Cameroon area. It is sparsely scattered and the habitat is declining through logging and the expansion of areas under cultivation.

Assessor: World Conservation Monitoring Centre Refs: 12597

\section{Oriciopsis glaberrima}

Rutaceae

Cameroon

Endemic to Cameroon, this small understorey tree occurs locally in some abundance in lowland swamp forest at Bertona, Doume, Lomie, Akonolinga and Sangmelima. The habitat is being lost to agricultural development in places.

Assessor: World Conservation Monitoring Centre

Refs: 12597

\section{Ormocarpopsis aspera}

Leguminosae

LR/nt

Madagascar

Widespread in central and west Madagascar, this lowland or submontane woodland species is uncommon and the remaining native vegetation is very fragmented and continuing to decline.

Assessor: Du Puy, D. \& H. Labat

Refs: 12353

\section{Ormocarpopsis calcicola}

Leguminosae

$\mathrm{EN} \mathrm{B1+2abc}$

Madagascar

A deciduous woodland species restricted to limestone outcrops in the Ankara Plateau of west Madagascar. Although it occurs within the protected Namoroka Reserve its range is restricted to an estimated $400 \mathrm{~km}^{2}$ $\left({ }^{*} \mathrm{AOO}\right)$ and areas outside the reserve are declining. It may now be restricted to a single locality within the reserve.

Assessor: Du Puy, D. \& H. Labat

Refs: 12353

\section{Ormocarpopsis itremoensis}

Leguminosae

CR B1+2abc Madagascar

A sclerophyllous woodland species that is known only from the small marble outcrops to the south of Amatofinandrahana on the eastem margin of the Itremo Massif in central Madagascar. These areas are being actively mined for marble and the forest remnants are also being rapidly degraded. Its range is estimated to be less than $10 \mathrm{~km}^{2}$ (*AOO). No protection exists in this area.

Assessor: Du Puy, D. \& H. Labat

Refs: 12353

\section{Ormocarpopsis mandrarensis}

Leguminosae

VU B $1+2 a b c$

Madagascar

Known from only two localities, this deciduous woodland species occurs in the upper Mandrare River basin and Ihosy River valley of south-central Madagascar. Its range is restricted to an estimated 1500 $\mathrm{km}^{2}\left({ }^{*} \mathrm{AOO}\right)$, where the vegetation is highly fragmented and decreasing.

Assessor: Du Puy, D. \& H. Labat

Refs: 12353

\section{Ormocarpopsis parvifolia}

Leguminosae

VU B1+2abc

Madagascar

A xerophytic scrub and woodland species confined to a small area of south and south-east Madagascar. Its range is estimated to be $15,000 \mathrm{~km}^{2}\left({ }^{*} \mathrm{EOO}\right)$ and includes 
Andohahela Reserve (Parcelle 2). All vegetation in this area is fragmented and declining.

Assessor: Du Puy, D. \& H. Labat

Refs: 12353

\section{Ormocarpopsis tulearensis}

Leguminosae

EN B $1+2 a b c$

Madagascar

This scrubland species is confined to the Mahafaly Plateau between the Manombo River and Itambono Corridor, with an estimated range of $5000 \mathrm{~km}^{2}$ (*EOO). The vegetation is fragmented, often disturbed and declining as a result of felling for charcoal and grazing.

Assessor: Du Puy, D. \& H. Labat

Refs: 12353

\section{Ormocarpum caerulum}

Leguminosae

VU D2

Yemen (Socotra)

A small tree or shrub which is relatively common in lowland and submontane woodland. It is an important cattle browse.

Assessor: Miller, A.G.

Refs: 19083

\section{Ormocarpum dhofarense}

Leguminosae

VU B I $+2 \mathrm{C}$

Oman, Yemen

A regional endemic from a small area of escarpment woodlands in Dhofar, Oman, and neighbouring Mahra, southem Yemen. Since 1975 the area in Oman has seen an influx of people and their livestock. There has been a subsequent rapid increase in the cutting of wood and grazing. Trees are also browsed by livestock.

Assessor: Ghazanfar, S.A.

Refs: 16380,17281

\section{Ormocarpum sennodes ssp. zanzibaricum}

Leguminosae

VU $B 1+2 b$

Kenya, Tanzania

A small tree found only in areas of dry coastal forest from the vicinity of the Shimba Hills in south-east Kenya, through eastem Tanzania to Zanzibar Island.

Assessor: Lovett, J. \& G.P. Clarke

Refs: $3356,6396,8814$

\section{Ormosia cruenta}

Leguminosae

DD

Panama

Collected only twice from the provinces of Chiriqui and

Coclé, the species and its status are very poorly known.

Assessor: Mitré, $\mathbf{M}$.

Refs: $7272,7980,14630,16772$

\section{Ormosia gracilis}

Leguminosae

LR/cd

Malaysia (Peninsular Malaysia)

A species of submontane primary rainforest, occurring up to $2000 \mathrm{~m}$. Some parts of the range are affected by increasing settlement and agriculture, but a sufficient part of the total population is believed to be contained in protective forests within the permanent forest estate.

Assessor: Chua, L.S.L.

Refs: 19073

\section{Ormosia grandistipulata}

Leguminosae

VU D2

Malaysia (Peninsular Malaysia)

This small tree or shrub is confined to rainforest in the state of Terengganu, in Peninsular Malaysia. It has been collected only once and little is known about its altitudinal range. The area is under some pressure from increasing settlement.

Assessor: World Conservation Monitoring Centre Refs: 19073

\section{Ormosia hosiei}

Leguminosae

LR/nt

China (Fujian, Gansu, Guizhou, Hubei, Jiangsu, Jiangxi, Shaanxi, Sichuan, Zhejiang)

Populations are wide-ranging, but large individuals are reduced to areas around temples and houses. The natural habitat of this species is in low-elevation broadleaved forest. Habitat conversion to agriculture and overexploitation of the species for its timber are the main causes of population declines.

Assessor: World Conservation Monitoring Centre

Refs: 1818, 11847

\section{Ormosia howii}

Leguminosae

EX

China (Guangdong, Guangdong - Hainan)

Despite extensive searches the species has not been found again in the two iccalities where it has been recorded, in Dialuo Mount Forest Region on Hainan Island and Yangchun County in Guangdong. It was known to be restricted to montane rainforest, exposed to various threats of cutting and encroaching agriculture. Assessor: World Conservation Monitoring Centre Refs: $1818,11725,11847$

\section{Ormosia jamaicensis}

Leguminosae

$\mathrm{EN} \mathrm{B1}+2 \mathrm{c}$

Jamaica

The species is known from a small range in Hanover in woodland on limestone hillsides.

Assessor: World Conservation Monitoring Centre

Refs: $401,5653,7980$

\section{Ormosia polita}

Leguminosae

VU B $1+2 c$

Malaysia (Peninsular Malaysia)

An endemic tree of Peninsular Malaysia, inhabiting primary lowland rainforest.

Assessor: Chua, L.S.L.

Refs: 19073

\section{Orophea palawanensis}

Annonaceae

VU $B 1+2 c$

Philippines

This tree is endemic to Palawan, found in forests at low and medium altitudes. The main island is a biosphere reserve.

Assessor: World Conservation Monitoring Centre Refs: 4986

\section{Orophea submaculata}

Annonaceae

VU B $1+2 c$

Philippines

A lowland forest species, confined to Palawan between 200 and $450 \mathrm{~m}$. The main island is a biosphere reserve. Assessor: World Conservation Monitoring Centre Refs: 4986,5651

\section{Orophea thomsoni}

Annonaceae

$\mathrm{EN} \mathrm{Bl}+2 \mathrm{c}$

India (Kerala, Tamil Nadu)

Four scattered occurrences are recorded, in two cases 
imprecisely, from the Anaimalai area and the Agastyamalai Hills. The species occurs in the understorey of evergreen forest between approximately 500 and $1000 \mathrm{~m}$.

Assessor: World Conservation Monitoring Centre Refs: 19144

\section{Orophea uniflora}

Annonaceae

VU B $1+2 c$

India (Kamataka, Kerala, Tamil Nadu)

An understorey tree of evergreen forest, ascending to altitudes of $1200 \mathrm{~m}$. It appears to be scattered sparsley in the southern end of the Western Ghats, including Wynaad in the Nilgiri Hills Biosphere Reserve.

Assessor: World Conservation Monitoring Centre

Refs: 14276, 19144

\section{Orphanodendron bernalii}

Leguminosae

$\mathrm{CRB} \mathrm{B}+2 \mathrm{c}$

Colombia

An endemic to Antioquia.

Assessor: Calderon, E.

Refs: 19069

\section{Osmoxylon arrhenicum}

Araliaceae

VU D2

Papua New Guinea (North Solomons)

Endemic to Santa Isabel, this species is known only from the site where it was first collected in steep hill forest at $700 \mathrm{~m}$.

Assessor: World Conservation Monitoring Centre

Refs: 19031

\section{Osmoxylon chrysanthum}

Araliaceae

VU D2

Papua New Guinea (North Solomons)

A small tree, known only from the type collection. It was found in a riverine community on the debris banks of a deep gorge at $300 \mathrm{~m}$ on Guadalcanal Island.

Assessor: World Conservation Monitoring Centre

Refs: 19031

\section{Osmoxylon cormeri}

Araliaceae

VU D2

Papua New Guinea (North Solomons)

Endemic to Guadalcanal, this small tree is known only from the type specimen collected at $1470 \mathrm{~m}$.

Assessor: World Conservation Monitoring Centre Refs: 19031

\section{Osmoxylon ellipsoideum}

Araliaceae

Papua New Guinea (North Solomons)

A many-branched tree, presently known only from areas of secondary or disturbed lowland hill forest in the Milne Bay District.

Assessor: World Conservation Monitoring Centre Refs: 19031

\section{Osmoxylon lanceolatum}

Araliaceae

VU D2

Papua New Guinea (Bismarck Archipelago)

An understorey tree, endemic to central and south New Ireland where it occurs in ridge-top forest on limestone between 750 and $850 \mathrm{~m}$.

Assessor: World Conservation Monitoring Centre Refs: 19031
Osmoxylon mariannense

Araliaceae

Northem Marianas

Endemic to the island of Rota, the species is scattered in moist forest on limestone. There have been no recent surveys but the population certainly contains fewer than 100 or possibly 50 trees, confined to an area of $15 \mathrm{~km}^{2}$. Lack of regeneration is a serious problem but the causes are unknown.

Assessor: Wiles, G.

Refs: 2474, 16676, 19175

\section{Osmoxylon miquelli}

Araliaceae

DD

Indonesia (Irian Jaya)

A sparsley branched tree, known from only a single imperfect collection of no precise locality. It is likely to come from Triton Bay, Fakfak District.

Assessor: World Conservation Monitoring Centre Refs: 19031

\section{Osmoxylon reburrum}

Araliaceae

Papua New Guinea (North Solomons)

VU D2

A small tree, so far known only from the type collection from the Malaita District.

Assessor: World Conservation Monitoring Centre Refs: 19031

\section{Osmoxylon whitmorei}

Araliaceae

VU D2

Papua New Guinea (North Solomons)

A small tree endemic to coastal forest in Guadalcanal; it is known only from the type collection.

Assessor: World Conservation Monitoring Centre

Refs: 19031

\section{Ostodes minor}

Euphorbiaceae

Sri Lanka

$\mathrm{CR} B 1+2 \mathrm{c}$

A tree restricted to lowland wet evergreen forest in south-west Sri Lanka. The species was previously found in the Haycock (Hinidumkanda) Biosphere Reserve. However, it was not found again during the extensive forest surveys conducted between 1991 and 1996 for the National Conservation Review, suggesting that the species is either extremely rare or possibly extinct. Assessor: World Conservation Monitoring Centre Refs: 17195,19112

\section{Ostrya rehderiana}

Corylaceae

CR D1

China (Zhejiang)

The wild population is now apparently confined to five damaged individuals on Xitianmu Mountain. The trees are protected but they do not appear to be regenerating naturally.

Assessor: World Conservation Monitoring Centre Refs: $1818,11725,11847$

\section{Otoba acuminata}

Myristicaceae

LR/nt

Costa Rica, Ecuador, Panama

The species is fairly common in lowland forest in Bocas del Toro in Panama and more scarce in Limon in Costa Rica. It is hoped that populations exist in La Amistad National Park in between these two sites and *TROPICOS also records the species in Ecuador. Although this suggests the species' range is wide, the 
known populations are not large and the habitat is greatly threatened.

Assessor: Mitré, M.

Refs: $7980,15037,16772$

\section{Otophora unilocularis}

Sapindaceae

China (Guangdong - Hainan)

The species is now presumed to be extinct from its only known location in thomy scrub on the seashore in Foluo, Ledong County, south-west Hainan. It was last seen in 1935.

Assessor: World Conservation Monitoring Centre

Refs: $1818,4246,11847$

\section{Ouratea amplectens}

Ochnaceae

VU Alc, B1+2c

Ghana, Liberia

A species which occurs commonly but only within a restricted and reduced area of wet evergreen forest. This habitat has experienced significant pressure from mining, logging and commercial forestry activities.

Assessor: Hawthome, W.

Refs: $2773,8369,12061$

\section{Ouratea cocleensis}

Ochnaceae

VU C $2 a$

Costa Rica, Panama

A species of mid-elevation rainforest, which has been collected from Valle de Antón in Coclé and more recently from the province of Panamá, including Altos de Campana National Park, where the population is well protected. Further investigation may reveal the species to be more widespread. There are several undetermined herbarium specimens, which may, prove identifiable to this species and a new record from Puntarenas indicates the species range extends into Costa Rica.

Assessor: Mitré, M.

Refs: 7272, 7980, 16772

\section{Ouratea elegans}

Ochnaceae

Jamaica

CR DI

A single individual, which has not been satisfactorily identified, is the only currently known specimen of the species. It is found in Copse Woods which is conserved by the landowners. Disturbance has been limited to hurricane damage.

Assessor: World Conservation Monitoring Centre

Refs: $401,5653,7980$

\section{Ouratea insulae}

Ochnaceae

EN C2a

Guatemala, Honduras, Mexico

The species occurs in moist lowland thickets, often in secondary growth.

Assessor: Nelson, $\mathrm{C}$.

Refs: 13995

\section{Ouratea jamaicensis}

Ochnaceae

LR/nt

Jamaica

A tree with an occasional distribution in central and westem parishes in woodland and pasture margins on limestone.

Assessor: World Conservation Monitoring Centre

Refs: 6057,7980

\section{Ouratea patelliformis}

Ochnaceae

DD

Panama

Known only from Pacora, in Panamá Province, the species has not been collected since it was first discovered, despite the area being relatively well explored. A revision of the genus suggests that the taxon is just a form of $O$. lucens.

Assessor: Mitré, $\mathbf{M}$

Refs: $7272,7980,16772$

\section{Ouratea quintasü}

Ochnaceae

VU D2

São Tomé \& Príncipe (Sāo Tomé)

This small tree is known from coastal areas in Angolares and Diogo Vaz. The island remains unexplored in places, although most of the forest below $1500 \mathrm{~m}$ was cleared in the first half of the century.

Assessor: World Conservation Monitoring Centre

Refs: 2724

\section{Ouratea schusteri}

Ochnaceae

VU B $1+2 c$

Kenya, Tanzania

A species of moist forest with populations in the Taita Hills, Kasigau, the Usambara and Uluguru Mountains.

Assessor: World Conservation Monitoring Centre

Refs: 6396, 12067

\section{Ouratea tumacoensis}

Ochnaceae

VU $B 1+2 c$

Colombia

An endemic of Nariño.

Assessor: Calderon, E.

Refs: 19069

\section{Oxandra leucodermis}

Annonaceae

LR/nt

Venezuela

Occurring in seasonally flooded evergreen forest, the species has been found in localities along Rio Casiquiare and Rio Negro in Amazonas.

Assessor: World Conservation Monitoring Centre

Refs: 19128

\section{Oxanthera aurantium}

Rutaceae

VU B $1+2 c$

New Caledonia

Assessor: Jaffré, T. et al.

Refs: 10351

\section{Oxanthera brevipes}

Rutaceae

VU B1+2c

New Caledonia

Assessor: Jaffré, T. et al.

Refs: 10351

\section{Oxanthera fragrans}

Rutaceae

$\mathrm{EN} \mathrm{B1+2c}$

New Caledonia

Assessor: Jaffré, T. et al.

Refs: 10351

Oxanthera neocaledonica

Rutaceae

EN B $1+2 c$

New Caledonia

Assessor: Jaffré, T. et al.

Refs: 10351 


\section{Oxanthera undulato}

Rutaceae

CR D1

New Caledonia

The species was last seen and collected in the vicinity of the upper Dothio. It is questionable whether it should now be considered extinct.

Assessor: Jaffré, T. et al.

Refs: 4492, 10351

\section{Oxera cauliflora}

Verbenaceae

VU B $1+2 c$

New Caledonia

Assessor: Jaffré, T, et al.

Refs: 10351

\section{Oxera crassifolia}

Verbenaceae

$\mathrm{LR} / \mathrm{cd}$

New Caledonia

Assessor: Jaffré, T. et al

Refs: 10351

\section{Oxera macrocalyx}

Verbenaceae

VU B $1+2 c$

New Caledonia

Assessor: Jaffré, T. et al.

Refs: 10351

Oxera nuda

Verbenaceae

VU B $1+2 c$

New Caledonia

Assessor: Jaffré, T. et al.

Refs: 10351

\section{Oxyanthus lepidus ssp. kigogoensis}

Rubiaceae

VU B1 $+2 d, D 2$

Tanzania

A small tree with a very restricted range, occurring within a $50 \mathrm{~m}$ altitudinal belt in moist montane forest in Kigogo.

Assessor: Lovett, J. \& G.P. Clarke

Refs: 3356,8814

\section{Oxyanthus pyriformis ssp. brevitubus}

Rubiaceae

VU B $1+2 b$

Kenya, Tanzania

In Kenya this taxon is recorded from dry forest on Emali and the Mutito Hills at medium elevations. It is also known from a similiar habitat in northern Tanzania.

Assessor: Lovett, J. \& G.P. Clarke

Refs: $6396,10351,12067$

\section{Oxyanthus pyriformis ssp. longitubus}

Rubiaceae

$\mathrm{EN} \mathrm{B} 1+2 \mathrm{c}$

Kenya

This small tree is known only from areas of moist forest in the Shimba Hills, Gongoni and Pangani. Only the Pangani site is unprotected.

Assessor: CAMP Workshop in Kenya

Refs: 6396, 19181

\section{Oxyanthus pyriformis ssp. tanganyikensis}

Rubiaceae

VU B $1+2 b$

Tanzania

A shrub or small tree from east and south-east Tanzania, restricted to moist forest or open woodland ranging from low to medium elevations.

Assessor: Lovett, J. \& G.P. Clarke

Refs: 8814, 10351

\section{Oxystigma msoo}

Leguminosae

VU B $1+2 b$

Kenya, Tanzania

This large tree is restricted to small areas of remaining moist or riverine forest from south-east Kenya to northeast Tanzania. The only records from Kenya are from Pangani and the Tana Delta.

Assessor: Lovett, J. \& G.P. Clarke

Refs: 6396, 10351, 12067

\section{Ozoroa namaquensis}

Anacardiaceae

Namibia, South Africa (Northern Cape)

A poorly known multi-stemmed species apparently confined to the lower Orange River Valley in the Goodhouse area of southern Namibia and the Northem Cape. It is recorded from at least three localities in *karroid shrubland in a semi-desert environment on nonperennial tributaries leading down to the Orange River. At one locality only a few plants were seen, but all were healthy and flowering profusely. Mining activities in the area could pose a threat. One locality was beside a former main road between South Africa and Namibia. It is likely that this species occurs elsewhere and a field assessment is required to determine its conservation status.

Assessor: Hilton-Taylor, C. et al.

Refs: 689,19218

Ozoroa reticulata var. nyasica

Anacardiaceae

VU D2

Malawi

This is a variant of a very polymorphic species. The taxonomy may need further confirmation. It is apparently confined to patches of montane woodland on Mount Mulanje. There have been considerable declines in the extent of forest and woodland on the mountain in the past, mainly through timber exploitation and also fires, but there is now some degree of protection. The conservation of remaining resources and prevention of illegal activities are now a high priority.

Assessor: World Conservation Monitoring Centre Refs: $5651,15477,18965$

\section{Pachyanthus pedicellatus}

Melastomataceae

LR/nt

Cuba

Occurring in montane rainforest especially along creeks, this endemic shrub or tree is restricted to the Sierra Maestra mountain range in eastern Cuba. It is still fairly common although in many places the species is becoming scarce.

Assessor: Areces-Mallea, A.E.

Refs: $16327,18485,19149$

\section{Pachypodanthium barteri}

Annonaceae

VU Alc

\section{Cameroon, Gabon, Nigeria}

A swamp forest tree, which appears to be rare. It is known to occur from south-west Nigeria to Gabon. Most parts of the range have suffered large-scale declines in its habitat because of logging and the demand for land for cultivation.

Assessor: World Conservation Monitoring Centre Refs: 4108, 11504 
Pachypodium namaquanum Apocynaceae

Namibia, South Africa (Northem Cape)

LR/nt

A spiny succulent tree recorded in *karroid shrubland along both sides of the lower Orange River Valley from the Tantalite Valley and Pella mountain range in the east to the Richtersveld, Huib-Hoch and Huns Mountains in the west. It has been recorded from more than 50 localities within an extent of occurrence of approximately $15000 \mathrm{~km}^{2}$. The subpopulations on the Namibian side of the Orange River are inaccessible and therefore generally secure. They are fairly large, with an average density of between 625 and 1100 individuals per hectare. Similar densities, with a range of ages, are also found on Pella Mountain. The species has been subjected to much illegal collecting, especially in the Richtersveld, as plants are highly sought-after on both the domestic and international markets. Artificially propagated plants are now widely available and the demand for wild-collected plants has effectively been reduced. There are further threats from mining activities in Namibia and intense grazing and trampling of the surrounding vegetation by domestic livestock in the Richtersveld, although this subpopulation is contained within a national park and provincial nature reserve. There are also low levels of recruitment in the latter subpopulation, apparently because of insect parasitism of the seeds. The species is also protected by law in both South Africa and Namibia and it is listed in ${ }^{*}$ CITES Appendix II.

Assessor: Hilton-Taylor, C, et al.

Refs: 689, 19141, 19218

\section{Pachystela subverticillata}

Sapotaceae

VU B I $+2 \mathrm{c}$

Kenya

A coastal shrub or small tree up to $8 \mathrm{~m}$, confined to a few isolated areas of moist or riverine forest and dense bushland/woodland.

Assessor: World Conservation Monitoring Centre

Refs: 1308, 6396

\section{Pachystigma loranthifolium ssp. loranthifolium}

Rubiaceae VU B $1+2 b$

Kenya, Tanzania

Ranging from south-east Kenya to north-east Tanzania, this small tree or shrub is confined to patches of dry coastal forest.

Assessor: Lovett, J. \& G.P. Clarke

Refs: $3356,6396,8814$

\section{Palaquium bataanense}

Sapotaceae

VU Ald

Indonesia, Philippines

A large tree of primary forests, this species is a source of red nato timber.

Assessor: World Conservation Monitoring Centre

Refs: 4919, 12937, 14573

\section{Palaquium bourdillonii}

Sapotaceae

VU $B 1+2 c$

India (Kerala, Tamil Nadu)

A relatively large tree, endemic to the southernmost part of the Western Ghats in the Agastyamalai Hills. It has been collected or recorded from approximately six localities of evergreen forest between 500 and $1300 \mathrm{~m}$. Large areas have been exposed to fires, grazing, the establishment of commercial plantations and cutting for fuelwood, but almost $1000 \mathrm{~km}^{2}$ of forest are now under protection within sanctuaries.

Assessor: World Conservation Monitoring Centre

Refs: $5651,14276,19144$

\section{Palaquium canaliculatum}

Sapotaceae

$\mathrm{EN} \mathrm{B1}+2 \mathrm{~cd}$

Sri Lanka

A rare tree restricted to lowland wet evergreen forest in south-west Sri Lanka. Only three localities were identified during the extensive forest surveys conducted for the National Conservation Review.

Assessor: World Conservation Monitoring Centre

Refs: 17195,19112

\section{Palaquium grande}

Sapotaceae

VUAlc

Sri Lanka

A tree restricted to the lowland wet evergreen forests of south-west Sri Lanka.

Assessor: World Conservation Monitoring Centre

Refs: 17195

\section{Palaguium impressinervium}

Sapotaceae

VU B1+2a

Malaysia (Peninsular Malaysia), Thailand

A very large tree of moist lowland and hill forest. The timber is traded internationally, but the greatest threat to the species is from the expansion of settlements.

Assessor: Chua, L.S.L.

Refs: 8464, 19073

\section{Palaquium laevifolium}

Sapotaceae

CR B $1+2 \mathrm{~cd}$

Sri Lanka

A species confined to lowland wet evergreen forest in south-west Sri Lanka. Only three trees were found in a single site, proposed for reserve status, during the extensive forest surveys conducted for the recent National Conservation Review.

Assessor: World Conservation Monitoring Centre

Refs: 17195,19112

\section{Palaquium luzoniense}

Sapotaceae

Philippines

VU Ald

This primary forest tree is a source of red nato timber and formerly provided gutta-percha for trade.

Assessor: World Conservation Monitoring Centre

Refs: 4919

\section{Palaquium mindanaense}

Sapotaceae

VU Alcd

Philippines

A timber species, endemic to the Philippines. Rates of habitat loss through logging and shifting cultivation have led to considerable population declines.

Assessor: World Conservation Monitoring Centre Refs: 4919

Palaquium neo-ebudicum

Sapotaceae

VU B $1+2 c$

Vanuatu

An endemic species to Vanuatu, occurring on the islands of Erromango, Pentecost and Banks. It is not uncommon but logging and habitat destruction have led to the species becoming increasingly hard to find. Assessor: World Conservation Monitoring Centre Refs: 11632 
Palaquium pauciflorum

Sapotaceae

VU Alc

Sri Lanka

A tree confined to the lowland wet evergreen forests of south-west Sri Lanka.

Assessor: World Conservation Monitoring Centre

Refs: 17195

\section{Palaquium petiolare}

Sapotaceae

$\mathrm{LR} / \mathrm{cd}$

Sri Lanka

Endemic to Sri Lanka, this canopy tree is restricted to the wet lowlands. It is one of the dominant canopy species in the Sinharaja Biosphere Reserve and also occurs in several other forest reserves.

Assessor: World Conservation Monitoring Centre

Refs: 17195,18515

\section{Palaquium philippense}

Sapotaceae

VU Ald

Philippines

A medium-sized tree, of lowland primary forests, which is used as a source of nyatoh timber.

Assessor: World Conservation Monitoring Centre

Refs: 2072, 4919, 14573

\section{Palaquium ravï}

Sapotaceae

$\mathrm{EN} \mathrm{B1+2c}$

India (Kerala, Tamil Nadu)

Collected twice, this relatively large tree is recorded from two localities of lowland evergreen forest in the region of the Anamalai Hills.

Assessor: World Conservation Monitoring Centre

Refs: 19144

\section{Palaquium regina-montium}

Sapotaceae

LR/cd

Malaysia (Peninsular Malaysia)

Occurring in montane and submontane rainforest areas, the species is protected within Taman Negara National Park and other protected forests within the permanent forest estate.

Assessor: Chua, L.S.L.

Refs: 14573, 19073

\section{Palaquium rubiginosum}

Sapotaceae

VU Alc, B1+2c

Sri Lanka

A tree restricted to the lowland wet evergreen forests of south-west Sri Lanka. This species was found in eight sites during the extensive forest surveys conducted for the National Conservation Review.

Assessor: World Conservation Monitoring Centre

Refs: 17195,19112

\section{Palaquium thwaitesii}

Sapotaceae

VU Alc

Sri Lanka

A tree restricted to the lowland wet evergreen forests of south-west Sri Lanka.

Assessor: World Conservation Monitoring Centre

Refs: 8203, 17195

\section{Palaquium zeylanicum}

Sapotaceae

VU D2

Sri Lanka

A newly described species from lowland dipterocarp forest in Morapitiya and Kanneliya Forest Reserves. In some places logging is threatening the habitat.

Assessor: World Conservation Monitoring Centre

Refs: 11086

\section{Palicourea calycina}

Rubiaceae

VU B1+2c

Ecuador

An endemic of the Ecuadorean High Andes, inhabiting areas of cloud forest between 3200 and $3290 \mathrm{~m}$ in the provinces of Carchi, Imbabura, Bolívar and Loja.

Assessor: World Conservation Monitoring Centre

Refs: 19119,19120

\section{Palicourea consobrina}

Rubiaceae

VU B $1+2 c$

Peru

Occurring between 2000 and $3000 \mathrm{~m}$, this forest species has been recorded only from the department of Cuzco.

Assessor: World Conservation Monitoring Centre

Refs: 1984

\section{Palicourea herrerae}

Rubiaceae

VU B $1+2 c$

Peru

Restricted to areas of cloud forest between 2500 and $4000 \mathrm{~m}$, the species is recorded in the departments of Cuzco and Huancavelica.

Assessor: World Conservation Monitoring Centre Refs: 1984

\section{Palicourea latifolia}

Rubiaceae

VU B $1+2 c$

Peru

Recorded only from the department of Huanuco, the species occurs in areas of forest between 1500 and $3000 \mathrm{~m}$.

Assessor: World Conservation Monitoring Centre

Refs: 1984

\section{Palicourea wilesii}

Rubiaceae

VU B $1+2 c$

Jamaica

A locally common species, occurring in shady woodland on limestone or shale in St Andrew, St Thomas and Portland between 280 and $1130 \mathrm{~m}$. Almost all the forest at these altitudes has been destroyed or severely degraded.

Assessor: Bellingham, $\mathbf{P}$.

Refs: $6057,7980,17743,19116$

\section{Pamphilia vilcabambae}

Styracaceae

VU B $1+2 c$

Peru

This species is restricted to cloud and *elfin forest between 2000 and $3000 \mathrm{~m}$ in the department of Cuzco.

Assessor: World Conservation Monitoring Centre Refs: 1984

\section{Pancheria humboldtiana}

Cunoniaceae

LR/cd

New Caledonia

Assessor: Jaffré, T. et al.

Refs: 10351

\section{Pancheria multijuga}

Cunoniaceae

LR/cd

New Caledonia

Assessor: Jaffré, T. et al.

Refs: 10351 
Pancheria robusta

Cunoniaceae

LR/cd

New Caledonia

Assessor: Jaffre, T. et al.

Refs: 10351

\section{Pandanus aldabraensis}

\section{Pandanaceae}

VU D2

Seychelles (Aldabra)

A small tree of mixed and tall scrub found only in the Gionnet Channel and in the Takamaka area on Picard and Grand Terre. The entire population occurs within an area of less than $1000 \mathrm{ha}$. The fruits are eaten and apparently dispersed by tortoises. The islands are protected within a Strict Nature Reserve. Only Picard has a small number of inhabitants in the research station. Assessor: Nature Protection Trust of Seychelles

Refs: 19027

\section{Pandanus balfourii}

Pandanaceae

VU D2

Seychelles

Endemic to the Seychelles, the species qualifies as threatened by virtue of its restricted distribution. Populations are healthy and stable.

Assessor: World Conservation Monitoring Centre

Refs: 16212,17229

\section{Pandanus carmichaelui}

Pandanaceae

CR DI

Mauritius

A low, sprawling shrub known only from a population confined to marshland at Le Petrin between 600 and $650 \mathrm{~m}$ in the south-west. Although the plants appear to flower and fruit regularly, no regeneration has been observed. The species has not been successfully brought into cultivation.

Assessor: Page, W.

Refs: $1411,2026,9120$

\section{Pandanus clandestinus}

Pandanaceae

LR/ed

New Caledonia

Assessor: Jaffré, T. et al.

Refs: 10351

\section{Pandanus decastigma}

Pandanaceae

VU B $1+2 \mathrm{C}$

New Caledonia

Assessor: Jaffré, T. et al.

Refs: 10351

\section{Pandanus decipiens}

Pandanaceae

VU B $1+2 c$

Philippines

This endemic tree of Palawan occurs in thickets and forests at low altitudes, often adjacent to mangrove swamp. The main island is a biosphere reserve.

Assessor: World Conservation Monitoring Centre

Refs: 4986

\section{Pandanus decumbens}

Pandanaceae

VU Bl $+2 c$

New Caledonia

Assessor: Jaffré, T. et al.

Refs: 10351
Pandanus gabonensis

Pandanaceae

VU D2

Gabon

A newly described species which is known only from an area near Mbel. It may be more widespread given that Gabon's forest are relatively unexplored. Most areas of forest, however, are now under concession to logging companies.

Assessor: World Conservation Monitoring Centre

Refs: 8572,14958

\section{Pandanus halleorum}

Pandanaceae

VU D2

Vanuatu

A species found only on Vanua Lava Island and at Tisbel on Malekula Island in medium-altitude forest. Assessor: World Conservation Monitoring Centre Refs: 9000

\section{Pandanus hornei}

Pandanaceae

VU D2

Seychelles

Once a dominant component of palm forest, the species is now restricted to small riverine areas on Mahe, Silhouette, Praslin and Curicuse. Historical clearance of mid-altitude forest has been the main factor causing the species' decline. Invasive plants are the most serious concem now. The species is present in several national parks.

Assessor: Nature Protection Trust of Seychelles

Refs: $16212,17229,19025$

\section{Pandanus joskei}

Pandanaceae

VU D2

Fiji

A species known from just two locations in Fiji, on Mount Korobamba on Viti Levu and on Koro Island, both at moderately high altitudes.

Assessor: World Conservation Monitoring Centre

Refs: 18818

\section{Pandanus kajui}

Pandanaceae

VU $B 1+2 c$

Kenya

A tree with prop roots, endemic to central Kenya. Assessor: World Conservation Monitoring Centre Refs: 6396,9151

\section{Pandanus lacuum}

Pandanaceae

$\mathrm{EN} \mathrm{B} 1+2 \mathrm{c}$

New Caledonia

Assessor: Jaffré, T. et al.

Refs: 10351

\section{Pandanus multispicatus}

Pandanaceae

VU D2

Seychelles

Usually a shrub less than $2 \mathrm{~m}$ high, but occasionally arborescent, the species is endemic to the Seychelles.

Populations are healthy and stable.

Assessor: World Conservation Monitoring Centre

Refs: 16212,17229

\section{Pandanus palustris}

Pandanaceae

CR D1

Mauritius

Like $P$. carmichalii, the species, which in this case is a tree growing to $10 \mathrm{~m}$, is found in the marshland at Le 
Petrin. Isolated individuals also occur on river courses of Mare aus Vacoas ('Lake of Pandanus'). Fewer than 20 individuals have been counted. No regeneration is observed and the plant has not been successfully brought into cultivation.

Assessor: Page, W.

Refs: $1411,2026,9120$

\section{Pandanus papenooensis}

Pandanaceae

LR/nt

French Polynesia (Society Is.)

The species is known only from Tahiti.

Assessor: Florence, J.

Refs: 14513

\section{Pandanus parvicentralis}

Pandanaceae

Gabon

The wild population remains unknown. The species is known only from herbarium specimens.

Assessor: World Conservation Monitoring Centre Refs: 8572

\section{Pandanus petersii}

Pandanaceae

Mozambique

Scattered in woodland remnants in swampy or wetland places, the species is confined to an area stretching from Namacurra to Quelimane and the Zambezi Delta. The populations are unprotected and contained within a zone which is under pressure from growing human populations and their activities.

Assessor: Burrows, P.

Refs: 19172

\section{Pandanus pyramidalis}

Pandanaceae

EX

Mauritius

Originally known from marshland areas on the central plateau, the last known individual died in 1995 of disease. It is possible that the species survives in areas which have not been surveyed.

Assessor: Page, W.

Refs: $1411,2026,9120$

\section{Pandanus sechellarum}

Pandanaceae

VU D2

Seychelles

Endemic to the Seychelles, the species qualifies as threatened by virtue of its restricted distribution. Populations are healthy and stable.

Assessor: World Conservation Monitoring Centre

Refs: 16212,17229

\section{Pandanus taveuniensis}

Pandanaceae

VU D2

Fiji

A tree confined to Taveuni Island, where the population is reported to be extensive.

Assessor: World Conservation Monitoring Centre Refs: 18818

\section{Pandanus tectorius var. uapensis}

Pandanaceae

French Polynesia (Marquesas Is.)

One of the numerous varieties of this Polynesian species. It is known only from Ua Pou in the Marquesas.
An important tree for various uses: a source of fibre, thatch, wood and also a famine food.

Assessor: Florence, J.

Refs: 434, 14513

\section{Pandanus teuszai}

Pandanaceae

Gabon

The population in the wild is unknown. The species is known only from herbarium specimens.

Assessor: World Conservation Monitoring Centre

Refs: 8572

\section{Pandanus thomensis}

Pandanaceae

São Tomé \& Príncipe (São Tomé)

VU D2

A tree known from several collections, both recent and old, from Rodia, Itheu das Rolas and S. António de Mussacavu. Areas of São Tomé remain to be explored, although most of the forest below $1500 \mathrm{~m}$ was cleared in the first half of the century.

Assessor: World Conservation Monitoring Centre Refs: 2724

\section{Pandanus verecundus}

Pandanaceae

CR DI

New Caledonia

Assessor: Jaffré, T. et al.

Refs: 10351

\section{Pappobolus sanchezii}

Compositae

VU D2

Peru

Known only from the type collection, the species occurs in cloud forest between 2500 and $4000 \mathrm{~m}$ in the department of Cajamarca.

Assessor: World Conservation Monitoring Centre Refs: 1984

\section{Paracalyx balfourii}

Leguminosae

Yemen (Socotra)

VU D2

A species of lowland dry woodland on Socotra and also Samha, one of The Brothers. Its occurrence is very scattered but populations are under no immediate threat. Assessor: Miller, A.G.

Refs: 2354, 19083

\section{Parajubaea torallyi}

Palmae

$\mathrm{EN} \mathrm{B1}+2 \mathrm{c}$

Bolivia

Endemic to the Bolivian Andes, the species is scattered in dry forest on steep rocky slopes between 2400 and $3400 \mathrm{~m}$ in inter-Andean valleys. There is little evidence of regeneration: most stands almost completely lack seedlings and juveniles. Although local communities are concerned about the species' conservation and two populations are now contained within a protected area at El Palmar, no research or action has been taken to deal with the lack of regeneration.

Assessor: Moraes, M.

Refs: 19118,19180 
Paramachaerium schunkei Leguminosae

VU D2

Peru

This lowland Amazon forest species is known only from the type collection from the department of Huanuco.

Assessor: World Conservation Monitoring Centre Refs: 1984

\section{Paranecepsia alchorneifolia}

Euphorbiaceae

Mozambique, Tanzania

VU $B 1+2 b$

A monotypic genus. It is found in remaining riverine forest or thicket in eastern Tanzania extending south into north-east Mozambique.

Assessor: Lovett, J. \& G.P. Clarke

Refs: $1308,3356,8814$

\section{Paranephelium hainanensis}

Sapindaceae

China (Guangdong - Hainan)

EN B $1+2 c$

A species with a highly restricted range, valuable as a timber and confined to woodland below $200 \mathrm{~m}$ in Yaxian County on Hainan Island. Scattered singly or in small stands, individuals have become scarcer because of cutting and habitat clearance. Remaining stands do not appear to be protected in any way.

Assessor: World Conservation Monitoring Centre

Refs: 1818,11847

\section{Parashorea aptera}

Dipterocarpaceae

Indonesia (Sumatra)

Found below $70 \mathrm{~m}$ in eastern Sumatra, this tree grows on sandy soils on low hills.

Assessor: Ashton, P.

Refs: $7673,9169,13857$

\section{Parashorea chinensis}

Dipterocarpaceae

EN Alcd, C2a, Dl

China (Guangxi, Yunnan), Viet Nam

An emergent tree, reaching heights of $80 \mathrm{~m}$, in primary forest areas within Mengla, Maguan and Hekou in Yunnan, parts of south-west Guangxi and the northem provinces of Viet Nam. In China only a few large trees are left, the Yunnan population being restricted to an area of $20 \mathrm{~km}^{2}$. Insect attacks, resulting in premature fruit-fall, are frequent. In Viet Nam the species is sometimes found in pure stands. Populations have been overexploited for their timber in both countries.

Assessor: Ashton, P.

Refs: $848,1818,11847,13857,15357,15754,19055$

\section{Parashorea densiflora}

Dipterocarpaceae

EN Alcd, $\mathrm{B} 1+2 \mathrm{c}$

Malaysia (Peninsular Malaysia)

A tree scattered throughout the lowland dipterocarp forest of Peninsular Malaysia, which is cut for gerutu timber.

Assessor: Ashton, P.

Refs: $5550,7673,9169,13857$

\section{Parashorea globosa}

Dipterocarpaceae

$\mathrm{EN} \mathrm{B} 1+2 \mathrm{e}, \mathrm{D} 1$

Indonesia (Sumatra), Malaysia (Peninsular Malaysia)

A tree suffering from degradation of the lowland dipterocarp forest.

Assessor: Ashton, P.

Refs: $5550,7673,9169,13857$

\section{Parashorea lucida}

Dipterocarpaceae

CR Alcd, Bl+2c, C2a

Indonesia (Kalimantan, Sumatra), Malaysia (Sarawak)

This species is found in mixed dipterocarp forest on hills.

Assessor: Ashton, $\mathrm{P}$.

Refs: $7673,9169,13857$

\section{Parashorea macrophylla}

Dipterocarpaceae

CR Alcd, B1+2c, C2a

Brunei, Malaysia (Sarawak)

A large timber tree which is confined to moist clay-rich soils in Sarawak and Brunei. An occurrence has been recorded in a proposed reserve.

Assessor: Ashton, $\mathrm{P}$.

Refs: $7673,9169,13857$

\section{Parashorea malaanonan}

Dipterocarpaceae

Brunei, Malaysia (Sabah, Sarawak), Philippines

A very large dipterocarp tree of lowland primary forest, which is used as white seraya timber and is the most important commercial timber of northem Borneo. This threatened species is located in a proposed reserve site.

Assessor: Ashton, $\mathrm{P}$.

Refs: $7673,9169,13857$

\section{Parashorea stellata}

Dipterocarpaceae

CR Alcd, B1+2c

Malaysia (Peninsular Malaysia), Myanmar, Thailand, Viet Nam

This slow-growing tree is found in seasonal lowland and evergreen dipterocarp hill forest.

Assessor: Ashton, P.

Refs: $7673,13857,19093$

\section{Parasitaxus ustus}

Podocarpaceae

LR/nt

New Caledonia

A small shrub which parasitises the roots of Falcatifolium taxoides. Although populations are small, the species is widely dispersed in cloud forest and under effective protection in Rivière Bleue Provincial Park. There are threats of mining in Mont Dzumac and Mont Paéoua.

Assessor: SSC Conifer Specialist Group

Refs: 12630,13041

\section{Parathesis amplifolia}

Myrsinaceae

VU C2a

Panama

Occurring in moist evergreen forest between 700 and $1500 \mathrm{~m}$, the species is known from two main areas, from Cerro Jefe in Chagres National Park and from Kunayala Indigenous Reserve. There are few collections but the forest is relatively extensive and well protected. Occurrences are also recorded in Fortuna Forest Reserve in Chiriqui and Valle de Antón in Coclé.

Assessor: Mitré, M.

Refs: $7272,7980,14873,16772$

\section{Parathesis aurantica}

Myrsinaceae

VU $B !+2 c$

El Salvador

Endemic to El Salvador, the species occurs in Chalatenango, Los Esesmiles and in the east of la Palma. 
It is found in montane pine-oak forest, where it is widely exposed to threats of logging, agriculture and pastoralism.

Assessor: World Conservation Monitoring Centre

Refs: 19030

\section{Parathesis bicolor}

Myrsinaceae

DD

Panama

The species is known from three collections: the type from the El Llano-Cartí highway, from Cerro Campana in Altos de Campana National Park and most recently in 1982 from a collection without a named locality but with co-ordinates which fall in the middle of the ocean.

Assessor: Mitré, $\mathbf{M}$.

Refs: 16772

\section{Parathesis congesta \\ Myrsinaceae}

VU B $1+2 c$

El Salvador

Confined to Chalatenango and El Imposible National Park, the species is scattered in forest areas up to $1200 \mathrm{~m}$. The main threats to the populations are posed by habitat loss through logging, forest management activities and the spread of agriculture. There are restrictions on these activities in the national park.

Assessor: World Conservation Monitoring Centre

Refs: 19030

\section{Parathesis glaberima}

Myrsinaceae

Panama

Known only from the type collection, gathered from Cerro Tute in Veraguas in 1975. There are problems of identification with the members of this family in Panama and a taxonomic revision is needed.

Assessor: Mitré, M.

Refs: 16772

\section{Parathesis panamensis}

Myrsinaceae

Colombia, Panama

The species is known only from the type collection, gathered in 1927 from Valle de Talamanca, Bocas del Toro. *TROPICOS records the species in Antioquia in Colombia but no further details are known.

Assessor: Mitré, M.

Refs: $7272,7980,14873,16772$

\section{Parathesis seibertii}

Myrsinaceae

Costa Rica, Panama

LR/nt

A common species of montane forest in Chiriquí, Panama, occurring in Volcán Barú National Park, La Amistad National Park, on both the Panama and Costa Rica sides, and Fortuna Forest Reserve. It is also reported from Bocas del Toro, Panama, and in high areas of the provinces of Alajuela and Puntarenas in Costa Rica.

Assessor: Mitré, M.

Refs: 16772

\section{Parathesis tenuifolia}

Myrsinaceae

DD

Panama

The species was described in 1971 on the basis of a single collection from Bocas del Toro in 1928. The exact locality from which the specimen was collected is not known. The family in Panama is in need of taxonomic revision.

Assessor: Mitré, M.

Refs: 16772

\section{Parathesis vulgata}

Myrsinaceae

EN C2a

Guatemala, Honduras

Mainly occurring at middle and upper elevations of mountain slopes, the species is found in areas of rainforest or cloud forest.

Assessor: Nelson, C.

Refs: 13995

\section{Parinari argenteo-sericea}

Chrysobalanaceae

VU D2

Malaysia (Sabah)

This tree, endemic to Sabah, is found in lowland forest and in forest along streams. It is known only from Lanad Datu, Sandakan and Tawau.

Assessor: World Conservation Monitoring Centre Refs: 19017

\section{Parinari papuana ssp. salomonense}

\section{Chrysobalanaceae \\ VU Alcd $+2 c d, B 1+2 a b c d e$}

Solomon Islands (Santa Cruz Is, South Solomon)

A lowland rainforest tree restricted to the Solomon Islands. It is locally common in parts of the New Georgia group. Populations are located in a prime logging area and the tree makes up a fairly large proportion $(6-10 \%)$ of the logs exported to Japan. Habitat loss is also a threat.

Assessor: Eddowes, P.J.

Refs: 19114

\section{Parkia harbesonii}

Leguminosae

VU B I +2c

Philippines

Endemic to Palawan, the species occurs in areas of lowland forest up to $150 \mathrm{~m}$. The main island is a biosphere reserve.

Assessor: World Conservation Monitoring Centre

Refs: 4986,18088

\section{Parkia korom}

Leguminosae

VU D2

Federated States of Micronesia

An endemic tree of the island of Ponape in Micronesia. It occurs in primary forest and provides a useful wood for constructing canoes. It does not appear to have been collected in the last 50 years.

Assessor: World Conservation Monitoring Centre Refs: 6835

\section{Parkia parrii}

Leguminosae

CR D1

Fiji

No record has been made of the species since the type collection, which was gathered in 1878 from Mbua Province, Vanua Levu. At the time of the collection the timber of the species was used for various purposes.

Assessor: World Conservation Monitoring Centre Refs: 6835,18818

\section{Parkia parvifoliola}

Leguminosae

VU D2

Palau

A primary forest tree, which is known only from the 
island of Babeldaop in the Republic of Palau. It does not appear to have been collected in the last 50 years.

Assessor: World Conservation Monitoring Centre

Refs: 6835

\section{Parkinsonia raimondoi}

Leguminosae

LR/nt

Somalia

Endemic to south-central Somalia, this species occurs in Acacia-Commiphora bushland on sand. The habitat continues to be degraded and destroyed by increasing agriculture and overcutting, particularly in the vicinity of Mogadishu.

Assessor: Thulin, M.

Refs: $7550,8697,18665$

\section{Parmentiera cereifera}

Bignoniaceae

$\mathrm{EN} \mathrm{C2a}$

Panama

Wild populations of the species occur in lowland evergreen forest on the Atlantic coast, either side of the Panama Canal, in Colón and Panamá Provinces. It is not a common species and in some places the habitat is under serious threat from logging. It is found in botanic gardens throughout the world.

Assessor: Mitré, $\mathrm{M}$.

Refs: $7980,15037,16772$

\section{Parmentiera dressleri}

Bignoniaceae

EN C2a

Panama

The species is restricted to lowland evergreen rainforest on the Atlantic side of Panamá and Colón Provinces. Populations are small and rare within an area which is potentially highly vulnerable to logging and habitat clearance. Some occurrences coincide with protected areas.

Assessor: Mitré, $\mathrm{M}$.

Refs: $14873,15037,16772$

\section{Parmentiera morii}

Bignoniaceae

CR C2a

Panama

The few collections made all come from the same area on a highway from El Llano to Cartí. Trees are found within deciduous rainforest between 250 and $400 \mathrm{~m}$. In recent years there has been much habitat clearance. It is possible that there are populations in the Kunayala Indigenous Reserve and Darién National Park, which would improve the species' status.

Assessor: Mitré, $\mathbf{M}$.

Refs: 5335, 7980, 13316, 16772

\section{Parmentiera stenocarpa}

Bignoniaceae

VU B $1+2 c$

Colombia

A Colombian endemic, known only from Antioquia and

Chocó.

Assessor: Calderon, E.

Refs: 7980,19069

\section{Parodiodendron marginivillosum}

Euphorbiaceae

VU Bl $+2 c$

Argentina, Bolivia

Endemic to the piedmont forest of north-west Argentina and Bolivia, the species occurs in an unprotected ecosystem, which is rapidly being replaced by agricultural systems.

Assessor: Prado, D.

Refs: 19122

\section{Pasania dodonaeifolia}

Fagaceae

EN Ala, Bl+2ab

Taiwan

The morphological similarity of the species to $P$. formosana and the existence of intermediate forms raise some doubt as to its current taxonomic status. Both species are confined to the Hengchun Peninsula, this taxon occurring in localities of lowland broadleaved forest in Tawu and Chinshuiying. The populations are small and little regeneration has been noted.

Assessor: Pan, F.J.

Refs: 3295, 19050, 19051

\section{Pasania formosana}

Fagaceae

CR D1

Taiwan

The notes under $P$. dodonaeifolia are relevant here. Both taxa are restricted to the Hengchun Peninsula and are morphologically closely related. This species is based on a single population of fewer than 50 individuals, confined to the windward slopes of Nanjenshan. Seed crops appear to be poor and heavily predated by squirrels. Little regeneration is evident. The location is contained within Kenting National Park.

Assessor: Lu, S.Y. \& F.J. Pan

Refs: 3295, 19050, 19051

\section{Paulownia kawakamii}

Scrophulariaceae

CR Al ace, $\mathrm{BI}+2 \mathrm{abc}, \mathrm{C} 2 \mathrm{ab}$

Taiwan

Only 13 mature trees appear to remain in the wild in the Chiayang area, Central Cross Island, Hwy. The mixed evergreen forest habitat has been extensively destroyed to make way for apple and peach orchards. The species has also been overexploited in the past for its valuable timber.

Assessor: Pan, F.J.

Refs: 3295, 19050

\section{Pauridiantha insularis}

Rubiaceae

VU D2

São Tomé \& Príncipe (São Tomé)

A small tree of montane forest. It was collected from Macambrara and Pico. No recent collections have been made.

Assessor: World Conservation Monitoring Centre Refs: 2724

\section{Pausinystalia brachythyrsum}

Rubiaceae

EX

Cameroon

The only evidence of this species is the type specimen, which was collected in 1746 in Bipinde in western Cameroon. The species may be considered to be extinct. Assessor: World Conservation Monitoring Centre Refs: 4509

\section{Pausinystalia lane-poolei ssp. lane-poolei}

Rubiaceae

VU B $1+2 c$

Ghana, Liberia, Sierra Leone

The range of this rare tree is almost confined to medium elevations in the Nimba Mountains in Liberia, possibly extending into Sierra Leone. It is also recorded in wet evergreen forest in Ghana. Mining for iron-ore, logging, 
the establishment of commercial plantations and the influx of people into these areas have caused large-scale destruction of the habitat.

Assessor: Hawthome, W.

Refs: $2773,4509,8369,12061$

\section{Pavetta abyssinica var. usambarica}

Rubiaceae

VU $B 1+2 b$

Tanzania

A variety endemic to the West Usambara Mountains, where it is found in moist semi-deciduous forest at elevations above $1675 \mathrm{~m}$.

Assessor: Lovett, J. \& G.P. Clarke

Refs: 3356, 10961

\section{Pavetta axillipara}

Rubiaceae

VU B1+2b

Tanzania

Restricted to the South Nguru Mountains, this small tree is located in a small area of moist forest at $1200 \mathrm{~m}$.

Assessor: Lovett, J. \& G.P. Clarke

Refs: 1308,3356

\section{Pavetta comostyla var. matengoana}

Rubiaceae

VU B $1+2 b$

Tanzania

One of the two distinct variants of the subspecies nyassica. This taxon is found only in a restricted area of dry montane forest on Lupembe Hill.

Assessor: Lovett, J. \& G.P. Clarke

Refs: 3356,8814

\section{Pavetta comostyla var. nyassica}

Rubiaceae

VU $B 1+2 b$

Malawi, Tanzania

This taxon is the more widespread of the two variants of the subspecies nyassica. It is distributed in two small areas of moist montane forest on Mount Rungwe in Tanzania and further south in Malawi.

Assessor: Lovett, J. \& G.P. Clarke

Refs: $1308,3356,8814$

\section{Pavetta holstii}

Rubiaceae

VU B1+2b

Tanzania

Populations are known from the East Usambara Mountains and the South Nguru Mountains. The species occurs at medium elevations in moist evergreen forest. Assessor: Lovett, J. \& G.P. Clarke

Refs: 3356,8814

\section{Pavetta intermedia}

Rubiaceae

VU B $1+2 c$

Democratic Republic of Congo, Uganda

A difficult species to identify and apparently uncommon. It has a restricted range in eastern DR Congo, extending into Uganda.

Assessor: *MUIENR

Refs: $1308,9837,16021$

\section{Pavetta johnstonii ssp. breviloba}

Rubiaceae

Tanzania, Zambia

VU B $1+2 b$

A dry montane forest shrub or small tree.

Assessor: Lovett, J. \& G.P. Clarke

Refs: 3356, 10961

\section{Pavetta kyimbilensis var. iringensis}

Rubiaceae

VU B1+2b

Malawi, Tanzania

A shrub or small tree of moist montane forests, above $1800 \mathrm{~m}$. The variety is known from the Udzungwa Mountains, Njombe and Rungwe Mountains in Tanzania, also occurring in Malawi. The type variety is more restricted in range.

Assessor: Lovett, J. \& G.P. Clarke

Refs: 3356,8814

\section{Pavetta kyimbilensis var. kyimbilensis}

Rubiaceae

VU B1+2b, D2

Tanzania

A small tree or shrub known from a single population in an area of moist montane forest on Mount Njombe in Tanzania. The other variant of the species is similarly restricted to East African montane forest but is more widespread.

Assessor: Lovett, J. \& G.P. Clarke

Refs: 3356,8814

\section{Pavetta lasioclada}

Rubiaceae

VU Alcd, B1+2c

Cameroon, Côte d'Ivoire, Ghana, Guinea, Mali, Sierra Leone, Togo

Ranging from Guinea to Cameroon, this species is found in areas of upland evergreen forest. This forest type has suffered from farming, fire, forest management activities and large-scale mining.

Assessor: Hawthome, W.

Refs: $2773,8854,12061$

\section{Pavetta linearifolia}

Rubiaceae

VU B $1+2 b$

Kenya, Tanzania

Ranging from the lower Tana and lower Galana area in Kenya to eastern Tanzania, this small tree or shrub is restricted to remaining areas of dry coastal forest.

Assessor: Lovett, J. \& G.P. Clarke

Refs: $3356,6396,12067$

\section{Pavetta lynesii}

Rubiaceae

VU $B 1+2 b$

Tanzania

Populations are restricted to areas of moist montane forest in Njombe, Udzungwa Mountains and Ukaguru.

Assessor: Lovett, J. \& G.P. Clarke

Refs: 3356, 10961

Pavetta macrosepala var. macrosepala

Rubiaceae

$\mathrm{VU} B 1+2 b$

Mozambique?, Tanzania

Restricted in range, this is a shrub or small tree found in dry deciduous coastal thickets on sand. It is possible that the range of this variety extends into Mozambique.

Assessor: Lovett, J. \& G.P. Clarke

Refs: $1308,3356,8814$

Pavetta macrosepala var. puberula

Rubiaceae

VU $B 1+2 b$

Tanzania

A variety restricted to coastal thickets in south-east

Tanzania.

Assessor: Lovett, J. \& G.P. Clarke

Refs: 3356,8814 
Pavetta manyanguensis

Rubiaceae

VU B $1+2 b$

Tanzania

An endemic to an area of moist montane forest at $1800 \mathrm{~m}$ on South Nguru.

Assessor: Lovett, J. \& G.P. Clarke

Refs: 3356,8814

\section{Pavetta mollissima}

Rubiaceae

VU Alc, BI+2c

Côte d'Ivoire?, Ghana

A small tree of wet evergreen forest, mainly in Ghana, possibly extending into Côte d'Ivoire. This forest has declined in extent because of the effects of mining, logging and the establishment of commercial plantations.

Assessor: Hawthome, W.

Refs: 12061

\section{Pavetta monticola}

Rubiaceae

VU D2

Equatorial Guinea (Annobón), São Tomé \& Príncipe (São Tomé)

A small tree known from several collections, some recent, in forest up to $1950 \mathrm{~m}$. Much of the rainforest below $1500 \mathrm{~m}$ on Sāo Tomé was felled in the first half of the century.

Assessor: World Conservation Monitoring Centre

Refs: 2724

\section{Pavetta nitidissima}

Rubiaceae

VU B1+2b, D2

Tanzania

A single population is known from an area of moist montane forest at Mwanihana in the Udzungwa Mountains.

Assessor: Lovett, J. \& G.P. Clarke

Refs: 3356, 10961

\section{Pavetta sepium var. massaica}

Rubiaceae

VU Bl+2b

Tanzania

A small tree or shrub, known from a single site of dry montane forest in east Tanzania.

Assessor: Lovett, J. \& G.P. Clarke

Refs: 3356,8814

\section{Pavetta sepium var. sepium}

Rubiaceae

VU B $1+2 b$

Kenya, Tanzania

In Kenya this variety has been recorded from groundwater or riverine forest and rocky bushland in the Taita Hills and Loitokitok. It also occurs in northern Tanzania.

Assessor: Lovett, J. \& G.P. Clarke

Refs: $3356,6396,8814$

\section{Pavetta sparsipila}

Rubiaceae

VU B $1+2 b$

Tanzania

A small tree or shrub restricted to moist evergreen forest in the North Uluguru Mountains.

Assessor: Lovett, J. \& G.P. Clarke

Refs: 3356,5204

Pavetta sphaerobotrys ssp. lanceisepala

Rubiaceae

VU B $1+2 b$

Tanzania

The range of this shrubby tree is restricted to north-east
Tanzania, where it occurs in patches of dry coastal forest.

Assessor: Lovett, J. \& G.P. Clarke

Refs: 3356,8814

Pavetta sphaerobotrys ssp. sphaerobotrys

Rubiaceae

VU B $1+2 b$

Tanzania

A shrubby tree confined to a few localities of dry coastal forest in Kilosa.

Assessor: Lovett, J. \& G.P. Clarke

Refs: 3356,8814

Pavetta sphaerobotrys ssp. tanaica

Rubiaceae

VU B1+2c

Kenya

A shrub or tree endemic to the lower Tana River, where it occurs in areas of riverine forest or woodland.

Assessor: World Conservation Monitoring Centre Refs: 6396

Pavetta subumbellata var. subcoriacea

Rubiaceae

VU B $1+2 b$

Malawi, Tanzania

A taxon known from a single locality of moist montane forest at Mufindi, Tanzania, and also from a population in Malawi.

Assessor: Lovett, J. \& G.P. Clarke

Refs: $1308,3356,8814$

\section{Pavetta tarennoides}

Rubiaceae

VU B $1+2 c$

Kenya

A shrub or tree, rarely described as climbing, endemic to the Shimba Hills.

Assessor: World Conservation Monitoring Centre

Refs: 6396

\section{Pavetta tendagurensis var. glabrescens}

Rubiaceae

VU $B 1+2 b$

Tanzania

A variant of a Tanzanian endemic. It is known from dry lowland forest in Mlinguru, Tendaguru and the Rondo Plateau.

Assessor: Lovett, J. \& G.P. Clarke

Refs: 3356,8814

Pavetta tendagurensis var. tendagurensis

Rubiaceae

$\mathrm{VU} \mathrm{B} 1+2 \mathrm{~b}, \mathrm{D} 2$

Tanzania

A poorly known small tree or bush which is known only from the type locality at Tendagun.

Assessor: Lovett, J. \& G.P. Clarke

Refs: 3356,8814

\section{Pavonia spicata var. troyana}

Malvaceae

LR/nt

Jamaica

The Jamaican variety of a Caribbean species. It occurs in woodland on limestone in the central and north-westem parishes.

Assessor: World Conservation Monitoring Centre Refs: 6057,7980 


\section{Peddiea kivuensis}

Thymelaeaceae

LR/cd

Democratic Republic of Congo

The distribution of this species is limited. It occurs in lowland closed forest in the Forestier Central.

Assessor: Ndjele, M.B.

Refs: 17185,17951

\section{Pelagodoxa henryana}

Palmae

CR B1+2d

French Polynesia (Marquesas Is.)

A monotypic palm genus restricted to Nuku Hiva in the Marquesas. It grows in rainforest at $40 \mathrm{~m}$. The main threats are grazing by feral pigs and land clearance for agriculture and human habitation.

Assessor: Johnson, D.

Refs: 19118

\section{Pelea obovata}

Rutaceae

EX

USA (Hawaii)

Assessor: World Conservation Monitoring Centre

Refs: 3372

\section{Pellacalyx yunnanensis}

Rhizophoraceae

$\mathrm{EN} \mathrm{BI}+2 \mathrm{c}, \mathrm{C} 2 \mathrm{a}$

China (Yunnan)

An evergreen tree known only from two localities in Mengla County, where it occurs in dense monsoon forest between 600 and $850 \mathrm{~m}$. The population has been reduced to a few hundred plants, including a few individuals within a nature reserve.

Assessor: World Conservation Monitoring Centre

Refs: $1818,11847,19055$

\section{Pellegriniodendron diphyllum}

Leguminosae

$\mathrm{LR} / \mathrm{nt}$

Cameroon, Côte d'Ivoire, Gabon, Ghana

Confined to areas of wet evergreen forest, where it can be common, this small understorey tree is found on both sides of the Dahomey Gap. There has been significant loss of this forest in all countries because of mining, logging and commercial forestry activities. It is a slowgrowing species from a monotypic genus.

Assessor: World Conservation Monitoring Centre

Refs: 8369, 12061, 12597, 19043

\section{Pennantia baylisiana}

Icacinaceae

CR D1

\section{New Zealand (North Is.)}

A species which has only ever been known from a single tree, discovered in 1946 on Great Island in Three Kings Islands Group. Although sexed as female, the tree has produced viable pollen and some seedlings have been raised ex situ. The decline of the species has been attributed to habitat destruction as a consequence of human occupation and browsing by goats.

Assessor: de Lange, P.J.

Refs: 4253, 9800, 17637, 19133, 19134

\section{Pentace acuta}

Tiliaceae

VU Bl+2c

Malaysia (Peninsular Malaysia)

A scattered tree of lowland and hill forest, known only from Bubu Forest Reserve in Perak and Bukit Bauk Forest Reserve in Terengganu.

Assessor: Chung, R.C.K.

Refs: 19073
Pentace excelsa

Tiliaceae

LR/ed

Malaysia (Peninsular Malaysia)

Known only from Gunung Mandi Angin in Terengganu and Gunung Tapis in Pahang, this large tree is common at $600 \mathrm{~m}$ in moist montane forest.

Assessor: Chung, R.C.K.

Refs: 19073

\section{Pentace exima}

Tiliaceae

VU B $1+2 \mathrm{C}$

Malaysia (Peninsular Malaysia)

A tree found scattered within open forest, usually occurring on the coastal hills of Penang, Perak and Pahang.

Assessor: Chung, R.C.K.

Refs: 19073

\section{Pentace grandiflora}

Tiliaceae

LR/cd

Malaysia (Peninsular Malaysia)

A locally common tree found in open moist forests of Bukit Bauk, Jerangau, Ulu Sungai Loh and Gunung Mandi Angin in Terengganu.

Assessor: Chung, R.C.K.

Refs: 8464, 19073

\section{Pentace microlepidota}

Tiliaceae

VU BI+2c

Malaysia (Peninsular Malaysia)

Scattered and rare, this tree grows in lowland and hill forests. The timber is used locally.

Assessor: Chung, R.C.K.

Refs: 19073

\section{Pentace perakensis}

Tiliaceae

VU D2

Malaysia (Peninsular Malaysia)

Scattered in lowland and hill open forest, this tree is known only from Lanit Hills, Perak, where it is threatened by tourism and expanding settlements.

Assessor: Chung, R.C.K.

Refs: 19073

\section{Pentace strychnoidea}

Tiliaceae LR/cd

Malaysia (Peninsular Malaysia)

An endemic tree most common in hill forest.

Assessor: Chung, R.C.K.

Refs: $8464,11145,19073$

\section{Pentagonia rubiflora}

Rubiaceae

Peru

Known only from the type collection, the tree occurs in lowland forest in San Martin. It is possibly a synonym of $P$. velutina.

Assessor: World Conservation Monitoring Centre Refs: 1984

\section{Pentapanax castanopsisicola}

Araliaceae

EN C2a

Taiwan

Usually an epiphytic shrub, the species is scattered in small populations throughout the central mountain range. Occurring in broadleaved evergreen forest at medium elevations, some populations are protected in 
Yushan National Park; others are under pressure from encroaching housing developments.

Assessor: Lu, S.Y. \& F.J. Pan

Refs: $3295,6469,19050,19051$

\section{Pentapanax henyri}

Araliaceae

$\mathrm{LR} / \mathrm{cd}$

China (Yunnan)

Endemic to parts of north-west and south-east Yunnan, the species occurs in subtropical monsoon forest between 1200 and $2600 \mathrm{~m}$. Its bark is widely used, and in some instances overexploited, for its medicinal properties. There are several occurrences within nature reserves.

Assessor: Sun, W.

Refs: 19055

\section{Pentaspadon motleyi}

Anacardiaceae

Indonesia (Irian Jaya, Kalimantan, Sumatra), Malaysia (Peninsular Malaysia, Sabah, Sarawak), Papua New Guinea (North Solomons, Papua New Guinea), Solomon Islands (South Solomon)

In Papua New Guinea, this species occurs mainly in primary forest on the banks of streams and rivers in the Gulf and Madang Provinces and Bougainville in the North Solomons. It is under great threat from habitat destruction in these areas and is considered to be endangered (EN C2a). The situation is likely to be similar elsewhere.

Assessor: World Conservation Monitoring Centre

Refs: 5550,9328, 11145, 12937, 17140, 19114

\section{Pera aperta}

Euphorbiaceae

Panama

Known only from the type specimen, it is uncertain whether the species is extinct or whether it has been incorrectly described as a separate taxon from $P$. arborea, which also occurs in the area. No specimens have been collected since 1941 .

Assessor: Mitré, M.

Refs: $7272,7980,16772$

\section{Perebea glabrifolia \\ Moraceae}

$\mathrm{CR} B \mathrm{BI}+2 \mathrm{bc}$

Brazil (Amazonas)

There exists only one collection, made in 1932 from Sāo

Paulo de Olivença.

Assessor: Pereira, J.P. et al.

Refs: 7980,15717

\section{Pericopsis elata}

Leguminosae

EN Alcd

Cameroon, Congo, Côte d'Ivoire, Democratic Republic of Congo, Ghana, Nigeria

A timber species, also known as Afromosia, which provides an important altemative to teak. It is a gregarious species, restricted to the drier parts of semideciduous forests in Central and West Africa. Since 1948 trade in the timber has soared. Levels of exploitation have been unsustainable in all countries and the species' habitat has declined. Regeneration is insufficient to replace lost populations. The species is currently listed in * CITES Appendix II.

Assessor: African Regional Workshop

Refs: $4506,6128,6718,8325,8369,14301,17408$

\section{Pericopsis mooniana}

Leguminosae

VUAled

Federated States of Micronesia, Indonesia (Irian Jaya, Java, Kalimantan, Moluccas, Sulawesi, Sumatra), Malaysia (Peninsular Malaysia, Sabah), Palau, Papua New Guinea, Philippines, Sri Lanka

A fairly large tree mainly found scattered within coastal forests. The species has been heavily exploited for its beautiful timber, which is in great demand and realises high prices. Supplies are limited and trade and export are minimal. It is threatened further by poor natural regeneration and lack of replanting. Very few stands remain in Sulawesi, it is thought to be almost extinct in Sabah, and it is considered to be rare or vulnerable in Peninsular Malaysia, Kalimantan and Sri Lanka. In Papua New Guinea, this species is restricted to the heavily logged Oriomo River in the Westem Province, where it is possibly now extinct.

Assessor: Asian Regional Workshop

Refs: $1517,4329,5550,8203,8865,12779,12937$, $13395,14573,17991,18796,19026,19112,19114$

\section{Peritassa killipii}

Celastraceae

VU D2

Peru

Known only from the type collection, the species occurs in lowland Amazon forest in the department of Loreto.

Assessor: World Conservation Monitoring Centre Refs: 1984

\section{Perrottetia excelsa}

Celastraceae

VU D2

Panama

There have been no records of the species since 1980 . The two collections known are from the same site. Fieldwork is needed in order to ascertain wether the species still exists.

Assessor: Mitré, M.

Refs: 15991,16772

\section{Perrottetia multiflora}

Celastraceae

LR/nt

Costa Rica, Panama, Venezuela

A cloud forest species which, in Panama, occurs in small populations only in Chiriquí and Darién. In Costa Rica populations appear to be larger and scattered throughout the country at elevations above $1000 \mathrm{~m}$. Records also exist from Venezuela and it is likely that the species will be found in Colombia. Most parts of the range are protected, although extensive agriculture is beginning to affect some high-altitude areas in Panama and Costa Rica.

Assessor: Mitré, M

Refs: $7272,15991,16772$

\section{Persea alpigena var. harrisii}

Lauraceae

LR/nt

Jamaica

This variety is hard to distinguish from the type variety. Both are endemic to the Blue Mountains, this form apparently being locally common in montane thickets on shale above $750 \mathrm{~m}$.

Assessor: World Conservation Monitoring Centre Refs: $6057,7980,12564$

\section{Persea brenesi}

Lauraceae

VU D2

Costa Rica

The species is known only from an area of wet 
evergreen forest, occurring between 1100 and $1200 \mathrm{~m}$, near La Palma de San Ramón. It is possible that the taxon represents a unusual form of $\boldsymbol{P}$. veraguasensis. Assessor: World Conservation Monitoring Centre Refs: 12587,14487

\section{Persea bullata}

\section{Lauraceae}

VU B $1+2 c$

Ecuador

A small tree of the High Andes, endemic to areas of montane and upper montane cloud forest between 2500 and $3500 \mathrm{~m}$ in the provinces of Loja, Chimborazo and Zamora-Chinchipe.

Assessor: World Conservation Monitoring Centre

Refs: 19119,19120

\section{Persea campii}

Lauraceae

VU B1+2c

Ecuador

A small tree of cloud forest between 2400 and $2900 \mathrm{~m}$ in the Ecuadorean High Andes, known only from Loja and Azuay Provinces.

Assessor: World Conservation Monitoring Centre

Refs: 19119,19120

\section{Persea floccosa}

Lauraceae

VU B $1+2 c$

Mexico (Chiapas, Oaxaca, Puebla, Veracruz)

Assessor: Ramirez-Marcial, N. \& M. González-Espinosa

Refs: $1857,10816,16121$

\section{Persea glabra}

Lauraceae

VU D2

Brazil (Bahia)

A shrub or tree, newly described and known only from the type collection, which was made in secondary vegetation at the edge of forest in Pico das Almas. Assessor: World Conservation Monitoring Centre Refs: 15421

\section{Persea indica}

Lauraceae

LR/cd

Portugal (Madeira), Spain (Canary Is.)

The wild origin of the species is a little obscure. It appears to have been introduced to the Azores three centuries ago. Occurrences on these islands are therefore excluded for the purposes of assigning an IUCN red list category. On Madeira and the Canaries, populations are known from remaining *laurisilva and cloud forest. Although the extent of the stands is much reduced as a result of past exploitation of the highly valued wood, the species is still abundant in parts of Madeira and the Canaries. It is listed in regional legislation and occurs within protected areas.

Assessor: Bañares, A. et al.

Refs: $5287,7222,19022,19131$

\section{Persea julianae}

Lauraceae

VU D2

Suriname

A poorly known species which has been collected only from a single locality at $1200 \mathrm{~m}$ on Julianatop.

Assessor: World Conservation Monitoring Centre

Refs: 19196

\section{Persea liebmanni}

Lauraceae

VU B1+2c

Mexico (Chiapas, Oaxaca, Puebla, Sinaloa)

Assessor: Ramirez-Marcial, N. \& M. González-Espinosa Refs: $1857,16121,16794$

\section{Persea lingue}

\section{Lauraceae}

LR/nt

Argentina (Chubut), Chile (Bíobío, La Araucania, Los Lagos, Maule, O'Higgins, Santiago, Valparaiso)

Distributed over much of the Central Depression up to $900 \mathrm{~m}$ in Chile, extending into Argentina, the species is widespread but suffering from extensive habitat loss. Logging, increasing agriculture and fires are the main concerns.

Assessar: González, M.

Refs: $5112,5448,7980,16328$

\section{Persea obtusifolia}

Lauraceae

VU $B 1+2 c$

Costa Rica, Panama

Occurring in montane *elfin forest or drier sites at higher elevations, the species is known solely from the easternmost parts of the Cordillera de Talamanca, extending into the Chiriquí highlands in Panama.

Assessor: World Conservation Monitoring Centre Refs: 12587,15037

\section{Persea philippinensis}

Lauraceae

Philippines

VU Alcd

An endemic to the Philippines. Rates of habitat loss through logging and shifting cultivation have led to considerable population declines.

Assessor: World Conservation Monitoring Centre

Refs: 2072, 4919, 7673, 18088

\section{Persea podadenia var. glabriramea}

Lauraceae

VU B $1+2 c$

Mexico (Veracruz)

Assessor: Ramirez-Marcial, N. \& M. González-Espinosa Refs: 1857,10816

\section{Persea ruizii}

Lauraceae

VU D2

Peru

The species is known only from the type collection taken from the department of Huánuco.

Assessor: World Conservation Monitoring Centre

Refs: 1984

\section{Persea schiedeana}

Lauraceae

VU Alc

Belize, Costa Rica, El Salvador, Guatemala, Honduras, Mexico (Chiapas, Oaxaca, Puebla, Quintana Roo, San Luis Potosí, Veracruz), Nicaragua, Panama

Occurring throughout Central America and Mexico, the species is confined to areas of forest above $1000 \mathrm{~m}$. It has become extremely sparse in some countries, such as Costa Rica and Panama, and it is almost extinct in El Salvador.

Assessor: World Conservation Monitoring Centre Refs: 15037, 16121, 16772

\section{Petrobium arboreum}

Compositae

EN D1

St Helena

The smallest of the cabbage trees. It is confined to damp areas of relict tree-fern thicket or cabbage-tree woodland 
on the upper slopes of the central ridge above $600 \mathrm{~m}$, principally at Cuckhold's Point, below Diana's Peak, Actaeon, above Grapevine Gut, Cabbage Tree Road. A total of approximately 150 plants exist. The genus is monotypic.

Assessor: Cronk, Q.C.B.

Refs: 9954, 11891, 19081

\section{Phaeanthus malabaricus}

Annonaceae

LR/nt

India (Kerala, Tamil Nadu)

Occurring in evergreen forest up to about $900 \mathrm{~m}$, this small tree was originally thought to be endemic to a small area in Wynaad and Tambracherry. Further collections have extended the species' range in the southem end of the Western Ghats, down to the Agastyamalai Hills. Much of the forest has experienced large-scale encroachment throughout the range, but substantial areas are now protected.

Assessor: World Conservation Monitoring Centre

Refs: 4799, 19144

\section{Phellodendron amurense var. wilsonii}

Rutaceae

Taiwan

A tree scattered in mixed submontane forest in the the north-east. The bark has been a popular constituent of medicinal products for a long time. The present status of the species requires further investigation. Forest clearance and overexploitation of the bark are the main causes for concem.

Assessor: World Conservation Monitoring Centre

Refs: 3295, 19050

\section{Phialanthus jamaicensis}

Rubiaceae

$\mathrm{EN} \mathrm{B1+2c}$

Jamaica

This species is uncommon and confined to a narrow altitudinal range, between 240 and $270 \mathrm{~m}$, in dry thickets on limestone in St Andrew and St Elizabeth. Populations have been recorded from the southern side of Long Mountain and Great Pedro Bluff.

Assessor: World Conservation Monitoring Centre

Refs: $401,5653,7980$

\section{Phialanthus revolutus}

Rubiaceae

$\mathrm{EN} \mathrm{B} 1+2 \mathrm{C}$

Jamaica

Confined to coastal thickets, the species is very rare and recorded only from St Catherine, Clarendon and Manchester Parishes.

Assessor: World Conservation Monitoring Centre

Refs: 401, 5653, 7980

\section{Philippia nyassana}

Ericaceae

VU D2

Malawi

Known only from Mount Mulanje, this species is scattered at the edges of montane forest and in the adjoining grasslands. There are threats of fire and in places encroaching agriculture and illegal collection of wood. The area is protected and the conservation of remaining natural resources and the control of exploitative activities are now a high priority.

Assessor: World Conservation Monitoring Centre

Refs: 5651,18965

\section{Phoebe bournei}

Lauraceae

LR/nt

China (Fujian, Guangdong, Guangxi, Guizhou, Hubei, Hunan, Jiangxi, Zhejiang)

A valuable timber, widely occurring as single trees or in groves in evergreen forest. Larger trees have become rare in places where there has been exploitation. The species' preference for fertile lowlands has also brought it into competition with the expansion of agriculture. Plantations have been established.

Assessor: World Conservation Monitoring Centre Refs: 1818,11847

\section{Phoebe chekiangensis}

Lauraceae

China (Fujian, Jiangxi, Zhejiang)

VU Bl $+2 c$

A large evergreen tree with a localised distribution in areas of evergreen broadleaved forest, where it frequently occurs as a dominant component. The species has been overexploited for its timber in most of its range and the habitat has deteriorated in many places.

Assessor: World Conservation Monitoring Centre Refs: 1818,11847

Phoebe nanmu

Lauraceae

China (Xizang, Yunnan)

$\mathrm{EN} \mathrm{Bl}+2 \mathrm{ce}$

In Yunnan the species is known mainly from populations in monsoon forest in the south and west. It is only recorded from Meitus in south-east Tibet (Xizang). During the last 10 years populations have been declining because of overcutting. The timber is excellent for building construction and furniture. Some areas of forest are protected.

Assessor: Sun, W.

Refs: $1818,11847,19055$

\section{Phoebe poilanei}

Lauraceae

VU D2

Viet Nam

Apparently endemic to Viet Nam, the species is located close to the Chinese border in Phong Tho, Lai Chau Province, between 1600 and $1700 \mathrm{~m}$.

Assessor: World Conservation Monitoring Centre Refs: 848

\section{Phoebe scortechinii}

Lauraceae

$\mathrm{LR} / \mathrm{cd}$

Malaysia (Peninsular Malaysia)

Recorded only from Maxwell's Hill in Perak, this tree is scattered in montane forest. Maxwell's Hill is a protected area.

Assessor: Kochummen, K.M.

Refs: 8464,19073

\section{Phoebe zhennan \\ Lauraceae}

VU Ald

China (Guizhou, Hubei, Hunan, Sichuan)

A valuable timber. Populations have been reduced in extent and are now mainly confined to semi-natural forest. Large individuals are left around temples, parks and villages.

Assessor: World Conservation Monitoring Centre Refs: 1818,11847

\section{Phoenicophorium borsigianum}

Palmae

LR/nt

Seychelles

A forest palm tree endemic to the Seychelles. This 
species is locally abundant and easily colonises bare eroded lands.

Assessor: Mungaiyan, P.

Refs: 19118

\section{Phoenix rupicola}

Palmae

LR/nt

India (Arunachal Pradesh, Meghalaya, Sikkim)

A small palm tree of rocky slopes, occurring in the lower Himalaya Mountains up to $450 \mathrm{~m}$. Increasing settlement of the area is the main threat.

Assessor: Johnson, D.

Refs: 19118

\section{Phoenix theophrasti}

Palmae

LR/nt

Greece (Crete), Turkey (Turkey-in-Europe)

A palm tree found in the sandy beds of temporary streams up to $250 \mathrm{~m}$. On Crete, there are eight populations; the largest contains a few thousand individuals and is protected under Greek law. Four populations are known in Turkey.

Assessor: Johnson, D.

Refs: 19118

\section{Pholidocarpus kingianus}

\section{Palmae}

VU B1+2c

Malaysia (Peninsular Malaysia), Singapore

Restricted to swamp forest in Peninsular Malaysia, this palm tree is threatened by rapid habitat conversion for agriculture and urbanisation.

Assessor: Saw, L.G.

Refs: 19118

\section{Pholidocarpus macrocarpus}

Palmae

VU B1+2c

Malaysia (Peninsular Malaysia), Thailand

A palm tree of swamp forest up to $500 \mathrm{~m}$, restricted to Peninsular Malaysia and Peninsular Thailand. Most of the swamp forests are subject to forest conversion and forestry activities.

Assessor: Saw, L.G.

Refs: 19118

\section{Photinia lasiogyna}

Rosaceae

VUAlcd

China (Guizhou, Hunan, Jiangxi, Sichuan, Yunnan, Zhejiang)

A relatively widespread species, occurring in broadleaved or mixed forest above $2000 \mathrm{~m}$. Habitat declines and degradation have reduced population sizes. Assessor: Sun, W.

Refs: 19055

\section{Photinia lasiopetala}

Rosaceae

VU D $1+2$

Taiwan

Occurring in broadleaved evergreen forest above $800 \mathrm{~m}$, the species is confined to a few populations in central Taiwan. Part of the range is covered by Taroko National Park. Other areas are susceptible to increasing housing developments.

Assessor: Lu, S.Y. \& F.J. Pan

Refs: 19050,19053
Photinia serratifolia var. tomentosa

Rosaceae

EN B1+2c

India (Tamil Nadu)

An endemic to the Nilgiris, occurring in montane forest above $1900 \mathrm{~m}$.

Assessor: World Conservation Monitoring Centre

Refs: 19144

Phragmotheca rubriflora

Bombacaceae

VU $B 1+2 c$

Colombia

An endemic to Antioguia.

Assessor: Calderon, E.

Refs: 19069

\section{Phylica polifolia}

Rhamnaceae

CR C2a

St Helena

Occurring now only as a low straggling bush, the last tree form specimen died recently at Blue Hill. Populations have been reduced to dry locations on cliffs, e.g. High Hill, Lot, between Distant Cottage and Asses' Ears. Although there may be up to 100 plants, their distribution is fragmented and they are vulnerable to competition from introduced plants.

Assessor: Cronk, Q.C.B.

Refs: 5556,19081

\section{Phyllanthus arbuscula}

Euphorbiaceae

LR/nt

Jamaica

A variable species with distinctive populations in middle-elevation and montane woodlands on limestone. In the western Blue Mountains, the population is restricted to a small area north of the Grand Ridge at the headwaters of the Mabess River.

Assessor: World Conservation Monitoring Centre Refs: $6057,7980,12564$

\section{Phyllanthus axillaris}

Euphorbiaceae

$\mathrm{EN} B 1+2 \mathrm{c}$

Jamaica

Known only from Trelawny, the species occurs very locally in dry scrubby woodland on rocky hillsides. There is a constant threat of overcutting and encroaching agriculture.

Assessor: Kelly, D.L.

Refs: 5653,19085

\section{Phyllanthus cauliflorus}

Euphorbiaceae

VU B $1+2 c$

Jamaica

Populations are known from Westmoreland and Hanover, where the species occurs locally in thickets and woodlands on limestone rocks.

Assessor: World Conservation Monitoring Centre Refs: 401, 5653, 7980

\section{Phyllanthus cladanthus}

Euphorbiaceae

LR/nt

Jamaica

An uncommon slender tree, occurring in thickets and woodlands on limestone, especially in wet areas. Assessor: World Conservation Monitoring Centre Refs: 6057,7980 


\section{Phyllanthus eximius}

Euphorbiaceae

VU $B 1+2 c$

Jamaica

Known only from Portland, the species occurs locally in wet mossy thickets and woodland on limestone areas.

Assessor: Kelly, D.L.

Refs: 401, 5653, 19085

\section{Phyllanthus fadyenii}

Euphorbiaceae

Jamaica

A very poorly known species, recorded only from a single herbarium specimen.

Assessor: World Conservation Monitoring Centre

Refs: $401,5653,7980$

\section{Phyllanthus gentryi}

Euphorbiaceae

EN D1

Panama

This shrub or small tree is known only from evergreen rainforest, often on slopes, in the Serranía de Pirre, close to the Colombian border. It is possible that the species range extends into Colombia. Regeneration appears to be good and the population is protected within Darien National Park.

Assessor: Mitré, $\mathrm{M}$.

Refs: 15037,16772

\section{Phyllanthus larifolius}

Euphorbiaceae

LR/nt

Jamaica

A shrub or small tree which occurs in some abundance in dry thickets on low limestone ridges, cliffs and ledges in St Andrew and St Catherine.

Assessor: World Conservation Monitoring Centre

Refs: 6057,7980

\section{Phyllanthus montanus}

Euphorbiaceae

LR/nt

Jamaica

An apparently abundant species occurring in western and central parishes in woodland and thickets on limestone.

Assessor: World Conservation Monitoring Centre Refs: 6057,7980

\section{Phyllanthus profusus}

Euphorbiaceae

VU Alc, B1+2c

Ghana, Guinea, Liberia

A species confined to the restricted areas where wet evergreen forest remains in parts of the Upper Guinea region. This habitat has been lost from the sites where mining, logging and commercial forestry have occurred. Assessor: Hawthorne, W.

Refs: 2773, 12061

\section{Phyllanthus watsonü}

Euphorbiaceae

LR/cd

Malaysia (Peninsular Malaysia)

Recorded only from north Johore and south Pahang, this rheophyte is confined to forest on the banks of Endau River. The area is protected within Endau-Rompin National Park.

Assessor: Kochummen, K.M.

Refs: 17140,19073

\section{Phyllostemonodaphne geminiflora}

\section{Lauraceae}

$\mathrm{EN} \mathrm{B} !+2 \mathrm{c}$

Brazil (Espírito Santo, Minas Gerais, Rio de Janeiro)

Last collected in 1978, the species is concentrated around Rio de Janeiro, but is also known from forests further inland.

Assessor: World Conservation Monitoring Centre

Refs: 7145

\section{Phyllostylon orthopterum}

Ulmaceae

VU B $1+2$ ac

Bolivia

Endemic to the piedmont forest in Bolivia, the species is confined to an unprotected ecosystem which is being rapidly replaced by agricultural systems.

Assessor: Prado, D.

Refs: 19122

\section{Phylloxylon arenicola}

Leguminosae

CR B $1+2 \mathrm{abc}$

Madagascar

A coastal forest and woodland species known only from Baie de Rigney and Baie d'Irodo forests in north-east Madagascar, with an estimated range of less than $10 \mathrm{~km}^{2}$ (*AOO). These areas are under severe local pressure from selective cutting and degradation.

Assessor: Du Puy, D. \& H. Labat

Refs: 12353

\section{Phylloxylon decipiens}

Leguminosae

EN B $1+2 a b c$

Madagascar

A deciduous woodland species known only from a very restricted area of north-east Madagascar. Its range is estimated to be $250 \mathrm{~km}^{2}$ (*EOO) based mainly on old records, and is likely to be considerably smaller. This species is declining through habitat destruction and selective cutting of its highly sought-after timber. It occurs within Analamerana Reserve.

Assessor: Du Puy, D. \& H. Labat

Refs: 12353

\section{Phylloxylon perrieri}

Leguminosae

EN A2d

Madagascar

A deciduous woodland species that is widespread but uncommon in west Madagascar. Its range extends an estimated $10,000 \mathrm{~km}^{2}\left({ }^{*} \mathrm{AOO}\right)$ but occurs within extremely fragmented and decreasing patches of vegetation. This species is selectively and intensively felled for its construction properties and for fuel. A rapid decline is expected. It is found within some reserves such as Ankarafantsika, Bemaraha and Namoroka. Assessor: Du Puy, D. \& H. Labat Refs: 12353

\section{Phylloxylon phillipsonii}

Leguminosae

CR B $1+2 \mathrm{abc}$ Madagascar

Known only from a single recent collection, this deciduous woodland species occurs in a highly populated area near a main road, south-east of Antsiranana in north Madagascar. Its range is probably considerably less than the estimated $100 \mathrm{~km}^{2}\left({ }^{*} \mathrm{EOO}\right)$, as there are very few remnants of native vegetation in the area. No conservation measures exist.

Assessor: Du Puy, D. \& H. Labat

Refs: 12353 


\section{Phylloxylon spinosa}

Leguminosae

$\mathrm{EN} B 1+2 \mathrm{abc}$

Madagascar

A deciduous species that is uncommon and restricted to two limestone outcrops in the northem tip of Madagascar: Montagne des Français and Ankarana Massif. Its estimated range is $100 \mathrm{~km}^{2}\left({ }^{*} \mathrm{AOO}\right)$ and includes the Ankarana Reserve. Selective and intensive felling for its favoured construction properties mean it is expected to decline rapidly.

Assessor: Du Puy, D. \& H. Labat

Refs: 12353

\section{Phylloxylon xiphoclada \\ Leguminosae \\ Madagascar}

$\mathrm{CR} \mathrm{Bl}+2 \mathrm{abc}$

An evergreen species last recorded over 40 years ago from a single very restricted area estimated to cover less than $10 \mathrm{~km}^{2}$ at Tampoketsa d'Ankazobe in central Madagascar. The vegetation is extremely degraded and declining and few small remnant forested patches remain.

Assessor: Du Puy, D. \& H. Labat

Refs: 12353

\section{Phylloxylon xylophylloides}

Leguminosae

Madagascar

VU A2cd

A widespread species in the evergreen, humid forests of north and east Madagascar, with a substantial population in the coastal forest in the south-east, north of Taolañaro. This last population contains many individuals but will be felled for the RTZ (QIT) titanium mines in the near future, reducing the known population by at least $20 \%$. The largest area of possible occurrence includes Andasibe/Perinet, Montagne d'Ambre and Mont Tsaratanana Reserves.

Assessor: Du Puy, D. \& H. Labat

Refs: 12353

\section{Physokentia dennisii}

Palmae

Solomon Islands (South Solomon)

A palm tree found in gullies and on lower hill slopes in damp shaded forests between 200 and $700 \mathrm{~m}$.

Assessor: Dowl, J.L.

Refs: 19118

\section{Physokentia tete}

Palmae

LR/nt

Vanuatu

Endemic to Vanuatu, this palm tree occurs in rainforest and mossy cloud forest between 200 and $1000 \mathrm{~m}$. It is regenerating well.

Assessor: Dowl, J.L.

Refs: 19118

\section{Physokentia thurstonii}

\section{Palmae}

LR/nt

Fiji

Small populations exist on mountain summits, such as Mount Kambalau, Mount Mariko, Mount Seatura and Mount Sori on Vanua Levu. There are also a few plants on Taveuni. Regeneration is apparent. Some areas are affected by logging.

Assessor: Fuller, D

Refs: 6053, 19118

\section{Phytelephas seemannii}

Palmae

Colombia, Panama

A small tree of lowland rainforest. Large populations remain along some rivers on the Pacific coast of Colombia. Seeds are used for vegetable ivory, which is traded at a minor international level. Conservation activities are taking place, and a recent project on the sustainable use of the seeds has resulted in local awareness of the importance of the species and its protection.

Assessor: Bemal, R.

Refs: 19118

\section{Phytelephas tumacana}

Palmae

EN B $1+2 c$

Colombia

An endemic palm of Colombia, found in lowland moist forest on alluvial soils. Populations have been severely decimated by agriculture and are now restricted to only a few rivers. The species has a variety of uses as a food, thatching and as a source of vegetable ivory. Utilization and trade continue at local and minor international levels.

Assessor: Bernal, $\mathbf{R}$.

Refs: 19118

\section{Picconia azorica}

Oleaceae

$\mathrm{EN} \mathrm{B} 1+2 \mathrm{c}$

Portugal (Azores)

Once a dominant component of forest between 300 and $600 \mathrm{~m}$ on all of the Azores, except Graciosa. Overexploitation of the wood and habitat loss have now led to the species becoming almost extinct on some islands. It remains scattered in coastal forest consisting mainly of introduced species.

Assessor: World Conservation Monitoring Centre

Refs: $1512,5287,7222,19131$

\section{Picconia excelsa}

Oleaceae

VU Cl, D2

Portugal (Madeira), Spain (Canary Is.)

The species has a fragmented distribution but still appears to be relatively frequent in areas of cloud forest above $1000 \mathrm{~m}$ on the Canaries. It is rare and scattered over a slightly wider altitudinal range in *laurisilva on Madeira. In the past it was exploited for its timber but is now included in regional legislation.

Assessor: Bañares, A. et al.

Refs: 4556, 19022, 19131

Picea alcoquiana var. acicularis

Pinaceae

VU D2

Japan

Endemic to the Yatsugadake Mountains this variety is restricted to a small area $\left(<100 \mathrm{~km}^{2}\right)$ of montane forest, most of it being state forest. It provides a useful timber.

Assessor: SSC Conifer Specialist Group

Refs: $374,13206,18751$

\section{Picea alcoquiana var. reflexa}

Pinaceae

VU D2

Japan

A few (<5) small populations in scattered locations are confined to the volcanic Akaishi range of central Honshu. They occur in mixed montane forest.

Assessor: SSC Conifer Specialist Group

Refs: $374,6879,13206$ 


\section{Picea aurantiaca}

Pinaceae

China (Sichuan, Xizang?)

$\mathrm{EN} \mathrm{B1}+2 \mathrm{abc}$

A species of montane coniferous forest confined to a small area west of Kangding in Sichuan. Forests in this area are increasingly under pressure from indiscriminate logging. Populations have declined and, as yet, there is no protection for the species.

Assessor: SSC Conifer Specialist Group

Refs: $374,11242,11847,13041$

\section{Picea brachytyla}

Pinaceae

VUAlcd

China (Gansu, Henan, Hubei, Shaanxi, Sichuan, Xizang,

Yunnan)

A widespread species valued highly for its timber. It occurs in montane coniferous forest, which is experiencing increasing rates of logging and deforestation throughout the species' range. Population declines are not documented but are believed to be considerable.

Assessor: SSC Conifer Specialist Group

Refs: $374,1818,11847$

\section{Picea brachytyla var. complanata}

Pinaceae

VU Alcd

China (Sichuan, Yunnan), India (Anunachal Pradesh), Myanmar

A valuable timber tree, widespread but suffering from overexploitation and loss of the montane forest habitat to logging and clearing.

Assessor: SSC Conifer Specialist Group

Refs: $374,6879,11847$

\section{Picea breweriana}

Pinaceae

LR/nt

USA (Califomia, Oregon)

A species of conservation concern because of its restricted range in the Siskiyou Mountains of south-west Oregon and north-west California. It is limited to areas of mixed conifer forest mostly on glacial moraines. It is too rare to be exploited for its timber but it is cultivated on a small scale as an omamental plant. Part of the range is also managed as a wilderness area in the Siskiyou National Forest.

Assessor: SSC Conifer Specialist Group

Refs: 13041

\section{Picea chihuahuana}

Pinaceae

$\mathrm{EN} \mathrm{B1}+2 \mathrm{e}$

Mexico (Chihuahua, Durango, Nuevo León)

A species known from about 25 sites, containing a few to several hundred trees, often in canyons or on moist north-facing scree slopes. Regeneration is poor and inadequate. A continued decline in the population, especially of seeding trees, is expected.

Assessor: SSC Conifer Specialist Group

Refs: $374,1539,14683,17554$

\section{Picea engelmannü ssp. mexicana}

Pinaceae

EN Ala, B1+2abc

Mexico (Chihuahua, Nuevo León)

The main population of this subspecies occurs at the type locality in coniferous montane forest in the Sierra de la Marta where it was nearly exterminated by a forest fire in 1975. There are possibly less threatened small populations at Cerro Mohihora in Chihuahua and in south-east Arizona.

Assessor: SSC Conifer Specialist Group

Refs: $374,6879,8661,17554$

\section{Picea farreri}

Pinaceae

$\mathrm{EN} \mathrm{B} 1+2 \mathrm{abc}$

China? (Yunnan), Myanmar

This species is confined to coniferous montane forest in the Fen-Shui-Ling Valley at the China-Myanmar border. There are unconfirmed reports of other populations, some occurring further north along the Salween-Irawaddy divide. Habitat loss and logging are serious threats but the current situation is not known because it has been impossible to visit the area.

Assessor: SSC Conifer Specialist Group

Refs: $374,3812,13041$

\section{Picea koraiensis var. pungsanensis}

Pinaceae

VU D2

North Korea

A useful timber tree which is restricted to a few localities of upland coniferous forest along the coast at Keizanchin, Mount Pungsan and Hamnam. There are no known measures to protect the species.

Assessor: SSC Conifer Specialist Group

Refs: 374,11117

\section{Picea koyamae}

Pinaceae

EN D 1

Japan

An endemic to the Yatsugadake Mountains in central Honshu. Fewer than 250 individuals have been recorded, in small groves. It has been the case that after typhoons the timber is harvested and the area is replanted with commercial species.

Assessor: SSC Conifer Specialist Group

Refs: 374, 13206

\section{Picea likiangensis var. hirtella}

Pinaceae

VU B1+2c

China (Sichuan, Xizang)

This variety is restricted to high-altitude coniferous forests in the mountains of west Sichuan and neighbouring Tibet. The tree provides a useful timber and levels of exploitation of both it and the forest in general have caused serious habitat fragmentation and population declines.

Assessor: SSC Conifer Specialist Group

Refs: 374,6879

\section{Picea likiangensis var. montigena}

\section{Pinaceae}

$\mathrm{EN} \mathrm{B1+2a}$

China (Sichuan)

A useful timber tree restricted to a small area of highaltitude coniferous forest in south-west Sichuan. Levels of exploitation of both the tree and the forest in general have caused population declines. There are no signs of the pressure easing and no protection measures are enforced.

Assessor: SSC Conifer Specialist Group

Refs: 374,18751

\section{Picea martinezii}

Pinaceae

CR B $1+2 c$

Mexico (Nuevo León)

This species has been treated as a synonym of $P$. chihuahuana. It is a timber tree confined to just two sites of montane forest near streams in Nuevo León. Timber 
has been extracted in recent years in the larger of the two populations. The other population has fewer than 15 individuals. Fire is the main threat.

Assessor: SSC Conifer Specialist Group

Refs: 17554

\section{Picea maximowiczii var. maximowiczii}

Pinaceae

VU B $1+2 c$ Japan

Two varieties are in the same situation of being confined to small and scattered populations in degraded montane woodland on Fuji-San and Yatsugatake Mountains. Both the habitat and the tree have been overexploited. Much of the habitat remains degraded and regeneration is poor. Assessor: SSC Conifer Specialist Group

Refs: 374, 13041, 13206

\section{Picea maximowiczii var. senanensis}

Pinaceae

VU B $1+2 c$

Japan

As with var. maximowiczii this taxon is confined to small and scattered populations in degraded montane woodland on Fuji-San and Yatsugatake Mountains. Overexploitation of the tree and the habitat has occurred in the past. Much of the habitat remains degraded and regeneration is poor.

Assessor: SSC Conifer Specialist Group

Refs: 374, 13041, 13206

\section{Picea morrisonicola}

Pinaceae

VU Alac

Taiwan

One of the most important timber species in Taiwan. It is usually associated with Tsuga chinensis in areas of montane coniferous forest. Populations have declined because of overexploitation. There are records of the species in Yushan and Shueipa National Parks.

Assessor: Lu, S.Y. \& F.J. Pan

Refs: 374, 2106, 6469, 19050, 19051

\section{Picea neoveitchit}

Pinaceae

$\mathrm{EN} \mathrm{B1}+2 \mathrm{ab}$

China (Gansu, Henan, Hubei, Shaanxi, Shanxi, Sichuan)

The species is very rare and scattered within its range in montane coniferous forest on the southern slopes of the Qinling range. The forest has experienced large reductions in extent and the entire population has declined in numbers, especially at Neixiang. A good stand is apparently still found in Xinja Shan.

Assessor: SSC Conifer Specialist Group

Refs: 374,1818

\section{Picea omorika}

Pinaceae

VU D2

Bosnia and Herzegovina

The Serbian spruce is known from fewer than 1000 trees, occurring in $60 \mathrm{ha}$ of montane forest entirely within Pancic Narodni Nature Reserve in the Tara Mountains. The only threat appears to come from competition with $P$. abies and Fagus orientalis. It is widely cultivated.

Assessor: SSC Conifer Specialist Group

Refs: $4978,5287,7222$

\section{Picea retroflexa}

Pinaceae

VU Bl $+2 a b c$

China (Sichuan)

A tall tree restricted to a small area of high-altitude cloud forest along the Yalong River and north and west of Kangding in south-west Sichuan. Levels of exploitation of the old growth coniferous forests are substantial and threatening the integrity of all populations.

Assessor: SSC Conifer Specialist Group

Refs: 374,11191

\section{Picramnia bullata}

Simaroubaceae

VU D2

Peru

Known only from the type collection, the species occurs in *terra firme forest in the department of Loreto. Assessor: World Conservation Monitoring Centre Refs: 1984, 17398

\section{Picrasma excelsa}

Simaroubaceae

VU Alcd Cuba, Dominican Republic, Haiti, Jamaica, Puerto Rico, St Vincent, Venezuela

A single population, now thought to be extinct, was once recorded from El Sabalo in Pinar del Rio Province, Cuba, where the habitat has largely been deforested. Elsewhere in the Greater Antilles, the species and habitat have also suffered from overcutting. A record exists from northern Venezuela.

Assessor: Areces-Mallea, A.E.

Refs: 19149

\section{Pierreodendron kerstingii}

Simaroubaceae

VU $B 1+2 c$

Benin, Côte d'Ivoire, Ghana, Togo

Occurring from Côte d'Ivoire to Benin, this is an uncommon species from a heavily exploited semideciduous forest habitat. The only other species in the genus, although apparently ecologically distinct, is very similar. If the two were to be taxonomically merged the species would be wide-ranging and at lower risk.

Assessor: Hawthome, W.

Refs: $2773,7111,8369,12061$

\section{Pilgerodendron uviferum}

Cupressaceae

VU Alcd+2cd

Argentina (Chubut, Neuquén, Rio Negro, Santa Cruz), Chile

Large-scale destruction of the forest during colonial times and the widespread opening up of the lowland areas have led to the extinction of the species from most of its original distribution. It is slow to mature and its regeneration is very poor, especially under a canopy. The species is listed in *CITES Appendix I. Assessor: SSC Conifer Specialist Group Refs: $278,374,5112,6036,13041,15251,19179$

\section{Pilocarpus goudotianus ssp. heterochromus}

Rutaceae

Colombia

An endemic to Huila.

Assessor: Calderon, E.

Refs: 7980, 19069

\section{Pimenta adenoclada}

Myrtaceae

VU B $1+2 c$

Cuba

Endemic to Cuba, this shrub or small tree is confined to coastal habitats in dry forests on limestone. Only areas which are unsuitable for agriculture or inaccessible have 
survived. Overcutting, burning and settlement are constant threats.

Assessor: Areces-Mallea, A.E.

Refs: $5435,5651,7980,19149$

\section{Pimenta cainitoides}

Myrtaceae

VU B $1+2 \mathrm{c}$

Cuba

Confined to rocky montane areas in Sierra Maestra and other mountain ranges in eastem Cuba, this species is not well collected. There has been extensive habitat loss from overcutting, mining and tourism but vegetation remains in areas which are inaccessible or unattractive to agriculture.

Assessor: Areces-Mallea, A.E.

Refs: $5435,5651,7980,11403,18485,19149$

\section{Pimenta ferruginea \\ Myrtaceae}

$\mathrm{EN} \mathrm{B} 1+2 \mathrm{c}$

Cuba

A poorly known species, found only in one location on the coast in Pinar del Rio Province. Overcutting and tourism are the main threats but vegetation remains in rugged and inaccessible areas. Fieldwork is necessary to locate viable populations.

Assessor: Areces-Mallea, A.E.

Refs: $5435,5651,7980,19149$

\section{Pimenta filipes}

Myrtaceae

VU B $1+2 c$

Cuba

Endemic to eastem Cuba, this small tree is found in dry forests, savannas and coastal areas. There is an unconfirmed record from a relatively inaccessible montane area in south-central Cuba. Logging, grazing, urban expansion and mining have significantly reduced the original populations. Tourism is also a major threat.

Assessor: Areces-Mallea, A.E.

Refs: 5435, 5651, 19149

\section{Pimenta haitiensis}

Myrtaceae

VU D2

Dominican Republic

A shrub or small tree restricted to a small area in Pedernales, where it occurs in a unique coastal xerophytic vegetation on 'dog tooth' limestone substrate. The leaves are a popular source of fragrance and are sold in markets. If exploitation increases, the species will become seriously threatened.

Assessor: World Conservation Monitoring Centre

Refs: 5435, 7980, 10197

\section{Pimenta jamaicensis}

Myrtaceae

LR/nt

Jamaica

A tree resembling $P$. dioica, the source of allspice. It is restricted to the highlands of Jamaica above $600 \mathrm{~m}$. A popular source of firewood but populations are probably most seriously threatened by habitat degradation.

Assessor: World Conservation Monitoring Centre Refs: $5435,6057,7980$

\section{Pimenta obscura}

Myrtaceae

VU B $1+2 c$

Jamaica

An uncommon small tree, closely related to $P$. dioica, the source of allspice. It is restricted to forest areas in the highlands of Cockpit Country.

Assessor: World Conservation Monitoring Centre

Refs: 401, 5435, 5653, 7980

\section{Pimenta odiolens}

Myrtaceae

VU D2

Cuba

A small tree restricted to the province of Baracoa. The habitat has experienced declines because of logging, overcutting, mining and tourism. Unspoilt areas remain where the terrain is rugged and inaccessible.

Assessor: Areces-Mallea, A.E.

Refs: $5435,7980,19149$

\section{Pimenta oligantha}

Myrtaceae

VU D2

Cuba

Known only from Sierra de Nipe in the Oriente, this shrub or small tree is poorly documented and confined to a habitat declining through logging, overcutting, mining and tourism. Only areas which are inaccessible remain relatively unspoilt.

Assessor: Areces-Mallea, A.E.

Refs: $5435,5651,7980,19149$

\section{Pimenta podocarpoides}

Myrtaceae

$\mathrm{EN} \mathrm{B} 1+2 \mathrm{c}$

Cuba

A morphologically interesting species which is known only from the type location, near a stream in Oriente Province. The habitat has been extensively degraded by logging, overcutting, mining and tourism. The spread of invasive plants along streams is also a major threat. Fieldwork is necessary to search for populations in more inaccessible, intact areas.

Assessor: Areces-Mallea, A.E.

Refs: $5435,5651,7980,19149$

\section{Pimenta pseudocaryophyllus var. hoehnei}

Myrtaceae

VU B $1+2 c$

Brazil (Santa Catarina, São Paulo)

A coastal forest taxon, known from about four localities in São Paulo and Santa Catarina Large-scale deforestation and habitat degradation have occured over the centuries. The type variety is found further inland. Assessor: World Conservation Monitoring Centre Refs: 5435,7980

\section{Pimenta racemosa var. hispaniolensis}

Myrtaceae

VU B1+2c

Dominican Republic, Haiti

A Hispaniola endemic found in remaining upland broadleaved forest in a number of locations. The decline in the extent of forest has been drastic.

Assessor: World Conservation Monitoring Centre

Refs: 5435,7980

\section{Pimenta racemosa var. ozua}

Myrtaceae

VU B1+2c

Dominican Republic, Haiti

Endemic to north-central Hispaniola, this variety grows in forest and woodland areas. The habitat has been drastically reduced in extent. This species has a use as a fragrance to a disinfectant called 'puro ozua'.

Assessor: World Conservation Monitoring Centre Refs: 5435,7980 


\section{Pimenta racemosa var. terebinthina}

Myrtaceae

Dominican Republic

Known only from the vicinity of Peninsular Samaná, this variety occurs in areas of forest on limestone. The forest has been dramatically reduced in extent and continues to be threatened by grazing, agricultural encroachment and logging.

Assessor: World Conservation Monitoring Centre Refs: 5435, 7980

\section{Pimenta richardii}

Myrtaceae

$\mathrm{EN} \mathrm{B} 1+2 \mathrm{c}$

Jamaica

A Jamaican endemic, known from just two locations of upland forest in Cockpit Country.

Assessor: World Conservation Monitoring Centre

Refs: $401,5435,5653,7980$

\section{Pinus albicaulis}

Pinaceae

VU Alc

Canada (Alberta, British Columbia), USA

A widespread species of subalpine and alpine woodlands in the Cascades, Sierra Nevada and Rocky Mountains in the USA and parts of Canada. Infestations of the introduced rust, Cronartium ribicola, have caused population reductions of 80 to $90 \%$, especially in the northern wetter parts of the range. In addition, populations in national parks are adversely affected by fire-suppression regimes and predation by Dendrococtonus ponderosae.

Assessor: SSC Conifer Specialist Group

Refs: 13041

\section{Pinus amamiana}

Pinaceae

VU D2

Japan

This species is known from scattered populations in lowland coniferous woodland on Yakushima and Tanegashima Islands. It was formerly exploited and seems slow to regenerate where conditions have become exposed.

Assessor: SSC Conifer Specialist Group

Refs: $374,4506,11191$

\section{Pinus aristato}

Pinaceae

USA (Arizona, Colorado, New Mexico)

LR/nt

A slow-growing species, usually occurring in open stands on high rocky slopes in the Rocky Mountains. Regeneration may be impeded by grazing livestock. Climatic changes may also be a factor. Most stands are protected from cutting or damage.

Assessor: SSC Conifer Specialist Group

Refs: 7222,13041

\section{Pinus armandï var. mastersiana}

\section{Pinaceae}

Taiwan

EN Alc

A timber tree endemic to Taiwan. Levels of exploitation and the degradation of its montane forest habitat have caused substantial declines in the population.

Assessor: SSC Conifer Specialist Group Refs: 374

\section{Pinus ayacahuite var. veitchii}

Pinaceae

$\mathrm{LR} / \mathrm{nt}$

Mexico

An important timber tree. It is scattered thinly in nine
Mexican states in coniferous montane forest. The population is concentrated around México city and must be under great pressure from urban and other developments. The timber is highly sought-after. More information may indicate that a threat category is appropriate.

Assessor: SSC Conifer Specialist Group

Refs: 7980

\section{Pinus balfouriana ssp. austrina}

Pinaceae

LR/cd

USA (California)

A number of isolated populations occur within protected areas in the Sierra Nevada at subalpine levels. The trees are extremely slow-growing and recruitment may be insufficient. Fire and grazing by wildlife are also problems. Populations are being monitored and protected against fire hazards.

Assessor: SSC Conifer Specialist Group

Refs: 374,13041

\section{Pinus balfouriana ssp. balfouriana}

Pinaceae

LR/cd

USA (California)

A few isolated populations occur at subalpine altitudes on the Klamath Mountains within USDA National Forest lands. The trees are extremely slow-growing and populations may be susceptible to fire and the grazing of wildlife. Old trees are protected from being cut or damaged.

Assessor: SSC Conifer Specialist Group

Refs: 13041

\section{Pinus brutia var. eldarica}

Pinaceae

Afghanistan?, Azerbaijan, Georgia, Iran?

The only certain population occurs on the AzerbaijanGeorgia border.

Assessor: SSC Conifer Specialist Group

Refs: $374,13041,18751$

\section{Pinus caribaea var. caribaea \\ Pinaceae}

VU Alc+2c

Cuba

A heavily exploited taxon of lowland and hill pine forest and mixed oak-pine forests on slatey rocks, occurring in Pinar del Rio and Isla de Pinos. Burning and logging of large areas of pine forest have transformed the habitat into savanna. Frequent fires also prevent regrowth of the species in favour of $\boldsymbol{P}$. tropicalis.

Assessor: SSC Conifer Specialist Group

Refs: $374,8646,13041,19149$

\section{Pinus cembroides ssp. lagunae}

Pinaceae

Mexico (Baja Califomia Sur)

VUAIc

Although this taxon is not a valuable timber tree, it is the only pine in this remote region and is exploited at a low level. It occurs in open stands in meadows or with oak above $1600 \mathrm{~m}$, mostly in La Laguna, covering a range of about $100 \mathrm{~km}^{2}$. The area is not protected and, although not easily accessible, it is susceptible to fire and overgrazing.

Assessor: SSC Conifer Specialist Group

Refs: $374,6004,8475,18751$ 
Pinus cembroides ssp. orizabensis

Pinaceae

Mexico (Puebla, Tlaxcala, Veracruz)

LR/nt

Assessor: SSC Conifer Specialist Group

Refs: $374,7980,8475,13041$

\section{Pinus clausa}

Pinaceae

LR/nt

USA (Alabama, Florida)

The sand pine is a useful species of lowland open forest and scrub on well-drained soils. Although it is in part dependent on fire for regeneration, it is also especially vulnerable to intense forest fires. There is no evidence to suggest that populations have declined, as yet.

Assessor: SSC Conifer Specialist Group

Refs: 374,13041

\section{Pinus contorta var. bolanderi}

\section{Pinaceae}

LR/nt

USA (Califomia)

A small tree endemic to the white sand pine barrens along the Mendocino coast. The area comes under various pressures from development, overland vehicles and fires.

Assessor: SSC Conifer Specialist Group

Refs: 374, 13041, 19193

\section{Pinus culminicola}

Pinaceae

$\mathrm{EN} \mathrm{B} 1+2 \mathrm{bc}$

Mexico (Coahuila, Nuevo León)

A decumbent shrub which occurs in monotypic stands on exposed rocky summits of Cerro Potosí and neighbouring peaks, covering an area of several hundred hectares. Growth and regeneration are slow and susceptible to fire. None of the populations is within a protected area. A road to an observatory gives easy access to the largest population.

Assessor: SSC Conifer Specialist Group

Refs: $374,1538,5194,7980$

\section{Pinus dabeshanensis}

Pinaceae

VU B $1+2 \mathrm{c}$

China (Anhui, Henan, Hubei)

Confined to upland mixed forest in parts of the Dabieshan, mature trees are few and rates of regeneration and growth are poor.

Assessor: SSC Conifer Specialist Group

Refs: 1818,11847

\section{Pinus dalatensis}

Pinaceae

VU B $1+2 c$

Viet Nam

Until recently the species was known from only one area of montane evergreen forest near Dalat. It has now been found in four adjacent provinces, extending into central Viet Nam, including four occurrences within nature reserves: Ngoc Linh, Chu Yang Sinh, Dao Ngoan Muc and Nui Ba. Populations remain low in numbers and are increasingly reduced to isolated areas.

Assessor: SSC Conifer Specialist Group

Refs: $374,848,4966,15357$

\section{Pinus densiflora var. funebris}

Pinaceae

DD

North Korea, Russia, South Korea?

Assessor: SSC Conifer Specialist Group

Refs: $374,3811,13041,18751$
Pinus fenzeliana

Pinaceae

LR/nt

China (Guangdong-Hainan, Guangxi, Hunan), Viet Nam Assessor: SSC Conifer Specialist Group

Refs: 374, 13041

\section{Pinus gerardiane}

Pinaceae

LR/nt

Afghanistan, China (Xizang), India (Jammu-Kashmir),

Pakistan

Populations are widespread in areas of montane open forest but they are small and low in density. In many areas the seed crop is exploited unsustainably but the effects on regeneration are not yet clear. In Afghanistan plantations have been established to supply the seeds. Assessor: SSC Conifer Specialist Group Refs: $256,374,4966$

\section{Pinus jaliscano}

Pinaceae

Mexico (Jalisco)

LR/nt

Confined to Sierra el Cuale in the north-west part of Sierra Madre del Sur, the species is present in mostly undisturbed areas of submontane pine-oak forest. Mining operations are under way in the area.

Assessor: SSC Conifer Specialist Group

Refs: $374,6004,7980$

Pinus krempfii

Pinaceae

VU B1+2c

Viet Nam

The species is known only from localised populations in Khanh Hoa and Lam Dong Provinces in the south. It occurs within Nui $\mathrm{Ba}$ and Dao Ngoan Muc Nature Reserves.

Assessor: Loc, Phan Ke

Refs: $848,11530,12455,19044$

\section{Pinus kwangtungensis}

Pinaceae

LR/nt

China (Guangdong, Guangdong - Hainan, Guangxi, Guizhou, Hunan), Viet Nam

The species' distribution is concentrated on the Nanling range, but extends into Hoa Binh and Cao Bang Provinces in Viet Nam. It is thought to exhibit a wide ecological tolerance and frequently occurs in pure stands, but much of the habitat has declined and populations are frequently reduced to steep cliffs or inaccessible places. In Viet Nam the population numbers are low and declining (EN D).

Assessor: SSC Conifer Specialist Group

Refs: $848,1739,1818,9492,11847,15357,19044$

\section{Pinus latteri}

Pinaceae

LR/nt

China (Guangdong, Guangdong - Hainan, Guangxi), Myanmar, Viet Nam

Assessor: SSC Conifer Specialist Group

Refs: 374,13041

\section{Pinus longaeva}

Pinaceae

VU B1+2e

USA (California, Nevada, Utah)

In most populations very old, senescent and even dead trees predominate. These are some of the oldest trees in the world, reaching ages of $\mathbf{4 8 7 0}$ years. Their growth rate is extremely slow. It is doubtful whether present rates of regeneration are sufficient to replace the population under present climatic and environmental 
conditions. Most areas where the species occurs are protected and cutting or gathering wood is prohibited. Assessor: SSC Conifer Specialist Group

Refs: $374,13041,19193$

\section{Pinus luchuensis}

Pinaceae

LR/nt

Japan (Ryukyu Is.)

Confined to Luchu in the Ryukyu Islands, stands occur frequently near sea-water. During and after the Second World War trees were heavily harvested. The present poor form of the remaining trees precludes further exploitation. Plantations have been established.

Assessor: SSC Conifer Specialist Group

Refs: 374,448

\section{Pinus massoniana var. hainanensis}

Pinaceae

$\mathrm{EN} B 1+2 b$

China (Guangdong - Hainan)

A variety confined to two main locations in the Yajia range on Hainan Island. It occurs individually or in small clumps on the margins of tropical montane rainforest and mossy summit woodland. There is a danger that the area will be taken over for commercial forestry management.

Assessor: SSC Conifer Specialist Group

Refs: $374,1818,11847$

\section{Pinus maximartinezii}

Pinaceae

$\mathrm{EN} \mathrm{B1+2bc}$

Mexico (Zacatecas)

A total population of fewer than 10,000 trees exists, within an area of approximately $10 \mathrm{~km}^{2}$, in montane dry forest on inaccessible summit ridges and eastern slopes of the Sierra de Morone near Juchipila. Regeneration is poor, possibly because the seeds are collected in considerable numbers for food. Cattle grazing and fires also pose threats. The land is privately owned but formal protection measures are being considered.

Assessor: SSC Conifer Specialist Group

Refs: $81,374,7980,9300$

\section{Pinus merkusii}

Pinaceae

VU B1+2ce

Indonesia (Sumatra), Philippines

An important timber tree known from open pine woodlands in Sumatra around Lake Toba following the mountains north-east, and also in the Philippines. High levels of exploitation have resulted in populations being reduced to very low levels in the Philippines. In Sumatra the timber continues to be extracted. The effects on the population here are yet to be confirmed but are not thought to be as severe.

Assessor: SSC Conifer Specialist Group

Refs: 374, 3091, 6405, 6646, 19093

\section{Pinus muricata}

Pinaceae

Mexico (Baja California), USA (California)

LR/nt

The species is known from occurrences on Santa Cruz and Santa Rosa Islands in Califomia and further down the Pacific coast in Mexico.

Assessor: SSC Conifer Specialist Group

Refs: 374, 4966, 7980, 13041

\section{Pinus nelsoni}

Pinaceae

VU C2a

Mexico (Coahuila, Nuevo León, San Luis Potosí, Tamaulipas)

A unique species widely scattered in small populations on mesas and in high valleys in the Sierra Madre Oriental. Populations are not larger than several hundred mature trees and are restricted to limestone sites. Overgrazing may pose a threat. None of the populations is protected.

Assessor: SSC Conifer Specialist Group

Refs: 374, 6004, 7980

\section{Pinus nigra ssp. dalmatica}

Pinaceae

VU B1+2c

Croatia

Known only from Brac, Hvar, Korcula and Pelijesac Islands on the Dalmatian coast, this subspecies occurs in stands above the Aleppo pine forest. There is evidence that this form hybridises with the mainland subspecies. Threats come from overgrazing and habitat degradation. Assessor: SSC Conifer Specialist Group Refs: 5194, 5287, 6004, 7222, 13041

\section{Pinus peuce}

Pinaceae

LR/nt

Albania, Bulgaria, Greece, Yugoslavia

Assessor: SSC Conifer Specialist Group

Refs: 374, 4506, 7222, 13041, 13573

\section{Pinus pinceana}

Pinaceae

LR/nt

Mexico (Coahuila, Hidalgo, Querétaro, San Luis Potosí, Zacatecas)

Trees are scattered in disjunct and small populations in submontane woodland or scrubland. The species is not under any protection anywhere but it occurs widely outside areas where woodland resources are being exploited.

Assessor: SSC Conifer Specialist Group

Refs: 374, 6004, 7980, 13041

\section{Pinus radiata var. binata}

Pinaceae

EN C1

Mexico (Guadalupe Is.)

Two populations exist on Cedros Island and Guadeloupe, which is an uninhabited island $250 \mathrm{~km}$ off the mainland. Each contains in the order of 400 mature trees. Regeneration on Guadeloupe is seriously impeded by feral goats. Attempts are being made to eradicate them.

Assessor: SSC Conifer Specialist Group

Refs: 6004, 7980, 13041, 19193

\section{Pinus radiata var, radiata}

Pinaceae

$\mathrm{LR} / \mathrm{cd}$

USA (Califomia)

The type variety of this widely planted species is restricted to three main areas; in Ano Nuevo, Cambria and the Monterey Peninsula. Only half of the historical range remains undeveloped on the Monterey Peninsula. Further land developments, genetic contamination, pine pitch canker disease and forest fragmentation are of some concern.

Assessor: SSC Conifer Specialist Group

Refs: 7222, 7980, 13041, 19193 


\section{Pinus rzedowskii}

Pinaceae

Mexico (Michoacan)

Three disjunct populations occur on Cerro Chiqueritas, Cerro Ocotoso and Puerto del Pinabete. Their distribution is restricted to limestone outcrops among huge boulders above $2100 \mathrm{~m}$. The two smallest populations contain fewer than 50 trees. Fire is a hazard but the trees are respected as being unique and are safe from exploitation.

Assessor: SSC Conifer Specialist Group

Refs: $6004,6541,7980,12985$

\section{Pinus squamata}

Pinaceae

CR D1

China (Yunnan)

Discovered in moist montane woodland in Qiaojiaxian in 1991 and described a year later, the species is so far known from a total population of 20 trees. More fieldwork is needed to establish the health and status of this population and whether there are any more subpopulations in the vicinity. The closest relative of the taxon is $P$. bungeana, which occurs $500 \mathrm{~km}$ to the south. Assessor: SSC Conifer Specialist Group Refs: 13041

\section{Pinus strobus var. chiapensis}

Pinaceae

VU $B 1+2 b$

Guatemala, Mexico (Chiapas, Guerrero, Oaxaca, Puebla, Veracruz)

A valuable timber tree, now restricted to small remnant populations in mixed or broadleaf montane forests. Overexploitation and the subsequent degradation and changes in the forest vegetation have caused the decline. Assessor: SSC Conifer Specialist Group

Refs: 3951, 6004, 7980, 13041, 18751

\section{Pinus tabuliformis var. henryi}

Pinaceae

LR/nt

China (Hubei, Shaanxi, Sichuan)

Assessor: SSC Conifer Specialist Group

Refs: 374, 11191, 13041

\section{Pinus taiwanensis var. damingshanensis}

Pinaceae

China (Guangxi, Guizhou)

An endemic to the Damingshan.

Assessor: SSC Conifer Specialist Group

Refs: 374,13041

\section{Pinus tecunumanii}

Pinaceae

VU A2c

Belize, El Salvador, Guatemala, Honduras, Mexico (Chiapas, Oaxaca), Nicaragua, Panama

A tree increasingly exploited for its quality timber. Although the exact limits of its range are imperfectly known, the species is found in upland valleys and plateaux, often growing on deep rich fertile soil, sometimes forming pure stands. These areas are frequently cleared and replaced by secondary shrubland, with $P$. oocarpa. Trees are large with a notably straight bole. The timber is highly valued in construction work. Plantations have been established but no conservation measures are in place.

Assessor: SSC Conifer Specialist Group

Refs: 7980, 13041, 16772
Pinus torreyana ssp. insularis

Pinaceae

USA (California)

EN D 1

Fewer than 250 trees exist in the coastal chaparral of Santa Rosa Island. The entire population is protected. Coastal abrasion and fires pose threats.

Assessor: SSC Conifer Specialist Group

Refs: 13041, 19193

\section{Pinus torreyana ssp. torreyana}

Pinaceae

EN C2b

USA (California)

There is a very small population of fewer than 1000 trees in suburban areas north of San Diego. Most of the population is protected within Torrey Pines State Park but trees on unprotected land are highly vulnerable to fire, recreation activities and urban development. There has been a recent serious infestation of five-spined ips bark beetle in the park, but it is now apparently contained.

Assessor: SSC Conifer Specialist Group

Refs: 13041,19193

\section{Pinus wangii}

Pinaceae

China (Yunnan), Viet Nam

EN B $1+2 b d$

Highly restricted in range and population numbers, the species is confined to evergreen submontane forest on limestone mountains in Xicho and Malipo, south-east Yunnan. There is a threat of continued logging. It is also recorded in Viet Nam but the population there is poorly known.

Assessor: SSC Conifer Specialist Group

Refs: $374,1818,11847,19044$

Piper amalago var. variifolium

Piperaceae

CR C2b

Jamaica

This variety is known only from the type, which was collected in Manchester. The species is endemic to Jamaica.

Assessor: World Conservation Monitoring Centre

Refs: 401, 5653, 7980

\section{Piper augustum var. cocleanum}

Piperaceae

LR/nt

Panama

Although the species ranges from Costa Rica to northem South America, this variant is thought to be endemic to Panama, where it occurs in a number of provinces, mainly in undisturbed rainforest up to $1300 \mathrm{~m}$. It is scarce outside protected areas. The taxon's range closely approaches both national borders and possibly extends into Costa Rica and Colombia, but is recognised there only at the species level.

Assessor: Mitre, $\mathrm{M}$.

Refs: 7980,16772

\section{Piper cordulatum}

Piperaceae

LR/nt

Costa Rica, Panama

A lowland rainforest species, well distributed in Panama, particularly in the Canal area and in a number of national parks. In recent years it has also been reported from Costa Rica in Corcovado National Park, where it appears to be common.

Assessor: Mitré, M.

Refs: 7272, 7980, 16772 
Piper distigmatum

Piperaceae

DD

Panama

A doubtful species known only from the type specimen of 1950.

Assessor: Mitré, M.

Refs: $7272,7980,16772$

\section{Piper fimbriulatum}

Piperaceae

LR/nt

Colombia, Costa Rica, Panama

Occurring over a wide altitudinal range, the species is relatively common on the Pacific slopes of Costa Rica, in all mountain areas of Panama and in the Chocó in Colombia. Almost all localities in Panama are in areas of minimal human impact.

Assessor: Mitré, M.

Refs: 16772

\section{Piper lucigaudens}

Piperaceae

$\mathrm{LR} / \mathrm{nt}$

Panama

Common in places, the species is recorded from various provinces in Panama in rainforest, generally at higher altitudes, but ranging from sea level to $2200 \mathrm{~m}$. There are a number of occurrences in protected areas and elsewhere in regions that are heavily influenced by human activities.

Assessor: Mitré, M.

Refs: $7272,7980,16772$

\section{Piper lucigaudens var. alleni}

Piperaceae

Panama

A doubtful variant of the species, which is known only from a type specimen collected from Darién Province. It is the only record of the species in the province.

Assessor: Mitre, $\mathrm{M}$.

Refs: $7272,7980,16772$

\section{Piper verrucosum}

Piperaceae

$\mathrm{LR} / \mathrm{nt}$

Jamaica

A tree with an occasional occurrence in central parishes in remaining areas of woodland on craggy limestone. Assessor: World Conservation Monitoring Centre Refs: 6057,7980

\section{Piptadenia weberbaueri}

Leguminosae

VU Bl+2c

Peru

The species occurs in areas of grassland and shrubland, between 1500 and $2000 \mathrm{~m}$ in the department of $\mathrm{La}$ Libertad.

Assessor: World Conservation Monitoring Centre Refs: 1984

\section{Piptostigma fugax}

Annonaceae

VU Alc, Bl+2c

Côte d'Ivoire, Ghana, Liberia

A species which can occur in some abundance, at least in Ghana. It is generally confined to wet evergreen forest, especially in upland areas. Much of the forest in this area has been adversely affected by mining, logging and commercial planting operations.

Assessor: Hawthome, W.

Refs: $2773,8369,12061$

\section{Piptostigma giganteum}

Annonaceae

VU B $1+2 c$

Nigeria

This species appears to be known only from the Oban Division of the Cross River National Park. Unprotected forest has been extensively logged and cleared for cultivation.

Assessor: World Conservation Monitoring Centre

Refs: 2773, 4977, 11504

\section{Piptostigma oyemense}

Annonaceae

VU D2

Gabon

A species known only from a collection in Oyem in the north, in an area which has been degraded to some degree. Much of Gabon's extensive forests have not been explored and are now under concession to logging companies.

Assessor: World Conservation Monitoring Centre Refs: 14958, 15790

\section{Pipturus argenteus var. argenteus}

Uricaceae

VU B $1+2 \mathrm{c}$

French Polynesia (Society Is.)

The species occurs on Moorea and Tahiti.

Assessor: Florence, J.

Refs: 14513

\section{Pipturus schaeferi}

Urticaceae

French Polynesia (Marquesas Is.)

VU B $1+2 c$

Populations are found on the islands of Fatu Hiva, Hiva $\mathrm{Oa}$ and Tahuata. The species occurs between 330 and $780 \mathrm{~m}$ in humid or riverine areas of forest or mesophyllous forest, and also in open dry rocky areas and basalt cliffs. It is relatively scarce and distributed in areas sensitive to degradation.

Assessor: Florence, J.

Refs: 19169

\section{Pisonia donnell-smithï}

Nyctaginaceae

VU B1+2c

El Salvador, Guatemala

A species occurring in areas of inundated and swamp forest. Little information is available on the conservation status of subpopulations but the habitat has suffered widely from logging, tourism and an expanding human population.

Assessor: World Conservation Monitoring Centre Refs: 4862, 4974, 19030

\section{Pisonia ekmani}

Nyctaginaceae

$\mathrm{EN} \mathrm{B1}+2 \mathrm{c}$

Cuba

A doubtful tree taxon found infrequently in Las Tunas and Hoguín Provinces.

Assessor: Areces-Mallea, A.E.

Refs: 11403, 18485, 19149

\section{Pisonia graciliscens}

Nyctaginaceae

$\mathrm{CR} B 1+2 \mathrm{c}$

An endemic to Tahiti.

Assessor: Florence, J.

Refs: 14513 


\section{Pisonia sechellarum}

Nyctaginaceae

Seychelles

A species known only from an area of 0.5 ha in a valley on Silhouette. The population is estimated to contain 190 trees, many of which represent the same individual and the genetic diversity is believed to be low. The area falls within a forest protected by the Nature Protection Trust of Seychelles. Numerous seeds are set but germination is poor. There has been no success in bringing the species into cultivation either. The tree's main pollinator (Epicroesa sp.) appears also to be its main seed predator.

Assessor: World Conservation Monitoring Centre

Refs: $10610,17229,19025$

\section{Pisonia siphonocarpa}

Nyctaginaceae

French Polynesia (Society Is.)

An endemic to Moorea.

Assessor: Florence, J.

Refs: 14513

\section{Pisonia wagneriana \\ Nyctaginaceae \\ USA (Hawaii)}

EN C2a

Endemic to Kauai the species is restricted to forested valleys up to $650 \mathrm{~m}$ from the Powerline Trail to the Maunahina-Wainiha drainage. It is thought a collection from Honopu Valley on the Napali coast may also represent this species.

Assessor: World Conservation Monitoring Centre

Refs: 3372

\section{Pistacia aethiopica}

Anacardiaceae

LR/nt

Eritrea (ex), Ethiopia, Kenya, Somalia, Tanzania, Uganda, Yemen

In the main part of its range in North and East Africa, the species is fairly abundant. There is an outlying population in Arabia, restricted to Jebel Iraf on the old North Yemen-South Yemen border. The woodland here is believed to be in good condition, although it may come under threat after the completion of a new road to the area. The tree produces a high-quality gum mastic and damage is frequently incurred from the tapping process. The populations around Nairobi are said to be wiped out from overexploitation. The species is also thought to be extinct in Eritrea.

Assessor: World Conservation Monitoring Centre

Refs: $1330,6396,19083$

\section{Pistacia cucphuongensis}

Anacardiaceae

VU D2

Viet Nam

Apparently endemic to Viet Nam, this shrub or small tree is confined to a single locality in Cuc Phuong, Ninh Binh.

Assessor: World Conservation Monitoring Centre

Refs: 848

\section{Pistacia mexicana}

Anacardiaceae

VU Alc

Guatemala, Mexico

Occurring in dry montane scrub or pine-oak formations, the species is restricted in altitudinal range and distribution. Populations are recorded from southern
Mexico and Guatemala. The habitat is considerably reduced by the effects of growing agriculture and pastoralism.

Assessor: Ramirez-Marcial, N. \& M. González-Espinosa Refs: 19161

\section{Pitavia punctata}

Rutaceae

EN Alcd

Chile (Bíobío, Maule)

A species which is known from two regions in central Chile, occurring in moist lowland forest in the Coastal Cordillera. Populations are under threat throughout the area, mainly from logging and forest management activities.

Assessor: González, M.

Refs: $7980,11147,16328$

\section{Pithecellobium gracile}

Leguminosae

VU B $1+2 c$

India (Kerala)

Known from seven collections, the species occurs in scattered localities of evergreen forest at low to medium elevations.

Assessor: World Conservation Monitoring Centre

Refs: 19144

\section{Pithecellobium grisebachianum}

Leguminosae

Argentina (Jujuy, Salta), Bolivia

VU B1+2ac

Endemic to the piedmont forest of north-west Argentina and Bolivia, the species is confined to an unprotected ecosystem which is being rapidly replaced by agricultural systems.

Assessor: Prado, D.

Refs: 19122

\section{Pilhecellobium johansenii}

Leguminosae

EN C2a

Belize, Guatemala, Honduras

A tree of the wet Atlantic lowlands, occurring in Lancetilla Biological Reserve.

Assessor: Nelson, C.

Refs: 13995

\section{Pithecellobium pithecolobioides}

Leguminosae

VU B1+2ac

Argentina (Chaco, Corrientes), Paraguay

An uncommon species, restricted to marginal forest along the banks of Ríos Paraná and Paraguay. Collections appear to be declining in number and in extent of occurrence. Existing threats to remaining populations include dam construction, tourism and fishing.

Assessor: Prado, D.

Refs: 1262,7980

\section{Pithecellobium savannarum}

Leguminosae

VU D2

Cuba

Endemic to serpentine areas in south-east Holguin, the species occurs in a habitat which has been largely replaced by secondary savanna and pastureland. Populations have survived best near watercourses. Assessor: Areces-Mallea, A.E.

Refs: $16327,18485,19149$ 


\section{Pilhecellobium saxosum}

Leguminosae

EN C2a

Guatemala, Honduras

A thicket species, usually occurring on rocky hillsides or plains, sometimes along creeks.

Assessor: Nelson, C.

Refs: 4974, 13995

\section{Pithecellobium stevensonii}

Leguminosae

EN C2a

Belize, Guatemala, Honduras

A tree restricted to mixed rainforest on Atlantic slopes.

Assessor: Nelson, C.

Refs: 13995

\section{Pittosporum aliferum}

Pittosporaceae

New Caledonia

$\mathrm{EN} \mathrm{B} 1+2 \mathrm{c}$

Assessor: Jaffré, T. et al

Refs: 10351

\section{Pittosporum artense}

Pittosporaceae

VU B $1+2 c$

New Caledonia

Assessor: Jaffré, T. et al.

Refs: 10351

\section{Pittosporum brevispinum}

Pittosporaceae

New Caledonia

Assessor: Jaffré, T. et al.

Refs: 10351

\section{Pittosporum collinum}

Pittosporaceae

New Caledonia

Assessor: Jaffré, T. et al.

Refs: 10351

\section{Pittosporum coriaceum}

Pittosporaceae

CR D1

Portugal (Madeira)

Few individuals are known in the wild, growing in deep ravines in the *laurisilva. A new population has recently been discovered, but total population numbers do not greatly exceed 30 trees. The entire range is contained within the National Park of Madeira, but there are still potential threats from fire and grazing. There is no observed natural seed germination, the only regeneration being vegetative. Efforts are being made to propagate the species, with limited success.

Assessor: World Conservation Monitoring Centre

Refs: 19080,19131

\section{Pittosporum dallit}

Pittosporaceae

New Zealand (South Is.)

VU B $1+2 \mathrm{c}$

A small tree confined to montane beech forest in the Tasman Mountains in north-west Nelson. Browsing by deer and possum is heavy.

Assessor: de Lange, $P_{.} J$

Refs: $902,9800,17637,19133,19134$

\section{Pittosporum eriocarpum}

Pittosporaceae

India (Himachal Pradesh, Uttar Pradesh)

$\mathrm{EN} \mathrm{B1}+2 \mathrm{c}$

A shrub or small tree recorded from Dehra Dun, Musoorie and Sahastradhara, where it has become so scarce that specific searches for it have failed to locate a single specimen. It was known to grow on hot rocky slopes up to $2400 \mathrm{~m}$. Large-scale lime quarrying and degradation of the habitat are likely to have contributed to the decline.

Assessor: World Conservation Monitoring Centre Refs: 2538

\section{Pittosporum fairchildii}

Pittosporaceae

New Zealand (North Is.)

VU D2

This small tree is endemic to the Three Kings Islands.

Assessor: World Conservation Monitoring Centre Refs: $902,9800,19133$

\section{Pittosporum gatopense}

Pittosporaceae

$\mathrm{EN} \mathrm{B} 1+2 \mathrm{c}$

New Caledonia

Assessor: Jaffré, T. et al.

Refs: 10351

\section{Pittosporum goetzei}

Pittosporaceae

VU B $1+2 d$

Tanzania

This species is restricted to the Ulugur Mountains, where it occurs over $2100 \mathrm{~m}$ in moist evergreen forest. Assessor: Lovett, J. \& G.P. Clarke

Refs: $3356,5204,10961$

\section{Pittosporum gomonenense}

Pittosporaceae

$\mathrm{EN} \mathrm{B} 1+2 \mathrm{c}$

New Caledonia

Assessor: Jaffré, T, et al.

Refs: 10351

\section{Pittosporum linearifolium}

Pittosporaceae

VU D2

Malaysia (Sabah)

Restricted to the Bukit Ampuan area in Ranau, this tree is found in hill forest up to $1200 \mathrm{~m}$.

Assessor: World Conservation Monitoring Centre

Refs: 19017

\section{Pittosporum muricatum}

Pittosporaceae

$\mathrm{EN} \mathrm{B1+2c}$

New Caledonia

Assessor: Jaffré, T. et al.

Refs: 10351

\section{Pittosporum napaliense}

Pittosporaceae

EN C2a

USA (Hawaii)

A small tree scattered in distubed *hala forest and wetter vegetation up to $550 \mathrm{~m}$ within an area stretching from Limahuli to Hanakoa Valley in north-western Kauai. The invasion of alien plant species has affected the habitat in many areas.

Assessor: World Conservation Monitoring Centre Refs: 3372

\section{Pittosporum obcordatum}

Pittosporaceae

New Zealand (North Is., South Is.)

LR/nt

Occurring on both islands in lowland kahikatea/matai forest, populations are scarce and small. In the 1981 Red Data Book of New Zealand there were estimated to be fewer than 50 individuals in total. Regeneration is reported to be good in places. Assessor: de Lange, P.J.

Refs: 902, 9800, 17637, 19133, 19134 
Pittosporum ornatum

Pittosporaceae

$\mathrm{EN} \mathrm{B} 1+2 \mathrm{c}$

New Caledonia

Assessor: Jaffré, T. et al.

Refs: 10351

\section{Pittosporum orohenense}

Pittosporaceae

French Polynesia (Society Is.)

VU BI $+2 \mathrm{c}$

This species is known only from Tahiti.

Assessor: Florence, J.

Refs: 14513

\section{Pittosporum paniense}

Pittosporaceae

VU D2

New Caledonia

Assessor: Jaffré, T. et al.

Refs: 10351

\section{Pittosporum patulum}

Pittosporaceae

New Zealand (South Is.)

Recorded as a small tree, the species is known from very few adult plants, occurring in beech forest. Seedlings and saplings are heavily browsed by deer and possums.

Assessor: de Lange, PJ.

Refs: $9800,19133,19134$

\section{Pittosporum pauciflorum}

Pittosporaceae

VU B $1+2 c$

China (Yunnan)

The species is confined to areas of mixed montane forest in Sichuan and north-west Yunnan. Extensive habitat losses and the popularity of the species in traditional medicine have caused the populations in the wild to decline.

Assessor: Sun, W.

Refs: 19055

\section{Pittosporum raivavaeense}

Pittosporaceae

CR B $1+2 \mathrm{c}$

French Polynesia (Tubuai Is.)

The species is known only from Raivavae.

Assessor: Florence, J.

Refs: 14513

\section{Pittosporum senacia ssp. wrighti}

Pittosporaceae

VU D2

Seychelles

Endemic to the Seychelles, the species qualifies as threatened by virtue of its restricted distribution. Populations are healthy and stable.

Assessor: World Conservation Monitoring Centre

Refs: 16212,17229

\section{Pittosporum silamense}

Pittosporaceae

VU D2

Malaysia (Sabah)

Endemic to Sabah, this small tree of hill forest seems to be restricted to Mount Silam in Lahad Datau District.

Assessor: World Conservation Monitoring Centre

Refs: 19017

\section{Pittosporum stenophyllum}

Pittosporaceae

$\mathrm{EN} \mathrm{B1}+2 \mathrm{c}$

New Caledonia

Assessor: Jaffré, T, et al.

Refs: 10351

\section{Pittosporum tanianum}

Pittosporaceae

EX

New Caledonia

The species was first discovered in 1988 from two specimens contained within a small patch of sclerophyllous forest on the island of Lepredour. Five years later both individuals died, one because the surrounding soil had eroded away. Intensive searches have failed to uncover additional specimens. Deer plague the remaining fragments of forest, totalling about Sha. Propagation of cuttings has failed.

Assessor: Jaffré, T, et al.

Refs: 4492, 10351

\section{Pittosporum terminalioides}

Pittosporaceae

USA (Hawaii)

VUAlce

A species scattered in dry to moist forest extending over a wide altitudinal range. Populations are recorded on Lanai, Maui and from Kilauea around the leeward side to the Kohala Mountains on Hawaii.

Assessor: World Conservation Monitoring Centre Refs: 3372

\section{Pittosporum turneri}

Pittosporaceae

New Zealand (North is.)

$\mathrm{LR} / \mathrm{cd}$

A small tree growing on frost flats and in clearings in montane forest. Browsing possums are causing damage to this species.

Assessor: de Lange, P.J.

Refs: 9800, 19133, 19134

\section{Pittosporum virgatum}

Pittosporaceae

New Zealand (North Is.)

LR/nt

The species has been recorded from the Auckland area, the Coromandel Peninsula and Great Barrier Island. Several hundred trees remain in the wild along forest margins, in scrubland and regenerating * kauri forest. It is locally abundant on Great Barrier Island. Habitat clearance for forestry and farming are responsible for past population declines. Most of the remaining colonies are found on land administered by the Forest Service.

Assessor: de Lange, P.J.

Refs: $902,9800,17637,19133$

\section{Pittosporum viridulatum}

Pittosporaceae

CR B $1+2 c$

India (Tamil Nadu)

A small tree, currently known only from a single record from a locality at the base of the Nilgiris.

Assessor: World Conservation Monitoring Centre Refs: 19144

\section{Placodiscus attenuatus}

Sapindaceae

EN Alc, Bl+2c

Côte d'Ivoire, Ghana

Although supportive evidence to indicate population declines is not available, the loss of the habitat of this species has been severe. It is found in one remnant area of coastal forest, which has been significantly reduced by farming, fuelwood collection and forestry plantations. It also occurs in moist evergreen or riverine forest.

Assessor: Hawthome, W. Refs: 8369, 12061, 15251 


\section{Placodiscus bancoensis}

Sapindaceae

Côte d'Ivoire, Ghana

Found solely in Ghana and neighbouring Côte d'Ivoire, this species is restricted to small areas of moist evergreen forest. Deforestation in this area has been caused by mining, logging and commercial forestry operations.

Assessor: Hawthome, W.

Refs: 8369,12061

\section{Placodiscus boya}

Sapindaceae

VU B $1+2 \mathrm{c}$

Côte d'Ivoire, Ghana

Known only from Ghana and neighbouring Côte d'Ivoire, this species occurs in relatively dry or semideciduous forest. It can be quite common but the restriction of the species' range and the severe losses of its habitat render it vulnerable.

Assessor: Hawthome, W.

Refs: 6127,12061

\section{Placodiscus bracteosus}

Sapindaceae

Côte d'Ivoire, Ghana

VU A1c, B1+2c

A species restricted to areas of moist evergreen forest in Ghana and neighbouring Côte d'Ivoire. Losses in the forest habitat have been incurred from mining, logging and commercial forestry activities.

Assessor: Hawthorne, W.

Refs: 8369, 12061

\section{Placodiscus oblongifolius}

Sapindaceae

VU Alc, B1+2c

\section{Ghana}

This a common tree in Ghana, but its range is restricted to evergreen forests in the Upper Guinea region. A large part of the habitat has suffered losses because of mining, logging and commercial forestry activities.

Assessor: Hawthorne, W.

Refs: 8369,12061

\section{Placodiscus paniculatus}

Sapindaceae

VU D2

Democratic Republic of Congo

A species of the Forestier Central. It is restricted to a zone in the north-east where it is apparently heavily utilised for arrow-making.

Assessor: Ndjele, M.B.

Refs: 17185,17951

\section{Placodiscus pseudostipularis}

Sapindaceae

$\mathrm{EN} \mathrm{B} 1+2 \mathrm{c}$

Côte d'Ivoire, Ghana, Liberia, Sierra Leone

Like $P$. attenuatus, this species occurs in remnants of coastal forest, where the effects of farming, fuelwood collection and commercial forestry have been severe. It is also found in areas of less disturbed wet evergreen or riverine forest but only in the Upper Guinea region.

Assessor: Hawthorne, W.

Refs: $2773,8369,12061$

\section{Placopoda virgata}

Rubiaceae

LR/nt

Yemen (Socotra)

A widespread species of low-altitude woodland and shrubland. It is abundant in places on the lower slopes of limestone mountains and summit plateaux. The populations are under no immediate threat.

Assessor: Miller, A.G.

Refs: 2354, 19083

\section{Pladaroxylon leucadendron}

Compositae

CR D1

St Helena

A small spreading tree, which is found in a number of localities between 720 and $800 \mathrm{~m}$ on the central ridge, particularly at High Peak, from Mount Actaeon to Cuckhold's Point, also at Cabbage Tree Road and Diana's Peak. The total population size is probably less than 50 individuals. Regeneration has been successful where invasive plants, such as New Zealand flax, have been cleared. The genus is monotypic.

Assessor: Cronk, Q.C.B.

Refs: 9954, 19071, 19081

\section{Plagianthus regius var. chathamicus}

Malvaceae

LR/nt

New Zealand (Chatham Is.)

This is the correct combination for the taxon $P$. chathamicus or $P$. betulinus var. chathamicus. It is a large tree of inland forest, occurring commonly in a few reserves.

Assessor: de Lange, P.J.

Refs: 902, 19133, 19134

\section{Plagiosiphon gabonensis}

Leguminosae

LR/nt

Gabon

A species found in areas of closed forest in Lopé Forest Reserve, Ndjolé-Koumamejong, Sindoro and near Lastoursville. The habitat is degraded where there has been logging. Gabon's extensive forests are relatively unexplored and are now under concession to logging companies.

Assessor: World Conservation Monitoring Centre Refs: 19043

\section{Planchonella contermina}

Sapotaceae

$\mathrm{EN} \mathrm{B1+2c}$

New Caledonia

The genus is no longer considered valid according to Pennington.

Assessor: Jaffré, T. et al.

Refs: 10351, 10781

\section{Planchonella daenikeri}

Sapotaceae

$\mathrm{EN} \mathrm{B} 1+2 \mathrm{c}$

New Caledonia

The species has been collected from forest on serpentine in a few localities from the north and south, including sites on the lower slopes of Massif Tiebaghi and Mont Kaala. The genus has been transferred to Pouteria.

Assessor: Jaffré, T. et al.

Refs: $10351,10781,12630$

\section{Planchonella kaalaensis}

Sapotaceae

$\mathrm{EN} \mathrm{B1+2c}$

New Caledonia

The genus is no longer considered valid according to Pennington.

Assessor: Jaffre, T. et al.

Refs: 10351, 10781 


\section{Platanus kerrii}

Platanaceae

Laos, Viet Nam

A large tree distributed widely at low altitudes in northem provinces of Viet Nam and Vieng Chan in Laos. It grows near streams on alluvium, gravel soils or mud flats. Natural regeneration and coppicing is strong. The wood is used only on a small scale because of its propensity for cracking and curving. In Viet Nam, the species has become threatened because of the rates of habitat loss.

Assessor: World Conservation Monitoring Centre

Refs: $848,11530,15357$

\section{Platycladus orientalis}

Cupressaceae

LR/nt

China (Gansu, Hebei, Henan, Shaanxi, Shanxi), Iran, Russia, Tajikistan, Uzbekistan

The species is apparently quite widespread but the range is confused by populations which may have been planted. It is very slow-growing.

Assessor: SSC Conifer Specialist Group

Refs: 374, 1956, 13041

\section{Platydesma remyi}

Rutaceae

EN C2a

USA (Hawaii)

A shrubby tree found only rarely in rainforest up to $1080 \mathrm{~m}$ in the Hamakua-Kohala area on Hawaii.

Assessor: World Conservation Monitoring Centre

Refs: 3372

\section{Platymenia foliolosa}

Leguminosae

VU Alcd

Brazil (Bahia, Ceará, Espírito Santo, Minas Gerais, Pernambuco)

A widespread species found in diverse habitats and climates, ranging from lowland rainforest to *cerrado. Selective exploitation of the timber, coupled with poor regeneration, is causing population declines, especially in the coastal areas of Espirito Santo.

Assessor: World Conservation Monitoring Centre Refs: 4506

\section{Platymiscium albertinae}

Leguminosae

$\mathrm{CR}$ C2b

Honduras

Of somewhat dubious nomenclature, the species is rarely collected and confined to dry forest along creeks. The population at the type locality has disappeared because of urban development.

Assessor: Nelson, C.

Refs: 13995, 14311

\section{Platymiscium gracile \\ Leguminosae}

VU D2

Peru

Known only from the type collection, the species occurs in lowland forest in the department of San Martin.

Assessor: World Conservation Monitoring Centre Refs: 1984

\section{Platymiscium pleiostachyum}

Leguminosae

EN Cl

Costa Rica, El Salvador, Nicaragua

Occurring in remnant dry forests and woodlands on flat ground, including disturbed or secondary forest, the species is scarce, individuals often show signs of genetic degradation and regeneration is largely absent. The timber is attractive and has been heavily exploited in Costa Rica but there is no evidence of it being present in international trade. The species is listed in Appendix II of * CITES.

Assessor: Americas Regional Workshop

Refs: 4862, 7980, 14487, 19179, 19185, 19186

\section{Platypterocarpus tanganyikensis}

Celastraceae

$\mathrm{CR} B 1+2 \mathrm{~b}, \mathrm{C} 2 \mathrm{~b}$

Tanzania

The species is known only from the dry montane forests of West Usambara. A substantial area of the forest in which it occurred was cleared in the mid-1960s and it may now be extinct. The genus is monotypic. The nearest related genus is Wimmeria in Central and South America.

Assessor: Lovett, J. \& G.P. Clarke

Refs: 3356, 10961

\section{Platyspermation crassifolium}

Escalloniaceae

LR/cd

New Caledonia

Assessor: Jaffré, T, et al.

Refs: 10351

\section{Pleioceras orientale}

A pocynaceae

VU D2

Mozambique

Only two localities are known, where the species occurs in lowland dry evergreen forest and deciduous coastal forest on sand. One is within $200 \mathrm{~m}$ of a new railway line.

Assessor: World Conservation Monitoring Centre Refs: 18965

\section{Pleiomeris canariensis}

Myrsinaceae VU C2a Spain (Canary Is.)

Known only from Gran Canaria and Tenerife, the species exists in fragmented populations in inaccessible areas of dry woodland. It is listed in government legislation of 1991.

Assessor: Bañares, A. et al.

Refs: 19022

\section{Pleiospermium longisepalum}

Rutaceae

VU B $1+2 c$

Malaysia (Sabah)

Endemic to Sabah, the species is found in primary and secondary inland forest up to an elevation of $1300 \mathrm{~m}$. It is located in the foothills and low mountainous regions of Kota Manudu, Ranau and Tambunan Districts and on the offshore islands of Pulau Banggi and Pulau Bohayan.

Assessor: World Conservation Monitoring Centre Refs: 19017

\section{Pleodendron macranthum}

Canellaceae

Puerto Rico

CR D1

A small tree of wet to moist submontane forest. Only three populations are known, accounting for 10-12 individuals. There are two individuals in El Yunque. The rest are found in Río Abajo State Park.

Assessor: World Conservation Monitoring Centre Refs: $7980,17124,17540$ 
Pleomele auwahiensis

Dracaenaceae

VU Alce

USA (Hawaii)

A species restricted to remnants of lowland dry forest in central Molokai and in more moist forest in Makawao and Olinda on Maui.

Assessor: World Conservation Monitoring Centre

Refs: 3372

\section{Pleomele fernaldii}

Dracaenaceae

EN C2a

USA (Hawaii)

Endemic to Lanai, the species is confined to remaining patches of lowland dry forest.

Assessor: World Conservation Monitoring Centre

Refs: 3372

\section{Pleomele forbesü}

Dracaenaceae

$\mathrm{EN} \mathrm{C2a}$

USA (Hawaii)

The main population is found in various lowland forest types in the Waianae Mountains on Oahu. There are occasional occurrences also in the Kolau Mountains. Assessor: World Conservation Monitoring Centre Refs: 3372

\section{Pleomele halapepe}

Dracaenaceae

VU Alce

USA (Hawaii)

This is a striking species which rarely flowers. It is restricted to dry and other lowland forest types on Oahu. Assessor: World Conservation Monitoring Centre Refs: 3372

\section{Pleomele hawaiiensis}

Dracaenaceae

EN C2a

USA (Hawaii)

A species of lowland dry forest on lava fields. It is currently recorded from six to eight populations in Puuwaawaa, the Kaloko/Kaloao area, the Kapua/Kahuku area and on Holei Pali. Population estimates lie between 300 and 400 individuals. The habitat is threatened with conversion for residential or recreational use. Grazers, invasive plants and fire are also problems. The species is protected by the US Endangered Species Act.

Assessor: World Conservation Monitoring Centre

Refs: 3372, 19037

\section{Pleurothyrium hexaglandulosum}

Lauraceae

VU D2

Costa Rica, Panama

Two collections have been made of this understorey tree. It occurs in lowland wet evergreen forest in Puntarenas Province in Costa Rica and in Colón in Panama.

Assessor: World Conservation Monitoring Centre

Refs: 12587,15719

\section{Pleurothyrium roberto-andinoi}

Lauraceae

CR C2a

Honduras

This species occurs in areas of riverine forest at medium elevations.

Assessor: Nelson, C.

Refs: 7534, 13995

\section{Plinia rupestris}

Myrtaceae

CR B $1+2 c$

Cuba

An imperfectly known species known only from a single locality in Cerro de Mendosa, Pinar del Rio Province. Apparently the species is surviving precariously in a very threatened area.

Assessor: Areces-Mallea, A.E.

Refs: 11403, 18485, 19149

\section{Podadenia thwaitesii}

Euphorbiaceae

CR B $1+2 \mathrm{c}$

Sri Lanka

A tree occurring in the lowland wet evergreen forests of south-west Sri Lanka. This species appeared to be fairly common during a previous survey, but it was not found at all during the extensive forest surveys conducted between 1991 and 1996 for the National Conservation Review.

Assessor: World Conservation Monitoring Centre Refs: 17195,19112

\section{Podocarpus acuminatus}

Podocarpaceae

Brazil (Amazonas), Venezuela

The species occurs in the Sierra de la Neblina, on both the Brazilian and Venezuelan sides, and on Chimantá and south-west Amuri-tepui. All areas are contained within effective national parks.

Assessor: SSC Conifer Specialist Group

Refs: 13041

\section{Podocarpus angustifolius}

Podocarpaceae

$\mathrm{CR} B 1+2 \mathrm{c}$

Cuba

A very rare tree, up to $10 \mathrm{~m}$ high, occurring in montane rainforests of Pinar del Rio Province and in the mountain ranges of south-central Cuba. Its habitat is degraded in places and the species seems particularly vulnerable to ecological impact.

Assessor: Areces-Mallea, A.E.

Refs: $2479,16327,19149$

\section{Podocarpus annamiensis}

Podocarpaceae

China (Guangdong - Hainan), Myanmar, Viet Nam

A tree scattered in forest areas on hillsides and ridges at medium altitudes. Populations confined to the mountains of southern Hainan Island in China are constantly subject to exploitation and have declined. Populations elsewhere are also subject to heavy logging.

Assesso:-: SSC Conifer Specialist Group

Refs: $374,1739,1818,5054,11191,11530$

\section{Podocarpus atjehensis}

Podocarpaceae

Indonesia (Sumatra), Papua New Guinea

The species occurs in the Gajo Lands in northem Sumatra and the Wissel Lakes in Papua New Guinea. Assessor: SSC Conifer Specialist Group Refs: $374,6851,13041$

\section{Podocarpus borneensis}

Podocarpaceae 


\section{Podocarpus costalis}

Podocarpaceae

Philippines, Taiwan

The species occurs in dry coastal scrubland or low forest in rocky or cliff top locations, mainly in Lanyu Island, Taiwan, and the Batan Islands in the Luzon Strait. The type collection was gathered from Luzon in the Philippines. The natural stands present in Taiwan before 1980 have been reduced to a few individuals as a result of whole plants being uprooted for the horticultural trade. It is also a popular omamental plant in the Philippines. The species is subject to CITES Appendix I restrictions.

Assessor: SSC Conifer Specialist Group

Refs: 2106, 6469, 10938, 11314, 13041, 19050, 19051

\section{Podocarpus decumbens}

Podocarpaceae

VU D2

New Caledonia

A species known from just three sites of high-altitude maquis in areas of high precipitation in the southem ultramafic massifs. All three sites are relatively inaccessible and well protected within Rivière Bleue Provincial Park and Montagne des Sources Nature Reserve.

Assessor: SSC Conifer Specialist Group

Refs: 9631,12630

\section{Podocarpus deflexus}

Podocarpaceae

$\mathrm{LR} / \mathrm{cd}$

Indonesia (Sumatra), Malaysia (Peninsular Malaysia)

A shrub or small tree of moist montane scrub, which is confined to Gunung Tahan in Pahang, Peninsular Malaysia, and the Gajo Lands in north Sumatra. The former locality is protected within Taman Negara National Park.

Assessor: Chua, L.S.L.

Refs: $374,6851,8464,13041,19073$

\section{Podocarpus dispermus}

Podocarpaceae

Australia (Queensland)

The species is confined to the Atherton Tableland in north-east Queensland.

Assessor: SSC Conifer Specialist Group

Refs: $707,13041,17200$

\section{Podocarpus fasciculus}

Podocarpaceae

VUAlcd

Taiwan

Although recognised as an endemic in Taiwan, populations on the Ryukyu Islands in Japan are also considered to belong to this species. In Taiwan populations are found in the north-central region, and in the far south in Tawushan Nature Reserve. Regeneration is poor.

Assessor: SSC Conifer Specialist Group

Refs: $374,2106,15406,19050,19051$

\section{Podocarpus gibbsii}

Podocarpaceae

VU D2

Malaysia (Sabah)

The entire range of the species is probably contained within Mount Kinabalu National Park, where it is confined to forest between 1200 and $2400 \mathrm{~m}$ on ultramafic substrates. The area is well protected but there is a potential threat presented by the attractiveness of the substrate for mining.

Assessor: SSC Conifer Specialist Group

Refs: $374,6851,12121,19125$

\section{Podocarpus globulus}

Podocarpaceae DD

Indonesia (Kalimantan), Malaysia (Sabah, Sarawak)

Assessor: SSC Conifer Specialist Group

Refs: $374,6851,13041$

\section{Podocarpus guatemalensis}

Podocarpaceae

Belize, Colombia, Costa Rica, El Salvador, Guatemala, Honduras, Mexico, Nicaragua, Panama, Venezuela A cloud forest species which has come under considerable threat throughout its range. Logging, grazing, increasing settlement and agriculture have brought about large declines in the habitat and reduced populations largely to remote inaccessible places.

Assessor: SSC Conifer Specialist Group

Refs: 374, 730, 3047, 4665, 10217, 13041, 15037, 18751,19206

\section{Podocarpus lambertii}

Podocarpaceae

Argentina (Misiones), Brazil (Bahia, São Paulo)

Assessor: SSC Conifer Specialist Group

Refs: $374,5112,5410,16525,19127$

\section{Podocarpus laubenfelsii}

Podocarpaceae DD

Indonesia (Kalimantan)

Assessor: SSC Conifer Specialist Group

Refs: $374,6851,13041,17855$

Podocarpus lophatus

Podocarpaceae

VU D2

Philippines

Known only from two collections from a single locality, the species is confined to the summit of Mount Tapulao in Luzon. No recent reports have been made and it is not known whether the population is still extant.

Assessor: SSC Conifer Specialist Group

Refs: $374,11314,19192$

\section{Podocarpus matudai}

Podocarpaceae

El Salvador, Guatemala, Honduras, Mexico (Chiapas, Puebla, Veracruz)

Assessor: SSC Conifer Specialist Group

Refs: $374,4974,5470,8870,10217,13041$

\section{Podocarpus micropedunculatus}

Podocarpaceae DD Indonesia (Kalimantan), Malaysia (Sabah, Sarawak)

Assessor: SSC Conifer Specialist Group

Refs: $374,1766,6851,13041$

\section{Podocarpus nakaii}

Podocarpaceae

EN Alad, C2a

Taiwan

Endemic to Taiwan, the species is restricted to a small area in the centre of the island in Nan Ton County. Populations are small and isolated in areas of 
broadleaved evergreen forest up to $1000 \mathrm{~m}$, where they are under threat from increasing settlement, forest management and agricultural activities.

Assessor: Lu, S.Y. \& F.J. Pan

Refs: $374,2106,6469,11191,19050,19051$

\section{Podocarpus nubigenus}

Podocarpaceae

LR/nt

Argentina (Neuquén), Chile (Aisén, Los Lagos, Magallanes)

A common species of low- to medium-altitude forest. Where it occurs in southern Chile there is the constant threat of logging and commercial forestry activities, e.g. planting eucalypts and Monterey pine.

Assessor: SSC Conifer Specialist Group

Refs: $4665,5112,13041,15384$

\section{Podocarpus pallidus}

Podocarpaceae

Tonga

An endemic to the east Tongan Islands.

Assessor: SSC Conifer Specialist Group

Refs: $374,9695,13041$

\section{Podocarpus parlatorei}

Podocarpaceae

Argentina, Bolivia, Peru

A cloud forest species threatened mainly by loss of habitat, although also an important commercial timber. Populations in Argentina are very small and scattered. Their exact locations are kept undisclosed for better protection. The species is listed in Appendix I of *CITES.

Assessor: SSC Conifer Specialist Group

Refs: 374, 12453, 14040, 19127, 19179, 19185

\section{Podocarpus pendulifolius}

Podocarpaceae

DD

Venezuela

Assessor: SSC Conifer Specialist Group

Refs: 374, 5411, 13041

\section{Podocarpus polyspermus}

Podocarpaceae

VU B $1+2 c$

New Caledonia

Assessor: Jaffré, T. et al.

Refs: $6851,10351,12630$

\section{Podocarpus roraimae}

Podocarpaceae

Venezuela

The species occurs on Mount Roraima and the mountains lying on the border between Venezuela and Guyana. The area is protected, although it is under some pressure from tourism.

Assessor: SSC Conifer Specialist Group

Refs: $374,5411,12192,13041$

\section{Podocarpus rusbyi}

Podocarpaceae

Bolivia

Assessor: SSC Conifer Specialist Group

Refs: $374,13661,19127$

\section{Podocarpus salignus}

Podocarpaceae

VU A1d+2b

Chile (Bíobío, La Araucania, Los Lagos, Magallanes, Maule, O'Higgins)

A species which is said to occur abundantly in areas of low- to medium-altitude forest in the central Andes and Coastal Cordillera, extending from Maule to Los Lagos (Regions VII-X). The habitat has been extensively logged and replanted with eucalypts and Monterey pine. Several botanical visits to the area have failed to find a single large mature individual.

Assessor: SSC Conifer Specialist Group

Refs: $4522,13041,16328$

\section{Podocarpus sellowii}

Podocarpaceae

DD

Brazil (Paraná, Sāo Paulo)

Assessor: SSC Conifer Specialist Group

Refs: $374,16525,16884,19127$

\section{Podocarpus smithii}

Podocarpaceae

LR/ed

Australia (Queensland)

The entire population is contained within the State Forest Reserve on Mount Lewis near Mossman, where the species is scattered in montane rainforest in summit localities. Felting is illegal without permission.

Assessor: SSC Conifer Specialist Group

Refs: 374, 3404, 7891, 13041

\section{Podocarpus spathoides}

Podocarpaceae

$\mathrm{DD}$

Indonesia (Moluccas), Malaysia (Peninsular Malaysia), Papua New Guinea, Solomon Islands (South Solomon)

The species is known from occurrences on Mount Ophir in Peninsular Malaysia, Morotai in the north Moluccas, Rossel Island in the Louisiade Archipelago of Papua New Guinea, and the Solomon Islands.

Assessor: SSC Conifer Specialist Group

Refs: 374, 6851, 13041, 16612

\section{Podocarpus subtropicalis}

Podocarpaceae

DD

China (Sichuan, Yunnan)

The species is known only from Mount Omei in Sichuan and Yunnan.

Assessor: SSC Conifer Specialist Group

Refs: 374,13041

\section{Podocarpus urbanii}

Podocarpaceae

LR/nt

Jamaica

The species is common to locally dominant in the montane rainforests of the Blue Mountains. At very high altitudes it is one of the commonest trees. Large populations exist on the Grand Ridge and in southern catchments. It is less common where slopes are steep or unstable.

Assessor: Bellingham, $\mathrm{P}$.

Refs: $374,2479,5214,19116$

\section{Poecilanthe ovalifolia}

Leguminosae

VU D2 Suriname

A rainforest tree, known only from an area along the Tapanahony River.

Assessor: World Conservation Monitoring Centre Refs: 6493, 19196

\section{Poecilanthe parviflora}

Leguminosae

DD

Argentina (Buenos Aires, Misiones), Brazil

Information is limited, but indicates that the species is endemic to an area extending from northem Argentina 
into the Rio Uruguay valley in Brazil.

Assessor: Prado, D.

Refs: 1262,7134

\section{Poeciloneuron pauciflorum}

Guttiferae

$\mathrm{CR} \mathrm{B} 1+2 \mathrm{c}$

India (Kerala, Tamil Nadu)

This species was collected just two or three times in 19th century from areas of evergreen hill forest in Travancore and Tirunelveli. It was once a useful timber. The habitat has been severely reduced in extent and recent botanical surveys have failed to locate any specimens. It is not known for certain whether the species is now extinct. Assessor: World Conservation Monitoring Centre Refs: 4799,19144

\section{Polyalthia angustissima}

Annonaceae DD

Malaysia (Peninsular Malaysia), Singapore, Viet Nam? Occurring in lowland forest below $100 \mathrm{~m}$, this species is known from localities in Johore and Bukit Timah Forest Reserve in Singapore. More information is needed to consolidate the species' occurrence in Viet Nam.

Assessor: World Conservation Monitoring Centre

Refs: 9199, 11530, 17140, 19073

\section{Polyalthia elmeri}

Annonaceae

VU B1+2c

Philippines

This tree is endemic to Palawan, located in thin forests near seashore. The main island is a biosphere reserve. Assessor: World Conservation Monitoring Centre Refs: 4986

\section{Polyalthia glabra}

Annonaceae

$\mathrm{CR} B \mid+2 \mathrm{C}$

Malaysia (Peninsular Malaysia)

Known only from two herbarium specimens, this tree was collected in lowland forest. The localities, one in Penang and the other in Malacca, are no longer forested. Assessor: Kochummen, K.M.

Refs: 19073

\section{Polyalthia hirtifolia}

Annonaceae

CR B $1+2 \mathrm{c}$

Malaysia (Peninsular Malaysia)

A lowland forest species, known only from a single collection from Pulau Betong Reserve in Penang. The area is threatened by increasing settlement and it is not certain whether this species still exists.

Assessor: Kochummen, K.M.

Refs: 19073

\section{Polyalthia pachyphylla}

\section{Annonaceae}

Malaysia (Peninsular Malaysia)

A lowland forest tree, recorded only from Lant in Perak. Its exact location is unknown.

Assessor: Kochummen, K.M.

Refs: 8464, 19073

\section{Polyalthia palawanensis}

\section{Annonaceae}

VU B1+2c

Philippines

A tree endemic to Palawan, found on dry forested slopes at low altitude. The main island is a biosphere reserve. Assessor: World Conservation Monitoring Centre Refs: 4986
Polyalthia rufescens

Annonaceae

India (Kerala, Tamil Nadu)

EN B $1+2 c$

A timber-yielding species of evergreen hill forest in the southem end of the Western Ghats. Populations are recorded from Cochin and Travancore in Kerala and Tirunelveli in Tamil Nadu. Cutting of the trees and habitat clearance for the cultivation of commercial crops have caused population declines.

Assessor: World Conservation Monitoring Centre

Refs: 4799,19144

\section{Polyalthia shendurunii}

Annonaceae

$\mathrm{EN} \mathrm{B1}+2 \mathrm{c}$

India (Kerala)

A medium-sized tree collected only from a small area of submontane evergreen forest in the Agastyamalai Hills on the Kerala/Tamil Nadu border. Large areas have been exposed to fires, grazing, the establishment of commercial plantations and cutting for fuelwood, but almost $1000 \mathrm{~km}^{2}$ of forest are now under protection within sanctuaries.

Assessor: World Conservation Monitoring Centre

Refs: 19144

\section{Polyceratocarpus scheffleri}

Annonaceae

VU $B 1+2 b$

Tanzania

Until recently this tall tree was known only from a few collections from the East Usambara Mountains. It has been subsequently discovered, in small populations, on the northern Uluguru and Udzungwa Mountains.

Assessor: Lovett, J. \& G.P. Clarke

Refs: $3356,5204,9302,11631$

\section{Polylepis besseri ssp. besseri}

\section{Rosaceae}

VU Alacd, B1+2c Bolivia

A subspecies which frequently hybridises with related species. It is confined to Cochabamba and Chuquisaca, where it occurs in small stands totalling no more than a few tens of square kilometres between 3000 and $4100 \mathrm{~m}$. Buming activities, combined with overgrazing, soil erosion and firewood collection, continue to have a serious impact on remaining populations.

Assessor: World Conservation Monitoring Centre

Refs: $3104,19020,19067$

\section{Polylepis besseri ssp. incarum}

Rosaceae

VU B $1+2 c$

Bolivia, Peru

A small tree growing in large stands on limestone hills, confined mainly to the northern part of the Titicaca basin, where it is the only naturally occurring Polylepis. Other Polylepis species have been planted in the area and the subspecies readily hybridises with $P$. racemosa ssp. iriacontandra. Populations in Bolivia may all be planted. It has been estimated that the stands cover $166 \mathrm{~km}^{2}$ in total. Growth rates are fast and the tree is a good candidate for reforestation programmes.

Assessor: World Conservation Monitoring Centre Refs: 3104, 19067

\section{Polylepis besseri ssp. subtusalbida}

Rosaceae

VU Alacd, B1+2c

Bolivia

This subspecies is variable and readily hybridises with other Polylepis in its range. It is endemic to areas of 
montane forest above $3000 \mathrm{~m}$ in central Bolivia. Fires and overcutting are the main causes of concern. Assessor: World Conservation Monitoring Centre Refs: $3104,19020,19067$

\section{Polylepis crista-galli}

Rosaceae

VU Alacd, B1+2c

Bolivia

This species was included within $P$. besseri. It is believed to be of hybrid origin. Small stands, totalling less than $100 \mathrm{~km}^{2}$ in area, occur in central to south-east Bolivia above $3200 \mathrm{~m}$. At lower elevations, down to $2500 \mathrm{~m}$, it is found in mixed Podocarpus-Alnus forest. Assessor: World Conservation Monitoring Centre Refs: $3104,19020,19067$

\section{Polylepis hieronymi}

Rosaceae

VU B1+2c Argentina, Bolivia

A small tree occurring in restricted areas of Podocarpus-Alnus forest in central and south-east Bolivia and north-west Argentina. Unusually for the genus, it readily colonises open and disturbed areas, where it is soon supplanted by slower-growing trees. This characteristic makes it useful in the reclamation of eroded slopes.

Assessor: World Conservation Monitoring Centre Refs: $3104,6802,19067$

\section{Polylepis incana}

Rosaceae

VU Alacd

Colombia? (Colombia?), Ecuador, Peru

The species' distribution is disjunct, ranging from north and central Ecuador to Ayacucho in Peru. Occurrences in Colombia and Bolivia are based on taxonomic misconceptions. Trees occur in small stands, pure or mixed with other Polylepis species, above $3300 \mathrm{~m}$. In all parts of the range the forests are severely affected by burning, as well as cutting for firewood and charcoal production. Commercial logging of this species, along with $\boldsymbol{P}$. weberbaueri, has taken place within the boundaries of Huascarán National Park. The destruction of Polylepis forest in Huancavelica, Ayacucho and Cuzco has been particularly thorough.

Assessor: World Conservation Monitoring Centre Refs: $1653,3104,6802,19020,19067$

\section{Polylepis lanuginosa}

Rosaceae

VU $B 1+2 c$

Ecuador

An endemic tree of cloud forest in the Ecuadorean High Andes, currently known to occur between 2750 and $3500 \mathrm{~m}$ in Bolivar, Chimborazo, Cañar and Azuay Provinces.

Assessor: World Conservation Monitoring Centre Refs: 19119,19120

\section{Polylepis microphylla}

Rosaceae

VU B $1+2 c$

Ecuador

A cloud forest shrub, growing to $30 \mathrm{~cm}$ in height, endemic to Bolivar Province in the Ecuadorean High Andes.

Assessor: World Conservation Monitoring Centre

Refs: 16239,19119
Polylepis multijuga

Rosaceae

VU B1 $+2 c, D 2$

Peru

The most primitive member of the genus, confined to two main locations, Chachapoyas in Amazonas, and northern Cajamarca. It occurs locally in humid montane forest.

Assessor: World Conservation Monitoring Centre

Refs: $1653,3104,6802,19067$

\section{Polylepis neglecta}

Rosaceae

VU Alacd, B1+2c

Bolivia

Recently discovered, the species occurs in more humid areas of Podocarpus-Alnus forest, mainly in the Chuquisaca and Cochabamba area. It rarely forms the dominant component. Continual buming of large areas of vegetation, firewood collection and charcoal production are causing the decline of these forests. Assessor: World Conservation Monitoring Centre Refs: $3104,19020,19067$

\section{Polylepis pauta}

Rosaceae

VUAlc

Ecuador, Peru

The tallest of the Polylepis species. It is restricted to remaining small areas of mixed montane forest between 1800 and $3600 \mathrm{~m}$ in northern Ecuador and in small areas of eastern central and south Peru. The habitat is threatened mainly by fires, which are lit to support grazing and which frequently encroach upon forested areas.

Assessor: World Conservation Monitoring Centre Refs: $3104,6802,12268,19067$

\section{Polylepis pepei}

Rosaceae

VU Alc

Bolivia, Peru

A small tree or shrub, rare and confined to a series of localities stretching along the eastern slope of the Cordillera Real from south-east Peru to north-east Bolivia, in the transition zone between humid montane forests and *puna grasslands. Its habitat is highly vulnerable to local activities, especially the fires which are induced to support grazing and which frequently encroach upon forested areas.

Assessor: World Conservation Monitoring Centre Refs: $1653,3104,6802,19067$

\section{Polylepis racemosa}

Rosaceae

VU Alc

Peru

This is a variable species known from restricted areas of humid montane forest, occuming from northem Peru to north-west Bolivia. Subspecies in Bolivia are described separately. In the northem part of the range specimens are almost exclusively cultivated. Natural stands occur from Huánuco southwards, generally above $3200 \mathrm{~m}$. The habitat has greatly declined because of continual buming, cutting for firewood and charcoal production. This species is fast-growing, more ecologically adaptable than others in the genus and a promising candidate for reforestation and agroforestry.

Assessor: World Conservation Monitoring Centre Refs: $3104,6802,12268,19067$ 


\section{Polylepis racemosa ssp. lanata}

Rosaceae

VU B1+2c, D2

Bolivia

This subspecies intergrades and hybridises with ssp. triacontandra. It is known only from the wetter parts of the Cordillera Tunari in Cochabamba, where it can form a dominant element of the vegetation. The continual buming of vegetation is clearly causing the decline in the extent of the forest.

Assessor: World Conservation Monitoring Centre Refs: 3104, 19067

\section{Polylepis racemosa ssp. triacontandra}

Rosaceae

$\mathrm{VU} \mathrm{B} 1+2 \mathrm{c}, \mathrm{D} 2$

Bolivia

This subspecies intergrades and hybridises with ssp. lanasa. It occurs within a small range above $3600 \mathrm{~m}$, at the upper limit of the humid montane forest in the Cordillera de Apolobamba. It is a fast-growing and frequently planted tree. Continual burning, as well as cutting for firewood and charcoal production, are causing declines in the extent of the forest.

Assessor: World Conservation Monitoring Centre Refs: 3104, 19067

\section{Polylepis reticulata}

Rosaceae

VU B $1+2 \mathrm{C}$

Ecuador

This Ecuadorean endemic inhabits cloud forest between 2850 and $4300 \mathrm{~m}$ in Napo, Pichincha, Tungurahua, Chimborazo, and Azuay Provinces.

Assessor: World Conservation Monitoring Centre

Refs: 16239,19119

\section{Polylepis rugulosa}

Rosaceae

VUAlc

Chile, Peru

Small and dispersed patches of the species occur in arid regions above $3400 \mathrm{~m}$ from Arequipa, Moquegua, Tacna and possibly Puno into northem Chile. It is generally the only tree in the area. The extent of the habitat is declining, with constant overgrazing and overcutting for firewood and charcoal production.

Assessor: World Conservation Monitoring Centre Refs: 3104, 19067

\section{Polylepis subsericans}

Rosaceae

VU Alacd, Bl+2c

Peru

Locally the species forms dense forest patches above $3400 \mathrm{~m}$, concentrated in Lima and adjacent Ica, extending into restricted areas further east. Declines in the extent of the forest are being caused largely by buming and charcoal production.

Assessor: World Conservation Monitoring Centre

Refs: $3104,6802,12268,19020,19067$

\section{Polylepis tarapacana}

Rosaceae

$\mathrm{LR} / \mathrm{nt}$

Argentina?, Bolivia, Chile, Peru

A small tree or shrub found only in sparse and scattered stands in the volcanic Westem Cordillera in the border regions of Bolivia, Peru and Chile. It is probably the only tree in the world growing up to altitudes of $5200 \mathrm{~m}$. Locally it is of great importance as a source of firewood and even of construction timber. Populations seriously declined in the past (more than three generations ago) but their present status appears to be stable.

Assessor: World Conservation Monitoring Centre Refs: $3104,6802,7980,19020,19067$

\section{Polylepis tomentella ssp. incanoides} Rosaceae

VU B1+2c, D2

Bolivia

A common tree, usually dominating, in a small area of forest, totalling about $20 \mathrm{~km}^{2}$, between 2500 and $3400 \mathrm{~m}$ in the Cochabamba area. Buming activities are a major threat to the habitat.

Assessor: World Conservation Monitoring Centre

Refs: 3104,19067

\section{Polylepis tomentella ssp. nana}

Rosaceae

$\mathrm{CR} \mathrm{B} 1+2 \mathrm{c}, \mathrm{C} 2 \mathrm{~b}$

Bolivia

A tiny shrub found in a very restricted mountainous locality, south-east of Cochabamba in northern central Bolivia. It occurs in degradod woodland, covering an area of just 75 ha, where it is affected by firewood collection and domestic grazing.

Assessor: World Conservation Monitoring Centre Refs: 3104,19020

\section{Polylepis tomentella ssp. tomentella}

Rosaceae

LR/nt

Bolivia

A variable subspecies. It is relatively widespread, occurring in dispersed stands between 3200 and $4500 \mathrm{~m}$ in south-east Bolivia extending into north-west Argentina. There are some large stands, up to $60 \mathrm{~km}^{2}$ in area, growing on lava and pumice where they are safe from buming.

Assessor: World Conservation Monitoring Centre

Refs: $3104,19020,19067$

\section{Polylepis weberbaueri}

Rosaceae

VU Alacd

Ecuador, Peru

The distribution of this species is disjunct. Populations occur in humid montane forest above $3000 \mathrm{~m}$ in central and south-west Ecuador, and in Peru in the north-west and further south in the Cordillera Blanca and CuzcoApurimac area. The species is particularly sensitive to buming. A forest covering $20 \mathrm{~km}^{2}$ in Cuzco was completely destroyed by burning two years ago. Remaining stands are almost exclusively reduced to boulder-scree, stream ravines and rock ledges, where they are sheltered from most fires. Both this species and $P$. incana are being logged inside Huascarán National Park.

Assessor: World Conservation Monitoring Centre Refs: $3104,6802,12268,19020,19067$

\section{Polyscias aemiliguineae}

Araliaceae

CR Alc, $\mathrm{Cl}+2 \mathrm{a}$

Réunion

Assessor: Strahm, W.

Refs: $12470,16426,19208$

\section{Polyscias dichroostachya}

Araliaceae

$\mathrm{EN} \mathrm{Alc+2e}$

Mauritius

Similar to Tabemaemontana persicarifolia but rarer, the species is found in small numbers in remaining dry forest.

Assessor: Strahm, W.

Refs: $9120,16426,19208$ 
Polyscias farinosa

Araliaceae

LR/nt

Ethiopia

A tree known as the baboon's chair. It appears to be confined to woodland along river systems. Although it is distributed in an area heavily influenced by agricultural activities and the expansion of the human population, regeneration is apparently good.

Assessor: World Conservation Monitoring Centre

Refs: $1330,4505,18523$

\section{Polyscias gracilis}

Araliaceae

CR D1

Mauritius

A small solitary tree occurring in Mondrain, Tamarind Falls and Piton du Fouge Ridge Forest. These areas are heavily invaded by exotic plants and animals. Regeneration is poor and the number of adult trees is estimated to be less than 20. The species has been propagated and reintroduced into Mondrain Nature Reserve.

Assessor: Page, W.

Refs: $1411,9120,16426$

\section{Polyscias kikuyuensis}

Araliaceae

VU B $1+2 c$

Kenya

Scattered in distribution but confined to wet upland forest in central Kenya, this species is highly valued at a national level for its timber. Exploitation and habitat loss have led to the species becoming rarer. The Kenyan Forestry authorities maintain plantations of it and also sell the seed. Populations in Mount Kenya National Park and other forest reserves are legally protected. Assessor: World Conservation Monitoring Centre Refs: $1308,6396,17859$

\section{Polyscias mauritiana}

Araliaceae

EN Alce

Mauritius

Assessor: Strahm, W.

Refs: $9120,16426,19208$

\section{Polyscias neraudiana}

Araliaceae

CR D1

Mauritius

A small tree known from fewer than 15 adult individuals, confined to plateau regions and the flanks of the northern mountain range, including Le Petrin Nature Reserve. The habitat is highly degraded and invaded by exotic species. Although seed production has been observed, there is no regeneration. The population in Le Petrin is fenced and weeded of exotic plants.

Assessor: Page, W

Refs: $1411,9120,16426$

\section{Polyscias nothisii}

Araliaceae

VU B $1+2 c$

New Caledonia

Assessor: Jaffré, T. et al.

Refs: 3356, 10351

\section{Polyscias paniculata}

Araliaceae

EN Alce

Mauritius

Assessor: Strahm, W.

Refs: $9120,16426,19208$

\section{Polyscias quintasii}

Araliaceae

São Tomé \& Príncipe (Príncipe, São Tomé)

An upland forest tree known from a few sites above $1000 \mathrm{~m}$ on Morro Claudino. Regeneration is reported to be very feeble or non-existent in the five sites where it has been studied. It yields a timber but not of great importance.

Assessor: World Conservation Monitoring Centre Refs: 2724, 19042, 19111

Polyscias stuhlmannü var. inarticulata

Araliaceae

VU $B 1+2 b$

Tanzania

A doubtful variety of a restricted-range species. It is scarce and confined to cloud forest at Shume-Mugamba in the West Usambara Mountains. The area has been extensively converted to agriculture.

Assessor: Lovett, J. \& G.P. Clarke

Refs: $3356,5204,8221$

\section{Polyscias stuhlmannii var. stuhlmannï}

Araliaceae

VU $B 1+2 b$

Kenya, Tanzania

This species occurs in the west Usambara and Uluguru Mountains and Teita. Threats exist from localised habitat degradation and changes in land use and management. The Usambara Mountains are the focus of a conservation programme. The split into two varieties may not be warranted.

Assessor: Lovett, J. \& G.P. Clarke

Refs: $3356,6396,12067$

\section{Polyscias tahitensis}

Araliaceae

French Polynesia (Society Is.)

$\mathrm{CR} B 1+2 \mathrm{c}$

An endemic of Raiatea and Tahiti.

Assessor: Florence, J.

Refs: 14513

\section{Polysphaeria macrantha}

Rubiaceae

VU B $1+2 b$

Tanzania

Endemic to the East Usambara Mountains, this small tree occurs in moist evergreen forest at medium elevations.

Assessor: Lovett, J. \& G.P. Clarke

Refs: 3356,10961

\section{Pomaderris hamiltonii}

Rhamnaceae

LR/nt

New Zealand (North Is.)

A small tree occurring sparsely in the North Island. Assessor: de Lange, P.J.

Refs: 902, 19133

\section{Pongamia velutina}

Leguminosae

VU B $1+2 c, C 2 a$

Papua New Guinea

A tree occurring in monsoon forest, Eucalyptus savanna and swamps near mangroves along the coast of the Central Province. Its restricted distribution, coupled with local exploitation, renders the species vulnerable. Assessor: Eddowes, P.J.

Refs: 19114 
Pongamiopsis amygdalina

Leguminosae

Madagascar

$\mathrm{EN} \mathrm{B1+2abc}$

Known from only two localities, this deciduous woodland species occurs in limestone areas in the Ankarana Massif and Montagne des Français in north Madagascar. Its range extends less than $300 \mathrm{~km}^{2}$ (*AO0). Populations near Antsiranana are declining as a result of forest degradation and selective felling.

Assessor: Du Puy, D. \& H. Labat

Refs: 12353

\section{Pongamiopsis viguieri}

Leguminosae

VU B 1 +2abc

Madagascar

This species is restricted to limestone outcrops in Namoroka and Bemaraha in west Madagascar. Covering an estimated $2000 \mathrm{~km}^{2}\left({ }^{*} \mathrm{AOO}\right)$, the population is declining, especially in the northern extremity (Mahajunga), where it may now be extinct.

Assessor: Du Puy, D. \& H. Labat

Refs: 12353

\section{Popowia beddomeana}

Annonaceae

$\mathrm{EN} \mathrm{B1+2c}$

India (Kerala, Tamil Nadu)

A species confined to wet evergreen forest on the upper slopes of the Agastyamalai Hills at the southem end of the Western Ghats. It grows mostly in inaccessible and undisturbed areas. Some parts have been exposed to fires, grazing, the establishment of commercial plantations and cutting for fuelwood, but almost $1000 \mathrm{~km}^{2}$ forest are now under protection within sanctuaries.

Assessor: World Conservation Monitoring Centre

Refs: 2538, 19144

\section{Popowia pauciflora}

Annonaceae

$\mathrm{CR} B 1+2 \mathrm{c}$

Malaysia (Peninsular Malaysia)

A tree known only from the type collection, found in lowland forest in Malacca. It is uncertain whether this species is still surviving.

Assessor: Kochummen, K.M.

Refs: 19073

\section{Popowia velutina}

Annonaceae

Malaysia (Peninsular Malaysia)

A rare lowland forest tree known only from two collections from Gopeng in Perak. It is uncertain whether the species is still surviving as the locality from which it was collected has recently been developed.

Assessor: Kochummen, K.M.

Refs: 19073

\section{Populus guzmanantlensis}

Salicaceae

$\mathrm{EN} \mathrm{B} 1+2 \mathrm{c}$

Mexico (Jalisco)

So far the species is known only from the southem part of the Sierra de Manantlan in Casimiro Castillo, Cuautitlán and Tuxcacyexco, growing in semi-deciduous forest between 800 and $900 \mathrm{~m}$.

Assessor: World Conservation Monitoring Centre

Refs: 15436,19068

\section{Populus ilicifolia}

Salicaceae

Kenya, Tanzania

VU B $1+2 c$

Restricted to the Tana, Athi and Uaso-Nyiro river systems in Kenya and the Ruvu river system of Tanzania, this species is one of the dominant components of riparian forest. The habitat is greatly reduced and the species is notably scarcer. Seed crops are frequently washed away in annual floods after vegetation clearance. In Kenya the habitat has also been widely irrigated and cleared for settlement programmes. On a local scale the species provides a wood preferred for making dug-out canoes.

Assessor: World Conservation Monitoring Centre Refs: 4506, 6396, 10961

\section{Populus mexicana ssp. mexicana}

Salicaceae VU Alc

Mexico (Chiapas, Oaxaca, Tabasco, Veracruz)

A relatively widespread endemic, occurring in rainforest in the Gulf and Pacific regions.

Assessor: World Conservation Monitoring Centre Refs: 5993,17609

\section{Portlandia albiflora}

Rubiaceae

Jamaica

A small tree or shrub known only from one locality in St Andrews on limestone rocks and cliffs. Similar specimens come from other parts of the island but their identity has not been confirmed.

Assessor: World Conservation Monitoring Centre

Refs: 5653,7980

\section{Portlandia grandiflora}

Rubiaceae

LR/nt

Jamaica

This species is fairly common but confined to thickets and woodlands on limestone. It is cultivated as an omamental in the Old World.

Assessor: World Conservation Monitoring Centre

Refs: 6057,7980

\section{Portlandia harrisii}

Rubiaceae

VU Bl+2c

Jamaica

Recorded from Clarendon and St Ann Parishes, this small tree or shrub occurs locally in thickets and open woodland on limestone.

Assessor: Kelly, D.L.

Refs: 5653,19085

\section{Potameia lotungensis}

Lauraceae

VU B $1+2 c$

China (Guangdong - Hainan), Viet Nam

In Viet Nam the species is very rare, occurring only between 900 and $1200 \mathrm{~m}$ in Tam Dao in Vinh Phu in the north. On Hainan Island there are records of the species in Lo Tung.

Assessor: World Conservation Monitoring Centre Refs: 848

\section{Poupartia borbonica}

Anacardiaceae

CR C2a

Mauritius, Réunion

The Mauritian population is known from fewer than five adult trees found in dry deciduous forest at the bases of the Chamarel range, Mont Briseé and Mont Creole. The species has also been propagated and reintroduced into 
Mondrain Nature Reserve. A few plants are grown in a nursery and elsewhere on lle aux Aigrettes. Information is required on the population in Réunion.

Assessor: Page, W.

Refs: $1411,9120,16426$

\section{Poupartia pubescens}

Anacardiaceae

EN C2a

Mauritius

Occurring as an occasional species in the south-west and lower eastern mountain ranges, fewer than 250 adult trees are believed to exist. Browsing of the seedlings by exotic deer is limiting regeneration.

Assessor: Page, W.

Refs: $1411,9120,16426$

\section{Pourouma hirsutipetiolata ssp. hirsutipetiolata}

Cecropiaceae

VU B $1+2 c$

Colombia

Assessor: Calderon, E.

Refs: 7980,19069

\section{Pourouma melinonii ssp. glabrata}

Cecropiaceae

Colombia, Panama

Assessor: Calderon, E.

Refs: 7980,19069

\section{Pourouma oraria}

Cecropiaceae

VU C1

Colombia, Panama, Peru

In Panama only two old collections are known but localities are unspecified. More recently the species has been identified in Colombia, occurring quite commonly in primary forest in Chocó, Boyacá, Valle and other regions. The species has been recorded in Peru, but not frequently. The habitat is declining through much of the species' distribution as a result of increasing settlement.

Assessor: Mitré, M.

Refs: $7272,7980,10481,16772$

Pouteria alnifolia var. sacleuxii

Sapotaceae

VU B $1+2 \mathrm{c}$

Tanzania

A variety endemic to Zanzibar Island. It occurs in small areas of moist semi-deciduous forest.

Assessor: Lovett, J. \& G.P. Clarke

Refs: 3356,8814

\section{Pouteria altissima}

Sapotaceae

LR/cd

Burundi, Cameroon, Central African Republic, Congo, Côte d'Ivoire, Democratic Republic of Congo, Ethiopia, Gabon, Ghana, Guinea, Kenya, Nigeria, Rwanda, Sierra Leone, Sudan, Tanzania, Uganda

Occurring in drier areas of semi-deciduous forest, this timber species is widespread throughout the African tropics. The species provides a general-purpose timber and is overexploited in parts of its range. In the timber industry, it is frequently confused with Aningeria robusta (now $P$. aningeri).

Assessor: African Regional Workshop

Refs: $2361,6128,6396,8369,10961,16021$

\section{Pouteria amapaensis}

Sapotaceae

A treelet newly described as a species and, at present,

known only from upland dry forest in Amapá.

Assessor: Pires O'Brien, J.

Refs: $1983,7980,8816$

\section{Pouteria amygdalina}

Sapotaceae

VU B $1+2 c$

Belize, Guatemala

The only certain occurrences of this tree are recorded in Petén in Guatemala and adjacent parts of Belize. The species is found in seasonal semi-evergreen forest over limestone in sites up to $800 \mathrm{~m}$.

Assessor: World Conservation Monitoring Centre

Refs: 8816

\section{Pouteria andarahiensis}

Sapotaceae

$\mathrm{EN} \mathrm{B} 1+2 \mathrm{~b}$

Brazil (Bahia)

At present, the Mucugê region of Bahia is the only site where this species is known. Logging is the most serious threat to its dry forest habitat.

Assessor: Pires O'Brien, J.

Refs: $1983,7980,8816$

\section{Pouteria anteridata}

Sapotaceae

LR/nt

Venezuela

A newly described species of northern Venezuela. Collections have been made from several localities of lowland rainforest in Barinas, Falcón, Yaracuy and Zulia.

Assessor: World Conservation Monitoring Centre Refs: 7980,8816

\section{Pouteria arcuata}

Sapotaceae

VU D2

Venezuela

This species is known only from the site where it was first collected in lowland rainforest in Amazonas.

Assessor: World Conservation Monitoring Centre Refs: 7980,8816

\section{Pouteria areolatifolia}

Sapotaceae

Guatemala

VU D2

Confined to La Cumbre in Petén, the species is found in lowland seasonal semi-evergreen forest.

Assessor: World Conservation Monitoring Centre

Refs: 7980,8816

\section{Pouteria arguacoensium}

Sapotaceae

$\mathrm{VU} B 1+2 \mathrm{c}, \mathrm{D} 2$

Colombia

A species which appears to be confined to a restricted area on the slopes of the Sierra Nevada de Santa Marta in Cesar. It is restricted to montane rainforest between 1300 and $2300 \mathrm{~m}$.

Assessor: Calderon, E.

Refs: $7980,8816,19069$

\section{Pouteria aristata}

Sapotaceae

VU B1+2c

Cuba

A shrub or small tree of coastal thickets and dry thickets on limestone hills. It has been recorded from the provinces of Pinar del Rio, Habana and Oriente and an unconfirmed report suggests it is also present in Las 
Villas. The species is rarely seen today because of extensive habitat degradation.

Assessor: Areces-Mallea, A.E.

Refs: 7980, 8816, 19149

\section{Pouteria atabapoensis}

Sapotaceae

LR/nt

Brazil (Amazonas), Venezuela

Only a few collections of this species are known. They originate from the Rio Negro above Manaus in Amazonas, Brazil, and from further north along Rio Atabapo in Amazonas, Venezuela.

Assessor: World Conservation Monitoring Centre

Refs: 7980,8816

\section{Pouteria austin-smithii}

Sapotaceae

VU D2

Costa Rica

A cloud forest species, endemic to Costa Rica and recorded from a few sites in Alajuela and Cartago. Assessor: World Conservation Monitoring Centre Refs: 7980,8816

\section{Pouteria bapeba}

Sapotaceae

VU B1 $+2 c, D 2$

Brazil (Bahia)

A tree species which is known only from the coastal rainforest of Bahia.

Assessor: Pires O'Brien, J.

Refs: $1983,7980,8816$

\section{Pouteria beaurepairei}

Sapotaceae

$\mathrm{LR} / \mathrm{cd}$

Brazil (Paraná, Rio de Janeiro, Santa Catarina, São Paulo)

A lowland rainforest treelet, confined to an area where logging activities are intense. A population is known to occur in Ilha do Cordosa State Park in Sāo Paulo.

Assessor: Pires O'Brien, J.

Refs: $1983,7980,8816$

\section{Pouteria belizensis}

Sapotaceae

VU B $1+2 c$

Belize, Guatemala, Mexico

A tree known from few collections. Occurrences have been recorded in Tabasco, from Lake Izabal and the Subin River in Guatemala and from an unknown locality in Belize.

Assessor: World Conservation Monitoring Centre

Refs: 8816

\section{Pouteria benai}

Sapotaceae

VU D2

French Guiana

Presumably a lowland forest species, known only from two collections.

Assessor: World Conservation Monitoring Centre

Refs: 7980,8816

\section{Pouteria bonneriana}

Peru

This species is known from just two collections from the Cerros Campanquiz in Loreto.

Assessor: World Conservation Monitoring Centre Refs: 7980,8816

\section{Pouteria bracteata}

Sapotaceae

$\mathrm{EN} \mathrm{B1}+2 \mathrm{c}$ Colombia

A large tree, newly described as a species and so far known with certainty only from the site where the type specimen was collected in montane forest on the Pacific slopes of Colombia in Valle. It is a large tree. Collections do not seem to have been made in the last 50 years. A second specimen is similar but only tentatively grouped with this species.

Assessor: Calderon, E.

Refs: $7980,8816,19069$

\section{Pouteria brevensis}

Sapotaceae

EN B $1+2 d$

Brazil (Pará)

Known only from a few collections in Breves, Marajo, this species is confined to non-flooded forest. Increasing settlement of the area poses the most serious threat.

Assessor: Pires O'Brien, J.

Refs: $1983,7980,8816$

\section{Pouteria brevipetiolata}

Sapotaceae

VU D2

Ecuador

A newly described species currently known only from the type collection from El Oro on steep forested slopes at about $800 \mathrm{~m}$.

Assessor: World Conservation Monitoring Centre

Refs: 7980,8816

\section{Pouteria briocheoides}

Sapotaceae

VU D2

Guatemala

Confined to a single known population in $\mathrm{La}$ Cumbre in Petén, the species is a component of seasonal semievergreen forest dominated by Manilkara zapota. Assessor: World Conservation Monitoring Centre Refs: 7980,8816

\section{Pouteria buenaventurensis}

\section{Sapotaceae}

Colombia, Panama

Ranging from sea level to $2000 \mathrm{~m}$, the species occurs in two main areas of wet rainforest: one in Panama in adjacent Colón and Panamá Provinces, the other in Colombia on the Pacific side in Norte de Santander and Valle.

Assessor: World Conservation Monitoring Centre

Refs: 8816

\section{Pouteria bullata}

Sapotaceae

VU B $1+2 c$

Brazil (Paraná, Rio de Janeiro, Sāo Paulo)

A tree which is restricted to coastal rainforest, up to $900 \mathrm{~m}$. Relatively few collections have been made and the continuing clearance of the habitat poses a serious threat to any remaining populations. The fruit is harvested locally.

Assessor: Pires O'Brien, J.

Refs: $1983,7980,8816$

\section{Pouteria butyrocarpa}

Sapotaceae

$\mathrm{EN} B 1+2 \mathrm{~b}$

Brazil (Bahia, Espírito Santo)

A large tree confined to a small area of wet coastal 
forest between southern Bahia and Espírito Santo. It is harvested locally for the fruit, oil and wood.

Assessor: Pires O'Brien, J.

Refs: $1983,7980,8816$

\section{Pouteria calistophylla}

Sapotaceae

VU B $1+2 c$

Costa Rica, Panama

Occurring in remnants of lowland forest, the species is scattered in several localities in Costa Rica and Panama.

Assessor: World Conservation Monitoring Centre

Refs: 8816

\section{Pouteria canaimaensis}

Sapotaceae

LR/nt

Venezuela

A shrub or small tree, which is known from a few sites of shrub savanna and periodically flooded areas in Bolívar.

Assessor: World Conservation Monitoring Centre Refs: 7980,8816

\section{Pouteria capacifolia}

Sapotaceae

LR/nt

Ecuador

Confined to areas of lowland rainforest up to $700 \mathrm{~m}$, the species is found in a small area of Pacific Ecuador in Los Ríos, where it is recorded from Río Palenque Biological Station, and Pichincha. It is sometimes very common in pasture, where it is protected as a shade tree. Assessor: World Conservation Monitoring Centre Refs: 7980,8816

\section{Pouteria chiricana}

Sapotaceae

VU D2

Panama

Information on this species may not be complete. Collections have been made from the provinces of Chiriqui and the Canal Zone from remaining areas of wet lowland forest. There is a possibly erroneous record from Costa Rica in the Flora of Panama checklist. Assessor: World Conservation Monitoring Centre Refs: 8816

\section{Pouteria chocoensis}

Sapotaceae

DD

Colombia

There is very little information on this species, there being only a single incomplete herbarium specimen. It was found in tall rainforest in the Chocó region in 1946. Assessor: World Conservation Monitoring Centre Refs: 7980,8816

\section{Pouteria cicatricata}

Sapotaceae

LR/nt

Brazil (Amazonas, Rondônia)

A newly described species. Historial collections indicate the species' range to be greater than $20,000 \mathrm{~km}^{2}$. More recent collections suggest there has been a reduction in this area.

Assessor: Pires O'Brien, J.

Refs: $1983,7980,8816$

\section{Pouteria cinnamomea}

Sapotaceae

$\mathrm{CR} B 1+2 \mathrm{c}$

Peru

Information on the species is poor. It is known only from the type collection made at the tum of the century in Cuzco, where it occurred in subxerophilous forest.
Much of the vegetation in the area is under threat from buming and clearance. The current status of the species, if it is still extant, is unknown.

Assessor: World Conservation Monitoring Centre Refs: 7980,8816

\section{Pouteria coelomatica}

Sapotaceae

Brazil (Bahia)

$\mathrm{EN} \mathrm{BI}+2 \mathrm{c}$

The type collection occurs in a farming area and is the only known occurrence of this species.

Assessor: Pires O'Brien, J.

Refs: $1983,7980,8816$

\section{Pouteria collina}

Sapotaceae

Colombia, Ecuador

VU D2

A Pacific coast tree with two populations, occurring in lowland rainforest in the Valle del Cauca in Colombia and from submontane rainforest in Alto Tambo in Esmeraldas in Ecuador.

Assessor: World Conservation Monitoring Centre Refs: 7980,8816

\section{Pouteria congestifolia}

Sapotaceae

VU B $1+2 c$

Costa Rica, Panama

Occurring in montane rainforest, the species is found along the continental divide of Costa Rica and Panama. Collections have been made from more than five localities in Alajuela, Cartago and Heredia in Costa Rica and in Chiriqui and Cocle in Panama.

Assessor: World Conservation Monitoring Centre Refs: 7980,8816

\section{Pouteria crassiflora}

Sapotaceae

VU B1+2c, D2

Brazil (Amapá)

A species which is known only from Amapá in nonflooded forests. The most serious threat to the species is logging.

Assessor: Pires O'Brien, J.

Refs: $1983,7980,8816$

\section{Pouteria cubensis}

Sapotaceae

$\mathrm{EN} B 1+2 \mathrm{C}$

Cuba

A Cuban endemic confined to seasonal rainforest and the lowest elevation wet montane rainforest in the Sierra Maestra mountain range between 200 and $900 \mathrm{~m}$. The habitat of this rare tree has been degraded in many places.

Assessor: Areces-Mallea, A.E.

Refs: $7980,8816,19149$

\section{Pouteria decussata}

Sapotaceae

$\mathrm{EN} \mathrm{B} 1+2 \mathrm{c}$

Brazil (Pará)

A few collections of this dry forest tree are known from north-west Para. Records show it occurs in some abundance in Jari on terraced hills, but its distribution is highly restricted.

Assessor: Pires O'Brien, J.

Refs: $1983,7980,8816$

\section{Pouteria dictyoneura ssp. dictyoneura}

Sapotaceae

VU B $1+2 c$

Cuba

The Cuban form of a Caribbean species, occurring 
infrequently in remaining areas of lowland semideciduous forest over limestone. The tree has been overexploited for its valuable timber and a great part of its habitat has been deforested.

Assessor: Areces-Mallea, A.E.

Refs: $7980,8816,19149$

\section{Pouteria espinae}

Sapotaceae

CR B $1+2 \mathrm{c}$

Colombia

This species is apparently confined to a small area of Magdalena on the slopes of the Santa Marta range, where it occurs in montane forest above $2000 \mathrm{~m}$.

Assessor: Calderon, E.

Refs: 7980, 8816, 19069

\section{Pouteria euryphylla}

Sapotaceae

CR B $1+2 \mathrm{C}$

Panama

Known only from the type collection, the species is recorded from rainforest at about $275 \mathrm{~m}$ in Chiriquí. Assessor: World Conservation Monitoring Centre Refs: 7980,8816

\section{Pouteria exstaminodia}

Sapotaceae

$\mathrm{EN} \mathrm{Bl}+2 \mathrm{~b}$

Brazil (Amapá)

A newly described species, at present known only from the site where it was first collected in non-flooded forest along River Vatuma.

Assessor: World Conservation Monitoring Centre

Refs: $1983,7980,8816$

\section{Pouteria filiformis}

Sapotaceae

VU D2

Costa Rica

A newly described species, so far known only from the type gathering in Limón in Allantic rainforest in the Hitoy Cerere Biological Reserve.

Assessor: World Conservation Monitoring Centre

Refs: 7980,8816

\section{Pouteria fossicola}

Sapotaceae

VU Bl $+2 \mathrm{c}$

Costa Rica, Panama

Distributed from central Costa Rica to central Panama, the species occurs in lowland evergreen forest and seasonal semi-evergreen forest up to $600 \mathrm{~m}$. Collections have been made from Cartago, Puntarenas and San José Provinces in Costa Rica and Coclé, Colón and Barro Colorado Island in Panama.

Assessor: World Conservation Monitoring Centre

Refs: 8816

\section{Pouteria foveolata}

Sapotaceae

VU D2

Costa Rica, Nicaragua

A buttressed tree, newly described as a species. It is confined to two main areas, in Chontales, Nicaragua, and in Manuel Antonio National Park, Costa Rica. Both are near sea level in lowland rainforest.

Assessor: World Conservation Monitoring Centre Refs: 8816

\section{Pouteria fulva}

Sapotaceae

EN B $1+2 d$

Brazil (Amazonas)

A species, newly described, known from just two collections from non-flooded lowland forest in the Rio Solimôes area in Amazonas.

Assessor: Pires O'Brien, J.

Refs: $1983,7980,8816$

\section{Pouteria furcata}

Sapotaceae

VU B $1+2 c$

Brazil (Maranháo, Piauí)

A newly described species, scattered in dry lowland forest and *cerrado. Some areas are under threat from expanding developments and land settlement.

Assessor: Pires O'Brien, J.

Refs: $1983,7980,8816$

\section{Pouteria gabrielensis}

Sapotaceae

$\mathrm{LR} / \mathrm{nt}$

Brazil (Amazonas), Colombia, Venezuela

Although occupying a relatively wide range in the Colombian, Venzuelan and Brazilian Amazon, the species is actually known from only a few collections from * várzea forest below $200 \mathrm{~m}$.

Assessor: World Conservation Monitoring Centre

Refs: 7980,8816

\section{Pouteria gigantea}

Sapotaceae

VUD2

Ecuador

A canopy tree known only from lowland rainforest in the Río Palenque Science Center in Pacific coastal Ecuador.

Assessor: World Conservation Monitoring Centre Refs: 7980,8816

\section{Pouteria glauca}

Sapotaceae

VU D2

Peru

A newly described species of lowland swampy forest. So far it has been collected from only two sites in Loreto.

Assessor: World Conservation Monitoring Centre

Refs: 7980,8816

\section{Pouteria gracilis}

Sapotaceae

VU D2

Peru

A newly described species, which has been recorded only from the site where it was first collected in Tocache Nuevo in San Martin in 1972. The population was found in rainforest between 700 and $800 \mathrm{~m}$.

Assessor: World Conservation Monitoring Centre Refs: 7980,8816

\section{Pouteria grandiflora}

Sapotaceae

$\mathrm{LR} / \mathrm{nt}$

Brazil (Bahia, Pernambuco, Rio de Janeiro)

A species distributed in * restinga, ranging over an area greater than $20,000 \mathrm{~km}^{2}$, assuming that populations still exist in the collection sites. Habitat clearance has been extensive and further evidence may reveal that the species has been lost from some of these sites.

Assessor: Pires O'Brien, J.

Refs: $1983,7980,8816$

\section{Pouteria hotteana}

Sapotaceae

$\mathrm{EN} \mathrm{B} 1+2 \mathrm{c}$

Haiti, Puerto Rico

Populations have been recorded in forest over limestone 
at about $1200 \mathrm{~m}$ in the Massif de la Hotte in Haiti and in Maricao Insular forest in Puerto Rico.

Assessor: World Conservation Monitoring Centre

Refs: 7931, 8816

\section{Pouteria izabalensis}

Sapotaceae

LR/nt

Belize, Guatemala, Honduras, Nicaragua

Ranging from Guatemala to Nicaragua, the species occurs in well-drained Atlantic forest near sea level. The wood has been used for railway sleepers in Guatemala. Assessor: World Conservation Monitoring Centre Refs: 8816

\section{Pouteria juruana}

Sapotaceae

$\mathrm{EN} \mathrm{B} 1+2 \mathrm{c}$

Brazil (Amazonas), Colombia

The species is known from two sites of lowland rainforest in westem Amazonia in Brazil and in the department of Putamayo in Colombia. More specimen data are needed to confirm its taxonomic status.

Assessor: Calderon, E.

Refs: $1983,7980,8816,19069$

\section{Pouteria kaieteurensis}

Sapotaceae

VU D2

Guyana

A newly described species, which appears to be confined to a single population on the Kaieteur Plateau in savanna and low savanna forest.

Assessor: World Conservation Monitoring Centre

Refs: 7980,8816

\section{Pouteria krukovit}

Sapotaceae

VU D2

Brazil (Acre), Peru

Known only from two collections, the species is found in lowland, periodically flooded forest at the mouth of Macauhan in Acré, and from Yanomono Explorama Camp in Loreto, Peru.

Assessor: World Conservation Monitoring Centre Refs: 7980,8816

\section{Pouteria latianthera}

Sapotaceae

$\mathrm{EN} \mathrm{B} 1+2 \mathrm{c}$

Brazil (Amapá)

A newly described species. At present it is known from only two sites in Amapá, in mixed lowland forest.

Assessor: Pires O'Brien, J.

Refs: $1983,7980,8816$

\section{Pouteria leptopedicellata}

Sapotaceae

VU D2

Costa Rica, Panama

Confined to lowland and submontane rainforest, the species has been recorded in just two isolated sites: one in Heredia in Costa Rica and the other from the Santa Rita Ridge in Panama.

Assessor: World Conservation Monitoring Centre Refs: 8816

\section{Pouteria longifolia}

Sapotaceae

VU B $1+2 c$

Bolivia, Peru

A tree of montane forest, occurring up to $900 \mathrm{~m}$, in Amazonian Peru and Bolivia. Populations have been recorded in two or three widely separated sites, one in San Martin in Peru, the others in La Paz in Bolivia. Assessor: World Conservation Monitoring Centre Refs: 7980,8816

\section{Pouteria lucens}

Sapotaceae

VU B1+2c

Brazil (Amazonas)

A tree which is known only from *igapo forest from upper Rio Negro and Rio Japurá regions.

Assessor: World Conservation Monitoring Centre

Refs: $1983,7980,8816$

\section{Pouteria macahensis}

\section{Sapotaceae}

$\mathrm{EN} B 1+2 \mathrm{c}$

Brazil (Bahia, Rio de Janeiro)

The type specimen was collected in 1910 from Rio de Janeiro. Otherwise known from Bahia, the species occurs in *restinga vegetation and inland forests.

Assessor: Pires O'Brien, J.

Refs: $1983,7980,8816$

\section{Pouteria macrocarpa}

Sapotaceae VU Ala

Brazil (Amazonas, Mato Grosso, Pará), Colombia, Costa Rica

The range of the species is extensive geographically and altitudinally. However, populations are rare and declining.

Assessor: Pires O'Brien, J.

Refs: 1983,8816

\section{Pouteria maguirei}

Sapotaceae

LR/nt

Brazil (Amazonas), Venezuela

A component of *igapó forest in southern Venezuela extending to the upper Rio Negro in Brazil.

Assessor: World Conservation Monitoring Centre

Refs: 7980,8816

\section{Pouteria micrantha}

Sapotaceae

$\mathrm{EN} \mathrm{B} 1+2 \mathrm{c}$

Cuba

A small tree apparently confined to submontane serpentine forest in what is known as the *manacles in the Sierra de Nipe, Oriente Province. The species is poorly known and has been rarely collected.

Assessar: Areces-Mallea, A.E.

Refs: $7980,8816,19149$

\section{Pouteria microstrigosa}

Sapotaceae

VU B $1+2 c$

Brazil (Bahia, Espírito Santo, Mato Grosso)

A newly described species with a restricted distribution in lowland rainforest, ranging from Bahia to Espirito Santo. The habitat has been extensively logged and cleared.

Assessor: Pires O'Brien, J.

Refs: $1983,7980,8816$

\section{Pouteria minima}

Sapotaceae

$\mathrm{EN} \mathrm{B} 1+2 \mathrm{c}$

\section{Brazil (Amazonas)}

A newly described species, the only records of which occur in two sites in the Rio Vaupes region in westem Brazilian Amazonia.

Assessor: Pires O'Brien, J.

Refs: 1983, 7980, 8816 


\section{Pouteria moaensis}

Sapotaceae

Cuba

A small tree known only from Sierra de Moa in Oriente Province, the site where it was first gathered in 1955.

The main threat to the species is from the mining of the ferritic soils.

Assessor: Areces-Mallea, A.E.

Refs: 7980, 8816, 19149

\section{Pouteria nemorosa}

Sapotaceae

VU B $1+2 \mathrm{c}$

Bolivia

A species with an anomalous floral structure compared to the rest of the family. A few recent collections now indicate that the species is not as rare as was once assumed.

Assessor: World Conservation Monitoring Centre

Refs: $7980,8816,19170$

\section{Pouteria nudipetala}

Sapotaceae

VU D2

Brazil (Amazonas), Peru

Only three collections have been made of this species. They originate from periodically flooded or *várzea forest at the mouth of Rio Embira in Amazonas, Brazil. and from upland forest in Loreto, Peru.

Assessor: World Conservation Monitoring Centre Refs: 7980,8816

\section{Pouteria oppositifolia}

Sapotaceae

VU BI+2c

Brazil (Amapá, Pará)

A species which appears to occur in both moist and drier lowland forest types. It is harvested locally for the timber.

Assessor: Pires O'Brien, J.

Refs: $1983,7980,8816$

\section{Pouteria oxypetala}

Sapotaceae

$\mathrm{EN} \mathrm{B1}+2 \mathrm{c}$

Brazil (São Paulo)

Currently known from just two collections taken from lowland secondary forest, this newly described species is threatened most seriously by increasing habitat clearance and settlement of the area.

Assessor: Pires O'Brien, J.

Refs: $1983,7980,8816$

\section{Pouteria pachycalyx}

Sapotaceae

CR B 1+2d

Brazil (Espírito Santo)

A newly described species. Present information suggests that it is confined to lowland rainforest on sandy soils in Linhares Forest Reserve.

Assessor: Pires O'Brien, J.

Refs: $1983,7980,8816$

\section{Pouteria pachyphylla}

Sapotaceae

VU $B 1+2 c$

Brazil (Amazonas, Rondônia)

A tree species which is confined to the Brazilian Amazon, where it occurs in periodically and permanently flooded forest. The habitat is generally threatened by logging activities.

Assessor: Pires O'Brien, J.

Refs: $1983,7980,8816$

\section{Pouteria pallens}

Sapotaceae

CR B $1+2 c$

Brazil (Rondônia)

A newly described species, currently known only from the site where it was first collected in 1963 from lowland

forest at Porto Velho.

Assessor: Pires O'Brien, J.

Refs: $1983,7980,8816$

\section{Pouteria pallida}

Sapotaceae

$\mathrm{EN} B 1+2 \mathrm{c}$

Dominica, Guadeloupe, Martinique, St Lucia

Endemic to the Windward Islands in the Caribbean, the species is found in lowland rainforest up to $600 \mathrm{~m}$. A single population is recorded on each of Dominica, Martinique, St Lucia and Guadeloupe, where the exact locality of the species is unknown. Little rainforest remains on Martinique. The species provides an excellent construction timber.

Assessor: World Conservation Monitoring Centre Refs: $\mathbf{8 8 1 6}$

\section{Pouteria peduncularis}

Sapotaceae

Brazil (Bahia)

A very poorly known species. The only knowledge of it comes from the herbarium type specimen, which was collected in the last century from a locality which has not been precisely recorded.

Assessor: World Conservation Monitoring Centre

Refs: $1983,7980,8816$

\section{Pouteria penicillata}

Sapotaceae

VU D2

Guyana

This species is known only from the site where it was first collected in 1941 in forest on laterite.

Assessor: World Conservation Monitoring Centre Refs: 7980,8816

\section{Pouteria peruviensis}

Sapotaceae

VU D2

Pen

Although the species is known only with certainty from the type collection, there may be other collections from the Amazon which belong to this taxon. The type specimen was gathered from rainforest in the Cerros Campanquiz in Loreto.

Assessor: World Conservation Monitoring Centre Refs: 7980,8816

\section{Pouteria petiolata}

Sapotaceae

VU B1+2c, D2

Brazil (Amazonas, Pará)

A newly described species, confined to two localities of non-flooded forests, including one in Ducke Forest Reserve. The most serious threat comes from continuing logging.

Assessor: Pires O'Brien, J.

Refs: $1983,7980,8816$

\section{Pouteria pimichinensis}

Sapotaceae

LR/nt

Venezuela

This shrub or bushy tree is known only from populations in Amazonas, occurring in savanna and occasionally along flooded river margins.

Assessor: World Conservation Monitoring Centre

Refs: 7980,8816 
Pouteria pisquiensis

Sapotaceae

VU D2

Peru

A tree known only from the type specimen, which was collected from lowland rainforest at Ucayali in 1942.

Assessor: World Conservation Monitoring Centre

Refs: 7980,8816

\section{Pouteria platyphylla}

Sapotaceae

LR/nt

Brazil (Amazonas, Mato Grosso), Peru

A tree of lowland rainforest. Few collections exist, one from Jenaro Herrera Arboretum in Loreto, Peru, and several from Amazonian Brazil.

Assessor: World Conservation Monitoring Centre

Refs: 7980,8816

\section{Pouteria polysepala}

Sapotaceae

$\mathrm{CR} B \mathrm{I}+2 \mathrm{c}$

Brazil (Amazonas)

A large tree. Its only known occurrence is at the mouth of the Rio Javari in non-flooded forest.

Assessor: Pires O'Brien, J.

Refs: $1983,7980,8816$

\section{Pouteria psammophila}

Sapotaceae

EN Alc, B1+2c

Brazil (Rio de Janeiro, Sāo Paulo)

A tree of *restinga vegetation and granitic outcrops along the Atlantic coast. Large areas of the habitat are being lost to housing, tourist and other developments. The species is recorded in the Ilha do Cardoso State Park in Sāo Paulo.

Assessor: Pires O'Brien, J.

Refs: $1983,7980,8816$

\section{Pouteria pseudoracemosa}

Sapotaceae

VU B $1+2 b, D 2$

Tanzania

A moist lowland forest tree known from three localities in Tanzania. A population is confined to Kimboza Forest Reserve, $4 \mathrm{~km}^{2}$ of forest in a densely populated area. The demand for land is high but two forest guards prevent illegal encroachment and activities. There are also populations also at low elevations in the East Usambara Mountains and North Udzungwa Mountains.

Assessor: Lovett, J. \& G.P. Clarke

Refs: 3356,8814

\section{Pouteria puberula}

Sapotaceae

VU D2

Venezuela

A newly described species, known only from the site where it was first collected in 1977 in rainforest at $750 \mathrm{~m}$ in Miranda.

Assessor: World Conservation Monitoring Centre

Refs: 7980,8816

\section{Pouteria pubescens}

Sapotaceae

VU D2

Brazil (Amazonas), Peru

This tree has been collected from just two sites so far, one in the Jenaro Herrera Arboretum in Loreto, Peru, and the other in Sāo Paulo de Olivença in Amazonas, Brazil.

Assessor: World Conservation Monitoring Centre Refs: 7980,8816
Pouteria putamen-ovi

Sapotaceae

VU D2

Brazil (Rondônia), Peru

A newly described species of non-flooded forest over sand. So far populations have been recorded from two sites in Loreto in Peru, including the Jenaro Herrera Arboretum, and from Rondônia in Brazil.

Assessor: World Conservation Monitoring Centre

Refs: 7980,8816

Pouteria retinervis

Sapotaceae

LR/cd

Brazil (Amazonas), French Guiana

Occurring in the Saül area of French Guiana and along the Rio Negro in Amazonas, Brazil, the species is found in non-flooded lowland forest.

Assessor: World Conservation Monitoring Centre Refs: 7980,8816

\section{Pouteria rhynchocarpa}

Sapotaceae

EN B $1+2 c$

Mexico (Veracruz)

A newly described species so far known only from Los Tuxtlas Biological Station in central Veracruz, where it occurs in lowland evergreen rainforest over black clay.

Assessor: World Conservation Monitoring Centre

Refs: $5651,7980,8816$

\section{Pouteria rigida ssp. rigida}

Sapotaceae

LR/nt

Brazil (Roraima), Guyana, Venezuela

A small tree or shrub found in sandstone scrub and forest islands in savanna, dwarf mossy forest over sandstone and Bonnetia forest up to $2200 \mathrm{~m}$.

Assessor: World Conservation Monitoring Centre

Refs: 7980,8816

\section{Pouteria rigida ssp. tomentosa}

Sapotaceae

LR/nt

Venezuela

This subspecies is confined to just a few sites of dwarf forest or low scrub on stony mountain slopes in Bolívar and Amazonas.

Assessor: World Conservation Monitoring Centre

Refs: 7980,8816

\section{Pouteria rigidopsis}

Sapotaceae

$\mathrm{LR} / \mathrm{nt}$

Venezuela

A tree of wet montane forest and shrubby cloud forest, confined to northem Venezuela, occurring in Anzoátegui, Distrito Federal, Monagas and Sucre. Assessor: World Conservation Monitoring Centre Refs: 7980,8816

\section{Pouteria rodriguesiana}

Sapotaceae

$\mathrm{LR} / \mathrm{nt}$

Brazil (Amapá, Pará), French Guiana, Suriname

A newly described species known from several sites in the Guianas and adjacent parts of Brazil, where it occurs in lowland rainforest, usually on non-flooded land up to $700 \mathrm{~m}$.

Assessor: World Conservation Monitoring Centre Refs: 7980,8816 


\section{Pouteria rufotomentosa}

Sapotaceae

VU D2

Guatemala

A rainforest species, which appears to be confined to Baja Verapaz in Guatemala.

Assessor: World Conservation Monitoring Centre

Refs: 7980,8816

\section{Pouteria sclerocarpa}

Sapotaceae

LR/nt

Colombia, Ecuador, Panama

A lowland rainforest species, known from scattered collections from the south of Panama in Darien Province and from single sites in Amazonian Ecuador and Colombia.

Assessor: World Conservation Monitoring Centre

Refs: 8816

\section{Pouteria semecarpifolia}

Sapotaceae

VU B $1+2 c$

Dominica, Guadeloupe, Martinique, St Lucia, St Vincent An endemic of the Windward Islands in the Caribbean. Populations are recorded in Castle Bruce and St Davis Parish on Dominica, Mome Larcheux and La Trinite on Martinique and sites on Guadeloupe, St Lucia and St Vincent. It is a lowland forest tree and apparently provides good construction timber.

Assessor: World Conservation Monitoring Centre

Refs: $7980,8816,10754$

\section{Pouteria sessilis}

Sapotaceae

VU D2

Peru

A newly described species, currently known only from the type locality in lowland rainforest in Jenaro Hertera Arboretum.

Assessor: World Conservation Monitoring Centre

Refs: 7980,8816

\section{Pouteria silvestris}

Sapotaceae

VU D2

Costa Rica

A newly described species, endemic to Costa Rica, where it has been collected twice from lowland rainforest in Heredia.

Assessor: World Conservation Monitoring Centre

Refs: 7980,8816

\section{Pouteria sipapoensis}

Sapotaceae

VU D2

Yenezuela

A newly described species which, so far, is known from just two collections in forest in southern Venezuela.

Assessor: World Conservation Monitoring Centre

Refs: 7980,8816

\section{Pouteria splendens}

Sapotaceae

LR/nt

Chile (Valparaiso)

A morphologically distinct member of the genus, confined to the coastal regions of central Chile, where it occurs in rocky ravines and coastal scrub.

Assessor: World Conservation Monitoring Centre

Refs: $7980,8816,11147$

\section{Pouteria squamosa}

Sapotaceae

$\mathrm{VU} B 1+2 \mathrm{c}, \mathrm{D} 2$

Guatemala, Mexico (Oaxaca, Veracruz)

A species of lowland evergreen forest, occurring in damp valleys and along streamsides. At present only three sites are recorded, one in Izabal in Guatemala and the other two in the Uxpanapa-Chimalapa region between Oaxaca and Veracruz States in Mexico.

Assessor: World Conservation Monitoring Centre Refs: 5651,8816

\section{Pouteria stenophylla}

Sapotaceae

EX

Brazil (Rio de Janeiro)

A tree known at one time to be confined to the coastal hill forest of Rio de Janeiro. Although the area has been visited numerous times by botanists, no recent record of the species has been made.

Assessor: Pires O'Brien, J.

Refs: $1983,7980,8816$

\section{Pouteria subsessilifolia}

Sapotaceae

CR B $1+2 d$

Brazil (Bahia)

A treelet which appears to be confined to a small area of sandy *campo rupestre vegetation, in marshy places, near Mucugê.

Assessor: Pires O'Brien, J.

Refs: $1983,7980,8816$

\section{Pouteria tarapotensis}

Sapotaceae

LR/nt

Per

Apparently a Peruvian endemic, although there are, as yet, unconfirmed reports of the species occurring in Panama. Populations have been recorded from lowland rainforest, sometimes periodically flooded, in Cocha Cashu in Madre de Dios, from the area of the Yurimagunas in Loreto and from Tarapoto in San Martin.

Assessor: World Conservation Monitoring Centre Refs: 8816

\section{Pouteria tarumanensis}

Sapotaceae

$\mathrm{EN} \mathrm{B1+2a}$

Brazil (Amazonas)

A species confined to non-flooded forest over sand in the centre of the Brazilian Amazon, especially in the region of Manaus. Logging activities and fires in the area are the most serious threats.

Assessor: Pires O'Brien, J.

Refs: $1983,7980,8816$

\section{Pouteria triplarifolia}

Sapotaceae

VU D2

Costa Rica

The species has been recorded from a single location in Puntarenas in wet hill forest at about $600 \mathrm{~m}$, near the coast.

Assessor: World Conservation Monitoring Centre Refs: 7980,8816

\section{Pouteria vernicosa}

Sapotaceae

VU B1+2c

Brazil (Amazonas), Peru

A newly described species, as yet known from just a few collections from lowland rainforest in Huánuco in Peru, and from various localities, including Ducke Forest Reserve in Amazonas, Brazil. Assessor: Pires O'Brien, J.

Refs: 7980,8816 


\section{Pouteria villamilii}

Sapotaceae

VU A1d

Philippines

This species occurs in primary lowland forest on the islands of Luzon and Siargao. Its timber is in short supply but is traded as white nato, together with that of other species of the genus.

Assessor: World Conservation Monitoring Centre Refs: 4919, 14573

\section{Povedadaphne quadriporata}

Lauraceae

VU B1 $+2 c, D 2$

Costa Rica

A species of wet submontane rainforest, known from sites in the San Ramón Forest Reserve, near Ciudad Quesada and east of Río Sarapiquí in Heredia Province. Assessor: World Conservation Monitoring Centre Refs: $2514,7980,12587$

\section{Pradosia argentea}

Sapotaceae

Peru

This species is known only from the type collection from the Cajamarca area dating back about 180 years. No record of the tree has been made since.

Assessor: World Conservation Monitoring Centre

Refs: 7980,8816

\section{Pradosia atroviolacea}

Sapotaceae

LR/nt

Brazil (Acre), Colombia, Peru

A species of lowland periodically flooded or nonflooded forest in westem Amazonia.

Assessor: World Conservation Monitoring Centre

Refs: 7980,8816

\section{Pradosia cuatrecasasii}

Sapotaceae

VU D2

Colombia

A large buttressed tree of lowland rainforest, currently known from just two collections from Valle.

Assessor: World Conservation Monitoring Centre

Refs: 7980,8816

\section{Pradosia decipiens}

Sapotaceae

CR B $1+2 a$

Brazil

The species is known only from the type collection from non-flooded lowland forest in the Rio Taruma region near Manaus.

Assessor: Pires O'Brien, J.

Refs: $1983,7980,8816$

\section{Pradosia glaziovii}

Sapotaceae

Brazil (Rio de Janeiro)

Two collections of this species were made in Rio de Janeiro. The area has since been extensively visited and no evidence of the species has been uncovered.

Assessor: Pires O'Brien, J.

Refs: $1983,7980,8816$

\section{Pradosia granulosa}

Sapotaceae

VU B1+2b

Brazil (Maranháo, Pará)

A newly described species, which appears to be confined to non-flooded forest in the north of Brazil.
The most serious threat is from mining activities.

Assessor: Pires O'Brien, J.

Refs: $1983,7980,8816$

\section{Pradosia kuhlmannii}

Sapotaceae

$\mathrm{EN} \mathrm{B1+2c}$

Brazil (Rio de Janeiro)

The species is apparently confined to lowland rainforest in Rio de Janeiro, where urban expansion exerts considerable pressure on the habitat. It has been frequently cited from other Brazilian states but these records have not been authenticated and confusion with another taxon is quite possible.

Assessor: Pires O'Brien, J.

Refs: $1983,7980,8816$

\section{Pradosia montana}

Sapotaceae

VU D2

Ecuador

A newly described species of deciduous forest recorded from a small area on the dry Pacific slopes.

Assessor: World Conservation Monitoring Centre Refs: 7980, 8816

\section{Pradosia mutisü}

Sapotaceae

EX

Colombia

A very poorly known species with no precise data on locality or habitat. It has been described from four collections made in the first half of the century.

Assessor: Calderon, E.

Refs: 7980, 8816, 19069

\section{Pradosia subverticillata}

Sapotaceae

VU B1+2c

Brazil (Amazonas, Pará)

A tree of the Brazilian central Amazon, known from just a few collections taken from non-flooded forest.

Assessor: Pires O'Brien, J.

Refs: $1983,7980,8816$

\section{Pradosia verrucosa}

Sapotaceae

CR B 1+2c

Brazil (Pernambuco)

A tree apparently confined to an area of seasonal forest in the Pernambuco Highlands. The habitat is under threat, particularly from agricultural expansion.

Assessor: Pires O'Brien, J.

Refs: $1983,7980,8816$

\section{Premna grandifolia}

Verbenaceae

VU B1+2c

Côte d'Ivoire

An endemic of the areas of remaining forest within the region of the Sassandra and Cavally Rivers. The largest part of the population occurs within Tai National Park. Outside the park the forest has been heavily logged and degraded.

Assessor: Assi, A.

Refs: 2773, 12822

\section{Premna hans-joachimii}

Verbenaceae

VU $B 1+2 b$

Tanzania

Currently the species is known only from Mlingur forest. This area has not been visited recently but, if it still exists, it is believed to be $10-20 \mathrm{~km}$ from Lindi. Specimens that possibly represent the same species have been found on the Rondo Plateau, where $140 \mathrm{~km}^{2}$ of 
mostly disturbed forest are protected by the activities of a forest management programme.

Assessor: Lovett, J. \& G.P. Clarke

Refs: 3356,8814

\section{Premna maxima}

Verbenaceae

VU B1+2c, D2

Kenya

A buttressed tree of upland moist evergreen forest, confined to small localities near Meru and Marsabit. The timber is used for making furniture and telegraph poles. The population in the Marsabit National Reserve is protected. The species is also being propagated as part of the Plant Conservation Programme in Kenya.

Assessor: World Conservation Monitoring Centre Refs: 6396, 10961, 17859

\section{Premna schliebenii}

Verbenaceae

VU $B 1+2 b$

Mozambique, Tanzania

A dry forest tree known from low elevations in the East Usambara Mountains and at Lipindi in Tanzania. The species also occurs in Mozambique.

Assessor: Lovett, J. \& G.P. Clarke

Refs: 3356, 10961

\section{Premna szemaoensis}

Verbenaceae

VU BI $+2 \mathrm{c}$

China (Yunnan)

Widely distributed but confined to south and south-west Yunnan, the species is found in sunny open forest between 500 and $1500 \mathrm{~m}$. The main cause of population reductions has been overexploitation of the timber, and possibly also of the bark for medicinal use. Regeneration is reported to be poor and few young trees can be found. Assessor: Sun, W.

Refs: $1818,11847,19050,19055$

\section{Premna tanganyikensis}

Verbenaceae

$\mathrm{VU} B 1+2 \mathrm{~b}$

Mozambique, Tanzania

A scandent shrub or small tree. In Tanzania two populations are known from patches of dry coastal forest. One is recorded in the Rondo Plateau, where the little remaining undisturbed forest is protected in a reserve with an active forest management programme, which discourages any illegal activities or encroachment. The other population is found at the Mozambique border at Kitangari. The species is also found in Mozambique.

Assessor: Lovett, J. \& G.P. Clarke

Refs: 3356,8814

\section{Prestoea tenuiramosa}

Palmae

LR/nt

Brazil (Amazonas), Guyana, Venezuela

Restricted to the Guyana Highlands, this palm tree grows in cloud forest between 1200 and $2000 \mathrm{~m}$.

Assessor: Henderson, A.

Refs: 19118

\section{Priotropis socotrana}

Leguminosae

VU D2

Yemen (Socotra)

A small tree or shrub which is scattered, occasionally common, in areas of moist submontane woodland. There are no immediate threats.

Assessor: Miller, A.G.

Refs: 2354,19083

\section{Prismatomeris andamanica}

Rubiaceae

India (Andaman and Nicobar Is. - Andaman Is.)

Collected from scrub along the fringes of evergreen forest in South Andaman Island, the species has not been found again since it was first discovered. The habitat has declined because of logging and increasing agricultural developments.

Assessor: World Conservation Monitoring Centre

Refs: 4799,7147

\section{Pritchardia affinis}

Palmae

CR Alce+2ce, B $1+2 a b c d e, C l+2 a$

USA (Hawaii)

Confined to an area stretching from South Kona to Punaluu, this tree is scattered in lowland open forest on the leeward coast and in inland gulches. About 60 trees are known in the wild, although some of these might be aboriginal. Regeneration is limited. Severe damage is caused by rats and pigs. The species is protected by the US Endangered Species Act.

Assessor: Gemmill, C.

Refs: 19118

\section{Pritchardia aylmer-robinsosii}

Palmae

CR Al ace+2ce, B1+2abcde, DI

USA (Hawaii)

Two individuals are confined to dry scrub on Kaali Cliff on Niihau Island.

Assessor: Gemmill, C.

Refs: 19118

\section{Pritchardia elliptica}

Palmae

DD

USA (Hawaii)

Restricted to Kumoa Valley, Lanai Island, the species was not found during a 1992 survey of the vicinity. The taxonomy is questionable.

Assessor: Gemmill, C

Refs: 19118

\section{Pritchardia forbesiana}

Palmae

EN Alacd, Bl+2d, Dl

USA (Hawaii)

A palm tree of wet montane open forest, restricted to Mount 'Eke in the Honokohau drainage basin in west Maui. Populations are recovering well in areas where feral pigs have been eradicated.

Assessor: Gemmill, C.

Refs: 19118

\section{Pritchardia glabrata}

Palmae

$\mathrm{EN} \mathrm{Alce+2ce,} \mathrm{Bl+2bcde,} \mathrm{Dl}$

USA (Hawaii)

A very small palm tree, known only from lao Needle in Maui, restricted to moist open forest and scrubland at about $550 \mathrm{~m}$. Damage is caused by feral pigs, rats and goats and competitive pressure is exerted by invasive plants such as Rubus rosifolius.

Assessor: Gemmill, C.

Refs: 19118

Pritchardia hardyi

Palmae

CR Alce, B1+2abce, D1

USA (Hawaii)

A small palm tree, up to $5 \mathrm{~m}$ high, scattered in wet open forest between 500 and $750 \mathrm{~m}$ along the Powerline Trail 
on Kauai Island. Only 30 individuals are known in the wild and regeneration is limited.

Assessor: Gemmill, C.

Refs: 19118

\section{Pritchardia kaalae}

Palmae

CR Alce+2ce, Bl+2abcde, $\mathrm{Cl}+2 \mathrm{a}$

USA (Hawaii)

A palm tree of lowland moist forest on slopes and cliffs between 450 and $980 \mathrm{~m}$. Fewer than 130 individuals are known from five populations in the central and northcentral Waianae Mountains. Regeneration is by seed predation by rats and goats. The species is protected by the US Endangered Species Act.

Assessor: Gemmill, C

Refs: 19118,19168

\section{Pritchardia lanaiensis}

Palmae

EN Al ce+2ce, B1+2abcde, D1

USA (Hawaii)

A palm of lowland mesic shrubland, confined to an area stretching from the upper Nannalli drainage gulch to the Waialala gulch. No regeneration has been observed and the species is suffering from seed predation by rats and deer.

Assessor: Gemmill, C.

Refs: 19118

\section{Pritchardia lanigera}

Palmae

EN B $1+2 \mathrm{c}$

USA (Hawaii)

Restricted to the Kohala Mountains on Oahu Island, this small palm tree occurs in dense rainforest on a flat, boggy plateau between 1000 and $2000 \mathrm{~m}$. Populations are in decline and there is limited regeneration. Habitat degradation caused by pigs is the major threat to the species.

Assessor: Gemmill, C.

Refs: 19118

\section{Pritchardia limahuliensis}

Palmae

CR Alce+2ce, B1+2abcde, Cl

USA (Hawaii)

Fewer than 100 individuals of this palm tree are known from Limuhuli Valley, Kauai, in lowland moist forest. Regeneration is limited, mainly because of seed predation by rats and pigs.

Assessor: Gemmill, C.

Refs: 19118

\section{Pritchardia lowreyana}

Palmae

VU Alc+2ce, B1+2abcde, D1

USA (Hawaii)

Known only from a few localities in lowland rainforest near the northern shore of Molokai Island, this small palm tree is not regenerating well because of seed predation by rats, pigs and goats.

Assessor: Gemmill, C.

Refs: 19118

\section{Pritchardia munroi}

Palmae

CR A2ce, D1

USA (Hawaii)

A single wild tree remains in lowland dry shrubland on the leeward side of Molokai Island. A second immature individual may exist. A fence has been erected to keep feral pigs and goats out of the immediate area. The species is protected by the US Endangered Species Act. Assessor: Gemmill, C.

Refs: 19118

\section{Pritchardia napaliensis}

Palmae

CR Alce+2ce, $\mathrm{B} 1+2 \mathrm{abcde}, \mathrm{Cl}+2 \mathrm{a}$

USA (Hawaii)

A palm tree of moist lowland forest, found along the Napali coast. Fewer than 90 individuals are left in the wild and regeneration is limited, mainly as a result of seed predation by rats and goats. A few trees exist within an enclosure but the fence is not secure. The species is protected by the US Endangered Species Act. Assessor: Gemmill, C.

Refs: 19118

\section{Pritchardia perlmanii}

Palmae EN Alce+2ce, B1+2abcde, $\mathrm{Cl}+2 \mathrm{a}$ USA (Hawaii)

Fewer than 500 individuals are scattered in moist lowland forest in Waioli Valley on Kauai Island. Regeneration is poor because of seed predation by rats and pigs.

Assessor: Gemmill, C.

Refs: 19118

\section{Pritchardia remota}

Palmae

EN A2ce, $\mathrm{B} 1+2 \mathrm{abcde}, \mathrm{Cl}+2 \mathrm{a}$

USA (Hawaii)

A palm tree of dry lowland scrub, known from only two populations containing approximately 680 individuals. The area is apparently free from feral animal. The species is proposed for inclusion in the US Endangered Species Act.

Assessor: Gemmill, C

Refs: 19118

\section{Pritchardia schattaueri}

Palmae

CR Alce+2ce, B 1+2abcde, Dl

USA (Hawaii)

Only 12 individuals in three populations remain in the wild in areas of lowland moist forest between 600 and $800 \mathrm{~m}$ on Hawaii. The remaining trees are threatened by seed predation, grazing and agriculture.

Assessor: Gemmill, C.

Refs: 19118

\section{Pritchardia thurstonii}

Palmae

LR/nt

Fiji

An important ornamental palm which is confined to the Lau Group in eastem Fiji. The species is locally abundant on limestone soils. It is widely cultivated.

Assessor: Fuller, D.

Refs: 6053, 19118

\section{Pritchardia viscosa}

Palmae

CR Alacde+2cde, B1+2abcde, Dl

USA (Hawaii)

A palm tree of open wet forest, restricted to the windward side of Kauai Island between 500 and $700 \mathrm{~m}$. Only two wild trees were known until recently, when two more were discovered; one of which has been harvested. Hurricane Iniki caused a decline in the population. The current threat is seed predation by rats, pigs and humans.

Assessor: Gemmill, C.

Refs: 19118 
Pritchardia waialealeana

Palmae

VU A2ce, B 1+2abcde, D1

USA (Hawaii)

Endemic to Kauai Island, this palm tree is scattered in wet lowland open forest between 450 and $800 \mathrm{~m}$. It is threatened by seed predation by rats.

Assessor: Gemmill, C.

Refs: 19118

\section{Prichardia woodfordiana}

Palmae

Solomon Islands (South Solomon)

Endemic to Nggela Island, this palm tree occurs in moist open forest up to $20 \mathrm{~m}$. There is some indication that the taxon represents a form of $P$. pacifica.

Assessor: Dowl, J.L.

Refs: 19118

\section{Pritchardiopsis jeanneneyi}

Palmae

CR D1

New Caledonia

The species occurs in the south-west on a steep slope on serpentine soils at $200 \mathrm{~m}$.

Assessor: Jaffré, T. et al.

Refs: 10351,19118

\section{Prosopis abbreviata}

Leguminosae

VU Bl $+2 c$

Argentina (Catamarca, Córdoba, San Juan, San Luis, Santiago del Estero)

A scrubland species restricted to semi-arid and arid areas of central-west Argentina. Its distribution is highly fragmented within an area that has had a long history of human colonisation and pastoralism.

Assessor: Prado, D.

Refs: $1262,5112,11140$

\section{Prosopis affinis}

Leguminosae

Argentina (Buenos Aires, Córdoba, Corrientes, Entre Ríos, Formosa, Santa Fé), Brazil (Rio Grande do Sul), Paraguay, Uruguay

Occurring in savanna and *campo, the species' range is large but declining in the face of increasing agriculture and cattle ranching, as well as other activities.

Assessor: Prado, D

Refs: $1262,5112,7134,17523$

\section{Prosopis alba}

Leguminosae

LR/nt

Argentina (Buenos Aires, Chaco, Córdoba, Corrientes, Entre Ríos, Formosa, Jujuy, Salta, San Luis, Santa Fé, Santiago del Estero), Bolivia, Chile?, Paraguay, Peru In recent years this timber species has been heavily exploited, notably in the provinces of Formosa, Chaco and Santa Fé in Argentina. The population structure is reported to be fundamentally changed and studies are under way to examine the consequences of these changes. Populations in Bolivia are less rare and threatened.

Assessor: World Conservation Monitoring Centre

Refs: $1262,4870,5112,7134,17523,19180$

\section{Prosopis caldenia}

Leguminosae

Argentina (Buenos Aires, Cóndoba, La Pampa, Mendoza, Rio Negro, San Luis)

At one time more widespread, the species was heavily exploited in the past as a source of wood and fuel. It is currently restricted to small areas of *campo and savanna in the centre-south of Argentina.

Assessor: Prado, D.

Refs: $1262,5112,7134$

\section{Prosopis nigra}

Leguminosae

DD

Argentina (Buenos Aires, Catamarca, Chaco, Córdoba, Corrientes, Entre Ríos, Formosa, Jujuy, Salta, San Luis, Santa Fé, Santiago del Estero, Tucumán), Bolivia, Paraguay, Unguay

An excellent timber tree, which occurs in abundance in lowland dry forest types. It is exploited widely as a timber, fuelwood and has various other uses.

Assessor: Prado, D.

Refs: $1262,5112,17523$

\section{Prosopis tamarugo}

Leguminosae

$\mathrm{LR} / \mathrm{cd}$

Chile (Tarapaca)

Found only in the northernmost province of Chile, the species occurs within a small area of dry woodland. It is an important local source of timber and fuel, and is even cultivated on a small scale. Attempts to plant the species within the area of its natural distribution have been successful.

Assessor: González, M

Refs: $4893,16328,17523$

\section{Protea aurea ssp. potbergensis}

Proteaceae

VU D2

South Africa (Western Cape)

This subspecies has a very restricted distribution. confined to Potberg Mountain in De Hoop Nature Reserve in the southern Cape. It grows on the lower slopes and flats at the base of the mountain in *fynbos in both sparse and dense isolated stands. An estimated 2000 plants exist within an area of $15 \mathrm{~km}^{2}$ (*AOO). There is no evidence of a population decline, but frequent fires in the past may have had some impact. The area is protected but being invaded by alien pine trees and *hakeas. Frequent fires could still pose a threat, as they may not allow sufficient time for plants to regenerate.

Assessor: Hilton-Taylor, C. et al.

Refs: 689,19218

\section{Protea comptonii}

Proteaceae

LR/nt

South Africa (KwaZulu-Natal, Mpumalanga), Swaziland There are two disjunct areas where the species is found; one in the Kaapse Hoop and Barberton areas of Mpumalanga, just extending into Swaziland, and the other in KwaZulu-Natal with subpopulations in Vryheid, Louwsburg, the Itala Game Reserve and in Ngotshe District. It is highly localised on steep south-facing slopes on quartzite outcrops in grassy savanna. It does, however, appear to be abundant or in pure stands in places. There is some evidence of decline in numbers and extent of occurrence. The species is sensitive to frequent burning and appears to have low recruitment. Plants are also heavily grazed by large game animals and the bark is removed for use in traditional medicine by local people. The species is legally protected throughout its range. It also occurs in one publicly 
owned conservation area, where fire management measures are in place, and also in a privately owned Natural Heritage Site.

Assessor: Hilton-Taylor, C. et al.

Refs: $689,3344,19218$

\section{Protea curvata}

Proteaceae

VU D2

South Africa (Mpumalanga)

Only two subpopulations are known, both are confined to dry summit ridges of schist hills on serpentine soils on the Drakensberg Escarpment near Barberton. It appears in low numbers in mixed savanna. There is no evidence of threats or population declines, but both subpopulations are on privately owned land and could easily be destroyed by any change in land-use.

Assessor: Hilton-Taylor, C. et al.

Refs: 689,19218

\section{Protea laetans}

Proteaceae

VU D2

South Africa (Mpumalanga, Northern Province)

Originally known only from a single locality at the Blyde River Canyon on the Drakensberg Escarpment, the species has since been found at another site on the escarpment north-east of Mariepskop. It is found on quartzite outcrops, where it forms an open Protea savanna woodland. One population occurs in a publicly owned conservation area and the other is in a privately owned reserve. No threats are known and no decline has been recorded. The species' relationship with $P$. gaguedi will be described in a forthcoming revision of Protea (Rourke in prep.).

Assessor: Hilton-Taylor, C. et al.

Refs: $689,15561,19218$

\section{Protea lanceolata}

Proteaceae

South Africa (Western Cape)

VU Alace

Found along the southem Cape coast from De Hoop to Mossel Bay, the species occurs on calcareous white sands in limestone *fynbos and often at the ecotone with thicket communities. Near Mossel Bay, it occurs on gravels. Stands are very dense in places. The area of occupancy is approximately $1000 \mathrm{~km}^{2}$. Agricultural activities, particularly planting of cereal crops, and coastal developments have resulted in the decline of the species in places and this is likely to continue, especially in the Mossel Bay area. More than half of the subpopulations are threatened by alien invasive species, particularly Australian Acacia species. A quarter of the known subpopulations occur in protected areas.

Assessor: Hilton-Taylor, C. et al.

Refs: 689,19218

\section{Protium attenuatum}

Burseraceae

DD

Dominica, Guadeloupe, Jamaica, Martinique, St Kitts and Nevis, St Lucia, St Vincent

A species endemic to the Lesser Antilles. The record for Jamaica is based on a single collection from 1786. It is either erroneous or the species has become extinct. Assessor: World Conservation Monitoring Centre Refs: 6057, 7980, 10754

\section{Protium connarifolium}

Burseraceae

VU $B 1+2 c$

Malaysia (Sabah), Philippines

A lowland forest tree, known only from Palawan in the
Philippines and a single collection from Sempoma, Sabah. The main island of Palawan is a biosphere reserve.

Assessor: World Conservation Monitoring Centre

Refs: 4986, 19017

\section{Protium correae}

Burseraceae

VU A2c

Colombia, Costa Rica, Nicaragua, Panama

The species has not been recorded in Panama since it was first collected in 1968. It is known from various collections in Nicaragua and Costa Rica and has been reported from Colombia. In Nicaragua it appears to be relatively common but generally confined to forest habitats, which are subject to increasing human disturbance.

Assessor: Mitré, M.

Refs: 11703,16772

\section{Protium inconforme}

Burseraceae

VU B $1+2 c$

Panama

Known only from Panama, the species is reported from four provinces, from the border with Costa Rica to the centre-east of the country. Occurring in forest types below $500 \mathrm{~m}$, populations in many parts of the species' range have been strongly affected by encroaching agriculture, cattle ranching and increasing settlement. There are populations within protected areas.

Assessor: Mitré, M.

Refs: $7272,7980,16772$

\section{Protium panamense}

Burseraceae

LR/nt

Costa Rica, Panama

The species occurs along the Atlantic slopes of Panama in lowland evergreen rainforest and in Limón and $\mathrm{La}$ Selva Biological Station in Costa Rica. Populations are noted to be large, healthy and for the most part unthreatened.

Assessor: Mitré, M.

Refs: $7272,8100,16772$

\section{Protium pittieri}

Burseraceae

VU A2c, E

Costa Rica, Panama

Populations in Panama are widespread on the Atlantic side of the provinces of Veraguas and Bocas del Toro. The species is also principally found on the Atlantic side of Costa Rica. Although numbers are small, the regenerative capacity of the species appears to be good. New roads have been built into Bocas del Toro, which have opened up new areas for settlement and logging. Assessor: Mitré, M

Refs: 15343,16772

\section{Protium tenuifolium ssp. meleodi}

Burseraceae

VU A2c

Panama

Endemic to Panama, the species is recorded only from the provinces of Panama and Darién. The collections from Panamá come from a restricted area and only a single population is so far known from Darién, within a national park. Regeneration appears to be sufficient. Assessor: Mitré, M. Refs: 7980,16772 
Protium tenuifolium ssp. sessiliflorum

Burseraceae

VU A2c

Costa Rica, Honduras, Nicaragua, Panama

In Panama, the species is widely distributed, especially in areas of lowland evergreen rainforest on the Pacific side, the largest populations being in the Canal and Darién regions. Regeneration appears to be healthy here. Elsewhere in the Panama and Costa Rica, populations are sparse, showing little recruitment, and imminently threatened with deforestation in places.

Assessor: Mitre, M.

Refs: 7980,16772

\section{Pramnopitys andina}

Podocarpaceae

VU Alcd, C2a

Chile (La Araucania, Los Lagos, Maule)

A timber tree with a fragmented distribution in low- to medium-altitude forest in the central Andean range. Populations are small, containing not more than a few hundred individuals, and exploitation is at a high level throughout the species' range, largely for the woodchip industry.

Assessor: González, M.

Refs: $7980,8136,13041,16328$

\section{Prumnopitys exigua}

Podocarpaceae

DD

Bolivia

Assessor: SSC Conifer Specialist Group

Refs: 13041

\section{Prumnopitys harmsiana}

Podocarpaceae

Bolivia, Colombia, Peru, Venezuela

Assessor: SSC Conifer Specialist Group

Refs: 2739, 3047, 3204, 4217, 4870, 5411, 12268, $13041,13661,19127$

\section{Prumnopitys ladei}

Podocarpaceae

LR/cd

Australia (Queensland)

Endemic to Mount Spurgeon near Mossman, the species is scattered in montane rainforest in summit localities. The entire population is contained within a state forest reserve and felling is illegal without permit.

Assessor: SSC Conifer Specialist Group

Refs: 7891, 13041, 17200

\section{Prumnopitys standleyi}

Podocarpaceae

Costa Rica

Endemic to Costa Rica, populations are known only from Volcan de Poas and Cerro las Vueltas.

Assessor: SSC Conifer Specialist Group

Refs: 13041

\section{Prunus adenopoda}

Rosaceae

EN Alc, B1+2c

Indonesia (Java)

A small tree which is confined to a few locations in the greatly diminished lowland coastal forests of Java. It is known from 10 collections, most of which are from the early 1900s; the last collection was made in 1960. Populations are found in Ujung Kulon National Park and on Nusa Kambangan, an island which is controlled by the Prison Service. Despite the very limited access to the island, the vegetation is threatened by timber thieves who are removing timber regardless of the armed guard patrol.

Assessor: Kalkman, C.

.Pefs: $563,9078,19045$

\section{Prunus africana}

Rosaceae

VU Aled

Angola, Burundi, Cameroon, Democratic Republic of Congo, Equatorial Guinea (Bioko), Ethiopia, Kenya, Madagascar, Mozambique, Rwanda, São Tomé \& Príncipe (São Tomé), South Africa (Eastern Cape, Guateng, KwaZulu-Natal, Mpumalanga, Northern Province), Sudan, Swaziland, Tanzania, Uganda, Zambia, Zimbabwe

Also commonly known under the name Pygeum africanum, this species is widespread from the African tropics to Madagascar and South Africa. Throughout much of its range, most notably Cameroon and Madagascar, the unsustainable exploitation of its bark and to a lesser degree its timber have caused rapid population declines. It is too rare in some countries to be of commercial use and is most commonly exploited for the local market. An important element in the ecosystem, it is reported to regenerate well. It is listed in *CITES Appendix II and protected in various protected areas.

Assessor: World Conservation Monitoring Centre

Refs: $2361,2773,6396,6718,9605,14778,16021$. 16730

\section{Prunus carolinae}

Rosaceae

CR B $1+2 c$

Colombia

An endemic to Cundinamarca.

Assessor: Calderon, E.

Refs: 19069

\section{Prunus ceylanica}

Rosaceae

EN B $1+2 c$

Sri Lanka

A rare species which was found in only three localities during the extensive forest surveys conducted for the National Conservation Review.

Assessor: World Conservation Monitoring Centre

Refs: 19112

\section{Prunus clementis}

Rosaceae

Indonesia (Sulawesi), Philippines

LR/nt

This tree occurs in primary and secondary forest on volcanic and ultrabasic soils on Mindanao Island in the Philippines, and north and central Sulawesi. There have been no recent collections from the Philippines and only a few new collections from Sulawesi. Central Sulawesi has the largest tract of forest on ultrabasic rock in the tropics.

Assessor: Kalkman, C.

Refs: 563, 19045

\section{Prunus ernestii}

Rosaceae

CR B $1+2 c$

Colombia

An endemic to Cundinamarca.

Assessor: Calderon, E.

Refs: 19069 


\section{Prunus grisea var. tomentosa}

Rosaceae

Philippines

VU Ald

An endemic variety to the Philippines. Rates of habitat loss through logging and shifting cultivation have led to considerable population declines.

Assessor: World Conservation Monitoring Centre

Refs: 4986

\section{Prunus kinabaluensis}

Rosaceae

$\mathrm{LR} / \mathrm{cd}$

Malaysia (Sabah), Philippines

This tree is found on Mount Kinabalu, Sabah, and has recently been discovered on Luzon in the Philippines. The population within Mount Kinabalu National Park is protected.

Assessor: Kalkman, C.

Refs: $563,1766,19045$

\section{Prunus laxinervis}

Rosaceae

VU D2

Indonesia (Kalimantan), Malaysia (Sabah)

This shrub or small tree is found in primary forest on Mount Kinabalu and in West Kalimantan. On Mount Kinabalu, this species has not been collected since 1930, although the area is well explored. The only specimen from West Kalimantan was collected in 1989.

Assessor: Kalkman, C.

Refs: 563, 1766, 19045

\section{Prunus lusitanica ssp. azorica}

Rosaceae

$\mathrm{EN} \mathrm{Bl+2ce}$

Portugal (Azores)

A low-growing tree which is found in deep narrow ravines and in stands of undisturbed laurel-juniper forest. Occurrences have been recorded from the islands of São Miguel, Terceira, São Jorge and Pico but in recent years only a few specimens have been found on Pico da Vara and Lombadas on Sāo Miguel and on Pico. Clearing of the habitat for agriculure and plantations, and the invasion of introduced plants and animals, are the most serious problems.

Assessor: World Conservation Monitoring Centre

Refs: 19131

\section{Prunus lusitanica ssp. hixa}

Rosaceae

VU D2

Portugal (Madeira), Spain (Canary Is.)

In Madeira, the species is known only from a single location on the north coast in a small area of the *laurisilva within the National Park of Madeira. There is no regeneration by seed and only one stand of planted specimens has produced seed crops. Only a few populations exist in the *laurisilva of the central Canary Islands.

Assessor: World Conservation Monitoring Centre

Refs: 19131

\section{Prunus lusitanica ssp. lusitanica}

Rosaceae

EN A2c

France, Morocco, Portugal, Spain

Widely scattered in moist forest enclaves in the Iberian Peninsula and in humid ravines in the north of the Rif Mountains in Morocco, the species represents a relict component of a Tertiary ecosystem which has retreated with the drying of the climate. Remaining populations are isolated and threatened with fire, overcutting and forest management activities, as well as a decline in the availability of water.

Assessor: Vivero, J.L. el al.

Refs: 7741

\section{Prunus mirabilis}

Rosaceae

Malaysia (Sabah)

VU D2

This tree is endemic to Mount Kinabalu, where it is found in mossy forest. It has been collected just four times, the most recent collection dating to 1964. This species is protected in Mount Kinabalu National Park.

Assessor: Kalkman, C.

Refs: $563,1766,19045$

\section{Prunus odorate}

Rosaceae

Malaysia (Peninsular Malaysia)

This species is confined to moist forest in the Cameron Highlands, in the state of Pahang. Information on the taxonomy and conservation of the species is insufficient. The area is experiencing increasing settlement and tourism. Populations are thought to receive some protection within the permanent forest estate.

Assessor: Chua, L.S.L.

Refs: $563,8464,19073$

\section{Prunus pulgarensis}

Rosaceae

Philippines

EN Alc

A small forest tree known from only four collections from mountains on Palawan and Luzon. Both islands have suffered from massive deforestation. No new material of this species has been collected since 1965 , even though there have been collecting expeditions to Palawan since.

Assessor: Kalkman, C.

Refs: $563,4986,19045$

\section{Prunus ramburii}

Rosaceae

Spain

VU B $1+2 \mathrm{C}$

A species endemic to the Andalusian Sierras, occurring in dry montane scrub, where populations are affected by fire, tourism and lack of pollinators. It is used locally to make an alcoholic drink. A conservation plan for the species is being developed by Cordoba Botanic Garden.

Assessor: Vivero, J.L. et al.

Refs: 5287, 7222, 7741

\section{Prunus rubiginosa}

Rosaceae

Philippines

A very rare forest tree known from only five collections from Luzon, Mindoro, Sibuyan and Mindanao Islands.

Assessor: Kalkman, C

Refs: 563

\section{Prunus subglabra}

Rosaceae

Philippines

VU D2

A small tree restricted to forest on Mount Pulog and Mount Tabayog on Luzon. Despite Mount Pulog being relatively well explored, the species remains poorly known and has been collected only three times, most recently in 1968 .

Assessor: Kalkman, C

Refs: 563,19045 


\section{Prunus taiwaniana}

Rosaceae

VU D1+2

Taiwan

Restricted to the northem part of the central mountain range, this omamental tree occurs in isolated populations in mixed montane forest. The species is unprotected throughout its range and observations indicate that regeneration is poor. The effects of increasing settlement of the land and forest management activities are also threatening some populations.

Assessor: Lu, S.Y. \& F.J. Pan

Refs: $6469,19050,19053$

\section{Prunus transarisanensis}

Rosaceae

$\mathrm{LR} / \mathrm{nt}$

Taiwan

A shrubby tree, endemic to Taiwan and widely scattered in the northern half of the central mountain range. It occurs in forest between 1600 and $2800 \mathrm{~m}$.

Assessor: Lu, S.Y. \& F.J. Pan

Refs: 6469, 19053

\section{Prunus turfosa}

Rosaceae

EN Alc $+2 c$

Brunei?, Indonesia (Kalimantan), Malaysia (Sarawak)

This tree is confined to peat-swamp forest in Sarawak, although a similar specimen has been collected from West Kalimantan on the border with Sarawak. It may also occur in Brunei Darusalaam. The peat-swamp forest of Sarawak has been licensed for timber extraction. There has been no botanical collecting in the area since 1961.

Assessor: Kalkman, C.

Refs: 563, 1766, 19045

Prunus villegasiana

Rosaceae

$\mathrm{EN} \mathrm{B} 1+2 \mathrm{c}$

Colombia

An endemic to Valle.

Assessor: Calderon, E.

Refs: 19069

Prunus walkeri

Rosaceae

VU Alc

Sri Lanka

A tree restricted to the lowland wet evergreen forests of south-west Sri Lanka.

Assessor: World Conservation Monitoring Centre

Refs: 15431, 17195

\section{Pseudagrostistachys africana}

Euphorbiaceae

VU Alc, B1+2c

Cameroon, Equatorial Guinea (Bioko, Equatorial Guinea), Ghana, Nigeria, São Tomé \& Príncipe (São Tomé)

A species which is found mainly in montane forest in the Lower Guinea region. In Nigeria it occurs only on the Obudu Plateau, where fires and encroaching agriculture are causing damage to the restricted areas of remaining vegetation in forested valleys. An anomalous occurrence is known in Ghana, where it is highly localised but common in evergreen rainforest along a river bank. General threats from mining, logging and commercial forestry can affect these areas. This is the only species in the genus.

Assessor: Hawthorne, W.

Refs: $2773,8369,8854,11504,12061$

\section{Pseudobombax argentinum}

Bombacaceae

DD

Argentina (Jujuy, Salta), Bolivia, Brazil (Sāo Paulo), Paraguay

A scarce species of low to middle elevation forest types. The Argentinian population is threatened because its habitat is rapidly being converted into cattle ranches. Assessor: Prado, D.

Refs: 1262,5112

\section{Pseudocarapa championü}

Meliaceae

VU Alc

Sri Lanka

A species restricted to the lowland rainforest in southwest Sri Lanka.

Assessor: World Conservation Monitoring Centre

Refs: 9176,17195

\section{Pseudoeugenia tenuifolia}

Myrtaceae

$\mathrm{EN} B 1+2 \mathrm{c}$

Malaysia (Peninsular Malaysia)

A lowland forest tree, known only from two collections. One collection originated from Kamasul Forest Reserve, which is now being established as an artificial plantation. It is hoped that there is a population within the Virgin Jungle Reserve in Selangor.

Assessor: Chua, L.S.L

Refs: 8464, 19073, 19182

\section{Pseudoglochidion anamalayanum}

Euphorbiaceae

$\mathrm{CR} B 1+2 \mathrm{C}$

India (Tamil Nadu)

A monotypic genus known only from the two collections from a small area of submontane forest in the Anamalai Hills in Coimbatore District. There are large areas of intact and well-protected forest. However, despite repeated botanical surveys, the species has not been found since 1912.

Assessor: World Conservation Monitoring Centre

Refs: 4799, 19144

\section{Pseudolmedia hirtula}

\section{Moraceae}

$\mathrm{EN} \mathrm{B1+2bc}$

Brazil

A forest species known only from the coastal region between Rio de Janeiro and Santa Catarina.

Assessor: Carauta, J.P.P.

Refs: $7980,15717,19101$

\section{Pseudopanax ferox}

Araliaceae LR/nt

New Zealand (North Is., South Is.)

A small tree with a local occurrence.

Assessor: de Lange, P.J.

Refs: 902, 9800, 19133

\section{Pseudopanax gilliesii}

Araliaceae

LR/nt

New Zealand (North Is.)

Thorough surveys have found this species to be widespread. It occurs as a small tree or shrub in regenerating *kauri forest and coastal shrubland in north Auckland. Regeneration is good and the species is often planted as an omamental.

Assessor: World Conservation Monitoring Centre Refs: $902,9800,17637,19134$ 
Pseudopanax scopoliae

Araliaceae

VU B1 $+2 c$

New Caledonia

Assessor: Jaffre, T. et al.

Refs: 10351

\section{Pseudophoenix ekmanii}

Palmae

CR Bl $+2 \mathrm{c}$

Dominican Republic

This palm tree is restricted to dry lowland scrub on the Barahona Peninsula. The population has been depleted by previous felling of trees for the production of palm wine. Present threats are grazing and agriculture.

Assessor: Johnson, D.

Refs: 19118

\section{Pseudophoenix lediniana}

Palmae

CR D1

Haiti

A rare palm tree restricted to dry scrub in river valleys in the south-west peninsula. In 1989 only 30 trees were found in the wild. Locally the fruit is fed to livestock.

Assessor: Johnson, D.

Refs: 19118

\section{Pseudosalacia streyi}

Celastraceae

VU A2c

South Africa (Eastem Cape, KwaZulu-Natal)

A shrub or small tree, endemic to Pondoland in southern KwaZulu-Natal and the eastern Transkei area of the Eastern Cape. It is found along sandstone streams or in moist places in evergreen forests, sometimes in small groves, near the coast from Uvongo to Port St. John's. At many localities there is poor regeneration. It occurs in a number of publicly owned protected areas in the region, including many of the demarcated forest areas in Transkei, which are no longer strictly protected. Habitat destruction through cutting for firewood and timber and increasing settlement pose a problem here and in southem KwaZulu-Natal.

Assessor: Hilton-Taylor, C. et al.

Refs: 689,19218

\section{Pseudosamanea cubana}

Leguminosae

VU B $1+2 c$

Cuba

Endemic to south-eastem Cuba, this tree grows in palmsavanna and subcoastal dry evergreen forest. The goodquality construction timber has been overexploited for years.

Assessor: Areces-Mallea, A.E.

Refs: 5994, 19149

Pseudosciadium balansae

Araliaceae

VU B $1+2 c$

New Caledonia

Assessor: Jaffré, T, et al.

Refs: 10351

\section{Pseudoscolopia polyantha}

Flacourtiaceae

LR/nt

South Africa (Eastern Cape, Western Cape, KwaZuluNatal)

A shrub or small tree, found mainly on forest margins in the Transkei, Eastern Cape, and southem KwaZuluNatal, with a disjunct distribution in the Noodsberg area of KwaZulu-Natal and a very strange isolated occurrence on the Piketberg in the Western Cape. Many of the subpopulations occur on soils derived from sandstone. The species occurs in the Umtamvuna Nature Reserve and in a number of demarcated forest areas in the Transkei, which are no longer strictly protected. Habitat destruction through cutting for firewood and timber and increasing settlement could pose a problem here, especially at forest margins.

Assessor: Hilton-Taylor, C et al.

Refs: 689,19218

Pseudospondias microcarpa var. hirsuta

Anacardiaceae

VU Bl+2c

Nigeria

A variety which is very similar to the Africa-wide type variety. It appears to occur in forest areas fringing forest-savanna mosaic only in south-west Nigeria. Forests in the country have been extensively logged and cleared for commercial and subsistence agriculture. Assessor: World Conservation Monitoring Centre Refs: 2773, 11504

\section{Pseudotaxus chienii}

Taxaceae

EN Alc

China (Guangdong, Guangxi, Hunan, Jiangxi, Zhejiang) A generally rare and scattered species occurring in densely forested areas in limestone gullies or on cliffs. In addition to habitat deterioration, the species appears to be suffering from inadequate pollination of female plants.

Assessor: SSC Conifer Specialist Group

Refs: $1818,11191,13041$

\section{Pseudotsuga macrocarpa}

Pinaceae

LR/nt

USA (Califomia)

Assessor: SSC Conifer Specialist Group

Refs: 374,13041

\section{Pseudotsuga sinensis var. brevifolia}

Pinaceae

VU B $1+2 c$

China (Guangxi)

The variety is given species status in China. It is confined to areas of sparse forest on limestone hills in south-west Guangxi and southern Guizhou. There is some overcutting.

Assessor: SSC Conifer Specialist Group

Refs: $374,11191,11847,13041$

\section{Pseudotsuga sinensis var. gaussenii}

Pinaceae

LR/nt

China (Anhui, Fujian?, Sichuan, Zhejiang)

The taxon is treated as a distinct species in China. Trees are scattered on slopes and in valleys below $1500 \mathrm{~m}$ in south-east Anhui, north Zhejiang and Jiangxi. There is also a record from Jianning in Fujian. Constant overcutting of the tree and its habitat are a threat and the seeds are said to have poor viability. A substantial population is protected in Lin'an County, Zhejiang.

Assessor: SSC Conifer Specialist Group

Refs: 374, 11191, 11847, 13041

\section{Pseudotsuga sinensis var. sinensis}

Pinaceae

VUAlcd

China (Guizhou, Hubei, Hunan, Shaanxi, Sichuan, Yunnan), Taiwan

The taxon is widespread, but scattered as isolated individuals or in small stands, primarily on mountain ridges in mixed submontane forest. The Taiwan populations are known in the country under the synonym $P$. wilsoniana. They are restricted to the central and 
northern parts of the main mountain range, where the forest is being extensively cleared for apple and peach orchards. The timber is extracted extensively throughout the species' range but most thoroughly in accessible areas.

Assessor: SSC Conifer Specialist Group

Refs: $374,1818,2802,19050,19127$

\section{Pseudoxandra williamsii}

Annonaceae

VU D2

Pen

Known only from the type collection, the species occurs in the department of Loreto.

Assessor: World Conservation Monitoring Centre

Refs: 1984

\section{Pseuduvaria cerino}

Annonaceae

VU D2

Malaysia (Peninsular Malaysia)

A lowland forest tree, known only from a single collection gathered in Bukit Bauk Forest Reserve, a permanent forest reserve in Terengganu.

Assessor: World Conservation Monitoring Centre

Refs: 8464, 19073

\section{Pseuduvaria galeata}

Annonaceae

LR/cd

Malaysia (Peninsular Malaysia)

Confined to south-east Johore, the collection localities of

this lowland forest species are being developed for agriculture and resorts. It may occur in the permanent forest reserves in this state.

Assessor: Kochummen, K.M.

Refs: 17140,19073

\section{Pseuduvaria nervosa}

Annonaceae

VU D2

Malaysia (Peninsular Malaysia)

A tree known only from a single collection from the hill forests at Ulu Berang-tersat, Terengganu. It is hoped that the species falls within the permanent forest reserve system.

Assessor: Kochummen, K.M.

Refs: 19073

\section{Pseuduvaria prainii}

\section{Annonaceae}

VU B $1+2 \mathrm{c}$

India (Andaman and Nicobar Is. - Andaman Is., Andaman and Nicobar Is. - Nicobar Is.)

A species endemic to the evergreen rainforest of the Andaman Islands and Great Nicobar Island. Large-scale logging has taken place on the Andamans and there is no doubt that the species has declined as a result.

Assessor: World Conservation Monitoring Centre

Refs: 4799

\section{Pseuduvaria taipingensis}

Annonaceae

LR/cd

Malaysia (Peninsular Malaysia)

A locally common species restricted to montane forest on Maxwell's Hill in Perak. This locality is going to be developed as a tourist resort but most of the existing forest will be conserved in the protected forests.

Assessor: Kochummen, K.M.

Refs: 19073

\section{Psidium cinereum}

Myrtaceae

LR/nt

Brazil

Assessor: Barroso, G.M.

Refs: 19097, 19098

\section{Psidium dumetorum}

Myrtaceae

EX

Jamaica

Once known from a restricted area of streamside thicket in Clarendon, the species has not been collected since 1976 and is now presumed extinct. The habitat in the area has been completely cleared.

Assessor: Kelly, D.L.

Refs: 5653, 19085

\section{Psidium harrisianum}

Myrtaceae

LR/nt

Jamaica

An uncommon small tree or shub. It appears on wooded rocky limestone hilltops in the central parishes.

Assessor: World Conservation Monitoring Centre

Refs: 401, 6057, 7980

\section{Psidium havanense}

Myrtaceae

$\mathrm{EN} \mathrm{B1}+2 \mathrm{c}$

Cuba

An uncommon shrub or small tree restricted to the remaining dry evergreen scrub and scrub forests on serpentine outcrops in the Habana and Ciudad de la Habana Provinces. Habitat loss from cutting, buming, grazing and housing development has caused a decline in the species.

Assessor: Areces-Mallea, A.E

Refs: $11403,18485,19149$

\section{Psidium rostratum}

Myrtaceae

VU D2

Peru

This species is restricted to coastal forest in the department of Tumbes.

Assessor: World Conservation Monitoring Centre

Refs: 1984

\section{Psidium rufum var, widgrenianum}

Myrtaceae

VU B1+2acd

Brazil

Assessor: Pires O'Brien, J.

Refs: 19097,19098

\section{Psidium sintenisii}

Myrtaceae

CR D1

Puerto Rico

A total of three or four very small populations are known from mossy wet forest on summits and peaks, principally in $\mathrm{El}$ Yunque. There is no evidence of regeneration.

Assessor: World Conservation Monitoring Centre

Refs: $7980,17124,17540$

\section{Psoralea arborea}

Leguminosae

South Africa (KwaZulu-Natal), Swaziland

The taxonomy and irue identity of this taxon is not fully resolved, especially its relationship with $P$. pinnata. A previous account by Prof. $C$. Stirton indicates that urban expansion, land drainage and dam building and frequent fires are major threats to the species. However as no 
information can be traced on its precise distribution and abundance its conservation status must remain data deficient.

Assessor: Hilton-Taylor, C. et al.

Refs: $689,19218,19219$

\section{Psychotria adamsonii}

Rubiaceae

DD

French Polynesia (Marquesas Is.)

The species has been collected only from Ua Pou from the Pepehitoua valley at about $760 \mathrm{~m}$.

Assessor: Florence, J.

Refs: 14513

\section{Psychotria alsophila}

Rubiaceae

VU Bl+2b

Kenya, Tanzania

Known only from Ngangao forest in the Taita Hills in Kenya and a slightly larger area in Tanzania, this shrub or small tree is restricted to patches of dry forest at medium to high altitude.

Assessor: Lovett, J. \& G.P. Clarke

Refs: $3356,6396,8814$

\section{Psychotria atricaulis}

Rubiaceae

LR/nt

French Polynesia (Society Is.)

The species is known only from Huahine.

Assessor: Florence, J.

Refs: 14513

\section{Psychotria beddomei}

Rubiaceae

$\mathrm{EN} \mathrm{B1}+2 \mathrm{c}$

India (Kerala)

Known only from the type collection, this small tree is recorded from a restricted area of forest at medium elevation, in the Agastyamalai Hills. Large areas have been exposed to fires, grazing, the establishment of commercial plantations and cutting for fuelwood, but almost $1000 \mathrm{~km}^{2}$ of forest are now under protection within sanctuaries.

Assessor: World Conservation Monitoring Centre

Refs: 5651,19144

\section{Psychotria bryonicola}

Rubiaceae

Jamaica

CR C2b

There is very little information on this species. It evidently occurs very rarely in Portland at $750 \mathrm{~m}$.

Assessor: World Conservation Monitoring Centre

Refs: 401, 5653, 7980

\section{Psychotria cathetoneura}

Rubiaceae

VU D2

Cuba

Confined to the forests of El Yunque de Baracoas in Guantánamo Province, this shrub or small tree is localised in a small area on limestone and dolomite.

Assessor: Areces-Mallea, A.E.

Refs: 11403, 18485, 19149

\section{Psychotria clarendonensis}

Rubiaceae

$\mathrm{EN} \mathrm{Bl+2c}$

Jamaica

Small populations are known only from Clarendon Parish, where they are restricted to rocky limestone hilltops at about $760 \mathrm{~m}$.

Assessor: Kelly, D.L.

Refs: 401, 5653, 7980, 19085
Psychotria clusioides

Rubiaceae

EN Bl $+2 \mathrm{C}$

Jamaica

A tree confined to rainforest on limestone in Portland between 530 and $600 \mathrm{~m}$.

Assessor: World Conservation Monitoring Centre

Refs: $401,5653,7980$

\section{Psychotria congesta}

Rubiaceae

DD

Jamaica

There are no recent records of this obscure species. It is believed to be endemic and is evidently very uncommon. There is a possibility that it is conspecific with $P$. dolphinensis.

Assessor: World Conservation Monitoring Centre Refs: 401,5653

\section{Psychotria cookei}

Rubiaceae

French Polynesia (Society Is.)

The species is known only from Raiatea.

Assessor: Florence, J.

Refs: 14513

\section{Psychotria crassipetala}

Rubiaceae

VU B $1+2 c$

Kenya

A shrub or tree to $12 \mathrm{~m}$, endemic to submontane forest in the Taita Hills.

Assessor: World Conservation Monitoring Centre Refs: $1308,6396,13072$

\section{Psychotria cyathicalyx}

Rubiaceae

VU $B 1+2 b$

Tanzania

A moist montane forest tree locally common in the West Usambara Mountains, the Uluguru Mountains and also Mount Kilimanjaro.

Assessor: Lovett, J. \& G.P. Clarke

Refs: 3356,8814

\section{Psychotria danceri}

Rubiaceae

CR B $1+2 \mathrm{C}$

Jamaica

Previously the species was known only from the type specimen with no definite locality. In 1992 a population was found in submontane rainforest on Holland Mountain.

Assessor: World Conservation Monitoring Centre Refs: 5653

\section{Psychotria dasyophthalma}

Rubiaceae

VU $B 1+2 c$

Jamaica

Known only from St Andrew and Manchester Parishes, the species is found in localised areas of dense thicket on limestone hills.

Assessor: Kelly, D.L.

Refs: 401, 5653, 7980, 19085

\section{Psychotria deverdiana}

Rubiaceae

$\mathrm{EN} \mathrm{B} 1+2 \mathrm{c}$

New Caledonia

Assessor: Jaffré, T, et al.

Refs: 10351 


\section{Psychotria dolichantha}

Rubiaceae

LR/nt

Jamaica

Known from the central parishes, the species is not uncommon and occurs in thickets and woodland on rocky limestone.

Assessor: World Conservation Monitoring Centre Refs: 6057,7980

\section{Psychotria domatiata}

Rubiaceae

$\mathrm{VU} B \mathrm{~B}+2 \mathrm{c}$

Jamaica

Confined to Portland, the species occurs in remaining areas of rainforest and mossy thickets on limestone between 530 and $900 \mathrm{~m}$.

Assessor: World Conservation Monitoring Centre

Refs: 401, 5653, 7980, 17743

\section{Psychotria dubia}

Rubiaceae

VU Alc

Sri Lanka

A species occurring in the lowland wet evergreen forests of south-west Sri Lanka.

Assessor: World Conservation Monitoring Centre Refs: 9176, 17195

\section{Psychotria elachistanthe}

\section{Rubiaceae}

VU B1 + 2b, D2

Tanzania

Endemic to the Uluguru Mountains, this species is confined to high elevations in moist evergreen forest.

Assessor: Lovett, J. \& G.P. Clarke

Refs: 3356,8814

\section{Psychotria foetens}

Rubiaceae

VU B $1+2 c$

Jamaica

An uncommon tree known only from localities in St Elizabeth and St Mary.

Assessor: World Conservation Monitoring Centre

Refs: 401, 5653, 7980

\section{Psychotria franchetiana}

\section{Rubiaceae}

French Polynesia (Society Is.)

Populations are recorded from Moorea and Tahiti.

Assessor: Florence, J.

Refs: 14513

\section{Psychotria gardneri}

\section{Rubiaceae}

$\mathrm{EN} \mathrm{B1}+2 \mathrm{C}$

Sri Lanka

A rare species found in only five localities during the extensive forest surveys conducted for the National Conservation Review.

Assessor: World Conservation Monitoring Centre

Refs: 19112

\section{Psychotria glandulifera}

Rubiaceae

$\mathrm{EN} \mathrm{B1+2c}$

Sri Lanka

A tree restricted to the lowland wet evergreen forests of south-west Sri Lanka. It was found in only five forests in the Ratnapura and Matara Districts during the extensive forest surveys conducted for the National Conservation Review.

Assessor: World Conservation Monitoring Centre

Refs: 8203, 17195, 18796

\section{Psychotria globicephala}

Rubiaceae

$\mathrm{EN} B I+2 \mathrm{C}$

India (Kerala, Tamil Nadu)

A shrubby species, collected from forest in approximately five localities between the southern Nilgiris and the Agastyamalai Hills.

Assessor: World Conservation Monitoring Centre

Refs: 14276,19144

\section{Psychotria goetzei var. goetzei}

Rubiaceae

VU $B l+2 b$

Tanzania

A variant of an east Tanzanian endemic. This is a shrub or small tree restricted to areas of moist evergreen forest over $1100 \mathrm{~m}$ in altitude.

Assessor: Lovett, J. \& G.P. Clarke

Refs: 3356,8814

\section{Psychotria goetzei var. platyphylla}

Rubiaceae

VU $B 1+2 b$

Tanzania

A variant of slightly lower altitudes than the type variety. It is" confined to areas of moist semi-deciduous forest between 950 and $1650 \mathrm{~m}$.

Assessor: Lovett, J. \& G.P. Clarke

Refs: 3356,8814

\section{Psychotria grandiflora}

Rubiaceae

EN C2a

USA (Hawaii)

Endemic to Kauai Island, the species occurs in rainforest between altitudes of 1040 and $1230 \mathrm{~m}$ in Kokee and Alakai Swamp.

Assessor: World Conservation Monitoring Centre

Refs: 3372

\section{Psychotria grantii}

Rubiaceae

$\mathrm{CR} B 1+2 \mathrm{C}$

French Polynesia (Society Is.)

The species is known only from Tahiti.

Assessor: Florence, J.

Refs: 14513

\section{Psychotria greenwelliae}

Rubiaceae

VU D2

USA (Hawaii)

A rainforest species known only in the vicinity of Kokee.

Assessor: World Conservation Monitoring Centre

Refs: 3372

\section{Psychotria guerkeana}

Rubiaceae

VU D2

São Tomé \& Príncipe (Sāo Tomé)

A shrub or small tree collected several times, recently mostly from Pico.

Assessor: World Conservation Monitoring Centre Refs: 2724

\section{Psychotria hanoverensis}

Rubiaceae

CR C2b

Jamaica

Confined to Hanover, the species is very uncommon and little known.

Assessor: World Conservation Monitoring Centre Refs: 401, 5653, 7980 


\section{Psychotria hierniana}

\section{Rubiaceae}

São Tomé \& Príncipe (São Tomé)

A species found in forest in the south-west of the island in Porto Alegre and Monte Café. Areas remain to be explored, although most of the original forest below $1500 \mathrm{~m}$ was cleared in the first half of the century.

Assessor: World Conservation Monitoring Centre

Refs: 2724, 10080

\section{Psychotria hobdyi}

Rubiaceae

EN C2a

USA (Hawaii)

A species very localised in distribution known only from the Milolii-Kopiwai area on Kauai within an altitudinal band of just $10 \mathrm{~m}$.

Assessor: World Conservation Monitoring Centre Refs: 3372

\section{Psychotria le-bronnecii}

Rubiaceae

French Polynesia (Marquesas Is.)

Populations are recorded from Fatu Hiva, Hiva Oa and Tahuata.

Assessor: Florence, J.

Refs: 14513

\section{Psychotria lepiniana}

Rubiaceae VU B $1+2 c$

French Polynesia (Society Is.)

The species is known only from Tahiti.

Assessor: Florence, J.

Refs: 14513

\section{Psychotria longipetiolata}

Rubiaceae

Sri Lanka

$\mathrm{EN} \mathrm{B} 1+2 \mathrm{c}$

Apparently confined to Ratnapura District, this rare species has been found in only three localities during the extensive forest surveys conducted for the National Conservation Review.

Assessor: World Conservation Monitoring Centre

Refs: 8203, 18796, 19112

\section{Psychotria macrocarpa}

Rubiaceae

India (Kerala, Tamil Nadu)

$\mathrm{EN} \mathrm{B} 1+2 \mathrm{c}$

This shrubby tree has been collected only once from evergreen forest in the Travancore range.

Assessor: World Conservation Monitoring Centre

Refs: 19144

\section{Psychotria megalopus}

Rubiaceae

VU B $1+2 b$

Tanzania

A shrub or small tree from moist montane forest known only from the Uluguru Mountains, Mahenge and Kigogo.

Assessor: Lovett, J. \& G.P. Clarke

Refs: 3356,8814

\section{Psychotria megistantha}

Rubiaceae

VU B $1+2 b$

Tanzania

Endemic to the North and South Uluguru Mountains, this shrub or small tree is confined to areas of moist montane evergreen forest.

Assessor: Lovett, J. \& G.P. Clarke

Refs: 3356,8814
Psychotria nilgiriensis var. astephana

Rubiaceae

EN B $1+2 c$

India (Tamil Nadu)

A shrubby tree of montane forest, occurring above $2000 \mathrm{~m}$. Only two collections are known, one from the Nilgiris and the other from the Palni Hills.

Assessor: World Conservation Monitoring Centre

Refs: 19144

\section{Psychotria pedunculata var. caudata}

Rubiaceae

LR/nt

Jamaica

One of two varieties of a Jamaican endemic, this is the less common one, confined to central parishes in margins of woodland on rocky limestone.

Assessor: World Conservation Monitoring Centre

Refs: 6057,7980

\section{Psychotria peteri}

Rubiaceae

$\mathrm{VU} B 1+2 \mathrm{~b}$

Tanzania

A species with a very restricted range, known from a small area of moist evergreen forest between 900 and $1000 \mathrm{~m}$ in the East Usambara Mountains. Population pressure and the demand for fertile land have caused a reduction in the forest but a conservation programme is now in place. There is a doubtful record from the Uluguru Mountains.

Assessor: Lovett, J. \& G.P. Clarke

Refs: 3356,8814

\section{Psychotria petitii}

Rubiaceae

VU B1+2c, D2

Kenya

This species is confined to upland moist evergreen forest in the Taita Hills. Specimens which are arguably a new and highly restricted species have been found at higher altitudes in the same location. It is not possible to keep the seeds in long-term storage but the Plant Conservation Programme in Kenya maintains a living collection.

Assessor: World Conservation Monitoring Centre Refs: $1308,6396,13072,17859$

\section{Psychotria plicata}

Rubiaceae

VU B $1+2 c$ Jamaica

A Cockpit Country endemic. It is uncommon and confined to Trelawny and St Ann, where it occurs in woodland on rocky limestone.

Assessor: Kelly, D.L.

Refs: $401,5653,7980,19085$

\section{Psychotria plurivenia}

Rubiaceae

Sri Lanka

$\mathrm{EN} \mathrm{B1+2c}$

During the extensive forest surveys conducted for the National Conservation Review, this species was found in only four of the localities surveyed. It appears to be restricted to the districts of Kegalle and Kandy.

Assessor: World Conservation Monitoring Centre Refs: 8203, 18796, 19112

\section{Psychotria pseudoplatyphylla}

Rubiaceae

VU $B 1+2 b$

Kenya, Tanzania

Ranging from the Taita Hills in Kenya to north-east 
Tanzania, this species is confined to areas of moist montane forest.

Assessor: Lovett, J. \& G.P. Clarke

Refs: $3356,6396,12067$

\section{Psychotria pulchra var. hispidula}

Rubiaceae

$\mathrm{EN} B 1+2 \mathrm{c}$

Jamaica

A variety of potential horticultural interest. It is known only from the parish of Trelawny from a locality at about $530 \mathrm{~m}$.

Assessor: Kelly, D.L.

Refs: 5653, 19085

\section{Psychotria siphonophora}

Rubiaceae

$\mathrm{EN} B 1+2 \mathrm{c}$

Jamaica

A limestone woodland species. It appears to have been collected from only a single location at about $600 \mathrm{~m}$ near Troy.

Assessor: Kelly, D.L.

Refs: $401,5653,7980,19085$

\section{Psychotria sordida}

Rubiaceae

$\mathrm{EN} \mathrm{Bl}+2 \mathrm{c}$

Sri Lanka

A rare species found in only two wet zone forests during the extensive forest surveys conducted for the National Conservation Review.

Assessor: World Conservation Monitoring Centre

Refs: 19112

\section{Psychotria speciosa}

Rubiaceae

CR B $1+2 c$

French Polynesia (Society Is.)

The species is endemic to Tahiti.

Assessor: Florence, J.

Refs: 14513

\section{Psychotria stenophylla}

Rubiaceae

VUAlc

Sri Lanka

This species was found in 17 localities during the extensive forest surveys conducted for the National Conservation Review.

Assessor: World Conservation Monitoring Centre

Refs: 8203, 18796, 19112

\section{Psychotria tahitensis}

Rubiaceae

$\mathrm{CR} \mathrm{B} 1+2 \mathrm{c}$

French Polynesia (Society Is.)

The species is endemic to Tahiti.

Assessor: Florence, J.

Refs: 14513

\section{Psychotria taitensis}

Rubiaceae

VU B $1+2 \mathrm{c}$

Kenya

A small tree of evergreen forest between 1400 and $1600 \mathrm{~m}$, endemic to Kasigau.

Assessor: World Conservation Monitoring Centre

Refs: $1308,6396,13072$

\section{Psychotria trichocalyx}

Rubiaceae

CR B $1+2 c$

French Polynesia (Society Is.)

An endemic to Tahiti.

Assessor: Florence, J.

Refs: 14513

\section{Psychotria tubuaiensis}

Rubiaceae

DD

French Polynesia (Tubuai Is.)

An endemic to Tubuai.

Assessor: Florence, J.

Refs: 14513

\section{Psychotria waasii}

Rubiaceae

U Alc, B1+2c

Sri Lanka

During the extensive forest surveys conducted for the National Conservation Review, this wet zone species was found in only seven of the surveyed sites.

Assessor: World Conservation Monitoring Centre

Refs: 19112

\section{Psychotria woytkowskii}

Rubiaceae

VU D2

Peru

This species is known only from the type collection taken from the department of Amazonas.

Assessor: World Conservation Monitoring Centre

Refs: 1984

\section{Psychotria zombamontana}

Rubiaceae

LR/nt

Tanzania, Zimbabwe

Confined to areas of moist montane forest, the species occurs in east and south Tanzania, Malawi and Zimbabwe.

Assessor: Lovett, J. \& G.P. Clarke

Refs: $3356,8814,13191$

\section{Psydrax faulknerae}

Rubiaceae

VU Bl+2b

Kenya, Tanzania

A species ranging from a few localities of dry coastal forest or thicket in Kenya to areas of east Tanzania.

Assessor: Lovett, J. \& G.P. Clarke

Refs: $3356,6396,8814$

\section{Psydrax kibuwae}

Rubiaceae

VU B $1+2 b, D 2$

Tanzania

A poorly known tree recorded only from the type, which was collected at Kiwanda along the Sigi River in the East Usambara Mountains.

Assessor: Lovett, J. \& G.P. Clarke

Refs: 3356, 10961

\section{Psydrax micans}

Rubiaceae

VU B $1+2 b$

Mozambique, Tanzania

A dry coastal forest small tree ranging from south-east Tanzania to Mozambique.

Assessor: Lovett, J. \& G.P. Clarke

Refs: $1308,3356,8814$

\section{Psydrax paradoxa}

Rubiaceae

VU B $1+2 c$

New Caledonia

Assessor: Jaffré, T. et al.

Refs: 10351

Pteleopsis barbosae

Combretaceae

DD

Assessor: Bandeira, S

Refs: 5117,18965 


\section{Pteleopsis habeensis}

Combretaceae

Ghana, Mali, Nigeria

EN Alc, B1+2c

Three localities, which account for little more than a few square kilometres, are known: the Bandiagara scarps in Mali, Yankari Game Reserve in Nigeria and the dry forests of Bui and Akosombo in Ghana. In Yankari it grows on rocky hills, in dense stands in an area that is under pressure from encroachment. In Ghana the establishment of a plantation and the influx of people into the area have caused declines in the species' habitat. Assessor: Hawthome, W.

Refs: $6127,7439,8369,12061$

\section{Pteleopsis tetraptera}

Combretaceae

LR/nt

Kenya, Tanzania

A species of coastal forest or scrub, occurring in a small area which is densely populated and much modified by human activities.

Assessor: World Conservation Monitoring Centre

Refs: $6396,9198,17787,18829$

\section{Pteralyxia kauaiensis}

Apocynaceae

USA (Hawaii)

EN C2a

This species grows on slopes and ridges in various lowland moist forest types. It is known from nine populations, consisting of between 500 and 1000 individuals in total. The habitat continues to be degraded by feral goats, pigs and invasive plants. The species is protected by the US Endangered Species Act.

Assessor: World Conservation Monitoring Centre

Refs: 3372, 19038

\section{Pteralyxia macrocarpa}

Apocynaceae

VU C2a

USA (Hawaii)

An endemic to Oahu Island, where the species is scattered sparsely in moist forest up to $730 \mathrm{~m}$ in the Waianae and Koolau Mountains.

Assessor: World Conservation Monitoring Centre

Refs: 3372

\section{Pterandra isthmica}

Malpighiaceae

EN C2b

Panama

The species is known only from populations in the proximity of the Cerro Azul to the north-east of the city of Panamá. It occurs sparsely in semi-deciduous rainforest between 600 and $900 \mathrm{~m}$. The population in Chagres National Park is well protected.

Assessor: Mitré, M.

Refs: $7980,15037,16772$

\section{Pterocarpus angolensis}

Leguminosae

LR/nt

Angola, Botswana, Democratic Republic of Congo, Mozambique, Namibia, South Africa (KwaZulu-Natal, Mpumalanga, Northem Province), Swaziland, Tanzania, Zambia, Zimbabwe

A key timber species throughout its distribution in woodland areas of East and Southern Africa. Large stands are known to still occur in places, particularly in protected areas in South Africa, Botswana and Namibia. In most regions, however, the species has become less frequent, especially where it is heavily used by local populations. There are attempts to exploit remaining stands sustainably or at least in a regulated way, but in most parts of the range there is no control over the rate of harvesting. Large individuals are reported to be suffering from fungal attack. Regeneration is sufficient but may be episodic, depending on fire or high rainfall. Individuals are reproductively mature at 15-20 years old.

Assessor: World Conservation Monitoring Centre Refs: $3344,6723,7550,9090,13370,17335,19172$, 19218

\section{Pterocarpus dalbergioides}

Leguminosae DD

India (Andaman and Nicobar Is. - Andaman Is.)

Endemic to the Andaman Islands, this tree is found in deciduous and semi-moist deciduous forests up to $100 \mathrm{~m}$. Trees are cut for narra timber.

Assessor: Asian Regional Workshop

Refs: 5651,9090, 14573

\section{Pterocarpus indicus}

Leguminosae VU Ald

Cambodia, India, Indonesia (Bali, Irian Jaya, Java, Kalimantan, Lesser Sunda Is., Moluccas, Sulawesi, Sumatra), Malaysia (Peninsular Malaysia, Sabah), Myanmar, Papua New Guinea (Bismarck Archipelago, North Solomons, Papua New Guinea), Philippines, Solomon Islands (South Solomon), Sri Lanka, Taiwan, Thailand, Vanuatu, Viet Nam (ex)

A widespread tree found in lowland primary and some secondary forest, mainly along tidal creeks and rocky shores. Populations have declined because of overexploitation, sometimes illegal exploitation, of the narra timber, as well as from increasing general habitat loss. The Viet Nam population has been extinct for some 300 years. An extensive forest survey in Sri Lanka has failed to find the species and information on populations in India, Indonesia and the Philippines indicate the species is seriously threatened. Exploitation of the few known stands in Peninsular Malaysia may have caused its extinction there and what are believed to be the largest remaining populations, in New Guinea, are being heavily exploited. Cultivated populations are widely distributed throughout the tropics.

Assessor: World Conservation Monitoring Centre

Refs: $4919,5550,6125,6156,6426,8058,9328,10013$, $10571,12779,12937,14573,17140,19057,19112$, 19147

\section{Pterocarpus marsupium}

Leguminosae

VU Alcd

Sri Lanka

This dry zone tree is declining in Sri Lanka, as it is exploited for its timber and its medicinal bark and latex. Assessor: World Conservation Monitoring Centre Refs: 1833,19110

\section{Pterocarpus mildbraedii ssp. usambarensis} Leguminosae

VU B $1+2 b$

Tanzania

The species is widespread, extending across the African continent. This is a distinct subspecies, confined to moist lowland forest in eastern Tanzania.

Assessor: Lovett, J. \& G.P. Clarke

Refs: $1308,3356,7550,11631$

Pterocarpus santalinus

Leguminosae

EN B 1+2de

India

Red sandalwood is restricted to the southern parts of the 
Eastern Ghats, where it occurs in dry deciduous forest. The tree is commercially valuable for its timber and for the extraction of dye, medicine and cosmetics. It has been overexploited in the past. International trade is now monitored through a ${ }^{*}$ CITES Appendix II listing and plantations are being established.

Assessor: CAMP Workshops on Medicinal Plants in India

Refs: $561,1228,6508,18325,19074$

\section{Pterogyne nitens}

Leguminosae

LR/nt

Argentina (Chaco, Corrientes, Formosa, Jujuy, Misiones, Salta, Tucumán), Bolivia, Brazil, Paraguay

The species' distibution is contained within an area of seasonally dry forest, extending from northem Argentina into Brazil, Paraguay and Boliva. The habitat is unprotected and in decline because of logging and encroaching agriculture and pastoralism. The species is sought-after as a source of timber. In Bolivia it is one of several species, native to semi-deciduous forest in eastern Santa Cruz, which are experiencing increased logging pressure.

Assessor: Prado, D

Refs: $1262,4506,11936,19170$

\section{Pherospermum kingtungense}

Sterculiaceae

$\mathrm{CR} \mathrm{B} 1+2 \mathrm{c}, \mathrm{C} 2 \mathrm{a}$

China (Yunnan)

Confined to Babianjiang in Yunnan, the species grows in forested valleys on limestone between 1400 and $1500 \mathrm{~m}$. There are very few adult individuals left, although the trees which have been cut are resprouting. The area is not protected and is susceptible to cutting and disturbance.

Assessor: Sun, W.

Refs: $1818,11847,19055$

\section{Pterospermum menglunense}

Sterculiaceae

$\mathrm{CR} \mathrm{B} 1+2 \mathrm{c}, \mathrm{C} 2 \mathrm{a}$

China (Yunnan)

A species confined to a single locality of monsoon forest on limestone hills in Menglun, Mengla County. The population is contained within Xishuangbanna Nature Reserve and should be protected, although illegal cutting is known to take place.

Assessor: Sun, W.

Refs: $1818,11847,19055$

\section{Pterospermum reticulatum}

Sterculiaceae

VU B $1+2 c$

India (Kamataka, Kerala, Tamil Nadu)

Reported to have been frequent in the past, this endemic of the Westem Ghats has become restricted to scattered populations in lowland evergreen forest. Both the tree and its habitat have been extensively exploited.

Assessor: World Conservation Monitoring Centre Refs: 4799,19144

\section{Pterospermum yunnanense}

Sterculiaceae

CR C2a

China (Yunnan)

A Yunnan endemic known only from two locations, Yiwa in Mengla County and Youluo Mountain in Jianghong County. The populations are relatively inaccessible on limestone cliffs and summit ridges. There are few mature individuals and regeneration is poor.

Assessor: Sun, W

Refs: $1818,11847,19055$

\section{Pterostyrax psilophylla}

Styracaceae

VU Alcd China (Guangxi, Guizhou, Hubei, Hunan, Sichuan, Yunnan)

Relatively widespread, the species is found through a range of altitudes and in various forest types. It is, however, not common and believed to be becoming scarcer because of habitat declines and degradation.

Assessor: Sun, W.

Refs: $1818,11847,19055$

\section{Pterygota bequaertii}

Sterculiaceae

VU Alcd

Cameroon, Côte d'Ivoire, Democratic Republic of Congo, Gabon, Ghana, Nigeria

A timber species occurring in forest areas in West and Central Africa. It is much rarer than, but commonly confused with, $P$. macrocarpa. The species appears to be suffering declines because of levels of exploitation through most of its range.

Assessor: Hawthome, W.

Refs: $2773,6127,6128,6718,12061$

\section{Pterygota macrocarpa}

Sterculiaceae

VUAled

Cameroon, Côte d'Ivoire, Ghana, Nigeria, Sierra Leone

A common tree of dry forests. Exploitation for the timber occurs at high levels throughout its range and is likely to be causing population declines. Regeneration is reported to be abundant in areas of logging damage.

Assessor: Hawthome, W.

Refs: $2773,6128,6718,12061$

\section{Ptilochaeta nudipes}

Malpighiaceae

VU B1+2ac

Argentina (Jujuy, Salta), Bolivia

Endemic to the piedmont forest of north-west Argentina and Bolivia, the species is confined to an unprotected ecosystem which is being rapidly replaced by agricultural systems.

Assessor: Prado, D.

Refs: 19122

\section{Ptychopyxis triradiata}

Euphorbiaceae

Malaysia (Peninsular Malaysia)

Only a single collection of the species has been made, gathered from Bota Kiri Forest Reserve in Perek. The surrounding areas are being developed.

Assessor: Kochummen, K.M.

Refs: 8464, 19073

\section{Ptychosperma bleeseri}

Palmae

CR Ale

Australia (Northem Territory)

Restricted to rainforest near Darwin, this palm tree is scattered in the lowlands up to $50 \mathrm{~m}$. The entire population consists of approximately 500 mature individuals and is believed to have stabilised since the exclusion of feral pigs and water buffaloes from the area.

Assessor: Dowl, J.L.

Refs: 19118 
Ptychosperma gracile

Palmae

EN Ala+2c

Papua New Guinea (Bismarck Archipelago)

Confined to New Ireland and New Britain, this palm tree is scattered in rainforest on both limestone and volcanic soils. Populations have declined because of rapid and extensive deforestation for plantation agriculture. This species can survive in open vegetation or in secondary forest if it is allowed to regenerate.

Assessor: Essig, F.B.

Refs: 19118

\section{Ptychosperma hentyi}

Palmae

EN Ala+2c

Papua New Guinea (Bismarck Archipelago)

A taxonomically unique palm tree of lowland forest, restricted to eastern New Britain. Rapid and extensive deforestation for plantation agriculture has caused population decline.

Assessor: Essig, F.B.

Refs: 19118

\section{Pullea perryana}

Cunoniaceae

LR/nt

Fiji

A fairly abundant tree, in forest and thickets on hillsides, crests and ridges in eastem Viti Levu. A single collection has been made in Ovalau.

Assessor: World Conservation Monitoring Centre

Refs: 5515, 6053, 18818

\section{Punica protopunica}

Lythraceae

VU D2

Yemen (Socotra)

The only congeneric relative of the pomegranate, $P$. granatum. The species remains widespread throughout the island on granite and limestone, occurring either as isolated individuals or as a co-dominant in patches of woodland or shrubland.

Assessor: Miller, A.G.

Refs: 2354,19083

Pycnandra kaalaensis

Sapotaceae

VU B $1+2 c$

New Caledonia

Occurring on ultramafic soils, the species is recorded from the base of various isolated massifs in the northwest, such as the southern slopes of Mont Kaala and Mont Poum.

Assessor: Jaffre, T, et al.

Refs: 10351,12630

\section{Pycnocoma littoralis}

Euphorbiaceae

VU $B !+2 b$

Kenya, Tanzania

This species is restricted to areas of dry coastal forest, often on coral, from south-east Kenya to eastem Tanzania.

Assessor: Lovett, J. \& G.P. Clarke

Refs: 3356,8814

\section{Pycnocoma macrantha}

Euphorbiaceae

VU B $1+2 b$

Tanzania

Restricted to moist evergreen forest at medium elevations, this small tree is known only from the East Usambara Mountains and the South Nguru Mountains.

Assessor: Lovett, J. \& G.P. Clarke

Refs: $2074,3356,17190$

\section{Pyracantha koidaumii}

Rosaceae

EN Alacd $+2 b d e, C 2 a$

Taiwan

The species range is confined to the valley between Hualien and Taitung on the eastem side of the island.

Shrubs are common in scrub along river banks and on lowland plains on sandy soils. No large individuals are found in the wild. Exploitation of the plant both for commercial trade and at a local level has led to population declines. Field surveys indicate that seedlings are scartered and few. No conservation or protection measures are in place.

Assessor: Pan, F.J.

Refs: $6469,19050,19053$

\section{Pyrenaria pahangensis}

Theaceae

LR/od

Malaysia (Peninsular Malaysia)

A shrub or small tree confined to lowland rainforest in Pahang. This species is protected in the Taman Negara National Park

Assessor: Chua, L.S.L.

Refs: 8464, 17140, 19073

\section{Pyrenaria serrata var. kunstleri}

Theaceae

VU $B 1+2 c$

Malaysia (Peninsular Malaysia)

A variety found in lowland forest in Kedah, Perak, Penang, Pahang and Selangor.

Assessor: Chua, L.S.L.

Refs: 19073

\section{Pyrus anatolica}

Rosaceae

LR/nt

Turkey

Assessor: Güner, A. \& J. Zielinski

Refs: $3489,4863,19165$

\section{Pyrus hakkiarica}

Rosaceae

Turkey

Assessor: Güner, A

Refs: $3489,4863,19165$

\section{Pyrus oxyprion}

Rosaceae

LR/nt

Turkey

Assessor: Güner, A. \& J. Zielinski

Refs: 3489,19165

\section{Pyrus salicifolia}

Rosaceae

LR/nt

Turkey

Assessor: Güner, A. \& J. Zielinski

Refs: $3489,7222,19165$

\section{Pyrus serikensis}

Rosaceae

VUB $1+2 c$

Turkey

Assessor: Güner, A. \& J. Zielinski

Refs: 3489

\section{Qualea calantha}

Vochysiaceae

VU D2

Peru

Known only from the type collection, the species occurs in Peruvian Amazon forest in the department of Loreto. Assessor: World Conservation Monitoring Centre Refs: 1984 
Qualea impera

Vochysiaceae

VU D2

Peru

The species is known only from the type collection taken from lowland Amazon forest in the department of Loreto.

Assessor: World Conservation Monitoring Centre Refs: 1984

\section{Quararibea aurantiocalyx}

Bombacaceae

EN C2a

Costa Rica, Panama

A species of evergreen rainforest with a restricted altitudinal range, occurring between 1000 and $1200 \mathrm{~m}$. In Panama the species is known only from a small population, containing few mature individuals, in the Cerro Tute in Veraguas. It is a little more widely distributed in Costa Rica, but again few mature individuals exist. The Panamanian population is unprotected and under some threat from deforestation. Further fieldwork is needed to search for populations in the intervening zone between these two locations.

Assessor: Mitré, M.

Refs: 7980,16772

\section{Quararibea dolichopoda \\ Bombacaceae}

EN C2a

Panama

Endemic to Panama, the species is known from a few collections taken from lowland semi-deciduous rainforest within an area stretching from the centre of the country to the Colombian border. It is not common and in most parts of its range the habitat is declining because of the increasing settlement of the land, ranching and agriculture. Only a small part of the population is protected within national parks.

Assessor: Mitré, $\mathrm{M}$.

Refs: $7980,8153,16772$

\section{Quararibea dolichosiphon}

Bombacaceae

VU D2

Panama

This species is known only from the type collection made in 1968.

Assessor: World Conservation Monitoring Centre

Refs: 15037,16772

\section{Quararibea gomeziana}

Bombacaceae

EN C2a

Costa Rica, Panama

Resticted to lowland forest in an area extending from north-west Panama to north-east Costa Rica, the species occurs in sparsely scattered small populations within a rapidly developing region. Only a single population in San Ramón in Costa Rica occurs within a forest reserve. All other populations are unprotected and under severe threat from agricultural and industrial developments, and from urbanisation.

Assessor: Mitré, M.

Refs: 7980,16772

\section{Quararibea jefensis}

Bombacaceae

CR C2a

Panama

The species has been collected only a few times, from lowland evergreen rainforest in two provinces. It does not appear to be common, although its full distribution may not yet have been revealed. Cerro Jefe is the only protected area in which the species occurs. Elsewhere the habitat is under threat from increasing settlement and industrial, touristic and agricultural developments.

Assessor: Mitré, $\mathbf{M}$.

Refs: 15037,16772

\section{Quararibea pendula}

Bombacaceae

EN C2a

Costa Rica, Panama

The species occupies a small area between north-east Costa Rica and north-west Panama, where it is restricted to lowland areas of semi-deciduous rainforest. In Costa Rica only a few records exist, all in the vicinity of Río Yorkin, very near the Panama border. There are various distinct occurrences in Panama, some in the the Palo Seco Protection Forest. Elsewhere the habitat is unprotected and extensively cleared for cultivating bananas, cocoa and other commercial crops.

Assessor: Mitré, M.

Refs: 7980,16772

\section{Quararibea platyphylla}

Bombacaceae

EN C2a

Costa Rica, Panama

A lowland rainforest species. In Costa Rica several collections have been made in Burica, Puntarenas, near the Panama border. In Panama collections have come from the Atlantic slopes through the length of the country to Colombia, into which it possibly extends. Populations are small and under pressure from increasing land settlement, logging and agriculture, particularly banana plantations.

Assessor: Mitré, M.

Refs: 16772

\section{Quararibea pterocalyx}

Bombacaceae

VU C2a

Colombia, Costa Rica, Panama, Venezuela

Scattered as isolated individuals, the species is distributed in lowland evergreen to semi-evergreen rainforest, preferring humid or swampy zones. It is recorded from Alajuela and Guanacaste in Costa Rica, from Bocas del Toro to Darién in Panama, being present in larger numbers in the Canal area and Barro Colarado Island, and from Urabá and other areas of Colonbia. No information is available on its distribution in Venezuela. Throughout the range the habitat is affected by the growing human population, agricultural activities and logging.

Assessor: Mitré, $\mathrm{M}$.

Refs: 16772

\section{Quararibea sanblasensis}

Bombacaceae

EN C2a

Colombia, Panama

In Panama, the species has been collected only from San Blas, very close to the border with Colombia, in lowland semi-deciduous rainforest along river banks. There are reported to be a few dispersed individuals, including a very few adult trees. The species' range in Colombia is restricted to a small area in Antioquia. Only the Panamanian population is contained within a protected area. The tree provides medicine, food, fuel, timber and oils at a local level.

Assessor: Mitré, $\mathbf{M}$.

Refs: 16772 


\section{Quararibea santaritensis}

Bombacaceae

Panama

The species' description is based on a single collection from 1932. It came from an area of deciduous woodland in the Santa Rita Hills, Colón. Much of this area has been cleared for agriculture and grazing.

Assessor: World Conservation Monitoring Centre

Refs: 7980,16772

\section{Quararibea velutina}

Bombacaceae

VU D2

Peru

Known only from the type collection, this Amazonian forest species occurs in Loreto.

Assessor: World Conservation Monitoring Centre

Refs: 1984

\section{Quararibea yunckeri}

Bombacaceae

CR C2a

Honduras

A rarely collected species, of somewhat uncertain nomenclature.

Assessor: Nelson, C.

Refs: 13995

\section{Quercus acerifolia}

Fagaceae

$\mathrm{EN} \mathrm{B} 1+2 \mathrm{c}, \mathrm{C} 2 \mathrm{~b}$

USA (Arkansas)

Three localities of this species are known, two of them having been discovered recently, in open glades and shrubland in central-west Arkansas. The populations are small, each numbering less than 500 , but stable and contained within a national forest. Data accumulated by Stoynoff and Hess support the contention that the taxon is a species and not a subspecies of $Q$. shumardii.

Assessor: Hess, W.J.

Refs: $8470,10353,19145$

\section{Quercus arkansana}

Fagaceae

VU D2

USA (Alabama, Arkansas, Florida, Georgia, Louisiana, Mississippi, Texas)

Fewer than five localities of this woodland species are known to exist. Populations are thought to be declining because of habitat destruction, mainly through grazing and conversion to farmland.

Assessor: Nixon, K. et al.

Refs: 9653

\section{Quercus aucheri}

Fagaceae

Greece, Turkey

A small tree very similar to $Q$. coccifera. It grows in the Aegean region on the Greek islands and in Anatolia in Turkey. Populations are localised and isolated.

Assessor: World Conservation Monitoring Centre

Refs: $2915,3489,4863,7538$

\section{Quercus $\mathbf{x}$ basaseachicensis}

Fagaceae

EN D1

Mexico (Chihuahua, Durango)

A hybrid between $Q$. rugosa and $Q$. depressipes known from four sites in Chihuahua and one in Durango in submontane woodland or scrub. The populations are isolated and none are believed to be large.

Assessor: Hess, W.J.

Refs: $7538,9653,19145$
Quercus benthamii

Fagaceae

VU Alc

Guatemala, Mexico (Chiapas, Oaxaca)

Until the taxonomy of Central American specimens is confirmed, the exact range of this species cannot be consolidated but could extend to southern parts of Central America. Because of the rate of destruction of the moist forest habitat in the last few decades the species qualifies as threatened.

Assessor: Nixon, K. et al.

Refs: $7980,9653,19161$

\section{Quercus boyntonii}

Fagaceae

$\mathrm{EN} \mathrm{B1+2c}$

USA

The status of this species is not well consolidated. It appears to have become extinct in the areas from which it was known. There is, however, a possibility that it occurs in Mississippi and Lousiana.

Assessor: World Conservation Monitoring Centre Refs: 19145

\section{Quercus brandegeei}

Fagaceae

Mexico (Baja California)

$\mathrm{EN} \mathrm{B1}+2 \mathrm{e}$

The species occurs in low density in a xeric habitat in the foothills of the Sierra Lazaro. The area is subject to grazing pressure. Regeneration has not been observed in recent years.

Assessor: Nixon, K. et al.

Refs: $7538,9653,12945$

\section{Quercus brenesii}

Fagaceae

\section{Costa Rica}

A taxonomically doubtful species, apparently endemic to the department of Alajuela.

Assessor: Nixon, K. et al.

Refs: $6678,7538,7980,9653$

\section{Quercus buckleyi}

Fagaceae

USA (Oklahoma, Texas)

VU D2

A tree confined to scrub on Edward's Plateau.

Assessor: Nixon, K. et al.

Refs: $3786,7538,9653,10353$

\section{Quercus bumelioides}

Fagaceae

VU Alc

Costa Rica, Guatemala, Honduras, Mexico (Chiapas), Nicaragua, Panama

The montane forest habitat of this species has suffered serious declines in past decades. The tree can grow to a large size and has obvious value as a timber tree.

Assessor: Nixon, K. et al.

Refs: $730,7538,9653,11715,19161$

\section{Quercus cedrosensis}

Fagaceae

VU D2

Mexico (Baja Califomia)

A species restricted to a specialised sclerophyllous habitat at lowland to montane altitudes. Cedros Island suffers from overgrazing by goats. More information on the regeneration of this species may allow it to qualify for the status of endangered.

Assessor: Nixon, K. et al.

Refs: $7538,8470,9653,12945$ 


\section{Quercus cerrioides}

Fagaceae

LR/cd

Spain

The taxonomic status of this localised oak is uncertain. It may be a hybrid. The taxon occurs in dry montane forest in Catalonia, Aragon, Mallorca, La Rioja and Navarra, possibly extending into France. Fire, forest management activities and hybridisation pose threats to the taxon.

Assessor: Vivero, J.L. et al.

Refs: 5287, 7222, 7741

\section{Quercus coahuilensis}

Fagaceae

DD

Mexico (Coahuila)

It is suspected that the species will prove to be threatened when the area of occupancy is calculated. taking into account the altitudinal range of the species.

Assessor: Nixon, K. es al.

Refs: 7538, 9653

\section{Quercus convallata}

\section{Fagaceae}

Mexico (Jalisco, Nayarit)

The taxonomic status of this species is dubious.

Assessor: Nixon, K, et al.

Refs: $7538,9653,14250$

\section{Quercus costaricensis}

Fagaceae

VU B $1+2 e$

Costa Rica

Occurring in the montane forest of Volcan Irazu and Cerro Chirripb, the species is restricted to an area of occupancy of less than $2000 \mathrm{~km}^{2}$. Although deforestation has been extensive in the past, these areas are now given some degree of protection.

Assessor: Nixon, K. et al.

Refs: $7980,9653,14487$

\section{Quercus deliquescens}

\section{Fagaceae}

VU D2

Mexico (Chihuahua)

A species of dry montane scrub, known only from, one population system in the valley of Rio Concho and north along Río Grande.

Assessor: Nixon, $\mathrm{K}$, et al.

Refs: $412,9653,11715$

\section{Quercus depressipes}

\section{Fagaceae}

Mexico (Chihuahua, Durango, Jalisco, Zacatecas), USA (Texas)

A shrub scattered in montane grasslands over a wide range. Population sizes and declines are not documented. The US locality is vulnerable but protected.

Assessor: Nixon, K. et al.

Refs: $7538,9653,10353,11715$

\section{Quercus devia}

\section{Fagaceae}

VU D2

Mexico (Baja Califomia)

Two or three populations occur in dry montane forest, where grazing pressure is high. The mainland Mexican species, $Q$. viminea, may be synonymous, in which case the species would qualify for a status of lower risk.

Assessor: Nixon, K. et al.

Refs: $7538,9653,11715,12945$

\section{Quercus dumosa}

Fagaceae

Mexico (Baja Califomia), USA (Califomia)

EN Alct2c

A number of populations (e.g. Santa Barbara, Hollywood and Griffith Park) have disappeared. The lowland scrub habitat of the remaining populations is under threat from pollution and the expansion of urban and industrial areas.

Assessor: Nixon, K. et al.

Refs: $7538,8470,9653$

\section{Quercus engelmannï}

Fagaceae

VUAlc

Mexico (Baja California), USA (Califomia)

Extensive declines of the sclerophyllous habitat of the species have been observed over the past 50 years. Regeneration of the species is poor and the remaining habitat is under threat from grazing and urban, agricultural and industrial developments. Only one tree remains on Santa Catalina Island in Califomia but part of the population on Santa Rosa is protected in the Santa Rosa Plateau Reserve.

Assessor: Nixon, $\mathrm{K}$. et al.

Refs: $7538,9653,19193$

Quercus excelsa

Fagaceae

DD

Mexico (Jalisco, Veracruz)

Assessor: Nixon, K. et al.

Refs: $7538,9653,14250$

\section{Quercus flagellifera}

Fagaceae

Guatemala

VUAlc

Confined to the moist montane forests of east and central Guatemala, the species has experienced declines in its habitat in the last 50 years. There are a number of estimated rates of deforestation: all exceed an annual rate of one percent.

Assessor: Nixon, K, et al.

Refs: 7980,9653

\section{Quercus galeanensis}

Fagaceae

VU D2

Mexico (Nuevo León, Tamaulipas)

A rare species, characterised by the leaves being vertically appressed to the twigs. Occurring in submontane to montane chaparral, it is restricted to two populations occupying a narrow band $(150 \mathrm{~km} \times 10$ $20 \mathrm{~km}$ ) from Galeana, Nuevo Leone, to the Miquihrana region in Tamaulipas.

Assessor: Nixon, K. et al.

Refs: 7538,9653

\section{Quercus georgiana}

Fagaceae

$\mathrm{EN} \mathrm{B1+2ce}$

USA (Alabama, Georgia, South Carolina)

Small isolated populations are restricted to granite outcrops, occupying an area less than $500 \mathrm{~km}^{2}$. The impact of tourism is considerable on Stone Mountain. Drought; poor regeneration, soil erosion and compaction are all weakening the status of the species. Assessor: Nixon, K. et al.

Refs: $3786,7538,9653$

\section{Quercus germana}

Fagaceae

VUAlc

Mexico

A species of submontane seasonal dry forest, which has 
experienced dramatic declines over the last few decades. Forest has been converted for agricultural use, especially coffee plantations. The trees are often decked with an array of densely packed epiphytes.

Assessor: Nixon, $\mathrm{K}$, et al.

Refs: $7538,9653,11715$

\section{Quercus graciliformis}

Fagaceae

$\mathrm{CR} \mathrm{C} 2 \mathrm{~b}$

USA (Texas)

One small isolated population exists in riparian oak woodland in the Chisos Mountains. The locality is threatened by the activities of tourists from a nearby camping ground and by occasional drought. Previous records from Mexico are erroneous.

Assessor: Nixon, K. et al.

Refs: 9653,10353

\section{Quercus gulielmi-treleasei}

Fagaceae

Costa Rica, Panama

The taxonomic status of the species is uncertain. It is confined to Chiriqui in Costa Rica and Cartago in Panama in wet montane forests.

Assessor: Nixon, K. et al.

Refs: 7980,9653

\section{Quercus hinckleyi}

Fagaceae

CR A2b, B1+2cd

Mexico?, USA (Texas)

A shrub with holly-like leaves, known from 11 isolated populations, nine of which are in the Big Bend Ranch State Natural Area. Most populations consist of fewer than 100 individuals and cover an area less than five acres. Historical climate change is thought to be the main factor that has caused the species to become rare. Hybridisation with other Quercus species, roadway construction, collecting by horticulturists, drought and grazing are threats today. Although acom yields are good, all reproduction appears to be vegetative. The species is protected by the US Endangered Species Act and a recovery plan was devised in 1992.

Assessor: Nixon, K. et al.

Refs: $7538,9653,10353,11683$

\section{Quercus hintonii}

Fagaceae

Mexico (México State)

CR B $1+2 \mathrm{ac}$

A submontane to montane dry forest species which is confined to a small area (less than $10 \times 10 \mathrm{~km}$ ) along a road. Much of the area is in the process of conversion into avocado plantations and human settlements.

Assessor: Nixon, K. et al.

Refs: 4934,9653

\section{Quercus hintoniorum \\ Fagaceae}

Mexico (Nuevo León)

VU D2

A montane forest species occurring in two nearby locations in the Sierra Lamata.

Assessor: Nixon, K. et al.

Refs: 9653

\section{Quercus hypoxantha}

Fagaceae

Mexico (Coahuila, Nuevo León)

It is suspected that this species will prove to be threatened when the area of occupancy is calculated taking into account the altitudinal range of the species. Assessor: Nixon, K. et al.

Refs: $4934,7538,9653$

Quercus ilex ssp. ballota

Fagaceae

$\mathrm{LR} / \mathrm{nt}$

Portugal, Spain

This species is present in a large part of the Iberian Peninsula within areas of lowland dry forest up to $2000 \mathrm{~m}$. It is locally abundant, forming extensive woodlands in places. Populations are exposed to overcutting, fires, expanding agriculture and declining water availability, but trees are legally protected throughout the range.

Assessor: Vivero, J.L. et al.

Refs: 7741

\section{Quercus invaginata}

Fagaceae

DD

Mexico (Coahuila)

It is suspected that the species will prove to be threatened when the area of occupancy is calculated taking into account its altitudinal range.

Assessor: Nixon, $\mathrm{K}$. et al.

Refs: $7538,9653,11715$

\section{Quercus x macdonaldii}

Fagaceae

VU D2

USA (California)

The species is restricted to a few scrubby localities in Santa Rosa, Santa Catalina and Santa Cruz Islands. Control of grazing and the removal of sheep have helped oak regeneration on Santa Cruz Island.

Assessor: Nixon, K. et al.

Refs: 9653, 10353

\section{Quercus macdougallii}

Fagaceae

VU D2

Mexico (Oaxaca)

A distinctive species known only from the type locality in the dry montane forests of Oaxaca. It has not been collected recently and it is biologically poorly known.

Assessor: Nixon, $\mathrm{K}$. et al.

Refs: $7538,9653,11715$

\section{Quercus miquihuanensis}

Fagaceae

$\mathrm{EN} \mathrm{B1}+2 \mathrm{e}$

Mexico (Nuevo León, Tamaulipas)

An endemic of Peña Nevada and Miquihuana, locally common in montane pine-oak forest and also chaparral, covering an area of less than $500 \mathrm{~km}^{2}$. Logging activities and overgrazing threaten the habitat.

Assessor: Nixon, $\mathrm{K}$, et al.

Refs: 7538,9653

\section{Quercus oglethorpensis}

Fagaceae

$\mathrm{EN} \mathrm{Bl+2ce}$

USA (Georgia, Mississippi, South Carolina)

This species is known from a small area in the piedmont of north-east Georgia, neighbouring westem South Carolina and also from a disjunct population in Mississippi. In total, approximately 1000 individuals, covering an area of occupancy less than $150 \mathrm{~km}^{2}$, are estimated to exist. The most common habitats are roadsides and old fence rows. A survey in 1985 failed to locate $11 \%$ of the previously known sites. Poor seed viability and chestnut blight are also reported.

Assessor: Nixon, K. et al.

Refs: 7538,9653 
Quercus parvula var. parvula

Fagaceae

$\mathrm{EN} \mathrm{BI+2ce}$

USA (Califomia)

Two small populations on Santa Cruz Island and five or six populations in Santa Barbara County are known. Occurring in maritime chaparral and pine forests, no population extends over more than $10 \mathrm{~km}^{2}$. Habitat degradation and grazing are threats on Santa Cruz Island.

Assessor: Nixon, K. et al.

Refs: $3786,9653,10353,14430$

\section{Quercus peninsularis}

Fagaceae

Mexico (Baja Califomia)

A montane species. The number of localities and population status are unknown.

Assessor: Nixon, K et al.

Refs: $7538,9653,12945$

\section{Quercus perpallida}

Fagaceae

Mexico (Baja Califomia Sur, Chihuahua, Sinaloa, Sonora)

Assessor: Nixon, K. et al.

Refs: 7538,9653

\section{Quercus petraea ssp. huguetiana}

Fagaceae

$\mathrm{LR} / \mathrm{cd}$

France, Spain

Occurring in moist forest up to altitudes of $1800 \mathrm{~m}$, the species is abundant over a relatively wide range. It is also legally protected in Spain.

Assessor: Vivero, J.L. et al

Refs: 7741

\section{Quercus praineana}

Fagaceae DD

Mexico (Jalisco, Sinaloa)

Assessor: Nixon, K. et al.

Refs: 7538,9653, 17165

\section{Quercus purulhana}

Fagaceae

VU Alc

Belize, Guatemala, Honduras, Mexico (Chiapas). Nicaragua

A montane forest species, abundant in areas, but subject to general declines in habitat.

Assessor: Nixon, K. et al.

Refs: $4974,9653,11715,19161$

\section{Quercus rapurahuensis}

Fagaceae

VU Alc

Costa Rica, Panama

A moist forest species which has been subject to the general forest declines in this area. Further investigation may show that the species is more seriously threatened.

Assessor: Nixon, $\mathrm{K}$. et al.

Refs: $7272,9653,11715,14487$

\section{Quercus robur ssp. imeretina}

Fagaceae

VU Bl+2c

Georgia, Russia

A rare tree endemic to Kokhida in western Georgia, with a small part of the range extending into Russia along the Black Sea coast. The population is declining through felling and agriculture. The wood is considered a valuable timber.

Assessor: Firsov, G.A.

Refs: 7538, 14458, 19056

\section{Quercus x robusta}

Fagaceae

DD

USA (Texas)

This species is confined to the Chisos Mountains in Brewster County, where it is found in moist wooded canyons.

Assessor: Hess, W.J.

Refs: 3786, 10353, 19145

\section{Quercus rysophylla}

Fagaceae

DD

Mexico (Nuevo León, San Luis Potosí, Tamaulipas)

The known populations are small but their extent is not known.

Assessor: Nixon, K. et al.

Refs: $4934,7538,9653,11715$

\section{Quercus skinneri}

Fagaceae

VU Alc

El Salvador, Guatemala, Henduras, Mexico (Chiapas)

The species is widespread and often occurs in abundance in moist montane forests. It is also frequently planted. General rates of deforestation in recent decades have caused significant population declines.

Assessor: Nixon, K. et al.

Refs: $7538,9653,11715,19161$

\section{Quercus skutchii}

Fagaceae

Guatemala, Mexico (Chiapas)

Assessor: Nixon, K. et al.

Refs: $7538,9653,11715$

\section{Quercus subspathulata}

Fagaceae

Mexico (Durango, Jalisco, Nayarit, Sinaloa)

VU Alc

A forest species which has suffered extensive destruction of its habitat.

Assessor: Nixon, $\mathrm{K}$ et al.

Refs: $7538,8470,9653,14250$

\section{Quercus $\times$ tardifolia}

Fagaceae

USA (Texas)

It is thought no more than five trees exist in dry montane woodlands in the Chisos Mountains. The hybrid is a product of $Q$. hypoxantha and $Q$. gravesii. One of the parents is now absent from the area.

Assessor: Nixon, $\mathrm{K}$ et al.

Refs: 9653,10353

\section{Quercus tomentella}

Fagaceae

VU Bl+2ce

Mexico (Guadalupe Is.), USA (Califomia)

The regeneration of the species is hampered by overgrazing in the dry forest areas to which it is restricted on the channel islands of Califomia and Guadelupe Island of Mexico. Populations on Guadelupe Island, in particular, have declined dramatically in recent years.

Assessor: Nixon, K. et al.

Refs: 5988, 7538, 7980, 9653, 10353, 19193 
Quercus tonduzii

Fagaceae

DD

Costa Rica

A species of uncertain taxonomic status, found in the mountains of central Costa Rica in Alajuela. One collection from 1896 is cited from Volcan Poas.

Assessor: Nixon, K. et al.

Refs: $7538,7980,9653,14487$

\section{Quercus undata}

Fagaceae

DD

Mexico (Durango)

Assessor: Nixon, K. et al.

Refs: 7538,9653

\section{Quercus uxoris}

\section{Fagaceae}

Mexico (Colima, Guerrero, Jalisco)

VU Alc

The extent of population declines is not documented but the level of forest destruction has been dramatic.

Assessor: Nixon, K. et al.

Refs: $7538,9653,17165$

\section{Quercus vincentensis}

Fagaceae

VU Alc

El Salvador, Guatemala, Mexico

Declines in population numbers have not been recorded but the species occurrence in an area of extensive forest destruction qualifies it as vulnerable.

Assessor: Nixon, K. et al.

Refs: 7538, 7980, 9653, 19161

\section{Quercus xalapensis}

Fagaceae

VUAlc

Mexico (Chiapas, Veracruz)

Assessor: Nixon, K. et al.

Refs: 7538, 9653, 19161

\section{Quercus zempoaltepecana \\ Fagaceae \\ Mexico (Oaxaca) \\ Assessor: Nixon, K et al. \\ Refs: 7538,9653}

\section{Quiina colonensis \\ Quiinaceae}

Costa Rica, Panama

A lowland rainforest species, occurring in Colón and Coclé Provinces in Panama and in Heredia and Puntarenas, including a locality in Corcovado National Park, in Costa Rica. There are also specimens which are tentatively identified as this species in Kunayala Indigenous Reserve. In most of its range, the species appears to be uncommon and under considerable pressure from increasing settlement, agriculture and development.

Assessor: Mitré, M.

Refs: $7980,15037,16772$

\section{Quiina jamaicensis}

Quiinaceae

$\mathrm{LR} / \mathrm{nt}$

Jamaica

A species with a local distribution confined to northwestem parishes in woodland on limestone.

Assessor: World Conservation Monitoring Centre Refs: 6057,7980

\section{Quiina schippui}

Quiinaceae

EN C2a

Belize, Guatemala?, Honduras

A species of moist forest, collected only once in Honduras. Its occurrence in Guatemala is uncertain. Various developments are causing considerable loss of habitat.

Assessor: Nelson, C.

Refs: 13995

\section{Radermachera ramiflora}

Bignoniaceae

LR/cd

Malaysia (Sabah)

Endemic to Sabah, this tree is found in rainforest and disturbed forest on hillsides up to $1500 \mathrm{~m}$, often on ultramafic soils. It is known from Mount Kinabalu, Ranau, Kota Marudu and Mount Rara.

Assessor: World Conservation Monitoring Centre Refs: 18327,19017

\section{Ramosmania rodriguesii}

Rubiaceae

Mauritius (Rodrigues)

Café marron is reduced to just one surviving individual. A fence is erected around it and continuing damage has led to construction of a further three fences. Cuttings have been propagated at Kew Botanic Gardens but attempts at re-introduction had failed until 1996, when cuttings raised in Rodrigues successfully rooted.

Assessor: World Conservation Monitoring Centre Refs: 18414,19199

\section{Randia aculeata var. jamaicensis}

Rubiaceae

VU B $1+2 c$ Jamaica

The species as a whole is distributed from Florida to Venezuela. This variety is endemic to Jamaica, where it is found in small populations in thickets and woodland on limestone in St Andrew and Clarendon between 210 and $790 \mathrm{~m}$.

Assessor: World Conservation Monitoring Centre Refs: $6057,7980,17743$

\section{Randia pleiomeris}

Rubiaceae

El Salvador, Guatemala

A rare species of forest and woodland understorey. There is no information on the status of its populations but the lowland habitat has experienced extensive declines, mainly through logging and expanding agriculture.

Assessor: World Conservation Monitoring Centre Refs: 4491, 4862, 4974, 19030

\section{Rapanea ceylanica}

Myrsinaceae

CR B1+2cd

Sri Lanka

A species occurring in lowland rainforest in south-west Sri Lanka. In previous surveys populations have been located in Sinharaja Biosphere Reserve. However, the species was not found during the extensive forest surveys conducted between 1991 and 1996 for the National Conservation Review, suggesting that it is either extremely rare or possibly extinct.

Assessor: World Conservation Monitoring Centre Refs: $9176,17195,19112$ 
Rapanea coclensis

Myrsinaceae

VU D2

Panama

A species known only from two collections.

Assessor: World Conservation Monitoring Centre

Refs: 16772

\section{Rapanea gilliana}

Myrsinaceae

VU A2c

South Africa (Eastem Cape)

A shrub or small tree which occurs in coastal forest and scrub on dunes or rocky outcrops from Humansdorp to Bathurst. Its range is slowly becoming fragmented by coastal developments, especially the construction of settlements and holiday resorts. The species occurs in at least two protected areas and possibly in a third.

Assessor: Hilton-Taylor, C. et al.

Refs: 689,19218

\section{Rapanea perakensis}

Myrsinaceae

LR/nt

Malaysia (Peninsular Malaysia)

A shrub or small tree inhabiting forested ridge tops between $700 \mathrm{~m}$ and $2100 \mathrm{~m}$. The species is recorded in Kelantan, Terengganu, Perak and Pahang and is afforded protection in Taman Negara National Park.

Assessor: Chua, L.S.L

Refs: 8464,19073

\section{Rapanea seychellarum}

Myrsinaceae

CR D1

Seychelles

The entire population amounts to fewer than 50 individuals. There are six sites on Mahé and single sites on Silhouette and Praslin. Montagne Planeau has a large and healthy population. Most other locations contain between one and five trees. No seedlings have been reported. Populations are recorded within Morne Seychellois and Praslin National Parks and in forest areas protected by the Nature Protection Trust of Seychelles.

Assessor: Nature Protection Trust of Seychelles

Refs: $10610,17229,19025$

\section{Rapanea striata}

Myrsinaceae

$\mathrm{EN} \mathrm{B1}+2 \mathrm{c}$

India (Karnataka)

The species is currently known from two records from widely separated localities in submontane evergreen forest in the Westem Ghats.

Assessor: World Conservation Monitoring Centre Refs: 19144

\section{Raphia australis}

Palmae

Mozambique, South Africa (KwaZulu-Natal)

This very large palm occurs in swamp forest around Kosi Bay in northern KwaZulu-Natal, extending northwards along the coast of southern Mozambique, occurring along river valleys, as far as Inhambane. The plants flower once, after about 30 years, and then die after setting fruit. They can form very dense groves and in some places they have naturalised after planting, e.g. at Mtunzini on the Zululand coast, which is now a national monument. The plants at Kosi Bay are not under threat and are contained within a conservation area, although local use of the plants is allowed. The 12 ha Bobole Special Reserve $40 \mathrm{~km}$ north of Maputo, is supposedly the most southerly occurrence of this species in Mozambique, and contains 150 plants. This subpopulation is under threat because of habitat clearance for subsistence agriculture within the reserve. Assessor: Hilton-Taylor, C. et al. Refs: $689,3018,6809,19118,19218$

\section{Rauvolfia sachetiae}

Apocynaceae

CR B $1+2 \mathrm{c}$

French Polynesia (Marquesas Is.)

Populations are known from Hiva Oa and Nuku Hiva.

Assessor: Florence, J.

Refs: 14513

\section{Ravenea albicans}

Palmae

EN D1

Madagascar

A palm known from two recently identified localities in lowland moist forest on ultramafic soil. One population contains up to 40 trees with trunks, 100 young trees without trunks and several seedlings.

Assessor: Dransfield, J. \& H.J. Beentje

Refs: 18986,19118

\section{Ravenea dransfieldii}

Palmae

VU C2a

Madagascar

A Madagascan endemic confined to moist forest in the area between Marojejy Mountains and Ifanadiana. Populations at Ifanadiana are under threat of destruction; population numbers at each site are low. Assessor: Dransfield, J. \& H.J. Beentje Refs: 18986,19118

\section{Ravenea glauca}

Palmae

Madagascar

VU D1

A Madagascan endemic confined to dry forest in the centre and south. The status of populations in Andringitra is unknown, no collections having been made there since 1922. Elsewhere it is known only from Isalo, where the population size is estimated to be made up of a few hundred individuals.

Assessor: Dransfield, J. \& H.J. Beentje

Refs: 18986,19118

\section{Ravenea hildebrandti}

Palmae

EN Alc

Comoros

Confined to the islands of Grand Comore, Moheli and Anjouan, the species is considered endangered because all forest in the Comoros Islands is under severe threat. No collections have been made for a considerable time. Assessor: Dransfield, J. \& H.J. Beentje Refs: 18986, 19118

\section{Ravenea julietiae}

Palmae

EN C2a

Madagascar

Occurring in moist lowland forest, the species is restricted to east Madagascar between Mananara Avaratra and Vangaindran. The population numbers are very low: fewer than 50 trees have been counted. The more southern localities, where most of the trees are found, are rapidly being destroyed. Assessor: Dransfield, J. \& H.J. Beentje Refs: 18986,19118 


\section{Ravenea krociana}

Palmae

VU D1+2

Madagascar

An endemic palm found only in one site at Andohahela in Madagascar, inhabiting submontane moist forest. There are approximately 60 individuals at this site.

Assessor: Dransfield, J. \& H.J. Beentje

Refs: 18986,19118

\section{Ravenea lakatro}

Palmae

EN D1

Madagascar

An endemic palm of eastern Madagascar, occurring between Andasibe and Vangaindrano. The species is found in a very limited number of sites in moist lowland forest on slight mid-slopes or ridge crests. Several of these sites are being rapidly destroyed. The population at Mantady consists of pruned rosettes as a result of the harvesting of the young leaves for fibre. The two more southerly populations contain fewer than 20 trunked trees.

Assessor: Dransfield, J. \& H.J. Beentje

Refs: 18986,19118

\section{Ravenea latisecta}

Palmae

EN D 1

\section{Madagascar}

This species is known from a single population of four trees at Andasibe in Madagascar. The habitat is submontane moist forest on steep slopes near the hill crest.

Assessor: Dransfield, J. \& H.J. Beentje

Refs: 18986,19118

\section{Ravenea louvelii}

Palmae

EN D1

Madagascar

Confined to Andasibe in Madagascar, this species inhabits moist forest on a steep slope near the crest between $800 \mathrm{~m}$ and $1000 \mathrm{~m}$. There are fewer than 25 individuals with trunks and rejuvenation is minimal. The population exists outside the protected area.

Assessor: Dransfield, J. \& H.J. Beentje

Refs: 18986,19118

\section{Ravenea madagascariensis}

Palmae

$\mathrm{LR} / \mathrm{nt}$

Madagascar

An endemic of central and east Madagascar, inhabiting moist to dry hill forest on steep slopes or hill crests between $25 \mathrm{~m}$ and $1700 \mathrm{~m}$. The species is fairly widespread and in some areas locally common. One population is protected in Mantady National Park.

Assessor: Dransfield, J. \& H.J. Beentje

Refs: 19118

\section{Ravenea moorei}

Palmae

CR D1

Comoros

Oniy two female palm trees are known from a patch of secondary submontane rainforest, last seen in October 1993.

Assessor: Johnson, D.

Refs: 19118

\section{Ravenea musicalis}

Palmae

VU D1+2

Madagascar

A true water palm, endemic to south Madagascar, where it inhabits flowing water to a depth of $0.5-2.5 \mathrm{~m}$ along a single river. The population consists of about 450 trees. This aquatic environment is very changable and the palm is somewhat exposed and vulnerable. Assessor: Dransfield, J. \& H.J. Beentje Refs: 18986,19118

\section{Ravenea nana}

Palmae

$\mathrm{EN} \mathrm{B1}+2 \mathrm{c}$

Madagascar

A palm confined to eastem Madagascar, between Marojejy and Andohahela, where it inhabits montane ericoid bush or forest on rocky sites on gneiss and quartzite. The species is known only from three localities and has not been collected for 30 years.

Assessor: Dransfield, J. \& H.J. Beentje

Refs: 18986,19118

\section{Ravenea rivularis}

Palmae

VU Alc

Madagascar

An endemic palm of south-central Madagascar, confined to Mangoky and Onilahy River Valleys. Only two populations are known, occurring in shallow standing water, river banks and swampy valley bottoms. Assessor: Dransfield, J. \& H.J. Beentje Refs: 19118

\section{Ravenea robustior}

Palmae

LR/nt

Madagascar

A Madagascan endemic occurring in moist forest in valley bottoms near water or on hill crests up to $1000 \mathrm{~m}$. Its occurrence, although widespread, ranging from Manongarivo to Marojejy and south to Andohahela, is not common. The species is recorded in Ranomafana National Park, Marojejy, Manongarivo Reserve and at Analamazaotra, but trees continue to be cut within the reserves. If harvesting of palm heart and cutting for the timber continue at present rates, the status of the species may become threatened.

Assessor: Dransfield, J. \& H.J. Beentje

Refs: 18986,19118

\section{Ravenea sambiranensis}

Palmae

VU Alc

Madagascar

Occurring in north-west, west and east Madagascar, the species is found in various habitats, such as littoral forest on white sand, dense moist forest, dry montane forest and riverine forest remnants in the west. Although widespread, the populations are small and threatened by felliing, exploitation of the palm heart and increasing settlement.

Assessor: Dransfield, J. \& H.J. Beentje

Refs: 18986, 19118

\section{Ravenea xerophila}

Palmae

EN D1

Madagascar

Known only from south Madagascar, between Ampanihy and Anpingaratra Mountains, the species inhabits dry spiny bush or low dry forest on laterite or gneiss. In recent studies two populations have been located, consisting of 65 trunked trees and 80 seedlings. Overgrazing is destroying the Tranoroa site.

Assessor: Dransfield, J. \& H.J. Beentje

Refs: 18986,19118 
Ravenia biramosa var. peruviana

Rutaceae

VU D2

Peru

A variety which is known only from the type collection taken from Amazonian forest in Loreto.

Assessor: World Conservation Monitoring Centre

Refs: 1984

\section{Ravenia swartziana}

Rutaceae

CR B $1+2 \mathrm{c}$

Jamaica

This species is known only from the type, collected at the beginning of the century.

Assessor: World Conservation Monitoring Centre

Refs: 401, 5653, 7980

\section{Rawsonia burtt-davyi}

Flacourtiaceae

VU B $1+2 b c, D 2$

Malawi

Originally known under the genus Dasylepis, this tree is confined to a small area of montane evergreen forest on Mount Mulanje. Although the habitat is protected as a forest reserve, there have been significant declines in its extent and quality because of exploitation for wood, encroachment of subsistence cultivation and fire. Plans have now been drawn up to ensure the conservation of the remaining natural resources and the prevention of further illegal activities.

Assessor: World Conservation Monitoring Centre

Refs: 10090,18965

\section{Rawsonia reticulata}

Flacourtiaceae

LR/cd

Malawi, Tanzania

A montane forest species, which is regarded as distinct but strongly resembles $R$. burt-davyi. A population occurs at the north of Lake Nyasa, the Tanzanian part of Lake Malawi, and the species is believed to range into northern Malawi.

Assessor: Lovett, J. \& G.P. Clarke

Refs: 3356, 8814

\section{Recchia simplicifolia}

Simaroubaceae

EN Alc, B1+2c

Mexico (Oaxaca, Veracruz)

A rainforest tree confined to high-precipitation forest in the Uxpanapa-Chimalapa region. This small genus is endemic to Mexico.

Assessor: World Conservation Monitoring Centre

Refs: 5651, 5993, 7180

\section{Reevesia rotundifolia}

Sterculiaceae

CR B $1+2 \mathrm{C}$

China (Guangxi)

The species is restricted to a few localities on Shiwanshan. It is a scarce component of the understorey in monsoon forest. Recent searches into some of the original locations have found the forest cleared and the population destroyed.

Assessor: World Conservation Monitoring Centre

Refs: 1818,11847

\section{Rehderodendron macrocarpum}

Styracaceae

LR/nt

China (Guangxi, Guizhou, Sichuan, Yunnan), Viet Nam

This is one of the dominant components of broadleaved semi-deciduous forest above $1200 \mathrm{~m}$ in south-west China, also occurring in scattered localities in northern and southem provinces in Viet Nam. Stands in China are said to have become more sporadic because of the extensive logging and clearing of the species habitat. The timber is used domestically.

Assessor: World Conservation Monitoring Centre

Refs: $1818,11847,15357,19055$

\section{Retrophyllum minor}

Podocarpaceae

$\mathrm{EN} \mathrm{Cl}+2 a$

New Caledonia

Populations of this small theophyte are very restricted in range, confined to river banks and lake shores on the Plaine des Lacs. Protection in the Chûte de la Madeleine Reserve is inadequate. There are threats from fluctuations in the water table and exposure to fires.

Assessor: Jaffré, T, et al.

Refs: 4391, 10351, 12630, 18751

\section{Retrophyllum piresii}

Podocarpaceae

DD

Brazil (Rondônia)

An endemic to Serra Pacas Novos.

Assessor: SSC Conifer Specialist Group

Refs: $374,4391,19127$

\section{Retrophyllum rospigliosii}

Podocarpaceae

Colombia, Ecuador, Peru, Venezuela

Assessor: SSC Conifer Specialist Group

Refs: 374, 3047, 4391, 10194, 18751, 19127

LR/nt

\section{Reutealis trisperma}

Euphorbiaceae

VUAlcd

Philippines

A timber species, endemic to the Philippines. Rates of habitat loss through logging and shifting cultivation have led to considerable population declines.

Assessor: World Conservation Monitoring Centre Refs: $2072,4919,5651,7673$

\section{Reynoldsia sandwicensis}

Araliaceae

LR/nt

USA (Hawaii)

A variable species of dry to occasionally moist forest up to $800 \mathrm{~m}$ on Niihau, Oahu, Molokai, Lanai, Maui and Hawaii Islands.

Assessor: World Conservation Monitoring Centre Refs: 3372

\section{Reynosia jamaicensis}

Rhamnaceae

$\mathrm{CR} B 1+2 c, \mathrm{C} 2 \mathrm{~b}$

Jamaica

The only known locality exists in a woodland area on limestone in Hanover Parish, part of the Dolphin Head. Assessor: World Conservation Monitoring Centre Refs: $401,5653,7980$

\section{Rhamnella gilgitica}

Rhamnaceae

Pakistan

A large shrub or tree, usually growing up to 5 to $7 \mathrm{~m}$, known only from the type gathering in Gilgit between 1600 and $2450 \mathrm{~m}$. The young shoots and leaves are used as fodder. More information may indicate a more serious threat category is appropriate.

Assessor: World Conservation Monitoring Centre

Refs: 5995 


\section{Rhamnidium caloneurum}

Rhamnaceae

DD

Panama

No new reports of the species have been made since the original collection was taken from Bocas del Toro. The general area of collection has been little studied.

Assessor: Mitré, M.

Refs: 7272, 7980, 16772

\section{Rhamnidium dictyophyllum}

Rhamnaceae

$\mathrm{EN} \mathrm{B} 1+2 \mathrm{C}$

Jamaica

A shrub or tree, very rare and confined to upland woodland in rocky limestone areas in Manchester Parish.

Assessor: World Conservation Monitoring Centre

Refs: $401,5653,7980$

\section{Rhamnus capraeifolia var. matudai}

Rhamnaceae

$\mathrm{EN} \mathrm{B1}+2 \mathrm{c}$

Mexico (Veracruz)

Assessor: Ramirez-Marcial, N. \& M. González-Espinosa

Refs: 7980,11723

\section{Rhamnus crenulata}

Rhamnaceae

$\mathrm{LR} / \mathrm{nt}$

Spain (Canary Is.)

Endemic to the Canary Islands, the species is distributed fairly abundantly in dry scrub. Housing developments, grazing and invasive plants all pose threats to the remaining populations. The species is listed in government legislation of 1991.

Assessor: Bañares, A. et al.

Refs: 19022

\section{Rhamnus glandulosa}

Rhamnaceae

$\mathrm{LR} / \mathrm{cd}$

Portugal (Madeira), Spain (Canary Is.)

Occurring in undisturbed cloud forest or *laurisilva above $800 \mathrm{~m}$, this uncommon species is largely contained within protected areas. The greatest threat to remaining populations comes from buming. It is covered by regional legislation.

Assessor: Bañares, A. et al.

Refs: $1512,19022,19131$

\section{Rhamnus integrifolia}

Rhamnaceae

VU D2

Spain (Canary Is.)

Found only in the Cumbres and Barrancos in the south of Tenerife, the species occupies a wide altitudinal range in dry woodland and scrub. Populations appear to be stable, although restricted. It is listed in govemment legislation of 1991.

Assessor: Bañares, A. et al.

Refs: 19022

\section{Rhaphithamnus venustus}

Verbenaceae

VU D2

Chile (Juan Fernández Is)

A tree of upper montane forest. Preliminary data indicate the species is confined to less than $100 \mathrm{~km}^{2}$. More detailed information on the species should become available to confirm this evaluation. The islands are designated as a national park and biosphere reserve and work is being carried out by *CONAF to save the native plants. There are two species in the genus, the second being found on mainland Chile.

Assessor: World Conservation Monitoring Centre

Refs: $3241,5651,7980,14140$

\section{Rhaptopetalum belingense}

Scytopetalaceae

Gabon

An endemic to the Belinga Mountains.

Assessor: World Conservation Monitoring Centre Refs: 15790

\section{Rhaptopetalum sindarense}

Scytopetalaceae

VU D2

Gabon

A species collected in areas of closed forest in Ngounye and in Lopé Forest Reserve. Much of Gabon's forests are poorly explored and it is possible the species has a wider range. There is concern over the extent to which these forests are now under concession to logging companies.

Assessor: World Conservation Monitoring Centre Refs: 7142, 14958, 15790

\section{Rheedia aristala}

Guttiferae

$\mathrm{EN} B 1+2 \mathrm{c}$

Cuba

Populations of this uncommon shrub or tree have been recorded from numerous localities of semi-deciduous forest on limestone or serpentine in western Cuba. The species is threatened by overexploitation, mainly as a source of medicine, and the habitat is threatened by urban development and conversion for agriculture, ranching and tourism.

Assessor: Areces-Mallea, A.E.

Refs: 9522, 11403, 19149

\section{Rhipidantha chlorantha}

Rubiaceae

VU B1+2b, D2

Tanzania

Endemic to the North Uluguru Mountains, this is a moist evergreen forest species recorded only at altitudes above $1450 \mathrm{~m}$. The genus is monospecific.

Assessor: Lovett, J. \& G.P. Clarke

Refs: 3356,5204

\section{Rhododendron album}

Ericaceae

VU B $1+2 c$

Indonesia (Java)

A montane forest species occurring between 1200 and $1700 \mathrm{~m}$ in remaining forest patches in west and central Java. These areas, although they are not as badly affected as forest at lower elevations, are under severe pressure from the activities of the surrounding human populations.

Assessor: World Conservation Monitoring Centre Refs: 9078

\section{Rhododendron cyanocarpum}

Ericaceae

VU D2

China (Sichuan, Yunnan)

Known only from Diancang Mountain in Yunnan and in Muli in Sichuan, the species occurs as a shrub or small tree in remaining areas of forest above $3000 \mathrm{~m}$. Overcutting and loss of the habitat are causing population declines.

Assessor: World Conservation Monitoring Centre Refs: 1818,11847 
Rhododendron dalhousiae var. rhabdotum

Ericaceae

VU B $1+2 c$

Bhutan, China, India (Arunachal Pradesh)

An epiphytic shrub or small tree collected in 1915 from Bhutan and subsequently from Kameng District in Arunachal Pradesh and China. Road building and other developmental projects are threatening the Indian population. It is a prize-winning omamental.

Assessor: World Conservation Monitoring Centre

Refs: 3013,7147

\section{Rhododendron fictolacteum}

Ericaceae

$\mathrm{LR} / \mathrm{cd}$

China (Sichuan, Yunnan)

A species of subalpine coniferous forest, occurring between 2800 and $3900 \mathrm{~m}$, in north-west Yunnan and Muli in south-west Sichuan. Some of the sites are designated nature reserves but the effectiveness of their protection should be monitored. Trees, especially the larger individuals, have been heavily cut for fuel wood in places.

Assessor: Sun, W.

Refs: $1818,11847,19055$

\section{Rhododendron jucundum}

Ericaceae

VU D2

China (Yunnan)

An endemic of Diancang Mountain in Dali, Yunnan. It occurs in subalpine coniferous forest between 3500 and $3900 \mathrm{~m}$, where it frequently appears crooked and contorted from the effects of strong winds and heavy snow. The area is designated a nature reserve but, at present, the management measures are not thought to be sufficient to ensure the species' protection.

Assessor: World Conservation Monitoring Centre

Refs: 1818,11847

\section{Rhododendron kanehirai}

\section{Ericaceae}

Taiwan

A beautiful ornamental shrub, which became extinct in 1984 during the construction of a dam and the flooding of its only known locality in the wild at Feitsui. For several centuries it has been in cultivation and is widely planted in gardens around the country.

Assessor: Lu, S.Y. \& F.J. Pan

Refs: 19050,19051

\section{Rhododendron loerzingii}

Ericaceae

VU B1+2c

Indonesia (Java)

This species is uncommon and confined to areas of scrub or grassland on Mount Tlerep, Merbabu and Sumbing. The soil is noted to be fertile. These areas, although less affected than those at lower elevations, are under severe pressure from the activities and demands of the surrounding human populations.

Assessor: World Conservation Monitoring Centre Refs: 9078

\section{Rhododendron protistum var. giganteum}

\section{Ericaceae}

CR C2b

China (Yunnan)

Fewer than 100 trees are thought to exist in an area of submontane evergreen broadleaved forest in Gaoligongshan in south-west Yunnan. This population was rediscovered in 1981, 62 years after its first collection. The area has been designated as a nature reserve and the species is in cultivated as an omamental. Assessor: Sun, W.

Refs: $1818,11847,19055$

\section{Rhododendron rex}

Ericaceae LR/nt

China (Sichuan, Yunnan), India (Arunachal Pradesh), Myanmar

A relatively widely occurring species in the wild and a famous ornamental in cultivation. The status of the population in China is believed to be endangered because of its restriction to small areas of subalpine evergreen forest, where fires and cutting have caused population declines in the past 10 years. A population is protected in Mount Wuliang Nature Reserve.

Assessor: World Conservation Monitoring Centre

Refs: $1619,1818,11847,19055$

\section{Rhododendron subansiriense}

Ericaceae

VU D2

India (Arunachal Pradesh)

This species is known only from the type specimen, which was gathered from mossy forest above $2600 \mathrm{~m}$.

Assessor: World Conservation Monitoring Centre

Refs: 1619

Rhododendron wattii

Ericaceae

VU D2

India (Manipur)

A species known only from the type locality.

Assessor: World Conservation Monitoring Centre

Refs: 1619

\section{Rhododendron wilhelminae}

Ericaceae

CR DI

Indonesia (Java)

This species has been found only once at $1350 \mathrm{~m}$ near the crater on Mount Salak. It may be a natural hybrid of $\boldsymbol{R}$. javanicum and $R$. malayanum.

Assessor: World Conservation Monitoring Centre

Refs: 9078

\section{Rhodognaphalon breviscupe}

Bombacaceae

VUAlcd

Cameroon, Congo, Côte d'Ivoire, Democratic Republic of Congo, Gabon, Ghana, Nigeria, Sierra Leone

A timber species of West and Central Africa. It occurs in various forest types, particularly secondary forest. Exploitation is moderate. Little is known about regeneration but it does not appear to be abundant and growth rates are slow.

Assessor: Hawthome, W.

Refs: $2362,6127,6718,11504,12061,17408$

\section{Rhodognaphalon mossambicense}

Bombacaceae

DD

Mozambique

Assessor: Bandeira, $\mathrm{S}$.

Refs: 5117

\section{Rhoiptelea chiliantha}

Rhoipteleaceae

China (Guangxi, Guizhou, Yunnan), Viet Nam

Occurring as a canopy tree in montane forest, the species is largely confined to southem China, with restricted populations in Lao Cai and Yen Bai just over the border into northern Viet Nam. Trees generally occur singly or in small groups. The species is a dominant element 
where recolonisation is taking place after forest clearance. The family is monotypic.

Assessor: World Conservation Monitoring Centre

Refs: 848, 1818, 11530, 11847, 15357, 19055, 19061

\section{Rhopaloblaste augusta}

Palmae

VU Alc

India (Andaman and Nicobar Is. - Nicobar Is.)

A palm tree of lowland forest in the moist hill valleys and slopes of Nicobar Island.

Assessor: Johnson, D.

Refs: 19118

\section{Rhopaloblaste elegans}

Palmae

DD

Solomon Islands (South Solomon)

A primary forest palm tree found in the moist lowlands of the Solomon Islands.

Assessor: Dowl, J.L.

Refs: 19118

\section{Rhopaloblaste singaporensis}

Palmae

LR/cd

Malaysia (Peninsular Malaysia), Singapore

Scattered in lowland rainforest, this species is common in south Peninsular Malaysia and in the remnant forests of Singapore. Healthy populations exist in protected areas. Outside the parks, populations are subject to forestry activities and are becoming locally extinct. Assessor: Saw, L.G.

Refs: 19118

\section{Rhopalostylis baueri var, baueri}

Palmae

$\mathrm{LR} / \mathrm{cd}$

Norfolk Island

This variety is now largely confined to rainforest in the national park on Norfolk Island. The Norfolk Island Group is a World Heritage Site. The species is widely cultivated and traded as an ornamental.

Assessor: Johnson, D.

Refs: 19118

\section{Rhopalostylis baueri var. cheesemanii}

Palmae

$\mathrm{LR} / \mathrm{cd}$

New Zealand (Kermadec Is.)

This variety is abundant in rainforest on Raoul Island of the Kermadec Group. Raoul Island is a nature reserve. The species is widely cultivated and traded.

Assessor: Johnson, D.

Refs: 19118

\section{Rhopalostylis sapida}

Palmae

LR/cd

New Zealand

An omamental palm tree found in lowland moist forest up to $400 \mathrm{~m}$.

Assessor: Dowl, J.L.

Refs: 19118

\section{Rhus aucheri}

Anacardiaceae

$\mathrm{LR} / \mathrm{nt}$

Oman

An Omani endemic which occurs commonly on rocky slopes and in wadis in the foothills of the Hajar Mountains in the north.

Assessor: Ghazanfar, S.A.

Refs: 16380
Rhus brenanii

Anacardiaceae

Tanzanja

A scandent shrub or a small tree known only from moist montane forests in the Mbeya range and the nearby Mount Rungwe. The forests are categorised as catchment forest reserves but fire is causing a decline in their extent in the Mbeya range.

Assessor: Lovett, J. \& G.P. Clarke

Refs: 3356, 10961

\section{Rhus delavayi}

Anacardiaceae

China (Sichuan, Yunnan)

LR/cd

Ranging throughout much of Yunnan and into Sichuan, the species is found in areas of monsoon forest between 1100 and $2500 \mathrm{~m}$. The oil from the seeds is used in cooking and soap-making. Seeds are collected in some quantity for this purpose. Habitat declines are also extensive but most of the species range is now contained within nature reserves.

Assessor: Sun, W.

Refs: 19055

\section{Rhus glutinosa ssp. abyssinico}

Anacardiaceae

LR/nt

Djibouti, Egypt, Eritrea, Ethiopia, Sudan

Scattered populations occur in evergreen bushland on the Gebel Elba in Sudan and Egypt, from the Tigray region northwards through Eritrea and possibly into Saudi Arabia. There is some intergrading with the other subspecies to the south.

Assessor: World Conservation Monitoring Centre

Refs: 1330, 2361

\section{Rhus thyrsiflora}

Anacardiaceae

LR/nt

Yemen (Socotra)

A fairly common tree, found in areas of submontane woodland. It is under no immediate threat.

Assessor: Miller, A.G.

Refs: 2354, 19083

\section{Rhynchocalyx lawsonioides}

Rhynchocalycaceae VU A2c

South Africa (Eastem Cape, KwaZulu-Natal)

A monotypic genus in a monotypic family endemic to Pondoland in southem KwaZulu-Natal and the eastem Transkei area of the Eastern Cape, where it is found on forest margins and along streams and rivers. It is locally common in places, although there is poor regeneration at some sites. There are subpopulations in a number of publicly owned protected areas in the region, including many of the demarcated forest areas in Transkei, which are no longer strictly protected. Habitat destruction through cutting for firewood and timber and increasing settlement could pose a problem here and in southem KwaZulu-Natal, where there is also concern over encroaching agriculture.

Assessor: Hilton-Taylor, C. et al.

Refs: $689,17410,19218$

Rhytidophyllum grande var. grande Gesneriaceae

$\mathrm{LR} / \mathrm{nt}$ Jamaica

The type variety of a Jamaican endemic, locally 
common in clearings and glades in forest or sheltered thickets on limestone.

Assessor: World Conservation Monitoring Centre

Refs: 6057,7980

\section{Rhytidophyllum grande var. Laevigatum}

Gesneriaceae

VU B1+2c

Jamaica

One of two varieties of a Jamaican endemic. It has a local distribution in St James and Trelawny, occurring in thickets and on open banks on rocky limestone.

Assessor: World Conservation Monitoring Centre

Refs: 401, 5653, 17743

\section{Ricinodendron heudelotii var. tomentellum}

Euphorbiaceae

VU B $1+2 b$

Kenya, Tanzania

A taxon of dry coastal forest distributed in the Shimba Hills, Rabai and Dzombo in south-east Kenya and parts of eastem Tanzania. It has suffered from habitat degradation in much of its range.

Assessor: Lovett, J. \& G.P. Clarke

Refs: 3356, 10961

\section{Rinorea antioguiensis}

Violaceae

$\mathrm{EN} \mathrm{B1+2c}$

Colombia

Although recorded as locally common, this small tree is still known only from its type location in lowland forests in Nechí.

Assessor: Calderon, E.

Refs: $7980,16331,19069$

\section{Rinorea bicornuta}

Violaceae

EN B $1+2 c$

Brazil (Amazonas)

A tree which is known only from the type collection made in 1927 near Tefé on a forested river bank.

Assessor: World Conservation Monitoring Centre

Refs: 7980,16331

\section{Rinorea brachythrix}

Violaceae

VU B $1+2 c$

Panama

A small tree, collected only from San Blás and Darién in various seasonal and non-seasonal lowland forest types.

Assessor: World Conservation Monitoring Centre

Refs: 7272, 7980, 16331

\section{Rinorea convallarioides var. marsabitensis}

Violaceae

VU D2

Kenya

A variety confined to submontane forest patches, which exist as islands surrounded by semi-desert vegetation, in Marsabit and Mathews. The habitat is not greatly threatened at present.

Assessor: World Conservation Monitoring Centre

Refs: $1308,6396,17859$

\section{Rinorea cordata}

Violaceae

$\mathrm{EN} \mathrm{B1+2c}$

Colombia

A distinctive species which is known only from the type location in rainforest in the northem part of the valley of Río Magdalena in north-west Colombia.

Assessor: Calderon, E.

Refs: $7980,16331,19069$

\section{Rinorea crenata}

Violaceae

LR/nt

Costa Rica, Panama

Confined to two forest refugia in Chiriqui and Darien in Panama and also apparently in Costa Rica, this species occurs over a wide altitudinal range, in the understorey of lowland forest and as an epiphyte in cloud forest.

Assessor: World Conservation Monitoring Centre

Refs: $5603,7980,14487,16331$

\section{Rinorea deflexa}

Violaceae

$\mathrm{EN} \mathrm{BI}+2 \mathrm{c}$

Ecuador

This small tree has not been collected anywhere other than the type locality in Chimborazo forest near Atacama.

Assessor: World Conservation Monitoring Centre

Refs: 7980,16331

\section{Rinorea endotricha}

Violaceae

LR/nt

Guyana, Venezuela

Although relatively widely ranging, this understorey species is confined to areas of primary forest in the lower Orinoco basin and adjacent areas in Guyana. Assessor: World Conservation Monitoring Centre Refs: 7980,16331

\section{Rinorea haughtü}

Violaceae

$\mathrm{EN} \mathrm{B1}+2 \mathrm{c}$

Colombia

This species occurs in lowland rainforest. It is probably endemic to north-west Colombia where it is known from three locations in Nechí and the valley of the Río Magdalena.

Assessor: Calderon, E.

Refs: 7980, 16331, 19069

\section{Rinorea hirsuta}

Violaceae

$\mathrm{LR} / \mathrm{nt}$

Colombia, Panama

An understorey species of lowland rainforest. It appears to be endemic to an area, exceeding $40,000 \mathrm{~km}^{2}$, in Chocó and adjacent forested areas in Panama, such as Nechí and Darién.

Assessor: World Conservation Monitoring Centre Refs: 7980,16331

\section{Rinorea hymenosepala}

Violaceae

$\mathrm{EN} \mathrm{Bl}+2 \mathrm{c}$

Colombia

Closely related to the more widespread $R$. ulmifolia, this species is known from two locations: one in the northern forests of the Rio Magdalena valley and the other near Sierra Nevada de Santa Marta.

Assessor: Calderon, E.

Refs: 7980, 16331, 19069

\section{Rinorea keayi}

Violaceae

LR/nt

Cameroon, Nigeria

The Nigerian population of this tree appears to be restricted to forested valleys on the Obudu Plateau, the northern division of Cross River National Park. Parts of the forest are showing signs of fire damage and there is growing pressure to convert areas into commercial plantations, especially for growing bananas. The species also appears to grow in dense populations in various 
forest types in Cameroon, on the central plateau as well as in the coastal forest.

Assessor: World Conservation Monitoring Centre

Refs: $2773,4977,9133,11504$

\section{Rinorea laurifolia}

Violaceae

$\mathrm{EN} \mathrm{B} 1+2 \mathrm{c}$

Colombia

This tree species is known only from the type collection, which was made in 1936 in the valley of Rio Magdalena.

Assessor: Calderon, E.

Refs: 7980, 16331, 19069

\section{Rinorea longistipulata}

Violaceae

VU D2

Brazil (Acre)

Confined to non-flooded forest, this species has not been collected from anywhere other than its type locality.

Assessor: World Conservation Monitoring Centre

Refs: 7980, 16331

\section{Rinorea marginata}

Violaceae

$\mathrm{CR} B 1+2 \mathrm{c}$

Colombia

A species collected only from the river banks of the southern Río Magdalena valley.

Assessor: Calderon, E.

Refs: $7980,16331,19069$

\section{Rinorea maximiliani}

Violaceae

CR B $1+2 \mathrm{C}$

Brazil (Espírito Santo)

The type locality, to which the species appears to be confined, was discovered nearly 200 years ago in an area of coastal rainforest of Espirito Santo.

Assessor: World Conservation Monitoring Centre

Refs: 7980, 16331

\section{Rinorea oraria}

Violaceae

VU D2

Venezuela

A species which appears to be confined to its type location on the slopes of the Coastal Cordillera in Venezuela, between 700 and $800 \mathrm{~m}$.

Assessor: World Conservation Monitoring Centre Refs: 798C, 16331

\section{Rinorea pectino-squamata}

\section{Violaceae}

VU D2

\section{French Guiana}

This species is known only from the 1982 type collection, located along a road in northern French Guiana.

Assessor: World Conservation Monitoring Centre Refs: 7980,16331

\section{Rinorea ramiziana}

Violaceae VU Alc, Bl+2c

Brazil (Espírito Santo, Rio de Janeiro)

Confined to coastal forest refuges and savanna forest, the species is known only from the north of Rio de Janeiro and Alegre.

Assessor: World Conservation Monitoring Centre Refs: 7980,16331
Rinorea squamata

Violaceae

Costa Rica, Honduras, Nicaragua, Panama

LR/nt

Well collected and apparently relatively abundant, this understorey species occurs in primary or disturbed lowland to submontane rainforest between south-east Nicaragua and Panama. It is also found in forestpasture margins.

Assessor: World Conservation Monitoring Centre

Refs: 9076, 13995, 14487, 16331

\section{Rinorea thomensis}

Violaceae

Sāo Tomé \& Príncipe (São Tomé)

VU D2

A species known from single collections made in the last century from Saudade, Santa Ana, Batepa and S. Carlos and from a more recent collection from Santarém. Most of the original forest below $1500 \mathrm{~m}$ was cleared in the first half of the century.

Assessor: World Conservation Monitoring Centre Refs: 2724,10080

\section{Rinorea ulmifolia}

Violaceae

VU B1+2c

Colombia

A species which, although endemic to north-west Colombia, is relatively well collected in the Río Magdalena valley from Bogotá to Sierra Nevada de Santa Marta.

Assessor: Calderon, E.

Refs: 7980, 16331, 19069

\section{Rinorea uxpanapana}

Violaceae

VU D2

Mexico (Veracruz)

An isolated and distinctive species of Rinorea, growing in seasonal forest on karst limestone. It is known only from the type collection of 1982, taken from Uxpanapa. Although there has been much deforestation, the areas on karst are generally unattractive to cultivate or log. The species appears to be more closely related to paleotropical members of the genus.

Assessor: World Conservation Monitoring Centre

Refs: $5603,5651,7980,8283,16331$

\section{Rinorea villosiflora}

Violaceae

$\mathrm{EN} B 1+2 \mathrm{c}$

Brazil (Maranháo)

Apparently confined to the type locality along a road in the estate of Santa Maria, this species occurs in nonflooded forest.

Assessor: World Conservation Monitoring Centre Refs: 7980,16331

\section{Robinsonella brevituba}

Malvaceae

VU Alc

Mexico (Oaxaca, Veracruz)

A species of high precipitation rainforest, occurring in the Tuxtepec and Uxpanapa-Chimalapa regions.

Assessor: World Conservation Monitoring Centre Refs: 5651, 5993

\section{Robinsonella mirandae}

Malvaceae

VU Alc, BI+2c

Mexico

Endemic to the Gulf region, this canopy tree is restricted to remaining areas of rainforest.

Assessor: World Conservation Monitoring Centre

Refs: 5993, 14293 
Robinsonella samaricapa

Malvaceae

Mexico (Oaxaca, Veracruz)

VUAlc

A large tree of high precipitation rainforest, occurring largely in the Uxpanapa-Chimalapa region.

Assessor: World Conservation Monitoring Centre

Refs: 5993

\section{Robynsia glabrata}

Rubiaceae

VUAlc

Côte d'Ivoire, Ghana, Nigeria

A species which is uncommon and located in the severely degraded dry forests of southem Côte d'Ivoire, Ghana and Nigeria. These areas are vulnerable to the effects of population growth and associated activities.

Assessor: Hawthome, W.

Refs: $2773,8369,12061$

\section{Rochefortia acrantha}

Boraginaceae

VU B $1+2 c$

Jamaica

A small tree or shrub, which is restricted to areas of woodland on rocky limestone in Trelawny and Westmoreland.

Assessor: World Conservation Monitoring Centre

Refs: 401, 5653, 7980

\section{Rollinia amazonica}

Annonaceae

VU D2

Colombia

This is a rare species restricted to low altitudes in Trapécio Amazonico.

Assessor: World Conservation Monitoring Centre

Refs: 2228, 6507, 6728, 7980

\section{Rollinia andicola}

Annonaceae

$\mathrm{LR} / \mathrm{nt}$

Ecuador, Peru

Restricted to areas of montane forest, between 1200 and $1900 \mathrm{~m}$, the species has not been widely collected although it does have a relatively wide extent of occurrence ( $>70,000 \mathrm{~km}^{2}$ ).

Assessor: World Conservation Monitoring Centre Refs: 6728,7980

\section{Rollinia bahiensis}

Annonaceae

VU BI+2c

Brazil (Bahia)

Confined to lowland coastal forests, this small tree is threatened with the loss of its habitat. It extends probably just over $20,000 \mathrm{~km}^{2}$.

Assessor: World Conservation Monitoring Centre

Refs: $2228,3912,6728,7980$

\section{Rollinia boliviana}

Annonaceae

$\mathrm{EN} \mathrm{B} 1+2 \mathrm{c}$

Bolivia

This species has only once been collected, in 1939 in Larecaja, La Paz.

Assessor: World Conservation Monitoring Centre

Refs: $2228,6728,7980,17460$

\section{Rollinia calcarata}

Annonaceae

$\mathrm{EN} \mathrm{B1}+2 \mathrm{c}$

Brazil (Acre)

This is an unusual species, which is known only from the type collection made in 1933 at the mouth of Rio Macauhan.

Assessor: World Conservation Monitoring Centre

Refs: $4624,6728,7980$

\section{Rollinia centrantha}

Annonaceae

Ecuador, Peru?

The species is known from two disjunct locations in the Amazon. The range may be found to be more extensive after further collections have been fully determined. The flower structure is the only feature that distinguishes this species from $R$. cuspidala.

Assessor: World Conservation Monitoring Centre

Refs: 6728,7980

\section{Rollinia chrysocarpa}

Annonaceae

VU D2

Ecuador? (Ecuador?), Peru

A distinctive species, known only from the type collection, within a $50 \mathrm{~m}$ altitudinal belt in the Peruvian Amazon. Similar, but undetermined, specimens occur in Napo, in Ecuador.

Assessor: World Conservation Monitoring Centre

Refs: $349,6728,7980$

\section{Rollinia ecuadorensis}

Annonaceae

VU B $1+2 \mathrm{c}$

Ecuador

A tree species with a range covering less than 20,000 $\mathrm{km}^{2}$, confined to lowland rainforest in Napo. It is found in the Jatun Sacha Biological Reserve.

Assessor: World Conservation Monitoring Centre

Refs: $2228,6728,7980,18190$

\section{Rollinia ferruginea}

Annonaceae

EN Alc $+2 c, B 1+2 c$

Brazil (Rio de Janeiro)

This species grows to a maximum of $2 \mathrm{~m}$. It is very rare and restricted to forests around the city of Rio de Janeiro, where increasing urbanisation places it under serious threat. It has been found on the north side of Tijuca National Park.

Assessor: World Conservation Monitoring Centre Refs: $6728,6767,7980$

\section{Rollinia helosioides}

Annonaceae

CR B1+2e, C1, D1

Brazil, Ecuador

Current information states that this species is reduced to a single tree in Jatun Sacha Biological Reserve, Ecuador. However, previous information suggests it may also be found in Brazil.

Assessor: Buitrón, X. et al.

Refs: $2228,6728,6767,7980,19195$

\section{Rollinia herzogii}

Annonaceae

LR/cd

Bolivia, Peru

This tree or shrub is recorded in forest and savanna areas in two disjunct locations in Pen, including Tambopata Wildlife Reserve, and in Bolivia.

Assessor: World Conservation Monitoring Centre Refs: 6728,7980

Rollinia hispida

Annonaceae

VU B $1+2 c$

Ecuador, Peru

A small tree confined to an area possibly less than 
$20,000 \mathrm{~km}^{2}$ in the Amazon of Peru and Ecuador. It occurs in Iparia National Forest.

Assessor: World Conservation Monitoring Centre

Refs: $349,6728,7980$

\section{Rollinia occidentalis}

Annonaceae

VU B $1+2 c$

Argentina, Bolivia

The species appears to be endemic to the piedmont forest of north-west Argentina and Bolivia, an unprotected ecosystem which is rapidly being replaced by agricultural systems.

Assessor: Prado, D.

Refs: 19122

\section{Rollinia pachyantha}

Annonaceae

$\mathrm{EN} B 1+2 c$

Colombia

The species is confined to lowland rainforest in Valle.

The site of a 1985 collection coincides with the proposed route for a road to a military base.

Assessor: Calderon, E.

Refs: $6728,7980,19069$

\section{Rollinia parviflora}

Annonaceae

LR/nt

Brazil (Rio de Janeiro)

A shrub or tree from forest in Rio de Janeiro. It is known from several locations and is not uncommon.

Assessor: World Conservation Monitoring Centre

Refs: 6728,7980

\section{Rollinia pickelii}

Annonaceae

VU B $1+2 c$

Brazil (Paraiba, Pernambuco)

This small tree is restricted to a fairly small area (< $20,000 \mathrm{~km}^{2}$ ) in the highly threatened * resting $a$ vegetation on the coast of Pararba and Pernambuco States.

Assessor: World Conservation Monitoring Centre

Refs: $6728,7980,14516$

\section{Rollinia rufinervis}

Annonaceae

Colombia

This species is known only from a small area along Rio Magdalena north-west of Bogotá.

Assessor: World Conservation Monitoring Centre

Refs: $2228,6728,7980,14516$

\section{Rollinia ubatubensis}

Annonaceae

LR/nt

Brazil (Sāo Paulo)

A forest tree, endemic to Ubatuba. It may extend over an area greater than $20,000 \mathrm{~km}^{2}$ but there is evidence that it is threatened.

Assessor: World Conservation Monitoring Centre

Refs: $6728,6767,7980$

\section{Rollinia velutina}

Annonaceae

$\mathrm{LR} / \mathrm{nt}$

Colombia, Venezuela

Fairly wide-ranging, the species is found in low-altitude forests in Boyacá to Barinas.

Assessor: World Conservation Monitoring Centre

Refs: 6728, 7980

\section{Rollinia xylopïfolia}

Annonaceae LR/nt

Brazil (Espínto Santo, Rio de Janeiro, São Paulo)

A small forest tree or shrub, which ranges over an area greater than $40,000 \mathrm{~km}^{2}$. It is also found on the margin of * campo cerrado.

Assessor: World Conservation Monitoring Centre Refs: 6728,7980

\section{Romeroa verticillata}

Bignoniaceae

VU $B 1+2 c$

Colombia

A monotypic genus, confined to Magdalena Valley in Boyacá and Santander.

Assessor: Calderon, E.

Refs: 7980, 19069

\section{Rondeletia adamsii}

Rubiaceae

VU B1+2c

Jamaica

An endemic to the Cockpit Country, occurring on rocky limestone in Clarendon and Trelawny.

Assessor: Kelly, D.L.

Refs: 401, 5653, 7980, 19085

\section{Rondeletia amplexicaulis}

Rubiaceae

$\mathrm{EN} B \mid+2 c$

Jamaica

Found in open glades or woodland on clay banks, the species is restricted to Trelawny.

Assessor: World Conservation Monitoring Centre Refs: 401, 5653, 7980

\section{Rondeletia brachyphylla}

Rubiaceae

$\mathrm{EN} \mathrm{Bl}+2 \mathrm{c}$

Jamaica

Occurring in small numbers on rocky serpentine hillsides, the species is confined to the southern John Crow Mountains between 750 and $900 \mathrm{~m}$.

Assessor: World Conservation Monitoring Centre Refs: 401, 5653, 7980, 17743

\section{Rondeletia cincra}

Rubiaceae

CR C2a

Jamaica

There appear to be only a few individuals, confined to the summits of Dolphin Head and Bubby Hill. There is evidence of selective logging and some hurricane damage.

Assessor: World Conservation Monitoring Centre Refs: $401,5653,7980$

\section{Rondeletia clarendonensis}

Rubiaceae

$\mathrm{EN} \mathrm{B1+2c}$

Jamaica

A rare small tree or shrub of exposed craggy sites on limestone. It is recorded only from the parishes of Clarendon and St Ann.

Assessor: Kelly, D.L

Refs: 5653, 19085

\section{Rondeletia dolphinensis}

Rubiaceae

$\mathrm{EN} \mathrm{B1+2c}$

Jamaica

A species known only from the summit slopes of Dolphin Head, where it occurs locally in moist forest on limestone between 450 and $500 \mathrm{~m}$.

Assessor: Kelly, D.L.

Refs: $401,5653,7980,19085$ 


\section{Rondeletia elegans}

Rubiaceae

VU B $1+2 c$

Jamaica

An uncommon tree or shrub, restricted to moist secondary forest on limestone hills in Portland and St Thomas between 360 and $680 \mathrm{~m}$. It resembles $R$. pallida, an equally rare species, and may not be worthy of taxonomic distinction. The habitat, especially in St Thomas, has been almost completely destroyed or severely degraded.

Assessor: World Conservation Monitoring Centre

Refs: $6057,7980,19116$

\section{Rondeletia galeottii}

Rubiaceae

VU A1c

Mexico (Oaxaca, Veracruz)

A species of high precipitation rainforest, occurring in the regions of Los Tuxtlas and Uxpanapa-Chimalapa.

Assessor: World Conservation Monitoring Centre

Refs: 5993

\section{Rondeletia glauca}

Rubiaceae

LR/nt

Jamaica

A scrambling shrub or tree, the species has a local distribution in woodland on sheltered limestone banks in St Catherine, Trelawny and St Ann.

Assessor: World Conservation Monitoring Centre

Refs: 6057,7980

\section{Rondeletia harrisii}

Rubiaceae

LR/nt

Jamaica

A small uncommon tree or shrub, restricted to Hanover, Trelawny and St Ann, where it occurs in woodiand on limestone.

Assessor: World Conservation Monitoring Centre

Refs: 6057, 7980

\section{Rondeletia hirsuta}

Rubiaceae

VU B $1+2 \mathrm{c}$

Jamaica

A small shrub or tree known only from Portland and St Thomas, where it occurs between 120 and $550 \mathrm{~m}$ in lowland forested ravines. In the more accessible places forest areas are almost completely destroyed or severely degraded.

Assessor: World Conservation Monitoring Centre Refs: 6057, 7980, 19116

\section{Rondeletia hirta}

Rubiaceae

VU B1+2c

Jamaica

A small tree or shrub which is locally frequent in St Andrew and St Thomas in thickets and woodland on steep rocky slopes between 240 and $900 \mathrm{~m}$. Most of the accessible areas of forest have been destroyed.

Assessor: Bellingham, P.

Refs: $6057,7980,19116$

\section{Rondeletia pallida}

Rubiaceae

VU $B 1+2 c$

Jamaica

Uncommon and confined to Portland and St Thomas, the species occurs up to $600 \mathrm{~m}$ in woodland on limestone, especially where it is wet. Most, if not all, of the forest, especially in the latter parish, has been destroyed or severely degraded.

Assessor: World Conservation Monitoring Centre

Refs: $6057,7980,19116$

Rondeletia peruviana

Rubiaceae

VU D2

Pen

A species which is recorded only from the type collection taken from Amazon forest in the department of Loreto.

Assessor: World Conservation Monitoring Centre

Refs: 1984

\section{Rondeletia portlandensis}

Rubiaceae

VU B1+2c

Jamaica

Recorded only from Portland, the species occurs in damp thickets and mossy forest on limestone. It has recently been found above Ecclesdown.

Assessor: Kelly, D.L.

Refs: 401, 5653, 7980, 19085

\section{Rondeletia racemosa}

Rubiaceae

VU B $1+2 c$

Jamaica

A tree of submontane forest in Portland, St Andrew and St Thomas. Almost all the accessible forest below $1400 \mathrm{~m}$ in the latter two parishes has been destroyed or severely degraded.

Assessor: World Conservation Monitoring Centre

Refs: $6057,7980,19116$

\section{Rondeletia subsessilifolia}

Rubiaceae

VU B $1+2 c$

Jamaica

Known only from Portland Parish, the species has a very local distribution, confined to mossy thickets in wet areas on limestone. There is also a putative specimen in the forest above Ecclesdown.

Assessor: Kelly, D.L.

Refs: 401, 5653, 7980, 19085

\section{Roscheria melanochaetes}

Paimae

LR/nt

Seychelles

A common palm tree found in moist forest on steep hillsides and slopes. Populations are restricted to Mahe, Praslin and Silhouette Islands. It regenerates well.

Assessor: Murugaiyan, P.

Refs: 19118

\section{Rosselia bracteata}

Burseraceac

VU B $1+2 c$

Papua New Guinea

A newly described genus, endemic to Rossel Island in the Louisiade Archipelago. The area was thickly forested a century ago.

Assessor: World Conservation Monitoring Centre Refs: 476

\section{Rothmannia annae}

Rubiaceae

VU Ala, D1+2

Seychelles

The only wild populations remaining are confined to the Aride Islands. Populations on Mahé, Silhouette, Praslin and Felicite Islands became extinct in the early part of the century. A count has been made of 922 mature plants which appear to be healthy and regenerating, although 
recent declines in numbers are thought to have been caused by shading from other species. Past declines on other islands are probably attributable to widespread forest clearance. Parasitism by the mealy bug (Icerya seychellarum), although often stated as a contributing factor, has little effect on the health and reproductive capacity of individuals. Aride Island is a Special Reserve.

Assessor: Nature Protection Trust of Seychelles

Refs: 10610, 11417, 17229, 19025, 19062

\section{Rothmannia macrosiphon}

Rubiaceae

VU B $1+2 b$

Kenya, Tanzania

A sometimes scrambling shrub or small tree. It ranges from moist coastal forests in Buda, Marenge, Shimba, Arabuko and Mangea in Kenya to areas of east and south-east Tanzania.

Assessor: Lovett, J. \& G.P. Clarke

Refs: 3356, 10961

\section{Roupala brachybotrys}

Proteaceae

VU B $1+2 c$

Ecuador

This Ecuadorean endemic inhabits cloud forest between

2600 and $2700 \mathrm{~m}$ in the province of Azuay.

Assessor: World Conservation Monitoring Centre

Refs: 19119,19120

\section{Roupala loxensis}

Proteaceae

VU $B 1+2 c$

Ecuador

This Ecuadorean endemic inhabits montane cloud forest in Loja Province.

Assessor: World Conservation Monitoring Centre

Refs: 19119,19120

\section{Roupala pinnata}

Proteaceae

VU $B 1+2 c$

Peru

This species is known from submontane forest up to about $3500 \mathrm{~m}$ in Huánuco.

Assessor: World Conservation Monitoring Centre Refs: 1984

\section{Roupala sphenophyllum}

Proteaceae

VU D2

Peru

A species which is known only from the type collection taken from Amazon forest in Loreto.

Assessor: World Conservation Monitoring Centre Refs: 1984

\section{Roystonea dunlapiana}

Palmae

$\mathrm{EN} \mathrm{B1}+2 \mathrm{c}$

Honduras, Mexico

In Honduras, the species occurs in humid forest in the Atlantic lowlands. The population is considered to be Critically Endangered (CR C2a). The wood is used for construction. The only other occurrence is recorded in south-east Mexico.

Assessor: World Conservation Monitoring Centre

Refs: $7645,12985,13995,16980$

\section{Roystonea lenis}

Palmae

VU DI+2

Cuba

Confined to Guantánamo Province, this early pioneer palm tree occurs in lowland open forest and anthropic landscapes between 350 and $420 \mathrm{~m}$. This species is difficult to distinguish from the common $R$. regia.

Assessor: Zona, $\mathbf{S}$.

Refs: 19118

\section{Roystonea princeps}

Palmae

LR/nt

Jamaica

An early pioneer which occurs in wetland areas below $10 \mathrm{~m}$ in the Great Morass region of western Jamaica. Two main populations exist, covering an area of less than $400 \mathrm{~km}^{2}$. The total population size is unknown but estimated at between 5000 and 10,000 individuals. Increasing settlement and the decline in soil water content are the main threats.

Assessor: Zona, S.

Refs: 19118

\section{Roystonea regia var. hondurensis}

Palmae

CR C2a

Honduras

This variety appears to be endemic to Honduras and confined to a small area of humid forest in the Atlantic lowlands. The timber is exploited for construction work. Assessor: Nelson, C

Refs: 7645,13995

Roystonea stellata

Palmae

EN D1

Cuba

Confined to Yagruma Terrace in the Maisí region of Cuba, this palm tree occurs in lowland open forest. For the last four decades, its preferred habitat has been converted to coffee plantations. No trees were found in 1990 during a search of the area.

Assessor: Zona, S.

Refs: 19118

\section{Ruagea microphylla}

Meliaceae

VU B $1+2 c$

Ecuador

This endemic tree of the Ecuadorean High Andes inhabits cloud forest between $2200 \mathrm{~m}$ and $2650 \mathrm{~m}$ in Loja Province.

Assessor: World Conservation Monitoring Centre Refs: 19119,19120

\section{Ruagea ovalis}

Meliaceae

VU D2

Bolivia

A rarely collected species confined to the eastem slopes of the Andes in Bolivia.

Assessor: World Conservation Monitoring Centre Refs: 7980,12281

\section{Rudgea microcarpa}

Rubiaceae

VU D2

Pen

Known only from the type collection, the species occurs in submontane forest in the department of Huánuco. Assessor: World Conservation Monitoring Centre Refs: 1984

\section{Rudgea obesiflora}

Rubiaceae

VU D2

Peru

Known only from the type collection, this lowland forest 
species was collected from the Amazon in Loreto. Assessor: World Conservation Monitoring Centre Refs: 1984

\section{Rudgea stenophylla}

Rubiaceae

VU D2

Pens

Known only from the type collection, the species occurs in lowland forest in the department of San Martin.

Assessor: World Conservation Monitoring Centre Refs: 1984

\section{Ruellia insignis}

Acanthaceae

VU D2

Yemen (Socotra)

A small tree or shrub which is scattered, occasionally common, in areas of moist submontane woodland. There are no immediate threats.

Assessor: Miller, A.G.

Refs: 19083

\section{Ruprechtia apetalo}

Polygonaceae LR/nt

Argentina (Catamarca, Córdoba, Jujuy, La Rioja, Salta, San Luis, Santiago del Estero, Tucumán), Bolivia

A species of scrubland and woodland. Although occurring widely, it is found in areas which are heavily degraded and overgrazed by goats, sheep and cattle. It is unknown whether the species is regenerating.

Assessor: World Conservation Monitoring Centre

Refs: $1262,5112,19170$

\section{Ryania speciosa var. mutisii}

Flacourtiaceae

Colombia

A Colombian form of a widespread South American species. It is believed to have occurred in Tolima and/or Cundinamarca.

Assessor: Calderon, E.

Refs: 7980, 19069

\section{Ryparosa fasciculata}

Flacourtiaceae

VU B $1+2 a$

Malaysia (Peninsular Malaysia)

A small tree of Malacca and Pahang, inhabiting lowland secondary forest up to $300 \mathrm{~m}$.

Assessor: Chua, L.S.L.

Refs: 8464, 19073

\section{Ryparosa scortechinii}

Flacourtiaceae

LR/cd

Malaysia (Peninsular Malaysia), Singapore

Inhabiting rainforest up to $900 \mathrm{~m}$, this small tree ranges from Penang and Kelantan southwards. Part of the range is contained within Taman Negara National Park.

Assessor: Chua, L.S.L.

Refs: $8464,9199,17140,19073$

\section{Rytigynia adenodonta var, adenodonta}

Rubiaceae

VU $B 1+2 b$

Malawi, Tanzania, Zambia

The higher altitude variant of the species. Populations are known from the Nyika Plateau within Malawi and Zambia and further north in parts of Tanzania, where there is dry montane forest.

Assessor: Lovett, J. \& G.P. Clarke

Refs: $1308,3356,8814$

\section{Rytigynia adenodonta var, reticulata}

Rubiaceae

Malawi, Tanzania, Zambia

VU B $1+2 b$

This variant, as with the type variety, occurs in dry montane forest in the Nyika Plateau and parts of Tanzania. It is restricted to lower altitudes, from 1800 to $1950 \mathrm{~m}$.

Assessor: Lovett, J. \& G.P. Clarke

Refs: $1308,3356,8814$

\section{Rytigynia binata}

Rubiaceae

VU B $1+2 b$

Tanzania

A dry coastal species endemic to east and south-east

Tanzania.

Assessor: Lovett, J. \& G.P. Clarke

Refs: 3356,8814

\section{Rytigynia bugoyensis ssp. glabriflora}

Rubiaceae

VU $B 1+2 b$

Malawi, Tanzania

A shrub or small tree confined to areas of moist montane forest in four localities, including Ukaguru, Rungwe and Songea in Tanzania.

Assessor: Lovett, J. \& G.P. Clarke

Refs: $1308,3356,8814$

\section{Rytigynia caudatissima}

\section{Rubiaceae}

VU B1+2b, D2

\section{Tanzania}

An endemic of the Udzungwa Mountains, restricted to an area of moist montane forest at Sanje.

Assessor: Lovett, J. \& G.P. Clarke

Refs: 3356, 10961

\section{Rytigynia celastroides var. nuda}

Rubiaceae

VU $B 1+2 b$

Tanzania

A variety confined to dry coastal forest areas in east and south-east Tanzania and on Zanzibar Island.

Assessor: Lovett, J. \& G.P. Clarke

Refs: 3356,8814

\section{Rytigynia eickii}

Rubiaceae

VU $B 1+2 b$

\section{Kenya, Tanzania}

A shrub or small tree ranging from the forest fringes and rocky bushland in the Taita Hills to areas of moist forest at medium elevation in eastern Tanzania.

Assessor: Lovett, J. \& G.P. Clarke

Refs: $3356,6396,8814$

\section{Rytigynia hirsutiflora}

Rubiaceae

VU $B 1+2 b$

Tanzania

An endemic of the North Udzungwa Mountains, the species is known from areas of moist montane forest at Sanje and Udekwa.

Assessor: Lovett, J. \& G.P. Clarke

Refs: 3356,8814

\section{Rytigynia induta}

Rubiaceae

VU B $1+2 b$

Keilya, Tanzania

A shrub or small tree confined to a few areas of forest or thicket in Kenya and to dry montane forest in Loliondo and Ufiomi in Tanzania.

Assessor: Lovett, J. \& G.P. Clarke

Refs: $3356,6396,12067$ 
Rytigynia lichenoxenos ssp. glabrituba Rubiaceae

VU B $1+2 b$

Tanzania

One of the subspecies of a Tanzanian endemic. It is found in moist montane forest at Mufindi in the Udzungwa Mountains and at Nditima along the upper Ruhudje River.

Assessor: Lovett, J. \& G.P. Clarke

Refs: 3356,8814

\section{Rytigynia lichenoxenos ssp. lichenoxenos}

Rubiaceae

VU B1+2b

Tanzania

Endemic to the South Uluguru Mountains, this subspecies is restricted to high-altitude moist evergreen forest.

Assessor: Lovett, J. \& G.P. Clarke

Refs: 3356,8814

\section{Rytigynia longipedicellata}

Rubiaceae

$\mathrm{EN} \mathrm{B} 1+2 \mathrm{bc}$

Tanzania

A species which appears now to be confined to the remaining areas of undisturbed coastal forest in the Rondo Forest Reserve $\left(140 \mathrm{~km}^{2}\right)$. The forest has been severely disturbed by logging, shifting cultivation, wood collection and plantation establishment in the past. The presence of forest management staff activities is helping to discourage local exploitation.

Assessor: Lovett, J. \& G.P. Clarke

Refs: 3356,16796

\section{Rytigynia nodulosa}

Rubiaceae

$\mathrm{VUB} 1+2 \mathrm{~b}$

Tanzania

An endemic of the cloud forests in the North Uluguru

Mountains.

Assessor: Lovett, J. \& G.P. Clarke

Refs: 3356,8814

\section{Rytigynia pseudolongicaudata}

Rubiaceae

VU $B 1+2 b$

Tanzania

A shrub or small tree occurring in moist montane forest areas in the Ukaguru Mountains, South Uluguru Mountains and at Mwanihana in the Udzungwa Mountains.

Assessor: Lovett, J. \& G.P. Clarke

Refs: 3356,8814

\section{Sabal bermudana}

Palmae

EN B $1+2$ cd

Bermuda

An endemic species confined to the few remaining patches of lowland dry or marshy scrub. The largest population is in Paget Marsh. This omamental palm tree is widely cultivated and traded intemationally. Natural stands are protected under the Tree Preservation Orders and the Woodland Preservation Orders.

Assessor: Johnson, D.

Refs: 19118

\section{Sabal gretheriae}

Palmae

VU D2

Mexico (Yucatán)

A palm confined to the Yucatán Peninsula, inhabiting open disturbed herbaceous vegetation on sandy soils at low elevations. It is used locally as a source of timber, food, fibre and thatching.

Assessor: Quero, H.J.

Refs: 19118

\section{Sabal pumos}

Palmae

VU Alc

Mexico

An endemic palm of Mexico confined to the Balsas Valley, where it is found on sandy soils in the transition zone between tropical deciduous forest and oak forest. Increasing agriculture is causing habitat loss.

Assessor: Quero, H.J.

Refs: 19118

\section{Sabal uresana}

Palmae

VUAlc

Mexico

An endemic palm of Mexico, confined to the Sierra Madre Occidental, where it is scattered in thom forest and oak forest along watercourses.

Assessor: Quero, H.J.

Refs: 19118

\section{Saccopetalum prolificum}

Annonaceae

VU Alcd

China (Guangdong - Hainan)

An endemic of Hainan Island, confined to remaining areas of semi-deciduous monsoon and rainforest in valleys below $500 \mathrm{~m}$. The species can occur commonly and regenerates well, but it is cut for its timber and has experienced rapid rates of decline in its habitat because of logging and the increase in the amount of land coming under cultivation.

Assessor: World Conservation Monitoring Centre Refs: 1818,11847

\section{Sageraea grandiflora}

Annonaceae

$\mathrm{EN} \mathrm{B1}+2 \mathrm{c}$

India (Kerala)

For a long time the species was known only from collections taken in the 19th century from Konni forest in Quilon District, a large part of which has been logged and replaced with commercial crops. The species now appears to be sparsely distributed in a few additional localities of lowland forest in the area.

Assessor: World Conservation Monitoring Centre Refs: 2538, 19144

\section{Sageraea laurifolia}

Annonaceae

LR/nt

India (Kamataka, Kerala, Tamil Nadu)

Assessor: World Conservation Monitoring Centre

Refs: 19144

\section{Sageraea thwailesii}

Annonaceae

$\mathrm{EN} \mathrm{B1}+2 \mathrm{c}$

Sri Lanka

A rare species found in wet and dry forest. During the extensive surveys conducted for the National Conservation Review, populations were found in single localities in Ratnapura District and Anuradapura District.

Assessor: World Conservation Monitoring Centre Refs: $15431,17195,19112$ 
Sakoanala madagascariensis

Leguminosae

Madagascar

A coastal, evergreen forest species confined to only four known localities, all in fragments of now very restricted $\left(200 \mathrm{~km}^{2} * \mathrm{AOO}\right)$ and continually decreasing forest in eastern coastal Madagascar, near Toamasina. Trees are selectively felled for construction timber.

Assessor: Du Puy, D. \& H. Labat

Refs: 12353

\section{Sakoanala villosa ssp. menabeensis}

Leguminosae

VU Bl+2abc

Madagascar

A rare and poorly known woodland species confined to the coastal plains of westem Madagascar, with a known distribution of $20000 \mathrm{~km}^{2}$ ("EOO). Vegetation in the area is already very fragmented and declining.

Assessor: Du Puy, D. \& H. Labat

Refs: 12353

\section{Sakoanala villosa ssp. villosa \\ Leguminosae \\ Madagascar}

$\mathrm{EN} \mathrm{B} 1+2 \mathrm{abc}$

A rare deciduous woodland subspecies confined to the Ankarana Massif and around Antsiranana at the northem tip of Madagascar, on limestone. Covering an estimated $250 \mathrm{~km}^{2}\left({ }^{*} \mathrm{AOO}\right)$, most of the area is very fragmented and declining rapidly. The Ankarana population is protected within the Ankarana Reserve.

Assessor: Du Puy, D. \& H. Labat

Refs: 12353

\section{Salacia lehmbachii var. manus-lacertae}

Celastraceae

VU D2

Gabon

An endemic of the Belinga Mountains. The vegetation in some areas is degraded by agricultural encroachment. Several other restricted-range variants of this species exist because of the tendency for variable characteristics to stabilise when populations become isolated.

Assessor: World Conservation Monitoring Centre

Refs: 12323

\section{Salacia lehmbachii var. pes-ranulae}

Celastraceae

$\mathrm{VUB}+2 \mathrm{c}$

Cameroon, Nigeria

This variety is localised in the remaining protected forests in the Oban Hills, extending into south-east d'Ebolowa in Cameroon. Forests outside these areas have been extensively felled and cleared for agriculture. Several restricted range variants of this species exist because of the tendency for variable characteristics to stabilise when populations become isolated.

Assessor: World Conservation Monitoring Centre

Refs: 4977,12323

\section{Salacia lehmbachü var, uregaensis}

Celastraceae

VU D2

Democratic Republic of Congo

This variety is known only from the type locality in the Forestier Central. Several other restricted-range variants of this species exist because of the tendency of variable characteristics to stabilise when populations become isolated.

Assessor: World Conservation Monitoring Centre

Refs: 12323

\section{Salacia miegei}

Celastraceae

VU B $1+2 \mathrm{c}$

Côte d'Ivoire

Endemic to Côte d'Ivoire, this species appears to be scattered throughout the country but only in remnants of primary forest. Extensive logging in the country in the last three decades has caused the rapid decline of forest.

Assessor: Assi, A.

Refs: 12822

\section{Salix floridana}

Salicaceae

VU B $1+2 c$

USA (Florida, Georgia)

A small tree, confined to scattered sites from Pulaski and Early Counties in southem Georgia to Lake and northern Orange Counties in central peninsular Florida. It grows in very wet soils, usually in dense swampy woods, often at streamsides. About 12-15 sites are known, in some of which the species may now be extinct.

Assessor: World Conservation Monitoring Centre Refs: 9254

\section{Salix kusanoi}

Salicaceae

EN C2a

Taiwan

A shrub or small tree which occurs in two widely separated localities, one in the north-east and the other in the southern tip of Taiwan. Populations are small and isolated, occurring in wetland areas or at the side of rivers or ponds. A large part of the habitat has been converted into paddy fields, fishing ponds and houses. No protection or conservation measures are in place.

Assessor: Lu, S.Y. \& F.J. Pan

Refs: 3295, 6469, 19050, 19053

\section{Salix magnifica}

Salicaceae

VUAlcd

China (Sichuan)

Confined to scattered localities in western Sichuan, the species is found in montane broadleaved evergreen forest in valleys by streams. Individuals are apparently becoming scarcer in places because of the destruction of the habitat. Populations on Mount Wolong are undisturbed as this is one of the sites where the giant panda occurs.

Assessor: World Conservation Monitoring Centre

Refs: 1818,11847

Salix tarraconensis

Salicaceae

CR B $1+2 \mathrm{c}$

Spain

A small shrubby tree, known from dispersed populations, generally consisting of between 10 and 40 individuals, within areas of sclerophyllous submontane scrub in the coastal cordillera between Castellon and Tarragona. The opening up of forestry roads has caused some habitat loss. Part of the range is protected within a national reserve.

Assessor: Vivero, J.L. et al.

Refs: $1512,7222,7741,13560$

\section{Sambucus palmensis}

Caprifoliaceae

CR C2a

Spain (Canary Is.)

A dioecious species known from a few scattered individuals in cloud forest on the islands of Tenerife, Gomera, Gran Canaria and La Palma. It has a very poor regenerative capacity and the few remaining populations are threatened to a degree by fire, grazing and 
overexploitation of the medicinal bark. The species is the focus of a rescue programme which is attempting to establish new populations. It is also listed in government legislation of 1991.

Assessor: Bañares, A et al.

Refs: 8716, 10862, 16500, 19022

\section{Sambucus tigranï}

Caprifoliaceae

VU D2

Former USSR

A shrub reaching $3 \mathrm{~m}$ in height, restricted to dry, stony slopes in the resort of Arzni, Mount Arayaz, and the Ervard Ravine, Armenia. It is a promising species for forestry.

Assessor: Firsov, G.A.

Refs: 19056

\section{Samyda glabrata}

Flacourtiaceae

VU B $1+2 c$

Jamaica

There is little distinction between this species and $S$. villosa. Both are uncommon, small trees. This species is known from St Thomas and Portland, where it is restricted to thickets on limestone in wet areas between altitudes of 250 and $900 \mathrm{~m}$.

Assessor: World Conservation Monitoring Centre

Refs: 6057,7980

\section{Samyda villosa}

Flacourtiaceae

VU B $1+2 c$

Jamaica

There is little distinction between this species and $S$. glabrata. It is uncommon and confined to pastures, thickets and woodland on limestone in Clarendon, Manchester and Trelawny.

Assessor: World Conservation Monitoring Centre Refs: 6057,7980

\section{Sandoricum vidalii}

Meliaceae

VU Alcd

Philippines

A timber species, endemic to the Philippines. Rates of habitat loss through logging and shifting cultivation have led to considerable population declines.

Assessor: World Conservation Monitoring Centre

Refs: 2072, 4919, 18088

\section{Santalum album}

Santalaceae

VU Ald

China, India (Kamataka, Tamil Nadu), Indonesia (Lesser Sunda Is.), Philippines

Sandalwood is a hemi-parasitic plant which is widely scattered in dry deciduous forests. Regeneration is mostly vegetative by wood suckers or coppicing and is very successful in places. Viable seeds are produced after five years and dispersed by birds. Fire, grazing and most importantly exploitation of the wood for fine furniture and carving and also oil are threatening the species. Export of the timber is banned from India but smuggling has assumed alarming proportions.

Assessor: Asian Regional Workshop

Refs: 6426, 6431, 8483, 9328, 12937, 13285, 19075 19076, 19077
Santalum fernandezianum

Santalaceae

EX

Chile (Juan Fernández Is)

Last seen in 1908, the species was cut to extinction for its aromatic wood.

Assessor: World Conservation Monitoring Centre

Refs: 3241,5651

\section{Santalum freycinetianum var. lanaiense}

Santalaceae

VU Alce

USA (Hawaii)

A relatively common species with three morphologically overlapping varieties. This variant is known from Lanai and Maui, where it occurs in a unique dry forest type which has steadily declined under the influence of grazing deer and spreading alien plant species.

Assessor: World Conservation Monitoring Centre Refs: 3372

\section{Santalum haleakalae}

Santalaceae

VU D2

USA (Hawaii)

Known only from Haleakala on East Maui, this small tree is scattered in alpine shrubland on dry slopes up to $2700 \mathrm{~m}$, especially in fogswept areas.

Assessor: World Conservation Monitoring Centre Refs: 3372

\section{Santalum insulare var. hendersonensis}

Santalaceae

VU D2

Pitcainı Islands

A variety of a widespread Polynesian species endemic to Henderson Island. In the plateau forests it is a semidecumbent tree, becoming more shrubby and scarcer in cliff and more open communities. The total population size is calculated to be between 2000 and 4000 plants. The regeneration potential of the taxon is likely to be affected by poor fruiting performance. It is also partially parasitic, which hampers the cultivation of the plant $e x$ situ. Related taxa have been widely exterminated from their range through exploitation for the perfume and incense industry. Henderson Island is a World Heritage Site.

Assessor: Waldren, $\mathrm{S}$.

Refs: 434, 8306, 13604

\section{Santalum insulare var. insulare}

Santalaceae

LR/nt

French Polynesia (Society Is.)

One of the numerous varieties of a variable species, found only on Tahiti.

Assessor: Florence, J.

Refs: 14513

\section{Santalum insulare var, marchionense}

Santalaceae

VU B $1+2 c$

French Polynesia (Marquesas Is.)

One of the numerous varieties of a variable species. This taxon was once abundant in areas of humid forest and was the main source of wood for early European colonists. Overexploitation led to extensive deforestation and the reduction of the taxon to small remnants of its former population.

Assessor: Florence, J.

Refs: 434,14513 
Santalum insulare var, margaretae

Santalaceae

French Polynesia (Tubuai Is.)

One of the numerous varieties of a variable species. It is known from a small population at Tanga on Rapa Iti.

Assessor: Florence, J.

Refs: 434, 14513

\section{Santalum insulare var, raiateense}

Santalaceae

LR/nt

French Polynesia (Society Is.)

One of the numerous varieties of a variable species. The main population occurs on Moorea. It is also known from Raiatea, where its status is critically endangered.

Assessor: Florence, J.

Refs: 14513

\section{Santalum insulare var. raivavense}

Santalaceae

CR B $1+2 \mathrm{c}$

French Polynesia (Tubuai Is.)

One of the numerous varieties of a variable species. It occurs only on Raivavae in the Tubuai Group.

Assessor: Florence, J.

Refs: 14513

\section{Santalum macgregorii}

Santalaceae

EN Alcd, Cl

Indonesia? (Irian Jaya?), Papua New Guinea

A parasitic or semi-parasitic species found in open savanna vegetation and in savanna forest in gullies in the eastern part of Western Province and possibly also in south-east Irian Jaya. As with all other sources of sandalwood, this species is overexploited for its scented wood, which is used for incense, perfume, essential oil and carving. In Papua New Guinea the exploitation began at the tum of the last century; now the resource is greatly depleted as there are few mature trees or virgin stands.

Assessor: Eddowes, P.J.

Refs: 19114,19147

\section{Santiria dacryodifolia}

Burseraceae

VU D2

Malaysia (Sarawak)

This small tree is uncommon in Sarawak, where it has been collected only once from a ridge top at $1400 \mathrm{~m}$ on Ulu Sungai Maria, Lawas.

Assessor: World Conservation Monitoring Centre

Refs: 19017

\section{Santiria impressinervis}

Burseraceae

VU D2

Malaysia (Sarawak)

Konwn only from the type, this small tree was found in old secondary forest near the Pamerario River at Bario in the Kelabit Highlands.

Assessor: World Conservation Monitoring Centre Refs: 19017

\section{Santiria kalkmaniana}

Burseraceae

VU A1c+2c

Malaysia (Sabah, Sarawak)

Rarely occuring, this tree of lowland and hill forest is known only from a few collections from Sabah and Sarawak.

Assessor: World Conservation Monitoring Centre

Refs: 19017

\section{Santiria nigricans}

Burseraceae

Malaysia (Sarawak)

VU B $1+2 c$

Endemic to Sarawak, this tree is scattered in mixed dipterocarp forest up to $1600 \mathrm{~m}$. So far it is known only from Sungai Jelalong, Selampit, Balingian, Mulu National Park and Lambir National Park.

Assessor: World Conservation Monitoring Centre Refs: 19017

\section{Santiria rubiginosa var. Latipetiolata}

Burseraceae

VU D2

Malaysia (Sarawak)

Endemic to Sarawak, this variety is known from only two collections from the Lambir National Park; it was found in mixed dipterocarp forest on ridges at $250 \mathrm{~m}$. Trees are cut for kedondong timber.

Assessor: World Conservation Monitoring Centre

Refs: 11145,19017

\section{Santiria rubiginosa var, pedicellata}

Burseraceae

EN Alc+2c

Malaysia (Sarawak)

This variety is common in the threatened swamp forests of Sarawak, a habitat type which has been licensed for timber extraction by the year 2000 . The wood is cut for kedondong timber; small amounts of Santiria timber are exported to Japan.

Assessor: World Conservation Monitoring Centre

Refs: $10148,11145,19017$

\section{Santiria sarawakana}

Burseraceae

VU D2

Malaysia (Sarawak)

This uncommon tree of lowland forest up to $120 \mathrm{~m}$ is endemic to Sarawak. It is known only from two collections, from the Miri and Sabel Forest Reserve. Assessor: World Conservation Monitoring Centre

Refs: 19017

\section{Sapindus oahuensis}

Sapindaceae

VUAlce

USA (Hawaii)

The species is found in various forest types up to $610 \mathrm{~m}$ in north-western Kauai and in the Waianae and Koolau Mountains on Oahu.

Assessor: World Conservation Monitoring Centre Refs: 3372

\section{Sapium aubrevillei}

\section{Euphorbiaceae}

VUAlc, Bl+2c

Côte d'Ivoire, Ghana

Restricted to wet evergreen forest, this species is known from a few scattered populations, e.g. in Atewa and Subri Forest Reserves in Ghana. It is also recorded in Côte d'Ivoire. In both countries these habitats have suffered from the effects of mining, logging and commercial forestry activities, e.g. parts of Subri Forest Reserve have been deforested for industrial plantations. Assessor: Hawthome, W.

Refs: $6127,8369,12061$

\section{Sapium bourgeaui}

Euphorbiaceae

VU Alc

Mexico (Chiapas, Oaxaca, Tabasco, Veracruz)

Endemic to the Gulf region, the species is restricted to 
the remaining rainforests, ranging no further north than southern Veracruz.

Assessor: World Conservation Monitoring Centre

Refs: 5993

\section{Sapium harrisii}

Euphorbiaceae

LR/nt

Jamaica

A pioneer species of the Blue Mountains. It occurs in colonies in forest gaps and as sparsely scattered large trees in submontane forest, especially on steep unstable slopes.

Assessar: World Conservation Monitoring Centre

Refs: $6057,7980,12564$

\section{Sapium luzonicum}

Euphorbiaceae

VU Alcd

Philippines

A timber species, endemic to the Philippines. Rates of habitat loss through logging and shifting cultivation have led to considerable population declines.

Assessor: World Conservation Monitoring Centre

Refs: $4919,5651,12937$

\section{Sapium saltense}

Euphorbiaceae

Argentina, Bolivia

VU B $1+2 c$

Thought to be endemic to the piedmont forest of northwest Argentina and Bolivia, the species occurs in an unprotected ecosystem, which is rapidly being replaced by agricultural systems.

Assessor: Prado, D.

Refs: 19122

\section{Sapium triloculare \\ Euphorbiaceae \\ Kenya, Tanzania}

VU B $1+2 b$

A population has recently been found in remnant forest at Pangani Rocks, in Kenya. Otherwise the species is known only from remaining dry coastal forest in east and south-east Tanzania,

Assessor: Lovett, J. \& G.P. Clarke

Refs: 2074, 3356, 5204, 6396

\section{Sapranthus longepedunculatus}

Annonaceae

CR D1

Panama

Apparently endemic to the Peninsula de Azuero in Panama, the species is known from the type collection, dated 1968 from Punta Blanca, Tonosf, and from a collection taken in 1997 from Cerro Hoya National Park, $5 \mathrm{~km}$ away. The species appears to be very scarce, occurring in lowland semi-deciduous forest.

Assessor: Mitré, M.

Refs: 16772

\section{Saprosma fragrans}

Rubiaceae

VU B $1+2 c$

India (Kerala, Tamil Nadu)

A shrubby tree, poorly collected and recorded from few scattered sites of low- to medium-elevation evergreen forest between Travancore, the Nilgiris and the northernmost part of Kerala.

Assessor: World Conservation Monitoring Centre Refs: 19144

\section{Saprosma scabridum}

Rubiaceae

$\mathrm{EN} \mathrm{B1}+2 \mathrm{c}$

Sri Lanka

Known from four collections in total, this endemic species is restricted to the wet forests of south-west Sri Lanka. two collections were made last century. The two recent collections were found in forest reserves during the comprehensive surveys conducted for the National Conservation Review.

Assessor: World Conservation Monitoring Centre

Refs: 8203, 16943, 18796, 19112

\section{Saraca asoca}

Leguminosae

India, Sri Lanka

VU B $1+2 c$

Occurring in the south and central Western Ghats and Sri Lanka, this small tree has become threatened in some parts of its range mainly through the loss of its habitat. No populations were found in Sri Lanka during the extensive forest surveys conducted between 1991 and 1996 for the National Conservation Review, suggesting the species is either extremely rare or possibly extinct. It is commonly cultivated and regarded as sacred. Medicinal extracts from the bark are commercially valuable and exported.

Assessor: CAMP Workshops on Medicinal Plants in India

Refs: $561,18325,19110,19112$

\section{Saraca celebica}

Leguminosae

LR/nt

Indonesia (Sulawesi)

This species, endemic to Sulawesi, is known from only five collections; it is found near lowland streams.

Assessor: World Conservation Monitoring Centre Refs: 4329, 19017

\section{Sarawakodendron filamentosum}

\section{Celastraceae}

VU D2

Malaysia (Sarawak)

A monotypic genus endemic to Sarawak. This small tree grows in mixed dipterocarp forest and *kerangas forest. It is known only from Nyabau Forest Reserve, Bako National Park, Sri Aman and Bayai.

Assessor: World Conservation Monitoring Centre Refs: 19017

\section{Sarcaulus inflexus}

Sapotaceae

VU B1+2c

Brazil (Amazonas, Mato Grosso)

A tree of the central Brazilian Amazon, where it occurs in non-flooded forest. Logging activities are a threat to some populations.

Assessor: Pires O'Brien, J.

Refs: $1983,7980,8816$

\section{Sarcaulus oblatus}

Sapotaceae

LR/nt

Ecuador

A tree of the Ecuadorean Amazon. It occurs in submontane forest in Morona-Santiago and the northeast of Zamora.

Assessor: World Conservation Monitoring Centre Refs: 7980,8816 


\section{Sarcaulus vestitus}

Sapotaceae

VU $B 1+2 c$

Brazil (Acre, Amazonas)

A species confined to *vánzea forest in the western Amazon of Brazil. Logging activities are the most serious threat to the area.

Assessor: Pires O'Brien, J.

Refs: $1983,7980,8816$

\section{Sarcaulus wurdackii}

Sapotaceae

VU D2

Peru

At present the species is known from just two herbarium collections. The specimens were collected from Amazonas in Peru, where they were found in lowland rainforest near Teniente Pinglo.

Assessor: World Conservation Monitoring Centre

Refs: 7980,8816

\section{Sarcomelicope glauca}

Rutaceae

CR B $1+2 \mathrm{C}$

New Caledonia

Assessor: Jaffré, T. el al.

Refs: 10351

\section{Sarcomphalus havanensis}

Rhamnaceae

$\mathrm{EN} \mathrm{B1}+2 \mathrm{c}$

Cuba

An endemic shrub or small tree confined to coastal thickets and dry evergreen forest. This very rare species has suffered from severe coastal habitat destruction throughout its range.

Assessor: Areces-Mallea, A.E.

Refs: 9522, 11403, 19149

\section{Sarcotheca laxa var. brigittae}

Oxalidaceae

VU B $1+2 c$

Indonesia (Sumatra)

Confined to Aceh, Sumatra, this variety occurs in lowland rainforest.

Assessor: Chung, R.C.K.

Refs: 19073

\section{Sarcotheca laxa var. hirsuta}

Oxalidaceae

VU Bl $+2 \mathrm{c}$

Malaysia (Peninsular Malaysia)

Scattered in lowland rainforest, this variety is confined to Johore.

Assessor: Chung, R.C.K.

Refs: 19073

\section{Sarcotheca laxa var, laxa}

Oxalidaceae

VU B $1+2 c$

Malaysia (Peninsular Malaysia)

A variety confined to north-west Peninsular Malaysia, where it is scattered in lowland moist forest.

Assessor: Chung, R.C.K.

Refs: 19073

\section{Sarcotheca laxa var. sericea}

Oxalidaceae

VU B $1+2 c$

Malaysia (Peninsular Malaysia), Singapore

This variety is confined to east Peninsular Malaysia, where it occurs in lowland rainforest.

Assessor: Chung, R.C.K

Refs: 9199,19073

\section{Sarcotheca monophylla}

Oxalidaceae

LR/nt

Malaysia (Peninsular Malaysia)

A tree scattered mainly in lowland secondary forest. Threats include logging and urban encroachment.

Assessor: Chung, R.C.K.

Refs: 8464,19073

\section{Sarcotheca ochracea}

Oxalidaceae

VU D2

Malaysia (Sarawak)

This small tree of mixed dipterocarp forest is uncommon and confined to Miri, Bintulu and Tatau.

Assessor: World Conservation Monitoring Centre

Refs: 19017

\section{Sassafras randaiense}

Lauraceae

VU A lad

Taiwan

A relict species confined to mixed evergreen forest above $1200 \mathrm{~m}$ in the central and northem parts of the main mountain range. Regeneration is rare and confined to gaps in the forest. Germinating seeds are frequently eaten by birds. There are two other members of the genus, which occur in China and North America.

Assessor: Lu, S.Y. \& F.J. Pan

Refs: 6469,19050, 19051

\section{Satakentia liukiuensis}

Palmae

Japan (Ryukyu Is.)

A palm tree endemic to Ishigaki Island and Iriomote Island in the southem Ryukyus. A reserve has been set up to protect the populations on Ishigaki Island.

Assessor: Johnson, D.

Refs: 19118

\section{Satranala decussilvae}

Palmae

EN D1

Madagascar

Endemic to Manara Biosphere Reserve, the species inhabits moist forest on shallow soils, overlying ultramafic rock. A single population is known, consisting of 30 trunked trees, 40 immature individuals and many seedlings.

Assessor: Dransfield, J. \& H.J. Beentje

Refs: 18986,19118

\section{Saurauia aequatoriensis}

Actinidiaceae

LR/cd

Ecuador

A tree species which is endemic to the Ecuadorean High Andes. It is confined to the area of the Sangay National Park, where it is characteristic of dense cloud forest and subAndean forest. The development of a road through the park is a major threat to the integrity of these protected habitats.

Assessor: World Conservation Monitoring Centre

Refs: 5651,19120

\section{Saurauia bogoriensis}

Actinidiaceae

$\mathrm{CR} B 1+2 \mathrm{c}$

Indonesia (Java)

Endemic to west Java, the species is known only from a 1975 collection made in the Ciapus Gorge on Mount Salak near Bogor city. More information is needed on its present status

Assessor: World Conservation Monitoring Centre

Refs: 9078 


\section{Saurauia bracteosa}

Actinidiaceae

VU B1 $+2 \mathrm{c}$

Indonesia (Bali, Java)

The species occurs throughout Java and also in Bali. Most of the forests in lowland areas have been cleared.

Assessor: World Conservation Monitoring Centre

Refs: 9078

\section{Saurauia cauliflora}

Actinidiaceae

VU B $1+2 c$

Indonesia (Java)

This species is confined to west Java. Most lowland forest has been cleared and population pressure continues to be the greatest threat to remaining forested aress.

Assessor: World Conservation Monitoring Centre

Refs: 9078

\section{Saurauia lanceolata}

Actinidiaceae

VU Bl+2c

Indonesia (Java)

This species is confined to west Java. Most lowland forest has been cleared and population pressure continues to be the greatest threat to remaining forested areas.

Assessor: World Conservation Monitoring Centre

Refs: 9078

\section{Saurauia latipetala}

Actinidiaceae

VU Alc

Guatemala, Mexico

A species of mesophyllous montane forest or cloud forest, occurring in the highlands of southern Mexico and Guatemala. The habitat has been considerably reduced by logging, increasing agriculture and ranching. Assessor: Ramirez-Marcial, N. \& M. González-Espinosa Refs: 19161

\section{Saurauia leucocarpa}

Actinidiaceae

VUAlc

Mexico

Assessor: Ramirez-Marcial, N. \& M. González-Espinosa Refs: 14932, 19203

\section{Saurauia mahmudii}

Actinidiaceae

$\mathrm{LR} / \mathrm{cd}$

Malaysia (Peninsular Malaysia)

This species is confined to open or closed rainforest at an altitude of 1500 to $1900 \mathrm{~m}$ in the Cameron Highlands of Pahang. Populations are given a degree of protection within the permanent forest estate.

Assessor: Chua, L.S.L.

Refs: 8464, 19073

\section{Saurauia malayana}

Actinidiaceae

Malaysia (Peninsular Malaysia)

Occurring in hill and submontane secondary forest of the Cameron Highlands, Pahang, the species receives a degree of protection within the permanent forest estate.

Assessor: Chua, L.S.L.

Refs: 19073

\section{Saurauia microphylla}

Actinidiaceae

VU B $1+2 \mathrm{C}$

Indonesia (Java)

A species distributed throughout Java. Most forest in lowland areas has been cleared and population pressure continues to be the greatest threat to remaining forested areas.

Assessor: World Conservation Monitoring Centre Refs: 9078

\section{Saurauia oreophila}

Actinidiaceae

VUAlc

Guatemala, Mexico

A species of mesophyllous montane forest, occurring in the highlands of Chiapas and Guatemala. The habitat has been considerably reduced by logging, increasing agriculture and ranching.

Assessor: Ramirez-Marcial, N. \& M. González-Espinosa Refs: 19161

\section{Saurauia rubens}

Actinidiaceae

Malaysia (Peninsular Malaysia)

LR/nt

Occurring in rainforest between 850 and $1400 \mathrm{~m}$, the species is found at Fraser's Hill in the Genting Highlands, Pahang, and on Gunung Mandi Agin in Terengganu. Part of the range is contained within Taman Negara National Park.

Assessor: Chua, L.S.L.

Refs: 8464,19073

\section{Saurauia seibertii}

Actinidiaceae

EN C2a

Panama

Occurring in cloud forest between 1000 and $2100+m$, the species is distributed in the high mountains of Chiriquí and Bocas del Toro. Only a few collections exist, taken from a very restricted but perhaps insufficiently explored area. Regeneration is observed to be poor. A population exists within Volcán Banu National Park

Assessor: Mitré, $\mathrm{M}$.

Refs: 7272,16772

\section{Saurauia serrato}

Actinidiaceae

$\mathrm{EN} \mathrm{B1}+2 \mathrm{c}$

Mexico

Assessor: Ramirez-Marcial, N. \& M. González-Espinosa Refs: $10079,12985,19203$

\section{Saurauia villosa}

Actinidiaceae

VU B1+2c

Mexico

Assessor: Ramirez-Marcial, N. \& M. González-Espinosa Refs: 14932, 19203

\section{Sauropus assimilis}

Euphorbiaceae

$\mathrm{CR} B 1+2 \mathrm{c}$

Sri Lanka

A tree occurring in lowland wet evergreen forest in south-west Sri Lanka. The species was previously found in a single site within the Sinharaja Biosphere Reserve. However, it was not found again the extensive forest surveys conducted between 1991 and 1996 for the National Conservation Review, suggesting the species is either extremely rare or possibly extinct.

Assessor: World Conservation Monitoring Centre Refs: 8203, 17195, 18796, 19112

\section{Sauropus elegantissimus}

Euphorbiaceae

$\mathrm{CR} B 1+2 \mathrm{c}$

Malaysia (Peninsular Malaysia)

The species has not been recorded since the type collection was gathered from Ulu Gombak Forest 
Reserve in Selangor, despite intense botanical work in the area.

Assessor: World Conservation Monitoring Centre Refs: 8464, 19073

\section{Saxegothaea conspicua}

Podocarpaceae

$\mathrm{LR} / \mathrm{nt}$

Argentina (Chubut, Neuquén, Rio Negro), Chile

A relatively common tree occurring in medium altitude deciduous forest. The habitat is extensively logged. The wood of this species is exploited but the associated broadleaved species are more heavily harvested.

Assessor: SSC Conifer Specialist Group

Refs: 727, 5112, 13041, 13295, 15415

\section{Scaevola chanii}

Goodeniaceae

VU D2

Malaysia (Sabah)

So far this small tree or shrub is known only from the upper montane forests of Mount Kinabalu between the altitudes of 2500 and $3000 \mathrm{~m}$.

Assessor: World Conservation Monitoring Centre Refs: 19017

\section{Scaevola muluensi}

Goodeniaceae

VU D2

Malaysia (Sarawak)

The shrub up to $1 \mathrm{~m}$ high, is found on exposed ridges and cliff faces of limestone. Only two collections are known from Gunong Api in the Gunong Mulu National Park. Assessor: World Conservation Monitoring Centre Refs: 19017

\section{Scaevola verticillata}

Goodeniaceae

VU D2

Malaysia (Sarawak)

Probably endemic, this very small tree or shrub is recorded only from Mount Tambuyukon in stunted subalpine vegetation on ultramafic soils at an elevation of $2500 \mathrm{~m}$.

Assessor: World Conservation Monitoring Centre

Refs: 19017

\section{Scalesia aspera}

Compositae

VU D2

Ecuador (Galápagos)

A bushy species, restricted to two small populations, occurring in lowland scrub in north-west Santa Cruz and Eden Islet. The former population is subject to grazing by introduced goats, but there is no firm evidence of decline.

Assessor: Tye, A. \& J. Loving

Refs: 19146, 19156, 19157

\section{Scalesia atractyloides}

Compositae

CR Alace, $\mathrm{Bl}+2 \mathrm{e}, \mathrm{Cl}+2 \mathrm{~b}, \mathrm{Dl}$

Ecuador (Galápagos)

A single population of three individuals exists in a crater on Santiago Island. In 1997, seven seedlings were also counted. The plants are subject to grazing by introduced goats, but a fence is under construction to prevent access. A single plant has been raised in cultivation in the Galápagos and the vegetatively produced offspring of two other adults are growing in Copenhagen Botanical Garden.

Assessor: Tye, A. \& J. Loving

Refs: 19146,19156
Scalesia baurii ssp. baurii

Compositae

VU D2

Ecuador (Galápagos)

Restricted to Pinzon Island, the subspecies occurs in areas of open woodland and scrub which are free of introduced herbivores. As long as goats and other grazing animals are denied access to the island, the populations are likely to remain stable.

Assessor: Tye, A. \& J. Loving

Refs: 19146,19156

\section{Scalesia baurii ssp. hopkinsï}

Compositae

VU D2

Ecuador (Galápagos)

Endemic to the islands of Pinta and Wolf, this shrub or small tree forms part of the open understorey in dry deciduous steppe forest. The population on Wolf is not suffering from grazing damage. On Pinta, the species is relatively common but subject to damage by introduced goats. Severe declines in this population were recorded in the 1970s. Since the goats have been more effectively managed, a rapid recovery in population numbers has been observed and the species is now believed to be stable.

Assessor: Tye, A. \& J. Loving

Refs: 5101, 14556, 19146, 19156

\section{Scalesia cordato}

Compositae

$\mathrm{EN} B 1+2 \mathrm{c}$

Ecuador (Galápagos)

A small tree which formerly made up extensive woodland on the slopes of two volcanoes, Sierra Negra and Cerra Azul on Isabela Island. A continuing decline in the extent of the woodland is evident. Damage is being caused by introduced herbivores, invasive weeds are causing habitat degradation and areas are being cleared by local inhabitants. There is also the constant threat of volcanic eruption.

Assessor: Tye, A. \& J. Loving

Refs: 5101, 14556, 19146, 19156

\section{Scalesia crockeri}

Compositae

VU D2

\section{Ecuador (Galápagos)}

Most typically a bush, the species is confined to areas of lowland scrub on three of the Galápagos Islands. There is a single population on North Seymour, two on Baltra and several small populations on the north and east coasts of Santa Cruz. There is no firm evidence of decline, despite the damage caused by introduced herbivores on Santa Cruz.

Assessor: Tye, A. \& J. Loving

Refs: 19146,19156

\section{Scalesia divisa}

Compositae

CR B1+2bcde

Ecuador (Galápagos)

Restricted to the north-eastem half of San Cristobal Island, the species, most typically occurring as a bush, has become scarce in areas where it was previously recorded as abundant. Introduced goats, the main cause of these population declines, continue to cause extensive damage to remaining stands.

Assessor: Tye, A. \& J. Loving

Refs: 19146,19156 


\section{Scalesia gordilloi}

Compositae

EN D1

Ecuador (Galápagos)

Confined to the south-west coast of San Cristóbal Island, this bushy species occurs in a single population of 200 to 300 individuals, including all age groups. The area is susceptible to damage caused by introduced herbivores and also, to some extent, by tourism.

Assessor: Tye, A. \& J. Loving

Refs: 19146

\section{Scalesia helleri ssp. helleri}

Compositae

VU D2

Ecuador (Galápagos)

A bushy species, existing in two populations. On Santa Fé Island, although population numbers have been severely reduced by introduced goats, it is hoped they will fully recover now that the animals have been eradicated from the island. The population on Santa Cruz Island is very low in numbers and confined to the south-east. Goats also cause damage here, but there is no firm evidence of population declines. There is some indication that this latter population actually represents a hybrid form between helleri and retroflexa.

Assessor: Tye, A. \& J. Loving

Refs: 19146, 19156

\section{Scalesia helleri ssp. santacruzinua}

Compositae

VU D2

Ecuador (Galápagos)

A bushy species, represented by several small populations principally confined to the south-west coast of Santa Cruz Island, with a few individuals on La Fe Islet. Although the Santa Cruz populations are subject to damage by introduced goats, there is no firm evidence of a decline. The species is used as a garden plant in Puerto Ayora on Santa Cruz.

Assessor: Tye, A. \& J. Loving

Refs: 19146, 19156, 19157

\section{Scalesia incisa}

Compositae

VU D2

Ecuador (Galápagos)

Endemic to San Cristobal Island, this small tree is scattered in a restricted area in the east. Trees are subject to damage by introduced goats, but there is no firm evidence of a population decline.

Assessor: Tye, A. \& J. Loving

Refs: 19146,19156

\section{Scalesia microcephala var. cordifolia \\ Compositae \\ Ecuador (Galápagos)}

$\mathrm{EN} \mathrm{Bl+2ce}$

One of two varieties, this tree forms woodlands on the high slopes of the volcanoes Wolf and Ecuador on Isabela Island. Introduced goats are responsible for damage to the trunks of mature trees and the lack of seedlings in the population. Volcanic eruptions pose an additional threat.

Assessor: Tye, A. \& J. Loving

Refs: $14556,19146,19156$

\section{Scalesia microcephala var. microcephala}

Compositae

Ecuador (Galápagos)

$\mathrm{EN} \mathrm{B1+2ce}$

This variety occurs in populations on the high slopes of Femandina Island and on Volcan Alcedo and Volcan Darwin on Isabela Island. A continuing decline in population numbers has been observed on Isabela, caused by the damage from introduced goats. There is an added threat of volcanic eruption.

Assessor: Tye, A. \& J. Loving

Refs: $14556,19146,19156$

\section{Scalesia pedunculata}

Compositae

VU Alace+2ce, Bl+2abce

Ecuador (Galápagos)

One of the largest growing Scalesia species. It forms compact woodlands in the highlands of San Cristobal, Santa Cruz, Santiago and Floreana. Recent declines in the extent of this habitat have occurred because of land settlement, grazing and the spread of invasive plants. These trends appear to be continuing. There is also a potential threat from volcanic eruption.

Assessor: Tye, A. \& J. Loving

Refs: $14556,19146,19156$

\section{Scalesia retroflexa}

Compositae

VU D2

Ecuador (Galápagos)

Six small populations occur within 6ha of open forest and scrub on the south-east coast of Santa Cruz Island. About 4600 plants, including 1400 adults, are thought to exist. Although there is evidence of damage by introduced goats, there is no firm indication that the population is declining as a result.

Assessor: Tye, A. \& J. Loving

Refs: 19146, 19156, 19157

\section{Scalesia stewartii}

Compositae

Ecuador (Galápagos)

VU D2

This tree species is restricted to a sparsely vegetated area in the east of Santiago Island and to a population of fewer than 250 individuals on the neighbouring islet of Bartolomé. The Santiago localities are vulnerable to introduced goats, although no decline in population numbers has yet been documented.

Assessor: Tye, A. \& J. Loving

Refs: 19146,19156

\section{Scalesia villosa}

Compositae

VU D2

Ecuador (Galápagos)

Typically occurring as a bush, the species is found on Floreana Island and the islets of Champion, Enderby, Caldwell and Gardner-near-Floreana. The population on the main island is subject to damage by introduced goats, although no decline in numbers has yet been documented

Assessor: Tye, A. \& J. Loving

Refs: 19146,19156

\section{Scaphium longiflorum}

Sterculiaceae

VU Bl+2c

Malaysia (Peninsular Malaysia)

Occurring in swampy or semi-swampy rainforest in the states of Kedah, Penang, Perak, Selangor and Johore, this tree is exploited as timber for major international trade and as a medicine for minor intemational trade. The greatest threats are increasing settlement and logging activities.

Assessor: Chua, L.S.L.

Refs: 8464, 19073 
Scaphopetalum parvifolium

Sterculiaceae

$\mathrm{VU} \mathrm{Bl}+2 \mathrm{c}$

Nigeria

This small forest tree is recorded from the Oban Hills, within Cross River National Park. Unprotected forest has been extensively logged and cleared for cultivation. Assessor: World Conservation Monitoring Centre Refs: 2773, 4977, 11504

\section{Schefflera agamae}

Araliaceae

EN Alc, B $1+2 c$

Philippines

This tree has been collected only once, 70 years ago, from lowland forest on rocky hilis in south Palawan. It is threatened by forest loss, although Palawan has experienced less intense deforestation than the other Philippine Islands. The main island of Palawan is a biosphere reserve.

Assessor: World Conservation Monitoring Centre

Refs: 4986

\section{Schefflera albido-bracteata}

Araliaceae

EN Alc, Bl+2c

Philippines

An epiphytic shrub or small tree known from only two collections from montane forest in the north-east of Mindanao. This species has not been collected since 1912.

Assessor: Frodin, D.

Refs: 4986,19079

\section{Schefflera apiculata}

Araliaceae

Indonesia (Moluccas)

A shrub or tree found on Bacan, Halmahera. Temate and Maluku, possibly extending to Waigeo, Irian Jaya. It is known from only a few collections but this could be due to undercollecting in the region. Varieties and subspecies are likely to be identified when more collections are made.

Assessor: Frodin, D.

Refs: 17232,19079

\section{Schefflera apioidea}

Araliaceae

VU B $1+2 c$

New Caledonia

A tree restricted to a very limited area of lowland forest on the west coast, where habitat destruction has been considerable. No new material has been recorded since the late $1800 \mathrm{~s}$. There is a possibility that the species is conspecific with $S$, veitchii, four specimens of which have been collected in the Bourail region.

Assessor: Jaffré, $\mathrm{T}$. et al.

Refs: 10351, 19079

\section{Schefflera beccariana}

Araliaceae

VU D2

Malaysia (Peninsular Malaysia, Sarawak)

This lowland forest species is known from two collections from Johore, Peninsular Malaysia, and two disjunct, slightly differing populations in Sarawak. The population in western Sarawak was rediscovered 62 years after it was first found near Kuching, an area extremely threatened by urban expansion. A specimen collected in the late 1800 s from Lingga Island is similar to this species.

Assessor: Frodin, D.

Refs: 17140,19079
Schefflera bourdillonï

Araliaceae

India (Kerala)

$\mathrm{EN} \mathrm{B1}+2 \mathrm{C}$

This shrub or small tree has so far been collected twice from montane forest in the Travancore Hills in the southem Westem Ghats.

Assessor: Frodin, D.

Refs: 15926,19079

\section{Schefflera brenesii}

Araliaceae

VU A2c

Costa Rica, Panama

This species is relatively common in moist evergreen forest and woodlands in the low mountains of Heredia, Alajuela, Guanacaste and Limón in Costa Rica. In Panama there are a few minor populations around the Canal region and in the province of Panamá and it is expected to be found further west. Some localities are within protected areas, where regeneration has been observed to be relatively good. Other areas are affected by the growing settlement of land, logging and extensive agriculture.

Assessor: Mitré, $\mathrm{M}$.

Refs: 7980,16772

\section{Schefflera capitulifera}

Araliaceae

VU D2

Indonesia (Sumatra)

A small hemiepiphytic tree collected five times in northem Sumatra. This distinctive species is found in montane forest and along forest edges in deep ravines. It is found in Gunung Leuser National Park

Assessor: Frodin, D.

Refs: 10547, 19079

\section{Schefflera cephalotes}

Araliaceae

$\mathrm{EN} \mathrm{B1+2c}$

Malaysia (Peninsular Malaysia, Sarawak), Singapore

A forest tree with a restricted and disjunct distribution. It is known from Penang Hill Reserve in Peninsular Malaysia and a site west of Kuching in Sarawak, where it is threatened by urban encroachment. The population in Singapore is presumed extinct.

Assessor: Frodin, D.

Refs: 9199, 19079

\section{Schefflera chapana}

Araliaceae

VU $B 1+2 c$

China (Yunnan), Viet Nam

Endemic to the Fan $\mathrm{Ci}$ Pan range, extending from northern Viet Nam into Yunnan, China, this tree is localised in forest between 1000 and $1200 \mathrm{~m}$.

Assessor: Frodin, D.

Refs: 11530, 19079

\section{Schefflera costata}

Araliaceae

VU D2

Fiji

This localised tree is known from two mountain tops: Tomauivi (Victoria Peak) and the west slopes of Taveuni. It is confined to small areas of rainforest over $900 \mathrm{~m}$. Its restricted distribution renders the species susceptible to stochastic events, but there are no direct threats at the present time.

Assessor: Frodin, D.

Refs: 18818,19079 


\section{Schefflera curranï}

Araliaceae

EN A1c, B1+2c

Philippines

A montane forest species found on ultramafic soils in central Palawan. It is known from only three herbarium specimens and was last seen in the 1970s-'80s.

Assessor: Frodin, D.

Refs: 4986, 19079

\section{Schefflera diplodactyla}

Araliaceae

VU D2

Ecuador

Extremely localised in eastem Ecuador, this tree is threatened by increasing settlement and oil exploration.

Assessor: Frodin, D.

Refs: 349,19079

\section{Schefflera dolichostyla}

Araliaceae

VU D2

Peru

Collected only once or twice, the species is restricted to cloud forest in the Peruvian Andes in the departments of Puno and Cuzco.

Assessor: World Conservation Monitoring Centre

Refs: 1984

\section{Schefflera euryphylla}

Araliaceae

VU D2

Peru

A cloud forest species, known only from the department of Junin in the Peruvian Andes.

Assessor: World Conservation Monitoring Centre

Refs: 1984

\section{Schefflera euthytricha}

Araliaceae

Fiji

A small tree found in the lowlands of Viti Levu.

Assessor: Frodin, D.

Refs: 18818,19079

\section{Schefflera fastigiata}

Araliaceae

EN Alc, B1+2c

Indonesia (Java)

This species is found in forest remnants on Nusa Kambangan and possibly Ujung Kulon. It was last collected in 1970. Nusa Kambangan is an island controlled by the Prison Service, with very limited access. However, the vegetation of the island is threatened by timber thieves, who are removing timber regardless of the armed guard patrol.

Assessor: World Conservation Monitoring Centre Refs: 9078,15417

\section{Schefflera gleasonii}

Araliaceae

VU D2

Puerto Rico

A montane forest tree confined to ultramafic soils in the central Punta range of Puerto Rico.

Assessor: World Conservation Monitoring Centre Refs: 7980

\section{Schefflera harmsii}

Araliaceae

Peru

A shrub or small tree of lowland forest on white sand, known only from a few collections, the last of which is dated 1974.

Assessor: World Conservation Monitoring Centre

Refs: 1984

\section{Schefflera kontumensis}

Araliaceae

$\mathrm{EN} B 1+2 c$

Viet Nam

Very localised in the central highlands of Viet Nam, this small tree is known from a single collection. The area is relatively poorly explored.

Assessor: Frodin, D.

Refs: 11530,19079

\section{Schefflera kuchingensis}

Araliaceae

$\mathrm{CR} B 1+2 \mathrm{c}$

Malaysia (Sarawak)

This multi-stemmed tree, which can be epiphytic, is known only from an area extremely threatened by urban expansion near Kuching. It is known from a total of four collections, two of which were recently gathered from the Sumengo Arboretum.

Assessor: Frodin, D.

Refs: 19079

\section{Schefflera lukwangulensis}

Araliaceae

VU BI+2b

Tanzania

Localised on ridge tops in upper montane forest, this species is restricted to the north and south Uluguru Mountains, the west Usambara Mountains and south Nguru. Changes to land use and local habitat degradation represent a threat. The Uluguru Mountains are the focus of a conservation programme.

Assessor: Lovett, J. \& G.P. Clarke

Refs: 5204, 8221, 11631

\section{Schefflera multifoliolata}

Araliaceae

$\mathrm{EN} \mathrm{B} 1+2 \mathrm{c}$

Indonesia (Sumatra)

A montane forest tree restricted to Gunung Sibajak, Sibalangit and Banda Baru of northern Sumatra. The species' description was based on eight specimens, the most recent of which was collected in 1983. The population on Gunung Sibajak is close to a popular tourist destination near Medan. The habitat is also threatened by shifting cultivation.

Assessor: Frodin, D.

Refs: 10547, 19079

\section{Schefflera nanocephala}

Araliaceae

LR/cd

Malaysia (Peninsular Malaysia)

Last collected in 1970, this small epiphytic tree occurs in montane forest and forest edges north of the Genting Highlands Casino complex and the Cameron Highlands. Populations receive a degree of protection within the permanent forest estate.

Assessor: Chua, L.S.L.

Refs: 8464, 19073, 19079

\section{Schefflera nervosa}

Araliaceae

VU D2

Malaysia (Peninsular Malaysia)

This species is known from three distinct forms, which could possibly be described as separate species. All are highly localised. The first form is confined to the Cameron Highlands; it has been collected twice from an isolated area, most recently in 1938. The second form, 
last seen in 1977, is from the Genting Highlands resort complex. The third form occurs locally in Terengganu, where is known from five collections, the most recent dating from the $1960 \mathrm{~s}$.

Assessor: Frodin, D.

Refs: 8464, 19073, 19079

\section{Schefflera palawanensis}

Araliaceae

Philippines

EN Alc

This suberect shrub or small tree reaches about $4 \mathrm{~m}$ in height. It is restricted to the north of Palawan, where it occurs in forest on limestone. Habitat loss is a threat.

Assessor: Frodin, D.

Refs: 4986, 19079

\section{Schefflera palmiformis}

Araliaceae

$\mathrm{EN} \mathrm{B1}+2 \mathrm{c}$

Viet Nam

This endemic tree is known from only a few collections in an area experiencing extensive habitat decline.

Assessor: Frodin, D.

Refs: 5054, 11530, 19079

\section{Schefflera procumbens}

Araliaceae

VU D2

Seychelles

The species is confined to Silhouette Island, having become extinct on Mahé largely through the degradation of its habitat. The six remaining populations are stable and confined to the main mountain ridges within an area of 100ha, which is under the protection of the Nature Protection Trust of Seychelles. Attempts to bring the species into cultivation have failed.

Assessor: Nature Protection Trust of Seychelles

Refs: 17229,19025

\section{Schefflera pueckleri}

Araliaceae

$\mathrm{LR} / \mathrm{cd}$

Malaysia (Peninsular Malaysia)

A rare large shrub or small tree found in montane cloud forest at about $1370 \mathrm{~m}$. Populations receive a degree of protection within the permanent forest estate in Perak and the Cameron Highlands in Pahang.

Assessor: Chua, L.S.L.

Refs: $8464,19073,19079$

\section{Schefflera seibertii}

Araliaceae

Costa Rica, Panama

In Panama the species is known only from the type collection made in 1940. Despite considerable botanical activity in the area, it has not been found there again. It is reported from the mountains of Alajuela in Costa Rica, but there is no additional information on this population. Field investigations are needed to determine whether the species still exists or whether it is a synonym of $S$. sphaerocoma.

Assessor: Mitre, M.

Refs: 7272, 7980, 15926, 16772

\section{Schefflera stearnü}

Araliaceae

$\mathrm{EN} \mathrm{Bl}+2 \mathrm{c}$

Jamaica

Endemic to Portland, this species occurs in moist thickets on limestone above $600 \mathrm{~m}$. There is some question of its being conspecific with $S$. sciodaphyllum. Assessor: World Conservation Monitoring Centre

Refs: $401,5653,7980$
Schefflera troyana

Araliaceae

VU B $1+2 c$

Jamaica

A Cockpit Country endemic, found in low densities in woodland and woodland margins on rocky limestone in the central and west-central parishes. The habitat is under the constant threat of being cut or cleared for agricultural expansion, e.g. at Peckham Woods.

Assessor: World Conservation Monitoring Centre

Refs: 5653,7980

\section{Schefflera urbaniana}

Araliaceae

Martinique

VU D2

A large tree, rare within dense humid forest, endemic to Martinique. It is known from only four collections from before the 1940s.

Assessor: World Conservation Monitoning Centre

Refs: 10754

\section{Schefflera veitchii}

Araliaceae

$\mathrm{EN} \mathrm{Bl+2c}$

New Caledonia

This tree is restricted to lowland forest below $100 \mathrm{~m}$ in the coastal semi-dry region around Noumea and Anse Vata in south-east New Caledonia. A lot of urban development has taken place in this region. Anse Vata is a fully developed beach resort area and the species was last collected there in 1925. It was collected in 1926 in the Montravel Reserve. It was introduced into cultivation in the 1860 s in the UK, where it became a popular table pot plant. It may still be in cultivation. The specimens from Bourail are most likely to be $S$. apioidea.

Assessor: Jaffré, T. et al.

Refs: 10351, 19079

\section{Schefflera wrayi}

Araliaceae

Malaysia (Peninsular Malaysia)

A small tree known only from one specimen collected in 1888 south of Ringlet. This remote locality has not been revisited.

Assessor: Chua, L.S.L.

Refs: 8464, 19073, 19079

\section{Schima wallichi var. pulgarensis}

Theaceae

Philippines

VU $B 1+2 c, D 2$

Endemic to Palawan, the species is confined to mossy scrub on ridges between 1000 and $1200 \mathrm{~m}$. The main island of Palawan is a biosphere reserve.

Assessor: World Conservation Monitoring Centre Refs: 4986

\section{Schinopsis haenkeana}

Anacardiaceae

VUAlcd

Argentina (Córdoba, San Juan, San Luis), Bolivia A characteristic tree of the Chaco Serrano. In Argentina populations range from the north-east up to San Juan, San Luis and Córdoba. The habitat is rapidly declining throughout the range, particularly in Córdoba. Assessor: World Conservation Monitoring Centre Refs: $1803,5112,13657$ 


\section{Schinus engleri}

Anacardiaceae

Argentina (Buenos Aires, Corrientes, Entre Ríos, Santa Fé), Brazil (Minas Gerais, Paraná, Rio Grande do Sul), Uruguay

Although widely occurring, the range of the species has probably receded greatly with the spread and intensification of agriculture.

Assessor: Prado, D.

Refs: 1262,7134

\section{Schinus gracilipes var. pilosus}

Anacardiaceae

VU B1+2c

Argentina, Bolivia

Endemic to the piedmont forest of north-west Argentina and Bolivia, the species occurs in an unprotected ecosystem, which is rapidly being replaced by agricultural systems.

Assessor: Prado, D.

Refs: 19122

\section{Schinus longifolius var. paraguariensis}

Anacardiaceae

VU D2

Paraguay

A species which ranges from Brazil to Argentina. This taxon represents a localised variety which occurs in a calcareous region in the upper reaches of the Rio Apa. It is known only from the type locality.

Assessor: Prado, D.

Refs: 1262,7980

\section{Schinus pearcei}

Anacardiaceae

Bolivia, Chile (Atacama), Peru

DD

A dryland species, which appears to be scarce, particularly in Chile, where it is restricted to the Atacama region.

Assessor: González, M.

Refs: 4870,16328

\section{Schinus venturi}

Anacardiaceae

VU B1+2c

Argentina, Bolivia

Endemic to the piedmont forest of north-west Argentina and Bolivia, the species occurs in an unprotected ecosystem, which is rapidly being replaced by agricultural systems.

Assessor: Prado, D.

Refs: 19122

\section{Schippia concolor}

Palmae

VU A2c

Belize

An omamental palm tree restricted to Mountain Pine Ridge and Cayo District, where it is scattered in open and closed dry forest up to $500 \mathrm{~m}$. The species is threatened by habitat destruction and encroachment by agriculture and forestry.

Assessor: Johnson, D.

Refs: 19118

\section{Schmardaea microphylla}

Meliaceae

VU Alc

Colombia, Ecuador, Peru, Venezuela

A small tree which is becoming increasingly scarce, occurring in the Andes from Venezuela to Pen. It is recorded from open pastures and dry forest at medium elevation and from cloud forest at $2700 \mathrm{~m}$ in Peru. Naturally uncommon, the species has come under intense pressure from habitat clearance. It is a monotypic genus.

Assessor: World Conservation Monitoring Centre

Refs: 7980, 12281, 19069

\section{Schoepfia arenaria}

Olacaceae

EN D1

Puerto Rico

A hemiparasitic tree, known from about four sites containing 120 individuals in total. Isabela harbours the largest population. The Pinones population was heavily hit by Hurricane Hugo, but has produced large seed crops as a consequence.

Assessor: World Conservation Monitoring Centre

Refs: 7980,17124

\section{Schoepfia harrisii}

Olacaceae

VU B $1+2 c$

Jamaica

A Cockpit Country endemic, occurring in the parishes of Clarendon and Trelawny on moist wooded limestone crags, between 600 and $900 \mathrm{~m}$.

Assessor: Kelly, D.L.

Refs: 5653, 19085

\section{Schoepfia multiflora}

Olacaceae

LR/nt

Jamaica

Known from the central parishes, the tree has an occasional distribution in woodland on rocky limestone. Assessor: World Conservation Monitoring Centre Refs: 6057,7980

\section{Schoutenia cornerii}

Tiliaceae

EN B $1+2 c$

Malaysia (Peninsular Malaysia)

A rare tree of lowland moist forest known only from Mersing and Mawai-Jemaluang, Johore.

Assessor: Chung, R.C.K.

Refs: 17140,19073

\section{Schoutenia furfuracea}

Tiliaceae

LR/cd

Malaysia (Peninsular Malaysia)

A tree of lowland moist forest known only from Ulu Sungai Anak Endau, Pahang.

Assessor: Chung, R.C.K.

Refs: 8464,19073

\section{Schoutenia kunstleri}

Tiliaceae

Malaysia (Peninsular Malaysia)

VU B1+2c

A rare tree known only from Penang, Perak and the east coast from Terengganu to Johore, where it grows in lowland rainforest.

Assessor: Chung, R.C.K.

Refs: 19073

\section{Schumacheria alnifolia}

Dilleniaceae

CR B1+2c

Sri Lanka

Only six individuals of this species were found in the Peak Wildemess Sanctuary during the extensive forest surveys conducted between 1991 and 1996 for the National Conservation Review, suggesting it to be either extremely rare or possibly extinct.

Assessor: World Conservation Monitoring Centre Refs: 19112 
Schumanniophyton problematicum Rubiaceae

VU Alc, Bl+2c

Côte d'Ivoire, Ghana, Sierra Leone

A species known from the restricted wet evergreen forests of the Upper Guinea region. The extent of these forests have declined because of mining, logging and the establishment of industrial plantations.

Assessor: Hawthome, W.

Refs: 2773, 8369, 12061

\section{Sciadopitys verticillata}

Sciadopityaceae

VUAlc+2c

Japan

A tree of low to medium elevations occurring in forested areas from Fukushima to Hiroshima on Honshu Island, and also on Shikoku and Kyushu Islands. It provides a useful timber and levels of exploitation have been considerable. It belongs to a monospecific family.

Assessor: SSC Conifer Specialist Group

Refs: 374,18751

\section{Sclerocarya gillettii}

Anacardiaceae

VU B $1+2 c$

Kenya

Endemic to a small area in eastern Kenya, this shrub or small tree occurs sparsely in localised areas of dry bushland on red sand.

Assessor: World Conservation Monitoring Centre Refs: 6396

\section{Sclerolobium beaureipairei}

Leguminosae

EN B $1+2 c$

Brazil (Rio de Janeiro)

Populations of the species are principally confined to forest on the slopes of the Serra do Mar.

Assessor: Vaz, A.M.S.

Refs: 19100

\section{Sclerolobium densiflorum}

Leguminosae

LR/nt

Brazil (Alagoas, Bahia, Pemambuco)

Known only from a restricted distribution in Atlantic forest, the species has suffered dramatic habitat declines and levels of exploitation.

Assessor: Vaz, A.M.S.

Refs: 19098,19100

\section{Sclerolobium denudatum}

Leguminosae

LR/nt

Brazil (Rio de Janeiro, Sāo Paulo)

Confined to Atlantic forest in the states of Sāo Paulo and Rio de Janeiro, the species has suffered dramatic habitat loss and has been extensively exploited for its timber.

Assessor: Vaz, A.M.S.

Refs: 19098,19100

\section{Sclerolobium pilgerianum \\ Leguminosae}

$\mathrm{EN} \mathrm{B} 1+2 \mathrm{~cd}$

Brazil (Rio de Janeiro)

A species of montane forest, confined to the slopes of the Serra do Mar.

Assessor: Vaz, A.M.S.

Refs: 19100

\section{Sclerolobium striatum}

Leguminosae

Brazil (Rio de Janeiro)

VU B $1+2 c$

Endemic to Atlantic forest in the one state in Brazil, the species has suffered dramatic habitat declines.

Assessor: Vaz, A.M.S.

Refs: 19098,19100

\section{Scolopia oreophila}

Flacourtiaceae

South Africa (KwaZulu-Natal, Mpumalanga)

This species is confined to a small area in the northem Drakensberg mountain range, where it occurs as scattered plants in Afromontane forest patches. It is also said to occur in North-West Province, but this is highly improbable. Two of the localities are in private nature reserves. There are taxonomic problems with the species, which need to be resolved before its conservation status is assessed

Assessor: Hilton-Taylor, C. et al.

Refs: 689,19218

\section{Scolopia steenisiana}

Flacourtiaceae

Malaysia (Peninsular Malaysia)

VU D2

Known from only two collections, this tree can be found in the open limestone rainforests of lowland Kelantan.

Assessor: Chua, L.S.L.

Refs: 8464, 19073

\section{Scolosanthus howardii}

Rubiaceae

$\mathrm{EN} \mathrm{B1}+2 \mathrm{c}$

Jamaica

A small tree or shrub which occurs very rarely on rocky limestone hills between 480 and $600 \mathrm{~m}$, only in the parish of Trelawny.

Assessor: Kelly, D.L.

Refs: 401, 5653, 19085

\section{Sebastiania alpina}

Euphorbiaceae

VU B $1+2 c$

Jamaica

A montane rainforest species found uncommonly in the western highlands above $750 \mathrm{~m}$.

Assessor: World Conservation Monitoring Centre

Refs: 401, 5653, 7980

\section{Sebastiania crenulata}

Euphorbiaceae

CR B $1+2 \mathrm{c}$

Jamaica

This species is known from the woodland on the summit of Bubby Hill. The area is susceptible to selective logging and other disturbances.

Assessor: World Conservation Monitoring Centre Refs: 401, 5653, 7980

\section{Sebastiania fasciculata}

Euphorbiaceae

EN B $1+2 c$

Jamaica

A shrub or small tree confined to a small area of woodland on limestone in Hanover.

Assessor: World Conservation Monitoring Centre Refs: $401,5653,7980$ 


\section{Sebastiania howardiana}

Euphorbiaceae

$\mathrm{CR} B 1+2 \mathrm{c}$

Jamaica

Apparently, the species is known only from the Ramgoat Cave area in Trelawny.

Assessor: World Conservation Monitoring Centre

Refs: $401,5653,7980$

\section{Sebastiania huallagensis}

Euphorbiaceae

VU D2

Peru

This species is known only from the type collection taken from the department of San Martin.

Assessor: World Conservation Monitoring Centre Refs: 1984

\section{Sebastiania lesteri var. glabrata}

Euphorbiaceae

$\mathrm{CR} \mathrm{B1+2c}$

Jamaica

A variety or possibly a distinct species. It occurs in St Elizabeth, where the only known population is on Top Hill. The area is susceptible to cutting and encroaching agriculture.

Assessor: World Conservation Monitoring Centre

Refs: 401, 5653, 7980

\section{Sebastiania lesteri var. lesteri}

Euphortiaceae

$\mathrm{CR} \mathrm{BI}+2 \mathrm{c}$

Jamaica

One of two threatened varieties of a Jamaican endemic It appears to be known from two populations. The one on Quaco Rock is probably extinct as the vegetation has been cleared, largely for charcoal production. There is also a population along the road between Balcarres and Sunbury.

Assessor: World Conservation Monitoring Centre

Refs: 5653,11802

\section{Sebastiania spicata}

Euphorbiaceae

$\mathrm{EN} B 1+2 \mathrm{C}$

Jamaica

Populations are restricted to Peckham Woods and Douglas Castle Woods. There is evidence of cutting and agricultural encroachment in both localities.

Assessor: World Conservation Monitoring Centre

Refs: 401, 5653, 7980

\section{Securinega flexuosa}

Euphorbiaceae

VU Alcd

Philippines

A timber species, endemic to the Philippines. Rates of habitat loss through logging and shifting cultivation have led to considerable population declines.

Assessor: World Conservation Monitoring Centre

Refs: 2072,4919

\section{Semecarpus acuminato}

Anacardiaceae

$\mathrm{EN} \mathrm{B1}+2 \mathrm{c}$

Sri Lanka

During the extensive forest surveys conducted between 1991 and 1996 for the National Conservation Review, this species was found in four rainforest localities including the Sinharaja National Heritage Wildemess Area.

Assessor: World Conservation Monitoring Centre Refs: 15431, 19112

\section{Semecarpus auriculata}

Anacardiaceae

LR/nt

India (Kamataka, Kerala, Tamil Nadu)

The main concentration of the species occurs in low- to medium-altitude forest in Travancore, along the border between Kerala and Tamil Nadu. Collections have also been made further north in the Western Ghats into Kamataka.

Assessor: World Conservation Monitoring Centre Refs: 15106,19144

\section{Semecarpus coriacea}

Anacardiaceae

$\mathrm{EN} \mathrm{B1+2c}$

Sri Lanka

During the extensive forest surveys conducted for the National Conservation Review, this tree was found in five localities, mainly in Nuwara Eliya District. It is present in the Peak Wilderness Wildlife Sanctuary. Assessor: World Conservation Monitoring Centre Refs: $15431,17759,19112$

\section{Semecarpus gardneri}

Anacardiaceae

VU Alc

Sri Lanka

A tree restricted to the lowland evergreen rainforests of south-west Sri Lanka.

Assessor: World Conservation Monitoring Centre Refs: 15431, 17195

\section{Semecarpus marginata}

Anacardiaceae VU Alc

Sri Lanka

A rare tree confined to wet evergreen lowland forest in south-west Sri Lanka.

Assessor: World Conservation Monitoring Centre Refs: 15431,17195

\section{Semecarpus moonii}

Anacardiaceae

VU AIc, BI $+2 \mathrm{c}$

Sri Lanka

Apparently restricted to wet forest in Galle, Kalutara and Ratnapura Districts, this species was found in nine localities during the extensive forest surveys conducted between 1991 and 1996 for the National Conservation Review.

Assessor: World Conservation Monitoring Centre Refs: 12129, 15431, 18796, 19112

\section{Semecarpus nigro-viridis}

Anacardiaceae

VU Alc

Sri Lanka

This species is scattered in the diminished wet evergreen lowland forests of south-west Sri Lanka.

Assessor: World Conservation Monitoring Centre Refs: 15431, 17195

\section{Semecarpus obovato}

Anacardiaceae

VU A $1 c, B 1+2 c$

Sri Lanka

A very rare species restricted to the wet zone of Sri Lanka. Until the National Conservation Review forest surveys of 1991-1996, this species went uncollected for over a century.

Assessor: World Conservation Monitoring Centre Refs: $15431,16943,18796,19112$ 
Semecarpus ochracea

Anacardiaceae

CR B $1+2 \mathrm{~cd}$

Sri Lanka

An endemic species scattered in lowland wet evergreen forest. It was not rediscovered during the extensive forest surveys conducted between 1991 and 1996 for the National Conservation Review, indicating it to be extremely rare or possibly extinct.

Assessor: World Conservation Monitoring Centre Refs: 17195,19112

\section{Semecapus parvifolia}

Anacardiaceae

VU Alc

Sri Lanka

A species occurring in lowland wet evergreen forests in south-west Sri Lanka. A population has been discovered in the dry zone in Rahuna National Park.

Assessor: World Conservation Monitoring Centre

Refs: 15431, 16943, 17195

\section{Semecarpus paucinervius}

Anacardiaceae

VU Bl+2c

Philippines

This tree is endemic to Palawan, found in forest along streams, at about $100 \mathrm{~m}$. The main island of Palawan is a biosphere reserve.

Assessor: World Conservation Monitoring Centre Refs: 4986

\section{Semecarpus pseudo-emergina}

Anacardiaceae

CR B1+2c

Sri Lanka

This species was recorded only once in Matara District during the extensive forest surveys conducted between 1991 and 1996 for the National Conservation Review. Assessor: World Conservation Monitoring Centre Refs: 19112

\section{Semecarpus pubescens}

Anacardiaceae

VU Alc

Sri Lanka

A rare species, restricted to lowland wet evergreen forest in south-west Sri Lanka.

Assessor: World Conservation Monitoring Centre

Refs: 15431,17195

\section{Semecarpus riparia}

Anacardiaceae

$\mathrm{EN} \mathrm{B} 1+2 \mathrm{c}$

New Caledonia

Assessor: Jaffré, T, et al.

Refs: 10351

\section{Semecarpus subpeltata}

Anacardiaceae

VU Alc

Sri Lanka

A species occurring in the lowland wet evergreen forests of south-west Sri Lanka.

Assessor: World Conservation Monitoring Centre

Refs: 15431, 17195

\section{Semecarpus walkeri}

Anacardiaceae

VU Alc

Sri Lanka

A species occurring in the lowland wet evergreen forests of south-west Sri Lanka.

Assessor: World Conservation Monitoring Centre

Refs: 15431, 17195

\section{Semiliquidambar cathayensis}

Hamamelidaceae

LR/nt

China (Fujian, Guangdong, Guangxi, Guizhou, Hunan, Jiangxi, Zhejiang)

A tree of lowland forests and open woodland by streamsides. The species distribution is relatively widespread in southem China, extending into Lang Son and Son La Provinces in Viet Nam. However, it is becoming scarcer because of overexploitation, habitat destruction and clearance for agriculture. The roots have various important medicinal uses.

Assessor: World Conservation Monitoring Centre

Refs: 1818, 11847

\section{Senecio lamarckianus}

Compositae

CR D1

Mauritius

Fewer than 12 adult individuals are known, most of them in Piton du Fouge Ridge Forest. There is a chance there are more individuals in more remote areas. The species has been propagated from cuttings and introduced into Mondrain Nature Reserve.

Assessor: Page, W.

Refs: $1411,9120,15251,16426$

\section{Senna caudata}

Leguminosae

Costa Rica, Panama

VU C2a

At one time the species was divided into the Panamanian form, var. caudata, known only from the type collection from the province of Panamá in 1911, and the Costa Rican form, var. diadema, with a fairly common occurrence in lowland rainforest in San José and Puntarenas. There have been no further collections of the species in Panama, despite the area round the type locality being relatively well known.

Assessor: Mitré, $\mathbf{M}$.

Refs: $7980,15037,16772$

\section{Senna dariensis var. hypoglauca \\ Leguminosae \\ Panama}

VU C2a

The species is distributed in rainforest up to $1000 \mathrm{~m}$ along the Cordillera Central, in the provinces of Veraguas, Coclé and Panamá. It is known from only a few records, but a large part of these mountains remains poorly explored. The populations in Campana National Park are well protected. In other areas there are strong influences from encroaching settlement, agriculture and pastoralism.

Assessor: Mitré, M.

Refs: 16772

\section{Senna domingensis}

Leguminosae

VU $B 1+2 c$

Cuba, Dominican Republic, Haiti

Known in Cuba from a single locality in the coastal areas of Daiquiri, Santiago de Cuba Province, this small tree occurs infrequently in dry evergreen shrubwood and shrubland on limestone. Its habitat type has been degraded in many places. Tourism is the major threat in Cuba. The species is more widespread and more common in Hispaniola.

Assessor: Areces-Mallea, A.E.

Refs: 19149 
Senna multijuga ssp. doylei

Leguminosae

Mexico (Chiapas, Oaxaca, Tabasco, Veracruz)

Confined to the Gulf region, this taxon occurs in remaining rainforest from northern Veracruz southwards.

Assessor: World Conservation Monitoring Centre

Refs: 5993

\section{Sequoia sempervirens}

Taxodiaceae

USA (Califomia, Oregon)

LR/cd

Assessor: SSC Conifer Specialist Group

Refs: 374, 3786, 7222, 13041

\section{Sequoiadendron giganteum}

Taxodiaceae

VU Alcd

USA (California)

An emergent of mixed montane forests. There was large-scale logging of populations between 1856 and 1955 , but $90 \%$ of the population is now protected. Fire prevention policy, causing a build-up of undergrowth, may have hampered regeneration in the past. Schemes to improve management and to plant trees on cleared land are in place.

Assessor: SSC Conifer Specialist Group

Refs: 7222,13041

\section{Serianthes calycina}

Leguminosae

VU C2a

New Caledonia

A species which can be divided into two varieties, both endemic to New Caledonia. It occurs in lowland areas of maquis or forest on ultramafic substrate in the northwest of Grand Terre and possibly also on Ile Yandé. These areas are unprotected and exposed to various threats from fire, mining activities and habitat clearance or degradation.

Assessor: Jaffré, T. et al.

Refs: 4492, 10351, 12630

\section{Serianthes margaretae}

Leguminosae

VU C2a

New Caledonia

A species which appears to have two disjunct populations. Both occur in littoral maquis on ultramafic soils, one near Koumac in the north-west and the other further south on the east coast.

Assessor: Jaffré, T. et al.

Refs: 10351,12630

\section{Serianthes melanesica var. meeboldii}

Leguminosae

VU D2

Fiji

An inadequately known tree, similar to the type variety and collected only once from Rewa Province, Viti Levu. Assessor: World Conservation Monitoring Centre Refs: 18818

\section{Serianthes myriadenia}

Leguminosae

LR/nt

French Polynesia (Marquesas Is., Society Is.)

In the Marquesas the species is confined to Nuku Hiva. In the Society Islands, populations are recorded from Moorea, Raiatea and Tahiti. The Raiatea population is critically endangered.

Assessor: Florence, J.

Refs: 14513
Serianthes nelsonii

Leguminosae

Guam, Northem Marianas

CR D1

A large tree of moist forest on limestone substrate. There are about 120 trees on Rota and only one remains on a military base on Guam. Lack of regeneration seems to be the main cause of the population decline. Possible causes include insect predation on the seeds, ungulate predation of the seedlings and seedling mortality caused by introduced mealybugs. The population on Rota is likely to decline as older trees die. The species is protected by the US Endangered Species Act and in government legislation in Guam and the Northern Marianas.

Assessor: Wiles, G.

Refs: 2196, 16676, 19175

\section{Serianthes petitiana}

Leguminosae

LR/cd

New Caledonia

Endemic to southern Grand Terre, the species occurs in lowland rainforest and maquis formations on ultramafic soil. Populations are believed to be effectively protected in Rivière Bleue Provincial Park.

Assessor: Jaffré, T. et al.

Refs: 10351,12630

\section{Serianthes rurutensis}

Leguminosae

CR B $1+2 \mathrm{c}$

French Polynesia (Tubuai Is.)

Little is known about the population on Ravivava, but on Rurutu the species is in a critical state.

Assessor: Florence, J.

Refs: 14513

\section{Serianthes vitiensis}

Leguminosae

VU D2

Fiji

Known only with certainty from Vanua Levu, the species has been collected from forest near creeks on the lower slopes of mountains in Mathuata Province.

Assessor: World Conservation Monitoring Centre Refs: 18818

\section{Sericanthe odoratissima var. odoratissima}

Rubiaceae

$\mathrm{VU} B 1+2 b$

Tanzania

The distribution of this small tree is not consolidated.

There is a population at Amani and possibly another at Ambangula at medium elevations in moist evergreen forest.

Assessor: Lovett, J. \& G.P. Clarke

Refs: 3356,8814

Sericanthe odoratissima var. ulugurensis

Rubiaceae

VU B $1+2 b$

Malawi, Tanzania

This variant is more widespread than the type variety and is restricted to montane forest at higher altitudes. Populations are known from the Uluguru Mountains, Mount Rungwe in Tanzania and also from Malawi.

Assessor: Lovett, J. \& G.P. Clarke

Refs: $1308,3356,8814$

\section{Sericanthe toupetou}

Rubiaceae

EN B $1+2 c$

Côte d'Ivoire, Ghana

The range of this species is restricted to wet evergreen forest in Côte d'Ivoire and neighbouring Ghana. It is 
uncommon and has suffered from the significant declines in its habitat caused by logging, mining and expansion of commercial plantations.

Assessor: Hawthome, W.

Refs: 6127, 12061,15251

\section{Sesbania coccinea ssp. atollensis}

Leguminosae DD

French Polynesia (Marquesas Is., Society Is., Tuamotu Is.)

A shrub or small tree known from five varieties which occur on various islands in the Marquesas, Tuamotu and Society Groups. Populations on Moorea, Raiatea, Tahiti, Tetiaroa are apparently now extinct and on other islands they are under some threat.

Assessor: Florence, J.

Refs: 14513

\section{Sessea brasiliensis}

Solanaceae

Brazil (Minas Gerais, Rio de Janeiro, São Paulo)

DD

An Atlantic forest species.

Assessor: Carvalho, L.d'A.F.

Refs: 19098, 19103

\section{Shorea acuminata}

Dipterocarpaceae

CR Alcd

Malaysia

A large dipterocarp of well-drained, undulating land, which is cut for its light and dark red meranti timber.

Assessor: Ashton, $\mathrm{P}$.

Refs: 9509, 13857

\section{Shorea acuminatissimo}

Dipterocarpaceae

CR Alcd

Indonesia (Kalimantan), Malaysia (Sabah)

An enormous tree, endemic to Borneo, found in lowland mixed dipterocarp forest, often on hills and ridges near the coast. The wood is used as yellow meranti. Some populations are known to occur in forest reserves.

Assessor: Ashton, P.

Refs: $7673,9169,13857$

\section{Shorea acuta}

Dipterocarpaceae

Brunei, Malaysia (Sarawak)

CR Alcd

Some populations of this species occur in forest reserves.

Assessor: Ashton, P.

Refs: $7673,9169,13857$

\section{Shorea affinis}

Dipterocarpaceae

EN Alcd

Sri Lanka

Relatively widely distributed in what remains of Sri Lanka's lowland wet evergreen forest, this dipterocarp is found scattered on deep rich soils on hillsides. The species is one of the dominant canopy species in the protected area at Sinharaja. However, it was not found during the extensive forest surveys conducted between 1991 and 1996 for the National Conservation Review, suggesting it has become extremely rare.

Assessor: Ashton, $\mathrm{P}$.

Refs: 13857, 15431, 17195, 18515, 19112

\section{Shorea agami}

Dipterocarpaceae

EN Alcd

Indonesia (Kalimantan), Malaysia (Sarawak)

This species, found on leached soils, is cut for its white meranti timber. There are populations also in forest reserves.

Assessor: Ashton, $\mathrm{P}$.

Refs: $7673,9169,13857$

Shorea agamii ssp. agamii

Dipterocarpaceae

Malaysia (Sabah, Sarawak)

EN Alcd

Populations of this species are known to occur in forest reserves.

Assessor: Ashton, $\mathrm{P}$

Refs: 9501, 13857

\section{Shorea albida}

Dipterocarpaceae

EN Alcd+2cd

Brunei, Indonesia (Kalimantan), Malaysia (Sarawak)

A large timber tree restricted to Brunei, Sarawak and West Kalimantan. It is a characteristic component of the threatened peat-swamp forests, sometimes occurring locally on podzolic soils in heath forest. An area of forest covering about 400,000 ha in Brunei may now contain the largest remaining undisturbed stand. Regeneration is reported to be non-existent.

Assessor: Ashton, P.

Refs: $7673,9169,13857,19749$

\section{Shorea almon}

Dipterocarpaceae

Malaysia (Sabah, Sarawak), Philippines

CR Alcd

A large tree, found on hills in lowland mixed dipterocarp forest. The red meranti timber is cut for plywood.

Assessor: Ashton, $\mathrm{P}$.

Refs: 7673, 13857

\section{Shorea alutacea}

Dipterocarpaceae

Malaysia (Sarawak)

Assessor: Ashton, $\mathrm{P}$.

Refs: $7673,9169,13857$

\section{Shorea andulensis}

Dipterocarpaceae

Brunei, Malaysia (Sarawak)

VU Alc, B1+2c, C2a, D1

A tree of mixed dipterocarp forest tree, suffering from habitat conversion.

Assessor: Ashton, $\mathrm{P}$.

Refs: 7673, 9169, 13857

\section{Shorea argentifolia}

Dipterocarpaceae

EN Alcd

Brunei, Indonesia (Kalimantan), Malaysia (Sabah, Sarawak)

A gregarious tree found on clay soils, exploited for its light red meranti timber. Some populations are known to occur in forest reserves.

Assessor: Ashton, $\mathrm{P}$.

Refs: $7673,9169,13857$

\section{Shorea asahii}

Dipterocarpaceae

CR Alcd, C2a, D1

Brunei, Malaysia (Sabah, Sarawak)

A tree that is restricted to the mixed dipterocarp forests of Bomeo. It is directly threatened by logging operations because its reproductive cycle exceeds the logging cycle. Assessor: Ashton, P.

Refs: $7673,9169,13857$ 
Shorea assamica ssp. assamica

Dipterocarpaceae CR Alcd, B1+2c

China (Yunnan), India, Malaysia (Peninsular Malaysia), Myanmar

This gregarious tree occurs on slopes and along rivers in lowland evergreen forest. The Chinese population is confined to Yingiiang and is threatened by conversion of the forest to agriculture. In India the species is known from healthy populations, which are regenerating well. The trees are cut for the commercially valuable plywood. Populations of the species are known to occur in some forest reserves.

Assessor: Ashton, $\mathrm{P}$.

Refs: $1818,3998,5550,9169,11847,13857$

\section{Shorea assamica ssp. globifera}

Dipterocarpaceae

CR Alcd

Indonesia (Moluccas, Sulawesi, Sumatra), Malaysia (Peninsular Malaysia), Philippines, Thailand

Assessor: Ashton, P.

Refs: $7673,9169,13857$

\section{Shorea assamica ssp, koordersü}

Dipterocarpaceae

Indonesia (Moluccas, Sulawesi), Philippines

CR Alc

Assessor: Ashton, $\mathrm{P}$.

Refs: $7673,9169,13857$

\section{Shorea assamica ssp. philippinensis}

Dipterocarpaceae

CR Alcd, C2a

Philippines

Assessor: Ashton, P.

Refs: $7673,9169,13857$

\section{Shorea astylosa}

Dipterocarpaceae

Philippines

CR Alcd, C2a

An endemic tree species of the disappearing lowland primary evergreen dipterocarp forests of the Philippines. The balau timber is used for good-quality construction.

Assessor: Ashton, P.

Refs: $7673,9169,13857$

\section{Shorea bakoensis}

Dipterocarpaceae

Malaysia (Sarawak)

Although the population of this species is extremely small, it does occur in a protected reserve.

Assessor: Ashton, $\mathrm{P}$.

Refs: 7673,13857

\section{Shorea balangeran}

Dipterocarpaceae

CR Alcd

Indonesia (Kalimantan, Sumatra)

This common tree of peat-swamp forest is a major source of red meranti timber.

Assessor: Ashton, $\mathrm{P}$.

Refs: $7673,9169,13857$

\section{Shorea balanocarpoides}

Dipterocarpaceae

EN Alcd

Brunei, Indonesia (Sumatra), Malaysia (Peninsular Malaysia, Sarawak)

This tree grows on yellow sandy loam on undulating land and ridges. It is used as yellow meranti and the illipe nuts are collected locally.

Assessor: Ashton, $\mathrm{P}$.

Refs: $7673,9169,13857$
Shorea bentongensis

Dipterocarpaceae

ENAlc

Malaysia (Peninsular Malaysia)

Endemic to Peninsular Malaysia, this tree is locally common in deep valleys. The wood is used as white meranti. However, the tree is slow-growing and cannot withstand logging because the reproductive cycle exceeds cutting cycles.

Assessor: Ashton, P.

Refs: $5550,7673,9169,13857$

\section{Shorea biawak}

Dipterocarpaceae

Brunei, Malaysia (Sarawak)

EN Alcd

Found in mixed dipterocarp forest, this tree is threatened by forest conversion and habitat degradation.

Assessor: Ashton, P.

Refs: $7673,9169,13857$

\section{Shorea blumutensis}

Dipterocarpaceae

CR Alcd+2cd

Indonesia (Sumatra), Malaysia (Peninsular Malaysia)

A slow-growing species of lowland dipterocarp forest, threatened directly by logging; the tree is unlikely to reach reproductive maturity within a logging cycle. It is currently being exploited for its yellow meranti timber. The species occurs in some forest reserves.

Assessor: Ashton, $\mathrm{P}$.

Refs: $5550,7673,9169,13857$

\section{Shorea bracteolata}

Dipterocarpaceae

EN A $1 c d+2 c d$

Indonesia (Sumatra), Malaysia (Peninsular Malaysia), Singapore

Found mostly on well-drained lowland coastal hills, this tree is heavily exploited for white meranti timber, especially in Peninsular Malaysia.

Assessor: Ashton, P.

Refs: $7673,9169,9199,13857,17140$

\section{Shorea brunnescens}

Dipterocarpaceae

Malaysia (Sarawak)

Assessor: Ashton, P.

Refs: 7673, 9169, 13857

\section{Shorea bullata}

Dipterocarpaceae

CR Alcd+2cd

Brunei, Malaysia (Sarawak)

A species of mixed dipterocarp forest. Some populations also occur in forest reserves.

Assessor: Ashton, $\mathrm{P}$.

Refs: $7673,9169,13857$

\section{Shorea cara}

Dipterocarpaceae

DD

Indonesia (Java)

Assessor: Ashton, $\mathrm{P}$.

Refs: 13857,16172

\section{Shorea carapae}

Dipterocarpaceae

Indonesia (Kalimantan), Malaysia (Sarawak)

Endemic to ridges and hill forests in Peninsular Malaysia, this tree is slow-growing and therefore directly threatened by logging operations. The tree is cut for balau timber.

Assessor: Ashton, P.

Refs: 7673,13857 


\section{Shorea chaiana}

Dipterocarpaceae

Malaysia (Sarawak)

Assessor: Ashton, $\mathrm{P}$.

Refs: $7673,9169,13857$

\section{Shorea ciliata}

Dipterocarpaceae

Malaysia (Peninsular Malaysia)

EN Alcd $+2 c d$

Assessor: Ashton, $\mathrm{P}$.

Refs: $5550,7673,11647,13857$

\section{Shorea collina}

Dipterocarpaceae

CR Alcd+2cd, C2a

Malaysia (Peninsular Malaysia), Singapore

A lowland tree which is cut for red balau timber. It is directly threatened by logging because its slow growth prevents the tree from reaching reproductive maturity within a logging cycle

Assessor: Ashton, P.

Refs: $5550,7673,9199,11647,13857$

\section{Shorea congestiflora}

Dipterocarpaceae

CR Alcd

Sri Lanka

A characteristic species of remnant lowland wet evergreen forest, forming one of the dominant components of the canopy in Sinharaja Biosphere Reserve. However, it was not discovered during the extensive forest surveys conducted between 1991 and 1996 for the National Conservation Review, suggesting that the species has become rare. It is an important component of plywood, which is mainly used to make tea chests.

Assessor: Ashton, P.

Refs: $13857,15431,17195,18515$

\section{Shorea conica}

Dipterocarpaceae

CR Alcd, C2a

Indonesia (Sumatra)

This species is found on undulating land near the coast. It is threatened by forest conversion and degradation.

Assessor: Ashton, P.

Refs: $7673,9169,13857$

\section{Shorea contorta}

Dipterocarpaceae

CR Alcd

Philippines

Endemic to the Philippines, this large tree is found in the ever-decreasing lowland seasonal semi-evergreen dipterocarp forest. It is suffering from exploitation for the light red meranti (or white lauan) timber.

Assessor: Ashton, P.

Refs: 7673, 9169, 13857

\section{Shorea cordata}

Dipterocarpaceae

Malaysia (Sarawak)

Assessor: Ashton, P.

Refs: $7673,9169,13857$

\section{Shorea cordifolia}

Dipterocarpaceae

CR Alcd

Sri Lanka

A canopy species that is endemic to the remaining fragments of lowland wet evergreen forest of Sri Lanka. Signs of regeneration are meagre. This tree was not found during the extensive forest surveys conducted between 1991 and 1996 for the National Conservation
Review, suggesting that it is either extremely rare or possibly extinct.

Assessor: Ashton, P.

Refs: $13857,15431,17195,19112$

\section{Shorea cuspidate}

Dipterocarpaceae

Malaysia (Sarawak)

EX

Assessor: Ashton, P.

Refs: $7673,9169,13857$

\section{Shorea dasyphylla}

Dipterocarpaceae

EN Alcd

Indonesia (Sumatra), Malaysia (Sarawak)

This tree is found in lowland mixed dipterocarp forest on well-drained land and is cut for light red meranti timber.

Assessor: Ashton, P.

Refs: $7673,9169,13857$

\section{Shorea dealbata}

Dipterocarpaceae

CR Alcd+2cd, C2a Indonesia (Sumatra), Malaysia (Peninsular Malaysia, Sarawak)

A tree that occurs locally on flat coastal swamps on yellow sandy soils and on low hills. It is exploited for its white meranti timber. The species also is found in forest reserves.

Assessor: Ashton, $\mathrm{P}$.

Refs: $5550,7673,9169,13857,17140$

\section{Shorea dispar}

Dipterocarpaceae

Malaysia (Sarawak)

An endemic tree of the threatened mixed dipterocarp forests of Sarawak.

Assessor: Ashton, P.

Refs: $7673,9169,13857$

\section{Shorea disticha}

Dipterocarpaceae

EN Alcd

Sri Lanka

A small tree with an extremely localised distribution in areas of lowland wet evergreen forest. It is found in Lenegal Kande Sinharaja Biosphere Reserve and has previously been reported from Kanneliya and Gilimale. The species is not of any economic importance because of its small size and scarcity.

Assessor: Ashton, P.

Refs: $13857,15431,17195,18515$

\section{Shorea domatiosa}

Dipterocarpaceae

EN Alcd, C2a

Brunei, Indonesia (Kalimantan), Malaysia (Sabah)

A tree occurring in lowland mixed dipterocarp forest.

Assessor: Ashton, P.

Refs: $7673,9169,13857$

\section{Shorea dyeri}

Dipterocarpaceae

EN Alcd

Sri Lanka

A sizeable tree found scattered in the remnants of lowland wet evergreen forest in the south-west corner of Sri Lanka. It is of local value as a construction timber, and occurs in some forest reserves.

Assessor: Ashton, P.

Refs: $13857,15431,17195$ 


\section{Shorea elliptica}

Dipterocarpaceae

CR Alcd, C2a

Indonesia (Kalimantan), Malaysia (Sarawak)

Confined to the lowland mixed dipterocarp forests of north-western Kalimantan and westem Sarawak, this tree is cut for red balau timber. Some populations occur in forest reserves.

Assessor: Ashton, $\mathrm{P}$.

Refs: $7673,9169,13857$

\section{Shorea faguetiana}

Dipterocarpaceae

EN Alcd

Indonesia, Malaysia (Peninsular Malaysia, Sabah,

Sarawak), Thailand

This tree is often found on well-drained clay soils on ridges and undulating land. The wood is utilised as yellow meranti timber. Populations have been found in forest reserves.

Assessor: Ashton, $\mathrm{P}$.

Refs: $9169,12937,13857$

\section{Shorea falcata}

Dipterocarpaceae

CR C2b

Viet Nam

Endemic to Viet Nam, this species may now be extinct.

Assessor: Ashton, $\mathrm{P}$.

Refs: 13857

\section{Shorea falcifera}

Dipterocarpaceae

EN Alcd

Indonesia (Kalimantan, Sumatra), Malaysia (Peninsular

Malaysia, Sarawak)

This lowland species cannot withstand logging because of its slow growth. Balau consignments are often made up of this species.

Assessor: Ashton, $\mathrm{P}$.

Refs: $5550,7673,9169,13857,18327$

\section{Shorea falciferoides}

Dipterocarpaceae

CR Alcd

Indonesia (Kalimantan), Philippines

A massive tree of mixed dipterocarp forest on clay soils, cut for balau timber. This slow growing species cannot reach reproductive maturity between logging cycles and is therefore threatened by logging activities.

Assessor: Ashton, $\mathrm{P}$.

Refs: $7673,9169,13857$

\section{Shorea falciferoides ssp. falciferoides}

Dipterocarpaceae

CR Alcd

Philippines

This subspecies is restricted to the Philippines; it grows in mixed dipterocarp forest and is confined to ridges in permanently wet areas.

Assessor: Ashton, P.

Refs: 9501,13857

\section{Shorea falciferoides ssp. glaucescens}

Dipterocarpaceae

CR Alcd

Brunei, Indonesia (Kalimantan), Malaysia (Sabah, Sarawak)

This subspecies is restricted to Bomeo, where it grows in mixed dipterocarp forest up to $600 \mathrm{~m}$.

Assessor: Ashton, P.

Refs: 9501, 13857
Shorea farinosa

Dipterocarpaceae

CR Alcd, C2a

Malaysia? (Peninsular Malaysia?), Myanmar, Thailand

Assessor: Ashton, $\mathrm{P}$.

Refs: $3998,7673,9169,13857,18243$

\section{Shorea flaviflora}

Dipterocarpaceae

Brunei, Malaysia (Sabah)

Assessor: Ashton, $\mathrm{P}$.

Refs: 13857,18327

\section{Shorea flemmichii}

Dipterocarpaceae

Brunei, Malaysia (Sarawak)

CR Alcd, C2a

A lowland tree locally distributed on deep yellow sandy soils and coastal hills. It is often cut for dark red meranti timber. The tree is slow-growing and directly threatened by logging because it cannot reach reproductive maturity within a cutting cycle. Populations are recorded from some forest reserves.

Assessor: Ashton, P.

Refs: $7673,9169,13857$

\section{Shorea foraminifera}

Dipterocarpaceae

Brunei

Assessor: Ashton, P.

Refs: $7673,9169,13857$

\section{Shorea foxworthyi}

Dipterocarpaceae

CR Alcd Indonesia (Kalimantan, Sumatra), Malaysia (Sabah, Sarawak), Thailand

A lofty tree that is a source of balau timber. Logging is a serious threat because the reproductive cycle of the species exceeds the present cutting cycle.

Assessor: Ashton, $\mathrm{P}$.

Refs: $7673,9169,13857$

\section{Shorea gardneri}

Dipterocarpaceae

Sri Lanka

CR Alcd

A large tree confined to the remaining $700 \mathrm{~km}^{2}$ of highland wet evergreen forest. It prefers deep welldrained soils. The timber is exploited for house building and bridge construction. It was not found during the extensive forest surveys conducted between 1991 and 1996 for the National Conservation Review, suggesting that the species is either extremely rare or possibly extinct.

Assessor: Ashton, $\mathrm{P}$.

Refs: $13857,15431,19112$

\section{Shorea geniculata}

Dipterocarpaceae

Brunei, Malaysia (Sarawak)

CR Alcd, C2a

A large tree occurring in mixed dipterocarp forest on leached yellow soils. It is valued as the most solid balau timber in Brunei. Directly threatened by logging, trees do not reach reproductive maturity in the time between logging cycles. Populations of the species occur in some forest reserves.

Assessor: Ashton, $\mathrm{P}$.

Refs: $7673,9169,13857$ 


\section{Shorea gibbosa}

Dipterocarpaceae

\section{Singapore}

An emergent lowland tree that grows on deep clay-rich soils that is cut for its yellow meranti timber. The illipe nuts are collected.

Assessor: Ashton, P.

Refs: 9199, 13857, 16104

\section{Shorea glauca}

Dipterocarpaceae

EN Alcd

Indonesia (Sumatra), Malaysia, Thailand

A semi-gregarious species that is found on rocky hillsides and ridges. It is cut for balau timber.

Assessor: Ashton, P.

Refs: $7673,9169,13857$

\section{Shorea gratissima}

Dipterocarpaceae

EN A1 cd, C2a

Indonesia (Sumatra), Malaysia (Peninsular Malaysia, Sabah), Myanmar, Singapore, Thailand

A large tree found on well-drained soil in coastal areas, felled for white meranti timber. Populations of the species occur in some forest reserves.

Assessor: Ashton, P.

Refs: $3998,7673,9169,9199,13857$

\section{Shorea guiso}

Dipterocarpaceae

CR Alcd

Indonesia (Sumatra), Malaysia, Philippines, Thailand,

\section{Viet Nam}

A lowland forest species from which red balau timber is harvested.

Assessor: Ashton, $\mathrm{P}$.

Refs: $7673,9169,13857,19093$

\section{Shorea hemsleyana ssp. grandiflora}

Dipterocarpaceae

CR Alcd, C2a

Indonesia (Kalimantan), Malaysia (Sarawak)

A localised subspecies found on shallow peat-swamp and on leached sandy soils. The species as a whole is protected for its illipe nuts in Sarawak.

Assessor: Ashton, P.

Refs: 9169, 13857

\section{Shorea hemsleyana ssp. hemsleyana}

Dipterocarpaceae

CR Alcd, C2a

Indonesia (Sumatra), Malaysia (Peninsular Malaysia)

A species found on leached sandy soils and in shallow peat-swamp. In Sarawak trees are protected for the illipe nuts.

Assessor: Ashton, $\mathrm{P}$.

Refs: 7673,13857

\section{Shorea henryana}

Dipterocarpaceae

EN Alcd

Cambodia, Laos, Malaysia (Peninsular Malaysia), Myanmar, Thailand, Viet Nam

A tree of seasonal wet and dry evergreen forest. The hard, heavy timber is used for ship building and, in the past, the resin (dammar) was tapped commercially. The species occurs in some forest reserves.

Assessor: Ashton, $\mathrm{P}$.

Refs: 9169, 12937, 13857
Shorea hopeifolia

Dipterocarpaceae

Indonesia (Sumatra), Malaysia, Philippines

A large tree often found along streams on clay-rich soils, it is a source of yellow meranti timber.

Assessor: Ashton, P.

Refs: $2072,7673,9169,13857$

\section{Shorea hypochra}

Dipterocarpaceae

CR Alcd

Cambodia, Malaysia (Peninsular Malaysia), Thailand,

Viet Nam

This large tree is found in semi-evergreen and evergreen lowland dipterocarp forest. It produces a good-quality resin (damar temak), which, in the past, was tapped commercially. The wood is used as white meranti timber.

Assessor: Ashton, $\mathrm{P}$.

Refs: $5550,7673,9169,13857$

\section{Shorea hypoleuca}

Dipterocarpaceae

CR Alcd

Brunei, Indonesia (Kalimantan), Malaysia (Sabah, Sarawak)

A slow-growing species of mixed dipterocarp forest, directly threatened by logging activities because trees do not reach reproductive maturity between the current logging cycles.

Assessor: Ashton, $\mathrm{P}$.

Refs: $7673,9169,13857$

\section{Shorea iliasii}

Dipterocarpaceae

Malaysia (Sarawak)

Assessor: Ashton, P.

Refs: $7673,9169,13857$

\section{Shorea inaequilateralis}

Dipterocarpaceae

Brunei, Malaysia (Sarawak)

CR Alcd, C2a

A species of the dwindling mixed peat-swamp forests, which is threatened by logging for its valuable construction timber, semayur. It is unlikely to survive logging because trees are slow-growing and do not reach reproductive maturity within a logging cycle.

Assessor: Ashton, $\mathbf{P}$.

Refs: $7673,9169,13857$

\section{Shorea inappendiculata}

Dipterocarpaceae

CR Alcd, C2a

Indonesia (Kalimantan), Malaysia (Sabah, Sarawak)

A tree found infrequently in lowland mixed dipterocarp forest on coastal hills. It is cut for balau timber but its slow growth does not allow it to reach maturity within the current logging cycle. Some populations are found in forest reserves.

Assessor: Ashton, P.

Refs: $7673,9169,13857$

\section{Shorea induplicata}

Dipterocarpaceae

CR A1cd, B1+2bde, C2a Indonesia (Kalimantan), Malaysia (Sarawak)

A tree which occurs in the transitional forest between heath and mixed dipterocarp forest. Forest degradation and logging have brought the species close to extinction. Its slow growth makes it particularly vulnerable to the affects of continual logging.

Assessor: Ashton, $\mathrm{P}$.

Refs: $7673,9169,13857$ 


\section{Shorea isoptera}

Dipterocarpaceae

Brunei, Malaysia (Sabah, Sarawak)

CR Alcd, C2a

A lowland tree which is particularly threatened by logging operations because of its slow growth.

Assessor: Ashton, $\mathrm{P}$.

Refs: $7673,9169,13857$

\section{Shorea johorensis}

Dipterocarpaceae

CR Alcd

Indonesia (Kalimantan, Sumatra), Malaysia (Peninsular Malaysia, Sabah, Sarawak)

A lofty tree that occurs locally on well-drained soils at low altitude. It produces a high-grade light red meranti timber and for this reason it is a priority plantation tree in Indonesia.

Assessor: Ashton, P.

Refs: $7673,9169,13857$

\section{Shorea kuantanensis}

\section{Dipterocarpaceae}

CR Alcd, C2a

Malaysia (Peninsular Malaysia)

The one locality in Kuantan, where the species was discovered, has now been converted into a plantation.

Assessor: Ashton, $\mathrm{P}$.

Refs: 5550, 7673, 9169, 13857

\section{Shorea kudatensis}

Dipterocarpaceae

Malaysia (Sabah)

CR Alcd, C2a

An endemic tree, which has suffered high rates of forest conversion and degradation and may now be extinct.

Assessor: Ashton, $\mathbf{P}$.

Refs: $7673,9169,13857$

\section{Shorea kunstleri}

Dipterocarpaceae

CR Alcd

Indonesia (Kalimantan, Sumatra), Malaysia (Peninsular Malaysia, Sabah, Sarawak)

A large tree specific to leached sandy clay soils, felled for its valued red balau or red meranti timber. Some populations of the species occur in forest reserves.

Assessor: Ashton, $\mathrm{P}$.

Refs: $7673,9169,13857$

\section{Shorea ladiana}

Dipterocarpaceae

Brunei, Malaysia (Sarawak)

CR Alcd, C2a

Confined to the diminishing mixed dipterocarp forests of north-west Bomeo, this tree is directly threatened by logging. Its slow growth and maturation rate make it particularly vulnerable to continual cutting. Some populations are found in forest reserves.

Assessor: Ashton, P.

Refs: $7673,9169,13857$

\section{Shorea lamellata}

Dipterocarpaceae

CR Alcd

Indonesia (Sumatra), Malaysia (Peninsular Malaysia)

A large tree that is found locally on ridges. The tree is cut for white meranti timber and the wood is tapped for its clear resin in Borneo.

Assessor: Ashton, P.

Refs: $5550,7673,9169,13857$

\section{Shorea laxa}

Dipterocarpaceae

Brunei, Malaysia (Sarawak)

CR Alcd

Confined to coastal hills, the species occurs in mixed dipterocarp forest of north-east Sarawak, Brunei and south-east Sabah. It is exploited for its locally valuable yellow meranti timber. Populations are recorded in some forest reserves.

Assessor: Ashton, $\mathrm{P}$.

Refs: $7673,9169,13857$

\section{Shorea lepidota}

Dipterocarpaceae

CR Alcd

Indonesia (Sumatra), Malaysia (Peninsular Malaysia)

A tree that occurs in lowland dipterocarp forest. The illipe nuts are collected on a small scale and the timber is used as light red meranti. The species occurs in some forest reserves.

Assessor: Ashton, $\mathrm{P}$.

Refs: $7673,9169,13857,17140$

\section{Shorea leprosula}

Dipterocarpaceae

EN Alcd

Indonesia (Sumatra), Malaysia (Peninsular Malaysia), Singapore, Thailand

This species is still found, sometimes in forest reserves, but it has suffered a massive population reduction mainly because of the rates of exploitation of its light red meranti timber.

Assessor: Ashton, $\mathrm{P}$.

Refs: $7673,9169,9199,13857,17140$

\section{Shorea leptoderma \\ Dipterocarpaceae}

Malaysia (Sabah)

A tree endemic to the lowland forests of Sabah.

Assessor: Ashton, P.

Refs: $7673,9169,13857$

\section{Shorea lissophylla}

Dipterocarpaceae

CR Alcd, $\mathrm{C} 2 \mathrm{a}$

Sri Lanka

A small tree found in patches on shallow poor soil. It regenerates prolifically. The species was found in 11 of the forests surveyed for the National Conservation Review.

Assessor: Ashton, $\mathrm{P}$.

Refs: $13857,15431,17195,19112$

\section{Shorea longiflora}

Dipterocarpaceae

CR Alcd, C2a

Brunei, Indonesia (Kalimantan), Malaysia (Sarawak)

A yellow meranti timber species, endemic to Bomeo, found scattered on shallow peat or yellow sandy soils. Some populations of the species occur in forest reserves. Assessor: Ashton, $\mathrm{P}$. Refs: $7673,9169,13857$

\section{Shorea longisperma}

Dipterocarpaceae

CR Alcd, C2a

Brunei, Indonesia (Sumatra), Malaysia (Sarawak)

An enormous tree of the declining mixed dipterocarp forests in Sumatra and northern Bomeo. It is felled for yellow meranti timber.

Assessor: Ashton, $\mathrm{P}$.

Refs: $7673,9169,13857$

\section{Shorea lumutensis}

Dipterocarpaceae

Malaysia (Peninsular Malaysia)

CR Alcd, C2a

Limited in its range, this timber species occurs along the coastal hills of the west coast of Peninsular Malaysia. 
Some trees are also found in forest reserves in this area. Assessor: Ashton, P.

Refs: $5550,7673,9169,13857$

\section{Shorea lunduensis}

Dipterocarpaceae

Malaysia (Sarawak)

CR Alcd, C2a

A tree confined to the diminishing mixed dipterocarp forests of Sarawak.

Assessor: Ashton, $\mathrm{P}$.

Refs: $7673,9169,13857$

\section{Shorea macrantho}

Dipterocarpaceae

CR Alcd, C2a

Indonesia (Sumatra), Malaysia (Peninsular Malaysia, Sarawak)

This species occurs in the declining mixed peat-swamp forests. The tree is exploited for its light or dark red meranti timber and its edible illipe nuts.

Assessor: Ashton, $\mathrm{P}$.

Refs: $7673,9169,13857,17140$

\section{Shorea macrobalanos}

Dipterocarpaceae

Malaysia (Sarawak)

CR Alcd, C2a

Endemic in Sarawak and eastem Kalimantan, this rare tree is found on clay-rich soils on hill ridges.

Assessor: Ashton, $\mathrm{P}$.

Refs: $7673,9169,13857$

\section{Shorea macrophylla}

Dipterocarpaceae

Malaysia (Sarawak)

This lowland tree is one of the fastest growing species of the genus. It is found frequently along rivers and in areas which are periodically inundated. The tree is cut for its light red meranti timber, but more importantly it is the major source of illipe nuts, which ensures its protection under Sarawak's Wildlife Protection Bill (1990).

Assessor: Ashton, P.

Refs: 13857, 17214

\section{Shorea macroptera ssp. baillonii}

Dipterocarpaceae

EN Alcd

Indonesia (Kalimantan), Malaysia (Sarawak)

Some populations of this tree occur in forest reserves.

Assessor: Ashton, P.

Refs: $7673,9169,13857$

\section{Shorea macroptera ssp. macroptera}

Dipterocarpaceae

CR Alcd

Indonesia (Sumatra), Malaysia (Peninsular Malaysia),

Singapore, Thailand

Assessor: Ashton, $\mathrm{P}$.

Refs: $7673,9169,9199,13857$

\section{Shorea macroptera ssp. macropterifolia}

Dipterocarpaceae

EN A1c

Brunei, Malaysia (Sabah, Sarawak)

The species is recorded in some primary forest reserves.

Assessor: Ashton, P.

Refs: $7673,9169,13857$

\section{Shorea macroptera ssp. sandakanensis}

Dipterocarpaceae

CR Alcd

Indonesia (Kalimantan), Malaysia (Sabah)

Assessor: Ashton, $\mathrm{P}$.

Refs: $7673,9169,13857$
Shorea malibato

Dipterocarpaceae

Philippines

This species occurs in non-seasonal evergreen forest in the Philippines. It is now very nearly extinct because of habitat loss.

Assessor: Ashton, P.

Refs: $7673,9169,13857$

\section{Shorea materialis}

Dipterocarpaceae

CR Alcd, C2a

Brunei, Indonesia (Sumatra), Malaysia (Peninsular Malaysia, Sarawak)

A tree of remaining patchy *kerangas vegetation on podzols and sandstone cuestas. It is cut for balau timber. The population in Peninsular Malaysia has declined because of overexploitation.

Assessor: Ashton, $\mathrm{P}$.

Refs: $5550,7673,9169,13857,17140$

\section{Shorea maxima}

Dipterocarpaceae

Malaysia (Peninsular Malaysia)

EN Alc

A relatively small tree that is scattered on hills and undulating land. The timber is used as yellow meranti, but its export has been banned.

Assessor: Ashton, $\mathrm{P}$.

Refs: $5550,7673,9169,13857$

\section{Shorea maxwelliana}

Dipterocarpaceae

EN Alc

Indonesia (Sumatra), Malaysia (Peninsular Malaysia)

One of the main balau timber trees, occurring locally in some abundance on low ridges. Some trees are found in forest reserves.

Assessor: Ashton, $\mathrm{P}$.

Refs: $7673,9169,13857$

\section{Shorea megistophylla}

Dipterocarpaceae

Sri Lanka

CR Alcd

An emergent tree, usually found by rivers and streams, confined to the remaining $1422 \mathrm{~km}^{2}$ of lowland wet evergreen forest in Sri Lanka. Trees have been selectively logged in Sinharaja Biosphere Reserve. The species was not found during the extensive forest surveys conducted between 1991 and 1996 for the National Conservation Review, suggesting that it is either extremely rare or possibly extinct.

Assessor: Ashton, $\mathrm{P}$

Refs: $13857,15431,17195,19112$

\section{Shorea micans}

Dipterocarpaceae

Malaysia (Sabah)

$\mathrm{CR} \mathrm{A} 1 \mathrm{c}, \mathrm{C} 2 \mathrm{a}$

A lowland tree found growing over the ultrabasic rocks in Sabah, threatened mainly by forest conversion.

Assessor: Ashton, $\mathrm{P}$.

Refs: $7673,9169,13857$

\section{Shorea montigena}

Dipterocarpaceae

CR Alcd

Indonesia (Moluccas, Sulawesi)

A tree located in $S$. selanica hill forest.

Assessor: Ashton, $\mathrm{P}$.

Refs: $7673,9169,13857$ 


\section{Shorea mujongensis}

Dipterocarpaceae

CR Alcd

Malaysia (Sarawak)

A magnificent yellow meranti timber species endemic to the fertile volcanic soils of the Hose Mountains in Sarawak.

Assessor: Ashton, $\mathrm{P}$.

Refs: $7673,9169,13857$

\section{Shorea myrionerva}

Dipterocarpaceae Sarawak)

A tree that is found on moist hillsides and along rivers. It is also found in some forest reserves.

Assessor: Ashton, P.

Refs: $7673,9169,13857$

Shorea negrosensis

Dipterocarpaceae

CR Alcd

Philippines

A large, often gregarious, tree that occurs in the remaining lowland seasonal and evergreen dipterocarp forest of the Philippines. The timber is used as red meranti.

Assessor: Ashton, $\mathrm{P}$.

Refs: $7673,9169,13857$

\section{Shorea oblongifolia}

Dipterocarpaceae

CR Alcd

Sri Lanka

This tree occurs mainly on hillsides and river banks in remaining fragments of lowland wet evergreen forests. Regeneration is somewhat sparse. Some populations occur in forest reserves.

Assessor: Ashton, P.

Refs: $12129,13857,15431,17195$

\section{Shorea obovoidea}

Dipterocarpaceae

Malaysia (Sarawak)

CR Alcd, C2a

This tree is found only in the threatened mixed dipterocarp forests of western Sarawak.

Assessor: Ashton, $\mathrm{P}$.

Refs: $7673,9169,13857$

\section{Shorea obscura}

Dipterocarpaceae

EN Alcd

Brunei, Indonesia (Kalimantan), Malaysia (Sabah, Sarawak)

Populations of this species occur in some primary forest reserves.

Assessor: Ashton, $\mathrm{P}$.

Refs: $7673,13857,15598$

\section{Shorea ochrophloia}

Dipterocarpaceae

Indonesia (Sumatra), Malaysia (Peninsular Malaysia)

A species, found locally on well-drained undulating lowlying ground. The timber is used as red meranti.

Assessor: Ashton, P.

Refs: $5550,7673,9169,13857$

\section{Shorea ovalifolia}

Dipterocarpaceae

Sri Lanka

CR Alcd, C2a

A dipterocarp, confined to the lowland and hill wet evergreen forests of south-east Sri Lanka, which is close to extinction because of the loss of its habitat. This tree was not found during the extensive forest surveys conducted between 1991 and 1996 for the National Conservation Review, suggesting that the species is either extremely rare or possibly extinct.

Assessor: Ashton, P.

Refs: 13857, 15431, 17195, 19112

\section{Shorea ovalis ssp. ovalis}

Dipterocarpaceae

EN Alcd

Indonesia (Kalimantan, Sumatra), Malaysia (Peninsular Malaysia, Sabah), Singapore

A widespread subspecies that is found in lowland mixed dipterocarp forest.

Assessor: Ashton, P.

Refs: $7673,9169,9199,13857$

\section{Shorea ovalis ssp. sarawakensis}

Dipterocarpaceae

CR Alcd

Malaysia (Sabah, Sarawak)

Endemic to northem Bomeo, this species is restricted to lowland mixed dipterocarp forest. Some populations are known to occur in primary forest reserves.

Assessor: Ashton, $\mathrm{P}$.

Refs: $7673,9169,13857$

\section{Shorea ovalis ssp. sericea}

Dipterocarpaceae

CR Alcd

Indonesia (Sumatra), Malaysia (Peninsular Malaysia)

This subspecies occurs in lowland mixed dipterocarp forest.

Assessor: Ashton, P.

Refs: $7673,9169,13857$

\section{Shorea ovata}

Dipterocarpaceae

EN Alcd

Indonesia (Sumatra), Malaysia, Philippines

A widespread species which is cut for its dark red meranti timber. The tree occurs in some primary forest reserves.

Assessor: Ashton, P.

Refs: 7673,13857

\section{Shorea pachyphylla}

Dipterocarpaceae

Brunei, Malaysia (Sarawak)

CR Alcd, C2a

A valuable dark red meranti timber species that is restricted to the highly threatened mixed peat-swamp forest, usually near the coast of north-west Borneo. It is particularly threatened by logging operations because it grows too slowly to reach reproductive maturity between cutting cycles.

Assessor: Ashton, P.

Refs: $7673,9169,13857$

\section{Shorea palembanica}

Dipterocarpaceae

Malaysia (Peninsular Malaysia, Sarawak)

CR Alcd

This large tree is a riverine and freshwater swamp species, which is exploited for its red meranti timber. It is protected under Sarawak's Wildlife Protection Bill (1990) as a major source of illipe nuts.

Assessor: Ashton, P.

Refs: $13857,17140,17214$

\section{Shorea pallescens}

Dipterocarpaceae

CR Alcd, C2a

Sri Lanka

A dipterocarp restricted to the lowland wet evergreen forests of Kegalle and the South Peak Sanctuary. The species is unable to reach reproductive maturity between 
the current cutting cycles. It was not found during the extensive forest surveys conducted between 1991 and 1996 for the National Conservation Review, suggesting that it is either extremely rare or possibly extinct.

Assessor: Ashton, $\mathrm{P}$.

Refs: $13857,15431,17195,19112$

\section{Shorea pallidifolia}

Dipterocarpaceae

CR Alcd, C2a

Indonesia (Kalimantan), Malaysia (Sarawak)

A tree of remaining fragments of heath forest in Sarawak. It is mainly threatened by habitat degradation. Some populations occur in forest reserves.

Assessor: Ashton, P.

Refs: $7673,9169,13857$

\section{Shorea palosapis}

Dipterocarpaceae

Philippines

A large tree that is found throughout the Philippines on well-drained soils in what is left of the evergreen mixed diptercarp forest. It is cut for its light red meranti timber.

Assessor: Ashton, $\mathrm{P}$.

Refs: $7673,9169,13857$

\section{Shorea parvifolia ssp. parvifolia}

Dipterocarpaceae

EN A1cd

Indonesia (Sumatra), Malaysia (Peninsular Malaysia),

Singapore, Thailand

The species is possibly the most common dipterocarp in Malesia. It is, however, heavily exploited as the main source of light red meranti timber in South East Asia.

Assessor: Ashton, P.

Refs: $7673,9169,9199,13857$

\section{Shorea parvifolia ssp. velutina}

Dipterocarpaceae

EN Alcd

Indonesia (Sumatra), Malaysia (Peninsular Malaysia)

The species is possibly the most common dipterocarp in Malesia. It is, however, heavily exploited as the main source of light red meranti timber in South East Asia. Some populations occur in primary forest reserves.

Assessor: Ashton, P.

Refs: $7673,9169,13857$

\section{Shorea pauciflora}

Dipterocarpaceae

EN Alcd

Indonesia (Sumatra), Malaysia (Peninsular Malaysia),

Singapore

An immense tree of lowland and hill forest on welldrained soils. The species is exploited for its valuable dark red meranti timber.

Assessor: Ashton, $\mathrm{P}$.

Refs: $7673,9169,9199,13857$

\section{Shorea peltata}

Dipterocarpaceae

CR Alcd, C2a

Indonesia (Kalimantan, Sumatra), Malaysia (Peninsular Malaysia)

A tree of mixed dipterocarp forest.

Assessor: Ashton, P.

Refs: $5550,7673,9169,13857$
Shorea platycapa

Dipterocarpaceae

CR Alcd

Indonesia (Sumatra), Malaysia (Peninsular Malaysia), Singapore

A timber tree specific to mixed peat-swamp forest.

Assessor: Ashton, P.

Refs: $7673,9199,13857,17140$

\section{Shorea platyclados}

Dipterocarpaceae

Indonesia (Sumatra)

EN Alcd

A species found in hilly and mountainous areas on deep fertile soils. It produces a fine dark red meranti timber. Some populations are found in primary forest reserves.

Assessor: Ashton, $\mathrm{P}$.

Refs: $7673,9169,13857$

\section{Shorea polyandra}

Dipterocarpaceae

CR Alcd

Indonesia (Kalimantan), Malaysia (Sabah, Sarawak)

An immense tree, endemic to Bomeo, where it is locally common on fertile clay-rich soil.

Assessor: Ashton, $\mathrm{P}$.

Refs: 7673,9169, 13857

\section{Shorea polysperma}

Dipterocarpaceae

CR Alcd

Philippines

A tree, endemic to the Philippines, which occurs in the remaining hill evergreen mixed dipterocarp forests. It is heavily exploited as the most important red meranti timber in the country. Populations are recorded in some forest reserves.

Assessor: Ashton, $\mathrm{P}$.

Refs: $7673,9169,13857$

\section{Shorea praestans \\ Dipterocarpaceae}

Malaysia (Sarawak)

CR Alcd, C2a

Confined to mixed dipterocarp forest in central Sarawak, this species is threatened by forest degradation.

Assessor: Ashton, $\mathrm{P}$.

Refs: $7673,9169,13857$

\section{Shorea pubistyla}

Dipterocarpaceae

Malaysia (Sarawak)

Some populations occur in primary forest reserves.

Assessor: Ashton, $\mathrm{P}$.

Refs: $7673,9169,13857$

\section{Shorea quadrinervis}

Dipterocarpaceae

EN Alcd

Malaysia (Sabah, Sarawak)

Confined to north-west Borneo, this tree is one of the major sources of light red meranti timber.

Assessor: Ashton, P.

Refs: 13857,16104

\section{Shorea resinosa}

Dipterocarpaceae

CR Alcd

Indonesia (Sumatra), Malaysia (Peninsular Malaysia Sarawak)

A tree with a local distribution in mixed dipterocarp forest. The timber is used as a minor white meranti timber. The main threat to the species is forest conversion and degradation.

Assessor: Ashton, P.

Refs: $5550,7673,9169,13857$ 


\section{Shorea revoluta}

Dipterocarpaceae

Brunei, Malaysia (Sabah, Sarawak)

CR Alcd, C2a

A tree endemic to fragments of heath forest in northem Borneo.

Assessor: Ashton, $\mathrm{P}$.

Refs: $7673,9169,13857$

\section{Shorea richetia}

Dipterocarpaceae

Indonesia (Kalimantan), Malaysia (Sarawak)

CR Alcd, C2a

This tree is endemic to the threatened mixed dipterocarp forests and heath forests of western Borneo. Some populations occur in primary forest reserves.

Assessor: Ashton, P.

Refs: $7673,9169,13857$

\section{Shorea rotundifolia}

Dipterocarpaceae

Malaysia (Sarawak)

Endemic to Sarawak, this tree is found in mixed dipterocarp forest.

Assessor: Ashton, P.

Refs: $7673,9169,13857$

\section{Shorea roxburghii}

Dipterocarpaceae

EN Alcd

Cambodia, India (Andhra Pradesh, Kamataka, Kerala, Tamil Nadu), Laos, Malaysia (Peninsular Malaysia), Myanmar, Thailand, Viet Nam

A widespread dipterocarp, unusual for its adaptation to withstand adverse climatic conditions and soil types. It occurs in dry evergreen or deciduous forest and bamboo forest, often on sandy soils. In India, there are healthy regenerating populations in the south. Some populations are recorded in forest reserves.

Assessor: Ashton, P.

Refs: $3998,7673,8483,9169,13857$

\section{Shorea rubella}

Dipterocarpaceae

Brunei, Malaysia (Sabah, Sarawak)

CR Alcd, C2a

A species found on lowland coastal hills, sometimes within primary forest reserves.

Assessor: Ashton, $\mathrm{P}$.

Refs: $7673,9169,13857$

\section{Shorea rugosa}

Dipterocarpaceae

Indonesia (Kalimantan)

CR Alcd, C2a

A large tree of mixed dipterocarp and heath forest, that also occurs in some primary forest reserves. The timber is used as dark red meranti.

Assessor: Ashton, $\mathrm{P}$.

Refs: $7673,9169,13857$

\section{Shorea sagittata}

Dipterocarpaceae

Malaysia (Sabah, Sarawak)

Assessor: Ashton, $\mathrm{P}$.

Refs: 7673,13857

\section{Shorea selanica}

Dipterocarpaceae

Indonesia (Moluccas)

CR Alcd

Endemic to the south-west Moluccas, this large tree, often the dominant species, occurs in lowland forest. It is exploited for its valuable red meranti timber.

Assessor: Ashton, P.

Refs: $7673,9169,13857$

\section{Shorea seminis}

Dipterocarpaceae

Malaysia (Sarawak), Philippines

CR Alcd

A fairly large riverine tree, often occurring in patches in lowland areas. The tree provides balau timber and illipe nuts, and is protected under the Sarawak's Wildlife

Protection Bill (1990).

Assessor: Ashton, P.

Refs: $7673,9169,13857,17214$

\section{Shorea singkawang}

Dipterocarpaceae

CR Alcd

Indonesia (Sumatra), Malaysia (Peninsular Malaysia), Thailand

A dark red meranti timber species, usually found near lowland streams. The illipe nuts are collected.

Assessor: Ashton, P.

Refs: 9501, 13857

\section{Shorea singkawang ssp. scabrosa}

Dipterocarpaceae

CR Alcd

Malaysia (Peninsular Malaysia)

This subspecies is restricted to coastal Pahang and Terengganu, where it grows in forest on low hills.

Assessor: Ashton, P.

Refs: 9501,13857

\section{Shorea slootenii}

Dipterocarpaceae

CR Alcd, C2a

Brunei, Indonesia (Kalimantan), Malaysia (Sabah, Sarawak)

This species is found on coastal hills, and in some primary forest reserves.

Assessor: Ashton, P.

Refs: $7673,9169,13857$

\section{Shorea smithiana}

Dipterocarpaceae

CR Alcd

Indonesia (Kalimantan), Malaysia (Sabah, Sarawak)

A large tree of lowland areas, threatened by rates of exploitation. It is the major source of light red meranti timber for north-east Borneo. Populations are found in some forest reserves.

Assessor: Ashton, $\mathrm{P}$.

Refs: $7673,9169,13857$

\section{Shorea splendida}

Dipterocarpaceae

EN Alcd

Malaysia (Sarawak)

A relatively small dipterocarp which occurs in river forest. The tree provides a light red meranti timber and is the one of the main sources of illipe nuts. It is afforded protection by Sarawak's Wildlife Protection Bill (1990).

Assessor: Ashton, P.

Refs: 13857,17214

\section{Shorea stenoptera}

Dipterocarpaceae

Malaysia (Sarawak)

EN Alcd

This timber species, locally common in the patchy lowland heath forest, has been planted for its especially large illipe nuts. This tree is protected under Sarawak's 
Wildlife Protection Bill (1990). Some populations also occur in primary forest reserves.

Assessor: Ashton, P.

Refs: 13857,17214

\section{Shorea stipularis}

Dipterocarpaceae

Sri Lanka

CR Alcd

This species was discovered in only 12 of the forests surveyed for the National Conservation Review.

Assessor: Ashton, P.

Refs: $12129,13857,15431,17195,19112$

\section{Shorea subcylindrica}

Dipterocarpaceae

CR Alcd, C2a

Malaysia (Sarawak)

A relatively small tree of mixed dipterocarp forest, threatened by the decline and degradation of its habitat.

Assessor: Ashton, P.

Refs: $7673,9169,13857$

\section{Shorea submoniana}

Dipterocarpaceae

EN Alcd

Malaysia (Peninsular Malaysia)

A large dipterocarp that is locally abundant on high hills in Peninsular Malaysia. It is cut for balau timber.

Assessor: Ashton, P.

Refs: $5550,11647,13857$

\section{Shorea sumatrana}

Dipterocarpaceae

CR Alcd

Malaysia (Peninsular Malaysia), Thailand

This tree can be found along the banks of slow-flowing rivers. The population in south-east Peninsular Thailand appears to be extinct. It is exploited for its balau timber and the illipe nuts are collected locally.

Assessor: Ashton, $\mathrm{P}$

Refs: 13857,17140

\section{Shorea superba}

Dipterocarpaceae

CR Alcd

Brunei, Malaysia (Sabah, Sarawak)

A species of mixed dipterocarp forest, which is the main source of balau timber for Sabah. Logging poses a severe threat because the trees are unable to reach reproductive maturity between cutting cycles. The species is known to occur in some primary forest reserves.

Assessor: Ashton, $\mathrm{P}$.

Refs: $7673,9169,13857$

\section{Shorea symingtonii}

Dipterocarpaceae

CR Alcd

Malaysia (Sabah)

This tree is endemic to the mixed dipterocarp forests of Sabah, where it is threatened by habitat conversion and degradation. The species also occurs in some primary forest reserves.

Assessor: Ashton, $\mathrm{P}$.

Refs: $7673,9169,13857$

\section{Shorea tenuiramulosa}

Dipterocarpaceae

CR C2a, D1

Malaysia (Sabah, Sarawak)

This tree appears to be confined to dry coastal ridges.

Assessor: Ashton, $\mathrm{P}$.

Refs: $7673,9169,13857$
Shorea teysmanniano

Dipterocarpaceae

EN Alcd

Brunei, Indonesia (Kalimantan, Sumatra), Malaysia (Peninsular Malaysia, Sabah, Sarawak)

A tree of mixed peat-swamp forest, exploited for its light red meranti timber.

Assessor: Ashton, P.

Refs: $7673,9169,13857,17140$

\section{Shorea thorelii}

Dipterocarpaceae

CR Alcd

Cambodia, Laos, Thailand, Viet Nam

Assessor: Ashton, $\mathrm{P}$.

Refs: 9169, 12937, 13857

\section{Shorea trapezifolia}

Dipterocarpaceae

CR Alcd

Sri Lanka

This tree is found in fragments of lowland and sometimes highland wet evergreen forest, usually on deep soils. Most of the habitat has been converted into plantations, resulting in the species becoming localised. It forms one of the dominant components of the canopy in the protected area at Sinharaja. The timber is harvested mainly for plywood. Regeneration is good where selective logging is taking place. No populations were found during the extensive forest surveys conducted between 1991 and 1996 for the National Conservation Review, suggesting that the species is either extremely rare or possibly extinct.

Assessor: Ashton, $\mathrm{P}$.

Refs: 13857, 15431, 17195, 18515, 19112

\section{Shorea tumbuggaia}

Dipterocarpaceae

DD

India (Andhra Pradesh, Tamil Nadu)

A small tree which occurs gregariously on slopes and peaks in dry savanna forest and dry mixed decidous forest. The habitat is threatened with conversion to agriculture. The wood is used for construction.

Assessor: Ashton, $\mathrm{P}$.

Refs: 13857

\section{Shorea uliginosa}

Dipterocarpaceae

VU Alcd

Indonesia (Kalimantan, Sumatra), Malaysia (Peninsular Malaysia, Sarawak)

Locally abundant in mixed peat-swamp forest, this species is cut for its dark red meranti timber.

Assessor: Ashton, $\mathrm{P}$.

Refs: $7673,9169,13857,17140$

\section{Shorea waltoni}

Dipterocarpaceae

Malaysia (Sabah)

CR Alcd

This tree grows on well-drained ground in the lowlands and is found in some primary forest reserves.

Assessor: Ashton, $\mathrm{P}$.

Refs: $7673,9169,13857$

\section{Shorea worthingtonii}

Dipterocarpaceae

EN Alcd

Sri Lanka

Isolated patches of this species are found scattered on well-drained soil in remaining lowland wet evergreen forests. Regeneration is poor. The species forms a dominant component in the canopy in the protected area at Sinharaja. It was not found during the extensive forest surveys conducted between 1991 and 1996 for the 
National Conservation Review, suggesting that the species is extremely rare.

Assessor: Ashton, P.

Refs: $13857,15431,17195,18515,19112$

\section{Shorea xanthophylla}

Dipterocarpaceae

CR Alcd

Brunei, Indonesia (Kalimantan), Malaysia (Sabah, Sarawak)

A tree that is found in mixed dipterocarp forest on hills in northern Bomeo. The wood is used as yellow meranti timber. The species also occurs in some forest reserves. Assessor: Ashton, P.

Refs: $7673,9169,13857$

\section{Shorea zeylanica}

Dipterocarpaceae

Sri Lanka

CR Alcd, C2a

A tree occurring in wet evergreen forest which becomes an emergent at higher altitudes. The wood is used in construction work. It was not discovered during the extensive forest surveys conducted between 1991 and 1996 for the National Conservation Review, suggesting that the species is either extremely rare or possibly extinct.

Assessor: Ashton, $\mathrm{P}$.

Refs: $13857,15431,17195,19112$

\section{Sibangea pleioneura}

Euphorbiaceae

VU B $1+2 \mathrm{c}$

Tanzania

The East African member of this small tropical African genus. It is endemic to the North Udzungwa Mountains where it is found in moist evergreen forest at medium elevations.

Assessor: Lovett, J. \& G.P. Clarke

Refs: 3356, 10961, 11631

\section{Sideroxylon acunae}

Sapotaceae

VU B $1+2 c$

Cuba

Related to $S$. angustatum, this species is also confined to Oriente Province.

Assessor: World Conservation Monitoring Centre

Refs: 7980,8816

\section{Sideroxylon altamiranoi}

Sapotaceae

VU B $1+2 c$

Mexico (Hidalgo, Querétaro)

Confined to Hidalgo and Querétaro States, the species has been recorded only a few times in montane forest and *matorral, from the lower limit of the pine-juniper belt.

Assessor: World Conservation Monitoring Centre Refs: 7980,8816

\section{Sideroxylon angustum}

Sapotaceae

$\mathrm{EN} \mathrm{B} 1+2 \mathrm{c}$

Cuba

A shrub or small tree of dry thickets, apparently restricted to the serpentine plateau of Sierra de Nipe between 300 and $500 \mathrm{~m}$. So far it has been collected just three times. Some taxonomic confusion exists.

Assessor: Areces-Mallea, A.E.

Refs: $7980,8816,19149$
Sideroxylon anomalum

Sapotaceae

VU D2

Dominican Republic

A species known only from the site where it was first collected in Barahona at about $700 \mathrm{~m}$.

Assessor: World Conservation Monitoring Centre

Refs: 7980,8816

Sideroxylon bullatum

Sapotaceae

VU B $1+2 c$

Jamaica

Confined to Portland, the species is found in wet areas of woodland on limestone, e.g. above Ecclesdown. The habitat has declined and continues to be threatened. Assessor: World Conservation Monitoring Centre Refs: $401,3932,5653,7980$

\section{Sideroxylon capiri ssp. capiri}

Sapotaceae

LR/nt

Mexico (Guerrero, Jalisco, México State, Michoacan, Morelos, Nayarit, Oaxaca)

Occurring relatively widely, the species ranges from Jalisco to Oaxaca in deciduous forest from near sea level up to $1600 \mathrm{~m}$.

Assessor: World Conservation Monitoring Centre Refs: 7980,8816

\section{Sideroxylon cartilagineum}

Sapotaceae

LR/nt

Mexico (Guerrero, Jalisco, Sinaloa)

This small tree occurs over an area extending from Sinaloa to Guerrero, restricted to deciduous and semideciduous forest, frequently on igneous rock. Assessor: World Conservation Monitoring Centre Refs: 7980,8816

\section{Sideroxylon confertum}

Sapotaceae

$\mathrm{VUB} 1+2 \mathrm{c}$

Cuba

Not a well-known species, it is confined to the provinces of Oriente and Pinar del Rio, where it occurs in forest by mangroves and also in dry *manacales up to $900 \mathrm{~m}$. Overexploited for its timber has caused population decline. Overcutting and clearing are constant threats to the habit.

Assessor: Areces-Mallea, A.E.

Refs: 7980, 8816, 19149

Sideroxylon contrerasii

Sapotaceae

LR/nt

Costa Rica, Guatemala, Mexico (Hidalgo, Oaxaca, Veracruz), Panama

A rainforest species of lowland to medium elevation, scattered sparsely over a relatively wide range. Populations occur on the Atlantic slopes of Mexico, Guatemala and Costa Rica and more recently it has been collected from Cerro Jefe in Panama.

Assessor: World Conservation Monitoring Centre Refs: 7980,8816

\section{Sideroxylon discolor}

Sapotaceae

VU D2 Yemen (Socotra)

Formerly known under a small genus Spiniluma, the species is confined to the Haggier Mountains, from where it has been collected twice. It occurs in moist 
seasonal woodland within a restricted range below $1000 \mathrm{~m}$. There are no immediate threats to the area. More freldwork is needed to estimate population numbers.

Assessor: Miller, A.G.

Refs: 2354, 19083

\section{Sideroxylon dominicanum}

Sapotaceae

VU B1+2c, D2

Dominican Republic

A small treelet recorded, up to now, only twice from forest on limestone.

Assessor: World Conservation Monitoring Centre

Refs: 7980,8816

\section{Sideroxylon durifolium}

Sapotaceae

VU $B 1+2 c$

Belize

A small tree which appears to be confined to the Jacinto Hills in Belize, although a specimen collected in Chiapas in Mexico could possibly be the same species.

Assessor: World Conservation Monitoring Centre

Refs: 7980,8816

\section{Sideroxylon eucoriaceum}

Sapotaceae

VU B $1+2 c$

Guatemala, Mexico (Veracruz)

Known only from a few collections, the species is recorded from lowland rainforest in Niño Perdido and Baja Verapaz in Guatemala and from submontane secondary forest in the Apatlanco area in Veracruz. Assessor: World Conservation Monitoring Centre Refs: 7980,8816

\section{Sideroxylon excavatum}

Sapotaceae

$\mathrm{EN} \mathrm{Bl}+2 \mathrm{c}$

Mexico (Guerrero, Oaxaca)

A newly described species of arid thom forest or oak forest on calcareous soil between 1600 and $2000 \mathrm{~m}$. It is known only from small populations in the Chilpancingo area in Guerrero and south of San Marcos Arteaga in Oaxaca.

Assessor: World Conservation Monitoring Centre

Refs: 7980,8816

\section{Sideroxylon fimbriatum}

Sapotaceae

Yemen (Socotra)

Collected only a few times, the species has a very scattered distribution in moist woodland on limestone and granite hills. The populations are under no immediate threat.

Assessor: Miller, A.G.

Refs: 19083

\section{Sideroxylon floribundum ssp. belizense}

Sapotaceae

VUAlc

Belize, Guatemala

A rainforest species, confined to lowland limestone sites in Izabal and Petén, in Guatemala, and to Toledo in Belize. The type subspecies is confined to Jamaica. Assessor: World Conservation Monitoring Centre Refs: 7980,8816

\section{Sideroxylon floribundum ssp. floribundum}

Sapotaceae

VU B $1+2 c$ Jamaica

A taxon endemic to the central parishes of Jamaica, where it occurs within restricted areas of forest between 600 and $760 \mathrm{~m}$.

Assessor: Kelly, D.L.

Refs: $6057,7980,19085$

\section{Sideroxylon hirtiantherum}

Sapotaceae

VU B1 +2c, D2

Guatemala

This species is known from a single locality at $\mathrm{La}$ Cumbre, Petén, where it is confined to lowland rainforest dominated by Manilkara zapota.

Assessor: World Conservation Monitoring Centre Refs: 7980,8816

\section{Sideroxylon ibarrae}

Sapotaceae

VU B1+2c, D2

Guatemala

Confined to lowland rainforest, this species has been collected only a few times from its range in Baja Verapaz.

Assessor: World Conservation Monitoring Centre Refs: 7980,8816

\section{Sideroxylon inerme ssp. cryptophlebia}

Sapotaceae

VU D2

Seychelles (Aldabra)

A frequent constituent of mixed scrub on most of the islands in Aldabra, Assumption, Cosmoledo and Astove. Trees are frequently infested by woolly coccids. They also provide fruit for the blue pigeon. The islands of Aldabra are protected within a Strict Nature Reserve. Strip-mining for phosphate or guano has taken place on Assumption and areas of Cosmoledo and Astove have been cleared and planted with coconuts and Casuarina. The species is found on the African mainland. Assessor: World Conservation Monitoring Centre Refs: 19027

\section{Sideroxylon jubillo}

Sapotaceae

VU B1 $+2 c$

Cuba

A valuable timber tree, up to $30 \mathrm{~m}$ tall, fairly widespread in the humid mountainous areas of eastem Cuba, where it grows in submontane and montane rainforest and seasonal evergreen forest. Population numbers continue to decline because of overcutting.

Assessor: Areces-Mallea, A.E.

Refs: $7980,8816,19149$

\section{Sideroxylon mermulana}

Sapotaceae VU C2a

Cape Verde, Portugal (Madeira), Spain (Canary Is.)

The species is commonly known under the epithet marmulano and may possibly be divided into different varieties on different island groups, particularly the Cape Verde populations. It occurs in lowland dry forest and xerophytic scrub. On the Canary Islands and Madeira the populations have become small and fragmented, and are under great pressure from grazing, buming and habitat conversion. The species is covered by regional legislation and occurs within protected areas.

Assessor: Bañares, A et al.

Refs: $1512,16500,19022,19131$

\section{Sideroxylon montanum}

Sapotaceae

LR/nt

Jamaica

The species occurs over a wide range of altitudes and soil types in the Blue Mountains. It is especially 
common on the Grand Ridge and on steep, sometimes unstable, slopes. At lower elevations there has been logging.

Assessor: World Conservation Monitoring Centre

Refs: 7980, 12564

\section{Sideroxylon octosepalum}

Sapotaceae

LR/nt

Jamaica

An uncommon species occurring in the central parishes on well-drained rocky limestone.

Assessor: World Conservation Monitoring Centre

Refs: 6057,7980

\section{Sideroxylon peninsulare}

Sapotaceae

VU B $1+2 \mathrm{c}$

Mexico (Baja Califomia Sur)

A small tree or shrub, which is confined to two sites along stream beds and gullies in the southem tip of Baja California.

Assessor: World Conservation Monitoring Centre

Refs: 7980,8816

\section{Sideroxylon persimile ssp. subsessiliflorum}

Sapotaceae

LR/nt

Mexico (Chihuahua, Colima, Durango, Jalisco, Sinaloa)

This is the more localised subspecies of a widely occurring Central American tree. Populations are found along watercourses in dwarf deciduous forest up to $1200 \mathrm{~m}$, covering a range from Chihuahua to Jalisco and Colima.

Assessor: World Conservation Monitoring Centre Refs: 7980,8816

\section{Sideroxylon retinerve}

Sapotaceae

CR C2a

Honduras

A small tree, confined to an area of submontane pineoak woodland and rocky thickets in central Honduras.

Assessor: Nelson, C.

Refs: $7980,8816,13995$

\section{Sideroxylon rotundifolium}

Sapotaceae

LR/nt

Jamaica

This species is actually quite common where it occurs in areas of woodland and thicket on limestone in central and westem parishes.

Assessor: World Conservation Monitoring Centre

Refs: 6057,7980

\section{Sideroxylon rubiginosum}

Sapotaceae

$\mathrm{CR} C 2 \mathrm{a}$

Dominican Republic

A very poorly known species. The type and only collection was taken from a hilltop in Santo Domingo in the early part of the century. It has not been recorded since.

Assessor: World Conservation Monitoring Centre Refs: 7980,8816

\section{Sideroxylon socorrense}

Sapotaceae

Mexico (Revilla Gigedo Is)

A tree known only from Socorro Island and the Revilla Gigedo Islands in humid forest up to $900 \mathrm{~m}$.

Assessor: World Conservation Monitoring Centre Refs: 7980,8816
Sideroxylon stevensonï

Sapotaceae

VU B1+2c

Belize, Guatemala

This species is restricted to Petén in Guatemala and adjacent Belize. It is found in lowland rainforest dominated by Manilkara zapota, ascending to medium elevations.

Assessor: World Conservation Monitoring Centre

Refs: 7980,8816

\section{Simira wurdackii}

Rubiaceae

VU D2

Peru

Known only from the type collection, the species occurs in Amazon forest in the department of Loreto.

Assessor: World Conservation Monitoring Centre

Refs: 1984

\section{Sindora beccariana}

Leguminosae DD

Indonesia (Kalimantan), Malaysia (Sabah, Sarawak)

Scattered in lowland dipterocarp forest, this uncommon species, as well as others in the genus, may be seriously threatened by large-scale exploitation of forest.

Assessor: Asian Regional Workshop

Refs: $662,1766,12937,14573$

\section{Sindora inermis}

Leguminosae

Indonesia (Sumatra), Philippines

The timber of this lowland forest species is used as sepetir. The supply is very limited.

Assessor: Asian Regional Workshop

Refs: $2072,4919,12937,14573$

\section{Sindora javanica}

Leguminosae

VU B1+2c

Indonesia (Java)

A rare tree restricted to the lowland forests of Preanger and Banjumas.

Assessor: World Conservation Monitoring Centre

Refs: 12937, 14573

\section{Sindora supa \\ Leguminosae \\ Philippines}

VU Ald

The timber of this species, found in Luzon and Mindoro, is locally important and the wood-oil also has a variety of uses.

Assessor: Asian Regional Workshop

Refs: 4919, 12888, 14573

\section{Sindora tonkinensis}

Leguminosae

Cambodia, Viet Nam

A slow-growing tree, sparsely but widely distributed in remaining areas of primary and slightly disturbed forest. In Viet Nam, the species produces one of the best woods in the country and is becoming increasingly scarce.

Assessor: World Conservation Monitoring Centre Refs: 848, 12563

\section{Sinojackia dolichocarpa}

Styracaceae

VU D2

China (Hunan)

A relatively newly discovered species, known only from populations on Huping Mountain and Tienping Mountain, where it occurs in forest areas between 400 and $800 \mathrm{~m}$. The former location is designated a nature 
reserve, but the habitat in both areas is susceptible to disturbance.

Assessor: World Conservation Monitoring Centre Refs: 1818,11847

\section{Sinojackia xylocarpa}

Styracaceae

$\mathrm{VU} B 1+2 \mathrm{ce}, \mathrm{D} 2$

China (Jiangsu)

A dwarf tree restricted to a few localities close to Nanjing. It occurs on hillsides below $400 \mathrm{~m}$. Although some populations appear to be protected, trees are still susceptible to being cut for firewood.

Assessor: World Conservation Monitoring Centre Refs: 1818,11847

\section{Sinoradlkofera minor}

Sapindaceae

VU D2

Viet Nam

A small tree or shrub which appears to be endemic to Vo $\mathrm{Xa}, \mathrm{Nam} \mathrm{Ha}$ Province, in northern Viet Nam.

Assessor: World Conservation Monitoring Centre

Refs: 848

\section{Sinowilsonia henryi}

Hamamelidaceae

LR/nt

China (Gansu, Henan, Hubei, Shaanxi, Sichuan)

Confined to central China, the species occurs in mixed forest on mountain slopes and river banks between 1100 and $1600 \mathrm{~m}$. One population is believed to be protected in Taibai Shan Nature Reserve. Elsewhere the species appears to be suffering from habitat degradation and declines. It is the only species in the genus.

Assessor: World Conservation Monitoring Centre

Refs: 1818,11847

\section{Sipanuna eggersï}

\section{Monimiaceae}

VU B $1+2 \mathrm{C}$

Ecuador

An endemic tree of Ecuador, inhabiting forest between $60 \mathrm{~m}$ and $2650 \mathrm{~m}$ in Bolívar Province.

Assessor: World Conservation Monitoring Centre

Refs: 19119,19120

\section{Siphoneugenia densiflora}

Myrtaceae

VU B1+2acd

Brazil

Assessor: Barroso, G.M.

Refs: 19097,19098

\section{Siphoneugenia occidentalis}

Myrtaceae

VU BI $+2 \mathrm{ac}$

Argentina (Jujuy, Salta), Bolivia

Endemic to the piedmont forest of north-west Argentina and Bolivia, the species is confined to an unprotected ecosystem which is being rapidly replaced by agricultural systems.

Assessor: Prado, D.

Refs: 19122

\section{Siphoneugenia widgreniana}

Myrtaceae

VU Bl +2 acd

Brazil

Assessor: Barroso, G.M.

Refs: 19097,19098
Sloanea acutiflora

Elaeocarpaceae

VU D2

Suriname

An upland rainforest tree, locally abundant in places. It

is endemic to Brownsberg and the Tapanahony River.

Assessor: World Conservation Monitoring Centre

Refs: 19196

\section{Slocnea gracilis}

Elaeocarpaceae

Suriname

An endemic to Brownsberg.

Assessor: World Conservation Monitoring Centre

Refs: 19196

\section{Sloanea lepida}

Elaeocarpaceae

New Caledonia

VU DI

This species has been collected only rarely, perhaps twice. It occurs in dense rairforest in Oua Némi and Mé Oué in the north of Grand Terre.

Assessor: Jaffre, T. et al.

Refs: 10351,12630

\section{Sloanea shankii}

Elaeocarpaceae

Honduras

A rarely collected species of lowland moist forest.

Assessor: Nelson, C.

Refs: 13995

\section{Sloanea suaveolens}

Elaeocarpaceae

New Caledonia

VU DI

A species which appears to be known from a single location on Mont Tonine, where it occurs in dense forest on schist substrate between 800 and $1000 \mathrm{~m}$.

Assessor: Jaffré, T. et al.

Refs: 10351,12630

\section{Solanum betaceum}

Solanaceae

Argentina? (Jujuy?, Tucumán?), Bolivia?

The native range of the tamarillo tree is not resolved. It is often thought extinct. Putative wild populations are small, occurring in restricted areas in Argentina and Bolivia. It is widely cultivated in the Andes, Europe, Africa and New Zealand. Wild representatives are important for the genetic improvement and understanding of cultivated forms.

Assessor: World Conservation Monitoring Centre

Refs: 11906, 16093, 17611

\section{Solanum bullatum}

Solanaceae LR/cd

Brazil (Bahia, Minas Gerais, Paraná, Rio de Janeiro,

Santa Catarina, São Paulo)

A relatively widely ranging species of Atlantic coastal forest.

Assessor: Carvalho, L.d'A.F.

Refs: 19098, 19103

\section{Solanum cajanumense}

Solanaceae

LR/nt

Colombia, Ecuador, Peru

A small tree of Andean forest, occurring especially on the western slopes, between 1500 and $3000 \mathrm{~m}$, from Columbia to northem Peru. The habitat is seriously threatened by encroaching agriculture and fires. The 
fruits are sweet and edible and are now being cultivated in New Zealand as a possible commercial fruit crop. Assessor: World Conservation Monitoring Centre Refs: $7980,9880,11906,17611$

\section{Solanum cinnamomeum}

Solanaceae LR/cd

Brazil (Minas Gerais, Rio de Janeiro, Sāo Paulo)

The species appears to occur in isolated populations, including some in protected areas.

Assessor: Carvalho, L.d'A.F.

Refs: 19098,19103

\section{Solanum circinatum ssp. ramosa}

Solanaceae

VU B $1+2 c$

Colombia

Ranging relatively widely, the subspecies occurs in rainforest and cloud forest, in the valleys of Magdalena, Cauca and Patía Rivers. It is geographically isolated from the more widespread type species.

Assessor: Calderon, $\mathrm{E}$.

Refs: $7980,9880,11906,17611,19069$

\section{Solanum corymbiflora ssp. mortoniana}

Solanaceae

VU D2

Brazil (Paraná, Santa Catarina)

Two localities are known, one in Paraná, south-east of Curitiba, and one around Sāo Joaquim. It occurs within an area of $10,000 \mathrm{~km}^{2}$, in clearings, thickets and waste places in the dwarf montane forest.

Assessor: World Conservation Monitoring Centre

Refs: 9880, 11906, 17611

\section{Solanum diploconos}

Solanaceae

LR/nt

Brazil (Minas Gerais, Paraná, Rio de Janeiro, Rio Grande do Sul, Santa Catarina, São Paulo)

This species has long been known under the name Cyphomandra fragrans. It is found in clearings and forest edges in Atlantic coastal rainforest and Araucaria forest, both of which have suffered heavy declines over the past centuries. The fruit are edible and are being tried in New Zealand as a potential commercial crop. Assessor: World Conservation Monitoring Centre Refs: 9880, 11906, 17611

\section{Solanum diversifolium ssp. diversifolium}

Solanaceae

LR/nt

Venezuela

Distributed in a restricted area of coastal Venezuela, this small tree colonises disturbed areas and light gaps in cloud forest over $500 \mathrm{~m}$.

Assessor: World Conservation Monitoring Centre

Refs: 7980,9880, 17611

\section{Solanum drymophilum}

Solanaceae

Puerto Rico

A spiny shrub or tree up to $10 \mathrm{ft}$. It occurs in thickets at the edge of pastureland, where it is vulnerable to cutting, buming and development. A total of between 50 and 150 individuals are known from a single site. If allowed to, it has the potential to become a weed in disturbed areas. Assessor: World Conservation Monitoring Centre Refs: $7980,17124,17540$
Solanum exiguum

Solanaceae

VU Bl+2c

Bolivia

A diminutive tree or shrub restricted to the valleys of Río Beni and Rio Chapare, where it is uncommon. Assessor: World Conservation Monitoring Centre Refs: $7980,9880,11906,17611$

\section{Solanum fallax}

Solanaceae

Colombia, Ecuador

An unusual species restricted to ravines and forest pockets in Jauneche forest in western Ecuador. It endures a more severe dry season than other species in this section of the genus.

Assessor: World Conservation Monitoring Centre Refs: $7980,9880,17611$

\section{Solanum fortunense}

Solanaceae

VU D2

Costa Rica, Panama

Panama may contain the only extant populations of this rare species. The taxon is restricted to montane or cloud forest between 900 and $1800 \mathrm{~m}$. Further fieldwork may indicate that a more serious threat category is appropriate.

Assessor: World Conservation Monitoring Centre Refs: $7980,9880,11906,17611$

\section{Solanum granulosum-leprosum}

Solanaceae

Brazil (Minas Gerais, Rio de Janeiro, Sāo Paulo)

Assessor: Carvalho, L.d'A.F.

Refs: 19098,19103

\section{Solanum inaequale}

Solanaceae

Brazil (Mato Grosso do Sul, Minas Gerais, Paraná, Rio de Janeiro, Santa Catarina, Säo Paulo)

A widespread species of montane forest.

Assessor: Carvalho, L.d'A.F.

Refs: 7980, 19098, 19103

\section{Solanum latiflorum}

Solanaceae

Brazil (Minas Gerais, Rio de Janeiro, São Paulo)

Quite well collected and widespread, this small tree is confined to the remaining areas of Atlantic coastal rainforest in the south-east of Brazil. This habitat has suffered large-scale destruction over the past centuries. Assessor: World Conservation Monitoring Centre Refs: 9880,17611

\section{Solanum leucodendron}

Solanaceae

LR/cd

Brazil (Minas Gerais, Rio de Janeiro)

Assessor: Carvalho, L.d'A.F.

Refs: 19103

\section{Solanum melissarum}

Solanaceae

LR/nt

Brazil (Bahia, Espírito Santo, Minas Gerais, Paraiba, Paraná, Rio de Janeiro, Santa Catarina, Sāo Paulo) A relatively widespread species of primary or secondary forest, often in Araucaria groves, on the Allantic coast. Declines in this habitat have been dramatic. Assessor: World Conservation Monitoring Centre Refs: 9880,17611 
Solanum ovum-fringillace

Solanaceae

CR B1+2c

Brazil (Pemambuco)

A small shrub or herb which may be extinct in the wild.

Collections, the last of which was gathered in 1933, originate from coastal *restinga vegetation in Pemambuco and *caatinga of Bahia. This is the only species in this section of the genus to be found in * caatinga.

Assessor: Bohs, L.

Refs: $9880,11906,17611$

\section{Solanum paralum}

Solanaceae

EN A1c

Brazil (Bahia, Rio de Janeiro, São Paulo)

An unusual species which is morphologically specialised to survive in * restinga vegetation along seashores. It is known from four collections, none more recent than 1971, from isolated localities on the south-east coast, where the loss of this habitat continues to be dramatic. Assessor: World Conservation Monitoring Centre Refs: 9880,1761$]$

\section{Solanum pinetorum}

Solanaceae

LR/nt

Brazil (Minas Gerais, Paraná, Rio de Janeiro, Santa Catarina, Sāo Paulo)

The northem populations in Minas Gerais, Rio de Janeiro and São Paulo are separated from those in the south by $250 \mathrm{~km}$ (and by morphologically different leaves and corolla). The species occurs in secondary vegetation and disturbed areas in primary forest, coastal cloud forest and Araucaria forest. Destruction of these forests has been extensive.

Assessor: World Conservation Monitoring Céntre Refs: 9880,11906, 17611

\section{Solanum roseum}

Solanaceae

VU B1+2c

Bolivia

A cloud forest species which is restricted to a small area in the department of $\mathrm{La} \mathrm{Paz}$, although it may appear in southem Peru. Habitat degradation has been caused by the expansion of agriculture and fires. This is one of the closest relatives to the tamarillo tree.

Assessor: World Conservation Monitoring Centre

Refs: $7980,9880,11906,17611$

\section{Solanum sibundoyense}

Solanaceae

VU D2

Colombia

A small cloud forest tree endemic to Sibundoy and surrounding areas, where it occurs between 1400 and $2300 \mathrm{~m}$. It produces some of the largest fruit in this section of the genus (which also contains the tamarillo) and would be a good candidate for trial as a commercial fruit despite its restriction to such a specialised habitat type.

Assessor: World Conservation Monitoring Centre

Refs: $7980,9880,11906,17611$

\section{Solanum sycocarpum}

\section{Solanaceae}

EN Alc

Brazil (Bahia, Espírito Santo, Rio de Janeiro)

An unusual succulent species, which has become specialised and is restricted to * restinga vegetation on seashores. It ranges over about $1000 \mathrm{~km}$ of the southern
Brazilian coast, where this habitat is seriously threatened and continues to decline.

Assessor: World Conservation Monitoring Centre

Refs: $7980,9880,11906,17611$

\section{Solanum tobagense}

Solanaceae

LR/nt

Guyana, Trinidad and Tobago, Venezuela

In the Guyana Highlands the species exists in two populations on either side of the Orinoco Delta. Some differentiation has evidently arisen between the populations but both are restricted to primary forest over $400 \mathrm{~m}$ or cloud forest.

Assessor: World Conservation Monitoring Centre

Refs. 7980, 9880, 11906, 17611

\section{Sonneratia hainanensis}

Lythraceae

China (Guangdong - Hainan)

CR D1

Only five specimens are known to exist, confined to mangrove forest in Wenchang County, Hainan. The species is adapted to immersion in salty water and periodic drought. The seeds produced are minute and, although numerous, signs of regeneration are lacking. Assessor: World Conservation Monitoring Centre

Refs: $1818,11725,11847$

\section{Sophora fernandeziana}

Leguminosae

VU D2

Chile (Juan Fernández Is)

Preliminary data indicate the species is confined to less than $100 \mathrm{~km}^{2}$. More detailed information on the species should become available to confirm this evaluation. The islands are designated as a national park and biosphere reserve and work is being carried out by *CONAF to save the native plants.

Assessor: World Conservation Monitoring Centre

Refs: $3241,5651,7980,14140$

\section{Sophora mangarevaensis}

Leguminosae

$\mathrm{EN} \mathrm{B} 1+2 \mathrm{c}$

French Polynesia (Tuamotu Is.)

Endemic to Mangareva.

Assessor: Florence, J.

Refs: 14513

\section{Sophora masafuerana}

Leguminosae

VU D2

\section{Chile (Juan Fernández Is)}

Preliminary data indicate the species is confined to less than $100 \mathrm{~km}^{2}$. More detailed information on the species should become available to confirm this evaluation. The islands are designated as a national park and biosphere reserve and work is being carried out by *CONAF to save the native plants.

Assessor: World Conservation Monitoring Centre

Refs: $3241,5651,7980,14140$

\section{Sophora raivavaeensis}

Leguminosae

EN B $1+2 c$

French Polynesia (Tubuai Is.)

An endemic to Raivavae.

Assessor: Florence, J.

Refs: 14513 
Sophora rapaensis

Leguminosae

French Polynesia (Tubuai Is.)

DD

Assessor: Florence, J.

Refs: 14513

\section{Sophora saxicola}

Leguminosae

EN B $1+2 c$

Jamaica

A rare and localised species, occurring on limestone cliffs and ledges in Trelawny. A single tree is recorded on Mango Tree Hill, near Spring Garden, in low disturbed woodland.

Assessor: Kelly, D.L.

Refs: 5653, 19085

\section{Sophora toromiro \\ Leguminosae}

Chile (Easter Is)

A shrub or small tree. The last wild specimen was a plant in Rano Kao in 1935. A few plants still exist in cultivation in botanic gardens but attempts at reintroduction of the species on Easter Island have failed.

Assessor: World Conservation Monitoring Centre

Refs: $7599,7980,15251$

\section{Sophora wightii}

Leguminosae

India (Tamil Nadu)

$\mathrm{EN} \mathrm{B} 1+2 \mathrm{c}$

Known only from the type collection, the species is located in the north of the Nilgiris, occurring in montane forest between 1350 and $2000 \mathrm{~m}$.

Assessor: World Conservation Monitoring Centre

Refs: 19144

\section{Sorbus amabilis}

Rosaceae

VU B $1+2 c$

China (Anhui, Fujian, Zhejiang)

A species occurring in small localised colonies in the margins or gaps of montane forest on Huangshan and Qingliang Mountain in southern Anhui, Lin'an and Longquan Counties in Zhejiang and Chong'an County in Fujian. Some of these areas are designated nature reserves. The degree of protection given to populations is however, largely unknown and the habitat continues to be cleared in places.

Assessor: World Conservation Monitoring Centre

Refs: 1818,11847

\section{Sorbus anglica}

Rosaceae

Ireland, United Kingdom (Great Britain)

VU D1

A shrub or small tree occurring locally in small populations, usually on Carboniferous limestone, on the edges of woodland or in scrub in Devon, north Somerset, the Avon Gorge, Wye Valley, Shropshire, Brecon, Montgomery, Denbigh and Kerry. The total population numbers about 600 individuals, the largest subpopulation being on Eglwyseg Mountain in Denbigh. The species is well protected in a number of nature reserves and Sites of Special Scientific Interest. Subpopulations have been noted to show some variability despite the species being an apomict. It is the product of a cross between $S$. aucuparia and $S$. rupicola. Assessor: Wigginton, M.J.

Refs: 7222, 7801, 15608, 19148

\section{Sorbus arranensis}

Rosaceae

VU DI

United Kingdom (Great Britain)

Scattered trees are confined to small remnants of woodland, mostly on inaccessible steep slopes, on very acidic soils in northern Arran. About 500 plants remain in the two known sites, most of the population being in Glen Diomhan Nature Reserve. Regeneration is believed to be insufficient for recruitment and grazing deer and sheep contribute to this failing. The species is apomictic and a fully fertile hybrid of S. aucuparia and S. rupicola. Assessor: Wigginton, M.J.

Refs: $7222,7801,19148$

\section{Sorbus austriaca ssp. croatica}

Rosaceae

LR/cd

Croatia

A Croatian endemic, restricted to Velebit Mountain, found growing in montane and alpine open dry forest. It is a slow-growing, xerophytic, heliophytic tree. The species range is almost entirely within a nature reserve and is not considered to be of conservation concern.

Assessor: Nikolic, T.

Refs: $7222,15608,19070$

\section{Sorbus badensis}

Rosaceae

VU D2

Germany

Endemic to the states of Bayern and BadenWürttemberg in southern Germany, this small tree or shrub occurs in woodlands and scrub on upland slopes. It is an apomictic species of the $S$. latifolia complex, originating from a cross between $S$. graeca and $S$. torminalis.

Assessor: Schmidt, P.A.

Refs: $1719,7222,15608$

\section{Sorbus bristoliensis}

Rosaceae

United Kingdom (Great Britain)

EN D1

Endemic to the Avon Gorge, both the Somerset and Gloucestershire sides, the species occurs on Carboniferous limestone in woodland and scrub. A population of about 100 plants exists and is increasing in number. The species is apomictic and the product of hybridisation between $S$. rupicola and $S$. torminalis.

Assessor: Wigginton, M.J.

Refs: 7222, 7801, 19148

\section{Sorbus decipiens}

Rosaceae

CR B1+2e, D1

\section{Germany}

An apomictic species of the $S$. latifolia complex, arising from a cross between $S$. aria and $S$. tomminalis. It is confined to submontane open woodland on one limestone hill in Burgberg. Thuringia State. At the beginning of the 19th century about 100 individuals were counted, but now only 50 individuals remain within an area of less than $100 \mathrm{~km}^{2}$

Assessor: Schmidt, P.A.

Refs: 1719

\section{Sorbus eminens}

Rosaceae

VU DI

United Kingdom (Great Britain)

A woodland tree, occurring very locally on Carboniferous limestone in the Wye Valley, the Avon Gorge, other locations in Somerset, and also in Bangor in North Wales, a population which was formerly placed 
under S. porrigentiformis. About 250 trees exist in total, the majority of which are in the Avon Gorge, where they are under some degree of protection and constructive management. The species is apomictic. There appears to be significant variation between populations and further studies are required to elucidate their exact origins.

Assessor: Wigginton, M.J.

Refs: $7222,7801,19148$

\section{Sorbus franconica}

Rosaceae

VU D2

Germany

A small tree or shrub, occurring in beech forest, pine plantation on limestone and at forest edges in three small areas in the state of Bayem, northem Bavaria. The species, an apomictic member of the $S$. latifolia complex, is thought to have originated from a hybridisation event between $S$. pannonica or $S$. aria and S. torminalis.

Assessor: Schmidt, P.A.

Refs: $1719,7222,15608$

\section{Sorbus heilingensis}

Rosaceae

VU D2

Germany

Confined to the limestone area between the villages of Heilingen and Reinstädt in the state of Thuringia, this large tree has an extent of occurrence of less than $100 \mathrm{~km}^{2}$. It is an apomictic species of the $S$. latifolia complex, originating from a cross between $S$. aria and $S$. torminalis.

Assessor: Schmidt, P.A.

Refs: $1719,7222,15608$

\section{Sorbus lancastriensis}

Rosaceae

LR/nt

United Kingdom (Great Britain)

A small tree of open woodland or woodland edges, occurring on Carboniferous limestone in a number of sites within a $30 \mathrm{~km}$ radius of Morecambe Bay. Most sites are protected or inaccessible. The species is apomictic, originating from a cross between $S$. aria and S. rupicola.

Assessor: Wigginton, M.J.

Refs: 7222, 7801, 19148

\section{Sorbus leptophylla}

Rosaceae

CR D1

United Kingdom (Great Britain)

A sprawling tree known only from populations on shady crags of Carboniferous limestone at two sites in Breconshire, both of which are given some form of protection. The population is stable and inaccessible to grazing animals. The latest count uncovered 44 trees. A small population of very similar trees is found at Craig Breidden in Montgomery. Further studies are needed to consolidate whether it belongs to this species.

Assessor: Wigginton, M.J.

Refs: $7222,7801,19148$

\section{Sorbus leyana}

Rosaceae

CR D1

United Kingdom (Great Britain)

About 20 trees are known in total from two sites on Carboniferous limestone cliffs in southem Breconshire. Both locations are given limited protection as Sites of Special Scientific Interest and a small number of plants raised from seed have been incorporated into the population. Quarrying has destroyed some of the former sites. The species is an apomictic product of a cross between $S$. aucuparia and $S$. rupicola.

Assessor: Wigginton, M.J.

Refs: 7222, 7801, 19148

\section{Sorbus maderensis}

Rosaceae

Portugal (Madeira)

CR DI

Endemic to Madeira, the species is reduced to a single population of about $\mathbf{3 0}$ trees in a small area of montane woodland at $1500 \mathrm{~m}$. Recent grazing control has helped to improve the prospects of regeneration. There are still potential threats from buming and collectors.

Assessor: World Conservation Monitoring Centre

Refs: $16500,19080,19131$

\section{Sorbus multicrenata}

Rosaceae

Germany

EN D1

Restricted to a single locality on the southern slope of a hill in Greifenstein near Blakenburg in the state of Thuringia, this species occurs within an area of $100 \mathrm{~km}^{2}$. It belongs to the $S$. latifolia complex, originating from hybridisation between $S$ aria and $S$. corminalis.

Assessor: Schmidt, P.A.

Refs: $1719,7222,15608$

\section{Sorbus parumlobata}

Rosaceae

CR D1

Germany

This tree is restricted to the limestone slopes south of Amstadt in Thuringia. There are fewer than 50 individuals. It belongs to the $S$. latifolia complex, originating from a cross between $S$. aria and $S$. torminalis.

Assessor: Schmidt, P.A.

Refs: $1719,7222,15608$

\section{Sorbus pseudofennica}

Rosaceae

VU D2

United Kingdom (Great Britain)

A small tree known from Glen Diomhan in Arran, where it occurs in scrub on steep granite crags and in remnant woodland on a stream bank. The area is remote and designated as a nature reserve. Signs of regeneration are evident but they are exceeded in rate by the natural loss of old trees. Attempts at supplementing the existing population of about 500 individuals by planting young trees has met with limited success. The parent species are believed to be $S$. arranensis and S. aucuparia.

Assessor: Wigginton, M.J.

Refs: $1719,7222,7801,19148$

\section{Sorbus pseudothuringiaca}

Rosaceae

VU DI+2

Germany

A shrub to medium-sized tree, confined to an area of less than $200 \mathrm{~km}^{2}$ in the mountain range of Fränkische Alb in the state of Bavaria. It is an apomictic species of the $S$. hybrida complex, originating from a cross between $S$. aria and S. aucuparia.

Assessor: Schmidt, P.A.

Refs: $1719,7222,15608$

\section{Sorbus subcordata}

Rosaceae

VU D1

Germany

Endemic to the state of Thuringia, this apomict is found

in a population of about 1000 individuals, on the 
limestone slopes south of Amstadt. It belongs to the $S$. latifolia complex, originating from a cross between $S$. aria and $S$. tominalis.

Assessor: Schmidt, P.A.

Refs: $1719,7222,15608$

\section{Sorbus subcuneata}

Rosaceae

United Kingdom (Great Britain)

VU D1

Occurring in oak woodlands, this apomictic species is confined to a small area along the Devon and Somerset coasts. Most of the small populations are stable, with the one noted exception being the potentially threatened population above High Town in Minehead.

Assessor: Wigginton, M.J.

Refs: $7222,7801,19148$

\section{Sorbus velebitica}

Rosaceae

Croatia

Taxonomically and nomenclaturally doubtful, the species is in need of further investigation.

Assessor: Nikolic, T.

Refs: $7222,15608,19070$

\section{Sorbus vexans}

Rosaceae

VUD1+2

United Kingdom (Great Britain)

A small tree, often multi-stemmed from the base. Populations occur in a small corridor of coast between Culbone in Somerset and an area just west of Trentishoe in Devon, where the species grows mainly in oak woodlands. There are no obvious threats to the populations, although inappropriate woodland management and the spread of Rhododendron are potential hazards. The species is apomictic.

Assessor: Wigginton, M.J.

Refs: $7222,7801,19148$

\section{Sorbus wilmottiana}

Rosaceae

CR D1

United Kingdom (Great Britain)

Known from both sides of the Avon Gorge in Somerset and Gloucestershire, the species is one of the rarest Sorbus species in the UK. As few as 20 trees may remain in woodland margins and on cliff edges with other rare Sorbus species. The area is managed so as to conserve the rare plants. However, there have been recent reports of the illegal collection and cutting down of trees.

Assessor: Wigginton, M.J.

Refs: 7222, 7801, 19148

\section{Sorindeia calantha}

Anacardiaceae

CR B $1+2 \mathrm{~d}$

Tanzania

Known only from a few collections, this species is confined to upper moist evergreen forest in the South Nguru Mountains.

Assessor: Lovett, J. \& G.P. Clarke

Refs: 3356, 10961

\section{Sorindeia mildbraedii}

Anacardiaceae

VU B $1+2 c$

Cameroon, Nigeria

This small forest tree is confined to an area extending from south-east Nigeria to Cameroon, including Oban Hills in Cross River National Park, where the population is relatively well protected. Unprotected forest has been extensively logged and cleared for cultivation. Assessor: World Conservation Monitoring Centre Refs: 4977, 11504

\section{Sorocea guilleminiana \\ Moraceae}

VU Alc

Brazil

An Atlantic forest species widely occurring in north, north-east and south-east Brazil. Populations have declined because of habitat loss and degradation and poor regeneration.

Assessor: Carauta, J.P.P.

Refs: 15717,19101

\section{Soulamea terminalioides}

Simaroubaceae

VU D2

Seychelles

Endemic to the Seychelles, the species qualifies as threatened by virtue of its restricted distribution. Populations are healthy and stable.

Assessor: World Conservation Monitoring Centre

Refs: 9859,17229

\section{Soyauxia talbotii}

Medusandraceae

$\mathrm{EN} \mathrm{B} 1+2 \mathrm{c}$

Nigeria

A small tree which is recorded only in south-east Nigeria. Unprotected forest has been extensively logged and cleared for cultivation. The family is endemic to West Africa.

Assessor: World Conservation Monitoring Centre

Refs: 2773, 11504

\section{Spachea correae}

Malpighiaceae

Costa Rica, Panama

VU Cl

A scarce rainforest species, which in Panama is known from only a few localities on the Atlantic slopes in the provinces of Colon and Bocas del Toro. The species is in danger of being lost from the Colon localities because the forest has rapidly disappeared in recent years. There is thought to be an occurrence in La Amistad National Park between Panama and Costa Rica and the species extends north on both Atlantic and Pacific sides up to the border with Nicaragua. Populations appear to be larger in protected areas, most notably in Corcovado National Park

Assessor: Mitré, M.

Refs: 7980, 15037, 16772

\section{Spathacanthus hahnianus}

Acanthaceae

LR/cd

Costa Rica, Guatemala, Honduras, Mexico, Nicaragua A species of moist seasonal montane forest or cloud forest. Although it is scarce, it is relatively wide-ranging and the habitat is well represented in protected areas. Assessor: Ramirez-Marcial, N. \& M. González-Espinosa Refs: 19161

\section{Spathandra barteri}

Melastomataceae

VU Alc, B1+2c

Ghana

A species which is rare and confined to small areas of swamp or riverine areas within evergreen forest. These areas have suffered losses from mining, logging and commercial forestry activities.

Assessor: Hawthorne, W.

Refs: 8369,12061 
Spathelia coccinea

Rutaceae

CR B $1+2 \mathrm{c}$

Jamaica

The species has been recorded only from two localities on limestone hills within five miles of Troy and on Donkey Trail Hill. The areas are susceptible to cutting and encroaching agriculture.

Assessor: World Conservation Monitoring Centre

Refs: 401, 5653, 7980

\section{Spathelia glabrescens}

Rutaceae

LR/nt

Jamaica

A gregarious species found in hilly areas in the central parishes. A distinct but similar species appears to have been found in Trelawny.

Assessor: World Conservation Monitoring Centre

Refs: 6057,7980

\section{Spiraeanthemum graeffei}

Cunoniaceae

EN D1

Fiji

A tree or shrub of dense forest and forest edges, occurring between 275 and $1050 \mathrm{~m}$. The species is known with certainty only from a few populations of about 20-30 plants in Viti Levu, although it has been erroneously recorded elsewhere. There are recorded occurrences in Nadarivatu and Tomanivi Nature Reserve.

Assessor: World Conservation Monitoring Centre

Refs: $5515,6053,18818$

\section{Spiraeanthemum serratum}

\section{Cunoniaceae}

EN D1

Fiji

A small tree or shrub of dense thickets on crests and ridges, occurring between 1100 and $1323 \mathrm{~m}$. Populations are few and small, containing about 20-30 plants, confined to Viti Levu and Taveuni.

Assessor: World Conservation Monitoring Centre

Refs: $5515,6053,18818$

\section{Spirotecoma apiculata}

\section{Bignoniaceae}

VU B $1+2 \mathrm{C}$

Cuba

Widespread in the Sagua-Baracoa serpentine mountain ranges of north-east Cuba, this small tree is typical of the pine forest belt between 600 and $900 \mathrm{~m}$ and is also found in the lowland serpentine shrublands in the subcoastal zone north of the Moa Mountains. The species is not yet uncommon but has suffered from overcutting and habitat loss.

Assessor: Areces-Mallea, A.E.

Refs: 7980,19149

\section{Spirotecoma holguinensis}

\section{Bignoniaceae}

Cuba

$\mathrm{EN} \mathrm{B} 1+2 \mathrm{c}$

A small tree up to $8 \mathrm{~m}$ tall, confined to dry scrub and scrub-woodland communities in the serpentine areas of north-east Holguín. Overcutting, overgrazing and urban expansion have confined the population to small areas. Assessor: Areces-Mallea, A.E.

Refs: 7980, 19149
Stadmannia oppositifolia ssp. rhodesiaca

Sapindaceae

$\mathrm{LR} / \mathrm{nt}$

Mozambique, South Africa (Northem Province), Zimbabwe

Nowhere common, this subspecies is found relatively widely on hills in the Zimbabwe savanna, in adjacent parts of Mozambique, Canicadoa and Rio dos Elefantes, and into Northem Province, South Africa. All the South African records are from Kruger National Park. Records from KwaZulu-Natal need confirmation.

Assessor: World Conservation Monitoring Centre Refs: $689,2044,5108,7401,19218$

\section{Stahlia monosperma}

Leguminosae

$\mathrm{EN} \mathrm{BI+2c,C2a,Dl}$

Dominican Republic, Puerto Rico, Virgin Islands (US)

Occurring at the margins of mangroves and in coastal forest, the species is extremely rare throughout its range. In Puerto Rico fewer than 20 trees are thought to exist in Boqueron and Sabana Graride. The wood is used in furniture-making.

Assessor: World Conservation Monitoring Centre

Refs: $7980,17124,17540$

\section{Staudtia pterocarpa}

Myristicaceae

São Tomé \& Príncipe (Sāo Tomé)

VU D2

A timber species once of lowland forest. Individuals are now found in areas which have been settled and cultivated, as most of the original forest below $1500 \mathrm{~m}$ was cleared in the first half of the century.

Assessor: World Conservation Monitoring Centre Refs: 2724,10080

\section{Steganotaenia commiphoroides}

Umbelliferae

$\mathrm{LR} / \mathrm{nt}$

Ethiopia, Somalia

One collection has been made in Ethiopia but otherwise the species is endemic to southern Somalia. The habitat is vulnerable to degradation caused by overcutting for charcoal production and expanding agricultural activities.

Assessor: Thulin, $\mathbf{M}$

Refs: 8697,18665

\section{Stemmadenia pauli}

Apocynaceae

VU BI+2c

Costa Rica

An understorey shrub or small tree restricted to forest in Puntarenas Province.

Assessor: World Conservation Monitoring Centre

Refs: 15491

\section{Stemonoporus acuminatus}

Dipterocarpaceae

EN Alc

Sri Lanka

A tree found only in small patches of remaining wet evergreen forest above $600 \mathrm{~m}$. This species was found in 13 of the sites surveys for the National Conservation Review.

Assessor: Ashton, P.

Refs: $13857,15431,17195,19112$

\section{Stemonoporus affinis}

Dipterocarpaceae

Sri Lanka

Endemic to Hunasgiriya, this small semi-gregarious tree is confined to the lower canopy of remaining patches of 
highland wet evergreen forest. This species was not found during the extensive National Conservation Review forest surveys, indicating that it is extremely rare or possibly extinct.

Assessor: Ashton, P.

Refs: $13857,15431,18796,19112$

\section{Stemonoporus angustisepalus}

Dipterocarpaceae

EN Alc

Sri Lanka

A tree restricted to lower montane forest. During the comprehensive National Conservation Review forest surveys, this species was found in only three localities in Kegalle and Ratnapura.

Assessor: Ashton, P.

Refs: 13857,19112

\section{Stemonoporus bullatus}

Dipterocarpaceae

EN Alc

Sri Lanka

This dipterocarp was known from wet evergreen forest in Kanneliya and Hinidumkande, however it was not found during the extensive National Conservation Review forest surveys, indicating that it is extremely rare or possibly extinct. Its taxonomic characteristics are doubtfully distinct from $S$. canaliculatus.

Assessor: Ashton, $\mathrm{P}$.

Refs: 13857,19112

\section{Stemonoporus canaliculatus}

Dipterocarpaceae

CR Alc

Sri Lanka

An understorey tree with a clumped distribution in remaining lowland wet evergreen forest in south-west Sri Lanka. This species was found in 11 forest sites during the extensive National Conservation Review forest surveys.

Assessor: Ashton, $\mathrm{P}$.

Refs: $13857,15431,17195,19112$

\section{Stemonoporus cordifolius}

Dipterocarpaceae

Sri Lanka

EN Alc

Localised on the southern slopes of Adam's Peak in Ratnapura District, this gregarious understorey tree occurs in highland wet evergreen forest. It was found in three sites surveyed by the National Conservation Review.

Assessor: Ashton, $\mathrm{P}$.

Refs: 13857, 15431, 19112

\section{Stemonoporus elegans}

Dipterocarpaceae

Sri Lanka

CR Alc

A species restricted to the southern slopes of Adam's Peak at around $1000 \mathrm{~m}$. This species was found in three of the sites surveyed for the National Conservation Review.

Assessor: Ashton, $\mathrm{P}$

Refs: 13857, 15431, 17759, 19112

\section{Stemonoporus gardneri}

Dipterocarpaceae

Sri Lanka

EN Alc

A small tree which dominates highland wet evergreen forest at higher altitudes, sometimes extending into montane forest on the south and east slopes of Adam's Peak and higher elevations of forest in Sinharaja. The species was found in only three of the sites surveyed for the National Conservation Review.

Assessor: Ashton, P.

Refs: $13857,15431,19112$

Stemonoporus gilimalensis

Dipterocarpaceae

CR Alc, C2a

Sri Lanka

A small tree known only from Gilimale forest in Ratnapura District. It was not found during the extensive forest surveys conducted between 1991 and 1996 for the National Conservation Review, suggesting that it is either extremely rare or possibly extinct.

Assessor: Ashton, P.

Refs: 13857,19112

\section{Stemonoporus gracilis}

Dipterocarpaceae

CR Alc, D1

Sri Lanka

This species is known only from an area of river bank on a tributary of the Kelani River. It was not found during the extensive forest surveys conducted between 1991 and 1996 for the National Conservation Review, suggesting that the species is either extremely rare or possibly extinct.

Assessor: Ashton, P.

Refs: 13857,19112

\section{Stemonoporus kanneliyensis}

Dipterocarpaceae

EN Alc, C2a

Sri Lanka

This species was found only once in Haycock Biosphere Reserve during the extensive forest surveys conducted between 1991 and 1996 for the National Conservation Review, suggesting that the species is either extremely rare or possibly extinct. The taxon is doubtfully distinct from $S$. reticulatus.

Assessor: Ashton, $\mathrm{P}$.

Refs: 13857,19112

\section{Stemonoporus laevifolius}

Dipterocarpaceae

EN Alc, B1+2c

Sri Lanka

This small tree was not found during the extensive forest surveys conducted between 1991 and 1996 for the National Conservation Review, suggesting that it is either extremely rare or possibly extinct.

Assessor: Ashton, $\mathbf{P}$.

Refs: 13857,19112

\section{Stemonoporus lanceolatus}

Dipterocarpaceae

CR Alc, D1

\section{Sri Lanka}

Confined to remaining patches of lowland wet evergreen forest, the species occurs in small clumps on steep rocky hillsides. It was found only once in Ratnapura District during the extensive forest surveys conducted between 1991 and 1996 for the National Conservation Review. Assessor: Ashton, P.

Refs:13857, 15431, 18796, 19112

\section{Stemonoporus lancifolius}

Dipterocarpaceae

CR A1c, D1

Sri Lanka

A very small tree which is found in a few hillside and river bank localities of lowland wet evergreen forest. It was found only once in Ratnapura District during the 
extensive forest surveys conducted between 1991 and 1996 for the National Conservation Review.

Assessor: Ashton, P.

Refs: 13857, 15431, 19112

\section{Stemonoporus latisepalus}

Dipterocarpaceae

CR B I+2c, D1

Sri Lanka

A single tree was found in Ratnapura District during the extensive forest surveys conducted between 1991 and 1996 for the National Conservation Review.

Assessor: Ashton, $\mathrm{P}$.

Refs: 13857,19112

\section{Stemonoporus marginalis}

Dipterocarpaceae

$\mathrm{CR} \mathrm{B} 1+2 \mathrm{c}, \mathrm{D} 1$

Sri Lanka

A spindly tree, known only from the type locality. This species did not tum up during the extensive National Conservation Review forest surveys, indicating that it is either extremely rare or possibly extinct

Assessor: Ashton, $\mathrm{P}$.

Refs: 13857,19112

\section{Stemonoporus moonü}

Dipterocarpaceae

CR C2a, D1

Sri Lanka

Confined to the Kalutara District, this small shrub is found in the understorey of swamp forests and in marshy, periodically inundated areas near slow-running streamlets. Most swamp forests have been converted to rice fields. It was found only once during the extensive forest surveys conducted between 1991 and 1996 for the National Conservation Review.

Assessor: Ashton, P.

Refs: 9169, 13857, 15431, 17759, 19104, 19112

\section{Stemonoporus nitidus}

Dipterocarpaceae

CR Alc, D1

Sri Lanka

This tree, known from a single collection, is limited to a few patches of lowland wet evergreen forest on ridges. It was not found during the extensive National Conservation Review forest surveys, indicating that it is either extremely rare or possibly extinct.

Assessor: Ashton, $\mathrm{P}$.

Refs: 13857, 15431, 18796, 19112

\section{Stemonoporus oblongifolius}

Dipterocarpaceae

EN Alc

Sri Lanka

This small tree is sparsely distributed in remaining patches of highland wet evergreen forest. It was found in only two sites during the extensive forest surveys conducted for the National Conservation Review.

Assessor: Ashton, P.

Refs: 13857, 15431, 18796, 19112

\section{Stemonoporus petiolaris}

Dipterocarpaceae

$\mathrm{CR} \mathrm{Al} \mathrm{c}+2 \mathrm{c}, \mathrm{C} 2 \mathrm{a}$

Sri Lanka

A small tree endemic to Kitulgala and Gilimale, where it grows on well-drained deep soil in lowland wet evergreen forest. It was not found during the extensive National Conservation Review forest surveys, indicating that it is either extremely rare or possibly extinct.

Assessor: Ashton, P.

Refs: $13857,15431,18796,19112$
Stemonoporus reticulatus

Dipterocarpaceae

EN Alc

Sri Lanka

A small tree confined to ridge crests in the remaining lowland wet evergreen forests of south-west Sri Lanka. It was found in only two forests during the extensive forest surveys conducted for the National Conservation Review.

Assessor: Ashton, P.

Refs: 13857, 15431, 17195, 19112

\section{Stemonoporus revolutus}

Dipterocarpaceae

EN Alc

Sri Lanka

A small tree of highland wet evergreen forest, known from one ridge overlooking the Sinharaja forest. It was found only once during the extensive forest surveys conducted for the National Conservation Review.

Assessor: Ashton, $\mathrm{P}$.

Refs: $13857,15431,19112$

\section{Stemonoporus rigidus}

Dipterocarpaceae

EN Alc

\section{Sri Lanka}

Found only in the Ambaganuwa region, this small tree had been collected only twice, in 1852 and 1860 , but in 1981 a population of several hundred trees was discovered on the southem forested slopes of Peak Wilderness between 1600 and $1800 \mathrm{~m}$. However, it was not found during the extensive National Conservation Review forest surveys, indicating that it is either extremely rare or possibly extinct.

Assessor: Ashton, P.

Refs: $13857,15431,18796,19112$

\section{Stemonoporus scaphifolius}

Dipterocarpaceae

EN Alc

Sri Lanka

This small tree is known only from the type collection. It did not tum up during the extensive National Conservation Review forest surveys, indicating that it is either extremely rare or possibly extinct.

Assessor: Ashton, $\mathrm{P}$.

Refs: 13857,19112

\section{Stenanona panamensis}

Annonaceae

EN C2a

Costa Rica, Panama

Small populations exist in the Bocas del Toro in Panama, and in Sixaola in Costa Rica. They occur in primary forest, principally along streams, covering a combined area of approximately $10,000 \mathrm{~km}^{2}$. The locations are affected by increasing habitat clearance and logging. It is possible that further populations remain to be found.

Assessor: Mitré, M.

Refs: $7272,7980,16772$

\section{Stenocarpus dumbeensis}

Proteaceae

New Caledonia

This species has been collected five times in the region of Nouméa above Koé. Despite this being the botanically best known area of Grand Terre, the species has not been found since 1905 .

Assessor: Jaffré, T. et al.

Refs: $4492,10351,12630$ 


\section{Stenocarpus heterophyllus}

Proteaceae

$\mathrm{EN} \mathrm{B1+2c}$

New Caledonia

Occurring in maquis, open forest and riverine vegetation, the species is confined to a few localities in the south-west.

Assessor: Jaffre, T, et al.

Refs: 10351,12630

\section{Stenocarpus villosus}

Proteaceae

CR D1

New Caledonia

A species restricted to the east coast, where it has been recorded on ultramafic substrate towards Balade and Canala. The last collection was gathered in 1860 and the species has not been found since. It is questionable whether it should not now be considered extinct.

Assessor: Jaffré, T, et al.

Refs: 4492, 10351, 12630

\section{Stephanopodium magnifolium}

Dichapetalaceae

VU D2

Brazil (Bahia)

A distinctive small tree known from one location in the Uruçua municipality of Bahia.

Assessor: World Conservation Monitoring Centre

Refs: 13112

\section{Stephanostegia capuronii}

Apocynaceae

LR/nt

Madagascar

Confined to the east coast, the species occurs in three disjunct areas between Antalaha and Ambila. It is found in sublittoral rainforest. The wood is useful and the species is a focus for silvicultural studies.

Assessor: World Conservation Monitoring Centre Refs: 6161

\section{Sterculia africana var. socotrana}

Sterculiaceae

VU A2d, D2

Yemen (Socotra)

A variety which is endemic to Socotra. It occurs in dry low-altitude woodland. The tree is important for its use as animal fodder and also potentially as a source of timber. Rapid development on the island may result in extensive cutting of trees for construction work.

Assessor: Miller, A.G.

Refs: 2354,19083

\section{Sterculia alexandri}

Sterculiaceae

VU C2a, D2

South Africa (Eastem Cape)

A small tree found on forest margins, in scrub, and on open slopes of valleys and ravines, sometimes near stream banks, in only a few localities: Winterhoek Mountains near Uitenhage, Van Staaden's Mountains near Port Elizabeth and near Kouga Dam at the start of the Baviaanskloof. It possibly occurs elsewhere in the remote Kouga Mountains and Baviaanskloof. All the subpopulations appear to be very small, with the one in Van Staaden's Wildflower Reserve possibly being the largest and best known. Another subpopulation in the Van Staaden's Valley was probably destroyed many years ago when a national road was built. There is a threat of habitat destruction through increasing settlement, industrial developments and frequent fires. Recruitment appears to be low, although plants coppice readily if damaged. $A$ few plants are protected in the Groendal Wilderness Area. The Van Staaden's Wildflower Reserve is not particularly well-managed at present.

Assessor: Hilton-Taylor, C. et al.

Refs: 689,19218

\section{Sterculia cinerea}

Sterculiaceae

LR/nt

Eritrea, Ethiopia, Sudan

The species apparently occurs disjunctly, with populations in lowland wooded grasslands in eastem Eritrea and in Illubabor in the west of Ethiopia. It is also reported in Sudan.

Assessor: World Conservation Monitoring Centre Refs: 5941

\section{Sterculia khasiana}

Sterculiaceae

India (Meghalaya)

An endemic tree of the Khasi Hills in Meghalaya, where it occured in subtropical forest between 1000 and $1500 \mathrm{~m}$. There have been significant declines in the extent of the habitat, largely caused by extensive agriculture and fires. The species has not been collected since 1877 and is presumed extinct.

Assessor: World Conservation Monitoring Centre Refs: 2538

\section{Sterculia schliebenii}

Sterculiaceae

VU D2

Kenya, Mozambique, Tanzania

Restricted to coastal forest, this species is known from only a few locations. In Kenya it occurs in the region of the Shimba Hills, and in Tanzania, Chitoa Forest Reserve $\left(8 \mathrm{~km}^{2}\right)$ is one of the two reserves which harbour a population. The extent of occurrence in Mozambique is little known.

Assessor: Lovett, J. \& G.P. Clarke

Refs: 6396, 16796

\section{Steriphoma macranthum}

Capparaceae

Colombia, Panama

A poorly known plant, which has been collected just twice. The type specimen was found in Pinogana District in Darién. The area, until now, has been difficult to access and is little studied. A second specimen came from Antioquia in Colombia in 1945.

Assessor: Mitré, M.

Refs: $7272,7980,16772$

\section{Storckiella vitiensis}

Leguminosae

VU D2

Fiji

Occurring on four of the high islands, the species is found in dense forest along creeks, rivers and their tributaries. It has not been collected frequently. Assessor: World Conservation Monitoring Centre Refs: 18818

\section{Streblorrhiza speciosa}

Leguminosae

Norfolk Island

Assessor: World Conservation Monitoring Centre

Refs: $3484,11400,13880$ 
Streblus sclerophyllus

Moraceae

VU $B 1+2 c$

New Caledonia

Assessor: Jaffré, T. et al.

Refs: 10351

\section{Strempeliopsis arborea}

Apocynaceae

VU B $1+2 \mathrm{c}$

Jamaica

A Cockpit Country endemic found in areas of woodland on craggy limestone.

Assessor: World Conservation Monitoring Centre

Refs: $401,5653,7980$

\section{Strychnos benthamii}

Loganiaceae

VU B $1+2 c$

Sri Lanka

This species has been found in only six forest sites during the extensive forest surveys conducted for the National Conservation Review.

Assessor: World Conservation Monitoring Centre

Refs: 19112

\section{Strychnos chromatoxylon}

Loganiaceae

Cameroon, Central African Republic, Côte d'Ivoire

This species is severely restricted in the Upper Guinea part of its range, where it was found once in riverine forest in Bafing, between Biankouma and Touba in Côte d'Ivoire. In Cameroon and the Central African Republic its status is not yet known.

Assessor: World Conservation Monitoring Centre

Refs: 12590,12822

\section{Strychnos mellodora}

Loganiaceae

VU $\mathrm{Bl}+2 \mathrm{bc}$

Kenya, Mozambique, Tanzania, Zimbabwe

Although the species ranges from Kenya to Zimbabwe, it exists in small and restricted pockets of moist forest, which have declined in extent over the past few decades. It has been found only once in the Shimba Hills in Kenya. In Tanzania it occurs in the East Usambara Mountains, the North Udzungwa Mountains, where it is very scarce, and the Ngurdota Crater on Mount Meru. The species is confined to Chirinda forest in Zimbabwe, where there is a well-protected healthy population. It has also been recorded from Garuso forest in central Mozambique.

Assessor: Lovett, J. \& G.P. Clarke

Refs: $3356,6396,6725,8814,16232$

\section{Strychnos millepunctata}

Loganiaceae

VU B1 $+2 \mathrm{c}$

Côte d'Ivoire

Represented by few known collections, this endemic of Côte d'Ivoire is scattered throughout the country in primary forest. Extensive logging has severely reduced the extent of forest in the country in the last three decades.

Assessor: Assi, A.

Refs: 12822

\section{Strychnos tetragona}

Loganiaceae

$\mathrm{CR} B 1+2 \mathrm{c}$

Sri Lanka

A tree confined to areas of lowland wet evergreen forest in south-west Sri Lanka. Only a single individual was found in Knuckles State Forest during the extensive forest surveys conducted for the National Conservation
Review between 1991 and 1996. Previous surveys recorded populations in Sinharaja Biosphere Reserve and Gilimale Forest Reserve.

Assessor: World Conservation Monitoring Centre

Refs: 9176, 17195, 19112

\section{Stuhlmannia moavi}

Leguminosae

Kenya, Madagascar, Tanzania

The accepted name for Caesalpinia insoliza, this taxon is recognised as a new genus. It is known from a few coastal forest fragments at Mwena River in Kenya and in several sites on the coastal plain between Pangani and Miligaji Rivers in Tanzania, including the relatively undisturbed Gendagenda Forest Reserve and a cattle ranch which may be added to the Sadaani Game Reserve. It is also reported from Madagascar.

Assessor: Lovett, J. \& G.P. Clarke

Refs: 1308, 4506, 6396, 12067, 16796

\section{Stylogyne darienensis}

Myrsinaceae

DD

Panama

Collected only once, the species is restricted to a region which has been poorly explored until now. Stylogyne is known from several collections in Darién, identified as other species.

Assessor: Mitré, M.

Refs: 16772

\section{Styrax argyrophyllus}

Styracaceae

VU D2

Peru

This species appears to be confined to the department of Cajamarca in the Andes, where it is known only from the type locality in submontane shrubland.

Assessor: World Conservation Monitoring Centre Refs: 1984

\section{Styrax crotonoides}

Styracaceae VU Bl+2c

Malaysia (Peninsular Malaysia), Singapore

This species inhabits both closed and open lowland rainforest and swamp or disturbed forests. Many such forests in the state of Johore have undergone conversion, particularly for housing developments.

Assessor: Chua, L.S.L.

Refs: 9199, 17140, 19073

\section{Styrax ferax}

Styracaceae

VU D2

Peru

So far known only from the type locality, the species occurs in lowland forest in the department of Junin. Assessor: World Conservation Monitoring Centre Refs: 1984

\section{Styrax foveolaria}

Styracaceae

VU D2

Peru

This species is known only from the type collection from the department of Huánuco.

Assessor: World Conservation Monitoring Centre Refs: 1984 


\section{Styrax fraserensis}

Styracaceae

VU D2

Malaysia (Peninsular Malaysia)

A rare species occurring at $1300 \mathrm{~m}$ on Frasers Hill, Pahang. The prime threat to this species is tourism.

Assessor: Chua, L.S.L.

Refs: 8464, 19073

\section{Styrax litseoides}

Styracaceae

VU D2

Viet Nam

A species apparently endemic to Viet Nam, where it is known only from Phu Loc in Lang Co in the centre of the country.

Assessor: World Conservation Monitoring Centre Refs: 848

\section{Styrax mathewsii}

Styracaceae

VU D2

Peru

Recorded only from the type collection, the species occurs in submontane forest in the department of Amazonas.

Assessor: World Conservation Monitoring Centre

Refs: 1984

\section{Styrax peruvianum}

Styracaceae

VU D2

Peru

This Andean species appears to be confined to Cajamarca, where it has been recorded only from the type collection taken from submontane shrubland.

Assessor: World Conservation Monitoring Centre

Refs: 1984

\section{Styrax portoricensis}

Styracaceae

CR D1

Puerto Rico

A total of four individuals are known from a single site of upper montane wet forest in the Caribbean National Forest.

Assessor: World Conservation Monitoring Centre

Refs: $7980,17124,17540$

\section{Styrax socialis}

Styracaceae

VU D2

Peru

A shrubland species, known only from the type collection in scrub occurring below $1500 \mathrm{~m}$ in Cuzco Department.

Assessor: World Conservation Monitoring Centre

Refs: 1984

\section{Styrax tafelbergensis}

Styracaceae

VU D2

Suriname

A rare endemic, known only from Tafelberg, where it is found in creek forest near the Table Mountain

Assessor: World Conservation Monitoring Centre

Refs: 6493,19196

\section{Suregada lithoxyla}

Euphorbiaceae

VU B $1+2 b$

Tanzania

Restricted to patches of moist evergreen forest in eastem Tanzania, this tree is known from Kimboza Forest Reserve, the East Usambara Mountains and possibly also the North Udzungwa Mountains. All these localities are in densely populated areas but are relatively well protected by guards or active conservation programmes. Assessor: Lovett, J. \& G.P. Clarke

Refs: 3356,8814

\section{Swartzia fistuloides}

Leguminosae

EN Alcd

Angola (Cabinda), Cameroon, Congo, Côte dTvoire, Democratic Republic of Congo, Equatorial Guinea, Gabon, Ghana, Nigeria

Although widespread in closed forests in West and Central Africa, the species is not common. It is exploited at a moderate level as a decorative timber. There is also evidence that regeneration may be hampered in places by the absence of its seed disperser, the elephant.

Assessor: African Regional Workshop

Refs: $2773,6128,6718,8369,17408$

\section{Swartzia macrophylla}

Leguminosae

EX

Colombia

Believed to be extinct, the species was recorded from an unspecified locality, probably in Antioquia.

Assessor: Calderon, $\mathrm{E}$.

Refs: $7980,8869,17690,19069$

\section{Swartzia nuda \\ Leguminosae}

Panama

$\mathrm{EN} \mathrm{B1}+2 \mathrm{c}$

A species which is known only from two localities, Isla Colon and Valle del Agua, in Bocas del Toro, where it occurs, fairly commonly, in lowland evergreen to semievergreen rainforest. There are some threats from logging and encroaching settlements and agriculture. Assessor: Mitré, $\mathbf{M}$.

Refs: $7980,16772,17690$

\section{Swartzia oraria}

Leguminosae

CR B $1+2 c$

Colombia

An endemic to Valle.

Assessor: Calderon, E

Refs: 7980,19069

\section{Swartria redivivo \\ Leguminosae}

VU D2

Suriname

An endemic species known only from the type locality along the Left Coppename River.

Assessor: World Conservation Monitoring Centre Refs: 19196

\section{Swartzia robiniifolia}

Leguminosae

$\mathrm{EN} \mathrm{B1}+2 \mathrm{c}$

Colombia

Endemic to Colombia, the species is recorded from Cauca, Santander and Tolima.

Assessor: Calderon, E.

Refs: 19069

\section{Swartzia santanderensis}

Leguminosae

$\mathrm{VU} \mathrm{B} 1+2 \mathrm{c}$

Colombia

An endemic of Santander.

Assessor: Calderon, E.

Refs: 7980,19069 


\section{Swida darvasica}

\section{Comaceae}

CR D1

Former USSR, Tajikistan

A shrub reaching up to $4 \mathrm{~m}$ or more in height, restricted to a single location in Darvaz, Tajikistan, consisting of only a few plants. It can be easily cultivated and has potential as an omamental.

Assessor: Firsov, G.A.

Refs: 4196, 19056

\section{Swietenia humilis}

Meliaceae

VU Alcd

Belize, Costa Rica, El Salvador, Guatemala, Honduras, Mexico, Nicaragua, Panama

A species of dry deciduous forest, savanna, rough scrub, rocky hillsides and cultivated fields. Trees are usually seen as scattered and isolated individuals, preserved in cultivated land and pastures. Large specimens are rare. The timber is used in local carpentry, but is of little commercial importance. The species is listed in Appendix II of *CITES.

Assessor: World Conservation Monitoring Centre Refs: 4974, 7980, 12281

\section{Swietenia macrophylla}

Meliaceae

VU Alcd +2cd

Belize, Bolivia, Brazil (Acre, Amazonas, Goiás, Maranháo, Mato Grosso, Pará, Rondônia, Tocantins), Colombia, Costa Rica, Dominica, Ecuador, El Salvador, French Guiana, Guatemala, Guyana, Honduras, Mexico (Quintana Roo), Nicaragua, Panama, Peru, Venezuela

A very large timber tree which has an extensive natural distribution in various forest types. This species is the most commercially important of the mahoganies. The level of exploitation has led to the exhaustion of supplies particularly in the northem parts of its range. The ecology of northern populations is relatively well understood whereas virtually nothing is known about Amazonian populations. Basic inventories are lacking for most of its range. Good stands apparently still remain in parts of Brazil and Bolivia. Regeneration of the species is stochastic, depending in nature on large-scale disturbance. This ecological strategy makes mahogany vulnerable to logging regimes. Harvesting and processing are generally only 50 percent efficient. There is, at present, little economic incentive to manage natural stands sustainably. Intemational trade in timber of the species is subject to the provisions of Appendix III of * CITES.

Assessor: World Conservation Monitoring Centre

Refs: $1957,4147,4217,4974,5124,6602,9076,12109$, $12268,12281,14717,14873,15539,16123,19170$

\section{Swietenia mahagoni}

Meliaceae

EN Alcd

Anguilla, Antigua and Barbuda, Bahamas, Cayman Islands, Colombia, Cuba, Dominica, Dominican Republic, Grenada, Guadeloupe (Guadeloupe, St Martin-St Barthelemy), Jamaica, Martinique, Montserrat, St Kitts and Nevis, St Lucia, St Vincent, Trinidad and Tobago, Turks and Caicos Islands, USA (Florida), Venezuela

The Caribbean mahogany is found on the Caribbean islands and also in south Florida in dry or moist forest, often on limestone. Its natural distribution is hard to ascertain as it has been widely cultivated. It was the first mahogany to appear in the European market five centuries ago. Natural stands are extensively exhausted and the species exhibits high levels of genetic erosion.
Remaining individuals are usually weedy trees or bushes. Small quantities of timber from plantations are occasionally available on the intemational market. The species is listed in Appendix II of * CITES.

Assessor: Americas Regional Workshop

Refs: $5519,6602,7630,12281,16261,19178,19179$, 19187

\section{Syagrus botryophora}

Palmae

Brazil (Bahia, Espírito Santo, Sergipe)

LR/nt

A tree of Atlantic coastal rainforest. The species responds badly to forest clearance. Seed production and seedling survival decline outside forest areas.

Assessor: Noblick, L.

Refs: 19118

\section{Syagrus glaucescens}

Palmae

VU Alc

Brazil (Minas Gerais)

A small palm tree of *cerrado and * campo rupestre on rocky outcrops, confined to Serra da Diamantina of Minas Gerais. Population numbers are declining at an alarming rate. Only a few small trees remain and mature individuals are almost completely absent from certain rocky areas. There is evidence that adult palms have been collected, possibly transplanted into cultivation. Assessor: Noblick, L.

Refs: 19118

\section{Syagrus macrocarpa}

Palmae EN C2a

Brazil (Espírito Santo, Minas Gerais, Rio de Janeiro)

The species is confined to Atlantic coastal forest. It is particularly rare in Espirito Santo. Trees are so sparsely scattered that outcrossing may be seriously limited. No large populations are known.

Assessor: Noblick, L.

Refs: 19118

\section{Syagrus stratincola}

Palmae

VU B1+2c

French Guiana, Guyana, Suriname

A palm tree that occurs in fewer than 10 localities on granite outcrops in low transitional moist forest in the Guianas. In French Guiana one of these sites is in Las Neuragus Nature Reserve. Fire and poor regeneration are the principal threats.

Assessor: de Granville, J.J

Refs: 19118

\section{Sympetalandra schmutzii}

Leguminosae

VU D2

Indonesia (Lesser Sunda Is.)

A large tree endemic to Flores Is.

Assessor: World Conservation Monitoring Centre

Refs: 1011

\section{Symphonia globulifera var. angustifolia}

Guttiferae

Panama

Assessor: Mitré, M.

Refs: $15309,16772,17397$

\section{Symphyochlamys erlangeri}

Malvaceae

$\mathbf{L R} / \mathrm{nt}$

Somalia

A tree from a monotypic genus. It is confined to southem Somalia where the habitat is extensively 
degraded because of overcutting for charcoal production and overgrazing.

Assessor: Thulin, $\mathbf{M}$.

Refs: 8697,18665

\section{Symplocos anamallayana}

Symplocaceae

$\mathrm{EN} \mathrm{Bl}+2 \mathrm{c}$

India (Kerala, Tamil Nadu)

A small tree of montane forest, occurring above $2100 \mathrm{~m}$.

Existing records and collections have all come from a restricted area within the Anamalai and Palni ranges.

Assessor: World Conservation Monitoring Centre

Refs: 8483, 19144

\section{Symplocos baehni}

Symplocaceae

VU D2

Peru

Only the type collection is known. It was recorded from the department of Junin.

Assessor: World Conservation Monitoring Centre

Refs: 1984

\section{Symplocos barberi}

Symplocaceae

India (Tamil Nadu)

$\mathrm{EN} \mathrm{B1+2c}$

This species is endemic to the Agastyamalai Hills at the southem end of the Western Ghats. Large areas have been exposed to fires, grazing, the establishment of commercial plantations and cutting for fuelwood, but almost $1000 \mathrm{~km}^{2}$ of forest are now under protection within sanctuaries.

Assessor: World Conservation Monitoring Centre

Refs: 5651

\section{Symplocos bractealis}

Symplocaceae

VU B1+2c

Sri Lanka

In the extensive surveys conducted for the National Conservation Review, this species was discovered in nine forest localities, mainly confined to Nuwara Eliya District.

Assessor: World Conservation Monitoring Centre

Refs: 15431,19112

Symplocos breedlovei

Symplocaceae

$\mathrm{EN} \mathrm{B1}+2 \mathrm{c}$

Mexico

Assessor: Ramirez-Marcial, N. \& M. González-Espinosa Refs: $3913,9227,19203$

\section{Symplocos calycodactylos}

Symplocaceae

VU B $1+2 c$

Malaysia (Peninsular Malaysia)

A species of hill and submontane forest up to $900 \mathrm{~m}$. A few collections have been made, from the states of Kedah and Perak. Logging and increasing settlement are the principal threats to remaining populations.

Assessor: Chua, L.S.L.

Refs: 8464,19073

\section{Symplocos canescens}

Symplocaceae

VU B $1+2 c$

Ecuador

An endemic of the Ecuadorean High Andes, currently known to occur in areas of cloud forest between 2500 and $3400 \mathrm{~m}$ in Loja and Zamora-Chinchipe Province. Assessor: World Conservation Monitoring Centre Refs: 19119,19120

\section{Symplocos carmencilae}

Symplocaceae

VU B $1+2 c$

Ecuador

An endemic tree of Ecuador, currently known to inhabit montane cloud forest in the High Andean areas of Imbabura.

Assessor: World Conservation Monitoring Centre

Refs: 19119,19120

\section{Symplocos clethrifolia}

Symplocaceae

VU B $1+2 c$

Ecuador

This tree is endemic to the High Andes of Ecuador where it inhabits cloud forest between $3000 \mathrm{~m}$ and $3500 \mathrm{~m}$. Currently known from Morona-Santiago, Azuay and Loja.

Assessor: World Conservation Monitoring Centre Refs: 19119,19120

\section{Symplocos coccinea}

Symplocaceae

VU Alc

Mexico (Oaxaca, Puebla, Veracruz)

A cloud forest species distributed in the Sierra Madre Oriental. Its range has declined and populations are reduced to areas that have escaped agricultural expansion, such as deep gullies.

Assessor: World Conservation Monitoring Centre Refs: 81, 16907, 19206

\section{Symplocos cordifolia}

Symplocaceae

VU B 1 +2c

Sri Lanka

During the extensive forest surveys conducted for the National Conservation Review, this species was apparently locally common but occurred in only six of the surveyed localities in the districts of Nuwara Eliya and Kandy.

Assessor: World Conservation Monitoring Centre Refs: $15431,17759,19112$

\section{Symplocos coronata var. coronata}

Symplocaceae

VUAlc

Sri Lanka

A variety restricted to the lowland wet evergreen forests of south-west Sri Lanka.

Assessor: World Conservation Monitoring Centre Refs: 15431,17195

Symplocos coronata var. glabrifolia

Symplocaceae

VU Alc

Sri Lanka

A tree restricted to the lowland wet evergreen forests of south-west Sri Lanka.

Assessor: World Conservation Monitoring Centre Refs: 15431,17195

\section{Symplocos costata}

Symplocaceae

VU B $1+2 c$

Indonesia (Sumatra)

Scattered in remnant montane and hill forest, the species occurs from areas in the west to as far east as Gunung Telomojo. This habitat has been almost completely cleared in areas below $1400 \mathrm{~m}$ and the pressures are intense on remaining areas.

Assessor: World Conservation Monitoring Centre Refs: 18840 
Symplocos cuneata var. acuta

Symplocaceae

VUAlc

Sri Lanka

A variety occurring in the lowland wet evergreen forests of south-west Sri Lanka.

Assessor: World Conservation Monitoring Centre

Refs: 15431, 17195

\section{Symplocos cuneata var. cuneata}

Symplocaceae

VU Alc

Sri Lanka

A tree occurring in the lowland wet evergreen forests of south-west Sri Lanka.

Assessor: World Conservation Monitoring Centre

Refs: 15431, 17195

\section{Symplocos diversifolia var. appressa}

Symplocaceae

$\mathrm{EN} \mathrm{B1}+2 \mathrm{c}$

Sri Lanka

The species was found in only two forest sites in Ratnapura District during the extensive forest surveys conducted for the National Conservation Review. The sites are not protected.

Assessor: World Conservation Monitoring Centre

Refs: 15431, 19112

\section{Symplocos diversifolia var. diversifolia}

Symplocaceae

$\mathrm{EN} \mathrm{B} 1+2 c$

Sri Lanka

The species was found in only two forest sites in Ratnapura District during the extensive forest surveys conducted for the National Conservation Review. The sites are not protected.

Assessor: World Conservation Monitoring Centre

Refs: 15431,19112

\section{Symplocos globosa}

Symplocaceae

VU B $1+2 c$

Ecuador

A cloud forest tree of the Ecuadorean High Andes, currently only known to occur in Cañar and Azuay Provinces.

Assessor: World Conservation Monitoring Centre

Refs: 19119,19120

\section{Symplocos hispidula}

Symplocaceae

VUAlc

Sri Lanka

A tree restricted to the lowland wet evergreen forests of south-west Sri Lanka.

Assessor: World Conservation Monitoring Centre

Refs: 17195

\section{Symplocos junghuhnii}

Symplocaceae

Indonesia (Java)

$\mathrm{EN} \mathrm{B1}+2 \mathrm{c}$

Occurring in the west in mixed montane forest at about $1750 \mathrm{~m}$, the species appears to be very rare. The pressures from encroachment and cutting exerted on the habitat at this high elevation are less intense than at lower levels but are still very strong.

Assessor: World Conservation Monitoring Centre

\section{Symplocos longipes}

Symplocaceae

LR/cd

Mexico

Assessor: Ramirez-Marcial, N. \& M. González-Espinosa Refs: 3913,9227

\section{Symplocos lugubris}

Symplocaceae

VU D2

Peru

Known only from the type collection, the species occurs in submontane forest in the department of Amazonas.

Assessor: World Conservation Monitoring Centre

Refs: 1984

\section{Symplocos macrocarpa ssp. kanarana}

Symplocaceae

India (Karnataka, Kerala)

VU B $1+2 c$

Although scattered over a wide area from north of the Kalinadi River in Karnataka to the Agastyamalai Hills in

Kerala, the taxon has rarely been collected or recorded.

It occurs in evergreen forest up to $1000 \mathrm{~m}$. The type subspecies is well collected but confined to the Agastyamalai Hills.

Assessor: World Conservation Monitoring Centre

Refs: 19144

\section{Symplocos mezii}

Symplocaceae

VU D2

A Peruvian endemic, known only from the type collection from the department of Cajamarca.

Assessor: World Conservation Monitoring Centre Refs: 1984

\section{Symplocos molinae}

Symplocaceae

Honduras

Assessor: Nelson, C.

Refs: 13995, 15830

\section{Symplocos nairii}

Symplocaceae

India (Tamil Nadu)

EN B $1+2 c$

A small tree of submontane evergreen forest, collected from two localities at the southern end of the Westem

Ghats.

Assessor: World Conservation Monitoring Centre

Refs: 19144

\section{Symplocos nivea}

Symplocaceae

Malaysia (Peninsular Malaysia)

$\mathrm{EN} \mathrm{B} 1+2 \mathrm{c}$

This endemic tree is scattered in lowland primary forest in Penang and Johore. Both states are undergoing rapid habitat clearance for increasing settlement.

Assessor: Chua, L.S.L.

Refs: 8464, 19073

\section{Symplocos octopetalo}

Symplocaceae

LR/nt

Jamaica

Occurring in the western Blue Mountains and John Crow Mountains, the species has an occasional to common distribution over most montane habitats between 1160 and $1700 \mathrm{~m}$.

Assessor: World Conservation Monitoring Centre

Refs: $401,5653,7980,19085$

\section{Symplocos oligandra}

Symplocaceae

India (Tamil Nadu)

$\mathrm{EN} \mathrm{B1+2c}$

An endemic tree of the Agastyamalai Hills at the southem end of the Western Ghats. The species has been collected only twice in areas of submontane evergreen forest. Large areas have been exposed to fires, grazing, 
the establishment of commercial plantations and cutting for fuelwood, but almost $1000 \mathrm{~km}^{2}$ of forest are now under protection within sanctuaries.

Assessor: World Conservation Monitoring Centre

Refs: 5651, 19144

\section{Symplocos peruviana}

Symplocaceae

VU D2

Peru

Known only from the type collection, the species is confined to the department of Cajamarca.

Assessor: World Conservation Monitoring Centre Refs: 1984

\section{Symplocos pulchra ssp. coriacea}

Symplocaceae

$\mathrm{EN} \mathrm{B1+2c}$

India (Tamil Nadu)

A small tree, known only from the type specimen collected from a restricted area of submontane forest in the Agastyamalai Hills. Large areas have been exposed to fires, grazing, the establishment of commercial plantations and cutting for fuelwood, but almost $1000 \mathrm{~km}^{2}$ of forest are now under protection within sanctuaries.

Assessor: World Conservation Monitoring Centre

Refs: 19144

\section{Symplocos pyriflora}

Symplocaceae

$\mathrm{LR} / \mathrm{cd}$

Malaysia (Peninsular Malaysia)

A shrub or small tree of moist submontane rainforest up to $1450 \mathrm{~m}$. This species is found in Taman Negara National Park and in protective forest within the permanent forest estate.

Assessor: Chua, L.S.L.

Refs: 8464, 19073

\section{Symplocos rimbachï}

Symplocaceae

VU B $1+2 c$

Ecuador

An Ecuadorean endemic, inhabiting cloud forest at $2600 \mathrm{~m}$ in the High Andean areas of Bolivar.

Assessor: World Conservation Monitoring Centre

Refs: 19119,19120

\section{Symplocos shilanensis}

Symplocaceae

$\mathrm{EN} \mathrm{B} 1+2 \mathrm{ab}, \mathrm{Cl}$

Taiwan

Known only from the Nanjenshan area in the Hengchun Peninsula, the species occurs in very small and isolated populations in lowland forest. Little regeneration is evident and the expansion of housing developments has caused declines in the habitat. The Kenting National Park covers the entire range.

Assessor: Pan, F.J.

Refs: $3295,19050,19053$

\section{Symplocos sousae}

Symplocaceae

Costa Rica, Mexico (Jalisco, Oaxaca)

A small tree of montane mesophyllous forest, between 2500 and $2700 \mathrm{~m}$. In Mexico it occurs only in the Sierra de Manantlán. More information is needed on its distribution elsewhere.

Assessor: World Conservation Monitoring Centre Refs: $7980,12985,13361,19068$

\section{Symplocos tacanensis}

Symplocaceae

VU B $1+2 c$

El Salvador, Guatemala

A cloud forest species confined to Monte Cristo and Esesmiles in El Salvador. More information is needed on the status of populations. The main threat to the habitat is fire.

Assessor: World Conservation Monitoring Centre

Refs: $3913,4862,4974,19030$

\section{Symplocos trichoclada}

Symplocaceae

VU D1+2

Taiwan

Two small populations are known to exist on Chiben Mountain in the south. Trees are scattered sparsely in mixed forest between 1800 and $2100 \mathrm{~m}$. Regeneration is noted to be poor and no conservation or protection measures are in place.

Assessor: Lu, S.Y. \& F.J. Pan

Refs: 19050,19053

\section{Symplocos tubulifera}

Symplocaceae

VU B $1+2 c$

Jamaica

An uncommon tree restricted to St Catherine and St Ann Parishes.

Assessor: World Conservation Monitoring Centre

Refs: 401, 5653, 7980

\section{Symplocos versicolor}

Symplocaceae

CR B $1+2 \mathrm{~cd}$

Sri Lanka

A species of lowland wet evergreen forest in south-west Sri Lanka. It has been recorded from several sites in Sinharaja Biosphere Reserve, but not during the extensive forest surveys conducted between 1991 and 1996 for the National Conservation Review.

Assessor: World Conservation Monitoring Centre

Refs: 17195,19112

\section{Synadenium compactum var. compactum}

Euphorbiaceae

VU $B 1+2 c$

Kenya

Endemic to central Kenya, this variety occurs in riverine or rocky sites in dry bushland. The habitat is threatened by encroaching agriculture and land settlement in the area. The Plant Conservation Programme in Kenya maintains living stocks for ex situ conservation. Assessor: World Conservation Monitoring Centre Refs: 6396, 10961, 17859

\section{Synapsis ilicifolia}

Bignoniaceae

$\mathrm{EN} \mathrm{B1}+2 \mathrm{c}$

Cuba

A rare shrub or tree, up to $15 \mathrm{~m}$ in height, locally confined to small areas of karstic semi-deciduous forest on limestone cliff in Santiago de Cuba Province.

Assessor: Areces-Mallea, A.E.

Refs: 11403, 18485, 19149

\section{Synsepalum aubrevillei}

Sapotaceae

VU Alc, B1+2c

Côte d'Ivoire, Ghana

A small rare tree confined to wet evergreen forests in Ghana and neighbouring Côte d'Ivoire. Significant parts of this forest have been lost to mining, logging and commercial forestry activities.

Assessor: Hawthome, W.

Refs: $2773,8369,12061$ 


\section{Synsepalum glycydorum}

Sapotaceae

VU B $1+2 c$

Nigeria

A small tree, apparently confined to the Oban Hills in Cross River National Park. Surrounding areas have been extensively logged and cleared for cultivation.

Assessor: World Conservation Monitoring Centre

Refs: 2773, 4977, 11504

\section{Synsepalum kassneri}

Sapotaceae

VU Bl+2c

Kenya, Mozambique, Tanzania, Zimbabwe

Widely known under the genus Afrosersalisia, this species is known from populations in the Shimba Hills in Kenya, coastal forest in Tanzania, Makurupini National Park $\left(1.5 \mathrm{~km}^{2}\right)$ in Zimbabwe and the lower slopes of the Chimanimani Mountains in Mozambique. It occurs in some abundance in some areas, especially towards the drier regions of forest, but it is being actively cut in places (e.g. Mangea in Kenya).

Assessor: World Conservation Monitoring Centre Refs: $5654,6396,6725,10781$

\section{Synsepalum subverticillata}

Sapotaceae

$\mathrm{EN} \mathrm{B1+2c}$

Kenya, Tanzania?

A small tree of moist semi-deciduous lowland forest or dense bushland. There are populations in Witu Forest Reserve, Gongoni Forest Reserve and the Shimba Hills National Reserve. It is also thought to extend into Tanzania. The entire species range is contained within protected areas, although there is no enforcement of protective measures.

Assessor: CAMP Workshop in Kenya

Refs: 19181

\section{Synsepalum tsounkpe}

Sapotaceae

$\mathrm{EN} \mathrm{B} 1+2 c$

Côte d'Ivoire

A coastal forest species known only from Côte d'Ivoire.

Clearing and degradation of the forest have been extensive in the last three decades. This species has local importance as a food sweetener.

Assessor: Assi, A.

Refs: 2773,12822

\section{Syzygium ampliflorum}

Myrtaceae

$\mathrm{CR} B 1+2 \mathrm{c}, \mathrm{C} 2 \mathrm{~b}$

Indonesia (Java)

The only known locality is in Mount Galunggung in forest from 1300 to $1400 \mathrm{~m}$, where it may have suffered damage from a volcanic eruption in 1982. The habitat is under constant pressure from the activities of surrounding populations.

Assessor: World Conservation Monitoring Centre Refs: 9078,19060

\section{Syzygium amplifolium}

Myrtaceae

VU D2

Fiji

A shrub or slender tree, known only from southern Viti

Levu in forested areas at elevations of $50-429 \mathrm{~m}$.

Assessor: World Conservation Monitoring Centre

Refs: 9078,18818

\section{Syzygium andamanicum}

Myrtaceae

India (Andaman and Nicobar Is. - Andaman Is.)

Endemic to the Andaman Islands, the species is known only from the type collections. There have been large declines in the extent of the forest habitat because of logging. It is not known whether the species is now extinct.

Assessor: World Conservation Monitoring Centre Refs: 427, 4799

\section{Syzygium assimile var. acuminata}

Myrtaceae

$\mathrm{EN} B 1+2 \mathrm{C}$

Sri Lanka

The species was found in only three localities during the extensive forest surveys conducted between 1991 and 1996 for the National Conservation Review. No information is available at the variety level.

Assessor: World Conservation Monitoring Centre

Refs: $15431,17759,19112$

\section{Syzygium beddomei}

Myrtaceae

$\mathrm{EN} \mathrm{B1}+2 \mathrm{c}$

India (Tamil Nadu)

A relatively large tree of submontane evergreen forest, known from a single collection in the Agastyamalai Hills and from a less precisely located record in the Anaimalai range.

Assessor: World Conservation Monitoring Centre

Refs: 19144

\section{Syzygium benthamianum}

Myrtaceae

VU B $1+2 c$

India (Kerala, Tamil Nadu)

A small tree of montane forest, occurring in the Nilgiris, the Agastyamalai Hills and a few scattered localities in between.

Assessor: World Conservation Monitoring Centre Refs: 19144

\section{Syzygium bourdillonï}

Myrtaceae

$\mathrm{EN} \mathrm{Bl}+2 \mathrm{c}$

India (Kerala)

A forest species recorded only from Merchiston in Trivandrum District and Colatoorpolay in Quilon District in a restricted area of forest. It is not known whether any populations still remain. There has been much habitat destruction in places and the species has not been collected since 1895 .

Assessor: World Conservation Monitoring Centre

Refs: 2538, 19144

\section{Syzygium caryophyllatum}

Myrtaceae

EN B1+2c

Sri Lanka

This species was found in three of the sites surveyed by the National Conservation Review. Apparantly it is restricted to forest in the wet zone.

Assessor: World Conservation Monitoring Centre Refs: 19112

\section{Syzygium chavaran}

Myrtaceae

EN B1 $+2 c$

India (Kerala)

A lowland forest species, known only from the type collection near the border with Tamil Nadu and from a field record on the coast.

Assessor: World Conservation Monitoring Centre Refs: 19144 
Syzygium cordifolium ssp. cordifolium Myrtaceae

VU Alc, Bl+2c

Sri Lanka

A subspecies confined to lowland rainforest in southwest Sri Lanka. The species as a whole was found in only seven of the forest sites surveyed for the National Conservation Review.

Assessor: World Conservation Monitoring Centre

Refs: 15431, 17195, 19112

\section{Syzygium cordifolium ssp. spissum}

Myrtaceae

VU Alc, B $1+2 \mathrm{c}$

\section{Sri Lanka}

This subspecies is restricted to lowland rainforest in south-west Sri Lanka. The species as a whole was found in only seven of the forest sites surveyed for the National Conservation Review.

Assessor: World Conservation Monitoring Centre

Refs: 15431, 17195, 17759, 19112

\section{Syzygium courtallense}

Myrtaceae

CR B $1+2$ cde

India (Tamil Nadu)

Recorded from a single locality in the Courtallam Hills, the species has not been found for over 100 years despite the area being accessible and visited by tourists. Apparently it is in cultivation in Sri Lankan gardens. Assessor: World Conservation Monitoring Centre Refs: 2538, 19144

\section{Syzygium cyclophyllum}

Myrtaceae

$\mathrm{CR} B 1+2 \mathrm{c}$

Sri Lanka

Only three trees were found in a single proposed reserve in Ratnapura District during the surveys conducted between 1991 and 1996 for the National Conservation Review.

Assessor: World Conservation Monitoring Centre Refs: 19112

\section{Syzygium densiflorum}

Myrtaceae

VU B $1+2 c$

India (Kamataka, Kerala, Tamil Nadu)

Collected seven times, the species occurs in scattered localities of montane forest, above $1500 \mathrm{~m}$, in the Nilgiris, Anamalai and Palni Hills.

Assessor: World Conservation Monitoring Centre Refs: 19144

\section{Syzygium discophorum}

Myrtaceae

Indonesia (Java)

$\mathrm{EN} \mathrm{B1}+2 \mathrm{c}$

This species is confined to Mount Willis in central Java in forest between 1300 and $1500 \mathrm{~m}$. Strong pressures are exerted by the activities of surrounding populations. Assessor: World Conservation Monitoring Centre Refs: 9078, 19060

\section{Syzygium fergusonii}

Myrtaceae

$\mathrm{EN} \mathrm{B1+2c}$

Sri Lanka

The species was found in three of the sites surveyed by the National Conservation Review. It appears to be locally common in Knuckles State Forest.

Assessor: World Conservation Monitoring Centre Refs: 19112

\section{Syzygium firmum}

Myrtaceae

VU Alc

Sri Lanka

A tree restricted to lowland rainforest in south-west Sri Lanka.

Assessor: World Conservation Monitoring Centre

Refs: 15431,17195

\section{Syzygium gambleanum}

Myrtaceae

India (Tamil Nadu)

A small-leaved tree collected only once in montane evergreen forest along the Muthukuzki River in Kannyakumari District. It is unlikely to be found again as the forest was extensively cleared for the construction of the Kothayar Dam.

Assessor: World Conservation Monitoring Centre Refs: 2538

\section{Syzygium makul}

Myrtaceae

VUAlc

Sri Lanka

A tree confined to scattered locations in lowland rainforest in south-west Sri Lanka.

Assessor: World Conservation Monitoring Centre

Refs: 15431,17195

\section{Syzygium manii}

Myrtaceae CR B1+2c

India (Andaman and Nicobar Is. - Andaman Is.)

A species known only from the type locality in semievergreen forest on Middle Andaman Island. There have been large declines in the extent of the habitat because of logging.

Assessor: World Conservation Monitoring Centre

Refs: 427, 4799

\section{Syzygium micranthum}

Myrtaceae

VU Alc

Sri Lanka

A tree restricted to lowland rainforest in south-west Sri Lanka.

Assessor: World Conservation Monitoring Centre

Refs: 15431,17195

\section{Syzygium microphyllum}

Myrtaceae

EN B $1+2 c$

India (Tamil Nadu)

Known only from the type locality, the species is endemic to a small area at the margin of montane forest in the Agastyamalai Hills. Although relatively intact, large parts of the forest have been affected by fires, grazing, the increasing incursion of commercial plantations and cutting for fuelwood. More information is needed on the status of the species and direct threats to its populations.

Assessor: World Conservation Monitoring Centre Refs: 5651,19144

\section{Syzygium minus}

Myrtaceae

EN D1

Fiji

This small tree is confined to the Mount Evans range on Viti Levu, where it is known from the type locality and two collections gathered from crest thickets between 760 and $850 \mathrm{~m}$.

Assessor: World Conservation Monitoring Centre Refs: 5372,18818 


\section{Syzygium myhendrae}

Myrtaceae

India (Kerala, Tamil Nadu)

A poorly known species of submontane forest, occurring at the southem end of the Western Ghats. Only two records are known, one from the Travancore range and the other from the Agastyamalai Hills.

Assessor: World Conservation Monitoring Centre

Refs: 19144

\section{Syzugium neesianum}

Myrtaceae

VUAlc

Sri Lanka

A tree restricted to lowland rainforest in south-west Sri Lanka.

Assessor: World Conservation Monitoring Centre

Refs: 15431, 17195

\section{Syzygium occidentale}

Myrtaceae

VU Ald

India (Karnataka, Kerala)

A small tree of lowland riverine forest, known from scattered collections mostly from the southern end of the Westem Ghats in Kerala but also from single isolated records in Kamataka.

Assessor: World Conservation Monitoring Centre Refs: 19144

\section{Syzygium oliganthum}

Myrtaceae

VU B $1+2 c$

Sri Lanka

Apparently confined to Nuwara Eliya District, this species was recorded from seven sites during the recent National Conservation Review forest surveys.

Assessor: World Conservation Monitoring Centre

Refs: 15431, 19112

\section{Syzygium palghatense}

Myrtaceae

CR B $1+2$ abcde

India (Kerala)

A large tree endemic to montane forest in the Palghat Hills. Recorded in the last century, it has not been found since. The habitat is considerably reduced in extent and it is unknown whether the species is still extant.

Assessor: World Conservation Monitoring Centre

Refs: 2538,19144

\section{Syzygium parameswaranii}

Myrtaceae

$\mathrm{EN} \mathrm{B1+2c}$

India (Tamil Nadu)

Known from two collections in two separate localities on the border with Kerala, the species is poorly known but appears to be confined to montane forest in the Agastyamalai Hills and Elamalai Hills.

Assessor: World Conservation Monitoring Centre

Refs: 19144

\section{Syzygium phaeophyllum}

Myrtaceae

CR D1

Fiji

A small tree of dense forest between 700 and $900 \mathrm{~m}$. Only the type collection, dated 1934 from Taveuni, is known.

Assessor: World Conservation Monitoring Centre

Refs: 5372,18818
Syzygium phyllyraeoides

Myrtaceae

Sri Lanka

A rare tree restricted to lowland rainforest in south-west Sri Lanka and previously known from Kanneliya Forest Reserve. It was not found during the extensive forest surveys conducted between 1991 and 1996 for the National Conservation Review, suggesting that the species is either extremely rare or possibly extinct. Assessor: World Conservation Monitoring Centre Refs: 17195, 19112

\section{Syzygium pondoense}

Myrtaceae

VU A2c, B $1+3 d$

South Africa (Eastern Cape, KwaZulu-Natal)

A shrub or small tree growing among sandstone boulders on islands in the bed of the Umtamvuna River in southem KwaZulu-Natal and in a number of river valleys in the Port Shepstone area, including the Lusikisiki and Bizana Districts of the Transkei in the Eastern Cape. In places it occurs in abundance, but it is susceptible to periodic flooding. The floods in 1978 destroyed most of the plants in the Umtamvuna River Valley, but the subpopulation was able to recover from the few remaining plants. Subpopulations are found in two provincial reserves and a number of demarcated forests, which are no longer strictly protected and under threat from increasing settlement and cutting for firewood and timber.

Assessor: Hilton-Taylor, C. et al.

Refs: 689,19218

\section{Syzygium ramavarma}

Myrtaceae

VU B $1+2 \mathrm{c}$

India (Kerala, Tamil Nadu)

A medium-sized tree of submontane evergreen forest. The main concentration of collections comes from the Agastyamalai Hills. A single collection has also been made in the Anaimalai Hills.

Assessor: World Conservation Monitoring Centre Refs: 19144

\section{Syzygium rotundifolium}

Myrtaceae

VU Alc, B1+2c

Sri Lanka

This tree occurs irrequently in upper montane rainforest. It was recorded in nine of the sites surveyed from the National Conservation Review.

Assessor: World Conservation Monitoring Centre

Refs: $15431,19106,19112$

\section{Syzygium spathulatum}

Myrtaceae

$\mathrm{EN} \mathrm{B} 1+2 \mathrm{c}$

Sri Lanka

An endemic tree found in wet and dry forest in Sri Lanka. The species was found in only five of the sites surveyed for the National Conservation Review, including an occurrence in a strict nature reserve.

Assessor: World Conservation Monitoring Centre Refs: $15431,17195,17759,19112$

\section{Syzygium spissum}

Myrtaceae

VU B $1+2 c$

Sri Lanka

The species was found in only seven of the sites surveyed for the National Conservation Review. Assessor: World Conservation Monitoring Centre Refs: 19112 


\section{Syzygium stocksï}

Myrtaceae

India (Kamataka, Kerala)

EN B $1+2 c$

A poorly known species, recorded twice from unspecified localities in the Wayanad area in Kerala and just over the border into Kamataka. It appears to occur in evergreen forest at about $800 \mathrm{~m}$.

Assessor: World Conservation Monitoring Centre Refs: 19144

\section{Syzygium sylvestre}

Myrtaceae

CR B1+2cd

Sri Lanka

This species is confined to lowland rainforest in southwest Sri Lanka. It was not found during the extensive National Conservation Review forest surveys, indicating that it is either extremely rare or possibly extinct.

Assessor: World Conservation Monitoring Centre Refs: 17195, 19112

\section{Syzygium travancoricum}

Myrtaceae

CR C2a

India (Kerala)

The total population is very small, numbering less than 200. The sacred grove of Aickad is reported to harbour four individuals and another population of 15 to 20 trees has been seen at Guddrikal. The swampy wetland habitat has been widely drained and converted into paddy fields. Assessor: CAMP Workshops on Medicinal Plants in India

Refs: $561,2538,4246,19144$

\section{Syzygium turbinatum}

Myrtaceae

$\mathrm{EN} \mathrm{B1}+2 \mathrm{c}$

Sri Lanka

This tree was found in only four of the sites surveyed for the National Conservation Review.

Assessor: World Conservation Monitoring Centre

Refs: 15431,19112

\section{Syzygium umbrosum}

Myrtaceae

$\mathrm{EN} \mathrm{B} 1+2 c$

Sri Lanka

A species found in only three of the sites surveyed during the extensive National Conservation Review, one of which is a strict nature reserve.

Assessor: World Conservation Monitoring Centre

Refs: 15431,19112

\section{Syzygium utilis}

Myrtaceae

DD

India (Karnataka)

A tree of evergreen forest, known from an imprecisely recorded collection taken from North Kanara.

Assessor: World Conservation Monitoring Centre

Refs: 19144

\section{Syzygium wolfii}

Myrtaceae

Fiji

A Fijian endemic known from the type collection on Viti Levu and five collections from Vanua Levu. The species occurs in dense or secondary forest, forest patches in open country, or on forested crests.

Assessor: World Conservation Monitoring Centre Refs: 5372,18818

\section{Syzygium wrighti}

Myrtaceae

VU D2

Seychelles

Endemic to the Seychelles, the species qualifies as threatened by virtue of its restricted distribution. Populations are healthy and stable.

Assessor: World Conservation Monitoring Centre

Refs: $9859,16212,17229$

\section{Syzygium zeylanicum var. ellipticum}

Myrtaceae

$\mathrm{EN} B 1+2 \mathrm{c}$

India (Tamil Nadu)

A small tree, known only from the type collection taken from montane forest in the Agastyamalai Hills. Large areas have been exposed to fires, grazing, the establishment of commercial plantations and cutting for fuelwood, but almost $1000 \mathrm{~km}^{2}$ of forest are now under protection within sanctuaries.

Assessor: World Conservation Monitoring Centre Refs: 19144

\section{Tabebuia anafensis}

Bignoniaceae

VU B $1+2 c$

Cuba

A shrub or small tree confined to Sierra de Anafe and other isolated limestone hills in Habana and Matanzas Provinces. There are active limestone quarries in this region.

Assessor: Areces-Mallea, A.E.

Refs: 11403, 18485, 19149

\section{Tabebuia arimaoensis}

Bignoniaceae

VU D2

Cuba

A small tree localised to the mountains of the Guamuhaya Massif.

Assessor: Areces-Mallea, A.E

Refs: 7980,19149

\section{Tabebuia bibracteolata}

Bignoniaceae

VU D2

Cuba

Confined to the northem karstic area of the Sierra Maestra in Santiago de Cuba Province, this uncommon shrub or small tree occurs locally in semi-deciduous and deciduous forest complex on eroded limestone.

Assessor: Areces-Mallea, A.E.

Refs: 7980, 11403, 19149

\section{Tabebuia dubia}

Bignoniaceae

VU $B 1+2 c$

Cuba

A canopy tree found mainly in montane serpentine rainforest thriving on acid ferralitic soils in the NipeBaracoa Massif. The species is not yet uncommon but overexploitation and habit disturbance have caused a decline in numbers. Logging, cutting and mining are constant threats.

Assessor: Areces-Mallea, A.E.

Refs: 7980,19149

\section{Tabebuia elongata}

Bignoniaceae

$\mathrm{EN} \mathrm{B1+2c}$

Cuba

An uncommon tree endemic to the Nagua mountain group in Sierra Maestra.

Assessor: Areces-Mallea, A.E.

Refs: 7980,19149 
Tabebuia furfuracea

Bignoniaceae

VU B $1+2 c$

Cuba

A shrub or small tree confined to the Sierra de Nipe mountain complex in Holguin and Santiago de Cuba Provinces. Logging and cutting have resulted in habitat degradation in places.

Assessor: Areces-Mallea, A.E.

Refs: 11403, 18485, 19149

\section{Tabebuia hypoleuca}

Bignoniaceae

$\mathrm{VU} \mathrm{B1}+2 \mathrm{c}$

Cuba

A tree endemic to the montane rainforests of Sierra Maestra and other mountains in Guantanamo Province. The species is still fairly common but populations have declined over the past few decades.

Assessor: Areces-Mallea, A.E.

Refs: 7980, 19149

\section{Tabebuia jackiana}

Bignoniaceae

VU D2

Cuba

A small tree of subalpine deciduous forest on eroded limestone, restricted to the 'mogote complex' in Pinar del Rio Province.

Assessor: Areces-Mallea, A.E.

Refs: $7980,11403,18485,19149$

\section{Tabebuia lapacho}

Bignoniaceae

VU B $1+2 \mathrm{ac}$

Argentina (Jujuy, Salta), Bolivia

Although in the past the species has been placed in synonymy with $T$. ochracea, the most recent work suggests that it is a valid entity, endemic to the piedmont forest of north-west Argentina and Bolivia. The ecosystem is entirely unprotected and in rapid decline as agriculture expands.

Assessor: Prado, D.

Refs: 5112, 7980, 19122

\section{Tabebuia oligolepis}

Bignoniaceae

VU B $1+2 \mathrm{c}$

Cuba

A species typically confined to the montane rainforests of the Sierra Maestra mountain range in Santiago de Cuba and Granma Provinces. This tree is not yet uncommon but habitat has been degraded in places and cutting is still a threat.

Assessor: Areces-Mallea, A.E.

Refs: $11403,18485,19149$

\section{Tabebuia platyantha}

Bignoniaceae

LR/nt

Jamaica

A tree sparsely scattered in central and western parishes in woodland on limestone.

Assessor: World Conservation Monitoring Centre

Refs: 6057,7980

\section{Tabebuia polymorpha}

Bignoniaceae

VU B $1+2 \mathrm{c}$

Cuba

Populations of this shrub or small tree are confined to areas of bare limestone with dry littoral scrub woodlands on the coastal terraces and seaside karstic slopes of eastern Cuba. Its habitat has been severely degraded in places by buming and cutting.

Assessor: Areces-Mallea, A.E.

Refs: 7980,19149

\section{Tabebuia shaferi}

Bignoniaceae

VU $B 1+2 c$

Cuba

A shrub or tree widespread in many forest types. Its habitat has been severely degraded in most places, especially in western and central Cuba. Cutting and clearing remains a threat in the remaining areas and in north-east Cuba mining is a major threat.

Assessor: Areces-Mallea, A.E.

Refs: 7980,19149

\section{Tabebuia striata}

Bignoniaceae

VU C2a

Colombia, Panama

In Panama, the species is recorded as locally common around the base of the mountains in Puerto Obaldia in Kunayala Indigenous Reserve, near the Colombian border, and from the north-east of Darién Province. It is more widely distributed on the Pacific coast and in Antioguia in Colombia, although these populations are, apparently, not large. The whole area is not well studied botanically and it is possible the species is more widespread. There is also little human impact, although the cultivation of marijuana is increasing.

Assessor: Mitré, $\mathrm{M}$.

Refs: $5335,7272,7980,16772$

\section{Tabernaemontana antheonycta}

Apocynaceae

VU B $1+2 c$

Brunei, Malaysia (Sabah, Sarawak)

A shrub or small tree occurring in the understorey of lowland forest up to $250 \mathrm{~m}$. So far it is known from a total of seven localities. In Brunei this species is confined to Mount Biang and in Sabah it is confined to Kota Kinabalu.

Assessor: World Conservation Monitoring Centre Refs: 7745

\section{Tabernaemontana apoda}

Apocynaceae

CR B1+2c

Cuba

A small tree or shrub, restricted to lowland areas and savanna in Sancti Spiritus Province. It has become rare, since much of the habital has been converted to agricultural land or pastures.

Assessor: Areces-Mallea, A.E.

Refs: $11403,18485,19149$

\section{Tabernaemontana cordata}

Apocynaceae

VUAlc

Philippines

A forest understorey species, often found along creeks, endemic to Mindanao Is.

Assessor: World Conservation Monitoring Centre Refs: 7745

\section{Tabernaemontana cumata}

Apocynaceae

$\mathrm{EN} \mathrm{B1}+2 \mathrm{c}$

Brazil

A small tree found on *terra firme forest in the vicinity of Manaus.

Assessor: World Conservation Monitoring Centre

Refs: 15491 


\section{Tabernaemontana gamblei \\ Apocynaceae}

India (Kerala, Tamil Nadu)

LR/cd

An understorey shrub or small tree which has been well collected in areas of submontane evergreen forest in the southem end of the Westem Ghats, occurring from Anaimalai to the southern tip of the Agastyamalai Hills. Assessor: World Conservation Monitoring Centre

Refs: 7745,19144

\section{Tabernaemontana heyneana}

Apocynaceae

LR/nt

India (Goa, Karnataka, Kerala, Maharashtra, Tamil Nadu)

A shrub or small tree, endemic to lowland south-west India, found in bush or forest up to $600 \mathrm{~m}$.

Assessor: World Conservation Monitoring Centre

Refs: 7745

\section{Tabernaemontana muricata}

Apocynaceae

$\mathrm{EN} \mathrm{B} 1+2 \mathrm{c}$

Brazil (Amazonas)

A small tree or shrub found in non-inundated forest near Manaus, Amazonas.

Assessor: World Conservation Monitoring Centre

Refs: 15491

\section{Tabernaemontana ochroleuca}

Apocynaceae

VU Bl $+2 \mathrm{c}$

Jamaica

A shrub or small tree which is localised in areas of hill forest between 300 and $500 \mathrm{~m}$ on Dolphin Head, Hanover Parish.

Assessor: Kelly, D.L.

Refs: 401, 5653, 7980, 15491, 19085

\section{Tabernaemontana oppositifolia}

Apocynaceae

VU D1+2

Puerto Rico

A shrub or small tree restricted to forest on limestone hilis.

Assessor: World Conservation Monitoring Centre

Refs: 15491

\section{Tabernaemontana ovalifolia}

Apocynaceae

$\mathrm{EN} \mathrm{B1+2c}$

Jamaica

A small tree which is known from three collections taken from limestone hillsides on Dolphin Head, Hanover Parish.

Assessor: Kelly, D.L.

Refs: 401, 7980, 15491, 19085

\section{Tabernaemontana persicariffolia}

Apocynaceae

EN Alc, B1+2bce

Mauritius, Réunion

A small tree distributed in areas of bush and forest from the coast to $1200 \mathrm{~m}$. It is very rare on Réunion but found in greater numbers on Mauritius, where it still survives in small area of relatively undisturbed dryland forest.

Assessor: Strahm, W.

Refs: $2000,7745,9120,12470,19208$

\section{Tabernaemontana polyneura}

Apocynaceae

LR/cd

Malaysia (Peninsular Malaysia)

A shrub or small tree inhabiting montane rainforest between 1000 and $1300 \mathrm{~m}$ in Perak, Pahang, Selangor,
Malacca. Populations are protected in Taman Negara National Park and within the permanent forest estate. Assessor: Chua, L.S.L.

Refs: 8464,19073

\section{Tabernaemontana remota}

Apocynaceae

Indonesia (Sulawesi), Papua New Guinea

VU B $1+2 c$

A shrub or small tree up to $10 \mathrm{~m}$ high, occurring in submontane scrub or forest. It is known from several collections from Sulawesi and Rossel Island of Papua New Guinea. The fragile ecosystem of Rossel Island is threatened by logging and mining activities.

Assessor: World Conservation Monitoring Centre

Refs: 7745,19032

\section{Tabernaemontana stenosiphon}

Apocynaceae

LR/nt

São Tomé \& Príncipe (São Tomé)

A common upland forest tree widely distributed over the island between 500 and $1600 \mathrm{~m}$. The species regenerates well.

Assessor: World Conservation Monitoring Centre Refs: 2724, 7745, 19042

\section{Tabernaemontana wullschlaegelii}

Apocynaceae

LR/nt

Jamaica

Endemic to Jamaica, this shrub or small tree is found in forest on limestone between 350 and $900 \mathrm{~m}$ in scattered localities throughout the island.

Assessor: World Conservation Monitoring Centre

Refs: 7980, 15491

\section{Tachigali tessmannü}

Leguminosae

Peru

An Amazon forest species, apparently restricted to Amazonas and Loreto Departments.

Assessor: World Conservation Monitoring Centre Refs: 1984

\section{Tahitia yescoana}

Tiliaceae

French Polynesia (Society Is.)

An endemic of Tahiti.

Assessor: Florence, J.

Refs: 14513

\section{Taiwania cryptomerioides}

Taxodiaceae

VU Ald

China (Guizhou, Hubei, Sichuan, Yunnan), Myanmar, Taiwan

A large slow-growing tree from a monotypic genus, although the Chinese/Myanmar populations are frequently refered to as $T$. flousiana. It is widely scattered as an emergent in mid- to high-elevation forest, usually with Chamaecyparis species. Population have declined because of forest clearance and logging. exacerbated by poor regeneration. Plantations have now been established.

Assessor: SSC Conifer Specialist Group

Refs: $374,6469,11847,19050,19051$

\section{Takhtajania perrieri}

Winteraceae

EN D1

Madagascar

A monotypic genus, first discovered in 1909 in the north-west of the island. Attempts to find the species 
again had failed until a healthy population of about 250 trees was recently discovered in the Anjahanaribe-Sud Special Reserve in the north-east, $150 \mathrm{~km}$ from the original locality.

Assessor: World Conservation Monitoring Centre

Refs: 19107,19190

\section{Talbotiella eketensis}

Leguminosae

$\mathrm{EN} \mathrm{B1}+2 \mathrm{c}$

Nigeria

A swamp forest species, found only in south-east Nigeria. In Eket the habitat appears to have been almost completely destroyed because of oil exploration operations. Elsewhere levels of logging and clearing are high outside protected areas.

Assessor: World Conservation Monitoring Centre

Refs: $450,2773,7550,11504$

\section{Talbotiella gentii}

Leguminosae

CR Alc, Bl+2c

\section{Ghana}

Endemic to Ghana, this evergreen tree occurs in tiny stands in rocky areas of dry forest. Records from Cameroon appear to be erroneous. The original area of dry forest has been extensively destroyed by incursions of people and subsequent exploitation of forested areas. This species is very slow-growing and does not seem to have a dispersal mechanism. It is considered to be the species with the highest conservation priority within Ghana.

Assessor: Hawthome, W.

Refs: $2773,8854,12061$

\section{Tannodia swynnertonii}

Euphorbiaceae

VU B1+2bc, D2

Mozambique, Tanzania, Zimbabwe

A number of small isolated populations exist. The Tanzanian population is confined to Mwanihana in the Udzungwa Mountains. In Zimbabwe, the species occurs in Chirinda forest, where it is a common understorey tree, and in the Vumba Mountains, near Mutare, where one or two individuals have been recorded. Poorly collected areas in Mozambique are expected to harbour additional populations.

Assessor: Lovett, J. \& G.P. Clarke

Refs: $3356,5108,6725,10961$

\section{Tapeinosperma campanula}

Myrsinaceae

VU D1

New Caledonia

Assessor: Jaffré, T. et al.

Refs: 10351

\section{Tapiphyllum schliebenii}

Rubiaceae

$\mathrm{EN} \mathrm{B1}+2 \mathrm{c}, \mathrm{C} 2 \mathrm{~b}$

Tanzania

The entire population is restricted to Litipo Forest Reserve, which covers $10 \mathrm{~km}^{2}$. This is a unique, almost completely deciduous patch of coastal forest. Logging in the past has removed all valuable timbers and has now been banned. There is some pressure from pole and fuelwood collection inside the southern perimeter and also generally from the demand for land for the cultivation of cash crops in the surrounding area.

Assessor: Lovett, J. \& G.P. Clarke

Refs: 10961,16796

\section{Tapirira bethanniana}

Anacardiaceae

VU D2

French Guiana

A newly described species of primary rainforest, endemic to French Guiana and principally found in the vicinity of La Fumee.

Assessor: World Conservation Monitoring Centre Refs: 7980

\section{Tapirira chimalapana}

Anacardiaceae

Mexico (Oaxaca, Veracruz)

A common canopy tree, endemic to the UxpanapaChimalapa area.

Assessor: World Conservation Monitoring Centre

Refs: 5651

\section{Tapiscia sinensis}

Staphyleaceae VU Alc

China (Anhui, Fujian, Guangxi, Guizhou, Hubei, Hunan, Jiangxi, Sichuan, Zhejiang)

A widely occurring species sparsely distributed in the Yangtze River basin in moist forest, usually at streamsides, on mountain slopes between 400 and $1600 \mathrm{~m}$. There is a long interval between fruiting seasons, which leads to naturally poor regeneration. Extensive disturbance, clearance and logging of the habitat have caused population declines over most of the species' range.

Assessor: World Conservation Monitoring Centre

Refs: 1818,11847

\section{Tapura arachnoidea}

Dichapetalaceae

VU D2

Gabon

A small forest tree, which is known only from a small area near Lastoursville. The area is under exploitation and there is a serious likelihood that the species' habitat is already lost.

Assessor: World Conservation Monitoring Centre Refs: 19043

\section{Tapura carinata}

Dichapetalaceae

Congo, Gabon

A species with a distinctive floral structure, known only from two collections from areas of closed forest. Further collecting may extend the distribution. There is concern about logging and the extent to which forest areas are now under concession to logging companies.

Assessor: World Conservation Monitoring Centre

Refs: 7359,14958

\section{Tapura ivorensis}

Dichapetalaceae

VUAlc, B1+2c

Côte d'Tvoire, Ghana

A small tree confined to the restricted area of wet evergreen forest in Ghana and neighbouring Côte d'Ivoire. This forest has been affected by mining, logging and commercial forestry activities.

Assessor: Hawthorne, W.

Refs: $8369,8854,12061$

\section{Tapura letestui}

Dichapetalaceae

VU D2

Congo, Gabon

A species of semi-deciduous forests, known only from two collections. It is possible that further collecting may extend the distribution. There is concern over logging 
and the extent to which forest areas are now under concession to logging companies.

Assessor: World Conservation Monitoring Centre

Refs: 7359,14958

\section{Tapura neglecta}

Dichapetalaceae

VU D2

\section{Gabon}

A small forest tree or shrub, which, at present, is known only from the two collections from Mandji and Ndjole. It is possible that the species may be found to be more widespread. There is concern over logging and the extent to which forest areas are now under concession to logging companies.

Assessor: World Conservation Monitoring Centre

Refs: $7359,15790,19043$

\section{Tapura orbicularis}

Dichapetalaceae

VU B1+2c

Cuba

Known only from the montane edaphic climax shrubwoods and forests of Sierra de Nipe in Holguín Province, this rare tree is suffering from habitat destruction resulting from logging and mining activities.

Assessor: Areces-Mallea, A.E.

Refs: $7980,11403,18485,19149$

\section{Taraktogenos annamensis}

Flacourtiaceae

VU Alcd

China (Guangxi, Yunnan), Laos, Viet Nam

Populations in China are localised, occurring in Mengla, Jiangchen, Jingping, Hekou and Pingbian in south Yunnan and Longzhou in south-west Guangxi. The species is said to be relatively common in central and northern Viet Nam. No information is available on the populations in Laos. The lowland forest habitat has suffered large-scale clearance and conversion to agriculture. Medicine and oil are harvested from the seeds.

Assessor: World Conservation Monitoring Centre Refs: $1818,11847,19055,19061$

\section{Tarenna agumbensis}

Rubiaceae

$\mathrm{EN} \mathrm{B1}+2 \mathrm{c}$

India (Karnataka)

A small tree, collected four times from separate localities of evergreen forest in southem Karnataka.

Assessor: World Conservation Monitoring Centre

Refs: 14276,19144

\section{Tarenna drummondii}

Rubiaceae

VU $B 1+2 b$

Kenya, Tanzania

A small tree or shrub known from areas of coastal forest at Shimba, Mrima, Marenje and Miongoni in Kenya and further south in east and north-east Tanzania.

Assessor: Lovett, J. \& G.P. Clarke

Refs: $3356,6396,8814$

\section{Tarenna luhomeroensis}

Rubiaceae

VU D2

Tanzania

Known only from the type, this tree occurs at Luhomero in moist forest at $1750 \mathrm{~m}$.

Assessor: Lovett, J. \& G.P. Clarke

Refs: 3356, 10961

\section{Tarenna monosperma}

Rubiaceae

$\mathrm{EN} \mathrm{B1+2c}$

India (Kerala, Tamil Nadu)

Poorly known, this shrubby species has been collected just three times from the Nilgiris, the Anamalai Hills and the Agastyamalai Hills.

Assessor: World Conservation Monitoring Centre

Refs: 427, 19144

\section{Tarenna nilagirica}

Rubiaceae

India (Kamataka, Kerala)

YU B $1+2 c$

A small tree of submontane forest, known from only a few collections, mainly from the Nilgiris but also from scattered localities extending into southem Karnataka. Assessor: World Conservation Monitoring Centre Refs: 19144

\section{Tarenna quadrangularis}

Rubiaceae

VU B $1+2 b$

Tanzania

An endemic from the Uluguru Mountains, restricted to upper moist evergreen forest.

Assessor: Lovett, J. \& G.P. Clarke

Refs: 3356,8814

\section{Taxodium mucronatum}

Taxodiaceae

DD

Guatemala, Mexico, USA (Texas)

Assessor: SSC Conifer Specialist Group

Refs: $374,4974,7395,13041$

\section{Taxus brevifolia}

Taxaceae

LR/nt

Canada (Alberta, British Columbia), USA (Idaho, Montana, Oregon, Washington)

Native populations have been under considerable pressure from the scale of exploitation of the bark by pharmaceutical companies. Plantation sources are now available. The species occurs in various national parks in the north-west.

Assessor: SSC Conifer Specialist Group

Refs: 374, 13041, 18751

\section{Taxus floridana}

Taxaceae

$\mathrm{CR} B !+2 \mathrm{c}$

USA (Florida)

Populations are unhealthy and highly restricted, occupying an area of less than $10 \mathrm{~km}^{2}$. They occur along the Appalachian River on steep rocky bluffs. A lowering of the water table in this limestone area may be responsible for significant levels of stress and the lowering of immunity to fungal diseases in the members of the population.

Assessor: SSC Conifer Specialist Group

Refs: 374, 13041

\section{Taxus globosa}

Taxaceae

LR/nt

Guatemala, Honduras, Mexico (Chihuahua)

In north-east Mexico the species is locally common. Some interest has been shown by pharmaceutical companies in its medicinal properties. There is no evidence of active exploitation.

Assessor: SSC Conifer Specialist Group

Refs: $374,1539,4974,5470,10217,13041$ 


\section{Xylopia elliotii}

\section{Annonaceae}

Côte d'Ivoire, Ghana

VU Alc, Bl+2c

A species restricted to small areas of wet evergreen forest in Ghana and neighbouring Côte d'Ivoire. This forest has declined through the effects of mining, logging and other commercial forestry activities.

Assessor: Hawthome, W.

Refs: 8369,12061

\section{Xylopia hastarum}

Annonaceae

LR/nt

Jamaica

Declines have been recorded in population numbers. The species is relatively widespread in woodlands on limestone. The timber is widely used and the trees are frequently coppiced.

Assessor: World Conservation Monitoring Centre

Refs: 6057,7980

\section{Xylopia lamarckii}

Annonaceae

CR D1

Mauritius

An estimate of fewer than 250 individuals exist in upland scrub and heathland on Mare Longue Plateau, Macchabe, Mont Cocotte and Brise Fer in the southwest. Most areas are heavily invaded by exotic species and no regeneration is apparent. Le Florin and Le Petrin Nature Reserves, which hold small populations, are fenced and weeded.

Assessor: Page, W.

Refs: $1411,9120,16426$

\section{Xylopia Latipetala}

Annonaceae

$\mathrm{EN} \mathrm{B} 1+2 \mathrm{c}$

Tanzania

A single population is known and thought to be confined to the undisturbed areas within Rondo Forest Reserve $\left(140 \mathrm{~km}^{2}\right)$. Large areas of the forest have been disturbed by logging, planting of commercial timbers, shifting cultivation and wood collection. Current forest management activities are discouraging the local exploitation.

Assessor: Lovett, J. \& G.P. Clarke

Refs: $3356,9302,16796$

\section{Xylopia longifolia}

Annonaceae

EN C2a

Panama

Known only from the Canal zone, the species occurs in dense forest, largely within national parks. Despite the protected status of these populations, there is concern that growing population pressure will result in much of this habitat being destroyed.

Assessor: Mitré, M.

Refs: 7980,16772

\section{Xylopia pierrei}

Annonaceae

VU Ala

Cambodia, Viet Nam

Assessor: Ban, N.T.

Refs: 848,19060

\section{Xylopia richardii}

Annonaceae

VU B $1+2 c$

Mauritius, Réunion

Generally a small shrub, but occasionally a tree, the species is scattered throughout scrub and transitional forest in south-west Mauritius. Regeneration is observed to be poor. Some populations, e.g. in Florin and Le Petrin Nature Reserves, are fenced and weeded of invasive species. Information on the population in Réunion has yet to be gathered.

Assessor: Page, W.

Refs: 1411,2000

Xylopia talbotii

Annonaceae

VU $B 1+2 c$

Nigeria

Populations of this forest tree were known in Eket and Oban. The latter is relatively well protected within the $3000 \mathrm{~km}^{2}$ of the southem division of the Cross River National Park. The former is likely to have been seriously or completely destroyed by oil exploration operations.

Assessor: World Conservation Monitoring Centre

Refs: 450, 2773, 11504

\section{Xylosma boulindae}

Flacourtiaceae

VU D1

New Caledonia

Assessor: Jaffré, T. et al.

Refs: 10351

Xylosma capillipes

Flacourtiaceae

$\mathrm{CR} B 1+2 \mathrm{c}$

New Caledonia

Assessor: Jaffre, T. et al.

Refs: 10351

\section{Xylosma crenatum}

Flacourtiaceae

USA (Hawaii)

CR C2a, D1

A tree of montane forest up to $1065 \mathrm{~m}$. Populations are known from Nualolo Trail, Kokee State Park, Napalikona Forest Reserve and Mahanaloa Valley, each consisting of between one and six individuals. Invasive plants and damage caused by feral pigs are major threats. The species is protected by the US Endangered Species Act.

Assessor: World Conservation Monitoring Centre

Refs: 3372,19038

\section{Xylosma fawcettii}

Flacourtiaceae

$\mathrm{LR} / \mathrm{nt}$

Jamaica

The species has an occasional distribution in the central parishes in thickets and woodland on limestone.

Assessor: World Conservation Monitoring Centre

Refs: 6057,7980

\section{Xylosma glaberrimum}

Flacourtiaceae

Brazil (Paraná, Rio de Janeiro, São Paulo)

The species is poorly known. Collections indicate that it occurs in * restinga and other Atlantic forest types.

Assessor: Torres, R.B.

Refs: 19098, 19099

\section{Xylosma grossecrenatum}

Flacourtiaceae

New Caledonia

Assessor: Jaffré, T. et al.

Refs: 10351 
Xylosma inaequinervium

Flacourtiaceae

New Caledonia

Assessor: Jaffré, T, et al.

Refs: 10351

Xylosma kaalense

Flacourtiaceae

VU B $1+2 c$

New Caledonia

Assessor: Jaffré, T. et al.

Refs: 10351

\section{Xylosma latifolium}

Flacourtiaceae

India (Kamataka, Kerala)

$\mathrm{EN} \mathrm{B1}+2 \mathrm{c}$

The type collection was taken from montane forest in the Bababudan range. An occurrence has also been recorded from Wayanad in Kerala.

Assessor: World Conservation Monitoring Centre

Refs: 19144

\section{Xylosma molestum}

Flacourtiaceae

VU D2

New Caledonia

Assessor: Jaffré, T. et al.

Refs: 10351

\section{Xylosma obovatum}

Flacourtiaceae

$\mathrm{EN} \mathrm{Bl+2c}$

Colombia

An endemic to Cesar.

Assessor: Calderon, E.

Refs: 7980,19069

\section{Xylosma pachyphyllum}

Flacourtiaceae

CR D1

Puerto Rico

A very rare dioecious tree, occurring in Cambalache forest in moist submontane limestone forest and in Maricao on serpentine gravel. Population estimates in 1989 were put at 14 individuals in total. There are threats from cutting, burning and the development of the area.

Assessor: World Conservation Monitoring Centre

Refs: 7980, 17124

\section{Xylosma palawanense}

Flacourtiaceae

VU B $1+2 c$

Philippines

A Palawan endemic, confined to remaining forest at low altitude. The main island of Palawan is a biosphere reserve.

Assessor: World Conservation Monitoring Centre Refs: 4986

\section{Xylosma peltatum}

Flacourtiaceae

$\mathrm{CR} \mathrm{B} 1+2 \mathrm{c}$

New Caledonia

Assessor: Jaffré, T. et al.

Refs: 10351

\section{Xylosma pininsulare}

Flacourtiaceae

CR B $1+2 \mathrm{C}$

New Caledonia

Assessor: Jaffré, T. et al.

Refs: 10351
Xylosma proctorii

Flacourtiaceae

VU B $1+2 c$

Jamaica

A Cockpit Country endemic, confined to areas of woodland on limestone in Manchester, St Ann and Trelawny Parishes.

Assessor: World Conservation Monitoring Centre

Refs: 5653,7980

\section{Xylosma ruizianum}

Flacourtiaceae

Peru

A species known only from the type specimen, which is recorded with no specific location.

Assessor: World Conservation Monitoring Centre

Refs: 1984

\section{Xylosma serpentinum}

Flacourtiaceae

VU D2

New Caledonia

Assessor: Jaffré, T. et al.

Refs: 10351

Xylosma suaveolens ssp. haroldii

Flacourtiaceae

Pitcairn Islands

A dioecious tree, often partially decumbent, endemic to Henderson. The taxon on the Pitcaim Islands has yet to be determined. On Henderson, it is widespread in plateau forest and drier areas. The population on Pitcaim has declined through habitat loss and cutting. Very few individuals there are expected to survive. The total population is estimated to be about 10,000 trees. Seeds are dispersed by the endemic fruit dove on Henderson but on Pitcaim there is a distinct lack of frugivorous birds. Henderson Island is a World Heritage Site.

Assessor: Waldren, S. \& N. Kingston

Refs: 8306, 13604, 19154

\section{Xylosma tuberculatum}

Flacourtiaceae

VU D2

New Caledonia

Assessor: Jaffré, T. et al.

Refs: 10351

\section{Xylotheca tettensis var. fissistyla}

Flacourtiaceae

VU B $1+2 b$

Tanzania

This may only be a form of the more widespread var. kirkii rather than a distinct variety. It is known only from small areas of coastal forest at Bagamayo and in the Pugu Hills, close to Dar es Salaam. Both areas are disturbed by various human activities. The Pugu Forest Reserve has an active conservation programme.

Assessor: Lovett, J. \& G.P. Clarke

Refs: $3356,5020,5204$

\section{Zanthoxylum albuquerquei}

Rutaceae

VUD2

Peru

Known only from the type collection, the species occurs in Amazon forests in Ucayali.

Assessor: World Conservation Monitoring Centre Refs: 1984

\section{Zanthoxylum atchoum}

Rutaceae

VU B $1+2 c$

Côte d'Ivoire

A Côte d'Ivoire endemic, this species occurs commonly 
in wet evergreen forest. The rate of decline of in the extent of these forests has been severe in the last few decades, largely because of logging. Remaining forested areas are small and generally confined to protected areas, especially Tai National Park.

Assessor: Assi, A.

Refs: 12822

\section{Zanthoxylum belizense}

Rutaceae

EN Alc, C2a

Belize, Costa Rica, Guatemala, Honduras, Mexico, Nicaragua, Panama

A tree of wet forest and thickets in the Atlantic lowlands.

Assessor: Nelson, C.

Refs: 13995

\section{Zanthoxylum brieyi}

Rutaceae

VU D2

Democratic Republic of Congo

Little is known about the population of this species other than that it occurs in Luki Reserve in Mayombe. The surrounding areas are heavily populated and pressures caused by logging, charcoal production and agricultural encroachment are severe.

Assessor: Ndjele, M.B

Refs: 17951

\section{Zanthoxylum chevalieri}

Rutaceae

VU A I c, $\mathrm{B} 1+2 \mathrm{c}$

Ghana

Not commonly recorded, this species occurs in evergreen forest in rocky or upland areas in the Upper Guinea region. The habitat has suffered from the effects of farming, fire, certain forestry management systems and large-scale mining.

Assessor: Hawthome, W.

Refs: 8369, 12061

\section{Zanthoxylum deremense}

Rutaceae

VU B $1+2 b$

Malawi, Tanzania

A species of moist forest of medium to high elevations. There are populations in parts of eastem Tanzania and Malawi.

Assessor: Lovett, J. \& G.P. Clarke

Refs: 3356,8814

\section{Zanthoxylum dipetalum var. dipetalum}

Rutaceae

LR/nt

USA (Hawaii)

The commoner variety of the two which are recognised. Populations are found on Kauai, Oahu, Molokai and Hawaii in dry to moist forest from low to medium elevation. Its wood was of great value in the past for resonant kapa logs which were beaten for the purpose of long-distance communication.

Assessor: World Conservation Monitoring Centre

Refs: 3372

\section{Zanthoxylum dipetalum var. tomentosum}

Rutaceae

CR B $1+2 c, C 2 a b, D 1$

USA (Hawaii)

This variety is considerably rarer than the type variety. It is known from approximately 24 individuals scattered on lava fields at Puuwaawaa in North Kona District on Hawaii. There are persistent threats from grazing ungulates and spreading invasive plants. The species is protected by the US Endangered Species Act.

Assessor: World Conservation Monitoring Centre

Refs: 3372, 19037

\section{Zanthoxylum fagara ssp. aguilarii}

Rutaceae

EN C2a

Guatemala, Honduras

A species of moist forest or thickets in ravines or sometimes dry hillsides.

Assessor: Nelson, C.

Refs: 13995

\section{Zanthoxylum ferrugineum}

Rutaceae

EN C2a

Belize, Costa Rica, El Salvador, Guatemala, Honduras, Nicaragua, Panama

A species of dry to humid pine forest, at middle elevations.

Assessor: Nelson, C

Refs: $13995,14487,18416$

\section{Zanthoxylum flavum}

Rutaceae

VU Alc

Anguilla, Bahamas, Bermuda, Brazil (Amazonas), Cuba, Dominican Republic, Honduras, Jamaica, Puerto Rico, St Lucia, USA (Florida)

A shrub or tree up to $15 \mathrm{~m}$ tall, occurring in thickets and woodland on rocky limestone. In Central America the species is represented by a single collection from Swan Island, Honduras. The species has been heavily exploited for its timber over a long period on all the West Indian islands. Stands are now largely depleted of mature trees and the timber is extremely rare in international trade.

Assessor: Areces-Mallea, A.E.

Refs: $3786,6057,13947,13995,19149,19188$

\section{Zanthoxylum gentlei}

Rutaceae

$\mathrm{EN} \mathrm{C} 2 \mathrm{a}$

Belize, Guatemala, Honduras

A species, of somewhat dubious nomenclature, occurring in humid forest in the Atlantic lowlands.

Assessor: Nelson, C.

Refs: 4974, 13995

\section{Zanthoxylum harrisii}

Rutaceae

VU B $1+2 c$

Jamaica

Until now, the species has been found only in low numbers in an area of humid woodland at $1060 \mathrm{~m}$ in Portland Parish. Observations in the 1980s also indicated that it may occur in Clarendon Parish.

Assessor: Kelly, D.L.

Refs: 401, 3932, 5653, 19085

\section{Zanthoxylum hartii}

Rutaceae

VU $B 1+2 c$

Jamaica

A species restricted to John Crow Peak, where it can be common or locally dominant on karst limestone near the summit. A few individuals were found on shale close to the limestone bluffs of the peak

Assessor: Kelly, D.L.

Refs: 401, 3932, 4089, 5653, 19085 


\section{Zarthoxylum haw ciiense}

Rutaceae

EN C2a

USA (Hawaii)

A species scattered mainly in dry forest on lava flows up to $1740 \mathrm{~m}$ on Kauai, Molokai, Lanai, Maui and Hawaii. At least 11 populations are said to remain on four of the islands, amounting to over 250 individuals. The majority of them are found on Hawaii at Puuwaawaa and Pohakuloa and areas in between. Competition with alien plants and feral and domesticated grazers continues to put pressure on the remaining populations. The species is protected by the US Endangered Species Act.

Assessor: World Conservation Monitoring Centre Refs: 19039

\section{Zanthoxylum heterophyllum}

Rutaceae

Mauritius (Mauritius, Rodrigues), Réunion

On Mauritius a population of fewer than 50 adult trees is estimated to exist in fragmented subpopulations in Trou du Douce on the east coast and Brise Fer Mountain in the south-west. Habitat degradation and the spread of invasive species appear to be limiting regeneration. More information is needed on the populations elsewhere.

Assessor: Page, W.

Refs: $1411,2000,9120,9426,12470,16426$

\section{Zanthoxylum holtrianum}

Rutaceae

VU B1 $+2 \mathrm{~d}, \mathrm{D} 2$

Tanzania

Only four collections of this subspecies have been recorded from remaining areas of dry coastal forest or bushland in south-east Tanzania.

Assessor: Lovett, J. \& G.P. Clarke

Refs: 2361,3356

\section{Zanthoxylum integrifoliolum}

Rutaceae

Philippines, Taiwan

In Taiwan, the species is restricted to forest areas on Lanyu Island. Fewer than 250 individuals are thought to be in existence here.

Assessor: World Conservation Monitoring Centre

Refs: 6469,19053

\section{Zanthoxylum kauaense}

\section{Rutaceae}

USA (Hawaii)

LR/nt

Relatively widespread, the species occurs in forest of various types over a wide altitudinal range on all the main islands except Niihau and Kahoolawe.

Assessor: World Conservation Monitoring Centre

Refs: 3372

\section{Zanthoxylum lindense}

Rutaceae

VU $B l+2 b$

Tanzania

Known from Maria Island and parts of south-east Tanzania, this sometimes scandent small tree or shrub occurs in dry coastal forest or bushland.

Assessor: Lovett, J. \& G.P. Clarke

Refs: 3356,8814

\section{Zanthoxylum nadeaudii}

Rutaceae

French Polynesia (Society Is.)

Populations are recorded from Raiatea, Tahaa and Tahiti.

Assessor: Florence, J.

Refs: 14513

\section{Zanthoxylum negrilense}

Rutaceae

$\mathrm{EN} \mathrm{BI}+2 \mathrm{c}$

Jamaica

Known only from Westmoreland Parish, the species occurs locally in woodland on rocky limestone.

Assessor: Kelly, D.L.

Refs: 401, 3932, 5653

\section{Zanthoxylum oahuense}

Rutaceae

VU C2a

USA (Hawaii)

A small tree of lowland rainforest confined to the Koolau Mountains on Oahu.

Assessor: World Conservation Monitoring Centre

Refs: 3372

\section{Zanthoxylum panamense}

Rutaceae

EN C2a

Costa Rica, Honduras, Panama

A species of uncertain nomenclature, found in monsoon forest and semi-evergreen forest mainly on the Caribbean side.

Assessor: Nelson, C

Refs: 13995

\section{Zanthoxylum penjaluensis}

Rutaceae

$\mathrm{CR} B 1+2 \mathrm{C}$

Indonesia (Java)

Few collections have been made of this species and they are all confined to Penjalu in forest at $720 \mathrm{~m}$. The habitat at this elevation has been almost completely cleared and pressures on remaining areas continue to be extreme. Assessor: World Conservation Monitoring Centre Refs: 9078

\section{Zanthoxylum procerum}

Rutaceae

EN C2a

Belize, Costa Rica, Guatemala, Honduras, Mexico, Nicaragua, Panama

Found on both sides of the continental divide, this species occurs in monsoon or semi-evergreen forest and cloud forest.

Assessor: Nelson, C.

Refs: 13995

\section{Zanthoxylum psammophilum}

Rutaceae

EN B $1+2 c$

Côte d'Ivoire

A species which is rare and endemic to coastal forest in Côte d'Ivoire. A significant part of these forests has been cleared and degraded.

Assessor: Assi, A.

Refs: 12822

\section{Zelkova abelicea \\ Ulmaceae}

VU B1+2ce, D2

Greece (Crete)

A small tree endemic to Crete, occurring in small numbers in 15-20 localities on the three main mountain massifs, especially at the south-east comer of the Omalos Plain. There are differences of opinion as to 
whether the extent of the species' occurrence is regressing or not. There is no doubt that grazing goats have a strong impact in places, but it has lessened over the past 80 years and the trees regenerate well by suckering. All shepherds' crooks in west Crete are made from the wood.

Assessor: World Conservation Monitoring Centre

Refs: $1890,5287,7222,16500,19018,19019$

\section{Zelkova carpinifolia}

Ulmaceae

$\mathrm{LR} / \mathrm{nt}$

Armenia, Azerbaijan, Georgia, Iran, Turkey

Assessor: Güner, A. \& J. Zielinski

Refs: $1956,3489,19165$

\section{Zelkova sicula}

Ulmaceae

CR C2b, Dl

Italy (Sicily)

Between 200 and 250 individuals exist in a single remote population extending $200 \mathrm{~m}$ along the banks of a stream on the northem slopes of the Iblei Mountains. The area is now fenced to prevent grazing and any other damage. Few flowering individuals have been seen in the last six years and the fruit produced appears to be sterile. Reproduction is largely vegetative.

Assessor: Garfi, G.

Refs: $6510,19150,19151$

\section{Zenia insignis}

Leguminosae

LR/nt

China (Guangdong, Guangxi, Guizhou, Hunan, Yunnan), Viet Nam

A large tree concentrated in limestone areas at low elevation. Populations are widespread throughout southem China and in several of the northem provinces of Viet Nam. In China constant overcutting of the tree and its habitat has resulted in the species becoming scarce. The species is apparently not specifically exploited in Viet Nam but is uncommon. It is the only member of the genus.

Assessor: World Conservation Monitoring Centre

Refs: $848,1818,8911,11847,15357,19055,19061$

\section{Zenkerella capparidacea ssp. capparidacea}

Leguminosae

VU B $1+2 b$

Tanzania

The type subspecies of a Tanzanian endemic. Populations are known from the Uluguru Mountains and South Nguru Mountains, where they are restricted to moist montane forest above $1430 \mathrm{~m}$.

Assessor: Lovett, J. \& G.P. Clarke

Refs: $3356,5204,8814$

\section{Zenkerella capparidacea ssp. grotei}

Leguminosae

VU B $1+2 b$

Tanzania

The more northerly distributed subspecies of this montane forest tree. Populations are known from the

East and West Usambara Mountains.

Assessor: Lovett, J. \& G.P. Clarke

Refs: $3356,5204,8814$

\section{Zenkerella egregia}

Leguminosae

VU $B 1+2 b$

Tanzania

A lowland forest species, restricted to the remaining forested areas at the foot of the East Usambara Mountains, Kimboza Forest Reserve at the foot of the Uluguru Mountains and possibly also in South Nguru.
These forests have declined heavily in the past because of the increasing clearing of land for agiculture. Continuing declines are prevented by the presence of forest guards and active conservation programmes.

Assessor: Lovett, J. \& G.P. Clarke

Refs: 3356, 5204, 10961, 11631

Zenkerella perplexa

Leguminosae

$\mathrm{VU} B 1+2 \mathrm{c}$

Tanzania

Known from only two sites this tree occurs in the Uluguru Mountains and Malundwe in areas of moist evergreen forest at medium elevations.

Assessor: Lovett, J. \& G.P. Clarke

Refs: $3356,8814,11631$

\section{Zeyheria tuberculosa}

Bignoniaceae

VU Alcd

Brazil (Espírito Santo, Minas Gerais, Rio de Janeiro, Sāo Paulo)

This pioneer species is found in rainforest, dry forest and * cerrado in south-east Brazil. This region is threatened by encroaching agriculture, ranching and charcoal production, which is causing a decline in this species.

Assessor: World Conservation Monitoring Centre

Refs: 4506

\section{Zieria chevalieri}

Rutaceae

VU B $1+2 c$

New Caledonia

Assessor: Jaffré, T. et al.

Refs: 10351

\section{Zimmermannia capillipes}

Euphorbiaceae

VU B $1+2 c$

Tanzania

The only populations known occur in areas of moist evergreen submontane forest in the East Usambara Mountains.

Assessor: Lovett, J. \& G.P. Clarke

Refs: 2074,3356

\section{Zimmermannia nguruensis}

Euphorbiaceae

$\mathrm{VU} B 1+2 \mathrm{c}, \mathrm{D} 2$

Tanzania

A small tree, which appears to be known only from the type collection, occurring in upper moist evergreen forest in the South Nguru Forest Reserve.

Assessor: Lovett, J. \& G.P. Clarke

Refs: 3356,8814

\section{Zimmermannia ovata}

Euphorbiaceae

VU D2

Kenya

Endemic to the drier parts of Ngangao forest in the Taita Hills, the species is known only from a small population containing few individuals. A population estimate may indicate that a more serious threat category is appropriate. Natural regeneration is not evident. The Plant Conservation Programme in Kenya is monitoring the species.

Assessor: World Conservation Monitoring Centre Refs: 6396,17859 


\section{Zimmermannia stipularis}

Euphorbiaceae

VU $B 1+2 b$

Tanzania

Restricted to eastem Tanzania, this species is found at

Mangalisa, Mpwapwa and Sao Hill in a montane dry forest habitat.

Assessor: Lovett, J. \& G.P. Clarke

Refs: 3356,8814

\section{Zinowiewia costaricensis}

Celastraceae

LR/nt

Belize, Costa Rica, Nicaragua, Panama

In Panama, the species appears to be at the limits of its range, occurring only rarely in Chiriquí. In other Central American countries the species is widespread in lowland evergreen rainforest between 1000 and $2500 \mathrm{~m}$. Most of the high-altitude locations are protected.

Assessor: Mitré, M.

Refs: $358,3156,9076,15037,16772$

\section{Zinowiewia micrantha}

Celastraceae

DD

Panama

The species is known only from the type collection, which originated from an area of Boquete, in Chiriqui, above $2000 \mathrm{~m}$. The taxonomic status of the species is doubtful. The only other Zinowiewia specimens collected in the area are of $\mathrm{Z}$. costaricensis.

Assessor: Mitré, $\mathrm{M}$.

Refs: $7980,15037,16772$

\section{Ziziphus celata}

Rhamnaceae

VU D1

USA (Florida)

Assessor: World Conservation Monitoring Centre

Refs: 19164

\section{Ziziphus hutchinsonï}

Rhamnaceae

VUAld

Philippines

An endemic species to the Philippines. Rates of habitat loss through logging and shifting cultivation have led to considerable population declines.

Assessor: World Conservation Monitoring Centre

Refs: 2072,4919

\section{Ziziphus mistol}

Rhamnaceae

Argentina (Catamarca, Chaco, Córdoba, Corrientes, Formosa, Jujuy, La Rioja, Salta, Santa Fé, Santiago del Estero, Tucumán), Bolivia, Paraguay

Widespread and widely used, the species occurs within an area of considerable human disturbance in dry subtropical forest in the Chaco.

Assessor: Prado, D.

Refs: 1262,7980

\section{Ziziphus pubescens ssp. glabra}

Rhamnaceae

Mozambique

Little information is available on this endemic of Mozambique. Few collections have been made.

Assessor: Bandeira, S.

Refs: 5117,18965

\section{Ziziphus robertsoniana}

Rhamnaceae

EN Bl+2abcde

Kenya, Tanzania

Occurring in areas of moist semi-deciduous coastal forest, the species is recorded from Kaya Diani, Gongoni Forest Reserve, Kaya Dzombo, Chale Island and Kaya Kinondo. More information is needed on the Tanzanian population. The loss and degradation of coastal forest continues at an alarming rate.

Assessor: CAMP Workshop in Kenya

Refs. 6396, 19181

\section{Ziziphus talanai}

Rhamnaceae

VU Aled

Philippines

A timber species, endemic to the Philippines. Rates of habitat loss through logging and shifting cultivation have led to considerable population declines.

Assessor: World Conservation Monitoring Centre

Refs: 2072,4919

\section{Zollingeria borneensis}

Sapindaceae

CR B $1+2 c$

Malaysia (Sabah)

A large, very distinctive tree known only from a few collections near Tawau. There is a possibility that this species is extinct, as it is suspected that the locality has been deforested.

Assessor: Adema, F.

Refs: 18389,19047

\section{Zollingeria dongnaiensis}

Sapindaceae

DD

Thailand, Viet Nam

In Viet Nam, the species is known from only two localities, one on the mainland in Bien Hoa and the other on the island of Con Son.

Assessor: World Conservation Monitoring Centre

Refs: 848

\section{Zygia lehmannii}

Leguminosae

$\mathrm{EN} \mathrm{B1+2c}$

Colombia

The species is known from Cauca according to confirmed records and from Valle from less definite records.

Assessor: Calderon, E

Refs: 19069

\section{Zygia oriunda}

Leguminosae

Peru

VU D2

Known only from the type collection, the species occurs in lowland Amazon forest in Loreto.

Assessor: World Conservation Monitoring Centre Refs: 1984

\section{Zygogynum cristatum}

Winteraceae

New Caledonia

VU B $1+2 c$

A notable species on account of its large flowers and numerous petals. It is known from just two upland locations on ultramafic soils in the region of Kouaoua at Me Ori and Aréha. The area is unprotected and exposed to threats from mining activities, fires and habitat clearance.

Assessor: Jaffré, T. et al.

Refs: 10351,12630 
Zygogynum oligostigma

Winteraceae

$\mathrm{EN} \mathrm{B1+2c}$

New Caledonia

Only a small tree or shrub. It is known from just two collections from the Kouaoua area in relict lowland forests and maquis on ultramafic substrate. The area is unprotected and exposed to threats from fire, mining activities and habitat clearance.

Assessor: Jaffre, T. et al.

Refs: 10351,12630

\section{Zygogynum tanyostigma}

\section{Winteraceae}

VU B $1+2 c$

New Caledonia

A small tree from wooded slopes on Mont Panié, collected infrequently at various altitudes. Although the area is given the status of a botanical reserve, it is thought that these plant populations are given insufficient protection.

Assessor: Jaffré, T. et al.

Refs: 10351, 12630 


\section{DATA SOURCES}

81 Vovides, A.P. 1981. Lista preliminar de plantas Mexicanas raras o en peligro de extinción. Biotica 6(2): 219-228.

Abeywickrama, B.A. 1983. Threatened or endangered plants of Sri Lanka and the starus of their conservation measures. pp. 11-18. In Jain, S.K. and Mehra, K.L. (eds.). Conservation of tropical plant resources. Howrah, Botanical Survey of India.

Webster, G. 1987. Annotations to: List of threatened plants of Latin America.

Boulos, Loutfy. 1996. Comments on North African trees.

Liogier, A. H. 1. La Flora de la Española. 3 vols. Dominican Republic: Universidad Central Del Este. Centénario de San Pedro de Macoris.

Gentry, A.H. 1975. Additional Panamanian Myristicaceae. Ann. Missouri Bot. Gard. 62: 474-479.

Rechinger, K.H. (ed.). 1963. Flora Iranica. Austria, Graz.

Moscoso, R.M. 1943. Catalogus Florae Domingensis I: Spermatophyta. New York: University of Santo Domingo. xlviii-732.

Pisano, E. 1983. The Magellanic tundra complex. Amsterdam: Elsevier. 295-328.

Hartley, T.G. 1979. A revision of the genus Tetractomia (Rutaceae), Journ. Amold Arb. 60(1): 127-153.

de Wilde, W.J.J.O. 1985. A new account of the genus Horsfieldia (Myristicaceae), Pt 3 Gardens' Bulletin 38(2): 185-225.

Veblen, T.T., C. Donoso, T. Kitzberger, \& A.J. Robertus. 1996. Ecology of southem Chilean and Argentinean Nothofagus forests. pp. 293-353. In Veblen, T.T. et al. The ecology and biogeography of Nothofagus forests.

Neill, David \& Walter Palacios. 1989. Arboles de la Amazonia Ecuatoriana. Quito, Ecuador: Dirección Nacional Forestal. 120pp.

Balick, Michael. (in preparation) Checklist of the plants of Belize, with annotations on common names and uses. (unpublished). 129pp.

Farjon, Aljos, Christopher N. Page, \& Nico Schellevis. 1993. A preliminary world list of threatened conifer taxa Biodiversity and Conservation 2: 304-326.

Brown, E. 1991. The quest for Jubaeopsis caffra, the pondoland palm. Principes 35(2): 99-101.

401 Kelly, D.L. 1988. The threatened flowering plants of Jamaica. Biological Conservation 46(3): 201-216.

412 Muller, C.H. 1979. Quercus deliquescens, a new species from Chihuahua, Mexico. Phytologia 42(2): 289-291.

Balakrishnan, N.P. 1982. Nomenclatural notes on some flowering plants - III. Bull. Bot. Survey India 22(1): 173-177.

Brown, F.B.H. \& E.D.W. Brown. 1931. Flora of Southeastern Polynesia. Bull. Bernice $P$. Bishop Mus.

448 Shimizu, Yoshikazu. 1992. Origin of Distylium dry forest and occurrence of endangered species in the Bonin Islands. Pacific Science 46(2): 179-196.

450 Keay, R.W.J. 1996. Letter to WCMC concerning threatened and endemic tree species in Nigeria.

Gómez-Campo, César et al. (eds.). 1996. Libro Rojo de especies vegetales amenazadas de las Islas Canarias. (unpublished). Lists 300 threatened species, including island and protected area location.

476 Forman, L.L., R.W.J.M. van der Ham, M.M Harley, \& T.J. Lawrence. 1994. Rosselia, a new genus of Burseraceae from the Louisiade Archipelago, Papua New Guinea. Kew Bull. 49(4): 601-621.

536 Islebe, Gerald. 1993. Will Guatemala's Juniperus-Pinus forests survive? Environmental Conservation 20(2): 167-168.

556 White, F. 1988. The taxonomy, ecology and chorology of African Ebenaceae. II. The nonGuineo-Congolian species of Diospyros (excluding sect. Royena), Bull. Jard. Bot. Nat. Belg. 58: 325-448.

559 Topp, J.M.W. 1988. An annotated check list of the flora of Diego Garcia, British Ocean Territory. Atoll Research Bulletin 313

561 Molur, $S$ et al. (eds.). 1995. Conservation assessment and management plan (CAMP) for selected species of medicinal plants of southem India. $108 \mathrm{pp}$.

563 Kalkman, C. 1993. Rosaceae. Flora Malesiana. Leiden: Flora Malesiana Foundation.

642 Lundell, C.L. 1984. Mesoamerican Celastraceae - II. Phyrologia 56(3): 137-140.

662 Hou, D. 1996. Caesalpinioideae. Flora Malesiana. Leiden: Flora Malesiana Foundation. 

of southern African plants. Strelitzia 4.Pretoria, South Africa: National Botanical Institute. $117 \mathrm{pp}$.

Hill, K. 1994. Extract from Flora of Australia Vol 48 - Gymnosperms. (unpublished). keys.

Schick, Muñoz.H. 1985. Annotations to the TPU list of threatened plants of Chile.

730 Stevens, W.D. Flora de Nicaragua (in preparation). (unpublished).

832 Chandrabose, M. N.C. Nair, \& V. Chandrasekaran. 1982. Two rare and threatened flowering plants of South India: rediscovered. Indian J. Forest. 5(2): 159-160.

842 Fukarek, P. 1959. Arbres et arbustes rares et menackes de la flore de Yougoslavie. pp. 159165. In IUCN. Animaux et vegetaux rares de la Région Mediterranéenne. Proceedings of the IUCN 7th Technical Meeting, 11-19 September 1958, Athens, vol. 5. Brussels: IUCN.

848 Ministry of Science, Technology and Environment. 1996. Sach do Viet Nam Phan Thuc Vat. Hanoi: Science and Technics Publishing House. 484pp.

849 Lughadha, Nic E. 1994. Notes on the Myrtaceae of the Pico das Almas, Bahia, Brazil. 49(2): 321-329.

875 de Wilde, W.J.J.O. 1987. Further supplementary data on Malesian Knema (Myristicaceae). Blumea 32: 115-141.

898 Peluso, Nancy Lee. 1992. The ironwood problem: (Mis) management and development of an extractive rainforest product. In Conservation Biology 6(2): 210-219.

902 Given, D.R. 1994. Letter to WCMC (Harriet Gillett) conceming threatened plants of New Zealand. Refers to datasource 19303.

942 Maas, P.J.M. 1988. Annotations to: List of threatened plants of Latin America.

1011 Whitmore, T.C., I.G.M. Tantra, \& U. Sutisna (eds.). 1989. Tree flora of Indonesia. Bogor, Indonesia: Forest Research and Development Centre. 119pp.

1030 Green, P S. 1994. A revision of Chionanthus (Oleaceae) in S America and the description of Priogymnanthus, gen nov. 49(2): 261-286.

1041 Houerou, H.N. 1969. Le végétation de la Tunisie steppique. Annales de I'Institut National de la Recherche Agronomique de Tunisie 42(5): 620.
Ramachandran, V.S. \& P. Bhargavan. 1984. Diospyros trichophylla Alston (Ebenaceae) - a new record for India. Indian J. Forestry 7(3): 247-248.

1080 van der Werf, H. 1988. A new species of Ocotea (Lauraceae) from Nicaragua and a note on Ocotea jorge-escobarii. Ann. Missouri Bot. Gard. 75(2): 723-727.

1086 Mondal, M.S. \& G.S. Giri (comps.). 1994. Draft CITES proposal by Botanical Survey of India to list Aquilaria malaccensis on Appendix II. 3pp.

1196 Mennega, A. 1981. Annotations: List of threatened plants of Middle America.

1228 Balakrishna, P. \& T. Ravishankar. 1993. Letter with list of corrections to TPU printout for India. 3pp.

1237 Nair, N.C. \& S.R. Srinivasan. 1982. Rediscovery of Eugenia discifera Gamble (Myrtaceae) and its lectotypification. Bull. Bot. Surv. India 22(1): 232-233.

1262 Prado, Darién Eros. 1996. Completed data collection forms for trees of Argentina and neighbouring countries.

1308 Turrill, W.B., E. Milne-Redhead, C.E. Hubbard, \& R.M. Polhill. 1952. Flora of Tropical East Africa. Published by the East African Community.

1330 Hedberg, Inga \& Sue Edwards (eds.). 1989. Flora of Ethiopia. Volume 3. Pittosporaceae to Araliaceae. Ethiopia \& Sweden: The National Herbarium, Addis Ababa \& The Department of Systematic Botany, Uppsala. 659pp.

1332 Wieringa, J.J. 1996. Additions to the Tree species evaluations using new CITES listing critesia' drafted by WCMC, September 1996.

1370 Iltis, H. 1981. Studies in the Capparidaceae XV: Capparis panamensis, n. sp. Ann Missouri Bot. Gard. 68: 681-685.

1411 Page, Wayne. 1997. Data collection forms completed on the threatened tree species of Mauritius.

1491 Ferguson, D.K. 1989. On Vietnamese Amentotaxus. Bull. Mus. Natn. Hist. Nat. Paris i1

1493 de Wilde, W.J.J.O. 1995. Census of Myristica (Myristicaceae) in New Guinea anno 1994. Blumea 40(2): 237-344.

1503 Prance, G.T. \& S. Mori. 1979. Lecythidaceae Part I. The actinomorphic-flowered New World Lecythidaceae (Asteranthus, Gustavia, Grias, Allantoma and Cariniana). Flora Neotropica. pp. 270. 
1512 Iriondo, J.M., L.J. De Hond, \& C. GómezCampo. 1993. Current research on the biology of threatened plant species of the Mediterranean Basin and Macaronesia: a database. (unpublished). Includes database printout of 201 threatened species with details of the organisation undertaking research. 209 pp.

1517 Anon. 1979. Tropical legumes: Resources for the future. Washington, DC: National Academy of Sciences.

1538 Riskind, D.H. \& T.F. Patterson. 1975. Distributional and ecological notes on Pinus culminicola. Madrono 23: 159-161.

1539 Gordon, A.G. 1968. The ecology of Picea chihuhuana Mart. Ecology 49: 880-896.

1546 Carter, Susan. 1992. Annotations to: Conservation status listing: Euphorbia. 59pp.

1551 Sykes, W.R. \& 1.A.E. Atkinson. 1988. Rare and endangered plants of Norfolk Island. Wellington: DSIR, Botany Division.

1577 Oliver, D., W.T. Thiselton-Dyer, D. Prain, \& A.W. Hill (eds.). 1868. Flora of tropical Africa. Ashford, Kent: English Ministry of the Colonies.

1609 Cunningham, A.B. 1993. African medicinal plants: setting priorities at the interface between conservation and primary healthcare. Paris: UNESCO. 50pp.

1619 Sastry, A.R.K. \& P.K. Hajra. 1983. Rare and endemic species of Rhododendron in India - A preliminary study. pp. 222-231. In An assessment of threatened plants of India. Naba Mudran Private Limited, Calcutta, India: Botanical Survey of India.

1632 Arvigo, Rosita, Michael Balick, \& Laura Evans (eds.). 1993. Rainforest remedies. One hundred healing herbs of Belize. United States: Lotus Press. 221 pp.

1653 Carpio, C. 1994. Annotations to: threatened plants of South America - Peru. 101 pp.

1660 East West Herbs Ltd. Price List and Catalogue. 5pp.

1685 Jones, D.T. 1987. Rare plant profile no. 1: Merrillia caloxylon (Rutaceae). Bot. Gard. Conserv. News 1(1): 38-42.

1719 Schmidt, P.A. 1997. Completed data collection form for Sorbus in Germany.

1736 Smith, Albert.C. 1954. Botanical studies in Fiji. Smithsonian Report: 305-315.

1738 Pennington, T. 1982. Annotations: List of threatened plants of Middle America.
1739 Pham-Hoáng, Hô. (ed.). 1991. An illustrated flora of Vietnam. Saigon: Mekong Press.

1766 Whitmore, T.C., I.G.M Tantra, \& U. Sutisna (eds.). 1989. Tree flora of Indonesia. Bogor, Indonesia: Forest Research and Development Centre. 429pp.

1803 Navarro, A.V. 1982. Annotations to: List of threatened plants of Middle America.

1818 National Environment Protection Bureau. 1987. The list of rare and endangered plants protected in China. Botanical Institute of Chinese Academy of Sciences, Beijing: Academy Press. 96pp.

1827 Lundell, C.L. 1966. Studies of tropical American plants - III. Wrightia 3(8): 161-172.

1833 Mabberley, D.J. 1987. The plant-book. Cambridge: Cambridge University Press. 707 pp.

1857 Kopp, L.E. 1966. A taxonomic revision of the genus Persea in the Western Hemisphere (Persea-Lauraceae). Mem. N.Y. Bot. Gard. 14(1): 1-120.

1881 Forero, E \& A H Gentry. 1989. Lista anotada de las plantas del departamento del Chocó, Colombia. Bibl. Jose Jeronimo Triana 10: 1. 142.

1890 Tzanoudakis, Dimitris \& Bertrand de Montmollin. 1996. Annotations to WCMC printout entitled 'Greece - nationally threatened taxa listed at WCMC' dated 16 October 1995. 42 pp.

1892 Xianpu, W. 1991. Review report on the course of protected areas in China. (unpublished). Document prepared for the Palaearctic Asia Regional Review to be presented at the Congress on World Parks and Protected Areas at Caracas, Venezuela, February 1992.

1956 Borodin, A.M. et al. 1985. Krasnaya kniga SSSR: redkie i nakhodyashchiesya pod ugrozoi ischeznoveniya vidy zhivotnykh i rastenii. - izdanie vtoroe [2]: tom pervyi vtoroi [1-2]. Moscow: Lesnaya Promyshlennost.

1957 Caribbean Conservation Association. (comp.). 1991. St Lucia: country environmental profile. St Michael, Barbados: Caribbean Conservation Association. $x x-332$.

1966 Graham, S.A. 1988. Annotations to: List of threatened plants of Middle America.

1972 Lundell, C.L. 1968. Studies of Tropical American plants - V. Wrightia 4(2): 79-96.

1983 Pires O'Brien, J. 1996. Data collection forms for Sapotaceae species in Brazil. 

Checklist: Catalogue of the Flowering Plants and Gymnosperms of Peru on the Web. http:/www.mobot.org/MOBOT/research/peru. html

2000 Strahm, W. 1987. Annotations to: Full list of species in the WCMC database for Mauritius and Rodrigues.

2026 Vaughan, R.E. \& P.O. Wiehe. 1953. The genus Pandanus in the Mascarene Islands. $O$. Linn. Soc. Bot. 55: 1-32.

2036 Adjanohoun, E.J. 1979. Benin. Part of appendix 10: Possibilities and needs for conservation of plant species and vegetation in Africa. pp. 91-92. In Hedberg, I. (ed.). Systematic botany, plant utilization and biosphere conservation. Stockholm: Almqvist \& Wiksell Intemational.

Timberlake, Jonathan. 1996. Notes on possible globally threatened tree species occurring in Africa that have been recorded from Zimbabwe. 2pp.

Cadet, Th. 1984. Liste et commentaires sur les plantes en danger des Mascareignes. Paris, Mimeo: Conservatoire et Jardins Botaniques de Nancy. 20pp.

2072 Forest Management Bureau. 1988. Natural forest resources of the Philippines. Department of Environment and Natural Resources, Manila. 62pp.

2074 Radcliffe-Smith, A. 1987. Euphorbiaceae Part 1 in Flora of Tropical East Africa. Polhill,R.M. (ed.). A.A. Balkema/ Rotterdam/ Brookfield.

2106 Huang, T.C. (ed.). 1994. Flora of Taiwan (2nd ed.). Taipei: Editorial Committee of the Flora of Taiwan. 1-648.

2147 de Wilde, W.J.J.O. 1996. Additional notes on species of the Asian genera Endocomia, Horsfieldia, and Knema (Myristicaceae). Blumea 41(2): 375-396.

2162 Anon. 1994. Red Book of the Ukraine. Kiev: Ukrainska Encyclopedia.

2196 Fosberg, F.R. 1973. On present condition and conservation of forests in Micronesia. In Pac. Sci. Assoc. Standing Comm. on Pac. Bot. Symposium: Planned utilization of the lowland tropical forests, August 1971. Bogor, Indonesia.

2226 Laubenfels, D. de. 1969. A revision of the Malesian and Pacific rainforest conifers. Joumal of the Amold Arboretum 50: 274-369.

2228 Maas, P.J.M. \& A.K. van Setten. 1987. Annotations to: List of threatened plants of Latin America.
Molina, A. 1951. Nuevas especies de plantas de la República de Honduras. Ceiba 1: 255 . 263.

2276 Center for Plant Conservation (CPC). 1990. Printout of CPC's data for North American plants.

2354 Miller, A.G. 1992. List of Socotran endemics with conservation status. Revised November 1991. (unpublished). 15pp.

2361 Friis, I. 1992. Forests and forest trees of Northeast Tropical Africa. Their natural habitats and distribution patterns in Ethiopia, Djibouti and Somalia. Middlesex, UK: HMSO. 396 pp.

2362 Erfurth, T. \& H. Rusche. 1976. The marketing of tropical wood. Rome: FAO. 60pp.

2418 Hawthome, W.D. 1993. East African coastal forest botany. pp. 57-99. In Lovett, J. \& S.K. Wasser (eds.). Biogeography and ecology of the rain forests of Eastern Africa.

2421 Figueiredo, Estrela. 1994. Diversity and endemism of angiosperms in the Gulf of Guinea islands. Biodiversity and Conservation 3: 785-793.

2422 Browne, F.G. 1955. Forest trees of Sarawak and Brunei and their products. Kuching: Government Printer. 369pp.

2428 Nooteboom, H.P. 1985. Notes on Magnoliaceae with a revision of Pachylamax and Elmerrillia and the Malesian species of Manglietia and Michelia. Blumea 31: 65-121.

2430 Balakrishnan, N.P. \& N.G. Nair. 1983. New taxa and record from Saddle Peak, Andaman Islands. Bull. Bot. Surv. India 24(1): 28-36.

2459 Gillett, Jan B., Roger M. Polhill \& Bernard Verdcourt (eds.). 1971. Leguminosae Part 4; Papilionoideae (1) \& (2) in Flora of Tropical East Africa. Milne-Redhead, E. \& Polhill, R.M. Crown Agents for Oversea Governments and Administrations.

2474 Wiles, Gary J. 1996. Letter to Julie Reay with annotations to Northern Marianas printout plus additional species. $2 \mathrm{pp}$.

2479 Staskiewicz, J. 1988. A taxonomic revision of the genus Podocarpus from the Greater and Lesser Antilles. Fragmenta Floristica et Geobotanica 33(1): 71-106.

2514 Burger, W. 1988. A new genus of Lauraceae from Costa Rica, with comments on problems of generic and specific delimitation within the family. Brittonia 40(3): 275-282.

2529 Webster, G. \& M.J. Huft. 1988. Revised synopsis of Panamanian Euphorbiaceae. Ann. Missouri Bot. Gard. 75(3): 1087-1144. 
2538 Nayar, M.P. \& A.R.K. Sastry (eds.). 1987. Red Data Book of Indian plants. Vol. 1. Calcutta: Botanical Survey of India. 367pp.

2562 Pereira Carauta, Jorge Pedro. 1989 Ficus(Moraceae) no Brazil: Conservaçao e taxonomia. Albertoa 2(1): 1-350.

2609 Sanjappa, M. 1994. Crudia (Leguminosae: Caesalpinioideae), a new generic record for India with a new species of the genus. Kew Bull. 49(3): 565-568.

2625 Kostermans, A. 1989. Comments on Indonesian timber species.

2627 Fosberg, F.R., Marie-Helene Sachet, \& Royce Oliver (comps.). 1979. A geographical checklist of the Micronesian Dicotyledonae. Micronesica 15(1): 41-295.

2652 Lafon, Ron. 1984. Euphorbia restricta Dyer: a visit to the habitat. The Euphorbia Joumal 2: 29-35.

2698 Nooteboom, H.P. (ed.). 1985. New records. Flora Malesiana Bull. 9(39): 294-304.

2724 Figueiredo, Estrela. 1997. Trees of S. Tomé and Príncipe. 7pp.

2739 Pinto, P. \& P. Ruiz. 1983. Flora of Colombia. Bogotá: Instituto de Ciencias Naturales.

2744 Ramamoorthy, T.P. \& E.M. Zardini. 1987. The systematics and evolution of Ludwigia sect. Myrtocarpus sensu lato (Onagraceae). Systematic Botany Monographs 19: 1-120.

2773 Hutchinson, J., J.M. Dalziel, \& F.N. Hepper. 1927. Flora of West Tropical Africa. Published by the English Ministry of State for the Colonies.

2802 Yeom, F. 1984. Lesser known tropical wood species: how bright is their future? Unasylva 36(146): 2-16.

2818 Waldren, Steve. 1993. Annotations and additions to TPU printout of the Pitcaim islands. (unpublished). Includes additions to Oeno. 7pp.

2863 Boulos, Loutfy, 1. Annotations to: the conservation status listing of endemic and threatened trees of the Mediterranean coast of Africa. 2pp.

2891 Phengklai, Chamlong. 1986. Study in Thai flora. Thai Forest Bulletin (Botany) 1(16): 2118.

2901 Westing, Arthur \& Carol Westing. Endangered species of Viet Nam. (unpublished). 7pp.

2909 Pipoly III, J.J. 1996. New species of Ardisia (Myrsinaceae) from Ecuador and Peru. Sida 17(2): 445-458.
2915 Boratynski, A. 1997. Letter to Sara Oldfield containing information and completed data collection forms on threatened woody species of Poland, Greece and Turkey. 2pp.

2935 Hazlett, D.L. 1979. Arboles maderables y otros árboles desconocidos de la Cordillera Nombre de Dios. Ceiba 23(2): 76-84.

2965 Lavin, M \& M Sousa. 1995. Phylogenetic systematics and biogeography of the tribe Robinieae (Leguminosae). Systematic Bot. Monographs 45: 1-165.

2989 Wurdack, J.J. 1988. Annotations to: the conservation status listing: Melastomataeae.

3013 Sahni, K.C. \& H.B. Naithani. 1979. A rare and spectacular rhododendron from Kameng District. Indian Forester 105(1): 77.

3014 Ferreyra, R. 1977. Endangered species and plant communities in Andean and coastal Peru. Bronx, New York: New York Botanical Garden. 150-157.

3018 Obermeyer, A.A. \& R.G. Strey. 1969. A new species of Raphia from northem Zululand and southern Mozambique. Bothalia 10(1): 29-37.

3047 Torres-Romero, Jorge H. 1988. Flore de Colombia. Bogotá: Instituto de Ciencias Naturales. 61pp.

3090 Suvatti, C. 1978. Flora of Thailand. Bangkok: Royal Institute.

3091 Smitinand, T. \& K. Larsen (eds.). 1970. Flora of Thailand. Bangkok: Applied Science Research Corporation and Thailand Institute of Scientific and Technological Research.

3092 Adam, P. 1992. Australian rainforests. New York: Oxford University Press. 137-178.

3104 Fjeldså, Jon \& Michael Kessler. 1996. Conserving the biological diversity of Polylepis woodlands of the highland of Peru and Bolivia. A contribution to sustainable natural resource management in the Andes. Copenhagen, Denmark: Nordic Foundation for Development and Ecology, NORDECO. 250 pp.

3122 Browne, F.G. 1955. Forest trees of Sarawak and Brunei and their products. Kunching: Government Printing Office.

3156 Vallester, E. 1983. Annotations to: Conservation status listing of plants of Middle America.

3181 Gunatilleke, C.V.S. \& I.A.U.N. 1987. Rare woody species of Sinharaja rain forest in Sri Lanka. In Kostermans, A.J.G.H. (ed.). Proceedings of the Third Round Table Conference on Dipterocarps. Jakarta, UnescoMAB and UNEP 519-530. 
Villa-Lobos, Jane. 1994. Annotations to: Conservation status listing of plants of South America made from origional data cards. 43394.

3241 Ricci, Marcia. 1990. Programa de conservación y recuperación de plantas amenazadas de Juan Fernandez. (Including annotations by $\mathbf{H}$. Synge).

3295 Yang, Jenq-Chuan \& Fuh-Jiunn Pan. 1996. The current status of native woody vegetation in Taiwan. pp. 89-108. In Hunt, D. (ed.). Temperate trees under threat.

3344 Braun, Kate. 1994. Swaziland National Trust Commission threatened plant database printout. 3pp.

3356 Lovett, Jon. 1996. Completed data collection forms for restricted range trees of Tanzania.

3372 Wagner, W., D. Herbst, \& S. Sohmer. 1990. Manual of the flowering plants of Hawaii. Honolulu: University of Hawaii Press, Bishop Museum Press. 1853pp.

3404 Williams, K.A.W. 1984. Native plants of Queensland Vol 2. Brisbane: Printcraft.

3467 McVaugh, R. 1963. Tropical Myrtaceae, Il. Fieldiana, Bot. 29(8): 391-532.

3476 Coode, M. 1982. Pers. comm.

3479 IUCN. 1990. La conservation des ecosystèmes forestiers du Gabon. IUCN, Tropical Forest Programme Series.

3484 Leigh, John H. 1982. Letter to TPU, 13 May 1982.

3489 Güner, A. \& J. Zielinski, J. 1996. The conservation status of Turkish woody flora. pp. 12. In Hunt, D. (ed.). Temperate trees under threat. Proceedings of an IDS symposium on the conservation status of temperate trees, University of Bonn, 30 Sept 1 Oct. 1994.

de Wilde, W.J.J.O. 1986. A new account of the genus Horsfieldia (Myristicaceae), Pt 4. Gardens' Bulletin 39(1): 1-65.

3619 Niyomdham, Chawalit. 1986. A list of flowering plants in the swamp area of peninsular Thailand. Thai Forest Bulletin (Botany) 1(16): 211-229.

Cheng, Wen-Chun. 1980. Sylva Sinica. Flora of Woody Plants in China Committee. 929pp.

Jaeger, Paul. 1984. Personal communication to Stephen Droop on the plants in Mali threatened with extinction. 4pp. de Wilde, W.J.J.O. 1997. A manuscript on Myristica (Myristicaceae). (unpublished).
3736 Güner, A. \& J. Zielinski (comps.). 1995. The conservation status of the Turkish woody flora. (unpublished). 17pp.

3738 Elliott, Stephen \& Joseph Brimacombe. 1985. The medicinal plants of Gunung Leuser National Park, Indonesia. 57pp.

3768 Dransfield, John. 1993. Conversation with Dennis Johnson.

3786 Center for Plant Conservation (CPC). 1992. Printout of CPC's data for North American plants.

3791 Mori, Scott A., Ghillean T. Prance, \& C. Zeeuw. 1990. Lecythidaceae - Part II: The zygomorphic-flowered New World genera (Couroupita, Corythophora, Bertholletia, Couratari, Eschweilera, \& Lecythis). Flora Neotropica, Monograph 21 (II). 376pp.

3811 Kolbeck, J. \& M. Kucera. 1989. A brief survey of selected woody species of North Korea. Pruhonice, Czechoslovakia: Botanical Institute, Czech Academy of Sciences.

3812 Page, C.N. 1980. Picea farreri, a new temperate conifer from upper Burma. Notes from the Royal Botanic Garden Edinburgh 38(1): 129-136.

3905 Sanchez Vindas, P.E. \& L.M. Ortega Torres. 1987. Nueva especie de Eugenia L. (Myrtaceae) de Veracruz, Mexico. Phytologia 63(5): 404-406.

3912 Smith, Lyman B. \& Robert Jack Downs. 1977. Pitcaimioideae, Tillandsioideae, Bromelioideae (Bromeliaceae). pp. 2142.

3913 Almeda, F. 1981. Annotations to: List of threatened plants of Middle America.

3917 Gonzalez Ayala, J. 1992. Lista preliminar de plantcs Salvadorenas amenazadas de extinción. 50 pp.

3925 Brenan, J.P.M. 1964. Leguminosae Part 2; subfamily Caesalpinioideae in Flora of Tropical East Africa. Milne-Redhead, E. \& Polhill, R.M. (eds.). Crown Agents for Oversea Governments and Administration.

3932 Adams, C.D. 1994. Letter from C. Dennis Adams to Harriet Gillett. 29pp.

3951 Dvorak, W.S. \& J.K. Donahue. 1992. CAMCORE Cooperative Research Review 1980-1992. Forestry Department, North Carolina State University, USA: CAMCORE (La Cooperativa de Recursos de Coníferas de Centroamérica y México). $94 \mathrm{pp}$.

3952 Standley, P.C. 1. Trees and shrubs of Mexico. Contrib. U.S. Nat. Herb. 232: 1-1727.

3969 Gómez, L.D. 1982. Annotations to: List of threatened plants of Middle America. 
3977 Nelson, C. 1986. Plantas nuevas para la Flora de Honduras IV y propuesta de la combinación. Ceiba 27(2): 181-226.

3998 FAO Regional Office for Asia and the Pacific. 1985. Dipterocarps of South Asia. Bangkok: FAO. $321 \mathrm{pp}$.

4013 Nasir, Yasin. 1991. Threatened plants of Pakistan. pp. 229-234. In Plant Life of South Asia, S.J. Ali \& A. Ghaffer (eds.).

4072 Miller, J. 1988. A revised treatment of Boraginaceae for Panama. Ann. Missouri Bot. Gard. 75(2): 456-521.

4074 Coode, M J E \& R Weibel. 1994. Elaeocarpus for Flora Malesiana - notes, new taxa and combinations in sect. Elaeocarpus. 49(2): 235 . 259.

4082 Kraus, Fred. 1991. Biodiversity conservation on Guana Island, British Virgin Islands. Road Town, Tortola, British Virgin Islands 138pp.

4089 Kelly, D.L. \& D. Burke. 1990. Endemic flowering plants of Jamaica under threat: a fresh report. (unpublished). Map. School of Botany, Trinity College, University of Dublin, Dublin 2, Ireland. 30pp.

4105 Fryxell, P.A. 1981. Annotations to: List of threatened plants of Middle America.

4108 Burkill, H.M. 1985. The useful plants of West Tropical Africa. The Royal Botanic Gardens, Kew. 1-960.

4147 García, R.D. \& I. Olmsted. 1987. Listado florístico de la Reserva Sian Ka'an. Puerto Morelos, Quintana Roo, Mexico 71pp.

4196 Takhtajan, A.L. 1981. Rare and vanishing plants of the USSR to be protected. Leningrad: Nauka. 202pp.

4217 Centro de Datos para la Conservación-CDC CVC. 1980. Lista preliminar de plantas especiales del Centro de Datos para la conservación, CDC-CVC. (unpublished). 10 pp.

4237 Maynard, A.C. 1986. Letter to H. Synge.

4246 Emanoil, M. (ed.). 1994. Encyclopedia of endangered species. IUCN-The World Conservation Union. Gale Research International Ltd. 1230pp.

4253 Given, D.R. 1988. Rare and endangered plants - protection and conservation. In Proceedings of the New Zealand Parks and Recreation Admin. Conference, 1987. 151-165.

4301 Gutierrez, Liliana \& Andrew P. Vovides. 1997. An in situ study of Magnolia dealbata Zucc. in Veracruz State: an endangered endemic tree of Mexico. Biodiversity and Conservation 6: 89-97.
Perez de La Rosa, J.A. 1985. Una nueva especie de Juniperus de Mexico. Phytologia 57(2): 81-86.

4329 Whitmore, T.C., I.G.M. Tantra, \& U. Sutisna (eds.). 1989. Tree flora of Indonesia. Bogor, Indonesia: Forest Research and Development Centre. 204pp.

4367 Womersley, J.S. \& E.E. Henty (eds.). 1978. Handbooks of the flora of Papua New Guinea. Melbourne University Press.

4377 Bompard, J.M. 1988. Wild Mangifera species in Kalimantan (Indonesia) and in Malaysia. Final report on the 1986-1988 collecting missions. WWF Project No. 3305. Rome, IBPGR, IUCN-WWF. .

4391 Page, C.N. 1988. New and maintained genera in the conifer families Podocarpaceae and Pinaceae. Notes From the Royal Botanic Garden Edinburgh 45(2): 377-395.

4460 Prance, G.T. 1991. Annotations to: List of threatened plants in Chrysobalanaceae, Dichapetalaceae, and Lecythidaceae.

4491 Williams, L.O. 1981. Annotations: List of threatened plants of Middle America.

4492 Bouchet, P., T. Jaffre, \& J. Veillon. 1995. Plant extinction in New Caledonia: protection of sclerophyll forests urgently needed. Biodiversity and Conservation 4: 415-428.

4505 Edwards, Sue. 1996. Comments on threatened Ethiopian trees.

4506 FAO Forestry Department. 1986. Databook on endangered tree and shrub species and their provenances. Rome: FAO. 524pp.

4508 Farjon, Aljos. 1994. Annotations to: Conservation status listing of conifers of the world dated 15 June 1994. 47 pp.

4509 Stoffelen, P., E. Robbrecht, \& E. Smets. 1996. A revision of Corynanthe and Pausinystalia (African Rubiaceae-Coptosapelteae). Botanical Joumal of the Linnean Society 120(4): 287-325.

4522 Rodríguez, R.R., O. Matthei, \& M. Quezada. 1983. Flora Arbórea de Chile. Chile: Universidad de Concepción. 408 pp.

4556 Bramwell, David \& Julio Rodrigo Perez. 1982. Prioridades para la conservación de la diversidad genética en la flora de las Islas Canarias. Botanica Macaronesica 10: 3-17.

4581 Beard, J.S. 1990. Plantlife in Western Australia. Kenthurst, NSW: Kangaroo Press. 319pp.

4616 Mori, Scott A. 1981. Annotations to: List of threatened plants of Middle America. 
Fries, R.E. 1937. Revision der Arten einiger Anonaceen-Gattungen, IV. Acta Horti Berg. 12(2): 221-288.

4627

Mohanan, M., A.N. Henry, \& N.C. Nair. 1982. Some rare and fast disappearing plants discovered in Trivandrum District, Kerala. Bull. Bot. Surv. India 22(1): 105-108.

4628 Supthut, D. 1994. Annotations to: conservation status listing of species of Didiereaceae.

4665 Buchholz, J. \& N.E. Gray. 1948. A taxonomic revision of Podocarpus II. The American species of Podocarpus: Section Stachycarpus. J. Amold Arboretum 29: 117-151.

4734 Lemmens, R, P Jansen, \& J Siemonsma. 1989. Plant resources of South-East Asia. Basic list of species and commodity grouping. Wageningen, Netherlands: PROSEA Project.

4799 Nayar, M.P. \& A.R.K. Sastry (eds.). 1990. Red Data Book of Indian Plants. Vol. 3. Calcutta: Botanical Survey of India. 27lpp.

4839 Kazmierczakowa, R. \& K. Zarzycki (eds.) 1994. Indeks lacinskich nazw opisanych gatunków z podaniem kateforii zagrozenia (synonimy zlozono kursywa) [Index of Latin names of species covered in the 'Polish Red Data Book of plants']. (unpublished). Includes threat categories. 301-303.

4861 Seymour, F.C. 1981. Annotations tu: List of threatened plants of Middle America.

4862 Aguilar, J.M. 1981. Annotations to: List of threatened plants of Middle America.

4863 Ekim, T., M. Koyuncu, S. Erik, \& R. Ilarslan et al. (eds.). 1989. Türkiye'nin tehlike altindaki nadir ve endemik bitki turleri. Ankara: 'Türkiye Tabiatini Konma Dernegi [Turkish Association for the Conservation of Nature and Natural Resources]. 227pp.

4870 Brako, L. \& J.L. Zarucchi. 1993. Catalogue of the flowering plants and gymnosperms of Peru. Mongr. Syst. Bot. (Missouri Bot. Gard.) 45: $1-1286$

4893 Benoit, C.I. (ed.). 1989. Red list of Chilean terrestrial flora. (Part One). Santiago: Chilean Forestry Service (CONAF). 151 pp.

4919 Penafiel, S. 1990. Annotation to list of tropical timbers for the Philippines.

4934 Martínez, M. 1974. Los enciños de México. An. Inst. Biol. Univ. Nal. Autón. México Ser. Botánica 45(1): 21-56.

4966 Little, E.L. \& W.B. Critchfield. 1966. Geographic distribution of the pines of the world. $100 \mathrm{pp}$.
4974 Standley, P.C., J.A. Steyermark, \& L.O. Williams. 1946. Flora of Guatemala. Fieldiana Bot. 24

4977 Schmitt, Klaus. 1996. Botanical survey in the Oban Division, Cross River National Park. (unpublished). Oban Hills Programme, Calabar. 5lpp.

4978 Silic, Cedomil. (ed.). 1996. The list of the vegetable species (Pteridophyta and Spermatophyta) for the Red Book of Bosnia and Herzegovina. Sarajevo: 1996. 20 pp.

4979 Van Rompaey, R.S.A.R. 1996. Rain forest refugia in Liberia. pp. 624-628. In van der Maesen, L.J.G., van der Burght, X.M. \& van Medenbach de Rooy, J.M. (eds.). The biodiversity of African plants. Proceedings Xivth Aetfat Congress, 22-27 August 1994, Wageningen, The Netherlands. Dordrecht: Kluwer Academic Publishers.

4986 Madulid, D.A. 1987. A checklist of the rare, endemic and endangered plants of Palawan. Philippine Scient. 24: 55-66.

5003 FAO. 1990. Report of the Seventh Session of the FAO Panel of Experts on Forest Gene Resources. Rome: Food and Agriculture Organization of the United Nations. 79pp.

5020 Sleumer, H. 1975. Flacourtiaceae in Flora of Tropical East Africa. Polhill,R.M. (ed.). Crown Agents for Oversea Governments and Administrations.

5054 Loc, Phan Ke. 1992. Annotations to: Conservation status listing for Vietnam dated 25 March 1992. (unpublished). 49pp.

5070 Weitzman, A. L. 1996. Conservation of Theaceae and Bonnetiaceae. (unpublished).

5100 Boulos, Loutfy. 1995. Notes on Acacia Mill. Studies in the Leguminosae of Arabia: 1. Kew Bulletin 50(2): 327-337.

5101 Hamann, Ole. 1993. On vegetation recovery, goats and giant tortoises on Pinta Island, Galápagos, Ecuador. Biodiversity and Conservation 2: 138-151.

5108 Wild, H. \& T. Müller. 1979. Rhodesia. Part of appendix to: Possibilities and needs for conservation of plant species and vegetation in Africa. pp. 99-100. In Hedberg, I. (ed.). Systematic botany, plant utilization and biosphere conservation. Stockholm: Almqvist \& Wiksell International.

5112 Chebez, Juan Carlos. 1994. Los que se van. Buenos Aires, Argentina: Albatros. 604pp.

5!17 Bandeira, Salomao. 1995. Data collection forms for tree species of Mozambique. 
5123 Waldren, S. 1995. Letter to Charlotte Jenkins conceming the taxonomy of Pitcaim Island endemics. $2 \mathrm{pp}$.

5124 Oldfield, S. 1995. Plants and the 1994 CITES conference. Plant Talk 1: 12-13.

5125 Schatz, G. 1985. A new Cymbopetalum (Annonaceae) from Costa Rica and Panama with observations on natural hybridization. Ann. Missouri Bot. Gard. 72(3): 535-538.

5134 Mori, S.A. et al. 1987. The Lecythidaceae of a lowland neotropical forest: La Fumee Mountain, French Guiana. Memiors of the New York Botanical Garden 44: 1-190.

5165 Wickens, G.E. 1979. Sudan. Part of Appendix to: Possibilities and needs for conservation of plant species and vegetation in Africa. pp. 8588. In Hedberg, I. (ed.). Systematic botany, plant utilization and biosphere conservation. Stockholm: Almqvist \& Wiksell International.

5194 Mirov, N.T. 1967. The genus Pinus. New York: Ronald Press Co. 602pp.

5204 Wingfield, R.C. 1979. Tanzania. Part of appendix to: Possibilities and needs for conservation of plant species and vegetation in Africa. pp. 95-99. In Hedberg, I. (ed.). Systematic botany, plant utilization and biosphere conservation. Stockholm: Almqvist \& Wilksell International.

5214 Grubb, P.J. \& E.V.J. Tanner. 1976. The montane forests and soils of Jamaica: a reassessment. Joumal of the Amold Arboretum 57: 313-368.

5226 Ingelög, Torleif, Roger Anderson, \& Martin Tjernberg (eds.). 1993. Red Data Book of the Baltic Region. Uppsala: Swedish Threatened Species Unit. 95pp.

5259 St. John, H. \& W.R. Philipson. 1960. List of the flora of Oeno Atoll, Tuamotu Archipelago, south-central Pacific Ocean. Trans. $R$. Soc. N.Z. $88(3)$ : $401-403$.

5287 Tutin, T.G et al. (eds.). 1964. Flora Europaea. Cambridge: Cambridge University Press. 5 vols, 1964-1980. 2nd ed. vol 11993.

5300 Read, J. \& G.S. Hope. 1996. Ecology of Nothofagus forests of New Guinea and New Caledonia pp. 200-256. In Veblen, T.T. et al. The ecology and biogeography of Nothofagus forests.

5335 Gentry, A.H. 1988. Annotations to list of threatened plants of Latin America.

5372 Smith, Albert C. 1969. Studies of Pacific Island plants, XXI. Pacific Science 3: 383393.
Andrae, F. \& A. Krapfenbauer. 1978. Die Vertalung der feinwurgelen von Sleineibe (Podocarpus lambertii) \& schmalbattriger (Araucaria angustifolia). Centralblatt Für Ads Gesante Forstwesen 95(2): 71-86.

5411 Laubenfels, D. de. 1982. Flora de Venezuela. Caracas: Instito Nacional de Parques, Educacion Ambiental. 71-86.

5435 Landrum, L.R. 1986. Campomanesia, Pimenta, Blepharocalyx, Legrandia, Acca, Myrrhinium, and Luma (Myrtaceae). Flora Neotropica, Monograph 45. 178pp.

5448 Muñoz Pizarto, C. 1971. Chile: plantas en extincion. Santiago: Editorial Universitaria. 248pp.

5470 Veblen, T.T. 1978. Guatemalan conifers. Unasylva 29(118): 25-30.

5515 Lear, Michael. 1994. Letter to Harriet Gillett dated 28 March 1994, enclosing extracts from "Plant Conservation in Fiji" written by Michael Lear and Beverley Woods in March 1992.

5519 Jiménez, J. de J. 1978. Lista tentativa de plantas de la República Dominicana que deben protegerse para evitar su extinción. Santo Domingo: Coloquio Internacional sobre la practica de la conservación. CIBIMA/UASD.

5525 Katende, A. 1996. Completed data collection form for Diospyros katendei. 1pp.

5550 Whitmore, T.C. 1990. Comments on draft listing of tropical timbers of Peninsular Malaysia.

5556 Royal Botanic Gardens Kew, \& Intemational Institute for Environment and Development. 1993. Report on sustainable environmental development strategy and action plan for St Helena. Vol. 3. Status of the endemic flora and preliminary recovery programmes. $95 \mathrm{pp}$.

5563 Given, David R. 1992. Letter to Hugh Synge concerning conservation status of New Zealand plants. 60pp.

5595 Gartland, S. 1991. Letter to Sara Oldfield listing trees which are probably endangered in Cameroon. 2pp.

5603 Hekking, W.H.A. 1988. Violaceae Part I Rinorea and Rinoreocarpus. Flora Neotropica. New York Botanical Garden.

5624 Fu, L.G. \& S.Z. Chen. 1981. Discovery and designation of Cathaya argyrophylla. Plant Joumal (Zhiwu Zazhi) 4: 1-42.

5626 Mansur-Azim, Nazneen. 1989. A tentative list of species threatened in Bangladesh (including endemics). 
WWF \& IUCN. 1994. Centres of plant diversity. A guide and strategy for their conservation. 3 volumes. Cambridge: IUCN Publications Unit.

5653 Kelly, D.L. 1994. Systematic list of threatened flowering plant species in the Jamaican flora. $77 \mathrm{pp}$.

5654 East African Discussion Group. 1996. Comments on East African threatened trees.

5658 St. John, H. 1987. An account of the flora of Pitcaim Island with new Pandanus species. Honolulu, Hawaii

5672 Polak, A.M. \& H.R. Rypkema. (ill.) 1992. Major timber trees of Guyana. Wageningen, The Netherlands: The Tropenbos Foundation. 272 pp.

5759 Ferguson, D.K. 1985. A new species of Amentotaxus (Taxaceae) from North Eastem India. Kew Bulletin 40(1): 115-119.

5811 Linnington, S. \& R.D. Smith. 1987. Deferred regeneration. A manpower-efficient technique for germplasm conservation. PL Genel. Resource. Newsl. 70: 2-12.

5901 Krasnitskii, A.M. 1978. Osnovye zadachi spetsializatsii zapovednogo dela. In Latvia. Akademiya Nauk Latviiskoi SSR. Institut Biologii. Rastitel'nyi mir okhranyaemykh territorii. Riga, Zinatne. 29-33.

5941 Edwards, Sue, Mesfin Tadesse, \& Inga Hedberg (eds.). 1995. Flora of Ethiopia and Eritrea. Volume 2, Part 2. Canellaceae to Euphorbiaceae. Ethiopia \& Sweden: The National Herbarium, Addis Ababa \& The Department of Systematic Botany, Uppsala. 455pp.

5942 Pires O'Brien, J. 1996. Data collection forms for Meliaceae species.

5966 Hughes, C. 1987. Annotations to: List of threatened plants of Middle America.

5970 Prance, Ghillean T. 1987. Annotations to: List of threatened plants of Latin America.

5988 US Department of the Interior. Fish and Wildlife Service. 1985. Review of plant taxa for listing as endangered or threatened species; notice of review. Federal Register 50(188): 39526-39584.

5993 Wendt, Tom. 1993. Composition, floristic affinities, and origins of canopy tree flora of Mexican Atlantic slope rain forests. pp. 595707. In Ramamoorthy, T.P., R. Bye, A. Lot \& J. Fa (Eds.). Biological diversity of Mexico. Origins and Distribution.
5994 Bameby, R.C. \& J.W. Grimes. 1996. Silk Tree, Guanacaste, Monkey's Earring. Bronx, New York: The New York Botanical Garden. 1-295.

5995 Baquar, S. R. 1995. Trees of Pakistan. Pakistan: Royal Book Company. 1-634.

6004 Perry, J.P. 1991. The pines of Mexico and Central America. Portland: Timber Press. $231 \mathrm{pp}$.

6013 de Jong, Piet. 1995. Annotations to conservation listing for Betula spp.

6036 Martinez, P.O. 1981. Flora and phytosociology of relict stands containing Pilgerodendron uviferum in San Pablode Tregua Farm. Bosque 4(1): 3-11.

6044 Supthut, D. 1994. Annotations to: conservation status listing of species of Apocynaceae.

6053 Lear, Michael \& Beverley Woods. 1992. Plant conservation in Fiji. WWF 3334. Small grants for plant conservation on islands (6) Fiji. 76 pp.

6057 Adams, C.D. 1972. Flowering plants of Jamaica Jamaica: University of the West Indies. 848pp.

6067 Hamilton, C. 1985. Notes and descriptions of seven new species of Mesoamerican Clethraceae. Ann. Missouri Bot. Gard. 72(3): 539.543.

6079 Farjon, Aljos. 1993. The taxonomy of multiseed junipers (Juniperus sect. Sabina) in SW Asia and East Africa. Edinburgh Joumal of Botany 49(3): 251-283.

6107 Little, Elbert L., Roy O. Woodbury, \& Frank H. Wadsworth. 1974. Trees of Puerto Rico and The Virgin Islands. Washington DC 20250: US Dept. of Agriculture, Forest Service.

6125 Lock, J.M. \& J. Heald. 1994. Legumes of Indo-China. The Royal Botanic Gardens, Kew. $164 \mathrm{pp}$.

6127 Hawthorne, W. 1990. Field guide to the forest trees of Ghana. Chatham: Natural Resources Institute, for the Overseas Development Administration, London. 278pp.

6128 Ake Assi, L. 1990. Annotated WCMC list of timber species for the Ivory Coast. (Côte d'Ivoire).

6144 Orchard, A.E. (ed.), 1994. Flora of Australia. Canberra: Australian Government Publishing Service.

6150 Witsberger, D. 1981. Annotations to: List of threatened plants of Middle America. 
6156 Wheatley, J.I. 1992. A guide to the common trees of Vanuatu. Port Villa, Vanuatu: Dept. of Forestry.

6161 Blaser, Jürgen. et al. 1993. Akon'ny ala. Numeros 12 et 13. Département des Eaux et Forêts. $166 \mathrm{pp}$.

6163 Rushforth, Keith. 1996. Threatened broadleaves. Aesculus wangii. Broadleaves 3: 4.

6190 He, Shan-an. 1989. Project proposal for Daozhen Reserve. (unpublished). Submitted to WWF.

6197 White, F, 1978. The taxonomy, ecology and chorology of African Ebenaceae, I. The Guineo-Congolian species. Bull. Jard. Bot. Nat. Belg. 48: 245-358.

6206 Smitinand, T. 1990. Annotated list of dipterocarps in Thailand.

6244 Schmitt, Klaus. 1994. Conversation with Harriet Gillett.

6247 Maas, P.J.M. 1987. Studies in Annonaceae. VII. New species from the Neotropics and miscellaneous notes. Misc. Publ. of Univ. of Utrecht Herb. 1: 249-278.

6308 Fryxell, P.A. 1977. New species of Malvaceae from Mexico and Brazil. Phytologia 37(4): 285-316.

6317 Anon. 1981. Descripción general y anatomica de 105 maderas del grupo Andino. Junac: Junta del Acuerdo de Cartagena. 44lpp.

6335 Witsberger, D. 1980. Tree species of El Salvador and their conservation status. (unpublished). $31 \mathrm{pp}$.

6362 Pipoly III, J.J. 1996. New species of Geissanthus (Myrsinaceae) from the Hylaea/Andean interface of Ecuador and Peru. Sida 17(2): 459-470.

6396 Beentje, Henk Jaap. 1994. Kenya trees, shrubs and lianas. Nairobi, Kenya: National Museums of Kenya. 722pp.

6405 Cooling, E.N.G. 1968. Pinus merkusii - fast growing timber trees of the tropics.

6426 Wildlife Trade Monitoring Unit. 1991. Provision of data on rare and threatened tropical timber species. Cambridge: World Conservation Monitoring Centre. 58pp.

6431 Balakrishna, P. 1993. Annotations to WCMC printout entitled 'Unresolved India - 534 records'. Includes letter to Kerry S. Walter dated 9 Aug 1993 and annotations to list dated 21 Sep 93.
6433

Diamond, J., A. Irwanto, A. Kayoi, K. Rumboirusi, J. Ratcliffe, F. Sadsuitubun, \& A. Samangun. 1983. Surveys of five proposed reserves in Irian Jaya, Indonesia: Kumawa Mountains, Wandamen Mountains, Yapen Island, Salawati Island, and Bantana Island, July-October 1983. (unpublished). 9-20.

6469 Taiwan Endemic Species Research Institute. 1995. Conservation status listing of plants in Taiwan (draft). (unpublished). 79 pp.

6493 Roosmalen, M.G.M. van. 1985. Fruits of the Guianan flora. Wageningen: Institute of Systematic Botany, Utrecht and Silvicultural Dept of Wageningen Agricultural University.

6507 Fries, R.E. 1957. New species of Annonaceae from the Upper Amazon Basin. Ark Bot. n.s. 3(18): 599-606.

6508 Molur, S. \& S. Walker. 1996. Report on Conservation Assessment and Management Plan (CAMP II). (unpublished). 147 pp.

6509 Pannell, C.M. 1992. A taxonomic monograph of the genus Aglaia Lour. (Meliaceae). London: HMSO. 1-379.

6510 Iriondo, J.M., L.J. De Hond, \& C. GómezCampo. 1994. Current research on the biology of threatened plant species of the Mediterranean Basin and Macronesi: a database. Bocconea 4: 385 .

6541 McVaugh, Rogers. 1992. Flora NovoGaliciana. Ann Atbor, Michigan: University of Michigan Herbarium. 467pp.

6596 Harling, G. \& B. Sparre (eds.). 1973. Flora of Ecuador. Stockholm, Sweden: Department of Systematic Botany, University of Goteborg, and the Section of Botany, Riksmuseum.

6602 Howard, R.A. (ed.). 1974. Flora of the Lesser Antilles; Leeward and Windward Islands. Jamaica Plain, Mass., Amold Arboretum. 6 vols, 1974-1989.

6605 Verdcourt, B. 1971. Hamamelidaceae in Flora of Tropical East Africa. Milne-Redhead, E. \& Polhill, R.M. (eds.).

6626 Almeda, F. 1983. Three new Mesoamerican species of Miconia (Melastomataceae). Brittonia 35(1): 42-48.

6646 Phengklai, Chamlong \& Sanan Khamsai. 1985. Some non-timber species of Thailand Thai Forest Bulletin (Botany) 1(15): 108-148.

6678 Jiménez, Q., Luis Poveda, Nelson Zamora, \& P. Sánchez. 1988. Arboles amenazados o en peligro de extinción para la Peninsula de Osa. (unpublished). 5pp. 
Nelson, C. 1984. Una Ocotea (Lauraceae), una Salvia (Labiatae) y una Eupatorium (Compositae) nuevos de Honduras. Ceiba 25(2): 173-176.

6718 Songwe, C. 1990. Revised preliminary list of timbers of Cameroon with conservation categories.

6723 Southem Africa Discussion Group. 1996. Comments on Southem African threatened trees.

6724 Todzia, C.A. 1988. Chloranthaceae. 140pp.

6725 Timberlake, J.R. 1996. Annotations to the conservation listing of trees of Zimbabwe.

6727 Phiri, P.S.M. 1996. Data collection form for Brachystegia bakeriana.

6728 Maas, P.J.M. \& L.Y.Th. Westra. et al. 1992. Rollinia. Flora Neotropica. Monograph 57. New York: New York Botanical Garden. $188 \mathrm{pp}$.

6729 Green, P.S. 1996. Annotations to the conservation listing of Chionanthus, Fraxinus, Notelaea and Olea.

6746 Thulin, Mats. 1997. Comments on the draft species summaries of trees occurring in Somalia.

6767 Maas, P.J.M. et al. 1990. Monugraph of Rollinia.

6802 Simpson, B. 1979. A revision of the genus Polylepis (Rosaceae: Sanguisorbeae). Smithsonian Contrib. Bot. 43: 1-62.

6809 Bandeira, S.O., L. Marconi, \& F. Barbosa. 1996. Preliminary study of threatened plants of Mozambique. 306-309. In L.J.G. van der Maesen, X.M. van der Burgt \& J.M. van Medenbach de Rooy (eds.). The biodiversity of African plants. Kluwer Academic Publishers.

6835 Fortune Hopkins, H.C. 1994. The Indo-Pacific species of Parkia (Leguminosae: Mimosoideae). Kew Bulletin 49(2): 181-234.

6845 Whitmore, T.C. 1980. Utilization, potential and conservation of Agathis, a genus of tropical Asian conifers. Econ. Bot. 34(1): 1-12.

6851 De Laubenfels, D.J. 1988. Coniferales. Flora Malesiana series I - spermatophyta, flowering plants 10(3)

6858 Andrienko, T.L. 1995. Annotations to WCMC list of plants of Ukraine, including new list of datasources for Ukraine. 4pp.
Farjon, Aljos. 1990. Pinaceae. Drawings and descriptions of the genera Abies, Cedrus, Pseudolarix, Keteleeria, Nothotsuga, Tsuga, Cathaya, Pseudotsuga, Larix and Picea. Königstein, Germany: Koeltz Scientific Books. 330pp.

Mohanan, M. \& A.N. Henry. 1982. Rediscovery of three rare and endemic plants of India. Bull. Bot. Surv. India 22: 236-237.

6972 Wolf, C.B. \& W.W. Wagener. 1948. The New World cypresses. Anaheim: Rancho Santa Ana Botanical Garden. 1-248.

6988 El Hadidi, M.Nabil, Monier M. Abdel Ghani, \& Ahmed G. Fahmy. 1992. The Plant Red Data Book of Egypt. Cairo: The Palm Press. $155 \mathrm{pp}$.

7058 Dowsett-Lemaire, F, \& R.J. Dowsett. 1988. Threats to the evergreen forests of southern Malawi. Oryx 22(3): 158-162.

7069 McPherson, G. 1988. A new species of Vantanea (Humiriaceae) from Panama. Ann. Missouri Bot. Gard. 75(3): 1148-1149.

7078 US Department of the Interior. Fish and Wildlife Service. 1978. Endangered and threatened species of the southeastem United States. Atlanta, GA, US Fish and Wildlife Service, Region 4. Iv.

7087 Kessler, Paul J.A., Kade Sidiyasa, Ambriansyah Zainal, \& Arifin Zainal. 1995. Checklist of secondary forest trees in East and South Kalimantan, Indonesia. 84pp.

7089 Bamps, P., N. Robson, \& B. Verdcourt. 1978. Guttiferae in Flora of Tropical East Africa. Polhill,R.M. (ed.). Crown Agents For Oversea Governments And Administrations.

7111 Souza, S. de. 1981. Letter to G. Lucas.

7134 Delucchi, Gustavo \& Rubén F. Correa. 1992. Situacion ambiental de la Provincia de Buenos Aires. A. Recursos y rasgos naturales en la evaluación ambiental. La Plata: Provinicia de Buenos Aires Comision de Investigaciones Cientificas. $39 \mathrm{pp}$.

7140 Standley, P.G. \& L.O. Williams. 1966. Flora Guatemala. Fieldiana: Botany Vol. 24. Part VIII. Nos. 1 \& 2.

7142 White, Lee. 1995. Réserve de la Lopé, Gabon. Etude de la végétation - rapport final. (unpublished). $163 \mathrm{pp}$.

7144 Rohwer, J.G. 1996. Letter to Sara Oldfield with information on Neotropical Lauraceae.

7145 Rohwer, Jens G. 1988. The genera Dicypellium, Phyllostemonodaphne, Systemonodaphne and Urbanodendron (Lauraceae), Bot. Jahrb. Syst. 110(2): 157-171. 
7147 Jain, S.K. \& R.R. Rao. 1983. An assessment of threatened plants of India. Proceedings of the seminar held at Dehra Dun, 14-17 Sept., 1981. Howrah, Botanical Survey of India. 334pp.

7154 Steenis, C.G.G.J. van. 1986. An interesting new species of Nothofagus from New Guinea (Fagaceae). Kew Bulletin 41(3): 732.

7180 Wendt, T. \& E.J. Lott. 1985. A new simpleleaved species of Recchia (Simaroubaceae) from southeastern Mexico. Brittonia 37(2): 219-225.

7181 Latiff, A. \& K. Mat Salleh. 1995. Alphonsea boniana Finet et Gagnep. (Annonaceae), new to Peninsular Malaysia, and notes on other Alphonsea species in the Peninsula. Malayan Nature Journal 49: 53-58.

7215 Bompard, J.M. \& A.J.G.H. Kostermans. 1985. Preliminary results of an IUCN/WWF sponsored project for conservation of wild Mangifera species in situ in Kalimantan (Indonesia). Montpellier, Laboratoire de Botanique Tropicale and Bogor, BIOTROP.

7221 Mianda-Bungi, N. 1988. Annexe: plantes endémique du Zaìre. (unpublished). Lists 1343 endemics. 255-355.

7222 Tutin, T.G., V.H. Heywood, N.A. Burges, D.H. Valentine, S.M. Walters \& D.A. Webb (eds.). 1995. Flora Europaea Vols. 1-5. Electronic dataset supplied by R.J Pankhurst, Royal Botanic Garden Edinburgh, May 1995.

7228 Koopowitz, H. \& H. Kaye. 1983. Plant extinction: a global crisis. Washington, DC: Stone Wall Press. 239pp.

7272 Woodson, R.E. et al. 1943. Flora of Panama. Ann. Missouri Bot. Gard. 30

7274 Imada, Clyde T., Warren L. Wagner, \& Derral R. Herbst. 1989. Checklist of native and naturalized flowering plants of Hawai'i. Bishop Museum Occasional Papers 29: 1-87.

7334 Radcliffe-Smith, A. 1992. The botany of Socotra. pp. 189-205. In Doe B. (ed.). Socotra. Island of tranquillity. London: IMMEL Publishing Limited.

7359 Breteler, F.J. 1991. Flore du Gabon. 32. Dichapetalaceae. Paris: Muséum National d'Histoire Naturelle. 221 pp.

7395 Zanoni, T.A. 1982. Flora de Veracruz. Xalapa, Veracruz: Instituto Nacional de Investigacions Sobre Recursos Bioticos.

7401 Palgrave, K.C. 1988. Trees of Southem Africa. Cape Town: Struik Publications. 959pp.

7424 Nicolson, D.H. 1979. List of threatened plants of Dominica with IUCN conservation categories. Threatened Plants Committee Survey: retumed list.
Boudet, G., J.-P. Lebrun, \& R. Demange. 1986. Catalogue des plantes vasculaires du Mali. Maisons Alfort, Institut d'Elevage et de Médecine Vétérinaire des Pays Tropicaux. 480pp.

7461 Partomihardjo, T. 1987. The ulin wood which is threatened to extinction. Duta Rimba 87(13): 10-15.

7501 Prance, Ghillean T. 1972. Chrysobalanaceae. Supplement to Chrysobalanaceae. 406pp.

7510 Pannell, C.M. 1997. Letter about changes in the taxonomy of Aglaia.

7534 Nelson, C. 1995. Annotations to: Conservation status listing of threatened plants of Honduras returned Febnuary 21, 1995.

7538 Govaerts, Rafael. 1994. Checklist of Quercus species world wide. (unpublished).

7550 Lock, J.M. 1989. Legumes of Africa; a checklist. Kew: Royal Botanic Gardens. 619pp.

7588 Secretaría de Desarrollo Urbano y Ecologia. 1991. Listado de especies raras, amenazadas, en peligro de extinción, o sujetas a protección especial, y sus endemismos en la República Mexicana. Flora terrestre y acuática. México: Secretaria de Desarrollo Urbano y Ecología. 9. 26.

7599 Zizka, Georg. 1991. Flowering plants of Easter Island. Frankfurt am Main, Germany: Palmengarten. 108pp.

7610 Holub, Josef, Frantisek Procházka, \& Jan Cerovsky. 1979. Seznam vykynulych, endemickych a ohrozenych taxonu vyssich rostlin kveteny CSR (1. verze). Preslia 51(3): 213-237.

7620 Thulin, M. 1996. Email to Liz Porter conceming the distribution and status of selected Commiphora species. 2pp.

7630 Correll, D.S. \& H.B. Correll. 1982. Flora of the Bahama Archipelago. Vaduz, Liechtenstein: Cramer. 1692pp.

7645 Glassman, S.F. 1972. A revision of B.E. Dahlgren's index of American palms. Cramer. 294pp.

7655 Stace, Clive. 1988. Annotations to: List of threatened plants of Latin America.

7673 van Steenis, C.G.G.J. 1948. Flora Malesiana. Leiden: Flora Malesiana Foundation.

7724 Johnson, Dennis V. 1994. Letter from SSC Palm specialist group to Hariet Gillett with list entitled 'Palm database changes/corrections, Group 10, April 1994'. 12 pp. 
Vivero, J.L, M. Clemente-Muñoz, \& E Hernadez-Bermejo. 1997. Completed data collection forms for threatened tree species in Spain.

Leeuwenberg, A.J.M. 1991. A revision of Tabemaemontana. One. The Old World species. Royal Botanic Gardens, Kew. 205pp.

7791 Sita, P. 1988. Annotations to: Draft IUCN list of plant taxa of Congo.

7801 Wigginton, Martin. 1995. British Red Data Books: vascular plants - draft list. (unpublished). Includes old and new IUCN categories. $8 \mathrm{pp}$.

7808 Fontes, J. \& S. Guinko, 1995. Carte de la végétation et de l'occupation du sol du Burkina Faso. Toulouse: Université Paul Sabatier. 67 pp.

7875 Roberts, E.H. \& R.H. Ellis. 1977. Prediction of seed longevity at sub-zero temperatures and genetic resources conservation. Nature 268: $431-433$.

7891 Briggs, J.D. \& John H. Leigh. 1988. Rare or threatened Australian plants. Australian National Parks and Wildlife Service. $277 \mathrm{pp}$.

7906 Reitz, Raulino, Roberto M. Klein, \& Ademir Reis. 1978. Projeto Madeira de Santa Catarina. Levantamento das espécies florestais nativas em Santa Catarina com a possibilidade de incremento e desenvolvimento. Itajaí, Santa Catarina: Herbário "Barbosa Rodrigues" HBR. 320pp.

7931 Woodbury, R.O. et al. 1975. Rare and endangered plants of Puerto Rico: a committee report. Commonwealth of Puerto Rico: USDA Soil Conservation Service and Dept. of Natural Resources. $85 \mathrm{pp}$.

7933 Chang, Ching-en. 1988. Threatened plants of Botel Tobago. (unpublished). $3 \mathrm{pp}$.

7950 Kubitzki, K. \& S. Renner. 1982. Lauraceae I (Aniba and Aionea). Flora Neotropica. New York: New York Botanic Gardens.

7951 Jansen-Jacobs, M.J. (ed.). 1995. Tiliaceae and Dipterocarpaceae. Flora of the Guianas. Koenigstein, Fed. Rep. of Germany: Koeltz Scientific Books.

7957 Pulle, A.A., J. Lanjouw, \& A.L. Stoffers (eds.). 1. Flora of Suriname. Amsterdam: Amsterdam Koloniaal Inst. Amsterdam.

7980 The Nature Conservancy. 1996. Natural Heritage Central Database. (Status and distribution data on Latin American plants, developed in collaboration with Latin American Conservation Data Centers and Missouri Botanical Garden.).
8013 de Wilde, W.J.J.O. 1990. Conspectus of Myristica (Myristicaceae) indigenous in the Moluccas. Blumea 35(1): 233-260.

8032 Quinn, C.J. 1982. The Taxonomy of Dacrydium Sol. ex Lamb emend de Laub (Podocarpaceae). Australian Joumal of Botany 30: 311-320.

8058 Womersley, J.S. \& J.B. McAdam. 1957. The forests and forest conditions in the territories of Papua and New Guinea Zillmere, Queensland: The Wilke Group. 22-23.

8100 Janzen, Daniel H. (ed.). 1983. Costa Rican natural history. Chicago and London: The University of Chicago Press. 816pp.

8106 Strahm, W.A. 1996. Annotation to: WCMC printout of Rodrigues - globally threatened taxa.

8136 Laubenfels, D. de. 1985. Taxonomic Revision of Podocarpus. Blumea 30(2): 251-278.

8142 Hong Kong Herbarium. 1978. Checklist of Hong Kong plants. Hong Kong: Government Printer.

8148 de Wilde, W.J.J.O. 1987. Additions to Horsfieldia (Myristicaceae) including four new species. Blumea 32(2): 459-472.

8153 Robyns, A. 1967. Bombacaceae Neotropicae Novae I. New species of Chorisia and Quararibea. Ann. Missouri Bot. Gard. 54: 184-186.

8203 Abeywickrama, B.A. 1990. The threatened plants of Sri Lanka. Sri Lanka: NARESA. Unesco - Man and the Biosphere National Committee for Sri Lanka. 56pp.

8221 Tennant, J.R. 1968. Araliaceae in Flora of Tropical East Africa. Milne-Redhead, E. \& Polhil!, R.M. (eds.). Crown Agents for Oversea Governments and Administrations.

8283 Wendt, T. 1983. Plantae Uxpanapae II. Novedades en Violaceae y Scrophulariaceae. Bol. Soc. Bot. Mexica 45: 133-140.

8295 Schouten, R.T. 1986. Revision of Gymnacranthera. Blumea 31(2): 455-485.

8306 Fosberg, F.R., G. Paulay, T. Spencer, \& R. Oliver. 1989. New collections and notes on the plants of Henderson, Pitcaim, Oeno and Ducie islands. Atoll Research Bulletin 329: 1-18.

8325 Anon. 1979. Other fast growing trees. pp. 193210. In Tropical legumes: Resources for the future. Washington, DC: National Academy of Sciences.

8369 Hawthome, W.D. 1995. Ecological profiles of Ghanaian forest trees. Oxford Forestry Institute. 345pp. 
8381 Rohwer, J. 1987. Annotations to: List of threatened plants of Latin America.

8400 US Fish and Wildlife Service. 1988. Recovery plan for three Florida pawpaws. US Federal Register 51(187): 34415-34420.20 pp.

8415 Hul, S. 1995. Flore du Gabon. 34. Flacourtiaceae. Paris: Musée National d'histoire Naturelle. 82 pp.

8451 Gentry, Alwyn H. 1992. Bignoniaceae - Part II (Tribe Tecomeae).

8464 Ng, F.S.P., C.M. Low, \& M.A.N. Sanah. 1990. Endemic trees of the Malay Peninsula. Kuala Lumpur: Forestry Department. 118pp.

8470 Nixon, Kevin. 1996. Comments in an email from Allen Coombes to Sara Oldfield concerning the list of threatened Quercus.

8475 Bailey, D.K. 1983. A new allopatric segregate from a new combination in Pinus cembroides Zucc. at its southem limits. Phytologia 54(2): 89-101.

8483 Balakrishna, P. 1993. Letter to Kerry S. Walter with corrections to Conservation Status Listing for India.

8503 Reynel, C. \& T. Pennington. 1989. Reporte sobre los cedros y su situación en el Perú, una contribucción al conocimiento y la conservación de las Meliáceas peruanas. Lima: Universidad Nacional Agaria La Molina, Centro de Datos Para la Conservación Perú. $100 \mathrm{pp}$.

8506 Villiers, J.-F. 1989. Flore du Gabon. Volume 31. Leguminosae: Mimosoideae. 185pp.

8507 van Gelderen, D.M., P.C. de Jong, \& H.J. Oterdoom. 1994. Maples of the world. Hong Kong: Timber Press Inc. 458 pp.

8553 Lundell, C.L. 1970. Studies of American plants, II. Wrightia 4(4): 129-152.

8572 Huynh, K.-L., I. Nordal, J.I. Iversen, \& J.-F. Villiers. 1986. Flore du Gabon. Volume 28. Pandanacées, Amaryllidacées, Hypoxidacées, Flagellariacées.

8646 Greaves, A. 1979. Descriptions of seed sources and collections for Pinus caribbaea.

8658 Detienne, P., D. Fouquet, \& B. Parant. 1990. Les bois Guyanais: propriétés et utilisation. [Guianese woods: properties and uses]. Bois et Forêts des Tropiques 219: 125-143.

8661 Taylor, R.J. \& T.F. Patterson. 1980. Biosystematics of Mexican spruce species and populations. Taxon 29(4): 421-467.
Thulin, M. 1996. Email to Sara Oldfield concerning the new status of rare Somali trees according to the revised IUCN red list categories.

8716 Anon. Threatened plants in protected areas of the Canary Islands (Spain). (unpublished).

8785 Hawthome, W. 1989. Letter to Sara Oldfield.

8805 Molina, A. 1974. Vegetación del Valle de Comayagua. Ceiba 18: 47-70.

8814 Lovett, Jon. 1996. Tanzanian forest trees with a restricted distribution.

8815 Varty, Nigel. 1996. Data collection forms for Brazilian Atlantic forest species.

8816 Pennington, T.D. 1990. Sapotaceae. Flora Neotropica, Monograph 52. Bronx, New York: The New York Botanical Garden. 770pp.

8842 Fairall, A.R. 1970. West Australian plants in cultivation. Perth: Pergamon Press.

8843 Elliot, W.R. \& D.L. Jones (eds.). 1982. Encyclopaedia of Australian plants suitable for cultivation. Melboume: Lothian Publishing Company Pty. Lid. 517 pp.

8854 Hall, J.B. 1979. Ghana. Part of appendix to: Possibilities and needs for conservation of plant species and vegetation in Africa. pp. 8891. In Hedberg, I. (ed.). Systematic botany, plant utilization and biosphere conservation. Stockholm: Almqvist and Wiksell.

8865 Whitmore, T.C. \& F.S.P. Ng (eds.). 1972. Tree Flora of Malaya. Kuala Lumpur: Longman.

8869 Centro Do Datos Para la Conservacion-CDCCVC. 1986. Lista preliminar de plantas especiales del centro de datos para la conservacion, CDC-CVC. (unpublished).

8870 Laubenfels, D. de. 1991. The Podocarpaceae of Costa Rica. Brenesia 33: 119-121.

8911 Loc, Phanke. 1992. Annotations to: the conservation status listing of threatened plants in China dated 7th April 1992.

8915 Meléndez, Esteban Núñez. 1982. Plantas medicinales de Puerto Rico. Universidad de Puerto Rico. 1-498.

8969 Fah, L.Y. 1987. A preliminary survey of Mangifera species in Sabah. Sandakan, Forest Research Centre. Project No. 3305/MAL 75.

8999 Todzia, Carol A. 1987. Annotations to: the conservation status listing for Ecuador dated 18 December 1987.

9000 Stone, Benjamin C. 1985. On the second collection of Pandanus halleorum. Kew Bulletin 40(2): 287-289. 
Soladoye, M.O. 1985. A revision of Baphia (Leguminosae-Papilionoideae). Kew Bulletin 40(2): 291-386

9058 Davis, P.H. 1. Flora of Turkey and the East Aegean Islands. 9 vols. Edinburgh: Edinburgh University Press.

9059 Thulin, M. 1993. Flora of Somalia - Vol 1. Surrey: RBG Kew.

9073 Janzen, Daniel H. \& Ronald Liesner. 1980. Annotated check-list of plants of lowland Guanacaste Province, Costa Rica, exclusive of grasses and non-vascular cryptogams. Brenesia: 15-90.

9076 Stevens, D. 1987. Annotations to: List of threatened plants of Middle America.

9078 Whitten, Tony, Roehayat Emon Soeriaatmadja, \& Suraya A. Afiff. 1996. The ecology of Java and Bali. The Ecology of Indonesia Series. Volume III. Republic of Singapore: Periplus Editions. 969pp.

9090 Anon. 1979. VI Luxury timbers. pp. 211-238. In Tropical legumes: resources for the future. Washington, DC: National Academy of Sciences.

9120 Strahm, W.A. 1993. The conservation and restoration of the flora of Mauritius and Rodrigues. (unpublished), Ph.D. Thesis (2 vols.), Reading University, UK.

9133 Achouundong, G. 1996. Les Rinorea comme indicateurs des grands types forestiers du Cameroun. pp. 536-544. In van der Maesen, L.J.G., van der Burght, X.M. \& van Medenbach de Rooy, J.M. (eds.). The biodiversity of African plants. Proceedings of the XIVth Aetfat Congress, 22-27 August 1994, Wageningen, The Netherlands. Dordrecht: Kluwer Academic Publishers.

9151 Beentje, Henk. 1995. Letter to Charlotte Jenkins with information regarding threatened plants in Kenya and threatened palms in Madagascar. 2pp.

9169 Ashton, P.S. 1990. Annotations to: conservation status listings for Dipterocarpaceae.

9173 Reitz, Raulino, Roberto M. Klein, \& Ademir Reis. 1983. Projeto Madeira de Rio Grande do Sul. Levantamento das espécies florestais nativas com possibilidade de incremento e desenvolvimento. Herbário "Barbosa Rodrigues" - HBR. 528pp.

9176 Gunatilleke, C.V.S. \& IAUN. 1985. A conservation and protection plan for the Sinharaja Forest. Draft. (unpublished). Includes list of plants and their uses and endemism.
9198 Luke, W.R.Q. 1991. A preliminary list of rare, vulnerable and endemic plants for Kenya (appendix B cntd.). pp. 25. The costs benefits and unmet needs of biological diversity conservation in Kenya.

9199 Ng, P.K.L. \& Y.C. Wee (eds.). 1994. The Singapore Red Data Book. Singapore: The Nature Society. $343 \mathrm{pp}$.

9227 Lundell, C.L. 1969. Studies of American plants, I. Wrightia 4(3): 97-128.

9254 Ward, D.B. (ed.). 1979. Rare and endangered biota of Florida: 5. Plants. Gainesville: University Presses of Florida. 175pp.

9262 Rohwer, J.G. 1993. Nectandra (Lauraceae). Flora Neotropica. New York: New York Botanic Gardens.

9263 Mori, S.A. \& G.T. Prance. 1993. Lecythidaceae. Flora of the Guianas. Koenigstein, Fed. Rep. of Germany: Koeltz Scientific Books.

9274 Nooteboom, H.P. 1996. The Magnoliaceae of China (Draft).

9291 Turrill, W.B. \& E. Milne-Redhead (eds.). 1956. Canellaceae in Flora of Tropical East Africa. Crown Agents for Oversea Governments and Administrations.

9300 Donahue, J.K. 1995. Observations on Pinus maximartinezii Rzedowski. Madrono 42(1): 19-25.

9302 Verdcourt, B. 1971. Annonaceae in Flora of Tropical East Africa. Milne-Redhead, E. \& Polhill, R.M. (eds.). Crown Agents For Overseas Govemments And Administrations.

9312 Loizeau, P. 1988. Annotations to: List of threatened plants of Middle America.

9328 Kostermans, A. 1990. Comments from Kostermans on a draft list of tropical timbers for Indonesia.

9379 WWF. 1980. Cagar Alam GN. Tangkoko-Dua Saudara, Sulawesi Utara - Management Plan 1981-1986. Bogor: WWF.

9426 Strahm, W. 1989. Plant Red Data Book for Rodrigues. Königstein: Koeltz Scientific Books. 241pp.

9492 Anon. 1994. English translation of the Flora Rei Popularis Sinicae (Flora of China). (unpublished).

9501 Ashton, P.S. 1982. Dipterocarpaceae. pp. $37-$ 552; 575-600. In van Steenis, C.G.G.J. (ed.). Flora Malesiana. 
9509

British Standards Institution. 1991. British standard nomenclature of commercial timbers including sources of supply. London: British Standards Institution. $123 \mathrm{pp}$.

Jardin Botánico Nacional, Havana, Cuba (HAJB). 1988. Retumed questionnaire: rare and threatened plants of Cuba. 4pp.

9570 Mukherjee, S.K. 1985. Systematic and ecogeographic studies of crop genepools: 1. Mangifera L. Rome, IBPGR Secretariat. 86pp.

de Wilde, W.J.J.O. 1984. Endocomia, a new genus of Myristicaceae. Blumea 30(1): 173196.

9605 Okullo, J.B. et al. 1997. Completed data collection forms for woody plants of Uganda.

9631 Watt, Alistair. 1996. Completed data collection forms for conifers of New Caledonia and Fiji.

9632 Pires O'Brien, J. 1996. Data collection forms for Lecythidaceae tree species.

9651 Lawesson, J.E. 1986. Report on the most threatened endemic plants in Galápagos. (unpublished). Santa Cruz, Charles Darwin Research Station. 10pp Annotated list; maps.

9653 Nixon, K., W. Hess, A. Coombes, \& M. Rodriguez. 1996. Discussions on the status of Quercus species in the Americas. Regional workshop for the Conservation and Sustainable Management of Trees project.

9695 Yuncker, T.G. 1959. Plants of Tonga. Bemice P. Bishop Museum Bulletin 220: 283.

9800 Oates, Michael R. \& Peter J. de Lange. 1995. Annotations to: Conservation status listing of plants of New Zealand. 2pp.

9836 Adams, Robert P. 1983. The junipers (Juniperus; Cupressaceae) of Hispaniola; Moscosoa 2(1): 77-89.

Pomeroy, D. \& T. Hart 1997. Additional comments on restricted range tree species of Uganda. 2pp.

9859 Friedmann, F. 1991. Flore des Seychelles.

9866 Mori, S.A. \& G.T. Prance. 1990 Lecythidaceae. Part II. Flora Neotropica. New York: New York Botanic Gardens.

9867 Wurdack, J.J., T. Morley, \& S. Renner. 1993 Melastomataceae. Flora of the Guianas. Koenigstein, Fed. Rep. of Germany: Koeltz Scientific Books.

9880 Bohs, L. 1994. Cyphomandra (Solanaceae) Flora Neotropica. Monograph 63. New York: The New York Botanical Garden. 175pp.
Oltean, M \& G Negrean. et al. 1994. Lista rosie a plantelor superioare din România. $52(2): 52$

9902 Lewis, G.P. 1987. Legumes of Bahia. Kew, England: Royal Botanic Gardens. 369pp.

9920 Johnson, D.V. 1988. Worldwide endangerment of useful palms. Adv. Econ. Bot. 6: 268-273.

9954 Seal, Ulysses S., Michael Maunder, Paul Pearce-Kelly, Georginna Mace, \& David Clark. et al. 1993. Conservation assessment and management plan. St. Helena Island. Kew: Royal Botanic Gardens. 305pp.

9957 Anon. 1994. Flora Conservation. Revised 1994 CAFF lists of flora at risk in the circumpolar Arctic. (unpublished). 39pp.

10013 Loc, Phan Ke. 1992. Annotations to: Conservation status listing for Philippines dated 6 April 1992. 49pp.

10079 Hunter, G. 1966. Mexican and Central American Saurauia (Dilleniaceae). Ann. Missouri Bot. Gard. 53(1): 47-89.

10080 Figueiredo, Estrela. 1994. Little known endemics collected by J. Espírito Santo in S. Tomé. Garcia de Orta, Sér. Bot. Lisboa 12(1): 121-124.

10090 White, F. 1983. The vegetation of Africa. A descriptive memoir to accompany the Unesco/AETFAT/UNSO vegetation map of Africa. Paris: Natural Resources Research 20, Unesco. $356 \mathrm{pp}$.

10147 Nelson, C. 1981. Annotations to: List of threatened plants of Middle America.

10148 World Conservation Union. 1990. Conservation atlas of tropical forests: Asia and the Pacific. New York: Simon and Schuster. 256pp.

10173 Popenoe, J. 1984. Threatened plants in the Bahamas. Threatened PL Newsl. 13: 11.

10194 White, S. \& f. Maldonado. 1991. The use and conservation of natural resources in the Andes of Southem Ecuador. Mountain Research and Development 11(1): 37-55.

10197 Hartshom, G. et al. 1981. Natural vegetation. pp. 13-21. In The Dominican Republic, country environmental profile, a field study. Virgina: Mclean.

10207 Hughes, Colin. 1997. Draft chapter on conservation from The genus Leucaena: a genetic resource handbook'. (unpublished). 12 pp. 
10217 Styles, B.T. \& C.E. Hughes. 1983. Studies of variation in Central American pines 3. Notes on the taxonomy and nomenclature of the pine and related gymnosperms in Honduras and the adjacent Latin American Republics. Brenesia 21: 269-291.

10218 Morley, T. 1976. Memecyleae (Melastomataceae). 295pp.

10263 Polak, A.M. \& H.R. Rypkema. (ill.). 1992. Major timber trees of Guyana. Wageningen: The Tropenbos Foundation. 272pp.

10348 Hartley, T.G. 1982. Maclurodendron: A new genus of Rutaceae from Southeast Asia. Gard. Bull. Sing. 35: 1-19.

10351 Jaffre, T., P. Bouchet, \& J.-M. Veillon. 1996. Threatened plants of New Caledonia: Is the system of protected areas adequate? Biodiversity \& Conservation: 36.

10353 Hess, William. 1996. Data collection forms for Quercus species.

10378 de Wilde, W.J.J.O. 1991. Conspectus of Myristica (Myristicaceae) in Australia, with the description of a new species from Queensland. Blumea 36(1): 183-190.

10395 Rodas, J. \& J. Aguilar. 1980. Lista de algunas especies vegetales en via en extinción. (unpublished).

10460 de Wilde, W.J.J.O. 1979. New account of the genus Knema (Myristicaceae). Blumea 25(2): $321-478$.

10471 Hooker, J.D. 1872. Flora of British India. London.

10480 Vovides, A.P. 1987. Annotations to: List of threatened plants of Middle America.

10481 Berg, C.C. 1988. Annotations to: List of threatened plants of Latin America.

10488 Marchant, N.G. et al. 1987. Flora of the Perth region. Perth: Department of Agriculture, Western Australia. 576 pp.

10536 Kemp, E.S. 1979. Swaziland. Part of appendix to: Possibilities and needs for conservation of plant species and vegetation in Africa. pp. 101-103. In Hedberg, I. (ed.). Systematic botany, plant utilization and biosphere conservation. - Stockholm: Almqvist \& Wiksell International.

10547 Whitmore, T.C. \& I.G.M. Tantra (eds.). 1986. Tree flora of Indonesia. Bogor, Indonesia: Forest Research and Development Centre. $381 \mathrm{pp}$.

10571 Papua New Guinea Department of Forests. 1989. Facts and figures 1989. Boroko NCD: Papua New Guinea Department of Forests. 46pp.
10592 Timberlake, Jonathan. 1996. Letter to Sara Oldfield containing synonymy of plant species in Zimbabwe.

10598 Maire, R. 1952. Flore de l'Afrique du Nord. Paris.

10610 Friedmann, F. 1991. The threatened plants of the flora of the Seychelles and their conservation. pp. 193-208. In Heywood, V.H. \& Wyse Jackson, P.S. (eds.). Tropical botanic gardens. Their role in conservation and development. San Diego: Academic Press Inc.

10625 Aparicio, Abelardo. 1995. Annotations to WCMC list of plants of Spain, including new list of datasources for Spain. 64pp.

10686 Anon. 1991. Estudio Nacional de Biodiversidad. 169-170.

10722 Ayensu, E.S. \& R.A. DeFilipps. 1978. Endangered and threatened plants of the United States. Washington, DC: Smithsonian Institution and World Wildlife Fund Inc. 403pp.

10733 Henry, A.N. \& M.S. Swaminathan. 1979. Rare or little known plants from south India. $J$. Bombay Nat. Hist. Soc. 76(2): 373-376.

10734 Purdie, A.W. 1985. Chordosparrium muritai (Papilionaceae) - a rare new species of New Zealand tree broom. New Zealand J. Bot. 23: 157-161.

10754 Fiard, Jean-Pierre. 1992. Arbres rares et ménacés de la Martinique. Martinique: Société des Galeries de Géologie et de Botanique de Fort-de-France. 152pp.

10781 Pennington, T.D. 1991. The genera of Sapotaceae. Royal Botanic Gardens, Kew \& New York Botanical Garden. 295pp.

10792 Rzedowski, J. 1981. Annotations: List of threatened plants of Middle America.

10808 Leigh, John H. \& J.D. Briggs. 1992. Threatened Australian plants. Australian National Parks and Wildlife Service. 120pp.

10816 Conzatti, C. 1988. Flora Taxonomica Mexicana. Volumen 1. México, D.F.: Consejo Nacional de Ciencia y Tecnologia. 1064pp.

10862 Bañares Baudet, A. 1990. La flora amenazada de los parques nacionales Canarios con especial referencia al Parque Nacional de Garajonay. (The threatened flora of the national parks of the Canary Islands with special reference to Garajonay National Park). pp. 87-90. In Hernández Bermejo, J.E., Clemente, M., Heywood, V. (eds.). Conservation techniques in botanic gardens. Germany: Koeltz Scientific Books. 
10919 Castillo-Campos, G. \& D.H. Lorence. 1985. Antirhea aromatica (Rubiaceae, Guettardeae), a new species from Veracruz, Mexico. Ann. Missouri Bot Gard. 72: 268-271.

10938 Tan, B.C., E. Femando, \& J.P. Rojo. 1986. An updated list of endangered Philippine plants. Yushania 3(2): 1-5.

10954 Kim, Yong Shik. 1992. List of rare and endangered plant species in Republic of Korea. (unpublished). 14pp.

10961 Knox, Eric B. 1995. The List of East African Plants (LEAP): An electronic database (Draft). $72 \mathrm{pp}$.

10965 Mori, Scott A. 1987. Annotations to: the conservation status listing: Lecythidaceae.

11038 Lan, K.M. 1984. A new variety of Amentotaxus argotaenia. Acta Phytotaxonomica Sinica 22(6): 492.

11085 Launert, E. \& G.V. Pope. 1991. Flora Zambesiaca. Volume 9. Ulmaceae, Cannabaceae, Moraceae, Cecropiaceae, Unticaceae, Casuarinaceae, Salicaceae, Ceratophyllaceae. London: Flora Zambesiaca Managing Committee. 135pp.

11086 Verdcourt, B. 1993. A new species of Palaquium Blanco (Sapotaceae) from Ceylon. Kew Bull. 48(2): 342.

11117 Lee, Tchang Bok. 1983. Endemic plants and their distribution in Korea. Bull. Kwanak Arboretum: 71-113.

11140 Chebez, Juan Carlos \& Eduardo Haene. 1989. Lista tentativa de plantas vasculares argentinas en peligro de extinción. (unpublished). 18 pp.

11145 Lemmens, R.H.M.J., I. Soerianegara, \& W.C. Wong (eds.). 1995. Plant resources of SouthEast Asia No. 5(2). Timber trees: minor commercial timbers. Leiden: Backhuys Publishers. 655 pp.

11147 Benoit, C. \& L. Ivan (eds.). 1989. Libro rojo de la flora terrestre de Chile. Santiago: Impresora Creces Ltd. 157 pp.

11191 Mill, Robert R. 1994. Annotations to Conifers - taxa listed on BG-BASE - status report as of 2 February $1994.43 \mathrm{pp}$.

11226 Lundell, C.L. 1974. Studies of American plants, VII. Wrightia 5(3): 51-72.

11242 Wang, S.Y. 1986. List of threatened plants of China. (unpublished). List with IUCN categories; endemism not given. 18pp.

11278 Kostermans, A.J.G.H. \& J.-M. Bompard. 1993. The mangoes. London: Academic Press Ltd. 233 pp.
11295 Giesen, W. 1987. Danau Sentarum Wildlife Reserve, inventory, ecology and management guidelines. Zeist, The Netherlands: World Wildlife Fund. 284pp.

11314 Laubenfels, D. de. 1978. The taxonomy of Philippine Coniferae and Taxaceae. Kalikasan $7(2): 117-152$.

11373 Nair, N.C. \& S.R. Sninivasan. 1983. On the rediscovery of Koilodepas calycinum Bedd. (Euphorbiaceae) and Holcolemma canaliculatum (Nees ex Steud.) Stapf. ex Hubbard (Poaceae) from south India. Bull. Bot. Surv. India 24(1): 241-242.

11374 Ortega Torres, E., L. Stutz de Ortega, \& R. Spichiger. 1989. Noventa especies forestales del Paraguay. 218 pp.

11380 Li, H.-L., T.-S. Liu, T.-C. Huang, T. Koyama, \& C.E. Devol. 1975. Flora of Taiwan. Taipei: Epoch.

11400 Given, D.R. 1975. Conservation of rare and threatened plant taxa in New Zealand - some principles. Proc. New Zealand Ecol. Soc. 22: 1-6.

11403 Borhidi, A. 1992. Letter to Hugh Synge concerning conservation status of Cuban plants. Includes annotations to 27 Aug 1991 TPU printout for Cuba. $60 \mathrm{pp}$.

11417 Tyzack, S. 1987. Notes on Wright's gardenia (Rothmannia annae), Aride Island, Seychelles. (unpublished). Results of a population census, with notes on fertilisation, germination, and dispersal. Management recommendations.

11449 Prospect. 1995. Species listing from the PROSPECT database.

11479 Guan, S.L. 1987. Conservation of the mango and its relatives in Peninsular Malaysia. Forest Research Institute of Malaysia. World Wildlife Fund Malaysia Project MAL 80/85. 29pp.

11504 Keay, R.W.J. 1989. The trees of Nigeria. Oxford: Oxford University Press. 476pp.

11509 Kessler, P. 1996. Goniothalamus majestatis, a new species of Annonaceae from Sulawesi, Indonesia. Blumea 41(1): 27-28.

11530 Loc, Phan Ke. 1986. Lists of rare and endangered plant species of Vietnam (19861988). (unpublished).

11577 Melville, R. 1970. Endangered plants and conservation in the islands of the Indian Ocean. In Papers and proceedings of the IUCN 11 th technical meeting, New Delhi, India, 25 28 November 1969. Switzerland, IUCN. 103 107. 
11631 Lovett, Jon \& I. Friis. 1996. Pattems of endemism in the woody flora of north-east and east Africa. pp. 582-601. In L.J.G. van der Maesen et al. (eds.). The biodiversity of African plants. The Netherlands: Kluwer Academic Press.

11632 Corrigan, H. \& C. Sam. 1996. Letter regarding conservation status of trees in Vanuatu.

$11647 \mathrm{Ng}$, F.S.P. \& C.M. Low. 1982. Checklist of endemic trees of the Malay peninsula. Kepong, Malaysia: Forest Research Institute. 94pp.

11683 US Department of the Interior. Fish and Wildlife Service. 1992. Hinckley oak (Quercus hinckleyi) recovery plan. Albuquerque, New Mexico: US Fish and Wildlife Service, Region 2. 39 pp.

11703 Porter, D.M. 1970. The rape of Panama. Missouri Bot. Gard. Bull. 58(1): 11-17.

11715 Breedlove, D.E. 1987. Annotations to: List of threatened plants of Latin America

11723 Johnston, M.C. \& L.A. Johnston. 1978. Rhamnus. 96pp.

11725 Walter, Kerry S. 1992. Trip report - Workshop on biodiversity data for the GEF Biodiversity Action Plan for China. Beijing, 9-13 November 1992. (unpublished). 9 pp.

11727 Rao, Y.S. 1992. Forest news. Tigerpaper 4: 5 7.

11785 Braun, Kate. 1992. Swaziland flora - species of possibly high conservation priority. (unpublished). Unpublished document, Swaziland National Trust Commission. 7pp.

11802 Proctor, George R. 1982. More additions to the flora of Jamaica. Joumal of the Amold Arboretum 63: 199-315.

11847 Fu, Li-kuo \& Jian-ming Jin (eds.). 1992. China Plant Red Data Book. Beijing: Science Press. xviii-741.

11886 Morin, Nancy R. (ed.). 1993. Flora of North America - North of Mexico. New York: Oxford University Press. 475pp.

11888 Güner, Adil. 1996. Email to Charlotte Jenkins concerning the status of Turkish plants. $1 \mathrm{pp}$.

11891 Holland, M, Q Cronk, D MacDonald, \& M Holland. 1986. The endemic flora of St. Helena. St Helena: The Government of St. Helena. 44pp.

11906 Bohs, L. 1997. Letter to Charlotte Jenkins with comments on restricted-range Cyphomandra species. 2 pp.

11936 López, J. \& Elbert L. Little. 1987. Arboles communes del Paraguay. Washington, DC: Peace Corps. 425pp.
11959 Maheshwari, J.K. 1971. The baobab tree: disjunctive distribution and conservation. Biol. Conserv. 4(1): 57-60.

12061 Hawthome, W. 1995. Categories of conservation priority and Ghanaian tree species. (unpublished). 1-38.

12067 Beentje, Henk Jaap. 1988. Atlas of the rare trees of Kenya. Utafiti 1(3): 71-125.

12109 Erfurth, T. \& H. Rusche. 1976. The marketing of tropical wood. Rome: FAO.

12114 Subramanian, K.N. \& B.G. Singh. 1986. Gymnacranthera canarica (King) Warb. - a tree species on the verge of extinction. (unpublished). Illus.

12121 Beaman, R.S. \& J.H Beaman. 1993. The Gymnosperms of Mt Kinabalu. Contributions from the University of Michigan Herbarium 19: $307-341$.

12129 Senaratna, Sonali. 1995. A critical anaylsis on the current status of $e x$ silu conservation strategies of Sri Lanka's flora and fauna and its overall importance in Biodiversity Conservation in Sri Lanka. (unpublished). Thesis submitted as part of M.Sc. degree. 138 pp.

12135 Ohba, H. 1995. List of endangered tree species of Japan. (unpublished). 4pp.

12192 Steyermark, J.A. 1986. Speciation and endemism in the flora of the Venezuelan tepuis. pp. 644. In High altitude tropical biogeography. New York: Oxford University Press.

12226 Barringer, K.A. 1984. A new species of Guatteria (Annonaceae) from Panama. Ann. Missouri Bot. Gard. 71(4): 1186-1187.

12268 Centro de Datos para la Conservación. 1986. Lista preliminar de plantas especiales. Limón, Peru: Centro de Datos para la Conservación. $19 \mathrm{pp}$.

12281 Pennington, T.D. 1981. Meliaceae. Flora Neotropica, Monograph 28. 470 pp.

12323 Hallé, N. 1986. Flore du Gabon. Volume 29. Celastraceae Hippocrateoideae. Paris: Muséum National d'histoire Naturelle. 287 pp.

12353 Du Puy, D. J. \& H. Labat. 1996. Data collection forms for Madagascan trees for the Conservation and Sustainable Management of Trees project.

12359 US Department of the Interior. Fish and Wildlife Service. 1991. Endangered and threatened wildlife and plants; determination of endangered status for 26 plants from the Waianae Mountains, island of Oahu, Hawaii. Fed. Register 56(209): 55770-55786. 
12389 Little, E.L. et al. 1974. Trees of Puerto Rico and the Virgin Islands, Second Volume. Washington, DC: USD.A. Forest Service. 1024pp.

12453 Sachsse, H. \& E. Schulte. 1987. Some important wood properties of the Bolivian Podocarpus parlatorei. Holz Als Roh-Und Werkstoff 45(12): 475-480.

12455 Loc, Phan Ke. 1992. Conversations with Prof. Phan Ke Loc.

12470 Dupont, J., J.-C. Girard, \& M. Guinet. 1989. Flore en détresse: Le Livre Rouge des plantes indigènes menacées à la Réunion. SREPEN \& Région Réunion Conseil Régional. 133 pp.

12509 Palmberg, C. 1987. Conservation of genetic resources of woody species. (unpublished). Rome: FAO. Paper prepared for Simposio sobre Silvicultura y Mejoramiento Geneti co. Cief. Buenos Aires, 6-10 April 1987. Includes lists of commercially exploited timber trees. $16 \mathrm{pp}$.

12563 Vu Van Dung \& Vu Van Can. 1991. Endangered forest plant species in Viet Nam. $\mathrm{Ha}$ Noi: Ministry of Forestry. Centre of Technical Scientific and Economical Information. $81 \mathrm{pp}$.

12564 Bellingham, Peter J. 1993. The effects of a hurricane on Jamaican montane rain forests. (unpublished). Ph.D. dissertation, University of Cambridge, UK. 41 pp.

12567 Barry, J.P. 1970. Essai de monographie du Cupressus dupreziana A. Camus, cyprès endémique du Tassili des Ajier (Sahara Central). Bull. Soc. Hist. Nat. Afrique Nord Alger 61: 95-178.

12584 Berg, C.C. 1972. Olmedieae, Brosimeae (Moraceae). 229pp.

12587 Burger, W. 1990. Flora Costaricensis. Lauraceae \& Hemandiaceae. Fieldiana Botany 23: 138 .

12590 Ake Assi, Laurent. 1988. Espèces rares et en voie d'extinction de la flore de la Côte d'Ivoire. (unpublished). 6pp.

12597 Peguy, Tchouto. 1997. Completed data collection forms for trees from the South West Province.

12630 Laubenfels, D.J. de. 1972. Flore de la Nouvelle-Calédonie et dépendances. Paris: Muséum National d'Histoire Naturelle. 167 pp.

12646 Wyse Jackson, P.S., W. Strahm, Q.C.B. Cronk, \& J.A.N. Pamell. 1988. The propagation of endangered plants in Mauritius. Moorea 7: 35-45.
12656 Laubenfels, D.J. de \& J. Silba. 1987. The Agathis of Espiritu Santo (Araucariaceae), New Hebrides. Phytologia 61: 448-452.

12663 Rohwer, Jens. 1997. Letter to Charlotte Jenkins with review notes on the species summaries for Nectandra. 2pp.

12756 Sleumer, H.O. 1980. Flacourtiaceae. 499pp.

12779 Verdcourt, B. 1979. A manual of New Guinea legumes. Botany Bulletin 11

12801 Synge, Hugh. 1992. Information collected for Biodiversity Status Report.

12822 Aké Assi, Laurent. 1995. Data collection forms for tree species of Côte d'Ivoire.

12827 Corner, E.J.H. 1988. Wayside trees of Malaya.

12837 Prado, Darién E. \& Peter E. Gibbs. 1993. Patterns of species distributions in the dry seasonal forests of South America. Ann. Missouri Bot. Gard. 80(4): 902-927.

12888 de Guzman, E.D., R.M. Umali, \& E.D. Sotalbo. 1986. Guide to Philippine flora and fauna. Univ. of Philippines, Nat. Resources Management Center.

12900 St. John, H. \& W.R. Philipson. 1962. An account of the flora of Henderson Island, South Pacific Ocean. Trans. R. Soc. N.Z Bot. 1(14): 175-194.

12937 Erfurth, T. \& H. Rusche. 1976. The marketing of tropical wood. (unpublished). FO: MISC/76/8.

12945 Wiggins, I.L. 1980. Flora of Baja Califomia Stanford: Stanford University Press. 1025pp.

12959 IUCN Protected Areas Data Unit. 1987. Directory of Indomalayan protected areas. Bhutan. Draft. Cambridge, IUCN Conservation Monitoring Centre.

12963 Lucas, Grenville Ll. \& Hugh Synge (comps.). 1978. The IUCN Plant Red Data Book. Morges, Switzerland: IUCN. 540pp.

12984 Güner, Adil. 1996. Annotations to the conservation status listing of woody plants of Turkey.

12985 Secretaria de Desarrollo Social. 1994. Las especies y subespecies de flora $y$ fauna silvestres terrestres y acuaticas en peligro de extinción, amenazadas, raras, y las sujetas a protección especial $y$ que establece especificaciones para su protección. Mexico City: Secretaria de Desarrollo Social.

13013 Wang, S. et al. 1988. [The present state of preservation of the precious, rare and threatened plants in Hubei, as well as the proposition for studying further these plants]. J. Wuhan Bot. Res. 6(3): 285-298. 
13041 Farjon, Aljos. et al. 1998. Data collection forms for conifer species completed by the SSC Conifer Specialist Group between 1996 and 1998.

13058 Gillett, Jan B. 1993. Annotations to WCMC printout entitled "Kenya Conservation Status Listing of Plants - annotated by Jan B. Gillett". 42pp.

13072 Gillett, Jan B. 1979. Kenya. Part of appendix to: Possibilities and needs for conservation of plant species and vegetation in Africa. pp. 93. 94. In Hedberg, I. (ed.). Systematic botany, plant utilization and biosphere conservation. Stockholm: Almqvist \& Wicksell International.

13073 Anon. 1992. Annex 1 - Species ecological status by category. pp. 42-59. UNEP Thailand Country Study on Biodiversity.

13112 Prance, G.T. 1994. Four new species of neotropical Dichapetalaceae. Kew Bull. 49(1): 129-136

13121 Koopowitz, Harold \& Hilary Kaye. 1990. Plant extinction: a global crisis. London: Christopher Helm.

13143 Nature Conservation Society of Japan, WWFJapan. 1987. The list of plants important for conservation (the primary edition). Angiospermae: Corypetalae. Tokyo: NACSJapan and WWF-Japan. 27pp.

13174 Hillcoat, D., G. Lewis, \& B. Verdcourt. 1986. A new species of Ceratonia (Leguminosae Caesalpiniodeae) from Arabia and the Somali Republic. Kew Bull. 35(2): 261-271.

13176 Prance, G T. 1994. Two new species of neotropical Chrysobalanaceae. 49(2): 359. 363.

13191 Timberlake, J. 1997. Letter to Charlotte Jenkins with comments on Zimbabwe tree species contained in WCMC databases. 1pp.

13204 Enright, N.J. 1982. The ecology of Araucaria species in Papua New Guinea, Joumal of Ecology 7

13205 Zanoni, T.A. \& R.P. Adams. 1979. The genus Juniperus (Cupressaceae) in Mexico and Guatemala: synonymy, key and distributions of the taxa. Bol. Soc. Bot. Mex. 38: 83-121.

13206 Hayashi, Y. 1952. The natural distribution of important trees indigenous to Japan. Conifers: Report 2.

13207 Verdcourt, B. 1968. Aquifoliaceae in Flora of Tropical East Africa. Milne-Redhead, E. \& Polhill, R.M. (eds.). Crown Agents for Oversea Govemments and Administrations.

13228 Lundell, C.L. 1974. Studies of American plants, VI. Wrightia 5(2): 23-44.
13250 Thome, J.M. 1979. Liberia. Part of appendix to: Possibilities and needs for conservation of plant species and vegetation in Africa. pp. 88. In Hedberg, I. (ed.). Systematic botany, plant utilization and biosphere conservation. Stockholm: Almqvist \& Wiksell International.

13285 Chandrasekharan, C. (comp.). 1995. Nonwood NEWS.

13295 Halloy, Stephan. 1994. Annotations to the Argentina WCMC printout dated 17 Jan 1994. (unpublished). 23pp.

13315 Fryxell, P.A. 1969. The genus Hampea (Malvaceae), Brittonia 21: 359-396.

13316 Gentry, A.H. 1980. Bignoniaceae Part I. (Crescentieae and Tourrettieae). 131pp.

13361 Almeda, F. 1982. Symplocos sousae, a new species of Symplocaceae from Mexico. Madroño 29(4): 255-258.

13370 Gelderblom, C.uroline. 1994. Letter from Caroline Gelderblom to Dr Kerry Walter concerning lists of threatened plants in Southern Africa dated 7 March 1994. 10pp.

13395 Tantra, G.M. 1983. Erosi plasma nutfah nabati dan Masalah Pelestariannya. Jumal Libang Pertanian 2(1): 1-5.

13404 Argus, G.W. \& D.J. Pryer. 1. Atlas of the rare vascular plants of Ontario. 4 parts. Ottawa: National Museum of Natural Sciences.

13560 Laguna, E. (comp.). 1994. Libro de la flora vascular rara, endémica o amenazada de la Comunidad Valenciana. Valencia: Conselleria de Medi Ambient de la Generalitat Valenciana. 275pp.

13573 Vangjeli, Jani, Babi Ruci, \& Alfred Mullaj. 1995. Libri i kuq. Bimët e kërcënuara e të rralla të Shqipërisë. Tirana: Akademia e Shkencave e Republikës Së Shqipërisë \& Instituti I Kërkimeve Biologjike Komiteti I Mbrojtjes Së Mjedisit. 169pp.

13574 Weitzman, A.L. 1995. Diversity of Theaceae and Bonnetiaceae in the montane Neotropics. pp. 365-375. In Churchill, S.P. et al.(eds.). Biodiversity and conservation of neotropical montane forests. New York: New York Botanical Garden.

13604 Waldren, Steve, J. Florence, \& A.J. ChepstowLusty. 1995. Rare and endemic vascular plants of the Pitcaim Islands, south-central pacific ocean: a conservation appraisal. Biological Conservation

13628 Holden, C. 1980. Rain forests vanishing. Science 208(4442): 378.

13657 Estenssoro, S. 1987. Lista preliminar de plantas especiales. La Paz: Centro de Datos para la Conservación. $17 \mathrm{pp}$. 
13661 Killeen, T.J. 1993. Guia de arboles de Bolivia. La Paz, Bolivia: Herbario Nacional de Bolivia.

13662 Ser, C.S. 1982. Malaysian timber - Merbau. Kuala Lumpur. Malaysian Timber Industry Board.

13686 Bertoni, Siemens. el al. 1994. Flora Amenazada del Paraguay.

13688 Mustant, P, J Juritz, C Makua, S.W. Van der Merwe, \& N. Wessels. 1995. Restoration of the clanwilliam cedar Widdringtonia cedarbergensis: the importance of monitoring seedlings planted in the Cederberg. South Africa. Biological Conservarion 72: 73-76.

13705 Breteler, F.J. 1996. Conversation with Charlotte Jenkins concerning the occurrence of a new Xanthocercis species in Gabon.

13789 Cullen, P.J \& J.B. Kirkpatrick. 1988. The ecology of Athrotaxis D. Don (Taxodiaceae). 2. The distribution and ecological differentiation of Athrotaxis cupressoides and Athrotaxis selaginoides. Australian Joumal of Ecology 36(5): 561-573.

13838 Wang, Xianpu, X. Jin, \& C. Sun. 1986. Burretiodendron hsienmu Chun \& How: its ecology and its protection. Amoldia 45(4): 4651.

13856 Du Puy, D. J., P. B. Phillipson, \& R. Rabevohitra. 1995. The genus Delonix (Leguminosae: Caesalpinioideae: Caesalpinieae) in Madagascar. Kew Bulletin 50(3): $445-475$.

13857 Ashton, P. 1996. Annotations to: Conservation status listing for Dipterocarpaceae.

13880 Green, Peter. 1991. Letter to Hugh Synge concerning conservation status of Norfolk and Lord Howe Islands plants. Includes annotations to 27 Aug 1991 TPU printouts for Lord Howe Island and Norfolk Island.

13930 Allan, H.H. 1961. Flora of New Zealand. Wellington: R.E.Owen, Government Printer. 1085pp.

13947 Chudnoff, M. 1984. Tropical timbers of the world. Forest Products Laboratory Madison, Wisconsin: United States Department of Agriculture. $464 \mathrm{pp}$.

13995 Nelson, C. H. 1997. Threatened trees of Honduras. $8 \mathrm{pp}$.

14002 Fourie, S.P. 1984. Threatened Euphorbias in the Transvaal. The Euphorbia Joumal 2: 75. 90.

14011 Chayamarit, Kongkanda. 1986. Leguminous plants in the mangrove formations in Thailand. Thai Forest Bulletin (Botany) 1(16): 119-153.
14040 Arce, S.J.P., C.S. Estenssoro, \& S.P. Ergueta. 1987. Diagnóstico del estado de la flora, fauna y communidades importantes para la conservación. Bolivia, La Paz, Centro de Datos para la Conservación. 98pp.

14140 Ricci, Marcia 1991. Letter to Hugh Synge concerning conservation status of plants of the Juan Femandez Islands. Includes annotations to 12 Aug 1991 TPU printout for the Juan Fernandez Islands. 10pp.

14208 Jenkins, M.D. (ed.). 1987. Madagascar. An environmental profile. Gland, Switzerland and Cambridge, IUCN/UNEP/WWF. 374pp.

14250 González Villarreal, L.M. 1986. Contribución al conocimiento del género Quercus (Fagaceae) en el estado de Jalisco. Guadalajara, México: Universidad de Guadalajara. 240pp.

14276 Nayar, M.P. \& A.R.K. Sastry (eds.). 1988. Red Data Book of Indian Plants. Vol. 2. Calcutta: Botanical Survey of India. 268pp.

14291 Teixeira, D.E. 1988. Amazonian timbers for the international market. Brasilia: Brazilian Institute for Forestry Development \& ITTO. 94pp.

14293 Wurdack, J.J. 1982. Annotations to: List of threatened plants of Middle America.

14301 CITES. 1992. CITES Appendices as of June 1992. (unpublished).

14311 Standley, P.C. \& L.O. Williams. 1951. Plantae Centrali-Americanae, II. Ceiba 1: 231-255.

14355 Schmidt, R. 1989. Current tropical moist forest management activities in Brazil. Rome: FAO. 29pp.

14407 Miller, J.S. 1987. Two new species of Cordia (Boraginaceae) from Central America. Ann. Missouri Bot. Gard. 74: 670-673.

14416 Paiva, J.A.R. 1970. Notes on Annonaceae. Bol. Soc. Brot. Ser.2 44: 369-373.

14418 Berhaut, J. 1971. Flore illustrée du Sénégal. Gouvemement du Sénégal, Ministère du Développement Rural.

14424 US Department of the Interior. Fish and Wildlife Service. 1985. Endangered and threatened wildlife and plants: final rule to determine Burus vahlii as an endangered species. Federal Register 50(156): 3257232575.

14430 Sternberg, Guy. 1996. Letter to Charlotte Jenkins conceming oaks of North America.

14448 Anon. 1985. In situ conservation of forest genetic resources in Peninsular Malaysia. pp. 32-49. In Forest Genetic Resources Information 14. Rome: FAO. 
14453 Dwyer, J. \& M.V. Hayden. 1966. Three new species of Neea (Nyctaginaceae) from Panama. Phytologia 14(3): 137-139.

14458 Degteva, S. 1995. Annotations to WCMC list of plants of the Russian Federation. 11pp.

14487 Standley, P.C. 1. Flora of Costa Rica. Field Mus. Nat. Hist., Bot. Ser. 18(1): 1-1616.

14490 Pradhan, Rebecca. 1993. Annotations to WCMC plant list for Bhutan dated 31 August 1993. 40pp.

14508 Jaffre, T., J.M. Veillon, \& J.F. Cherrier. 1987. on the occurence of two Cupressaceae, Neocallitropsis pancheri and Libocedrus austrocaledonica in the Mt Paéua area and new sites for the gymnospems in New Caledonia. Bulletin de Museum National d'Histoire Naturelle Section B Adansonia 9(3): 273-288.

14513 Florence, J. 1996. Liste des espèces endémiques de Polynésie Française avec leur répartition géographique et leur statut IUCN, tirée de la banque de données botaniques NADEAUD. (unpublished). $56 \mathrm{pp}$.

14516 Fries, R.E. 1934, Revision der Arten einiger Anonaceen-Gattungen, III. Acta Horti. Berg. 12(1): $1-220$.

14541 Jones, David. 1986. Status of Malaysian Rutaceae (unpublished list). 3pp.

14556 Lawesson, J.E., H. Adsersen, \& P. Bentley. 1987. An updated and annotated checklist of the vascular plants of the Galapagos Islands. Aarhus, Denmark: University of Aarhus. Reports from the Botanical Institute No. 16. 74pp.

14573 Soerianegara, I. \& R.H.M.J. Lemmens (eds.). 1993. Plant resources of South-East Asia 5(1). Timber trees: major commercial timbers. Wageningen: Pudoc Scientific Publishers. 610 pp.

14630 Rudd, V. 1981. Annotations: List of threatened plants of Middle America.

14667 Katende, A.B. 1993. Annotations to: TPU conservation status report for Uganda dated 29 Jun 1993. 33pp.

14683 Rushforth, K. 1986. Mexico's spruces - rare members of an important genus. Kew Mag. 3(3): 119-124.

14717 Jiménez Madrigal, Quirico. 1993. Arboles maderables en peligro de extinción en Costa Rica. San José, Costa Rica: Museo Nacional de Costa Rica. 121 pp.

14719 Breteler, F.J. 1989. The Connaraceae. A taxonomic study with emphasis on Africa. Wageningen Agricultural University. 403pp.
14778 Cunningham, A.B. \& F.T. Mbenkum 1993. Sustainability of harvesting Prunus africana bark in Cameroon. People and Planis Working Paper 2: 1-28

14811 Sidiyasa, K. 1996. Alstonia beatricis (Apocynaceae), a new species from Irian Jaya, Indonesia. Blumea 41(1): 29-31.

14873 Asociación Nacional para la Conservación de la Naturaleza. 1990. List of threatened and vulnerable plants of Panama. (unpublished).

14883 Nicolson, D.H. 1977. Endemic species of dicots in Dominica. Pers. comm.

14911 Forero, E. 1983. Connaraceae. Flora Neotropica, Monograph 36. 208p.

14932 Sosa, V. (ed.). 1978. Flora of Veracruz. Instituto de Investigaciones sobre Recursos Bíticos.

14953 Lorence, D.H. 1983. First record of Elaegia (Rubiaceae) in Mexico, with description of a new species, E. uxpanapensis. Bol. Soc. Bot. Mexico 45: 65-69.

14958 White, Lee. 1997. Conversation with Charlotte Jenkins concerning the status of tree species and forests in Gabon.

15017 Alder, D. 1989. Natural forest increment, growth and yield. pp. 47-52. Wong, J.L.G. (ed.), Forest Inventory Project, Seminar Proceedings, 29-30 March 1989, Accra.

15037 d'Arcy, W.G. 1987. Flora of Panama: checklist and index. Monographs in Systematic Botany 17: $1-1000$.

15106 Henry, A.N. \& M.S. Swaminathan. 1983. On the rediscovery of two rare endemic plants of India. Bull. Bot. Surv. India 24(1): 234-235.

15188 Boggan, J., V. Funk, C. Kelloff, M. Hoff, C. Cramers, \& C. Feuillet. 1992. Checklist of the plants of the Guianas (Guyana, Surinam, French Guiana). Washington, DC: Biological Diversity of the Guianas Program, Smithsonian Institution. $381 \mathrm{pp}$.

15251 HMSO. 1. Index Kewensis plantarum phanerogamarum. Kew: Royal Botanic Gardens.

15309 Maguire, B. 1977. Notes on Clusiaceae, chiefly of Panama. I. Phytologia 36(4): 391 407.

15310 Pipoly, J.J. 1987. Annotations to: List of threatened plants of Latin America.

15343 Daly, D. 1988. Annotations to: List of threatened plants of Latin America.

15346 Pérez-Jiménez, A. 1982. Jatropha chamelensis (Euphorbiaceae), nueva especie de costa de Jalisco, México. Bol. Soc. Bot. Méx. 42: 35-39. 
15357 Chinh, N. N. et al. 1996. Vietnam forest trees. Hanoi: Agricultural Publishing House. 1-788.

15360 Timberlake, J.R. \& P. Shaw (eds.). 1994. Chirinda forest - a visitor's guide. Harare, Zimbabwe: Division of Research \& Development, Zimbabwe Forestry Commission. 158pp.

15371 Spichiger, R., J. Méroz, P.-A. Loizeau, \& L Stutz de Ortega. 1990. Contribución a la flora de la Amazonia Peruana. Genève: Conservatoire et Jardin Botanique de Genève. $565 \mathrm{pp}$.

15377 US Deptartment of State. 1983. Czechoslovakia. 7 pp.

15384 Marticorena, C. 1986. Annotations to: the conservation status listing of threatened plants of Chile.

15406 Villasenor, José Luis, Patricia Dávila, \& Fernando Chiang. 1990. Fitogeografía del Valle de Tehuacán-Cuicatlán. Biol. Soc. Bot. México 50: 135-149.

15415 Stein, A.H. 1956. Natural Forests of Chile. Unasylva 10(4): 155-161.

15417 Hommel, P.W.F.M. 1987. Landscape ecology of Ujung Kulon (West Java, Indonesia). Wageningen: Privately published doctoral thesis. 206pp.

15421 Van der Werff, H. 1993. Persea glabra, a new species of Lauraceae from Bahia. Kew Bull. 48(1): 25-27.

15431 Dassanayake, M.D. \& F.R. Fosberg (eds.). 1980. A revised handbook to the flora of Ceylon. New Delhi: Amerind Publ. Co.

15436 Orgaño del Gobierno Constitucional de los Estados Unidos Mexicanos. 1994. Dario Oficial de la Federación. 3-24.

15477 Leon, Chris. 1991. Conversation with Kerry Walter concerning conservation status of Ozoroa reticulata.

15478 Encarnación, F. 1983. Nomenclatura de las especies forestales comunes en el Pen. Lima $147 \mathrm{pp}$.

15491 Leeuwenberg, A.J.M. 1994. A revision of Tabemaemontana. Two. The New World species and Stemmadenia. Royal Botanic Gardens, Kew. 450pp.

15533 Herbst, Derral. 1991. Annotations to WCMC plant list for Guam.

15539 IBAMA. 1992. Lista oficial de espécies da flora Brasileira ameaçadas de extinçao. (unpublished). 4pp.
15561 Matthews, W.S., A.E. Van Wyk, \& G.J. Bredenkamp. 1992. Endemic flora of the North-Eastem Transvaal Escarpment, South Africa. Biological Conservation 63: 83-94.

15598 Nooteboom, H.P. (ed.). 1987. Report of the 1982-1983 Bukit Raya expedition. Leiden: Rijksherbarium. 93pp.

15608 Tutin, T.G., N.A. Burges, A.O. Chater, J.R. Edmondson, V.H. Heywood, D.M. Moore, D.H. Valentine, S.M. Walters, \& D.A. Webb. (ed.). 1993. Flora Europaea Volume 1. Cambridge, UK: Cambridge University Press. $581 \mathrm{pp}$.

15615 Stanley, \& Ross. 1989. Flora of South Eastern Queensland. Brisbane: Qsld. Dept. Primary Industries.

15616 Ibanez, J.M. et al. 1989. Data on a population of Tetraclinis articulata (Vahl) Masters. Ecologia 3: 99-106.

15649 Baum, David. 1995. A systematic revision of Adansonia (Bombacaceae). Ann. Missouri Bot. Gard. 82: 440-470.

15714 van der Werff, H. 1994. Annotations - list of threatened plants of South America. 159-165.

15717 Pereira, J.P., C. Sastre, \& S. Romaniuc. 1996. Indice das espécies de Moráceas do Brasil. Albertoa 4: 77-96.

15719 van der Werff, H. 1988. Eight new species and one new combination of Neotropical Lauraceae. Ann. Missouri Bot. Gard. 75(2): $402-419$.

15754 Kostermans, A.J.G.H. (ed.). 1987. Proceedings of the Third Round Table Conference on Dipterocarps. Jakarta: Unesco. 657pp.

15790 Aubreville, A. \& J.-F. Leroy. 1961. Flore du Gabon. Published by the Gabon Govemment through Muséum National d'Histoire Naturelle, Paris.

15791 Pennington, R. Toby. 1993. Manuscript (Ph.D. dissertation) on Andira.

15828 Argus, G.W \& K.M Pryer. 1990. Rare vascular plants in Canada. Ottawa: Canadian Museum of Nature. $191 \mathrm{pp}$.

15830 Williams, L.O. 1967. Tropical American plants, VIII. Fieldiana Bot. 31(10): 249-269.

15892 Vázquez-G, J.A. 1994. Magnolia (Magnoliaceae) in Mexico and Central America: a synopsis. Brittonia 46(1): 1-23.

15919 de Wilde, W.J.J.O. 1984. A new account of the genus Horsfieldia (Myristicaceae), Pt 1. Gardens' Bulletin 37(2): 115-179. 
15926 Frodin, David. 1997. Conversation with Charlotte Jenkins concerning the taxonomy of Schefflera species.

15965 Smith, Albert C. 1971. Studies of Pacific Island Plants, XXII. Pacific Science 4: 491501 .

15966 Whitmore, T.C. (ed.). 1972. Tree Flora of Malaya - a manual for foresters Vol. 1. Hong Kong: Longman. 470 pp.

15991 Lundell, C.L. 1985. Neotropical species of the genus Perrottetia (Celastraceae). Phytologia 57(3): 231-237.

16021 Katende, A.B. 1995. Annotations to: WCMC printout of Trees of Uganda dated 23 Nov. 1995. 137pp.

16031 Baldwin, M.F. (ed.). 1992. Natural resources of Sri Lanka: conditions and trends. Colombo: Natural Resources, Energy and Science Authority of Sri Lanka. 280pp.

16093 National Research Council. 1989. Lost crops of the Incas: little known plants of the Andes with promise for worldwide cultivation. Washington DC: National Academy Press. 415 pp.

16095 Queiroz, L.P.De. 1994. Cratylia bahiensis (Leguminosae: Papilionoideae), a new species from Bahia, Brazil. Kew Bull.: 769-773.

16104 MacKinnon, J. \& I. Warsito. 1982. Gunung Palung Reserve Kalimantan Barat: preliminary management plan. Bogor: UNDP/FAO. 40pp.

16111 Bokhari, M.H. 1975. A new record of Cupressus in SW Iran. Notes from the Royal Botanic Garden Edinburgh 33(3): 445-447.

16121 Smith, N.J.H., J.T Williams, Donald L Plucknett, \& Jennifer P. Talbot. 1992. Tropical forests and their crops. USA: Comell University. 568pp.

16123 Sociedade Botânica do Brasil. 1992. Centuria plantarum Brasiliensium extintionis minitata. Sociedade Botânica do Brasil. 175pp.

16172 Nooteboom, H.P. 1984. A new Shorea from Java. Flora Malesiana Bull. 9(1): 44-45.

16212 Friedmann, F. 1991. Annotations to Threatened Plant Unit printout for the Seychelles (granitic islands) dated 12 Sep 1991. (unpublished). 6pp.

16232 Timberlake, Jonathan. 1996. Letter to Sara Oldfield listing Zimbabwe tree and tree/shrub species which are threatened, endemic or of restricted distribution.

16235 Howard, Richard A. Ferns and flowering plants of Montserrat. (unpublished). 36pp.
16239 Romoleroux, Katya. 1996. Rosaceae in the High Andes of Ecuador. pp. 407-413. In Churchill, S.P. et al.(eds.). Biodiversity and conservation of neotropical montane forests. New York: The New York Botanical Garden.

16250 Ohwi, J. 1965. Flora of Japan (in Englist). Washington, DC: Smithsonian Institution. 1067pp.

16261 Proctor, George R. 1984. Flora of the Cayman Islands. Royal Botanic Gardens, Kew: London, HMSO. 834pp.

16292 Whitmore, T.C. 1966. Guide to the forests of the British Solomon Islands. Oxford: Oxford University Press. 208pp.

16327 Brito, A. A. 1995. Letter to Wendy Strahm including annotations to: List of threatened trees of Cuba. 1-5.

16328 González Cangas, Mauro. 1996. Completed data collection forms for tree species of Chile.

16331 Hekking, W.H.A. 1988. Violaceae Part 1 Rinorea and Rinoreocarpus. Flora Neotropica. Monograph 46. 207 pp.

16380 Ghazanfar, Shahina A. 1995. Plant conservation in Oman. Part 1. (unpublished). Compiled with Anthony G. Miller, Ian McLeish, Tom A. Cope, Phil Cribb and Salim H. Al Rawahi. 62pp.

16394 Kostermans, 1. 1986. Annotations to: List of mangoes in the CMC database.

16409 Melville, R. \& H.M. Heybroek. 1971. The elms of the Himalaya. Kew Bull. 26(1): 5-28.

16426 Bosser, J., Th. Cadet, H.R. Julien, \& W. Marais. 1976. Flore des Mascareignes: La Réunion, Maurice, Rodrigues. The Sugar Research Institute, Mauritius; ORSTOM, Paris; Royal Botanic Gardens, Kew.

16427 Chepstow-Lusty, Alex. 1992. Letter about the conservation status of plants from Henderson Island. 2pp.

16435 Abraham, Z. \& B.N. Mehrotra. 1983. Some observations on endemic species and rare plants of the montane flora of the Nilgiris, South India. J. Econ. Taxon. Bot. 3(3): 863867.

16438 Jain, S.K. \& A.R.K. Sastry (comps.). 1983. Materials for a catalogue of threatened plants of India. Howrah, Botanical Survey of India. 69pp.

16458 Lamprecht, H. 1989. Silviculture in the tropics. Germany: GTZ.

16500 Anon. 1993. Draft Document - Trade status of habitat directive species for inclusion in EC trade regulation. 1-36. 
16516 Quero, H.J. \& R.W. Read. 1986. A revision of the palm genus Gaussia. Syst. Bor. 11(1): 145154.

16525 Reitz, P.R. \& R.M. Klein. 1966. Flora Illustrada Catarinense Araucariaceae. Santa Catarina, Brazil: Itaja. 45-47.

16551 Rongo, Teariki. 1993. Cook Islands. Regional Environment Technical Assistance Project.

16595 Ntima, O.O. 1968. The Araucarias - fast growing timber trees of the tropics.

16608 Bingham, Mike. 1994. Letter received by Mrs Caroline Gelderblom with comments on the WCMC printout for Zambia.

16612 Hancock, I.R. \& C.P. Henderson. 1988. Flora of the Solomon Islands.

16640 Jain, S.K. \& A.R.K. Sastry. 1980. Threatened plants of India: A state of the art report. New Delhi: Botanical Survey of India and Man and Biosphere Committee. 48pp.

16676 Wiles, G.J., J.H. Schneinen, D. Nafus, L.K. Jurgensen, \& J.C. Manglone. 1996. The status, biology, and conservation of Seranthes nelsonii (Fabaceae), an endangered Micronesian tree. Biological Conservation

16700 Percy, D.M. \& Q.C.B. Cronk. 1997. Conservation in relation to mating system in Nesohedyotis arborea (Rubiaceae), a rare endemic tree from St. Helena. Biological Conservation 80(2): 135-146.

16730 Cunningham, A.B. 1991. Development of a conservation policy on commercially exploited medicinal plants: a case study from southem Africa. pp. 337-358. In Akerele, O., Heywood, V. \& Synge, $H$. (eds.). Conservation of medicinal plants. Cambridge: Cambridge University Press.

16765 Amerson, A.B., W.A. Whistler, \& T.D. Schwaner. 1982. Wildlife and wildlife habitat of American Samoa. II: Accounts of flora and fauna. Washington, DC, US Fish and Wildlife Service. $151 \mathrm{pp}$.

16772 Mitré, Martin E. 1997. Completed data collection forms for trees of Panama.

16781 Stainton, J.D.A. 1972. Forests of Nepal. London: John Murray Ltd. 174pp.

16794 Long, A. \& M. Heath. 1991. Flora of the El Triunfo Biosphere Reserve, Chiapas, Mexico: Ann. Inst. Biol. UNAM Sev. Bot. 62(2): 133172.

16796 Clarke, G.P. \& J. Lovett. 1996. Data collection forms for tree species of Tanzania.

16822 Styles, B.T. \& F. White. 1991. Meliaceae in Flora of Tropical East Africa. Rotterdam: A.A. Balkema. 68pp.
16884 Silba, J. 1984. An international census of the Coniferae. Phytologia 7: 3-79.

16898 Anon. Endemic flora of Puerto Rico and the Virgin Islands.

16907 Vovides, A.P. 1986. Relación de plantas Mexicanas raras o en peligro de extinción. (unpublished). Veracruz: INIREB. 7pp.

16916 Gunatilleke, I.A.U.N. \& C.V.S. 1984 Distribution of endemics in the tree flora of a lowland hill forest in Sri Lanka. Biol. Conserv. 28(3): 275-285

16925 Rao, Y.S. 1992. Forest news. Tigerpaper 4: 9 11.

16943 Green, Michael J.B. \& E.R.N. Gunawardena. 1993. Conservation evaluation of some natural forests in Sri Lanka. 163 pp.

16973 Berendsohn, W. 1987. Letter to Jane VillaLobos.

16980 Johnson, Dennis V. 1992. Annotation to printout: Palm database changes; New World. Group 3, July 1992. (unpublished). 4pp.

16987 United States of America. 1991. Proposal to include Guaiacum officinale on Appendix II of CITES. Submitted for 8th Meeting of Conference of the Parties to CITES, 2-13 March 1992, Kyoto, Japan. (unpublished). 22pp.

17038 Burton, Fred. 1993. Letter to WCMC including list of status of endemic plants in the Cayman Islands. $7 \mathrm{pp}$.

17122 Brown, F.B.H. 1935. Flora of Southeastern Polynesia. B.P. Bishop Museum Bulletin: 1386.

17124 Anon. 1992. Report on the rare plants of Puerto Rico. St. Louis, Missouri: Center for Plant Conservation, Missouri Botanical Garden.

17140 Said, I.M. \& Z. Rozainah. 1992. An updated list of wetland plant species of Peninsular Malaysia, with particular reference to those having socio-economic value. Asian Wetland Bureau. 109pp

17153 Bridson, D.M. 1994. Additional notes on Coffea (Rubiaceae) from tropical East Africa. Kew Bull. 49(2): 331-342.

17165 McVaugh, R. 1974. Flora Novo-Galiciana. Ann Arbor, Michigan: University of Michigan Press.

17176 de Wilde, W.J.J.O. 1981. Supplementary data on Malesian Knema (Myristicaceae) including three new taxa. Blumea 27(1): 223-234. 
17185 Mianda-Bungi, Ndjele. 1988. Catalogue des plants endémiques du Zaire. (unpublished). Includes letter from author to Robert Madams. 7pp.

17186 Tripp, K.E. 1995. Cephalotarus. The plum yew. Amoldia 55(1): 24-40.

17190 Carter, Susan \& A. Radcliffe-Smith. 1988. Euphorbiaceae Part II in Flora of Tropical East Africa. Polhill,R.M. (ed.). A.A. Balkema/ Rotterdam/ Brookfield.

17195 Gunatilleke, I.A.U.N. \& C.V.S. 1991. Threatened woody endemics of the wet lowlands of Sri Lanka and their conservation. Biological Conservation 55(1): 17-36.

17200 Briggs, J.D. \& John H. Leigh. 1988. Rare or threatened Australian plants. Melbourne, Australia: CSIRO Publications.

17214 Anon. Dun - select committee on flora and fauna. (unpublished).

17229 Robertson, S.A. 1989. Flowering plants of the Seychelles. Royal Botanic Gardens, Kew. $327 \mathrm{pp}$.

17232 Whitmore, T.C., I.G.M. Tantra, \& U. Sutisna (eds.). 1989. Tree flora of Indonesia. Bogor, Indonesia: Forest Research and Development Centre. 186pp.

17235 Suselo, T.B. 1987. Autecology of $E$. zwageri T. \& B. (Lauraceae) as applied to forest regeneration. Bogor: BIOTROP.

17278 Kostermans, A.J.G.H. 1973. A forgotten Ceylonese cinnamon-tree (Cinnamomum capparu-coronde BI.). Ceylon J. Sci. (Bio. Sci.) 10(2): 119-121.

17281 Schembri, P.J. \& J. Sultana (eds.). 1989. Red Data Book for the Maltese Islands. Malta: Department of Information. 142pp.

17286 De Iongh, H., B. Van Helvoort, A. Sumaryoto, \& H. Sutanto. 1982. An ecological survey of the Kangean Island archipelago in Indonesia. Ijsselstein $55 \mathrm{pp}$.

17335 Timberlake, J.R. 1995. Annotations to WCMC printout entitled 'Conservation status listing for Zimbabwe'. 79 pp.

17368 Hunt, David R. (ed.). 1996. Temperate trees under threat. International Dendrological Society. 200pp.

17397 Robson, N. 1987. Annotations to: List of threatened plants of Latin America.

17398 Thomas, W.W. 1990. A new species of Picramnia (Simaroubaceae) from Amazonian Peru. Brittonia 42(3): 171-174.
17408 Hecketsweiler, P.H. 1990. Incomplete list of the commercially exploited timber species of Congo (Brazzaville).

17410 Dahlgren, Rolf \& Abraham E. Van Wyk. 1988. Structures and relationships of families endemic to or centered in southem Africa. Monogr. Syst. Bot. Missouri Bot. Gard. 25: 194.

17460 Fries, R.E. 1941. Neue amerikanische Annonaceen. Acta Horti Berg. 13(3): 103-116.

17523 Anon. 1979. Prosopis species. pp. 153-161. In Tropical legumes: Resources for the future. Washington, DC: National Academy of Sciences.

17540 Martorell, L.F., A.H. Loigier, \& R.O. Woodbury. 1981. Catálogo de los nombres vulgares y científicos de las plantas de Puerto Rico. Boletin 263, Universidad de Puerto Rico. Río Piedras, Puerto Rico, Recinto de Mayaguez, Estación Experimental Agrícola. $231 \mathrm{pp}$.

17554 Patterson, T. 1988. A new species of Picea (Pinaceae) from Nuevo Leon, Mexico. Sida 13(2): 131-136

17609 Wendt, T. 1993. Composition, foristic affinities, and the origins of the canopy tree flora of the Mexican Atlantic slope rain forests. pp. 595-680. In Ramamoorthy, T.P., R. Bye, A. Lot, J. Fa (eds.). Biological Diversity of Mexico. New York: Oxford University Press.

17610 Friis, I. 1989. A synopsis of Buxaceae in Africa south of the Sahara. Kew Bulletin 44: 293-299.

17611 Bohs, L. 1995. Transfer of Cyphomandra (Solanaceae) and its species to Solanum. Taxon 44(4): 587-593.

17636 Kirkpatrick, J. 1989. The conservation and reservation status of Tasmanian higher plants. Hobart: Department of Parks, Wildlife and Heritage.

17637 Williams, G.R. \& D.R. Given. 1981. The Red Data Book of New Zealand: rare and endangered species of endemic terrestrial vertebrates and vascular plants. Wellington, N.Z: Nature Conservation Council. 175pp.

17678 Chayamarit, Kongkanda. 1985. Studies in Thai flora. Thai Forest Bulletin (Botany) 1(15): 15 21.

17690 Cowan, R.S. 1968. Swartzia (Leguminosae). Flora Neotropica. Monograph 1.227p.

17692 Sidiyasa, K. 1997. Revision of Alstonia worldwide. ( $\mathrm{Pr}_{\mathrm{s}} \mathrm{D}$. thesis). (unpublished). 
17743 Adams, C.D. 1971. Miscellaneous additions and revisions to the flowering plants of Jamaica II. Phyrologia 21(2): 65-71.

17759 Werner, Wolfgang. 1995. Annotations to WCMC printout entitled 'Conservation status listing for Sri Lanka'. 85 pp.

17787 Wickens, G.E. 1971. Tropical African Plants: XXXI. Kew Bull. 25(2): 173-190.

17854 Cremers, G. 1994. Annotations to: Threatened plants of French Guiana (South America). 56pp.

17855 Tioong, S.K.K. 1984. Podocarpus laubenfelsii ; a new species from Bomeo. Blumea 29: 523 524.

17859 Achieng', S. et al 1996. Completed data collection forms for trees endemic to Kenya.

17951 Ndjele, Mianda-Bungi. 1997. Completed data collection forms for tree species of Democratic Republic of Congo.

17991 Whitten, A.J., M. Mustafa, \& G.S. Henderson. 1987. The ecology of Sulawesi. Yogyakarta: Gadjah Mada Univ. Press. 777pp.

18022 de Wilde, W.J.J.O. 1997. Notes on Southeast Asian and Malesian Myristica and description of new taxa (Myristicaceae). Blumea 42(1): $111-190$.

18039 Miller, J.S. 1987. Annotations to: List of threatened plants of Latin America.

18088 Collins, N.M., J.A. Sayer, \& T.C. Whitmore (eds.). 1991. The conservation atlas of tropical forests: Asia and the Pacific. London: Macmillan Press Ltd.

18136 Manning, W.E. 1957. The genus Juglans in Mexico and Central America. J. Amold Arbor. 38: 121-150.

18145 Lucas, G.U. 1968. Icacinaceae in Flora of Tropical East Africa. Milne-Redhead, E. \& Polhill, R.M. (eds.). Crown Agenis for Oversea Governments and Administrations.

18150 Wendt, T., S.A. Mori, \& G.T. Prance. 1985. A new family for the flora of Mexico. Brittonia 37(4): 347-351.

18170 Boland, D.J., M.I.H. Brooker, G.M. Chippendale, N. Hall, B.P.M. Hyland, R.D. Johnston, D.A. Kleing, \& J.D. Turner. 1962. Forest trees of Australia. Melboum: Thomas Nelson \& CSIRO.

18187 de Wilde, W.J.J.O. 1991. The genera of Myristicaceae as distinguished by their inflorescences, and the description of a new genus, Bicuiba. Beitr. Biol. Pflanzen 66: 95 125.
18190 Fries, R.E. 1939. Revision der Arten einiger Anonaceen-Gattungen, V. Acta Horti Berg. 12(3): 289-577.

18243 Smitinand, T. \& T. Santisuk. 1981. Dipterocarpaceae of Thailand with special reference to silvicultural ecology. Malaysian For. 44(2): 377-385.

18251 Jessup, L.W. \& WJ.J.O. de Wilde. 1993. Myristica lancifolia Poiret (Myristicaceae) new to Australia. Blumea 38(1): 39-43.

18252 de Wilde, W.J.J.O. 1994. Taxonomic review of Myristica (Myristicaceae) in the Pacific. Blumea 38(2): 349-406.

18325 FRLHT. 1995. Plants under threat - new list forged AMRUTH 5: 2-3.

18327 Whitmore, T.C., I.G.M. Tantra, \& U. Sutisna (eds.). 1989. Tree flora of Indonesia. Bogor, Indonesia: Forest Research and Development Centre. $181 \mathrm{pp}$.

18388 Rudjiman. 1987. A revision of Beaumontia Wallich, Kibatalia G.Don. and Vallariopsis. Agricultural University of Wageningen Papers 85

18389 Adema, F., P.C. Leenhouts, \& P.C. van Welzen. 1994. Sapindaceae. Flora Malesiana. Leiden: Flora Malesiana Foundation.

18411 Hamann, Ole. 1991. Indigenous and alien plants in the Galápagos Islands: problems of conservation and development. pp. 169-192. In Heywood, V.H. \& Wyse Jackson, P.S. (eds.). Tropical botanic gardens. Their role in conservation and development. San Diego: Academic Press Inc.

18414 Tirvengadum, D.D. 1989. Ramosmania rodriguesii, nouvelle rubiacée endémique de Rodrigues (Mascareignes). C.R. Soc. Biogéogr. 65(1): 13-20.

18416 Holdridge, L. 1982. Annotations: List of threatened plants of Middle America.

18427 Standley, P.C. \& L.O. Williams. 1952. Ocho géneros de árboles y arbustos nuevos para Centro América. Ceiba 3: 24-35.

18432 Anon. 1994. Collections of the US National Herbarium, Smithsonian Institution, Washington DC.

18485 Borhidi, A. \& O. Muñiz. 1983. Catálogo de plantas Cubanas amenazadas o extinguidas. La Habana: Acad. Ciencias de Cuba. 85pp.

18501 Figueiredo, Estrela. 1996. Plant life: Lasiodiscus. Gulf of Guinea Conservation Newsletter. No. 3: 6.

18515 Zoysa, N. de \& R. Raheem. 1990. Sinharaja - a rainforest in Sri Lanka. Colombo: March for Conservation. 6lpp. 
18523 Edwards, Sue \& Zemede Asfaw. 1992. The status of some plant resources in parts of Tropical Africa. Botany 2000: East and Central Africa. NAPRECA Monograph Series No. 2. Addis Ababa: NAPRECA, Addis Ababa University,

18665 Thulin, Mats. 1996. Annotations to: the conservation listing for trees of Somalia.

18674 de Wilde, W.J.J.O. 1985. A new account of the genus Horsfieldia (Myristicaceae). PL. 2. Gardens' Bullesin 38(1): 55-144.

18697 Hind, DJ.N. 1994. New Compositae from the Serra Do Grao Mogol (Mun. Grao Mogol, Minas Gerais, Brazil) and the surrounding area. Kew Bull.: 511-522.

18710 Hara, H., W.T. Stearn, \& L.H.J Williams. 1. An enumeration of the flowering plants of Nepal. London, British Museum (Natural History)

18751 Farjon, Aljos, 1994. Annotations to: Conservation status listing of conifers of the world dated 2 February 1994.

18796 Wijesinghe, L.C.A., I.A.U.N. Gunatilleke, S.D.G. Jayawardana, S.W. Kotagama, \& C.V.S. Gunatilleke. 1990. Biological conservation in Sri Lanka (A national status report). Colombo: Natural Resources, Energy and Science Authority of Sri Lanka. 64pp.

18802 Sutter, H. 1986. Annotations to: List of plants in the WCMC database for Burma.

18818 Smith, A.C. 1979. Flora Vitiensis Nova: a new Flora of Fiji. Hawaii, Pacific Tropical Botanic Garden.

18829 Wickens, G.E. 1973. Combretaceae in Flora of Tropical East Africa. Polhill, R.M. (ed.). Crown Agents for Overseas Governments and Administrations.

18833 Shapcott, A. 1991. Studies in population biology and genetic variation of the Huon pine (Lagarostrobos franklinii). Hobart: The National Rainforest Conservation Program and Department of Parks, Wildlife and Heritage, Hobart and Dept. of the Arts, Sports, the Environment and Territories.

18839 Andrews, F.W. 1950. The flowering plants of the (Anglo-Egyptian) Sudan. Arbroath, Scotland: Buncie.

18840 Parnadjaja. 1988. Vegetation analysis and mapping by remote sensing techniques as a database for the management of the Kerinci Seblat National Park, Sumatra.

18965 Exell, A.W., H. Wild, A. Fernandes, J.P.M. Brenan, \& E. Launert (eds.). 1. Flora Zambesiaca. Volumes published up until 1996. London, Crown Agents.
18986 Dransfield, J. \& H.J. Beentje. 1995. Palms of Madagascar. Royal Botanic Garden, Kew. $500 \mathrm{pp}$.

19005 Clark, T.W. \& R.D. Dom (eds.). 1979. Rare and endangered vascular plants and vertebrates of Wyoming. 78pp.

19017 E. Soepadmo and K.M. Wong. 1995. Tree Flora of Sabah and Sarawak. Kuala Lumpur. Ampang Press Sdn. Bhd. 513 pp.

19018 Rackham, O. \& J. Moody. 1996. The making of the Cretan landscape. Manchester University Press. 237 pp.

19019 Zaffran, J. (ed.). 1990. Contributions à la flore et à la végétation de la Crete. Aix en Provence: Université de Provence. 615 pp.

19020 Kessler, M. 1997. Comments on the conservation status of Polylepis species. 2 pp.

19021 Trehane, P. 1997. Comments on Abies nebrodensis.

19022 Bañares, A. et al. 1997. Completed data collection forms for the trees of the Canary Islands.

19023 Murugaiyan, P. 1997. Completed data collection forms for tree species of the Seychelles.

19024 Baum, D. 1997. Comments on a new population of Adansonia suarezensis found in Madagascar.

19025 Gerlach, J. (ed.). 1997. Seychelles Red Data Book - 1997. Seychelles: The Nature Protection Trust of Seychelles. 122 pp.

19026 Meijer, W. 1997. A conversation between Amy MacKinven and Dr W. Mejier regarding possibly extinct trees of Sabah.

19027 Fosberg, F.R. \& Renvoize, S.A. 1980. The flora of Aldabra and neighbouring islands. Kew. Bull. Add. Ser. 7: 1-358.

19028 Singh, M. 1997. Letter to Charlotte Jenkins concerning the conservation status of Euphorbia santapauii.

19029 Singh, M. 1994. Succulent Euphorbiaceae of India. New Delhi, India 55 pp.

19030 Nohemy Ventura, E. 1997. Completed data collection forms for trees of El Salvador.

19031 Conn, B.J. (ed.). 1995. Handbooks of the Flora of Papua New Guinea. Melboume University Press. 1-292.

19032 Johns, R.J. 1993. Biodiversity and conservation of the native flora of Papua New Guinea. pp. 15-75. In Papua New Guinea conservation needs assessment. PNG: Government of Papua New Guinea. 
19033 The Nature Conservancy. 1996. Natural Heritage Central Database. (Status and distribution data on North American plants, developed in collaboration with the Association for Biodiversity Information, US and Canadian Natural Heritage Programs and Conservation Data Centers, and North Carolina Botanical Garden Biota of North America Program.)

19034 US Fish and Wildlife Service. 1996. Endangered and threatened wildlife and plants; endangered status for the plant Delissea undulata. US Federal Register 61(198): 53124-53130.

19035 US Fish and Wildlife Service. 1996 Endangered and threatened wildlife and plants; determination of endangered and threatened status for fourteen plant taxa from the Hawaiin Islands. US Federal Register 61(198): 5310853124.

19036 US Fish and Wildlife Service. 1996. Endangered and threatened wildlife and plants; determination of endangered or threatened status for nineteen plant species from the island of Kauai, Hawaii. US Federal Register 61(198): 53070-53089.

19037 US Fish and Wildlife Service. 1996. Endangered and threatened wildlife and plants; determination of endangered status for thirteen plants from the islands of Hawaii. State of Hawaii. US Federal Register 61(198): 53137 53153.

19038 US Fish and Wildlife Service. 1995. Recovery plan for the Kaua'i plant cluster. Portland, Oregon: US Fish and Wildlife Service. 290 pp.

19039 US Fish and Wildlife Service. 1996. Recovery plan for the Big Island plant cluster. Portland, Oregon: US Fish and Wildlife Service. 176 pp.

19040 US Fish and Wildlife Service. 1996. Recovery plan for Molokai plant cluster. Portland, Oregon: US Fish and Wildlife Service. 143 pp.

19041 US Fish and Wildlife Service. 1996. Recovery plan for Koolau Mountain plant cluster. Portland, Oregon: US Fish and Wildlife Service. $124 \mathrm{pp}$.

19042 Rosseel, J. 1997. Email message to Charlotte Jenkins concerning endemic trees to Sảo Tomé.

19043 Breteler, F.J. 1997. Letter to Charlotte Jenkins containing annotations to the draft species summaries for Gabonese trees.

19044 Loc, Phan Ke. 1997. Letter to Sara Oldfield containing a list of the threatened Gymnosperms of Vietnam and their IUCN red list categories.
19045 Kalkman, C. 1997. Personal communication with Amy MacKinven concerning threatened tree species in Rosaceae.

19046 Sidiyasa, K. 1997. Personal communication with Kade Sidiyasa, Ph.D. student at the Rijksherbarium/Hortus Botanicus, Leiden.

19047 Adema, F. 1997. Personal communication with Amy MacKinven.

19048 Anon. 1994. Proposal to include Diospyros celebica in Appendix II of CITES.

19049 Davies, J. 1997. Email messages from Jon Davies regarding tree species under threat in Brunei, including Shorea albida, Agathis bormeensis, Dryobalanops rappa.

19050 Pan, F.J. 1997. Completed data collection forms for Taiwanese trees.

19051 Lu, S.Y. \& F.J. Pan. 1996. Rare and endangered plants in Taiwan I. 163 pp.

19053 Lu, S.Y. \& F.J. Pan. 1997. Draft copy of rare and endangered plants in Taiwan II.

19054 Flanagan, M. 1997. Threatened broadleaves Fagus hayatae Palib. Broadleaves, Newsletter of the IUCN-SSC Temperate Broadleaved Trees Specialist Group 4: 5-6.

19055 Sun, W. 1997. Completed data collection forms for trees of Yunnan.

19056 Firsov, G.A. 1997. Completed data collection forms for Russian trees.

19057 Frodin, D. et al. 1997. Discussion of the working groups at the Conservation and Sustainable Management of Trees workshop held in Hanoi, Viet Nam.

19058 Anonymous. 1997. Inclusion of Aquilaria malaccensis in Appendix II of CITES - India. (unpublished).

19059 Soehartono, T. 1997. The overview of trade in Gaharu in Indonesia. (unpublished).

19060 Ban, N.T. 1997. Some remarks on the red list summary report. 1 pp.

19061 Dzung, et al. 1997. Conversation with Charlotte Jenkins concerning tree species in Viet Nam also found in Yunnan.

19062 Gerlach, J. 1997. Comments on the trees of the Seychelles and their evaluation according to 1994 IUCN red list categories. 2 pp.

19063 Phengklai, C. 1989. Personal communication from C. Phengklai.

19064 Kumar, A. 1994. Personal communication to M. Read and S. Oldfield. 
19065 Sidiyasa, K. 1994. Letter to Sara Oldfield re:Diospyros celebica, Intsia bijuga and Intsia palembanica.

19066 Madulid, D.A. 1996. Letter to A. MacKinven dated 11th July, 1996 re: Diospyros pilosanthera and Diospyros philippinensis.

19067 Fjeldså, J. 1997. Comments on Polylepis species and their evaluation.

19068 Cházaro Basáñez, M., J. Guerrero-Nuño \& G. Arcelia López-Coronado. 1993. Conserideraciones preliminares sobre las plantas endémicas, raras, vulnerables o en peligro de extinción de Jalisco, México. Tiempos de Ciencia 30: 11-19.

19069 Calderon, E. (comp.). 1997. Lista de plantas Colombianas en peligro. July 1997 Version. Instituto de Investigacino de Recursos Biologicas Alexander von Humboldt. (unpublished). $14 \mathrm{pp}$.

19070 Nikolic, T. 1997. Completed data collection forms on Croatian trees.

19071 Smith, D. 1997. The progress and problems of the 'Endemic Section' of St. Helena Island. Oryx 31(3): 218-224.

19072 Hou, D. 1996. Caesalpinioideae. Flora Malesiana. Leiden: Flora Malesiana Foundation.

19073 Chua, L. et al. 1997. Completed data collection forms for endemic trees of Peninsular Malaysia.

19074 Anonymous. 1997. Proposal in include Pterocarpus santalinus in Appendix II of CITES. (unpublished).

19075 USDA. 1990. Proceedings of the symposium on Sandalwood in the Pacific. April 9-11, 1990. Honolulu, Hawaii

19076 Monk, K.A. et al. 1997. The ecology of Nusa Tenggara and Maluku. Oxford: Oxford University Press.

19077 Coppen, J.J.W. 1995. Flavours and fragrances of plant origin. Rome: FAO.

19078 de Wilde, W.J.J.O. 1997. Annotations to draft species summaries for Myristicaceae.

19079 Frodin, D. 1997. Conversation with Amy MacKinven, regarding the conservation status of Schefflera.

19080 Femandes, F. 1997. Restoration programme for Madeira's endangered plants. Plant Talk 10: 19.

19081 Cronk, Q.C.B. 1997. The endemic flora of St Helena (in press).
19082 de Wilde, W.J.J.O. 1997. Further additional notes on Knema and Myristica (Myristicaceae).

19083 Miller, A.G. 1997. Completed data collection forms and comments concerning the threatened trees of Socotra and Yemen.

19084 de Wilde, W.J.J.O. 1997. The myrmecophilous species of Myristica (Myristicaceae) of New Guinea. (unpublished).

19085 Kelly, D.L. 1997. List of threatened trees in the Jamaican flora, not in 'Draft species summaries: Jamaica' WCMC 24/04/97. (unpublished).

19086 US Fish and Wildlife Service. 1997. Draft Kauai II: Addendum to the recovery plan for the Kauai plant cluster. Portland, Oregon: US Fish and Wildlife Service. $80 \mathrm{pp}$.

19087 US Fish and Wildlife Service. 1997. Recovery plan for the Maui plant cluster (Hawaii). Portland, Oregon: US Fish and Wildlife Service. $130 \mathrm{pp}$.

19089 US Fish and Wildlife Service. 1997. Draft recovery plan for Kokia cookei. Portland, Oregon: US Fish and Wildlife Service. 57 pp.

19090 Kessler, P. 1997. Data collection forms for Malesian Annonaceae.

19091 Nghia, N.H. 1997. Completed data collection forms for Vietnamese Dalbergia spp.

19092 Peguy, T. 1997. Comments from Thchouto Peguy on the draft species summaries for Cameroon.

19093 Nghia, N.H. 1997. Letter to Sara Oldfield from Dr.Nghia regarding threatened Vietnamese trees.

19095 Pires O' Brien. 1997. Additional information on Brazilian tree species.

19096 Cavalcanti, T.B. 1997. Completed data collection forms for Lythraceae species in Brazil.

19097 Barroso, G.M. 1997. Letter to Joaquina Pires O'Brien containing information on species of Myrtaceae in Brazil.

19098 Varty, N. \& Guadagnin, D.L. 1996. Annex 10: Arboreal species of the Atlantic forests (from Base de Dados Tropical of the Funfaçâo Tropical de Pesquisas e Tecnologia 'André Tosello'). In Information sources on the biology, conservation and trade of tree species in Brazil. Report for the Conservation and Sustainable Management of Trees Project.

19099 Torres, R.B. 1997. Completed data collection forms for species of Lacistema, Trema and Flacourtiaceae in Brazil. 
19100 Vaz, A.M.S. 1997. Completed data collection forms for species in the subfamily Caesalpinoideae in Brazil.

19101 Carauta, J.P.P. 1997. Completed data collection forms for species of Moraceae in Brazil.

19102 Peixoto, A.L. 1997. Completed data collection forms for species of Monnimiaceae in Brazil.

19103 Carvalho, L.d'A.F. 1997. Completed data collection forms for species of Solanaceae in Brazil.

19104 Wemer, W.L. 1989. Aspects of conservation of endangered plants in Sri Lanka. 35-40.

19105 Silva, N.M.F. 1997. Completed data collection form for species of Combretaceae in Brazil.

19106 Werner, W.L. 1982. The upper montane rain forests of Sri Lanka. The Sri Lanka Forester 15(3\&4): 119-129.

19107 Walker, M. 1997. This Week - Lucky find.

19108 Thulin, M. 1997. Email to Charlotte Jenkins with comments on the status of Boswellia spp., Conocarpus lanciifolius and Wendlandia arabica. 1 pp.

19110 Hamilton, A. 1990. Provisional list of endangered medicinal plants. (unpublished).

19111 Cukier, M. 1997. Technical report on the status of a number of endemics to São Tomé. (unpublished).

19112 Green, M.J.B. and E.R. N. Gunawardena (comps.). 1997. Designing an optimum protected areas system for Sri Lanka's natural forests. (unpublished). Prepared by IUCN-The World Conservation Union and the World Conservation Monitoring Centre for the Food and Agriculture Organisation (FAO) of the United Nations.

19113 Stevens, P.F. 1997. Annotations to a listing of draft species summaries for New Guinea for the Conservation and Sustainable Management of Trees project.

19114 Eddowes, P.J. 1997. Completed data collection forms for New Guinea.

19115 Du Puy, D. 1997. Completed data collection forms on Madagascan Dalbergia species.

19116 Bellingham, P. 1997. Comments on tree species in the Blue Mountains.

19117 Middleton, D. 1997. Conversation between David Middleton and Amy MacKinven regarding the threat status of Apocynaceae trees.

19118 Johnson, D. et al. 1997. Completed data collection forms for palms.
19119 Jorgensen, P.M. \& C. Ulloa Ulloa. 1994. Seed plants of the High Andes of Ecuador - a checklist. Denmark: Department of Systematic Botany, University of Aarhus \& Departamento de Ciencias Biológicas, Pontificia Universidad Católica del Ecuador. 443 pp.

19120 Jorgensen, P.M. \& S. León In Prep.. 1997. Catalogue of vascular plants of Ecuador. Monogr. Syst. Bot. Missouri Bot. Gard.

19121 Llamozas, S. 1996. Completed data collection forms for tree species of Argentina.

19122 Prado, D.E. 1995. Selva pedemontana: contexto regional y lista florística de un ecosistema en peligro. In Brown, A.D. \& H.R. Grau (eds.). Investigación, conservación y desarollo en selvas subtropicales de montaña: 19-52.

19123 Pennington, T.D. 1997. The genus Inga. Botany. The Royal Botanic Garden, Kew. 844 pp.

19124 Harcourt, C.S. \& J.A.Sayer. 1996. The conservation atlas of tropical forests: The Americas. New York : Simon \& Schuster Macmillan.

19125 Beaman, J.H. 1997. Completed data collection forms for conifers of Mount Kinabalu, Sabah.

19126 Molloy, B.P.J. 1997. Completed data collection forms for conifers of New Zealand.

19127 Gardner, M. 1997. Completed data collection forms for South American conifers.

19128 Steyermark, J.A., P.E. Berry \& Holst, B.K. 1996. Flora of the Venezuelan Guyana. Vol 2. Pteridophytes, Spermatophytes Acanthaceae Araceae. Portland, Oregon: Timber Press.

19129 Pannell, C. 1997. Comments regarding the threat status of Aglaia trees.

19130 Sandiford, M. 1997. Completed data collection form on Bombacopsis quinata.

19131 Fernandes, F. et al. 1997. Completed data collection forms for the trees of Madeira.

19132 Satabia, B. 1997. Letter to Sara Oldfield listing Cameroonian timber trees rendered vulnerable through exploitation.

19133 de Lange, P.J. 1997. Threatened woody dicots: candidate listings from the New Zealand Botanical Region. (unpublished).

19134 Oates, M.R. \& P.J. de Langes. 1996. The current status of woody vegetation in New Zealand. In Hunt, D. (ed.). Temperate trees under threat. Proceedings of an IDS symposium on the Conservation Status of Temperate Trees, 30 Sept-1 Oct 1994. 
19135 INEFAN. 1997. Especies maderables en proceso de extincion que ameritan ser preservadas. (unpublished). Institute Ecuatoriano Forestal y de Areas Naturales y Vilda Silvestre, Sept 1997.( Govemmental).

19136 Taber, A, G. Navarro \& M. Angel. 1997. A new park in the Bolivian Gran Chaco - an advance in tropical dry forest conservation and community-based management. Oryx 31(3): 189-198.

19137 Burton, F. 1996. Completed data collection forms for tree species of the Cayman Islands.

19138 Frodin, D.G. \& R. Govaerts. 1996. World checklist and bilbliography of Magnoliaceae.

19139 Mack, A. 1997. E-mail from Andy Mack regarding the Aglaia mackiana. (unpublished).

19140 Fortune-Hopkins, H. \& Menzies, J.I. 1995. The Flora of Motupore Island. University of PNG Press.

19141 Midgley, J.J. et al. 1997. Population ecology of tree succulents (Aloe and Pachypodium) in the arid western Cape: decline of keystone species. Biodiversity and Conservation 6: 869876.

19142 Pedralli, G. 1997. Comments on threatened species of Lauraceae.

19143 Phillips, B.A. 1981. Data sheet for Elaeodendron laneanum A.H. Moore.

19144 Ramesh, B.R. \& J.-P. Pascal. 1997. Atlas of endemics of the Western Ghats (India). Distribution of tree species in the evergreen and semi-evergreen forests. Institut Français de Pondichéry. 403 pp.

19145 Hess, W.J. 1996. Completed data collection forms for Quercus acerifolia, $Q . \quad x$ basaseachicensis, $Q$. boytonii and $Q$. gravesii.

19146 Tye, A. \& J. Loving. 1997. Completed data collection forms for Scalesia species on the Galápagos.

19147 Eddowes, P.J. 1997. Letter to Sara Oldfield containing annotations to the 'Draft red list summary report for Papua New Guinea trees'.

19148 Wigginton, M.J. In Prep.. (ed.). 1997. Red Data Book for vascular plants. 3rd edition. Peterborough: JNCC.

19149 Areces-Mallea, A.E. 1997. A listing of threatened Cuban trees prepared for the Conservation and Sustainable Management of Trees project.

19150 Garfi, G. 1997. Completed data collection form for Zelkova sicula.

19151 Bennett, K. 1997. Completed data collection form for Zelkova sicula.
19152 Sandiford, M. 1997. Additional comments on Bombacopsis quinata.

19153 Donoso, C. 1996. Ecology of Nothofagus forests in Central Chile. pp. 271-292. In Veblen, T.T. et al. The ecology and biogeography of Nothofagus forests.

19154 Waldren, S. \& N. Kingston. 1997. Threatened trees and shrubs of Pitcaim Island: update October 1997. (unpublished).

19155 Tye, A. 1997. Amendments to the species summaries of threatened trees of the Galápagos.

19156 Eliasson, U. 1974. Studies in Galápagos plants. XIV. The genus Scalesia Am. Opera Botanica 36

19157 Arsiniegas, M. 1996. Caracterización, evaluación y conservación de cuatro especies de plantas endémicas que se hallen en peligro de extinción en las islas Galápagos: Calandrinia gaiapagosa, Lecocarpus daminii, Scalesia helleri, Scalesia retroflexa. (unpublished). Tesis de Ing. Forestal, Univ. Téc. 'Luis Torres', Esmeraldas, Ecuador.

19158 Hiepko, P. 1993. Olacaceae. Flora of the Guianas. Koenigstein: Fed. Rep. of Germany: Koeltz Scientfic Books.

19159 Chanderbali, A. 1997. Completed data collection form for Chlorocardium rodiei.

19160 Carter-Holmes, S. 1997. Completed data collection forms for 2 Tanzanian Monadenium species.

19161 Ramirez-Marcial, N. \& M. GonzálezEspinosa. 1997. Completed data collection forms of threatened tree species in Chiapas.

19162 Hawthorne, W. \& C. E. Hughes. 1997. Bioquality of the forests of Quintana Roo. ODA Mexico: Quintana Roo Fcrest Management Project. Biological Component Phase 1. (unpublished).

19163 Flora of North America Editorial Committee. 1997. Flora of North America. Volume 3. Oxford University Press.

19164 Southeast Environmental Research Program, Florida International University and Center for Plant Conservation. 1995. An action plan to conserve the native plants of Florida. (unpublished).

19165 Güner, A. 1997. Completed data collection forms for trees ofTurkey.

19166 Timyan, J.C. \& S. F. Reep. 1994 Conservation status of Atralea crassipatha (Mart.) Burret, the rare and endemic oil palm of Haiti. Biological Conservation 68: 11-18. 
19167 U.S Fish and Wildlife Service, Division of Endangered Species. 1991. Species accounts. WWW site, cited December 1997. URL: http:/www.fws.gov./ r9endspp/endspp.html

19168 US Fish and Wildlife Service, Pacific Region. 1997. Draft recovery plan for Oahu plants. Portland, Oregon: US Fish and Wildlife Service.

19169 Florence, J. 1996. Gallicae Polynesiae florae Praecursores. 1. Nouveautés taxonomiques dans les Euphorbiaceae, Piperaceae et Urticaceae. Bull. Mus. Natl. Hist. Nat. section B. Adansonia 18(3-4): 239-274.

19170 Killeen, T. 1997. Comments on the species summaries for Bolivia.

19171 Dieringer, G. \& J.E. Espinosa. 1994. Reproductive ecology of Magnolia schiedeana (Magnoliaceae), a threatened cloud forest tree species in Veracruz. Bulletin of the Torrey Botanical Club 121(2): 154-159.

19172 Burrows, J. 1997. Comments and completed data collections forms for species of Southern Africa.

19174 Sun, W. 1997. Conservation status of trees of Yunnan (mainly NW part). A report for the Regional Workshop of the Conservation and Sustainable Management of Trees project. (unpublished).

19175 Wiles, G. 1996. Completed data collection forms for threatened trees of Guam.

19177 Burger, W. \& M. Huft. 1995. Euphorbiaceae. Flora Costaricensis. Fieldiana Botany 36: 169.

19178 Carrington, S. 1993. Wild plants of Barbados. Hong Kong: Macmillan Press Ltd. 128 pp.

19179 WCMC. (comp.). 1996. Report of the Second Regional Workshop, held at CATIE, Turrialba, Costa Rica, 18-20 November 1996. Conservation and Sustainable Management of Trees project. (unpublished).

19180 Ibisch, P.L. \& I. Vargas. 1997. Comments on the species summaries for Bolivia.

19181 Luke, Q. (ed.). 1996. Conservation Assessment and Management Planning (CAMP) Workshop for selected species of the Kenya coastal forests. (unpublished). National Museums of Kenya - Darwin course: Plant conservation techniques for East Africa. 20-25 November 1996.

19182 Chua, L.S.L. 1997. Fax to Sara Oldfield concerning the status of certain Malaysian tree species.

19183 Wickens, G.E. 1995. Edible nuts. Non-wood Forest Products 5. Food and Agriculture Organization of the United Nations. $197 \mathrm{pp}$.
19184 Weyland Vieira, M.C. 1990. Phytogeography and conservation of forests in Monte Belo, Minas Gerais - case study: Fazenda Lagoa. Rio de Janeiro

19185 Blaser, J. 1996. Silvicultural considerations of listing timber species in Appendices I, II and III of CITES. Working document for the 2nd meeting of the CITES Timber Working Group. (unpublished).

19186 Madrigal, Q.J. 1993. Arboles maderables en peligro de extinction en Costa Rica. San José, Costa Rica: INCAFO.

19187 Rodan, B.D., A.C. Newton \& A. Verissimo. 1992. Mahogany conservation: status and policy initiatives. Environmental Conservation 19:331-338.

19188 Flynn, J.H. 1994. A guide to useful woods of the world. Portland, Maine: King Philip Publishing Co.

19189 van Welzen, P.C. 1997. Comments on trees of Sapindaceae in New Guinea.

19190 Schatz, G.E. \& A. Ramisamihantanirina. 1998. Takhtajania perrieri rediscovered. Nature 391: 133-134.

19191 Farjon, A. \& A. Griffiths. 1998. Completed data collection form for Cupressus atlanticus.

19192 de Laubenfels, D.J. 1998. Completed data collection forms for selected conifer species.

19193 Tibor, D. (comp.). 1998. Threatened tree information from the California Native Plant Society. (unpublished).

19194 van de Hoek, R. 1997. Email to Amy MacKinven containing information on Santa Catalina Island endemics.

19195 Buitrón, X. 1996. List of endangered and possibly endangered species of Ecuador produced in the Workshop Flora Specialists of Ecuador for the National Biodiversity Diagnostic, November 1996. (unpublished).

19196 Werkhoven, M.C.M. 1997. Threatened trees of Suriname. A list compiled for the WCMCISSC Conservation and Sustainable Management of Trees project. (unpublished).

19197 Carter, S. \& U. Eggli. 1997. The CITES checklist of succulent Euphorbia taxa (Euphorbiaceae). German Federal Agency for Nature Conservation. 70 pp.

19198 Rodrigues, W.A. 1997. Information on Brazilian species of Myristicaceae.

19199 Anon. 1998. Mascarene survivor cloned. Plant Talk: 15 
19200 Spongberg, S.A. 1997. Franklinia alatamaha Marshall. Extinct in the wild: an early example. Broadleaves. Newsletter of the IUCN-SSC Temperate Broadleaved Trees Specialist Group 5: 7-9.

19202 Clemente, M. (ed.). 1997. Actas de la Septima Reunion del Comite de Flora, San José, Costa Rica 11-15 Noviembre 1996. 111 pp.

19203 González-Espinosa, M. 1997. ECOSUR baso de datos.

19204 Mauchamp, A., I. Aldaz, E. Ortiz \& H. Valdebenito. 1998. Threatened species, a reevaluation of the status of eight endemic plants of the Galápagos. Biodiversity and Conservation 7: 97-107.

19205 Anon. 1994. Proposal to transfer Aloe helenae and A. suzannae from Appendix II to Appendix I of CITES. Ninth Conference of the Parties to CITES, Fort Lauderdale, USA.

19206 Vovides, A.P. 1998. Completed data collection forms for selected Mexican tree species.

19207 Hammerton, J.L. 1998. Fax to Sara Oldfield concerning the endemic trees and shrubs in the Bahamas and their status according to the Department of Agriculture.

19208 Strahm, W. 1998. Correspondence with Charlotte Lusty containing preliminary evaluations for tree species of Réunion, Rodrigues and Mauritius.

19209 Molur, S. \& S. Walker (eds.). 1998. Report on selected medicinal plants of Northem, Northeastem and Central India resulting from a Conservation Assessment and Management Plan (CAMP) workshop, held in the Forest Department of Uttar Pradesh, Lucknow 21-25 January 1997. Zoo Outreach Organisation.
19210 Atkin, J. 1998. Comments on tree species from Paraguay.

19211 Clement, C.R. 1991. Amazonian fruits: a neglected and threatened, but potentially rich resource. Diversity Magazine

19212 Green, C.L. 1995. Natural colourants and dyestuffs. A review of production and development potential. Non-Wood Forest Products 4. Rome: Food and Agriculture Organization of the United Nations.

19213 Phillips, O., A. Gentry, C. Reynel, P. Wilkin, C. Galvez-Durand. 1993. Table of the useful woody plot species at Tambopata, Madre de Dios, Peru, from a paper entitled "Quantitative ethnobotany and conservation" submitted to Conservation Biology. (unpublished).

19214 Golte, W. 1996. Exploitation and conservation of Fitzroya cupressoides in southem Chile. In Hunt, D. (ed.). Temperate trees under threat.

19216 Mitré, M. 1998. Email to Charlotte Lusty with details of the relationship between Caryocar costaricense and $C$. amygdaliforme.

19217 Pennington, T.D. 1998. Letter to Amy MacKinven with comments on draft species summaries for Inga.

19218 Hilton-Taylor, C. (comp.). 1998. Assessment of Southern African Trees for WCMC.

19219 Stirton, C.H. 1989. A revision of Otholobium C.H. Stirton (Papilionoideae, Leguminosae). Ph.D. thesis, University of Cape Town. (unpublished).

19220 Jordaan, M. 1995. A taxonomic revision of the spiny members of the subfamily Celastroideae (Celastraceae) in southern Africa. M.Sc. thesis, University of Pretoria. (unpublished). 



\section{APPENDIX 1}

\section{GLOBALLY THREATENED TREE SPECIES OF AUSTRALIA}

This list of globally threatened trees species of Australia has been prepared by Lyn Meredith, Threatened Species and Communities Section, Environment Australia. The species included are those which have a conservation rating which equate with the pre 1994 IUCN categories of $\mathbf{E}$ (Endangered) and V (Vulnerable). The species list is derived from Briggs, J. and Leigh, J. (1996) Rare or threatened Australian plants. CSIRO, Melbourne. 466pp. This national listing, ROTAP, includes approximately 5,000 taxa of Australian native plants. ROTAP uses a binary coding system for categorising threat developed and refined over several years but based on the IUCN categories. Species in the supporting ROTAP database have been flagged as trees for inclusion in this Appendix to The World List of Threatened Trees. Environment Australia has commenced compiling a list of nationally threatened Australian plants according to the 1994 IUCN categories and criteria, in cooperation with Australia's state conservation agencies.

Acacia araneosa

Acacia auriculiformis

Acacia caerulescens

Acacia camei

Acacia cretacea

Acacia crombiei

Acacia georgensis

Acacia grandifolia

Acacia latzii

Acacia perangusta

Acacia peuce

Acacia pubifolia

Acacia wardellii

Acronychia littoralis

Alloxylon flammeum

Archidendron lovelliae

Archontophoenix myolensis

Austromyrtus fragrantissima

Baloghia marmorata

Banksia brownii

Banksia verticillata

Bosistoa selwynii

Bosistoa transversa

Canarium acutifolium var. acutifolium

Codonocarpus pyramidalis

Cryptocarya foetida

Cupaniopsis tomentella

Davidsonia pruriens var.

jerseyana

Diospyros mabacea

Diploglottis campbellii

Endiandra cooperiana

Endiandra floydii

Endiandra hayesii

Eucalyptus absita

Eucalyptus alligatrix ssp. limaensis

Eucalyptus aquatica

Eucalyptus argophloia
Eucalyptus argutifolia

Eucalyptus articulata

Eucalyptus balanites

Eucalyptus beaniana

Eucalyptus beardiana

Eucalyptus bennettiae

Eucalyptus benthamii

Eucalyptus blaxellii

Eucalyptus brevipes

Eucalyptus burdetriana

Eucalyptus cadens

Eucalyptus caleyi ssp. ovendenii

Eucalyptus camfieldii

Eucalyptus camphora ssp. relicta

Eucalyptus cannonii

Eucalyptus ceracea

Eucalyptus cerasiformis

Eucalyptus clandestina

Eucalyptus conglomerata

Eucalyptus copulans

Eucalyptus coronata

Eucalyptus crenulata

Eucalyptus crispata

Eucalyptus crucis ssp. crucis

Eucalyptus crucis ssp. praecipua

Eucalyptus cuprea

Eucalyptus dolorosa

Eucalyptus glaucina

Eucalyptus goniantha ssp. goniantha

Eucalyptus hallii

Eucalyptus imlayensis

Eucalyptus impensa

Eucalyptus infera

Eucalyptus insularis

Eucalyptus johnsoniana

Eucalyptus kabiana

Eucalyptus kartzoffiana

Eucalyptus langleyi
Eucalyptus lateritica

Eucalyptus leprophloia

Eucalyptus leptoloma

Eucalyptus mckieana

Eucalyptus merrickiae

Eucalyptus mooreana

Eucalyptus morrisbyi

Eucalyptus nicholii

Eucalyptus olivacea

Eucalyptus paedoglauca

Eucalyptus parramattensis ssp.

decadens

Eucalyptus parvula

Eucalyptus phylacis

Eucalyptus platydisca

Eucalyprus pruiniramis

Eucalyptus pulverulenta

Eucalyptus pumila

Eucalyptus raveretiana

Eucalyptus recurva

Eucalyptus rhodantha

Eucalyptus rhodantha var. petiolaris

Eucalyptus rhodops

Eucalyptus robertsonii ssp.

hemisphaerica

Eucalyptus rubida ssp. barbigerorum

Eucalyptus rubida ssp. canobolensis

Eucalyptus rubida ssp. septemflora

Eucalyptus scoparia

Eucalyptus steedmanii

Eucalyptus strzeleckii

Eucalyptus suberea

Eucalyptus synandra ssp. synandra

Eucalyptus terrica

Eucalyptus tetrapleura

Eucalyptus virens

Eucalyptus xanthope

Floydia praealta 
Fontainea australis

Fontainea oraria

Fontainea venosa

Hakea trineura

Jagera javanica ssp. australiana

Livistona drudei

Livistona mariae

Lomatia tasmanica

Macadamia integrifolia

Macadamia temifolia
Macadamia tetraphylla Macaranga polyadenia Mitrantia bilocularis

Musa fitzalanii

Normanbya normanbyi

Ochrosia moorei

Oreodendron biflorum

Owenia cepiodora

Planchonella eerwah

Pomaderris parrisiae
Ristantia gouldii

Symplocos baeuerlenii

Syzygium hodgkinsoniae

Syzygium moorei

Toechima pterocarpum

Wodyetia bifurcata

Wollemia nobilis

Xanthostemon oppositifolius

Xanthostemon youngii 


\section{GLOBALLY THREATENED TREE SPECIES OF JAPAN}

This list comprises tree species taken from the 1997 Red List of Japanese Vascular Plants compiled by the Threatened Species Committee, Japan Society of Plant Taxonomists; Yahara, T., Kato, T., Inoue, K., Yokota, M., Kadono, Y., Serizawa, S., Takahashi, H., Kawakubo, N., Nagamasu, H., Suzuki, K., Ueda, K. and Kadota, Y. The species have been evaluated as globally threatened (EW, CR, EN or VU) according to the 1994 IUCN Red List Categories.

Abelia chinensis var. ionandra
Acer miyabei
Acer miyabei var. shibatai
Acer oblongum var. isoanum
Acer pycnanthum
Ardisia montana
Barringtonia asiatica
Betula chichibuensis
Betula davurica
Berula ovalifolia
Bredia okinawensis
Breynia formosana
Bryanthus gmelinii
Buxus liukiuensis
Buxus microphylla var, sinica
Buxus microphylla var. insularis
Callicarpa formosana
Callicarpa kochiana
Callicarpa longissima
Callicarpa nishimurae
Callicarpa oshimensis var.
okinawensis
Callicarpa shikokiana
Caryopteris incana Celtis biondii var.
insularis
Chamaedaphne calyculata
Chionanthus retusu
Choerospondias axillaris var.
japonica
Chosenia arbutifolia
Cinnamomum daphnoides
Citrus nippokoreana
Cirrus tachibana
Claoxylon centenarium
Colubrina asiatica
Corylopsis glabrescens
Corylopsis gotoana var. pubescens
Corylopsis spicata
Crataegus chlorosarca
Crepidiastrum ameristophyllum
Crepidiastrum linguifolium
Cryptocarya chinensis
Cyclobalanopsis hondae
Daphne pseudo-mezereum var.
koreana
Daphnimorpha capitellata

\begin{tabular}{|c|c|}
\hline Dendrocacalia crepidifolia & Lonicern linderifolia \\
\hline Deutzia uniflora & Lonicera linderifolia var. konoi \\
\hline Diospyros eriantha & Lonicera maackii \\
\hline Diplomorpha pauciflora & Lonicera maximowiczii var. \\
\hline Discocleidion ilmifolium & sachalinensis \\
\hline Drypetes integerrima & Lonicera ramosissima var, kinkiensis \\
\hline Elaeagnus matsunoana var. & Lonicera vidalii \\
\hline hypostellata & Loropetalum chinense \\
\hline Entada phaseoloides & Magnolia pseudokobus \\
\hline Euchresta formosana & Magnolia tomentosa \\
\hline Euonymus chibai & Malus spontanea \\
\hline Euonymus oligospermus & Maytenus diversifolia \\
\hline Euonymus yakushimensis & Melastoma pentapetalum \\
\hline Eurya emarginata var, minutissima & Melastoma tetramerum \\
\hline Eurya zigzag & Menziesia goyozanensis \\
\hline Evodia nishimurae & Menziesia multiflora var. purpurea \\
\hline Fatsia oligocarpela & Menziesia purpurea \\
\hline Ficus iidaiana & Menziesia yakushimensis \\
\hline Forsythia togashii & Metrosideros boninensis \\
\hline Gardenia boninensis & Morinda umbellata var. hahazimensis \\
\hline Gardneria shimadae & Morus boninensis \\
\hline Geniostoma glabra & Murraya koenigii \\
\hline Grewia biloba & Myoponum bontioides \\
\hline Hydrangea involuculata & Myrsine okabeana \\
\hline var.takaraensis & Osbeckia chinensis \\
\hline Hydrangea liukiuensis & Osmanthus okinawensis \\
\hline Hydrangea serrata var minamitanii & Osteomeles anthyllidifolia \\
\hline llex beecheyi & Paliurus ramosissimus \\
\hline llex dimorphophylla & Photinia serrulata \\
\hline llex macrocarpa & Photinia wrightiana \\
\hline llex matanoana & Picea koyamae \\
\hline llex mertensii & Picea maximowiczii \\
\hline Illigera luzonensis & Picea shirasawae \\
\hline Jasminum superfluum & Pieris japonica var, koidzumiana \\
\hline Juniperus sibirica & Pinus armandii var. amamiana \\
\hline Lagerstroemia subcostata & Pittosporum beecheyi \\
\hline Lespedeza bicolor var. melanantha & Pittosporum chichijimense \\
\hline Ligustrum tamakii & Pittosporum parvifolium \\
\hline Lindera communis var, okinawensis & Planchonella boninensis \\
\hline Lonicera alpigena ssp. glehnii & Planchonella obovara var. dubia \\
\hline Lonicera alpigena ssp. glehnii var. & Polyalthia liukiuensis \\
\hline viridissima & Prunus incisa var. bukosanensis \\
\hline Lonicera cerasina & Pseudotsuga japonica \\
\hline Lonicera chamissoi & Psychotria homalosperma \\
\hline Lonicera chrysantha var, crassipes & Rhamnella franguloides var. \\
\hline Lonicera demissa var. borealis & inaequilatera \\
\hline
\end{tabular}


Rhamnus calicicola

Rhamnus ishidae

Rhamnus kanagusuki

Rhamnus liukiuensis

Rhamnus yoshinoi

Rhododendron amagianum

Rhododendron amamiense

Rhododendron boninense

Rhododendron dauricum

Rhododendron degronianum ssp.

mettemichii var.kyomaruense

Rhododendron dilatatum var, boreale

Rhododendron dilatatum var.

satsumense

Rhododendron eriocarpum var.

lawadae

Rhododendron keiskei var.

hypoglaucum

Rhododendron kiyosmense ssp.

mayebarae

Rhododendron kiyosmense ssp.

mayebarae var. ohsumiense

Rhododendron komiyamae

Rhododendron makinoi

Rhododendron mucronulatum var.

ciliatum

Rhododendron nudipes var.

kirishimense
Rhododendron osuzuryamense

Rhododendron parvifolium

Rhododendron pentaphyllum var.

villosum

Rhododendron sanctum

Rhododendron sancrum var.

lasiogynum

Rhododendron scabrum

Rhododendron uwaense

Rhododendron viscistylum var.

amakusaense

Rhododendron yakuinsulare

Rhododendron yedoense var.

pooukhanense

Rhus javanica

Ribes ambiguum

Rosa hirtula

Rubus chingii

Rubus lambertianus

Rubus tawadanus

Salix hidaka-montana

Salix hukaoana

Salix nummularia ssp. pauciflora

Salix nupifraga

Salix taraikensis

Salix yezoalpina

Sophora franchetiana

Sophora tomentosa
Spiraea media var. sericea Spiraea nipponica var. ogawae Spiraea salicifolia

Stachyurus macrocarpus

Symplocos boninensis

Symplocos confusa

Symplocos kawakamii

Symplocos pergracilis

Syzygium cleyeraefolium

Terminalia nitens

Tilia mandschurica

Tilia rufo-villosa

Tripterygium doianum

Tsusiophyllum tanakae

Vaccinium amamianum

Vaccinium microcarpum

Vaccinium sieboldii

Vibumum boninsimense

Vibumum carlesii

Vibumum koreanum

Vitex quinata

Vitis amurensis var. shiragai

Vitis quinqueangularis

Weigela florida

Wikstroemia pseudoretusa

Zabelia integrifolia 


\section{NOT EVALUATED \\ GLOBALLY THREATENED TREE SPECIES}

The 1997 IUCN Red List of Threatened Plants, published this year, includes tree species which are categorised as threatened according to the pre 1994 IUCN Red List Categories. Although the list was used as a basis for the work to compile The World List of Threatened Trees, not all of the tree taxa included were evaluated for various reasons which are outlined in the introduction. The following taxa represent those trees categorised as $\mathbf{E}$ (Endangered) or V (Vulnerable) in the 1997 IUCN Red List of Threatened Plants, which are believed to be taxonomically valid but which have not been evaluated for the present publication.

\section{Acanthaceae}

Sanchezia klugii

\section{Actinidiaceae}

Saurauia chaparensis

Saurauia molinae

Saurauia oroquensis

\section{Anacardiaceae}

Astronium gracile var. acuminatum

Comocladia undulata

Mangifera lambii

Poupartia castanea

Semecarpus supanduriformis

\section{Annonaceae}

Anaxagorea silvatica

Annona domingensis

Guatteria cargadero

Melodorum fuscum

Miliusa tectona

Orophea salicifolia

Orophea torulosa

Phoenicanthus coriacea

Phoenicanthus obliqua

Polyalthia angustifolia

Polyalthia moonii

Polyalthia persicaefolia

Popowia parvifolia

Sageraea listeri var. andamanica

Sageraea reticulata

Stelechocarpus longipes

\section{Apocynaceae}

Alstonia curtisii

Aspidosperma chodatii
Mucoa panichenkoana

Parahancomia krukovii

Parahancormia oblonga

Parahancomia peruviana

Petchia ceylanica

Aquifoliaceae

llex cassine ssp. mexicana

llex micrantha

llex nannophylla

llex rarasanensis

\section{Araliaceae}

Cussonia kirkii var, bracteata

Cussonia kirkii var. quadripetala

Dendropanax morbifera

Didymopanar gleasonii

Meryta angustifolia

Meryta latifolia

Oreopanax dussii

Oreopanax nicaraguensis

Polyscias rivalsii

Sinopanax formosana

\section{Betulaceae}

Betula apoiensis

Betula megrelica

\section{Bignoniaceae}

Amphitecna costata

Amphitecna macrophylla

Amphitecna megalophylla

Amphitecna silvicola

Amphitecna steyermarkii

Amphitecna tuxtlensis

Jacaranda acurifolia

Jacaranda bullata
Jacaranda carajasensis

Jacaranda caucana ssp. calycina

Jacaranda crassifolia

Jacaranda egleri

Jacaranda ekmanii

Jacaranda grandifoliolata

Jacaranda intricata

Jacaranda montana

Jacaranda nigosa

Jacaranda selleana

Jacaranda subalpina

Parmentiera valerii

Sparattosperma catingae

Spirotecoma spiralis

Tabebuia acunana

Tabebuia arianeae

Tabebuia botelhensis

Tabebuia bureavii

Tabebuia caleticana

Tabebuia capotei

Tabebuia conferta

Tabebuia cristata

Tabebuia del-riscoi

Tabebuia dominguensis

Tabebuia jojoana

Tabebuia multinervis

Tabebuia ophiolitica

Tabebuia paniculata

Tabebuia polyantha

Tabebuia reticulata

Tabebuia riodocensis

Tabebuia selachidentata

Tabebuia zanonii

Tabebuia zolyomiana

Tecoma tanaeciiflora

Bombacaceae

Durio macrantha

Quararibea costaricensis

Spirotheca rhodostyla 


\section{Boraginaceae}

Bourreria radula

Cordia acunae

Cordia corallicola

Cordia decandra

Cordia iberica

Cordia intricata

Cordia lauta

Cordia skutchii

Cordia suffruticosa

Cordia van-hermannii

\section{Brunelliaceae}

Brunellia boliviana var. boliviana

Brunellia briquetii

Brunellia brunnea

Brunellia bullata

Brunellia carpishensis

Brunellia comocladifolia ssp.

cundinamarcensis

Brunellia comocladifolia ssp.

guadalupensis

Brunellia comocladifolia ssp.

josephensis

Brunellia comocladifolia ssp. ptariana

Brunellia coroicoana

Brunellia cuatrecasana

Brunellia cutervensis

Brunellia cuzcoensis

Brunellia dichapetaloides

Brunellia diversifolia

Brunellia dulcis

Brunellia espinalii

Brunellia foreroi

Brunellia gentryi

Brunellia glabra

Brunellia hexasepala

Brunellia hiltyana

Brunellia hygrothermica

Brunellia integrifolia ssp. mollis

Brunellia latifolia

Brunellia littlei

Brunellia oliveri

Brunellia pallida

Brunellia pitayensis

Brunellia propinqua ssp. susaconensis

Brunellia putumayensis

Brunellia rhoides

Brunellia stuebelii

Brunellia trianae

Brunellia velutina

\section{Buddlejaceae}

\section{Buddleja longifolia}

\section{Burseraceae}

Crepidospermum cuneifolium

Crepidospermum multijugum

Protium melinonis

Protium nitidifolium

Protium pilosum

\section{Capparaceae}

Capparis nitida

Forchhammeria polyandra

\section{Caricaceae}

Carica chilensis

Carica cnidoscoloides

Carica horovitziana

\section{Caryocaraceae}

Caryocar edule

Caryocar glabrum ssp. album

Cecropiaceae

Coussapoa ferruginea

Pourouma bolivarensis

Pourouma elliptica

Pourouma herrerensis

Pourouma napoensis

Pourouma phaeotricha

Pourouma stipulaceae

\section{Chloranthaceae}

Hedyosmum goudotianum var.

mombachanum

Hedyosmum pungens

\section{Chrysobalanaceae}

Couepia bondarii

Couepia carautae

Couepia caryophylloides ssp. glabra

Couepia coarctala

Couepia cognata var major

Couepia cognata var. membranacea

Couepia exflexa

Couepia insignis

Couepia longipetiolata

Couepia martinii

Couepia meridionalis

Couepia monteclarensis

Couepia nutans

Couepia parvifolia

Couepia pernambucensis

Couepia platycalyx

Conepia recurva

Couepia reflexa

Hirtella aramangensis

Hirtella barnebyi

Hirtella barrosoi

Hirtella conduplicata

Hirtella floribunda

Hirtella glaziovii

Hirtella insignis

Hirtella liesneri

Hirtella orbicularis

Hirtella parviunguis

Hirtella pauciflora

Hirtella racemosa var.

glandiapedicellata

Hirtella racemosa var.

glandipedicellata

Hirtella racemosa var. hispida

Hirtella radamii

Hirtella santosii

Hirtella subglanduligera

Licania bellingtonii

Licania buxifolia

Licania cecidiophora

Licania couepiifolia
Licania cuatrecasasii

Licania dodsonii

Licania grandibracteata

Licania heteromorpha var. revoluta

Licania indurata

Licania lamentanda

Licania littoralis var. cuneata

Licania maranhensis

Licania miltonii

Licania nelsonii

Licania niloi

Licania occultans

Licania pakaraimensis

Licania retifolia

Licania riedelii

Licania santosii

Licania silvatica

Licania spicata

Licania teixeirae

Parinari alvimii

Parinari brasiliensis

Parinari euadenia

Parinari littoralis

\section{Combretaceae}

Terminalia bentzoe ssp.

rodriguesensis

Terminalia luteola

Terminalia psilantha

Terminalia simulans

Terminalia vitiensis

\section{Compositae}

Eupatorium borinquense

Fulcaldea laurifolia

Olearia pachyphylla

\section{Connaraceae}

Connarus ecuadorensis

Connarus megacarpus

Rourea antioquensis

\section{Cornaceae}

Cornus asperifolia

Cormus kousa var, yaeyamensis

\section{Corylaceae}

Carpinus rankanensis var. rankanensis

\section{Dichapetalaceae}

Stephanopodium angulatum

Stephanopodium blancherianum

Stephanopodium engleri

Stephanopodium estrellense

Tapura amazonica var. manausensis

Tapura bullata

Tapura colombiana

Tapura ferreyrae

Tapura haitiensis

Tapura juliani

Tapura lanceolata

Tapura peruviana var. peruviana

Tapura tessmannii 


\section{Dracaenaceae}

Beaucamea pliabilis

\section{Ebenaceae}

Diospyros bambuseti

Diospyros campechiana

Diospyros conzatii

Diospyros diversifolia

Diospyros engleri

Diospyros gracilis

Diospyros johnstoniana

Diospyros kerrii

Diospyros koenigii

Diospyros longepilosa

Diospyros oaxacana

Diospyros opaca

Diospyros rekoi

Diospyros saxosa

Diospyros thaiensis

Diospyros trianthos

\section{Elaeagnaceae}

Elaeagnus arakiana

Elaeagnus yakushimensis

\section{Elaeocarpaceae}

Elaeocarpus costatus

\section{Ericaceae}

Bejaria cubensis Bejaria imthumii Bejaria ledifolia Bejaria nana

Bejaria neblinensis

Bejaria steyermarkii

Bejaria subsessilis

Bejaria zamorae

Elliotria racemosa

Erica calerviflora

\section{Erythroxylaceae}

Erythroxylum affine Erythroxylum andrei Erythroxylum baracoense Erythroxylum bezerrae Erythroxylum bicolor Erythroxylum bradeanum Erythroxylum buxus Erythroxylum carthagenense Erythroxylum clarense Erythroxylum columbinum Erythroxylum ellipticum Erythroxylum foetidum Erythroxylum glazioui Erythroxylum grandiflorum Erythroxylum guanchezii Erythroxylum hamigerum Erythroxylum horridum Erythroxylum lancifolium Erythroxylum leal-costae Erythroxylum ligustrinum var. carajasense Erythroxylum loretense Erythroxylum lygoides
Erythroxylum macrocalyx Enythroxylum mattos-silvae Erythroxylum membranaceum Erythroxylum mikanii Erythroxylum nitidum Enthroxylum occultum Erythroxylum ovalifolium Erythroxylum petrae-caballi Enythroxylum reticulatum Erythroxylum ruryi Erythroxylum santosii Erythroxylum splendidum Erythroxylum steyermarkii Enythroxylum stipulosum Enythroxylum tianguanum Enythroxylum tucuruiense Enythroxylum undulatum Erythroxylum vasquezii Erythroxylum virgultosum

\section{Euphorbiaceae}

Adelia vaseyi

Aporusa incisa

Croton pilgerii

Croton poecilanthus

Croton pyriticus

Drypetes dussii

Drypetes lanceolata

Drypetes leiocarpa

Drypetes triplinervia

Euphorbia hubertii

Euphorbia quadrialata

Jatropha costaricensis

Manihot michaelis

Margaritaria holteana

Phyllanthus valerii

Sapium laurocerasus

\section{Fagaceae}

Lithocarpus craibianus

Lithocarpus echinops

Pasania nantoensis

Pasania shinsuiensis

Quercus acuminata

Quercus hondai

Quercus imeretina

Quercus listeoides

Quercus sicula

Flacourtiaceae

Banara kuhlmannii

Banara larensis

Banara portoricensis

Banara quinquenervis

Banara selleana

Banara splendens

Banara trinitatis

Banara wilsoni

Carpotroche froesiana

Carpotroche ramosii

Casearia bahiensis

Casearia catharinensis

Casearia ilicifolia

Casearia luetzelburgii

Casearia manausensis

Casearia melliodora

Casearia mestrensis
Casearia neblinae

Casearia nigricolor

Casearia paranaensis

Casearia sessiliflora

Casearia zahlbruckneri

Dovyalis spinosissima

Euceraea sleumeriana

Homalium glabrifolium

Homalium peninsulare

Homalium schlichtii

Laetia ovalifolia

Lunania dentata

Lunania tenuifolia

Mayna hystricina

Ryania dentata var. dentata

Ryania dentata var. toxica

Xylosma avilae

Xylosma bolivianum

Xylosma glaucescens

Xylosma longipetiolatum

Xylosma lucidum

Xylosma martinicense

Xylosma raimondii

Xylosma roigiana

Xylosma sanctae-annae

Xylosmi schroederi

Xylosma terrae-reginae

\section{Guttiferae}

Calophyllum amblyphyllum Calophyllum calaba var. calaba Calophyllum calaba var. worthingtonii Calophyllum leucocarpum

Clusia plukenetii

Garcinia adinantha

Garcinia clarensis

\section{Hamamelidaceae}

\section{Trichocladus dentatus}

HoplestigmataceaE

Hoplestigma pierreanum

Icacinaceae

Citronella apogon

Cirronella engleriana

Citronella ilicifolia

Citronella megaphylla

Citronella melliodora

Discophora montana

\section{Juglandaceae}

Alfaroa guanacastensis

Alfaroa manningii

Alfaroa williamsii ssp. tapantiensis

Alfaroa williamsii ssp. williamsii

Juglans pyriformis

Oreomunnea mexicana ssp.

costaricensis

\section{Lacistemataceae}

Lacistema macbridei

Lacistema serrulatum 


\section{Lauraceae}

Aniba ramageana

Beilschmiedia berteroana

Beilschmiedia miersii

Caryodaphnopsis inaequalis

Cinnamomum glanduliferum

Cryptocarya gregsonii

Licaria sericea

Litsea mysorensis

Mezilaurus caatingae

Mezilaurus duckei

Mezilaurus mahuba

Mezilaunus micrantha

Mezilaurus opaca

Mezilaurus palcazuensis

Mezilaurus pyriflora

Mezilaurus quadrilocellata

Mezilaurus thoroflora

Ocotea caundato

Ocotea laevigata

Ocotea lancilimba

Ocotea mascarena

Ocotea moschata

Persea meyeniana

Persea nummularia

Persea shaferi

Persea urbaniana

Pleurothyrium grandiflorum

Pleurothyrium westphalii

\section{Lecythidaceae}

Eschweilera cabrerana

Eschweilera calyculata

Eschweilera collinsii

Eschweilera hondurensis

Eschweilera klugii

Eschweilera paniculata

Eschweilera revoluta

Eschweilera rufifolia

Foetidia mauritiana

Foetidia rodriguesiana

Gustavia acuta

Gustavia flagellata var. costata

Gustavia flagellata var. flagellata

Gustavia gentryi

Gustavia inakuama

Gustavia parviflora

Gustavia tejerae

Gustavia terminaliflora

\section{Leguminosae}

Acacia mbuluensis

Albizia aylmeri

Amherstia nobilis

Caesalpinia barahonenensis

Caesalpinia buchii

Calliandra nervosa

Cassia bucherae

Cassia scleroxyla

Centrosema seymourianum

Cojoba chazutense

Copaifera camibar

Copaifera chodatiana

Copaifera langsdorffii var. glabra

Coursetia polyphylla var. acutifolia

Dalbergia decipularis

Dalbergia frutescens var. tomentosa
Dimorphandra coccinea

Dimorphandra dissimilis

Dimorphandra gigantea

Dimorphandra ignea

Dimorphandra jorgei

Dimorphandra loretensis

Dimorphandra mediocris

Dimorphandra williamii

Dimorphandra wilsonii

Erythrina acunae

Erythrina dominguezii

Erythrina furcatifolia

Erythrina greenwayi

Hymenaea davisii

Loesenera walkeri

Lonchocarpus ferrugineus

Lonchocarpus monticolus

Lonchocarpus morenoi

Lonchocarpus pilosus

Lonchocarpus verrucosus

Macrolobium costaricense

Mora abbottii

Neochevalierodendron stephanii

Parkia bahiae

Parkia truncata

Peltophorum berteroanum

Piptadenia hassleriana

Piptadenia paraguayensis

Pithecellobium abbotti

Prosopis atacamensis

Prosopis rojasiana

Prosopis rubriflora

Robinia viscosa var. hartwegii

Sabinea carinalis

Sclerolobium costaricense

Sesbania goetzei ssp. multiflora

Stryphnodendron porcatum

Swartzia acutifolia var. leiogyna

Swartzia acutifolia var. parvipetala

Swartzia acutifolia var. submarginata

Swartzia acutifolia var. ynesiana

Swartzia amazonica var. amazonica

Swartzia amazonica var. cinerea

Swartzia amplifolia var. rigida

Swartzia amshoffiana

Swartzia angustifoliola

Swartzia anomala

Swartzia apetala var. blanchetii

Swartzia apiculata

Swartzia aptera

Swartzia benthamiana var. yatuensis

Swartzia brachyrachis var.

colombiana

Swartzia brachyrachis var. peruviana

Swartzia buntingii

Swartia cabrerae

Swartzia caribaea

Swartzia caudata

Swartzia costata

Swartzia cupavenensis

Swartzia curranii

Swartzia davisii

Swartzia dolichopoda

Swartzia duckei

Swartzia fanshawei

Swartzia fimbriata

Swartzia floribunda

Swartzia foliolosa

Swartzia fraterna

Swartzia froesii
Swartzia gigantea

Swartzia grazielana

Swartia haughtii

Swartzia hostmannii

Swartzia iniridensis

Swartzia jenmanii

Swartzia katawa

Swartzia lamellata var. kaieteurensis

Swartzia lamellata var. lamellata

Swartzia latifolia var. Latifolia

Swartzia leblondii

Swartzia leiogyne

Swartzia littlei

Swartia longicarpa

Swartzia longipedicellata

Swartzia longistipitata

Swartzia lucida

Swartzia macrostachya var.

glabrifolia

Swartzia macrostachya var.

kuhlmanni

Swartzia macrostachya var.

macrostachya

Swartzia macrostachya var. riedelii

Swartzia magdalenae

Swartzia maguirei

Swartzia mangabalensis

Swartzia monachiana

Swartzia mucronifera

Swartzia oblonga

Swartzia pachyphylla

Swartzia panacoco var, altsonii

Swartzia panacoco var.

kamarangensis

Swartzia panacoco var. panacoco

Swartzia panacoco var. sagotii

Swartzia panacoco var. sandwithiana

Swartzia panacoco var. tepuiensis

Swartzia parvifolia

Swartzia pernitida

Swartzia phaneroptera

Swartzia piarensis

Swartzia pickelii

Swartzia pittieri

Swartzia prolata

Swartzia racemosa var. Klugii

Swartzia racemosa var. major

Swartzia riedelii

Swartzia roraimae

Swartzia schunkei

Swartzia sericea var. emarginata

Swartzia sprucei var. sprucei

Swartzia trinitensis

Swartzia ulei

Swartzia vaupesiana var. glauca

Swartzia vaupesiana var. vaupesiana

Swartzia velutina

Swartzia wurdackii

Swartzia xanthopetala

Tessmannia martiniana var. pauloi

Lythraceae

Tetrataxis salicifolia

Magnoliaceae

Magnolia palescens

Magnolia poasana

Magnolia sororum ssp. lutea 


\section{Pachylamax pleiocarpa}

\section{Malpighiaceae}

Bunchosia acuminata

Bunchosia articulata

Bunchosia macilenta

Bunchosia pauciflora

Bunchosia quaesitor

Bunchosia systyla

\section{Malvaceae}

Dendrosida batesii

Dendrosida breedlovei

Dendrosida parviflora

Hibiscus boryanus

Hibiscus columnaris

Hibiscus fragilis

Hibiscus genevii

Hibiscus liliiflorus

Robinsonella erasmi-sosae

Sida eggersii

\section{Melastomataceae}

Axinaea sodiroi

Dissotis aprica

Dissotis arborescens

Dissotis bussei

Dissotis glandulicalyx

Memecylon cordarum

Memecylon greenwayii

Memecylon myrtiforme

Meriania acostae

Meriania almedae

Meriania amplexicaulis

Meriania brevipedunculata

Meriania kirkbridei

Meriania loxensis

Meriania maguirei

Meriania parvifolia

Meriania stellata

Miconia chiriquiensis

Miconia foveolata

Miconia fulvostellata

Miconia pycnoneura

Mouriri ambiconvexa

Mouriri angustifolia

Mouriri arborea

Mouriri bahiensis

Mouriri cearensis ssp. carajasica

Mouriri doriana

Mouriri exadenia

Mouriri floribunda

Mouriri froesii

Mouriri gonavensis

Mouriri gonavensis var. gonavensis

Mouriri gonavensis var, hottensis

Mouriri lancifolia

Mouriri megasperma

Mouriri micradenia

Mouriri micranthera

Mouriri monopora

Mouriri myrtilloides ssp. orinocensis

Mourini obtusiloba

Mouriri pachyphylla

Mouriri regeliana

Mouriri steyermarki

Mouriri tessmannii
Mouriri viridicosta

Ossaea krugiana

Pachyanthus oleifolius

Tibouchina chamaecistus

Votomita pubescens

\section{Meliaceae}

Cedrela weberbaueri

Dysoxylum patersonianum

Guarea costata

Trichilia pachypoda

Trichilia stipitata

Trichilia trifolia ssp. palmeri

Turraea decandra

Turraea laciniata

Turraea rigida

Turraea trichopoda

\section{Meliosmaceae}

Meliosma abbreviata

Meliosma corymbosa

Meliosma hachijoensis

Meliosma nanarum

Meliosma peytonii

Meliosma solomonii

Meliosma vasquezii

\section{Monimiaceae}

Tambourissa cocottensis

Tambourissa pedicellata

Tambourissa quadrifida

Tambourissa sieberi

Tambourissa tetragona

\section{Moraceae}

Brosimum utile var. allenii

Dorstenia excentrica

Ficus pseudopalma

Naucleopsis chiguila

Naucleopsis jamariensis

Naucleopsis naga

Naucleopsis pseudo-naga

Naucleopsis riparia

Perebea guianensis ssp. hirsuta

Perebea guianensis ssp. pseudopeltata

Perebea longepedunculata

Trophis cuspidata

Trophis involucrata

\section{Myricaceae}

Myrica califomica

Myrica phanerodonta

\section{Myristicaceae}

Otoba parvifolia

Staudria kamerunensis

\section{Myrsinaceae}

\section{Ardisia magdalenae}

Badula balfouriana

Badula borbonica var. borbonica

Badula borbonica var. macrophylla

Badula decumbens
Badula fragilis

Badula multiflora

Badula nitida

Badula ovalifolia

\section{Myrtaceae}

Amomyrtus luma

Calyptranthes elegans

Calyptranthes krugii

Eugenia chrysobalanoides

Eugenia crassipetala

Eugenia gryposperma

Eugenia jeremiensis

Eugenia octopleura

Eugenia rodriguesensis

Eugenia stahlii

Eugenia stewardsonii

Eugenia vaughanii

Monimiastrum fasciculatum

Myrceugenia acutiflora

Myrceugenia schultzei

Myrcia borhidii

Myrcia edulis var. dominicana

Myrcianthes ferreyrae

Myrcianthes fragrans var. simpsonii

Syzygium balfourii

Syzygium bijowxi

Syzygium cylindricum

Syzygium populifolium

Syzygium vaughanii

\section{Nyctaginaceae}

Guapira leonis

Guapira suborbiculata

Pisonia costata

Pisonia suborbiculata

Olacaceae

Dulacia tepuiensis

Heisteria asplundii

Heisteria maytenoides

Heisteria skutchii

Schoepfia tepuiensis

Oleaceae

Chionanthus acunae

Chionanthus ayresii

Chionanthus boutonii

Chionanthus broomeana var.

broomeana

Chionanthus moncadae

Fraxinus latifolia

Fraxinus papillosa

Fraxinus texensis

Osmanthus rigidus

\section{Pandanaceae}

Pandanus barklyi var. macrocarpus

Pandanus conglomeratus

Pandanus drupaceus

Pandanus glaucocephalus

Pandanus iceryi

Pandanus incertus

Pandanus macrostigma

Pandanus microcarpus 
Pandanus obsoletus

Pandanus prosiramus

Pandanus spathularus

Pandanus sphaeroideus

Pandanus vandermeerschii

\section{Pellicieraceae}

\section{Pelliciera thizophorae}

\section{Pinaceae}

Pinus arizonica var. stormiae

Pinus brutia var. pityusa

Pinus bungeano

Pinus torano

Pseudolarix amabilis

Pseudotsuga japonica

Tsuga chinensis var, oblongisquamata

Tsuga chinensis var, robusta

\section{Pittosporaceae}

Pittosporum balfourii

Pittosporum bracteolatum

\section{Podocarpaceae}

Dacrydium leptophyllum

Nageia fleuryi

Podocarpus costaricensis

Podocarpus hispaniolensis

Podocarpus humbertii

Podocarpus purdieanus

\section{Polygalaceae}

Monnina idroboana

Monnina membranifolia

\section{Polygonaceae}

Coccoloba caravellae

Coccoloba fawcettii

Coccoloba priorii

\section{Proteaceae}

Helicia ceylanica

\section{Ouiinaceae}

Froesia venezuelensis

\section{Rhamnaceae}

Colubrina cubensis

Colubrina cubensis var. floridana

Colubrina johnstonii

Rhamnus glaucophylla

Rhamnus lindeniana

Rhamnus lojaconoi

Rhamnus pirifolia

Rhamnus serovschanica

Ziziphus bidens

Ziziphus guaranitica
Rhizophoraceae

Cassipourea adami

Cassipourea firestoneana

Rosaceae

Crataegus pojarkovae

Malus sylvestris var. microphylla

Prunus darvasica

Prunus pruninosa

Pyrus kawakamii

\section{Rubiaceae}

Alseis dariensis

Alseis perwviana

Amaioua magnicarpa

Antirhea obrusifolia

Bertiera bistipulata

Borojoa atlantica

Borojoa panamensis

Cephaelis croatii

Chassalia boryana

Chassalia capitata

Chassalia coriacea var. coriacea

Chassalia coriacea var. johnstonii

Chassalia grandifolia

Chassalia lanceolata ssp. lanceolata

Chassalia lanceolata ssp. latifolia

Chimarrhis microcarpa

Chione darienensis

Chione panamensis

Cinchona carabayensis

Cinchona delessertiana

Cinchona nitida

Cinchona rufinervis

Coussarea durifolia

Coussarea mori

Coussarea neei

Coussarea veraguensis

Duroia genipifolia

Faramea bocataurensis

Faramea ovalis

Faramea pauciflora

Faramea standleyana

Femelia pedunculata

Gaertnera boivini

Gaermera calycina

Gaertnera crassiflora

Gaertnera hirtiflora

Gaertnera longifolia var. longifolia

Gaermera longifolia var. pubescens

Gaermera noddosa

Gaertnera oxycarpa

Gaertnera pendula

Gaertnera quadriseta

Gaertnera truncata

Genipa curviflora

Gleasonia duidana var. latifolia

Guettarda amblyophylla

Guettarda brenesii

Guettarda cobanensis

Guettarda cobrensis

Guettarda nervosa

Gueltarda organosia

Guettarda petenensis

Guettarda retusa

Guettarda roigiana

Guettarda sanblasensis

Henriquezia jenmanii
Henriquezia nitida var. longisepala

Hillia chiriquiensis

Ladenbergia laurifolia

Mussaenda landia var. holosericea

Palicourea montensis

Palicourea ochnoides

Palicourea rigidifolia

Palicourea veraguensis

Platycarpum acreanum

Platycarpum duckei

Platycarpum eglandulosum

Platycarpum egleri

Platycarpum froesii

Platycarpum maguirei

Plarycarpum negrense var. glaucum

Plarycarpum negrense var, negrense

Platycarpum orinocense var.

grandiflorum

Platycarpum schultesii var. schultesii

Psychotria calophylla

Psychotria catillicalyx

Psychotria croceovenosa

Psychotria hexandra var. hosakana

Psychotria hexandra var, oahuensis

Psychotria hexandra var. rockii

Psychotria hexandra var. st.-johnii

Psychotria nubiphila

Psychotria ostaurea

Psychotria panamensis

Psychotria pleeana

Psychotria quadrangulata

Psychotria santaritensis

Psychotria taurina

Psychotria tutensis

Ramosmania heterophylla

Randia mira

Raritebe darienensis

Remijia chelomaphylla

Rondeletia cooperi

Rondeletia kirkbridei

Rondeletia panamensis

Rondeletia platysepala

Rondeletia salicifolia var. salicifolia

Rudgea coronicarpa

Scyphochlamys revoluta

Scyphostachys pedunculatus

Simira darienensis

Simira maxonii

\section{Rutaceae}

Amyris madrensis

Erythrochiton incomparabilis

Esenbeckia cormuta

Esenbeckia feddemae

Esenbeckia macrantha

Esenbeckia nesiotica

Euodia littoralis

Euodia obtusifolia var. brachypoda

Metrodorea maracasana

Pilocarpus demerarae

Zanthoxylum caudatum

Zanthoxylum panicularum

Zanthoxylum parvum

Zanthoxylum pistaciiflorum

Salicaceae

Populus cataracti

Salix arizonica 
Salix paludicola

Salix planifolia ssp. tyrrellii

Salix sessilifolia

Salix silicicola

Sapindaceae

Hypelate trifoliata Sapindus grandifolius

\section{Sapotaceae}

Bumelia acunae

Bumelia revoluta

Bumelia tenax

Bumelia thomei

Chrysophyllum eggersii

Diploknema siamensis

Ecclinusa dumetorum

Labourdonnaisia glauca

Labourdonnaisia revoluto

Lecomtedoxa heitzana

Madhuca kerrii

Madhuca punctata

Madhuca tokinsis

Mimusops andamanensis

Mimusops erythroxylon

Mimusops petiolaris

Mimusops zeylanica

Palaquium garrettii

Palaquium punctatum

Payena thorelii

Pouteria boninensis

Sarcosperma siamensis

Sideroxylon boutonianum

Sideroxylon eriocarpum

Sideroxylon galeatum

Sideroxylon grandiflorum

Sideroxylon majus

Sideroxylon sessiliflonum

Sideroxylon tenax

Sideroxylon thomei

\section{Simaroubaceae}

Picramnia dwyeri

Picrasma cubensis

Simaba praecox

\section{Solanaceae}

Brunfelsia clarensis

Brunfelsia dwyeri

Brunfelsia lactea

Brunfelsia linearis

Brunfelsia picardae

Cestrum jimenezii

Cestrum moaense

Lycianthes beckneriana

Lycianthes howardiana

Sterculiaceae

Astiria rosea

Ayenia cajalbanensis

Bytmeria scopiura

Cola crispiflora

Dombeya mauritiana

Dombeya populnea

Dombeya rodriguesiana

Herrania balaensis

Sterculia zeyianica

Theobroma cimolinae

Trochetia iriflora

Trochetia uniflora

Symplocaceae

Symplocos ciponimoides

Symplocos lanala

Symplocos moaensis

Theaceae

Eurya boninensis

Gordonia zeylanica

Ternstroemia elliptica

Temstroemia heptasepala

Temstroemia rostrata

Theophrastaceae

Clavija repanda

Thymelaeaceae

Daphnopsis grandis

\section{Tiliaceae}

Neosprucea sucumbiensis

Tilia chyugokuensis

\section{Trigoniaceae}

Trigonia macrantha

Ulmaceae

Ampelocera glabra

\section{Urticaceae}

Obetia ficifolia

Rousselia erratica

\section{Verbenaceae}

Citharexylum sulcatum var. hirtellum Violaceae

Gloeospermum sclerophyllum

Leoniz occidentalis

Melicytus latifolius

Melicytus novae-zelandiae ssp.

centurionis

Rinorea djalonensis

\section{Vochysiaceae}

Callisthene hassleri

Vochysia duquei

Vochysia oppugnata

\section{Winteraceae}

Tasmannia purpurascens

Zygophyllaceae

Porlieria chilensis 



\section{APPENDIX 4}

\section{IUCN RED LIST CATEGORIES}

Prepared by the

IUCN Species Survival Commission

As approved by the

40th Meeting of the IUCN Council

Gland, Switzerland

30 November 1994 


\section{INTRODUCTION}

The threatened species categories now used in Red Data Books and Red Lists have been in place, with some modification, for almost 30 years. Since their introduction these categories have become widely recognised internationally, and they are now used in a whole range of publications and listings, produced by IUCN as well as by numerous governmental and non-governmental organisations. The Red Data Book categories provide an easily and widely understood method for highlighting those species under higher extinction risk, so as to focus attention on conservation measures designed to protect them.

The need to revise the categories has been recognised for some time. In 1984, the SSC held a symposium, 'The Road to Extinction' (Fitter \& Fitter 1987), which examined the issues in some detail, and at which a number of options were considered for the revised system. However, no single proposal resulted. The current phase of development began in 1989 with a request from the SSC Steering Committee to develop a new approach that would provide the conservation community with useful information for action planning.

In this document, proposals for new definitions for Red List categories are presented. The general aim of the new system is to provide an explicit, objective framework for the classification of species according to their extinction risk.

The revision has several specific aims:

to provide a system that can be applied consistently by different people;

to improve the objectivity by providing those using the criteria with clear guidance on how to evaluate different factors which affect risk of extinction;

to provide a system which will facilitate comparisons across widely different taxa;

to give people using threatened species lists a better understanding of how individual species were classified.

The proposals presented in this document result from a continuing process of drafting, consultation and validation. It was clear that the production of a large number of draft proposals led to some confusion, especially as each draft has been used for classifying some set of species for conservation purposes. To clarify matters, and to open the way for modifications as and when they became necessary, a system for version numbering was applied as follows:

Version 1.0: Mace \& Lande (1991)

The first paper discussing a new basis for the categories, and presenting numerical criteria especially relevant for large vertebrates.

Version 2.0: Mace et al. (1992)

A major revision of Version 1.0, including numerical criteria appropriate to all organisms and introducing the non-threatened categories.

Version 2.1: IUCN (1993)

Following an extensive consultation process within SSC, a number of changes were made to the details of the criteria, and fuller explanation of basic principles was included. A more explicit structure clarified the significance of the non-threatened categories. 
Version 2.2: Mace \& Stuart (1994)

Following further comments received and additional validation exercises, some minor changes to the criteria were made. In addition, the Susceptible category present in Versions 2.0 and 2.1 was subsumed into the Vulnerable category. A precautionary application of the system was emphasised.

Final Version

This final document, which incorporates changes as a result of comments from IUCN members, was adopted by the IUCN Council in December 1994.

All future taxon lists including categorisations should be based on this version, and not the previous ones.

In the rest of this document the proposed system is outlined in several sections. The Preamble presents some basic information about the context and structure of the proposal, and the procedures that are to be followed in applying the definitions to species. This is followed by a section giving definitions of terms used. Finally the definitions are presented, followed by the quantitative criteria used for classification within the threatened categories. It is important for the effective functioning of the new system that all sections are read and understood, and the guidelines followed.

\section{REFERENCES}

Fitter, R., and M. Fitter, ed. (1987) The Road to Extinction. Gland, Switzerland: IUCN.

IUCN. (1993) Draft IUCN Red List Categories. Gland, Switzerland: IUCN.

Mace, G. M. et al. (1992) "The development of new criteria for listing species on the IUCN Red List." Species 19: 16-22.

Mace, G. M., and R. Lande. (1991) "Assessing extinction threats: toward a reevaluation of IUCN threatened species categories." Conserv. Biol. 5.2: 148-157.

Mace, G. M. \& S. N. Stuart. (1994) "Draft IUCN Red List Categories, Version 2.2". Species 2122: $13-24$.

\section{PREAMBLE}

The following points present important information on the use and interpretation of the categories (= Critically Endangered, Endangered, etc.), criteria (= A to E), and sub-criteria (= a,b etc., i,ii etc.):

\section{Taxonomic level and scope of the categorisation process}

The criteria can be applied to any taxonomic unit at or below the species level. The term 'taxon' in the following notes, definitions and criteria is used for convenience, and may represent species or lower taxonomic levels, including forms that are not yet formally described. There is a sufficient range among the different criteria to enable the appropriate listing of taxa from the complete taxonomic spectrum, with the exception of micro-organisms. The criteria may also be applied within any specified geographical or political area although in such cases special notice should be taken of point 11 below. In presenting the results of applying the criteria, the taxonomic unit and area under consideration should be made explicit. The categorisation process should only be applied to wild populations inside their natural range, and to populations resulting from benign introductions (defined in the draft IUCN Guidelines for Re-introductions as "..an attempt to 
establish a species, for the purpose of conservation, outside its recorded distribution, but within an appropriate habitat and eco-geographical area").

\section{Nature of the categories}

All taxa listed as Critically Endangered qualify for Vulnerable and Endangered, and all listed as Endangered qualify for Vulnerable. Together these categories are described as 'threatened'. The threatened species categories form a part of the overall scheme. It will be possible to place all taxa into one of the categories (see Figure 1).

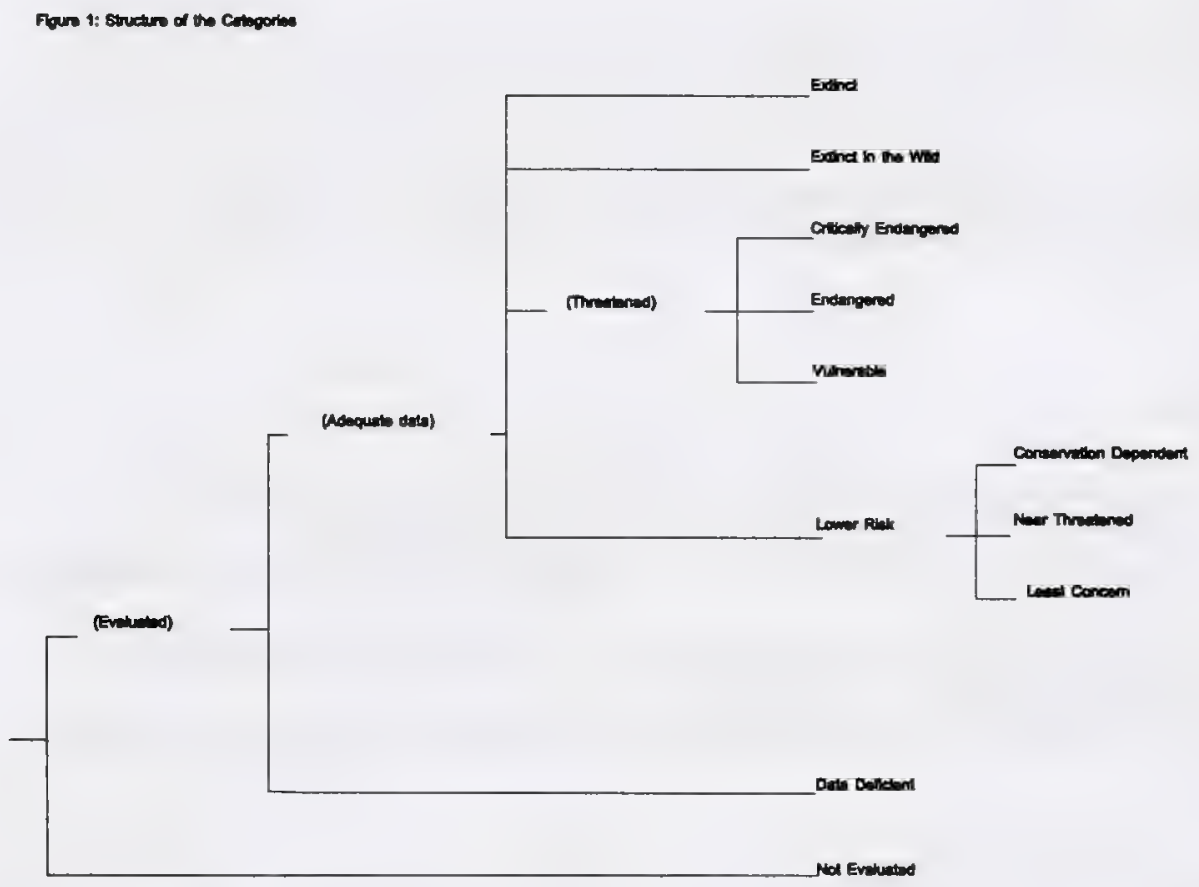

\section{Role of the different criteria}

For listing as Critically Endangered, Endangered or Vulnerable there is a range of quantitative criteria; meeting any one of these criteria qualifies a taxon for listing at that level of threat. Each species should be evaluated against all the criteria. The different criteria (A-E) are derived from a wide review aimed at detecting risk factors across the broad range of organisms and the diverse life histories they exhibit. Even though some criteria will be inappropriate for certain taxa(some taxa will never qualify under these however close to extinction they come), there should be criteria appropriate for assessing threat levels for any taxon (other than micro-organisms). The relevant factor is whether any one criterion is met, not whether all are appropriate or all are met. Because it will never be clear which criteria are appropriate for a particular species in advance, each species should be evaluated against all the criteria, and any criterion met should be listed. 


\section{Derivation of quantitative criteria}

The quantitative values presented in the various criteria associated with threatened categories were developed through wide consultation and they are set at what are generally judged to be appropriate levels, even if no formal justification for these values exists. The levels for different criteria within categories were set independently but against a common standard. Some broad consistency between them was sought. However, a given taxon should not be expected to meet all criteria (A-E) in a category; meeting any one criterion is sufficient for listing.

\section{Implications of listing}

Listing in the categories of Not Evaluated and Data Deficient indicates that no assessment of extinction risk has been made, though for different reasons. Until such time as an assessment is made, species listed in these categories should not be treated as if they were non-threatened, and it may be appropriate (especially for Data Deficient forms) to give them the same degree of protection as threatened taxa, at least until their status can be evaluated.

Extinction is assumed here to be a chance process. Thus, a listing in a higher extinction risk category implies a higher expectation of extinction, and over the time-frames specified more taxa listed in a higher category are expected to go extinct than in a lower one (without effective conservation action). However, the persistence of some taxa in high risk categories does not necessarily mean their initial assessment was inaccurate.

\section{Data quality and the importance of inference and projection}

The criteria are clearly quantitative in nature. However, the absence of high quality data should not deter attempts at applying the criteria, as methods involving estimation, inference and projection are emphasised to be acceptable throughout. Inference and projection may be based on extrapolation of current or potential threats into the future (including their rate of change), or of factors related to population abundance or distribution (including dependence on other taxa), so long as these can reasonably be supported. Suspected or inferred patterns in either the recent past, present or near future can be based on any of a series of related factors, and these factors should be specified.

Taxa at risk from threats posed by future events of low probability but with severe consequences (catastrophes) should be identified by the criteria (e.g. small distributions, few locations). Some threats need to be identified particularly early, and appropriate actions taken, because their efiects are irreversible, or nearly so (pathogens, invasive organisms, hybridization).

\section{Uncertainty}

The criteria should be applied on the basis of the available evidence on taxon numbers, trend and distribution, making due allowance for statistical and other uncertainties. Given that data are rarely available for the whole range or population of a taxon, it may often be appropriate to use the information that is available to make intelligent inferences about the overall status of the taxon in question. In cases where a wide variation in estimates is found, it is legitimate to apply the precautionary principle and use the estimate (providing it is credible) that leads to listing in the category of highest risk.

Where data are insufficient to assign a category (including Lower Risk), the category of 'Data Deficient' may be assigned. However, it is important to recognise that this category indicates that data are inadequate to determine the degree of threat faced by a taxon, not necessarily that the taxon is poorly known. In cases where there are evident threats to a taxon through, for example, deterioration of its only known habitat, it is important to attempt threatened listing, even though 
there may be little direct information on the biological status of the taxon itself. The category 'Data Deficient' is not a threatened category, although it indicates a need to obtain more information on a taxon to determine the appropriate listing.

\section{Conservation actions in the listing process}

The criteria for the threatened categories are to be applied to a taxon whatever the level of conservation action affecting it. In cases where it is only conservation action that prevents the taxon from meeting the threatened criteria, the designation of 'Conservation Dependent' is appropriate. It is important to emphasise here that a taxon require conservation action even if it is not listed as threatened.

\section{Documentation}

All taxon lists including categorisation resulting from these criteria should state the criteria and sub-criteria that were met. No listing can be accepted as valid unless at least one criterion is given. If more than one criterion or sub-criterion was met, then each should be listed. However, failure to mention a criterion should not necessarily imply that it was not met. Therefore, if a reevaluation indicates that the documented criterion is no longer met, this should not result in automatic down-listing. Instead, the taxon should be re-evaluated with respect to all criteria to indicate its status. The factors responsible for triggering the criteria, especially where inference and projection are used, should at least be logged by the evaluator, even if they cannot be included in published lists.

\section{Threats and priorities}

The category of threat is not necessarily sufficient to determine priorities for conservation action. The category of threat simply provides an assessment of the likelihood of extinction under current circumstances, whereas a system for assessing priorities for action will include numerous other factors concerning conservation action such as costs, logistics, chances of success, and even perhaps the taxonomic distinctiveness of the subject.

\section{Use at regional level}

The criteria are most appropriately applied to whole taxa at a global scale, rather than to those units defined by regional or national boundaries. Regionally or nationally based threat categories, which are aimed at including taxa that are threatened at regional or national levels (but not necessarily throughout their global ranges), are best used with two key pieces of information: the global status category for the taxon, and the proportion of the global population or range that occurs within the region or nation. However, if applied at regional or national level it must be recognised that a global category of threat may not be the same as a regional or national category for a particular taxon. For example, taxa classified as Vulnerable on the basis of their global declines in numbers or range might be Lower Risk within a particular region where their populations are stable. Conversely, taxa classified as Lower Risk globally might be Critically Endangered within a particular region where numbers are very small or declining, perhaps only because they are at the margins of their global range. IUCN is still in the process of developing guidelines for the use of national red list categories.

\section{Re-evaluation}

Evaluation of taxa against the criteria should be carried out at appropriate intervals. This is especially important for taxa listed under Near Threatened, or Conservation Dependent, and for threatened species whose status is known or suspected to be deteriorating. 


\section{Transfer between categories}

There are rules to govern the movement of taxa between categories. These are as follows: (A) A taxon may be moved from a category of higher threat to a category of lower threat if none of the criteria of the higher category has been met for 5 years or more. (B) If the original classification is found to have been erroneous, the taxon may be transferred to the appropriate category or removed from the threatened categories altogether, without delay. (C) Transfer from categories of lower to higher risk should be made without delay.

\section{Problems of scale}

Classification based on the sizes of geographic ranges or the patterns of habitat occupancy is complicated by problems of spatial scale. The finer the scale at which the distributions or habitats of taxa are mapped, the smaller will be the area that they are found to occupy. Mapping at finer scales reveals more areas in which the taxon is unrecorded. It is impossible to provide any strict but general rules for mapping taxa or habitats; the most appropriate scale will depend on the taxa in question, and the origin and comprehensiveness of the distributional data. However, the thresholds for some criteria (e.g. Critically Endangered) necessitate mapping at a fine scale.

\section{DEFINITIONS}

\section{Population}

Population is defined as the total number of individuals of the taxon. For functional reasons, primarily owing to differences between life-forms, population numbers are expressed as numbers of mature individuals only. In the case of taxa obligately dependent on other taxa for all or part of their life cycles, biologically appropriate values for the host taxon should be used.

\section{Subpopulations}

Subpopulations are defined as geographically or otherwise distinct groups in the population between which there is little exchange (typically one successful migrant individual or gamete per year or less).

\section{Mature individuals}

The number of mature individuals is defined as the number of individuals known, estimated or inferred to be capable of reproduction. When estimating this quantity the following points should be borne in mind:

Where the population is characterised by natural fluctuations the minimum number should be used.

This measure is intended to count individuals capable of reproduction and should therefore exclude individuals that are environmentally, behaviourally or otherwise reproductively suppressed in the wild.

In the case of populations with biased adult or breeding sex ratios it is appropriate to use lower estimates for the number of mature individuals which take this into account (e.g. the estimated effective population size). 
Reproducing units within a clone should be counted as individuals, except where such units are unable to survive alone (e.g. corals).

In the case of taxa that naturally lose all or a subset of mature individuals at some point in their life cycle, the estimate should be made at the appropriate time, when mature individuals are available for breeding.

\section{Generation}

Generation may be measured as the average age of parents in the population. This is greater than the age at first breeding, except in taxa where individuals breed only once.

\section{Continuing decline}

A continuing decline is a recent, current or projected future decline whose causes are not known or not adequately controlled and so is liable to continue unless remedial measures are taken. Natural fluctuations will not normally count as a continuing decline, but an observed decline should not be considered to be part of a natural fluctuation unless there is evidence for this.

\section{Reduction}

A reduction (criterion $\mathrm{A}$ ) is a decline in the number of mature individuals of at least the amount (\%) stated over the time period (years) specified, although the decline need not still be continuing. A reduction should not be interpreted as part of a natural fluctuation unless there is good evidence for this. Downward trends that are part of natural fluctuations will not normally count as a reduction.

\section{Extreme fluctuations}

Extreme fluctuations occur in a number of taxa where population size or distribution area varies widely, rapidly and frequently, typically with a variation greater than one order of magnitude (i.e., a tenfold increase or decrease).

\section{Severely fragmented}

Severely fragmented is refers to the situation where increased extinction risks to the taxon result from the fact that most individuals within a taxon are found in small and relatively isolated subpopulations. These small subpopulations may go extinct, with a reduced probability of recolonisation.

\section{Extent of occurrence}

Extent of occurrence is defined as the area contained within the shortest continuous imaginary boundary which can be drawn to encompass all the known, inferred or projected sites of present occurrence of a taxon, excluding cases of vagrancy. This measure may exclude discontinuities or disjunctions within the overall distributions of taxa (e.g., large areas of obviously unsuitable habitat) (but see 'area of occupancy'). Extent of occurrence can often be measured by a minimum convex polygon (the smallest polygon in which no internal angle exceeds 180 degrees and which contains all the sites of occurrence). 


\section{Area of occupancy}

Area of occupancy is defined as the area within its 'extent of occurrence' (see definition) which is occupied by a taxon, excluding cases of vagrancy. The measure reflects the fact that a taxon will not usually occur throughout the area of its extent of occurrence, which may, for example, contain unsuitable habitats. The area of occupancy is the smallest area essential at any stage to the survival of existing populations of a taxon (e.g. colonial nesting sites, feeding sites for migratory taxa). The size of the area of occupancy will be a function of the scale at which it is measured, and should be at a scale appropriate to relevant biological aspects of the taxon. The criteria include values in $\mathrm{km}^{2}$, and thus to avoid errors in classification, the area of occupancy should be measured on grid squares (or equivalents) which are sufficiently small (see Figure 2).

\section{Location}

Location defines a geographically or ecologically distinct area in which a single event (e.g. pollution) will soon affect all individuals of the taxon present. A location usually, but not always, contains all or part of a subpopulation of the taxon, and is typically a small proportion of the taxon's total distribution.

\section{Quantitative analysis}

A quantitative analysis is defined here as the technique of population viability analysis (PVA), or any other quantitative form of analysis, which estimates the extinction probability of a taxon or population based on the known life history and specified management or non-management options. In presenting the results of quantitative analyses the structural equations and the data should be explicit. 


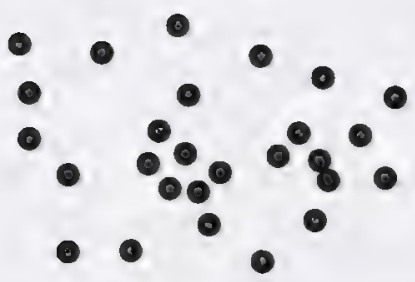

A
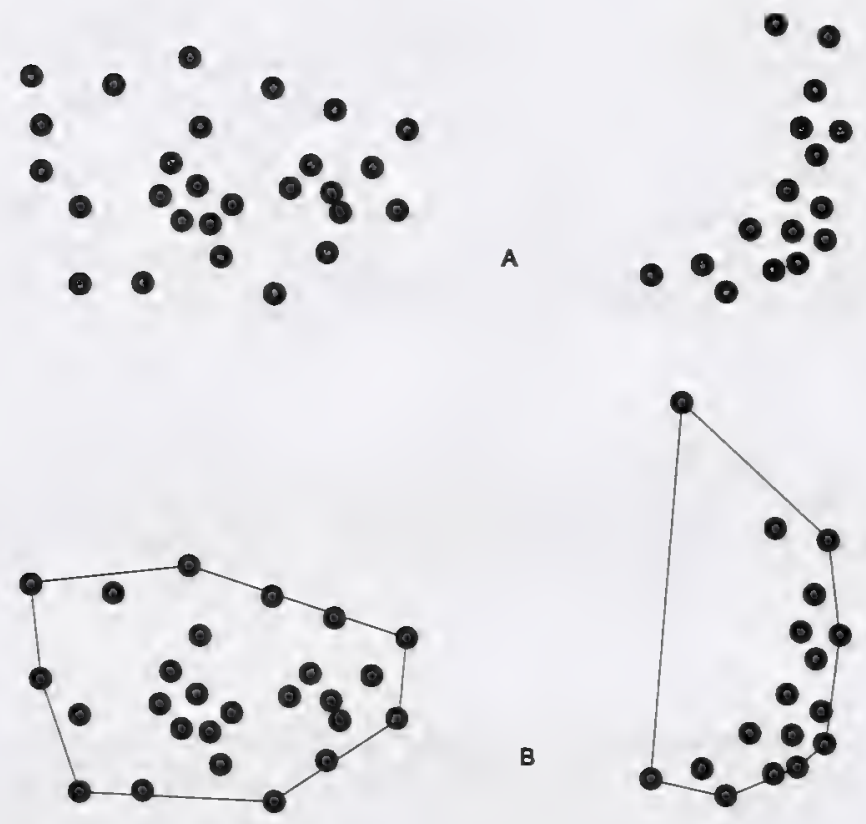

B
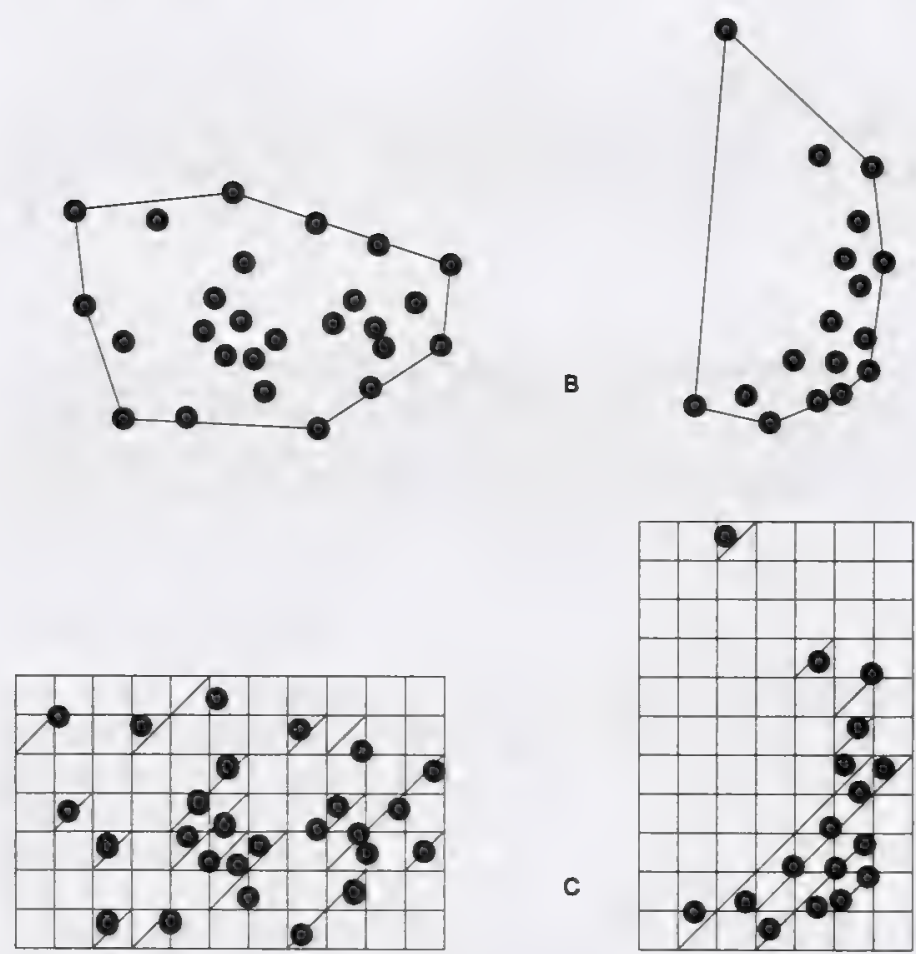

Figure 2:

Two examples of the distinction between extent of occurrence and area of occupancy. (a) is the spatial distribution of known, inferred or projected sites of occurrence. (b) shows one possible boundary to the extent of occurrence, which is the measured area within this boundary. (c) shows one measure of area of occupancy which can be measured by the sum of the occupied grid squares. 


\section{EXTINCT (EX)}

A taxon is Extinct when there is no reasonable doubt that the last individual has died.

\section{EXTINCT IN THE WILD (EW)}

A taxon is Extinct in the wild when it is known only to survive in cultivation, in captivity or as a naturalised population (or populations) well outside the past range. A taxon is presumed extinct in the wild when exhaustive surveys in known and/or expected habitat, at appropriate times (diurnal, seasonal, annual), throughout its historic range have failed to record an individual. Surveys should be over a time frame appropriate to the taxon's life cycle and life form.

\section{CRITICALLY ENDANGERED (CR)}

A taxon is Critically Endangered when it is facing an extremely high risk of extinction in the wild in the immediate future, as defined by any of the criteria (A to E).

\section{ENDANGERED (EN)}

A taxon is Endangered when it is not Critically Endangered but is facing a very high risk of extinction in the wild in the near future, as defined by any of the criteria (A to E).

\section{VULNERABLE (VU)}

A taxon is Vulnerable when it is not Critically Endangered or Endangered but is facing a high risk of extinction in the wild in the medium-term future, as defined by any of the criteria (A to D).

\section{LOWER RISK (LR)}

A taxon is Lower Risk when it has been evaluated, does not satisfy the criteria for any of the categories Critically Endangered, Endangered or Vulnerable. Taxa included in the Lower Risk category can be separated into three subcategories:

1. Conservation Dependent (cd). Taxa which are the focus of a continuing taxon-specific or habitat-specific conservation programme targeted towards the taxon in question, the cessation of which would result in the taxon qualifying for one of the threatened categories above within a period of five years.

2. Near Threatened (nt). Taxa which do not qualify for Conservation Dependent, but which are close to qualifying for Vulnerable.

3. Least Concern (Ic). Taxa which do not qualify for Conservation Dependent or Near Threatened.

\footnotetext{
'Note: As in previous IUCN categories, the abbreviation of each category (in parenthesis) follows the English denominations when translated into other languages.
} 


\section{DATA DEFICIENT (DD)}

A taxon is Data Deficient when there is inadequate information to make a direct, or indirect, assessment of its risk of extinction based on its distribution and/or population status. A taxon in this category may be well studied, and its biology well known, but appropriate data on abundance and/or distribution is lacking. Data Deficient is therefore not a category of threat or Lower Risk. Listing of taxa in this category indicates that more information is required and acknowledges the possibility that future research will show that threatened classification is appropriate. It is important to make positive use of whatever data are available. In many cases great care should be exercised in choosing between DD and threatened status. If the range of a taxon is suspected to be relatively circumscribed, if a considerable period of time has elapsed since the last record of the taxon, threatened status may well be justified.

\section{NOT EVALUATED (NE)}

A taxon is Not Evaluated when it is has not yet been assessed against the criteria.

\section{THE CRITERIA FOR CRITICALLY ENDANGERED, ENDANGERED AND VULNERABLE}

\section{CRITICALLY ENDANGERED (CR)}

A taxon is Critically Endangered when it is facing an extremely high risk of extinction in the wild in the immediate future, as defined by any of the following criteria (A to E):

A) Population reduction in the form of either of the following:

1) An observed, estimated, inferred or suspected reduction of at least $80 \%$ over the last 10 years or three generations, whichever is the longer, based on (and specifying) any of the following:

a) direct observation

b) an index of abundance appropriate for the taxon

c) a decline in area of occupancy, extent of occurrence and/or quality of habitat

d) actual or potential levels of exploitation

e) the effects of introduced taxa, hybridisation, pathogens, pollutants, competitors or parasites.

2) A reduction of at least $80 \%$, projected or suspected to be met within the next ten years or three generations, whichever is the longer, based on (and specifying) any of (b), (c), (d) or (e) above.

B) Extent of occurrence estimated to be less than $100 \mathrm{~km}^{2}$ or area of occupancy estimated to be less than $10 \mathrm{~km}^{2}$, and estimates indicating any two of the following:

1) Severely fragmented or known to exist at only a single location.

2) Continuing decline, observed, inferred or projected, in any of the following:

a) extent of occurrence

b) area of occupancy

c) area, extent and/or quality of habitat

d) number of locations or subpopulations 
e) number of mature individuals.

3) Extreme fluctuations in any of the following:
a) extent of occurrence
b) area of occupancy
c) number of locations or subpopulations
d) number of mature individuals.

C) Population estimated to number less than 250 mature individuals and either:

1) An estimated continuing decline of at least $25 \%$ within 3 years or one generation, whichever is longer or

2) A continuing decline, observed, projected, or inferred, in numbers of mature individuals and population structure in the form of either:
a) severely fragmented (i.e. no subpopulation estimated to contain more than 50 mature individuals)
b) all individuals are in a single subpopulation.

D) Population estimated to number less than 50 mature individuals.
E) Quantitative analysis showing the probability of extinction in the wild is at least $50 \%$ within 10 years or 3 generations, whichever is the longer.

\section{ENDANGERED (EN)}

A taxon is Endangered when it is not Critically Endangered but is facing a very high risk of extinction in the wild in the near future, as defined by any of the following criteria ( $A$ to $E$ ):

A) Population reduction in the form of either of the following:

1) An observed, estimated, inferred or suspected reduction of at least $50 \%$ over the last 10 years or three generations, whichever is the longer, based on (and specifying) any of the following:
a) direct observation
b) an index of abundance appropriate for the taxon
c) a decline in area of occupancy, extent of occurrence and/or quality of habitat
d) actual or potential levels of exploitation
e) the effects of introduced taxa, hybridisation, pathogens, pollutants, competitors or parasites.

2) A reduction of at least $50 \%$, projected or suspected to be met within the next ten years or three generations, whichever is the longer, based on (and specifying) any of (b), (c), (d), or (e) above.

B) Extent of occurrence estimated to be less than $5000 \mathrm{~km}^{2}$ or area of occupancy estimated to be less than $500 \mathrm{~km}^{2}$, and estimates indicating any two of the following: 
1) Severely fragmented or known to exist at no more than five locations.

2) Continuing decline, inferred, observed or projected, in any of the following:
a) extent of occurrence
b) area of occupancy
c) area, extent and/or quality of habitat
d) number of locations or subpopulations
e) number of mature individuals.

3) Extreme fluctuations in any of the following:
a) extent of occurrence
b) area of occupancy
c) number of locations or subpopulations
d) number of mature individuals.

C) Population estimated to number less than 2500 mature individuals and either:

1) An estimated continuing decline of at least $20 \%$ within 5 years or 2 generations, whichever is longer, or

2) A continuing decline, observed, projected, or inferred, in numbers of mature individuals and population structure in the form of either:
a) severely fragmented (i.e. no subpopulation estimated to contain more than 250 mature individuals)
b) all individuals are in a single subpopulation.

D) Population estimated to number less than 250 mature individuals.

E) Quantitative analysis showing the probability of extinction in the wild is at least $20 \%$ within 20 years or 5 generations, whichever is the longer.

\section{VULNERABLE (VU)}

A taxon is Vulnerable when it is not Critically Endangered or Endangered but is facing a high risk of extinction in the wild in the medium-term future, as defined by any of the following criteria (A to E):

A) Population reduction in the form of either of the following:

1) An observed, estimated, inferred or suspected reduction of at least $20 \%$ over the last 10 years or three generations, whichever is the longer,, based on (and specifying) any of the following:
a) direct observation
b) an index of abundance appropriate for the taxon
c) a decline in area of occupancy, extent of occurrence and/or quality of habitat
d) actual or potential levels of exploitation
e) the effects of introduced taxa, hybridisation, pathogens, pollutants, competitors or parasites.


2) A reduction of at least $20 \%$, projected or suspected to be met within the next ten years or three generations, whichever is the longer, based on (and specifying) any of (b), (c), (d) or (e) above.

B) Extent of occurrence estimated to be less than $20,000 \mathrm{~km}^{2}$ or area of occupancy estimated to be less than $2000 \mathrm{~km}^{2}$, and estimates indicating any two of the following:

1) Severely fragmented or known to exist at no more than ten locations.

2) Continuing decline, inferred, observed or projected, in any of the following:
a) extent of occurrence
b) area of occupancy
c) area, extent and/or quality of habitat
d) number of locations or subpopulations
e) number of mature individuals.

3) Extreme fluctuations in any of the following:
a) extent of occurrence
b) area of occupancy
c) number of locations or subpopulations
d) number of mature individuals.

C) Population estimated to number less than 10,000 mature individuals and either:

1) An estimated continuing decline of at least $10 \%$ within 10 years or 3 generations, whichever is longer, or

2) A continuing decline, observed, projected, or inferred, in numbers of mature individuals and population structure in the form of either:
a) severely fragmented (i.e. no subpopulation estimated to contain more than 1000 mature individuals)
b) all individuals are in a single subpopulation.

D) Population very small or restricted in the form of either of the following:

1) Population estimated to number less than 1000 mature individuals.

2) Population is characterised by an acute restriction in its area of occupancy (typically less than $100 \mathrm{~km}^{2}$ ) or in the number of locations (typically less than 5). Such a taxon would thus be prone to the effects of human activities (or stochastic events whose impact is increased by human activities) within a very short period of time in an unforeseeable future, and is thus capable of becoming Critically Endangered or even Extinct in a very short period.

E) Quantitative analysis showing the probability of extinction in the wild is at least $10 \%$ within 100 years. 



\section{APPENDIX 5}

\section{STANDARD DATA COLLECTION FORM}

The data collection form was designed specifically to provide a framework for experts to review existing data as well as provide new data on threatened tree species. Several thousand forms have been completed by over 300 experts and their contents entered directly into the Tree Conservation Database.

Section 1 of the form was pre-filled with information from the Threatened Plants Database on taxonomy, distribution and conservation status together with common names and uses where known. Experts were asked to verify information in this section. Section 2 of the form was designed to record the 1994 IUCN category and criteria and to record summary notes on the conservation status of the species. Section 3 allows for the provision of supplementary information on uses, ecology and bibliographic references. 


\begin{tabular}{|l|l|}
\hline Section 1 - Nomenclature and Occurrence \\
\hline Scientific name & \\
\hline $\begin{array}{l}\text { Other scientific name(s) in current } \\
\text { use }\end{array}$ & \\
\hline Family & \\
\hline Common names & \\
\hline $\begin{array}{l}\text { Distribution at BRU* level } \\
\text { (*Basic Recording Unit) }\end{array}$ & \\
\hline Old Global IUCN threat category & \\
\hline Uses & \\
\hline Is the taxonomy above correct? & \\
\hline $\begin{array}{l}\text { Is the distribution complete? If not, in } \\
\text { which additional countries or states can } \\
\text { the species be found? }\end{array}$ & \\
\hline $\begin{array}{l}\text { If the species distribution is confined to } \\
\text { a particular area? (e.g. a mountain } \\
\text { range) Please give the details }\end{array}$ & \\
\hline
\end{tabular}

\section{Section 2 - Conservation Status}

\begin{tabular}{|c|c|c|c|}
\hline $\begin{array}{l}\text { Is this species of conservation concern } \\
\text { in any part of its range? Please specify } \\
\text { where }\end{array}$ & $\square$ Yes & & $\square$ No \\
\hline $\begin{array}{l}\text { Revised global IUCN threat category } \\
\text { (1994) }\end{array}$ & $\begin{array}{l}\square \text { EX } \\
\square \text { LRcd }\end{array}$ & $\begin{array}{ll}\square \text { EW } & \square \text { CR } \\
\square \text { LRnt } & \square \text { LRlc }\end{array}$ & $\begin{array}{l}\square \text { VU } \\
\square \text { NE }\end{array}$ \\
\hline \multicolumn{4}{|l|}{ Criteria (e.g A.1.(d) ete.) } \\
\hline \multicolumn{4}{|l|}{$\begin{array}{l}\text { Comment } \\
\text { Please use this space to sum up the status } \\
\text { of the species. Please include any } \\
\text { information about the population size or } \\
\text { decline, restricted range, ecological or } \\
\text { taxonomic uniqueness, characteristics } \\
\text { of regeneration or reproductive } \\
\text { strategy, and any indications of the } \\
\text { fragility of the state of the species, } \\
\text { especially where data are insuficient to } \\
\text { assign a threat category }\end{array}$} \\
\hline $\begin{array}{l}\text { Threats } \\
\text { If multiple threats please indicate order } \\
\text { of concern - use } 1 \text { for the most serious } \\
\text { threat(s) }\end{array}$ & $\begin{array}{l}\text { [] Felling } \\
\text { [] Fire } \\
\text { [ ] Pests \& Diseases } \\
\text { [ ] Seed Predation } \\
\text { [] Mining } \\
\text { [] Agriculure } \\
\text { [] Expansion of humar } \\
\text { [ ] Other major threat: }\end{array}$ & $\begin{array}{l}\text { [] Grazing } \\
\text { [] Natural Disaster } \\
\text { [] Invasive species } \\
\text { [] Tourism } \\
\text { an habitation }\end{array}$ & $\begin{array}{l}\text { [ ] Exploitation of plant parts } \\
\text { [ ] Pollution } \\
\text { [ ] Lack of dispersal/pollination agents } \\
\text { [ ] Poor regeneration for unknown reasons } \\
\text { [] Inctustrial development } \\
\text { [ ] Forestry } \\
\text { [ ] Decline in soil water content }\end{array}$ \\
\hline $\begin{array}{l}\text { Conservation measures } \\
\text { Please give the details of any on-going } \\
\text { conservation activities, including legal } \\
\text { measures, presence in protected areas, } \\
\text { management practices and ex siru } \\
\text { conservation, especially where the } \\
\text { species is categorised as LRcd }\end{array}$ & & & \\
\hline
\end{tabular}




\section{Section 3 - Uses and Ecology}

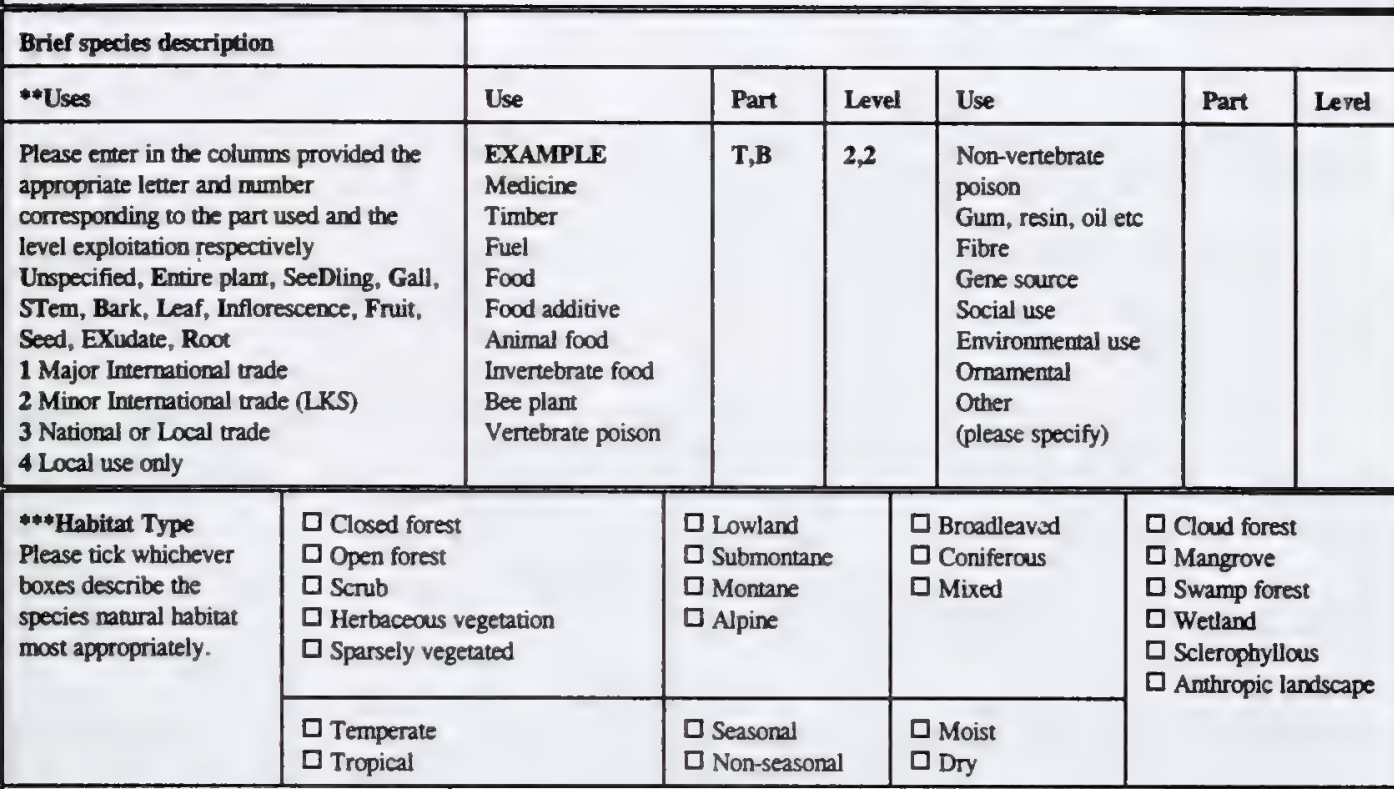

Please define habitat type furcher if necessary

\section{Species associations}

\begin{tabular}{|c|c|c|c|}
\hline Regeneration guild & $\square$ Early pioneer & $\square$ Late secondary & $\square$ Primary \\
\hline Spatial distribution & $\square$ Abundant & $\square$ Scantered & $\square$ Clumped \\
\hline
\end{tabular}

\section{Obligative species dependencies}

Dispersal/pollination agents

Altitudinal range in metres

$\operatorname{Min}$ $\operatorname{Max}$

\begin{tabular}{|l|l|l}
\hline Status of the species in cultivation & $\square$ Plantation grown $\square$ Widely cultivated $\square$ Small scale $\square$ None \\
\hline
\end{tabular}

\section{Relevant references}

Please cite any references used to

complete this form

* Please indicate the uses of species only when relevant to human use e.g. Only those plants eaten by invertebrates such as silkworms, lac insects etc. should be indicated as invertebrate food. Bee plants are those which are used for honey production. Animal food refers to those plants eaten by domesticated animals. Environmental use refers to shade trees, windbreaks and trees used in erosion control etc. Examples of plants of social use are narcotics, contraceptives, plants of rinual significance etc.

** Closed forest consists of trees with interlocking crowns. Open forest (woodland) contains trees with crowns not interlocking. Herbaceous vegetation is dominated by non-woody plants with scattered trees.

\begin{tabular}{|l|l|}
\hline Your name & Date
\end{tabular}





\section{GLOSSARY AND ABBREVIATIONS}

AETFAT
AOO
Caatinga
Campo
Campo cerrado
Campo rupestre
CBD
Cerrado
CIFOR.
CITES
CNPS
CONABIO
CONAF
CSIRO
ECOSUR
EOO

\section{Elfin forest}

FAO

FCAP

FTEA

Fynbos

GIS

Granodiorite

Hakeas

Hala forest

Igapó

IBAMA

IDS

INEFAN

\section{ICRAF}

IPGRI

ITTA

ITTC

ITTO

IUCN

Kahikatea/matai forest
Association for the Taxonomic Study of the Flora of Tropical Africa.

Area of Occupancy, a term which is used in the application of the IUCN Red List Categories. It is defined in Appendix 4.

Xerophytic scrubland in areas of alternating flood and drought, found in South America.

An open formation, largely composed of shrubs and grasses, found in South America.

Savanna with trees, found in South America.

An open formation on rocky soil in South America.

Convention on Biological Diversity

A shrubby savanna-like vegetation, found in South America.

Center for International Forestry Research

Convention on International Trade in Endangered Species of Wild Fauna and Flora.

Califomia Native Plant Society.

Mexican Commission on Conservation and Use of Biodiversity (Mexico).

Corporación Nacional Forestal (Chile)

Commonwealth Scientific Industrial Research Organisation (Australia).

Colegio de la Frontera Sur (Mexico).

Extent of Occurrence, a term which is used in the application of the IUCN Red List Categories. It is defined in Appendix 4.

Forest with a canopy about $5 \mathrm{~m}$ high, gnarled growth; the highest of the montane vegetation formations.

Food and Agriculture Organisation of the United Nations.

Faculdade de Ciências Agrárias do Pará (Brazil).

Flora of Tropical East Africa.

A term which refers to a flora and vegetation type unique to the South African Cape; evergreen sclerophyllous shrubland.

Geographic Information System.

Coarsely crystalline acid igneous rock.

Members of the Proteaceae family.

Coastal forest dominated by Pandanus tectorius, found in Hawaii.

An Amazonian forest or woodland type flooded by black waters.

Instituto Brasileiro de Meio Ambiente e dos Recursos Naturais Renováveis (Brazil).

International Dendrological Society.

Institute Ecuatoriano Forestal y de Areas Naturales y Vilda Silvestre (Ecuador).

Intemational Centre for Research in Agriculture

International Plant Genetic Resol :es Institute.

International Tropical Timber Agreement

International Tropical Timber Council.

International Tropical Timber Organisation

The World Conservation Union.

A New Zealand forest type, consisting of Dacrycarpus dacrydioides and Prumnopitys taxifolia 
Karroid shrubland

Kauri forest

Kerangas

\section{Kloofs}

Laurisilva

Manacales

Mata do cipó

Matorral

MUIENR

NBI

NYBG

PROSEA

Puna

Restinga

\section{ROTAP}

SARARES

SSC

Shola forest

Tepui

Terra firme forest

TNC

TROPICOS

Tropophilic

TWG

Várzea

Wallaba forest

Wattles

WCMC
Arid shrubland, dominated by succulent species, found in the Karoo, a vast arid plain in the South African Cape.

A forest type dominated by Agathis in South-East Asia and the Pacific.

Heath forest of invariably low stature, lacking emergents and confined to organic white sand and podsol soils. It occurs mainly on raised beach terraces or on sandstone ridges and plateaux in South-East Asia.

An Afrikaans word for a gully, ravine or valley, usually with steeply inclined or rocky sides.

Evergreen laurel forest, e.g. in the Canary Islands.

A specific altitudinal zone in Cuba between 300 and $900 \mathrm{~m}$.

Vine forest, largely confined to the Amazon.

A general term used in South America to described scrub or shrubland.

Makere University Institute of Environment and Natural Resources (Uganda).

National Botanical Institute (South Africa).

New York Botanical Garden.

Plant Resources of South-East Asia.

High Andean grasslands.

Coastal dune woodland or scrub in areas of northern and eastern South America and Mexico.

Rare or Threatened Australian Plants (Australia).

Southern African Threatened Plants Database (South Africa).

IUCN Species Survival Commission.

Patches of stunted evergreen hill forest with temperate and tropical components, occurring in Peninsular India and Sri Lanka, usually restricted to hill folds and surrounded by extensive grassy downs.

Tabletop mountains found in the Guyana Shield in northern South America.

Upland, unflooded forest in South America.

The Nature Conservancy (USA).

A nomenclatural database held at Missouri Botanical Garden.

Pertaining to marked periodic fluctuations of light, temperature and moisture.

CITES Timber Working Group.

An Amazonian forest type on sedimentary soil; subject to annual flooding by white water.

A forest type dominated by Eperua spp.

Acacia species.

World Conservation Monitoring Centre. 





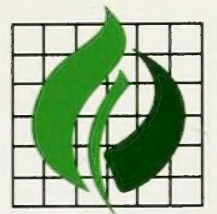

\section{WORLD CONSERVATION MONITORING CENTRE}

The World Conservation Monitoring Centre, based in Cambridge, UK, is a joint venture between three partners in the World Conservation Strategy and its successor Caring for the Earth: IUCN - The World

Conservation Union, UNEP - United Nations Environment Programme, and WWF - World Wide Fund for Nature. The Centre provides information services on the conservation and sustainable use of species and ecosystems and supports others in the development of their own information systems.

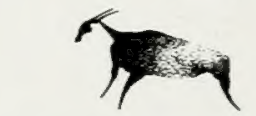

Species Survival Commission

The Species Survival Commission (SSC) is one of six volunteer commissions of IUCN - The World Conservation Union, a union of sovereign states, government agencies and non-governmental organizations. The SSC's mission is to conserve biological diversity by developing and executing programmes to save, restore and wisely manage species and their habitats. A volunteer network

comprised of nearly 7,000 scientists, field researchers, government officials and conservation leaders from nearly every country of the world, the

SSC membership is an unmatched source of information about biological diversity and its conservation. As such, SSC members provide technical and scientific counsel for conservation projects throughout the world and serve as resources to governments, international conventions and conservation organizations. 